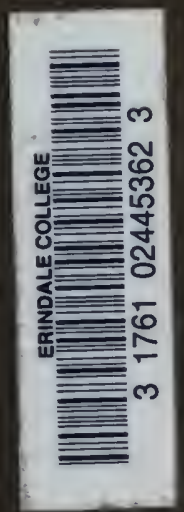




\section{JULIA:! J. NADOLNY}

Nofural History Booksellers NEW BRITAIN, CONN. U.S. A 
DEC 161993

$$
\text { JAN- } 41994
$$

MAR 241995

\title{
OCT 021995
}

\author{
DEC 21999 \\ OCT - 82003
}






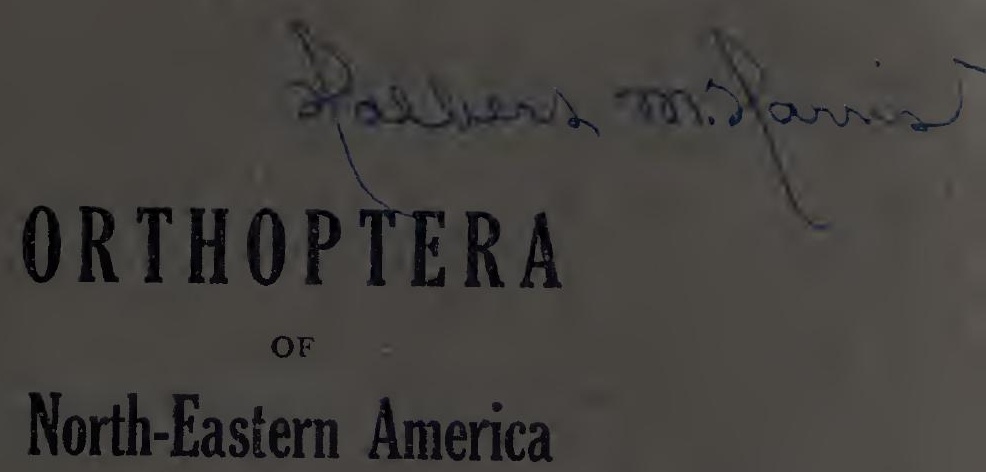

W, S. BLATCHLEY 



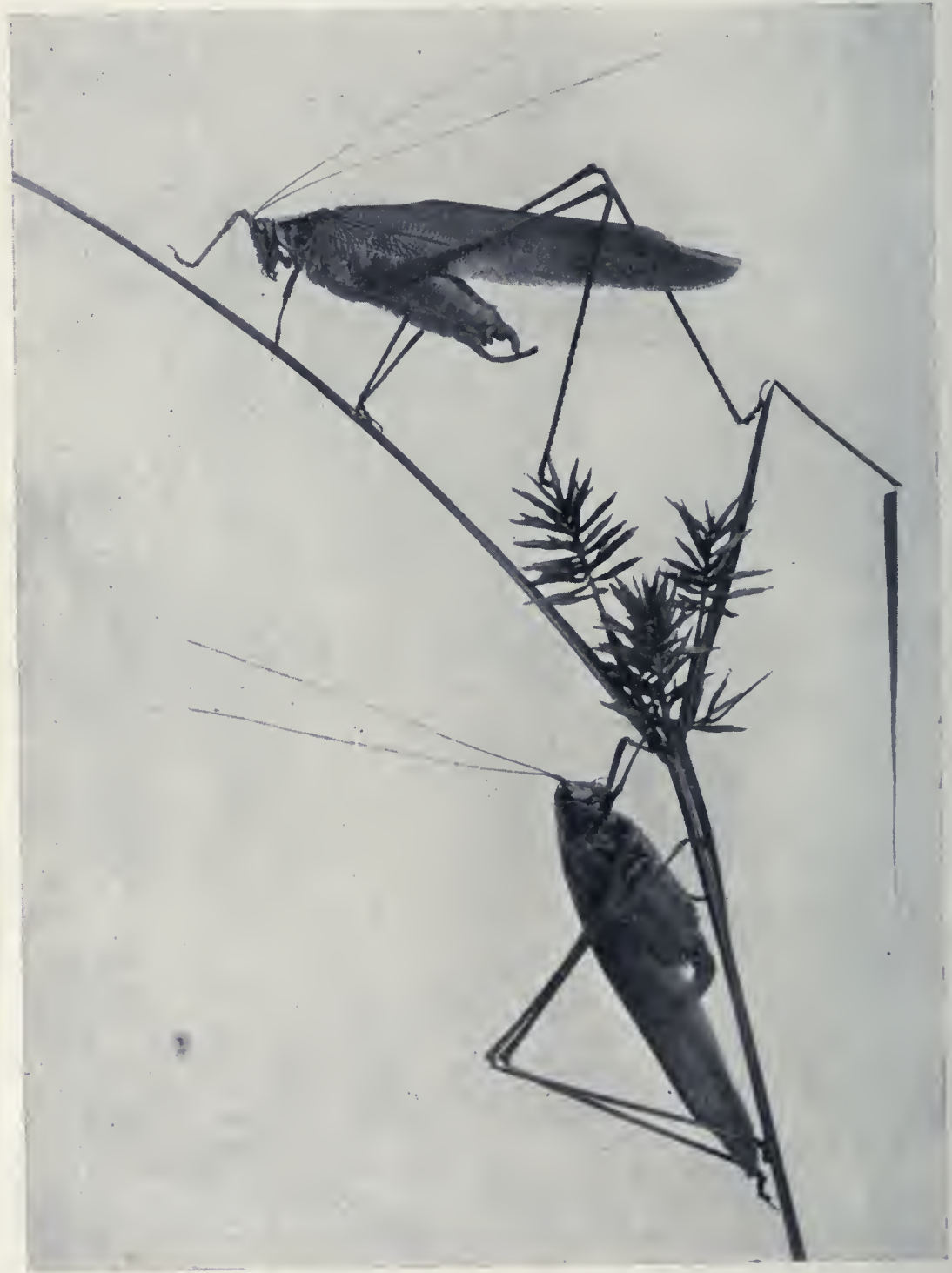

Texan Katydids, Scudderia texensis S. \& Z., on a Senge. Male above, female below. (From a photograph of living speci. mens by Dr. J. L. Hancock, Lakeside, Mich.) 


\section{ORTHOPTERA}

\section{$\mathrm{OF}$ \\ NORTHEASTERN AMERICA}

With Especial Reference to the Faunas

of Indiana and Florida

By

W. S. BLATCHLEY

Author of "Gleanings from Nature," "The Coleoptera cf Indiana," "Woodland Idyls," "The Indiana Weed Book," etc., etc.

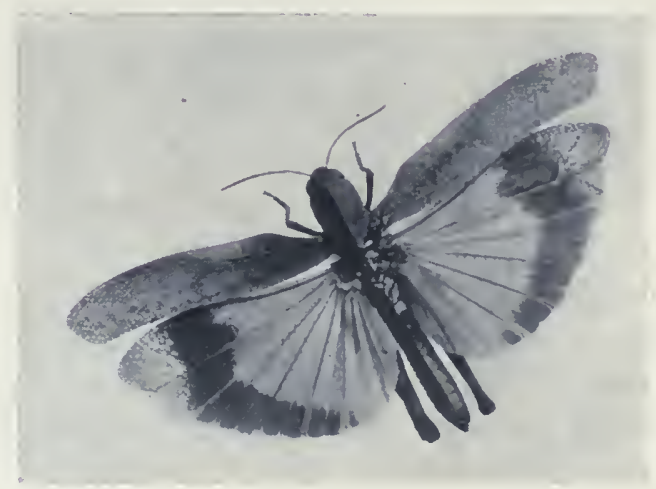

"And a locust unto Mahomet said: 'We are the army of the great God; we produce ninety-nine eggs; if the hundred were completed, we should consume the whole earth and all that is in it."

-Arab Legend.

1920

The Nature Publishing Company

INDIANAPOLIS 
"The land is as the garden of Eden before them, and behind . them a desolate wilderness; yea, and nothing shall escape them."

-Joel, $I I, 3$.

Chiefs, who no more in bloody fight engage, But wise through time and narrative with age, In summer days like grasshoppers rejoice,

A bloodless race, that sends a feeble voice."-Homer.

Copyright, 1920

By W. S. Blatchley.

"Green little vaulter, in the sunny grass,

Catching your heart up at the feel of June,

Sole noise that's heard amid the lazy noon,

When even the bees lag at the summoning brass."-Leigh Hunt.

"Crowds of bees are giddy with clover,

Crowds of grasshoppers skip at our feet,

Crowds of larks at their matins hang over,

Thanking the Lord for a life so sweet."-Jean Ingelow.

\section{ERINDALE COLLEGE LIBRARY}




\section{INTRODUCTION.}

There has long been need of a single comprehensive manual on the Orthoptera of the Eastern United States. The original descriptions and information regarding the distribution and habits of these interesting insects are scattered through scores of books and pamphlets which the student lias to consult in order to correctly determine the rarious species which he may collect or have at hand. Many of these works are out of print or very difficult to obtain. For that reason the beginner is often discouraged at the very start and the study of Orthoptera has, therefore, not kept pace with that of other orders of insects whose literature is more available.

The present work has been prepared to supply the need above mentioned. It is an outgrowth or expansion of my "Orthoptera of Indiana" issued in 19013 and long since out of print. In that work 148 species were described and keys given for their determination. Since its issue the researches of Rehn and Hebard, Caudell, Morse, Hancock, Walker, 1)avis and other special students of United States Orthoptera have brought about numerous changes in the nomenclature of the group and have added many new forms to the known fauna of our country. The great majority of Orthoptera inhabiting the United States east of the Mississippi River and Canada east of the 90th Meridian (the territory covered by this work) are now known. The nomenclature-always flexible and in the end largely dependent upon the view-point of the student-is fairly well established. The time is, therefore, deemed propitious for the appearance of such a work and it is offered as the best that I can accomplish with the facilities at my command.

In the preparation of this manual I have ever had in mind the needs of the tyro and not those of the specialist in Orthoptera, the primary object in view being a simple work which would enable beginners in the most direct way possible to determine the scientific names and arrange and classify the Orthoptera in their collections. As far as possible easily understood words and terms have been used in the keys and descriptions, and many of the subdivisions adopted by other authors have been omitted in order to render the work less technical and.more easily followed. Keys to families, subfamilies, tribes, genera and species have been made an important feature of the work. These keys are based on the more salient or easily recognized characters separating the divi- 
sions to which they pertain. In most instances, to aroid repetition and sare space, these character's are not re-mentioned in the descriptions which follow, and the keys should therefore aluays be used in connection with the descriptions. Moreover, it should be remembered that the character's used and statements made both in keys and descriptions are to be considered as applying only to those species occurring in the territory covered by this work. They may be, and in general are, capable of much wider application but it is not safe to assume that such is the case.

Following the description of each species are notes on its distribution, food habits, song, ete. The general range or area of distribution given is based not only on my personal collecting in Indiana and Florida, but also on the specimens which lave been examined in other cabinets and on the published local lists and other works cited in the Bibliography as well as manuscript lists furnished by several persons. The synonymy of many species is, however, so involved that the range as given, especially where it extends beyond our territory, is to be considered as open to correction. The dates of oceurrence as given are usually the earliest and latest at which the species has been noted in the locality cited and do not therefore necessarily show the actual time of its appearance or disappearance.

Of the $3 \% 3$ species and 58 varieties of Orthoptera recognized or recorded as inhabiting the territory corered I lave been able to examine personally the types, or undoubted correctly identified paratypes, of all but fire. ${ }^{1}$ The great majority of the species treated are represented in my own collection. The somrce of the specimens at hand as I wrote the descriptions is usually given in the notes following each description. Thus "Takelnurst, $\mathrm{N}$. Jer. (Davis)" means that the specimens at hand were taken at Lakehurst and loaned or presented to me by W. T. Davis; while "Ormond and Dunedin, Fla. (W. S. B.)" signifies that the specimens examined were taken by myself at the localities nentioned. After preparing the greater part of the text I visited Cambridge and Wellesley, Mass., Staten Island, N. Y. and Philadelphia, Pa., to examine the species not previously seen and to study the types and other specimens in the Scudder, Morse, Davis and Philadelphia collections. These contain the great majority of all the types of the United States species. Other cotypes or paratypes from

'These are Phvllozates chlorophca Blanch., a inantid of doubtful occurrence in the Southern States; Heteronemia larissimus, and $H$. teranus Brunner, two phasmids of doubtful status; Belocephalus excazatus Davis, the unique type of which is in the American Museun of Natural History, which Institution I did not find opportunity to visit, and Ceuthophilus scabripes (Hald.), a camel cricket, the type of which is lost and the status therefore doubtful. 
the U. S. National Museum collection at Washington were kindly loaned me from time to time by $A$. $\mathrm{x}$. Caudell. The native and introduced and establíshed species are numbered consecutively throughout the work, while those included but un-numbered represent adrentire forms which hive occasionally been taken within our bounds but which are as yet not known to breed and live throughout the year in any one locality.

Cuassificatiox.-The classification followed in this work ${ }^{\text {fi is }}$ not that of any one previous author, and may therefore not neet with the full approval of the up-to-date specialists in Orthoptera. In the names which I have adopted for the higher groups, I have not'always followed "The Entomological Code"2 nor the rulings of the International Commission of Zoological Nomenclature. There has been in recent years, too much of a tendency to split hairs, to divide and subdivide the old well known groups into an infinite number of minor ones which lead nowhere in particular and only serve to confuse the beginnei. The law of strict priority ${ }^{3}$ and its resultant ruling of basing the name of a subfanily or tribe upon the oldest generic name included are all right in the main, but when they lead up to two such similar names as Acridinae and Acrydiinae, confusion is sure, to result, and priority should give way to simplicity. - In sucly cases the names adopted by the more recent specialists are giren in parenthesis and the student can use them if he so desires.

As with the higher groups so with the genera. I have not always adopted the generic names which have been proposed in recent years for certain of our species. A genus should be based on certain definite and fixed structures and once so founded all species then or thereafter assigned to that genus should possess those structures. Strictly speaking, a genus does not exist in nature but is only an artificial concept proposed br man to enable him the more readily to "group his species. As to what really constitutes a set of generic characters there are about as many individual opinions as there are proposed or adopted genera. iry reasons for rejecting or adopting certain questionable genera are usually set forth and the student can use his own judgment as to whether they are sound or not.

2Tnis code, prepared at Washington-in $\mathrm{x}$ 'rz by those two eminent American ento. mologists, Nathan Banks and A. N.-Caudell, is, in the main, an excellent thing for beginners but a number of its rulings have not been adopted by some of the leading entomologists of the country.

"If strict priority in the naming of the higher groups be insisted upon, the name Orthoptera itself, first used by Latreille in 1796 and later more definitely by Olivier in $181 \mathrm{I}$, would have to give way to Dermaptera, the name proposed for the group by DeGeer in 1773 , or to Ulonata, that proposed by Fabricius in 1775. 
The subgenera and other minor groups of certain authors are not generally recognized in this work. In their place and solely to shorten and simplify the keys I have sometimes used "groups" or "series," usually without definite names, as they lead up more easily and with less confusion to the main object sought-the scientific name of the specimen in hand.

Synonym of Species.-As already noted the synonymy of many species of Orthoptera is greatly confused. This is due to several causes, chief among which are the following: a.-Variation in the length of tegmina and wings. These organs of flight often vary exceedingly in individuals of the same species, thus causing the insects to appear so different in general facies that both the long- and short-winged forms have been often described under different names: $b$.-Variation in color. Many of the first described species were based mainly upon color characters alone. As is well known, these are dependent largely upon local environment and are therefore usually unreliable in the fixing of species. Where the habitat is essentially the same throughont a large area the color is more stable and can then often be used as an important specific or varietal character; c.-Variation in the secondary genital organs, especially those of the male. The size and form of certain abdominal appendages, as the male furcula and cerci, the form of and degree of emargination of the subgenital and supra-anal plates, the length, form and armature of the ovipositor, have been much used in the past as distinguishing characters in the separation of species. In the majority of forms these organs are fairly stable and can be satisfactorily so used, but in some they vary greatly. This is especially true of the cerci of the male and too many races, varieties and even species have been founded upon slight differences in the structure of those organs; d.-Brief descriptions of the early known American species by European writers. A number of the more common American species of Orthoptera were first described, usually in two or three lines, by foreign authors who nerer saw the insects in the field, and knew nothing of their distribution, habitat or variations. These brief descriptions were sufficient to enable their authors to distinguish the species at hand from all others known to them, but are wholly inefficient when it comes to separating them from the large number of closely allied species now known. The types of many of the species described by DeGeer, Burmeister, Serville and even Saussure and Redtenbacher, are destroyed or inaccessible, so that it is often impossible to state what form 
they had in hand. Much confusion in synonymy has therefore resulted by "guessing" at what they had, as each of our American authors has usually come to a different conclusion, and described or named his own species accordingly. Unless some easily distinguished or reliable character was given by the European author by which the American insect has been or is readily distinguished, or until a direct comparison with the type, if the latter is available, has been made by some competent Orthopterologist and the American conspecies thereby reliably determined, it is often better, in my opinion, to disregard these old European names and to adopt later ones of undoubted status.

While the law of priority has been usually followed in the naming of the species in this work, there are some instances where the rulings leading up to it were technical, or, in my opinion, nonsensical, and I have therefore retained a better known name in preference to the one which, in accordance with strict priority, has been recently assigned by other authors. In such cases I have mentioned in the text or footnote my reasons for not adopting the proposed change in names.

Throughout the work I have used trinominals to designate races, varieties, variants, subspecies, incipient species and sometimes even color varieties, usually noting which of these minor forms I consider the third name to represent. The name of the typical variety, if more than one exists, is not printed as a trinominal. I thus use Nomotettix cristatus (Scudder), not Nomotettix eristatus cristatus (Scudder). In many cases I have not recognized the so-called geographical races of recent authors. Where a well known species ranges over a large area, the different environments due to altitude, variation in mean annual temperature, atmospheric conditions, difference in topography, drainage and soils, varied food plants and many other causes, are sure to bring about certain changes in its external structure. If only the extremes of these variants be at hand ther are often so different in appearance as to cause them to be considered races or even different species. However, where a large series from all parts of the range are present, intermediates are almost. sure to be found and there is little use and often much resulting confusion in giving or recognizing a name for each slightly variable form.

Where, in the original description, the specific name was placed by the author in a genus different from that to which it is now referred, the name of the author or its abbreviation is placed in parenthesis. 
The known synonyms of each species of Orthoptera belonging to our fauna are usually mentioned in the notes following the description of that species. A list of these synonyms, arranged alphabetically by both genera and species, with reference to tie species to which each is now accredited and the page of its description, will be found just before the general index of this work.

Bibliography.-The bibliography near the end of this volume is not a complefe list of the works pertaining to the Orthoptera of, Northeastern Anerica but contains only the names of those works to which especial reference has been made in the text, and a few additional ones which it was thought might at times be of use to the student of our. fauna. In the bibliography the list of papers is arranged alphabetically by authors and each author's works chronologically by years. Where more than one paper by the same author appeared in any one year the letters $a, b$, $c$, etc. follow the year. Thus, a citation in the text to Davis $(1912 \mathrm{a}, 124)$ will be found by reference to the bibliography to refer to page 124 of his paper entitled "Three New Species of Belocephalus from Florida," published in the. Journal of the New York. Entomological Society, Vol XX, pp. 122-125. After the name of each genus and each species, as recognized in this work, is given the name of the author with year and page number of the work where the genus was founded or the species originally described. Thus, Beloecphalus sabalis"Davis, 1912a, 123, refer's to the original description of that species on page 123 of the paper above mentioned; while Belocephalus Scudder, 1875,458 , means, as a reference to the bibliography will show, that the genus Belocephalus was founded by Scudder on page 458 of his "Century of Orthoptera Decade II. Locustarix," which appeared in the Proceedings of the Boston Society of Natural History, Vol XVII, pp. 454-462. As the joint works of Rehn \& Hebard are so numerous and the references to them so many, the abbreviations $R$. \& $H$. have been, for the most part, used for citation to them throughout the text.

No attempt has been made to make reference to all the mentions of each species in the works cited, as such complete srnonymy would fill a volume by itself. Special students, who wish a more extended synonymy, are referred to Scudder's "Index to North American Orthoptera," which includes every known reference to each species up to the close of the year 1900. A manuscript continuation of this index has been made by $A$. N. Candell which, it is hoped, will soon be published. Another work, indispensable to the special student, is Kirby's "Synonymic Catalogue 
of Orthoptera," published in three rolumes $(1904,1906,1910)$, which deals with the Orthoptera of the world, but contains many errors in the synonymy of the Nortl American forms.

Measurearexts.-The measurements used in this work are given in millimeters or decimals thereof. A millimeter $(\mathrm{mm})=$. .0394 , or a little more than $1 / 25$ of an inch. For all practical purposes it may be remembered that $2.5 \mathrm{~mm} .=1 / 10$ inch $; 3 \mathrm{~mm} .=$ $1 / \mathrm{s}+\mathrm{inch} ; 4 \mathrm{~mm} .=1 / 6+\mathrm{inch} ; 5 \mathrm{~nm} .=1 / 5$ inch $; 7.5 \mathrm{~mm} .=3 / 10$ inch; $10 \mathrm{~mm} .=2 / 5$ inch $; 12.5 \mathrm{~mm} .=1 / 2$ inch; $15 \mathrm{~mm} .=3 / 5$ inch; $17.5 \mathrm{~mm} .=7 / 10$ inch; $20 \mathrm{~mm} .=4 / 5$ inch.

The measurements as given are usually those of the extremes of the series at hand and thus represent fairly well the rariation in size of the different parts measured. The length of the body is taken from the tip of the rertex to the apex of the subgenital plate in male and base of oripositor in female.

Habits and Songs of Orthoptera. - The habits of any form of animal life are usually of especial interest to the student of natural history. Each individual of the myriad living moving forms found upon this old earth of ours has its daily rontine of life,-its journeys great or small, its quest for food, its search for a mate, its care of offspring, its place of hiding, its means of selfprotection, its limits in hours or days or years of life,-its final passing back to the dust of the common mother-to that matter which is indestructible, ret erel mutable-ever ready to become a living, moving part of a mite $0 r^{\circ}$ a man, a mouse or an elephant. Of all these forms of life none are more interesting in habits than the Orthoptera which, while few in numbers as compared with the great bulk of insect life, have a history reaching back far beyond that of man himself. For they were the first musicians of the eartl, and by the means of their shrilling organs enlivened the solitudes of the strange old Deronian forests with their lore calls and wooing notes. Hancock in his charming work "Nature Sketches in Temperate America," has described the habits of many Orthopterons. Scudder has set their songs to music. Hebard and Walker, Somes and Morse, Davis and Allard, Piers and Fox have described their notes, their haunts, their daily labits. From the writings of all these and many others I have gleaned and have included in the notes on earlh species those observations which it was thought would be most interesting. To some this mingling of the poetical with the technical may be deemed out of place in a work like this, but Grant Allen has well said: "Our thoughts about nature and nature's objects are often too largely 
interwoven with hard technicalities concerning rotate corollas and pedicellate racemes, and I, for my part, am not ashamed to confess that I like sometimes to see the dry light of science diversified with some will-o'-the-wisp of pure poetical imagination."

Acknowledgments.-As already noted, this work is based largely upon my former one-" "The Orthoptera of Indiana." In the preparation of that, as well as in my earlier studies of the group, I was greatly aided by two men to whom I wish to first pay tribute. One was Sanuel H. Scudder of Cambridge, Mass.a man noted for his varied accomplishments-a devoted student of insects, especially of butterflies and Orthoptera. He was the father of American Orthopterology, and to him more than to all his predecessors and contemporaries combined is due our present knowledge and classification of the group. When, in 1861, he wrote his first paper on Orthoptera fewer than 60 species were recognized from North America and a number of those were synonyms. In 1900, when he issued his second Catalogue 856 species were included, 385 of which had been described by him. A number of these have since been shown to be synonyms, for his later work, especially on Ceuthophilus and Melanoplus, was hurried and many mistakes naturally resulted. Of his published papers on Orthoptera no fewer than 81 are included in the bibliography accompanying this work, while a large number of others dealing with extra-limital species are not mentioned. Always willing to answer questions and ever interested in any new form which was discovered, his counsel was to me for many years both helpful and inspiring. His collection of Orthoptera with its many types is now in the Cambridge Museum of Comparative Zoology, where it is one of the lode-stars which attract to that Mecca of entomologists those interested in Orthoptera from all parts of the world.

Another who aided in solving many a knotty problem in my old tyro days was Lawrence Bruner, then as now the Professor of Entomology in the University of Nebraska. He has long been interested not only in the Orthoptera of this country but in those of South America, and lias published many papers and described many of the species belonging to our fauna. His cabinet of North American forms with its numerous types is now a part of the Philadelphia collections.

When I began the preparation of this work I realized that I would have to call many times upon the present-day special students of North American Orthoptera, those who have kept the 
science growing since the new century was uslered in. They are few in number but rich in lore, in enthusiasm and especially in a willingness to help a fellow-student when he sends out an S. O. S. for aid of any kind. To A. N. Caudell of the U. S. National Museum at Washington, D. C., I am indebted for many favors. Long a devoted student of the group, and an especial adept in the intricacies of the knotty problems of its nomenclature; he has been especially kind in answering the many questions which I have asked and in loaning me numerous volumes and many specimens for study. W. T. Davis of New Brighton, Staten Island, X. Y., who is not only a student of Orthoptera, but also a naturalist of high rank and interested in all forms of living things, has aided me greatly in many ways. His private collection of Orthoptera is rich not only in large series of some of the scarcer forms but in numerous types of the species he has described. From it he has loaned or presented me examples of many rare species. He has also furnished many notes on distribution and habits of various forms. Jas. A. G. Rehn and Morgan Hebard of Philadelphia, Pa., have loined me numerous specimens and have rerified or identified for me many others. Since 1900 they have built up at the Philadelphia Academy of Natural Sciences one of the largest and most complete collections of Orthoptera in the world-one rich in types not only of their own description, but of otler authors. Their published monographs and other papers on North American Orthoptera are numerous and most valuable, and from them I have drawn freely for the pages which follow. Dr. J. T. Hancock of Chicago, Ill., the noted authority on the Tetrigidae of the world, has furnished me many notes on the distribution of the grouse locusts and loaned me numerous specimens of that interesting group. A. P. Morse of Wellesley, Mass., has shown me many faror's. He has been for thirty or more years a special student of New England Orthoptera, and has also collected extensively in the Southern and Pacific states. His numerous types and other specimens have been placed freely at my service and he has furnished a number of notes on distribution and habits. Dr. E. M. Walker, of the University of Toronto, the leading student of Orthoptera in Ontario, has sent me much data regarding the forms found in eastern Canada, and from his writings and those of Piers and Morse $I$ have gained much of the information given regarding the species found in the extreme eastern part of the territory covered. Dr. H. Fox of Macon, Ga., who has published interesting papers on the Orthoptera of Pennsylvania, New Jersey, In- 
diana and Virginia, has furnished me numerous specimens and has contributed a manuscript list of the species taken near Clarksville, Tenn. T. H. Hubbell of the University Museum of Zoology at Ann Arbor, Mich., prepared for me a similar list of Michigan species and kindly loaned specimens for examination. Otliers who contributed distribution data, specimens or $^{\circ}$ other helpful aid were the late Chas. A. Hart of Urbana, Ill.; Wm. J. Gerhard of the Field Museum, Chicago; Prof. J. R. Watson, Dr. E. H. Berger and P. TV. Fattig of Gainesville, Fla.; H. P. Loding of Mobile, Ala.; Prof. H. Garman of Lexington, Ky.; Nathan Banks of Canbridge, Mass.; Dr. Wm. A. Riley of the University of Minnesota; Myron H. Swenk of Lincoln, Neb.; J. R. Malloch of Urbana, Ill.. and Chas. A. Dury of Cincinnati, Ohio.

It is a pleasure to acknowledge and extend thanks to all the parties above mentioned, for, situated as I have been far from any large collection or reference library, the work in its present form would not have been possible had it not been for the aid so freely given.

\section{Relation of ix Orthopteron to Other Animals.}

If we compare the body of a locust or other insect; with that of any vertebrate animal, as a fish, bird or squirrel, we find at once great and important differences. The vertebrate is an animal with an inner bony skeleton, two pairs of jointed limbs or appendages, and breatles by means of lungs or gills, according as it dwells in air or water. The locust is an animal which las no inner skeleton or bones whatever, but only a hard crust on the surface which surrounds the muscles and vital organs. : This crust is composed of separate rings, placed end to end.

Animals whose-bodies are thus composed of rings are called Articulata. They are in turn divided into two great groups, the Vermes and the Arthropoda. The Vermes (worms) have all the rings composing the body very nearly alike, not hardened into an outer crust or exoskeleton, and without paired limhs which are jointed. The Arthropods luave a part of the rings bearing paired jointed appendages, and have the cuticle or outer surface consisting largely of a peculiar substance called "chitin," which is secreted or exuded by the cells which compose the cuticle. Chitin itself is insoluble and is not composed of cells, but consists of fine. irregular plates. It hardens the cuticle and thus aids the latter in protecting delicate vital organs within, and also in forming a framework to which the muscles of movement may be attached. Between 
the joints the cuticle is deroid of chitin and is thin, delicate and flexible, thus allowing the necessary freedom of motion.

The Arthropoda are divided into four classes, as follows:

(a) Crustacea (crayfish, Iobster, etc.), mostly aquatic; having the head and thorax usually united and distinct from the abdomen; breathing by means of gills or directly through the skin, the exoskeleton with carbonate and phospate of lime in addition to chitin.

(b) Arachnida (spiders, mites, etc.), terrestrial; head and thorax usually combined, and bearing four pairs of legs; breathing by means of trachea.

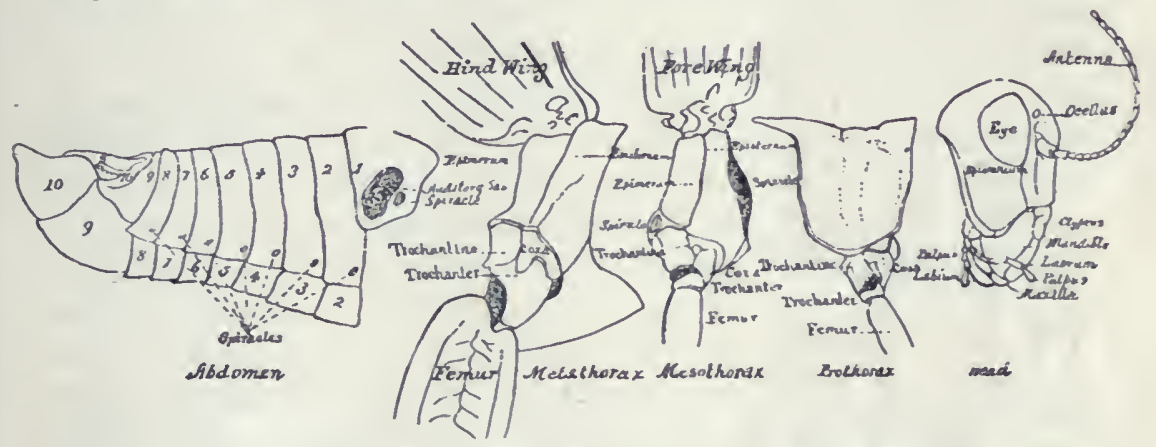

Fig. 1. Body of a locust, side view, showing the rings of which the body is composed, the thorax being separated from the head and abdomen and divided into its three segments. (After Packard.)

(c) Myriapoda (mrriapods, centipedes, etc.), terrestrial; usually worm-like, with only the head distinct; legs numerous; breathing by means of trachea.

(d) Insecta (grasshoppers, flies, beetles, etc.), in great part terrestrial; legs six; adults usually with one or two pairs of wings; breathing by a system of tubes called trachere, which branch and ramify through every portion of the body, and which open externally in about ten places on each side of the body instead of at the front end. "The rings of the body are grouped in three regions; the head, the thorax and the abdomen. In general it may be said that the head contains or bears the organs of sense and of prehension and mastication of food; the thorax the organs of locomotion, and the abdomen those of reproduction.

\section{The External, Axatomy of a Locust.}

Having thus shown that a locust belongs to the class Insecta it is thouglit best, before giving its relation to the other orders 
of that class, to describe briefly the external parts of a typical specimen. The beginner may thus the more readily grasp the name and location of the parts used in classification, as well as the meaning of many of the technical terms which, of necessity, have to be used in such a work as this. The three regions of the body, the head, the thorax, and the abdomen, with their appendages, will therefore be considered in order.

The Hend.-The head of the locust is composed of four or more segments or rings, solidly fused together to form a single cavity or hard box of chitin, known as the epicranium. This contains the brain and accessory ganglia, and the mouth cavity. It bears or gives support to the antennae, mouth parts, eyes and ocelli; also internally to the muscles moving the mandibles or jaws. The broad basal portion of the epicranium back of the eyes is known as the occiput, the narrower portion between the eyes,

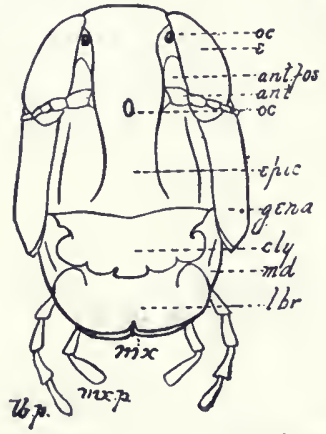

Fig. 2. Front view of the head of a locust. (After Lugger). the vcrtex, while the long frontal portion as far down as the prominent transwerse suture is the front or face.

The short plate $(c l y)$, below or in front of the epicranium, is the clypeus. Below this and hinged to its front edge is a movable flap known as the labrum (lbr) or upper lip, to which are attached a pair of jointed labial palpi. This forms the roof or covering of the front part of the mouth, within which are the large, black-tipped, toothed jaws or mandibles ( $m d$ ), which are so attached to the epicranium as to move only in and out or to and from a median line. As has been shown by Nininger (Psyche, XXII, 13) the two mandibles in Orthoptera are not alike as is generally supposed, but the left one is slightly the larger and projects beyond the right one ventrally when closed. The distal ends of the two mandibles are beveled differently so that when closed the beveled surfaces are contiguous throughout and do not meet on the median line but always to the right of it. Inserted on the sides of the head just behind the mandibles and arched over the tongue will also be found a pair of accessory jaws, the maxillae $(m x)$, each of which is composed of three parts, the most important being the jointed maxillary palpus. The segments of these palpi are usually five in number and vary in size and form in different groups therefore being often used in classification. The development and shape of these maxillae in the lo- 
cust, as well as in other Orthoptera, depend rery largely upon the nature of the food, as these organs serve not only to seize and hold the food in the mouth, but also as accessory jaws, aiding the mandibles in rendering the food more suitable for swallowing. Their palpi are not only organs of touch, but in many cases act as hands in helping to prehend and carrying morsels of food to the mouth.

Above the clypeus, is a ridge extending upward along the median line of the face to the vertex. This is the frontal costa, and its characters are often used in classification. In one species it may be sulcate or grooved, in another, flat. Its edges, or carince

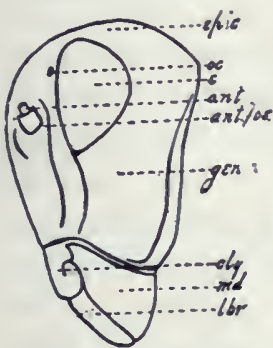

Fig. 3. Side view of head. (After Lug ger.) may be parallel the full length or may direrge or converge. Its width and prominence are also often mentioned.

The region on the side of the head, behind the eve and above the base of the mandibles, is the cheek or gena (yen.). To its inner wall is attached the large muscle which moves the mandible.

The eyes of a locust are five in number, two large compound ones and three small, simple ones. The compound eves are present in all Orthoptera. In the locust they vary in shape, but for the most part are oral, and are located on the upper portion of the sides of the head. Each is made up of many thousands of six-sided facets or lenses, in each of which a single filament of the optic nerve ends. The simple eyes or ocelli (oc.) are absent in some Orthoptera, as the Tettigoniidae, some of the Gryllidae and the females of some Mantidae, but are present in the locust. Two of them are situated just above the base of the antennae, close to the inner margins of the compound eyes, while the third is located near the middle of the frontal costa. Their position varies in the different families of Orthoptera, and there are but two in the Gryllotalpinæ or mole crickets.

These ocelli are thought to be inherited from the obscure eres of the worm-like ancestry of the locust, while the many facetted compound eres of insects and crustaceans have been erolved to satisfy the needs of the more recent existence of these groups.

The antennce (ant.) of the locust are simple, many jointed appendages, located on the face between the eyes and articulating with the head by a ball and socket joint. They are principalls organs of touch, but are also supposed to contain the nerves of 
smell. They vary much in length and form among the different families of Orthoptera, the rariation being the result of adaptation to their peculiar surroundings and habits. For instance, in those camel crickets (Ceuthophitus), which dwell in caves, they are very much longer than in those members of the same genus which dwell above ground. Characters pertaining to their form, length, and point of union with the head, are much used in classifieation. Such terms as filiform, clavate, setaceous, etc., relating to their form, are defined in the accompanying glossary.

Characters pertaining to the vertex, or that part of the epicranium, between the eyes, are much used in separating the different species of Orthoptera. The central portion of the vertex, known as the disk $(d v)$ or scutellum $(s v)$ is often depressed, or sepal-

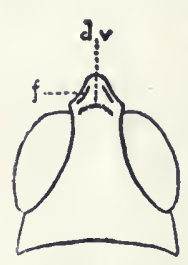

Fig. 4. Showing. 4. Showdisk and foveolie of vertex.' (After $\mathrm{L}$ u g. ger.) rated from the remainder. Its bounding walls are termed lateral carine and often a median carina divides it into two parts. The front portion, or apex, often called the fastigium, is variable in form and its characters are also much used. On the outer side of. and a little below the front half of each lateral carina of the rertex there is, in many Orthoptera, a little space or concavity bounded by elevated ridges. These spaces are the lateral fovcole $(f$.$) and their varia-$ tions in size and form also afford characters much used in classification.

The Thorax axd its Appendages.-The middle region of the body of a locust or other insect is called the thorax. To study its parts aright, the wings and legs attached to it should be removed, when it will be seen to consist of three rings or segments. These are known as the prothorax. mesothorax and metathorax. Within these rings are located the muscles for moving the wings and legs, as well as some of the digestive organs.

The prothorax of the locust (Fig. 5) has its entire dorsal surface, and sides in great part, covered by a large sunbonnet-shaped piece known as the pronotum ( $m \circ \mathrm{o}$. This varies much in sliape and size in the different families, of Orthoptera., Its upper surface is called the disk, and its sides the lateral lobes. Raised lines known as the lateral carine usually separate the disk from the sides, while often a third line, the modian carina runs length wise through the middle of the disk.

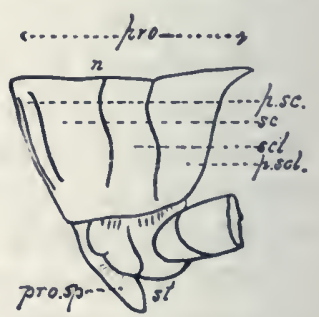

Fig. 5. Side view of prothorax of a locust. (After Lugger.) 
This may be high or low, crested, arched, distinct, aborted, etc. It is usually cut by one or more notches formed by shallow grooves or sulci which cross the disk of the pronotum and extend down its sides. The hindmost of these sulci or grooves divides the disk of the pronotum into two parts known as the prozona (pz) and metazona (mz). The fore and hind margins of the disk of pronotum may be truncate, rounded, angled, notched, etc. The surface of the disk is usually smooth, but sometimes wrinkled and may be rugose or roughened with numerous tubercles.

The under or ventral side of the prothorax is

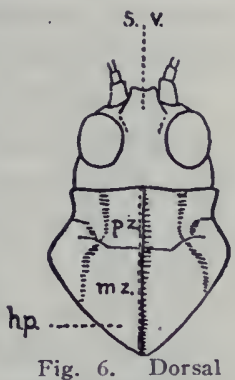

Fig. 6. Dorsa view of head and pronotum. (After Lugger.) a narrow, somewhat movable piece called the prosternum. On its center it often bears a tooth or spine (pro. sp.), the presence or absence and shape of which form characters used in classification. Near the outer ends of the prosternum are shallow sockets in which are attached the front pair of legs.

The mesothorax and metrthorar. the second and third secrments of the thorax, are, in the locust, rather firmly united with the basal abdominal segment of the abdomen to form a firm walled box, though in the Blattidae they are distinct. The upper

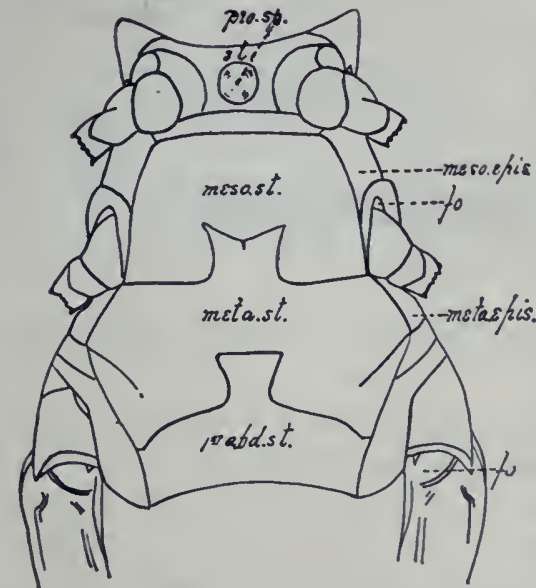

Fig. 7. Lower or ventral view of the thorax of a locust. (After Lugger.) portion of these segments is, in most Orthoptera, partly or wholly covered by the pronotum or base of the outer wings. To the mesothorax are attached the tegmina or outer pair of wings and the second or middle pair of legs. To the metathorax are ioined the inner wings and the third or hind pair of legs. The under or rentral portion of these segments are called, respectively the mesosternum and metasternum. (Fig. T.) The former in the locust is composed of a front transverse portion, with two nearly rectangular lobes projecting backward. Between these lobes is dore-tailed a squarish tongue, or forward prolongation of the metasternum. The latter is united with the 
basal abdominal segment by the dove-tailing of a similar but narrower tongue between its lobes. The side pieces of the mesothorax and metathorax are called pleurites and bear the prefixes meso and meta.

The wings are thin, broad, more or less leaf-like folds of the integument or body covering, which are joined to the thorax and moved by powerful muscles located within the thoracic cavity. The first or outer pair of wings of the locust and other Orthoptera serve as shields or covers for the more delicate inner pair. In the text which follows they are called tegmina. Each wing cover or tegmen is a thin, more or - Iéss transparent, leathery ${ }^{\circ}$ parchment-like plate of chitin, strengthened by a network of tubes called nerves or veins. The spaces enclosed by the reins and their cross branches are called cells. When folded and at rest upon the body the outer face of the tegmen of a locust is vertical, with the front or costal margin below, and the posterior or sutural margin lying along the back; that of the left tegmen slightly overlapping the right.

The principal veins of the tegmen of a locust diverge from the basal end and are seven in number. The one nearest the front or lower margin of the tegmen is the submarginal or costal vein $(r)$.

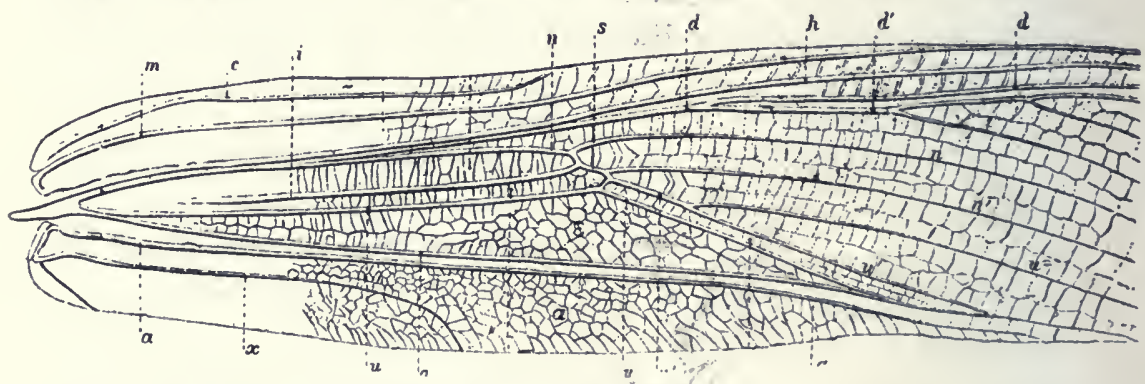

Fig. 8. Right tegmen of a locust, showing the venation. The names of the veins designated by the letters are given in the text. (After Saussure.)

It is undivided, and may usually be traced for a little nore than half the length of the tegmen, though in some locusts it is lacking. The second and longer vein, also undivided, is the modiastinal $(\mathrm{ii})$. The third and much larger vein is the humcral $(h)$, sometimes called the subcostal. It gives rise to several large branches, the sulddivisions of which form the framework of the greater part of the tegmen. The larger of these branches $(d)$, is known as the discoidal rein, its branches being designated as $d^{\prime}$, $d d^{\prime \prime}$, ete. The fourth or median vein $(n)$, is much smaller and soon divides into 
branches of nearly equal size. Above or behind the median rein is sometimes present a short, undivided rein (i), known as the intercalary rein. Next in order is the ulnar vein (u), which gives off several branches $\left(u^{\prime}, u^{\prime \prime}\right.$, etc.). The upper division of this rein $(o)$ is known as the posterior ulnar or the submedian vein. Close to and parallel with it near the upper or hind margin of the tegmen, is the undivided anal vein ( () , while the uppermost vein of the tegmen, also undivided, is the arillary vein $(x)$.

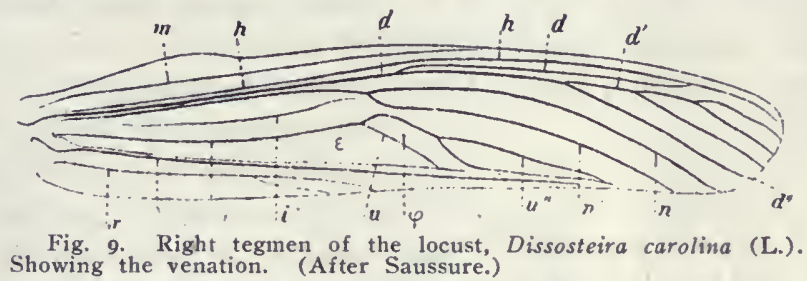

The tegmen is divided by these veins into three areas: The costal $\mathrm{or}^{\circ}$ marginal area $(I I)$ forms the lower or front edge of the wing cover and is bounded above and behind by the humeral vein. The median or discoidal area $(D)$ is much the largest and lies between the humeral and posterior ulnar veins. The anal or dorsal area $(X)$ is the free margin lying along the back above and behind the anal vein. The posterior end of the tegmen $(A)$ is known as the apical margin.

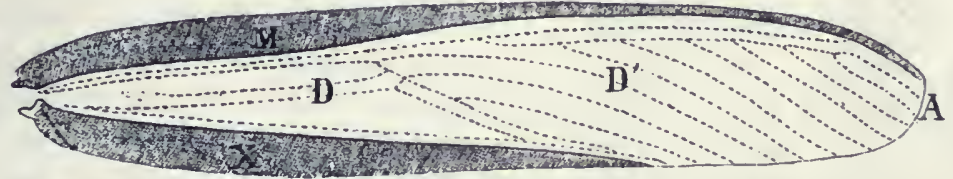

Fig. to. Right tegmen of a locust, showing the "areas" designated in the iext. (After Salıssure.)

The inner or serond pair of wings are joined to the metathorax, and when at rest lie folded beneath the tegmina. If, in a fresh example, the dark colored marginal vein be pulled outward or forward with a pair of forceps, it will be seen that the wing is a thin, parchment-like membrane. with a stiff front edge, which is nearly straight, while the rounded onter and hind margins are thin and flexible. When in flight, the wing is fully extended, its upper surface being convex, while its front margin is rendered still more rigid by being overlapped by the internal margin of the upper wing or tegmen. The numerous reins radiating from the base are so arranged that their elasticity causes the wing to fold upon itself like a fan as soon as its margin is released. The prin- 
cipal veins correspond in position to those of the tegmina, and have the same names. Both tegmina and wings are wanting in a number of species of Orthoptera, while in others the tegmina are present and the wings absent.

The legs of a locust are six in number, arranged in pairs, one pair being joined to each of the divisions of the thorax. The first and second pairs are, in the leaping Orthoptera, much smaller than the third, but the number and name of the joints is the same. They unite with the body at a different angle from the hind or third pair, and are therefore adapted to crawling and clinging to grass stems or other support rather than to leaping.

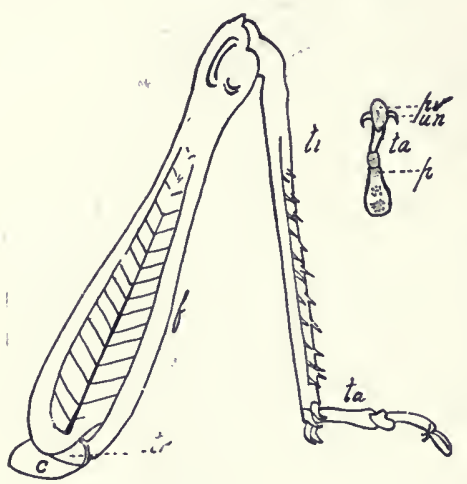

Fig. I1. Hind leg of a locust. (Af ter Lugger.)

The lind pair or leaping legs of the locust are composed of five parts: The coxa $(c)$, or basal division, which is joined to the metathorax; a small segment, the trochanter (tr), immovably joined to the upper apical portion of the coxa; the femur $(f)$, a long, swollen, club-shaped segment, which makes up nearly half the length of the limb. When the insect is at rest, it extends upward and backward, with its apical end above the dorsal surface of the body. This segment contains powerful leaping muscles. The tibia $(t i)$ is about as long as the femur but is very slender and of uniform diameter. When at rest it extends downward and backward, at an acute angle from the apex or knee of the femur, but in the act of jumping it is jerked backward against the ground or other support, into which the tibial spurs are driven, then the sudden straightening of the legs by the powerful internal muscles propels the insect into the air. In leaping the tibia is kept from wobbling by a lobe extending back each side of its base, from the apex of the femmr. The tibia usually beals on each of its upper outer margins a row of spines, and at the end one or more pairs of longer spines or spurs known as calcaria. The tibiae of the fore legs of a number of Orthoptera are much modified for use in burrowing or prehending food. The tursus ( $t a$ ) or foot of the locust is made up of three movable joints. ${ }^{4}$ The first and longest has upon its lower surface a soft

${ }^{4}$ In the grouse locusts or Tetrigida and the sand crickets or Tridactylina the fore and middle tarsi have but two joints, while the tarsi of most Tettigoniidix have four and those of the Blattidx, Mantidxe and Phasmidxe five. 
pad or pulvillus $(p)$ which, by its adhesion to foreign bodies, serves as a point of resistance in leaping. The second joint is much shorter and carries a smaller pad. The third joint is long and slender, with two curved pointed claws or ungues (un), between which is a concave sucking disk or pad, known as the arolium.

The Abdomex.-The abdomen or hind portion of the body of the locust (Fig. 1) is composed of ten more or less complete segments, so united as to be movable in a small degree. Each segment is composed of two parts, a tergum or upper portion, and a sternum or under piece. The tergum is crested or bent in the median line to form a ridge, the two sides, sloping downward, being known as tergites. The sternum of the first or basal abdominal segment is united firmly to that of the metathorax. The tergites of this segment, in the locust, each contain a large opening closed by a membrane, the anditory organ or ear. However,

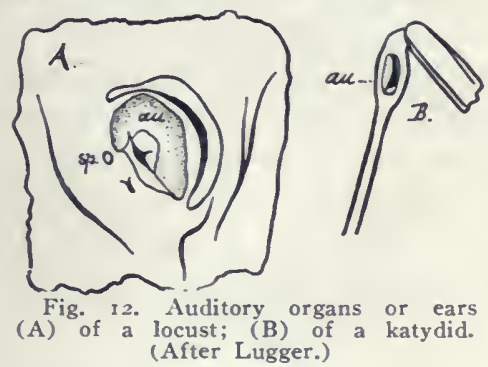
the ears of many Orthoptera are borne upon the basal portion of the front tibiae. Eight of the abdominal segments of the locust have a small opening on the lower margin of each tergite. These are spiracles or external openings of tubes which serve as air passages. The ninth and tenth abdominal segments of the locust are more or less modified in both sexes. The abdomen of the female ends in a double pair of short curved movable horny plates, known as the valves of the ovipositor. In the other families of Orthoptera in which the ovipositor is visible, these plates vary greatly in form and size. The valves in the female locust are used in forcing the earth aside, thus forming a pit in which the eggs are deposited. Between and hidden by them is the ovipositor proper.

The ventral portion of the last abdominal segment of the male locust is a large, upcurred, spoon-shaped piece known as the $s u b$ genital plate. Attached to the tergum of the next to the last segment are a pair of appendages known as the cerci. In the male locust these are unjointed, and in the different species vary much in size and shape, often affording valuable characters for classification. In many of the other families they are jointed, and more or 


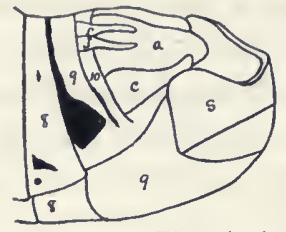

Fig. 13. Tip of abdomen of male locust: $a$, supra-anal plate; $c$, cerci; $f$, furcula; $s$, sub-
genital plate; 8,9 , Io, genital plate; 8 , 9 , I 0 ,
abdominal s e $\mathrm{g}$ m e $\mathrm{n}$ ts. (After Hart.)

less hairy. The cerci of the female locust are much smaller thin those of the male, and in other Orthoptera are often wanting. The tergum or upper portion of the tenth abdominal segment is a triangular, of ten thick solid plate, known as the supra-anal plate. At the base of this plate and resting upon it, a pair of projections, known as the furcula, are usually present in the male. In certain genera of locusts the shape, size and relative position of these afford valuable specific characters. Lying within the carity of the subgenital plate, and occupying the space beyond the tip of the supra-anal, there is in the Melanopli a structure covered with a soft integument. This is known as the pallium and is used to some extent in classification.

The above constitute the more important external parts of the locust, the characters of which are used in determining the name and position of any member of the order Orthoptera. As will he seen in the pages which follow, these different parts vary much in size and in form, but the names given to them apply as well to the members of one family as to another. By referring to the accompanying figures, and by observing arefully the parts of the specimen in hand, the beginner need have little hesitation in deciding as to whether the description agrees with that specimen.

The Reration of Orthop'tera to Other Insects.

All true insects can be separated into one or the other of two great groups, based upon the kind of changes or transformations which they undergo before reaching the adult or winged stage. To one group-the Mctabola-belong those insects which mdergo what is termed a complete metamorphosis. In this group there are four distinet stages-the egg. larval, pupal and imago-in the order named. No insect is hatched from the egg with wings, and when an insect reaches the winged stage it is adnlt. and never grows thereafter. Thus the gnats and midges are not the soms and daughters of the larger flies. lout are full grown inserts of themselves, which are undergoing the fourth or last stage of their lives. The serond, the larval or worm-like stige, is the one in which the insect of this group is commonly the most injurious. for then it eats roraciously, and then is the only period of its life when it grows in size. The pupal. or third stage, is usually a quiescent one, the insect eating nothing and not increasing in size. 

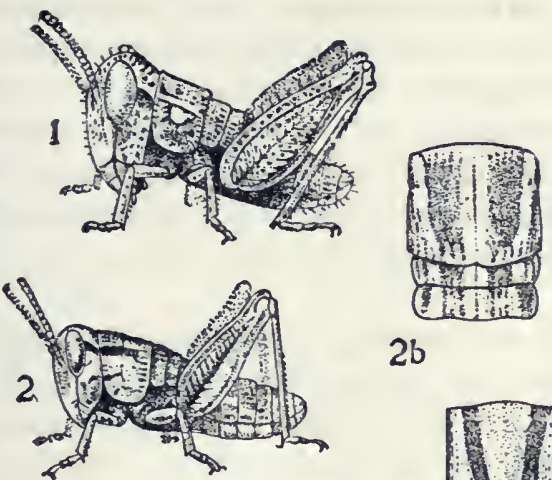

$2 \mathrm{~b}$
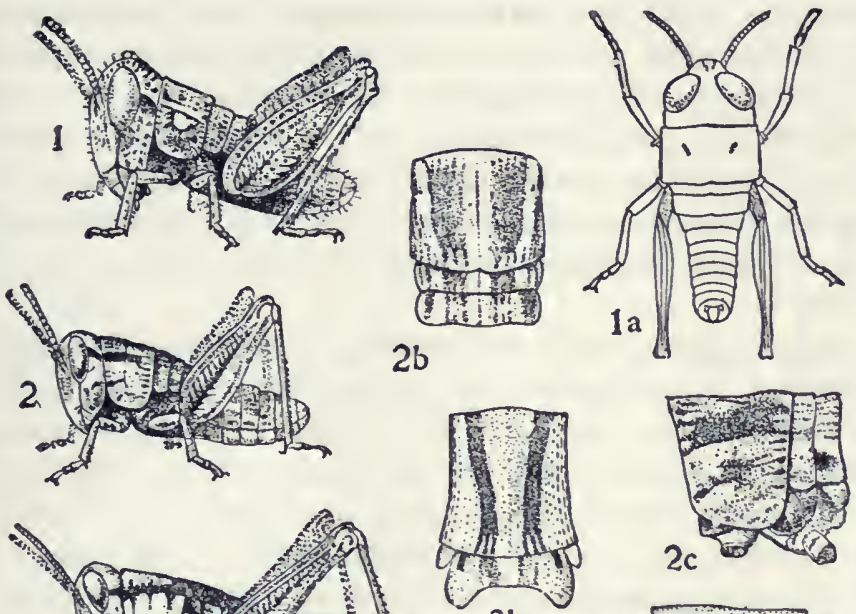

3

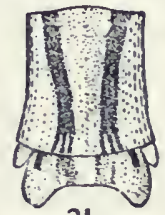

$3 \mathrm{~b}$
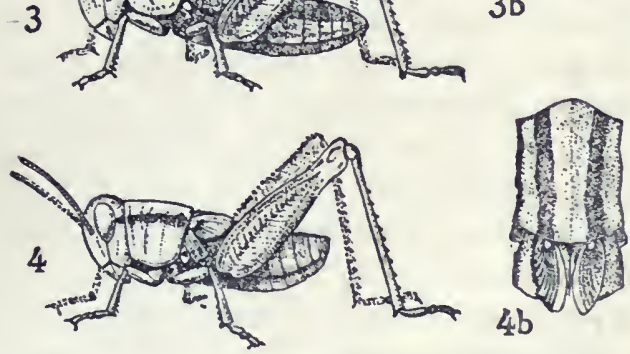

$3 c$
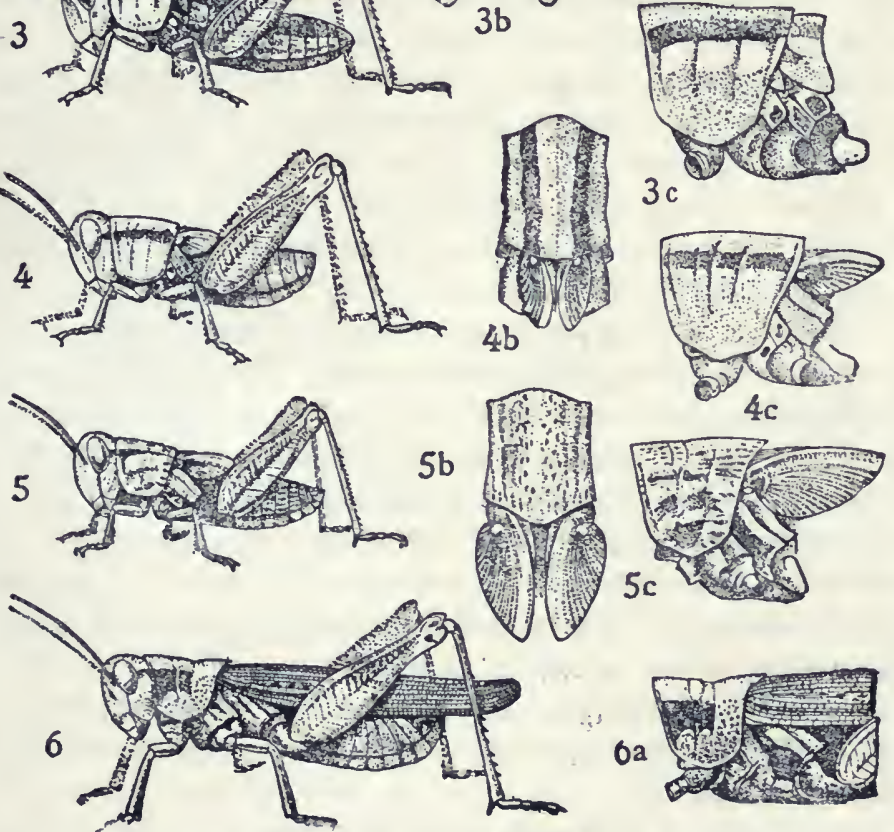

Fig. 14. Partial metamorphosis of Melanoplus femur-rubrum, showing the five nymph stages, and the partial growth of the wings, which are first visible externally in $3,3 \mathrm{~b}, 3 \mathrm{c}$. (After Packard.). 
but undergoing great changes of form. Thus the homely and often repulsive grubs, maggots and caterpillars, which are the larval forms of the beetles, flies and butterflies, respectively, enter the third stage as worm-like crawling creatures, and emerge from it as beautiful winged forms, sometimes glistening and gleaming with all the colors of the rainbow. This change of life and form is undoubtedly of great advantage to the most of this group of insects, as it tends to prevent the extinction of the species; since, if at a given moment the parents were swept out of existence, the young, living in a different station, would continue to represent the species.

The second group, the Hetcrometabola, comprises those insects in which the metamorphosis is incomplete; the young, when hatched from the egg being wholly wingless and of the same general form as the parent. As the insect grows it moults its skin a number of times and wings derelop gradually, there being no sharp line defining the larval and pupal stages. The young of all stages are called nymphs and continue active and feed from the time of hatching until they reach the final moult and energe therefrom mature or in the imago stage. The number of moults which Orthoptera undergo varies in the different families. In the true locusts there are five, while cockroaches and some mantids are said to have as many as seven:

It is to this second group, the Heterometabola, whose members undergo an incomplete metamorphosis, that the Orthoptera, the order of which this paper treats, belong. From other order's of the group, as the Hemiptera or true bugs, Odonata or dragonflies, etc., the Orthoptera may be known by having the wings, when present, net veined, four in number, the outer pair leathery or parchment-like and usually overlapping when at rest; the inner pair thinner, more delieate and folded in plaits like a fan; mouth parts biting; hind legs in the greater number of forms, greatly enlarged for leaping. The name Orthoptera is derived from two Greek words, orthos, straight, and pteron, a wing, and refers to the longitudinal folding of the hind wings. The fore wings, or tegmina, are not used in flight, the hind pair alone being used for that purpose.

\section{Enemins of Orthoptera.}

With the exception of the Mantids, all oul Orthoptera are injurious, most of them being vegetable feeders. Were it not for the many natural enemies which prey upon them, they would 
abound each season in such vast numbers as to prove a veritable scourge. These enemies are many of them parasites which live only upon Orthopterous forms, and when the latter are abundant the parasites also increase in number, and soon devastate the hordes of insects. Besides these parasites, many predaceous or beneficial insects feed upon locusts and crickets; and birds, both wild and domesticated, are exceedingly fond of them. These parasites, predaceous insects and birds are, therefore, of great benefit to the farmer, and he should do all in his power to increase their number, in order to keep within bounds the different species of Orthoptera.

Vegetable Parasites.-Among the most common parasites of locusts are two or three species of vegetable fungi, which in wet seasons attack them, sap their reins and in time destroy many of their tissues. One often finds, after a long, damp spell in late

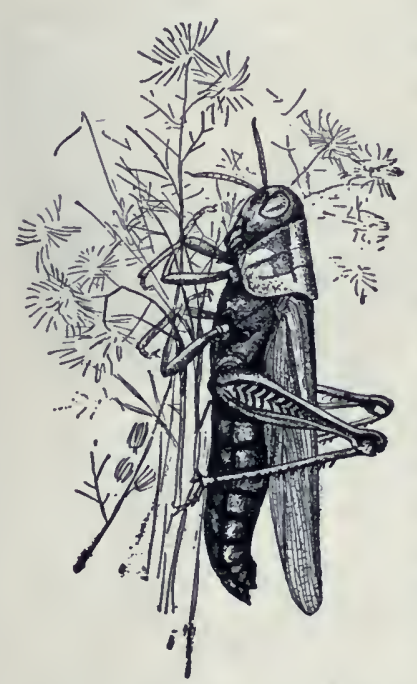

Fig. 15. Locust- Melanoplus bivittatus (Say)-killed by a fungus. (After Lugger.) summer, many dead speeimens of our larger locusts clinging to the tops of weeds. A close examination will show that their bodies are soft, and issuing from them in many places are the ends of fungus tubes. These locust fungi, Entomopthora calopteni Bessy, Empusa grilli Fres., and sporotrichum globuliferum speg., for some unexplained reason often impel the insects affected to climb some tall weed or grass stem and cling to it with such tenacity that the body remains long after death. The spores given off from the fungus of the diseased or dead locust, are more widely scattered by this peculiar habit which the host insect has of climbing tall weeds, as they can the more readily be dispersed over wide areas. Besides these fungus parasites, other vegetable bacteria attack locusts in favorable seasons. But this takes place only in long warm, damp spells; during which the locust has sought shelter and been deprived of food. Many are then often congregated together and one individual affected by the disease may inoenlate hundreds. In a dry season, the locusts and green grasshoppers are much more healthy and abundant and the damage which they do is much greater than in a wet one. 
In our northern states the number of Orthoptera and other insects which will be present in any summer depends largely upon the character of the preceding winter. Most insects pass the winter in either the egg or the pupal stage; since these forms can readily withstand long and severe cold weather, in fact may be frozen solid for weeks and retain life and vigor, both of which are shown when warm weather and food appear again. Indeed, it is not an unusually cold winter, but one of successive thawings and freezings, which is most destructive to insect life. A mild winter encourages the growth of mold which attacks the hibernatting larva and pupæ as soon as, from excess of rain or humidity, they become sickly; and it also permits the continued activity of insectivorous mammals and birds. Thus, moles, shrews, and field mice, instead of burying themselves deeply in the ground, run about freely during an open winter and destroy enormous numbers of pupx; while such birds as the woodpeckers, titmice and chickadees are constantly on the alert, and searching in every crevice and cranny of fence and bark of tree for the hibernating eggs and larva.

Axinal Parasites.-A number of parasites belonging to the animal kingdom use as their chief hosts the bodies of locusts and other member of the order Orthoptera. Among the more common of these animal parasites is the red locust mite, Trombidium lo-

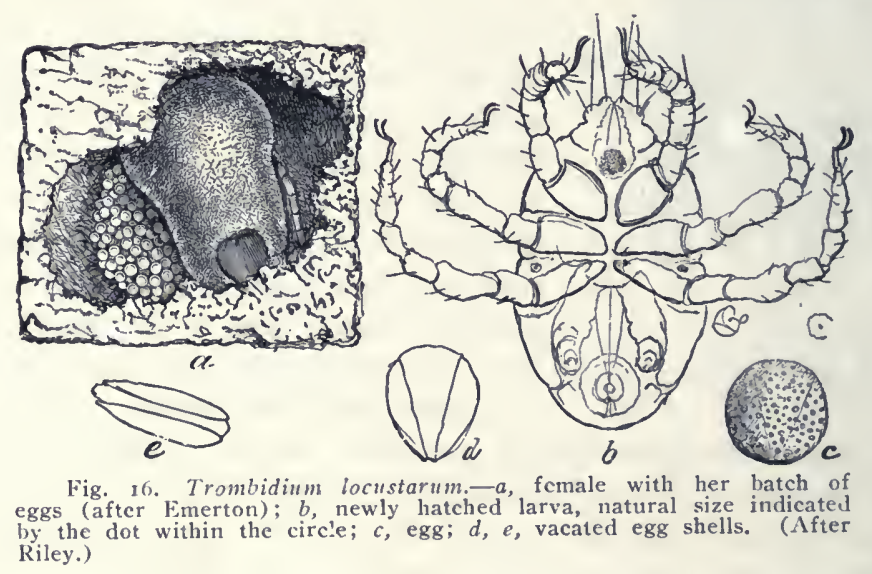

custarum Riley. On the first warm, sunny days of spring, as soon as the surface of the earth is fairly dry and warm, scores of minute "red spiders" can be seen along any pathway in the woods and fields. They are especially common if locusts were abundant 
the year before. These red spiders are in fact mature red mites. the two sexes of which are shown in Fig. 17. Soon after appearing in spring, the sexes mate and the female soon deposits $300 \mathrm{or}$ more small, globular eggs at a depth of a few inches in the soil. From each of these eggs there hatches, about the time the young locusts appear, a minute six-legged mite, which runs actively about in search of some host to which it may attach itself. When it happens upon a young locust, it fastens itself to the wings, wing pads $\mathrm{or}^{\circ}$ abdomen and uses its mouth parts to suck up the fluid portions of its host. In a short time its bods increases in size, the legs grow smaller, and the mite resembles a small, globular mass of blood attached to the locust. Sometimes as many as twenty mites can be counted on a single host. When thus infested, the locust often becomes disabled, and drags itself about

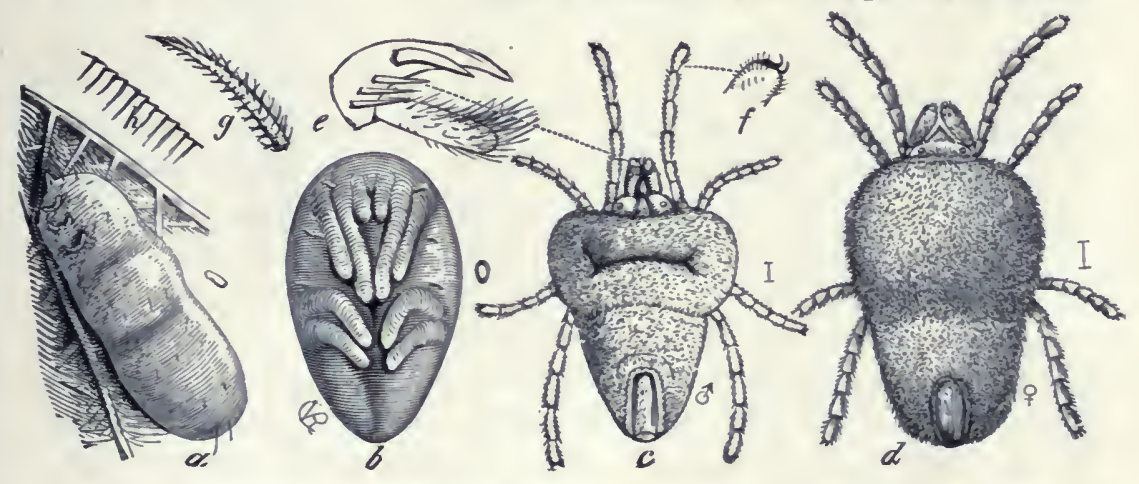

Fig. 17. Trombidium locustarum Riley.-u, nature larva when about to leave the wing of a locust; $b$, pupa; $c$, male adult when just from the pupa; $d$, female-the natural sizes indicated to the right; $\epsilon$, pupal claw and thumb; $f$, pedal claws; $g$, one of the barbed hairs $h$, the striations on the larval skin. (After Riley.)

in a clumsy fashion, eats less and dies early, often before the mating and egg-laying season has arrived. In the swollen and almost legless condition which the nite soon attains, it can not more about, and so remains in one position until full grown, when it drops to the ground and enters the pupal stage from which it emerges as the "red spider-kin" of spring. It often becomes mature in late autumn and passes the winter in the ground where it is not idle, except when the temperature sinks below the freezing point. It feeds upon all sorts of soft food, and whenerer it has access to the eggs of locusts it greedily eats them. In soil containing eggs of locusts large numbers of these mites congregate. They creep into every hole in search of these eggs and thrive upon sucl rich food. The great advantage of fall plowing over all 
other remedies against locusts is seen in regard to these red mites, as the plowing of fields in which the eggs of locusts have been deposited will destroy the young locusts hatching from them, but not the mites, which can easily work their way toward the surface.

Other parasitic animals besides these mites often attack the different speeies of Orthoptera. On a number of occasions I have found protruding from the abdomens of green grasshoppers and erickets a slender "hair worm" or "horse-hair snake," a species of Gordius. If the body of such grasshopper or cricket be cut open the interior is often found to be almost filled with this parasite, which is many times longer than its host, and it will be seen that all the important organs of the latter are pressed to one side and unable to perform their necessary functions. Locusts so affected are seldom able to propagate their kind.

Among insect enemies of the Orthoptera, which aid largely in keeping down their numbers, are "Tachina Flies," "Flesh Flies," "Bee Flies," and "Blister Beetles." Tachina flies are mostly of a gray color, and resemble large house flies. In fields where locusts are abundant, one of these flies may often be seen hovering over a large specimen, awaiting a farorable opportunity to deposit one or more of its eggs on the neck or beneath the wing. These eggs hatch into larve or maggots which eat their way into the body of the locust. There they seem to aroid the most vital parts, but feed upon the fatty secretions stored up for future use of the reproductive organs. Locusts so affected have a soft, flabby body, and can often be readily eaught by the hand. They never mate, and perish much sooner than the healthy, unaffected individuals.

The flesh flies of the genus Surcophaga attack locusts, katydids and grasshoppers in much the same manner as do the tachina flies, and their maggots are often found existing as true parasites upon the vitals of these Orthopterous insects. When the maggots of these flies become full grown, they burrow through the body wall of the loeust and drop to the ground, where they enter the earth and pass through the pupal stage from which they emerge as fully winged insects, ready for attack upon a new gen. eration of locusts. Webster (1907) records the receiving from Wyoming of a large number of dead specimen of Mclanoplus differentialis (Thos.) which had been doing much damage to alfalfa. When received the material was full of the maggots and pupe of Sarcophaga georgiana Wied. 
The egg clusters of locusts, erickets and other Orthoptera in the ground are often attacked by the larval forms of bee flies and blister beetles. The bee flies are of a blackish gray color, densely corered with pale yellow hairs, and in June and July may often be seen hovering above the ground, or feeding upon the honey of various species of wild flowers. Their eggs are laid among or close to the egg masses of the locust, and their larve feed upon and destroy myriads of the eggs of the locusts and crickets.

A dozen or so species of blister beetles or "old fashioned potato beetles" of the genera Macrobasis and Epicauta occur in our

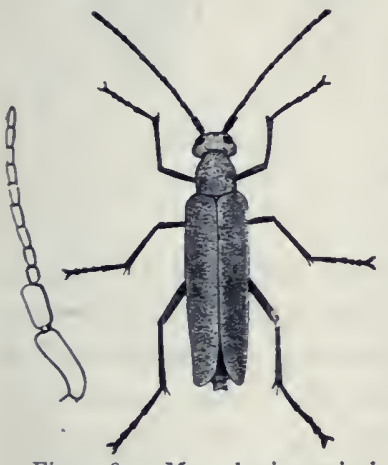

Fig: 18. Macrobasis unicolor Kirby. The ash-gray blister beetle. Female. $\mathrm{X}^{\text {(After Chittenden.) }}$

Eastern States and in the winged or full grown stage are often very injurious to potatoes and allied plants. The eggs of the blister beetles are laid in the ground in late summer, and the larva soon hatch and more actirely about in search of animal food, in the form of egg masses of other insects. They liare often been found feeding upon the eggs of locusts and other Orthoptera and are undonbtedly of much aid in keeping within bounds these injurious forms.

Many of the ground beetles or Carabida feed, during both their larval and mature stages, upon locust eggs. More than 500 species of this family of beetles occur east of the Mississippi, and all are beneficial. In the mature stage they are long legged, rapid moving forms, which mostly hide by day beneath logs and rubbish and run actively about at night in search of some form of flesh upon which they may make a meal. Since insect life is the most common form which they find on or beneath the ground, it is but natural that most of their food is composed of it. The species of Calosoma, Agonoderus and Harpalus, examples of which are figured herewith, are among the most common and beneficial of this family of beetles. The larvie of Harpalus may, in autumn, often be found feeding on the egg masses of the locust.

Higher in the scale of animal life are many forms which are among the best friends the farmer possess, yet many of them he destroys on sight through ignorance of their beneficial habits. Chief among these are skunks, shrews, moles, salamanders, toads and snakes. Skunks are rery fond of both grasshoppers and their 
egg masses, as well as of white grubs and larve of many other injurious insects, and one can often see where they have dug small eavities in the ground in search of this form of food. They are regarded by the U. S. Biological Survey, which has made a special

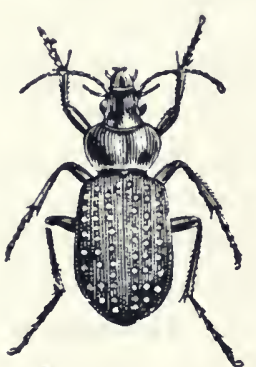

a

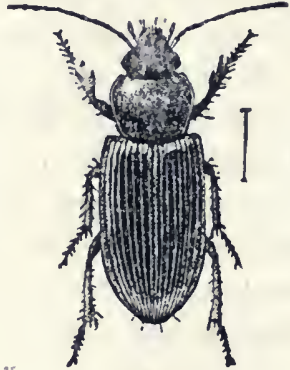

b

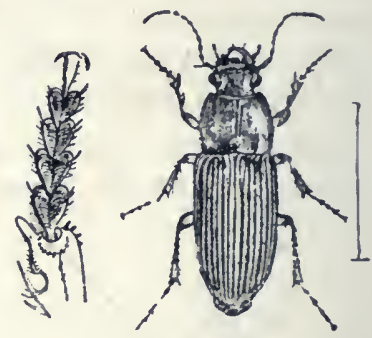

c

Fig. 19. $a$, Calosoma calidum Fab. $\times$ I.2; $b$, Agonoderus pallipes Fab. $X$ 5; $c$, Harpalus pennsylvanicus DeJ. $\times 2$.

study of their habits, as the most useful of our wild mammals and therefore deserve protection rather than destruction by the farmer. Both shrews and moles are burrowing mammals which feed almost wholly upon insect life. True, the latter sometimes destroy the seeds of corn and vegetables, but the good which they do in destroying the eggs and larva of injurious insects far outweighs the bad. Salamanders, or ground puppies, live beneath logs and chunks and burrow into the surrounding region in search of eggs and larve, while toads and snakes feed largely upon the young and mature of grasshoppers and locusts, yet all are usually destroyed at sight by farmers or their sons.

More than 100 species of birds are known to use as food either the young or full grown individuals of many kinds of Orthoptera. The U. S. Biological Survey at Washington and other authorities, have made investigations of the stomaclss of many species of birds, and have found that the following are some of the more common birds of our Eastern States which feed largely upon locusts and grasshoppers.

Partial List of Eastein Birds Which are Krowy To Fefi Upox OztiopTERA.

Franklin's Gull.

Black Tern.

American Bittern.

Least Bittern.

King Rall.
Sora.

Great Blue Heron.

rilson's Snipe.

Golden Flover.

Barn Owl. 
Screech Owl.

Red-tailed Hawk.

Red-shouldered Hawk.

Broad-winged Hawk.

Black Hawk.

American Sparrow Hawk.

Yellow-billed Cuckoo.

Black-billed Cuckoo.

Red-headed Woodpecker.

Hairy Woodpecker.

Downy Woodpecker.

Flicker.

Night Hawk.

Whip-poor-will.

Phoebe.

Kingbird.

Prairie Horned Lark.

Blue Jay.

Common Crow.

Bobolink.

Cowbird.

Red-winged Blackbird.

Meadow Lark.

Killdeer.

Quall.

Ruffed Grouse.

Prairie Hen.

Wild Turkey.

Mourning Dove.
Marsh Hawk.

Baltimore Oriole.

Common Blackbird.

Song Sparrow.

Chipping Sparrow.

Vesper Sparrow.

Chewink.

Dickcissel.

Scarlet Tanager.

Butcher Bird.

Red-eyed Vireo.

Yellow-throated Vireo.

Black-poll Warbler.

Pine Warbler.

Golden Warbler.

Water Wagtail.

Yellow-breasted Chat.

Mockingbird.

Catbird.

Tufted Titmouse.

White-breasted Nuthatch.

Ruby-crowned Kinglet.

Brown Thrasher.

Wilson's Thrush.

Wood Thrush.

Hermit Thursh.

House Wren.

Robin.

Bluebird.

Of the foregoing list, those which feed mainly on Orthoptera during the summer season are the hawks, blackbirds, crows, blue jay, prairie chicken, nockingbird and bluebird. .11 of the birds mentioned are, howerer, beneficial in the highest degree and should, at all times, be protected from their enemies, chief among which is the youth with his shotgun, or the small boy with egghunting proclivities.

\section{Prevextive and Remedial Measures Agalsst Destructive}

\section{Locusts.}

Aside from the locusts or shorthorned grasshoppers, few of our Orthoptera ever appear in such numbers as to do excessive damage. Howerer, almost every summer there is in some of our Eastern States an outbreak of locusts which, for" a time, cause serious loss. In 1918 they appeared in greater numbers and were more destructive throughout Indiana than for many years. While 
this work is not intended as an economic treatise there are four methods of preventing or dealing with a locust outbreak which are practical in application and of low cost. These should be known to every farmer and are briefly stated as follows:

Destroying the Eggs.-This is a preventive measure which is practical when an outbreak is feared in any locality. It may be easily accomplished by either plowing, disking or $^{\circ}$ cultivating in late fall or winter all waste lands such as roadsides, ditch banks, margins of cultivated fields, uncultivated fields and grassy margins along fences. Fields in young clover or alfalfa which cannot be plowed should be thoroughly disked in fall and harrowed in early spring. Stirring the soil to a depth of two or three inches will usually be sufficient, as the eggs are laid in clusters within that distance from the surface and the stirring breaks up the egg clusters, exposes them to their natural enemies or buries them so deep that the young never emerge.

Destroying With Poisonen Biat.-After the grasshoppers have appeared in numbers they can be killed by a poisoned bait scattered freely about throughout their haunts. Two formulas for this bait have both been used with success. As given by J. J. Davis, ${ }^{5}$ they are as follows:

\section{Poisoned Brax and Sawdust Bait.}

Bran (half and half bran and sawdust, or sawdust alone).......25 lbs.

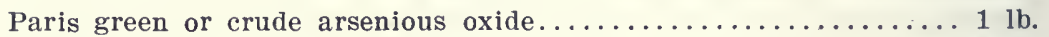

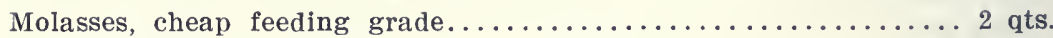
Lemons, bananas or oranges...................... fruits.

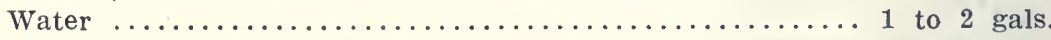

The poison should be thoronghly mixed with the bran. The water, molasses and finely chopped fruit are then mixed and added to the poisoned bran. Thoroughly mix and add water if necessary. The mixture should be wet so that it will mold in the hands, but shonld not be soppy. Coarse bran is the best material for making the bait, but the use of half hardwood sawdust and half bran, or of sawdust alone as a substitute for bran, gives very good results. The bait should be scattered broadcast early in the morning, at the rate of seren to ten pounds to the acre.

\section{Tire Cridde Mixture.}

This consists of one-half barrel of fresh horse droppings, one pound of Paris green or crude arsenious oxide, or one and one-half pounds of

"Grasshopper control in Indiana."-Circ. No. 88, Purdue Univ., Agri. Exper. Stat., I919, 1-8. See also. Farmers' Bulletin No. 69 r. 
white arsenic; six or eight lemons, oranges or bananas or one and onehalf ounces of cheap lemon extract, and water to make a wet but no: sloppy mash. These ingredients are thoroughly mixed and scattered broadcast, the same as recommended for poisoned bran bait.

Use of A "Hopperdozer" or "Grasshopper CAtcher."-These two devices for catching grasshopper's where they are too plentiinl have both been extensirely used with great success. Webster (1907) describes a (heaply constructed but efficient hopperdozer as follows: "It is constructed of sleet iron, preferably galvanized, of reasonable thicliness to insure strength, and, except for the end pieces, made of a single sheet ten or twelve feet long and 26 inclses in width. . The front is formed by turning up one edge a comple of inches, and the back may be turned uj) a foot. thus making a shallow pan one foot wide. with the back the same height and with the front two inches high. Ends are riveted in and soldered. Rumners of old wagon tire are plated at each end, and another in the center is turued orer in the front and back to strengtlen the pan at these points. These rumners are riveted to the pan. and should extend both backward and forward in order to orercome to some extent the inegualities of the ground and canse the hopperdozer to run more smoothly. Ry soldering it about the heads of the rivets the pan will be made watel-tight. A central partition six inches high will keep the contents from flowing to one side and running orer the edge on uneven ground. The pan is filled with water on which is poured enougl kerosene to cover it with a film, a horse is hitched to the end rumers. and the outfit is then ready for use. As the hopperdozer is drawn over the ground the locusts will either jump into the kerosene and water direct or against the back and drop into it and there be killed. By using longer, wider, and heavier sheet iron a larger and stronger pan can be made and this furthel strengthened by additional runners; a horse can then be hitched to each end. or the pan may be mounted on low wlieels. Crude oil or tar may be used instead of kerosene and water."

The "Grasshopper Catcher" is a somewhat similar device, but instead of killing the locusts by having them fall into a kerosene mixture, it is arranged so that when they strike the upright metal back they fall to the bottom and back tlrough a narrow trap opening into a screened box. This has a hinged lid and when full. the locusts can be easily remored into sacks and hung up to dry for poultry feed. Full details explaining the structure of this device are given in the Purdue circular above cited. The dried locusts are rich in protein and make an excellent winter food for poultrer. 
Utilization of Poultry.-Where locusts are abundant each season farmers can protect their erops and at the same time make a profit off the insects by keeping large flocks of poultry. This has been done many times in Kansas and other locust-infested States. Portable poultry yards which can be easily moved from one point to another will keep a flock of chickens in plentiful food and at the same time rid large areas of the locust pest.

About the best remedy for Orthoptera on a farm is a large flock of turkeys. Under the leadership of an experienced gobbler, almost their entire time during the summer and fall months is spent in wandering over the fields and pastures in search of the fat and juicy nymphs of locusts, grasshoppers and crickets. Indeed, most of the luscious white and brown meat of our Thanksgiving and Christmas dinners was once grass, then grasshoppers, and finally turkey. No better and more practical remedy can be devised, for the damage which the insects do, especially in these days of "turkey trusts," is often more than compensated by the value of the pounds of flesh which this domesticated fowl stores up from its favorite food of locusts..

\section{The Collecting and Preservation of Orthoptera. ${ }^{6}$}

As will be noted in the pages which follow, each species of Orthoptera has its favorite local habitat or chosen haunt, the place where it finds the struggle for existence least fierce, food most abundant, protection or concealment from its enemies most easy. Here the collector will find that species most abundant and for the beginner a few directions for its capture and preservation will perhaps be useful.

Insect Nets.-The most efficient device for taking the majority of forms of Orthoptera is a strong sweep net. The frame of the folding steel landing net made for fishermen and sold in most sporting-goods houses serves admirably for the frame of a sweep net. When unfolded it should have a diameter of about 16 inches; and the handle should be preferably of one piece and not over 30 inches long. The bag should be made of light canvas or very heavy unbleached muslin and should be 20 to 24 inches in depth. Such a net can be easily used with one hand both in sweeping from side to side herbs and small shrubs as one walks leisurely along, or it ean be used more forcibly in quick upward sweeps against the branches of larger shrubs and trees, thus jar-

${ }^{6}$ For more detailed directions on this subject see Bruner (1895a) or Banks (r909.) 
ring the insects into the net, where they can be captured with fingers or forceps, or by placing the mouth of the killing bottle

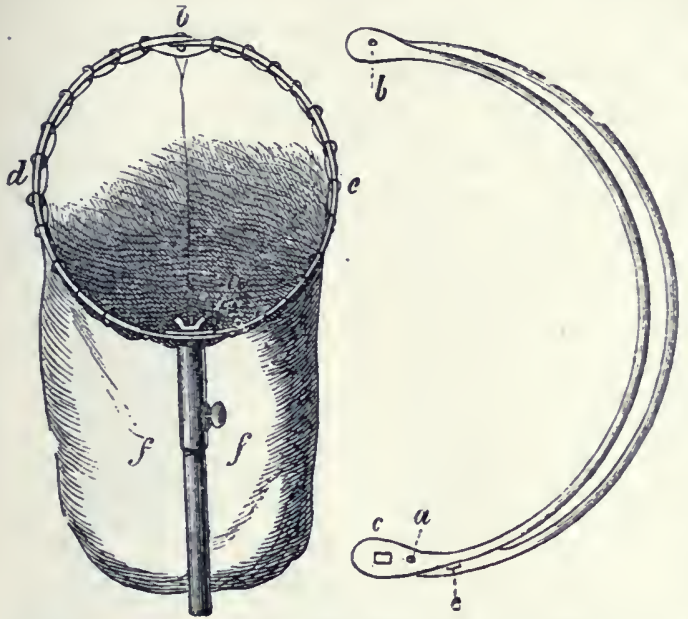

Fig. 20. One form of a sweeping or beating net opened and attached to handle, with frame of same folded. (After Kiesenwetter.) quickly orer them. This net also serves well instead of an umbrella as a beating receptable. For this purpose it is held under the foliage with one hand while the limb is struck a quick, sharp downward blow with a strong stick. The sweep net serves best in the capture of such Orthoptera as do not fly quickly as mantids, phasmids, most katydids, long-horned grasshoppers, tree crickets, ground and sand crickets, etc.

For the quick flying or leaping Orthoptera, as the short-horned locusts, species of Scudderia, etc., a strong butterfly net with the bag of gauze, bruxelle or mosquito netting will be most useful. With this the insect may usually be taken by a quick swoop just as it rises, or by bringing the net suddenly down over it from above, as it rests on the ground. The thin meshed bag has the advantage of the insect being readily visible when captured, whereas one must open the sweep net and peer into its depths, thus giving many a fine specimen a chance to dart out and away. A cheap frame for either sweep or butterfly net can be made of a piece of heary No. 4 or larger wire bent into the proper form with about three inches of each end bent in such a way that they can be made parallel and then forced into the end of a bamboo or other handle.

Another device used by collectors is the forceps net made of two rings fire or six inches in diameter, each with gauze stretched tightly across it, the two handles to which the rings are attached being hinged like a pair of large shears and the rings tightly fitting when closed. This net is useful in taking tree crickets and other Orthoptera which have been located by their song at night. 
It is opened and then clapped suddenly together abont the insect which is held tightly botween the two pieces of gaume mntil remored. Many Orthoptera ran also be taken by beating into an ofern umbrella, but quick action is usually necessan to aptures the sperinen after it is once in the mgainly receptacle.

Most of the gromd revickets hide by day in burrows or bencath stores, logs, piles of dead leaves or other debris, while roarhes hide beneath loose bark or behind signs attached to trees. These norturnal forms ('an usually easily be taken by overturning their corer and rapturing with fingers or forceps. Mole crickets ma often be found beneath a stone or chunk at the end of their burl.ows, or by digging with a spade or trowel into the mlick about the border of a lake or pond.

Trappixg Jars.--W. 'T. Davis and others have had much success in taking camel-crickets. (Centhophilus) and other terrestrial species by trapping with a special molasses bait. This bait is made by taking a pint of cane or Ner Orleans molasses (not corn syrup) and adding to it a teaspoonful of fusel oil. Into an old tin or wide mouthed jar or bottle this bait is poured to a depth of about one-third of an inch. The jar is then sunk in the gromul to the level of its $1 m 0 n t h$ and a chip or flat stone placed at an incline just above it to keep out rain or falling debris. If risited two or three times a week many insects will be found which. when removed with forepes into a box, then thrown into water for half an hour and afterward dried, will be ready for momting. These traps are most sucressful when placed along woodland paths, border's of ficlds, near an old $\log$, a pile of stomes or base of a cliff, especially where dead leaves or other debris ocrurs in quantity.

Night Colfectixc.-Many rare species of nocturnal Orthoptera can best be captured by using a flash light or small (amp) acetylene lantern after night. They will then be found moring freely about over foliage ol along pathways. Many can be located by their night song. By taking two cross-bearings, thus closely al) roximating the exact locality of the singer, it can be cantionsly approached and captured with net or hand. Numerons sjeries of Orthoptera are attracted by light, and good night collecting will often be found at the proper season beneath or near the electric street lights of cities and towns.

Kuldixg Botrus.-After capturing a specimen for a cabinet it is best to kill it as quickly as possible before its antennae, legs or other delicate apjendages are broken. This is best accom- 
plished by the cyanide bottle, which is made by placing in a large monthed bottle (one of the form shown in Fig. 21, about fire inches high by two and a half in diameter, is preferable for $\mathrm{Or}^{\circ}$ thoptera) small broken pieces of potassium or sodium cyanide to a depth of two-thirds of an inch. ('orer this with one-half inch of plaster paris. Moisten the latter with just enough water to cause it to set and hold the cyanide in place. Then cover with two thicknesses of blotting paper so cut as to closely fit the inside of the bottle. Keep the bottle tightly corked and in a place

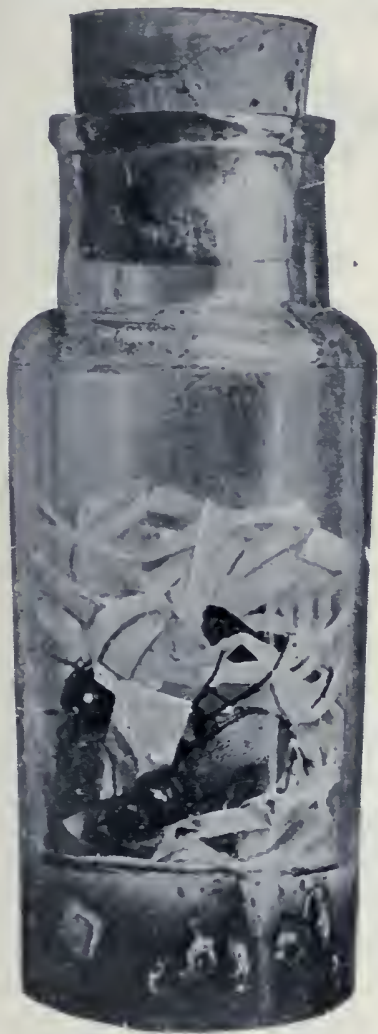

Fig. 21. A cyanide bottle with paper strips enclosed to keep the insects from josiling too freely. (After Banks.) where children camot reach it, as the cyanide in an! form is a most deadly moison. Any Orthopteron placed in the bottle will usually be killed in a few minutes. Several bottles of different size for both large and small specimens should be taken on each day's trip. After six months or more the cranide usually loses its poisonons qualities and must be renewed or the bottle discarded for a fresh one.

A small wooden or tin box with layers of felt or cotton should be taken into the field and after a half dozen $o^{\circ}$ so sperimens have been killed in the bottle they should be remored to this box, as ther are apt to be broken if carried about for several hours. The cranide bottle after being used several times for large Orthoptera will often be found to contain much moisture. It should then be wiped out with dry rotton and new pieces of blotting paper substituted for the moist ones. A large bottle with a solid lump or two of cyanide held in place by a mass of cotton or slureds of tissue paper can be temporarily nsed for very large specimens.

After the day's collecting the specimens should be either mounted or, if away from home, packed for carrying or shipment. They are best transported by placing between laser's of felt or rotton in small cigar boxes. If in a moist climate and packed too rlosely they are apt to mold in a short time. With the larger spec- 
imens this can often be prevented by slitting the abdomen along the middle or sides of under surface with a pair of sharp pointed seissors and removing the intestines and other internal organs with a pair of forceps. Then wipe out the eavity with a small piece of cotton and stuff with loose raw cotton or very small pieces of cheese-eloth, taking eare not to fill too full and distend the abdomen beyond its original size. Press the sides of the ab-

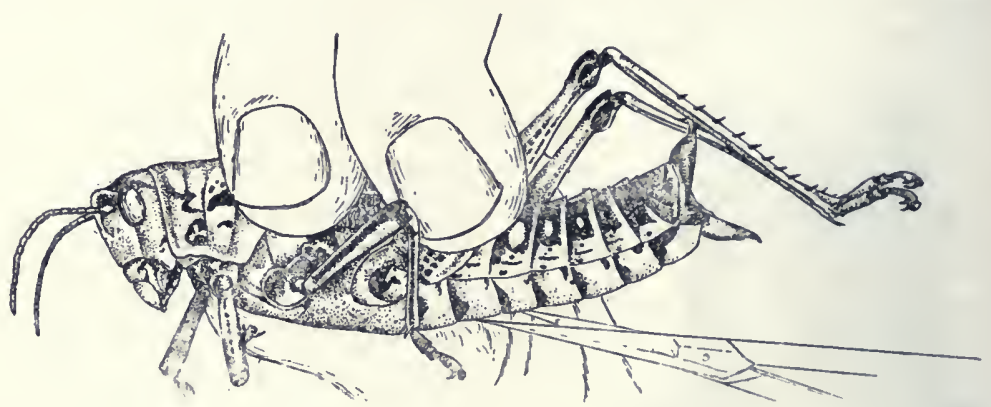

Fig. 22. Showing method of slitting abdomen of large Orthopteron. (After Bruner.)

domen gently into shape and mount on a pin or pack for shipment. Speeimens so stuffed do not become soft and turn dark, but retain their original color and are less apt to be attacked by museum pests or mold.

Labelling Specimexs. - With each" layer of specimens in a box place a label giving the date and place of capture and an accession number referring to a similar number in a note book giving any special data regarding the oceurrence, song, food plant or other information concerning the speeimens which may be of value in the future. When mounted each pin should bear below the insect a locality and date label and also an accession number referring to note book data. Without such labels a specimen is of little scientific value. Personally I would at any time rather have a label without a specimen than a specimen without a label.

Dried specimens can be relaxed sufficiently for mounting by placing between thoroughly moistened layers of blotting paper in a tightly elosed box or other receptacle for 10 or 15 hours. If the weather is very warm a drop or two of carbolic acid or alcohol had best be sprinkled over the blotting paper. The mold on specimens can be removed by using a camel's hair brush and alcohol to which a few drops of carbolic acid have been added. 
Preserving the Natural Colors.-Most Orthoptera retain their natural colors after drying, but the green or bright colored ones usually fade to a dull yellow or other hue. This can be prerented by placing the specimens, when first captured, in a solution of 19 parts water and one of commercial formalin. If on a long collecting trip, they should be packed closely enough to prerent jostling and should be removed, dried and mounted after two or three weeks' stay in the solution.

Prnsing Specrams.--In pinning specimens of Orthoptera for the cabinet care should be taken to so locate and pass the pin as

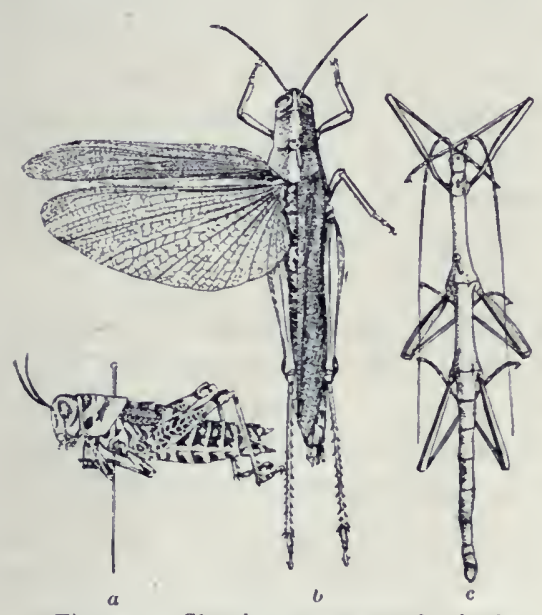

Fig. 23. Showing manner of pinning Orthoptera, spreading wings, arranging autenna, etc. (After Bruner.) to hold solidly the insect and at the same time not interfere with its future study. In the locusts, katydids and other jumping forms the pin should be pushed through the right side of the metazona, inclining the point slightly backward so that it will pass throngh the metasternum, thereby holding the body rigidly in place. In the roaches, mantids, etc., it should be inserted behind the pronotum through the right tegmen near the middle of the body, care being taken not to run it through the base of any leg. After mounting and labelling, the pin should be run through the lid of a pasteboard box, or thin piece of cork placed on supports, far enough for the bottom of the specimen to be brought down to the level of the box cover or cork. the tibiae being folded back under the femora or the legs crossed so as to take up as little room as possible and ret be available for study. One specimen of each species should have the left tegmen and wing spread out and pinned at right angles to the body, so that the reining and color of the inner wing may be studied. The antennae, when long, should be bent back along the sides of the body. The "tray" or lid of specimens should then be placed in a drying cage, which is easily made by screening two sides of a narrow box standing on end with fine mesh wire, thus allowing the air to pass through and at the same time preventing the speci- 
mens front becoming infested with the eggs of dermestids and other museum pests : small cleats tacked at intervals on the inside will serre to support the pasteboard trays. After drying for a week or so the specimens can be transferred to permanent cabinet boxes, which should be as nearly dust-proof as possible.

Earwigs. small crickets and other minnte forms shonld be monnted (as is the beetle in Fig. 24) with transparent glue or

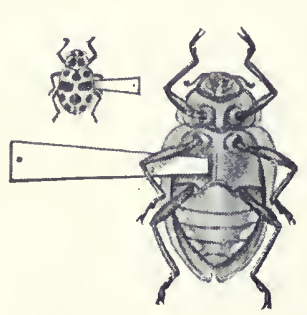

Fig. 24. Showing method of gluing an in-

(After Banks.) shellac on the tip of a small narrow triangular card through the base of which a pin has been run. Only a rery small amount of the glue is necessary, it being most readily applied to the card with the tip of a wooden toothpick. The legs should be carefully spread before mounting and the body then pressed down firmly on the glued card, which should be placed at right angles on the left side of the pin with the head of the insect away from the person.

Musecu Pests.-On account of their bulky bodies Orthoptera are especially subject to the attacks of museum pests. Flakes of napthaline kept in each box will usually serve as a repellant for such pests. Each box should be examined three or four times a year, and if by dust, exuria or other debris, the presence of pests is indicated, a few drops of carbon bisulphide should be poured in the box and the lid quickly closed. The rapor of this will soon destroy the eggs, larvæ or other living form of any pest. 


\section{A DESCRIP'TIVE CATALOGEE OF THE ORTHOPTERA OF THE EAS'TERY UNITED S'TATES ANI FASTERY

$$
\text { C.INADA. }
$$

As represented in the territory corered by this work the order ORTHOPTERA, defined on p. 24, may be subdivided into foul classes or suborders, which in turn are rejresented by eight families. ${ }^{7}$ The suborder's nua be distinguished by the following:

$$
\text { KEY TO SUBORDERS OF EASTERI ORTHOPTERA. }
$$

a. Abdomen of both sexes terminating in horny forceps-like appendages: body short, narrow, more or less flattened; head horizontal, the mouth in front; tegmina, when present, leathery, very short, without veins, meeting in a straight line down the back; tarsi 3-jointed, usually without arolia. Suborder I. Dermaptoria. p. 42.

aa. Abdomen not terminating in forceps-like appendages; tegmina usually membranous or parchment-like, thickly veined, not meeting in a straight line down the back, but usually overlapping.

b. Legs of equal or nearly equal size, the hind femora not enlarged for leaping; organs for producing sound absent; tegmina ard wings of nymphs, when present, in a normal position; ovipositor concealed.

c. Body short, broad, oval, depressed; head almost wholly concealed beneath the pronotum, the mouth posterior when at rest; ocelli generally two; pronotum shield-shaped, transverse; legs with coxæ depressed and femora compressed. Insects of rapid motion.

Suborder II. Ctrsoria, p. 59.

cc. Body elongate, narrow; head free, not covered by pronotum, the latter usually longer than broad; ocelli three or wanting; legs slender, rarely depressed. Insects of slow motion.

Suborder III. Gressoria, p. 114.

$b b$. Legs of unequal size, the hind femora fitted for leaping, being much thickened and swollen, and usually much longer than the middle femora; organs for producing sound usually present; tegmina and wings of nymphs, when present, in a rerersed position; ovipositor usually exserted so as to be plainly visible.

Suborder IV. SALTAToRia, p. 148.

TThe eight families of Orthoptera hereinafter treated comprise all those represented in North America, with the exception of the Grylloblattida. a family fonnded by E. II. Walker (1914, 93) for a small wingless thysanuriform insect, Grylloblatta campodeiformis Walker, taken on Sulphur Mountain, Banff, Alberta, and therefore, for ihis work, extralimital. The females possess an exserted ovipositor, similar to that of certain Tettigoniidx, and thereby differ from all other known non-saltatorial Orthoptera. Students interested in this remarkable insect, which forms a sort of "living forsil" or connecting link between the Orthoptera genuina as treated in this work and other nore primitive orders of insects, as the Isoptera and Plecoptera, are referred to the paper bv Walker (loc. cit.) and also to four others by Dr. G. C. Crampton, nuhlisher! in the Entomological News (XXVI, 1915, 337; XXV1I. 1916, 241: X.X. 1910.42. 6it) and the Canadian Entomologist (XLIX, 1917,213 ); also to one by Walker (Can. Ent., LI, 1919, 13I). 


\section{Suborder I. DERMAPTORIA.}

(Dermaptera. Euplexoltera.)

This suborder is represented in the United States by the single family Forficulidae, which comprises those Orthopterous insects commonly known as "earwigs." They form a rery compact and easily recognized group, though their relationship to other insects is somewhat difficult to ascertain. That they existed as far back as Mesozoic time is proven by their remains which have been found in the European rocks of that age, while in this country 20 or more fossil forms have been described by Scudder from the Tertiary formations of Cenozoic time, mainly from the famous Florissant Basin in South Park, Colorado. The first of the present living species described were placed by their author, Linnaens, in the genus Forficula and assigned to the order Coleoptera. They were later shifted about from one order to another under the names Forficula, Forficulariae, etc., until 1831, when Latreille separated them from the other Orthoptera under the name Dermaptera, a name meaning "skin" + "wing" and already used by DeGeer in 1773 for the entire group of Orthoptera. Other names since proposed for them have been Dermaptoptera by Burmeister and Euplexoptera by Westwood, both in 1839. By most American anthors they have been hitherto regarded as a separate order under either the name Dermaptera or Euplexoptera. I prefer to treat them as a suborder of Orthoptera, coördinate with Cursoria, Gressoria, etc.

\section{Family I. FORFICULID $\approx .^{8}$}

The Earwigs.

The living species of earwigs range in length from 2.5 to 37 mm., and have the body narrow and flat, the thorax and abdomen broadly connected; head short, more or less heart-shaped and horizontal; mandibles strong; antenna 10- to 35-jointed, the second joint always very small; thorax short, often slightly narrower than the head and in our species usually almost square. The tegmina or wing covers are leathery or horny in texture, meet in a

\footnotetext{
${ }^{8}$ Burr $(1911,6)$ treats the earwigs of the world as a separate order, Dermaptera, and recognizes three suborders, Arixenina, Hemimerina and Forficulina, the latter, only, being represented in this country. I consider these as families of the suborder Dermaptoria. IIe characterizes his suborder Forficulina, the equivalent of our family Forficulidx, very briefly as follows:

"Ovinarous: eyes well developed; mandibles normal; fully winged or apterous; cerci modified into strongly chitinized horny forceps; inner lobe of maxilla with four apical teeth; not parasitic."
} 
straight line down the back, are without reins and corer only a portion of the abdomen. The inner wings, when present, are usually very large, rounded, and bear numerous radiating veins which act like the bars of a fan in folding and unfolding the wings. When at rest, these wings are folded both lengthwise and crosswise beneath the protecting tegmina. They vary much in size and derelopment even in the same species, and Burr (1910, 451) has well said that "the abbreviation of the wings is a very common character among earwigs and is absolutely valueless as a specific character, although it somewhat alters the superficial appearance of the specimens." The abdomen ends in a pair of appendages which somewhat resemble forceps, whence the family name Forficulidæ. These doubtless represent the cerci of other suborders of Orthoptera, and vary much in shape according to species but are always more simple in the female than in the opposite sex. Were it not for these appendages the earwigs would resemble very closely some of the Staphylinidae or rove beetles of the order Coleoptera, the semblance being increased by most species of each group curving the abdomen upward when disturbed. Those species which possess inner wings use the forceps to aid in folding these organs after flight, and they perhaps also aid to some extent as clasping organs during the mating of the sexes. The legs are of nearls equal size, the hind femora not enlarged; tarsi never more than three-jointed and usually without pads between the claws. No organs for producing sound are present, and as far as known hearing organs are also absent. The sexes are distinguished br the structure of the forceps, or by the number of rentral segments in the abdomen, there being eight in the male and six in the female. In some tropical species the forceps are longer than the abdomen, while in others they are noted for the variety of their teeth and curves.

Certain earwigs possess what are known as "fœtid glands," whicls open at the hind margins of the dorsal plates of the second and third abdominal segments. From these thes can squirt forth to a distance of three or four inches a yellowish-brown liquid or emulsion, having the odor of a mixture of carbolic acid and creosote. This is used for defense as a repellant against their enemies.

Latreille (1831) states that: "The digestive canal of an earwig consists of an cesophagus, a large elongated crop, and a short gizzard furnished internally for trituration with six ridges in the 
form of lancets, separated by as many grooves. This gizyard opens by a valve into the stomach proper. Attached to the floor of the stomarch are numerons hepatic ressels, each with a beak-like termination, a circumstance which remores these insects from the ('oleoptera, where they were placed by Linueus, and approximates them to the other Orthoptera. The stomach opens into a small intestine. which is followed by a crecum and a rectum."

The name "earwig" was given to these insects in linrope, where they are abmulant and better known than in this comntry. There it is a common belief among peasants and the uneducated masses that they will, when opportmity offers, enter the ears of lumman beings and injure the sense of hearing. Such belief is, of course, nonsensical, the insect being wholly harmless. Howard $(1902,346)$ states that an early adrocate of the doctrine of similia. similibus curantm.9 prescribed earwigs, dried, pulverized and mixed with the urine of a liare, as a remedy for deafness.

Like the members of the family Blattidre, the flat body enables earwigs to live in cracks and crannies in walls and floors, beneath rubbish and the barks of logs and stumps, or between the bases of the leaves and the stems of rushes and grasses. From these retreats they come forth only by night, some to feed upon dead insects, small snails and other sluggish moving forms, while others live chiefly uron decaring vegetable matter, but often do much damage by eating ripe fruit, tender shoots and corollas of flowers, ete. ${ }^{10}$ They seem to prefer damp situations, and the majority of species occur mainly among reeds and beneath debris near the borders of lakes, rivers or the sea. Latreille ${ }^{11}$ sars: "These insects are very common in cool and damp places, frequently collect in troops under stones and the bark of trees, are very injurious to our cultivated fruits, devom even their dead congeners, and defend themselves with their pincers, which frequently vary in form, according to sex." Like other noctnrmal insects they are attracted by light, and on the ground beneath the elec.tric lights of cities in Florida and Old Mexico, the writer hats found one or two of them in numbers.

The fentale earrig is sald to brood over the eggs, but to abandon the yomg soon after they are hatehed. In this she resembles some of oml common myrialods of the genus Litholbins. which are often foumd heneath logs and rubbish curled up aromnd their eggs.

"Like things are cured by like things. ${ }^{10}$ See under Forficula anricularic, p. 5 .

${ }^{11}$ ln ('uvier's Inimal Kingdom, 18,31, IV, 5 . 
but which are nerer seen in company with the roung. Kirlos and Fipence, in their renowned classic (1859), 204). ('iting DeGreer (177:. .45). mention this habit as follows: "This cmious insect so unjustly traduced by a rulgar prejudice, approaches the habits of the hen in her care of her family. She absolutely sits upon her eggs as if to hatch them, and guards them with the greatest care. DeGeer, having found an earwig thus occupied, remored her into a box where was some earth. and scattered the eggs in all directions. she soon, howerer, collected them one by one with her jaws into a heap, and assidnonsly sat nyon them as hefore. The roung ones. whirh resemble the parent except in wanting elrtia and wings, and, strange to say, are as soon as born larger than the equs which rontained tiven. immediately upon being hatched creep like a brood of clickens nuder the belly of the mother, who rer'y quietly suffers them to jush between lier feet. and will often. as legreer found, sit orer them in this posture for some hours." Fischel (1853, (i2) also states that "the female lays the ecros, guards and even carries them about. so that they can always e:joy the moisture necessary for their derelopment."

About 400 species of earwigs have been described, mostly from tropical and semitropical countries, where they are common in the cities along the sea coast. Many of the suecies are cosmopolitan in distribution. their form enabling them to hide readily in the crevices of ships and their cargoes, and thus be horne to all lats of the earth. Inland, especially in temprerate and cold regions, they are scarce. In Indiana, for example. only three spec. (cies are known, and in all Canada but one. while in Florida !) of the 12 speries hereafter treated have been taken. Their wide disnoibution by commere has led to much confusion in synonymy, some of the sprecies laving been described under a dozen or more names.

Only 15 native or established species of earwigs are at present known from America north of Mexiro. Of these 12. belonging to three subfamilies. occur in the territory covered hy this work. The principal literature treating of these is as follows: ${ }^{12}$

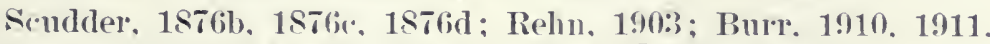
1911a ; Candell, 191:3. 5ั95; R. \& H., 1914e; Hebard, 1917.

KEY TO SEBFAMILIFS OF FORFICTLID.E.

a. Second tarsal joint cylindrical, not prolonged leneath the third.

b. Antennæ with 16 to 30 segments, the fourth. fifth and sixth to-

13For full titles of papers see the Bibliography. 
gether rarely longer than the first.

I. LabiduriNe, p. 46.

$b b$. Antennæ with 11 to 15 segments, the fourth, fifth and sixth together longer than first (Fig. 25, a.)

II. Labinate, p. 49.

aa. Second tarsal joint lobed and prolonged beneath the third. (Fig. 25, c) ; antennæ with 12 to 15 joints.

III. FORFICULINA, p. 54.
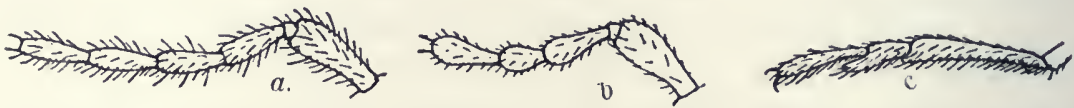

Fig. 25. a. Basal joints of antennx of Labia showing relative proportions of segments; $b$, same of Prolabia; $c$, tarsus of Forficula showing lobe of the second segment. (After Caudell.)

(After Caudcll.)

\section{Subfamily I. LABIDURIN E.}

Body not strongly flattened; pro- and mesosterna not narrowed behind; legs stout and short; abdomen slightly dilated beyond the middle. Two genera occur with us, easily separated as follows:

KEY TO GENERA OF LABIDURINA.

a. Tegmina and wings wholly wanting; sixth joint of antennæ a littie longer than broad; cheeks behind the eyes, when viewed from above, slightly longer than the eyes. (Fig. 26, c.).

I. Axisolabis.

$a a$. Tegmina and wings present; sixth antennal joint no longer than broad; cheeks no longer than the eyes. (Fig. 26, b.)

II. LABIDURA.

I. Anisolabis Fieber 1853, 257 (Gr., "unequal" + "forceps.")

Body long, rather slender, wholly apterous, of nearly equal width throughout; antennæe scarcely half the length of body; second and third abdominal segments often with small lateral folds or tubercles; subgenital plate rounded, male, triangular, female; forceps short, pointed, the right leg curved in more than the left, male, short and nearly straight, female. Two cosmopolitan species occur in North America. ${ }^{13}$

KEY TO NORTII AMERICAN SPECIES OF ANISOLABIS.

a. Antennæ 24-jointed; apical third of antennæ without pale segments.

1. MARITIMA.

${ }^{18}$ A single specimen of a third, Anisolabis (Euborellia) ambigua Borelli, described from Costa Rica and frequent in the West Indies, has been recently taken by Hebard at Miami, Fla. It is probably only an adventive not as yet established in Florida. 
aa. Antennæ 15 or 16-jointed; one or two segments of apical third of an tennæ pale.

2. Axxulipes.

1. Axisolabis maritima (Géné), 1832, II, 224. Seaside Earwig.

Blackish or dark mahogany-brown, shining; legs and under surface yellowish; antennæ pale brownish-yellow, pubescent, 24-jointed. Legs of forceps of male remote at base, finely crenulate within, strongly curved inwards; of female contiguous at base, crenulate within, feebly curver and usually slightly crossed and bent upward at tip. Length of body, 18-20; of forceps, $3 \mathrm{~mm}$.

Dunedin, St. Petersburgh, Sarasota, Cape Sable, Long Kè and Key West, Fla., Dec. 20-Mch. 25. (W. S. B.). Frequent throughout the winter beneath piles of seaweed, boards, half buried logs and other debris just above high water mark, where it lives as a scavenger. When their cover is removed they run about with abdomen curved upward and forceps widely opened, ready to nip auy approaching enemy. Recorded also by Rehn, Hebard and Daris from numerous localities along the east coast of Florida between Jacksonville and Key West; January-September. This is a cosmopolitan species occurring in this country along the coast from Maine to Texas, and is seldom found far from salt water. Morse (1919a, 21) states that along the New England coast it hibernates as an adult, the eggs being laid in summer.

\section{Axisolabis Axxulipes ${ }^{16}$ (Lucas), 1847, LXXXIV. Ring-legged Earwig.}

Black or dark brown, shining; legs and under surface yellowish, the middle of femora and base of tibiæ usually annulate or ringed with fuscous; antennæ reddish-brown, paler at base, 15- or 16-jointed, the thiru and fourth joints from apex usually pale, the last two dark. Forceps of male with legs contiguous only at base, of female nearly contiguous throughout; in both sexes crenulate on inner edge and curved upward and inward at tips, more strongly so in male. Length of body $9-11$; of forceps $1.5-2 \mathrm{~mm}$.

Lakeland and Ft. Myers, Fla., Feb. 13-23 (W. S. B.) ; Key West and Delray, Fla., Jan. 19_July 7 (Hebard) ; Agr. College,

${ }^{11}$ This species was recently assigned to Euborellia Burr, a genus erected for those species which "agree generally with Anisolabis, in which genus it was formerly included, but which are distinguished by the possession of rudimentary elytra which are never free, but attached to the mesonotum." (Burr, 1911, 30.) Later (1915, 545) he says that the genus Euborellia "is now very much altered," the validity of the feature of the rudimentary wings as a generic character having been rightfully questioned by Zaher. "A remarkable fully winged aberration of annulipes having been discovered, Euborellia will now contain totally apterous and also fully winged species. It is now to be defined by cnaracters of the genitalia of the male," which he describes and then adds: "Perhaps this feature may be regarded as a generic character," Caudell (Ms.) states that he doubts the validity of Euborellia, as it is "based wholly on a concealed genital character present only in the male sex." "Since Burr also seems to doubt the sufficiency of his characterization based only on the male genitalia, this earwig is here retained under the name by which it has long been known, Anisolabis annulipes. 
Miss. (I'ecd). This s]ecies ocemes beneath rubbish in both dry and damp localities; also beneath signs on trees, and a single specimen was taken at Lakeland from beneath a pile of old pajer on the floor of a racant honse. Davis $(1914,192)$ recorded the finding of a female and sixteen young in a cell under an old railload tie at Pablo Beach, Fla., Sept. ¿־, 1913. R. \& H. (1905, 31) state that at Key West it was taken in numbers by Hebard heneath coquina rocks, sometimes in company with 1. maritima. and also with one or two large scorpions.

This, the A. arteca of Scudder (1ST6b, 251) and of Caudell $(1905,216)$ is also a cosmopolitan species, widely distributed by commerce. The first specimens recorded from the Cnited states (R. \& H.. 1904. TTS) were collected at Thomasville. Ga., though sperimens at luand were taken by H. E. Weed at Agricultural College, Miss., 20 years hefore. Adrentive specimens have been rerolded from Massachusetts, Connecticnt, Pennsylynia, and the bistrict of Colmubia, but its range in this country as given by Hebard $(1917,313)$ is from Raleigh, $\times$. Car., and Macon, Ga., southway and westward along the coast to Texas, being "generally distributed and numerous in southern Florida, the Florida keys and southern coastal California." It ranges much farther. inland than does maritima, from which it can be readily distingnished ly its shorter and narrower body, ringed legs and pale postapical joints of antenna.

\section{LAInHris Leach, 1815, 118. (Gr., "folceps" + "tail.")}

Body long, slender. not strongly depressed ; tegmina and wings both well developed; antenne with 27-30 joints, the first clavate, as long as the fourth to sixth inclusive; abdomen somewhat swollen or convex, esprecially above, the second and third segments without lateral folds or tubercles; first tarsal joint equal to the other two mited, second not lobed.

3. Labinkm midexs (Olivier), 1791, 466. Striped Earwie.

Color somewhat variable, usually reddish-brown; pronotum, and teg. mine: fuscous-brown with a median stripe and narrow margins dull yellow; abdomen dark brown above and below, the sides paler; legs and under surface, except abdomen, pale yellow; antennæ brownish-yellow. Tegmina one-half longer than pronotum, the surface rugose-granulate, as are also the short projecting tips of the wings. Abdomen more finely granulate, the anal segment with two small remote teeth. Forceps long, slender, pointed feebly curved, their legs in male remote at base, their lower inner edges finely crenulate and with a blunt tooth just behind the mid- 
dle; those of female approximate at base, coarsely crenulate along the inner edge, the left one slightly overlapping the right at tip. Length of body, $13-20$; of tegmina, $3.5-3.8$; of forceps, ô, $7-11$, , $5-6 \mathrm{~mm}$.

Sanford, Dunedin, Ft. Myers, Moore Haven and Utopia, Fla., Dec.-Apr. (W. S. B.), numerous examples taken singly or in pairs beneath cover along the margins of ponds and lakes. It also occurs beneath debris along the seashore and is attracted by light. Rehn, Hebard and Davis record it from Lakeland, Miami, Key West, Punta Gorda and other points along the coast of southern and western Florida, March-Nor. R. \& H. $(1912,237)$ state that individuals from Key West "were exceedingly repulsive owing to the fact that they emitted an odor suggesting carrion, but eren more nauseating. This seemed to originate not from an ejected secretion, but from the oily surface of the bods."

This is also an introduced cosmopolitan species, its known range in the United States extending from Raleigh, $\mathbf{X}$. Car., south and west to Louisiana and Texas. It is listed by Scudder (1900, 4) as Labidura riparia Pallas $(1773,72 \pi)$, described from Siberia. but Burr $(1911,37)$ considers Olivier's species as distinct.

\section{Subfamily II. LABIIN E.}

Burr (1911, 46) briefly characterizes his family Labiidæ (equivalent to our Labiinæ) as follows: "Antennæ with not more than 25 segments; second tarsal joint cylindrical; femora not compressed, smooth; pygidium free." Three of the four North American genera of this subfamily occur in our territory.
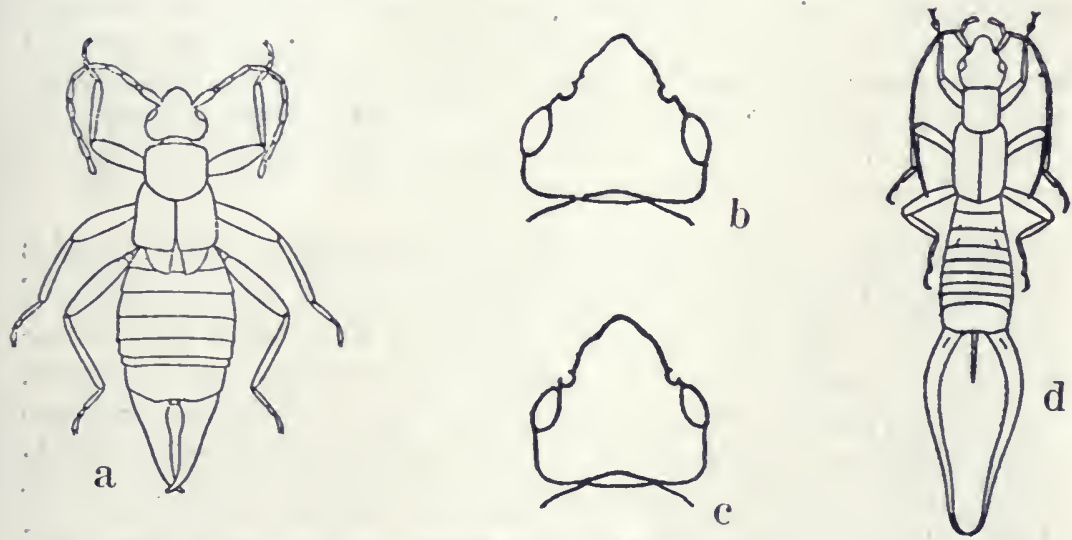

Fig. 26. $a$, Labia rehni Heb., female $\times 7 ; b$, head of Vostox; $c$, of Labia, showing length of cheeks behind the eyes; $d$, Doru davisi R. \& H.. male. $X$ 2.8. (After Caudell and R. \& H.) 
KEY TO GENERA OF SUBFAMILY LABIINæ.

a. Cheeks as viewed from above shorter than the eyes. (Fig. 26, b); sixth antennal joint much shorter than the first. I. Vostox.

$a a$. Cheeks as viewed from above as long as or longer than the eyes (Fig. 26, c.) ; sixth antennal joint as long as, or but slightly shorter than, the first.

b. Body pubescent; fourth antennal joint cylindrical, as long as third (Fig. 25, a.); smaller, not over $7 \mathrm{~mm}$. in length, including forceps. II. LABIA.

$b b$. Body glabrous; fourth antennal joint more or less conical, distinctly shorter than third (Fig. 25, b.); larger, 8 to $10 \mathrm{~mm}$. in length, including forceps.

III. Prolabia.

\section{Vostox Burr, 1911a, 59. (Without meaning.)}

Body flat, long, slender, the sides of abdomen straight; head broad, the sutures strong and deep; eyes large, prominent, longer than the first antennal segment; antennæ 14-15 jointed, the first joint no longer than 4 th and 5th together; tegmina and wings present; tarsi long and slender, the first joint longer than the next two united; second and third abdominal segments with lateral folds; forceps of medium length, nearly straight, their legs not crossed at tips. "Allied to spongiphora but differs in the smaller stature, longer and more slender tarsi with shorter second and longer first segments." (Burr, 1911, 51). One species is known from the United States.

4. Vostox BRUndeipennis (Serville), 1839, 30. Brown-winged Earwig.

Head, thorax and tegmina almost black, shining; abdomen, forceps and under surface dark chestnut brown; exposed portion of inner wings half the length of tegmina, yellow, dark brown at tips; legs brownishyellow; antennæ pale brown. Forceps stout, tapering, pointed, incurved near tips, their legs crenulate along the lower inner edge and in male armed with a more or less prominent tooth at or in front of middle; in female with a large quadrate tooth at basal fourth. Length of body, 8.5 -9.5 ; of tegmina, 2.2 ; of forceps, $3-4 \mathrm{~mm}$.

Marion Co., Ind., Nov. 10-19, 1917; one male, three females and two nymphs taken by Philip Spong from beneath bark of dead beech. The male has the right leg of forceps only threefourths the length of left one, and lacking the usual median tooth. Dunedin, Fla., Dec. 3 and Jan. 1, four females from beneath the close fitting bark of dead water oak, five feet above the ground; Okeechobee City, Fla., March 6, a dozen or more beneath bark of dead maple in a former cypress swamp. (W. S. B.) Recorded also from St. Augustine, Palatka, Ormond and Enterprise, Fla. 
(R. \& $H ., 1916,112)$, and taken in number's by Hebard at Thomasville, Ga., from beneath bark of dead magnolia (R. \& $H$. . 1904, 778). Ranges from Pennsylvania, Southern Ohio (Dury), Central Indiana and Southern Illinois (Gerhard), south and west to Columbia, Texas, but usually rare wherever found (Hebard, 1917, $315)$; from "New Jersey to Nebraska, Texas and Arizona" ( Scudder). Serville's types were from Philadelphia.

\section{Labia Leach, 1815, 118. (Gr., "a holder or forceps.")}

Body flattened, slender, the abdomen slightly widened at middle; head narrow, the sutures subobsolete; eyes small, not as long as first antennal segment; antenna about half as long as body, 10-13-jointed, the segments obconical, about three times as long as broad; tegmina and wings present in our species; first and third tarsal joints equal, the second minute, simple, compressed; forceps seldom more than half as long as abdomen, those of male slightly or strongly curved, horizontal; of female simple, straight, incurved at tip, usually unarmed. Three species are known from this country.

KEY TO YORTH AMERICAN SPECIES OF LABIA.

a. Tegmina nearly twice as long as pronotum (Fig. 27); forceps of female unarmed on lower inner margins.

b. Legs uniform brownish-yellow; last ventral of male with a prominent tooth projecting backward from middle of hind margin.

5. MIXOR.

bb. Legs more or less infuscated throughout and darker at base; last ventral of male unarmed.

6. CURVICAUDA.

aa. Tegmina only slightly longer than pronotum (Fig. 26 a.); forceps of female armed with minute blunt teeth along the lower inner mar. gins.

7. REHYI.

5. LABIA Mrxor (Linnæus), 1758, 423. Little Earwig.

Body thickly clothed with fine yellowish pubescence. Head and sides of abdomen nearly black; mouth parts, antennæ, thorax, tegmina, exposed parts of wings and middle of upper side of abdomen, yellowish-brown; last segment of abdomen and forceps, reddish-brown; legs and last two joints of antennæ honey-yellow. Antennæ 10-12-jointed. Pronotum subquadrate, narrower than head, scarcely longer than broad. Tegmina nearly twice as long as pronotum, the wings, when at rest, extending fully half their length beyond their tips. Forceps of male rather stout, about three-fourths the length of abdomen, minutely toothed on inner edge. Length of body 4-5; of tegmina, 1.5; of forceps, $\hat{o}, 2, q, 1.2$ mm. (Fig. 27.) 

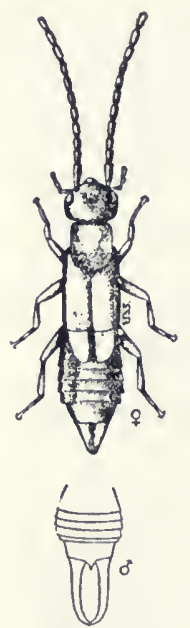

Fig. 27. La. bia minor (L.) Female. $X 4$. male showing form of forceps. (After

Lugger.)

Grand Chain, Posey Co., Ind., May 12 (W. S. $B$.), one male from beneath the bark about the base of a sycamore tree; Marion Co., Ind., June 14 ( $H$. Morrison), one female at light. A second specimen from Marion Co. was taken on the wing April 20 by Philip Spong. Probably occurs frequently throughout the State, but overlooked on account of its small size.

This little earwig is an introduced European species which has become widely distributed in this country; ranging from Quebee and Ottawa, Canada, where it is the only earwig known, west to Nebraska and Manitoba and south to Georgia. It is recorded also from Southern California by Hebard $(1917,317)$. Burr $(1897,15)$ states that it is "common in England and may often be taken in June on hot evenings, flying about with Rove Beetles orer flowers and dung-hills. In the cold weather it takes refuge among stones, in eracks, ete." Labia minuta Scudder $(1862,415)$ is a

synonym.

6. Labia Curvicauda (Motschulsky), 1863, 2. Curved-tailed Earwig.

Dark brown, the head often blackish; antennæ brown, the tenth or eleventh segment paler; legs brownish-yellow, the femora often blackish at base. Pronotum longer than wide, rounded behind. Abdomen slight. ly dilated, the last segment paler, impressed at middle, narrow, with a small tubercle each side above the insertion of forceps. Legs of male for. ceps remote and dilated at base, then strongly incurved and attenuated, meeting or overlapping at tips, and forming a semi-circle; of female near. ly straight, contiguous, unarmed. Length of body 5.5; of tegmina, 1.5; of wings, 2 ; of forceps, $1-1.3 \mathrm{~mm}$.

A tropical cosmopolitan species taken in this country only at Long Key, Fla., where it was found in numbers in Mareh, 1910, by Rehn and Hebard $(1912,237)$. It oceurred only at the moist bases of the leaves in the dying tops of cocoanut palnis which had been prostrated the previous year by a hurricane. More than 130 specimens were secured. One female guarding a tiny heap of eggs was noted. When uncovered she immediately started to remore these, taking two or three at a time to a spot an inch or two away. The types of Motschulsky were from Ceylon. The males of curvicauda are easily distinguished from those of minor by the much more strongly curved legs of the forceps and by the lack of pro- 
jecting tooth on the last ventral, while the females differ only in the color of the legs.

7. Labia Rehri Hebard, 1917, 317. Rehn's Earwig.

Resembles $L$. minor in form, size, and pubescence. Color much as there, the sides of abdomen darker. Differs in having the eyes much smaller, only three-fifths the length of cheek, in minor only very slightly shorter than cheek; tegmina shorter, only a little longer than pronotum, in minor nearly twice as long as that organ; wings projecting beyond tegmina less than half the pronotal length, in minor fully the pronotal length. Forceps of female "with ventro-internal margins not attingent, not perfectly straight, and armed with microscopic, blunt serrulations." Length of body, 4.5; of pronotum, .9; of tegmina, 1.1; of forceps, $1.4 \mathrm{~mm}$. (Fig. $26, a$.

Known only from the unique female type taken at Key West, Fla., July 7, 1912, from between boards in a woodshed. First recorded as $L$. minor ( R. \& $H ., 1914 c, 37 \tau)$. An examination of the type at Philadelphia showed it to be very distinct from $L$. minor in the characters as given.

III. Prolabia Burr, 1911a, 60. (Gr "for" + Labia.)

"Agrees generally with Labia but the segments of the antennæ beyond the third are all short, and generally more or less conical or pyriform." (Burr, 1911, 57.) Two species occur in the southeastern United States.

KEX TO SPECIES OF PBOLABIA.

a. Segments of apical half of antennæ fusiform; last ventral segment of male only twice as broad as long, the pygidium quadrate; inner wings usually present, shorter than tegmina in the form burgessi.

8. PULCHELLA.

aa. Apical segments of antennæ strongly clavate; last ventral of male three times as broad as long, the pygidium tapering behind; inner wings absent.

9. ARACIIIDIS.

8. Prolabia pulchella (Serville), 1839, 42. Handsome Earwig.

Dark, chestnut-brown, shining, glabrous; apical third of abdomen and

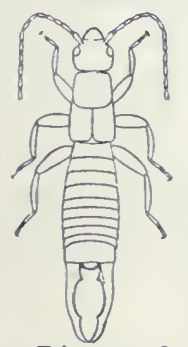

$\mathrm{F}$ i 8.28 Male of form burgessi $\times 4$. forceps reddish-brown; antennæ dusky, paler at base, 13-15 jointed; legs pale yellow. Pronotum slightly longer than broad, sides straight, hind margin broadly rounded. Tegmina half as long again as pronotum; exposed portion of wings, when present, half as long as tegmina, brownish-fuscous with a yellow spot at base. Forceps of male slender, about half as long as abdomen, their legs widely separated at base, gently curved, each with a large subbasal tooth on inner lower margin, and usually a smaller one at apical third on upper margin; of female with legs approximate at base, slightly upturned and incurved on apical half, the left one crossing the right near tips, the inner lower edge crenulate, and with a blunt tooth at base. Length of body. $6-6.5$; of tegmina, 1.6; of forceps, $2.3-2.5 \mathrm{~mm}$. (Fig. 28.) 
Ormond, Gainesville, Sanford, Miakka and Dunedin, Fla., Nov. -Apr. (W. S. B.). Common beneath bark of dead pine trees and taken also, but much less frequently, from beneath that of magnolia and oak; the winged form much less common than the wingless (burgessi Scudder). Occurs throughout Florida except on the Keys. Widely distributed over the Southern United States, ranging from Raleigh, N. Car., and central Alabama south and west to Waco, Texas. R. \& H. $(1904,779)$ record the taking of more than 150 specimens during several visits to a single dead magnolia tree near Thomasville, Ga. Servifle's type was from Niagara, N. Y., and was probably an adventive at that place. This is one of the few native earwigs of this country, and has been described under at least five different names, viz., pulchella Serv., guttata, burgessi and melancholica Scudder, and unidentata Burr nec. Beauv. The fact that the preapical teeth of the male forceps are often absent has led to part of this synonymy.

9. Prolabia arachidis (Yersin), 1860, 509. Brown Earwig.

Dark, chestnut-brown, glabrous, mouth parts and antennæ dull yellow; legs brownish-yellow, the femora often with a fuscous tinge at base. Antennæ 11- to 14-jointed. Pronotum quadrate, paler at the sides. Tegmina one-half longer than the pronotum; inner wings usually abbreviated or wanting. Forceps of male slightly more than half as long as abdomen, feebly curved, each leg with a very small basal and preapical tooth on inner edge; of female one-third as long as abdomen, the inner edge finely toothed, the legs incurved and crossing at tips. Length of body, $6.5-8$; of tegmina, $1.3-1.5$; of forceps, ô, 2.4 , $\$, 1.8 \mathrm{~mm}$.

Brighton, Mass., Feb. 1, a number of adventive specimens taken from a slaughter house (Morse). A tropical cosmopolitan species taken at Homestead, Fla., by Rehn \& Hebard (1914c, 377) July 10-12. They were found in the greasy kitchen of a boarding house, and after dark "would appear in numbers, accompanied by swarms of the roach, Periplaneta amcricana, but specimens of the earwig were secured with difficulty, as they were very active and scuttled away into cracks in the walls and tables at the first approach of a light." A single female is also recorded from Aiken, Fla. (Caudell, 1913, 598), and a number of adventive specimens from Boston, Mass. The type of Yersin was from sonthern Europe, where it occurs in and about houses. Labia brunnea Scudder $(1876 b, 258)$, described from Cuba, is a șnonym.

\section{Subfamily IIT. FORFICULIN $\approx$.}

Body moderately depressed, the abdomen more strongly so in our species; antennal segments cylindrical or subcylindrical, the 
fourth not longer than third; second joint of tarsi dilated on each side to form a heart-shaped lobe and prolonged beneath the third. Two genera occur in our territors.

KEY TO THE EASTERT GENERA OF FORFICULIT:.

a. Antennæ 12-jointed, the fourth segment twice as long as broad; legs of male forceps widely separated and feebly depressed at base and then only on the inner margin. (Fig. 29.)

I. Doru.

aa. Antennæ 14- or 15-jointed, the fourth segment less than twice as long as broad; legs of male forceps contiguous at base where they are strongly depressed and much broadened.

II. Forficula.

I. Doru Burr, 1907, 123. (Gr., "spear.")

Antenna with segments three and four nearly equal; pronotum longer than wide; inner wings (in our species) usually rudimentary; abdomen subparallel, feebly dilated; pygidium of male armed with a distinct tubercle or spine.

KEY TO EASTERT SPECIES OF DORU.

a. Form robust; spine of pygidium of male distinctly shorter than the last ventral segment. (Fig. 29.)

10. ACULEatuM.

aa. Form much more slender; spine of pygidium of male as long as the last rentral. (Fig $26, d$.)

11. DAVISI.

10. Doru aculeatum (Scudder), 1876f, 262. Spine-tailed Earwig.

Dark chesnut brown; palpi, legs, edges of pronotum and outer two.

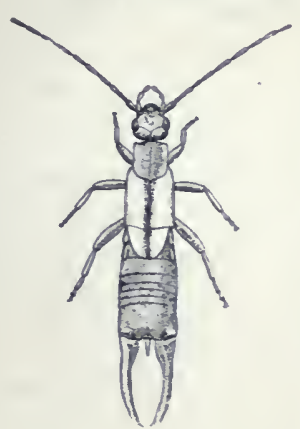

Fig. 29. Doru aculeatum (Scudder.) Male $\times$ 2.5. (Original.) thirds of tegmina yellow. Pronotum longer than broad, narrower than head. Tegmina nearly twice as long as pronotum, truncate; inner wings usually aborted. Forceps of male, three-fourths as long as abdomen slender, curved, bent down. ward a little at basal third, becoming again hor. izontal a little before the tip, a pointed tooth present at second bend; of female shorter than those of male, their legs nearly straight, the lower inner edges very finely crenulate and usually contiguous for most of their length, the tips incurved. Length of body, $\hat{\delta}, 8-11$,,$+ 7.5-10$; of tegmina, $\hat{o}$ and ㅇ, 2.5-3: of forceps, $\hat{\delta}, 4 . \overline{-}-6, \hat{q}, 3-3.5$; of pygidial spine, $\hat{\delta}, . \delta-1 \mathrm{~mm}$.

Posey Co., Ind., April 9 ; fifteen specimens from beneath rubbish and leares in woods along the north bank of the Ohio Rirer. one mile southwest of Mt. Vernon; Kosciusko Co., Ind., June 24, a dozen or more taken by sweeping sedges and high marsh grasses along the edges of James Bar, Tippecanoe Lake (W. S. B.). 
Mineral Springs, Oct. 2 (Gerhard). Agricultural College, Mich., July 14 (Weed). Ranges from New Jersey and southern Michigan west and south to Nebraska, Georgia and Louisiana.

Hebard $(1917,322)$ states that three specimens from Morgan City, La., are the only ones known having the inner wings fully developed. This earwig is usually found only on grasses and sedges growing near or even in water, ${ }^{15}$ and probably hibernates as imago beneath rubbish in the vicinity. Burr $(1910,464)$ and Caudell $(1913,596)$ have placed aculeatum as a synonym of Doru lineare (Esch.), but comparison with specimens of lineare in my collection from Orizaba, Mexico, show that Rehn \& Hebard (1914e, 90) are fully justified in considering the two distinct.

\section{Donu Davisi Rehn \& Hebard, 1914e, 95. Davis's Earwig.}

Differs from aculeatum in its much more slender body, in having the forceps of male longer than abdomen, more slender, curving feebly downward in basal third, thence upward to apex, the preapical tooth wanting; pygidial spine of male distinctly longer and more acicular; the females differ from those of aculeatum only in the more slender form and in being somewhat paler. Length of body, $\hat{o}, 11-5$, ㅇ, $8.3-8.5$; of pronotum, $\hat{\delta}, 1.9$, ㅇ, 1.6; of tegmina, $\hat{\delta}, 2.7-3$, $९, 2.1-2.6$; of forceps, $\hat{\delta}$, $6.5-8.7$, ㅇ, $3.3-3.5$; of pygidial spine, $\hat{\delta}, 1.8-2.2 \mathrm{~mm}$. (Fig. 26 d.)

The types of R. \& H. were taken by W. T. Davis, May 2, 1912, from the South Bay of Lake Okeechobee, Fla. He states ( $R$. \& $H$., 1914d, 98): "A winding path led along the shore of South Bas, between the water and the thick growth of custard-apple trees, and on the low tangled vegetation bordering this path we found D. davisi in considerable numbers." On March 2, 1913, this slender-bodied earwig was first seen by the writer when three pairs were taken on the north margin of Lake Okeechobee. On March 8 two additional males were found at Pelican Bay on the southeastern shore of the lake. At both places it was beaten or swept from vegetation within 50 feet of the border of the lake.

In 1918 a second trip was made by me to Lake Okeechobee, one of the objects in view being a search for additional specimens of Doru davisi. On March 2, a single specimen was accidentally discovered while sifting for beetles in a low wet tract about five miles southeast of Moore Haven. The place where found was part of the old custard-apple margin of the lake, now drained and partly grown up to arrow-leaf, saw-grass and other semiaquatic regetation. After an homr's search the abiding place of 322).

${ }^{15}$ Caudell, Proc. Ent. Soc., Wash., XVII, 1916, 217; Fox (1917, 206); Hebard (1917, 
the earwig was finally found to be between the bases of the leaves and stems of the arrow-leaf, and especially those of the saw-grass, Cladium effusum (Sw.), the latter plant being the one which almost exclusively covers thousands of acres of the Everglade Region south and southwest of Lake Okeechobee. Once located, the earwigs were found to be very abundant, 93 being taken in fifteen minutes by cutting off the clumps of grass just below the surface of the ground and shaking them over a rubber cloth. This incident is but evidence of the fact that almost any insect supposed to be rare is in reality plentiful enough once its favorite habitat or hiding place is discovered. The localities above given are the only ones at present known from which this handsome earwig has been taken. It will doubtless be found in southern Florida over much of the area covered by the saw-grass.

\section{Fonficula Linnæus, 1758, 423. (L., "scissol's.")}

Antenna in our species 14-15-jointed, the fourth joint obconical, half the length of third, 7-14 cylindrical, more than four times as long as broad; pronotum almost square, the liind angles rounded; wings slightly surpassing tegmina; abdomen not expanded at niddle, the third and fourth dorsal segments with lateral folds; first tarsal joint slightly longer than third; second short, dilated and lobed at apex, passing beneath the third. One widely distributed species occurs with us.

12. Forficula auricularia Linnæus, 1758, 423. Common European Earwig.

Dark reddish-brown; basal joints of antennæ, sides of pronotum, hind margins of abdominal segments, forceps and legs paler; tegmina and wings dull yellow. Tegmina one-half longer than pronotum. Forceps of male about as long as abdomen, their legs flattened and broadened at base, then usually curved almost into a semi-circle, armed on the inner side at base with a large quadrate crenulate tooth, and another at beginning of curve; legs of female forceps slightly curved, crenulate on inner margin and crossing at tips. Length of body, 10-12; of tegmina, 2; of forceps. ô, 4-7, ㅇ, $3 \mathrm{~mm}$.

While adventive examples of this cosmopolitan species have been recorded a number of times from the eastern United States, it did not become established as a resident member of our fauna until about 1912, when a colony appeared at Newport, Rhode Island, which was first reported by Glaser (Psyche, XXI, 1914, 157). This has increased so rapidly in numbers and threatens to become such a pest that a special bulletin ${ }^{16}$ treating of it has been

${ }^{16}$ D. W. Jones, Bull. 566, U. S. Dep. Agr., June 18, I9r7. 
prepared and issued by the U. S. Bureau of Entomology. In this it is stated that the sexes mate in late autumn, the male dying soon after. The female soon deposits 50 to $90 \mathrm{eggs}$ in the ground and then hibernates near them at a depth of two to eight inches, those which survive emerging in the spring to attend the larræ in their early stages. The young appear about May 5th, and, passing through four larval stages, become adults by the middle of July. As larva they feed on the tender green shoots of clover, grass, lima beans and on the buds and petals of dahlias, roses and other cultivated plants. The adults feed largely on the stamens and petals of flowers, doing immense damage where present in such numbers as at Newport, where Jones says that on one estate, when the porch awnings were let down each morning, over a quart of the earwigs dropped out and were swept up and burned, and that 300 specimens were seen by him at one time in one of the servants' halls. By 1916 the colony had spread over ten square miles of territory. As remedies poison baits of stale bread and Paris green proved very effective in early spring, and poison and contact sprays later in the season.

In my former work $(1903,171)$ I recorded this earwig, on the authority of Rehn $(1903,125)$, as having been taken at Lafayette, Ind., by the late F. M. Webster. Caudell (1907a, 170), has shown that the specimens so recorded were taken by Webster in Tasmania. Burr $(\mathbf{1 8 9 7}, \mathbf{1 6})$ states that in England auricularia is well known to every one and is quite ubiquitous, but its home seems to be under bark of trees, planks, stones, on flowers, fruit; ete. Latreille $(1831,6)$ says that the two sexes of this species when in coitu, are united end to end, a statement not substantiated by any other author.

Aside from the species above considered but one other earwig has been recorded from the eastern United States. This was an adventive example of Spandex pcrchcroni (Guer. \& Perch.), a Brazilian species, taken in Massachusetts, and described by Scudder $(1862,415)$ as Spongophora bipunctata. It was recorded by him $(1900,6)$ as Forficula percheroni. Guer.-Perch., and by Caudell (1913, 599) as Psalis percheroni. The three extralimital species from North America not included.in this work are: (1). Spongovostox apicclentatus (Caudell), a native species known only from Arizona; (2). Chelisoches morio (Fabr.), a tropical adventive form now established at Menlo Park, California, and (3). Doru lincarc (Esch.), a Mexican and South American form which occurs also in Texas, Arizona and Southern California. 


\section{Suborder II. CURSORIA.}

This suborder, as characterized in the key, p. 41, contains only one family, the Blattidæ, which is represented in all parts of the earth. The name Cursoria, derived from the Latin and meaning "punner," was first used by Latreille (1817) to comprise all the nou-saltatorial Orthoptera, or the earwigs, cockroaches, mantids and walking-sticks. Westwood in 1839 restricted the name Cursoria to the Blattidie or cockroaches, giving to the other groups the names Euplexoptera (Forficulide), Ambulatoria (Phasmide) and Raptoria (Mantida). Fieber, in 18533, united the last two in the one suborder Gressoria. The characters of the suborder Cursoria are those of its single famils as given below.

\section{Family II. BLATTID.E.}

\section{The Cockronches.}

"On every dish the booming beetle falls, The cockroach plays, or caterpillar crawls;

A thousand shapes of variegated hues Parade the table or inspect the stews. When hideous insects every plate defile, The laugh how empty and how forced the smile."

The members of the family Blattidie, commonly known as cockroaches, may he known from the other families of non-saltatorial Orthoptera by their depressed, oral form; by their nearly horizontal head which, when at rest, is bent under and almost concealed by the broad pronotum, so that the mouth projects back between the bases of the first pair of legs; by their slender. depressed legs of almost equal length and size. and by the absence of either oripositor or forcipate appendages at the end of the abdomen.

They have the antenna setaceous, rarely swollen and plumose near base, inserted just below the middle of the eres, composed of rery many exceedingly short segments and often longer than the body; mandibles strong. toothed; maxillae with 5- and labium with 3-jointed palpi ; eyes usually large, reniform, finely facetted; ocelli or simple eres usually present in the fully winged forms, located near the inner borders of the antennal sockets, absent or greatly reduced in size when the wings are abbreviated or wanting. and then often represented by small, pale ocellar spots; pronotum generally more or less elliptical or suborbicular, with rounded angles, and often projecting over the head; tegmina mem- 
branous, corneous or leathery, usually more or less translucent and, when well developed, overlapping along their sutural margins; in the female of many species rudimentary or sometimes wholly wanting. Four main veins or nervures arise near the basal margin of each tegmen, their position and names being shown in Fig. 30. The wings are always shorter than the tegmina, but are usually fully developed when the latter are long, though sometimes, even then, rudimentary or absent. When the

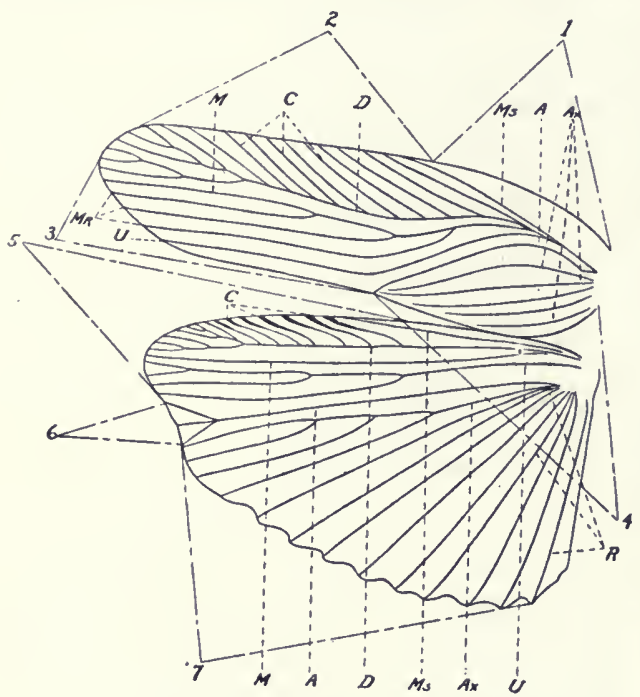

Fig. 30. Diagram of the left tegmen and wing of a Blattid. 1, Marginal field; 2, scapular field; 3, discoidal field; 4, anal field; 5, anterior field; 6, intercalated triangle; 7, posterior field. Ms.Mediastine vein; $D$, discoidal vein; $C$, costal veins; $M$, median vein; Mr., branches of median vein; $U$, ulnar vein; $\mathbf{A}$, anal sulcus; $\mathbf{A x}$, axillary vein; $\mathbf{R}$, radiate veins. (After Hebard.) tegmina are reduced in size, the wings are correspondingly smaller. They are membranous in structure, often very delicate, the names and position of their principal veins being shown in the accompanying digram, Fig. 30.

The abdomen is large, broad, and composed of ten segments, each with a dorsal and a ventral plate; however, only seven or eight of these are usually visible. The first one behind the metanotum above is known as the median dorsal segment, the next as the basal or first dor-

sal segment. In the males of many species one or both of these have the upper surface more or less specialized or modified. The tenth dorsal plate is known as the supra-anal and its shape and structure are much used in elassification. Nine ventral plates are visible in the male and seven in the female, the last one in both sexes being known as the subgenital plate. This in the male usually bears near its apex two small unjointed appendages called styles. The tenth dorsal segment also bears a pair of jointed appendages known as cerci, which vary much according to speeies, in length, number of joints, etc. The rings or segments of the abdomen overlap each other and are capable of great extension and depression, so that these insects seem to be pre-eminently fitted 
for living in the narrow crevices and cracks which ther inhabit. This peculial structure was doubtless acquired when living beneath stones and bark before man came into being, and has enabled them, like the earwigs, to hide in the crevices of ships and especially in cargoes of fruit, and tropical and semitropical forms have thus been scattered to all parts of the earth.

The legs of a cockroach are of a peculiar structure in that they have the coxie very large and flattened, thus serving to protect the ventral surface of the thorax; femora long, compressed, their lower border with two keels or margins which are usually armed with spines, these rarying much in size and number; tibiæ hearily armed with spines both above and beneath; tarsi 5-jointed, the first joint much the longest, the last one with two claws, with or without a lobe or arolium between them, the others usually each with a pad or pulvillus beneath. The structure of the legs enables the cockiroaches to run with such great swiftness that they seldom use the wings in trying to escape pursuit, and has given the name Cursoria or runners to the suborder of which they form the only familil.

From the other Orthoptera the Blattida differ widely in the manner of oriposition, as the eggs are not laid one at a time, but all at once in a peculiar capsule or egg case called an oötheca. These capsules rary in the different species as regards the size, shape, and the number of eggs they contain, but they are all very similar in structure (Fig. 31). Each one is divided lengthwise by a membranous partition into two cells. Within each of these cells is a single row of crlindrical pouches, somewhat similar in appearance to those of a cartridge belt, and within each pouch is an egg.

The female cockroach often runs about for sereral days with an oötheca protruding from the abdomen, but finally drops it in

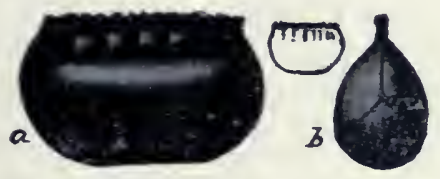

Fig. 3r. Oötheca of Periplaneta americana (L.) $a$, side: $b$, end view. Natural size indicated by outline fig. ure. (After Howard.) troduced tropical species, Panchlora cubensis (Sauss.), being riviparous, the soung emerging alive from the body of the parent. roung, in time, emerge. While this method of oviposition is the one practiced by all the species of common occurrence in the United States, there seem to be exceptions to it, as Dr. C. V. Riler has recorded (1891a) the fact of an ina suitable place and from it the 
and a careful dissection of the latter showing no trace of either eggs or oötheca.

Shelford $(1906,235)$ states that "the position of the ootheca when carried by the female before deposition is not a character of subfamily importance." I do not regard it as even a character of specific importance, for in two females of each of two species of Parcoblatta at hand with oötheca protruding, viz., uhleriana and pennsylvanica, one of each has the oötheca projecting with edge uppermost, the suture above, the other with side uppermost, the suture at side. Hebard $(1917 \mathrm{a}, 4)$ has also recorded the females of $P$. pennsylvanica "with oötheca both dorsad and laterad," and has mentioned also two closely related species of Cariblatta with similar conditions.

All roung cockroaches resemble the parent in form, but are wholly wingless, the wings not appearing until after the fifth or last moult. The young are often mistaken for the mature by persons who have not made a careful study of the life history of the insects; and those of one or two well known and common forms hare, in the past, been described or figured as distinct wingless species by some of the leading Entomologists of the country.

Most roaches are omnivorous but they live chiefly upon animal and regetable refuse. The majority of our species, especially those which are natives, live under leaves, bark and other cover in the country, but many of the introduced species are domiciliary and where present in numbers are among the worst of insect household pests. In Brazil they are so common in country houses that nobody pays much attention to them. There they have, says Herbert H. Smith, "an unpleasant way of getting into provision boxes and they deface books, shoes and sometimes clothing, and eat off the wall paper in unsightly patches in search of the paste beneath. At Corumba, in the house where we were staring there were nearly a dozen children, and every one of them had their eyelashes more or less eaten off by the cockroaches, a large brown species. The erelashes were bitten off irregularly, in some places quite close to the lid, and as the children had rery long black eyelashes, their appearance thus defaced was odd enough."

ReMedies For RoAches.-A common remedy for roaches consists in the liberal use of pyrethrum powder or buhach, and when this is persisted in considerable relief will be gained. It is not a perfect remedy, however, and is at best but a temporary expedient, while it has the additional disadvantage of soiling the shelves or other objects over which it is dusted. When used it should be fresh and liberally applied. Roaches are 
often paralyzed by it when not killed outright, and the morning after an application the infested premises should be gone over and all the dead or partially paralyzed roaches swept up and burned. Flour of sulphur dusted about where roaches abound has proven very effective as a repellent.

Another remedy which may be used for any of the household species is a mixture of plaster of Paris, one part, and flour, three or four parts, in a saucer, and placed where the roaches abound, with another flat plate nearby, containing pure water, both supplied with several bridges to give easy access, and one or two thin boards floating on the water touching the margin. The insects readily eat the mixture, become thirsty and drink, when the plaster sets and clogs the intestines. The insects disappear in a few weeks, the bodies no doubt being eaten by the survivors.

There are many proprietary substances which claim to be fairly effective roach poisons. The only one of these that has given very satisfactory results is a phosphorous paste, also sold in the form of pills. It consists of sweetened flour paste containing 1 to 2 per cent. of phosphorus, and is spread on bits of paper or cardboard and placed in the runways of the roaches. It is also a repellent.

For no other insects have so many quack remedies been urged and are so many newspaper remedies published. Many of them have their good points, but the majority are worthless. In fact, rather than put faith in half of those which have been published, it were better to rely on the recipe current among the Mexicans :

"To Get RID of Cockroaches.-Catch three and put them in a bottle, and so carry them to where two roads cross. Here hold the bottle upside down, and as they fall out repeat aloud three credos. Then all the cockroaches in the house from which these three came will go away."

To the paleontologist interested in tracing back the ancestry of insects, the Blattidæ become at once a group of surpassing interest, for the oldest known insect is a fossil cockroach, Palcoblatta douvillei Brogn., from the Silurian sandstone of France. Between 130 and 140 fossil species of the family are known from the Paleozoic rocks of the United States, principally from the Carboniferous formations, but some from all ages as far back as the middle Silurian. That most eminent authority on insect paleontology, S. H. Scudder, has written of the cockroach: "Of no other type of insect can it be said that it occurs at every horizon where insects have been found in any numbers; in no group whatever can the changes wrought by time be so carefully and completely studied as here; none other has furnished more important evidence concerning the phylogeny of insects."

The Blattidæ are pre-eminently tropical insects, and though abundantly represented in individuals, the number of species inhabiting the United States is comparatively few, but 43 and one variety being treated in Hebard's Monograph of the Group. These 
are divided among nine subfamilies and 26 genera. Aside from several subtropical forms, which are often introduced in bananas and other fruit, but which soon die, and are, therefore, considered only as adventives, 30 species and two varieties or races are recognized as residents of the territory covered by this work. These represent ten of the subfamilies and 19 of the genera recognized by Hebard. Of the 30 species, 12 are established adventives, the other 18 being native or indigenous species, as are also the two races. In addition to these, three of the adventive species representing one additional subfamily and two genera, are included, as they are so frequently introduced with tropical fruits that they will probably be seen by many of our future students.

Aside from the general works on Orthoptera cited in the Bibliography, the principal literature treating more or less extensively of the Blattidæ occurring in the Eastern United States is as follows:

Saussure, 1863, 1869a, 1870, 1872; Brunner, 1865; Rehn, 1903, 1903a, 1903b ; Shelford, 1906, 1907, 1907a, 1908, 1908a, 1910a ; Rehn \& Hebard, 1910; Caudell, 1913; Hebard, 1916a, 1916b, 1916c, $1917 \mathrm{a}$.

The following key to subfamilies is mainly a composite of parts of those of Scudder $(1897 \mathrm{e}, 12)$, Caudell $(1913,600)$ and Hebard (1917a, 11-22), the last named being a key to genera and species only. It must be remembered that a subfamily is only an artificial individual concept created for the purpose of facilitating the systematic naming of the species of any group. Subfamilies do not exist in nature and the recognition of them here is only to render shorter and more easily followed the keys to the genera of which they are composed. The characters of chief importance generally used in separating the subfamilies of Blattidie are those pertaining to the armature of the lower border of the femora, the structure of the tegmina and wings, the form of the supra-anal and subgenital plates and the presence or absence of arolia and pulvilli. To these have been added other character's pertaining to size, color, etc., in order to enable beginners to more easily place their specimens.

KEY TO FASTERT SUBFAMILIES OF HLATTIDE.

a. Middie and hind femora armed beneath along one or both margins with two or more distinct spines; tegmina present, often abbreviated in the female.

b. Pronotum and tegmina smooth or but sparsely haired or pilose. 
c. Supra-anal plate not bilobed; form not strongly depressed.

d. Smaller, the pronotum less than $7 \mathrm{~mm}$. in length; structure moderately delicate; styles of male not slender, elongate, straight processes of equal length; subgenital plate. of female simple.

I. Pseldo ropixa, p. 66.

dd. Larger, the pronotum $7 \mathrm{~mm}$. or more in length; structure heavily chitinous, femoral spines very heavy; styles of male slender, elongate, straight processes of equal length set in sockets on margins of subgenital plate (Fig. 34, F.); subgenital plate of female compressed so as to form a carina or ridge on its under side and divided so as to be bivalved (Figs. $32, \mathrm{C} ; 34, \mathrm{E}$.$) .$

IV. Blattixæ, p. 93.

cc. Supra-anal plate weakly bilobed in both sexes; size medium, length of body, 15-20 mm.; form strongly depressed; tegmina and wings of female fully developed, falling slightly short of apex of abdomen; pronotum dark brown, bordered in front and on sides with yellow.

III. EPILAMPRINe, p. 92.

$b b$. Pronotum and tegmina rather densely clothed with fine, silky pubescence; very large, adventive species, 27 or more $\mathrm{mm}$. in length.

II. Nyctoborixe, p. 91.

$a a$. Lower margins of middle and hind femora unarmed, or armed with hairs and bristles only, or with one or two apical or sub-apical spines.

e. Tegmina present in males, wanting in females of Arenivaga and Compsodes.

$f$. Surface of pronotum and tegmina glabrous; anal field of wings folding like a fan; subgenital plate of female simple, except in Chorisoneura.

g. First four tarsal joints each with a pad (pulvillus) beneath; ocellar spots present; wings without an appendicular field; supra-anal plate weakly bilobed.

$h$. Smaller, length of body less than $25 \mathrm{~mm}$.; hind margin of pronotum strongly obtuse-angulate at middle; blackish brown or pale green, the pronotum without discal spots; arolia present.

V. PAxchlorixe, p. 103.

$h h$. Larger, length more than $40 \mathrm{~mm}$; pronotum subelliptical, buffy with a blackish-brown central area containing pale .markings; arolia absent.

VI. BLABERIX.æ, p. 106.

gg. Fourth tarsal joint alone with a pulvillus beneath; ocelli and ocellar spots absent; wings with an appendicular field; supra. anal plate not bilobate; subgenital plate of female either simple or with a linear cleft or sulcus at apex; large arolia pres. ent; small species, length of body less than $10 \mathrm{~mm}$.

IX. OXYhaLOIN E, p. 111.

ff. Surface of pronotum and tegmina hairy; anal field of wings not folding fan-wise.

$i$. Ocelli of males minute, or wanting, the ocellar areas not defined; tegmina and wings usually present in both sexes and projecting beyond apex of abdomen (Fig. 49, D.); arolia and 
pulivilli usually present; subgenital plate of female valvular; length of body less than $9 \mathrm{~mm}$. VII. Conydirse, p. 107.

ii. Ocelli of males large, the ocellar areas strongly defined; teg. mina and wings absent in female (Fig. 49, F.); arolia and pulvilli absent; subgenital plate of female simple; length of body, 10 or more mm. VIII. Polyphagix e. p. 109.

$e e$. Tegmina and wings wholly wanting; form elongate; color shining blackish-brown, glabrous; arolia wanting; subgenital plate of female wanting (Fig. 43. D.) X. PANesturne, p. 113.

\section{Subfamily I. PSEUDOMOPINE.}

This subfamily, to which 16 of the 33 species of roaches found in our territory belong, is the equivalent of the Phyllodromina of most foreign authors, of the Blattinæ of Scudder (1897c, 12) and in great part of Caudell (1913, 601). Our eastern species vary greatly in size and in the development of the female tegmina, but agree in having the body glabrous; tegmina of a delicate structure; ulnar vein of wings, in all the genera but Symploce, with branches all complete to the apical margin; femora armed beneath; tarsal claws not toothed; arolia present.
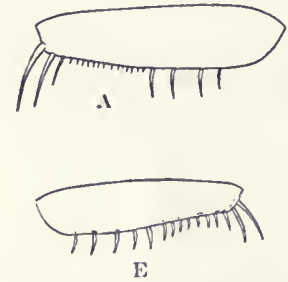
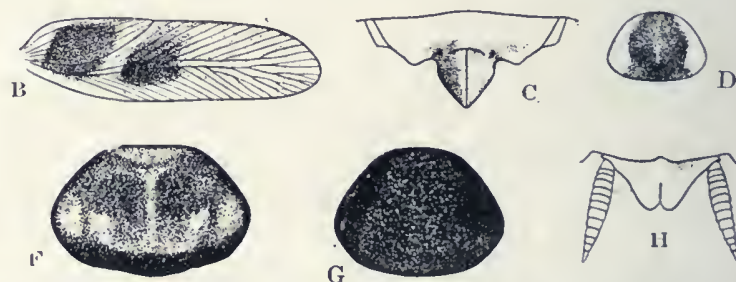

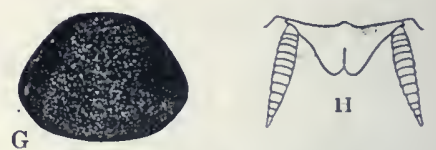

G

Fig. 32. A, Fore femora of Ischnoptera showing form of spination mentioned in a. of generic key to Pseudomopinæ; B, tegmen of Supella; C, ventral view of subgential plate of Periplaneta; D, pronotum of Supella; E, fore femur of Symploce, showing form of spination mentioned in aa. of key to Pseudomopinæ; F, pronotum of Periplaneta brunnea Burm.; $\mathrm{G}$, pronotum of $P$. fuliginosa (Serv.); H. dorsal view of supra-anal plate and cerci of female of P. brunnea Burm. (After Hebard.)

\section{KEY TO EASTERN GENERA OF PSEUDOMOPINA.}

a. Lower front margin of fore femora armed on basal half with a row of stout spines, these abruptly succeeded on apical half by a row of much shorter and more delicate spinules (Fig. 32, A.).

b. Fourth tarsal joint only with a pulvillus (small pad) beneath.

c. Tegmina abbreviated, subtruncate behind, covering less than half the abdomen in both sexes; pronotum buffy with a lengthwise undulating blackish-brown band each side of middle, which ex. tends backward onto tegmina; styles of male very short, broad and fused with the margin of the subgenital plate; length of body less than $10 \mathrm{~mm}$. (Fig. 33, A.) I. Aglaopteryx, p. 68.

cc. Tegmina fully developed (in our species), extending beyond apex of abdomen in both sexes; pronotum not distinctively marked 
as above; styles of male elongate, heavy, contiguous at middle; length of body, 10.5-13 mm. (Fig. 33, B.)

II. Latiblattelta, p. 69 .

bb. Joints 1 to 4 of tarsi each with a pulvillus beneath; tegmina of males extending beyond apex of abdomen; of females not reaching apex except in Parcoblatta caudelli.

d. Uniform blackish or brownish-black above, the tegmina of males often paler brown; sixth dorsal abdominal segment of male deeply emarginate at middle of hind margin, and bear. ing two minute projections which are armed above with elongate microscopic teeth; styles of male not deflexed, unequal, the right one the stouter and curred inward; tegmina of female subquadrate, obliquely truncate, their sutural margins feebly overlapping (Fig. 36.) VI. IschNopTERA, p. 75.

dd. Color not uniform blackish or brownish-black above; sixth dorsal of male without toothed projections; styles of male slender, deflexed, cylindrical processes, the right one slightly the longer.

VII. Parcoblatta, p. 77.

aa. Lower front margin of fore femora armed with a row of spines which decrease gradually in length and size toward apex (Fig. 32, E.); joints 1 to 4 of tarsi each bearing a pulvillus beneath.

$e$. Ulnar vein of wings with all the branches reaching the apical margin; tegmina not truncate in female; hind margin of pronotum not obtuse-angulate at middle.

$f$. Pronotum without two dark brown stripes; styles of male distinct.

g. Larger, length of body $11-12 \mathrm{~mm}$; tegmina extending beyond abdomen, male, to its apex, female, their color pale brown with two darker brown blotches on basal half; pronotum clay-yellow, the disc brownish, darker at base (Fig. 32, B, D.) ; styles of male large, elongate, extending along the margin of subgenital plate.

III. SUPELLA, p. 70.

gg. Smaller, length of body $6-8 \mathrm{~mm}$.; tegmina uniform pale brownish-yellow, variable in length in male, shorter than abdomen in female; pronotum brownish-yellow, disc marked with small spots of darker brown; styles of male similar, minute, rounded, their tips armed with curved spinules (Fig. 34, A, B.)

IV. Cartblatta, p. 71.

ff. Pronotum brownish-yellow with two stripes of darker brown; styles of male indistinct or wanting; tegmina extending beyond apex of abdomen in both sexes; length of body, 10.5-12.5 $\mathrm{mm}$. (Fig. 35.)

V. Blattella, p. 73.

ee. Ulnar vein of wings with some of the branches incomplete, not reaching apical margin; color uniform clay-yellow; tegmina of female subquadrate, truncate, much shorter than abdomen, their sutural margins feebly overlapping, of male reaching beyond apex of abdomen; hind margin of pronotum feebly obtuse-angulate; left style of male curved, twice as long as right one; length of body 11-14 mm. (Fig. 34, D.)

VIII. SYMPLOCE, p. 90. 


\section{Aginopterix Hebard 1917a, 30. (Gr., "beautiful" + "wing.")}

Form rather broad, structure delicate; head broad, eyes widely separated; tegmina and wings alike in both sexes, the latter absent in our species; cerci short, flattened above, 12-jointed;

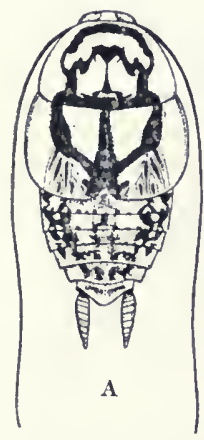

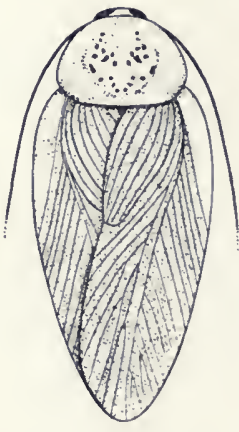

B

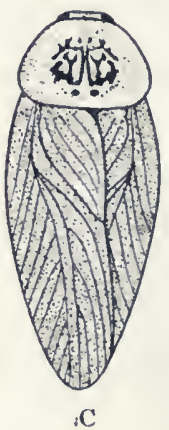

C

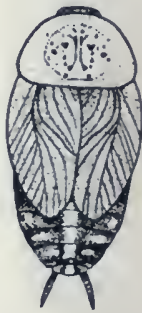

D

Fig. 33. A, Aglaoptervir gemma Heb., male $\times 3$; B, Latiblattella rehni Heb., female $\times 3$; C, Cariblatta lutea (S. \& Z.), male. X 4.5; D, Cariblatta lutea minima Heb., male $\times$ 4.5. (ifter Hebard.)

apex of front femora with two long spines on lower margin. Other characters as given in generic key. One species, many times recorded from the Southern United States as Ceratinoptera diaphana (Fab.), occurs in our territory.

13. Aglaopteryx gemma Hebard, 1917a, 32. Little Gem Cockroach.

Head clay-yellow with a broad, dark brown band on under side between the eyes, this sometimes continued downward on the face; pronotum transparent buffy, its disc bordered in front and each side with a narrow blackish-brown stripe, this broadening toward base, disc also with an anchor-shaped cross-bar of dark brown; tegmina buffy with the black length. wise stripe of pronotum extending obliquely back along the anal field to suture and continuing along it to tips; dorsal surface of abdomen blackish-brown marked with dull orange; legs and under surface buffy, the abdomen margined with blackish-brown. Pronotum with front margin transverse, side margins broadly convex, hind margin feebly bisinuate, front and hind angles broadly rounded. Tegmina subquadrate, a little longer than wide, extending only slightly beyond first dorsal segment ol abdomen; their tips broadly rounded. Oötheca $2.8 \times 4.8 \mathrm{~mm}$; the suture with a row of 18 blunt teeth. Length of body ${ }^{17}$, $\hat{\delta}, 7.5-8.9$, ᄋ, 8.6-9.7; of pronotum, ô, 2.7-3, $\&, 2.9-3.2$; of tegmina, $\hat{\delta}$ and $\$, 3.5-4.1 \mathrm{~mm}$.

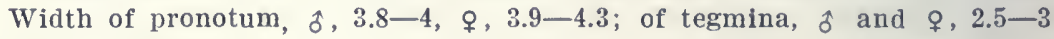
mm. (Fig. 33, A.)

${ }^{1 i}$ The measurements following the descriptions of Blattidx in this work are the extremes of the two sexes as given by Hebard (1917a). He, having had many more examples before him than are available to me, was able to chow much better the variability in size of each species. The length of body is considered as the length from the vertex to the end of the subgenital plate of the dried insect. 
This prettily marked speeies has been taken by R. \& H.,' Davis and others at Pensacola, River Junction, Newberry, Gainesville, Ortega, Miami, Long Key and Key West, Fla., and Nassau, Bahama Isles. North of Florida it is known from Georgia to Houston, Texas, in the states along the Gulf Coast, the type being from Mobile, Ala. In Florida it was found in winter and spring beneath bark, bases of leaves of cocoanut palm, limestone and coquina boulders and under signs attached to trees, the latter hiding place being a favorite one throughout its range.

\section{Latiblatrella Hebard, 1917a, 36. (L., "broad" + "little cockroach.")}

Medium sized species of broad form and delicate strueture having the eyes well separated, ocelli distinct; tegmina delicate, often much abbreviated in female, their seapular field broad; wings lyyaline; subgenital plate of male fusing with the styles, of female produced; lower front margin of fore femora armed beneath as deseribed in " $a$ " of generic key and with three long, stout spines near apex; middle and hind femora armed beneath with elongate, moderately stont spines. Two species from the United States are deseribed by Hebard, one of them from our territory.

14. Latiblattella Rehni Hebard, 1917a, 38. Rehn's Cockroach.

Dull yellow, the tegmina and wings almost transparent; head, face and disc of pronotum usually with numerous small blackish-brown spots legs and middle of abdomen above and beneath dull yellow; sides of abdomen, cerci and extreme bases of tibial spines dark brown. Head with inter-ocular area flattened. Pronotum broadest one-third from base, the sides thence rapidly converging and broadly rounded into apex, hind angles broadly rounded, hind margin truncate. Tegmina and wings very delicate, the former elongate with numerous veins. Sixth dorsal segmen of male abdomen with a deep semicircular depression at middle, from which arises a large blunt knob covered with agglutinated hairs. (Fig. 34 , C.) Subgenital plate of male triangular and upturned between the styles, which are stout and bent inward along its margins. Length of body, $\hat{o}, 10.7-12.9$, $\$, 10.8-12.2$; of pronotum, ô, $2.8-3.4$,, $3.1-3.7$, of tegmina, $\hat{\delta}, \mathbf{1 1 . 4 - 1 3 . 7}$, $+10.3-11.7 \mathrm{~mm}$. Width of pronotum, $\hat{\delta}$ an 1 ㅇ, 4.2-4.7; of tegmina, $\hat{\delta}$ and $ᄋ, 3.4-4.4 \mathrm{~mm}$. (Fig. 33 , B.)

Dunedin, Fla., March 18, June 11; on the former date beneath bark of dead pine, on the latter at poreh light; Bassenger, Fla., Feb. 28, by beating Spanish moss, Dendropogon usneoides (L.) (W. S. B.). Relın, Hebard, Davis and otlers have recorded it under the names Blattella adspersicollis Stal, Neoblattclla adsper- 
sicollis Stil and $N$. detersa Walker, from 15 different localities between Newberry and Big Pine Key, Fla., the 86 specimens examined by Hebard having been taken at all seasons of the year and principally beneath signs attached to trunks of pine trees. When disturbed they seldom attempt flight, but run about to hide in erevices in the bark or drop to the ground. The most northern point at which it has been found is Newberry, Fla.

\section{Supella Shelford, 1911, 155. (Gr., "house.")}

Medium sized species of very slender form, having the eyes well separated, the interocular area flattened and raised to form a rounded angulation with the ocellar area; tegmina narrow, delicate, with 9 to 11 strongly oblique discoidal sectors; wings hyaline; subgenital plate of male elongate-triangular, fusing with the styles; of female large, broad, not strongly produced; legs very slender" front femora armed beneath as described in "a $a$ " of generic key and with two uneculual spines near apex; first tarsal segment longer than the others united.

15. Supella suleldectilium (Serville), 1839, 114. Brown-banded Cockroach.

Clay-yellow; head pale brown, face darker; pronotum with sides yellowish transparent, disc chestnut-brown, this hue often expanded to cover the entire basal third; tegmina variable, usually pale brown with a paler band at basal third separating two darker brown blotches (Fig. 32, B, D.) ; legs and under surface clay-yellow. Pronotum one-third wider than long, narrowed from basal third to apex, disc feebly convex; sides narrow, moderately deflexed, their margins slightly upcurved, all the angles rounded, hind margin feebly convex. Sixth dorsal segment of $\hat{\delta}$ abdomen with a median, circular, deeply depressed area containing a low conical tuft of agglutinated hairs. Length of body, $\hat{\delta}, 11.4$, $ᄋ, 11.5$; of pronotum. $\hat{\delta}, 2.8$,,+ 3.5 ; of tegmina, $\hat{\delta}, 11.5$, $ᄋ, 8 \mathrm{~mm}$. Width of pronotum, $\hat{\delta}, 3.6$,

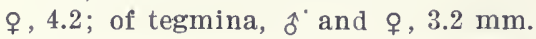

A tropical species of wide distribution taken in the United States only at Miami and Key West, Fla. At the latter place Rehn \& Hebard found it in small numbers, July 3-7, under the counters of a fruit store, in folds of old burlap bags, where it had as company four other species of circumtropical cockroaches. It is a house-dwelling species, raries much in color, and according to Shelford (1911) has been described under ten different specific names besides the one it rightfully bears; the first record from the United States, that of Rehn from Miami, Fla. (1903, 125), being one of these, Phyllodromin cubcnsis (Sanss.). 


\section{Cariblatta Hebard, 1916b, 148. (Carib + Blatta.)}

Very small cockroaches of a slender form; eyes well separated, inter-ocular area weakly flattened; tegmina delicate, not broad; wings hyaline; dorsal surface of male abdomen not modified; subgenital plate of male, in our species, broadly produced in the form of a quadrangle between the styles; lower front margin of fore femora armed as described in "aa" of generic key and with two unequal spines near apex.
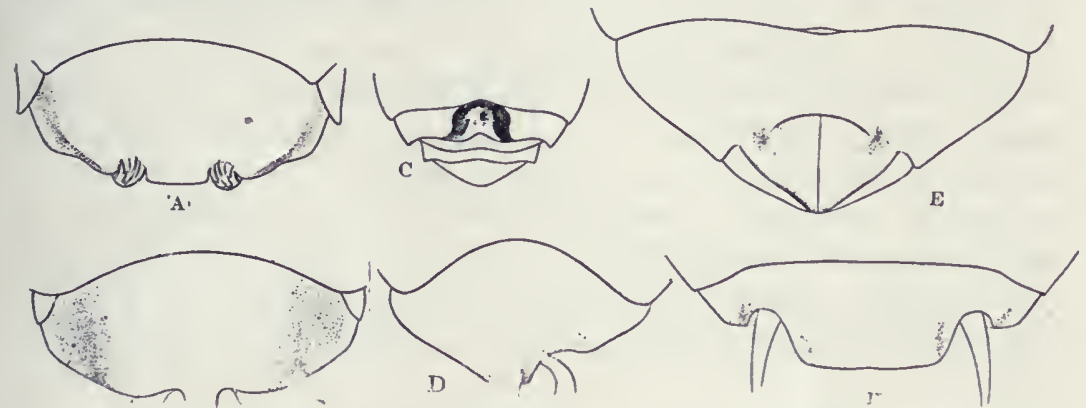

Fig. 34. Subgenital plates of Blattidx-ventral views-A, of male of Cariblatta lutea (S. \& Z.) ; B, of male of Cariblatta lutea minima Heb.; C, dorsal view of end of male abdomen of Latiblattella rehni Heb. showing specialized sixth segment; D, subgenital plate of male of Symploce lita Heb.; E, of female of Eurycotis floridana (Walk.); F, of male of same species. (After Hebard.)

Ten species are known, mostly from the West Indies and northeastern South America, and from the regions in which the Carib Indians were native, whence the generic name. Of these one species and a geographical race occur in our territory.

16. Cariblatta lutea (Saussure \& Zehntner), 1893, 48. Small Yellow Cockroach.

Pale brownish-yellow; head pale brown with a band between the eyes, and usually some spots on face, dark brown; disc of pronotum usually marked with numerous more or less distinct small brownish spots, the sides transparent; abdomen above usually maculate with blackish. brown; legs and under surface brownish-yellow, the abdomen often in great part darker. Pronotum one-third wider than long, widest at basal fourth, apex narrower than base, hind margin truncate, front one broadly rounded. Tegmina not quite reaching apex of abdomen, male, distinctly shorter, female, their tips rounded. Wings equal in length to tegmina. Male with produced portion of subgenital plate between the styles nearly three times as broad as long (Fig. 34, A.); styles in the form of small rounded knobs, slightly longer than wide, armed above with minute spin. ules directed forward. Subgenital plate of female large, boat-shaped, the apex broadly rounded. Length of body, $\hat{\sigma}, 5.8-8.1$, $\uparrow, 7-9.5$; of pronotum, $\hat{o}, 1.8-2.1$, ․ $2.2-2.6$; of tegmina, $\hat{o}, 5.2-6.6$, 오 $4.9-6 \mathrm{~mm}$. 
Width of pronotum, $\hat{o}, 2.6-2.8$, $\uparrow, 2.8-3.6$; of tegmina, $\hat{o}, 2-2.1$, 우 2.1-2.6 mm. (Fig. 33, C.)

Ormond, Sanford, Takeland, LaBelle, Moore Haven, Sarasota and Dunedin, Fla.; frequent in all stages throughout the winter and spring months beneath leaves, boards, decaying palmetto logs, piles of weeds and other cover on the ground, especially in dry sandy localities (W. S. B.). Recorded as Ceratinoptera lutea (S. \& Z.) by Rehn, Hebard, Davis and others from Jacksonville, St. Augustine, LaGrange, Lakeland, Carrabelle and River Junction, Fla., June-Sept. Ranges from Roanoke Island, N. Car., west and south to Louisiana. A single example also recorded from Cuba (Hebard, 1917a, 51). This and its variety are among the smallest cockroaches found in our territory, and when uncovered run rapidly to find a new hiding place. A female with oötheca protruding was taken March 20, 1919. The oötheca was carried with suture at side, and was $2.2 \times 3 \mathrm{~mm}$. in size, with sutural edge slightly curved and bearing a row of minute widely spaced knobs.

16a. Cariblatta lutea minina Hebard, 1916b, 170. Least Yellow Cockroach.

Differs from lutea only in its average smaller size, slightly paler color, shorter tegmina (those of male reaching base of apical fourth of $a b$ domen), rudimentary inner wings and especially in the produced portion of the subgenital plate of male between the styles, which is much narrower, being subquadrate or slightly longer than wide. (Fig. 34, B.) The females are separable only by the smaller size and shorter tegmina of minima. Length of body, ô, 5.4-7.7, ㅇ, 5.8-8; of pronotum, ô, 1.8-2.1, \&, 2.-2.3; of tegmina, $\hat{\delta}, 3.6-5$, 우 $3.6-4.7 \mathrm{~mm}$. Width of pronotum $\hat{o}$ and $ᄋ, 2.6-3.3$; of tegmina, $\hat{o}$ and 오, 1.7-2.2 mm. (Fig. 33, D.)

Dunedin, Sarasota, Ft. Myers, Cape Sable, and Lake Okeechobee, Fla., Feb. 23-March. 14 (W. S. B.). At Cape Sable it was found in numbers in the bases of the tufts of coarse grasses growing just back of the sea beach. Recorded as Ceratinoptera lutea (S. \& Z.) by Rehn, Hebard and Davis from numerous localities in southern Florida and the Florida Keys as far north as Punta Gorda, March-Nov. Habits the same as those of typical lutea. In all the male specimens taken the form of projecting portion of subgenital plate is without apparent intergradation and minima is therefore retained as a distinct variety or southern race. Dunedin is the most northern point at which it has been taken. 


\section{Buattelda Caudell, 1903b, 234. (L., "small" + Blatta.)}

Rather small, narrow species having the head long, almost hidden by the small, suborbicular pronotum; eyes well separated, interocular area not flattened, ocellar spots distinct; tegmina delicate, narrow, not abbreviated; wings hraline; subgenital plate of male asymmetrical, of female large, convex, truncate; lower front margin of fore femora armed beneath as described in " $a a$ " of generic kes, and with three longer, unequal spines near apex; tarsal joints elongate, arolia very small.

17. Blattella germavica (Linnæus), 1767, 668. German Cockroach.

Dull brownish-yellow, the females often darker; all the limbs much paler than the body; disc of pronotum with two dark brown, longitudi. nal stripes separated by a yellowish one; antennæ dark brown, exceeding slightly the tips of the closed tegmina. Tegmina and wings of male extending to end of abdomen, those of female slightly longer. Body of male longer and narrower than that of female; middle of sixth abdominal segment with two deep, rounded fossæ separated by a narrow ridge on basal portion and deeply concave behind; styles very minute, the left one the larger, small, rounded, decurved. Length of body, $\hat{\delta}, 10.5-11.4$, 9 1112.8; of pronotum, $\hat{\delta}, 2.4-2.8$, ᄋ, $3-3.3$; of tegmina, $\hat{\delta}, 9.7-10.2$, 우, $10.8-11.9 \mathrm{~mm}$. Width of pronotum, $\delta, 3.1-3.7$, ᄋ, $3.8-4.2 \mathrm{~mm}$. (Fig. 35. )

Abundant throughout Indiana, especially, in the cities and towns; Moore Haven and Sarasota, Fla., Jan. 25-Feb. 21 (W. S. B.). Recorded also from Gainesville, Miami, Big Pine Key and Key West, Fla., at the latter place swarming in a hotel cupboard (Hebard, 1917a, 59). Ranges throughout the United States and the greater part of Canada, being most abundant in the Central States. In addition to the two common names already given it is known as the "Water Bug," and Burr (1897, 24) states that in Russia it is called the "Prenssenschabe" or Prussian Roach, while in Germany it is known as the "Russen" or Russian Roach. Piers $(1918,247)$ says that the local name in Nora Scotia is the "Yankee settler."

In Indiana and the Eastern United States it is best known as the "Croton bug," so called because it made its appearance in New York City in numbers about the time the Croton Aqueduct was completed. It is a native of Central Europe, but like the Oriental roach, has become cosmopolitan. In Europe it is found in woods as well as in houses. In America it seldom, if ever, occurs in numbers in the country, but is one of the worst insect pests with which the inhabitants of the larger cities of the United States 
have to deal. It is the most fecund of all roaches and the seasons of mating and hatching of the young are perhaps, more irregular than in any other species. Adult forms are evidently to be found at all seasons of the year, as I have taken them in December, April and October. It is not so much a lover of filthy surroundings as is the Oriental roach, and hence frequents more often than that

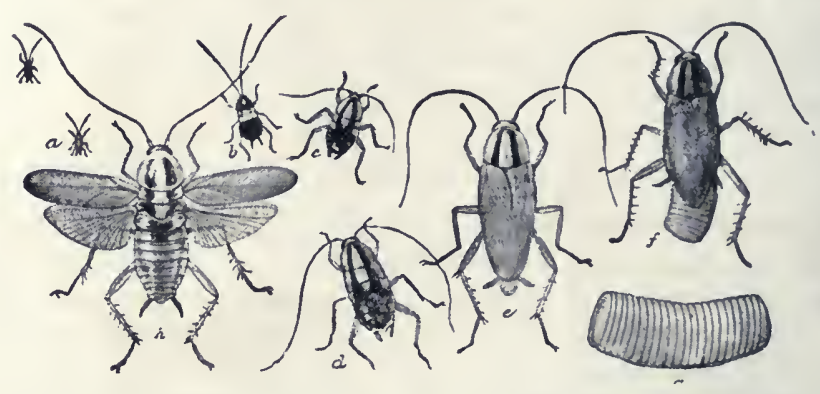

Fig. 35. Blattella germanica (L); $a$, first stage; $b$, second stage; $c$, third stage; $d$, fourth stage; $e$, adult; $f$, adult female with egg case; $g$, egg case, enlarged; $h$, adult, with wings spread. All natural size except $g$. (After Howard \& Marlatt.)

species the dwellings of the better class of people. It delights in warm, moist places, and is especially abundant and destructive in buildings which are heated by steam. As an evidence of its abundance under favorable conditions it may be stated that in 1890 a single person captured for me over 30 adult specimens and fully half that number of roung, in less than ten minutes, in the kitchen of the leading hotel of the city of Terre Haute. Where it once obtains a foothold and the surroundings of temperature and food supply are favorable, it is almost impossible to eradicate, as its small flattened form enables it to hide and breed in cracks and crevices which none of the other roaches can enter.

Like many other omnirorous animals, Croton bugs find in wheaten flour a food substance which is rich in nutrition and easily digested, and so they prefer wheat breads and starchy materials to all other foods. On account of this liking they often do much harm to cloth bound books by gnawing their corers in search of the paste beneath.

They also seem to have a peculiar liking for paints of various kinds, and Glover $(1875,132)$, states that in his office "They made a raid on a box of water colors where they deroured the cakes of paint, vermilion, cobalt and umber alike; and the only vestiges left were the excrements in the form of small pellets of rarious colors in the bottom of the box." 
The oötheca of the Croton bug is very light brown, a little orer twice as long as broad, $7.5 \times 3.5 \mathrm{~mm}$., with the sides somewhat flattened and the edges parallel. Within it the eggs, thirty-six in number, are arranged in the usual two rows. It is carried about by the mother roach for several dars with from half to threefourths of its length protruding from the abdomen, and when dropped in a favorable place the roung, evidently very soon, emerge from it; for in a bottle in which a female with protruding oötheca was placed at eleven o'clock $\mathrm{p}$. $\mathrm{m}$. the soung were found to have emerged on the following morning at eight. Ther were then wholls white, except the lateral edges of the abdomen, where a blackish tinge was evident. By five o'clock in the afternoon of the same dar, having meanwhile eaten their fill of moistened wheaten bread, they had become too large for their skins, and had monlted for the first time. They then measured $3 \mathrm{~mm}$. in length, and the head, pronotum, abdomen, and apical half of antennæe were black, while the other two thoracic rings and the basal half of antennæe were a grayish white. The half grown young are very dark brown, with the first four or five segments bordered with yellow, and with traces of a lighter median stripe.

VI. Ischxoptera Burmeister, 1838, 500. (Gr., "slender" + "wing.")

As restricted by Hebard (1917a, 61), this genus is represented in North America by only one species of medium size and less delicate structure than in the preceding genera. It has the head elongate; ocelli distinct; dise of pronotum in male with two broad, elongate impressions which converge behind; tegmina of male much surpassing the abdomen, their discoidal sectors weakly radiating; ulnar vein of wings with three to seven basal branches incomplete; tegmina of female and sixth dorsal abdominal segment of male as described in generic key; serenth dorsal abdominal segment of male with a narrow elevated ridge between the armed projections of the sixth segment; lower front margin of fore femora armed as described in " $a$ " of ker, and also with three stout unequal spines near apex; tarsi elongate. small arolia present.

18. Ischyoptera DEROPELTIFORMis (Brunner), 1865, 87. Dark Wood Roach.

Males very slender, their tegmina notably narrow; females larger and stouter. Color uniform dark mahogany brown, shining; tegmina of males often a paler brown; wings of male transparent, slightly infus. 
cated, the veins and front border pale brown; tibiæ, tarsi and sometimes the entire legs pale reddish-brown. Pronotum of male flat, semi-orbicular the sides strongly declivent, hind margin slightly rounded; of female much broader, less declivent, hind margin truncate. Inner wings of female small pads, shorter than tegmina. Subgenital plate of male with a broad impression at apex, styles as described in generic key; subgenital of female very broadly rounded at apex. Length of body, $\hat{\delta}, 11.7-17$, ㅇ, 11.4-17.8; of pronotum, $\hat{\delta}, 3.2-4.4$, o , 4-5.2; of tegmina, $\hat{\jmath}, 14.1-$ 19.6 , \&, 3.8-6.9 mm. Width of pronotum, ô, $4.3-5.4$,, $4.9-7.3$; of tegmina, ô, 4-5.6, ㅇ, 4-6 mm. (Fig. 36.)

This handsome native species, described by Brunner in 1865 from "Amerique du Nord," was not again recognized from this country until 1893, when specimens were taken by me on May 28 and June 18 beneath logs in a low sandy woods near Terre Haute,

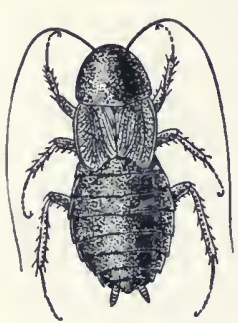

Fig. 36. Fe. male, $X$ r.3. (Or. iginal.)

Ind. These I soon afterwards described and recorded (1893a, 160) as Temnopteryx deropeltiformis Brunner. On July 12, 1594, a single female was captured while feeding upon a flesly fungus (Agaricus) in dense woods eight miles west of Terre Haute, in Marshall Co., Ill.; while in June, 1902, a number were taken from beneath flat stones and rubbish on the tops of high hills near Wyandotte Cave, Crawford Co., Ind. These and the Vigo Co. specimens were described and recorded by me $(1903,177)$. Since that date the species las been found to be widely distributed over the Eastern United States, its known range being from West Creek, N. J., and Enola, Pa., west and south to Ottawa, Kansas, and Victoria, Texas.

In Florida it has been taken by me at Ormond and Lake Okeechobee, March 1-April 15, and, mostly as Temnopteryx deropeltiformis, Ischnoptera nigricollis or $I$. johnsomi has been recorded numerous times from Jacksonville and Cedar Keys sonth to Homestead and Key West. Hebard has shown (1917a, 63) that the single male from Crawford Co., Ind., described by me $(1903,186)$ as doubtfully that of Ischnoptera intrienta sp. nov., was a freshly moulted male of $I$. deropeltiformis; as was also a small male from St. Augustine, Fla., described by Rehn (1903d, 234) as Ischmoptera johnsoni; also that I. nigricollis Walker $(1868,118)$ is the same as Brunner's species.

This handsome roach is essentially a ground-frequenting. forest-loring insect, hiding beneath corer in or about the edges of deep woodland, more frequently in damp places, and rarely taken beneath bark, signs or at lights. When uncovered the males often 
fly actively away, while the females can but crawl, and that rather sluggishly for a Blattid, toward the nearest new hiding place. At a point four miles southeast of Moore Haren, Fla., a half dozen or more adults and numerous nymphs were taken March 1, 1918, from beneath weeds, grass and other debris washed up on the beach of Lake Okeechobee.

VII. Parcoblatta Hebard, 1917a, 70. (Gr., "frugal" + Blatta.)

The Wood-RodCHes.

Medium sized species, the male with bods oblong, rather narrow, the female broader, more compact; pronotum feebly convex, more strongly so on sides, that of male usually elliptical, more or less narrowed in front, the disc usually with two oblique impressions, its hind margin broadly rounded; in the female usually suborbicular, without discal impressions, the hind margin truncate; tegmina membranous, more or less translucent, extending berond apex of abdomen in all males, not reaching apex in females except in caudelli, their discoidal sectors weakly radiating; wings hyaline, their ulnar vein feebly curved and with one to six basal incomplete branches; styles of male as described in generic key; front femora armed beneath as in Ischnoptera.

Twelve species, all native to America, are recognized by Hebard, nine of which occur in the Eastern United States. Until Hebard issued his excellent Monograph (1917a), the species of this genus, as far as synonymy goes, were a badly mixed lot. This was due to the fact that the sexes differ so widely in appearance that they have been described as different suecies, and often placed in wholly different genera. Most of the original descriptions were made by foreign entomologists, who nerer saw a specimen in the field, and for that reason knew nothing of the relationship of the different individuals before them. However, the two sexes are so seldom found mating, that eren the field naturalists cannot be certain as to their relationship. Previous to 1903 , Saussure, followed by Scudder, had described both sexes of Temnoptery.x as being short-winged, and the females of sereral species of Parcoblatta had been described as distinct species and placed in that genus. They had also stated in their "Kers to genera of Blattine" that in the genus Ischnoptera (Parcoblatta of Hebard) the "tegmina are completels developed or in the female rarely abbreviate." In my work of 1903 I first showed that the males of Temnopteryx were macropterous, and first properly correlated 
the sexes of Parcoblatta pennsylvanica, and also concluded as the result of extended field work and comparisons, "that the species of Phyllodromia and Temnoptery $x$ listed ${ }^{18}$ by Scudder in his Catalogue $(1900,8)$ are but the females of certain species of Ischnoptera," and they were first so placed, though not always correctly as to species, in my "Orthoptera of Indiana."

Rehn \& Hebard (1910), in studying all their known species of North American Ischnoptera (Parcoblatta), followed up this problem of sex correlation, and when through stated that "every species of the genus known from within our limits has the sexes correlated, with the result that Temnopteryx and Loboptera (with the exception of one species) are eliminated from our fauna." They failed, however, to properly place the sexes of several species, and thus left the group still very much confused.

Hebard has sliown that the males of each species of Parcoblatta have one or more of the dorsal abdominal segments modified or "specialized" in a different way, and has used this as the principal character in separating that sex. Since the removal or spreading of both tegmina and wings is necessary to see this character, and since the specialization is more or less microscopic in nature, an attempt has been made in this work to separate the males by more obvious characters, but the modification of the segments for each species is mentioned either in the key or in the descriptions.
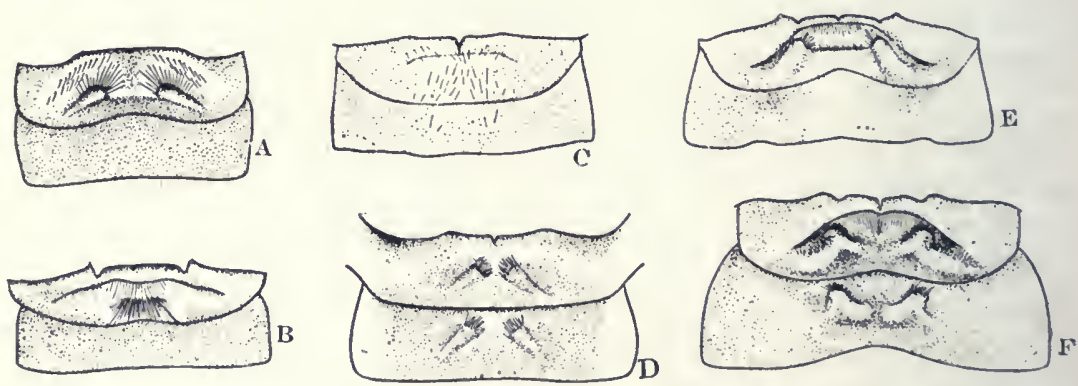

Fig. 37. Showing specialization of median and first dorsal abdominal segments of the males of Parcoblatta. A, of $P$. uhleriana Sauss.; B, P. zebra Heb.; C, $P$. virginica (Brunn.); $\mathrm{D}, P$. lata (Brunn.); E, P. divisa (Sauss.); F, P. pennsylvanica (DeG.). (After Hebard.)

KEY TO EASTERY SPECIES OF PARCOBLATTA.

a. Female with inner wings absent and tegmina represented by very small oblong pads, separated by more than twice their width (Fig. 39 , A.) ; male with dorsal segments of abdomen unmodified; head

${ }^{18} \mathrm{He}$ did not, for some reason, list Temnopteryx deropeltiformis. 
and pronotal disc shining blackish-brown; average length of body, $\hat{\delta}, 11.3$; of tegmina, $12.7 \mathrm{~mm}$.

19. Bolliaxa. aa. Female with inner wings present, often very short, and tegmina not as above; male with one or more of dorsal segments modified.

b. Tegmina of female strongly abbreviated, covering not more than one-half the abdomen; males with disc of pronotum not distinctly darker than sides and nearly uniform in color with tegmina.

c. Females shining blackish-brown, their tegmina subtriangular: separated by a space equal to one-fourth their width, their hind margins oblique; males pale brownish-yellow, their tegmina much wider than pronotum, their supra-anal plate only twice as broad as long, its apex broadly rounded; median dorsal ab. dominal segment of male with two raised ridges at middle each bearing on basal portion a heavy tuft of hairs (Fig. 37, A.); average length of body, $\hat{o}, 15.3$, of tegmina, $17 \mathrm{~mm}$.

20. UHLERIAYA.

cc. Females reddish-brown or brownish-yellow, the abdomen ofteu darker, their tegmina subquadrate, slightly orerlapping; males almost uniform brownish-yellow in hue.

d. Length of body, ô, not over 16.5 , of tegmina, not over $17 \mathrm{~mm}$., females with tegmina covering only basal third of abdomen, their hind margins almost squarely truncate; tegmina of male but slightly wider than pronotum.

$e$. Smaller and more slender, average size of pronotum of female, 3.5x4.4 mm.; male with a large area at middle of median dorsal abdominal segment supplied with minute scattered hairs (Fig. 37, C.) and with supra-anal plate four times as broad as long, squarely truncate; pronotum of male elliptical, widest at middle, not distinctly narrowed in front; average length of body, $\hat{\jmath}, 13$, of tegmina, $15 \mathrm{~mm}$.

21. VIRGINicA.

ee. Larger and broader, average of pronotum of female, $4 \times 5.6$ $\mathrm{mm}$; modified abdominal segment of male much as in uhleriana; pronotum of male longer, more narrowed in front, widest slightly behind the middle; arerage length of body, $\hat{\delta}, 14.6$; of tegmina, $15.7 \mathrm{~mm}$. 22. FULVEscexs.

$d d$. Length of body, ô, $17.5-21.5$, of tegmina, $17.8-22 \mathrm{~mm}$.; females with hind margins of tegmina broadly rounded; middle of median and first dorsal abdominal segments of male each with two feeble elevations convergent in front and sup. plied with a heavy tuft of hairs (Fig. 37, D.); average size of pronotum of $\$, 5.4 \times 7.5 \mathrm{~mm}$.

23. LATA.

$b b$. Tegmina of female much less abbreviated, reaching beyond middle of abdomen, their tips never truncate; those of male delicate in structure and fully developed.

$f$. Tegmina of female not surpassing the abdomen, sustained flight impossible; disc of pronotum of male, at least in part, darker than sides.

g. Dorsal surface of abdomen dull yellow, banded with brown; 
male with tegmina very delicate, and middle of median dorsal abdominal segment with a broad, heavy tuft of agglutinated hairs, and also with a low, hairy transverse ridge in front of this tuft (Fig. $37, \mathrm{~B}$.) ; average length of body, $\hat{o}$, 14.7, of tegmina, $15.2 \mathrm{~mm}$.

24. ZEBRA.

gg. Dorsal surface of abdomen not banded; tegmina of male dark brown, their margins paler; disc of pronotum distinctly dark. er than sides; seventh dorsal abdominal segment of male produced so as to almost wholly conceal the eighth.

$h$. Larger, average size of pronotum of female, $5 \times 6.1 \mathrm{~mm}$.; median and first dorsal abdominal segments of male each concave at base, the concavity overhung with two elevations which are heavily supplied with hairs on the under surface (Fig. 37, F.) ; average length of body, of, 20.7, of tegmina, $21.2 \mathrm{~mm}$.

25. PENXSYLVAXICA.

$h h$. Smaller, average of pronotum of female, $4.3 \times 5.6 \mathrm{~mm}$., its sides less strikingly pale; median dorsal abdominal segment of male alone modified as in pennsylvanica (Fig. 37, E.); average length of body, $\hat{o}, 16.6$, of tegmina, $18.6 \mathrm{~mm}$.

25a. DIVISA.

ff. Tegmina of female surpassing the abdomen, sustained flight possible in both sexes; size small, form slender; color pale brownish-yellow; two male abdominal segments modified as in lata; average length of body, $\hat{\delta}, 14$, of pronotum, 3.1, of tegmina, $14.6 \mathrm{~mm}$.

26. CAUDELLI.

19. Parcoblatta bolliana (Saussure \& Zehntner), 1893, 40. Boll's WoodRoach.

Small slender species, the females stouter and more compact, with distinctly broader head and pronotum. Male with head, disc of pronotum and base of tegmina dark brown, shining, finely and sparsely pubescen with suberect yellowish hairs; legs, lateral margins of pronotum and apical portion of tegmina paler brown; ocellar spots and an area between the thoracic impressions dull yellow. Female chocolate brown, the legs usually darker than those of male. Ocelli well defined, male, represented by small spots, female. Pronotum widest slightly behind the middle, that of male with two distinct oblique impressions connected near base by a short transverse one. Tegmina of female as described in key, their outer margins straight, upcurved; inner ones obliquely rounded into apex. Supraanal plate of male about twice as broad as long, feebly declivent toward apex; of female with a blunt median carina, the apex broadly rounded. Length of body, ô, 10.1-12.8, ㅇ, $9-10.7$; of pronotum, $\hat{o}, 2.7-3$, 오, $2.9-$ 3 ; of tegmina, $\hat{o}, 11.7-13.6$,, $1.7-1.9 \mathrm{~mm}$. Width of pronotum, $\hat{o}$, $3.6-4.2$, ㅇ, 3.9-4.4; of tegmina, ô, 3.8-4.6, ㅇ, 1.4-1.7 mm. (Fig. 39, A.)

Ranges from Raleigh, N. Car., and Brunswick, Ga., north to southern Illinois and Nebraska City, Neb., and west and south to the Mexican border; not yet recognized from either Indiana or Florida. It is the only one of our nine eastern species of the 
genus in which one or more of the dorsal abdominal segments of the male are not modified and the tegmina of the female are smaller and more widely separated than in any of the others. The 86 specimens recorded by Hebard were taken from 33 different localities within the range above mentioned between April 27 and July 21, a few at light, or trapped in molasses jars, but the habitat of most not mentioned. Brimley $(1908,16)$ states that it and other native roaches are all found near Raleigh $\mathrm{N}$. Car., "under the thick covering of pine straw lying on the ground in pine woods." In the western part of its range it becomes much paler, in some specimens the head only being dark. The Kakerlac schefferi Rehn $(1904 \mathrm{~g}, 72)$ is a synonym.

20. Parcoblatta umleriana (Saussure), 1862a, 169. Uhler's Wood-Roach.

Male.-Size medium, form rather slender. Nearly uniform pale brown-

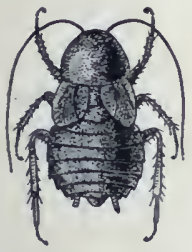

Fig. 38. Fe male. $X$ I.3. (Original.) ish-yellow, tegmina often somewhat darker; head with a broad brownish stripe extending from between middle of $€$ yes downward two-thirds the length of face. Ocelli distinct. Pronotum subelliptical, widest at middle, the angles all rounded, the discal oblique impressions rather deep. Cerci slender, 11-jointed, the fifth to ninth joints with inner apical angles slightly prolonged. Subgenital plate slightly keeled along middle of apical half, with a concavity each side of keel; styles short, awl-shaped, equal. Female.-Broader, with head wider. Color variable, usually shining blackish-brown, the legs, except the trochanters, and margins of tegmina chestnut brown; sometimes entirely dark reddish-brown except the abdomen. Pronotum suborbicular, widest near base, front margin rounded, hind one truncate, discal impressions absent. Tegmina as described in key, at most reaching base of second abdominal segment. Wings very rudimentary. Oötheca $3.4 \times 6 \mathrm{~mm}$., its suture witk a row of minute, well spaced conical projections, on each side of which is a moderately deep groove. Length of body, $\hat{o}, 13.3-16.5, \$, 9.8-14$; of pronotum, $\hat{\delta}, 2.9-3.6$, $~, ~ 3.4-4.2$; of tegmina, $\hat{o}, 15.7-18.8$, $\&, 3.2-6.3 \mathrm{~mm}$.

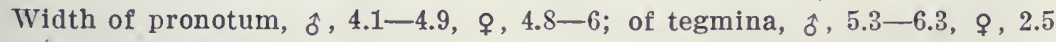
$-3.7 \mathrm{~mm}$. (Fig. 38.)

Steuben, Marion, Lawrence and Crawford counties, Indiana, May 26-Aug. 7 (W. S. B.). The females were first described by me as Ischnoptera intricata sp. nov. $(1903,186)$. Those from Crawford Co. were found beneath corer on the slopes of high wooded hills, those from Steuben Co. beneath chunks near the border of a lake, two of the females (Aug. 7) with oötheca protruding. In Florida $P$. uhleriana is known only from Pablo Beach, Aug. 11 (Hebard, 1917a, 114). It ranges from Massachu- 
setts and Saginaw Bay, Mich., west to Iowa City, Iowa, and south to Florida and Mississippi.

This is essentially a forest-loving species, usually occurring beneath leaves and other debris on or along the borders of heavy hardwood timber. The males are often attracted to light and the females to a bait of molasses. The latter sex appears to be much the more abundant, especially in Indiana, and 994 of the 1232 adult specimens examined by Hebard were females. The short separated tegmina and shining black color easily distinguishes them from allied species, while the males are with difficulty separated from those of fulvescens and virginica. Platamodes unicolor and Ectobia lithophila Scudder $(1862,417,418)$ are synonmys, being based respectively on the male and nymph, while, as noted above, Ischnoptera intricata Blatch. $(1903,186)$ is the female, the type of that sex, as designated by Hebard, being a specimen taken in Crawford Co., Ind., July 2, 1902, and now in my collection.
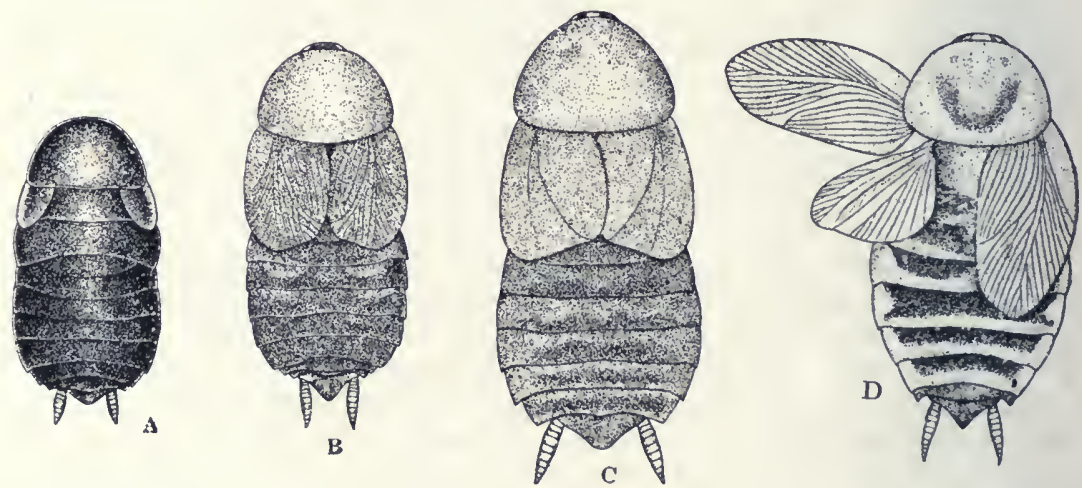

Fig. 39. Females of Parcoblatta $\times$ 3. A, P. bolliana (S. \& Z.); B, $P$. virginica (Brunn.); ${ }^{39}$, P. fulvescens (S. \& Z.); D, P. zebra (Heb.) (After Hebard.)

21. Parcoblatta virginica (Brunner), 1865, 86. Virginia Wood-Roach.

Male.-Size small for the genus, more slender than uhleriana. Uniform pale brownish-yellow, the disc of pronotum and sometimes the head slightly darker. Ocelli distinct. Pronotum as in uhleriana but smaller with oblique impressions more distinct. Tegmina wider than pronotum, but distinctly narrower than in uhleriana. Cerci slender, 10-jointed, none of the joints with inner apical angles prolonged. Subgenital plate roughly subquadrate, feebly concave near apex; styles shorter and less tapering than in uhleriana. Female small, more slender than in the preceding or the next species. Color more or less variable, usually with head and abdomen chestnut-brown, pronotum and tegmina dark reddish-brown, 
their margins paler; legs and under surface brownish-

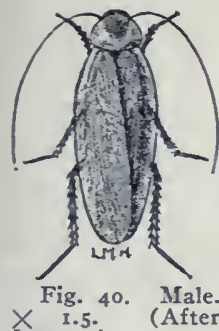
yellow. Head broader than in $\hat{o}$. Pronotum as in uhleriana but distinctly smaller. Tegmina quadrate, their sutural margins overlapping, hind margins subtruncate, usually slightly emarginate near the sutural angle, reaching the middle of second dorsal segment. Wings represented by small pads. Length of body, $\hat{\delta}$, 11.5-15.4, ㅇ, 10.3-12.5; of pronotum, $\hat{\delta}, 2.7-3.6$, 우, $3.2-3.8$; of tegmina, $\hat{\delta}, 12.8-16.7$, 우 $3.3-4.9 \mathrm{~mm}$. $\times$ 1.5. (After Width of pronotum, $\delta, 3.4-4.4$; $\$, 4.1-4.9$; of tegmina, ô, 4.3-5.7, , 2.7-3.3 mm. (Figs. 39, B, 40.)

Frequent throughout Indiana, May 5-Aug. 22. Hibernates in the nympl stage beneath half buried logs and other debris, the males reaching maturity about May 1st, when they are often glegarious beneath loose bark and under chunks and rubbish in open woods. The females inature a few weeks later, and in Indiana are found in July with oötheca protruding. Ranges from Maine to Minnesota, Nebraska and Kansas, south to North Carolina, Kentucky and Alabama. Frequents the borders of open woods and cultivated fields, being less of a forest-loving species than uhleriana. The males are frequently taken at light, but the females probably range but a short distance from their original hatching place.

In "The Orthoptera of Indiana" this species was placed as a synonym of uhleriana, the females of that species being then unknown as such. I. borealis Brunner (1865, 133) is the male of virginica, he having described both sexes in the same work as distinct species of different genera. His type of virginica was from Draper's Valley, Va., and that of borealis from "Amerique du Nord."

22. Parcoblatta Fulvescexs (Sauss. \& Zehnt.), 1893, 36. Fulvous WoodRoach.

Male.-Size medium, form rather slender. Uniform pale brownish-yellow, the pronotum and legs sometimes darker; cerci usually dark brown. Pronotum subelliptical, widest slightly behind the middle, the oblique im. pressions of disc weakly defined, and apical angles more broadly rounded than the hind ones. Tegmina slightly narrower than in uhleriana. Cerc: slender, 11-jointed, none of the segments with inner apical angles prolonged. Styles slender, awl-shaped, the right one slightly the stouter and borne in a cup-shaped elevation or knob placed just beneath the apical margin of subgenital plate. Female-Larger than in uhleriana. Head and pronotum usually pale reddish-brown and apical halves of abdominal segments darker brown; tegmina reddish-brown, the sides paler; legs and under surface brownish-yellow. Tegmina and wings as in virginica, but 
larger. Length of body, $\hat{\delta}, 12.5-16.5$, ㅇ, 10.8-15.5; of pronotum, $\hat{\delta}$, $3.3-4$, ᄋ, 3.8-4.9; of tegmina, $\hat{\delta}, 14-18.2$, ㅇ, $3.1-5.6 \mathrm{~mm}$. Width of pronotum, $\hat{\delta}, 4.3-5.3$ ㅇ, $4.6-6.6$; of tegmina, $\hat{o}, 4.3-5.6$, ㅇ, $3.3-4.7 \mathrm{~mm}$. (Fig. 39, C.)

Crawford Co., Ind., June 3. Ormond, Dunedin, Sarasota, Gulfport, Ft. Myers and Lake Okeechobee, Fla., Jan. 24-April 1 (W. S. B.). 'This roach is frequent near Dunedin, Fla., beneath drift, cow-dung, the base of thistle leaves, boards, etc., in dry, sandy localities, a female with oötheca protruding on March 28 . Recorded also by other collectors from $15^{\circ}$ additional localities in Florida, and is the only common nember of the genus in that State, throughout which it doubtless occurs. Ranges from Long Island, N. Y., west to southern Indiana, Dallas Co., Iowa, and Arkansas, south and southwest to the southern keys of Florida, and Zavalla Co., Texas. Occurs under debris, bark of logs, etc., usually in open pine woods of sandy regions. Treated by R. \& H. $(1910,439)$ as a southeru variety of uhleriana, the males being rery similar and distinguished mainly by the pale face, longer pronotum with discal impressions less distinct, and by cluaracters of cerci and insertion of right style as above given. If Hebard has correctly placed the females of uhleriana, that sex is very different in the two species and fulvescens is a distinct and valid species mainly austral in its distribution.

The oötheca of fulvcscens is bean-shaped, very dark brown, about $3.8 \times 8.5 \mathrm{~mm}$. in size, the sutural edge being broadly curved and with about 40 minute crimps or folds.

\section{Parcoblatta lata (Brunner), 1865, 135. Broad Wood-Roach.}

Male-Size large, form robust. Pale reddish-brown, the head often in part darker; legs and margins of thorax and elytra yellowish translucent; antennæ, abdomen above and its sides beneath pale brown; cerci dark brown. Pronotum suborbicular, longer in proportion to its width than in the last three species, widest at middle, its oblique impressions distinct. Tegmina notably wider than pronotum, extending much beyond the abdomen. Supra-anal plate triangular, its apex broadly rounded. Subgenital plate feebly concave on right side near apex; styles slender, straight, awlshaped. Female-Large, robust. Pronotum much larger than that of male, its front margin rounded, hind one truncate. Tegmina quadrate-ovate, reaching apex of second dorsal segment. Wings small, narrow, their tips acute. Supra-anal plate keeled above, its apex bluntly rounded. Subgenital plate strongly convex. Oötheca $4 \times 9 \mathrm{~mm}$., its suture feebly curved and with a row of about 30 small equidistant ${ }^{10}$ knobs. Length of body, $\hat{\delta}, 17$.

MHebard (1917a, 111, 1,31) states that the oötheca of $P$. Mhlcriana and $P$. lata "are carried with the suture laterad." Specimens of both are at hand with the oótheca protruding with suture dorsad. 
$5-21.5$,, $15.7-22$; of pronotum, $\delta, 4.1-5.2$, ९, 4.8-6.2; of tegmina, $\hat{\delta}$, $17.8-22$,, $5.9-8 \mathrm{~mm}$. Width of pronotum, of, $5.4-6.7$,, $6.7-8.2$; of tegmina, ô, 5.2-6.8, $\circ, 4.7-5.7 \mathrm{~mm}$.

Crawford, Gibson and Posey Cos., Ind., June 6-July 10, one male, numerous females; the latter sex most common and with oötheea protruding the latter part of .June (W. S. B.). In Crawford Co. they were taken from beneath rocks on the sides and crests of the higher hills, especially in limestone glades where the red cedar abounds. In Florida it has been recorded from Jacksonville, Ortega, Gulf Hammock, Tallahassee, River Junction, Marianna and De Funiak Springs, March-Sept, and probably occurs only in the northern third of the State. Ranges from Delaware and Maryland west and south to St. Louis, Mo., and Beaumont, Texas. A single adrentive specimen was taken in a house at Wellesley, Mass., by A. P. Morse.

In the Southern States this roach is usually found beneath the loose bark of pine logs and stumps, or beneath signs attached to pine trees. It is the largest of the species of Parcoblatta whose males are pale brown in color, and is only equalled or exceeded in size by $P$. pennsylvanica. It was described by me $(1903,183)$ as Ischnoptera major S. \& Z. (1893, 54), which name is a synonym of $P$. lata, but my description was the first one of the female. I. hyalina Seudder $(1869,307)$ and $I$. couloniana (R. \& H., 1910, $433)$ nec Saussure (1862) are also synonyms.

\section{Parcoblatta zerra Hebard, 1917a, 89. Banded Wood-Roach.}

Male-Rather small, slender. Head dull yellow, a brownish stripe extending from the ocelli down the face; disc of pronotum reddish-brown, sides translucent yellow, basal fourth darker brown; tegmina transparent, brownish-yellow; under surface and cerci dark brown, as is also the basal half of each dorsal segment of abdomen; legs yellow. Interocular space one-third that between the antennal sockets. Pronotum elliptical, widest at middle, all the angles, sides and hind margin broadly rounded, oblique impressions deep. Apical half of supra-anal plate concave and strongly bent downward, forming a transverse ridge at point of bend, the apex, broadly rounded. Cerci elongate, rather stout, the apical segment pale. Subgenital plate feebly concave each side toward apex; styles short, cylindrical, the right one slightly the larger and feebly curved. Female-Larger and more robust. Head yellow with a transverse bar of brown between the antennæ; disc of pronotum and tegmina reddish-brown, the sides of both transparent yellow; legs, middle of ventral surface of abdomen and narrow sides and apical half of each dorsal segment yellow. Interocular space much broader than in $\hat{\delta}$. Pronotum widest near base, hind margin truncate. Tegmina reaching apex of fifth dorsal segment, sublanceolate, their tips rounded. Supra-anal plate triangular, projecting beyond apex 
of subgenital plate, its apex obtusely pointed. Length of body, $\hat{o}, 13-16$, 오, 11.5-14.5; of pronotum, $\hat{o}, 3.1-3.7$, ㅇ, 3.7-3.9; of tegmina, $\hat{o}, 13$. $9-16.1$, ㅇ $6.9-7.7 \mathrm{~mm}$. Width of pronotum, ô, $3.9-4.7$, ㅇ, $4.8-5.2$; of tegmina, ô, 4.3-5.4, ᄋ, 3.6-3.8 mm. (Fig. 39, D.)

Knox Co., Ind., June 8-9, one male, two females, taken from beneath a $\log$ in a cypress swamp ( W. S. B.). Known elsewhere only from Havana and Pulaski, Ill., Rives, Tenn., Lakeview and Hattiesburg, Miss., West Monroe and Mansura, La., and Dallas and Victoria, Texas; May-Sept. Of the 12 specimens known to Hebard one was taken in a cavity of a dead sweet gum, two beneath a sign on pine tree and one at light.

25. Parcoblatta Pennsyluanica (DeGeer), 1773, 537. Pennsylvania Wood-Roach.

Male-Large for the genus, moderately broad. Head chestnut-brown, sides of face pale; pronotum with hind margin and disc dark brown, sides yellowish transparent, as are also the margins of tegmina for three-fourths their length; disc of tegmina reddish-brown; abdomen and cerci chestnut-brown; legs yellow, the tibiæ and tarsi often pale brown. Interocular space flattened, finely rugose, its width one-third less than that between antennal sockets. Pronotum sub-elliptical, widest slightly behind middle, hind margin feebly rounded, oblique impressions distinct. Supraanal plate concave, its apical half often deflexed. Subgenital plate onehalf wider than long, convex except near apex where it is narrowed and often concave near the styles. Left style slightly stouter and more deflexed than right one. Female-Large, robust. Color of $\hat{o}$, the disc of thorax often paler; dorsal surface of abdomen dark chestnut-brown, its edges paler; middle of abdomen beneath pale. Head larger than in $\hat{o}$, the interocular space equal to that between antennal sockets. Pronotum widest near base, hind angles more sharply rounded than in male. Tegmina variable in length, usually covering two-thirds or more of abdomen, their tips broadly rounded. Supra-anal plate triangular, feebly concave each side near base, its apex usually sharply rounded. Subgenital plate strongly convex, twice as wide as long, broadly rounded at tip. Length of body, $\hat{\delta}, 16.8-24.5$, ․ , 12.7-18; of pronotum, ô, 4.2-5.3, ㅇ, 4.3-5.8; of tegmina, $\hat{\delta}, 17.3-25.1$,, $6.4-13.9 \mathrm{~mm}$. Width of pronotum, $\hat{\delta}, 5.4-$ 6.9 ; ㅇ, 5.1-7.2; of tegmina, ô, 5.4-7.7, ․, 4.2-5.7 mm. (Figs. 41, 42.)

In Indiana the Pennsylyania wood-roach is the most common of our native species, having been taken in the State wherever collections have been made, beneath the loose bark of logs and old stmmps. It is usually seen in the wingless stages, the mature individuals being common only from May 15th to October. The half grown young are of a shining, dark brown color, the dorsal surface of thoracic segments often paler. As the long-winged males are attracted by light, country houses are often badly 


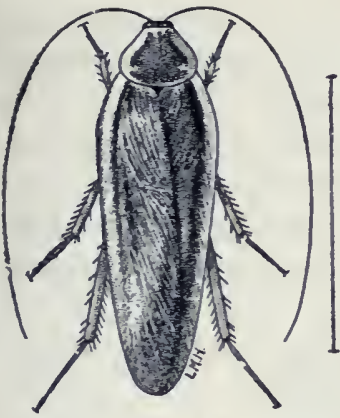

ig. 4I. Male. (After

infested with them; and where food is scarce, the wall paper is sometimes much injured for the sake of the paste beneath. What the hordes of young which dwell under the bark of logs lire upon is a question as ret unsettled, but the larra of other insects undoubtedly form a portion of their food, as in two instances I have found them feeding upon the dead grubs of a Tenebrio beetle; while living as well as decaying vegetable matter probably forms the other portion. The mating of the imagoes probably occurs in late spring and early summer, the newly hatched young being most abundant from mid-August until December. Females with oötheca protruding hare been taken as early as May 19th and as late as September 3d. The young in various stages of growth survive the winter in the places mentioned, they being the most common insects noted in the woods at that season. Cold has seemingly but little effect upon them, as they scramble away almost as hurriedly when their protective shelter of bark is removed on a day in mid-January with the mercury at zero, as they do in June when it registers 100 degrees in the shade.

The empty oötheca of this species are very common objects beneath the loose bark of logs and especially beneath the long flakes of the shellbark hickory. Ther are chestnut brown in color, from 5 to $9 \mathrm{~mm}$. in length by $4 \mathrm{~mm}$. in breadth, and are much less flattened than those of Blattella germanica. The dorsal or entire edge is slightly curved, or bent inward, after the fashion of a small

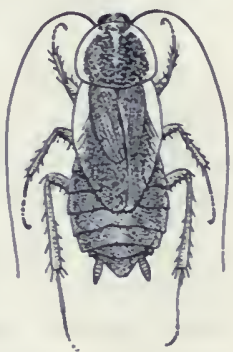

Fig. 42. Female. $\times$ r.5. (Original.) bean, while the other edge is minutely serrate. The young, after hatching, evidently escape in the same manner as do those of the Oriental roach, as no break is visible in the empty capsule. The tegmina of the female are more rariable in length than in other of our native species of Blattidx, in two Indiana specimens at hand reaching the apex of the 7 th dorsal segment, while in two others they cover only one-third the abdomen.

The Pennsylvania wood-roach ranges from Quebec and Ontario, Canada, and Scarboro, Maine, west to Minnesota, Nebraska and Kansas, and south to Thomasville, Ga., and Brownsville, 
Texas. The female was first described by Scudder $(1862,419)$ as Ectobia flavocincta. This name was first correlated as the female of pennsylvanica in my Orthoptera of Indiana $(1903,179)$. The males have been described under five additional specific names, viz., borealis, couloniana and nortoniana Saussure (1862a, 166, $169)$; translucid $\iota$ Saussure $(1864,85)$, and incqualis S. \& Z. (1893, $36)$, and the female under one, marginata Scudder (1872, 251). The I. incqualis S. \& Z. of my former work $(1903,182)$ and of Rehn \& Hebard $(1910,427)$ are shown by Hebard $(1917 a, 140)$ to represent only a color phase of $P$. pennsylvanica.

25a. Parconiatta pennsylvanica divisa (Sauss. \& Zehnt.), 1893, 40.

Male-Differs from pennsylvanica in its usually smaller size and often slightly paler coloration, the dark disc of pronotum frequently divided by a paler line, and that of tegmina sometimes pale brownish-yellow instead of reddish-brown; also in having the median dorsal segment of abdomen alone modified, and the supra-anal plate subtriangular, its median portion narrower, more strongly concave and declivent. Females differ only in their smaller size and proportionally narrower pronotum, with its lateral margins less strikingly pale. Length of body, $\hat{o}, 13.8-17.6$, $\&, 12.7-$ 16.5; of pronotum, $\hat{o}, 3.6-4.6$, 우 $3.7-4.9$; of tegmina, $\hat{o}, 16.4-20.8$, 우, $7.2-10.8 \mathrm{~mm}$. Width of pronotum, ô, 4.8-6.2,,$+ 4.7-6.6$; of tegmina, ô, $5.1-6.6$, \&, $4-4.9 \mathrm{~mm}$. (Fig. 43, B.)

Ranges from New Jersey and Pennsylvania, south and west to Thomasville, Ga., and Lafayette, La. Occurs under the bark of pine and sweet gum and beneath signs on trees; the females and young trapped in molasses jars. No definite fixed character of specific value separating this form from pennsylvanica has been pointed out by Rehn \& Hebard in either their 1910 or 1916 papers, and the only one given by Hebard (1917a) is the lack of specialization in the basal abdominal segment of divisa. R. \& H. (1916, 115), state that "divisa is clearly a derivative of the pennsylvanica stock representing an adaptation of that type in the lower country of the southeastern States as I. p. incqualis is in the central States," the difference being that intergraded specimens have been found between incqualis and pennsylvanica but not between the latter and divisa. Hebard (1917a, 134) states that "due to the decided individual variation found in divisa and the very great plasticity in peninsylvanica, rare females are most difficult to distinguish, as in them great convergence in many features usually of distinct value occurs." The measurements as given under the two forms show that in erery case the maximum in divisa is greater than the minimum in pennsylvanica, and in sereral in- 
stances both minimum and maximum of divisa fall between those of pennsylvanica. Taking these facts into consideration and after examining both forms as represented in the Davis and Philadelphia collections, I believe that divisa is but a southern race or variety of pennsylvanica and have so placed it above. Two females of divisa in the Hebard collection from Opelika, Ala., have the tegmina surpassing the abdomen.
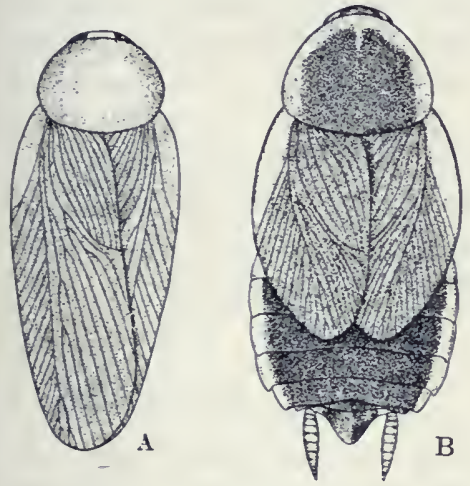

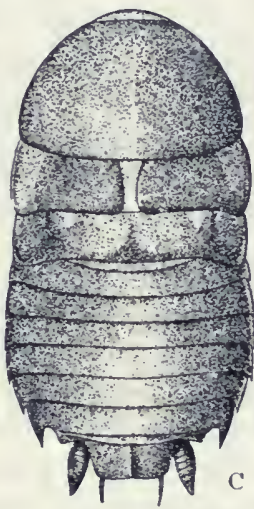

Fig. 43. A, Parcoblatta caudelli Heb., female; B, $P$. p. divisa (S. \& Z.), female; C, Eurycotis floridana (Walk.), male; D, Cryptocercus punctulatus Scudd., female.

(A, B \& $\mathrm{C} \times 3 ; \mathrm{D} \times$ 1.5.) (After Hebard.)
26. Parcoblatia caudell Hebard, 1917a, 122. Caudell's Wood-Roach.

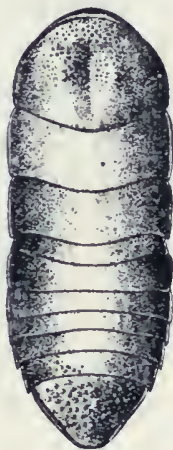

$\mathrm{D}$

Male-Size small for the genus, form slender. Head pale clay-yellow, the occiput, a transverse bar at middle of face, disc of pronotum and dorsal surface of abdomen brownish-yellow; tegmina pale brown; legs and under surface pale clay-yellow, the abdomen with a brownish tinge. Head and pronotum as in fulvescens. Tegmina fully developed, slightly wider than pronotum. Supra-anal plate with apex bluntly rounded and declivent. Cerci slender, elongate. Subgenital plate feebly convex, except near styles, where it is slightly concave, the apex almost truncate. Styles small, slender, cylindrical, subequal in length to the distance between their bases. Female-Smaller than $\hat{\jmath}$. Uniform pale brownish-yellow, the legs, margins of thorax and elytra paler. Interocular space broader than $\hat{o}$, subequal in width to the distance between the antennal sockets. Pronotum suborbicular, widest just behind the middle, the disc with oblique impressions very faint. Tegmina shorter than in $\hat{o}$, but extend. ing beyond apex of abdomen. Supra-anal plate half as long as broad, subtriangular, the apex subacute and surpassing the hind margin of subgenital plate, the latter twice as wide as long, convex, its hind margin broadly

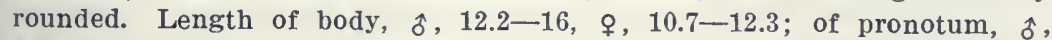
$2.9-3.4$,, $3.2-3.6$; of tegmina, $\hat{o}, 11.8-16$,, $11.4-11.8 \mathrm{~mm}$. Width of pronotum, $\hat{\delta}, 3.9-4.7$, $\uparrow, 4.1$; of tegmina, $\hat{o}, 3.9-5.2$,, $3.8-4 \mathrm{~mm}$. (Fig. 43 A.)

Crawford Co., Ind., June 30, 1902, one female (W. S. B.). 
Ranges from Virginia and District of Columbia west and south to southern Indiana, Arkansas and Waco, Texas; not yet known from Georgia or Florida. Nothing distinctive of its habits is known, except that one specimen was found beneath a sign. It is the smallest of the pale brown species of the genus and the male abdomen is modified like that of the largest, $P$. lata. The Indiana specimen above mentioned served as the female type of I. insolita R. \& H. (1910, 450), a name which has been placed in synonymy by Hebard, as the male type proved to be that sex of a Texan species, $P$. deserto $R$. \& H.

\section{VIIT. Symploce Hebard, 1916c, 3555. (Gr., "woven together.")}

Rather small, pale, slender species having the pronotum of male evenly convex without discal impressions, its hind margin feebly prolonged backward at middle into an obtuse angle; discoidal sectors of tegmina longitudinal; discoidal vein of both tegmina and wings forked; subgenital plate of male asymmetrical; lower front margin of fore femora armed as described in " $a a^{\text {" of }}$ generic key, and also with three longer unequal spines at apex (Fig. 32, E). Six species are known, five from the West Indies and the one below.

\section{Symploce lita Hebard, 1916c, 357. Unadorned Cockroach.}

Male-Pale reddish-yellow, translucent; legs and abdomen pale brownish-yellow, the apex of latter and cerci darker. Eyes large, ocelli distinct. Pronotum suborbicular, one-fourth wider than long, its sides declivent, their margins divergent behind and rounding into the hind margin. Tegmina very delicate, fully developed. Sixth dorsal abdominal segment with two small median basal depressions separated by a triangular ridge which is thickly clothed with hairs. Supra-anal plate much wider than long, its side margins armed with a row of minute spines. Subgenital plate with right margin oblique, prolonged and upturned at apex, the short right style with a spine at base; left margin concave near apex, the left stylo more slender, curved, twice as long as right one, and armed with two minute spines. (Fig. 34, D.) Female-Eyes smaller, interocular space much broader; hind margin of pronotum very weakly obtuse-angulate. Tegmina subquadrate, their hind margins subtruncate, with outer apical angles rounded. Wings much shorter than tegmina. Supra-anal plate triangular, its apex bluntly rounded. Length of body, $\hat{\delta}, 11.5-14$, $q$, 11-12.3; of pronotum, ô, 3.2-3.7, ᄋ, 3.4-3.7; of tegmina, $\hat{\delta}, 11.1-12.8$, , $3.9-4.8 \mathrm{~mm}$. Width of pronotum, $\hat{\delta}$ and $\mathcal{q}, 4.1-4.6$; of tegmina, $\hat{o}$ and ㅇ, $3-3.7 \mathrm{~mm}$.

Known only from Key West, Fla., San Jose del Cabo, Lower California, and Vera Cruz, Mexico. The unique Key West male type was taken July 4, in a cupboard of a hotel in company with 
Blattella germanica and Supella supellectilium, and was first recorded by Rehn \& Hebard (1914c, 378) as Ischnoptera rufescens (Beaur.). It is possible that the Key West type was only an adrentive in our territory, it being the only Florida specimen known.

\section{Subfamily II. NYCTOBORINAE.}

Large tropical species having the body relrety sericeous abore; eyes almost contiguous; tegmina leathers in structure, reaching to or much besond the apex of abdomen; apical half of lower front margin of fore femora armed beneath with numerous small spines of almost equal length; middle and hind femora armed beneath on hind margin with four to six large spines; joints 1 to 4 of tarsi with pulvilli beneath; supra-anal plate of both sexes triangularly produced; subgenital plate of female not compressed and bivalved.

I. Nyстовов Burmeister, 1838, 501. (Gr., "night" + "food.")

Two species of this genus occur frequently in the eastern United States, but onls as adrentives, being introduced with bananas and other tropical fruits. As both hare been recorded from numerous localities, it is thought best to include them in this work, though there is little chance of them ever becoming established unless it be in extreme sonthern Florida.

(-). Nyctobora xoctivaga Rehn, 1902d, 3. Great Brown Roach.

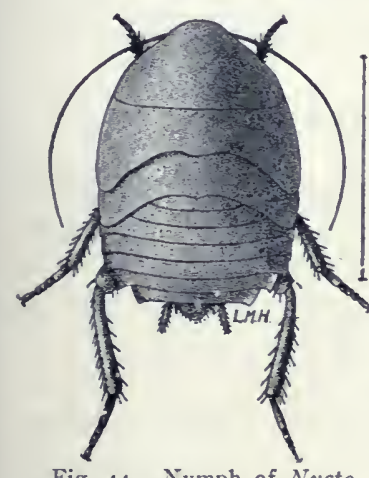

Fig. 44. Nymph of Nyctobora noctiz'aga Rehn. (After Lugger.)

Male-Dark chestnut brown, above thickly clothed with minute yellowish prostrate hairs; legs and under surface reddish-yellow, the face, middle of abdomen, tibiae, tarsi and cerci brownish-black. Antennæ as long as the body, filiform. Pronotum widest near base, the sides thence regularly converging to the rounded apex, the latter therefore much nar. rower than base, which is broadly rounded. Tegmina extending much beyond apex of abdo. men, their tips broadly rounded; anal field large, almost semicircular. Cerci stout, somewhat flattened. Subgenital plate with right margin longer and more oblique than left; left style more slender and twice the length of right one. Female similar to male but broader. Subgenital plate with sides straight, feebly converging, apex sub-truncate, slightly upcurved. Length of body, $\widehat{\delta}, 30-35$; of pronotum, 10; of tegmina, $38 \mathrm{~mm}$. Width of pronotum, $\hat{\sigma}, 13-14$; of tegmina, $15 \mathrm{~mm}$. 
Gibson Co., Ind., March 18, one male; Marion and Vigo counties, Ind., three nymphs; all taken about stores and probably introduced with bananas (W. S. B.). Hebard (1917a, 264) records it as an adventive from 20 localities ranging from Ontario and Massachusetts to Alberta and California. Relın's type was a male from Machuca, Nicaragua. This is probably the species listed by Scudder $(1900,9)$ as $N$. holosericca Klug.

(—). Nyctobora levigata (Beauv.), 1805, 228.

Thorax almost black, its apex and sides bordered with yellow, disk finely and rather thickly punctate Tegmina chocolate-brown, the margins of basal halves pale yellow; disk, except at base, punctate, like thorax, each puncture bearing a very short yellowish hair. Under surface and legs uniform dark brown.

Often confused with $N$. limbata (Thunb.), but easily separated "by the shorter, more ovate form, much larger and nearly semicircular pronotum, with caudal margin nearly straight; by the shorter tegmina and wings which but slightly or not at all surpass the apex of abdomen, by the more robust limbs, the much less velutinous surface and the uniformly colored coxæ and femora." (R. \& $H$.) Length of body, $\delta, 27.2$, \&, 26.527.8 ; of pronotum, $\hat{o}, 9$, ㅇ, 8.2-8.6; of tegmina, $\hat{o}, 23.5$, 우, 20.3-21.€ $\mathrm{mm}$. Width of pronotum, $\hat{\delta}$ and $\uparrow, 12-13.2$; of tegmina, $\hat{\delta}, 10.7$, $\subsetneq$, $10 \mathrm{~mm}$.

This handsome roach is a native of Hayti and Jamaica, and adventive specimens have been taken at Toronto, Ontario, and in a dozen localities in New England, New Jersey and Pennsylvania. It has been recorded by Scudder, Rehn and Henshaw as $N$. scricea Burn. R. \& H. $(1914 \mathrm{~g}, 121)$ have treated the synonymy of $N$. lavigata in detail.

\section{Subfamily III. EPILAMPRIN $\mathbb{E}$.}

Medium sized, strongly flattened tropical species, having the antennæe setaceous; tegmina and wings fully dereloped, the ulnar vein of wings with about 11 incomplete branches; supra-anal plate weakly bilobate in both sexes; styles of male slender, set in sockets. A single genus is represented in southern Florida.

I. Leurolestes Rehn \& Hebard, 1914c, 379. (Gr., "flat" + "plunderer.")

Pronotum not covering vertex of head, its hind margin very broadly rounded; lower front margins of fore femora armed beneath on basal half with a few short, heavy spines, on apical half with numerous very short spinules and with a single long spine at apex; other femora armed with a few seattered stout spines; joints $1-4$ of tarsi witl pulvilli; arolia distinct. 
28. Leurolestes Pallidus (Brunner), 1865, 286.

Male-Head dark brown, with two or three narrow pale stripes between the eyes; pronotum with disc dark reddish-brown, the sides and apex yellow, the paler color invading the darker in front and on sides; tegmina pale translucent brown, the marginal field yellowish; abdomen dark brown, its sides paler. Ocelli large, distinct. Pronotum subelliptical feebly convex, its sides strongly declivent, front margin feebly rounded. Tegmina slightly exceeding apex of abdomen. Supra-anal plate transverse, delicate, feebly bilobed. Cerci 10 -jointed, very short, stout, taper ing, sub-depressed. Subgenital plate asymmetrical, its left margin broadly rounded from base to middle of right margin, the latter concave near base; styles slender, cylindrical, the right one-half as long as the cerci. Female - Larger, head wider. Tegmina and wings barely reaching apex of abdomen. Length of body, $\hat{\delta}, 15.2-17.3$, ㅇ, 18.5-20; of pronotum, ô, $3.3-$ 3.9 , ᄋ, 4.1-4.3; of tegmina, $\hat{\delta}, 12.4-13.6$,, $14.8-15.2 \mathrm{~mm}$. Width of pronotum, $\hat{o}, 4.9-5.7$, ९, $6.1-\mathcal{C} .4$; of tegmina, $\hat{\jmath}, 4.2-4.5$, ㅇ, $4.7-5 \mathrm{~mm}$. (Fig. 45 B.)
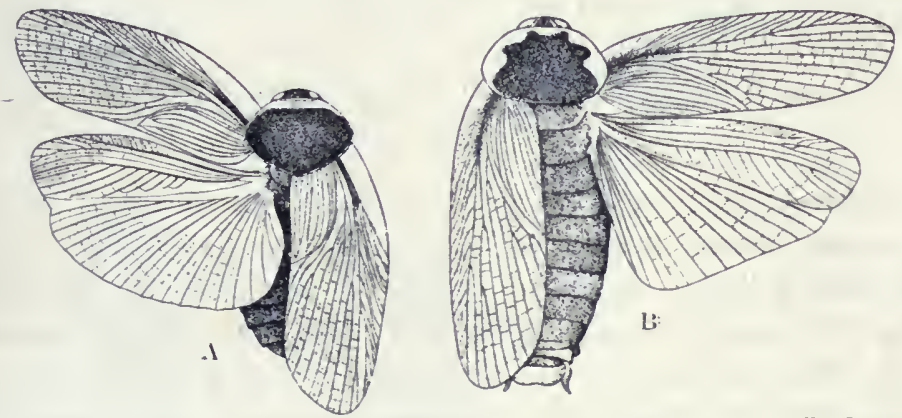

Fig. 45. A, Pycnoscchus surinamensis (Linn.) female $X$ r.6.; B, Leu. rolestes pallidus (Brunn.) male $X$ 2. (After Hebard.)

Key Largo and Key West, Fla., March, July. At Key West a large number were taken July $3-7,1912$, by Rehn \& Hebard from a pile of old burlap bags and in cracks under the stands of a fruit store, where it was in company with four other cosmopolitan roaches. L. pallidus is a house-dwelling species of wide distribution in tropical America and in the past has been much confused with Nyctobora levigata (Beauv.), which is a much larger and darker species. In general facies it resembles closely Pycnoscelus surinamensis (I.).

\section{Subfamily IV. BLATTINÆ.}

Large or medium, mostly cosmopolitan species, having, in addition to the characters mentioned in the key to subfamilies, the head with occiput usually exposed; ocelli or ocellar spots rarely 
absent; tegmina leathery or strongly chitinous; subgenital plate of male rounded at apex, that of female boat-shaped, its apical portion valvular.

This subfamily, as here characterized, corresponds to the Periplanetinæ of Scudder $(1897,12 ; 1900,8)$. Three genera are represented in our territory.

KEY TO EASTERN GENERA OF BLATTINA.

a. Tegmina in both sexes not reaching apex of abdomen.

b. Arolia minute or absent, less than half the length of claws; teg. mina covering about two-thirds of abdomen, strongly overlapping, $\hat{o}$, represented by small oval, widely separated pads, .

I. Blatta.

bb. Arolia large, fully one-half as long as claws; tegmina represented in both sexes by very short, subquadrate pads, either feebly overlapping, or slightly separated at suture. (Fig. 43, C.)

II. EurYcotis.

aa. Tegmina in both sexes extending much beyond the apex of abdomen.

III. PERIPlaneta.

I. Blatta Linnæus, 1758,424 . (L., "An insect that shuns the light.")

Medium sized robust species having the antennæ elongate, setaceous; interocular space, male, slightly wider than that between the bases of antennæ; wings of female absent or greatly reduced; lower front margin of fore femora armed with numerous rather stout, feebly curved spines which decrease gradually in length toward apex, and with three larger unequal ones near apex; other femora armed beneath with fewer, stouter, more widely separated spines; joints 1 to 4 of tarsi each bearing a small pulvillus, first joint of hind tarsi longer than the others united.

29. Blatta orientalis Linnæus, 1758, 424. Oriental Cockroach.

Male-Nearly uniform shining dark chestnut-brown; pronotum and tegmina often slightly paler; legs and under surface dark chestnut-brown. Pronotum suboval, widest behind the middle, its angles and sides broadly rounded, disc with a broad impression each side on basal third. Supraanal plate twice as wide as long, carinate above at middle, its apex truncate. Cerci short, flat or feebly concave above, widest at middle, their tips acute Subgenital plate transverse, convex except near apex, the latter rounded. Styles slender, cylindrical, straight, equal in length to the distance between their sockets and the base of subgenital plate. Female - Larger and stouter than $\hat{\imath}$, head wider, the interocular space greater. Nearly uniform shining blackish-brown, the legs slightly paler. Pronotum much larger, widest near base, the latter truncate. Supra-anal plate subtriangular, strongly keeled, its apex feebly concave. Subgenital plate as 
described in key to subfamilies. Length of body, ô, 20-24, ․, 18-23; of pronotum, ô, 5.7-6.3, 우, 6.1-7.1; of tegmina, ô, 11.9-16.7, ㅇ, 4.8$6.8 \mathrm{~mm}$. Width of pronotum, ô, 7.1-7.9, ९, 8.2-9.6; of tegmina, $\hat{o}$, $5-6.7$, , $2.8-4.2 \mathrm{~mm}$. (Fig. 46.)

In Indiana the Oriental roach is found in all the larger towns and cities, and is one of the most noisome and disagreeable insects with which certain classes of their inhabitants have to contend. It seldom occurs in houses in thinly settled localities, and never, as far as my observation goes, beneath the bark of logs and stumps. In Florida it probably occurs in the larger towns throughout the State, but is recorded only from Miami and West Palm Beach (Caudell, 1905, 216). It is a cosmopolitan species which has spread throughout the tropical and temperate zones and is known in this country from Halifax, N. S., Toronto, Ontario, and New Haven, Conn., west to Minnesota and Southern California and south to Florida and Texas. Hebard (1917a, 176) states that in Philadelphia it appears in swarms during the month of May coincident with the arrival of the shad in the Delaware River, and is therefore locally known as the Shad Roach.

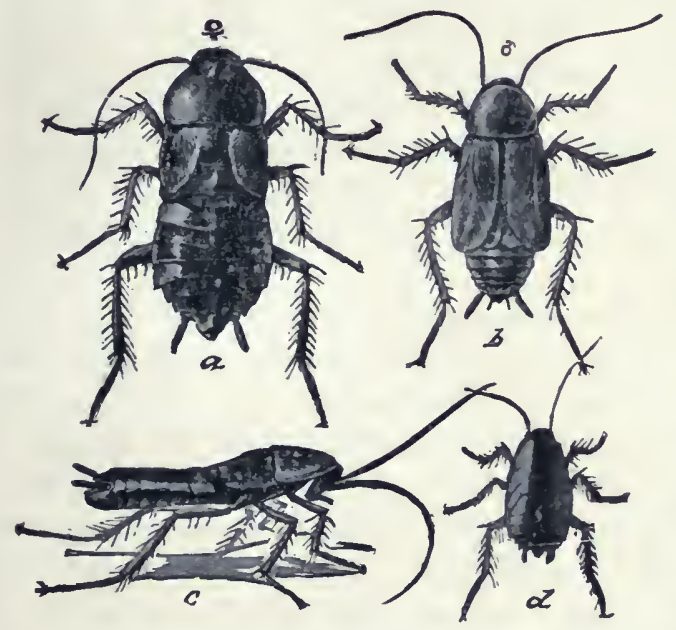

Fig. 46. Blatta orientalis L; $a$, female; $b$, male: $c$, side view female; $d$, half grown specimen. All natural sizes. (After Howard \& Marlatt.)

As its name indicates, the Oriental roach is a native of Asia, but has been carried from one country to another by shipping. It delights in filth and darkness, and hence in the bolds of vessels, the cellars and basements of tenement houses and in all damp, dirty places it swarms by thousands, undoubtedly doing much good as a scavenger, but infinitely more harm on account of its omnivorous and insatiable appetite. Like most other members of the family, it feeds mainly at night, appearing to detest and avoid light, as one can readily prove by taking a lighted lamp suddenly into its haunts, when a hurried scrambling will take place toward its daylight retreats, and but a few mo- 
ments will elapse before the last of the busy marauders will have disappeared. Of this and other species Marlatt (1902) has written :

"The damage they do is not only in the products actually consumed, but in the soiling and rendering nauseous of everything with which they come in contact. They leave, wherever they occur in any numbers, a fetid, nauseous odor, well known as the 'roachy' odor, which is persistent, and can not be removed from shelves and dishes without washing with soap and boiling water. Food supplies so tainted are beyond redemption. This odor comes partly from their excrement, but chiefly from a dark colored fluid exuded from the mouth of the insect, with which it stains its runways, and also in part, doubtless, from the scent glands, which occur on the bodies of both sexes between certain segments of the abdomen, and which secrete an oily liquid possessing a very characteristic and disagree. able odor. It frequently happens that shelves on which dishes are placel become impregnated with this roachy odor, and this is imparted to and retained by dishes to such an extent that everything served in them, particularly liquids, as coffee or tea, will be noticed to have a peculiar, disgust. ing, foreign taste and odor, the source of which may be a puzzle and will naturally be supposed to come from the food rather than from the dish.'

The Oriental roach is probably the most carnivorous of all our Blattidx, though, like most others, it is fond of starchy food. It is known to feed upon meat, cheese, woolen clothes, and even old leather, and is said to be especially fond of the festive "bed-bug," Acanthia lectularia L., which soon disappears from a house infested with the Oriental roach. This roach is, however, far too great a nuisance in itself to be introduced as a means of eradicating even the bed-bug.

The eggs of the Oriental roach are sixteen in number, and the large, horny capsule or oötheca in which they are packed is carried about by the mother for a week or longer when she drops it in a warm and sheltered place. Along one side of the capsule, which resembles in form and color a diminutive seed of the papaw, Asimina triloba Dural, is a seam where the two edges are cemented closely together. When the young are hatched they excrete a liquid which dissolves the cement and enables them to escape without assistance, leaving their infantile receptacle as entire as it was before they quitted it.

This species is notably gregarious in habit, the individuals living together in colonies in the most friendly way, the small ones being allowed by the larger ones to sit on them, run over them and nestle beneath them without a show of resentment. The roung pass through a variable number, sometimes as many as seren, 
moults, the skin splitting along the back and the insect emerging white and soft, but soon hardening and assuming its normal color.

\section{Eurrcotis Stål, 1874, 13 iGr., "broad" + "form.")}

Large robust species having the interocular area wider than that between the antennal sockets; tegmina not extending beyond the metanotum, their hind margins truncate; wings absent; front femora armed beneath much as in Blatta, the spines fewer, stouter and less curved; tarsi stout, the basal joint especially so, the first four joints with pulvilli; arolia very large, spinulose.

30. Eurycotis Floridaxa (F. Walker), 1868, 135. Large Florida Roach.

Male-Nearly uniform dark mahogany-brown, legs usually, and pro. notum sometimes, reddish-brown; nymphs usually with the sides of promeso- and metanota broadly margined with yellow (sabalianus of Scud. der). Pronotum suborbicular, feebly convex, finely and unevenly punctate, hind angles obtuse, front ones broadly rounded into apex, hind mar gin truncate. Tegmina subquadrate, finely and rather densely punctate, their outer apical angles rounded and slightly prolonged. Outer apical angles of fourth to seventh dorsal abdominal segments acute, gradually produced, those of the sixth and seventh forming sharp spines. Supraanal plate twice as wide as long, its hind margin broadly emarginate and hairy. Cerci short, flattened, pointed. Subgenital plate transverse. strongly emarginate at the insertion of the styles, which are elongate, rather stout and tapering to an acute apex. (Fig. 34, F.) Female-Very similar to 8 ; cerci shorter. Supra-anal plate longer, more narrow, its apex more deeply emarginate. Subgenital plate as shown in Fig. 34, E. Oötheca $7 \times 14 \mathrm{~mm}$, dark brown, the sutural edges raised and bearing about 16 rather sharp serrations.

Length of body, $\delta, 31-35$, $\uparrow, 30-39.5$; of pronotum, ô, $9.6-10.4$, ९, 9.3-11.8; of tegmina, $\hat{\delta}, 6.7-7.3$,, $7.3-8.2 \mathrm{~mm}$. Width of pronotum. ô, 13.2-15.2, ᄋ, 13.9-16.4; of tegmina, ô, 7.7-8.7, ᄋ, $8.2-9.3 \mathrm{~mm}$. (Fig. 43, C.)

This, one of the two native species of the subfamily, abounds throughout Florida, including the sonthern kers, and is one of the most ill-smelling insects on the Continent of America, far outstinking any member of the order Hemiptera. Outside of Florida it has been recorded only from St. Simon's and Billy's Islands, and St. Mary's, Ga., and Biloxi. Miss., though it doubtless occurs in many localities in sonthern Georgia and Alabama. In centralwestern Florida it is abundant in all stages during the winter and spring months, especially between the basal leaves of the large air plant, Tillandsia utriculata L., beneath the loose bark of logs and stumps, in and beneatl decaying palmetto trunks and leares, under piles of weeds and rubbish, in fact, anywhere it can find shel- 
ter from the orb of day; for, like others of its kind, it is a nightprowling insect, going forth only after darkness has come in seareh of provender or a mate. Davis states that "at night, with the aid of a lantern, it was often found walking about on low bushes, for it is a fair climber in spite of its clumsy appearance." When disturbed the adults emit a greasy liquid which saturates the atmosphere for a rod or two in every direction with its repellent odor.

The Platyzosteria ingens and the $P$. sabalianus of Scudder $(1877 \mathrm{a}, 92,93)$ are synonyms, the latter being based on the nymph stage, with yellow borders of the notal segments, as was also Periplaneta semipicta F. Walker $(1868,141)$. The writer (1902, 44,217 ) first showed that sabalianus represented only the immature wingless stage of ingens, the latter name being reduced to synonymy by Rehn (1903a, 277). Traces of the yellow pronotal markings of the young are often found in the adults.

\section{Periplaneta Burmeister, 1838, 502. (Gr., "around" + "a wanderer.")}

Large, stout species, having the antennæ very long and slender; eyes less separated than are the antennal sockets; pronotum convex, with sides deflexed; tegmina leathery, extending beyond apex of abdomen in both sexes, their front and hind margins rounded; wings with costal veins frequently forking, ulnar vein with a few basal incomplete branches; subgenital plate of male symmetrical, its styles elongate, slender, set in sockets on the sides near apex; lower front margin of fore femora armed with a row of rather stout spines, longest near middle of base and with three long, unequal spines near apex; lower margins of other femora with stout, elongate spines; first joint of hind tarsi longer than the others united; arolia small.

Three introduced species of wide distribution and one native one occur in the eastern United States.

KeY to EASTERN SPECiES OF PERIPlaneta.

a. Color not shining solid blackish-brown.

$b$. Supra-anal plate prolonged beyond the subgenital plate, its apex rounded, deeply notched (Fig. 49, A, C, ); thorax yellow with two large blotches of chestnut-brown; median dorsal abdominal segment of male not modified.

31. AMERICANA.

bb. Supra-anal plate not prolonged beyond the subgenital, its apex truncate, feebly notched (Fig. 49, B,) ; median dorsal segment of ô modified. 
Putnam and Marion counties, Ind.; April 29-Dec. 15. Gainesville, Dunedin and Sanford, Fla., March 6-May 30 (W. S. B.). This is by far the largest cockroach found in Indiana and doubtless occurs in all the larger towns of the State. It was formerly found in numbers in some of the leading hotels and in the State House at Indianapolis, but usually confines itself to the basement and first floor, and appears to be much more cleanly in its choice of an abiding place than does the closely allied Oriental roach. It is, as its specific name indicates, a native of tropical and subtropical America; but, like B. orientalis, it has spread to the four corners of the earth. In Florida it has been taken by R. \& $H$. and other's at numerous localities throughout the State, being abundant in a houseboat at Pine Channel, and in a fruit store at Key West. Elsewhere it oceurs in this country from New York west to Minnesota and south to California and New Mexico, but in the more northern states is probably to be considered as adrentive rather than firmly established. South of the United States, it is found generally over the Continent and adjacent islands (Hebard, 1917a, 181).

Catesby, as far back as 1748 , wrote of this species in Carolina ${ }^{20}$ as follows: "The coekroaches here are very troublesome and destructive vermin, and are so numerons and voracious that it is impossible to keep rictuals of any kind from being devoured by them without close covering. They are flat, and so thin that few chests or boxes can exclude them. They eat not only leather, parchment and woolen, but linen and paper. They disappear in winter and appear most numerous in the hottest dars in summer. It is at night they commit their depredations, and bite people in their beds, especially children's fingers that are greasy. They lay innumerable eggs, creeping into the holes of old walls and rubbish, where they lie torpid all the winter. Some have wings and others are without-perhaps of different sexes."

Cateshy's wingless examples were in all probability the young, as, like most other insects, the wings are not acquired until the final moult. Marlatt $(1902,8)$ says that the "domesticity of the American roach resulted from ages of association with the aborigines. It has now become thoroughly cosmopolitan. and is unquestionably the most injurious and annoying of the species oreurring on ressels. It is sometimes numerons also in greenlonses, causing considerable injury to tender plants. It is a notorious house pest. and oceasionally vies with the German roach in its injuries

${ }^{20}$ Natural History, Carolina, I748, Vol. II, p. Io. 
to book bindings. The backs, sometimes entirely, of both cloth and leather bound books, are eaten off to get at the starchy paste used in the binding."

The young of the American roach require about a year to reach maturity. The rate of growth of it and other species depends, howerer, largely on the food and temperature conditions, and under unfarorable circumstances the nrmph stage is much prolonged. The abundance of roaches is, therefore, apparently not accounted for so much by their rapidity of multiplication as by their unusual ability to preserve themselves from ordinary means of destruction and by the scarcitr of natural enemies.

\section{Periplayeta Brtxyea Burmeister, 1838, 503. Large Brown Roach.}

Male-Smaller and slightly broader than americana. Color much as there, the pronotum with discal brown blotches much less distinct, some times almost wanting, the disc then yellow with hind margin blackishbrown and side margins more narrowly so (Fig. 32, F.) Interocular area broader, about two-thirds that between the bases of antennæ. Thorax wider, more strongly elliptical, less narrowed in front, the discal impressions less evident. Tegmina and cerci shorter, the latter (4.3-5 $\mathrm{mm}$.) acute but much less tapering. Median dorsal abdominal segment with a broad, shallow depression at middle of base, this bearing a heavy tuft of silky hairs. Supra-anal plate wholly corneous, entire or very feebly notched, its apex broadly rounded. Subgenital plate as in americana. the stlyes as long as the plate. Female-Differs from that of americana as does the $\hat{\delta}$, and in having the supra-anal plate much less prolonged and but feebly notched at apex (Fig. 32, H.) Length of body, $\hat{\delta}, 25.1-28.5$, ㅇ, 26.5-33; of pronotum, ô, 6.7-7.9, ㅇ, 7.9-8.9; of tegmina, $\hat{\delta}, 24.3-$ 29.9 , $९, 23.8-26.5 \mathrm{~mm}$. Width of pronotum, $\delta, 9-10.8$, ᄋ, 10.6-11.7; tegmina, ô, 8.5-9.9, ㅇ, 9.3-10 $\mathrm{mm}$.

Ormond, Utopia, Cape Sable and Key West, Fla., February 23-April 11 (W. S. B.). Taken in houses, beneath bark of stump and at light. Recorded also from nine other localities south of Gainesville and Hastings, Fla. Outside of Florida it is known in this country only from Asheville, N. Car. (adrentive), Billy's Island and Thomasrille, Ga., and Willacy Co., Texas. It is a house-dwelling, circumtropical species, very common in Tropical America. P'eriplanete truncata Krauss is a synonym.

33. Periplaneta australasie (Fabricius), 1775, 271. Australian Roach.

Male-Smaller than americana, more slender than brunnea. Vertex black; face yellow, mottled with brown; pronotum yellow, with a large sharply defined bilobed black spot, hind margin rather broadly, the other margins narrowly edged with black; tegmina reddish-brown, the basal third with a narrow yellow submarginal stripe; legs and under surface 
pale reddish-brown, the middle of abdomen, and cerci darker. Pronotum subelliptical, three-tenths wider than long, widest behind the middle, all the sides and angles rounded, discal impressions absent. Median dorsai segment modified as in brunnea. Supra-anal plate with apex feebly concave. Cerci as in brunnea. Apex of subgenital plate broadly emarginate at middle. Female-More robust, colored as in $\hat{o}$, pronotum broader anả more convex. Tegmina broader and less elongate. Supra-anal plate feebly notched at apex. Length of body, $\hat{\delta}, 23.6-25.5, \quad$ ․ $24.3-29$; of pronotum, ô, $6.2-7.2$, ․․ 7.8-8.8; of tegmina, $\hat{o}, 24.8-26.3$, ㅇ, 22.9-25.7 mm. Width of pronotum, $\hat{o}, 8.3-9.3, \stackrel{\imath}{.} 10-11.4$; of tegmina, $\hat{o}, 7.9-$ 8.4, \&, 8.7-9.7 $\mathrm{mm}$ (Fig. 48.)

Sanford and Dunedin, Fla.; Nov. to March. Frequent at Dunedin beneath logs, old burlap bags and other corer in old

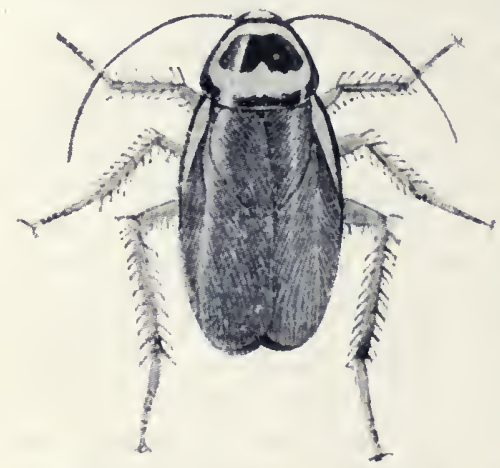

Fig. 48. Female, life-size. (After Howard \& Marlatt.) orange orchards, often in company with Pycnoscelus surinamensis and Eurycotis floridana. Occurs throughout central and southern Florida from Cedar Keys and Fernandina south to Miami and Key West. Common beneath signs on trees near borders of towns and in and about old houses and hotels. Scudder (1877a, 94) first recorded it from the United States, his specimens haring been sent to him from Green Cove Springs, Fla., under the name of the "Florida Cockroach," the party sending stating that it "frequently occurs in the pitchers of Sarracenia, has been abundant in Florida for 18 years, and is the torment of housekeepers." Davis (R.\& H., 1914, 100) states that "at Punta Gorda there was a vacant house at the end of the town frequented at night by a Nanny and Billy goat, and on warm erenings many Periplaneta australasio would run about on the piazza floor and on the sides of the house. They were seen feeding on the excrement of the goats and were no doubt to a great degree dependent upon them." It also is a circumtropical species and is not established in this country north of Florida, though adventive specimens have been taken in many of the eastern and norther'n States and even as far north as Montreal and Toronto, Canada. Where introduced by accident into greenhouses, it increases in number's very rapidly and sometimes becomes a serious pest. ${ }^{21}$

\footnotetext{
${ }^{21}$ Entom. News, XVI, 1905, 183.
} 
34. Periplaneta fuligixosa (Serville), 1839, 70. Smoky Brown Roach.

Male-Size of australasice, form stouter. Usually uniform shining brownish-black, the tegmina, mouth parts and legs tinged with reddishbrown; rarely dark reddish-brown, the head, pronotum and legs chestnutbrown (Fig. 32, G.) Pronotum and cerci as in australasic. Median segment of male abdomen modified as in brunnea. Supra-anal plate with apical margin feebly notched and with two minute rounded projections beneath the apex of notch. Subgenital plate with apex broader than in australasia and distinctly notched as there. Female-Similar to $\hat{o}$, the supra-anal plate as in $q$ of australasia. Length of body, $\hat{\sigma}, 24.5-29, q$, $25.5-32.5$; of pronotum, $\hat{\delta}, 6.9-7.8, \uparrow, 7.2-8.5$; of tegmina, $\hat{\delta}, 25.6-$ $28.6, \&, 22.7-26.4 \mathrm{~mm}$. Width of pronotum, $\hat{\delta}, 8.8-10$,, $9.7-11.2$; of tegmina, ô, 8.2-9.4, ᄋ, 8.6-9.7 mm.

Taken by R. \& H. at Fernandina, Jacksonville, Tallahassee and De Funiak Springs, Fla., Aug.-Sept.; at Jacksonville abundant on the wharves at night. A native species, occurring in the southern States from central coastal Texas, eastward to Brunswick, Ga., and will probably be found only in the northern third of Florida. Usually occurs out of doors, beneath signs and other cover in the vicinity of towns. Recorded many times as P. brunnea Burm. A number of specimens in the Urbana, Illinois collection were taken in a greenhouse in Chicago.

\section{Subfamily V. PANCHLORINE.}

Hind margin of pronotum with an obtuse angle at middle; tegmina and wings fully developed; ulnar vein of wings with numerous incomplete branches; femora unarmed beneath, except sometimes with a single apical spine; lower front margin of fore femora usually heavily fringed with hairs; tarsal joints very elongate, slender; pulvilli and arolia present.

Two genera, each represented by a single species, occur in our territory.

KEY TO EASTERY GEXERA OF PAXCHLORIY E.

a. Basal segment of hind tarsi naked beneath; general color brown; basal half of tegmina with numerous rows of punctures.

I. Pycroscelus.

aa. Basal segment of hind tarsi hairy beneath; general color pale green; tegmina without rows of punctures.

II. Paxchlora.

I. Prcxoscelus Scudder, 1862, 421. (Gr., "thick" + "tarsi.")

Medium sized species with pronotum convex, its sides declivent; apex broadly rounded; hind margin broadly obtuse-angulate; tegmina of male extending much beyond apex of abdomen, 
of female usually slightly surpassing the apex, often a little shorter; subgenital plate of male without styles; femora all with a single stout apical spine beneath; lower front margin of fore femora fringed with hairs, the basal ones the longer, those on apical half spiniform; arolia small. The male of our only species has been found but once in this country, although more than 400 females have been taken and recorded.

\section{Pycroscelus surtimamensis (Linnæus), 1767, 687. Surinam Roach.}

Female-Head and most of pronotum shining blackish-brown; tegmina dull brownish-yellow; clypeus and front margin of pronotum yellow, this often extending very narrowly along the sides; legs and under surface brownish-yellow, the sides and apex of abdomen darker. Head flat tened, sparsely punctate, the interocular area equal in width to that between the large ocellar spots. Pronotum evenly convex, widest behind the middle, hind angles rounded, front ones wanting, disc finely and sparsely punctate. Basal half of tegmina with rows of punctures each side of the veins. Supra-anal plate twice as wide as long, apical half finely carinate at middle, apex broadly rounded. Cerci very short, acute, their separate segments indistinct. Subgenital plate large, convex at base, concave along the sides near apex which is rounded. Male-More slender, the teg. mina much longer, supra-anal plate more delicate in structure, more prolonged, broadly rounded, not carinate. Cerci much longer than in $\$, 12$ or 13-jointed, the apical joints much the longer; styles absent. Subgenital plate more than twice as broad as long, its apex sligbtly incurved, subtruncate, feebly and broadly emarginate. Length of body, $\hat{\sigma}, 16.8,9,16.3-$ 23 ; of pronotum, ô, 4.8, $ᄋ, 4.8-5.8$; of tegmina, ô, 18.9 , $\&, 13.6-19 \mathrm{~mm}$. Width of pronotum, $\hat{\sigma}, 5$,,$+ 5.9-7.6$; of tegmina, $\hat{\delta}, 6$, $+5-6-6 \mathrm{~mm}$. (Fig. 45, A.)

Ormond, Sanford, Dunedin and Sarasota, Fla., Nov. to March ; beneath chunks, piles of weeds and other cover (W. S. B.). Recorded from 14 additional localities in all parts of Florida. It is a circumtropical species, established in the southern States from Brownsville, Texas, east to and throughout Florida, and often found as adventive in greenhouses as far north as New England.

Hebard $(1917 a, 196)$ states that in addition to the large series from the southern States, he examined "nearly 200 specimens, chiefly from the West Indies and Mexico, without finding a single male, adult or immature, from the American Continent. This may possibly indicate that with us the species is parthenogenetic."

Davis (1919a) says that 66 specimens from southern Florida taken by him were all females, but that among seven individuals found January 12, among the straw in the winter quarters of the giant land turtles in the Reptile House of the New York Zoolog- 
ical Society, there was a single male, easily told by its smaller body and longer cerci. He suggests that as it "is well known that among some of our native roaches the females long outlive the males, it is quite possible that the males of the Surinam roach occur in very early spring in southern Florida."

P. obscumis Scudder $(1862,422)$, the genotype, was based on a single specimen taken "in the woods under stones" near Greenfield, Mass. He stated that it was a male, and described the styles as "slender, cylindrical, bluntly pointed, of about the length of the cerci and inserted just within them." Hebard (1917a, 193) states that the specimen is a jurenile female of $P$. surinamensis, and unquestionably adventive. How a female could possess the styles described by Scudder passeth understanding.

\section{Paxchlora Burmeister, 1838, 506. (Gr., "all" + "green.")}

Pronotum convex, its sides declivent and hind margin obtuseangulate; tegmina and wings extending much beyond apex of abdomen in both sexes, the ulnar vein of the latter with 9 to 13 short, strongly oblique incomplete basal branches; lower front margin of fore femora (in cubensis) with a few hairs on basal half, these succeeded toward apex by a more closely set row of shorter hairs; other femora unarmed or with a single short apical spine; first tarsal joint hairy beneath at base and with a large, rounded pulvillus on apical half; arolia rather large.

(一). Paxchlora cubexis Saussure, 1862a, 230. Green Cuban Roach.

Male-Size medium, rather slender, structure delicate. Uniform pale green above; occiput, pronotum and tegmina with a yellowish-white sub marginal line; legs and under surface greenish-white; tegmina often with a small dark brown dot at apical third. Eyes separated by only oneeighth their greatest diameter. Pronotum widest behind the middle, where its margin is subangulate, disc finely, transversely rugose. Supra-anal plate twice as wide as long, its apical margin broadly concave, feebly notched at middle. Cerci short, broad, their segments indistinct. Sub. genital plate much wider than long, its apex truncate; styles small, cylindrical, one-third the length of cerci. Female-Slightly larger, the eyes more widely separated. Supra-anal plate prolonged, its apex with a deep median notch or cleft. Subgenital plate feebly notched at.middle of apex. Length of body, $\hat{o}, 12.2-14, \uparrow, 15.7-18$; of pronotum, $\hat{\delta}, 3.8-4.3$, 우, $4.9-5.6$; of tegmina, $\hat{\delta}, 15.4-16$, 우 $18.3-20 \mathrm{~mm}$. Width of pronotum, ô, 5-5.3, \&, 5.9-6.7; of tegmina, ơ, $4.8-5$, ᄋ, $5.7-6.2 \mathrm{~mm}$.

Marion Co., Ind., April 23, Sept. 27; Dunedin, Fla., Feb. 1 (W. S. B.) ; adventive specimens introduced with bananas. A 
handsome tropical American species of wide distribution, established in this country only near Brownsville, Texas, but often introduced with tropical fruits; records of adventive specimens being given by Hebard $(1917 \mathrm{a}, 269)$ from numerous places in New England and the northern United States. Recorded by Scudder, Felt and others as $P$. poeyi, viridis, nivea, hyalina, exolita and virescens. Of these names $P$. poeyi Sauss. is a synonym of cubensis, the others, names or synonymys of extra-limital species. Hebard states that he does not believe that cubensis "can establish itself in temperate climates except under artificial conditions. In the tropies it is essentially an out-door dweller and cannot readily adapt itself to artificial surroundings as can the domiciliary forms." Riley (1891a) has shown that P. cubensis (viridis) is viviparous.

\section{Subfamily VI. BLABERIN Æ.}

Very large species having the tegmina and wings fully developed, the former with numerous oblique discoidal sectors; femora unarmed or supplied with few spines; tarsal joints stout, with very large pulvilli; arolia absent.

\section{Blaberus Serville, 1831, 37. (Gr. "harmful".)}

Head with vertex hidden by pronotum, the latter large, convex; supra-anal plate bilobate in both sexes; lower front margin of fore femora armed on basal half with a few short spines, these succeeded by a row of close-set stout hairs and a single stout, short apical spine, a similar spine also present on the other femora.

36. Blaberus cranififer Burmeister, 1838, 516. Glant Death's-head Roach.

Male-Head blackish-brown, ocelli and clypeus yellow. Pronotum dull yellow, with a large shield-shaped shining blackish-brown spot, containing four pale markings suggesting the human eyes, nose and mouth: tegmina dark blackish-brown more or less dull yellow at base and middle and along the costal margin. Pronotum subelliptical, the front and hind margins rounded. Tegmina very broad, their tips broadly rounded. Supra-anal plate prolonged, subquadrate, its apex slightly bilobed. Cerci slender, 17-jointed, tapering, acute. Subgenital plate asymmetrical, with margin rounded from base of left side to middle of right one, then concave and much softer to base of right side; styles minute, cylindrical, the right one the longer. Female similar, the subgenital plate larger and more convex, its apical margin broadly rounded and slightly produced. Length of body, ô, 42.2-45.1, $९, 48.7-54.8$; of pronotum, ô, 12.3-13.6, ᄋ, 14.314.6 ; of tegmina, $\hat{\delta}$ and $\$, 48-51.8 \mathrm{~mm}$. Width of pronotum, $\hat{\delta}, 17.3-$ 18.9, $९, 20.9-22.1$; of tegmina, $\hat{\delta}, 18.8-19.4$, $९, 19.8-20.6 \mathrm{~mm}$. 
This, the largest cockroach found in the United States, is established at Key West, Fla., where it was taken by R. \& H. in numbers July 7, 1912, from beneath boards in a wood shed, and first recorded by them $(1914 \mathrm{c}, 381$ ) as Blaberus atropos (Stoll). "It was well known to the natives about Key West, where it is found in wood piles, under boards and other refuse about the town. The insects, when exposed, either remained motionless or scuttled toward another place of concealment with no great speed. The nymphs were usually found half buried in loose, damp earth under boards, where they remained motionless, looking much like lumps of earth until disturbed." It is a Tropical American species, common in Cuba, Mexico and British Honduras.

\section{Subfamily VII. CORYDIINAE.}

Head globose; ocelli absent or minute, the ocellar areas not strongly defined; pronotum and tegmina when present in part rather thickly covered with hairs; middle and hind femora unarmed, or with only one or two apical spines. Two genera are represented in Florida.

KEX TO EASTERN GENERA OF CORYDIIN

a. Ocelli present, very small, convex; pulvilli and arolia present; teg. mina present in both sexes.

I. Holocompsa. aa. Ocelli absent; pulvilla and arolia wanting; tegmina absent in female.

II. Compsodes.

I. Horoconpsa Burmeister, 1838, 491. (Gr., "elegant.")

Very small species having the eyes widely separated, ocelli very minute; tegmina divided obliquely into two portions, the basal one opaque and hairy, the other membranous and glabrous; wings as long as tegmina, their reins mostly subobsolete, the discoidal rein with an elongate costal swelling; supra-anal plate in both sexes feebly bilobate; subgenital plate of female valvular with basal margins of valves forming an acute keel; lower front margins of fore femora armed on apical half with a row of minute spines and with two stout apical spines, the last one much the longer; tarsi small, first and second joints with minute subapical pulvilli, third and fourth joints with larger ones; arolia present.

37. Holocompsa xitidula (Fabricius), 1871, I, 345. Small Hairy Roach.

Male-Head, under surface and legs blackish; antennæ blackish with three or four joints on apical half pale; pronotum and opaque basal portion of tegmina black with a greenish tinge; wings and apical portion of 
tegmina hyaline. Pronotum convex, the narrow sides strongly declivent, front and hind margins transverse, front angles broadly rounded, hind ones obtuse. Cerci 8-jointed, tapering to an acute apex. Subgenital plate with the left margin rounded, right one feebly concave; styles minute, elongate, the left one slightly the larger. Female-Larger, broader, the tegmina and wings less projecting beyond apex of abdomen; colored as in male, the bluish-green tinge more evident; pronotum reddish-brown, often darker near base; head slightly darker, legs and under surface brownish. yellow. Subgenital plate as above described. Length of body, $\hat{o}, 4.8-5$, ㅇ, $5.3-6.2$; of pronotum, $\hat{\delta}, 1.6-1.8$, $ᄋ, 1.9-2.2$; of tegmina, $\hat{o}$ and $q$, $4.4-5 \mathrm{~mm}$. Width of pronotum, ô, $2.1-2.2$, ․ $2.6-2.9 \mathrm{~mm}$. (Fig. 49 , D.)

This small, easily distinguished roach is established in the United States as far as known, only at Key West, Fla., where R. \& H. (1914c, 381) found 26 specimens in company with four other species, in the folds of some old burlap bags under the counter of a fruit store, and with Blaberus craniifer between old boards in a wood shed. It is a house-dwelling species, widely distributed throughout tropical America. A single adrentive specimen has been taken at Washington, D. C.

\section{Conrsodes Hebard, 1917a, 208. (Gr., "neat looking.")}

Very small, slender species, having the interocular space subeqnal to that between the antennal sockets, male, much wider, female; pronotum of male transverse, elliptical, with a median linear and broad oblique lateral sulci; pronotum of female with front margin broadly rounded into hind one, the latter straight, the hind angles rather sharply rounded; tegmina of male pilose, the marginal and scapular fields very narrow; cerci of male elongate, tapering to an aciculate point, of female short, tapering to acute apex. Other characters as given in key.

38. Compsodes cucullatus (Saussure \& Zehntner), 1894, 111. Small Hooded Roach.

Pale brownish-yellow; head and apex of abdomen beneath fuscous: pronotum chestnut-brown, its front margin paler; tegmina of male surpassing the abdomen, brown, the medio-discoidal area in part hyaline; wings dusky-hyaline. Eyes and entire head concealed by the hood-shaped front margin of pronotum. Supra-anal plate of male broader than long. truncate, its base bi-impressed; subgenital plate rounded. Other characters as given above. Length of body, ô, 3.5; of pronotum, 1.8; of tegmina, $6.2 \mathrm{~mm}$. Width of pronotum, $2.4 \mathrm{~mm}$.

Four males of this little roach were taken at light by Schwar\% and Barber on Paradise Key, twelve miles southwest of Homestead, Fla., Feb. 19-24, 1919. It was described from Guatemala. No females are as yet known. 


\section{Subfamily VIII. POLYPHAGINA.}

Species of medium size in which the sexes are widely dissimilar, the females being wingless with much smaller more narrow eyes and ocelli represented by indistinct spots (Fig. 49, F) ; males with pronotum and tegmina thickly covered with hairs, the tegmina in our species with reins distinct, and marginal field narrow, only one-fourth the sub-basal width of the tegmen; lower margin of all the femora unarmed; middle and hind femora armed abore with a single stout, elongate, genicular spine; styles absent.

One of the three recognized genera of the subfamily is representer in Florida.
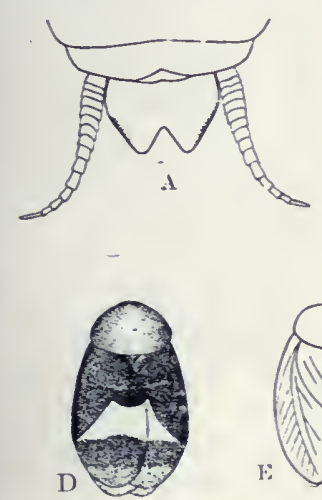
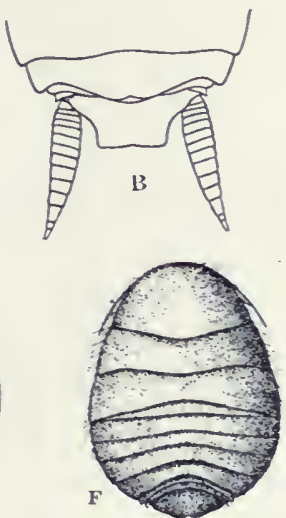
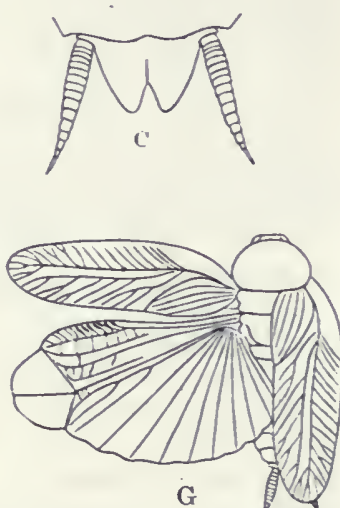

Fig. 49. A, B \& C, Dorsal views of apical portion of abdomen and cerci $X 2.5 ; \mathrm{A}$, of Periplaneta anericana (L.), male; B, of $P$. anstralasic (Fab.), male; $C$, of $P$. americana (L.), female; D, Holoccmpsa nitidnla (Fab.), female $X 3$; E, Plectoptera floridana Heb., female $X 3 ; \mathrm{F}$, Arenizaga apacha (Sauss.), female $X 2 ; \mathrm{G}$, Chorisoneura texensis (S. \& $\mathrm{Z}$.), male $\times$ 3. (After Hebard.)

\section{Arexivag. Rehn, 1903e, 181. (Gr. "sands" + "wandering.")}

This genus differs from its nearest ally, Eremoblatta Rehn, in the males having the transrerse clypeal swelling of face deeply concave, with ocelli more prominent; middle and hind tibia with six instead of seven apical spurs, and armed beneath with 4 to 6 , instead of only two, subapical spines; tarsi rerr slender and elongate; abdomen naked beneath.

Hebard (1917a) recognized four species, all from the desert regions of the southwestern United States west of central Texas. A single male of another species had previously been taken by me at Dunedin, Fla. Not recognizing it from the descriptions in his Monograph, I sent it to Hebard, stating that it was a supposed new species of Arenivaga near apacha. He returned it as Areni- 
vaga apacha Sauss., stating: "I cannot be absolutely positive of this determination without removing the subgenital plate. Do you remember definitely getting this specimen in Florida? I cannot believe it ever came from there, but if it did it must have come in on some train from the western desert. This insect is not a native of Florida." It was then sent to Caudell who replied that it was an Arcnivaga allied to apacha, and perhaps a new species, adding: "Could you by any means have made an elror in labelling this specimen? It should be from Texas or farther west." Soon afterward he received two females from a Florida correspondent, and described the species as new, my Dunedin male thus serving as the type of the only species of the subfamily known east of the Mississippi. The facts as above given are mentioned only to show that in the study of such mobile forms of life as insects it is not safe to conclude that any genus or even species is confined to a definite region, and that one may hunt over a well known area for years and yet not discover a form which may be brought to light by some future collector.

\section{Arenivaga floridensis Caudel1, 1918b, 156. Florida Sand Roach.}

Male-Broadly oval, much less elongate than in any other member of the genus. General color fuliginous or dark smoky brown; pronotum with a large, reniform central piceous blotch, front and side margins broadly pale transparent yellowish, basal fourth fuscous enclosing two yellowish dots; tegmina smoky brown, the humeral angle paler; face, under surface and legs pale brownish yellow. "The sinistral concealed plate and the genital hook are about as in $A$. erratica but the inferior dextral plate is more regular in shape than in that species, though agreeing with it in being unarmed; the superior dextral plate is shaped as in erratica and allies but instead of being armed at the base of the inner excavation with a sharp spine as in erratica and apacha it is there furnished with an ele. vated rounded ridge which, from an apical view, looks like a rounded subclavate projection, similar to that of genitalis, but from a lateral view ap. pears to be the terminus of an elongate elevated ridge." (Caudell.)

Female-Broadly oval widest about the middle. "Color almost black, the limbs and lower surface partially lighter; pronotum with disk bordered somewhat broadly on the anterior and lateral margins with reddishyellow, the meso- and metanotum similarly margined laterally; segments of abdomen each marked laterally with a black spot, with usually some lighter lateral areas wholly or partially surrounding these black lateral spots." Length of body, $\hat{\sigma}, 13$; of pronotum, $\hat{\delta}, 4.2-4.5$; $ᄋ, 5$; of tegmina, $\delta, 13.5-15 \mathrm{~mm}$. Width of pronotum, $\hat{\delta}, 6-6.5$,, $\mathrm{s}$; of metano tum, $\stackrel{+}{11}$; of tegmina, $\hat{o}, 10-11 \mathrm{~mm}$.

Known only from Dmedin, Lakeland and Auburndale, Fla. 'Two males have been taken by me at Dunedin, one (Type No. 21 , 
880 , U. S. N. M.) was found on the ground beneath some cabbage palmetto leaves, April 10, 1915. The other was taken while it was flying slowly and close to the ground across a sandy roadway on March 5, 1919. Two females were collected at Auburndale by N. R. Wood and sent to Caudell, and Davis found a single male among his series of Pycnoscclus. It was taken at Lakeland Mas 4, 1912.

\section{Subfamily IX. OXYhaLOINE.}

Species of small size, haring the head broad; ocelli absent or indicated by spots; middle and fore femora armed beneath with a single elongate apical spine; supra-anal plate of female distinctly emarginate; fourth joint of tarsi alone (in our genera) with a pulvillus; large arolia present.

KEY TO EASTERT GEXERA OF OXYHALOIXE.

a. Subgenital plate of female cleft at apex; tarsal claws simple; styles of male concave, their bases contiguous, arising from the middle of hind margin of subgenital plate; length of body, $\hat{\jmath}, 7.8-8.3 \mathrm{~mm}$.

I. Chorisoreura.

aa. Subgenital plate of female simple; tarsal claws with two minute teeth on middle of inner margin; styles slender, cylindrical, arising each side of the subquadrate emarginate apical portion of subgenital plate; length of body, $\hat{\delta}, 5.4-5.7 \mathrm{~mm}$.

II. Plectopteri.

I. Chorisoxeura Brunner, 1865, 255. (Gr., "separate" + "reins")

Head triangular; eyes widels separated; pronotum broad, its sides rounded, feebly declivent; tegmina delicate, narrow, strongly tapering to the sharply rounded apex; wings fully developed, with 10 to 13 costal veins, the majority of which are clarate at apex, their appendicular field slightly wider than long; lower front margin of fore femora with a fringe of hairs, those on apical half spiniform.

40. Chorisoxeura Texexsis Sauss. \& Zehnt., 1893, 80. Small Yellow Texas Roach.

Male-Nearly uniform pale reddish-brown; sides of pronotum, marginal field of tegmina and wings transparent, often with a yellowish tinge. Head about as broad as long, the interocular space nearly as wide as that between antennal sockets. Pronotum subelliptical, hind margin subtruncate, front one feebly rounded. Sixth dorsal abdominal segment with a small rounded area at middle of base thickly corered with agglutinated hairs. Supra-anal plate twice as wide as long, its hind margin feebly rounded. Cerci 9-jointed, fusiform, their upper surface depressed and concave. Female-Very similar to male, the supra-anal plate transverse and 
with a median lengthwise sulcus, its apical half triangular, feebly prolonged, the apex notched. Subgenital plate large, its apical half subquadrate and deeply cleft. Length of body, $\hat{\delta}, 7.8-8.3$, ㅇ, $7.3-8.4$; of pronotum, $\delta, 1.6-2.1$, 우, 1.7-2:2; of tegmina, $\delta, 7.2-9.3$, 우, $6.8-8.6 \mathrm{~mm}$. Width of pronotum, $\hat{\delta}, 2.6-3$,, , $2.4-3.2$; of tegmina, $\hat{\delta}$ and $ᄋ, 2.3-2.9$ mm. (Fig. 49, G.)

Ormond, Eustis, Sanford, Sarasota and Dunedin, Fla., Feb. 1 - Apr. 13; beneath dead leaves in oak woods and beaten from foliage of oak and bay berry; one Dunedin specimen at light, June 20 (W. S. B.). Recorded also from Atlantic Beacl, Jacksonville, Orlando, Lakeland and Ḱey Largo, Fla., by R. \& H., Davis and others, March 18-Aug. 25. It is a native species, ranging from Tryon, N. Car., south and west to Brownsville, Texas. C. plocea Rehn $(1904 c, 164)$ from South Carolina is a synonym.

\section{Plactoptera Saussure, 1864, 173. (Gr., "plaited" + "wing.")}

Very small oral species having the dorsal surface convex, smooth, shining; head triangular, the angles broadly rounded; eyes widely separated, ocelli absent; tegmina reaching tip of abdomen; wings elongate, rery delicate, their appendicular field very large; sixth dorsal segment of male modified as in Chorisoneura. Other characters as given in key.

41. Plectoptera floridana Hebard, 1917b, 251. Small Florida Roach.

Male-Pale brownish-yellow with a tawny tinge; head, with a narrow transverse brown line between the eyes; tegmina, wings and sides of pro notum transparent with a yellow tinge; legs and abdomen pale reddish brown. Interocular space wide, but less than the broad one between antennal sockets. Pronotum narrowly elliptical, convex, the sides more strongly so, front margin truncate, hind one feebly rounded. Supra-ana! plate nearly twice as wide as long, its apical portion triangular, feebly con cave and with blunt apex Cerci 6 -jointed, flattened, the apex acuminate. Subgenital plate small, sides converging to the subquadrate emarginate apex, which bears at middle an acute triangular process, on either side of which are borne the small, slender, subequal styles. Females-Very similar in color; abdomen dark brown with sides of segments yellow. Interocular space broader than in male; supra-anal plate distinctly notched at apex; subgenital plate large, broadly concave at sides near bases of cerci. Length of body, male and female, $4.9-5.7$; of pronotum, 1.3-1.6; of tegmina, 4.4-5.1. Width of pronotum, $2.1-2.4$; of tegmina, $1.8-2 \mathrm{~mm}$. (Fig. 49 , E.)

Key West, Fla., March 3, 1919; two adults, three nymphs, taken by beating (W. S. B.). Known in the United States only from Cocoanut Grove, Jan. 19) B Big P'ine Key and Key West, Fla., 
March 15, July 6-7. Those at Big Pine Key were beaten by R. \& $\mathrm{H}$. from tall bushes on the edge of a mangrove swamp, while at Key West they were mainly secured by beating the foliage of a holly, Ilex cassine I. Recorded by R. \& H. (1905, 33; 1912, 241; 1914c, 382) as Plectoptera poeyi (Sauss.), a closely related Cuban species.

\section{Subfamily X. PANESTHINE.}

Large robust species having the surface leathery; ocelli, tegmina and wings absent in our species; last dorsal and ventral abdominal segments very large, triangular, completely concealing the supra-anal and subgenital plates and genitalia; legs stout; lower front margin of fore femora armed only with three short, stout, equal spines near apex; other femora either unarmed or with two similar subapical spines; first four tarsal joints with heary pulvilli; arolia absent (Fig. $43, \mathrm{D}$ ). One genus is represented in this country.

I. Cryptocercus Scudder, 1862, 419. (Gr., "hidden" + "cerci.")

Eyes very small, convex, subequal in size to the antennal sockets; pronotum convex, broader than long, disc with a wide, deep median depression, front margin broad and slightly upturned to form a hood above the head. Other characters as given above.

42. Cryptocercus punctulatus Scudder, 1862, 420. Brown Wingless Cockroach.

Dark chestnut-brown, shining; the apical margins of the dorsal segments paler; antennæ and legs reddish-brown. Eyes and vertex concealed by pronotum; face finely and sparsely punctate. Pronotum roughened with small, scattered granular tubercles and with a few larger ones each side of median depression; hind margin truncate, front one broadly rounded. Dorsal segments finely and sparsely' punctate, the last two or three with numerous small rounded tubercles, the terminal segment trian. gular with lateral margins raised and apex truncate. Cerci hidden, but stout, rather short, tapering, the joints indistinct. Sixth ventral segment produced to meet the last dorsal one, its apex rounded and sides finely granulate. Female inseparable externally from the male. Length of body, $\hat{o}$ and $9,23.5-29$; of pronotum, $7.1-8 \mathrm{~mm}$. Width of pronotum, $9-9.9 \mathrm{~mm}$.

This peculiar roach occurs in hilly or mountainous regions from New York and Maryland, southwest to northern Georgia and central Kentucky; also in Oregon, Washington and California. ${ }^{22}$ It appears from the records to be most abundant in Vir-

${ }^{22}$ Scudder, Psyche, IX, I90I, 288. 
ginia and North Carolina, where it is usually found in the sapwood of decaying cliestnut or pine logs.- At Glendale. Oregon, Hebard (1917a, 257) found two colonies "in fir logs only where the wood was soggy and the bark stripped easily. There directly under the bark and in burrowings in the sapwood the series was taken. Individuals eat their way throngh the sapwood. preferring the places where it is soft, soggy and decayed." Shelford (1907a, 4) states that the Panesthina "seem to derive their nompishment from the decayed wood in which they burrow."

\section{Suborder III. GRESSORIA.}

Orthopterous insects haring the body long and slender; head exserted, often separated from the prothorax by a deep constriction; legs slim, the hind femora not enlarged. The name Gressoria, proposed by Fieber in 1853 to include the mantids and walking-sticks, is derived from the Tuatin and means "a walker." Fischer (1853) and Gerstrecker (1863) adopted the name as proyosed by Fieber. While it has not been much used in America, it affords a valid and easily understood term and is therefore used in this work, as proposed by Fieber, to include the two following families:

KEY TO FAMILIES OF SUBORDER GRESSORIA.

a. Front pair of legs raptorial, fitted for grasping; head strongly compressed, oblique, mouth inferior; eyes very large; ocelli three, rarely wanting; pronotum usually longer than any other segment; cerci jointed; subgenital plate of males bearing styles.

Family III. MANTIDE, p. 115.

aa. Front pair of legs not raptorial, their femora usually slender and curved at base; head usually subquadrate, almost horizontal, mouth sub-inferior; eyes small; ocelli usually wanting; pronotum rarely longer than head; cerci not jointed; styles absent.

Family IV. Phasmide, p. 130.

The priority or rather inferiority of the Mantida is well set forth by Scudder (1869b) as follows: "The specialization of their anterior legs marks the higher structure of the Mantidae, but they show their affinity to the Blattida and their inferiority to the Phasmide in their flattened abdomen, the tendency of the prothorax to become broad and flat, the structure of the external genital organs, the position of the liead, and the exclusion of the eggs in a single (.Juster, enclosed in an oötheca.

"The relation of the Pluasmida to the saltatorial Orthoptera is also shown in the cylindrical body and, to some degree, in the structure of the external genital organs." 


\section{Family III. MAXTID.E.}

if'

The Mlatins or Praying Ixsects.

This family is composed of elongate. slow moving insects, the most noticeable charactel of which is the possession of a front pair of legs so modified as to be fitted for grasping and holding their prey. The old name giren to the gloup by IVestwood was therefore Raptoria or glaspers. The head is short, much wider than long, triangular. rertical, and loosely joined to the thorax in such a manner as to be freely movable; antenna slender, nsually filiform, rarely half as long as the body; eyes rery large, convex, prominent; ocelli three in number ${ }^{23}$ arranged on a triangular eleration just above the insertion of antenna; pronotum in most of our species usually sereral times longer than broad, with the broadest portion in front of the middle and above the point of attachment of the long fore coxre; both inner and outer wings present (except in the females of Oligony.x and Thesprotia) but often shorter than the abdomen in the females; the abdomen of that sex often much broader than that of the male, and withont a risible oripositor. Both sexes have a pair of short jointed cerci attached to the sides of the supra-anal plate, while the males have also a pair of much shorter styles near the apex of the subgenital plate. They have the fore legs stont and raptorial, the tibia terminating in a long claw and with the long, slender, five-jointed tarsi, when at rest, bent back into a groove on the under side of the spinous femur; middle and hind pairs of legs long, slender, and fitted for slow motion. As with the other non-saltatorial families, ears and organs for producing sound are absent.

The members of this family have numerous popular names, the most common of which are the "praying insects" or "soothsayers," given them on account of the position which they take when at rest or when waiting to grasp another insect. The knees are then bent and the front legs held as though in supplication. In the southern States they are often called "mule killers." from the foolish belief that the brownish liquor which they give off from the mouth is fatal to mules. This name is, howerer, also applied to the "whip-scorpion," Thelyphorus gigantens Iuras, a large membel of the order Arachnida, which inhabits that region. Other common names for the mantids are "devil-horses" and "rearhorses," given them on account of the long. slender thorax which,

${ }^{23}$ The ocelli are wanting in the females of Thesprotia. 
when raised, makes them look like tiny giraffes. This attitude is assumed for defense and aggression and the insects are noted for their ferocity, pugnacity and tenacity to life.

The mantids are all carnivorous, feeding principally upon the different forms of other insects. They are thus in the main beneficial, in this respect differing widely from all other members of the order Orthoptera, unless it be the tree crickets of the genus Oêcanthus, some of which are said to feed upon plant lice. They capture their prey by stealth, either awaiting motionless its near approach or crawling towards it very slowly, and when within reaching distance, seizing it with a sudden and rapid movement. Like other predatory insects, they have very voracious appetites. A male of the European species, Mantis religiosa L., which was introduced on nursery stock into New York State, was observed to eat, in one day, three large grasshoppers and a daddy-long-legs, and then tackled another mantis from which he was separated with difficulty. The eggs of mantids are numerous and are enclosed in a corresponding number of cells, arranged in regular rows and united in an ovoid mass, attached to twigs, walls or other support (Fig. 52). They are covered by a fibrous substance exuded by the female, which hardens when exposed to air and holds them firmly together.

The members of the family are widely distributed throughout the

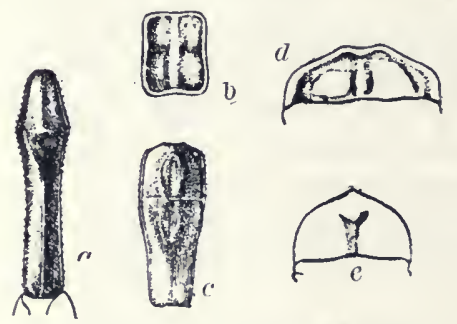

Fig. 5o. Structures of Mantidx. a, Pronotum of Stagmomantis. showing shape; $b$, of Mantoida; $c$, of Gonatista; $d$, facial shield of Stagmomantis, showing width as com. pared with height; $e$, same of Mantis. (After Caudell.) tropics, and our species are mostly c onfined to the southern States, only five being recorded from north and east of the Ohio River, two of these loeing introduced forms. The prin(ipal literature dealing especially with the North American species is as follows: Saussure, 1869, 1870a, 1871, 1871a, 1872; Westwood, 1889; S'auss. \& Zehnt., 1894; Scudder, 1896; Caudell, 1913; R. \& H., 1916; Davis, 1918, 1919.

Representatives of three of the six recognized subfamilies of Mantidx occur in the eastern States.

KEY TO SUB-FAMILIES OF UNITED STATES MANTIDA.

aa. Head unarmed; upper surface of middle and hind femora and tibiæ rounded.

b. Pronotum at least twice, and usually three or more times as long as broad and noticeably broadened in front, usually at the point of insertion of the fore coxæ (Fig. 50, a. e.)

I. Maxtix.e, p. 117. 
bb. Pronotum subquadiate, but little longer than broad, its sides parallel (Fig. 50, b.)

II. ERemiaphilinæ, p. 128.

aa. Head armed at middle with a pair of processes, as long as the bead itself; upper surface of middle and hind femora and tibiæ carinate.

III. Vative, p. 129.

\section{Subfamily I. MANTIN E.}

'To this subfamily, as characterized in the key, belong eleven of the fourteen genera of Mantidx known from the United States. Of these seven are represented in the region east of the Mississippi River, six of them by only a single species each.

KEY TO EASTERI GENERA OF MANTIX.E.

a. Front tibia one-half or more the length of front femur; form robust that of female usually the more so; tegmina and wings present in both sexes.

b. Margin of abdomen in both sexes entire; broadest part of pronotum far in advance of middle, the sides in front of this again more or less converging to apex, which is rounded (Fig. 50, a.)

c. Larger, pronotum more than $.0 \mathrm{~mm}$. in length.

d. Tegmina of female notably shorter than the abdomeu; facial shield, (just below the antennæ) traniverse, distinctly more than twice as wide as high (Fig. 50, d.) I. Stagmomaxtis.

$d d$. Tegmina of both sexes reaching or exceeding the tip of abdomen; facial shield not more than twice as wide as high (Fig. 50, e.)

e. Inner surface of front coxæ with a large oval piceous spot on basal third; tips of tegmina and wings broadly rounded; length of body not over $60 \mathrm{~mm}$.

II. Maxtis.

$e e$. Inner surface of front coxæ without a piceous spot; tips of tegmina and wings acutely rounded; length of body 80 or more $\mathrm{mm}$.

III. Paratexodera.

cc. Smaller, length of pronotum less than $10 \mathrm{~mm}$. IV. Callimantis. bb. Margin of abdomen in female lobed, in male more or less serrate; broadest part of pronotum beginning about the middle, the sides nearly parallel from there to apex, which is almost truncate (Fig. 50, c.)

V. Govatista.

aa. Front tibia not more than one-third the length of front femur; form very slender in both sexes; tegmina and wings absent in the females.

$f$. Front tibiæ longer than their apical claws; pronotum strongly narrowed in front of middle, its fore and hind sections sub-equal in length.

VI. Oligoryx.

ff. Front tibiæ distinctly shorter than their apical claws; hind section of pronotum about three times as long as front one. VII. THEsprotia.

I. Stagmomaxtis Saussure, 1869, 56. (Gr., "stigma bearing" + "prophet.")

Body of male narrow, of female much broader. Head large, compressed, triangular; antenna short, slender, inserted about 
the middle of face below the center of eyes; rertex narow, transverse, a little elevated above the eyes. Pronotum rery long, in our species forming two-fifths the whole body. its apical third wider, with edges carinate and, in female, armed with minnte distant teeth. 'Tegmina of female broad, oparque and bearing a spot or stigma of different texture near the renter; tegmina of male narrow, longer than abdomen, with stigma often indistinct or wanting; wings of female, when expanded, of the form of a quarter circle, those of male longer and narrower. Abdomen of female large, more or less dilated; that of male narrow, the sujra-anal plate small, its apex rounded; subgenital plate very large, its apical third much narrowed, styles rery short.

Stagmomantis is an exclusively American genus, 20 species, inostly from Central and Sonth America, laving been recognized by Kirby $(1904,252)$. A number of these are now known to be synonyms but several lave since been described. Only five are known from the United States, and of these but two occur east of the Mississippi, the other three ranging from Texas to California.

KEY TO EASTERN SPECIES OF STAGMOMANTIS.

a. Female with abdomen subfusiform, broadest about the fourth segment; tegmina broad, reaching apical third of abdomen, their stigmatic patch black, conspicuous.

43. CAROLINA.

aa. Female with abdomen subcylindrical, of nearly equal width throughout; tegmina narrower, reaching only to middle of abdomen, their stigmatic patch pale, inconspicuous or sub-obsolete.

44. FLORIDEXSIS.

43. Stagmomaxtis Carolixa (Johannson), 1763, 396. Carolina Mantis.

Male, grayish-brown; tegmina semi-transparent, grayish, more or less mottled with smoky brown, sometimes almost wholly of the latter color: body and legs often in part greenish-yellow; inner wings hyaline, sometimes tinged with pinkish. Female either greenish-yellow with bright

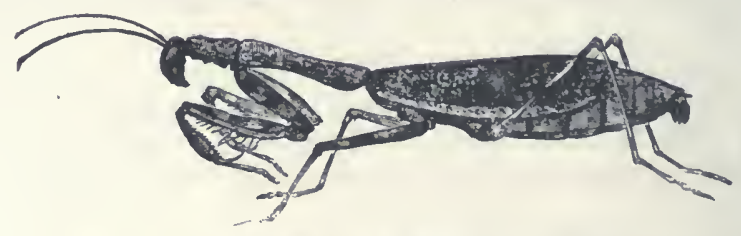

Fig. 51. Stagmomantis carolina (Johann.) female.

green tegmina and legs (irrorata Linn.) or dark brown like the $\hat{o}$; stig. matic patch black bordered with pale yellow, more distinct in the green form. Length of body, $\delta, 4 S-55$,,, $51-57$; of pronotum, $\hat{\delta}, 15-17.5$, ․, 19-22; of tegmina, ô, 32-38, ․, 20-23 mm. (Fig. 51.)

A species of sonthern range, occurring frequently in the southern half of Indiana and quite common in the counties hordering 
the Ohio River. It extends as far north as Marion and Putnam counties, where it is found sparingly, though a dozen or more specimens have been brought to me in Indianapolis, all of them females. S. G. Evans, of Eransville, in a letter says: "The Mantids are found here of all sizes and colors, the eggs and young being almost as common as mosquitoes. I have. on sereral occasions, placed male and female together in a glass jar, and the female always deroured the male, and generally while in the act of copulating, the bodies remaining together until the male was almost consumed." At Indianapolis the females eridently reach maturity about September 1st, most specimens being brought in about that date or later; the green and brown forms of the female being about equally numerous. In Putnam County it has been noted by John S. Michaels, near Bainbridge. A pair, both of the dark hue, were found mating in Perry Co., Sept. 25. They were on the stem of a weed within a foot of the ground and the abdomen of the female was greatly distended by the large mass of eggs enclosed.

S. carolina oceurs throughout Florida, having been recorded from-numerous localities from Jacksonville, Live Oak and Pensacola south to Homestead and Key West, the dates ranging throughout the year. Nymphs have been taken by me at Okeechobee City, Cape Sable and Key West in February and March. A female from Punta Gorda is recorded by R. \& H. (1914d) as "having the body $75 \mathrm{~mm}$. and the pronotum $27.5 \mathrm{~mm}$., in length." In Florida this mantis is usually found in the undergrowth of pine woods, paImetto scrub, etc., though it is liable to occur anywhere about orchards, gardens and borders of cultivated fields.

The Carolina mantis ranges from central Ohio (Kostir) and Indiana east to Pennsylvania and southern New .Jerser, west to Nebraska and Utah and south to Arizona. Mexico and Cuba. Adrentive specimens have also been recorded from Rhode. Island and New York. The type of Bactromantis rirga Scudder (1896, 213) at Cambridge shows that it was hased upon an immature male of S. carolina. so that both the genus Bactromantis and the species fall in srnonrmy. Mantis vhecleri Thos. (18T5. 849). MI. stolli Sauss. $(1869,65)$ and $.1 \%$. dimidinta Sanss. $(1871.48)$ are also regarded as synonyms.

When in the presence of its prey the Carolina mantis moves almost imprerceptibly along. stealing toward its rictim like a cat approaching a mouse. When sufficiently near, the foreleg is sud- 
denly extended to its full length and the unlucky insect is immediately caught and impaled by the spines between the tibia and femur, carried to the mouth and deliberately eaten piecemeal while yet alive and struggling to escape. When the two sexes are captured and placed together the female soon begins to feed upon her liege lord, and finally devours all portions of him which are in the least degree digestible. Riley $(1869,169)$ states that their prey consists mainly of flies, but that he has "know them to attack various kinds of butterflies, including the male bag-worm, grasshoppers and caterpillars of many kinds, and in one instance a single female mantis devoured eleven living Colorado potato beetles during one night, leaving only the wing cases and parts of the legs."

The eggs of the Carolina mantis are laid in cases or masses, about an inch long, which are attached to the twigs of trees or

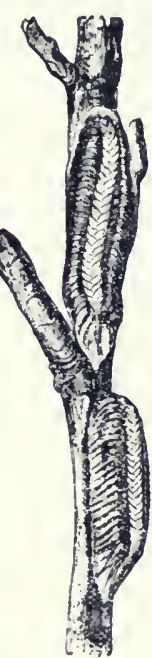
other support (Fig. 52). The case is tough and horny, and the eggs are laid in parallel rows, twenty to forty in a row, issuing from a common longitudinal middle line. All of the eggs stand on end and are inclined somewhat toward the central channel. A cluster of eggs has a braided appearance, but consists simply of a continuous ribbon of mucus folded in close flutings and having an egg deposited in the bight or angle of each fold. The eggs are deposited simultaneously with the deposition of this ribbon by the mother insect, and the whole mass is at first soft and flexible, but rapidly hardens by exposure to the air. In this manner the species survives the winter and in May, when insect life begins to abound, the young emerge and use their prominent, staring eyes to good advantage in seeking plant lice and other minute forms Fig. 52. Egg. which furnish them their first of many meals. The
cases of Stag-

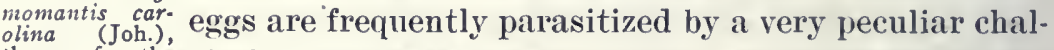
three
natural fourths
size. (After Riley.) tough egg mass with its long ovipositor, and whose larvæ feed upon the eggs. Thus egg masses taken by the observer in the winter and kept for the hatching of the young will frequently in the spring give out those parasites instead of the young mantids.

44. Stagmomantis Floridensis Davis, 1919, 4. Larger Florida Mantis.

More slender than S. carolina. Body and legs greenish-yellow; teg- 
mina of $q$ green, often with front margin yellowish, of $\hat{\delta}$, hyaline, the stigmatic patch faint in $q$, absent in $\hat{o}$. Pronotum slender, its greatest.

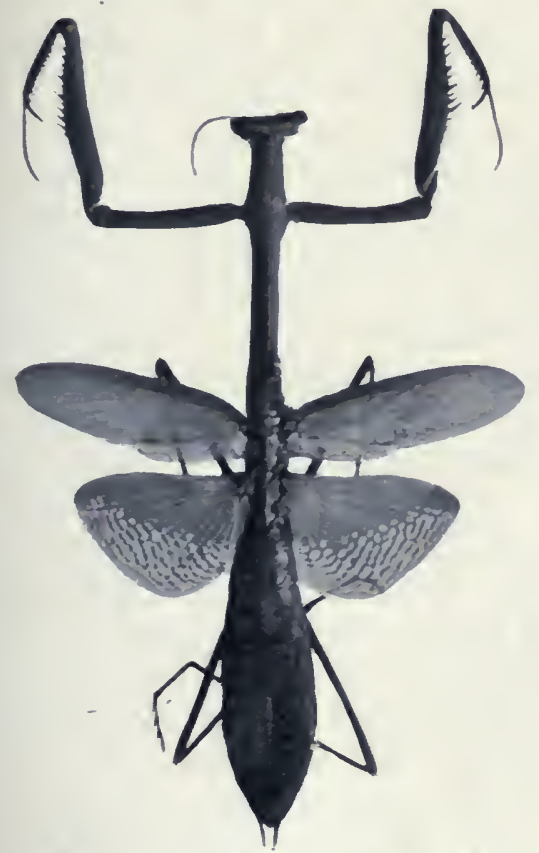

Fig. 53. Female, type. (After Davis.) width contained a little over five times in the length. Inner wings yellowish, tessellate on the outer half only, the basal portion and front margin without translucent spaces. Length of body, $\hat{o}$, 62 , ᄋ, 58-71; of pronotum, ô 22 , ㅇ, 24-27.5; of tegmina, ô, 38 , ㅇ, 22-24; of hind femora, $\hat{o}$, 17, ㅇ, 18-21 mm. (Fig. 53.)

Dunedin. Fla., Oct. 25, one female; Utopia, Fla., March 4, one nymph (W.S.B.). Described from Punta Gorda and Parish, Fla., and also recorded by Daris, loc. cit., from Pablo Beach, Carrabelle, La Grange and Everglade, JulySeptember. Not known outside of Florida, where it is said by Davis to be associated with and about equally as common as S. carolina.

\section{Mantis Linnæus, 1758, 425. (Gr., "a seer or prophet.")}

Medium sized species distinguished from Stagmomantis by the characters giren in the key and by having the tegminal stigma of female wanting or of the same color as the tegmina. Pronotum in our single introduced species proportionally shorter and broader than in stagmomantis, the margins in the female finely and densely serrate for three-fourths of their length. Subgenital plate of male smaller and less tapering and the cerci and styles longer and stouter. Nine species are recognized by Kirby, all inhabitants of the Eastern Continent.

45. Maxtis Religiosa Linnæus, 1758, 426. Praying Mantis, European Mantis.

Female, elongate robust; $\hat{o}$, more slender. Body and legs green or greenish-yellow; tegmina of $q$ broader, uniform grass-green, those of $\hat{\sigma}$ paler green, often almost hyaline, narrowly edged with brown, in both sexes reaching or slightly surpassing the tip of abdomen; wings as long as tegmina, transparent or very pale green. Pronotum of male with sides 
very finely serrate in front of the dorsal transverse impression. Length of body, ô, 47-51, ᄋ, 52-56; of pronotum, ô, $13-15$, ㅇ, 16.5-18; of tegmina, $\hat{\sigma}, 33-35$, ᄋ, $38-40 \mathrm{~mm}$.

An introduced European species, first recorded from the United States as occurring near Rochester, N. Y., by Slingerland, ${ }^{24}$ nnder the name of Stagmomantis carolina, and next by Scudder, ${ }^{25}$ under its true name. The specimens at hand were taken at Rochester in September, 1913, so that it apjears to have become thoroughly established, not only at Rochester, but also through egg('ases from there at Ithaca (Daris, 1918). Kirby (1904, 250) gives its distribution as "Southern and Central Europe, Northern and Wester'n Asia and Northern Africa." Latreille (1831,9) states that it is very common in the southern parts of France and Italy, that it is sometimes brown and immaculate, and that the Turks entertain for it a religious respect. An egg-case at hand is oval, $20 \times 40 \times 15 \mathrm{~mm}$. in size, and less compact than that of the Carolina mantis. The young, when first liatched, are said to be much elongated and to have a singular habit of suspending themselves from the egg-case by slender threads attached to the cerci. The females are said by Schmaltz, ${ }^{26}$ who collected them in numbers at Rochester, to hide under long grasses and to attach their eggcases to weeds or grasses within two or three inches of the ground. He states also that both sexes vary greatly in color, some indiriduals, being almost gray while others are green, yellow, pale brown or dark brown.

\section{Paratexonera Rehn, 1903g, 705 (Gr., "slender" + "neck.")}

Tery elongate, robust species having the head broad, the facial shield about twice as wide as high; pronotmm rather short, stont, lut feebly widened at transrerse impression which is not less than one-fomtl from apex, side margins in female, finely and thickly serrate, apex broadly rounded; tegmina and wings fully developed, more or less livaline in botlı sexes, their tips subacute, stigma absent; front legs stont, their coxa with the lower margin strongly toothed. This genus was separated by Relun from Tenodera Burm. with the following species as the type.

\section{Paratexoneli sixexsis (Saussure), 1871a, 295. Chinese Mantis.}

Females with body and legs green or greenish-yellow, tegmina and wings green, subhyaline; males either of the same hue or wholly brown, or brown with the marginal field of tegmina green, and with both tegmina

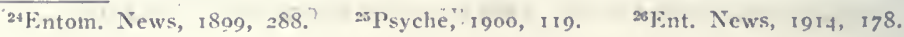


and wings more strongly hyaline. Pronotum of $\hat{f}$ subcarinate; of $q$ strongly carinate behind the transverse impression, in front of which it is bicarinate with the carinæ granulate. Tegmina with the marginal field very large; wings with the discoidal vein biramose. Length of body, $\hat{o}$, $\$ 3-87, \uparrow, 85-104$; of pronotum, $\hat{o}, 27-30, q, 27-31$; of tegmina, $\hat{o}, 60-$ 62 , $\&, 5 \delta-64 \mathrm{~mm}$.

This lar.ge Asiatic species was accidentally introduced by a nurseryman at Mt. Airy, near Philadelphia, Pa., about 1896, and seems to have become thoroughly established. Laurent states (Ent. Teus. 1902, 62) that at Mt. Airy it "likes blackberry and briar bushes as a place of abode and avoids low ground with low herbage." From 150 to 300 young emerge from each egg mass in June, and mature about the first of October. It is a rery beneficial insect and egg masses from the IIt. Airy colony have been introduced at many points in New Jersey, New York and Connecticut, but at no place do they seem to have done as well as at the point of original introduction. Davis (1918) has given an interesting account of the attempts to increase the distribution of this beneficial mantis in the region mentioned. Saussure's types were from Ningpo, China, and it is a well known insect in that country and Japan. Although a native of a semi-tropical region, it seems to be able to withstand without difficulty the rigors of the Pennsylrania winters.

Weiss (1914) has giren a description of the egg-case of $P$. sinensis stating that it is peculiar in that it consists of a central, somewhat horny core containing the eggs. These are arranged in from 12 to 18 layers. averaging 15 eggs each, or a total average of 225 eggs in each case. The central core is surrounded by a porous rind or onter fibrous envelope "which undoubtedly serves to protect the eggs from moisture and sudden changes in temperature." A number of tests made by him showed that the interiors of nests entirely immersed in water for an hour and three-quarters remained perfectly dry. At the end of two hours the outer rind became moist but the water had not reached the core. The average thickness of the core was $12 \mathrm{~mm}$., and of the enveloping rind $5.6 \mathrm{~mm}$., while the arerage weight of a nest or case was 1.63 grams, of a core, 1.34 grams and of a rind .29 grams, "showing that five-sixths of the total weight consists of the core containing the eggs, the remaining sixth of the porous protecting rind."

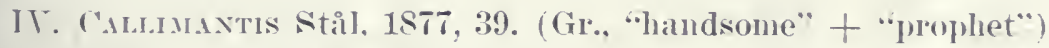

Short. slender bodied species having the head rather small, compressed: antenure shorter than pronotum in both sexes; face deeply roncaive between the eyes; ocelli of medium size. Pronotum short, its basal portion very slender, the apical one as wide again, 
elongate-oval, with sides at middle nearly parallel and apex and base rounded. Tegmina and wings narrow, shorter than abdomen in female, equal to it in male; the anal and axillary veins of tegmina free and simple throughout. Front legs stout, their tibia three-fifths the length of femur, armed with numerous small spines. Abdomen of female fusiform, of male slender; supra-anal plate prolonged in the form of a tongue. Two species are known, one occurring in the West Indies, the other in our Southern States.

47. Caldimantis floridana Scudder, 1896, 210. Smaller Florida Mantis.

Male, pale brownish-yellow; tegmina and wings hyaline flecked with fuscous, stigma wanting; tibiæ of middle and hind legs greenish. Pronotum of $\hat{\sigma}$ with sides unarmed, its widened front portion sulcate just behind and in front of the transverse impression. Hind femora without apical spine. Length of body, $\hat{o}, 35$; of pronotum, 9 ; of tegmina, $22 \mathrm{~mm}$.

The above deseription is that of a male taken near Brownsville, Texas. Scudder's unique type was from Florida without definite locality. The female is as yet unknown and the range of the species undetermined.

\section{Gonatista Saussure, 1869, 54. (Gr., "a kneeler.")}

Body short and broad in female, more slender in male; head short, compressed; antenna inserted opposite the base of eres, hair-like, half the length of body; eyes very large, globose, prominent; ocelli large in male, much smaller in female; face in appearance somewhat excavated on account of the prominent eyes. Pronotum about two and a fourth times as long as broad, disk depressed, but with an elevation or hump on front and middle thirds with a depression between and with two small tubereles on hind margin, widest about the middle, front margin truncate, with angles rounded; sides of front half parallel, those of posterior half feebly converging to base (Fig. 50, c). Tegmina of female broad, covering three-fourths of abdomen; stigma small, narrow, often indistinct; those of male narrower, surpassing the abdomen, more membranous; wings ample, about as long as tegmina. Fore legs rather stout, their tibia with five or six large spines on lower outer border, with numerous small ones intervening; inner border with twelve or more strong spines. Abdomen of male depressed, of medium width, with margin feebly serrate; of female large and broad, the border coarsely serrate or lobed.

Gonatista is an American genus, three of the four species rec- 
ognized by Caudell (1912) occurring in the West Indies, the other one in our Southern States.

48. Goxatista grisea (Fabricius), 1793, 22. Grizzled Mantis.

Female grayish, more or less mottled with fuscous; tegmina with two oblique fuscous crossbars on apical half; inner wings bluish-black, their margins hyaline; fore legs gray tinged with greenish and sprinkled with fuscous; middle and hind legs with narrow fuscous crossbars. Male with body and legs dull yellow, the latter barred with fuscous; tegmina and wings hyaline, the former usually more or less thickly sprinkled with small fuscous spots and larger blotches. Pronotum not carinate in either sex, its front half with a narrow median groove; side margins in female finely serrate. Length of body, $\hat{\delta}, 36-38$, , 37-40; of pronotum, $\hat{\delta}, 9-11$, 옹 10-11; of tegmina, $\hat{o}, 30-33$, ㅇ, $18-23 \mathrm{~mm}$.

Known from Indiana only by a single female collected by S. G. Erans at Evansville, who wrote that he must have supposed it to be a short-bodied form of S. carolina, and therefore has no record of date or exact locality of its capture. It may therefore have been introduced on tropical fruits. Dunedin, Florida, Feb. 5June 4 (W. S. B.) ; the latter specimen at porch light. Gainesville, Fla., Aug. 13; on magnolia. West Palm Beach, Mar 22_June 12; a half dozen adults and nymphs, resting on gray bark and therefore almost invisible (Dury). R. \& H. give numerous additional records from the southern third of Florida, stating (1914c, 383) that at Key West they "were taken chiefly from gumbo-limbo trees in the heary key sclub jungle and also on sea grape. The insects were always on the trunks or branches, generally about six feet above the ground. Ther were perfectly protected when in their resting position, being then closely pressed against the bark of the tree. When disturbed they would make off with a rapid scuttling run."

In this country the grizzled mantis occurs from extreme southern Florida northward to Sarannah, Ga., and Charlestown, S. C. It has also been recorded from Texas, Cuba and San Domingo. Scudder, Saussure and Kirbs all regarded Mantis reticulata Thunb. and M. phryganoirles Serv. as șnonyms, but Caudell (1912) restored both names as valid species, basing his table wholly on the length and maculation of the male tegmina, two exceedingly variable characters. One of the males of G. grisea from West Palm Beach has the tegmina but $30 \mathrm{~mm}$. in length and aInost immaculate, which would cause it to run by Caudell's table to phryganoides Serv., and it is very doubtful whether that species will stand. 


\section{VT. OLigoxyx Saussure, 1869, 5S. (Gr., "few" + "slines.")}

Tery slender species having the head broad, strongly rompressed; antennæe setaceous, pubescent, half as long as body, male, one-half shorter, female; eyes prominent; ocelli very large in male, very small in female; vertex in the form of a ridge with a jrominent tuberele at each end. Pronotnm slender. finely rarinate, dilated just in front of middle, thence narrowed to the rounded apex; basal half broader with sides parallel, margins distinctly serrate, female, minutely so, male. 'Tegmina and wings of male membranons, narrow, not passing the fifth segment of abdomen; of female wholly wanting. Legs very slender; inner margin of upper surface of front coxæ abruptly dilated at apex; front tibia very short, with but four to six spines, the terminal one very large. Abdomen in both sexes slender, cylindrical; supra-anal plate very long, lanceolate; cerci in our species awl-shaped, cylindrical.

This is also an exclusively American genus represented in Mexico, Central and South America by a half dozen or more species and in the Lastern United States, as far as known, by only one.

49. Oligonyx scudderi Saussure, 1870b, 239. Scudder's Mantis.

Male brownish-yellow, more or less mottled with fuscous; legs, pro. notum and margins of wings pubescent. Tegmina of male as long as the wings, both very thin, translucent, their tips rounded; in female represented only by lateral prolongations of the meso- and metathorax. Front tibiæ only one-third the length of femur, armed with five spines. Length of body, $\delta$ and $\$, 34-37$; of pronotum, $\delta, 7-8$, $ᄋ, 9$; of tegmina, $q$, $24 \mathrm{~mm}$.

Sanford, Fla., March 2S, (W. S. B.). This graceful little mantis ocenrs only in the Sonthern States, having been recorded by R. \& H. (1916, 123) from South Carolina, Georgia and Florida. In Florida it has been taken at Crescent City, Punta Gorda and Miami, and doubtless occurs in small numbers throughout the State. It is usually found ('lose to the gromud, on the grass and other mndergrowth of pine woods. O. uhleri Still (187t, 66i), described from Louisiana. was considered by Candell to be only a dark form of scudderi, and his opinion is uplocld ly R. \& H. A Texan form, 0 . bollianus Sauss. \& Zehnt. (1894, 173) is reagreded by the same antlorities as only a variety of scurlseri. A recold of O. scurldrei from New Mexico by Scudder and Cockerell (1902, 20) probably refers to this form. 


\section{TII., THEslroth stal, 1S7T, 4 .}

Tery slender elongate species, laving the liead strongly compressed; antenna filiform, more than lialf the length of bodr, male, muclı shorter, female; eres large, obovate; ocelli in our species absent in female; rery large in male. Pronotum verr long. linear, feebly dilated above the fore coxa, thence narrowed with sides almost parallel to the subtruncate apex; tegmina and wings of male about two-thirds as long as abdomen, their tips rounded. Abdomen very long and slender in both sexes; supra-anal plate lanceolate, carinate above, projecting much beyond the subgenital plate, which in the male is angulate each side at tip at the insertion of the slender tapering strles. Front legs very slender, coxie and femora subequal in length; tibia only one-fomth the length of femur, bearing three slender subapical black-tipped spines and a much longer, stouter terminal one. The species of this genus are confined to the Western Continent, five being known from South America and one from the Southern United States.

50. Thesprotia gramixis (Scudder), 1877a, 90. Grass-like Mantis.

Pale brown or brownish-yellow; head, pronotum and legs sparsely dotted with fuscous; antennæ, pronotum, abdomen and margins of wings pubescent. Head with a strong triangular tubercle above each eye. Pronotum finely carinate above, the carina evanescent in front; sides minutely toothed in both sexes. Tegmina and wings of male hyaline, the former the shorter, reaching base of fourth abdominal segment, the wings protruding 3-4 $\mathrm{mm}$. beyond their tips. Cerci 7 -jointed, about $4 \mathrm{~mm}$. in length, depressed, pubescent. Length of body, ô, 47-50,,$+ 52-56$; of pronotum, $\hat{\delta}, 12.5-14$, ᄋ, 16-19; of tegmina, ô, $18-21 \mathrm{~mm}$.

This, our most slender-bodied mantid, has been taken by me at Sanford, Sarasota, Dunedin, Lakeland, Ft. Mrers, Key West and LaBelle, Fla., Nor. 1-April 10. About Dnnedin it occurs throughont the winter on wire grass and other undergrowth in open pine woods, and has been frequently taken therefrom while sweeping for beetles. Four males were taken, Dec. 11 and March 2.2, on the screen door of mr residence, and were perhaps attracted by light. Scudder's unique male type was from Ft. Reed, Fla., and the species has been recorded from many different localities throughout the state. R. \& H. (1905) state that it is often found "in the pine straw of the pine woods which it so closely resembles as to be invisible when stationary." They also mention (1914d. 101) a specimen from Punta Gorda 60.5 mm. in length. Scudder records the species from Georgia and R. \& H. (1916. 124) give 
six different localities in that State at which it had been taken. Of these Isle of Hope was the most northern and they state that it will doubtless be found to occur in southern South Carolina. It has been received by Davis from Mississippi and a female in the U. S. National Museum is labelled New York, but doubtless represents an adventive or accidentally introduced specimen.

\section{Subfamily II. EREMIAPHILIN F.}

In this subfamily the body is rather slender, pubescent; head large, eyes prominent, globose; pronotum short, subquadrate, not dilated above the front coxæ (Fig. 50, b) ; tegmina elongate, membranous; legs short, slender; abdomen filiform, flattened; supraanal plate very short. A single genus and species represent the subfamily in the United States.

\section{Mantoida Newm., 1838, 178. (Gr., "prophet" + "like.")}

In addition to the characters of the subfamily as above given, this genus has the front of head vertical, antenna rather stout, much longer than body; wings shorter than tegmina, their axillary field much shorter than the humeral one; front tibix terminating in a stout claw or spine; middle and hind legs densely clothed with seta-like hairs. Our only species is

51. Maxtoina mayA Sauss. \& Zehnt., 1894, 125. Little Yucatan Mantis.

Female fulvous-testaceous. Head large; eyes very prominent, globose; ocelli small rounded-oval; occiput black with broad yellow median stripe; face and antennæ blackish-fuscous, first joint of latter testaceous beneath. Pronotum black with median vitta and lateral margins dull yellow. Tegmina and wings nebulous-hyaline, with brownish ferruginous reins, the costal margins darker; tegminal stigmata vitreous. Legs testaceous; front femora stout, angulate within at base, their spurs brown; front tibiæ black above the apex, spines and apex also black, seven spines on inner side longer than claw, four on outer side; middle and hind tibia: and tarsi armed beneath with a row of minute spines along each margin, their tips densely spinulosely pilose. Abdomen slender, blackish-fuscous, beneath and at apex varied with testaceous or fuscous. Supra-anal plate strongly developed, transverse, obtusely angulate; subgenital plate of equal length. Length of body, $\$, 15.5$; of pronotum, 2.3 ; of front femora, 3.3 ; of tegmina, $12.5 \mathrm{~mm}$.

This little mantid was described from northern Yucatan and the first record for this country was that of Caudell (Can. Ent., 1911, 156), based on a specimen from Florida (probably from Kissimmee) found in the collection of the late Chas. Palm. It was labelled "Mrantispa. sp. Neuropt," as it bears a close resemblance 
to the members of the Neuroptoid genus Mantispa. This was noted by Saussure who states $(1871,10)$ : "Ces insectes ont les facies de Neuropteres, et Perty les arait meme classes dans cet ordre." A second specimen, which I saw at Philadelphia, was taken at Key West, July 7,1912 , by R. \& H., who state that it "was taken while swiftls running about on the ground under high jungle brush." There is no other record of its occurrence within our bounds, but it will probably be found in small numbers throughout subtropical Florida.

\section{Subfamily III. VATINE.}

Elongate slender species, having the antennæ of male pectinate or serrate; middle of head armed with two corneous processes which are united at base; middle and hind femora and tibia multi-carinate above. This subfamily is represented in the United States by two genera, a single species of one being recorded from the eastern portion.

\section{Phyllorates Kirby, 1904, 302. (Gr., "leaf" + "prophet.")}

Head triangular, transverse; antennæe of male serrate or subpectinate; pronotum slender, feebly and gradually dilated in front, the broader portion more or less rhomboidal with apex rounded; tegmina and wings fully developed; front legs slender, their tarsi rather short and broad.

(-). Phyllovates chlorophed (Blanchard), 1836, pl. 135. Greenishbrown Mantis.

Female in great part green; male usually brown, with tegmina and wings hyaline, their marginal field and tips green. Frontal prccesses of head $3-3.5 \mathrm{~mm}$. in length, more slender in male. Pronotum narrow, elongate, carinate and finely granulate above, the margins finely serrate, more finely and less densely so in male. Tegmina of female greenish. opaque with usually a fuscous band near apex, their marginal field wide, strongly concare near apex; those of male more narrow with front border subsinuate, feebly concave at middle; wings of female fuscous-brown, greenish-brown toward apex. Length of body, $\hat{\delta}, 65$, 9,67 ; of pronotum, ô, 29, ․, 31; of tegmina, ô, 48, ९, $40 \mathrm{~mm}$.

Blanchard's type of this mantis was from Watertown, Y. Y., and was probably accidentally introduced. Scudder has recorded it from the "Gulf States" and (1896, 209) more definitely from Lonisiana. It is known from Central America, oceurs throughont Mexico. and is liable to be found anywhere in the extreme sonthern portion of the area corered by this paper. It is therefore included as an adrentire species which has not ret become a known resident. 


\section{Family IV. PHASMIDA.}

\section{The Walking-Sticks.}

This family of non-saltatorial Orthoptera comprises the insects commonly known as walking-sticks. The North American species have the body elongate, very slender, subcylindrical; head free, nearly horizontal, usually subquadrate; antennæe long, rather stout; eyes small, ocelli often absent; pronotum very short; abdomen elongate, composed of ten segments, the basal one usually closely united with the metathorax, often invisible; tegmina and wings absent (except in the genus Aplopus), the location of the wings generally indicated by a stationary wing-like pad, bearing a gland; legs very long and slender, of nearly equal size; tarsi, in our eastern genera, 5-jointed, terminated by two claws between which is a large pad (arolium) ; ovipositor concealed by the subgenital plate; cerci not jointed.

Our species of Phasmidae are remarkable for their resemblance to twigs of different plants, while some of the tropical species are so modified as to resemble leaves, frequently bearing so close a resemblance to the foliage as to deceive a keen observer. Their movements are, in general, very slow, though the males can run with some rapidity when in pursuit of the opposite sex. They feed during their entire lives upon leaves, being especially fond of those of oak and wild cherry. The eggs are dropped loosely and singly upon the ground by the mother, where they remain through the winter, thus tiding the insect over the cold season. The outer case or shell of the egg is hard and often sculptured, and those of our common species resemble seeds or small beans. The young, when hatched, trust to chance and their peculiar shape to escape those higher animal forms which are ever ready to prey upon every moving object which promises them a bit of sustenance. The largest living insects are walking-sticks, found in Borneo and other East India Islands, two of the wingless forms having the body $33 \mathrm{~cm}$. or 13 inches in length.

That the Phasmidae have the power of reproducing their lost or broken legs has been shown by Scudder. Such restored limbs are much smaller and have but three or four tarsal joints, ${ }^{27}$ the usual fourth joint being absent. If the leg is removed in front of the trochanto-femoral joint it is never reproduced.

The family is, in the main, a tropical one, and is feebly rep-

${ }^{27}$ Proc. Bost. Soc. Nat. Hist., XII, $2868,138$. 
resented in the United States, where but fire of the 16 recognized subfamilies are known to occur. Three of these subfamilies are represented in the Eastern United States by six genera and eleren species. The following literature treats especially of the North American representatives of the family: Riley, 1879; Scudder, 1895, 1901; Caudell, 1903a, 1913, 1918; Brunner, 1907; Sererin, 1911, 1911a, 1913; R. \& H., 1916; Somes, 1916.

$$
\text { KEY TO EASTERX SUBFAMILIES OF PHASMIDE. }
$$

a. Mesothorax four or more times as long as prothorax; hind and middle tibiæ not deeply emarginate beneath at apex.

b. Tegmina and wings absent; median segment not or barely longe: than broad; head unarmed above.

I. Bacuxculixe, p. 131.

$b b$. Adults with short tegmina and wings; median segment longer than broad; head armed above with two short horns.

II. Phibalosomixe, p. 143.

aa. Mesothorax never more than three times as long as prothorax; hind and middle tibiæ broadly and deeply emarginate beneath at apex, thus forming a cavity to receive the base of the tarsi when bent upon them.

III. Axisomorphixæ, p. 144.

\section{Subfamily I. BACUNCULINÆ.}

This subfamily comprises the longest and most slender of our North American walking-sticks. They have the mesothorax usually five or more times as long as prothorax; antenne in our eastern genera more than twice as long as the front femora; tibiæ without a sunken areola beneath the apex; tarsi fire-jointed. Seren of the United States genera belong to this subfamily. Of these representatives of four have been recorded from the area corered by this work.

\section{KEY TO EASTERT GEXERA OF BACUXCULIX.E.}

a. Head subquadrate or subcylindrical, usually distinctly longer than broad, attached obliquely or horizontally; small or medium sized species, rarely over $95 \mathrm{~mm}$. in length; hind femora without a row of spines beneath; cerci of male not spatulate.

$b$. Hind femora of both sexes armed beneath with a subapical spine, prominent in male, smaller in female; middle femora of male usually distinctly thicker than the hind ones; head subquadrate, but slightly longer than broad.

I. Dlapheromera.

$b b$. Hind femora unarmed beneath; middle femora of male not or bur slightly thicker than the hind ones.

c. Middle femora armed beneath with a distinct subapical spine; head subcylindrical, twice or more as long as broad.

II. MANOMERA.

cc. Middle femora not spined beneath.

III. HeTERoNeMiA. 
aa. Head short, ovate, scarcely longer than broad, attached subvertically; very large species, length 115 or more $\mathrm{mm}$.; hind femora, at least in female, with a median row of strong spines beneath; cerci of male broadly spatulate.

IV. MEgapIIASMA.

I. Diapheronera Gray, 1835, 18. (Gr., "unequal" + "thigh.")

Body long, slender, subcylindrical; head smooth, obliquely attached to thorax; antennx inserted in front of eyes; pronotum
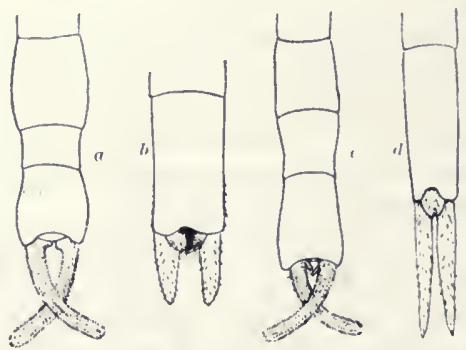

Fig. 54. Apical portions of abdomen of Phasmidx, showing relative length of segments, cerci, etc.; $a$, of Diapher oncra femorata Say, male, $b$, female; c, of Manomera blatchleyi Caud.,

curyed; those of female short, straight. The species of this genus are widely distributed over the Cnited States east of the Rocky Mountains, three of the seven recognized having been recorded from east of the Mississippi.

KEY TO EASTERX SPECIES OF DIAPHEROMERA.

a. Seventh segment of abdomen distinctly longer than elghth in both sexes (Fig. 54, a) ; base and apex of ninth abdominal segment of male subequal in width; meso- and mentanotum without median black dorsal stripe.

$b$. Cerci of male with a blunt basal tooth or tubercle; cerci of female about half as long as the last dorsal segment (Fig. 54, b.)

52. FEMORATA.

$b b$. Cerci of male with an acute and slender basal tooth; cerci of female more slender, almost or quite as long as the last dorsal segment (Fig. 54, d.)

53. VEIIEI.

aa. Seventh and eighth segments of abdomen subequal in length; apex of ninth abdominal segment of male inflated, nearly half as broat again as base; cerci of male without a basal tooth or tubercle; mesoand metanotum with a broad blackish dorsal stripe.

54. CAROLIXA. 
52. Diapheromera feMorata (Say), 1824a, 297. Common.Walking-stick.

Color variable, being either gray, brown or greenish-brown; body of

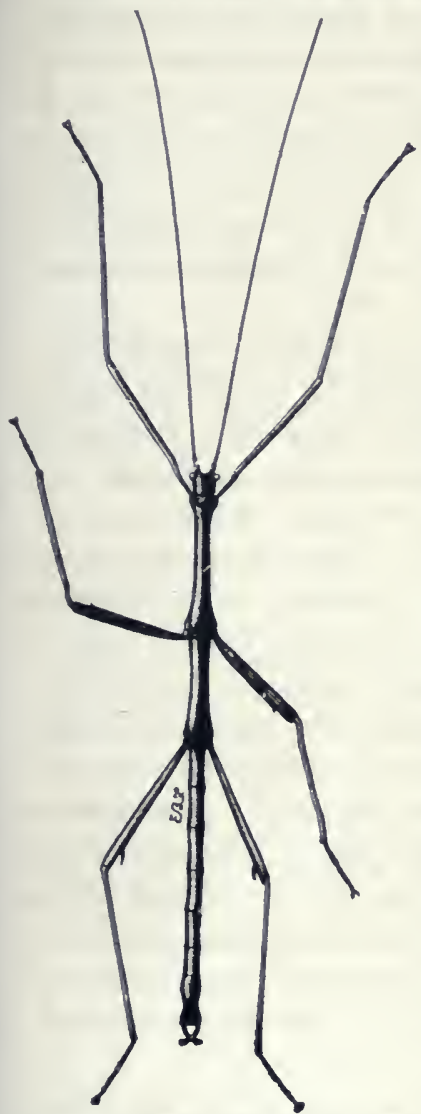

Fig. 55. Diapheromera femorata (Say.) Male. male usually greenish-brown, sometimes almost wholly green; head yellowish with three vague lengthwise fuscous stripes; front legs and tibiæ of the others usually green; middle femora often banded with dark gray; female duller, usually grayish-brown, often with paler specks and mottlings on head and back. Head smooth in both sexes, subquadrate; eyes round, more prominent in male; antennæ very slender, about as long as body. Abdomen smooth, basal segment about twice as long as broad in female, three times as long as broad in male, seventh segment in male three times as long as eighth. Cerci of male cylindrical, oval at apex, clothed with short stiff hairs, strongly curved inward and usually crossing near middle; of female, straight. stout, rather blunt, pubescent. The mals is easily distinguished by the shorter ani more slender body, longer legs and antennæ, narrower and less dilated front femora, swollen middle femora and by the greater stoutness of the subapical spines beneath the middle and hind femora. Length of body, $\delta, 68-84, \&, 70-101$; of antennæ, $\hat{\delta}, 58-65$, $q, 45-57$; of mesothorax, $\hat{\delta}, 17-18$, $ᄋ, 16-20$; of metatho$\mathrm{rax}, \hat{\delta}, 15-16$, $९, 13.5-18$; of hind $\mathrm{fe}-$ mora, ô, 19.5-21, o, 15-19 $\mathrm{mm}$. (Fig. 55.)

This walking-stick is quite a common insect throughout Indiana, though the arerage observer will probably see but one or two of them a year. They reach maturity in August, and may then often be found upon the leares of oak or wild cherry, especially on isolated trees along fence rows. One of my students at Terre Haute once brought in on October 15, a hundred or more which he had gotten from a wild cherry tree on whose leares they had been feeding. It moves very slowly and has a habit of remaining motionless and apparently dead for a considerable length of time. On such occasions it usually stretches itself out from a twig with its front legs and antenna extended, and can then 
scarcely be distinguished from a prolongation or branch of the twig. Many people who see them thus for the first time and afterwards watch them moving slowly away, can scarcely be persuaded that they are not real twigs, gifted in some mysterious manner with life and motion. On September 18, 1918, they were found in numbers in a grove of the black locust in Putnam County, 40 or more specimens being secured in a few minutes. They were usually found mating on the boles of the locust and when approached and touched would drop to the ground and there remain motionless.

D. femorata is the most common and widely distributed Phasmid in the United States, ranging from Maine to the Rocky Mountains, north to central Ontario and Selkirk, Manitoba, and soutlı and southwest at least to northern Florida, northern Texas and the Organ Mountains, New Mexico. In Florida it has been recorded from Monticello by Davis (1915) and several specimens labelled "Gainesville, Aug. 15" are in the collection of the Florida Experiment Station. R. \& H. $(1916,124)$ record it from Virginia, North and South Carolina, and from numerous stations in Georgia, and state that a male from Albany, Ga., is $84.5 \mathrm{~mm}$. in length, and that the material from the four states mentioned "was all taken in the undergrowth of pine and oak woods." A female at hand from near Mobile, Ala., $101 \mathrm{~mm}$. in length, has one of the hind legs aborted, the length of the femur being but 19 and of the tibia $11 \mathrm{~mm}$. as against 24 and $27 \mathrm{~mm}$. for the same segments of the opposite leg. The basal joint of the tarsus is less than onethird that of the corresponding normal one and only two additional joints are present.

This is the only North American walking-stick abundant enough to be of economic importance. In feeding they eat the edges of a leaf, preferably those of an oak or wild cherry, usually straddling it with their legs, and in an hour will devour a piece an inch long by a third of an inch wide. Riley (1879) records that on occasions they are so numerous as to do much damage to oak, hickory, locust and other trees. In Yates Co.. New York, he once found them very abundant in a woodland of 50 acres, which they had attarked in numbers two and four years previously. He states that:

"By the middle of August the bulk of the pests were going through their last moult, and by the end of autumn they had stripped most of the trees, showing, however, a decided preference for the black, red and rockchestnut caks, over the white oaks and hickorles, which they affect but 
little until after the first mentioned trees are stripped. The underbrush was also effectually cleaned of its foliage, and the insects hung from and clung to the bare twigs and branches in great clusters. They settled to roost on the witch-hazel, but did not defoliate it until the other trees men. tioned were pretty bare. Sumach and thorn were also little affected, while peach and apple in an adjoining orchard were untouched. Whenever they had entirely stripped the trees and shrubs they moved in bodies to fresh pastures, crowding upon one another and covering the ground, the fence rails, and everything about them so that it was impossible for a person to enter the woods without being covered by them. The timber affected could be recognized by its seared and leafless appearance from a great distance, and upon entering the woods the ear was greeted by a peculiar seething noise, resulting from the motion of the innumerable jaws at work on the leaves. Their depredations first began to attract attention soon after wheat harvest, and were most noticeable in September. The injury to the trees done in 1874 and 1876 was manifest in the death of most of the black oaks, and, according to the owner's observations, trees die in three years after the first attack."

The eggs, of which each female lays about 100, are a little less than $3 \mathrm{~mm}$. in length, long oval in shape and of a polished black color with a whitish stripe on one side. They resemble a small, plump bean or seed of other leguminous plant. They are simply dropped loosely upon the ground from whatever height the female may happen to be, and says Riley: "During the latter part of autumn where the insects are common, one hears a constant pattering, not unlike drops of rain, which results, from the abundant dropping of these eggs, which in places are so thick among and under the dead leaves that they may be scraped up in great quantities. The eggs remain upon the ground all through the winter and hatch for the most part during the month of May. Some of them, however, continue hatching much later, so that all through the summer and eren into the fall, young individuals may be found. When first hatched the young measure $4.5 \mathrm{~mm}$. and with their feelers and legs outstretched, near double that length. They are invariably, during early life, of a pale yellowish-green color. The insect changes very little in appearance from birth to maturity except so far as color is concerned, and moults but twice. Growth is rapid, averaging, under favorable circumstances, about six weeks from birth to adult. With age the green color gives way to various shades of gray and brown. In this way we find great correspondence with its surroundings. While the vegetation is green, the walking-sticks are.green also; when the foliage turns in autumn, they change color correspondingly, and when the foliage is stripped they so closely resemble, both in appearance and color, the twigs upon which they rest-the habit of stretching out the front legs and feelers greatly enhancing the resemblance-that when they are few in number it is difficult to recognize them. A few green specimens, more particularly of the males, may always be found, even among the mature individuals."

It will be noted that Riley, in the above account. which was the first one attempting to give in detail the life histors of $D$. 
femorata, states that the young "moult but twice." Our knowledge of the life history of other Orthoptera would tend to show that this was an error and Severin has proven it to be so by rearing 100 examples of the species under conditions as normal as possible. He states (1911) that "23 per cent. moulted four times, 76 per cent. five times and only one per cent. six times." - He adds that since the insect usually eats parts, or all of its cast-off skin it is possible that Riley overlooked some of the moults on this account. He also states that those specimens "which moulted four times reached sexual maturity on an average in 50 days, while those which monlted five times required 57.5 days, on an average before beginning the egg-laying period. * * * The eggs, after passing out of the raginal orifice, may be retained for a number of hours within the peculiar 'external uterus' formed by the oripositor."

The thick-thighed walking-stick appears to be abundant in any certain locality only every other year. This is in part due to an increase of the insect's natural enemies on those years in which they are most abundant. These enemies are several species of true bugs (Heteroptera), crows and other birds. The main reason for the greater number of walking-sticks in alternate years is, however, thought to be due to the fact that the larger proportion of the eggs, especially those laid late in the autumn, take two years in hatching. If at any time the insect threatens to become injurious in woodlands, it can be held in check by burning the leaves on the ground in the winter season, thus destroying the hibernating eggs.

\section{Diapheromera veliet Walsh, 1864, 410. Prairie Walking-stick.}

Form, size and color much as in $D$. femorata, the middle femora of male not usually banded with gray as in that species. Head slightly more elongate. Male with seventh abdominal segment no longer than ninth, in femorata one-third longer; eighth segment two-thirds as long as seventh; cerci with a very slender, sharp curved spine on inner side near base, instead of a blunt tubercle as in femorata. Female with emargination at apex of ninth abdominal segment deep, broadly rounded, in femorata more shallow, triangular, with apex acute; subapical spine beneath the middle and hind femora often very small. Length of body, $\hat{\delta}, 61, \dot{\phi}, 74$; of mesonotum, $\hat{o}, 14$, $ᄋ, 16$; of metanotum, $\hat{o}$ and $q, 12$; of hind femora, $\hat{o}$ and $\$, 18 \mathrm{~mm}$.

Walsh's male type of this walking-stick was from Nebraska, and one of his female cotypes from Illinois. Its main distribution is west and sonthwest of the Mississippi, extending from Staples 
and Pipestone, Minn., to Colorado, Texas and Mexico. East of that river it has been recorded from New York, New Jersey, Maryland, Virginia, Georgia and Illinois, but Caudell has shown (1918) that the majority of these records are probably based on individnals of his Manomera blatchleyi, a speeies rery closely resembling D. velici. The eastern limits of the range of veliei eannot, therefore, be given with certainty, but it has been taken by Somes at Memphis in the northeastern corner of Missouri and at Elmira in eastern Iowa, and therefore very probably oceurs in Illinois and other states bordering the Mississippi. Somes (1916) states that veliei "averages smaller than femorata, especially in the males, and these also tend to brighter coloration, being often quite distinctly marked with two light colored lateral stripes, the pleura being light colored in life, though after drying the color is less distinet. It frequents tall grasses and low brush rather than trees and tall shrubs, being often found on such plants as Audropogon scoparius Mx., Lespedeza capitata Mx. and Salix humilis Marsh."

54. Diafieromera carolixa Scudder, 1901, 188. Carolina Walking-stick.

"Stouter than D. femorata, testaceo-castaneous, glistening; thorax with a rather broad median bronze-fuscous stripe, not reaching the median segment, and interrupted at posterior end of mesonotum; fore legs greenish, antennæ testaceous; thorax with excessively fine transverse striation. Mesothorax and metathorax (including median segment) of similar length. Seventh and eighth abdominal segments of subequal length, each faintly. enlarging from base, the ninth a little shorter, apically inflated and subglobose, nearly half as broad again at apex as at base, the cerci much as in D. femorata, but stouter, more compressed and without basal tooth. Length of body, $\hat{\sigma}, 67$; head, 3 ; mesothorax, 13.5; fore femora, 20.5; hind femora, $19.5 \mathrm{~mm} . "$ (Scudder.)

The above is the original description of the unique male type of this well marked Phasmid which was collected in North Carolina by Morrison. An examination of it at Cambridge shows that it has the cerei rather strongly ineurred and flattened, being fully twice as thick rertically as horizontally, with the apical half subspatulate within; ninth segment of abdomen globose, scarcely longer than wide; seventh and eighth segments subequal, each slightly broader than long and a little shorter than the ninth. The only specimen known, other than the type, is a male taken by Mrs. A. T. Slosson at Lake Toxaway, N. C., and now in the Daris collection. It agrees fully with Scudder's description as emended above and there can be no doubt of its specific standing. The shining dark dorsal stripe, narrow on pronotum and much wider 
on meso- and metanotum, is a striking character. The sides of the seventh and eighth abdominal segments also bear a curved black stripe, and the subapical spines of under surface of middle and hind femora are shining black.

\section{Manomera Rehn \& Hebard, 1907, 283. (Gr., "thin" + "thighs.")}

Very closely allied to Diapheromera. Head more slender, smooth, swollen in front, twice or more as long as broad, attached horizontally to the thorax; antenna about two and a half times as long as the front femora; middle femora armed beneatlı with a slender subapical spine, lind femora unarmed; cerci of male stont, cylindrical, pubescent, decurved and incurved, sometimes crossing near middle and armed on the inner side at base witl a spine or tubercle (Fig. 54, c) ; cerci of female slender, lanceolate, about as long as the ninth abdominal segment (Fig. 54, d.).

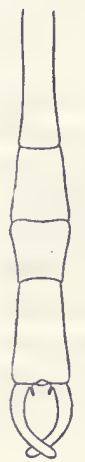

$a$

This genus is characterized very briefly by its authors thus: "From Diapheromera, IInomera can be separated in the male by the slender head, absence of candal femoral spines, uninflated median femora and more elongate abdominal appendages." Now the middle femora of the male of $M$. blatehleyi are distinctly inflated, and the cerci of the male of no species of Manomera are more elongate than those of $D$. femorata. while tlie long female cerci are paralleled in that sex of $D$. velici. This leares only the more slender head and the absence of spines on hind femora as the valid characters separating the two genera. Since these femoral spines are often absent in the females of Dia-

Fig. 56. Apical portions of abdomen of males of Manomera. a $M$. temuescens; $b$. $M$. brachypyga. $\times$ 3. ${ }^{\circ}$ (After R. \& H.)

pheromera it will be readily seen that ILanomera has a very precarious standing. The species at present ascribed to the genus may be separated as follows:

KEY TO THE SPECIES OF TIIE GENUS MANOMERA.

a. Middle femora of male not or scarcely thicker than the hind ones; head slender, more than twice as long as broad.

b. Seventh, eighth and ninth abdominal segments of male together one-half longer than sixth; ninth segment cylindrical, distinctly longer than wide, male, longer than prothorax, female; cerci of 
male with a slender sharp tooth at base. (Fig. 56, a.)

55. TENUESCENS.

$b b$. Serenth, eighth and ninth abdominal segments of male together no longer than the sixth; ninth segment but slightly longer than wide, enlarged at apex, male, equal in length to prothorax, female; cerci of male with a swollen, blunt, oblique basal tooth. (Fig. 56, b.)

56. BRACHYPYGA.

aa. Middle femora of male distinctly thicker than the hind ones; heat shorter, stouter, about twice as long as broad; cerci with a blun: tooth at base. (Fig. 54, c.)

57. BLATCHLEYI.

55. Maxomeba texuescexs (Scudder), 1900, 95. Slender-bodied Walkingstick.

Male very slender, elongate; female much stcuter and longer. Male brown, female green above, both brownish-yellow beneath; sides of male usually with a fuscous stripe, bordered below with yellow, the legs in part greenish. Head slender, one-third longer than pronotum. Male with seventh and ninth abdominal segments subequal in length, each slightly longer than the eighth and about one-half as long as sixth; subgenital operculum slender, strongly spatulate, reaching the tip of the eighth segment. Female with ninth segment slightly longer than seventh, its apex truncate; cerci very slender, strongly tapering, as long as the ninth seg. ment, their margins minutely serrate. Length of body, $\delta, 63-67,9,85-$ 110 ; of head, ô, 3.2-3.5, ㅇ, 3.5-5.5; of mesothorax, ô, 16-17, ᄋ, 19-24;

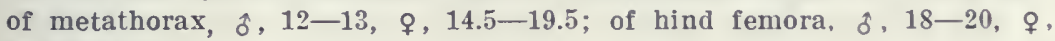
24-26 $\mathrm{mm}$.

A Southern species whose known range is from Selma and Winter Park, North Carolina to Southern Florida. Numerous nrmphs have been taken about Dunedin in February and March. They are pale grass-green and were swept from huckleberry and other low shrubs in open pine wools. Scudder's types were from Cedar Keys and Capron, Fla., and it las been recorded from numerous localities from Jacksonville and Live Oak in the north, to Homestead and Punta Gorda in the south. Adults are found from April to Norember on wire grass. saw palmetto and other undergrowth in open pine woods, rarely on vegetation in low. daup places. Jfanomera orthostylus Caudell (1913. 612) has been shown by R. \& H. $(1916,125)$ to be a șnonsm of $M$. tenucscens. having been based on a male in the instar preceding maturity. the cerci of the male in the nymph stages being straight. pilose and delicate in structure.

56. Maxomera brachypya Rehn \& Hebard, 1914c, 384. Short-rumped Walking-stick.

Very similar to $M$. tenuescens agreeing in general form, color and structure, but differing in the much shorter serenth, eighth and ninth 
abdominal segments and the form of the apex of the male abdomen, as described in the key and shown in Fig. 56. The female differs from that sex of tenuescens in having the sixth dorsal segment considerably longer than the seventh and eighth, the ninth segment equal in length to thorax and the subgenital plate rounded or subtruncate, with caudal margin very little produced. Length of body, $\hat{\delta}, 69.6-88.5$, ㅇ, 92.6 ; of mesothorax, ๙ิ, 15.8-21.4, \&, 21; of hind femora, ô, 20-25.3, ㅇ, $23.8 \mathrm{~mm}$.

Originally described from Homestead and Detroit, Florida, July 10-12; San Pablo, Aug. 13, and Miami (female and. 11 nymphs), March 28. Since recorded from Marco, LaBelle, La Grange and Charlotte Harbor, Fla. Tike M. tenuescens, it occur's mainly on the undergrowth of pine woods. Davis (1914) states that at La Grange, Sept. 9-12, with the aid of a lantern he found both $M$. tenucscens and brachypyga at night, when they were active and walking about on the low vegetation in the pine woods.

57. Maxomera BLAtChleyi (Caudell), 1905c, 212. Blatchley's Walkingstick.

Form shorter and proportionally slightly stouter than in tenuescens. Color the same as that of $D$. veliei the males usually somewhat darker than those of that species and with a pale lateral stripe extending back to hind femora. Head subcylindrical, feebly enlarged in front. Pronotum narrower and but slightly shorter than head. Length of mesonotum fourfifths that of metanotum and median segment combined. Seventh and eighth abdominal segments of male subequal in length, each slightly shorter than ninth, the latter in female feebly and broadly emarginate. the supra-anal plate small, triangular, carinate above. Cerci of male cylindrical, scarcely at all tapering, decurved and incurved as in $D$. femorata, the subbasal tooth on the inner margin very short, blunt; cerci of female slender, straight, tapering, as long as the ninth segment (Fig. $54, d$.) Legs stouter proportionally than those of tenuescens; middle femora of male very finely serrate beneath and armed near apex with a stout, blunt, nearly horizontal spine; those of female slender, the spine short, straight. Length of body, $\hat{\delta}, 58$, $\uparrow, 67$; of head, $\hat{\delta}, 3, \mathcal{\imath}, 4 ;$ of mesonotum, $\delta, 13$, $\$, 15-16$; of metanotum, $\delta$ and $\rho, 12$; of hind femora, ô, 20, 우, 18-20; of cerci, 우, $3.7 \mathrm{~mm}$.

The types of this walking-stick in the U. S. National Museum were taken by me near Bass Lake, Starke Co., Ind., Aug. 20, 1!02, and no additional specimens have since been personally collected. It doubtless occurs, however, throughout the northern half, perhaps over the entire State. A female is at hand from Cedar Point, Ohio, and Kostir (1914, 371) states that numerous females but no males were taken at that place. Hart $(1907,259)$, recorded it as occurring on lank prairie regetation throughout Illinois. and also from Genera, Wis. Gerluard has sent me a male and two females 
taken at Argo, Ill., July 27, and has collected others at Palos Park and Fourth Lake, Ill. Somes (1916) records II. blatchleyi from Iowa and Missouri, the sexes occurring in about equal numbers. Elsewhere the males seem to have been very scarce.

As noted above under $D$. veliei, many if not all the eastern records of that species probably refer to 1 . blatchleyi, the females especially of the two forms being rery difficult of separation. Daris (Ms.) states that he now considers the species occurring about New York City, and formerly thought to be $D$. veliei, as $M$. blatchleyi. but that no males have as yet been taken on either Long or Staten Islands, although the females are fairly common on golden-rod, asters and associated plants: Morse $(1919,16)$ records an adult female and nymph of blatchleyi from Greenwich, Conn. The known range of blatchleyi therefore extends from Kansas and Oklahoma to Tirginia and Connecticut.

Under the generic heading I have referred to the close relationship between the genera Diapheromcra and Iranomcra. The species blatchleyi seems to be a sort of connerting link between the two. The rather short head and thick middle thighs of male would refer it to the former and the unarmed hind femora to the latter genus.

III. Heteroxemid Gray, 1835, 13. (Gr., "different" + "race.")

Head of male marmed, of female with two longitudinal ridges between the eyes; first abdominal segment longer than wide; hind femora of female suberual in length to that of the four basal abdominal segments combined, of male much longer than those segments; all the femora unarmed; cerci of male of similar shape and proportions as those of Diapheromera.

Two species of this genus were described by Brunner (1907, 336 ). both of which were in part from localities within the area corered by this paper. Caudell (1913.613) states that they "are very probably synonyms of other species, but until the types are seen it is not deemed advisable to so place them." The females were separated by Brunner as follows:

KEY TO EASTERX SPECIES OF HETEROXEMLA.

a. Second and third segments of abdomen scarcely longer than broad: cerci short.

58. Lærissimus.

aa. Second and third segments of abdomen twice as long as broad; cerci long, lanceolate.

59. TEXAXUS. 
58. Heteronemia Levissimus Brunner 1907, 338. Smooth-backed Walking-stick.

"Female.-Body wholly smooth. Head not longer than pronotum. Front femora equal to mesonotum. Second and third abdominal segments subequal, as long as wide. Anal segment semicylindrical, emarginate. Cerci short, terete; operculum obtuse; ovipositor free. Length of body, 60 ; of mesonotum, 15; of metanotum, 12.5; of front femora, 15; of hind femora, $14 \mathrm{~mm}$. (Brunner.)

Brunner's types of this species were from St. Louis and "Lacus, Ontario." Caudell suggests that the type may have been a young female of Diapheromera femorata.

59. Heteroxemia texaxus Brunner, 1907, 333. Texas Walking-stick.

"Head elongate, longer than pronotum. Femora short, the middle ones subincrassate, scarcely longer than metanotum. Anal segment of male strongly fornicate. Cerci curved. Ninth ventral segment very short. Subgenital plate large, hood-shaped. Abdomen of female smooth. Cerci long, terete, acuminate. Operculum lanceolate, acuminate, not reaching the tip of ninth segment. Length of body, $\hat{\delta}, 47, \&, 65-84$; of mesonotum, $\hat{\delta}, 10, q, 14-18$; of front femora, $\hat{o}, 12, q, 17$; of hind femora, $q$, 15-20.5 mm." (Brunner.)

This species was described from Texas and New York.

IV. Megaphasua Caudell, 1903a, 878. (Gr., "large" + "apparition.")

Walking-sticks of very large size having the head short, smooth, rounded, subrertical; antenna more than twice as long as front femora; pronotum about one-fourth the length of mesonotum and with a deep median transverse impression; meso- and metanotum subequal in length, both with a fine median carina; middle and hind femora swollen in both sexes, the middle ones thicker than hind ones in male, both armed with a prominent subapical spine beneath. Cerci stout, those of male somewhat spatulate, decurved, their tips meeting but not crossing; of female less than half the length of last abdominal segment. The type of the genus and only known species is

\section{Mrgaphasma Dextricus (Stål), 1875, 76. Giant Walking-stick.}

Form elongate, robust as compared with that of preceding species; the female much the more so. Brownish-yellow or fuscous with legs paler, body and legs of male often in part green, sometimes maculate or banded with gray. Pronotum about as long as head, with broad, deep median transverse impression and a much finer longitudinal one. Seventh and 
eighth abdominal segments subequal in length, each shorter than ninth. Front legs much longer and more slender than either of the other pairs; middle and hind femora in both sexes thick, 4-sided, broadest beneath, their surface rough, the carinæ granulate or finely dentate, the median line below finely toothed in male, more strongly so in female. Length of body: $\hat{\delta}, 117, \uparrow, 123-150$; of pronotum, $\hat{\delta}$ and $\$, 5.5$; of mesonotum, $\hat{\delta}, 22, \uparrow$, 24 ; of front femora, ô, 29, $q, 27$; of hind femora, $\hat{o}, 26, \hat{q}, 23 \mathrm{~mm}$.

Stal's type of this giant walking-stick was a female from Opelousas, La. It has since been recorded from Alabama, Iowa, Missouri, Texas and New Mexico, and Caudell (Ms.) states that a female taken on a porch near Louisville, Ky., in 1911 is now in the U. S. National Museum. Somes (1916) states that it is not uncommon in the Ozark region of Missouri and has been taken by him as far north as Hamburg and Clarinda, Iowa. It is found, he says, "on shrubs and trees and does not apparently differ greatly in habits from the well-known Diapheromera femorata." Near Victoria, Texas, Mr. dentricus is said to be rather common on wild grape rines in the wooded bottom lands.

This is the largest Phasmid known from the United States, a female in the Philadelphia collection measuring $150 \mathrm{~mm}$. in length. In size it is approached, however, by the females of Aplopus mayeri, one of which, in the Davis collection, measures $118 \mathrm{~mm}$., while $\mathrm{R}$. \& H. record others as reaching a length of $127.5 \mathrm{~mm}$. excluding the oviscapt.

\section{Subfamily II. PHIBALOSOMINA.}

This subfamily is represented in extreme southern Florida by a single species belonging to the following genus:

\section{Aplopus Gray, 1835, 34. (Gr., "single" + "foot.")}

Elongate, robust species having the head short, subvertical, armed abore with two short unequal horns or spines, the right one the larger; antenna rather stout, setaceous, slightly more than half the length of body, male, one-fourth shorter, female; mesonotum more than twice as long as metanotum; tegmina and wings present in the form of short oral or oblong pads; legs slender, not very elongate; middle and hind femora armed beneath with several short, sharp spines and terminating at knees in a pair of similar spines.

Fifteen species of the genus were recognized by Kirby (1904, $363)$, all of them from the West Indies, Central and South America. The following species has been since described: 
61. Aplopus MAYeri Caudell, 1905b, 83. Mayer's Walking-stick.

Male greenish-yellow, the tegmina and wings darker; female fuscousbrown, the head, pronotum, sides of metanotum and femora and terminal abdominal segments more or less blotched with chalky white; males with sides of tegmina and abdominal segments usually marked lengthwise with white. Pronotum subquadrate, deeply impressed transversely, the front portion with a faint longitudinal impression and a pair of short black-tipped spines, hind one with a pair of similar but smaller spines in female: mesonotum of male with eight or ten, of female with 20 or more, scattered similar spines. Tegmina very short, oval, strongly veined, their tips obliquely rounded; wings oblong, projecting 2 or $3 \mathrm{~mm}$. beyond the tegmina. Front legs more slender, and but slightly longer than middle ones their femora with basal third strongly narrowed and more or less curved; middle and hind femora of female with their dorsal carinæ crested near apex. Apex of male abdomen moderately enlarged, the seventh and eighth segments subequal; ninth slightly shorter, subquadrate; the seventh nearly as long as the next two in female. Cerci of male stout, cylindrical, blunt, decurved, a little shorter than the ninth segment. Length of body, $\hat{\sigma}, 83-93$,,$+ 114-127$; of antennæ, $\hat{o}, 53$, $\&, 45$; of mesonotum, $\hat{\delta}, 20, \hat{q}, 26-28$; of metanotum, $\hat{\delta}, 6, \uparrow, 8$; of tegmina, $\hat{\delta}, 7, \uparrow, 8.5$; of front femora, $\hat{o}$ and $q, 20$; of hind femora, $\hat{\delta}, 21, q, 22 \mathrm{~mm}$.

This is the only winged Phasmid known from the United States. The first specimens were taken at Loggerhead Key, Dry Tortugas, Fla., and were recorded, described and figured by Caudell (1904) as Haplopus evadne Westwood, a Santo Domingo species. A number of additional specimens, taken later on the same island by Dr. A. G. Mayer, were afterward submitted to the same authority, who concluded that his first identification was wrong, and described them (loc. cit.) under the name they now bear. In 1912, R. \& H. visited Loggerhead Key and secured a number of specimens, finding them only on bushes of the bay cedar, Suriana maritima L. They record $(1914 c, 357)$ the species also from Bird Key and Garden Keys of the Tortugas groups, and from Key West and Long Key, July 3-13. It is also known from Key Largo and Everglade, Fla., a specimen from the latter point, taken by Davis, being the only one known from the mainland of the State. The large size and bizarre aprearance of this Phasmid suggest its tropical origin, and it is very probable that in time it will be found to inluabit some of the adjacent West India Islands, while in Florida it will probably be found only in the subtropical area of the extreme southern portion.

\section{Subfamily IIT. ANISOMORPHIN}

Rather short, robust species having the antenna more than twice as long as front femora; mesonotum not mole than three 
times as long as pronotum; intermediary segment invisible; coxæ visible from above; tibix deeply and widely notched at apex below, thus forming a "sunken areola" which receires the base of tarsi when the latter are reflexed. To this subfamily, as at present restricted, belongs in our fauna only the single genus:

\section{Axisonorpha Gray, 1835, 1S. (Gr., "unequal" + "form.")}

Bodr broad and stout, especially so in female; head horizontally attached to the thorax, unarmed, not more than one and a half times as long as broad. Pronotum furnished with distinct odoriferous glands; mesonotum nearly one-fourth longer than metanotum; legs unarmed, stout, thick, unequal, the middle pair the shortest; abdominal segments, especially those of female, subquadrate or transverse, the serenth and ninth subequal in length; cerci of both sexes short, stout, cylindrical, pubescent.

Five species are kuown, all from the Western Continent, two of them occurring in our territory. When disturbed or picked up, they have the power of exuding from glands beneath the prothorax a vapor from the male and a white milky fluid from the female. - This is spurted out through a pore near the front angles of the pronotum and possesses a peeuliar, though somewhat pleasing odor, which has been likened to that of the common ererlasting, Gnaphatium obtusifolium L. The secretion is doubtless used as a defense against certain enemies, being probably rery distasteful. and perhaps harmful, to birds and rapacious insects. Seud$\operatorname{der}^{\circ}\left(18 \sigma_{6 g}\right)$ has noted this secretion, and concludes that the Phasmidre with their slender form and sluggish morements hare especial need of such a weapon as these glands furnish.

KEY TO YORTH AMERICAX SPECIES OF ANISOMORPIIA.

a. Larger, male averaging 45 , female about $65 \mathrm{~mm}$. in length; black dorsal and lateral stripes broad, conspicuous; head distinctly longer than broad.

62. BUPRESTOIDES.

aa. Smaller, male averaging not more than 35 , female about $55 \mathrm{~mm}$.; dorsal and lateral dark stripes narrow, inconspicuous; head but slightly longer than broad.

63. FERRUGINEA.

62. ANisomorpha bUprestoides (Stoll), 1813, 68. Larger Striped Walking-stick.

Male brownish-yellow, female usually more or less fuscous, both with a broad blackish stripe extending along the back from front of head to tip of abdomen, and another each side; legs dark brown, often paler in male. Head somewhat swollen in front, about one-third longer than broad; antennæ about three times as long as front femora. Pronotum nearly twice 
as long as broad, marked lengthwise and crosswise by a feeble median impressed line, and bearing each side near the front angle a circular pore, connected with a hidden gland. Metanotum usually furnished with several rounded black granules along the sides of its front half. Seventh segment of female bearing beneath an elongate scoop-shaped process which conceals the genital organs; male with a similar shorter triangular pro. cess. Cerci of male deflexed strongly downward; of female projected horizontally backward and extending slightly beyond the apex of ninth segment. Length of body, ô, 39-47, $q, 61-77$; of head, $\hat{\delta}, 3.5-4$, $q$, 6 ; of pronotum, $\hat{\delta}, 3.5-4$, ㅇ, $6-6.5$; of mesonotum, ô, $7-9$, ㅇ, 12-16; of metanotum, ô, $6-7.5$, $\dot{\imath}, 10-12$; of hind femora, $\hat{o}, 9.5-10$, ㅇ, $14-$ $17.5 \mathrm{~mm}$.

Gainesville, Sanford, Dunedin, Cape Sable and Key West, Fla., Nov. 4-March 29 (W. S. B.) ; several pairs taken, usually in copulation, the female stretched straight out along the stems of weeds or coarse grasses. At Dunedin one pair was taken December 12 on Hog Island, three miles across from the mainland. Recorded from numerous localities between Jacksonville and Pensacola on the north and Miami and Key West. It occur's more abundantly in moist situations, often beneath the loose bark of pine logs and stumps or between or beneath boards. From December to April about Innedin, the brownish-gray nymphs are frequently swept from dwarf huckleberry and other undergrowth in open pine woods.

Davis (1914) states that: "This fat and lubberly insect, which is always ready to squirt a charge of acrid, condensed-milklike fluid at the collector, was in evidence at all the places visited. While it has been my experience in various parts of Florida to find more nymphs of this species in the spring, yet adults may be found at any season, and each female usually has attached to herself one of the diminutive males. At night the insects become much more active."

This stout-bodied walking-stick, often called the "musk-mare," is found only in the southern states, ranging from South Carolina throngh Georgia and Florida, and west at least to Agricultural College, Miss., two specimens from that place having been given me by the late Mr. I. MI. Underwood.

63. Axisomorpila ferruginea (Beauvois), 1805, 167. Lesser Striped Walking-stick.

Fuscous or ferruginous, with inconspicuous, narrow, dusky, dorsal and lateral stripes; these in the female less distinct, often obsolete on a portion of the abdomen; antennæ dull reddish-brown; under side of body dull clay 
yellow, brownish when dried; legs reddish-brown, head but little longer than broad. Tubercles on sides of mesonctum more distinct. Body of

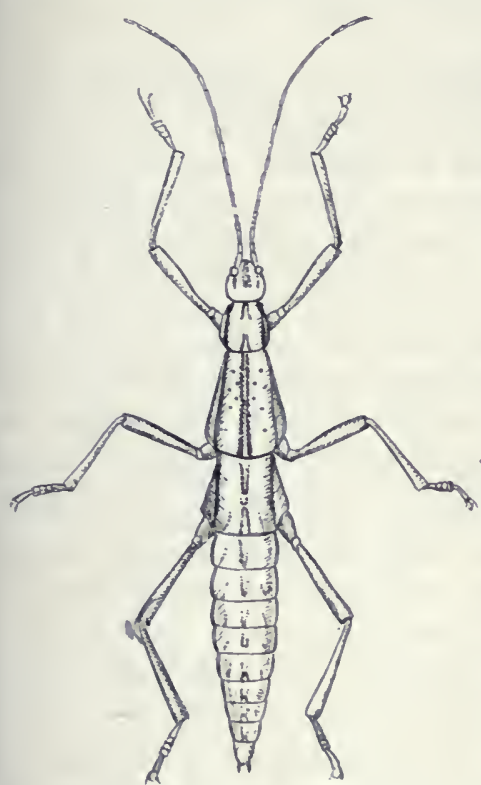

Fig. 5 - Female. Natural size. (After Caudell.) female six to six and a half times longer than broad; of male, about twelve times as long as broad. Ninth segment of male abdomen much more deeply notched at apex than in $b u$ prestoides. Length of body, ô, 3036 , ․ $50-56$; of head, ô, 3, ᄋ, 5.5; of antennæ, $\hat{\delta}, 22$, $\uparrow, 34$; of mesonotum, $\hat{\delta}, 5-6$, ㅇ, $9-10$; of metanotum, ô, 4-5, 오, 8-9.5; of hind femora, $\hat{o}$, 9, ९, $12 \mathrm{~mm}$, (Fig. 57.)

This walking-stick has been taken in Indiana only near Wyandotte, Crawford Co.. Grand Chain, Posey Co., and Medora. Jackson Co., having been found in large numbers in all three localities. The first ones noted were in Crawford Co. on June 2S, 1902, when the young about an inch and a half long were found beneath loose flakes of bark on oak and other trees. In the first week in Neptember I again visited the locality and found scores of pairs of them, all mating, beneath the loose bark of old oak snags and stmmps. A half dozen or more pairs were often found within an area of a foot or two square, the large, heary bodied female bearing her diminutive liege lord npon her back. None of the specimens noted were feeding, thongh they probably live upon the leares of oak and other trees. The species was later found in number's in Posey and Jackson Connties, and probably occurs in most of the counties bordering the Ohio River. It is but one of many forms of insect and plant life which have their most northern habitat in the southern third of Indiana.

The range of A. ferruginen is given by R. \& H. (1916, 12 $\mathbf{\imath})$ as extending from "just north of the Ohio River, sonth over the Mississippi to the Gulf States, west to extreme southeastern Nebraska and eastward through the Appalachians in Virginia and in the high portions of the Carolinas and Georgia." It is known from Union Co., Ill., and a specimen in the U. S. Yational Museum collection is from Arcadia, Ia. Candell's Florida record (1903a) is now known to have been based on a specimen of buprestoides. 


\section{Suborder IV. SALTATORIA.}

The Leaping Or'hopter.

Orthoptera of very diverse appearance but all agreeing in having the head vertical; face often oblique; hind femora very much stonter, or very much longer, or both stouter and longer than the middle ones; tibia armed with numerous spines; stridulating organs usually present; ovipositor, with few exceptions, free and exserted.

The name Saltatoria is derived from the Latin saltator, "a dancer," and was first applied by Latreille (1817) to those Orthoptera having the hind legs fitted for leaping. Belonging to this class or suborder are four families which comprise the great majority of our best known Orthoptera. They are the true "hoppers" or leaper's of the order; their hind limbs, in the course of ages, having become so modified as to be adapted in the highest degree to the life which they lead. Possessing, also, in many instances, ample organs of flight, which enable them when disturbed to move rapidly to a distance, the males have evolved in connection therewith organs of sound, by which they may call the members of the opposite sex to them. Were it not for these calling organs the two sexes would, during their varied movements, often be widely separated, and perhaps be unable to locate one another after settling in a new position. The males alone possess these organs of sound, and they only when wings are present. All the wingless forms lack also "auditory organs" or ears, since these would be useless unless some means of producing sound were present.

KEY TO THE FAMILIES OF SALTATORIA.

a. Antennæ much shorter than body, variable in form; ocelli three; tarsi usually 3-jointed; calling organs of male, when present, (except in Oedipodinæ) situated on the hind femora and lower border of tegmina; organs of hearing, when present, located on basal segment of abdomen; ovipositor composed of two pairs of short. horny, more or less curved plates, whose tips diverge.

b. Pronotum narrowed behind and prolonged backward to or beyond the tip of abdomen; tegmina represented by small oval lobes or scales on the sides of the body and covering only the bases of the wings; tarsi of fore and middle legs 2-jointed; claws of tarsi without a pad (arolium) between them; size very small, length of female not over $17 \mathrm{~mm}$. Family V. Tetricid.E, p. 149.

bb. Fronotum never extending over the abdomen; tegmina usually well developed and in repose covering wholly or in great part 
the inner wings, sometimes much abbreviated or even wanting; all the tarsi 3-jointed; arolia present; size larger, length of female rarely less than $20 \mathrm{~mm}$. Family VI. ACrIDIDe, p. 187. aa. Antennæ much longer than the body, bristle-shaped, delicately tapering; ocelli often wanting; tarsi 3 - or 4-jointed; calling organs of male, when present, situated on the anal or dorsal field of the tegmina; organs of hearing. when present, located near the base of the fore tibiæ, rarely on the prosternum; ovipositor (except in certain crickets) an elongated, horny blade or needle, its parts compact.

c. Tarsi 4-jointed; ocelli generally wanting; tegmina with sides sloping, the calling organ of male, when present, located on their basal half, and limited to the anal area; ovipositor, when exexserted, forming a strongly compressed, generally sword-shaped blade, the tip not expanded. Family VII. TetTugoxidde. p. 453. cc. Tarsi 3 -jointed ${ }^{28}$; ocelli variable; tegmina flat above, the sides bent abruptly downward, the calling organ of male, when present, extending across both thelr anal and median areas; ovipositor, when exserted, forming a nearly cylindrical straight or upcurved needle, the tip often enlarged. Family VIII. Grylidis, p. 638.

\section{Family V. TETRIGIDA.}

\section{(ACRYDIIDE.)}

\section{The Grouse or Prgiry Locusts.}

The members of this family ${ }^{29}$ are our smallest locusts and among the smallest of Orthoptera. They are easily known from all other Saltatoria by having the pronotum prolonged and tapering backward to such an extent that it reaches to or beyond the tip of abdomen; tegmina rudimentary, represented only by small oval lobes or scales, placed on the sides of the body and usually covering only a small portion of the base of wings; the latter usually present and well developed, especially in their anal area, though both they and tegmina in a few species wanting; prosternum prolonged in front by a half circular "chin piece" which envelopes the maxillae and other mouth parts like a muffler; arolia absent. The males of most species are much narrower

${ }^{28}$ Rarely in Tridactylinæe one- or two-jointed or in part wanting. The antenna in that subfamily and the Gryllotalpinæ are shorter than the body.

${ }^{29}$ The characters separating the grouse locusts from the larger short-horned locusts (Acridida) are so fixed and striking that $\mathrm{I}$ have raised the former to family rank. Not only are the external differential characters between the two families far greater than those separating any two families of Coleoptera, but they present in their spermatogenesis a distinction of family rank. In the subfamilies Tryxalinæ and Oedipodinæ the spermatogenial number of chromosomes is twenty-three, while in the Tetrigidre, according to Robertson (Journ. Morph. XXVI, No. I) there are fourteen in the female and thirteen in the male. Harmon (Biol. Bull. XXIX, No. 4) also found only thirteen in Paratettir. This great reduction in the number of chromosomes is additional evidence in support of their being ranked as a family. I have not followed the rule of basing the family name on the oldest generic one included as it would then be too similar to Acrididæ. The student can use Acrydiidre instead of Tetrigidre if he so desire. 
bodied than the females and have the subgenital plate conical or triangular, and supra-anal plate lanceolate or triangular; cerci very small, cylindrical or conical. The valves of the ovipositor are armed with small rounded teeth on their onter edges, and their extremities are sharply divergent.

In addition to the characters mentioned the Tetrigida have the eyes conspicuous, globular or subelliptic; ocelli three, arranged in the form of a triangle, the median or apical one being in the lower portion of the groove of frontal costa; antenna 12 to 22-jointed, usually cylindrical or filiform; face with a frontal costa extending down its middle, this often more or less forked, its branches sometimes widely divergent; head above bounded in front by the fastigium, the latter usually with a transverse carina; vertex behind the fastigium and between the eyes, varying much in form and size and usually divided by a lengthwise median carina; mper or dorsal surface of pronotum extremely variable in

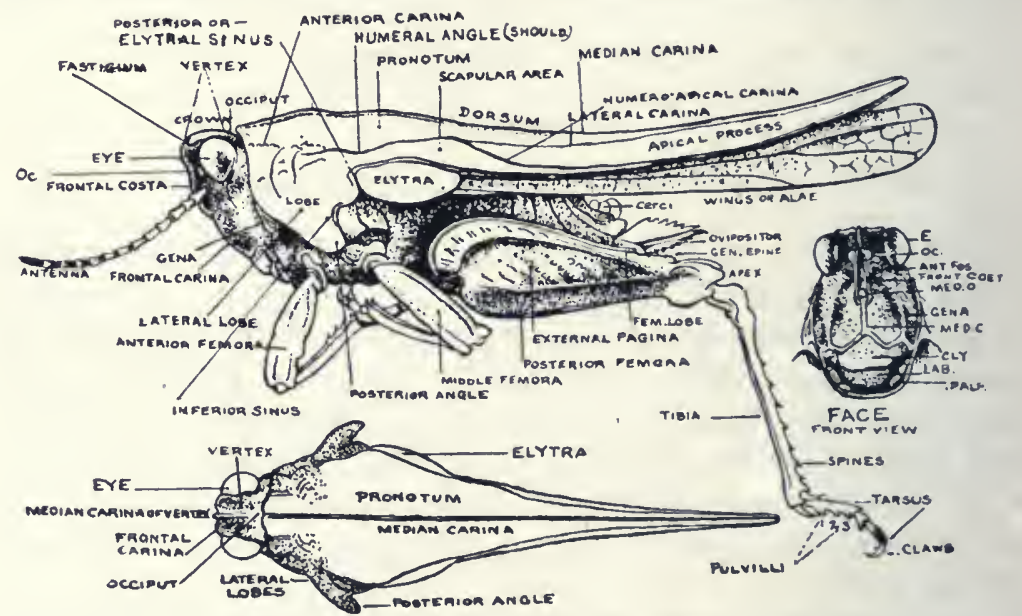

Fig. 58. Side view of a grouse locust giving the names of the different external parts. The face is shown at the right, the pronotum and head below. ( $\triangle$ fter IIancock.)

form and rugosity, lateral lobes with hind border more or less sinuate, usually with two distinct notches or simuses, the uppermost one, known as the tegminal or superior sinus, enclosing the base of tegmina, the lowermost or inferior sinus usually much the wider, the median lobe between them variable in form, as is also the lower posterior lobe or angle, beneath the inferior sinus; legs more or less compressed; hind femora much enlarged; hind tibie with numerous spines; fore and middle tarsi with only two visible segments, the terminal one three or four times as long as the 
basal; hind tarsi with three segments, the first usually longer than third, the second very short. These rarious external parts of a grouse locust are excellently shown in the accompanying figure from Hancock. The pronotum varies much in length and color, even in the adults of the same species, and much of the earlier synonymy is due to a failure to recognize the long and short pronotal forms or the color variations as belonging to the same species. During the last moult the tegmina, which in the earlier stages are hidden beneath the pronotum, take their place at the side of the body in the superior posterior sinus and the wings become folded and extended beneath the pronotal process.

In Indiana these little Orthoptera are the only locusts which pass the winter in the imago or mature stage. On the approach of winter they hide beneath chunks, chips, rubbish, the loose bark of logs, or beneath the bottom rails of old fences. Sometimes a warm sunny day in mid-winter tempts them forth in numbers, and on such oceasions, the earth seems to swarm with them as ther leap before the intruder, their hard bodies striking the dead leaves with a sound similar to that produced by falling hail. If the winter is an open one, with alternate periods of thawing and freezing, many of them doubtless perish. On the first warm dars of spring they can be collected by hundreds from any grasscovered hillside having a sunny southern exposure, or from sandy places along the margins of lakes and streams.

Allard (1916) has aptly deseribed their habits thus: "Smallest of all the Acridiide and among the most interesting are the odd-shaped grouse-locusts. These tiny creatures, which leap almost as actively as fleas, are exceedingly difficult to discern in their natural environment of earth and dead regetation. As one sweeps a net over the surface of the dry leaves in the woods there is an audible rustling as the tiny creatures hop about very much like tiny toads. At rest, their odd little bodies and sombre hues of grays. yellows and browns assimilate them perfectly with the mottled carpet of dried leares, grasses, pebbles, bits of dead bark and woods among which they dwell."

Hancock (1902) has also written entertainingly of their habits as follows:

"The jump of the grouse locust is peculiar in that it is quick and inconspicuous and in this that it alights almost invariably on the ground The young of the larger Orthoptera usually alight on grass or stems of plants, dodging behind them for protection. The remarkable color of these little Tetrigians, harmonizing in every instance with the soil, makes 
it sometimes difficult to locate them. This protective resemblance is carried out to perfection, the little insects living on the soil scattered with debris faded out by the hot sun, and the lights and shadows, in whatever way they play, are copied exactly. No shade, color or arrangement of markings seems impossible of simulation, and every individual is a study in color harmony.

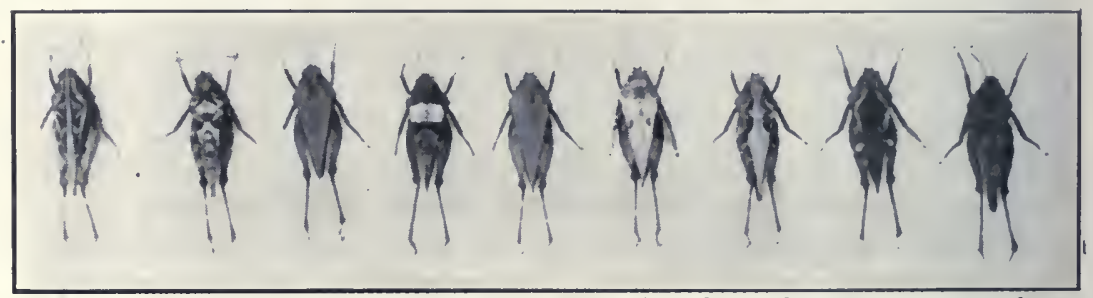

Fig. 59. Showing variations in the color of the short form of a common grouse locust, Acrydium ornatum Say. (After Hancock.)

"The grouse locusts feed upon the vegetable mold or decomposing soil sometimes mixed with algæ, or on the lichens, mosses, tender sprouting grasses, sedges, germinating seeds of plants and debris found in such situations. Farticularly sought-after morsels are the various colored surface clays and the black muck, consisting of rich vegetable mold. They are ravenous eaters, as one might infer from the dietary list just mentioned, and the fecal excrement, on reaching the end of the abdominal appendages, is thrust away from the body by a rapid kick of the hind tibia.

"In the middle of May (Illinois) the first eggs are laid in the ground, the female accomplishing this act by making a shallow burrow with her ovipositor. The young larvæ, hatched from this brood, mature by fall, passing the following winter in the adult state. The broods hatched in late June and early July are often immature by the time winter arrives, and we find them hibernating in the pupal state. Thus it is that the Tetrigidæ are about the earliest insects to be found in the spring, appearing as early as March. The time of incubation varies with the temperature, the early broods of Acrydium (Tettix) hatching in twenty-three days, but as the days become warmer this period is shortened to sixteen days. The numker of eggs of Acrydium and Paratettix vary considerably, but there are more often ten, thirteen or sixteen in each burrow; in Tettigidea varying from twelve to twenty-six.

"During the life of these little Tetrigians they are more or less constantly in danger of enemies among the arachnida, insecta, and some of the vertebrata. The larva of a red mite (Trombidian) is one of the most frequent sources of annoyance. Acting as a parasite the Trombidian larva clings on the body and attaches itself out of the reach of the victim. There it remains to sap the juices of the host's body. It is found on many species. Among insect pests, ants and bugs are sometimes deadly to them. In a wet ditch in June the writer found a number of small, dark-brown ants dragging along the ground a female Acrydium ornatum which had just been killed by them. When endeavoring to capture some grouse locusts at the same place my attention was drawn to a colony of these ants 
acting in a panicky state of excitement, the cause of this being that they had darted upon the insect the author was pursuing, tumbling it over and biting it saragely about the neck. The little locust finally escaped by a vigorous jump.

"According to P. R. Uhler, (1884) Galgulus oculatus, a true bug, is a serious enemy. 'This insect may often be seen,' says Uhler, 'in the month of May walking about between the stones on the low banks of brooks and streams, where Tettix and Batrichidea abound, watching an opportunity to seizc one of these insects, and when the favorable moment arrives, leaping suddenly upon one of them, clasping it with tight embrace between the front femora and tibiæ and then sucking out its vital juices.' Toads, fishes and birds also feed upon them when opportunity offers."

The Tetrigida are widely distributed over the earth, many of the tropical species having the pronotum strongly compressed and bearing a resemblance to the dried leaves among which they live on the ground, while some have it extremely rough, or even spiny to aid in imitating their natural surroundings. In his principal treatise on the group (1906) Hancock recognized 98 genera and 434 nominal species as known at that time. Of these 21 genera and 99 species had been previously (1902) deseribed by him as inhabiting North and Central America, Mexico and the West Indies. While several valid species have since been described from this country, a number of those recognized by Hancock have been proven to be mere races or varieties of the older known species, so that in the present work only seven genera, 16 species and eight varieties are recognized as occurring in the Eastern United States and Canada. These represent but two of the nine sections or subfamilies of Hancock (1906).

The principal literature treating especially the North American species of Tetrigide is as follows: Bolivar, 1857; Morse, 1894, 1894a, 1895, 1899, 1900 ; Hancock, 1896, 189S, 1898a, 1899, 1900, 1902, 1906, 1909, 1918; Rehn of Hebard, 1916; Hebard, 1919.

$$
\text { KEY TO EASTERY SUBFAMILIES OF TETRIGID } \mathrm{E}^{30}
$$

a. Antennæ with 12 to 14 joints; front femora more or less compressed and carinate above; pronotum with dorsal front margin subtruncate (Fig. 2b) rarely (Nomotettix) angulate- produced forward. (Fig. 1d.)

I. Tetrigine, p. 155.

aa. Antennæ with 20 or 22 joints; front femora distinctly and broadly grooved or sulcate above; pronotum with front dorsal margin rounded or angulate-produced over the head (Fig, 5.)

II. BatrachidiNe, p. 179. ${ }^{30}$ All Figures below 6 cited in this key, and on the succeeding pages treating of this
family, refer to those of Plate II. 
PI.ATE II.

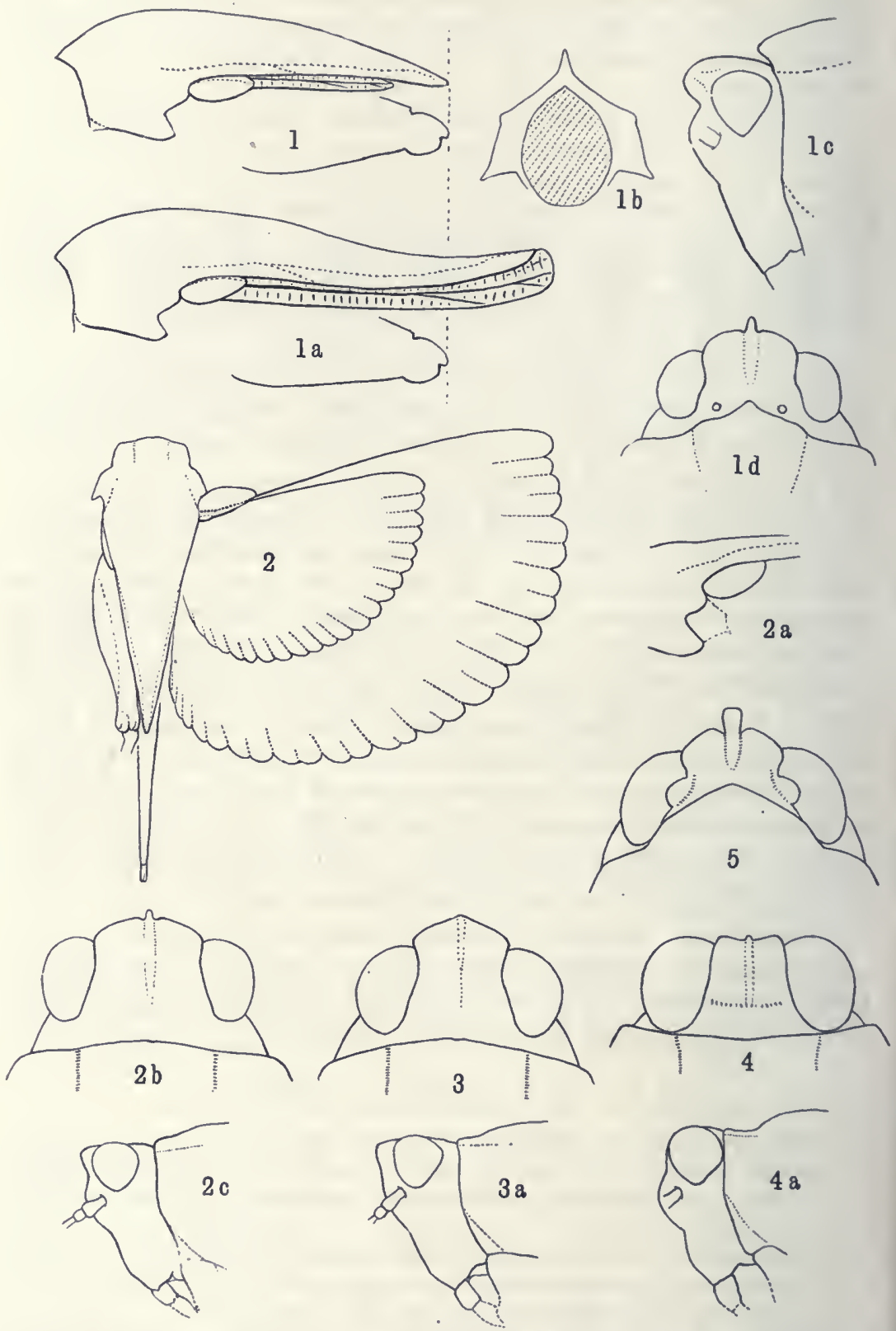

Plate I1.-Fig. 1. Nomotettix cristatus (Scudd.), side view of pronotum of short form; $1 a$, side view of same, long form; $1 b$, cross section; $1 c$, profile of head; $I d$, bead and front margin of pronotum from above. Fig. 2. Acrydium ornatum Say, combination figure to show from above outlines of pronotum and wings of both long and short forms; $2 a$. showing sinuses of hind margin of lateral lobe; $2 b$. head from above; $2 c$. profile of head. Fig. 3. Acrydium granulatum Kirby, head from above: $3 a$, profile of head. Fig. 4. Paratettix cucullatus (Burm.), head from ahove; $4 a$. profile of head. Fig. 5. Tettigidea lateralis parvipennis (Harris), head from above. (After Morse.) 


\section{Subfamily I. TETRIGINE.}

In addition to the characters given in key the members of this subfamily differ from those of Batrachidina in having the body much more slender; ridges of frontal costa more or less divergent or forked above the ocellus; antenna inserted opposite the lower border of eyes; pronotum more tapering, less tectiform, more often granulate, but usually less rugose, its median carina usually higher, often cristate; hind tarsi with first segment distinctly longer than third. Five genera are recognized as being represented in our territory.

\section{KEY TO EASTERN GENERA OF TETRIGIXA.}

a. Vertex more or less produced forward beyond the front of eyes, viewed from above distinctly wider than one of them, its front margin angulate or rounded, not truncate (Figs. $2 b, 3$ ); dorsal surface of pronotum usually tectiform or sloping between the shoulders.

b. Ridges of frontal costa but feebly forked; front dorsal margin of pronotum when truncate not advanced upon the head to the eyes (Figs. 2b, 3); front of vertex, viewed from the side, angulate or subrounded.

c. Pronotum with its median carina raised in the form of a crest and more or less arched lengthwise, its dorsal front margin produced in an angle over the back of head (Figs. 1, 1d); teg. minal or upper notch of lateral lobe of pronotum only about one-half as deep as the lower one; posterior process of pronotum usually much abbreviated (Fig. 1.) I. Noмotertix, p, 156.

cc. Pronotum with median carina low, not arched, its dorsal front margin truncate or very obtuse-angulate (Figs. 2b, 3); hind margin of lateral lobes strongly bisinuate, the tegminal sinus usually nearly as deep as the lower one (Fig. 2a.)

II. ACRYDIUM, p. 161.

$b b$. Ridges of frontal costa with their lower halves widely divergent or forked; front dorsal margin of pronotum advanced upon the head to the eyes; vertex usually much wider than one of the eyes, its front, when viewed from the side, distinctly rounded.

III. NeOTETTIX ${ }^{s i}$, p. 171.

aa. Vertex not at all or barely advanced beyond the eyes and usually narrower than one of them, its front margin truncate or nearly so; dorsal surface of pronotum convex between the shoulders, its front margin reaching the eyes, (Fig. 4.)

d. Frontal costa, in profile, feebly but distinctly sinuate in front of eyes (Fig. 4a); vertex truncate, narrower than or subequal in width to one of the eyes (Fig. 4), its frontal carinulæ interrupted

${ }^{31}$ After examing the tyre of Neotettix proazus R. \& H. at Philadelphia and taking into consideration the fact that the long-winged form mentioned by Fox (j918) had the hind margin of pronotum bisinuate, I follow Hebard (1919) in making the genus Car'o-
tettir Hancock (1918), a synonym of Neotetir. 
by the median carina but not reflexed backward at middle; antennæ 14-jointed, inserted distinctly below the eyes; pronotum granulose, rarely finely scabrous.

IV. Paratettix, p. 175.

dd. Frontal costa not at all sinuate; vertex subtruncate, in female dis tinctly wider than one of the eyes, its frontal carinulæ open in front on each side next to the median carina and curved or reflexed backward; antennæ 13 -jointed, inserted scarcely below the eyes; dorsal surface of pronotum distinctly rugose.

V. Apotettix, p. 178 .

\section{Nomotetтix ${ }^{32}$ Morse, 1894a, 150. (Gr., "pasture" + Tettix.)}

Small feebly compressed species, having the front of rertex rounded or slightly angulate and distinctly advanced in front of eyes, carinate, the occiput usually with a yair of minute tubercles behind the middle of eyes (Fig. 1d); antenna short, filiform, with 12, rarely 13 segments; frontal costa deeply sulcate, usually sinuate opposite middle of eyes, its ridges acute, subparallel; pronotum as described in key, its lateral lobes bisinuate behind, the tegminal sinus shallow, the lower one much deeper; tegmina narrow, their tips obtuse; hind femora large, swollen, basal joint of hind tarsi longer than the next two united.

Nine or ten nominal species of this genus have been described from the Eastern United States and Canada, but Rehn \& Hebard (1916, 127) have stated that a study of 458 specimens "offers convincing proof that but one species of Nomotettix exists in this portion of North America. ${ }^{33}$ This species is divided into five geographic races which are typical over certain areas but which intergrade so gradually that series of specimens from numerous localities between those where the typical forms are found, show intermediates of every degree." Typical examples of all of these so-called races are before me and a careful study of them. with the keys and descriptions of both Hancock and R. \& H., show that they possess no fixed character's by which they can be satisfactorily separated by any key. I regard one of them, arenatus, as only an intermediate or intergrading form and three of the others as only geographic forms or races of the first named species, but retain their names as trinomials in order that the student, if he so desires, may use the racial name in the placing of his specimens.

${ }^{82}$ The suffix "tettix" used as a part of most of the generic names in this family, is the Greek for "grasshopper."

${ }^{\circledR}$ They evidently did not take into consideration $N$. parvus Morse (1895, 14) and $N$. sinuifrons Hancock $(1899,278)$, both of which were described from St. Anthony Park, Minn. The former species is probably valid and, according to Somes (1914, 10) bas been taken at several localities in Minnesota. Since its known range is extralimital it is not farther considered in this work. $N$. sinutrans is the same as E. M. Walker's borealis and is treated below as a race of $N$. cristatus, Hancock's name having priority. 
64. Nomotetrix cristatus (Scudder), 1862, 478. Crested Grouse Locust.

Grayish or fuscous brown, the disc of pronotum often ornamented with one or two triangular velvety black or black and white spots. Vertex nearly twice as wide as one of the eyes and extending in front of them, its front border broadly rounded or more or less obtuse-angulate, median carina prominent. Frontal costa deeply sinuate opposite middle of eyes. Pronotum with front dorsal margin advanced in an angle over the head sometimes to the posterior third of eyes; median carina strongly crested and arcuate. In the shorter and more common form the pronotum ex. ceeds but slightly the tip of abdomen and the wings do not reach its apex; in the long form the pronotum extends $2-3 \mathrm{~mm}$. and the wings $3-4 \mathrm{~mm}$. beyond the tip of abdomen. Length of body, short form, $\hat{\delta}, 7.7-9$,, , S.C-10.2; of pronotum, $\hat{\delta}, 7.1-8.5, \rho, \delta-9.5$; of hind femora, $\delta, 4-6$, ․, $5-6 \mathrm{~mm}$. Length of body, long form, $\hat{\jmath}, 11-11.5$,,$+ 11-12.5$; of prcnotum, $\hat{o}, 9.5-10.7$, $9,9.8-11.5$; of hind femora, $\hat{o}$ and $ᄋ, 5-5.3 \mathrm{~mm}$. (Fis. 1.)

Yortlı Madison, Conn., Aug. 17 (IV. S. B.). Bererly, Mass., April 24 (Morse). This, the typical form and genotyle of Tomotettix, was described from Massachusetts and ranges from Ontario and Nova Scotia throughout New England, New York and northern Pennsylvania soutl to Mt. Pisgah. N. Car. In New England Mor'se (1S94a, 15\%) states that "it is found everywhere on light soils, but especially in dry pastures and other wild land sparsely covered with a scanty growth of curling tufts of Danthonia grass, scraps of Cladonia lichens and the leathery leaves of Antennaria. It is perhaps somewhat more plentiful in the damper portions of such localities, but differs much from the other species of the subfamily Tetrigina in this particular, the others preferring soils perpetually moist or even the shores of lakes and streams." Batrachidea carinata Seudder $(1862,479)$ is a name given the long winged form of typical cristatus (Fig. 1 a), and is rery scarce, but one or two to the hundred of the short form being found by Morse in Massachusetts.

64a. Nomotettix CRistatus compressus Morse, 1895, 15. Western Crested Grouse Locust.

Typical examples of this race or form differ from typical cristatus in having the front margin of pronotum projecting more strongly orer the head and the median carina a little higher, more strongly compressed, more evenly curved and often so thin in section that, when held against the light, the punctuations of its surface appear translucent. Length of body, $\hat{\delta}, 7.5-8.4,9,8-9.5$; of pronotum, $\hat{\delta}, 7.3-7.8$,., $8-8.8$; of hind femora, $\hat{o}, 4.3-6$, ㅇ, $5-6 \mathrm{~mm}$.

Originally described from North Carolina, this race or form 
of the crested grouse locust is known from sonthern New Jersey and eastern Pennsylvania west to Michigan and Illinois and south to Georgia. It is the only form of Nomotettix known from Indiana where it probably occurs throughont the State. In the sonthern counties it makes its home on semi-barren rocky ridges and the sides of dry sunny banks in pastures where the grass is scant or has been cropped short, and where the species of "everlasting" (Antennaria and Anaphalis), delight to grow. In such places it may be taken by the score in late antumn or early spring. At Dune Park, Porter Co., it lives, says Hancock (1902, 59) "on dry sandy soil, lightly covered with fragments of twigs, leaves, and rarious fine debris accumulated from past seasons. Among the sand dunes it frequently seeks retreat in the clumps of prickly pear cactus on mossy covered ground slightly sheltered by trees. It is a curious little species, and though sometimes quite common locally, it requires the exercise of tact on hands and knees to capture the sprightly little insects. In the cool October mornings they do not appear to jump far, but as the sunlight warms the ground they become more active. Some are then in the last pupal stage, but the majority are adult."

But three specimens of the long form, atavus Blatchley (1903, 219) have been taken among the hundreds of short-winged ones collected in Indiana, a male in Vigo county and a female in each of Lake and Perry counties. On account of the greater length of the pronotum, its median crest does not appear so prominent nor so strongly arched in the long form as in the more common one.

Morse, in his notes following the original description of $N$. compressus, doubted its validity, and R. \& H. and Hancock have showns that it merges and intergrades with cristatus so that at most it must be considered as only a geographic race.

64b. Nomotettix cristatus floridanus Hancock, 1902, 64. Florida Crested Grouse Locust.

As represented in southern Florida, this race differs from typical cristatus mainly in its distinctly more prominent eyes and much more ru gose surface of pronotum. The vertex, viewed from the side, is slightly more acute-angulate, the median carina of pronotum a little less elevated and the tegmina notably smaller. Length of body, $\hat{\delta}, 6.8-7.2$, o, $7.8-$ 8.2 ; of pronotum, $\hat{\delta}, 6.5-6.8, \uparrow, 7.5-7.8$; of hind femora, $\hat{\delta}, 4.1-4.4$, $\&$, $4.7-5.2 \mathrm{~mm}$.

Port Orange, Fla., June 5 (Hancock's type) ; Sarasota. Sanford, Jakeland, LaBBelle and Dunedin, Fla., Nor. 9-April 5 
(W. S. B.) ; Tifton, Ga., June 6 (type of N. arcuatus). A comparison of the types of both $N$. floridanus and $N$. arcuatus shows little appreciable difference, except in the less rugose surface of the pronotum and slightly more curved median carina of the latter. R. \& H. $(1916,133)$ state that floridamus "was founded merely on an intensification of the characters which constitute the race arcuatus," and that floridamus is "known only from southern and central Florida, in the northern part of its range, gradually intergrading with arcuatus." Since floridanus has page priority I have dropped the name arcuatus, the form to which it has been referred being only a connecting link or intermediate form between the southern race floridanus and typical cristatus, and, quoting R. \& H. $(1916,151)$, "the uselessness of a name for intermediates between weakly defined geographic races does not require comment.". Were no intermediate forms known, the examples from central and southern Florida are sufficiently distinctive in their larger eves and strongly rugose pronotum to have specific rank.

A single male of $N$. $c$. floridunus with caudate or long pronotum was taken near Lakeland, Feb. 16, 1919, and is the first long form of this race to be recorded. In color it is pitchy black with a small white spot on each shoulder. The tip of the pronotum extends $2 \mathrm{~mm}$. beyond the hind femora and is surpassed $.8 \mathrm{~mm}$. by the folded inner wings. Is in $Y$. c. compressus the long pronotum with apparently lower, less curred crest gives it a vers different facies from the short fornu.

In addition to the localities given the race floridanus has been recorded by $\mathrm{R}$. \& $\mathrm{H}$. under that name from Iakeland, Ft. Myers, and LaBelle, Fla. (1914d), and as arcuatus from Jacksonville, Baldwin, Atlantic Beach and Live Oak $(1916,132)$. They record the race arcuatus Hancock also from North and South Carolina, Georgia and Mississippi. while under the name Tomotettix cristatus denticulatus it was described and recorded br Morse (1906, 119) from Oklahoma and Texas. Scudder (1STTa, 90) recorded Batrachidea cristata from Ft. Reed, Fla., his specimens probably representing the race florillamus.

About Dunedin N. c. floridanus occurs in numbers from Norember to April, perhaps throughout the year. in the low grasses and other regetation along the sandy margins of ponds or small lakes, its habitats being much more hygrophilous than those of the northern forms cristatus and compressus. It seems also to rary more in color than does compressus in Indiana, a number of the 
specimens taken near Dunedin being a uniform pitclyy black, while several of them have a large white saddle-shaped blotch across the middle of the pronotum. Others are grayish-white with a pair of relvety black spots in front of humeral angles and another larger pair behind them. That the intermediate form, hitherto known as arcuatus, has a similar love for moist surroundings is shown by R. \& H., who state that in North Carolina and Georgia "it was widely distributed and sometimes abundant in the undergrowth of the long-leaf pine woods, particularly where the ground is low, sandy and water-soaked. It has also been found abundant in low spots covered with short green grasses in the midst of saw palmetto flats."

64c. Nomotettix cristatus sixuifroxs Hancock, 1899, 278. Northern Crested Grouse Locust.

This northern form or race differs from cristatus in having the vertex projecting a shorter distance in front of eyes, its median carina less prominent and when viewed from the side, the angular excavation of the frontal costa above the bases of the antennæ more shallow. Antennæ one-fourth shorter than in cristatus; eyes slightly more prominent. Pronotum more rugose-scabrous and with front margin less projecting over the head. Length of body, $\$, 8.5$; of pronotum, 8; of hind femora, $5-5.6 \mathrm{~mm}$.

A comparison of Hancock's type of $N$. sinuifrons taken at St. Anthony Park, Minn., and a cotype of $N$. borealis E. M. Walker (1909, 173) shows them to be the same as surmised by Hancock (1918), the only erident difference being the slightly wider vertex of the former. N. borealis was deseribed from two females taken on the shore of Diamond Lake, 'Temagami District, Ont., Sept. 7, 1908 , and has not been recorded elsewhere. They were found in company with Acrydium acadicum (Scudder), on a strip of dry, sandy soil along the border of a sphagnum bog, and separated from the lake proper by a narrow ridge a few feet in height covered with serub pine and blueberries. Outside of Minnesota the only record for N. sinuifrons under that name is by Smith (1910, 178) from Lakehurst, N. J.

In addition to Nomotettix cristutus Scudder and its races, described above, I have examined, through the kindness of Dr. Han. cock, the tyjes of Nomotettix validus and $N$. arcticus Hancock $(1909,415)$. These undoubtedly represent the short and long forms respectively of a Nomotcttix very distinct from $N$. cristatus. However, the exact locality at which they were taken is a matter 
of doubt, as they formed a part of the W. W. Saunders collection purchased by Mrs. F. W. Hope and presented by her in 1873 to the University Museum, Oxford, England. They were labelled briefly "Amer. b.," which R. Shelford, Curator of the Museum, interpreted to Hancock as "North America." Dr. Hancock states (Ms.) that they are "probably from the eastern part of Canada in the neighborhood of Hudson Bay, judging from other material examined at the same time." A brief comparatire diagnosis of the species is therefore included as follows:

(—). Nomotetrix ralidus Hancock, 1909, 415.

Stouter than $N$. cristatus. Dark gray, the median crest of pronotum in the type dull yellow. Vertex with front margin obtuse-angulate, more strongly produced in front of eyes than in cristatus, its median carina slender, more elevated, continuous with the frontal costa, the latter not excavated or concave between the eyes as in cristatus, its branches narrow, distinctly divaricate, nearly as much so as in Neotettix. Pronotum with front dorsal margin more obtuse and less produced forward than in cristatus. Median carina lower and less arched than there;posterior process acute, reaching almost to tips of hind femora; tegminal sinus almost obsolete, lower one wide, rather deep, the lobe between them evident only as a convexity of the hind margin. Length of body, short form, $\$, 11$; of pronotum, 8.8; of hind femora, $6.5 \mathrm{~mm}$. Long form, length of body, $\%, 13$; of pronotum, 11.5; of hind femora, $5.5 \mathrm{~mm}$.

Two females, with origin as above given, were described by Hancock. I consider lis $\mathrm{N}$. arcticus only the long form of validus. The body is more slender, but the characters of rertex, frontal costa, etc., are the same.

\section{Acridiun Geoffroy, 1764, 390. (Gr., "a locust.")}

This genus, which replaces Tetrix Latreille (1802), (Tettix Charp., 1841 of most authors). comprises those grouse locusts having the rertex wider than one of the eres, and distinctly produced in front of them (Figs. 2b, 3), its front margin either subacute, subangulate or rounded, carinate at middle; antennse often shorter than head, 12- to 14-jointed, nerer reaching the shoulders; pronotuni more or less rugose-granulate, with median carina usually distinct but not arched or raised as in Yomotettix. front margin truncate or feebly angulate, posterior process acute, very often abbreriated, the apex reaching the end of abdomen in short forms and usually extending much beyond it in long ones of the same species; hind femora swollen but more slender than in Nomotettix; hind tibix feebly enlarged near apex, their carine short. spinose; first joint of hind tarsi distinctly longer than third. 
Hancock (1906) lists 49 nominal known species, 17 of them from North America, but a number of these are now known to be only long- or short-winged forms or geographic races of the same species, only five valid species and three races or varieties being recognized from our territory.

\section{KEY TO EASTERN SPECIES OF ACRYDIUM.}

a. Median carina of pronotum more or less distinctly elevated along its entire length; dorsal surface of pronotum higher in the middle, sloping on the sides, more or less rugose or wrinkled as well as granulated; sides of vertex sinuate, its disc therefore feebly narrowed opposite the middle of eyes.

$b$. Front of vertex, viewed from above, obtusely angulate, its median carina not projecting beyond the sides (Fig. 3.)

c. Body very slender, the pronotum relatively narrow between the shoulders and posteriorly attenuate; frontal costa, viewed from the side, very slightly sinuate between the eyes; upper or tegminal sinus of lateral lobes nearly as deep as the lower one.

65. GRANULATUM.

cc. Body stouter, the pronotum much broader between the shoulders, much less attenuate but acute posteriorly; frontal costa viewed in profile distinctly sinuate between the eyes; tegminal sinus obviously more shallow than the lower one.

66. BRUNNERI.

$b b$. Front of vertex, viewed from above, convex or rounded, its median carina distinctly projecting as a small tooth beyond the sides (Fig. 2b.)

d. Median carina of pronotum not elevated or compressed and curved between and before the shoulders; frontal costa but slightly sinuate between the eyes; form more slender.

67. ORxATUM.

dd. Median carina of pronotum between and before the shoulders obviously more elevated, compressed and more or less curved; frontal costa distinctly concave or sinuate between the eyes; form more robust.

$e$. Tegminal sinus almost as deep as the inferior one; middle femora enlarged, in male nearly one-half as wide as long; pronotum more slender, in short form distinctly surpassing the tips of hind femora. 67a. IrAxсоскI.

$e e$. Tegminal sinus much more shallow than the inferior one; mid. dle femora three times or more as long as wlde; pronotum broader and shorter, in the short form scarcely reaching the tips of hind femora.

68. ACADICUM.

aa. Median carina of pronotum Indistinct, not at all or very little elevated; dorsal surface of pronotum flat or nearly so, the surface

st Hancock (1909, 414) described Tettix (Acrydium) americana and its short form dimorpha from specimens in the Oxford (England) University Museum. Since their original locality is in doubt, heing designated only as "Amer. b.," they are not consid. ered in this work. 
granulated, rarely rugose; sides of vertex subparallel, its disc not narrowed opposite the middle of eyes.

g. Pronotum granulose, its lateral carinæ only moderately compressed, its dorsal surface not suddenly strongly narrowed behind the shoulders; oblique ridges of hind femora feeble.

$h$. Body rather slender, the posterior portion of pronotum prolonged, acute; vertex distinctly depressed in front; eyes prominent; frontal costa feebly sinuate, narrowly sulcate. 69. ARExosuM.

$h h$. Body more robust, the pronotum less prolonged posteriorly (Fig. 62.); rertex but little depressed in front; eyes of medium size; frontal costa, viewed from the side, distinctly sinuate between the eyes.

69a. oвscurum.

gg. Pronotum rugose-granulose, its lateral carinæ decidedly compressed and dorsal surface strongly narrowed behind the shoulders; oblique ridges on outer face of hind femora strong.

69b. BLATCHLEY.

65. Acrydum graxulatum Wm. Kirby, 1837, 251. Granulated Grouse Locust.

Body, especially that of male, very slender. Color variable, usually wholly grayish or reddish-brown, sometimes blackish; pronotum often with a median yellowish band along the full length, rarely with irregular brown or black spots preceded by a white or cream-colored saddle-like marking. Surface of pronotum and legs finely granulated; the dorsal surface of the former also rugose with numerous very short ridges or tubercles. Vertex as described in key, its front border considerably advanced in front of eyes; face very oblique; eyes small. Pronotum with front margin truncate, posterior process attenuate, the apex acute, passing the hind femora $2-4.5 \mathrm{~mm}$.; median carina prominent throughout but not crested. Wings reaching to or slightly beyond tip of pronotum; in life bluish or bottle-green in color. Length of body, $\hat{\delta}, 8.5-13.5$; 오 , 11-15.3; of pronotum, $\hat{\delta}, 8-11.5$,,$+ 12-13.5$; of hind femora, $\hat{\delta}, 6$, 우, $7 \mathrm{~mm}$. (Fig. 60.)

Lake, Porter, Fulton, Marshall, Marion and Franklin counties, Ind., Feb. 20 -Oct. 7 ; LaSalle Island and South Haren, Mich., June 1-July 29 (W. S. B.). Doubtless occurs throughout Indiana, but much more abundant in the northern portion, as it

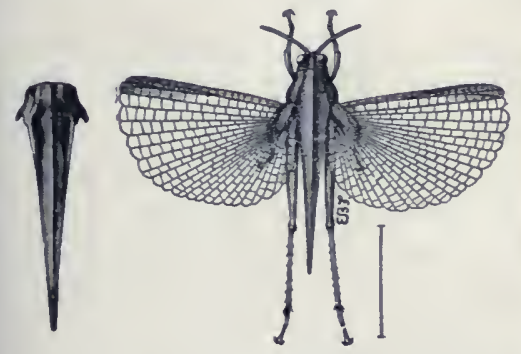

Fig. Co. Male. $\times 2:$ pronotum of two color varieties. ranges from Nova Scotia and throughout $\mathrm{New}$ England westward to the Pacific and northward through British America, Kirby's unique type having been taken in Lat. 65 degrees. It is not recorded south of New Jerser, southern Indiana and Kansas. 
This slender grouse locust has an especial liking for marshy and boggy tracts about the margins of lakes and tamarack swamps, though it is likely to occur anywhere in low wet woods, and one specimen was taken in Marion County April 15, while swimming on the surface of a woodland pond. It is sometimes, however, found in dry localities as Somes $(1914,11)$ records noting a colony in a sandy. cultivated field in Iowa, at least a mile from any stream or body of water, where they were feeding upon the tender stems of young grain. In Vigo Co., Ind., it was found hibernating February 20 beneath logs along the sandy border of a large river-bottom pond. The light band along the middle line of pronotum is in a high degree protective when the locusts dwell among the grasses and sedges of marshy tracts, as it harmonizes with the dried blades of these plants.

Hancock $(1902,72)$ records the finding of gramulatum in Wisconsin on the ground "about prostrate tree trunks, which were molding in decay and covered with greenish lichens and mosses. The yellowish and brownish fallen leaves were everywhere scattered over the bed of the forest. Occasionally, when the wind was not blowing, I was able to mark the presence of the little locusts by the sonnd made as they jumped upon the dried leaves." Morse (1894a, 163) says that "in New England this species prefers sedgy meadow lands and swales on sandy soil oceasionally flooded by rains or freshets and perpetually moist. The bulk of my specimens were taken on a boggy swamp which had been filled in with sand, and on which water stood more or less of the time." Baker fonnd gramulatum hibernating beneath stones at Ft. Collins, Col., while in Michigan Hebard took it in early July about marshy spots on logging trails where they were very active, springing several feet when flushed. Scudder (1S9Se) states that it has several times been taken close to the summit of Mt. Washington and occurs everywhere in New England.

A form with the pronotum and wings more or less abhreviated is occasionally found with the common form of gramulatum. 'To it Hancock has given the varietal name varicgatus. ${ }^{35}$ Tettix Inygeri Hancock $(1897,109)$, recorded from Minnesota and Illinois, is a synonym of granulatmm. It was distinguished only ly having the front border of vertex convex instead of obtuse-angulate, and both Hancock $(1902,73)$ and Somes $(1914,11)$ record the finding

${ }^{2}$ Another form with wider pronotum, the incurvata IIancock, described from Wash-ington, Colorado and New Mexico, is listed by Morse (rgrg) from Northern New Eng. land as a variety of granulatum. Its status is as yet uncertain. 
of numerous intermediate connecting forms. T. morsei Hancock $(1899,280)$ is also a synonsm, as noted by its author $(1906,58)$.

66. ACRYdiUM BRUXYeri (Bolivar), 1887, 266. Brunner's Grouse Locust.

Body broad, granulate; fuscous or dark brownish-yellow, often with two black spots on pronotum. Vertex twice as wide as one of the eyes, strongly advanced in frout of them, its front margin obtuse-angulate; sides broadly emarginate opposite the middle of eyes, the vertex, therefore, broader in front of the emargination. Pronotum with front margin truncate, nearly reaching hind border of eyes; posterior process acute, scarcely reaching apex of hind femora (short form) or distinctly surpassing them in the long form, caudata Hancock $(1906,59)$; median carina distinct but low. Tegmina elongate-oval, their tips rounded; wings equalling or slightly surpassing the apex of pronotum. Length of body, short

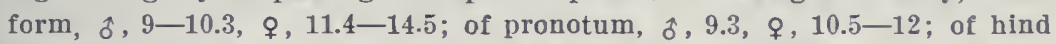
femora, $\hat{o}, 5-6, \uparrow, 6-6.6 \mathrm{~mm}$. Long form, length of body, 15.5; of pronotum, 13.8; of hind femora, $6.2 \mathrm{~mm}$.

Isle Royale and Porcupine Mts., Mich. (Hubbell) ; Kaslo, B. C. (Caudell). Known only from Canada, Michigan and the North. western United States. Bolivar's types were from Hudson Bay. E. M. Walker $(1909,174)$ has recorded it from Temagami Falls and Algonquin Park, Ontario, the single specimen from the former locality heing a macropterous male, having the pronotal process extending $4 \mathrm{~mm}$. and the wings $4.7 \mathrm{~mm}$. beyond the tips of hind femora. It was found Sept. 2 in a small opening on a portage through a forest of mixed white pine, spruce, balsam, canoe birch, etc. The pair at hand from Michigan seem to be intermediate between the brachypterous and macropterous forms, the pronotum in both slightly surpassing the hind femora, in the male br about $2 \mathrm{~mm}$. The specimens from the Hancock and U. S. National Museum collections were taken by Caudell at Kaslo, B. C., July 2-Aug. こ, and are all brachypterous. Hancock $(1902,76)$ records it from Oregon, Green River, Wyoming and Tennessee Pass, Colorado. Tettix tentatus Morse $(1899,200)$ is a synonym.

\section{Acrydium orxatum Say, 1824, 10. Ornate Grouse Locust.}

Size medium, form slender. Color extremely variable, usually dark grayish, sometimes rusty brown ol fuscous; often ornamented with two or four irregular velvety brown spots on dorsal surface of pronotum, more rarely a large whitish spot in front of these; hind femora often with one or two white blotches on the outer face (Fig. 59.) Surface of pronotum and legs everywhere finely granulate; posterior half of pronotum usually rugose with numerous short, oblique wrinkles or ridges. Vertex as described in key, its front border distinctly projecting in front of eyes. Pronotum variable in length, in the long form less prolonged backward 
than in granulatum, its dorsal front margin truncate; median carina distinct but not as high as in granulatum. Inner wings fully developed, extending slightly beyond apex of pronotum (Fig. 2.) The short form, T'ettix triangularis Scudder $(\mathbf{1 8 6 2}, 475)$ appears somewhat stouter, due to the abbreviated pronotum which is more acute and reaches only the tips of hind femora, while the wings do not extend beyond its apex (Fig. 2.) The two forms have been proven by Hancock to interbreed and the measurements intergrade, the following being the extremes. Length of body ô, $8.5-12.5$, ㅇ, $9-13.5$; of pronotum, ô, $7.5-10.5$, 오, 8-12; of hind femora, ô, $4.5-5.5$, ᄋ, $5-7 \mathrm{~mm}$. (Fig. 59.)

The ornate grouse locust is a common species throughout Indiana, and may be found any month in the year, but is most abundant in late autumn and early spring, occurring then usually along the edges of dry open woods and on gravelly hillsides, while in summer it is occasionally found in company with Paratettix cucullatus (Burm.) about the borders of streams and ponds. It sometimes makes its home in grassy plots and lawns, especially those which are wooded, in the outskirts of cities, and is then often seen sunning on the cement and other sidewalks along their margins. The form triangularis more often occurs in sandy localities, and in some places far outnumbers the typical form.

On a bright sunny afternoon in late Norember, I once found both forms of ornatum very common on a sloping hillside two miles north of Indianapolis. A clover field was here adjoining an open woods pasture, and the second crop had been cut in October for the seed. Many of the dead stalks had fallen close along the fence row separating the fields, and here the little locusts were in abundance, their bodies all grayish-brown, and corresponding very closely to the dead clover stems; so closely, indeed, that they were not visible until they hopped, and then had to be "marked down" before they were captured. Beneath the bottom rails of the old fence they had found a comfortable abiding place and winter retreat, and on this bright afternoon had been tempted forth to bask in the sunlight and perchance to feed npon the green clover leaves which were yet abundant in places among the dead and fallen stems.

A. ornatum ranges from New England and Ontario west to Alberta and Colorado and south and southwest to North Carolina, Tennessee, Mississippi, Texas and New Mexico. It is recorded by Scudder from the summit of Mt. Washington, and in the northern states is often found in company with Nomotctix cristatus and Acrydimm granulatum, though usually preferring dryer localities than does the latter species. 
A study of the type and other specimens of Tettix crassus Morse $(1899,201)$ from both the Morse and the U. S. National Museum collections, shows no characters sufficiently distinctive to separate it from ornatum. Three of the specimens labelled crassus from the National Museum collection I regard as only slender bodied males of the long form, or typical ornatum, one of them, from Constantine, Mich., having been determined by Hancock, and furnishing the basis for his Michigan record of crassus $(1906,59)$, which is the only record from the eastern States, it having been described from Colorado and recorded from British Columbia, Nebraska, New Mexico, Missouri and Kansas. Morse agrees with me, not only in making crassus a synonym of ornatum, but in reducing his hancocki to varietal rank.

67a. Acrydum orvatum Haxcocki (Morse), 1899, 200. Hancock's Grouse Locust.

A variety of $A$. ornatum Say, with which it agrees in color, granula. tion and rugosity of surface, but differs in its more robust form, with wider and slightly more projecting vertex, and "notably in the enlarged middle femora, the expanded portion of the latter in the male being neary or quite one-half as broad as long (in ornatum seldom more than onethird), the difference less noticeable in the female." Pronotum with humeral angles more pronounced and mid-carina slightly more elevated in

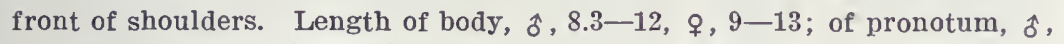
8.5-11, ․, 8-12; of hind femora, $\hat{o}, 5$, ㅇ, 5.5-6 $\mathrm{mm}$.

Marshall, Marion, Vigo and Crawford counties, Ind., May 20Nov. 3 (W. S. B.). Morse's cotypes were in part from Vigo County. Ranges from Montreal west to Saskatchewan, and widely distributed in the Upper Austral and Transition zones of the U. S., west to Colorado and south to North Carolina, Tennessee and Central Arkansas, occurring most generally on moist upland soils of sandy texture, especially on high elerations. In Indiana it frequents the same localities as $A$. ornatum. the two being often found in company. Forms with both long and short pronotum are known, the name abbreviatum having been given to the short one, which is usually the more abundant. In the long form the pronotum and wings pass the hind femora about $3.5 \mathrm{~mm}$.

68. ACrydium ACAdicum (Scudder), 1875f, 345. Acadian Grouse Locust.

Body robust. Color grayish- or clay-yellow, the pronotum often with a small black spot each side in front of humeral angles and a larger one behind them, these sometimes separated by a wide saddle-shaped white spot; hind femora with a few scattered black markings. Vertex more than twice as broad as one of the eyes, strongly advanced in front of them, the front margin rounded or feebly obtuse-angulate, its median carina dis- 
tinctly projecting. Frontal costa distinctly sinuate opposite middle of eyes, its sides parallel and sulcus rather wide and deep. Pronotum with front margin truncate and posterior process acute; dorsal surface finely and evenly granulate, notably widened between the shoulders, the humeral angles obtusely rounded; tegminal sinus small, shallow, the lower one widely angulate, the median lobe between the two feebly developed. Tegmina elongate-oval, their tips subacuminate. Wings extending to or nearly to apex of pronotum. Length of body, $\$, 9.5-10$; of pronotum, $9-9.6$; of hind femora, 5.5-6 mm. (Fig. 61.)

This is also a species of northern range, Scudder's type being from Lake of the Woods, Ontario. Recorded in our territory from

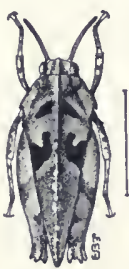

Baraga County, Michigan, July 5-Ang. 1. (Rehn, 1904 d, 232) ; Diamond Lake, Temagami District and Ft. William, Ontario (E. M. Walker, 1909, 175). Knnown also from Clieboygan Co., Mich., Aweme, Manitoba, St. Anthony l'ark, Minn., Steamboat Springs and San Louis, Colorado, Nebraska and northern New Mexico. Walker's specimen from Ft. Williams was a Fig. 6r. Fe. long form female, with body 11 and pronotum 12.2

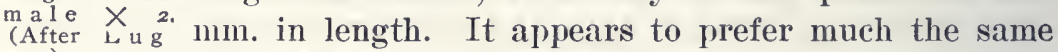
ger.) habitats as does $A$. granulatum, occurring about the edges of peat bogs and cedar swamps and along the banks of streams. A St. Anthony Park specimen has a large white spot across the pronotum at its widest part, this bordered in front by two small and behind by two larger triangular black velvety spots. The males appear to be very scarce. There are none in the National Museum or Hancock collections and the only specific mention of them is by Rehn $(1904,232)$, who records two from Pequaming, Mich.

69. Acrydium arexosum (Burm.), 1838, 659. Sanded Grouse Locust.

Body rather slender; pronotum everywhere minutely granulate but little rugose or wrinkled. Color grayish or blackish, often with a large squarish white spot on dorsal surface between the humeral angles, this spot usually with traces of black on its hınd margin. Vertex, viewed from above, nearly twice the width of one of the eyes, extending but little beyond front of them, its front margin subtruncate; median carina indistinct, scarcely if at all projecting. Antennæ slender, the joints elongate. Pronotum as described in key, front margin truncate, posterior portion usually prolonged and extending much beyond the hind femora; tegminal sinus rather deep, the lower sinus wider and deeper, the lobe between them prominent, obtuse. Tegmina elongate-oval, their tips obtusely rounded. Inner wings fully developed, a little surpassing the tip of pronotum. Front femora sinuate or lobed beneath. Length of body, $\delta, 8-12$, ९, $9-14$; of pronotum, $\hat{\delta}, 9.8-10.5$, ô, $12-13$; of hind femora, $\hat{o}, 4.3-5$,

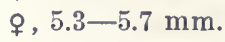


Common throughout southern Indiana, Kosciusko county only in the northern portion; April 9-Oct. 4. Leon County and Jacksonville, Fla., February-April ( $R$. \& $H .$, 1904). Ranges from Indiana and Virginia west and south to Nebraska, Louisiana and Texas. Common throughout the southern States except peninsular Florida, where it is replaced by the race blatehleyi. In Indiana it frequents upland woods which are dry and open, being seldom found in the vicinity of water. Elsewhere it is said to occur mainly on sandy loams in company with other xerophilous species of the family. From A. ornatum it may be easily separated by its more slender form, flatter and less projecting parallel-sided rertex, more depressed pronotum with less prominent median carina, and by its evenly and finely granulated surface. The annulations of antenna and legs are much less distinct than in ornatum and the general color is not so variable. A short form is known but is very scarce.

69a. Acridiun Arexosum onscurum (Hancock), 1896, 239. Obscure Grouse Locust.

A form or variety of arenosum with which it agrees in color. Distinguished by the slightly larger size, with vertex less depressed in front; frontal costa in profile more projecting beyond the eyes, the sinuation more distinct between their lower portion, viewed in front the costa more appreciably furcate. Eyes smaller. Pronotum strongly constricted before the shoulders, less prolonged backward than in arenosum; the median carina indistinct through most of its length, a little raised on anterior third. Tegmina more elongate. Inner wings extending slightly beyonc tip of pronotum. Length of body, $\hat{\delta}, 11-11.7$, $\&, 13-13.9$; of pronotum, $\hat{o}, 9.8-11$, ․ 11.5-13; of hind femora, $\hat{\delta}, 4.5-5.2$, 오 $5.5 \mathrm{~mm}$. (Fig. 62.)

Vigo, Marion and Lake counties, Indiana, Apr. 6-Nor. 7. Range in general more northern than that of typical arenosum,

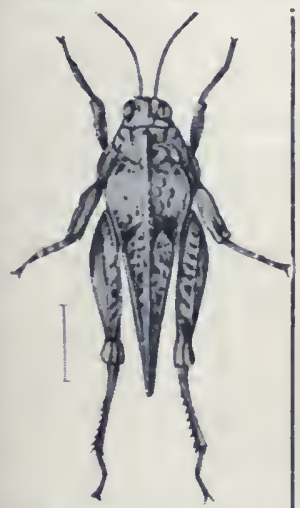

Fig. 62. Female $\times$ 2.3. (After Hancock.) extending through the upper Carolinian and Transition zones in eastern North America or from Truro, Nora Scotia, DeGrassi Point, Ont., and eastern Maine, west to St. Anthony Park, Minn., and Nebraska, sonth to Maryland, Virginia, northern Georgia, Missouri and Kansas. Intergrades with typical arenosum in the sonthern part of its range, and rery close to it whererer found. In Indiana it occurs with arenosum, and Hancock wrote me when returning some specimens, that some of them labelled by him as obscurum "shade off into forms approaching arenosum." 
Synonyms of this variety or of typical arcnosum are Tettix angustus Hancock $(1896,238)$, which he later placed $(1902,89)$ "as a variety which merges into arenosum on the one side and obscurum on the other"; T. gibbosa Hancock, which was considered by me $(1903,225)$ as "only a shorter and wider form of arenosum haring the pronotum a little more constricted than usual in front of the shoulders"; and T. inflatus, decoratus and fluctuosus Hancock, which have since been stated by their author $(1902,90)$ to be synonyms. Rehn (1904f, 326) says that "the separation of obscurum, arenosum and gibbosum is a task which is practically hopeless. There is some evidence in retaining obscurum as a geographic race of arenosum, but gibbosum is inseparable from obscurum." In their latest paper treating of the Tetrigidæ (1916, 134) R. \& H. have retained obscurum as a geographic race, but have (wrongfully, I think) replaced the name with angustum, which Hancock, as above quoted, says is an intermediate form between arenosum and obscurum, and as such has no standing.

69b. Acrydum arenosum Blatchleyi (Hancock), 1902, 91. Blatchley's Grouse Locust.

A very slender southern form of arenosum from which it is distinguished by having the pronotum and femora more rugose-tuberculate, the lateral carinæ of pronotum more decidedly compressed and its dorsal surface behind the shoulders strongly compressed or narrowed. The frontal costa, viewed in profile, is distinctly advanced beyond the eyes and strongly sinuate between their lower portions. Pronotum usually attenuate and distinctly surpassing the tips of hind femora but sometimes much shorter, more acute and surpassing the femora only $.5 \mathrm{~mm}$.; lower sinus of lateral lobes much narrower and deeper than in arenosum. Tegmina oblong-oval, their tips obtusely angulate. Wings slightly shorter or subequal in length to pronotum. Hind femora with numerous strong oblique ridges on outer face. Antennæ and tibiæ annulate. Length of body, $\hat{o}, 9-9.5$,, , $9-11.5$; of pronotum, $\hat{\sigma}, 8-8.5$, $\$, 8.6-10.7$; of hind femora, $\hat{\delta}$ and $\rho$, $5-5.3 \mathrm{~mm}$.

Ormond, Fla., Apr. 9, 1899 (type) ; Dunedin, Fla., Jan. 22Apr. 1; LaBelle, Fla., Feb. 25 (W. S. B.). Deep Lake, Fla., Apr. 13 ( $R$. \& $H ., 1914 d)$. The above are the only known stations of this grouse locust. At Dunedin specimens have been taken on sereral occasions by sweeping a recently cleared space along the margins of a garden which occupies a large tract of rich soil on the former side of a wet hammock, and is still in great part surrounded by a dense hammock growth. Only two or three individuals were taken at a time. The sweeping yielded also Tettigidea later. 
alis Say and Anaxipha pulicaria (Burm.), the latter not being found elsewhere on the mainland about Dunedin.

Scudder (1S7Ta, 90) recorded Tettix arenosus from Ft. Reed, Fla., and stated that "it is closely allied to T. rugosa Scudd., but the wings scarcely surpass the pronotum, a feature which appears to be constant." Since this character is true of A. a. blatchleyi and not of $A$. a. arenosum, his specimens were probably of the former race.

\section{Neotettix Hancock, 1898, 13S. (Gr., "new" + Tettix.)}

Short, rather stout species having the body granulate or rugose; vertex wider than one of the eyes, its front margin convex or rounded, riewed from the side slightly advanced in front of eyes (Fig. 62a); frontal costa convex, not sinuate between the eyes, its branches, viewed in front. strongly divergent or forked; antennze rather stout, short, composed of 12, rarelr 13, segments; pronotum with its front dorsal margin adranced over the head to the eyes, posterior process acute and usually not or barely reaching tips of hind femora, surpassing them in the long forms; its dorsal surface more or less tectate between the shoulders, median carina distinct, usually more elevated between and in front of shoulders; tegmina elongate-elliptical, sometimes rery minute, their tips rounded or subacuminate; wings either aborted or fully dereloped and slightly passing the apex of pronotum; hind femora rather short; hind tarsi with first segment distinctly longer than second and third united, the pulvilli acutedbut more or less flat below. Ten species have been described from North America, but R. \& H. $(1916,135)$ have shown that six of them are synonyms. The three found in our territory are separated as follows:

KEY TO EASTERY SPECIES OF NEOTETTIX.

a. Hind margin of lateral lobes of pronotum bisinuate; tegmina always well developed and exposed; pronotum with front dorsal margin truncate and median carina not strongly compressed, elevated and curved.

b. Pronotum with dorsal surface finely granulose, sometimes feebly tuberculate, its hind process in short forms narrowly acute at tip; ridges on outer face of hind femora not prominent.

70. FEMORATES.

bb. Pronotum with dorsal surface distinctly rugose-tuberculate, usually strongly so between the shoulders, the short ridges usually paired and regular, more prominent in the female; hind process of pronotum in short form much stouter and obtusely 
rounded at tip; hind femora with oblique ridges on outer face strongly developed.

71. BOLTERI.

aa. Hind margin of lateral lobes unisinuate, the tegminal sinus absent (short form) feebly bisinuate (long form); tegmina very minute, $\hat{o}$, larger but almost concealed, $q$; pronotum with front dorsal margin obtuse-angulate and median carina elevated, compressed and arched much as in Nomotettix.

72. PROAVUS.

70. Neotettix femoratus (Scudder), 1869, 306. Short-legged Grouse Locust.

Short, robust. Usually uniform light fuscous or grayish-brown; pronotum oftentimes with an oblique black bar behind each shoulder, these sometimes bordered in front with white, its median carina rarely dull yellow throughout; antennæ and tibiæ annulate with paler. Vertex slightly wider than one of the eyes, male, one-half wider, female, more or less concave each side of median carina, its front margin feebly rounded. Frontal costa, viewed in profile, slightly produced in front of eyes, narrowed and compressed at point of union with median carina of vertex. Eyes globose, prominent. Pronotum as described in key, its apex in short form acute, not quite reaching tips of hind femora, in long form surpassing them by $3 \mathrm{~mm}$; median carina distinct throughout; tegminal sinus shallow, the lower one deep, acute, the lobe between them rather sharply rounded. Wings in short form not reaching tip of pronotum, in long form surpassing them $1.5 \mathrm{~mm}$. Length of body, $\hat{\delta}, 8-8.5$, ㅇ, 9-10; of pronotum, $\hat{\delta}, 7-8$, ․ $7.5-8.5$; of hind femora, $\delta$ and $\$, 5-5.6 \mathrm{~mm}$. Of long form, $\hat{o}$, length of body, 11.5; of pronotum, 9.5 ; of hind femora, $5.5 \mathrm{~mm}$.

Crawford County, Ind., July 25, one male, long form ; Dunedin, Lakeland, LaBelle and Moore Haven, Fla., Jan. 9.-March 30, short form (W.S.B.) ; Thomasville, Ga., June 19-Sept. 23 (Hebard) ; Bloomington, Ind. (U. S. N. M. Coll.). From Florida it luas also been recorded from eleven other localities between Pablo Beach, Gainesville, Miami and Ft. Myers, and probably occurs throughout the State. Ranges from Staten Island, N. I., Maryland and southern Indiana, south and west to Florida, Colmmbia, Tesas, Oklahoma and Iowa. At Dunedin it was found only along the sandy margins of recently drained ponds in company with $N$. $c$. floridanus Hck. and Apotettix rugosus Scudd. In other places it is recorded as occurring in open pine woods and palmetto scrub.

Morse $(1907,25)$ says femoratus is "one of the most plentiful of 'Tettigina in the southeastern quarter of the country, often occurring in great abundance in specially favorable localities, generally preferring sandy soils which are frequently or perjetually moist." At Waycross, Ga., 152 specimens were equally divided between the long and short forms, but long-winged examples are usually much fewer, ranging from 5 to 20 per cent. At Dune- 
din but four of the long form have been fonnd among the 30 or more taken. Morse $(1904,25)$ and R. \& H. $(1916,135)$ have shown that $N$. bolivari Hancock $(1898,139)$ and its long form, longipennis Hancock $(1902,165)$, as well as $N$. rotundifrons and N. variabilis Hancock are all synonyms of $\mathrm{N}$. femoratus.

71. Neotettix bolteri Hancock, 1898, 139. Bolter's Grouse Locust.

Body short, robust. Dark gray or fuscous, tibiæ and tarsi annulate with light and dark, ovipositor brown. Vertex nearly twice as wide as one of the eyes, its median carina visible only on front half, front border rounded. Frontal costa, viewed from the side, strongly convex between the bases of antennæ. Eyes prominent, subglobose. Pronotum with dorsal front margin truncate, reaching the eyes; lateral carinæ in front of shoulders high and distinct; posterior process with sides converging gradually to a rather obtuse apex, which terminates just above the base of ovipositor; tegminal sinus very shallow, almost obsolete, the lower one narrower and deeper than in femoratus, the lobe between them much more broadly rounded. Tegmina oblong, the apical half rounded. Wings abbreviated, three-fourths the length of posterior portion of pronotum. Length of body, $\hat{\delta}, 6.8, \uparrow, 8-10$; of pronotum, $\hat{\delta}, 8.2, q, 7-8.5$; of hind femora, $\hat{\jmath}, 4.2$, $\$, 5-6 \mathrm{~mm}$.

Knnox Countr, Ind., April 23, nymphs; July 1-6, adults (W. S. B.). Occurs throughout Florida, there being numerous records from Barrancas and Monticello to Miami and Key West. Ranges from Petersburg. Virginia and southern Indiana south to Key West. Fla., and west to eastern Texas.

The first Indiana specimen, a female, was taken from the border of a large eypress swamp in Knox County on July 6, 1902. A second risit to the place on April 23,1903 , resulted only in the finding of four half-grown nymphs. The whole swamp was then corered with water several feet in depth, and the roung were found in company with the soung and adults of other Tetrigids on the higher ground bordering the water, within ten feet of its margin and only a few rods from the nearest cypress trees. On July 1, two additional females were taken at the same place and the species was described by me $(1903,226)$ as Neotettix hancocki. This name, as well as $N$. coarctatus Hancock $(1902,165)$ and A potettix minutus R. \& H. $(1905,34)$ have been placed in synonsmy under bolteri by R. \& H. $(1916,144)$. Ontside of Indiana bolteri is said to occur in marshy sink holes, in wet weedy spots and among low undergrowth in pine woods. The form with long pronotum. minutus R. \& H., is so far known only from central and sonthern Florida. 
From M. femoratus, its nearest ally, bolteri is easily recognized by its slightly more bulky form, the more convex and prominent frontal costa, larger eyes, higher lateral carinæ of pronotum behind the eyes, and especially by the prominent tubercles on the surface of the front dorsal half of pronotum. The tegmina are shorter and broader, the upper notch of lateral lobe of pronotum more shallow, and the median lobe more rounded than in femoratus.

72. Neotettix proavus Rehn \& Hebard, 1916, 139. Forked-face Grouse Locust.

Rather large, compressed. Color variable, usually fuscous-black or dark brown with an oblique velvety black triangular spot behind each shoulder; lateral lobes and hind portion of pronotum sometimes paler brown, rarely uniform pale brown throughout; antennæ annulate with brown. Vertex about twice as wide as one of the eyes, concave each side of its median carina; frontal costa with forks strongly diverging to the antennal bases, then subparallel to the median ocellus. Eyes feebly flattened, moderately prominent. Antennæ short, 12-jointed. Pronotum strongly compressed, its crest distinctly curved in front of shoulders, less so behind them; its front margin reaching middle of eyes; humeral angles very obtuse; posterior process acute, not reaching tips of hind femora; dorsal surface with numerous small rounded tubercles or granules, these larger between the shoulders. Wings abbreviate, two-thirds the length of pronotum. Valves of ovipositor compressed, strongly toothed. Length of body, $\hat{o}, 8.1-8.5$,,$+ 9.9-10.4$; of pronotum, $\hat{o}, 7.3-7.8$,, 8.5 ; of hind femora, $\hat{\jmath}, 5-5.3$, ㅇ, $6 \mathrm{~mm}$.

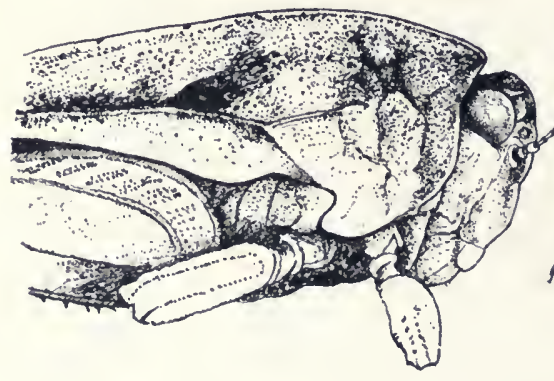

$a$

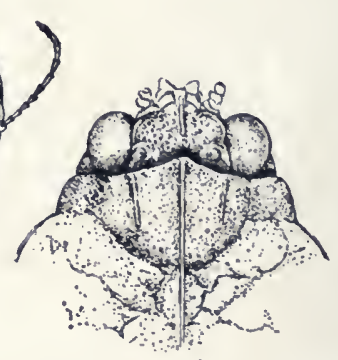

b

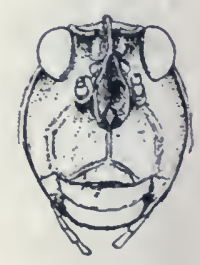

c

Fig. 62a. Neotettix proaz'us, R. \& H. a, Female, side view, showing crested pronotum; $b$, dorsal view of head and front part of pronotum; $c$, front view of head showing forked frontal costa. (After Hancock.)

Clarksville, Tenn., June $19-25(F \circ x)$. Taken by R. \& H. at Macon, Buckhead and Jasper, Ga., and Murphy, N. Car., July 25August 2. These are the only recolds so far known. It is a rery distinct and aberrant species, strongly resembling Nomotettix cris- 
tatus but larger, more robust and with the furcate frontal costa and characters of vertex of Neotettix. ${ }^{36}$ It may be considered a connecting link between the two genera.

Fox (Ms.) states that about Clarksville, Tenn., C. proavus is found "in May and June in more or less open sun-lit areas on mossy, grassy or leaf-covered ground in upland or hillside woods, occurring in much the same type of surroundings as Spharagemon bolli, Melanoplus scudderi and Melanoplus luridus. It is decidedly local or sporadic in its occurrence." He has described (1918) a long-winged or caudate female form of proavus found at Clarksville, having the tegminal sinus clearly defined and the tegmina quite well developed and plainly visible.

\section{Paratettix Bolivar, 1887, 270. (Gr., "near" + Tettix.)}

From the other grouse locusts the members of this genus may be readily known by the vertex being short, narrow, never wider than one of the eyes and not extending in front of them (Fig. 4), its front margin truncate and disk concave each side of the median carina; frontal costa prominent between the antennæ, feebly sinuate between the eyes which are prominent and subglobose; antennæ filiform, a little longer than head, 14-jointed; pronotum with dorsal surface flattened, convex between the shoulders, its front margin truncate, advanced forward upon the head to eyes; its posterior process usually prolonged, the median carina low; tegmina oval or elongate, punctate; wings usually fully developed, rarely abbreviated; lind tibia with their apical third.gradually enlarged and spinose; first joint of hind tarsi longer than third, pulvilli of second and third joints covered with numerous fine points or spicules.

KEY TO EASTERN SPECIES OF PARATETTIX.

a. Pronotum longer, its apex subulate, usually much surpassing the tips of hind femora, its median carina feebly elevated throughout its length.

73. CUCUllatus

aa. Pronotum shorter, its apex acute, not reaching tips of hind femora, its median carina distinctly elevated throughout.

74. TOLTECUS.

73. Paratettix cucullatus (Burmeister), 1838, 658. Hooded Grouse Locust.

Moderately robust, the pronotum smoothly and evenly granulate. Color usualiy a uniform yellowish-gray, sometimes russet-red or dull

${ }^{36}$ As Hebard (1919) has shown, the Caz'otettix apterus Hancock (1918, 345) is a mere form of $N$. proavus. It was described from specimens of proavus taken by Fox at Clarksrille, Tenn., and now in my collection, the differences pointed out by its author being based upon the printed descriptions of proavus and not by comparison with the type of that species. 
black, the tibiæ annulate with light and dark. Vertex slightly narrower than one of the eyes, male, equal in width to one of them, female, reaching nearly to front border of eyes; median carina faint, not projecting in front; disc feebly but acutely notched opposite middle of eyes, its front portion shorter and narrower than hind one. Frontal costa but slightly advanced in front of eyes, its branches but feebly divergent, the sulcus narrow, deep. Pronotum with dorsal surface almost flat, median carina wanting or indistinct on front portion, low on the elongated posterior pro-

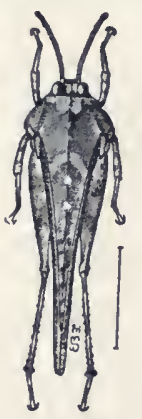

Fig. 63. Male $X$ 2.5. (After Lugger.)

Common throughout southern Indiana, less so in the northern portion; Feb. 21-Nov. 28; Livingstone, Ky., June 21; Mobile, Ala., Aug. 30; Agrieultural College, Miss., Ang. 22; Chester and Pine Bluff, Ark., Sept. 1-Oct. 23; Sherman, Texas, July 5. In Florida it has been recorded only from Marianna, but specimens are in the Gainesville collection labelled "Lake City, June 3." Ranges from Ontario and New England, west to Minnesota and Colorado and sonth to northern Florida and central Texas.

In Indiana the hooded gronse locust is found throughout the year, hibernating in winter beneath logs and otler cover close to its farorite summer haunts. These are the damp sandy or muddy banks of ponds, lakes and streams, where from midsummer to late autumn it is found by hundreds, usually in company with Galgulus oculatus and other semi-aquatic insects. Its modest hues agree admirably with such surroundings, thus furnishing the insect valuable protection against its foes. When disturbed it more often flies than leaps, its flight being more prolonged than that of any other of the Indiana Tetrigians, and often alights upon the water, where it swims with ease, its dilated hind tibia being then of much aid to its onward progress. Morse $(1894 \mathrm{a}, 164)$ states that it is common at Ithaca, New York, "along the stony margins of the creeks and exactly matehes in tint the fragments of slate-gray shale on which it deliglits to sun itself, becoming in consequence 
almost invisible on alighting." The short-winged form appears to be very scarce, Morse $(1907,26)$ recording three from Gulfport, Miss., where ther were found near a spring on the edge of the sea beach.

$P$. texanus Hancock $(1902,113)$ I regard as an absolute synonrm of cucullatus. In his key he separates texanus only by the "stouter middle femora with inferior margin decidedly undulate," while in his description he gives no additional characters which will not apply to cucullatus. Certain it is that the specimens in ny collection from Texas, Mississippi and Arkansas, which were named texanus for me by Hancock, and which should represent that species as far as locality goes, cannot be separated from Indiana cucullatus, since the lower margin of middle femora in the latter species varies from decidedly undulate to almost entire.

74. Paratettix toltecus (Saussure), 1861, 401. Toltecan Grouse Locust.

A short, rather broad form differing from cucullatus by characters given in key and by having the median carina of vertex distinct on front portion, the concavity each side deeper; branches of frontal costa more widely separated; pronotum more rugose, its median and anterior carinæ higher; tegminal sinus very shallow, the lobe beneath it shorter, much less rounded. Middle femora shorter with strongly compressed margins, the lower one strongly lobed behind the middle. Length of body, $\hat{\delta}, 8$, , 10; of pronotum, $\hat{\delta}, 6$, $q, 7$; of hind femora, $\hat{o}, 5, \uparrow, 6 \mathrm{~mm}$.

This species is in the Philadelphia collections from Homestead and Grand Ridge, Fla. These are the only stations at which it has been taken east of the Mississippi, it being a Mexican species but known in the United States from Arizona, California, New Mexico, Colorado and Nebraska. At Santa Fe and Las Vegas, New Mexico, it was taken by $R$. \& $H$. in wet grassy places along the borders of streams and at Tucson, Arizona, was found 3,876 feet above tide. Specimens in $\mathrm{mr}$ collection from Bill William's Fork, Arizona, resemble nymphs of cucullatus in their short, squat form, but are stouter and easily separated by the characters above givell. A long form from Mexico has been named sonorensis by Hancock $(1902,121)$. A supposed long form, P. toltecus extensus Morse (1899, 198), described from Arizona and California, is treated by Hancock $(1902,117)$ as the long form of a new species described by him as $P$. morsei (loc. cit. 119). If this be true, Morse's name extcnsus has priority orer the name morsei which represents the short form. 


\section{Aротеттіх Hancock, 1902, 99. (Gr., "separate" + Tettix.)}

Rather slender, medium sized species having the head covered by the pronotum to the eyes; antenna stouter than in Paratettix; eyes smaller, globose; vertex as described in generic key, its "front border formed of little concave carinæ, lying each side of the midcarina, and which are elevated and flexed backwards at the inner side of anterior half of the eyes," its dorsal surface appreciably wider behind; frontal costa rather widely and shallowly sulcate, strongly advanced in front of eyes and convex between the bases of antennæ; pronotum as in Paratettix, its median carina more distinct than in P. cucullatus. Other characters as given in key. Six species are recognized from the American Continent by Hancock $(1906,64)$, one of which occurs in our territory.

75. Apotettix Rugosus (Scudder), 1862, 476. Rough-backed Grouse Locust.

Rather slender, the pronotum strongly tapering behind. Fuscous, dark brown or dark gray, usually nearly uniform, rarely with a broad white blotch across the shoulders of pronotum; hind femora in part paler. Vertex as wide as or slightly wider than one of the eyes in male, one-third to one-half wider in female, disc deeply concave each side of median carina. Pronotum with front margin truncate, hind portion strongly attenuate, dorsal surface with numerous rounded and oblong tubercles; median carina interrupted or wanting between the shoulders, rather strongly elevated and slightly curved in front of them; humeral angles obtuse; lateral lobes with hind margin strongly bisinuate; tegminal sinus wide, shallow; lower one narrow, much deeper, the lobe between them rounded. Tegmina elongate-oval, their tips obliquely rounded; wings passing the apex of pronotum. Middle femora undulate beneath; hind ones rather slender, their outer surface strongly rugose. Sub-anal plate of male acutely notched at tip. Length of body, $\delta, 8-10$, $ᄋ, 10-12$; of pronotum, $\hat{\jmath}, 11-13.3$,, $13-15.6$; of hind femora, $\hat{o}, 5-5.5$, , $6-6.5 \mathrm{~mm}$.

Ormond, Sarasota, LaBelle, Moore Haren and Dunedin, Fla., Dec. 1-April 10 (W. S. B.) ; common at Dunedin along the mucky margins of recently drained pouds, where they are usually taken by sweeping. When flushed they make one or two strong flights, sometimes for a distance of 40 feet, then squat close to the surface, and if carefully marked down can be readily picked up with the fingers. Two of the Dunedin females have a broad white saddleshaped spot on pronotum and a pale stripe along the middle of hind femora. At Ormond it was frequent in damp places along roadsides and abont the borders of low, cultivated grounds. Recorded also by Scudder from Fort Reed and by Davis and R. \& H. from numerous localities from Jacksonville and Cedar Keys south 
to Miami and Punta Gorda, and probably occurs everywhere throughout peninsular Florida. North of that State it is definitely known only from Tybee and St. Simon's Islands, Ga., though Bruner has recorded it from Nebraska and Bolivar from Mexico. No examples of a short-winged form have as yet been noted.

\section{Subfamily II. BATRACHIDINE.}

The members of this subfamily are distinguished mainly by the characters giren in the key, p. 153 . In addition they have the size large and form robust for the family; frontal costa narrow, its ridges obtuse, subcontiguous, subparallel and continuous with the median carina of vertex; ejes large, oval or subtriangular, not strongly convex, their upper inner border encroached upon by a surall crescentic lobe of the rertex; antennæ inserted between the lower halves of eyes; pronotum strongly tectiform, usually with more or less obvious lengthwise ruga, its median ridge nerer strongly carinate or cristate; first joint of hind tarsi not longer than third. Two genera are represented in the Eastern States.

KEY TO EASTERN GEXERA OF BATRACHIDINA.

a. Body robust, subglobose (Fig. 64.) ; lateral carinæ in front of shoulders wanting; pronotum convex above, feeble punctate. I. PAxilla.

aa. Body narrower, more slender (Fig. 66) ; lateral carinæ present; pronotum between the carinæ more or less concave and rugose, granulose or wrinkled.

II. TettigideA.

\section{Paxilla Bolivar, 1887, 294. (Lat., "A small peg.")}

Form robust, compressed. Head broad; rertex short, curved in front, transversely carinate each side, disc with a prominent lengthwise median carina projecting in front of eyes and rounded into the frontal costa, the latter narrowly sulcate above the median ocellus; antennæ 22-jointed; eyes rather small, subtriangular, the apex above; pronotum compressed, its front margin acuteangulate, extending over head to median carina of rertex; posteriorly subacute, its apex reaching end of abdomen, male, base of ovipositor, female, falling short of tips of hind femora in both sexes; tegmina narrow; wings abbreviated; hind femora rather stout, broad; hind tibia with numerous spines; first joint of hind tarsi sulcate above, as long as the next two united. One species only is known.

76. Paxilla obesa (Scudder), 1877b, 34. Obese Grouse Locust.

Chocolate-brown, shining; the dorsal surface and lower third of lateral lobes of pronotum and lower part of face often pale brown. Prono- 
tum with median carina, viewed from the side, broadly arched, highest between the shoulders; surface rather coarsely and sparsely punctate, often finely rugose in front of shoulders; hind margin of lateral lobes bisinuate, tegminal sinus small, shallow, lower one broadly concave, the lobe between them short, broadly rounded. Tegminæ almost smooth. Outer face of hind femora with numerous fine scattered granules or scales. Length of body, $\hat{\delta}, 9-10.5$, $\&, 12-14.5$; of pronotum, $\hat{o}, 8-9.2, \&, 11-12$;

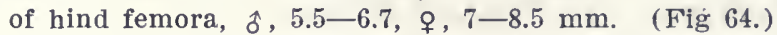

Hastings, Fla., Sept. 30 (Morse); Mobile and Delchamps, Ala. (Loding). A southern species, originally described from Georgia

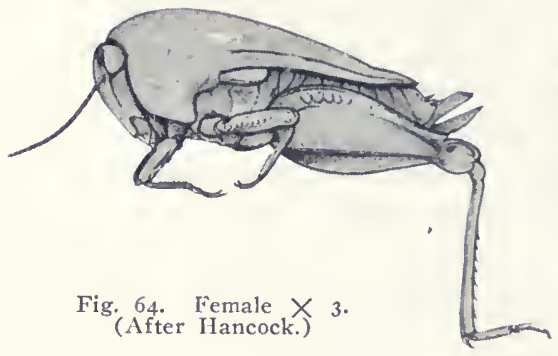
and ranging from Newbern, N. Car., to southern Florida and Mobile, Ala. In Florida it has been recorded from De Funiak Springs, Jacksonville, Gainesville, Port Orange, Hastings, Homestead and Detroit, April-October. At the last two localities R. \& H. found it "in the low undergrowth of pine woods in not the usual very wet situations," while at Newbern, N. Car., it was taken by them "in a wet meadow in company with Clinoecphalus elegans and Melanoplus decorus." It seems to be widely scattered and scarce throughout its range, not over half a dozen specimens being recorded from any one locality, except Homerville, Ga., and Hastings, Fla., where it was found in sone numbers in "low, blackish, water-soaked ground covered with low bog plants (sun-dews, pitcher plants, etc.) in pine woods."

\section{Tettigidea Scudder, 1862, 476. (Gr., "grasshopper.")}

Species of robust form, having the head larger and face less oblique than in preceding genera; vertex equal to or much exceeding the width of one of the eyes, carinate at middle, the front border more or less rounded, sides concave; frontal costa strongly advanced in front of eyes, continuous with median carina of vertex, in front narrowly sulcate; antenne stout, 22-jointed; pronotum with front dorsal margin either rounded, angulate, acute or cuspidate, more or less projected forward onto the head; posterior process either attenuate and passing tips of hind femora or acute and shorter; dorsal surface finely granulate and usually more or less rugose lengthwise, its median carina distinct but not prominent; lower posterior angle of lateral lobes much smaller than in 
preceding genera; tegmina elongate, narrow, often with a pale spot near apex; wings in the long forms passing tips of pronotum; first and third joints of hind tarsi either subequal in length or the first slightly the longer. Males much more slender than females, and as both pronotum and wings vary much in length in the same species, much confusion of synonymy has resulted.
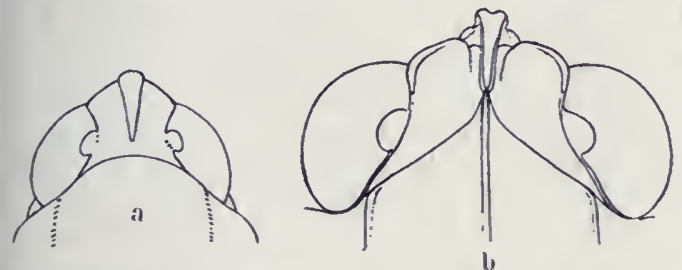

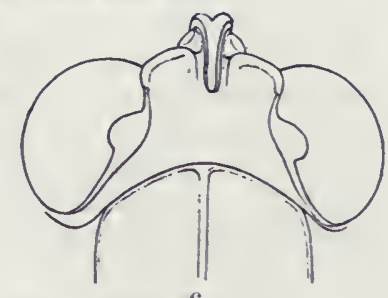

Fig. 65. Showing form of vertex and front margin of pronotum of Tettigidea. a, $T$. prorsa Scudd.; $b, T$. armata Morse; $c, T$. lateralis (Say). All greatly enlarged. (After Hancock.)

KEY TO EASTER SPECIES OF TETTIGIDEA.

a. Front dorsal margin of pronotum obtusely angulate or rounded, feebly prolonged over the head, seldom reaching and never extending beyond the middle of eyes (Fig. 65, c.)

$b$. Visible portion of vertex scarcely longer than wide, its front margin rounded, not distinctly produced in front of eyes; head wide, not subconical.

c. Antennæ slender, filiform, the joints of middle third at least three times as long as broad; eyes prominent; front margin of pronotum.usually broadly rounded (Fig. 65, c.); frontal costa more slender.

77. LATERALIS.

cc. Antennæ stouter, the joints of middle third distinctly flattened and not more than twice as long as broad; eyes smaller; front margin of pronotum usually obtusely angulate (Pl. II. Fig. 5); frontal costa stouter, more prominent.

77a. PARVIPENNIS.

$b b$. Visible portion of vertex distinctly longer than wide, its front margin obtusely angulate and projecting in front of eyes, its sides widely emarginate, the concavity forming a regular curve about the contour of the eyes; head narrow, subconical. (Fig. $65, a$.)

78. PRORSA.

aa. Front dorsal margin of pronotum produced on the head and between the eyes often nearly to their front in the form of an acute angle or sharp cusp (Fig. 65, b.)

d. Median carina of vertex but little projecting beyond the eyes; pronotum broad across the shoulders, its dorsal surface strongly rugose or wrinkled, its median and lateral carinæ well developed.

79. ARMATA.

$d d$. Median carina of viertex more projecting; pronotum narrow across the shoulders, its dorsal surface finely wrinkled, its carinæ but slightly developed.

79a. SPICATA. 
77. Tettigidea lateralis (Say), 1824, 10. Black-sided Grouse Locust.

Rather robust; pronotum in long form strongly attenuate behind, especially so in males. Color above grayish, light brown or fuscous, sides blackish; tegmina with a small white spot near tips, hind femora often with pale spots or bands; male with lower part of face, mouth parts and lower third of lateral lobes of pronotum ivory white. Vertex about as wide as one of the eyes, male, one-half wider, female, feebly projecting in front of eyes, its sides strongly concave; median carina distinct but low on front half. Pronotum granulate and with distinct branching lengthwise rugæ; its process in long form slightly surpassing tips of hind femora, in short one reaching only to tip of abdomen; median carina low but distinct throughout; humeral angles scarcely evident; lateral lobes distinctly bisinuate behind, the tegminal sinus deeper and more narrow than the lower one, the lobe between them short, rounded, the lower posterior lobe acute. Tegmina elongate, their tips obliquely rounded; wings in long form surpassing the tip of pronotum 1 to $2 \mathrm{~mm}$., in short one not reaching it. Femora with margins entire, hind ones rather stout, their outer surface granulate and with faint oblique ridges. Length of body, $\hat{o}, 10-13$, ㅇ, 12-17; of pronotum, ô, $9-10$, $\&, 10-14$; of hind femora, o, $5-6$, \&, 6.5-7.5 mm. (Fig. 66.)

Southern half of Indiana, common, April-December; not recognized north of Marion and Putnam counties. Recorded also

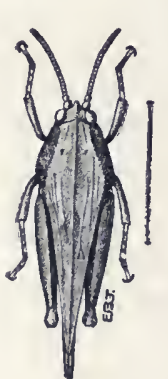

Fig. 66. Fe. male $X 2.2$. (After L u g. form. ger.) from numerous localities throughout Florida and probably the most abundant grouse locust in the State, though apparently less common in its southern third. All specimens taken by me in Florida or recorded from there are of the long form, as are the great majority of those seen from Indiana, and R. \& H. (1916, 151) state that 90.6 per cent. of the specimens in their extensive collections are of this form, but that material taken near streams or in swampy places in heary forest show a strong predominance of the abbreviate About Dunedin T'. lateralis occurs in numbers along the sandy margins of ponds and lakes, usually in company with Nomotettix cristatus floridanus and Apotettix rugosus, and also less commonly in open places in pine woods, while in Indiana its habitats are the same as those of its variety parvipennis, described below. Caudell $(1905,216)$ states that a specimen taken by him at Sanford, Fla., "jumped into a shallow pool of water in its efforts to escape, and when I attempted to pick it up it deliberately dove to a blade of grass fully an inch below the surface of the water, where it remained grasping the stem with its legs for several seconds." 
T. lateralis ranges from New Jersey and central Indiana west and south to Florida, Louisiana, Oklahoma and New Mexico, and is said by Rehn $(1909,201)$ to occur "all over the Island of Cuba." Tetrix polymiorpha Burmeister (1838, 659), is a name given to the short form while Tettigidea medialis Hancock $(1902,152)$ is an intermediate form connecting typical lateralis with its northern race parvipennis.

An examination of the type of T'ettigidea acuta Morse (1895, 15) leads me to place it as a form representing an individual rariation of $T$. lateralis. It is, as it were, a sort of connecting link between lateralis and armata. being lateralis with a short, acute projection of front margin of pronotum and armata with shorter cusp than usual and a more convex pronotum. It is known only from three females in the Cambridge collection in New York and one in the Hebard collection taken by Daris on Staten Island.

77a. Tettigidea lateralis Paripexis (Harris), 1841, 152. Sedge Grouse Locust.

This, the northern race of lateralis, differs from the typical form mainly by the characters given in the key. In general the body is more robust, the humeral angles more pronounced and the outline of the dorsal surface of pronotum more irregular in front of the shoulders. The shorter, stouter joints of the antennæ, less prominent eyes, and the usually more distinct angulation of the front border of the pronotum (Pl. II, Fig. 5.) in parvipennis are the most obvious characters separating the two forms. In color they are alike, while in Indiana specimens the pronotum is more strongly rugose than in lateralis. The measurements are approximately the same, those of the short form, or typical parvipennis, belng slightly less than those of the corresponding form of lateralis.

T. parripennis is a rery common grouse locust throughout northern Indiana, frequenting drs upland woods, fence rows. and low marshy tracts; but in the southern portion it is largely replaced by lateralis. Its mating season appears to be the whole rear round. as I have taken specimens in copulation in nearly evers month, even on sunny days in mid-winter. It hibernates usually in small colonies or groups-as many as eleven having been found huddled together within the space of a few square inches on the under side of a $\log$ or chunk. Walker has found it hibernating in a beetle-boring in a log, the hole being completely hidden by the bark. The general color of the pronotum raries greatly in different examples, each insect seemingly seeking that local habitat which corresponds closely to its hue.

It ranges throughout the Transition and Upper Austral life 
zones of the eastern United States, occurring generally in Ontario and New England, and at least as far south as Ocean City, N. J., thence west to Iowa and Minnesota, its southern range overlapping that of lateralis in the lower portion of the Upper Austral zone. R. \& H. $(1916,151)$ state that intermediate forms connecting the two races occur in the pine barrens and adjacent coastal strip of New Jersey, in Delaware, Maryland and northern Virginia, southern Mllinois, Missouri, Tennessee and northern Georgia, Hancock's medialis being based on such connecting forms. In Iowa parvipennis is said by Ball $(1897,238)$ "to be abundant in low timberland where the undergrowth is short."

Hancock $(1902,149)$ gives an interesting account of the color phases of parvipennis as noted near Twin Lakes, Wis., stating that they were "amazingly variable but the hue of every insect was perfectly in keeping, with the environment. Here one would be on the lichens, another on the swamp grass, and still others on the black muck, and yet all, generally speaking, accorded with the surroundings. The dried specimens have since changed so that whole rows of specimens which, when fresh, presented the prettiest variations, now present a dark uninteresting hue." He also describes $(1894,483)$ a migration in September, 1893, when the long-winged form of parvipennis was present in great numbers in the city of Chicago, and Rehn (1902c) mentions a similar flight as occurring in Philadelphia in September of that year. The long form of parvipennis described by Morse (1895, 109) under the name pennata is more common in Indiana than the typical short one described by Harris, and Ball states that in Iowa pennata is much the more abundant, but Morse $(1894 a, 166)$ says that in New England the short form is about three times as common as the long one.

78. Tettigidea Prorsa Scudder, 1877b, 34. Cone-headed Grouse Locust.

Form rather slender, face strongly oblique. Dark brown, the dorsal surface of pronotum often paler than the lateral lobes; male with face and lower portion of lateral lobes usually dull yellow; antennæ yellowish, darker toward tips. Vertex as described in key, its median carina low, blunt, continuous with the frontal costa, their point of union, viewed in profile, obtuse-angulate, the costa prominent between the antennæ, narrowly sulcate. Pronotum with dorsal surface evenly granulate and with feeble longitudinal rugæ between the shoulders; front margin broadly rounded; posterior process in the more common short form reaching only to base of ovipositor, female, its apex rather broad, obtuse; in long form surpassing tips of hind femora; median carina low but distinct; tegminal sinus narrow, shallow, lower one a broad, shallow concavity, the lobe be- 
tween them very short. Tegmina elongate, narrow. Wings no longer than pronotum, short form; extending 1 to $2 \mathrm{~mm}$. beyond its tip, long form. Length of body, $\hat{\delta}, 8.5-10.8$,,$+ 11-13.2$; of pronotum, $\hat{o}, 7.5-$ 8.6,, , 9-10.5; of hind femora, ô, 5 , ㅇ, $7 \mathrm{~mm}$.

A very distinct and well marked species ranging from Beach Haren, N. J., through North and South Carolina to southern Georgia, its distribution being erratic and discontinuous. Morse (1904, 27) records it as occurring on wet ground near a stagnant pool at Denmark, S. Car.; while R. \& H. state that it "prefers areas in pine woods of low black, water-soaked ground covered with low bog plants," though sometimes found in wet meadows in company with Tettigidea lateralis and Paxilla obesa. It appears to be a rare species wherever found, no more than three or four individuals being recorded from any one locality except at Homerville, Ga., and Yemassee, S. Car., where $\mathbf{1 6}$ and 59 were respectiveIy taken. To the long form the name elongata was given by Morse $(1895,16)$.

79. Tettigidea armata Morse, 1895, 107. Armored Grouse Locust.

Form usually longer and more robust than in $T$. lateralis, notably so in the females. Color dark gray or brown above, blackish on sides, the tegmina with a white spot on their apical third; hind femora usually more or less mottled with whitish on their outer face. Vertex but little projecting beyond front of eyes and scarcely wider than one of them; frontal costa, viewed from the side, prominent, its sulcus very narrow. Pronotum as described in key, its median carina distinct, sharp, nearly horizontal, its dorsal surface strongly roughened with rather long wrinkles, the sides in front of the shoulders a little excavated; hind margins of lateral lobes strongly bisinuate, tegminal sinus deep, acute, lower one broad, shallow, the lobe between them short, rounded. Tegmina elongateoval, their tips subacute. Wings in long form slightly surpassing the tip of pronotum, which extends 2 to $3.5 \mathrm{~mm}$. beyond tips of hind femora; in short form the wings shorter than pronotum, the latter reaching only to base of ovipositor in female. Length of body, $\hat{\delta}, 8.5-12.8_{i}$ 우 $11.5-17$; of pronotum, $\hat{o}, 7.5-11.5$,, $11.5-16$; of hind femora, $\hat{o}, 5.5-6$, , $7-8 \mathrm{~mm}$.

This grouse locust occurs sparingly throughout Indiana, adults being found from April to November. Morse's types were taken by me in Vigo County, where it occurred in small numbers along the wooded margin of a large lowland pond. In the northern counties it frequents woods about the margins of lakes and is usually found closer to water than is $T$. lateralis. In Florida it has been definitely recorded only from Jacksonrille, Monticello and Deep Lake, April-Oct. R. \& H. (1916, 153) give its range as extending from "Staten Island, N. Y., south to extreme southern 
Florida and westward as far as Riverside, Ill., Howe, Okla., and Dallas, Texas." They state that the short form (depressa Morse) is more common than the long one throughout its range, a condition not existing in Indiana, where the long one is much the more common. T. davisi Morse $(1908,25)$ is a synonym.

79a. Tettigidea armata spicata Morse, 1895, 108. Spined Grouse Locust.

"A small, slender, southern species, intermediate in structure of vertex between apiculata and armata, but more nearly allied to the latter. The vertex is more projecting than in armata, the body narrower across the shoulders, the lateral carinæe of pronotum but slightly developed, the median carina less distinct and the disc more finely rugulose. Length of body, $\hat{o}, 11.6$,, $15.6-16.2$; of pronotum, $\hat{o}, 10.5$, $q, 14.4$; of hind femora, ô, 5.5, ㅇ, $7.6 \mathrm{~mm} . "$ (Morse).

The above is the original description of $T$. spicata, which was described from one male from Georgia and two females from Florida. Specimens taken by me in Knox and Posey counties, Ind., and named spicata by Hancock, and others taken and so named by Daris from Wilmington, N. Car., and Lake Okeechobee, Fla., and by Hancock from Opelousas, La., are at hand, and a careful comparison shows that the vertex proper is not more projecting but the point of union of its median carina with the frontal costa is slightly more prominent. As pointed out by $\mathrm{R}$. \& $\mathrm{H}$., "the more areuate character of the dorsum of pronotum in transverse section between the humeral angles is one of the most apparent characters" distinguishing spicata from typical armata. These differences, however, are of less systematic value than those separating lateralis from its northern race parvipemnis, and I therefore regard spicata as only a slender-bodied southern race or form of armute. In addition to the localities above given $T$. a. spicata has been taken by me at Ormond, Fla., and is recorded from numerous localities between Jacksonville, Miami and Everglade in that State, occurring for the most part in low moist spots in pine woods and in bare spots along the edges of red mangrove swamps. It is known also from Georgia, Alabama and Louisiana.

A study of the type of $T$. apiculata Morse $(189.5,16)$ described from New Orleans, La., shows it to be very closely related to both armate and its race spicata, and a large series would perhaps show that spicata is only an intermediate or connecting link between the other two, and that all three are in reality but one species, which will have to bear the name apiculata, since that form was described in March, the others in September of the same year. I might add that aside from the prolongation of the front margin 
of pronotum into a cuspidate point, which $\mathrm{R}$. \& H. $(1916,152)$ show to be a variable character, there is little to separate $T$. $a r^{-}$ mata from $T$. lateralis and time mar prove that the two species of Tettigidea recognized by Say and Scudder, viz., lateralis and prorsa, are all that really occur east of the Mississippi River.

\section{Family VI. ACRIDID $\mathrm{E}^{37}$}

\section{The Locusts or Short-Horved Grasshoppers.}

To this family of saltatorial Orthoptera belong those shorthorned grasshoppers or locusts which are so common in our meadows and pastures and along our roadsides from mid-April until after the heary frosts of late autumn. They hare the antennæ, with few exceptions, much shorter than body, filiform, clubbed or ensiform in shape, the joints distinct, and often, especialls toward the base, depressed; head usually short, and in the leading subfamilies extended horizontally; ocelli always present, and foreolæe usually so; pronotum rariable in form and size, forming a buckler or saddle-shaped shield covering the three segments of thorax; tegmina and wings, when present and in repose, resting partly horizontal on the dorsal surface of abdomen and partly reflexed against its sides; auditory or hearing organ located on the side of the basal ring of abdomen; front and middle legs subequal in size, much smaller and shorter than the hind ones, the femora of the latter being, as in the other saltatoria, very much enlarged in their basal halves; tarsi 3 -jointed and similar in structure on all the legs, the first joint, usually the longest, with the under side marked with two cross impressions which, when viewed from below, make it appear to be composed of three segments; third or apical segment of tarsus ending in a pair of curved claws which enable the insect to catch and cling to blades of grass and other objects on which it may alight, these claws with a pad (arolium) between them; oripositor consisting of four short, horny pieces, the so-called valves, projecting from the tip of the abdomen, two of which curve upward and two downward.

The family name Acridida is derived from the Latin Acridium. meaning "a locust" and to the people of ancient times the "grasshopper" of to-day. was the "locust," one of the seren plagues of Egypt. The scientific men of this country have long endearored to have our American Acridians called "locusts" but the majority of the people persist in calling them "grasshoppers," and give the name "locust" to those noisy insects which once each seventeen

${ }^{37}$ Locustidæ of Kirby (1910) and recent authors. 
years invade our fields and forests in such countless numbers. The name "jumping grasshoppers" is also sometimes given our Acrididx to distinguish them from the "green" or "long-horned" grasshopper's belonging to the genera Orchelimum and Conocephalus of the fanily Tettigoniida. Latreille $(1831,15)$, in comparing the Acrididx with the other families of Saltatoria says of the former: "They leap better, fly higher and longer, and feed voraciously on vegetables."

The call notes made by the males of the Acrididx are produced in two ways and in the daytime only. One group, whose members call only when at rest, stridulate by

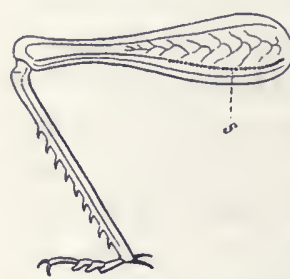

Fig. 67. Inside of hind femora of a locust; $s$. ridge with teeth. rubbing the inner surface of the hind femur against the lower outer edge of the tegmina. Landois has shown that in this group the inner surface of the femur is furnished along the lower margin with a longitudinal row of minute, lancet-shaped, elastic teeth, ranging in number from 85 to 93 , which are scraped across the edge of the tegmina, thus causing them to vibrate and produce a low, buzzing sound (Figs. 67, 68). Those Acrididæ which stridulate in this manner are mostly members of the subfamilies Tryxalinæ and Locustinx. Allard (1916) says that "at best their stridulations are hardly more than a brief lisping or a noisy crepitation," and states that the notes of two of the Tryxalinx, Chorthippus curtipennis (Harr.) and Eritettix simplex (Scudd.) are produced by "sawing both thighs simultaneously upon the edges of the tegmina." In the genus Mecostethus

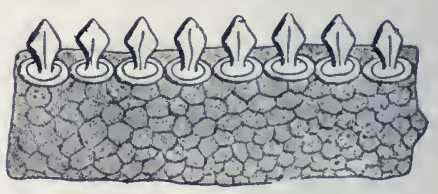

Fig. 68. Ridge and teeth of hind femur greatly enlarged. (After Landois.)

the teeth are borne on the intercalary vein of the tegmina and some of its branches, the ridge of the femur being smooth.

The member's of the subfamily Oedipodina usually sound their call during flight by rubbing together the upper surface of the front edge of the wings and the under surface of the tegmina, thus producing a sharp, crackling sound which has been likened to that of burning stubble. However, some of the Oedipodina stridulate at lest as well as during flight. Thus say's Scudder $(1893,63)$ "Acridians shuffle, rustle and crackle, while crickets shrill and creak and Locustarians scratch and scrape." By paying close attention, the observer can soon learn to know each species by its 
peculiar call. Like the other families of saltatorial Orthoptera, the males alone of the Acrididæ have musical organs, which is quite the reverse among some animals higher in the scale of life, where the females make most of the music and oftentimes much of the noise.

\section{“Happy the locusts' lives, \\ Since they all have noiseless wires."}

The great majority of Acridida in the latitude of Indiana pass the winter in the egg stage, the eggs being deposited by the mother

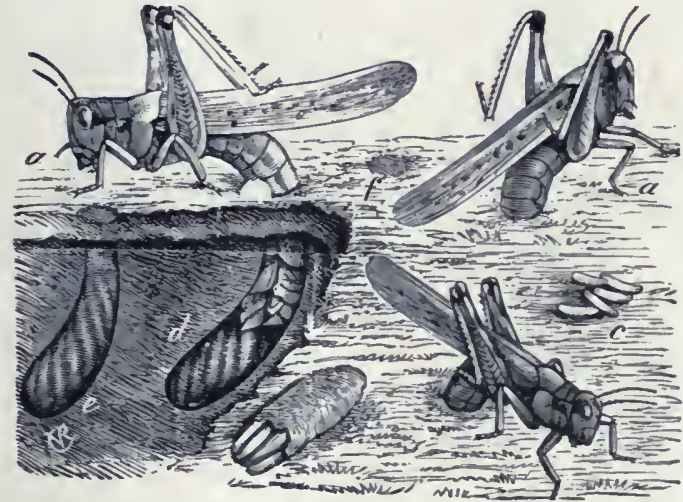

Fig. 69. Locust in the act of laying eggs. (After Fig. insect in earls autumn. When reads to oviposit she forms a hole in the ground or other nidus to a depth corresponding to the length of her abdomen.

The eggs are then deposited one at a time to the number of 30 to 60 , being placed in regular order in this hole. During the process a glutinous fluid is emitted around them

which at length hardens and binds them together, thus forming a bean-shaped mass. The hole above the mass is then closed with dirt intermixed with this fluid which, when it hardens, renders it partially imperrious to water. However, if the winter is an open one with numerous (changes of temperature, many of the eggs are apt to be destroyed. By far the larger number of eggs are deposited in the earth in the manner shown in Figs. 69 and 70 . A few species, however, oviposit in rotten or decaring wood. About mid-April the eggs begin to hatch and the sprightlr little insects, devoid of wings but otherwise like their
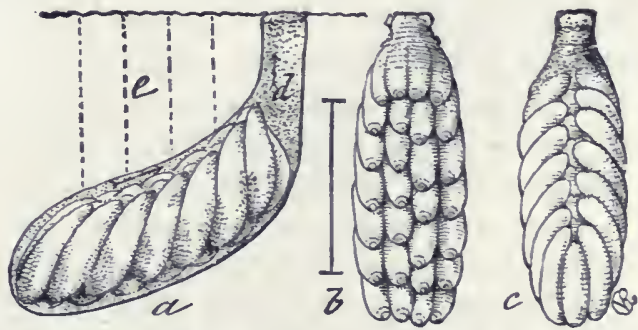

Fig. 7o. Egg mass of locust. $a$, from the side, within burrow; $b$, from beneath; $c$, from above; enlarged. (After Riley.) parents, are soon seen on erely hand. 
Born with one earthly desire-a voracious appetite-and with one valuable possession-a pair of strong, broad jaws, which move in and out like the blades of a pair of scissors-the little hopper soon begins to use the latter to appease the former, and during his early life spends most of his time in gnawing away at the soft, green succulent grass which surrounds him on every side. Such a procedure ean have but one result. His body soon becomes too big for its surroundings. Something must give way, and that
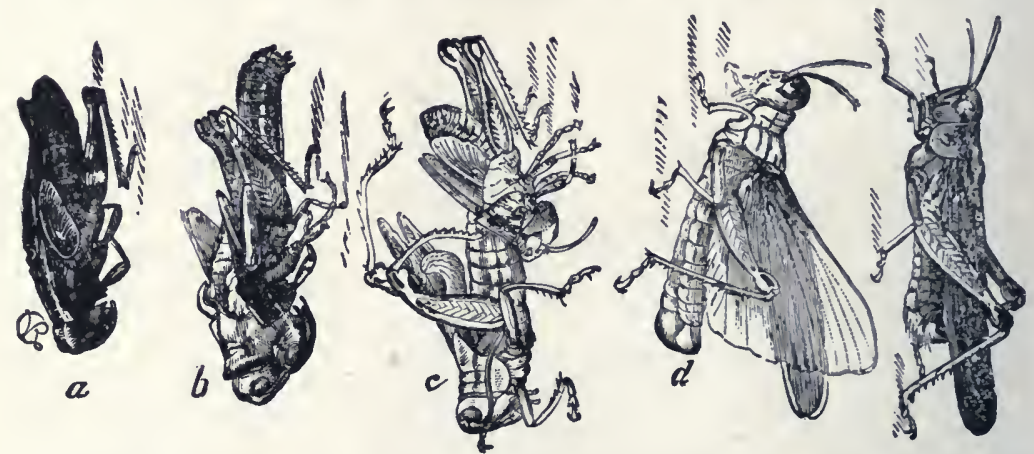

Fig. 7 r. Molting of a locust. $a$, nymph ready to change; $b$, the skin split along the back and the adult emerging; $c$, continues the process; $d$, the adult insect drying out; $e$, perfect adult. (After Riley.)

something is his skin. He easts it aside, however, with but little reluctance, for a new one is ready to take its place, and immediately begins to satiate his appetite once more. Five successive times his skin gets too small for his body and is cast aside. Between each of these moults the wings are growing, and when the fifth skin is shed le emerges a mature and full fledged insect.

However, all locusts do not pass the winter in the egg stage. In the southern States, especially in Florida, the adults of a number of species ean be taken almost any time between November and March if one will only search for them in the proper places. During the seven winters spent by the writer in central-western Florida the adults of 30 species of the family Acridida have been secured, some of them being very abundant in their favorite abiding places. A number of others winter there as nymphs, and in Indiana and other northern states three or four species hatch in early autumn and the young in various stages can, in suitable loealities, be seen jumping vigorously about on any warm sunny day in mid-winter. If their presence at such a season comes to the attention of a newspaper reporter, the press of the entire region is apt to teem with warnings of a coming "grasshopper 
plague," of which the youngsters are thought to be the advance guard. These hibernating roung are the first to reach maturity the next spring, in Indiana usually becoming full grown about the 20th of April.

In the latitude of central Indiana the heyday of the mature locust's life lies between the dates of mid-August and mid-October. Then it is that their love calls are most numerous, that their ambitions in life are satisfied, and that the eggs, destined to carry the race through the rigors of an approaching winter, are deposited in the earth. As the cooler days of Norember draw nigh their ranks grow rapidly less, and yet, with the exception of one place, their dead bodies are seldom met with. That exception is the tops of tall weeds where, oftentimes eren so early as September, the bodies of the more common species are seen (Fig. 15), their limbs tightly grasping the branches or leaves of the plant on which they rest. Why this position is taken by them before death I cannot say. Of course it is nonsense, but I have often asked myself the question: "Is it assuming too much of them to suppose that, haring lived their allotted time, or being presed upon by some invisible but insidious animal or plant parasite, and feeling their death throes coming on, they choose to fly or climb to the most elevated position available, there to take a farewell view of their summer's home?"

A number of species of Acrididx, especially of those belonging to the genus Melanoplus, possess, in the adult stage, only rudimentary tegmina and wings, and resemble immature insects or nymplis in appearance. A close examination will show, however, that these adults have the tegmina in the proper position, while in the immature stages of these and other forms, the tegmina and wings are inverted, being twisted about so that the faces and margins are just the opposite to what they are in the perfect insect.

About 140 species of the family Acridida are known from the eastern United States. These are dirided among three subfamilies, each of which is represented in our eastern fauna by numerous species.

\section{KEY TO THE SÜBAMILIES OF ACRIDIDE.}

a. Prosternum without a spine or tubercle between the front pair of legs.

$b$. Face more or less oblique, usually meeting the vertex at an acute angle; foveolæ usually absent or invisible from above; median carinæ of pronotum never raised in the form of a crest or cut by more than one sulcus; wings nearly uniformly transparent, 
never brightly colored or with a black band.

I. Tryxaline, p. 192.

bb. Face nearly or quite vertical and rounded at its junction with the vertex; foveolæ present and visible from above; median carina of pronotum often more or less crested and usually cut by more than one sulcus; wings usually bright colored and generally with a black band.

II. OEDIPODIN E, p. 243. aa. Prosternum armed between the front legs with a distinct conical or cylindrical tubercle; face vertical or nearly so; pronotum with dorsal surface flattened, never strongly crested, tuberculate or rugose; wings, when present, transparent, never with contrasting colors.

III. Locustine, p. 302.

\section{Subfamily I. TRYXALIN Æ.}

\section{(ACRIDINE.)}

\section{The Slant-Faced Locusts.}

The members of this subfamily liave the vertex horizontal or a little ascending; face usually decidedly oblique and meeting the vertex at an acute angle; lateral foreola sometimes present and well developed, in most of our eastern genera absent or invisible from above; eyes usually longer than that portion of the cheeks below their orbits; antenna variable, sometimes depressed toward base and acuminate, usually inserted between the middle or below the middle of eyes; pronotum with surface of dorsal field generally smooth, prozona not shorter than metazona, front and hind margins of nearly equal width, lateral carina usually distinct; tegmina and wings often short and imperfectly dereloped. long and short winged forms of the same species being not uncommon; tegmina with intercalary vein generally wanting, costal area often expanded and regularly reticulate by transverse reins.

Certain forms of Tryxalinse are very difficult to distinguish from some of the Oedipodina, and their reference to either group, as Brunner $(1893,103)$ has said, "est un peu arbitraire et repose sur l'estimation personelle"; i. e., somewhat arbitrary and a matter of individual opinion. In general it may be said that the Tryxalina have more slender bodies than the Oedipodina, and often somewhat elongate, cone-shaped heads, recalling the Copipliorina of the Tettigoniida. The coloration is also more variable, there being often distinctly green and brown forms with all the intermediate tints in the same species. In our eastern species of Oedipodinae this variation oceurs only in the genus Chortophaga. This variation of coloration is used as a means of protection, often rendering the insect almost invisible when feeding. The hind legs are more slender than those of most of the Oedipodinae and the 
leaping power is therefore lessened; while in many of the smaller species the wing expanse is too small to admit of sustained flight.

Our eastern members of Tryxalinæ for the most part frequent the borders of marshes and damp prairie meadows, making their home among the tall rank grasses and sedges which there abound. They usually move by flying, making no noise while on the wing. Several species, however, delight in sandy or elayey places, where clumps of bunch and wire grass furnish them protection and food. Their inner wings are never bright colored and showy as in the next subfamily, and their tegmina have, for the most part, remained a green or straw color in order to harmonize with their chosen abiding places. The males stridulate, or call the opposite sex to them, only when at rest by rubbing the inner surface of the hing thighs against the lower edges of the wing covers. No one of our speeies, unless it be Chorthippus curtipennis (Harr.), occurs in sufficient numbers to do much damage to regetation, and some of them are among the least common of the Acridida. In Indiana and other northern states the winter of all is passed in the egg stage, but farther south, especially in Florida, adults of a half dozen or more species occur in numbers during that season.

Aside from the general works on Orthoptera whose titles are given in the Bibliography, the following treat especially of North Ameriean Tryxalinæ: Scudder, 1890, 1898a, 1899, 1899a; Morse, 1896 ; MeNeill, 1S97; R. \& H., 1916; Rehn, 1919.

Thirty-eight genera and 90 speeies of Tryxalinæ were listed by Scudder (1900) from the United States, mostly from the region west of the Mississippi, and a half dozen or more species have since been described. Of these 16 genera and 26 species are known from the Eastern States, no fewer than 9 genera being represented by only a single speeies. For convenience of treatment the genera are grouped into five tribes distinguished as follows:

KEX TO EASTERI TRIBES OF SUBFAMILY TRYXALIX E.

a. Antennæ ensiform or triquetrous, strongly depressed at base and distinctly acuminate (Fig. 72); median carina of pronotum cut much behind the middle; face very strongly oblique; lateral carinæ of pronotum straight and parallel, except in Mermiria.

Tribe I. Tryxalixi, p. 194.

aa. Antennæ linear or filiform, sometimes narrowly depressed toward base; median carina of pronotum usually cut at or not far behind the middle; lateral carinæ often more or less converging at middle.

b. Foveolæ of vertex wanting or invisible from above; face usually distinctly oblique or declivent. 
c. Disk or scutellum of vertex with a distinct longitudinal median carina; antennæ usually more or less flattened but not strongly tapering.

Tribe II. Amblytropid, p. 207.

cc. Disk of vertex without a median carina; antennæ filiform, rarely flattened, usually not longer than head and thorax together.

Tribe III. ORPHULI, p. 222.

$b b$. Foveolæ of vertex always present, visible from above (Fig. 84,

c.) ; face usually nearly vertical.

d. Median carina of pronotum not high and sharp and not cut in or in front of middle; intercalary vein of tegmina not very strong; vertex without a median carina, its lateral foveolæ large, distinct.

Tribe IV. Chorthippi, p. 233.

dd. Median carina of pronotum high and sharp, cut in or in front of middle by the principal sulcus (Fig. 83, e, $f$, ); intercalary vein of tegmina very strong; vertex with a more or less distinct median carina, its foveolæ small, triangular and basal.

Tribe V. Mecostethi, p. 238.

\section{Tribe'I. TRYXALINI.}

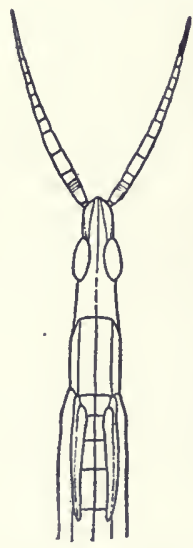

Fig. 72. Head and pronotum of Radinotatum showing ensiform antennix, short wings, e t c. (After R.\&H.)

Slender bodied grasshoppers having the sexes very unequal in size, the males much the smaller; head conical, horizontal or ascending, vertex distinctly produced in front of eyes, its apex more or less angulate; foreolæ wanting or indistinct; face strongly declivent; antennx strongly triquetrous or ensiform, usually equal to head and pronotum in length, female, or longer, male; pronotum with median carina distinct, front margin truncate, lateral lobes vertical. The tribe, as thus defined, is represented in our territory by four genera.

KEY TO EASTERY GENERA OF TRIBE TRYXALINI.

a. Head distinctly longer than pronotum, strongly ascending; knees, of hind femora with their apical angles strongly produced; spines of outer margin of hind tibiæ minute, about 25 in number; tegmina much shorter than abdomen. (Fig. 72.)

I. Radinotatum.

aa. Head sometimes equalling, never exceeding the pronotum in length, feebly ascending or subhorizontal; knees of hind femora with apical angles not produced but roundly deflexed; spines of outer margin of hind tibiæ stouter, not over 20 in number.

b. Prosternum without a tubercle between the front coxæ; front half of lower margin of lateral lobes of pronotum strongly oblique; sides of fastigium strongly curved, its apex distinctly rounded. 
bb. Prosternum with a distinct tubercle or low transverse ridge between the front coxæ; lower margin of lateral lobe straight or feebly sinuate throughout its length; sides of fastigium straight or slightly curved, its apex usually feebly rounded or more or less acuminate.

c. Vertex with a distinct median carina; tegmina and wings usually much shorter than the abdomen; outer carina of hind tibiæ with 14-17 spines; male with a stridulating rasp on hind femora; subgenital plate of male conical, more than twice as long as wide at base (Fig. 83, c.); sides of head and pronotum normally without a brown stripe.

III. Psecdopomala.

cc. Vertex at most.with only a faint trace of a median carina; tegmina and wings reaching or exceeding tip of abdomen; outer carina of hind tibiæ with $18-22$ spines; male without stridulating rasp on hind femora; subgenital plate of male usually scarcely longer than wide at base; sides of head and pronotum with a reddish or dark-brown postocular stripe.

IV. MERMIRIA.

I. Radicotatum McNeill, 1897, 199. (Gr., "a very slender thing.")

Form very slender, subcylindrical, compressed; head elongate, ascending; vertex projecting in front of eyes a distance equal to length of eyes, its sides broadly flattened, disk concare and with a long, distinct median carina, apex rounded or subangulate; face very strongly oblique, its frontal costa high and narrow between the antennæ, lower and somewhat wider below them, its sulcus distinct but shallow; eyes very long, their upper surface nearly horizontal; antennæ triquetrous, strongly tapering; pronotum

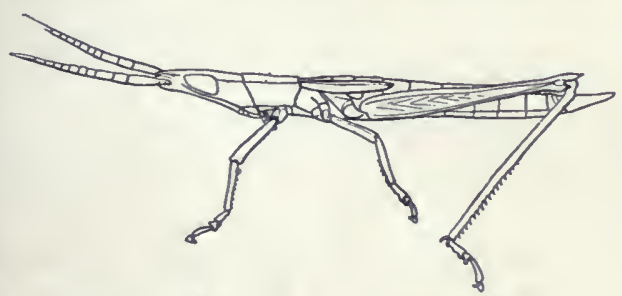

Fig. 73. Male, $X$ 1.5. (After R. \& H.) much shorter than head, its carinæ distinct and parallel, lateral lobes vertical, their front margin strongly oblique, lower one nearly straight, hind one broadly emarginate; tegmina a n d wings rudimentary; subgenital plate of male longer than thorax, lanceolate, acute; hind femora very slender, shorter than abdomen, female, reaching base of subgenital plate, male, their knees with apical angles strongly produced, the outer projection the shorter. One species is known.

80. Radixotatum BRevipeñe (Thomas), 1873, 58. Long-headed Locust.

Pale brown or grayish-brown, the upper surface, tegmina and legs often in part green. Antennæ slightly shorter than head and thorax, female, 
equal to or slightly exceeding their length, male. Median carina of pronotum very feebly cut by the transverse carina one-fourth from base, the latter truncate or nearly so. Tegmina about as long as pronotum, very narrow; bluntly pointed, separated by twice their width. Length of body,

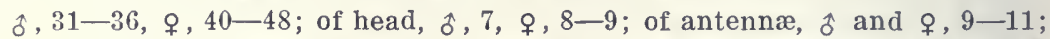
of pronotum, $\hat{o}, 4-4.5$,, $5.5-6$; of tegmina, $\hat{o}, 4.5-6$,,$+ 5-6.5$; of hind femora, $\hat{\delta}, 13.5-15$, $\circ, 17-19 \mathrm{~mm}$. (Fig. 73.)

This easily recognized locust occurs everywhere throughout the mainland of Florida on the wire grass and other undergrowth of open pine woods and among the tall grasses and sedges along the margins of ponds and lakes. In the northern and central parts of the State the majority of the eggs probably hatch in late summer and early autumn, as the most of those mentioned in the numerous records of Davis and $R$. \& $H$., as noted at that season, are nymphs. About Dunedin the nymphs far outnumber the adults between November and February 1st. After that date the adults begin to be more plentiful and by April 15 the most of those noted are mature.

In general appearance $R$. brevipenne is one of the most peculiar of our North American Acrididx, its form and color serving it admirably for protection among the tall grasses and pine needles. The first specimens ever seen by me were taken near Ormond, Fla., in March, 1899, and my field notes regarding them were afterwards published $(1902,149)$ as follows: "The first mature males of the slender-bodied, grayish-brown locust, Radinotatum brevipenne (Thos.) were seen on March 22. To-day (April 5) the adult females are abundant. It is the most curious Orthopteron found here at this season and has been recorded only from one or two points in Florida. Here it is common on the clumps of wire grass, in sandy places along the edges of woodland paths and old fields. Its short wings prevent it from flying, and as it is but a poor leaper, it is readily taken with the fingers. It relies upon protective mimicry as its chief mode of defense; hence its organs of locomotion, wings and legs, have developed but little, the former being mere pads, the latter very slender and used mainly for walking and for clasping the stems of grass. The brown, linear body, when extended lengthwise along a dead grass stem, is scarcely noticeable, so closely does its hue correspond to that of the grass. The insect remains motionless until about to be seized, when it sometimes gives a short leap to one side."

The known range of $R$. brevipenne extends from Yemassee, S. Car., Augusta and Macon, Ga., sontl throughout Florida, and as 
far west as Greenrille, Alabama, and Agricultural College, Miss. Kirby $(1910,101)$ gives "Florida and Mexico" as its habitat. I can find no other record of its having been found ing the latter country.

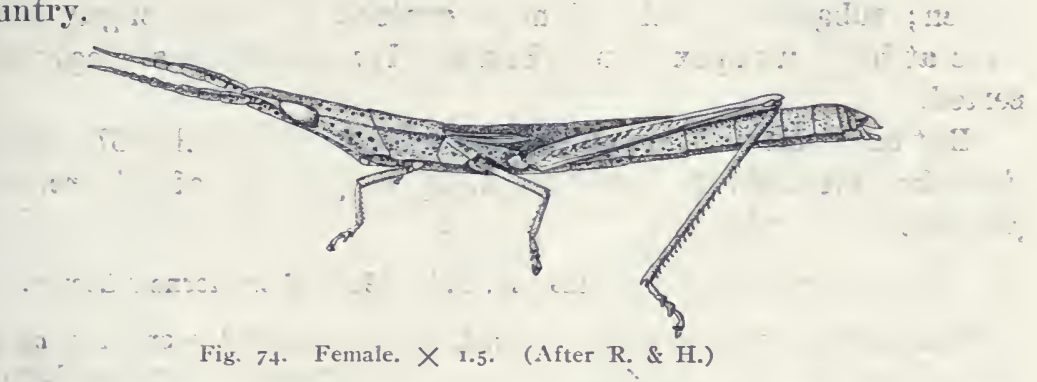

A so-called geographic race or subspecies of $R$. brevipenne was described by R. \& H. $(1912,246)$ as $R$. b. peninsulare (Fig. 74), they stating that it differs from typical brevipenne "in the longer head with much more produced rostrum and more concave face, longer antennæ, pronotum with shallower lateral lobes, more linear and usually shorter tegmina, longer and more slendel caudal femora and more delicate, shorter, genicular angles." All the distinctions as given are comparative only and may be found in any large series of specimens taken almost anywhere in Florida. They later $(1914 d, 103)$ state that two males and four females taken at Iakeland, Fla., "are absolutely intermediate between typical brevipenne and b. peninsulare in character." Notwithstanding this admission, they state in their latest mention of $R$. brevipenne $(1916,155)$ that "in central Florida the species intergrades with its geographic race $R$. brevipenne peninsulare." I have given abore the distinctions of peninsulare as set forth by its authors in order that the future student may apply that name to his southern Florida specimens if he so desires.

II. Trrxalis Fabricius, 1775, 279. (Gr., Troxallis = Gryllus.)

Vertex horizontal, semi-elliptical, projecting in front of eyes a distance about equal to that between them; disk with sides flattened, apex rounded, median carina very fine; antennæe flattened at base, acuminate, about as long as head and pronotum (Fig. 84, b) ; frontal costa with sides subparallel, shallowly sulcate, female, more deeply so, male; pronotum with disk flat, the three carinæ parallel, distinct, the median cut by one sulcus much behind the middle; lateral lobes vertical, parallel, slightly longer than high with front and hind margins oblique, the former 
straight, the latter sinuate; tegmina and wings fully developed, subequal in length; hind femora slender, their tips reaching, female, or exceeding by nearly half their length, male, that of abdomen; subgenital plate of male conical, scarcely longer than wide at base, its apex acute (Fig. 83 , d) ; ovipositor strongly exserted.

But one species is known, the T. angusticornis Stål $(1873,105)$, described from South Carolina, being a synonym of Dichromorpha viridis (Scudd.).

81. Tryxalis brevicornis (Linnæus), 1764, 398. Short-horned Locust.

Form, rather robust for the tribe, the males much the smaller, more

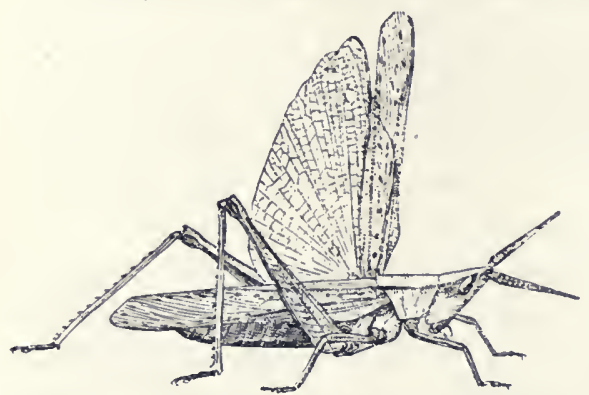

Fig. 75. Female, natural size. (After Beutennuller.) compressed. Females dimor. phic as to color, being either pale green with tegmina more or less dotted with brown, or with entire body nearly uniform rusty brown, often with a darker postocular line along head and upper sides of pronotum; males usually with dorsal surface, face and tibiæ of front and middle legs bright green, the other parts pale brown; wings transparent, the veins greenish. Pronotum with lateral carinæ slightly cut by all the transverse sulci, disk with hind margin feebly obtuse-angulate; metazona three-fourths as long as prozona, its surface rougher. Tegmina and wings more than one-third longer than abdomen, male, but slightly exceeding its tip, female. Length of body, $\hat{\delta}, 19-25$, \&, 32-35; of antennæ, $\hat{\delta}$ and $\$, 10-11$; of pronotum, $\hat{\delta}, 4.5-5, \&$, $6-6.5$; of tegmina, $\hat{o}, 20-21$,,, $30-31$; of hind femora, $\hat{o}, 14, q, 20 \mathrm{~mm}$. (Fig. 75.)

This curious long-headed locust occurs in suitable localities throughout Indiana. It frequents only the tall grasses and sedges along the margins of lakes, ponds, streams and swales, and in such localities is usually locally abundant. In central Indiana it reaches maturity about July 20, and in the northern part of the State a fortnight later. The hind legs are rery slender as the insect seldom leaps when disturbed, but uses the wings in strong. zig-zag, noiseless flight, usually alighting on a stem of grass or sedge a dozen rods away. Frank Hay, of Bass Iake, Starke County, reported a flight of this species after dark on the evening of August 13. Iarge numbers flew onto his porch and against the house and many were captured and used for fish bait. 
Although Scudder in his Catalogue gives the range of $T$. brevicornis as "southern U. S.," it has been taken by Walker (1902a, 251) as far north as Point Pelee, Ont., while Beutenmüller (1894, 291) has recorded it from Long Island, N. Y., and Smith from New Jersey, where it is found in both fresh and salt marsh areas, but more abundant in the latter. From the points mentioned its known range in this country extends west to eastern Nebraska and south and southwest to northern Florida, Mobile, Ala., Franklin, La., and central Arkansas, the Nebraska and Arkansas records being the only ones from west of the Mississippi. East of that stream, from Illinois and Maryland to Florida, it appears to occur frequently in suitable localities, judging from the records of Morse $(1904,28)$ and R. \& H. $(1916,155)$. In Florida, however, it seems to be quite scarce and no specimens have been taken by me though a male is at hand taken July 22 on the University grounds at Gainesville. The only localities recorded by others from the State are Atlantic Beach, Marianna, Monticello and Everglade. The single female taken at the last named place by Daris is said by R. \& H. $(1914 \mathrm{~d}, 104)$ to measure $39.4 \mathrm{~mm}$. in length of body and to be the largest individual seen from any locality between New Jersey and Buenos Aires, Argentina, to which point the species ranges.

\section{Pseudopomala Morse, 1896, 325 .}

Slender-bodied species having the head conical; vertex semielliptical, horizontal, female, slightly ascending, male, extending in front of eyes a distance equal to its basal width; disk with sides flattened, concave each side the distinct median carina, apex feebly obtusely rounded; frontal costa rather low and wide, narrowed above the antennæ, divergent below, widely and shallowly sulcate; antennæ strongly ensiform (Fig. 84, a), equalling, female, or one-half longer, male, than length of head and thorax; pronotum about one-fourth longer than head, tricarinate, the carina parallel, all cut by the principal sulcus distinctly behind the middle; lateral lobes vertical, their front margin straight, oblique, hind ones feebly concave; hind femora slender, subequal to or slightly shorter than abdomen in both sexes; ovipositor short, scarcely exserted, the lower valves furnished with a strong tooth each side.

This genus, as founded by Morse, was placed in the subfamily Tryxalina. In this he was followed by McNeill (1897, 208). Scudder did not coincide with this placement, and (1899e) placed 
it in the tribe Mesopes, which, in his Catalogue, is located near the beginning of the Acridinæ (Locustinæ). While the prosternum bears a tubercle, it is very short and obtuse, and the other characters are so decidedly those of the Tryxalinæe that $I$ have no hesitancy in so placing it. But one speçies is known.

82. Pseudopomala BRachyptera (Scudder), 1862, 454. Bunch-grass Locust.

Slender, strongly compressed. Above pale brown or drab, yellowish below; antennæ, hind tibiæ, knees and tibial spines with tips fuscous;

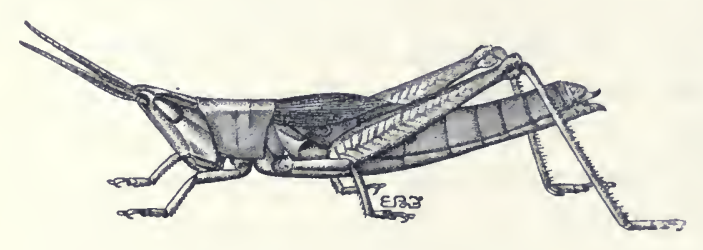

Fig. 76. Female. $\times$ 1.5. (After Lugger.) tegmina and upper surface of head and pronotum often with small scattered fuscous dots. these sometimes merged to form a dark stripe along the side of head and pronotum. Disk of pronotum with hind margin truncate; metazona two-thirds as long as prozona, its surface finely rugose. Tegmina usually abbreviated, about three-fourths as long as hind femora, their tips sharply rounded, male, as long as head and thorax with tips acuminate, female; wings half as long as tegmina; both in occasional examples as long as hind femora and then with tips rounded in both sexes. Length of body, $\hat{o}, 23-27,2$, $27-30$; of head and pronotum, of, 7.3-8.5, $\$, 9.5-11.5$; of antennæ, $\hat{\delta}, 9.5-11.5$, $ᄋ, 8.5-10$; of tegmina, short-winged, $\hat{\delta}, 9-12.5$,,, $7-12$; of tegmina, long-winged, $\hat{o}, 15.5-17$, $ᄋ, 18-22$; of hind femora, $\hat{\delta}, 13.5-15.5$,, $14-19 \mathrm{~mm}$. (Fig. 76.)

Sherborn, Mass., July 15 (Morse) ; Gardiner's Island, X. Y., Aug. 23 (Davis). Of its habits Morse has written (1896, 3S2) as follows: "This peculiar locust is not uncommon locally on the coarser grasses found in waste lands, especially upon a species of bunch-grass (Andropogon scoparius Michx.) everywhere abundant. Though a good leaper and fairly active, it is not shy and seeks safety in attempting to escape observation by sidling around the grass stems rather than by active retreat. I once saw a longwinged female fly several feet, proving that with the possession of the means came the power of flying. Its sluggish habits, however, in connection with its linear form, render it less likely to attract the attention of its enemies, and to the biologist it is perhaps the most interesting of our New England locusts on that account. It must be seen in the living state to lave its full beauty appreciated. The singular, almost grotesque, yet graceful form interests even the casual observer, and its coloration of lilaceous 
drab, giving it almost the appearance of being clothed with a delicate bloom, pleases the most fastidious eye." Fox $(1914,486)$ states that inland in New Jersey and Pennsylrania it frequents dry scrubby areas, usually in sylvan surroundings, but along the coast it is partial to the fringes of marsh elder, Ira frutescens L., along the edge of the salt marshes. At Fern Hill, Pa., it was noted as exceptionally common on serpentine barrens.

Scudder's type of $P$. brachypter $a$ was from Princeton, Mass., and Morse states that it doubtless occurs throughout New England. Scudder $(1900,46)$ gives its range as "Northern United States east of the Rocky Mountains"; but it is as yet not known from Indiana, and west of New England has been definitely recorded only from New York, Pennsylvania, New Jersey, Michigan, Iowa, Nebraska, Minnesota and eastern Wyoming. In Nebraska Bruner mentions it (1893a) as "not at all rare orer the entire State; most common eastward and northward." McNeill (1897, 210) gives its range as "Northern United States east of the Sierra Nerada Mountains," and adds: "Its distribution throughout the territory it inhabits is comparatively irregular. There is a gap in this range extending from Illinois to New York and Pennsylvania, but since it is found in New England and from Iowa to Utal, there is little doubt but that its non-occurrence in the intermediate area is due to the fact of its extreme rarity." R. \& H. (1905) erroneously recorded it, on a specimen wrongly labelled, from Chokoloskee, Fla.

Although the males of $P$. brachyptera have well developed stridulating organs the only record of their use which can be found is that given by Shull (1911). He states that adults were observed at Sand Point, Saginaw Bay, Mich., June 2i-July 21, where they occurred in open woods, patches of tall grass, and on grassy sand dunes. "The males were often found in song, especially in the morning. They usually perched on some dead grass stem, drew up the tibiæ against the femora like a folding pocketrule, and scraped the leg up and down over the wing covers. The rate of stridulation varied from five and a half to nine double strokes (up and down) per second, and some twenty complete vibrations were made in succession, followed by a period of rest about half as long."

The long-winged form, reversa Morse, is not rare in New England, and is known from Nebraska and Michigan. The Opomala aptera Scudder $(1869,305)$ described from a single Penn- 
sylvania female and otherwise unknown, is very probably a synonym of $P$. brachyptera. The description is based largely upon the color; the length being given as $35 \mathrm{~mm}$., and that of the tegmina as $6 \mathrm{~mm}$. The type is lost.

\section{Mermiria Stål, 1873, 90, 102.}

Elongate, moderately slender species having the head slightly ascending, rather long, equalling or but slightly shorter than the length of pronotum; rertex horizontal, triangular or semi-elliptieal, its sides distinctly raised, apex either rounded or more or less acute, median carina faint or wanting; face strongly oblique, more so in male, frontal costa prominent, parallel and deeply sulcate above the ocellus, sometimes more shallowly and slightly divergent below; antennæ strongly ensiform, equalling, female, or exceeding, male, the head and pronotum in length; pronotum long, with disk slightly tectiform, hind margin truncate, feebly rounded or slightly obtuse-angulate; lateral earinæe usually indistinet or wanting, median one cut by the principal suleus much behind the middle; lateral lobes vertical and parallel, front and hind margins oblique, lower one slightly sinuate; tegmina and wings fully developed, equalling or slightly exceeding the tip of abdomen; hind femora long and slender; prosternum armed between the front femora with a small obtuse tubercle; subgenital plate of male conical, shorter than the preceding ventral segment; ovipositor small, short, feebly exserted.
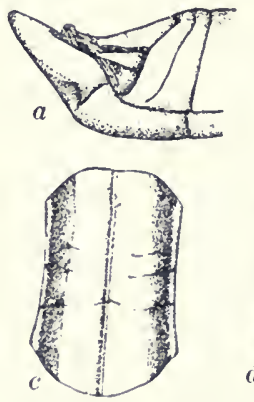

Fig. 77. Structures of Mermiria.
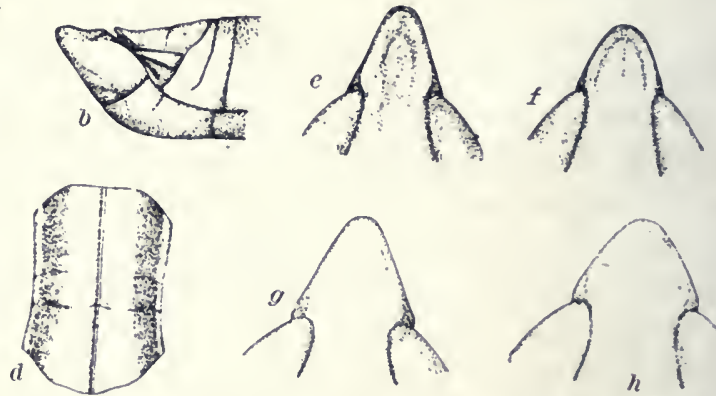

$a$, Apex of abdomen of male of neomexicana; $b$, same of bivittata; $c$, dorsal view of pronotum of alacris; $d$, same of bivittata; $e$, dorsal view of fastigium of alacris; $f$, same of neomericana; $g$, same of intertexta; $h$, same of bivittata. (After Rehn.)

Seven North American species were recognized by Scudder $(1899 \mathrm{a}, 41)$; eight by Kirby $(1910,104)$, and six species and one variety or subspecies by Rehn (1919). Four species and one variety have been recorded from the Eastern States, but no one of them has as yet been taken in Indiana. 
KEY TO EASTERN SPECIES OF MIERMIRIA.

a. Lateral carinæ of pronotum distinct (Fig. 77, c.) ; head of female as long as or slightly longer than pronotum (Fig. 78 , A.); subgenital plate of male strongly produced and acuminate (Fig. $77, a_{0}$ )

b. Fastigium triangular, its sides nearly straight and tip narrowly rounded (Fig. 77, e.); tegmina largely green; hind margin of pronotum slightly obtusely angulate or rounded. 83. ALACRIS.

$b b$. Fastigium semi-elliptical, the sides more strongly curved and tip broadly and bluntly rounded (Fig. $77, f_{.}$) ; tegmina usually transparent brown, the marginal field alone tinged with green; hind margin of pronotum subtruncate. 84. NEovexicaxa.

aa. Lateral carinæ wholly wanting or (intertexta) feebly indicated (Fig. $77, d$. ); head of female distinctly shorter than pronotum (Fig. 78, B.); subgenital plate of male rather short, conical, blunt at tip (Fig. 77, b.)

c. Fastigium of vertex more prominent and angulate, its greatest width not more than its length in front of eye (Fig. 77, g.); frontal costa distinctly narrowed at point of union with vertex, its sulcus deep throughout; lateral carinæ evident but faint.

85. INTERTEXTA.

cc. Fastigium of vertex bluntly rounded, its greatest width more than its length before front margin of eye (Fig. $77, h_{\text {. }}$ ); frontal costa but slightly narrowed at point of union with rertex, its sulcus shallow and below the ocellus evanescent; lateral carinæ wanting.

d. Male without a pale subcostal stripe on basal half of tegmina; vertex with a more or less distinct median carina; general color greenish.

86. BivitTATA.

dd. Male with a subcostal pale stripe on basal half of tegmina; vertex without a median carina; general color buffy.

87. MACCLUNGI.

83. Mermiria ALACris Scudder, 1877b, 30. Lively Locust.

Elongate, rather robust; color largely green; head green, with a median reddish-brown stripe above, and a broader postocular one, each side, all three often extending back to hind margin of pronotum; face with a narrow similar stripe each side; tegmina green, usually with a narrow reddish stripe reaching from base three-fourths or more to apex along the median area; antennæ and tibiæ reddish-brown; hind femora dull green tinged with fuscous brown. Pronotum and head subequal in length, the former with lateral carinæ distinct on prozona, which is twice as long as metazona. Tegmina and wings extending slightly beyond tip of abdomen. Subgenital plate of male very strongly produced. Length of body, $\hat{\sigma}$,

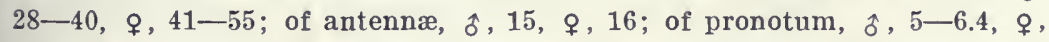

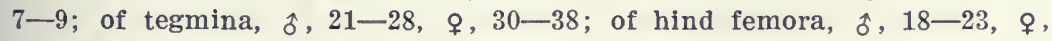
$28-29 \mathrm{~mm}$.

Dunedin, Fla., Oct. 29, one female (W. S. B.); Mobile, Ala., Aug. 25, Sept. 19 (Loding) ; Macon, Ga., Oct. 12 (For). Record- 
ed elsewhere in Florida from numerons stations as far south as Ft. Myers. It is mainly a dry-land species, inhabiting the tall grasses and the undergrowth of open pine woods, though sometimes found on bunch grass in old fields or the borders of swampy timbered areas. Adults have been taken from mid-July to the last of November. The reddish-brown stripes have in life a purplish or rosaceous tinge, and the insect is one of the most handsome of the Tryxalina. Its known range in our territory is from central North Carolina and northern Georgia, south and west to Ft. Myers and Dunedin, Fla., Mobile, Ala., and Hattiesburg, Miss. West of the Mississippi it has been recorded by Morse from Wilburton and Shawnee, Okla., and by McNeill and Scudder from Dallas, Texas. As first pointed out by Morse $(1907,27)$ M. vigilans Sendder (1899a, 43) is a synonym; as is also the $M$. rostrata McNeill $(1897,207)$ from Mackay, Oklahoma.

\section{Mermiria neomexicana (Thomas), $1870,77$.}

Form rather slender, compressed. Color pale brown, the head and marginal field of tegmina sometimes green, and then the dorsal field of the latter tinged with reddish; median stripe of head often faint or wanting, the lateral ones as in bivittata. Head as long as thorax; vertex as described in key, often with a faint median carina; sulcus of frontal costa rather shallow, with sides feebly divergent below the ocellus. Pronotum with lateral carinæ entire, distinct but low; metazona one-half the length of prozona. Tegmina and hind femora reaching tip of abdomen. Subgenital plate of male strongly tapering, slightly shorter than the preceding segment. Length of body, $\hat{\delta}, 27-35$, 우 $37-52$; of pronotum, $\hat{\delta}$, $4.1-5.8$, ㅇ, $6-8$; of tegmina, $\hat{o}, 17-27$, 오 , 23-33; of hind femora, ô, 16-21, ᄋ, $20-28 \mathrm{~mm}$. (Fig. 78 , A.)
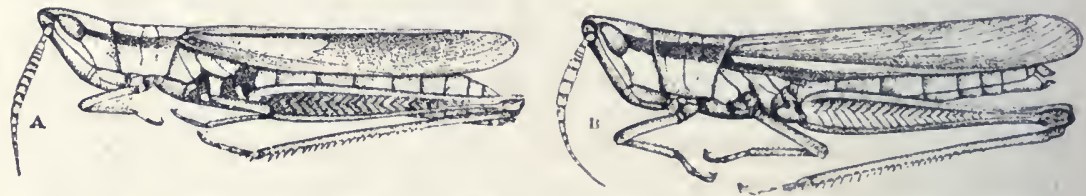

Fig. 78. Females of Mermiria. A, M. neomericana' (Thos.); B, M. bivittata (Serv.). Natural size. (After Rehn.)

This species is included in this work on the strength of the Illinois records by Hart $(1907,231)$ and Vestal $(1913,20)$. Hart reported it as taken with $M$. bivittata (macclungi) near Havana and Teheran, August 18-Sept. 2, being "found among long bunch grass between the sand dunes." The types of Thomas were from northeastern New Mexico, and its known range extends from northwestern Illinois west to eastern Montana and sonth and southwest to central and western Texas, sonthern Arizona and 
Durango, Mexico. Specimens at hand receired from Bruner are labelled "Western Nebraska," and he records it (1893a, 22) as occurring upon the prairies of the entire State, frequenting rather high grounds in preference to low ones. Morse $(1907,28)$ records it from Oklahoma and Texas, and adds that "it is characteristic of the drier parts of the prairie-plains and is often locally abundant." II. belfragii Stål $(1873,102)$ described from Texas, is regarded as a synonym.

\section{Mermiala ixtertexta Scudder, 1899a, 42.}

Close to bivittata, the principal differences given in the key. The brown median stripe on head and thorax is usually present and the lateral ones distinct. "Fastigium in both sexes scarcely broader than its length beyond the narrowest part of vertex (Fig. 77, g) ; triangular, male, or subtriangular, female, with straight, male, or arcuate, female, sides and blunt apex, the margins slightly ascending and with faint or no median carina." Disk of pronotum more than twice as long as broad, lateral carinæ evident but rague, median one rather strong, hind margin feebly obtuse-angulate. Tegmina and wings reaching, hind femora slightly exceeding, the tip of abdomen. Length of body, $\hat{\delta}, 31-42, \uparrow, 46.5-57$; of antennæ, $\hat{\delta}, 18, \uparrow$, 15 ; of pronotum, $\delta, 5-7$,, $7.6-9$; of tegmina, $\hat{\delta}, 23-28$, ㅇ, 33-40; of hind femora, $\hat{\delta}, 18-22$, $ᄋ, 26-31 \mathrm{~mm}$.

Ocean View, Va., Aug. 9 (Caudell); Millenbeck and Portsmouth, Ta., Aug. S., Oct. 3 (Fox) ; Dunedin, Fla., Oct. $2 S$ (W. S. B.). In Florida this locust has been recorded by Davis and $R$. $\mathbb{E}$ H. from a dozen different localities from Jacksonville and Cedar Keys southward, and it doubtless occurs throughout the State, including the southern keys. It is a lover of moist places and is usually to be found among the tall grasses and weeds of both salt and fresh water marshes, but sometimes occurs in the undergrowth between the adjacent dunes. Morse (1904, 29) states that it is a "shy and active insect, flying freely and far, and on alighting dodges quickly around the grass stems to escape observation, or, slipping nimbly downward and backward, seeks to hide itself." Scudder's types were from Georgia and Eagle Pass, Texas, and its known range extends from New Jerses and Virginia, south and southwest to the latter place.

86. Mermiria bivitita (Serville), 1839, 589. Two-striped Mermiria.

Form rather robust for the genus. Male usually greenish or citronyellow, with tegmina pale brown at base, becoming darker brown apically; female usually darker, the upper surface often with a purplish tinge, tegmina dark brown with a distinct greenish-yellow subcostal stripe; both sexes with a shining chocolate-brown postocular stripe extending along the upper third of lateral lobes and sometimes with a reddish-brown me- 
dian one on occiput; hind femora reddish or purplish-brown; hind tibiæ red, the spines tipped with black. Head of male but slightly shorter than pronotum, of female, distinctly shorter. Vertex as described in key, the angle at juncture of frontal costa and fastigium rather broadly rounded. Hind margin of pronotum broadly obtusely angled. Tegmina slightly surpassing tips of hind femora in both sexes. Subgenital plate of male with apex forming a short, rather blunt compressed cone. Length of body, $\hat{o}, 29-37$, 우, 40-51; of pronotum, $\hat{o}, 4.6-6$, ㅇ, 7-8.4; of tegmina, $\hat{\delta}, 20-27$, $\uparrow, 30-36$; of hind femora, $\hat{\delta}, 17-21, \mathcal{\imath}, 25-30 \mathrm{~mm}$. (Fig. 78, B.)

The above is a description of the form placed under Serville's name bivittata by Rehn, specimens of which were examined by me at Philadelphia. It is very close to the typical form of $M$. maculipennis Bruner $(1890,54)$ described from Texas, the females being very difficult to separate.

As placed above $M$. bivittata ranges from eastern North Carolina and northern Florida west to central Texas and northward west of the Mississippi to West Point, Nebraska and Keoluk, Iowa. From Florida it is known only by two males, taken at Pablo Beach and Ft. Barrancas. According to Rehn it frequents for the most part "areas of rich high grass, with or without intermingled weeds." At Lane, S. Car., it was locally abundant "in the high grasses of long-leaf pine woods," while in Texas it was found on grasses in both post oak and open short-leaf pine forests. Adults occur from June 30 (Texas) to Oct. 1 (Iowa).

In the past this species has been much confused with $M$. maculipcnnis and its variety, macclungi, but in addition to the characters given above it differs generally by the color which is a "more decided and richer green and a clearer, more transparent red-brown."

87. Mermiria maculipendis Macclungi Rehn, 1919, 111. McClung's Locust.

Form slender for the genus. Pale wood-brown or dirty cream-buff more or less greenish-yellow beneath; behind each eye a rather wide purplish-brown stripe usually extends backward to hind margin of pronotum; head of male sometimes with a similar median stripe; antennæ and hind tibiæ reddish; tegmina in both sexes with a narrow greenish submarginal stripe on basal half; wings transparent; knees of hind legs and tibial spines tipped with black. Pronotum but slightly narrowed at middle, median carina distinct, metazona two-thirds the length of prozona, finely reticulate; hind margin feebly subangulate. Tegmina and hind femora reaching the tip of abdomen, female, slightly surpassing it, male. Length of body, $\hat{\delta}, 26-32$, 오 $36-45$; of antennæ, $\hat{\delta}, 13-15, ㅇ, 12-14$; of pronotum, $\hat{\sigma}, 4.1-5, \uparrow, 5.5-7$; of tegmina, $\hat{\delta}, 19-23,9,27-32$; of hind femora, $\hat{o}, 15-18$,, $21-26 \mathrm{~mm}$. 
Lincoln, Neb., Sept.; Logan Co., Kansas, August (Bruner). This variety or subspecies of the southwestern $M$. maculipennis Bruner has been hitherto recorded by most American authors as opomala bivittata or Mermiria bivittata (Serv.). Its known range extends from northwestern Illinois west and north to southern Montana and northern Utah, and south to southern Missouri and southwestern Kansas. In Illinois Hart $(1907,231)$ states that it was taken with $M$. neomexicana at Havana and at Teheran "among long bunch grass, Panicum virgatum L., in an old blowout between sand dunes"; also at Tamaroa and Chautauqua. Rehn states that it frequents for the most part patches and stretches of sparse short grass and has been taken as adult from July 8 to Sept. 14.

The three forms, bivittata, maculipennis and macclungi, are very closely related and were it not that Mcclung has shown the chromosomes of the first two named to be different, I should place them as did Scudder (1899a) as one widely distributed and variable species under the name of bivittata Serv.

Tribe II. AMBLYTROPIDI.

Shorter and usually proportionally stouter species than those of the preceding tribe, having the antenna distinctly flattened (except in Amblytropidia) but not ensiform or triquetrous; head not conical, never longer than pronotum, not or very feebly ascending; vertex with a distinct median longitudinal carina, its apex usually rounded and sides not or but slightly raised; foveolæ wanting or invisible from above; face distinctly oblique but much less so than in the Tryxalini; pronotum with lateral lobes less distinctly vertical, lateral carina usually converging at middle and diverging on metazona, parallel in two genera; median carina usually cut once in or not far behind the middle; tegmina with tips rounded; wings transparent. Six genera represent the tribe in the Eastern States.

KEY TO EASTERX GENERA OF AMBLYTROPIDI.

a. Hind tibiæ armed on the outer margin with 18 to 21 rather small spines; color of female usually largely green; sexes very unequal in size.

I. Syrbula.

aa. Spines on outer side of hind tibiæ 10-15 in number; color of female, in great part at least, brown or grayish-brown; sexes more equal in size.

b. Disk of pronotum with lateral carinæ converging near middle (feebly so in Eritettix) and closer together there than at either the front or hind margin. 
c. Apical spurs on inner side of hind tibiæ very unequal in length, the middle one sometimes twice as long as the others; occiput and often the disk of pronotum with supplementary carinæ.

d. Antennæ-depressed and somewhat clavate toward apex (Fig. $83, h)$; tegmina as long as the abdomen; lateral carinæ subparallel.

II. ERITETTIX.

dd. Antennæ depressed toward base and narrowed toward apex, which is blunt; tegmina shorter than abdomen; lateral carinæ much curved inward at middle. III. PeDeticum.

cc. Apical spurs on inner side of hind tibiæ subequal; occiput and pronotum without supplementary carinæ; all carinæ of pronotum cut much behind the middle by the principal sulcus; antennæ of male twice or more the length of pronotum, their basal halves strongly flattened.

IV. Cinlealtis.

$b b$. Disk of pronotum with lateral carinæ, when present, strictly parallel or diverging very slightly on the metazona.

e. Head and thorax striped with brown; scapular area of tegmina dilated, subhyaline; pronotum with lateral carinæ very faint or wanting; supplementary carinæ usually present in female; smaller, female not over $22 \mathrm{~mm}$. in length. V. Ampiritoryus.

ee. Color uniform brown or grayish-brown; scapular area of tegmina not dilated, opaque; lateral carinæ of pronotum evident; supplementary carinæ wanting; larger, female 27 or more $\mathrm{mm}$. in length.

VI. AMBLytrofida.

I. Syrbula Stål, 1873, 90, 102.

Head nearly, female, or fully, male, as long as pronotum; occiput moderately rounded and feebly ascending; rertex subtriangular, its sides rather prominent, median carina distinct, front margin subangulate, deflexed and rounded into the frontal costa; antenna filiform, flattened toward base, expanded apically in the male; frontal costa wide, narrowed at apex, deeply sulcate, male, feebly so, female; pronotum with the three carina distinct, the lateral gently or strongly sinuate, so that the disk is plainly narrower at middle, all cut by one sulcus slightly behind middle; lateral lobes of pronotum abont as high as long, their front and hind margins moderately oblique, the latter slightly sinuate, the lower margin more or less undulate; tegmina well dereloped, equalling or slightly exceeding the abdomen in both sexes, those of male distinctly, regularly reticulate except in the anal and scapular areas, which are widened, those of female feebly reticulate and not expanded in the areas mentioned; hind femora un. usually long and slender, surpassing the tips of tegmina in our species; subgenital plate of male acutely conical, not longer than the preceding segment; ovipositor moderately exserted. 
Ten species of the genus are listed by Kirby $(1910,107)$, of which four occur in the United States, the others in Mexico. But one is known from our territory.

88. Syrbula Adilnabilis (Uhler), 1864, 553. Handsome Locust.

Male much smaller and more slender than female, its general color olive-brown and yellowish; face yellowish, the corners of mouth pitchbrown; antennæ with basal two-thirds yellowish, the apical club-shaped portion with one side fuscous, the other pale; a narrow line running obliquely backward from each eye to the pronotum and the lateral carinæ and lower fourth of lateral lobe of pronotum, yellowish; tegmina brownish, the disk more or less dusky near base; hind femora yellowish with two or three oblique dusky bars on upper outer face, knees black; hind tibiæ pale, the spines tipped with black. Female, face and sides of head green, antennæ pale at base, the apical hall usually dusky; a pale reddish-brown stripe extends from tip of vertex backward to hind margin of pronotum, this bordered each side by a black stripe which is much narrower on head; sides of pronotum green with a fuscous bar across the middle; tegmina smoky brown, the dorsal and costal fields each with a bright green stripe, the latter notched above by the serrations of a fuscous stripe, which lies between the two green areas; wings smoky brown, tinged with greenish yellow at base; hind femora with upper lateral carinæ whitish, upper outer face green, the lower reddish-brown; hind tibiæ as in male; ground color of female rarely brown, that of male rarely green. Structural characters as given under the genus heading. Length of body, $\hat{\sigma}, 22-27$, 우 $35-40$; of antennæ, ô, $9.5-11$, ᄋ , 10-10.5; of pronotum, ô, 4.5-5, 우, $6-6.5$; of tegmina, $\hat{\delta}, 18-20, \uparrow, 26-27$; of hind femora, $\hat{\delta}, 17.5-19$, ㅇ., $24-26 \mathrm{~mm}$.

This prettily colored locust is nowhere common in Indiana, having been taken sparingly only in the southern half of the State and Tippecanoe Co. in the north. It frequents, for the most part, high, open uplands, where the soil is poor and corered with seant regetation, though it is sometimes found in timothy meadows and along roadsides where the grass has been cropped short. But few individuals have been noted in any one locality. It reaches maturity about August 1st. The males differ so much in size and color from the other sex that they are very apt to be considered a distinet species. As the slender legs indicate, the morements are made mostly by the wings, the flight being rapid and noiseless.

In Florida it appears to be widely distributed through the northern part of the State, numerous records haring been made as far south as Gainesville. Below that place, so far as known, only two specimens, both females, have been taken, one at Miami by R. \& H., Sept. 1, which measured $45.2 \mathrm{~mm}$. in length, the other by the writer at Dunedin, Dec. 24. There it oceurs on wire grass in open pine woods. 
The range of S. admirabilis is given by McNeill as "United States east of the Rocky Mountains, extending as far north as Nebraska and northern Illinois, and on the Atlantic coast to Maryland." It is not recorded from New England, Iowa or Michigan, but has been taken in central Ohio. It is known from Pennsylvania and New Jersey, and occurs most commonly south and southwest from the latter State, having been recorded as far at least as Victoria, Texas (Caudell, 1903, 781) and La Trementina, New Mexico. Morse $(1907,28)$ says that it "is one of the commonest and most generally distributed locusts in the South, occurring most abundantly among grasses in dry stations and waste places." In Virginia Fox (1917) records it as: "A frequent and widely distributed species in old neglected fields and pastures, especially those overgrown with Andropogon and other coarse and dry grasses; less commonly found in open woodland scrub." The only account of its stridulation which can be found is by Allard (1916) who says: "The male is rather musical, producing a weak, lisping stridulation at intervals-s-s-s-s-s-s-s-s-s-s-s, by sawing the hind femora upon the edges of the tegmina."

\section{Eritettix Bruner, 1890, 56. (Gr., "heath" + "grasshopper.")}

Species of small size having the head conical, horizontal; vertex triangular, broader than long, its sides raised and apex obtusely rounded; occiput with three carinæ, one median and two supplementary, the latter often feeble, extending from pronotum to opposite front margin of eyes and there bending and joining the lateral carinæ of vertex; foveolæ present below the vertex, small, subtriangular, not visible from above; frontal costa rather wide, sulcate, with sides feebly diverging from slightly above the ocellus downward; antennæ not reaching base of pronotum, flattened toward base, enlarged toward apex; pronotum tricarinate and also often with a pair of supplementary carinæ, all cut by the principal sulcus distinctly behind the middle; disk with hind margin feebly obtuse-angulate, prozona twice as long as metazona; lateral lobes about as wide as long, their front and hind margins slightly oblique, lower one with front half distinctly ascending; hind femora rather stout, extending beyond tip of abdomen; apical inner spur of hind tibia more than twice as long as the one adjoining; subgenital plate of male conical, obtuse, ascending; ovipositor with valves scarcely exserted.

A North American genus to which Kirby accredits eight spe- 
cies, several of which are now known to be synonyms. But one occurs in the Eastern States.

89. Eritettix stmplex (Scudder), 1869, 305. Velvet-striped Locust.

Short, rather robust. Pale brownish-yellow; dorsal surface of head and thorax in the typical form with a pair of blackish-brown stripes beginning at the base of vertex and extending back to hind margin of pronotum, these limited inwardly by the supplementary carinæ of head and pronotum; when the supplementary carinæ of pronotum are absent, these dark stripes are wanting, the occiput and disk of pronotum then being wholly pale brown, but the sides of head and pronotum with a broad brown postocular stripe extending back to base of tegmina; apical half of antennæ fuscous; basal half of tegmina often with an indistinct dark median stripe bordered below with one of greenish-white; tibial spines tipped with black. Pronotum with lateral carinæ either subparallel or feebly yet evidently bent inward just in front of middle; supplementary carinæ usually distinct, sometimes faint or wholly wanting; tegmina surpassing the tip of abdomen about $3 \mathrm{~mm}$. in both sexes. Length of body, $\hat{\delta}, 16-17, q$, 22-24; of antennæ, $\hat{o}, 5.5-6, \uparrow, 5$; of pronotum, $\hat{\delta}, 4.5, q, 5$; of tegmina, $\hat{o}, 12.5-13, \uparrow, 13-17$; of hind femora, $\hat{o}, 10-12$, $ᄋ, 13-15 \mathrm{~mm}$. (Fig. $83, h$.)

Charlottesville, Va.; Clarksville, Tenn., Apr. 21-May 24 $(F \circ x)$; Fayetteville, Ark., April 20 (MCNeill). The Arkansas specimens were sent to me about 1900 , under the name Eritettix virgatus Scudder. Thes agree in all particulars with specimens of the typical form of $E$. simplex received from Fox. McNeill's table $(1897,218)$ separating the species of Eritettix was based largely upon the color of the pronotum and the presence or absence of its supplementary carina, characters which are now known to be exceedingly variable in the same species. There is little doubt, therefore, but that the records of the $E$. virgatus of Bruner and Hart (nec. Scudder) from Nebraska and Illinois refer also to $E$. simplex as at present recognized by R. \& H. Since they have combined E. cavinatus (Scudd.) with simplex, there is but the one species known east of the Mississippi, its known range extending from New Haven and other points in Connecticut (Britton, 1904) west to eastern Nebraska and northwestern Arkansas, and southwest at least to northeastern Alabama and Buckhead, Georgia.

Fox (1917) states that in Virginia $E$. simplex is "frequent in old neglected fields and pastures, especially those overrun with Andropogon and other coarse grasses." Rehn \& Hebard (1910a, 626) recorded it as locally plentiful at Sulphur Springs, N. Car., where it occurred "in the low grasses of the treeless slopes and 
valleys." They first ealled attention to the marked dimorphism in the species, but stated that "between the two types are numerous individuals which seem to bridge more or less completely the gap between the extremes." Later $(1916,159)$ they stated that 159 adults in their collection showed that "individuals having a strongly defined median pronotal stripe lave strongly defined supplementary carina, while those having the dorsum of the pronotum unicolorous wholly lack supplementary caring." This is true of the series at hand from which the above description was drawn up. Fox says that "both forms are frequent at Charlottesville, Va., the typical form being the more abundant. Both have the same habitat preferences and life histories and are almost invariably associated with each other. Although typical examples of both races are eommon, the writer has never found any individuals bridging the gap between them." As both these anthorities assert that the absence of supplementary carina on the pronotum is alucays associated with a lack of the dorsal dark stripes, this fact is evidence that the atypical form possessing these characters is at least a distinet variety or color phase. Since it has no name. I herewith propose for it that of dorsalis var. nov.

The Gomphoccrus carinatus of Seudder $(1875 \mathrm{~g}, 511)$, a name based on a three-line footnote, has been placed as a synonym of E. simplex by R. \& H. (1910a, 626). It is the Eritettix carinatus of Britton (1904), of Walden (1911), of Morse (1907), and of Allard (1916). The last named author has given a description of its stridulating laabits as follows: "I first met this little Acridian early in April at Thompson's Mills, Ga., in an old pasture grown up to broom grass. It keeps well down in the grass, moving about oceasionally to stridulate. If it leaps and alights near the top of a grass stalk, it moves backward down the stalk until near the gromnd. Its notes are faint, lisping phrases of a few seconds duration, and are at intervals repeated six or eight times in quick sucression: sic-a-sic-a-sic-a-sic-a-sic-a-sic-sic-a-sic-a-sic-a-sic, -ete. This grasshopper is most active when the sun is shining. Its notes resemble those of stenobothrus curtipenmus rery much, and are produced in the same manner by sawing both thighs simultaneously upon the edges of the tegmina."

\section{Penwricum MrNeill, 1S:T, 216. (Gr., "a leaper.")}

Siperies of sulall size having the head horizontal, oceiput with supplementary carina as in Eritettix; rertex short with sides raised and rounded or subangulate, median (arina strong. apex 
obtusely angled, frontal costa wide, narrowing above the antennæ, deeply sulcate, male, shallowly, female; antenna flattened, of nearly equal size throughout, shorter than head and thorax in both sexes; disk of pronotum with hind margin truncate, lateral carina strongly incurved at middle, none of the carina cut by the transrerse sulci which are rerry faint; lateral lobes about as high as long, front and hind margins feebly oblique, lower one nearly straight; tegmina and wings rudimentary; hind femora rather stout, scarcely surpassing the tip of abdomen, female, strongly so, male; hind tibiæe with about 12 spines on outer margin, apical inner spur one-half longer than the others; subgenital plate of male subcrlindrical, rery obtuse; ovipositor distinctly exserted.

McNeill founded the genus Pedctieum for our only species. Scudder (189Sa, 239) claimed that this name was preoccupied by Pedeticus Laporte in Hemiptera, and proposed in its stead Macneillic. In this he was controverted by Caudell (1915, 1916a), but upheld by Hebard $(1916,17 ; 1916 d)$. As these two eminent authorities cannot agree I have retained the older name until, as Hebard suggests, the case is settled by a "final decision of the International Commission."

90. Pedeticum obscunum (Scudder), 1877a, 88. Obscure Locust.

Short, robust; the male much the smaller and more slender. Dark brownish-yellow or grayish-brown, usually nearly uniform, male; when supplementary carinæ are present on pronotum, both sexes with a wide median dorsal white, yellowish or buff stripe extending from tip of vertex nearly or wholly to end of abdomen, this bordered each side by one of blackish-brown; female rarely with green lateral markings on pronotum and tegmina; apical half of antennæ fuscous. Occiput with supplementary carinæ in both sexes connected with the median carina by numerous small transverse carinæ; pronotum of male rarely, of female usually, with supplementary carinæ and then with pale dorsal median stripe as above noted. Tegmina of female small, elongate-oval pads about one-third the length of abdomen and well separated above; of male sublanceolate, feebly overlapping and about three-fourths the length of abdomen. Wings represented by small narrow pads. Length of body, $\hat{\delta}, 13.5-15$, ㅇ, 21-24; of antennæ, $\hat{\delta}, 7, \uparrow, 6$; of pronotum, $\hat{\delta}, 3.5-4$, 오 $4.5-5$; of tegmina, $\hat{o}$, 6.5 ,, 6 ; of hind femora, ô $9.3-10$, ㅇ, $12-13 \mathrm{~mm}$.

Ormond, Sanford, Miami. Sarasota and Dunedin, Fla.; Oct. 25-April.10 (T. S. B.). Both adults and nymplis are frequent about Dunedin throughout the winter on and among the clumps of wire-grass and other undergrowth in open pine and oak woods. They usually occur in small colonies which are limited to an area 
of a few square rods, each colony probably remaining close to its hatching point, the short wings precluding a wider dispersion. When disturbed, the males leap actively two or three times, then settle down, but the females are more clumsy and after one jump often attempt to escape observation by burrowing among the fallen leares or grass stems. Scudder's types were from Ft. Reed, Fla., and the species has been recorded from many localities in that State, throughout which it doubtless occurs and to which, as far as the recolds show, it is restricted, Live Oak being the most northern point at which it has been found.

The Eritettix sylvestrus of the writer (1902, 192, 219) was based, as has been pointed out by $R$. \& H. $(1912,251)$, on two females of the form of $P$. obscura having the supplementary carinse of pronotum distinct and the median dorsal buff stripe fully developed. The name sylvestrus may therefore be retained for that color phase or variety of the species. The typical form is like that of Eritettix simplex in that all specimens known having a wholly unicolorous dorsum of the pronotum, have also the supplementary carinae of pronotum wholly wanting.

\section{Chlowatis Harris, 1841, 148. (Gr., "grasshopper.")}

Medium sized, rather robust species, having the head short, obtuse, feebly ascending; vertex triangular, its sides but little elevated, disk more concave in male than female, median carina short but distinct, foreolae wanting; frontal costa prominent, more or less rounded above the antenna, flat or feebly sulcate below the ocellus; pronotum with three carina equally distinct. lateral carina more or less incurved, especially in female, so that the middle of disk is plainly narrowed; lateral lobes of pronotum slightly longer than high, fore and hind margins straight, oblique, lower margin with posterior half nearly horizontal, its front portion strongly ascending; tegmina of female abbreviated (rarely fully developed), those of male well developed, with costal area dilated and strongly reticulate; lind femora of medium size, banded on the upper outer face; hind tibia with about 12 spines on each outer margin; subgenital plate of male conical, blunt, strongly ascending, equal to or shorter than the preceding segment; ovipositor slort, little exserted, the upper valves enlarged and strongly toothed above at base.

KEY TO EASTERN SPECIES OF CIILGALTIS.

a. Hind margin of disk of pronotum truncate; male with lateral lobes of pronotum black, and antennæ nearly twice as long as head and 
pronotum together.

91. CONSPERSA.

aa. Hind margin of pronotum obtusely rounded (Fig. 82); male with lateral lobes of pronotum brown, and antennæ only one-third longer than head and pronotum together.

92. ABDOMYNALIS.

91. Chlealtis coxspersa Harris, 1841, 149. Sprinkled Locust.

Male usually light brown above, always with a broad shining black bar wholly covering the lateral lobes of pronotum; tegmina without spots or with a few faint dusky ones; hind tibiæ red or yellowish, knees black. Female varying from dull clay-yellow to dark brown, with tegmina usually more or less sprinkled with small black spots, and sides of pronotum with only traces of the dark bar. Tegmina of female covering half of abdomen, those of male reaching nearly to its tips; inner wings shorter,

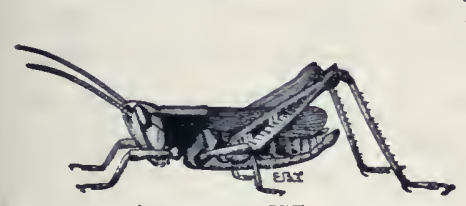

Fig. 79. Chlocalt is conspersa Harr. Male. (After Lugger.)

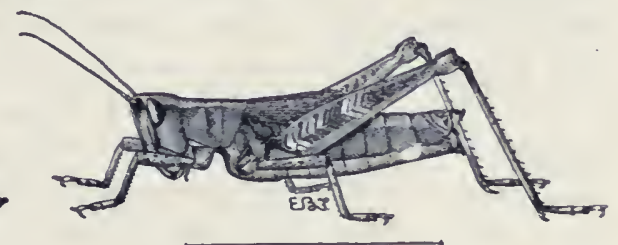

Fig. 8o. Female. $X$ 1.5. (After Lugger.)

nearly abortive in both sexes. Ovipositor of peculiar structure, being fitted for boring in wood, its upper valves short, broad, the posterior edge toothed like a saw; lower ones with a strong hooked tooth at tip (Fig. 84, d.) Other structural characters as given under the genus heading. Length of body, $\hat{\delta}, 15-20, \uparrow, 20-28$; of antennæ, $\hat{\delta}$ and $q, 10-12$; of tegmina, $\hat{o}, 8-12, \hat{\imath}, 8-10$; of hind femora, $\hat{o}, 13.5, \hat{\imath}, 16 \mathrm{~mm}$. (Figs. 79 and 80.)

This haudsome nood-brown locust occurs throughout Indiana, but nowhere in numbers. It makes its home in thickets, in the borders of open woods, in grassy plots alongside old rail fences, and oftentimes along the borders of streams in woodland pastures, but is seldom seen in damp localities. In such places its hues correspond so closely with those of the dead leaves, fallen grass stems and other surroundings that it is seldom the insect is noted until it leaps clumsily to one side. Mature males have been taken in Vigo County on June 19th, an early date for locusts which have hatched from the egg in spring. A single female with tegmina reaching slightly berond tip of abdomen was taken in Vigo County. The ordinary short-winged female is apt to be confused with the brown females of Dichromorpha viridis, but can be readily distinguished by the presence of the median carina of vertex, and the curved lateral carinæ of pronotum.

The general range of $C$. conspersa is northern, extending as far as known, from Maine north and west to the Severn River, 
Ontario, Banff, Alta., northern Minnesota and northern Colorado, south and southwest to Virginia, North Carolina and northwestern Arkansas. In Virginia and North Carolina it is mainly confined to the mountainous regions. In Pennsylvania Fox records it $(1914,493)$ as "typically a denizen of moist woodland, frequenting grasses and sedges around wet depressions," a habitat widely at variance with that noted by me in Indiana and Connecticut. The long-winged form, prima Morse $(1896,420)$ is very scarce, not over a dozen specimens, all females, having been recorded.

Of its habits near Pequaming, Mich., Rehn (1904d), quoting Hebard, says: "The females are very easy to eapture when found. They are, of course, unable to fly, and their jump lacks entirely the elasticity so characteristic of the males, the latter being about the best jumpers of any of the Orthoptera found in the eastern United States. They have a powerful spring, but it is their quickness which renders them so difficult to eapture. When alarmed, they are not content with one spring to a place of apparent safety, but jump about with such speed that they can hardly be followed with the eyes, and never cease their rapid succession of jumps until deep under the nearby vines, twigs or dead grasses, where they cannot be induced to stir, and owing to their color are perfectly safe. I have never scen a specimen where there was not a thick tangle somewhere near in which to hide. I was only able to catch them by listening until one of the musicians gave his tsikk-tssikk-tssikk, which was always lustily delivered; then approaching within a few feet I would wait, knowing that, if not as yet alarmed, the sound would be repeated in a few seconds. If my approach had been sufficiently stealthy, the musician would at length disclose his position by giving a eautious tsili. Pouncing upon him while busy stridulating, I could usually take him before he could get in position to spring. So keen and shy are they, however, that often, after a careful adrance, occupying several minutes, the singer would notice me when still sereral feet distant, and would not again make a sound, no matter how long I remained motionless."

Interesting accounts of the egg-laying habits of the female of vonspersa have been given by both S. I. Smith $(1868,146)$ and Scudder $(1874,372)$. I have, on a number of occasions, noted the females with the abdomen inserted in soft or decaying wood, and once in Vigo Co., Ind., on August 11, a female was discovered in the act of boring a hole in the upper edge of the topmost board of 
a six-plank fence. The abdomen was curved downward, and the toothed forcipate valves of the ovipositor used as pincers with which small pieces of wood were broken off. When discovered the abdomen was inserted nearly one-lialf an inch in the pine board, and the upper edge of the opening about the sides of the abdomen was covered with small pieces of the wood, just as the dust or borings will accumulate about the edge of a hole which a carpenter is boring. I stood by and watched her work for ten or more minutes, when she suddenly stopped, withdrew her oripositor and hopped away. Along the fence, within a distance of 30 feet, I found 15 other holes, 11 of which were fresh, while the others had evidently been bored the previous year. Most of these holes were on the upper edge of the top board, which was in all cases of pine and perfectly sound. None of the holes contained eggs, most of them being less than half an inch in depth. On July 21st, and September 21st, I have found them with the abdomen inserted full length in stumps or logs, and when removed, eggs were found in the lower horizontal portion of each carity. On the former date the female was oripositing after dark in an oak $\log$ which served as part of a bridge across a stream. Smith (loc. (it.) has suggested that the reason for so few holes being finislied is that the wood proves too hard, and the insect tries for a softer place, or, many of them may be disturbed during the process of oriposition.

\section{Scudder (loc. cit.) says :}

"The wood must be firm enough to retain the eggs well in place, and soft enough to absorb much moisture in the spring. Upright pieces of timber are never chosen, but rather short sticks of decaying, charred or pithy wood, which can not easily be broken or blown against the rocks. Holes are frequently made three-quarters of an inch deep, and abandoned because the spot proves unsuitable. In a stick about a foot and a half long, and two or three inches wide, I counted 75 borings, only three or four of which had been used as nests. The number of imperfect to perfect holes must be as 25 to one. When a good piece of wood is discovered, the nests are crowded thickly together; and a stick less than two inches in diameter and five inches in length contained 13 completed nests. The holes are pierced at a slight angle to the perpendicular, away from the insect; they are straight for about a quarter of an inch, then turn abruptly and run horizontally along the grain for about an inch.

The eggs (from 10 to 14 in number) are almost always laid in the horizontal portion of the nest; they are cylindrical, tapering toward the ends, but not at all pointed, and measure from five to five and a half millimeters in length, by one and one-eighth in breadth; the ends are equally and regularly rounded. They vary in tint, some being almost colorless, 
and others of a faint yellow. After the eggs have been carefully packed away in the sawdust made by the abrasion of the sides of the hole, they are covered above with a whitish froth, and the hole is sealed up just below the surface of the wood with a black glutinous secretion, excessively hard. smooth and shiny, and the upper surface slightly concave. In the spring the moisture doubtless softens these coverings so that the young grasshoppers can easily escape. Many old nests may be found uncovered and filled with the shells of the eggs, but none in which the cover is still retained."

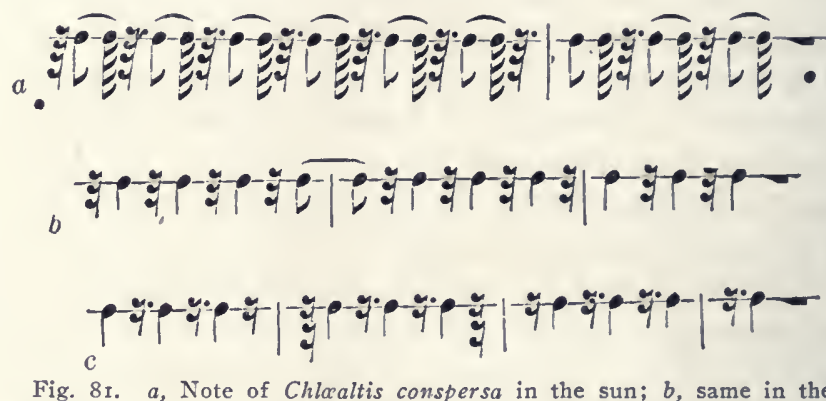
Fig. 81. a, Note of Chlocaltis conspersa in the sun; $b$, same
shade; $c$, note of Chorthippus curtipennis. (After Scudder.)

The stridulation of the sprinkled locust has been described by Scudder $(1874,370)$ thus: "Its song is of varied rapidity, according to the amount of sunshine; in the sun it makes from nine to twelve notes, at the rate of 53 in 15 seconds; the usual number of notes is ten. In the shade the rate falls to 43 in 15 seconds, the number of notes remaining the same (Fig. 81, $a, b$.). The femur is evidently scraped gently upon the elytron to produce the sound, for frequently, at the commencement, two or three noiseless morements are made, the leg failing to touch the wing-cover. I once found three males singing to a single female, who was busily engaged in laying eggs in a stick of wood, two of the males being near enough each other to cross antennæ."

92. Ceilacaltis abdominalis (Thomas), 1873, 74 .

Easily distinguished from conspersa by the characters given in key and by the shorter tegmina and hind tibiæ. Color nearly uniform dark brown, hind tibiæ and basal three-fourths of antennæ dull red, dark bands on outer face of hind femora less distinct. Occiput more convex than in conspersa, vertex broader, with median carina shorter, the disk in male less concave. Disk of pronotum of female, shorter and broader, the metazona more rugose-punctate. Tegmina of female shorter, covering only one-third of abdomen, more strongly reticulate, their tips suddenly sharply acute. Hind femora of female shorter than abdomen. Subgenital plate of male longer and more acute than in conspersa. Length of body, $\hat{\delta}, 18-$

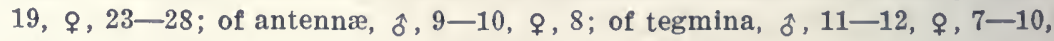
of hind femora, $\hat{o}, 12-13, \uparrow, 13-16 \mathrm{~mm}$. (Fig. 82.) 
The types of Thomas were from Montana and the specimens at hand are from the Big Horn Mountains, Wyoming. While the

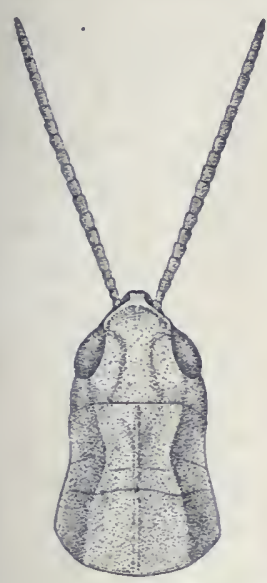

Fig. 82. Dorsal view of head and pronotum of female. $\times$ 3. (After R. \& H.) main distribution of the species is in the Northwest, ranging from northern Minnesota, wester'n Yebraska and central Colorado to Idaho and northwestern Alberta, and southwest to Beulal and Cloudcroft, New Mexico, it extends eastward at least to Nipigon and the Severn River, Ontario, and has been taken at Isle Royale, the Porcupine Mountains, Pequaming, and in Dickinson Co., Mich. At Nipigon Walker $(1909,176)$ found both long-winged and shortwinged forms, the tegmina of the former measuring, male, $18-19$, female $21-22 \mathrm{~mm}$. About Pequaming, Mich., Hebard took seren specimens, all males. "On Sept. כ two were captured while stridulating on the top of some decked hemlock logs. They were very spry, somewhat resembling in their movements and the sounds which they produce the males of conspersa."

The records show that $C$. abdominalis is essentially a mountain-loring species. Near Fort William, Ont., Walker found it "most numerous on the summit of Mt. McKay, where it frequented the small openings in the scrubby woods." Bruner (1897, 128) says that it "occurs only in extreme western Nebraska, where it is partial to north hill-slopes and steep canõn walls." R. \& H. $(1906,367)$ record it from Mammoth Hot Springs, Yellowstone Park and Maniton, Colo. At the former place it was found in a small glade at the top of the foot hills, the males being "very quick and wary, but the females extremely heary and slow, appearing to rely a great deal on their protective resemblance to a bit of twig. The stridulation of the male much resembles that of C. conspersa but is not nearly so loud."

\section{T. Amphitorxus MeNeill, 1897, 196. (Gr., "both sides" + "well rounded.")}

Medium sized Tryxalinæ having the head short, horizontal; vertex advanced in front of the eye less than half the interocular width, its disk feebly concave each side the short median carina, apex obtusely rounded, sides scarcely elevated; frontal costa wide, shallowly sulcate at and slightly above the ocellus, nearly flat and with margins a little dirergent below; antennæ filiform, fee- 
bly flattened, shorter, female, or equalling, male, the length of head and pronotum; disk of pronotum somewhat tectiform, its hind margin slightly rounded, median carina distinct, eut at or slightly behind middle by the principal suleus; lateral lobes slightly higher than long, front margin obligne, hind one nearly vertical, lower one with front half ascending; tegmina and hind femora exceeding the abdomen in both sexes; hind tibia with 12 13 spines on outer margin; subgenital plate of male short, ascending, obtuse; ovipositor with upper valves included, lower ones feebly exserted.

The range of one of the two known western species overlays our territory.

93. Ampintornus Bicolor (Thomas), 1872, 465. Bicolored Locust.

Rather slender, the male but little the smaller. Brownish-yellow; dorsal surface with a broad yellow stripe beginning at vertex and usually extending back nearly or fully to tips of tegmina, this bordered below each side with a brown stripe of almost equal width and length; sides of head and pronotum also with a narrower yellow postocular stripe extending backward along the costal margin of tegmina; a broad, oblique yellowish stripe starting near base of antennæ extends down each cheek and back across the lower edge of pronotal lateral lobe, and a narrow yellow stripe extends from below each eye back along the middle of each lateral lobe; hind femora with three oblique fuscous bars on outer face, knees black; hind tibiæ blue, their spines tipped with black. Structural characters as given above. Length of body, $\hat{\delta}, 17-19, \quad$, $20-22$; of antennæ, $\hat{\delta}, 9$,, 8 ; of tegmina, $\hat{\delta}$ and $ᄋ, 15-17$; of hind femora, $\hat{o}$ and $q$, $12-13 \mathrm{~mm}$.

This handsome Tryxalid is a species of western range or, as Bruner has put it, a "characteristic species of the Great Plains." It is included here on account of its occurrence in Illinois, it hav. ing been recorded by Hart $(1907,231)$ as occurring at the "Devil's Neck," a large area of barren sands and blowouts ten miles north of Havana. There it was found only on grassy dune summits near the middle of an old post-glacial lake. Hart (1917, Ms.) says: "We have numerous specimens, all from the one vicinity north of Havana. I liave not found it established elsewhere, but expect it may occur in the sand regions between Galena and Savanna along the Mississippi in northwestern Illinois which I have not yet visited."

Specimens at hand are from Colorado, Valentine, Nebraska and Morton and Ford counties, Kansas. Thomas gave the locality of his types as "Colorado and Wyoming east of the mountains, where it is quite common." McNeill (1897, 225) records it also 
from Nontana, Kansas and Nebraska, and Walker $(1906,55)$ from as far northwest as Vernon, B. C. It is also known from Aweme, Manitoba, and has been recorded by Bruner (1855a) from Yakima River, Waslı., and by R. \& H. from Salt Lake City, Utalı. Gillette (1904, 24) mentions it as "a very common species on dry grassy slopes orer all the eastern portion of Colorado, particularly northward, near and for some distance within the first foothills. Specimens have been taken at an altitude of 8,000 feet. This insect doubtless causes heary losses on the native pasture lands of the State."

The name of this species was changed by Thomas (1873. 82) from bicolor to coloradus, the former name being preocenpied in Stenobothrus. It is therefore mentioned by many of the older anthors as Stenobothrus coloralus Thos. MeNeill (1597, 224), when he founded the genus Amphitornus, restored the original name bicolor. In many specimens the median dorsal stripe extends only to base of thorax. A variety having the dorsal surface wholly brown was given the name unicolor by Thomas $(1873,81)$. VI. -Amblitropidis Stil, 1873, 93, 107. (Gr... "blunt" + "keel.")

Syeeies of medium size having the head short, obtuse, feebly ascending; vertex with disk convex, sides not raised, median ('arina low; apex declivent and rounded into the frontal' costa, the latter wide, not suleate, its margins parallel; antenna filiform, rather stont, not flattened, slightly shorter than head and thorax in both sexes; pronotum with disk flat, hind margin sharply but obtusely angulate, median carina distinct, cut near the middle, lateral earinæe parallel, low but evident; lateral lobes slightly higher than long, front and hind margins nearly vertical, lower one with front portion strongly ascending; tegmina and wings surpassing the tip of abdomen; hind femora stont. their outer face convex; hind tibia with 13 to 15 spines on outer margin; subgenital plate of male conical, subacute, feebly ascending. not longer than the preceding segment; valres of oripositor exserted.

Kirby $(1910,114)$ recognizes 13 species, two of them, one of which is a synonym, from the United States. the others from Mexico, Central and Sontl Inerica.

94. Avblytropidia occidextalis (Saussure), 1861, 317. Blunt-beaded Locust.

Rather robust, moderately compressed. Color variable, ranging from blackish-brown to ashy-gray, the females usually a seal-brown, often with the dorsal surface dull clay-yellow; median carina and upper fourth of 
lateral lobes of pronotum, outer face of hind femora and apical third of antennæ and tibiæ more or less fuscous; tegmina, especially of female, often with small fuscous mottlings; lower face of hind femora red. Structural characters as above given. Length of body, $\hat{\sigma}, 19-24$, , $27-32$; of antennæ, ô, 7-7.5, ㅇ, 6-6.5; of pronotum, $\hat{o}, 4.2-4.8$, 우, $5-6$; of tegmina, $\hat{\delta}, 17-19$, $\uparrow, 20-23$; of hind femora, $\hat{\delta}, 13-15.5$, , $17-20 \mathrm{~mm}$.

In Florida this sombre-brown Tryxalid has been taken by me at every place collections have been made, and, judging from the numerous records, it doubtless occurs throughout the State, including the southern keys. About Dunedin it is one of the most common Acridida of the winter months, occurring both as adult and nymph in old fields and open pine woods. The adults, when flushed, often fly long distances and frequently dive headlong into a tuft of grass where they attempt to burlow out of sight. In the pine woods, however, they often remain motionless until closely approached, depending upon their color resemblance to that of the pine needles for protection.

The range of occidentalis is given by McNeill as "the Gulf States north to Tennessee and Georgia and west to Colorado and Arizona." His mention of the last two states was evidently a mistake as it cannot be substantiated from any other source, and the only Tennessee record extant is that of the type by Saussure. It occurs, howerer, as far northeast as southeastern Virginia, where Fox (1917) found it in late autumn near Deanes and Gilmerton in "the low grassy undergrowtl of open woodlands of oak, loblolly pine and sweet gum." North of Florida its known range is therefore from Virginia west and south to Tennessee, Arkansas, Oklahoma and Texas, it having been recorded from Bonita, Denison, Houston and Dallas, in the.latter State. Scudder's type of A. subhyalina (1S75g, 511), now recognized as a synonym of occidentalis, was from the last named place.

The Chloaltis canadensis of Provancher $(1876,135)$, described from Quebec, Can., is stated by Scudder (1877a, 8S) to be the same as his $A$. subhyalina. If so, it must have been based on introduced specimens, as it has not since been noted north of Virginia. The description of the Stcnobothrus subconspcrsus of $\mathrm{F}$. Walker (1870, 755) from St. John's Bluff, Fla., agrees in most particulars with $A$. occidentalis and it also may be regarded as a synonym.

\section{Tribe III. ORPHULI.}

Rather slender, small or medium sized species, having the antenna short, filiform, rarely somewhat flattened toward base; 
liead horizontal, shorter than thorax; rertex withont a median carina, its sides distinctly raised above the level of disk; foreolae wanting or invisible from above; face but moderately oblique; jonotum with lateral carina alwass distinct, usually curved inward at middle, supplementary carina absent; tegmina often abbreviated, their costal area not dilated; wings transparent, their radial veins in apical third swollen and constricted in the males.
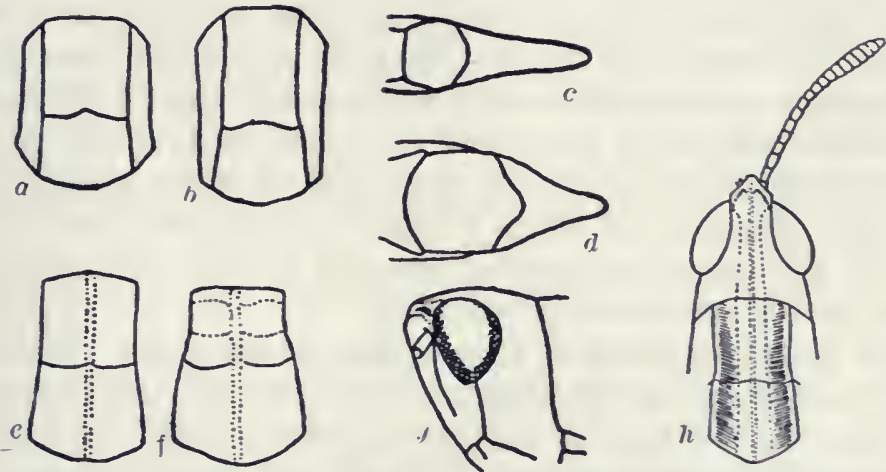

Fig. 83. Structures of Tryxalinx. $a$, Disk of pronotum of Dichromorpha; $b$, same of Clinocephalus; $c$, tip of abdomen of Pseudopomala from below; $d$, same of Tryxalis; $e$, disc of pronotum of female of Mecostethus piatypterus; $f$, same of $M$. lineatus; $g$, side view of head of female of Or. phulella pelidna; $h$, dorsal view of head and pronotum of Eritettix simplex. (After Morse and Walden.)

KEY TO EASTERI GEXERA OF ORPHULI.

a. Pronotum with prozona not much longer than metazona, the lateral lobes deeper than long; lateral carinæ strongly incurved at or near middle; tegmina and wings subequal to or longer than abdomen; foveolæ of vertex more or less evident.

I. ORPH ULELLA.

aa. Pronotum with prozona distinctly longer than metazona, the lateral lobes longer or fully as long as deep; lateral carinx parallel or but feebly incurved; tegmina normally abbreviated, shorter than abdomen; foreolæ of vertex wanting.

b. Lateral carinx of pronotum parallel throughout (Fig. 83, a.); lateral lobes vertical or nearly so, flat above and meeting the disk at nearly a right angle; tegmina usually much shorter than abdomen in both sexes.

II. Dichromorpha.

bb. Lateral carinæ feebly but distinctly diverging on metazona (Fig. 83, b); lateral lobes slightly convex above; tegmina nearly as long as abdomen in male.

III. Chixocephalus.

I. Orphulet.a Giglio-Tos, 1894, 10. (Gr., Orphula + "little.")

Tertex nearly horizontal, never extending in front of eyes a distance greater than its own width; lateral foreolae usually distinct as narowly triangular impressed spaces on side margins of 
vertex, but invisible from above; frontal costa rather high, often sulcate only in the region of the ocellus; antenna filiform, sometimes feebly depressed and acuminate; pronotum with median carina sharp, cut in or just behind the middle, its lateral carina diverging both on prozona and metazona so that the center of disk is notably narrower than either the front or hind margin; lateral lobes no longer than ligh, their front margin oblique, nearly straight, hind one less oblique, more or less sinuate, lower one plainly angulate near middle, its front portion strongly ascending; tegmina very narrow, the intercalary vein wanting, the upper ulnar vein apically joining the lower ulnar much beyond the end of baso-discal field; hind femora of medium size, surpassing tip of abdomen; hind tibixe with 10 to 12 spines on outer margin, their inner apical spurs subequal; subgenital plate of male shorter than preceding segment, its apex broadly rounded; ralves of ovipositor moderately exserted.

An American genus of large size to which Kirby (1910, 119) accredited 41 species, 13 from the United States, the others from the West Indies, Mexico, Central and South America. It is the most widely distributed genus of North American 'Tryxalina, and the most abundant in species. However, only four are definitely known from the Eastern States.

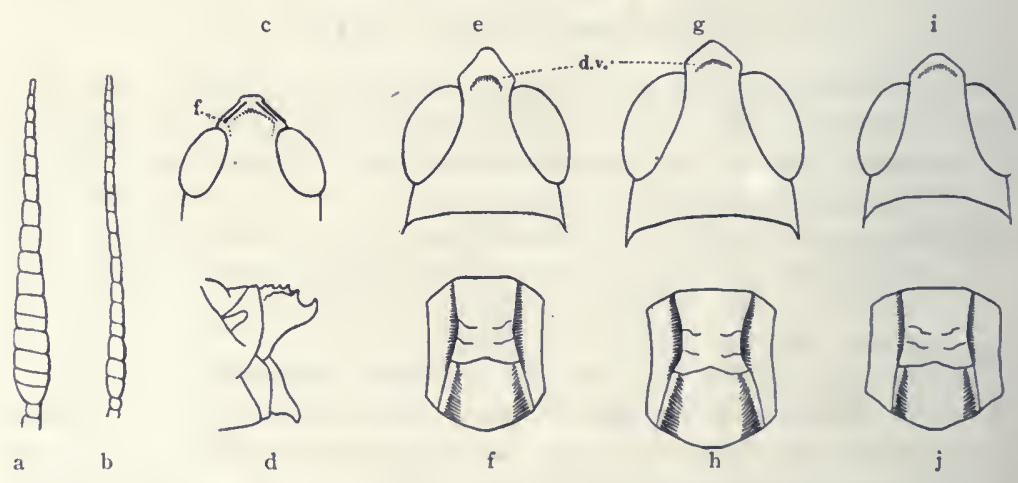

Fig. 84. Structures of Tryxalinx. a, Ensiform antennx of Pseudopomala; $b$, same of male of Tryxalis; $c$, head of Chorthippus, showing foveola; $d$, tip of female abdomen of Chlacltis abdominalis; $e$ and $f$, dorsal views of head and pronotum of Orphuella olivacea; $g$ and $h$, same of $O$. pelidna; $i$ and $j$, same of $O$. sfeciosa. (After MIorse.)

KEY TO EASTERN SPECIES OF ORPHULELLA.

a. Lateral carinæ of pronotum distinctly more widely separated at hind margin than at front one; vertex in both sexes with its apex acute or rectangular (Fig. 84 , $e$ to $h$ ); lateral foveolæ distinct; tegmina longer than abdomen.

b. Prozona and metazona subequal in length; antennæ as long as 
or longer than head and pronotum together, feebly if at all flattened, not acuminate at apex.

95. PELIDX...

bb. Prozona longer than metazona; antennæ shorter than head and pronotum together, strongly flattened on basal half, their apical fourth distinctly acuminate.

c. Tegmina distinctly surpassing the tips of hind femora, rarely maculate along the discoidal area; pronotal lateral carinæ entire.

96. OLIVACEA.

cc. Tegmina just reaching, female, or feebly surpassing, male, the tips of hind femora, and with numerous quadrate fuscous spots along the discoidal area; lateral carinæ usually widely interrupted on the prozona.

97. HALOPHILA.

aa. Lateral carinæ of pronotum but slightly more widely separated at hind margin than at front one; vertex of female with apex blunt, rounded, of male, rectangular (Fig. $84, i, j$ ); foveolæ indistinct; tegmina rarely exceeding the abdomen; prozona longer than metazona.

98. SPECIOSA.

95. Orpinuledta pelidna (Burmeister), 1838, 650. Spotted-winged Locust.

Slender, compressed, the male distinctly the smaller. Head and disk of pronotum either brown or green; a broad reddish-brown or black band behind the eye reaches back to hind margin of pronotum, this limited above by the whitish lateral carinæ; sides of pronotum below the band brownish; metazona with an elongate triangular black spot each side; tegmina either brown or largely green, usually with a median row of equidistant subquadrate black spots, and often a few black spots below the median ones; abdomen reddish-brown, the sides spotted with black; hind femora reddish-brown with traces of fuscous cross-bars; hind tibiæ pale brown, annulate with whitish near base. Vertex with margin distinctly raised above the disk, its central depression removed from apex one-third to one-fourth the width of vertex; antennæ but little depressed, slightly longer than head and pronotum, the middle joints three to four times as long as wide. Hind femora of male extending $2-3 \mathrm{~mm}$. beyond end of abdomen, slightly exceeded by the tegmina; hind femora and tegmina of female slightly surpassing the tip of abdomen. Other structural characters as given in key. Length of body, $\hat{o}, 14.5-21$, 우, 17-24; of antennæ, $\hat{\delta}, 5-7.5$, ᄋ, 5.5-7; of tegmina, $\hat{\jmath}, 13-17$, \&, 15-20; of hind femora, $\hat{\delta}, 9-12$, $९, 11-14 \mathrm{~mm}$. (Fig. 85.)

Although this small spotted locust is said to occur in abundance in the Tnited States east of the Rocky Mountains, it is scldom met with in Indiana. I have taken it but twice within the State, viz., July 21, 1897, when it was found in abundance about the margins of a small lake in one of the valleys among the sand dunes near Millers, Lake Co., and July 16, 1912, in some low meadows near Bass Lake, Starke Co. When flushed it uses both wings and legs, and when close pressed often burrows into the fallen grass in an attempt to escape detection. Of 22 speci- 


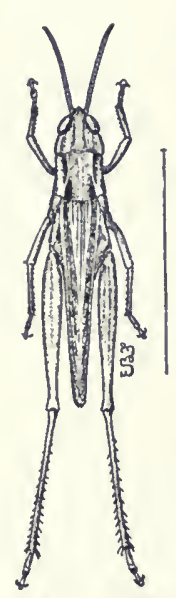

Fig. 85. Female. $\times \quad \mathbf{r . 5}$. (After $\mathrm{L}$ u g. ger.) having been recorded from various parts of New Eng-

mens taken but four were females, three of these being of the green variety. Five of the males were also partly green, the remainder brown and fuscous.

In Florida $O$. pelidna is a common insect everywhere throughout the mainland and on the adjacent keys. It is also found in various parts of Cuba and the Isle of Pines. About Dunedin it occurs in small numbers throughout the winter but becomes more frequent in February and March, when it is found esper.ially in grassland which is becoming green, after having been recently burned over. Some of the specimens taken in such places are almost black, their hue then corresponding very closely to that of the charred and blackened soil.

The range of $O$. pelidna north of Florida is about land to Texas, New Mexico and Los Angeles, Cal. It is known also from Sarnia, Ontario, Minnesota and Colorado, and between the limits of these records it may be looked for anywhere. Morse (1896, 409) states that in New England pelidna "begins to appear about the middle of July, being a week or two later than speciosa, and may be found during the remainder of the season. It is an active and alert species, leaping well and also flying freely and well, sometimes for two or three rods. It is found on the drier portions of the land adjoining salt marshes, on the more densely grassed portions of ground just inshore of the sandy beaches, and on sandy or loamy soil farther inland."

The only reference to the stridulation of pelidna which can be found is by Walker (1902a, 252) as follows: "The males produced a rapid, rattling sound when flying, like the various members of the Oedipodina, but the sound did not last more than a second."

The 0 . pratorum Scudder $(1899,179,186)$ was separated from pelidna only by the comparative length of the antenna of male and by the greater size; his table giving "antenna considerably longer than head and pronotum together" for pratorum, and "no longer or scarcely longer than head and pronotum together" for pelidna. As R. \& H. (1910a, 627) have pointed out, almost all eastern specimens of what is generally known as pelidna would, by Scudder's antennal character, fall under pratorum. Specimens at hand from several localities sent in as pratorum cannot be separated by any 
fixed character from pelidna, and I follow $R$. \& $H$. in making Scudder's name a synonym. The Stenobothrus maculipennis and S. propinquans of Scudder $(1862,458,461)$ were placed by their author in his "Catalogue" as synonyms of pelidna.

96. Orpholella olfvacea (Morse), 1893, 477. Olive Salt Marsh Locust.

Elongate, slender, compressed. Above usually olive-brown, often pale green, paler brown below; a narrow dark postocular stripe usually extending back along the upper fourth of lateral lobes of pronotum; the black triangular spots on metazona, faint or wanting; tegmina, especially in the green specimens, often with a median row of small nearly confluent dusky spots for one-third to two-thirds their length; wings transparent, their veins dusky; antennæ dusky at tips. Vertex triangular, in male with sides strongly raised, acute-angled at apex, angulate near front bor. der of eye (Fig. 84, e); in female, broader, the apex more obtusely angled. Frontal costa narrower and more deeply sulcate and angulate at junction with vertex, not rounded as in pelidna. Antennæ about equal in length to head and thorax. Pronotum with lateral carinæ low, converging from in front only to the first transverse sulcus, then distinctly diverging to hind margin which is very feebly rounded; all the carinæ cut slightly behind the middle, the metazona two-thirds the length of prozona. Tegmina surpassing tips of hind femora $2-3 \mathrm{~mm}$. Length of body, $8,16.5-20$, ㅇ, 2128 ; of antennæ, $\hat{\delta}, 6-7$,, 6 ; of tegmina, $\hat{\delta}, 14-17, q, 17-21$; of hind femora, ô, 10-11, ㅇ, 12-14.5 $\mathrm{mm}$.

Greenwich, Conn., Aug. 25-28 (Morse). A submaritime species described from Connecticut and ranging along the ocean border of the coastwise states from Massachusetts to Corpus Christi, Texas. In Florida it has been recorded only from Pablo Beach, Cedar Keys, Fort Barrancas and Warrington, Aug. 4-15. Morse (loc. cit.) says: "It was locally very plentiful in the salt marshes, its green and olivaceous tints closely matching in color the marsh grasses in which it made its home. The ground beneath was often overflowed at high tide, and offered a retreat to myriads of fiddler crabs, being much wetter and of a wholly different character from the situations frequented by pelidna and spcciosa." Later (1904, $30)$ he calls it "a maritime species of austral origin and distribution, ranging from Darien to the Bermudas, and known on our coast from Connecticut to western Florida. It is a halophilous campestrian species found only in salt marshes or along the shores of brackish inlets, often plentiful locally. This species, with its companions Paroxya atlantica and floridana and Orchelimum herbaccum, are characteristic of the Juncus fringes of the tidal inlets and pools of the southern coast, equally quick to seek safety in flight, or if hard pressed, to drop downward into the protecting shelter at the bases of the tall, sharp pointed culms." 
97. Oriliulelda halophlla Rehn \& Hebard, 1916, 166. Salt-loving Locust.

Size medium, form of female robust for the genus. Color very variable, ground hue of males usually brown, of females greenish-yellow or green to brown; discoidal area of tegmina in most specimens with a row of large subquadrate fuscous blotches for three-fourths or more its length, these often accompanied by a row of smaller similar spots above and below; sides of head and upper fourth of pronotal lateral lobes usually with a postocular dark stripe as in pelidna, these and the triangular spots on metazona more distinct in green individuals; outer face of hind femora with more or less distinct oblique fuscous bars. Vertex much as in olivacea, slightly wider than there and with apex less acute in the male. Frontal costa narrow and sulcate throughout, male, wider, more feebly sulcate and divergent below, female. Antennæ as in olivacea, less strongly but distinctly tapering near apex. Lateral carinæ of pronotum usually broadly interrupted at middle of prozona, feebly converging to the second transverse sulcus then distinctly divergent to the hind margin. Tegmina just reaching or exceeding by $1 \mathrm{~mm}$. the tips of hind femora. Length of body, $\delta, 17.5-19$,, $21.5-26$; of antennæ, $\delta$ and $\$, 6.5-7$; of pronotum, $\hat{\delta}, 3.5-3.8$, ᄋ, 4.3-5; of tegmina, $\hat{\delta}, 13.5-15.5$, $\$, 17-20$; of hind fe. mora, ô, 9.5-11.5, \&, 13-15.5 mm. (Fig. 87, A.)

Dunedin and Kéey West, Fla., Dec. 12-March 14 (IV. S. B.). At Dunedin this seaside 'Tryxalid has been taken only about the middle of Hog Island, two miles or more from the mainland. There it occur's along the low sandy stretches just inside the border of mangroves which fringe the eastern side of the island. These sandy areas are often orerflowed at high tide, and are scantily covered with a species of wire-grass and a fleshy-leaved seaside plant, Batis maritima $\mathrm{I}$. Here the locust and the fiddler crabs flourish together in harmony, the former having been taken on several occasions thronghont the winter. In life the females are often a purplish-gray with the numerous black blotehes of tegnina standing ont prouninently and giving the owner a strikingly mottled appearance. At Key West the speeies was abundant in early Marcll in company with $O$. pelidna among the scattered regetation growing on the coral rocks northeast of the city.

As the specific name indieates, $C$. halophila is, like olivacea. a submaritime species, and is recorded by R. \& H. (loc. cit.) from Punta Gorda, Key West and other islands sonth of Florida; Corpus Christi and Point Isabel, Texas, and Tampico, Mexico. It replaces olivacea, of which it may prove to be only a sonthern variety, along the coasts and on the keys of sontlern Florida, but oceurs in company with it at Corpus Christi, Texas.

98. Orpindeilda sieciosA (Scudder), 1862, 458. Pasture Locust.

Shorter and smaller than pelidna. Ground color either green or brown as in that species; tegmina elther brown, green or purplish-red, 
the median row of spots smaller, fewer in number, often wanting; dark bar beghind eye more faint than in pelidna, seldom crossing onto the metazona; hind femora greenish or brownish, not banded; hind tibiæ dull brown or yellowish, without paler ring near base. Vertex broader and blunter than in pelidna, the margins scarcely raised above the disk, often with a faint median carina on its front half, the central depression close to apex (Fig. 84, i.) Antennæ about as long as head and pronotum, plainly flattened, the middle segments nearly twice as long as broad, the apical fourth tapering. Median carina of pronotum cut slightly behind the middle by the principal sulcus. Tegmina usually reaching tip of abdomen, female, tip of hind femora, male, often shorter. Length of body, $\hat{o}, 13-15$, $\uparrow, 17-21$; of antennæ, $\hat{o}, 4.5-6.5$, $\uparrow, 5-6.5$; of tegmina, $\hat{\delta}, 11-13$, $q$, $11-16$; of hind femora, ô, $9-10$, ㅇ, $10-12 \mathrm{~mm}$.

Of this species. usually almndant where found, only three specinens have been collected by me in Indiana, and it is known from only three locations in the state. A male and female were taken July 25 from the side of a lailway a mile sontheast of Hammond. Lake Co., and a single male near Bass Lake, Ntalke Co., Ang. 30. Fox (1915, 22) records the taking of four specimens near Lafayette from dry, open, grassy tracts on untilled land. Its scarcity in Indiana is strange as Hart $(1907.231)$ states that it is found in "all Illinois, especially on dry soils ; taken at light."

The records of the species show its known range to extend from New England, where it is aplarently very common, north and west to Toronto, Ont.. ${ }^{38}$ Minnesota and wester'n Nebraska, and south and southwest to Tirginia. Sibreveport. La.. northern Alabama, and northwestern Arkansas, where McNeill (1S99.53) mentions it as occurring only in a few widely scattered localities. In northern Illinois he found it confined to the tops and sides of hills. Morse calls it "a northern offshoot of an austral genus adapted to more boreal conditions." and has written of it (1S96. 410) as reaching maturity in New England the first week in July, and being "one of the most plentiful and wide-spread of our locusts, but owing to its small size and non-migratory habits, it does not attract the attention given to the larger and consequently more destructive species. While somewhat local, it is found nearly everywhere on dry, sandy or loamy soils. It moves chiefly by leaping. but readily takes wing on occasion, flying, howerer. but a few feet. Active and alert in the hot, sunny weather of mid-summer, it can best he sermed by sweeping the net rapidly over the ground, a dozen or more specimens being the result of a few minutes work."

\footnotetext{
${ }^{3 \times}$ Scudder $(1899,184)$ records it from Nova Scotia on the authority of Piers, but the latter author (1918, 265) says there is no known definite record of its occurrence in that Province.
} 
The principal synonyms of speciosa are Stenobothrus aqualis and bilineatus Scudder $(1862,459,460)$ and S. gracilis Scugdder $(1872,250)$.

\section{Dichromorpha Morse, 1896, 326. (Gr., "two" + "colored.")}

Vertex much shorter than broad, its sides strongly elevated, meeting in front in a blunt point, median carina and lateral foreola wholly wanting; frontal costa feebly sulcate, narrowed above the antennæ, its sides subparallel; antennæ about the length of head and pronotum together, the joints moderately flattened; pronotum with disk flat, the carinæ distinct, straight, parallel, all eut behind middle by the principal sulcus; lateral lobes perpendicular, longer than deep, the front and hind margins strongly oblique, the latter plainly sinuate, lower margin strongly undulate; tegmina usually more or less aborted, rarely reaching the end of abdomen; hind femora stout, not banded; hind tibia with ten spines on outer margin, the inner apical spurs subequal; subgenital plate of male short, conical, ascending, obtusely pointed; valves of ovipositor strongly exserted.

99. Dichromorpha virinis (Scudder), 1862, 455. Short-winged Green Locust.

A medium sized robust species, the male much the smaller Color of male dull brown, disk of pronotum and dorsal field of tegmina usually bright green, rarely brown, face pale yellowish-brown; female either bright green or dirty brown, often with a narrow dark line beginning behind the eye and running along the upper portion of lateral lobe of pronotum; the green form sometimes with sides of abdomen and upper face of hind femora blotched with fuscous. Tegmina ovate-lanceolate, about half the length of abdomen, female, three-fourths its length, male; very rarely reaching to or beyond the tip of abdomen. Hind femora reaching tip of abdomen, female, surpassing it one-third their length, male. Length of

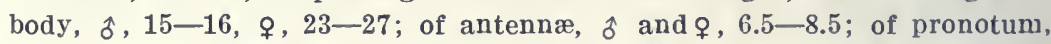
$\hat{\jmath}, 4, \uparrow, 6$; of tegmina, $\hat{\jmath}, 6-9$, ᄋ, $8-9$; of hind femora, $\hat{\delta}, 9.5-11.5$, 오, 14-15 mm. (Fig. 86.)

This is a common locust throughout Indiana, frequenting the border's of open woods, fence rows, roadsides, and especially the vicinity of the coarse grasses which grow along the margins of lakes, ponds and other wet places. There, as long as motionless, they are invisible, and there they flourish in peace and countless numbers. In southern Indiana $D$. viridis reaches maturity lỵ July 1st, and the sexes may be found mating from then until after heary frost. The brown female far outnumbers the green one in this state, especially during the autumn days, when their hues 


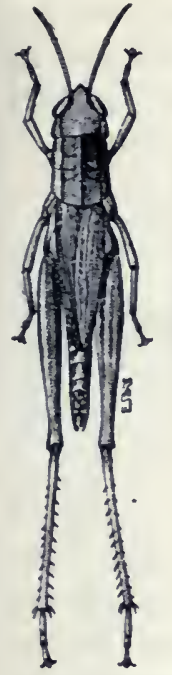

Fig. 86. Female. $X$ 1.5. (After Lugger.)

correspond so closely to the dead leaves which cover their haunts of the summer months. The green backed males are, however, the prevailing form of that sex at all seasons. The long-winged form has not, as yet, been taken in Indiana. The wings of the other form are too short for flight, and it tries to escape when disturbed only by leaping clumsily.

In Florida it is also common, having been taken by me at Sanford, Lakeland, Sarasota and Dunedin and recorded from numerous stations on the mainland as far south as Fort Myers, Citrus Center and Palm Beach. About Dunedin both nymphs and adults are found throughout the winter, usually along the margins of ponds and wet depressions in old fields and open pine woods. There the brown form of the male occurs more plentifully than in Indiana, and pairs hare been noted mating in December.

North of Florida the known range of $D$. viridis extends from Massachusetts and southern New Hampshire, west to Minnesota and middle Nebraska and south and southwest.to northwestern Arkansas, central Oklahoma and Houston, Texas. It has not been recorded from Canada nor from Michigan, though it doubtless occurs in the southern part of that State. The long-winged form, punctulata Scudder $(1862,455)$ appears to be very scarce outside of New England, and is apparently confined to the female sex. Morse $(1896,383)$ reports that out of 330 New England adults in his collection 20 are macropterous females with tegmina areraging $19 \mathrm{~mm}$. in length, five being brown and 15 green; the others all brachypterous, 13 males and 43 females being of the brown and 147 males and 107 females of the green phase. The brown form is the Chlocaltis brunnen Scudder (1875g, 510) described from Dallas, Texas. The Truxalis angusticomis Stal $(1873,105)$ described from South Carolina is also a synonym.

When the late spring and earls summer have been more than usually damp in Indiana, hundreds of dead and dying specimens of D. viridis and of Melanoplus bivittatus (Say), are often to be seen in late July in the tops of iron weeds. They are principally females, and their death is probably due to the insect fungus, Entomophthora calopteni Besser, an interesting account of which appeared in Bull. 22, U. S. Dept. Agr., 1890. 104. The disease is, perhaps, more abundant on account of the roung being exposed 
to so much dampness' in May and.June. In two instances females of Mclanoplus differentialis (Thos.) have been discovered feeding upon the dead bodies of $D$. viridis, the abdomen and soft portions of thorax having been wholly devoured.
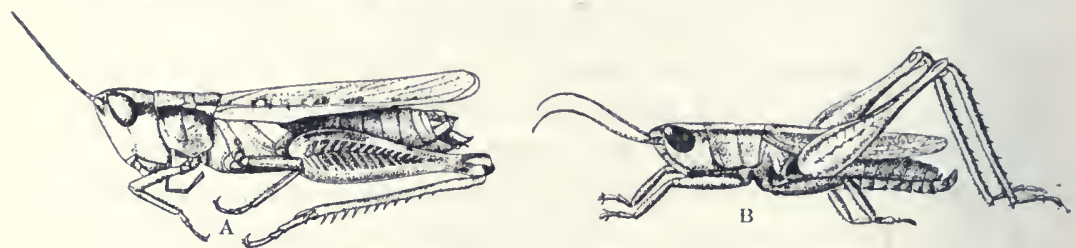

Fig. 87 . A, Orphulella halophila R. \& H., female; B, Clinocephalus elegans Morse, male, $\times$ 1.5. (After R. \& H.)

III. Clinocephalus Morse, 1896, 326. (Gr.,"inclined" + "head.")

Medium sized, robust species, having the vertex horizontal, triangular, shorter than the interocular width, its sides strongly elevated, angulate opposite front margin of eyes, apex acute or rectangular, male, blunt and rounded, female; frontal costa rather deeply sulcate, feebly narrowed and rounded into vertex; antennæe filiform, slender, slightly longer than head and pronotum, male, reaching metazona, female; pronotum longer than front femora, hind margin feebly rounded, earina all eut much behind the middle, the lateral ones parallel on prozona, feebly divergent on metazona, the latter one-half the length of prozona; lateral lobes with outline and margins as in Iichromorpha; tegmina and wings moderately developed but shorter than abdomen, both with ulnar area strongly widened at middle and discoidal area narrowed; hind femora stout, slightly surpassing the abdomen, female, more strongly so, male; hind tibia with 13 spines on onter margin, the inner apical spurs subequal; subgenital plate of male as in $D$. viridis; valves of ovipositor moderately exserted. One species is known.

\section{Clinocepinalus elegans Morse, 1896, 326, 402. Elegant Locust.}

Rather stout, feebly compressed, the male much the smaller. Light olive-green to dark greenish-brown; head with a shining dark brown postocular stripe each side, this extending back on upper fourth of pronotal lateral lobes, sometimes onto costal area of tegmina; brown forms rarely with marginal field of tegmina green. Tegmina variable in length, usually covering three-fourths or more of abdomen, but never extending be-

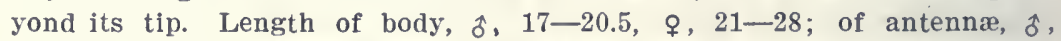
$7.5-8$, $ᄋ, 5-6$; of tegmina, ô, 10.5-12.5, $ᄋ, 12-17.5$; of hind femora. ô, $10-12.5$, ९, $12.5-17.5 \mathrm{~mm}$. (Fig. 87, B.)

A submaritime species taken by me only at Dunedin, Fla., Oct. 23-Jan. 29. Ranges from Long Island, N. Y., to Dickinson, Texas, 
usually along the coast line but sometimes inland (Faretteville, N. Car., and Stonewall, Miss.) for 8.5 or more miles. In Florida it has been recorded from numerous points along the Atlantic Coast from Jacksonville to Key West, along the Gulf Coast from Pensacola to Fort Myers, and inland from Gainesville, Lakeland and LaBelle. At Dunedin one or two pairs have been taken on several oceasions on Hog Island, where it was found among dense clumps of a tall grass. One brown female, collected Oet. 23, has a broad median, dark brown stripe extending from tip of rertex back to middle of dorsal field of tegmina, this bordered each side by a slightly narrower stripe of dull clay-yellow.

Fox $(1917,211)$ says of it: "This speeies, in spite of its usual oceurrence within the range of tidal inflnence, is not a true maritime form. Its farorite haunts are the low, damp or marshy tracts forming the border zones of tidal marshes where fresh water prevails, and where the species shows a marked preference for the somewhat restricted areas occupied by the marsh spikegrass, Distichlis spicata (L.), but also occurs in somewhat smaller numbers in the more extensive areas of Scirmus amcricanus Pers. and Spartina patens (Ait.) and much less frequently in the tall reeds, Spartina cynosuroides (L.). In true salt marsh-namely, that occupied by the smooth marsh-grass, S. glabra Muhl._it does not normally oecur. Occasionally it is taken in inland localities; thus, at Tappahannock two adults were observed in a grassy fresh water bog fully four miles from the river."

The Clinocephahus pulcher R. \& H. (1905. 36), deseribed from Miami, Fla., is conceded by its anthors $(1916,172)$ to be a synonym of elegans.

\section{Tribe IV. CHORTHIPPI.}

As represented in the eastern States this tribe embraces Tryxalins, of rather small size, having the vertex with median earina absent or very faint, foreolæ always present, large and visible from above (Fig. 84, c); face more nearly rertical than in the preceding tribes; antennæ filiform, sometimes flattened toward base, never strongly tapering; median carina of pronotum low but distinet, cut in or behind the middle by the principal suleus; intercalary rein of tegmina present but not strong.

$$
\text { KEY TO EASTERY GENERA OF CHORTIIPPI. }
$$

a. Lateral carinæ of pronotum present and almost equally distinct on both prozona and metazona; inner apical spurs of hind tibiæ subequal in length; broadest part of male tegmina lying beyond the middle.

I. Chorthippus. 
aa. Lateral carinæ distinct only on metazona, absent or very faint on prozona; inner apical spurs of hind tibiæ very unequal, the second or inferior nearly twice the length of first; broadest part of male tegmina situated at the middle.

II. Ageneotetix.

\section{Chonthuppus Fieber, 1852, 1. (Gr., "grass" + "horse.")}

Slender bodied species, having the vertex triangular, its apex obtuse, female, acute, male; foveols present as distinct, narrow, oblong impressions; frontal costa wide, sulcate only around or below the ocellus; antennæ flattened toward base, subequal in length to, female, or much longer than head and pronotum, male; pronotum with median carina distinct, cut very slightly behind middle by the principal sulcus; lateral carinæ incurved so that the middle of disk is narrower than either the fore or hind margin; lateral lobes of pronotum about as long as deep, their front margin oblique, straight, hind and lower margins sinuate; tegmina variable in length, usually fully developed in male; wings a little shorter than tegmina; hind femora rather slender, not transversely barred; hind tibia with 12-13 spines on outer margin; subgenital plate of male conical, obtuse, ascending; valves of ovipositor short, plainly exserted.

The generic name Chorthippus Fieber (1852) is in part at least synonymous with Stenobothrus Fischer (1853) and the American species ascribed by Scudder in his Catalogue to Stenobothrus are now to be referred to the present genus. Many of the early American writers accredited to stenobothrus numerous species now recognized as belonging to other genera, Thomas (1873) having so placed no less than 16 species. As at present limited, Stenobothrus is not represented in America.

101. Chorthippus curtipeñis (Harris), 1835, 56. Marsh Meadow Locust.

Small, slender, compressed. Color exceedingly variable, usually light brown above, with a black bar each side extending back from eye along the upper half of lateral lobe of pronotum; beneath yellowish, the sides of abdomen spotted with black and hind knees of the same color; face and lower sides of pronotum sometimes gray or even green; antennæ brownish-yellow at base, the apical halves brown or black. Vertex often with a faint trace of a median carina. Lateral carinæ of pronotum converging on the prozona to first sulcus, then diverging to hind margin which is obtusely angulate. Tegmina in most females about three-fourths the length of abdomen, in males usually reaching tip of abdomen, though they may be longer or shorter in elther sex. Hind femora in short-winged male sur. passing tegmina $2-3$, in female, $3-5 \mathrm{~mm}$., in long-winged form reaching to or surpassing tips of tegmina $1-2 \mathrm{~mm}$. The males are apt to be mistaken for those of Chlxaltis conspersa, but may be easily distinguished by the presence of foveolæ, narrower black bar on sides of pronotum and 
smaller and more slender body. Length of body, $\delta, 13-15$, , 15-24; of antennæ, $\hat{\delta}, 8.5-10.5$, $\uparrow, 6.5-8$; of tegmina, $\hat{\delta}, 8.5-15, ㅇ, 7-16$; of hind femora, ô, 10.5-11.8, 오, 11.5-14 $\mathrm{mm}$.

This is a rery common locust throughout northern Indiana, but has not been taken south of Putnam and Vigo counties. It abides in low, wet prairies, swales, damp meadows, and especially in the vicinity of tamarack swamps. These conditions of local habitat are common in the northern half of the State, but scarce or wanting in the southern half, except in the extensive lowlands along the Wabash River in Knox and Gibson counties, but there the locust seems to be absent. In Putnam County it occurs in blue-grass pastures along the banks of streams in open woodland, and begins to reach maturity about June 20th. By July 1st, it has become fairly common, and it may be taken until mid-October or even later, if the frosts are not too severe. In Indiana the male seems everywhere less abundant than the female, and is an active and noiseless flier. The female, being usually shorter winged, endeavors to escape by leaping and tumbling, and, says MeNeill, "its astonishing facility as a tumbler and contortionist generally discourages all but the most determined efforts for its capture."

If the records can be relied upon, the range of $C$. curtipennis is almost as great as that of any other North American locust. It is mainly, however, an inhabitant of the Transition and Canadian zones, and of mountainous regions where similar climatic conditions prevail. It occurs in all parts of New England, and is found from Cape Ray, Newfoundland (Hebard. 1915a) north and west in Canada to Nipigon, Ont., and Vernon, B. C., it being by far the most abundant Orthopteron in the less dry parts of Saskatchewan and Alberta (Walker). In the United States it is known to occur as far west as Soldier Mountain, Idaho and Sappington, Mont., and southwest to Beulah, N. Mex. In the eastern States it is not known south of the mountains of North Carolina, where it ranges from an altitude of "about 3,200 feet to the highest points in the State where suitable environment occurs." From Maryland west to eastern Nebraska it is not recorded south of central Indiana and central Illinois. At Pequaming. Mich., Hebard found it fairly swarming by the middle of July in meadows of tall grass, and was able at any time to take a dozen or more with a few sweeps of the net.

Scudder $(1874,373)$ has given a description of the song habits of curtipennis as follows: "When about to stridulate, these insects place themselves in a nearly horizontal position, with the head a little elevated; they then raise both hind legs together, the 
hind tibix bent back snugly against the femora during the morement, and grate the thighs against the outer surface of the tegmina. The first one or two morements are frequently noiseless or faint. In sunny weather the notes are produced at the rate of about six a second, are continued from one and a half to two and a half seconds, and when undisturbed are repeated with intermissions of from five to six seconds (Fig. 81, c.). When the sky is overcast the movements are less rapid."

Piers (1918, 269) says that the stridulation or call of curtipennis "sounds like the lisping syllables thru. thru, thru, repeated from about seven to ten times and lasting altogether three or four seconds. It is a soft, dreamy, lulling sound of the country and quite characteristic of a quiet, hot forenoon in August and September and is still heard (in Nova Scotia) in October."

The Stcnobothrus longipennis Scudder (1862. 45T) was a name given to the long-winged form and the $s$. coloradensis MeNeill $(1897,262)$ is a synonym.

\section{Ageneotetrix MeNeill, 1897a, 71. (Gr., "beardless" + "grasshopper.")}

Short, rather stont speeies having the vertex feebly declivent, its sides sharp and meeting in front almost at a right angle, lateral foveolæ very distinet, rectangular or four-sided, abont twice as long as broad; frontal costa with sides feebly diverging from vertex to clypeus, sulcate only around and below the ocellus; antenna slightly, female, or distinctly, male, longer than head and pronotum together; pronotum with median carina, cut once behind the middle by the principal sulcus, lateral carinæ strongly sinuate or curved inward, hind margin of metazona broadly rounded or obtusely angulate; lateral lobes of pronotum deeper than long, their front and hind margins nearly straight and vertical, lower margin with its front half strongly ascending; tegmina and wings well developed, slightly shorter than or equalling the aldomen, female, usually slightly surpassing its tip, male; hind femora rather stont, distinctly surpassing the tip of abdomen, male, equalling it, female; hind tibia with 9-11 spines on onter margin; subgenital plate of male broadly, obtusely conical; valves of ovipositor but little exserted, the tip only heing visible.

Kirby $(1910,134)$ aceredits six species to Agcncotettix. all from the United States. Of these only the Chrysochraon deorum Scudd. (1876a, 262) occurs east of the Mississippi. An examination of the types of three of the others, viz., Avilocara scudderi 
Bruner (1890, 63), Ageneotettix oceidentalis Bruner (1904, 58) and A. arenosus Hancock (1906a, 255) shows that they are only forms of deorum, which were separated mainly on the widely variable characters of wing length, color, number of spines on hind tibiae and degree of the apical angle of fastigium.

102. Agexeotettix deorum (Scudder), 1876a, 262. Sand Lacust.

Short, rather stout species, the male moderately the smaller. General color dull brown above, yellowish-white below; tegmina brown or grayish-brown, usually with numerous small darker brown, quadrate spots, these sometimes almost confined to a median row; many specimens with a dull yellowish band reaching from vertex backward across the middle of occiput and pronotum to tipz of tegmina; sides of head usually with an indistinct blackish bar extending from eye back across the upper half of pronotal lateral lobes; metazona with a more or less distinct elongate triangular black spot each side; hind femora dull reddish-brown with three blackish crossbars on upper outer face; hind tibiæ bright coral red with a whitish basal ring, their knees deep black. Fastigium often more or less acute-angled, male, obtuse-angled, female. Length of body, $\hat{o}$, $10.5-15$, ㅇ, 15-22; of antennæ, $\hat{\delta}, 8.5-10$, $\uparrow, 7-7.5$; of tegmina, $\hat{\delta}$, $7-11$,,, $9-14$; of hind femora, ô, 8-10.5, \&, 9.5-12.5 mm. (Fig. 88.)

Vigo Co., Ind., July-Oct. (W. S. B.) ; Chicago, Ill., JulyAug. (Hancock) ; Lincoln, Neb., Sept. (Bruner). This small, dull colored locust has been taken in lndiana only from the sandy bed of the old Wabash and Erie Canal, five miles north of Terre

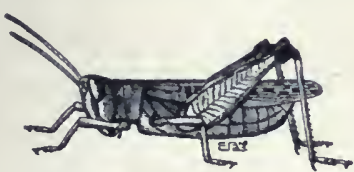

Fig. 88. Male. $\times$ 1.5. (After Lugger.) Haute, Vigo County. Here it was first found on July 6, 1892, and afterward in September and October, 1893. On one side of the canal, at the point mentioned, was a large pond, occupying perhaps 50 acres of the Wabash River bottoms, and on the other side a sandy hill or bluff of the river, which was covered with typical prairie grasses and plants. The locust was found only in an area of about five acres, on the side of the hill, and in the bed of the canal. When disturbed it leaps vigorously, and without noise, for several times in succession; then settling down on a sandy spot, it will allow a close approach, evidently relying upon the similarity of color between its body and the sand to shield it from observation.

The Vigo Co. and Chicago records are the most eastern for the species, though it probably occurs over other sand-covered areas in the western third of Indiana. Its known range extends from central-western Indiana north through Wisconsin and Minnesota to Aweme, Man., and Medicine Hat, Sask., west to Montana and southwest to Kansas, northern Texas and New Mexico. In north- 
ern Illinois Hart $(1907,231)$ reports it as "abundant in all blowsand areas." R. \& H. $(1906,372)$ mention it as one of the most plentiful species encountered in Montana and Colorado, occurring "in many of the arid localities and swarming on the prairies." Morse $(1907,32)$ calls it a "widely distributed species, locally common, especially on sandy soil with a sparse clothing of herbage," while Somes $(1914,31)$ says that in Minnesota it sometimes occurs in tall or close grasses, when it endeavors to escape by diving headlong to the ground and crawling among the stems.

The Indiana and Chicago specimens (arenosus Hancock) are somewhat smaller and darker than those from Lincoln, Neb. (typical scudderi Brun.), but present no structural differences worthy of placing them as distinct; while Gillette and Bruner (1904) have doubtfully, and R. \& H. (1906) more certainly expressed their opinion that scudderi is only a synonym of deorum.

\section{Tribe V. MECOSTETHI.}

Species of rather large size, having the head horizontal; vertex short, its disk with a distinct median carina; foveolre very small, triangular, sometimes almost obsolete, situated on the base of each of the raised margins of vertex; face subvertical; lateral carinæ of pronotum usually less distinct than the median one, sometimes cut by all the sulci; tegmina well developed, always surpassing the abdomen, their intercalary vein stout, nearer the ulnar than the radial vein; inner apical spurs of hind tibix subequal. But one genus represents the tribe in our territory.

I. Mecostethus ${ }^{39}$ Fieber, 1852, 1. (Gr., "long" + "breast.")

In addition to the characters above given, our species of this genus agree in having the rertex horizontal, its sides raised and apex usually slightly rounded; antenns filiform, equal to, female, or longer, male, than head and pronotum together; frontal costa wide, sulcate, with sides divergent below the ocellus; pronotum with disk rugose, median carina sharp, cut in or in front of middle by the principal sulcus, metazona as loug as or longer than prozona, its hind margin obtusely angled; latelal lobes about as high as long, their front margins perpendicular, hind ones slightly oblique, lower ones with front half ascending; tegmina of inale

\footnotetext{
${ }^{89}$ This generic name, which has been in common use in this country, has been recently replaced by Kirby, R. \& H. and others by Arcyptera. Hebard stating (Ms.) that the type of Mecostethus is grossus, which is generically distinct. Kirby (10ro, 144) makes alliaceus Germ. the type of Mecostethus. As both Brunner (1893, 123) and Burr $(1904,321)$ make the presence of the intercalary vein in Mecostethus the principal character separating that zenus from Arcyptcra and allied genera, and as this vein is present and prominent in all our three species and has been used hy Scudder, McNeill and others as the principal differential character of Mecostethus, I retain that generic name in preference to Arcyptera in which, according to Burr, the intercalary vein is absent.
} 
with the prominent intercalary vein provided with a rasp for stridulating; prosternum usually with an obtuse tubercle between the front femora; hind femora rather long and slender, exceeding the abdomen, male, reaching base of ovipositor, female, their lower face usually coral red; subgenital plate of male acutely produced, being at least twice as long as its greatest width; valves of ovipositor strongly exserted, the upper pair with minute teeth along their upper margin. The three known American species, all described by Scudder, occur in the Eastern United States.

KEY TO EASTERT SPECIES OF MECOSTETHUS.

a. Median carina of pronotum cut in front of middle, the prozona shorter than the metazona (Fig. $83, f$ ) ; lateral carinæ distinctly diverging on metazona.

b. Tegmina with a pale submarginal stripe two-thirds their length along the costal area; intercalary vein of male with low, dull teeth; lateral carinæ cut by all three sulci in front of middle.

103. LINEATUS.

$b b$. Tegmina without pale stripe; intercalary vein of male with longer sharp, minute, closely-set teeth; lateral carinæ cut only by first and third sulci.

104. GRACILIS.

aa. Median carina of pronotum cut in the middle, the pro- and meta-zona subequal in length (Fig. $83, e$ ); lateral carinæ subparallel, scarcely diverging behind, cut at middle only by third sulcus; costal area of tegmina without pale stripe.

105. PLATYPTERUS.

103. Mecostethus lineatus (Scudder), 1862, 462. Striped Sedge Locust.

Rather robust, strongly compressed. General color dark purplish. brown; head with a narrow yellowish line extending from upper border of each eye back along the lateral carina of pronotum, this bordered below by an indistinct dark band along the upper half of lateral lobe; wings dusky, the basal half with a yellowish tinge; hind femora with outer face yellowish or reddish brown, darker above, lower face either yellowish or bright coral red, knees black; hind tibiæ yellowish, annulate with paler near base, the spines black; females usually much darker than males, with yellow line on head and tegmina often obscure. Vertex wide, triangular, its apex subtruncate and rounded into frontal costa, foveolæ distinct. Pronotum strongly rugose, with lateral carinæ low, subparallel on prozona, distinctly diverging on metazona. Tegmina longer and narrower proportionally than in the other species. Hind femora slender, reaching or slightly passing tip of abdomen, female, surpassing it $2-3 \mathrm{~mm}$., male.

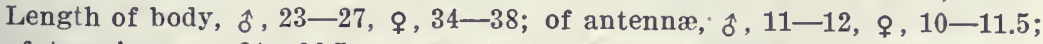
of tegmina, $\hat{\delta}, 21-26.5$, 우, 26-31.5; of hind femora, $\hat{\delta}, 14.5-18$, 우, $18-21 \mathrm{~mm}$.

This large and handsome Tryxalid occurs in isolated areas in the northern half of Indiana, where it is found only in low, boggy meadows, being more abundant in those bordering lakes or tamarack swamps. The males seem to far ontnumber the females, and 
are much more wild and active, taking to flight when a person is a dozen yards distant. They use the wings only in escaping, flying swiftly and noiselessly for 50 to 100 feet and alighting on the stems of the tall grasses and sedges among which they have their homes. The only way in which I have been able to effect their capture was by running after them and swooping them with the net as they arose or before they had time to arrange their legs for the upward impetus at the beginning of a new flight. The females are more bulky and lubberly than the males, and are usually seen in more open places, where the grass is shorter, and hence are more easily taken. The earliest date at which mature specimens have been seen was July 13th, in Fulton County, and the latest, October 25th, near Bass Lake, Starke County, though they may occur both before and after these dates.

The records show that $M$. lineatus occur's in suitable habitats over the greater part of New England and ranges from Nora Scotia north and west to Nipigon, Ontario, Red River, Manitoba, Minnesota and eastern Nebraska, and south to southern New Jersey and central Indiana, though Scudder gives its distribution as "Northern United States east of the Rocky Mountains." It is known from Isle Royale and Dickinson Co., Michigan, and appears to have been taken at only two or three localities in the northern third of Illinois and Iowa. Somes $(1914,27)$ found it in numbers in all stages near Lake of the Woods, Minn., in July, and says that the "young are miformly much darker than the adults, some being nearly black, and save for the peculiarly trim pronotum do not suggest the species."

104. Mecostethus gracilis (Scudder), 1862, 463. Graceful Sedge Locust.

Shorter and proportionally stouter than lineatus. General color pale brown, the yellow markings of head and thorax less distinct; tegmina uniform brown; wings as in lineatus; hind femora reddish-brown, coral-red beneath and often within, knees fuscous; hind tibiæ dull yellow, with a pale ring near base. Vertex narrower, more pointed, its apex subacute, male, obtusely rounded, female, foveolæ longer, narrower, much less distinct; frontal costa more shallowly sulcate below the ocellus. Pronotum shorter, its disk less rugose, lateral carinæ more divergent on metazona. Tegmina shorter, broader, often not reaching tip of abdomen in female; teeth of intercalary vein of male very numerous, as high as wide, acutely pointed. Hind femora reaching tip of abdomen, male, middle of ovipositor, female. Length of body, $\hat{\delta}, 19-23$, ․, 26-33; of antennæ, $\delta, 9-10$, ㅇ, 8.5-9.5; of tegmina, $\hat{\delta}, 16.5-21$, $९, 17-23.5$; of hind femora, $\hat{\delta}$, $12-14$, , $14.5-16 \mathrm{~mm}$.

Greylock Mountain, Adams, Mass., Aug. 17 (Morse). The range of gracilis is about the same as that of $1 \%$. lineatus but in 
general more northern, extending from Newfoundland and Nova Scotia north and west through Canada to Edmonton, Alta., and in the United States from Maine to the Black Hills of South Dakota. West of New England it is not recorded south of Michigan and Minnesota, except from eastern Nebraska, where Bruner (1897) reported it as quite common in meadows and along streams.

Of its habits in New England Morse $(1896,444)$ says: "Both sexes fly well, but the male is the more active and appears three or four times as plentiful. I have found it in wet sedgy meadows, in bushy swamps and on mountain tops. On Greylock it is common in the low grasses and bushes of the extreme summit, and on Mt. Washington in the sedgy area called the 'cow pasture.' It is rather shy, taking readily to wing and flying straight for two or three rods, then dropping rather suddenly into the grass." Somes (1914) calls it "an especially attractive insect, its trim, neat lines and pleasing coloration serving to distinguish it from its congeners. All of our captures of it in Minnesota were accidental in sweeping and in every case it has been taken from Carices."

Near Pequaming, Mich., Hebard found it abundant in a clearing of several acres in the woods, Ang. 1-21, and says:

"The grass growing over the lower portion of this clearing was very thick and high and on approaching it on the morning of Aug. 1, a new sound met my ears; a loud, harsh, connected stridulation, repeated at intervals of a few seconds. Following up these sounds $I$ was at length able to procure several specimens of this beautiful insect. They had all very recently emerged and were easy to capture with the net as they flew up, but when on alighting they hid in the grass, they were almost impossible to find, as they blended exactly with their surroundings. The females did not appear till a week later and, at the best time of the season, a morning's search would never reveal more than two or three of them; they were very lubberly and could hardly jump. The life color of the male was a rich grass-green, beautifully shaded and contrasting strongly with the carmine of the inner surfaces of the hind femora, while that of the female was yellowish-brown, the red inner surfaces of hind femora much paler than in the male."

Of the stridulating, organs of $M$. gracilis Piers $(1896,215)$ says: "The stridulating area of the wing of this species is large and prominent and stridulation may be easily produced in the dead insect by moving the hind femora against the wings." Scudder $(1893,76)$ describes the note, stating that it is louder than that produced by any other Tryxalid and can be heard at a distance of 50 feet. "It usually makes four notes but the number is some- 
times greater. The first, a quarter of a second in length, is duller than the others and is followed by a pause of a quarter of a second. The other notes are of the same length but sharply sounded, and follow each other rapidly."

105. Mecostethus platypterus (Scudder), 1862, 463. Broad-winged SedgeLocust.

More slender and compressed than either lineatus or gracilis. Dark reddish-brown, the yellow marking of head and pronotum almost obsolete; male with supra-anal plate, styles and a median stripe on ninth abdominal segment black; color otherwise as in gracilis. Vertex obtusely triangular, its median carina high; foveolæ very faint; antennæ of male longer, darker and more slender than in gracilis. Disk of pronotum of almost equal width throughout, the metazona only rugose. Tegmina of male longer and narrower than in gracilis, surpassing tips of hind femora $1-3$ mm., the rasp of intercalary vein much as in gracilis. Length of body,

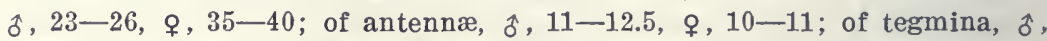
$19-21$, ㅇ, 24-25; of hind femora, ô, 15-16.5, ᄋ, $17.5-20.5 \mathrm{~mm}$. (Fig. 89.)

Thompson, Conn., Aug. 25 (Morse). A scarce species known in New England only from Massachusetts and Connecticut and recorded elsewhere only from Illinois, Iowa and Minnesota. As in the other species the females seem to be much the less abundant, but this is probably due to their sluggish habit of tumbling down and hiding when approached rather than taking to flight like the more active males. At Thompson, Conn., Morse (1896, 445)

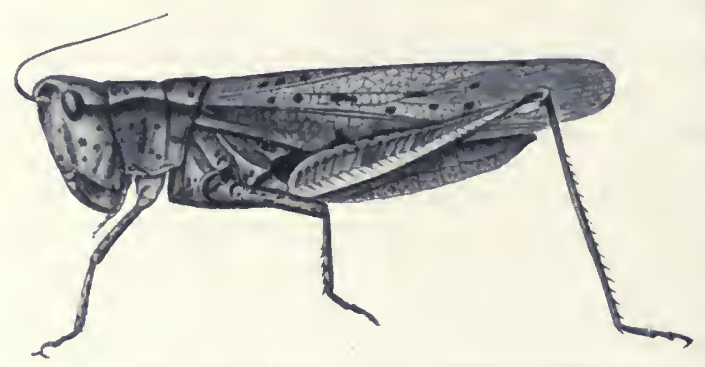

Fig. 89. Male. $\times$ ז.8. (After Somes.)

"found it in company with lineatus and impossible to distinguish from that species when flying, though its flight is less sustained and it is decidedly mole difficult to fluslı."

In Illinois Hart (1907, 231) has recorded it only from low ground on a glacial flood plain at Teheran, June 22, and from dense grass in wet ground at Champaign, July 31. The Iowa record (Ball, 1S97) is based on a single specimen from a meadow at Little Rock. In Minnesota Somes $(1914,28)$ reports it as occurring at Mesaba and Allen Junction. July 25, in the dense tangles of tamarack swamps, the inmature stages being not at all rare, but only a few adults found. 


\section{Subfamily II. OEDIPODINE.}

\section{The Band-Wingen Locusts.}

This subfamily includes those genera of locusts having the prosternum unarmed with tubercle or spine; face nearly rertical instead of oblique, head rounded at point of union with vertex and face; fastigium or front of vertex sloping sharply downward; foveola present but usually small and shallow; antenna filiform or sublinear and usually inserted above the middle of eyes, sometimes almost above the eyes themselves; eyes shorter than in the Tryxalina, being rarely longer than that portion of the cheeks below their orbits; dorsal field of pronotum with hind margin much wider than front one, its surface generally wrinkled or covered with small tubercles; lateral carina faint, often wanting; median carina (except in Arphia) cut by one or two sulci, often laised in a sharp ridge or crest; tegmina and wings always fully developed, the latter, in most species, brightly colored. All of our genera belong to the division Oedipodinit0 of Saussure, in which the ocelli are placed near the eyes and in which the outer margin of hind tibire lacks an apical spine next the spurs.

The members of this subfamily are, when at rest with the tegmina closed, usually dull brown or grayish in color, and they dwell, for the most part, on bare clayey or rocky slopes, stretches of sand, along roadsides and railways, or in closely cropped meadows. There the hues of the tegmina usually larmonize in a marvelous manner with the background of the environment. Earth tints, rock and sand textures, the infinitely varied browns, greens and grays of living and dead vegetation, are often represented in spots and streaks on the tegmina of the locust, the effect being to merge the insect so intimately with its background that as long as motionless it is effectively hidden from the observation of its foes.

The great majority of our species of Oedipodina have the inner wings in part black, the greater portion being yellow or red. When in flight they are therefore very conspicuous objects, being often mistaken for butterflies by persons who have given little attention to nature. The purpose of this bright coloration has been discussed by many naturalists and several theolies liave been set forth, explaining why it is of advantage to the locusts. Morse $(1897,7)$ claims that the bright colors of the wings are "in no sense protective and bear no relation to the environment of the insect, but are probably of value in the mating of the sexes."

${ }^{40}$ Based upon the old world Oedipoda Serville ( 183 I, 287) meaning "swollen" + "foot." 
Later $(1907,9)$ he adds: "The flight of one of these locusts attracts attention by its crepitating character; the conspicuous wing-colors, red or yellow and black, in strong contrast, render its flight easy to follow, and it is very frequently followed by others of its kind, which drop to the ground in close proximity to it. There can be no doubt in the mind of one who has watehed these actions repeated over and over, of the value of these colors as a means of signalling, of attracting attention, and thereby effecting or maintaining communication between the sexes or the individuals of a community."

Vosseler $(1902,16)$ has suggested that the bright hues of the inner wings constitute a "contrast mimicry," enabling the owner to dazzle or confuse any pursuer by suddenly closing them and dropping quickly to the ground, where the dull colored tegmina blend so closely with the surroundings that the enemy searches in vain for the brilliant object it was endeavoring to capture a moment before. As mentioned by both Hart and Somes, the Catocalie among moths present a similar case of bicolored protective coloration, having the outer wings dull gray or brown corresponding to the hue of the tree bole on which they habitually rest. while the inner ones are as brightly colored as that of any butterfly. "When the moth alights, the gray outer wings instantly fold over the bright inner ones, thus causing the insect to 'fade away' in a bewildering manner."

Since the flight of the Oedipodinge is almost always accompanied by a stridulation or crepitation, I believe that the theory of Morse is much the more plausible, and that the bright colors are for the keeping in touch one with another of the members of a locust colony rather than to be used as a sort of camouflage to dazzle their pursuers. Since the bright colored wings are possessed by both sexes, they cannot be accounted for by the theory of natural sexual selection, as might be the case were ther present in the males alone.

The ground color of the inner wings and the hind tibia often varies much in the same species, shading from dull white through rellow and orange to rermilion red, and, in the case of the tibire, sometimes to blue. The greater intensity of color is in part due to age, and perhaps in part to the higher temperature of the locality where found, though other factors doubtless enter into its cause. Bruner (1893c) and Hart $(1907,214)$ have cited evidence to show that a red coloration of wings and tibia seems to be associated with that of a humid environment, while individuals or 
species with inner wings yellow or hind tibiæe blue usually occur in an arid or sandy region.

The members of the subfamily Oedipodinæ are peculiar in that the males of most of them and the females of a few stridulate while on the wing, producing a rather harsh, crackling or rattling note by rubbing the under surface of the tegmina against certain veins on the upper surface of the inner wings. The sound seems to be under control of the insect, for they often make it when suddenly alarmed, or cease making it if too greatly frightened. Some of them produce a uniform rattling note during the entire period of flight, which is generally in a straight course. Others make the call only during certain intervals of flight. These change the direction of flight at will, and at every turn emit two or three short; rattling sounds. A number of species also sound a different call when at rest, in the same manner as do the Tryxalinæ, by rubbing the hind femora against the intercalary vein of the tegmina, which is toothed or roughened to aid as a sounding organ.

In general the Oedipodina, especially those with colored wings, are rery shy, alert, and difficult to capture. Owing to their wariness they can usually be taken only by first flushing them and then marking down the exact spot on which they alight. Then by approaching carefully one can either throw the net suddenly flat down over them, or, holding it in readiness, can swoop them quickly as they arise. Those with unicolored or faintly clouded inner wings, as the species of Cammula, Chortophaga. etc., are less wary, usually more abundant in individuals and frequent more open places, so that they are less difficult to capture. In the latitude of Indiana three or four species of Oedipodinæ pass the winter as nymphs or half-grown young. These nymphs reach maturity abont mid-April and are the first Acridians of large size to be seen in the spring. The majority of our species, howerer, pass the winter, as do most other locusts, in the egg stage.

Aside from the general works on Orthoptera the literature which will be of especial interest to the student of the Oedipodinæ of the eastern States is as follows: Scudder, 1875a, 1875c, 1876, 1890, 1892, 1900c ; Saussure, 1884, 1888; Morse, 1894b, 1895a, 1897; MeNeill, 1900, 1901; Blatchler, 1903; R. \& H., 1916.

The subfamily is represented in our territory by 12 genera, 25 species and three races or varieties. All the genera are indigenous, and their species are confined to North and Central America. For convenience of treatment the genera are grouped into two tribes as follows: 
KEY TO TRIBES OF EASTERN GENERA OF CEDIPODINA.

a. Median carina of pronotum either entire or cut by only one transverse sulcus. ${ }^{41}$ (Fig. 90, a, c.)

Tribe I. Hippisci, p. 246.

aa. Median carina of pronotum cut by two sulci, the front notch often much less distinct than the hind one (Fig. 106,c.)
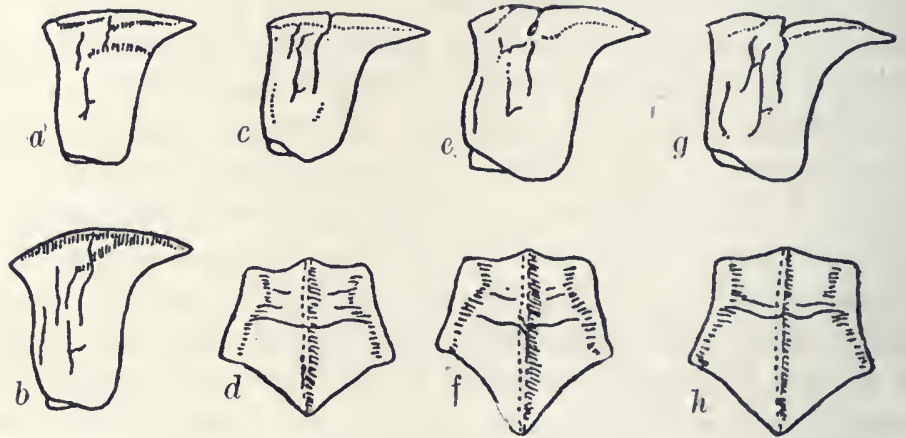

Fig. 90. Side and dorsal views of the pronotum of Arphia and Sphar. agemon. $a$, of Arphia sulphurea; $b$, of $A$. xanthoptera; $c$ and $d$, of Sphar. agemon bolli; $e$ and $f$, of $S$. zuyomingianum; $g$ and $h$, of $S$. saxatile. (After Morse and Walden.)

\section{Tribe I. HIPPISCI.}

This tribe comprises our largest, most widely distributed and best known Oedipods, and some of them are among the largest of our eastern locusts. Our eight genera representing the tribe may be separated by the following table in which I have made use of many characters not of generic importance, in order that the beginner may the more readily determine the specimens in hand.

\section{KEY TO EASTERN GENERA OF TRIBE HIPPISCI. ${ }^{42}$}

a. Median carina of pronotum raised in a distinct crest which is usually entire, rarely very feebly cut by the principal sulcus (Fig. 90, $a$. b) ; tegmina subcoriaceous or leathery in texture, densely and irregularly reticulate; inner wings brightly colored, red or yellow at base.

I. Arphia, p. 248.

aa. Median carina of pronotum less prominent, always distirctly cut by one sulcus (Fig. 90,,$e$ ); tegmina with aplcal half membranous and regularly reticulate.

b. Basal portion of inner wings pellucid or transparent, sometimes

"Very rarely a specimen of Scirtetica, one of the genera of Hippisci, has the median carina of prozona feebly cut by the front transverse sulcus, thus causing an evident second notch. More rarely the front notch in Psinidia, a genus of Trimerotropi, is subobsolete or very faint.

${ }^{42}$ I have not followed R. \& H. in separating Pardalophora Saussure from Hippiscus as the principal distinguishing character he gives $\left(188_{4}, 83\right.$ ) for the latter, viz., the dividing of the disk of the vertex by transverse and longitudinal carina into four areola, is an individual and not even a specific, let alone a generic character. In at least half of the specimens of both $H$. phanicopterus and $H$. haldemanni at hand these carina are as plainly visible as in $H$. rugosus, while in the others they are wholly wanting. 
faintly yellow, not distinctly bounded by a blackish border but with the outer half tinged with fuscous.

c. Pronotum with its disk tectiform, the sides sloping downward, its dorsal front margin acute-angulate; hind femora, without dark cross bars on lower outer face. II. ChoвtopHaGa, p. 254.

cc. Pronotum with its disk flat or nearly so, its dorsal front margin obtuse-angulate or truncate; hind femora with dusky cross-bars on their outer face.

d. Disk of pronotum rugose, its median carina distinct, higher . on prozona than on metazona, distinctly cut by the principal sulcus; frontal costa of male strongly sulcate throughout their full length.

III. Excoptolophus, p. 258.

dd. Disk of pronotum not rugose, its median carina low, of equal height throughout, faintly cut by the principal sulcus: frontal costa of male sulcate only below the ocellus.

IV. Camela, p. 260.

bb. Basal portion of inner wings red, orange, black or yellow in color, when not black, distinctly bounded outwardly with a blackish border (Fig. 106, a.)

$e$. Body, especially that of female, robust; pronotum with its disk rugose or with numerous tubercles, the lateral lobes with principal sulcus faint or obsolete; base of inner wings red or yellow; sides of tegmina usually with a number of large rounded or subquadrate dark spots. V. Hippiscus, p. 262.

ee. Body more slender, often compressed; pronotum with disk almost smooth, the lateral lobes with principal sulcus distinctly developed; base of inner wings black or pale yellow; tegmina with numerous small dark spots which are sometimes united into cross bars.

f. Inner wings black with a yellow border; intercalary vein of tegmina very distinct, arcuate, remote from the median vein.

VI. Dissosteir., p. 271.

$f f$. Inner wings yellow, apically hyaline, and with a black or fuscous curved median band; intercalary rein of tegmina less distinct, hardly arcuate, nearer the median than the ulnar vein.

g. Median carina of pronotum crested, deeply notched by the principal sulcus, arched on the metazona as viewed in profile (Fig. 96, c); tegmina rather broad, the intercalary vein sinuous.

VII. Spharagenox, p. 275.

gg. Median carina low, nearly straight throughout, but feebly notched (Fig. 96, d); tegmina very narrow, the intercalary vein straight, subobsolete:

VIII. ScikTeticA, p. 283.

I. Arphia Stål, 1S73, 113, 119.

Rather large, robust species, having the body more or less compressed; vertex horizontal, either subpentagonal or triangular, its disk with a distinct, usually deep concavity, this often divided by a transrerse curved impression slightly behind the middle; median 
carina usually present, sometimes obsolete in front of the impression; foveole present, rather large, shallow, rlomboidal or triangular; antennx about as long as head and pronotum together; pronotum with its front margin usually bluntly angulate and produced forward upon the posterior third of occiput, median carina compressed, higher than usual, not or very feebly cut by the principal transverse sulcus; lateral carinæ rounded, distinct only on - metazona; lateral lobes deeper than long, their front margin slightly sinuate, hind one more or less oblique, lower one with front half obliquely ascending, its posterior angle rather broadly rounded; tegmina somewhat leathery in texture, densely and irregularly reticulate, the apical third only with distinct cells or spaces between the venules; intercalary vein closer to median than to ulnar vein; wings brightly colored, yellow or red at base; hind femora stout, their basal halves depressed and dilated; valves of ovipositor moderately exserted, the upper ones with their apical halves slightly inturned and narrowly spoon-shaped.

Kirby $(1910,194)$ accredits 34 species to the genus, 24 of them being from the United States, the others from Mexico and Central America. A number of his names are synonyms, it being doubtful if over a dozen valid species occur in the United States. of these only four are known from our territory.

KEY TO EASTERN SPECIES OF ARPHIA.

a. Frontal costa with sides subparallel, scarcely narrowed above the antennæ, feebly or not at all sulcate.

$b$. Median carina of pronotum cristate, not cut by the principal sulcus, viewed in profile distinctly arched; front margin of disk of pronotum obtusely-angled, hind one acute-angled (Fig. 90, b.)

106. XANTHOPTERA.

$b b$. Median carina of pronotum but little elevated, almost straight, cut near the middle but not notched; front margin of disk obtusely or scarcely at all angulate.

c. Metazona thickly granulated, its hind margin acute-angled; concavity of vertex with median carina faint or wanting; frontal costa without trace of median carina on upper third; basal portion of wings yellow.

107. GRAXULATA.

cc. Metazona with only a few small scattered granules, its hind margin obtuse-angled; concavity of vertex very deep, its median carina distinct, interrupted by the cross impression; frontal costa with a more or less distinct median carina on upper third; base of wings deep red, rarely yellow.

108. PSEUDONIETANA.

aa. Frontal costa with sides converging above the antennæ, almost meeting at point of, union with the vertex, distinctly sulcate below the ocellus; median carina of pronotum low, nearly straight, entire (Fig. 90, a) ; foveolæ broader than long.

109. SULPIIUREA. 
106. Arphia xaxthoptera (Burmeister), 1838, II, 643. Autumn Yellowwinged Locust.

Robust, moderately compressed, the males but little the smaller. Color varying from very dark to pale reddish-brown, head and pronotum usually lighter than tegmina, the latter in female often sprinkled with numerous darker brown spots; inner wings with basal two-thirds either deep yellow or orange-red, the outer third with a curved fuscous bar from which a dark ray near costal margin extends backwards one-third the distance to base of wing; hind femora dull grayish-brown, the upper outer face with two or three oblique blackish bars, knees fuscous, preceded by a pale ring; hind tibiæ dusky with a pale ring near base; ventral surface dark brown to almost black. Differs from sulphurea, with which it is commonly associated in the eastern states, by its larger size and by having the concavity of disk of vertex wider, subtruncate in front, its sides not meeting but continuous with those of frontal costa, the latter with sides not converging to apex; foveolæ smaller, subtriangular; median carina of pronotum higher, more distinctly arched and hind margin of pronotum more acute. Length of body, $\hat{\delta}, 21-27$, $ᄋ, 28-34$; of antennæ, $\hat{\delta}, 10-11$, ㅇ, 9-11.5; of tegmina, ô, $23-28$, ᄋ, $25-30$; of hind femora, $\hat{\delta}, 15-18$, ᄋ, 17-19 mm. (Fig. 91 and title page.)

This is a common locust throughout Indiana, beginning to reach maturity in the central part of the State, from eggs hatched in the spring, about July 20, and existing until November 1, or later. It frequents the stubble of wheat, clover and timothy fields, the banks along railways and the borders of high, dry, open woodlands and roadsides. One-third or more of the males have the inner wings a deep orange yellow, but not more than one-sixth of

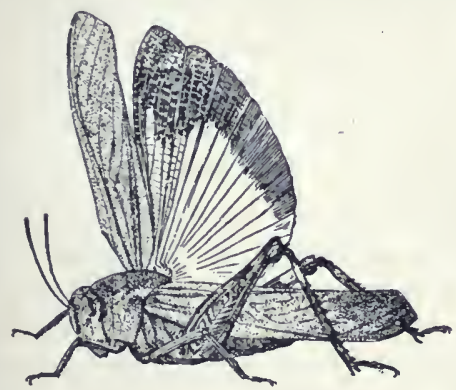

Fig. 9r. Male, natural size. (After Beutenmuller.) the females have them so colored. The orange-winged males are usually darker in color, sometimes almost black, and the clacking sound made in stridulation is seemingly louder and more prolonged than in the yellow-winged forms. This sound is made as the insect rises from the ground, and at times at the points of turning in its zigzag flight. It is a stronger and more active flier than sulphurea and its note is louder and readily distinguished from that of the latter.

In Florida $A$. xanthoptera has been taken from numerous stations in the northern third of the State, where it occurs in pine woods undergrowth, but it is not known south of Orange City Junction. The range of xanthoptera extends from southern New England, where it is common, west to Minnesota and western Ne- 
braska, and south and southwest to central Florida, Oklahoma and northern Texas. It is not recorded from Canada, nor from Michigan, but it doubtless occurs in the latter State.

In Illinois Hart reports the proportion of orange-winged individuals to be much greater than that noted above for Indiana specimens, but states $(1907,258)$ that in a sand region in southern Wisconsin, where hundreds were seen every day, but a single orange-winged specimen was observed during five weeks' collecting. He therefore concludes that the yellow-winged form is that of the more arid environment. On the contrary, in New England, only the yellow-winged form is known, and Fox $(1914,496)$ states that he has never seen in the field a red or orange-winged specimen in Pennsylvania or New Jersey, and adds: "The usual explanation that the red-winged phase is due to greater humidity is difficult to harmonize with the almost exclusive prevalence of the yellow-winged type in our region, which is much more humid than the States west of the Appalachians." Of its habits in Virginia he says (1917): "In a general way xanthoptera shows greater latitude in its choice of habitats than sulphurea. Both are dryland forms and flourish only in untilled areas, but xanthoptera does not show any marked preferences for woodland associations; occurring as frequently in campestral stations as in sylvan. In open country it usually occurs in old waste fields and pastures over-pun with coarse grasses and weeds, and the grassy tangles bordering cultivated fields; in woodland surroundings it frequents the low, briery scrub and coarse herbage of clearings and borders."

The Ocdipoda carinata Scudder $(1869,306)$ I regard as only a form of $A$. xanthoptera, with a slightly higher and more arcuate crest of pronotum, more finely granulate prozona and more slender hind femora. It has been recorded from Illinois by Thomas (1880) and McNeill (1891) and from Minnesota by Somes. Specimens from Kansas distributed as carinata by Snow are undoubtedly the same as Indiana xanthoptera.

107. Arphia granulata Saussure, 1884, 67. Southern Yellow-winged Locust.

Size and form of A. sulphurea. Color of that species, the tegmina of nales, as there but less often, with a dull clay-yellow stripe along part or all of the overlapping dorsal field, and those of females often, of males rarely, thickly sprinkled with paler spots; wings with dark ray near cos. tal margin extending two-thirds to base as in sulphurea; hind tibiæ usually pale with a fuscous ring at basal third and another near apex. Vertex and frontal costa much as in xanthoptera, the concavity of the former deeper; foveolæ suboval or subtriangular. Median carina of pronotum low, faintly cut but not notched at middle, the entire disk and often the lateral lobes and occiput thickly covered with small tubercles or granules. 


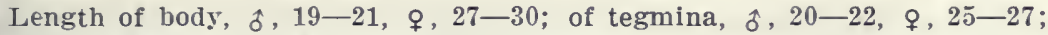
of hind femora, $\hat{o}, 12-13$, ㅇ, $15-16 \mathrm{~mm}$.

This modest brown yellow-winged locust has been taken by the writer in Florida at all points where collections have been made. At Ormond it was found mating on March 11, and at Dunedin both adults and nymphs occur in small numbers throughout the winter. It is found principally in old fields, open pine woods and along roadsides and railways. Its flight is usually short, and stridulation while on the wing much more feeble than that of xanthoptera or even sulphurea. It has been recorded by other collectors from numerous stations in Florida as far south as Key West, and is the prevailing form of Arphia throughout the State, its congeners, xanthoptera and sulphurca, being confined to the northern third. Ontside of Florida, gramulata is said bs $\mathbf{R}$. \& $\mathbf{H}$. $(1916,176)$ to be "known from Wilmington, N. Car.. and Waynesville, Ga., westward as far as Thomasville, Ga.," while Davis has received it from Casar, Miss. Scudder (1900) accredits it b5 mistake to Nebraska, probably on a doubtful determination by Bruner $(1897,130)$.

108. Arphia Pseudonietaxa (Thomas), 1870, 82. Northwestern Redwinged Locust.

Size and form of sulphurea but somewhat more slender. Color extremely variable, usually darker than sulphurea, the male sometimes nearly black, often with a dorsal sutural clay-yellow stripe on tegmina. both sexes, but especially the females, often grayish-brown with numerous fuscous spots and blotches, giving them a decidedly mottled appearance. Prozona sometimes with a pale cross-bar, appearing like a collar; basa) portion of wings bright orange-red, very rarely deep yellow; hind femora and tibiæ as in sulphurea. Vertex with concavity elongate-oval, wider in female; apex truncate, closed in front, sides continuous with those of frontal costa; foveolæ large, shallow, rhomboidal. Frontal costa with sides of upper third feebly converging, its median carina usually forking just above the ocellus. Pronotum with front margin subtruncate or obtusely rounded, median carina low, slightly higher on prozona, cut but only faintly notched in front of middle; metazona nearly flat, often with a large shallow basal impression each side. Length of body, $\hat{o}, 22-24$,

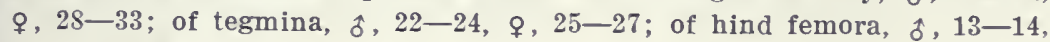
ㅇ, $15-16 \mathrm{~mm}$.

South Haven and South Frankfort, Mich.; Sidney and Talentine. Neb.; Golden, Colo.; Pine Bluff, Wyo.; Brandon. Man., and Victoria, B. C. Scudder gives its range as "U. S. and Canada west of Mississippi River," but it is known from Nipigon and Sudbury, Ontario, and has been taken at a half dozen or more points in Michigan, being the only Arphia recorded from that State. It is also said by Thomas $(1880,109)$ to occur occasionally 
in extreme northwestern Illinois. Under the name of A. tenebrosa Scudd., a synonym, it has been recorded by Saussure $(1888,165)$ from as far west as Vancouver and California, and southwest from Kansas and New Mexico. His California record may have been a mistake, as specimens at hand from both California and Arizona received under the name $A$. tenebrosa are undoubtedly distinct. In Colorado, Montana and Utah it appears to be common, Gillette (1904) stating that in Colorado it occurs to the New Mexico line.

Of the habits and stridulations of pseudonietana in Minnesota Somes $(1914,36)$ has written: "For the most part it is found in open places on dry soil, being often very abundant on gravel hills. It has a flight which is strong, but not so vigorous as that of carinata or xanthoptera, and its ærial stridulation is less noticeable than in these. It is a very beautiful insect and in flight appears almost like some brilliant butterfly. On a clear, hot day in June we once noted two males of this species standing facing one another about two inches apart. First one would raise the hind femora and rub them briskly against the sides of the tegmina a number of times, producing a dull, rasping sound which to our ears was certainly poor music; then he would drop to a position of attention and his vis-a-vis would go through the same performance. This was continued for some time and we at length left the two isolated 'fiddlers' on their hillside. Was this in some way a competition or merely for the pleasure of the music?"

Of its stridulation as observed at Sand Point, Mich., Shull (1911) says: "The flight of this species is often accompanied by a rapid clacking of the wings. When this occurs the flight is irregular and butterfly-like. Without clacking flight is direct and well controlled. A flight of 13 yards withont sound occupied 3.2 seconds, while one of 12 yards with stridulation required 4.8 seconds. All the individuals observed alighted on sand."

As already mentioned, the Oedipoda tenebrosa Scudder (1S72, 251) is a synonym, as are also Arphia sanguinaria Stål (1873.119), Tomonotus tenebrosus Thos. $(1873,107)$ and $T$. nietams Thos. $(1880,108)$.

109. Arpiria sulphurea (Fabricius), 1781, 369. Sulphur-winged Locust.

Smaller than A. xanthoptera, the male especially more slender. Color varying from dark brown, almost blackish in some males, to pale brown; tegmina of males often with a pale yellowish band along the dorsal or hind margin; those of the lighter colored females often thickly sprinkled with small fuscous spots; wings with basal two-thirds bright sulphur-yel low; outer third with a dusky curved band, from which a distinct dark 
ray runs nearly to base of wing, near the front or costal margin; hind femora with outer face either uniform dark brown with a pale ring near knee, or with alternating bands of black and white, which are more plainly visible on inner face; hind tibiæ dusky black or blue-black, with a pale ring near base; abdomen reddish-brown or yellowish. Vertex with front half of the deep concavity strongly ascending, median carina distinct but low, sides forming an acute angle at apex. Pronotum with front margin rounded or obtuse-angled, median carina entire, feebly arched, basal margin right-angled, disk more or less rugose (Fig. 90, a.) Length of body, $\hat{\delta}, 17-22$, $q, 26-30$; of antennæ, $\hat{\delta}$ and $\$, 6-7.5$; of tegmina, $\hat{\delta}, 18.5-$ -23 , , 21-26; of hind femora, ô, 11-14.5, ᄋ, 14-17 mm. (Fig. 92.)

The sulphur-winged locust is a common insect throughout Indiana, making its home in dry upland pastures and meadows. along roadsides and on gravelly and rocky slopes. It passes the winter in the nymph stage, sheltered beneath logs, chunks and rubbish, and begins to reach maturity in central Indiana about May 1st, being preceded only by Chortophaga viridifasciata. It is most abundant in June, and about July 15th begins to be replaced by its congener, A. xanthoptera. However, examples have been taken in Marion County as late as September 10th. The male, when disturbed, moves in short, jerky flights, sounding its cymbals while in the air at every turn. The sound is a sharp, erackling note, and is seemingly under the control of the insect. Many of the young and a few of the adults which appear in spring: $\mathrm{r}^{\circ}$

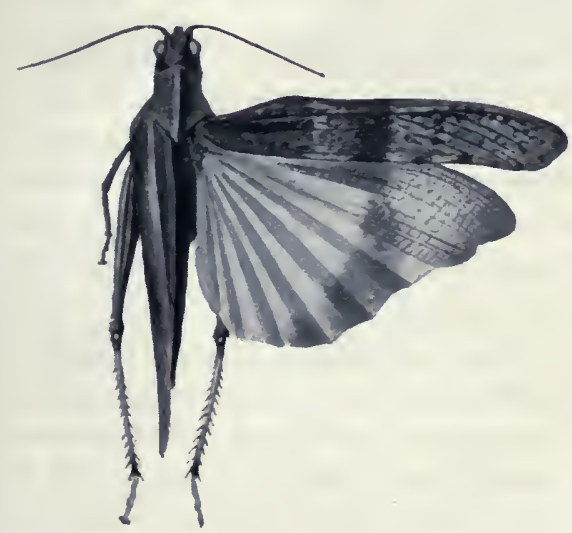

Fig. 92. Male. $\times$ 2. (After Somes.) those which live on high, rocky woodland slopes where lichens are abundant, often have the pronotum and hind femora prettily marked $\mathrm{or}^{\circ}$ spotted with grayish and greenish in imitation of those lowly plants.

The range of $A$. sulphurea extends from New England and Ontario west to Minnesota and easter'n Nebraska, and south and southwest to northern Florida, Oklahoma and Texas. The only definite record from Florida is from Leon Co., near the northern border, where Hebard found it in small numbers in pine woods, containing many scrubs oaks, the young being plentiful throughout the winter months among dead leaves under the oak and hickory trees.

In Ontario sulphurea has been definitely recorded only from 
'I'oronto and Sarnia, though Caulfield (1SSS) states that it "ocrurs generally" throughout that province. Acudder (1900) gives its range as "U. s. and Canada east of Rocky Mts.," but it laas not been recorded from Canada west of Ontarjo, it being apparently replaced in the western provinces by A. pseudonietana (Thos.) and A. frigida s.endd. In this country the main distribution. like that of ranthoptera, appears to be east of the Mississippi, as whererer found west of that stream it appears to be scarce, it having been so recorded in the Iowa, Minnesota and Nebraska lists.

Thronghout its range the sulphur-winged locust apjears to winter in the nymph stage and to become mature and largely disapuear before xanthoptera, hatched from the eggs in spring, lecomes abundant. It is said by Morse (1897, 51) to oceur thronghout New England, "being found nearly everywhere in dry jastures in spring and early summer, its rattling stridulation being one of the constant features of a ramble in such places at that stason. Its flight, particularly that of the male, is less extended than that of xanthoptera, being often limited to a few feet, but sometimes continued for three or four rods. Its course is often circling with an abrupt curve and a sudden drop into the grass and bushes at the end."

\section{I1. Chortopilaga Saussure, 1884, 43, 72. (Gr., "herb" + "to eat.")}

Medium sized locnsts, having the body rather slim, compressed, punctate or finely wrinkled; vertex horizontal, triangular, its apex truncate, sides not prominent, median carina wanting; foveolar very shallow, elongate, triangular; frontal costa prominent, rather narrow, punctate, sulcate below the ocellus, the margins of upper fourth slightly converging to meet those of vertex; antenna no longer than head and pronotum together, the joints short. somewhat flattened; pronotmm with disk roof-shaped, its front marein bluntly angulate, projected slightly forward on the occipnt, hind margin acute-angled; median carina not prominent, straight and but faintly notched slightly before the middle by the principal suleus; lateral carina visible only on the metamona, rounded and indistinct, female, plainly visible, male; lateral lobes of pronotmm a. in Irphia, the lower josterior angle less rounded ; tegmina narrow, surpassing the abdomen, apical lualf membranous, the intercalary rein romning midway between median and nluar veins: wings pellucid, ontwardly tinged with fuscous, basally faintly so with yellowish, the reins but slightly swollen; hind fenor:a of medium size, surpassing the abdomen, male, slightly shorter, female; ovipositor as in Arphia. 
Harris $(1841,146)$ founded the genus Tragocephala to include the then known species of this genus, but that name was found to be preoccupied by Dupont in Coleoptera. In the dimorphic coloration, form of head and habitats of its species, Chortophaga forms a sort of connecting link between the Oedipodinse and the Tryxalinæ, it being formerly classed with the latter. It is the only genus of Oedipodina whose members are notably dichromatic. Kirby $(1910,198)$ accredits four nominal species to the genus, two from the United States, one from Cuba and one from Costa Rica. A fifth has been since described. Two of these forms inhabit our territory, one of them being herein regarded as only a variety of the other.

\section{KEY TO EASTERY FORMS OF CHORTOPHAGA.}

a. Disk of vertex distinctly longer than broad, male, its greatest width subequal to its length, female; hind femora not barred on upper outer face.

110. ViRtDifaschta.

aa. Disk of vertex almost as broad as long, male, slightly broader than long, female; upper outer face of hind femora usually blotched with fuscous.

110a. aUstralior.

110. Chortophaga vikidifasciata (Degeer), 1773, 498. Northern Greenstriped Locust.

Color dimorphic, either largely green with a small amount of brown

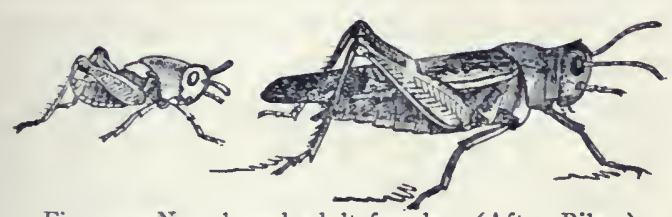

Fig. 93. Nymph and adult female. (After Riley.) upon the tegmina ( $v i$ ridifasciata) or wholly brown (infuscata Harris, 1841,147 ). Speci. mens are common, how. ever, which can be re. ferred to either form. the color being a mixture. The more pronounced green examples, with head, pronotum, outer face of hind femora and basal two-thirds of median field of tegmina grass-green, upper dorsal field, and apical third of tegmina, as well as a narrow stripe along their lower or costal margin, ash. brown, abdomen reddish-brown; head, pronotum and hind femora rarely reddish-purple instead of green. Brown form with apical halves of tegmina darker, their sides often containing a few light spots. Hind tibiæ brown or pale blue with a white ring near base. Color of wings and structural characters as given under generic heading. Length of body, $\hat{o}$, $17-24, \uparrow, 22-32$; of antennæ, $\hat{\delta}, 7-8, \uparrow, 6-7$; of tegmina, $\hat{\delta}, 17-21$, 오, 18-25; of hind femora, $\hat{\delta}, 11-13$, 우, $13-15 \mathrm{~mm}$. (Fig. 93.)

In Indiana this is the first locust to reach mattrity in spring from hibernating nymphs, specimens haring been taken in Vigo County as early as April 15th. It is a common species throughout the State, making its home in blue-grass pastures, and especially in the grassy tracts along rail fences between upland woods 
and cultivated fields and meadows. It also occurs on sunny sloping hillsides and railway embankments. In fact, mature individnals may occur anywhere in dry grassy places from mid-April till November 1st. In such localities the young, in company with those of Arphia sulphurea, may be seen on all sunny winter days when the mercury is above the freezing point. At such times they often climb or leap upon the lower rails of fences or sides of stumps, there resting in and apparently enjoying the sunshine. The species is said to be double brooded in some localities, but in Indiana, as far as known, it is single brooded, the young hatching in August and September and undergoing three or four moults before winter.

In Minnesota Somes $(1914,40)$ says of it: "Excluding the Tettigida, C. viridifaseiata may be considered our Orthopteron 'harbinger of spring,' being normally the first locust to appear as adult. We have noted it in some numbers near Minneapolis'as early as April 1, while in Iowa we have taken it a month earlier. It is apparently double-brooded, as we have found the young swarming in lowland meadows as early as June 26 and again in September."

Of the egg-laying habits of viridifasciate Hancock $(1911,410)$ writes: "At Millers, Ind., June 5, I found a female laying her eggs in damp sand at the border of a pond. When I approached she had her abdomen buried quite deeply. After 15 minutes she moved away from the place. I carefully unearthed the burrow, finding it to be $27 \mathrm{~mm}$. deep, and at the bottom, the eggs, 25 in number, were laid in a compact mass. They were bound together with a white mucous, and there was quite an amount of this substance lying above the eggs in the burrow."

This green-striped or dusky locust is one of the most widely distributed of North American Oedipods, its known range including the New England states and southern Ontario and extending west to Moose Jaw, Sask., Minnesota and northern Colorado, and south and southwest to Georgia, Oklahoma and Texas. Morse $(1907,34)$ calls it "one of the most ubiquitous locusts of the eastern half of the continent, inhabiting a great variety of environments, chiefly campestral and on soil containing a moderate amount of moisture. It is one of the few species which has apparently extended its range down the Mississippi River along the levees, being common on the higher ground near the river and on embankments along canals."

In Indiana, as elsewhere throughout its range, green females and brown males are the predominating forms, not more than 20 
per cent. of the females in Indiana being brown, and a much smaller proportion of the males being green. The male, when disturbed, usually flies but a few rods, moving in a circling or zigzag course, and producing a low but distinct shuffling or rattling noise during the whole of its flight. The female moves noiselessly and more directly to a greater distance, her flight being often abruptly ended by a headlong dire into weeds or other concealing regetation.

The more important known synonyms of $C$. viridifasciata, the names of which have many times been used in American literature when referring to that species, are Gryllus virginianus Fabr. (1775, 291), Locusta infuscata Harris (1841, 147), Tomonotus zimmermanni Sauss. (1861, 320) and Locusta radiata Harris $(1841,148)$. Besides these it has been referred to casually under three or four other scientific names.

110a. Chortophaga viridifasciata aUstralior Rehn \& Hebard, 1911, 589, Southern Green-striped Locust.

"Differs from C. viridifasciata in the less strongly keel-like median carina of the pronotum, in the less acute angle of the caudal margin of the pronotum, in the broader fastigium and in the markedly different color pattern, which is essentially that of $C$. cubensis." "Green phase--Head, pronotum, pleura, caudal femora, a longitudinal bar on the medio-proximal portion of tegmina, a median and a costal premedian patch on the same, apple-green; remainder of tegmina and venter brownish. **** Dorsum of caudal femora marked with 3 patches of clove-brown, the median the largest and triangular in shape; ventral faces of caudal femora black with two whitish bands, one median, the other preapical; caudal tibiæ glaucous, the genicular extremity clove-brown with a broad yellowish-white annulus. Wings with the disk yellow. Brown phase--Similar to the green one except that the green of the latter is replaced with clay-color, ochraceous or ochraceous-buff much marked with clove-brown on the head, pronotum

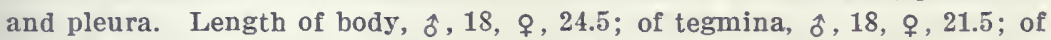
caudal femora, ô, 12, ㅇ, $13.8 \mathrm{~mm} . "$ (R. \& $H$.

The above are the essential parts of the original description of this southern form. A careful comparison of mans individuals of viridifasciata from Indiana and australior from Florida, shows that only one structural character between the two is apparently fixed, riz., that pertaining to the proportional greater width of the vertex in austratior. The height of the median carina and the degree of angulation of hind margin of metazona show individual rariations, which are as marked in specimens from the north as from the south. Scudder (1S75c, 4S2) set forth in parallel columns the differences between New England, Texas and Florida specimens of viridifasciata, and the only structural difference of any note which he gives between the first and last is that pertain- 
ing to the width of the fastigium of vertex. As to the color, viridifasciata is notable for its variation in that character; so much so, indeed, that it has more synonyms than any other North American locust, the majority of these being based on color alone. Specimens at hand from Dunedin, Fla., are wholly without trace of fuscous blotches on the dorsal face of hind femora, so that in the key this difference, thought to be constant, had to be modified by the word "usually." I therefore regard anstralior as, at the most, only a southern geographic race or variety of viridifasciata. R. \& H. (loc. cit.) have stated that it is closer to cubensis Scudder than to viridifasciata, and as it cannot be any closer to the latter species than it is without becoming an absolute synonym it is very probable that time will show that all three forms, viridifasciata, cubensis and australior, named in the order of their description, are but variations of one widely distributed and exceedingly variable North American species which will retain DeGeer's name.

In Florida $C . v$. australior has been taken by me at all points where collections have been made, and it is recorded from many different localities by other collectors, so that it doubtless occurs everywhere throughout the State. Like the northern form it frequents old fields, gardens and waste places along roadsides, railways and the borders of forests, but is rarely if ever found far within the woodlands. About Dunedin both adults and nymphs occur throughout the winter, the latter being, however, in various stages, by far the more common. As in the north, the brown males greatly outnumber the green ones, but the brown females are much more numerous proportionally than in the northern form. A number of individuals have been taken with the head, pronotum and hind femora of a handsome and striking reddish-purple hue, but this also happens occasionally in viridifasciata as noted by the writer $(1903,259)$. The range of the form australior is given by R. \& H. $(1916,179)$ as extending "from the Dry Tortugas, Fla., northward to Savannah, Ga., the most northwestern localities at which it has been found being Tifton, Albany and Spring Creek, Ga., and Fort Barrancas, Fla." It has several times been recorded from Florida under the names Chortophaga viridifasciata and Encoptolophus costatus.

III. Excoptolophus Scndder, 1875c, 478. (Gr., "cut" + "crest.")

Body a little shorter and stouter than in Chortophaga, compressed as there, the head more swollen; rertex broadly triangular, the apical half sloping feebly downward, disk with a deep concavity, its sides low; median carina present on basal half of con- 
cavity ; foreola distinct, elongate, triangular; frontal costa narrow, strongly sulcate throughout, male, only above ocellus, female, the sides converging on upper third to meet those of vertex; antennæ equalling head and pronotum together, female, a third longer, male, the joints of apical half moderately flattened; pronotum with front margin truncate, hind one forming a rather sharply marked right angle; median carina distinct, slightly higher on prozona, cut by the principal sulcus into two nearly equal halves, lateral carinæ plainly visible only on metazona, the latter with disk flat, feebly rugose; lateral lobes of pronotum deeper than long, their disks concave, much wrinkled, front and hind margins nearly vertical, lower one with its posterior half rounded, front one oblique, ascending; tegmina rather broad and short, their tips broadly rounded, slightly surpassing abdomen in both sexes; intercalary vein distinctly nearer the ulnar than the median rein; hind femora a little shorter than abdomen, female, slightly surpassing it, male; valves of ovipositor distinctly exserted.

To Encoptolophus, as above defined, Kirby $(1910,200)$ accredits 11 species, nine from the United States and two from Mexico. But one of them inhabits our territory.

111. Excoptolophus sordidus (Burmeister), 1838, 643. Clouded Locust.

Rather short, robust, the males distinctly the smaller. Color dull rusty, yellowish or smoky brown, varied with small mottlings of darker and lighter shades; pronotum in living specimens often with a distinct pinkish-buff $x$-shaped mark on its disk; antennæ pale brown at base, the apical half darker. Tegmina with two pale transverse bars on middle of sides, which contrast plainly with the larger dark patches' between and on either side of them. Wings transparent, yellowish at base, outer half smoky brown, the apex darker, the veins next the costal margin distinctly swollen. Hind femora indistinctly banded with dull yellowish and dark brown; hind tibiæ fuscous-brown with a pale ring near base. Structural characters as given above. Length of body, ô, 19-22, ㅇ, 24-32; of antennæ, $\hat{\delta}, 11-12$,, $8-9$; of tegmina, $\hat{\delta}, 17-19$,, $21-25$; of hind femora, ô, 11-13.5, ㅇ, 14-16 mm. (Fig. 94.)

The clouded locust is common throughout Indiana, maturing in the central portion about August 1, from eggs hatched in spring,

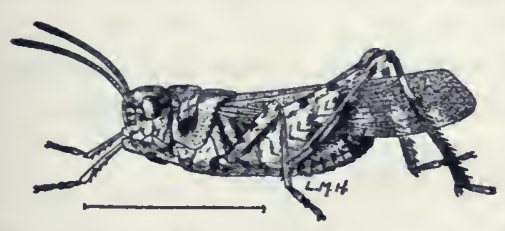

Fig. 94. Male. (After Lugger.) and existing till December 1 , provided the autumn is a favorable one. It frequents only dry upland timothy and clover meadows, blue-grass pastures, roadsides, etc. When living in woodland pastures it frequents sunny spots, seldom alighting in the shade when flushed. The male strid- 
ulates on the wing during short flights, seldom, if ever, in the more prolonged ones, which it makes when frightened. The note is a harsh droning or buzzing sound, somewhat resembling that of a bumble-bee, but louder. It is begun after the insect has risen three or four feet above the ground, and is continued until it begins to descend, being kept up continuously while it is flying horizontally. The females usually leap for the first two or three times they are disturbed, but if flushed a number of times they use the wings in endeavoring to escape.

The general range of $E$. sordidus is northern, extending from New England and Ontario west to Minnesota and Nebraska, and south and southwest to North Carolina and Tennessee, the single Florida record (Seudder 1875c, 479) having been based on a wrong identification. Morse $(\mathbf{1 8 9 7}, \mathbf{6 6})$ states that it is very common throughout New England, especially "in late summer and fall, at which season the dull rattling of the countless numbers which rise before the stroller on a sunny day is almost continual. "It is recorded by Walker (1902a, 25.3) from a number of points in southern Ontario, but west of that province is replaced by $E$. parvus Scudd. It is known from Wayue and Washtenaw Counties, Mich. (Huわbell), and is said to be common in Iowa, throughout southern and western Minnesota, and over most of eastern Nebraska. In Virginia Fox reports it as "one of the most abundant grasshoppers in the dry pastures of the high. intermontane valleys."

Morse $(1896 a, 19)$ describes the courtship of two males kept in captivity with a female as follows:

"Aroused by her near presence they crawled rapidly about and as they approached her would stop, stridulate for a second with their hind thighs, and excitedly leap toward or upon her, when being repulsed they would repeat the operation. The sound produced was a very high pitched ' $i$-ch $i$ $i$-chi-i-chi-i-chi, Another sound of an entirely different character was made in a different manner. The hind thighs, instead of being closely applied to the wing covers, were spread somewhat apart and violently vibrated, moving, as nearly as could be judged, up and down with extreme rapidity and striking as they did so upon the bottom of the box. The sound produced was a peculiar ' $r-r-r-r d$ ' or ' $r-r-r-r t$ ' low in tone and of considerable volume."

The Lorvista nebulosa Harris $(18+1,146)$ and the Oedipoda pellucida Provancher $(1883,41)$ are synonyms of $E$. sordidus.

IV. Cameula Stål, 1873, 114, 120.

Body short, size below the average for the Oedipodina; head compressed; rertex with disk orate-oblong in male, broader in fe- 
male, its front half declivent, apex rounded, sides low but distinct, median carina very faint, female, often absent. male; foreolæ shallow, narrowly triangular; frontal costa not prominent, flat or nearly so, narrowed near union with rertex; antennæ short, filiform; pronotum as in key, its front margin truncate, hind one obtuse-angled, median carina low, cut by a small notch slightly in front of middle, more deeply in female; lateral carina distinct on both prozona and metazona; lateral lobes of pronotum deeper than long, their front margin nearly rertical, hind one slightly oblique, lower one as in Encoptolophus; tegmina narrow, surpassing the abdomen, the apical third remotely reticulate, the cells quadrate; wings pellucid with dusky renules; hind femora equalling or slightly exceeding the abdomen, their upper margin sharp, somewhat crested; valves of oripositor strongly exserted.

The only species of the genus occurs throughout the northernmost United States and southern Canada from the Atlantic to the Pacific. In the marking of the tegmina, form and color, it looks much like a diminutive Hippiscus.

\section{Camnula pellucida (Scudder), 1862, 472. Clear-winged Locust.}

Small, slender, compressed, the size and tegminal markings very variable. General color light brown, face reddish-brown; antennæ yellowish at base, apical half dusky; a dark triangular spot behind the eye, and an oblong vertical black spot on the lateral lobe of prozona. Tegmina smoky. brown, with several darker rounded spots on sides, these separated by lighter yellowish blotches; dorsal surface usually with a dull yellow stripe along the overlapping margins; wings transparent, with dark nervules. Hind femora yellowish-brown, with two or three blackish bars on outer face, the knees fuscous; hind tibiæ yel'owish-brown, basal fourth paler. Abdomen yellowish beneath, the sides darker. Structural characters as above given. Length of body, $\hat{\delta}, 17-21, \uparrow, 21-25$; of antennæ, $\hat{\delta}, 7-9$, ․ $6-8.5$; of tegmina, $\hat{\delta}, 16-19$, $\&, 19-22$; of hind femora, $\hat{\delta}, 10-12$, ९, 11-14 mm. (Fig. 95.)

This small, dull colored Oedipod has been taken in Indiana only near Bass Lake, Starke Co. Here a half dozen specimens, all that could be found during a two-hour's' search, were taken Aug. 21 from a low marshy tract, on which the grass had been cropped short. When flushed, the males flew noiselessly 30 to 50 feet, then dropped down and squatted low between the grass blades. The single female was more clumsy and did not take to wing. All were found within an area of 100 square feet. It is probable that the species occurs in isolated localities throughout the northern third of the State.

In New England Morse (1897, 80) says that it begins to mature about July 1, and may be found during the rest of the sea- 


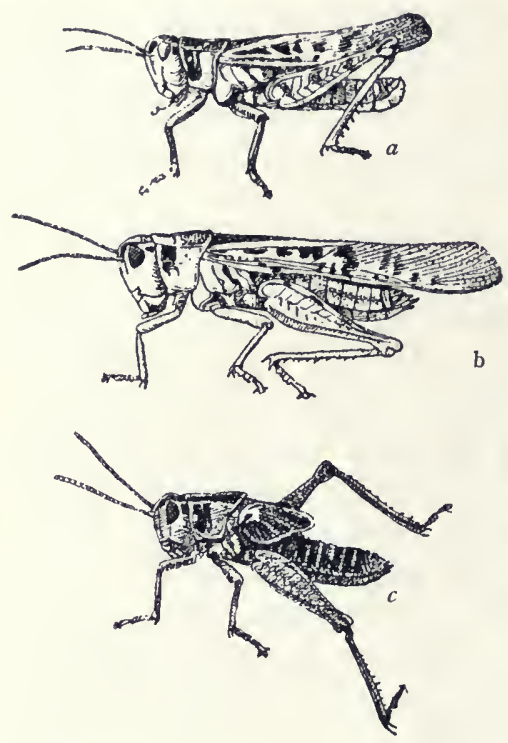

Fig. 95. $a$, Adult male; $b$, female; $c$, nymph; slightly enlarged. (After Simpson.)

son. "It is extremely common, even abundant locally, throughout the northern part of New England, being probably the most numerous in point of individuals of any of our Oedipodinæ. It is found in dry grassy pastures and other untilled land, preferably on high ground. The flight is silent or slightly rustling, usually low, short and direct, resembling that of a large Melanoplus; when with the wind, however, it is occasionally prolonged for several rods in il straight line."

The general range of $C$. pellucida is northern bat extends across the continent from Nora Scotia and New England, its southern limit east of the Mississippi being Monterey, Va., northern Pennsylvania and northern Indiana and Illinois. West of that stream it occurs as far south as western Nebraska and Chama, New Mexico, and is abundant in California. In some localities it occurs in sufficient numbers to be ranked as a serious pest. Gooderham $(1917,26)$ says that in Nova Scotia it is very common and their most injurious locust. In Idaho and Utah it has often done much damage to growing crops, so much so, indeed, that it was the subject of a special circular issued by the United States Division of Entomology (Simpson, 1903).

Writing of it in Minnesota, Somes $(1914,44)$ says:

"In the field it is apparently more free from the attacks of Trombidium and other parasites and less susceptible to fungus diseases than the Melanopli, although confined in our cages it died off very largely from fungous troubles. Normally it is found on high, dry solls and at times in some abundance even in the more open parts of forests. Its flight is swift and direct without marked aerial stridulation. In the field this species oviposits during the latter part of August, the pods being rather short, stout, considerably curved, and not firmly cemented. These pods are deposited just below the surface of the soll, among the roots of grasses or in some ceser even above the surface amid the dead grass, and contain from 20 to 30 eggs each"

V. Hrrriscus Saussure, 1861, 398. (Gr., "horse" + "little.") Species of large size and robust form, having the head large, 
subglobose, the cheeks swollen; vertex with disk usually broadly triangular, its sides distinct but not sharp; apex rounded or obtuselr angulate, more or less declirent; median carina present, at least on posterior half, and continued back over the occiput in the form of a small central ridge; foveolæe present, shallow, usually triangular in form; antennæ little, if any, longer than head and pronotum together, filiform, the joints of apical halves feebly flattened; pronotum with disk flat or nearly so, usually rugose and bearing a number of rounded or oblong tubercles, its front margin truncate, hind one usually obtuse or right-angled; median carina rather prominent, in our eastern species cut once by the principal sulcus; lateral carinæ usually extending a short distance in front of this sulcus, but not cut by it; lateral lobes of pronotum about as long as deep, constricted near middle, their front margin slightly sinuate, hind one oblique or subvertical, lower one with its posterior half rounded, front half obliquely ascending. its lower hind angle usually broadly rounded; tegmina considerably exceeding the abdomen; hind femora stout, depressed. dilated at base, the inner face usually bicolored; hind tibix pale red or rellow, their spines black; valves of ovipositor robust, strongly exserted.

As already noted, R. \& H., following Kirby, have raised Saussure's subgenus Pardalophora (1S84, 83) to generic rank. That subgeneric name was based primarily on the absence of cross carinæ of the vertex, thus leaving its disk entire instead of quadripartite as in Hippiscus rugosus. I have pointed out (footnote. P. 246) that this is a minor character, the transverse carina being almost as often present as absent in indiriduals of the same species. The other characters used by Sanssure in separating the two subgenera. riz.. the form of the frontal costa and length and form of metazona, I regard as of specific value only as they are so regarded in Arphia. I therefore follow Scudder $(1892,265)$ in discarding Pardalophora and placing all our eastern species under the older name Hippiscus. Under the two names, Hippiscus and Pardalophora. Kirbs $(1910,203,206)$ places 14 species, 12 belonging to the U. S. fauna, the other two to that of Mexico. Some of these are known synonyms and only four occur in the eastern States. Ther romprise the largest and in places some of the most common of our Oedipodinæ.

\footnotetext{
KEY TO EASTERN SPECIES OF HIPPISCUS.
}

a. Metazona distinctly longer than prozona, its hind margin c.cute-angled (Fig. 96, b); vertex with front half of disk prolonged, narrowing gradually; ulnar area of tegmina dark, but without distinct spots; wings pinkish-red at base.

113. APICULATUS. 
aa. Metazona and prozona subequal in length, the former with hind margin right-angled or obtuse-angled (Fig. 96,a); vertex with front half of disk not prolonged, narrowing rapidly; ulnar area of tegmina distinctly spotted; wings, (except rarely in haldemanii) yellow or orange-red at base.
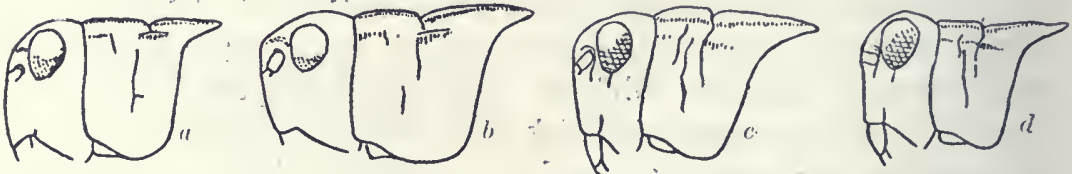

Fig. 96. Side views of head and pronotum. a, of Hippiscus rugosus; $b$, of $H$. apiculatus; $c$, of Spharagemon bolli; $d$, of Scirtetica picta. (After Morse and Walden.)

b. Frontal costa strongly sulcate below the ocellus, distinctly narrowed between or above the antennæ; opposite apical spurs of hind tibiæ subequal in length.

c. Inner face of hind femora banded with black, blue at base; tu-bercles on disk of metazona rounded or oblong, not forming ridges parallel to hind margin.

114. PIIENICOPTERUS.

cc. Inner face of hind femora uniform yellowish; tubercles on disk of metazona more or less united to form obliqua ridges parallel to hind margin.

115. HALDEMANII.

$b b$. Frontal costa but feebly sulcate below the ocellus, not narrowed above the antennæ; opposite apical spurs of hind tibiæ very unequal in length.

116. Rugosus.

113. Hippiscus apiculatus (Harris.), 1835, 576. Coral-winged Locust.

Very large, robust, the females much the more so. General color ashbrown, darker above, the cheeks paler; antennæ yellowish at jase, the apical two-thirds gradually darkening to fuscous. Pronotum with a short, dark brown, lengthwise bar on middle of lateral lobes, below which the lobe is usually paler than above. Apical inird of tegmina blotched with fuscous and black, the humeral angle light brown, the discoidal and ulnar areas usually almost immaculate; basal portion of wings bright coral-red (rarely yellow), this bordered without by a curved fuscous band which reaches anal angle and sends a broad submarginal ray along the frcnt or costal margin nearly to base. Inner face of hind femora with basal half black (prussian blue in life), apical half yellow with a mediar black bar; outer face with indistinct bars of black; hind tibiæ dull yellow, sometimes with an orange tinge. Vertex prominent, its sides low, distinct, not unlting in front but continuous with those of frontal costa; median carina reaching center of disk; foveolæ triangular, very small. Frontal costa almost flat, feebly sulcate below the ocellus, the upper third slightly narrowed. Antennæ short, equalling length of head and pronotum, the joints a little flattened. Pronotum with disk almost flat, but little wrinkled, granulate and bearing a few small rounded black tubercles; median carina low, distinct, cut much in front of middle by principal sulcus; lateral carinæ distinct only on metazona. Hind femora very broad, the upper and lower carinæ prominent, arcuate. Length of body, $\hat{o}, 25-30, \%, 36-44$; of antennæ, $\hat{\delta}, 11-13, q, 12-14$; of pronotum, $\hat{\delta}, 8$, 오 11 ; of tegmina, ô, $24-31$, ㅇ, 32-37; of hind femora, ô, 15-18, \&, 19-23 mm. (Fig. 97.) 
This is the H. tuberculatus Beauv. of most authors, including myself $(1903,265)$. R. \& H. (1910a, 630) have shown that Beaurois $(1805,145)$ gave the name of a European species, Gryllus tu-

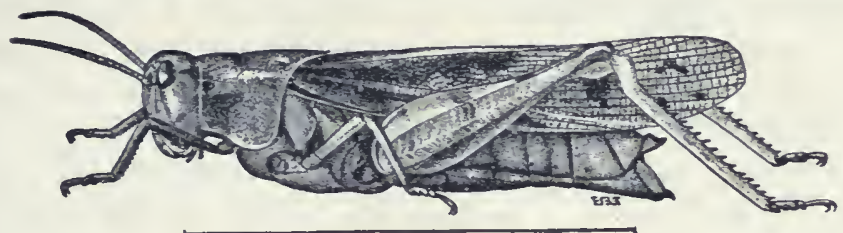

Fig. 97. Female. (After Lugger.)

berculatus Fab., to a figure of our American insect, supposing them to be identical. They have therefore substituted the next oldest name, apiculatus Harris, for tuberculatus.

The female of the coral-winged locust is the largest and most bulky of our Indiana Oedipodina. The males, as the measure-

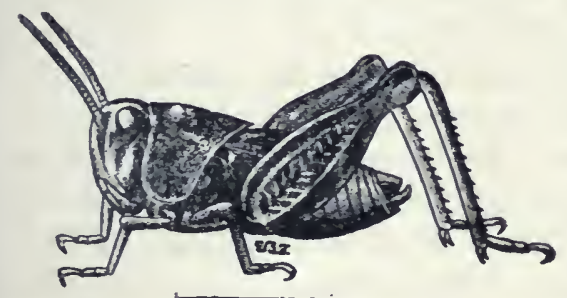

Fig. 98. $\begin{gathered}\text { Hippiscus apiculatus (Harris). } \\ \text { Nymph. (After Lugger.) }\end{gathered}$ ments show, are much smaller. This locust probably occurs throughout the State, but is most abundant in the southern or driftless portion, where the soil is poor and the hills high, and in the northwest portion, where the sand corered area is extensive. It has not been noted in the richer and more level regions of the central and eastern portions of the State. The winter is passed in the nymph stage, thie young being "curious little depressed, toad-like objects" (Fig. 98) of a dull leaden color. Mature examples have been taken in Monroe County as early as April 20th, and in Crawford County as late as July 10th. The northern examples are smaller, darker colored, and may probably be found a month later.

This locust frequents, for the most part, timothy meadows, upland pastures, roadsides, and especially bare or scantily vegetated slopes and sandy plains. When in flight it is verr conspicuous, owing to its large size and bright-colored inner wings. The males are read $y$ and active flyers, moving rapidly for quite a distance, making, meanwhile, a loud rattling note which can be heard at a distance of several rods. The females seldom take to wing, but leap clumsily when approached, and are more readily captured. The head, pronotum and hind femora are often largely greenish.

H. apiculatus occurs throughout New England and ranges from Maine and Montreal north and northwest to Hudson Bay, 
Great Slave Lake and Alberta, Canada, west in this country to Montana and Wyoming and south and southwest to North Carolina, Virginia, Missouri and Kansas. It is recorded from Florida by Saussure $(1884,88)$ and from Mexico by F. Walker, but these records were probably based on wrong identifications. Scudder $(1892,303)$ reports it from Nova Scotia, but it is not listed by either Piers or Gooderham, and Piers $(1918,278)$ says that he is "very strongly of the opinion that some mistake was made by Scudder in his record." In Ontario, Walker $(1898,260)$ found "great disparity in the relative number of the two sexes," stating that in five years he had seen more than 100 males, but only four females. There it occurs "on light sandy soil, covered preferably with rather long grass and generally with other plants, as lupine, scrub oak, blueberries, etc. It appears from about the 12th of May till near the end of June, the nymphs being found late in autumn and again in early spring. Wherever I have fourd this species it has been associated with Arphia sulphurea."

The rarity of the females noted by Walker is probably not so much a reality as a successful hiding by that sex, as in this and inany other of our larger locusts the female relies upon concealment for escape rather than upon flight, as does the more active male. The Oedipoda obliterata Burm. and Locusta corallina Harris are synonyms of $H$. apiculatus. The latter has also been confused many times by American writers with $H$. phœnicopterus (Burm.), it having been treated under that name by Scudder (1862) and Thomas (1873).

114. Hippiscus PHCENicopterus (Burmeister), 1838, 643. Orange-winged Locust.

General color ash or reddish-brown, the males darker; face ash-brown or clay-yellow; occiput and disk of pronotum dark brown; all of these parts, as well as the upper and lower outer faces of hind femora often prettily tinged with greenish. Tegmina ash-brown, with numerous large dark brown or blackish spots, those of female more distinct, the light interspaces being wider, the largest of these spots on the lower third being just behind the expanded basal lobe. Wings deep orange (rarely yellow) at base, this hue bordered behind by a curved black band extending from costal margin to anal angle, this sending off nearly to base the usual dark submarginal spur; apical fourth transparent and smoky, the extreme tip in male with one or two fuscous blotches. Inner face of hind femora deep blue, with an orange bar near apex; outer face reddish or yellowish-brown, with three black bars on upper portion. Hind tibiæ yellowish, often tinged with orange, the spines tipped with black. Vertex prominent, basal twothirds broad, sides distinct, suddenly converging opposite front half of eyes but not uniting in front; disk with median carina low and in females often with a cross carina on posterior half; foveolæ small, distinct, trian- 
gular. Frontal costa as in key, the upper third narrowed, punctate. Antennæ slightly shorter than head and pronotum, female, equalling their length, male; filiform, the segments feebly flattened. Pronotum with disk a little wrinkled on prozona, covered somewhat regularly with small rounded tubercles, these more prominent in female; metazona flat, its hind margin right-angled, male, obtuse-angled, female; median carina low but distinct, cut by principal sulcus slightly in front of middle; lateral carinæ subobsolete, with traces only on metazona. Tegmina with basal lobe of lower margin noticeably expanded, especially in female. Hind femora broadly dilated, the upper and lower margins much elevated, sharp, curved. Length of body, $\hat{\delta}, 31-33$, ㅇ, 42-45; of antennæ, $\hat{o}, 12.5$, 우 13.5 ; of pronotum, $\hat{\delta}, 8.5$,,+ 11 ; of tegmina, $\hat{\delta}, 27-33$,,$+ 38-43$; of hind femora, $\hat{o}$, $17-18$, 오, $21-23 \mathrm{~mm}$.

This large and handsome locust has been taken in Indiana only in Crawford, Lawrence and Jennings counties. In the vicinity of Wyandotte Cave, Crawford Co., it is, in the latter half of June and first part of July, one of the most common of the Oedipodina. It occurs only on the uplands, where it frequents grain fields, open bare places in the woods, roadsides and timothy meadows. The male, when flushed, flies rapidly for a long distance, making a low rattling note while in the air ; the female, as in kindred species, is too heavy-bodied to take to wing gracefully, and therefore more often mores by leaping. In the vicinity of North Vernon and Mitchell, males only were seen. It probably occurs throughout the southern third of the State, where it doubtless winter's in the nymph stage.

The range of $H$. phonicopterus is, in the main, confined to the Austral life zone, extending from southern New Jersey westward to southern Indiana, Moline, Illinois, and eastern Nebraska, and soutl and southwestward to Florida, Mississippi, Oklahoma and Texas. In Florida it has been taken by me only in the nymph stage, at Ormond, Sanford and Dunedin. About Dunedin the nymphs are quite common in February and March along the railway embankments, roadsides and sandy spots in open pine woods. It is recorded from numerous places in northern Florida, but is uncommon in the southern portion, though taken at Miami.

Morse $(1907,34)$ states that "in early summer it is the commonest species of the genus from Arkansas eastward, frequenting fields and waste grounds, and sometimes entering the more open forests." Vestal $(1913,21)$ sars that in central Illinois it is common in bunch grass on sand prairies, winters in the nymph stage and matures probably late in Mas. He adds: "There is in IIlinois a time adjustment with species of Hippiscus much as in $A r$ phia. H. apiculatus is the earliest, followed by phonicopterus and haldemanii, which in turn gives place to rugosus." Ocdipoda dis- 
coidea Serv. (1839, 724) and Hippiscus texanus Scudd. (1892, 286) are now regarded as synonyms of $H$. phnnicopterus.

\section{Hipriscus haldemanil (Scudder), 1872, 251. Haldeman's Locust.}

Form and size of phonicopterus the males much the smaller. General color grayish-brown, varied with numerous dark spots Face ash-gray, the cheeks and a spot back of eye paler; vertex, occiput and disk of pronotum darker; lateral lobe of prozona with a black bar at middle. Tegmina with a narrow yellowish line along each humeral angle, dorsal area brownish, unbroken; sides with dark spots as shown in Fig. 99. Wings with basal half lemon-yellow or orange-red, rarely pinkish; the remaining portion as in phonicopterus. Hind femora with inner face bright yellow; ${ }^{43}$ the outer one brownish-yellow with traces of three very oblique cross bars. Hind tibiæ light yellow, tinged with orange in the male. Vertex broad, its

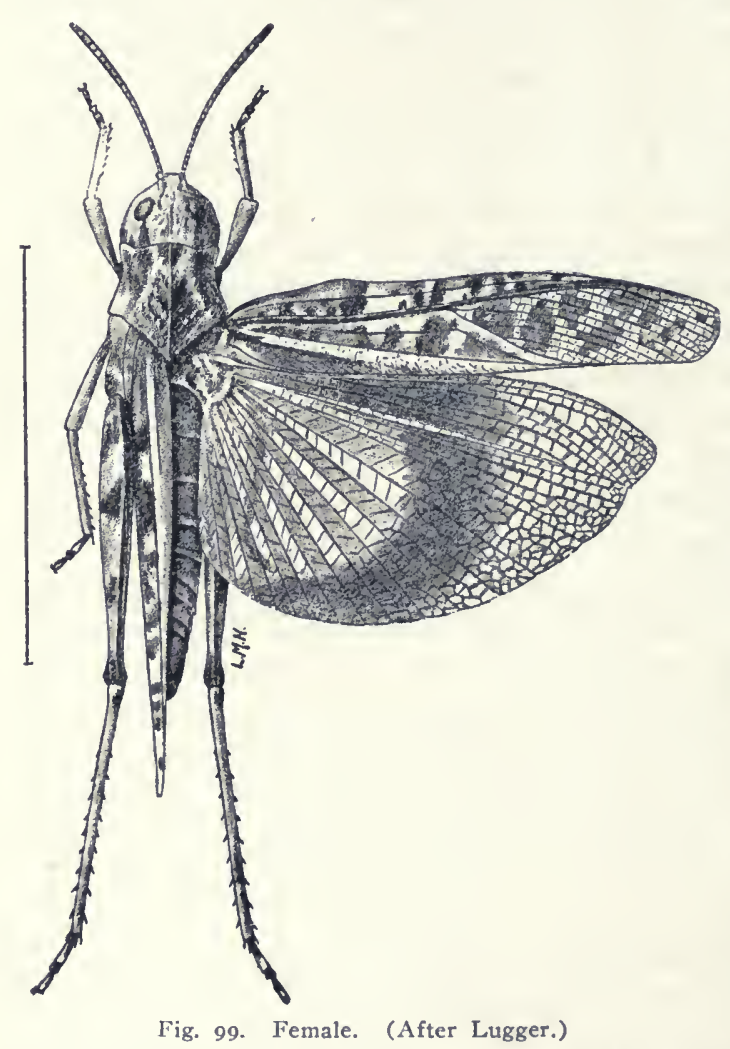
disk circular or subquadrate narrowed in front, often containing several mi. nute tubercles, sides low, distinctly curved, median carina reaching the center, females often, with $\mathrm{z}$ transverse carina behind the middle; foveolæ small but dist i n c t, triangular. Face nearly vertical. Antennæ slender, about the length of head and pronotum together. Pronotum short. the prozona subcylindrical, constricted; metazona as in key, its hind margin right angled, male, obtuseangled, female; median carina low in female, indistinct on prozona, cut slightly in front of middle by the principal sulcus; lateral carinæ distinct on hind part of prozona and front half of metazona. Tegmina surpassing the abdomen about one-fourth their length. Hind femora relatively slender, much narrower proportionally than in any other of our species of Hippiscus, reaching tlp of abdomen, female, slightly

${ }^{43}$ Thomas (1873, 13r) says: "Inside of posterior femora and posterior tibix a bright coral red," but this does not hold good of Indiana and Nebraska specimens at hand. 
passing it, male. Length of body, $\hat{\delta}, 27-35$, $q, 42-46$; of antennæ, $\hat{\delta}$,

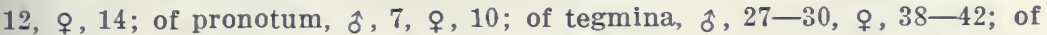
hind femora, $\hat{o}, 15-17$, 오, 21-23 mm. (Fig. 99.)

This species has been taken in Indiana only near Pine, Lake County, where eight specimens were secured on June 20. They mere found on open, sparsely regetated sandy tracts, about a fourth of a mile back from the shore of Lake Michigan. One of the females has the inner wings pinkish or coral-red, as in tuberculatus; two have them orange-red, the other yellow. Of the four males, two have yellow and two orange-colored wings. This is the most eastern record for the species, and it probably occurs in Indiana only in the sand-covered area of the northwestern portion.

The known range of $H$. haldemanii extends from northwestern Indiana to Colorado, south to southern Illinois and middle Kansas. It is not recorded in any of the Canadian lists, though it probably occur's in southern Manitoba. From Illinois Hart (1907, 232) has recorded it as common in the sand region, associated with H. phonicopterus. He adds: "The intercalary vein in Hippiscus, especially in this species and phonicopterus, is quite prominent and bears a row of minute tubercles, as in Mecostethus; and the upper carina of the internal face of the lind femur is rubbed against it. causing a distinct rasping stridulation. The sound may be easily produced in this way in freshly killed individuals. In all the Illinois Oedipodina the same structure of the intercalary rein occurs, and presumably also the same habit of stridulation by means of it when not flying."

Bruner $(1897,131)$ says that haldcmanii is "one of the most common large mottled locusts in eastern and middle Nebraska," but in Minnesota Somes found it very scarce and says: "It is more solitary in habit than most members of the genus, but one specimen being found in each of three localities, these among the low scattered grasses of rery drs soils." It is not listed by Gillette (1904) from Colorado, though recorded from there br Scudder $(1892,286)$. The Hippiscus namus Saussure $(1884,86)$, described from Colorado, is regarded as a synonym and the Illinois records of Ocdipoda neglccta Thos. and the Hippiscus tubereulatus of IrXeill $(1891,63)$ are to be referred to haldemanii.

116. Hippiscus Rugoses (Scudder), 1862, 469. Wrinkled Locust.

Form rather bulky, short-bodied. General color light to dark brown; face and abdomen brownish-yellow; disk of pronotum with a pale, x-shaped mark, often absent in female. Antennæ yellow at base, apical half reddish-fuscous. Tegmina ash-gray, often darker in male, the sides and dorsal area with numerous dark brown or fuscous oblong or rounded spots, those on middle of sides larger; apical third often semi-transparent, with 
spots much smaller and more irregular in shape. Wings with basal half varying from a pallid tint through pale lemon-yellow to deep orange, the outer half with curved black band and transparent apex as in phonicopterus. Hind femora bright yellow within, with three transverse bars of black; dull clay yellow without, with three more or less distinct, very oblique fuscous bars. Hind tibiæ yellow, with a paler ring near base. Occiput convex; vertex with disk ill defined, almost flat, strongly declivent, broader than long in both sexes, the median carina extending to front border and with oblique cross carinæ dividing the disk into four subequal portions, the front pair the more distinct; lateral foveolæ shallow, elongate-triangular. Frontal costa broad, flat, punctate. Antennæ about as long as head and pronotum, female, a third longer, male. Pronotum with median carina low, cut near middle by the principal sulcus; metazona flat or nearly so, not greatly widened, its hind margin obtuse-angled, surface with numerous low, oblong-elongate glistening tubercles, its lateral lobes thickly punctate and lateral carinæ ill defined. Tegmina relatively broad, exceeding the abdomen in both sexes. Hind femora moderately slender, equalling or surpassing the abdomen by one-fourth their length, the basal half depressed. dilated. Length of body, $\hat{o}, 28-36$,,$+ 37-42$; of antennæ, $\hat{o}, 12-13$, , 11-12; of pronotum, $\hat{o}, 7$, $\uparrow, 9$; of tegmina, $\hat{o}, 24-32$, ㅇ, $28-36$; of hind femora, $\hat{\delta}, 16.5-18$, $ᄋ, 21-23 \mathrm{~mm}$. (Fig. 100.)

This is the most common species of Hippiscus in Indiana, being especially abundant in the central and southern portions, but

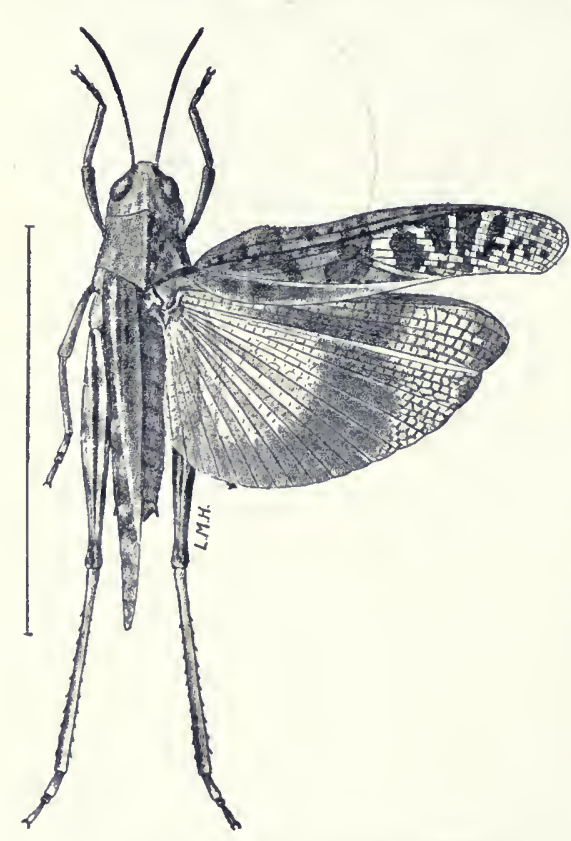

Fig. roo. Male. (After Lugger.) scarce in the north, where it has been collected only in Fulton and Marshall coun. ties. In central Indiana it begins to reach maturity about July 20th, from eggs hatched in the spring. Iike others of its kind, it frequents only dry, upland localities, being especially abundant in open woodland pastures, timothy and clover meadows, along roadsides and rail fences. The males are shy, usually taking to flight when an intruder is a lod away and moving in a straight line in the direction they happen to be headed, without noise, save the rustling of their wings. The females are very clumsy, being readily picked up with the fingers. I have often placed one of them on the palm of one hand and with 
the other stroked gently its back and antennæe without haring it attempt to escape. Mating takes place in late August and September, and the males then mostly perish, while the females are to be found much longer, sometimes as late as November 5th. Orange-winged females of rugosus are more common than males, probably one third of them having the wings of that hue.

The general range of $H$. rugosus extends from Maine and Massachusetts, where it is rare, west to Colorado and south and southwest to northern Florida, Mobile, Ala., Oklahoma and central Texas. It is not recorded from Canada or Michigan, but occurs throughout Illinois, Iowa and Nebraska, and has been taken at several points in Minnesota. In Florida it has been recorded only from De Funiak Springs, Live Oak and Jacksonville. Allard $(1916,277)$ calls it "a most clumsy, inactive locust, readily captured and without distinct stridulation."

In my former work $(1903,272)$ I pointed out that $H$. variegatus Scudder (1892, 301) is only a little stouter bodied, lighter colored form of rugosus. In this I have been followed by R. \& H. $(1916,182)$, who state that $H$. compactus and $H$. suturalis Scudder $(1892,288,301) ; H$. citrinus Scudder $(1901 d, 88)$ and $H$. immaculatus Morse $(1906,119)$ are, in their opinion, also synonyms of $H$. rugosus; all having been based particularly upon minor color differences, or upon "other characters which are without exception worthless, due to their variability or to the fact that they are so slight as to be unappreciable."

VI. Dissosteira Scudder, 1876, 511. (Gr., "double" + "barren.")

Medium or large sized locusts, having the body slender, strongly compressed; vertex with disk sub-pentagonal or orate, the front half declivent; sides narrow; sharp, converging in front of eves, the front margin a low angulate ridge, female, or angulate depression, male; median carina present but indistinct; foveolæ short, triangular; frontal costa sulcate and a little narrowed below the ocellus; pronotum with disk of prozona tectiform, its front margin subangulate, of metazona flat with hind margin obtuse-angled; median cariua high, sharp, on metazona strongly arched, cut distinctly in front of middle by a deep, oblique notch; lateral carinæ rounded, cut by the principal sulcus and subobsolete in front of it; lateral lobes of pronotum deeper than long, their front margin rertical, hind one oblique, lower one with posterior half rounded, anterior half oblique; tegmina broad, much exceeding the abdomen, their apical third membranous; intercalary vein very distinct and nearly intermediate between median and ulnar veins; 
wings long, wide, black, with a narrow, yellowish outer border, apex fuscous; hind femora slender, a little shorter than abdomen in both sexes; valves of oripositor curved, acute, feebly exserted. Six species of the genus are accredited to the United States, one of which inhabits our territory.

117. Dissosteira carolixa (Linnæus), 1758, 433. Carolina Locust. Black-winged Locust.

General color varying from light grayish-yellow through bright red-

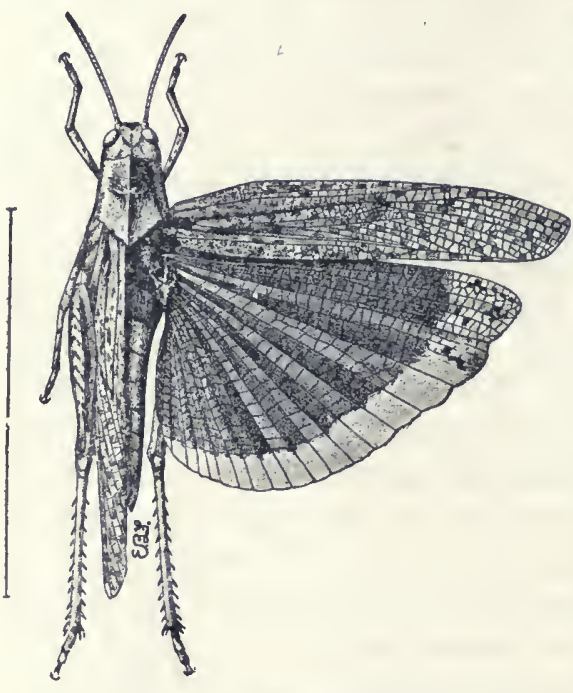

Fig. IoI. Dissosteira carolina (Linn.). Female. (After Lugger.) dish brown to dark fuscous, usually dull ashy-brown, sprinkled with numerous small dusky spots; these most numerous on pronotum and tegmina, on the latter sometir.es forming three more or less distinct crossbands. Wings deep black except the outer border, which is pale greenish-yellow, the apex smoky gray with a few darker spots. Hind femora reddish-brown, faintly annulate with paler near knee and with three broad black bands on inner face, upper outer face indistinctly barred with fuscous. Hind tibiæ yellow. ish or dusky. Length of body, $\hat{o}, 24-33$, ᄋ, 33-40; of antennæ, ô, 9.5-11, ㅇ, 11.5-13; of pronotum, $\hat{o}, 7$, ․, 10 ; of tegmina, $\hat{\delta}, 29-34$, ㅇ, $36-43$; of hind femora, $\hat{o}, 13-15$, ㅇ, 16-20 mm. (Fig. 101.)

The black-winged locust occurs everywhere throughout Indiana and to the casual observer appears to be our most common species, but there are a dozen which are more abundant. Its numbers appear multiplied because it frequents the highways and by-ways of man rather than the pastures and meadows where other grasshoppers are wont to congregate. Moreover, when disturbed, it more often betakes itself to the bare earth than to the green grass. Why this absurd taste asks the person uninitiated in the doings of nature's objects. For the simple reason that the dust of the roadside and the gravel ballast of the railway correspond so closely with the color of its back that its best friends and worst enemies will orerlook it if it will only remain quiet. Yea, even that sharp-eyed connoisseur of grasshopper tid-bits, the 
turkey gobbler, oftentimes walks right over it, mistaking it for a wayside pebble.

Mature specimens of this "Carolina locust," hatched from eggs in spring, have been taken in Vigo County, Ind., as early as June 14 th and as late as Norember $22 \mathrm{~d}$. It is usually common and mating by July 5th. Either there are two broods each year, or else the eggs hatch at irregular intervals, as freshly moulted individuals have been observed on a number of dates in September, and as late as October 14th. On one occasion, while passing through a wheat field in late September, I observed clinging to the stems of weeds, sereral specimens of what appeared to be the bodies of grasshoppers with the wings of the common sulphur-yellow butterfly attached to them. Such a combination aroused my curiosity, but a closer examination proved them to be specimens of this common black-winged loeust which had just moulted for the last time, and spread ont their soft wings to dry. The inner wings, instead of being black, were light yellow, but in three or four hours thereafter had changed to their usual color.

This locust is often seen along the walks and in the yards of our larger cities and I have seen specimens about the base of the Soldier's' Monument in the very center of the city of Indianapolis. Both sexes use the wings almost wholly in their travels, and when flushed move in a noiseless, zigzag, seemingly aimless manner for quite a distance, the flight being often more like that of a butterfly than of a locust. Their hind legs are used only in giving themselves an upward impetus from the ground and hence are much smaller proportionally than are those of such locusts as leap rather than fly, while their wings are much longer and stronger.

The Carolina locust is apparently scarce in Florida and confined to the northern portion of the State. It has not been taken by me therein, but has been recorded from Jacksonville and Enterprise by Scudder (1877a, 89) and from Marianna by Morse. Specimens are in the Gainesrille collection from Lake City, and a pair at land from Gainesville were taken Sept. 20 by Fattig.

The distribution of $D$. carolina is as wide as that of any other of our locusts, being practically coextensive with America north of Mexico. Scudder gives its range as "U. S. and Canada, ocean to ocean ;" Kirby, as "N. America," and Fox, "All temperate North America from the Atlantic to the Pacific." It is, says Morse $(1897,87)$ : "Probably the best known of any of the Oedipodinx, owing to its conspicnous black wings and habit of frequenting roadsides. From the prevailing brown tints of its color it has in some localities received the name of 'Quaker.' In correla- 
tion with its large wing expanse its flight is powerful and erratic, and in hot August afternoons it may often be seen hovering motionless in the air or dancing up and down above a particular spot and stridulating, an act which is doubtless to be considered as a sort of courtship. It is an alert species, well able to take care of itself, and on warm days rather difficult to capture."

In Indiana I have often observed this curious ærial hovering, not only by the black-winged locust, but by Spharagemon bolli and other Oedipods. Townsend $(1891,44)$ has written of it as follows:

"On August 24 I noted an individual of $D$. carolina perform three times in succession, and then another alighted on the ground by its side. They ran by each other several times, apparently clasping, probably in conflict, for I am quite sure they were both males. At last one of them flew away and the other soon after renewed the performance. In going through with it they rise at first about three or four feet, making a light purring or beating sound, and then rising higher, change the motion of the wings. when a curious sharp, see-sawing sound is produced. Some rise even higher than six feet in the last act, others only two or three feet. Many do not remain in just the same place while hovering, but vary, falling or jerking about while endeavoring to keep the same point in the air. of course some excel others in the beauty and ease with which they accomplish the feat and I am of the opinion that the females are sensitive to the grace with which it is performed."

\section{Somes $(1914,53)$ says:}

"From a distance this performance of $D$. carolina resembles the hovering of the 'Mourning Cloak' butterfly, Euvanessa antiopa, more than the actions of a grasshopper. This habit is occasionally seen in a few other related insects, such as some of the Arphias, Camnula pellucida, and Circotettix verruculatus. It has been thought by some to be in some way attractive to the opposite sex, but as Hancosk $(1911,342)$ has noted, we often find this demonstration occurring only when males are near, and on the whole it appears more likely a form of play, possibly akin to the jumping contests of small boys. The insect is very social in its habits and individuals meeting will sometimes pause and wave the antennæ with every appearance of an informal conversation. The males are very ardent in their courtship, and on one occasion we found four unsuccessful males clinging to a mating pair so closely as to form a compact mass of locusts, not even releasing their hold when we rolled them gently down an incline."

McNeill (1887, 58) has shown that while the length of body is greater in D. longipennis Thos. than in D. carolina, the tegmina are ploportionally longer in both sexes of carolina and absolutely longer in the male of that species, so that the latter, in spite of the names, is the long-winged form. However, D. longipemis, which ranges from "Idalo and Montana to New Mexico and Texas," has other characters sufficiently defining it as a ralid species. 


\section{Spharagemon Scudder 1875a, 467. (Gr., "to crackle.")}

Medium sized species, having the bods slender, more or less rompressed; head somewhat swollen above; rertex shaped much as in Dissosteira, but the sides converging more rapidly, median carina faint or wanting, angled front margin absent, foveolæe wider and more distinct; frontal costa narrow, sulcate, at least below the ocellus, its margins feebly converging above the antennse and continuous with those of vertex; antenna in both sexes about as long as hind femora, filiform, the joints of basal third slightly flattened; pronotum with disk of metazona flat, that of prozona more or less tectiform; median carina usually high, strongly compressed, cut slightly in front of middle by a deep but narrow notch, that portion on metazona usually more or less arched; lateral carine usually distinct only on metazona; lateral lobes as in Dissosteira; tegmina relatirely shorter than in Dissostcira, the intercalary vein less distinct and nearer the median than the ulnar vein; wings yellow, with a dark curved median band, the outer portion hyaline; hind femora rather stout and short, equalling or slightly surpassing the tip of abdomen; hind tibiae, in our species, usually with at least the apical half red; valves of oripositor short, but little exserted.

This genus is so closely related structurally to Dissostcira that Saussure $(1884,135)$ placed it as a subgenus under that name, though spharagemon has priority. Both Scudder (1875a) and Morse (1895a) have published revisions of the genus, treating the species known to them at the dates given. All the forms are very closely related, so much so, indeed, that a satisfactory separation of the species is a most perplexing problem to the systematist. Morse considered several of our eastern forms as only geographic races of the older named species, but Scudder evidently did not agree with him for in his catalogne (1900) he failed to list Morse's var. scudderi either as a variety or synonym, and placed wyomingianum as a distinct species and not as a variety of collare. If this omission and placement were intentional and not an oversight he was, from my viewpoint, not far wrong in his conclusions.

In regard to the general color of the various forms, Morse (1895a, 288) has well said: "Variation in color in this genus, in common with other Oedipodinæ, counts for very little; the same species or race may be of all shades from a general dark fuscous to a pale buff or even a bright reddish-brown, even in specimens from the same spot, yet it is probable that the general tint of a large series will be found to agree with the color of the soil of the locality or other peculiarity of environment." 
Kirby, who does not recognize races or varieties in his Catalogue, though he includes numerous known synonyms as species, accredits to Spharagemon $(1910,233) 11$ species, ten from the United States and one from Mexico. I believe that two of the socalled varieties of Morse are valid species, and recognize five species as inhabiting the Eastern States.

\section{KEY TO EASTERN SPECIES OF SPHARAGEMON.}

a. Hind tibiæ with a distinct pale ring on basal third, back of or behind which is a black one of equal width; median carina of pronotum equally compressed throughout (Fig. 90, c, d.)

b. Apical two-fifths of hind tibiæ bright coral-red; hind margin of metazona of male obtuse- or at most right-angled. 118. BorLI.

$b b$. Apical two-fifths of hind tibiæ dull brownish-yellow, tinged with fuscous; hind margin of metazona of male acute-angled.

119. CREPITAXS.

aa. Hind tibiæ usually wholly red or dull yellow, rarely with a pale subbasal ring, and this then without a black one behind it; basal or distal third of prozonal disk more or less elevated and broadly joined to median carina, making the latter unequally compressed at that point (Fig. 90, e, g.)

c. Median carina of prozona with upper edge more or less sinuate; hind margin of metazona obtuse- or at most right-angled; hind tibiæ with an ill defined pale ring near base.

d. General color grayish-brown, the tegmina distinctly mottled and barred with fuscous; median carina of pronotum relatively high, distinctly arched on metazona; posterior prozonal tip of median carina projected back partly over the deep suboblique notch. (Fig. 90, g.)

120. SAXATILE.

dd. General color purplish-brown, the tegmina but feebly maculate; median carina of pronotum, especially in female, very low, nearly straight on metazona; posterior prozonal tip of carina not projected backward over the shallow nearly vertical notch.

121. PLANUM.

cc. Median carina of prozona cristate with upper edge straight or feebly arched, its hind margin strongly projected backward to partly or wholly cover the very oblique notch (Fig. 90,e, $f$ ); hind margin of metazona acute-angled; hind tibiæ without a pale ring at base.

122. WYOMINGIANUM."

\section{Spharagemon Bolli Scudder, 1875a, 469. Boll's Locust.}

Size large for the genus, the males but little the smaller. Ground color variable, that of male usually grayish or fuscous, of female rusty brown or pale buff, the face grayish or yellowish; antennæ brownish or grayish at base, fuscous at apex. Tegmina sprinkled throughout with minute blackish spots, these in male aggregated into three more or less distinct dark cross bars; female often with only faint traces of these bars

${ }^{44}$ A northwestern species, $S$. collarc Scudder, has been recorded from northern Illinois by Scudder $(1875 \mathrm{a}, 470)$ and from northern Indiana by Morse (1895a, 297), but these records were probably based on $S$. wyominginnum as no specimens of undoubted collarc from either of these two states have been taken in recent years. 
visible. Wings pale greenish-yellow at base this hue followed by a broad median curved fuscous band which gives off an inward projecting spur near front margin; apical third of wing transparent smoky, the extreme tip in male often of same hue as median band. Hind femora with alternating bars of black and yellow, three each, on inner face; outer face dull yellowish or grayish-brown with three or four oblique indistinct dark brown bands; hind tibiæ as described in key. Vertex almost flat, its sides low, converging in front to meet those of frontal costa; foveolæ distinct, triangular. Pronotum with disk but feebly rugose; median carina higher in male than in female, prozonal portion more cristate than metazonal, the latter more elevated in front than behind, the notch of carina subvertical. Length of body, $\hat{\delta}, 20-28$, ㅇ, $27-36$; of antennæ, ô, 12-15, 오, 13-16; of pronotum, $\hat{\delta}, 7$,,, 9 ; of tegmina, $\hat{\delta}, 25-32$,, $27-34$; of hind femora, ô, 14-16, ․ , 13-19 mm. (Figs. 96c., 102.)

This is a common locust throughout the central and southern thirds of Indiana, but much less numerous northward, where it

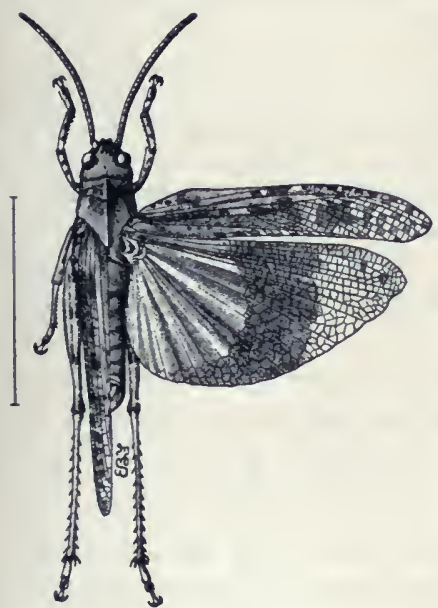

Fig. 102. Male. (After Lugger.) seems to be replaced in part by $S$. uyomingianum, though it has been taken in Starke and Lake counties. It frequents paths and bare places in dry upland woodland pastures, especially those which include the slopes of high hills, roadsides and stubble fields. In the northern counties it is found most abundantly along the sandy edges of woodlands and in old fields. In Crawford County mature specimens from eggs hatched in spring, have been taken on June 25th; in Vigo County, on June 30th. The males fly much farther than the females and on arising from the ground emit a short and rather low rattling note. The females are clumsy in their movements, and prefer, after being flushed once or twice, to lie still when approached, as close to the ground as possible, relying upon their protective coloration to prevent discovery.

The known range of $S$. bolli is a wide one, extending from Maine and southern Ontario, west to Aweme, Manitoba and Colorado, and south and southwest to northern Florida, Oklahoma, central Texas and Las Vegas, New Mexico. In Florida it appears to be scarce, the only definite known locality being Tallahassee, the other records from the northern part of the State being based on S. crepitans. In Ontario Walker $(1898,261)$ found it common 
locally between June 24 and October, its stridulation being "a rapid and rather loud rattling sound resembling that of Arphia sulphurea." Morse (1907,37) says that: "It is one of the few sylvan geopliilous locusts, its distribution coinciding with that of dry woodlands. In the Northern States it frequents old sandy fields as well as the more open woods and forest paths and margins. It is widely and generally distributed in suitable localities throughout its range, never becoming abundant even locally."

Individuals of $S$. bolli, like those of $D$. carolina and other Oedipods, have, in late summer, the peculiar habit of sustaining themselves in the air, about three feet above the ground, for several minutes. While poising in this manner above one spot, they make a dry, rustling note, which is perhaps a call to some nearby member of the opposite sex. The S. balteatum Scudder $(1875 a, 469)$ is a synonym of S. bolli.

119. Spilaragemon crepitans (Saussure), 1884, 140. Crepitating Locust.

This form was separated by Saussure as a variety of bolli, his brief differential diagnosis, freely translated, being as follows: "More slender: crest of pronotum lower, scarcely arcuate, dorsum (of pronotum) densely granulate. Wings narrower, the apex hyaline; humeral field narrower, with apex subparabolic, the fuscous fascia of disk narrower. Hind femora more slender, their lower margin less dilated. Length of body, $\&, 36$; tegmina, $36 \mathrm{~mm}$."

S. crepitans was placed as a distinet species by Morse (1895a, 290 ) and I believe justly so. The two forms can be readily dis. tinguished by the claracters given in the key; R. \& H. $(1916,185)$ stating that numerous specimens show clearly that "the candal tibire are never as highly eolored as in $\$$. bolli, and are in the majority of cases cinnamon-buff." The specimens at hand show that the median fuscous band of wing is wider than in bolli. not narrower as stated by Saussure; and that the disk of pronotum does not appreciably differ in its granulation or rugoseness. However, the front margin of prozona is more distinctly angulate and the general coloration more uniform.

Saussure's type of erepitans, evidently a unique female, was from Georgia, and the species is known only from that State and Florida. In Florida it has been recorded by R. \& H. (loc. cit.) from Jacksonville, Carrabelle, Cedar Keys and Key West, they stating that it has nerer been found far inland from the ocean. Howerer, specimens in the Gainesville collection were "taken July 28 , on a dry slope in an open field near a stream, about a mile west of the University:" (Watson.) At Cumberland Island, Ga., it was found by $R$. \& H. to be "abundant on the sandy soil of a 
live-oak hammock," and at other localities usually among palmetto scrub. At Key West it was taken by them, July 7 , under bushes in high jungle undergrowth of the keys, where its flight was usually low and for short distances.

120. Spharagemox saxatile Morse, 1894b, 229. Ledge Locust.

Size medium, rather stout, less compressed than bolli. General color as in key, darker above, paler below. Occiput blackish, face and cheeks gray, punctate with black and brown; antennæ with basal two-thirds annulate with dull yellow and fuscous, apical third uniform fuscous. Pronotum gray, mottled with black, disk usually with a broad $\mathrm{x}$-shaped ashgray blotch, widest on metazona. Tegmina brownish at base, then usually trifasciate with fuscous; tips transparent, dotted with fuscous. Basal twofifths or more of wings sulphur-yellow, this bordered without by a broaa fuscous band, from which a subcostal spur projects half way to base; apical fourth of wing transparent with veins and small spots fuscous. Hind femora ash-gray barred with fuscous; inner face yellow with four blackish bands, the two basal ones more or less united. Hind tibiæ coral-red, a pale ring near base, spines tipped with black. Vertex elongate-oval, disc concave, sides distinct, converging in front, median carina evident but faint; foveolæ small, shallow, subtriangular or $\nabla$-shaped, the basal side not closed. Frontal costa narrow, distinctly sulcate from antennæ downward, male; wider, sulcate only below the ocellus, female. Pronotum with prozona constricted, rugose; metazona broad, flat, its hind margin obtuseangled, female, right-angled, male; median carina as described in key, higher and cristate on prozona, gradually lower to apex on metazona (Fig. 90, g) ; lateral carinæ distinct on metazona and apical third of prozona. Tegmina strongly surpassing abdomen in both sexes. Hind femur reaching tip of abdomen, female, exceeding it $2-3 \mathrm{~mm}$., male. Length of

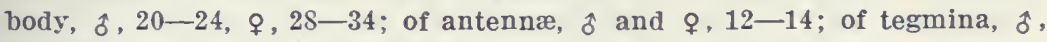
$21-25$,, $25-31$; of hind femora, ô, $11.5-14$, $~, 14-17 \mathrm{~mm}$.

Living specimens of this landsome rock frequenting locust were first seen by me at North Madison, Conn., Aug. 26-2S, 1896. Specimens had been previously received from Morse, and I was on the lookout for it. Ther were found only on the highest ledges in sunny open glades along the Hammonasset River. In my field note book I wrote at the time: "Spharagemon saxatile occurs only on the lichen-corered tops of the ledges. The males are rery shy and difficult to approach, moving slort distances with a quick, almost noiseless flight, in longer ones making a rather loud rattling sound. Their hues accord so perfectly with the lichens and grap rocks that they must be marked down carefully and even then cannot always be seen until ther move. A female flutters down within three feet of where I am seated. No sooner does she alight and compose herself than two males, resting nearby but before unnoticed, make a rush for her. With short ado one mounts her back and the other jumps on top of the two. Soon discorer- 
ing his mistake he leaps down behind them and sulks in disappointment. Arising stealthily with a quick motion I throw the net flat down over them and capture the trio at one stroke."

In the notes following his original description, Morse says: "I have named this species saxatile for the reason that it finds life most to its taste in unsettled somewhat wooded districts of a rocky, often elevated character. Here it finds a congenial home and may be seen during the latter lialf of the season crawling actively about over the lichened ledges, whose tints harmonize with its own, or flying from one to another, stridulating loudly as it goes. In its fresh state it is one of the most handsome of our New England locusts and even cabinet specimens vividly recall the cool gray of the rocks, the glory of the golden-rod and the tints of the reddened stems of trailing vines. So well do the colors of its body match those of its chosen haunts-the pale greenish-gray and ashy of the paler rocks and their lichen coverings, the brown and black of other lichens and the darker hornblende and iron-stained weathered rocky fragments,-that it is quite difficult to distinguish when at rest, and being an extremely alert insect some strategy is required for its capture."

The known range of saxatile is a limited one, extending from Massachusetts and Connecticut south and soutlwestward in the mountains to Maryland and Virginia.

\section{Spharagemon Planum Morse, 1904a, 13.}

Form and size of $S$. bolli, the body less compressed. General color purplish-red in life, fading to dark purplish-brown. Antennæ as in saxatile. Tegmina feebly maculate with fuscous, the usual transverse fuscous bars faint or wanting. Wings as in $S$. bolli. Hind femora with two more or less distinct fuscous bars on outer face; inner face yellow with three black bars, the two basal ones broadly connected along the middle and lower margin. Hind tibiæ with knees black, bordered behind by a pale ring, apical two-thirds coral-red, the sides sometimes tinged with fuscous near the pale basal annulus. Vertex as in saxatile; foveolæ smaller, less distinct, the basal side distinctly margined. Frontal costa with sulcus shorter, more shallow, male, longer and deeper, female, than in corresponding sexes of saxatile. Pronotum with median carina of almost equal height throughout; much lower and less arched in both sexes than in saxatile; prozona not constricted nor with its surface rugose as there, the first transverse sulcus almost cutting its crest at basal third; metazona with hind margin obtuse-angled in both sexes; lateral carinæ rounded and indistinct on metazona, absent on prozona. Tegmina broader than in saxatile, the dilation at basal third of costal margin more evident. Hind femora reaching tip of abdomen, male, 3 to $4 \mathrm{~mm}$. shorter than abdomen, female. Length of body, $\hat{\delta}, 23, \uparrow, 33$; of tegmina, $\hat{\delta} ; 23, \stackrel{\circ}{,}, 29$;

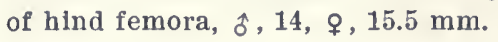


Jarman Gap, Va., Aug. $1(F o x)$. This locust was, strangely to say, placed as a rariety of saxatile by Morse, but in color, in structure of facial costa, and especially in form and height of median carina of pronotum, it is very distinct. Aside from the structure of the median pronotal carina it is much closer to bolli than to saxatile. not only in form and size, but also in color and general facies. Moreover, it is not a saxicolons species, restricted to bare rock surfaces, as is saxatile, but has the same haunts as bolli, as is shown by the notes of both Morse and Fox. The former (1904, 36) states that at the typical locality, Wrtheville, Va., he "found it plentiful locally on a thinly grassed, gravelly hill-slope, accompanied by its congener, bolli, and exactly matching in coloration the purplish-red iron-bearing fragments of rock and soil on which it made its home." Fox (1917) says that: "At Jarman Gap it occurred in considerable numbers in a closely grazed grassy pasture on the summit of a ridge, while at Monterey it was common on the ligher and steeper slopes, on cleared but untilled rocky ground close to the margin of the woods, frequenting bare, thinly grassed (Danthoniu) or briery areas. In all places it was associated with S. bolli."

If planum is a variety of anything it must be one of bolli, but the characters as above set forth in the ker and description are deemed sufficient to raise it to specific rank. There is a possibility that it may have been originally a hybrid of bolli and saxatile, partaking somewhat of the characters of both. Aside from the localities mentioned it is recorded only from Lehigh Gap, Pa. (Rehn, 1902c), under the name of Trimcrotropis citrina Scudd.

122. SpHaRAgenox Wyomixglaxum (Thomas), 1872, 462. Mottled Sand Locust.

Smaller and more slender than our other eastern species. General color pale yellowish- or pinkish-brown, everywhere sprinkled and spotted with darker brown or fuscous; face ash-gray or yellowish, sprinkled with minute darker spots Antennæ fuscous at tip, paler toward base. Sides of pronotum with two indistinct dusky bands, the upper in the place of the lateral carinæ on prozona. Tegmina with three transverse bars of fuscous spots, the dorsal field often brownish-red. Win;s similar to thos: of bolli, the median black band narrower toward the anal angle which it reaches. Hind femora pale brown or gray, with traces of four fuscous cross-bars; within sulphur-yellow, with three or four more or less complete black bars, the two basal ones often united. Hind tibiæ coral-red or pinkish, paler at base; spines with extreme tips black. Vertex, viewed from above, about as broad as eye, median carina usually evident but faint. Eyes of male larger and more prominent than usual. Pronotum with disk flat on metazona, somewhat sloping on prozona, slightly angulate in front, acute-angled behind; median carina high, compressed. arched 
on both pro- and metazona, especially on latter; prozona in male with crest of carina distinctly sloping toward head; notch plainly oblique, very narrow, often nearly or wholly closed above by the overlapping ends of the carina (Fig. 90,e, f.) Tegmina surpassing femora by about one-third their own length. Legs and ventral portion of jouy usually very pubes cent, with long grayish hairs. Length of body, $\hat{\delta}, 19-25$, $q, 24-30$; of antennæ, $\delta, 10-12.5$, ㅇ, $10-13$; of prorotum, $\hat{\delta}, 5-7$, ㅇ, $6.5-7.4$; of

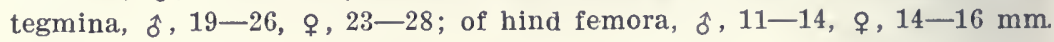
(Fig. 103.)

This small, but handsome, locust is quite common in the sand covered areas of the northern third of Indiana. The earliest date

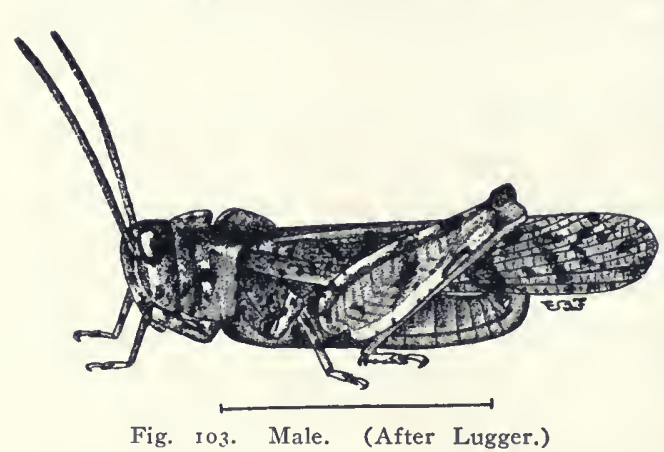

for the adult is July 14th, in Fulton County, when it was found in numbers and had probably been mature for a week or longer. It occurs most abundantly along the thinly regetated sandy tracts twenty rods or more back from the water margin of lakes, in old sandy cultivated fields and along railways and roadsides. In such localities it is often found in company with Psinidia fenestralis and less frequently with S. bolli. It seldom leaps when disturbed, but uses the wings to propel itself in a flight of about 30 yards; the males making a faint crackling noise as they clear themselves from the earth, while the females are noiseless. In a corn field near Lake Maxinkuckee, I once found wyomingianum very common on August 17th, over about two acres of the most sandy portion. Resting on the soil between the rows, they were very difficult of detection, and eight times out of ten were not seen until flushed, unless they had previously been "marked down" as they alighted. A few were also taken from the sandy margin of the lake, but careful search over a wide extent of territory failed to reveal them elsewhere. It will probably be found in the ricinity of most of the lakes of the State.

This locust, as above defined, I consider sufficiently distinct to retain as a valid speeies under the name given it by Thomas. It was so retained by Scudder (1900) though made a variety of collare by Saussure and Morse and a synonym of collare by Kirby. The two forms overlap in distribution and perhaps merge where so orerlapping. The retaining of wyomingianum as distinct is therefore more or less arbitrary and a matter of individual opin- 
ion. The eastern form described by Morse (1894b, 226) as $S$. aquale scudderi and afterward $(1895 \mathrm{a}, 297)$ changed to $S$. collare scudderi I regard, however, as an absolute synonym of wyomingianum. In none of his papers lias Morse given any fixed characters separating the two forms, and in his Key to New England Oedipodina $(1897,35)$ he does not recognize vyomingianum as inhabiting New England, though Walden (1911) records it from a number of localities in Connecticut. The comparative distinctions given by Morse of greater size of scudderi and different fasciation of inner face of hind femora will not hold. Specimens of undoubted uyomingiamm at hand from northern Indiana and Illinois and Gainesville, Fla., exceed in size any measurement given by Morse for scudderi, and R. \& H. $(1916,187)$ show that the same is true of specimens from Virginia and Georgia. The black bars on inside of hind femora of wyomingianum vary from two to four, being sometimes connected and often not, so that their value as a distinetive character is nil.

The known distribution of wyomingianum, as here recognized, is a wide one, extending from Maine and southern Ontario west to Minnesota, Wyoming, Utah and Colorado, and south and'southwest to North Carolina, Georgia and northern Florida, where it has been recorded only from Fernandina, Gainesville and Live Oak. In Oklahoma and Texas it appears to be replaced by S. cristatum Scudd., distinguished mainly by its higher median carina, which will probably prove to be only a race or variety of wyomingianum. The latter is said by Bruner to inlabit the high prairies of Nebraska.

Of the oceurrence of wyomingiamum in Minnesota Somes (1914, 57) says: "We have, as yet, found this species only in the southeastern part of the State, usually on the sandy margins of the Mississippi and its tributaries. Upon the almost clear sand which it frequents, its pale color and-faintly marked pattern blend beautifully with the lights and shadows, rendering it almost invisible until it moves. Its flight is swift and strong, though not usually prolonged, and it rises with almost the swiftness of a Cicindela."

The S. oculatum Morse $(1894 \mathrm{~b}, 232)$ is a synonym and the New England records of S. aquale Say by Harris and Scudder are also to be referred to voyomingianum.

VIII. Scirtetica Saussure, 1884, 135. (Gr., "to leap" + "grasshopper.")

Small slender bodied, moderately compressed species, having the disk of vertex rather narrow, elongate-oval, its sides low, con- 
verging but not meeting either before or behind, the hind border therefore sub-obsolete; median carina evident but faint; foveolæ short, broadly triangular; eyes of moderate size, strongly convex; frontal costa narrow, sulcate throughout, male, below the antennæe, female, sides parallel, feebly converging at junction with vertex; antennx filiform, one-half or more longer than head and pronotum together, male, one-fourth, female; prozona rather strongly constricted, its front margin truncate; metazona wide, flat, nearly smooth, its hind margin strongly obtuse-angled; median carina very low, cut in front of middle by the principal sulcus (Fig. 96, d) ; prozonal portion slightly the higher, sinuate, rarely feebly cut by the first transverse suleus; lateral lobes deeper than long, front margin vertical, hind one nearly so, lower one as in Dissosteira; tegmina and wings narrow, the latter colored as shown in Fig 104 ; hind femora slender, slightly surpassing tip of abdomen, male, reaching tip or a little shorter, female; hind tibiæ in great part red; valves of ovipositor slender, but feebly exserted. One species and a geographic race occur in the Eastern States.

KEY TO EASTERN FORMS OF SCIRTETICA.

a. Basal third or more of wings pale sulphur-yellow; hind tibiæ with both pale and fuscous rings near base usually well defined.

123. MARMORATA.

aa. Basal third or more of wings orange or chrome-yellow; hind tibia without distinct fuscous ring behind the pale one, the latter poorly defined.

123a. PICTA.

123. Scirtetica marmorata (Harris), 1841, 145. Northern Marbled Locust.

Color exceedingly variable, usually ash-gray, more or less mottled and barred with brown and fuscous; sometimes bright reddish-brown or the hue of hematite. Face usually gray with dark spots; occiput brown with

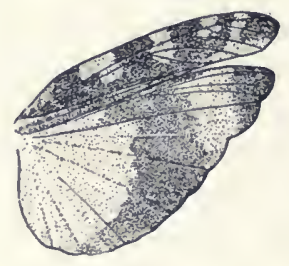

Fig. 104. Tegmen and wing of male of $S$. margray spots; antennæ dull yellow at base, apical third darker. Pronotum grayish-yellow with a blacl: bar behind eye and another below, or black. ish-fuscous with pale blotches; sometimes reddishbrown with lower sides only pale; often with a broad $\mathrm{x}$-shaped dull yellow mark on disk. Teg. mina usually brown or blackish, with two or three large subquadrate pale spots on apical two-thirds of costal field, the basal one the longer; often grayish, thickly mottled with fuscous dots and blotches. Front and middle femora gray, annulate with fuscous; hind femora dull yellow with two or three curved fuscous bars on outer face; within yellow with three black bars. Hind tibiæ with pale ring at base, followed by dark one of equal width, apical half or more coral-red. Undet surface dull yellow. Structural characters as above given. Length of body, ๙ิ, $15-19$, ㅇ, 22-25; of antennæ, $\hat{\delta}, 10.5-12.5$, ㅇ, $9.5-10.5$; of 


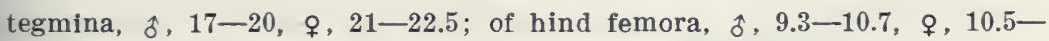
$12.5 \mathrm{~mm}$.

Provinceton, Mass.; North Haven, Conn. (Morse) ; Gravenhurst and Serern River, Ont. (Waller). A handsome mottled species of limited distribution, recorded definitely only along or within a few miles of the coast in Massachusetts, Connecticut and New Jersey, and from several points in Ontario and Michigan.

Harris (1862, 179) calls it: "One of our prettiest species found in the open places contiguous to or within pitch-pine woods, flying over the scanty grass and reindeer moss which grow in these situations. It appears in the perfect state from the middle of July to the mirdle of October." Morse (1S97, 89) says: "Like the species of Spharagemon it is a wide-awake and rather shy lo. cust, best secured by marking down and approaching cautiously, capturing it with a swift sweep of the net as soon as within striking distance. Its stridulation and flight are very similar to those of s. bolli."

At Douglas Lake, Mich., Testal (1914, 107) found it rather numerous in July and August in an open forest among the undergrowth of bracken fern and blueberry, and states: "It appears to he associated with lichen surfaces in rather open situations, somewhat after the manner of Trimerotropis saratile McN., the markings giving it much of the general appearance of the lichens upon which it rests."

123a. Scirtetica мarmorata Picta (Scudder), 1877b, 31. Southern Marbled Locust.

Differs from marmorata by the characters given in key and by having the wings broader, their greatest width contained 1.5 to 1.7 times in greatest length, instead of 1.8 to 1.9 times as in marmorata; fuscous wing. band broader, usually as broad as the width of the yellow disk and continued around nearly to anal angle. Disk of pronotum never with an $\mathrm{x}$ shaped pale mark. Tegmina usually darker, the pale spots smaller, more numerous and more generally distributed, the dark cross-bars between the pale ones not as well defined. Median carina of pronotum lower, especially so in female, the prozonal portion less sinuous and more evenly compressed, the disk of prozona less constricted. Length of body, $\hat{\sigma}$,

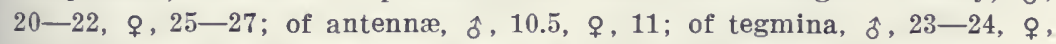

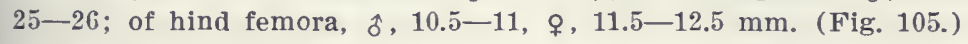

This is a common sand-frequenting species in Florida, and has been taken by me at all collecting stations above Ft. Myers and Miami, and by others from numerous localities both inland and near the coast thronghout the State. About Dumedin it occurs in both nymph and adult stages during the entire winter, frequenting bare sandy places in open woods, sandy paths and road- 


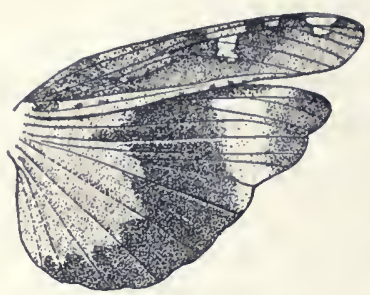

Fig. 105. Tegmen and wing of male of $S$. m. picta. $\times 1.5$. (After R. \& H.)

ways, and the sparsely clothed sandy stretehes just back of the beach on the Gulf side of Hog Island. The specinens taken at the latter place were much paler than those from the mainland and were at first thought to be Trimerotropis maritima (Harris).

Morse $(1904,37)$ first suggested the possibility of picta being a southern race of marmorata, an opinion accepted by $\mathrm{R}$. $\&$ H. $(1912,254)$ after the comparison of numerous specimens from North Carolina showing intergrading characters. The known range of s. $m$. picta extends from Southern Pines, N. Car., west to Augusta, Ga., and south and southwest thronghout peninsular Florida and to Gulfport, Miss. Throughout this range it is found usually in small colonies, in sandy spots of open woods, often in company with Psinidia fencstralis (Serv.), being more abundant immediately along the seacoast than farther inland. Fresh specimens easily rank among the most handsome of our southern locusts. I first became acqnainted with picte at Ormond, Fla., in March. 1899, and a field note regarding its habits $(1902,84)$ is as follows: "In an old orange orchard I found the male of the particolored sand locust, Scirtetica picta (Scudd.), more abundant than at any time before. He has the most prolonged stridulation of any locust known to me. He zig-zags in his flight almost at right angles, sometimes staying in the air for half a minute, flying all about an acre or more, and finally alighting on the sand within a yard of where he arose. All the time he is up he sounds his musical organ with every stroke of his wings, making a lond $z$-rr-zrr-zrr, like the subdued note of the harvest fly, Cicada pruinosa L., or the prolonged and angry buzz of a big bumble-bee. This locust has so far been recorded only from Georgia and Florida, though it will doubtless be found farther north in sandy fields close to the coast."

\section{Tribe II. TRIMEROTROPI.}

The members of this tribe of Oedipodinse are generally smaller and much less bulky than those of the preceding genera. All agree in having the median carina of pronotum (except in Mestobregma) very low, nearly straight, eut feebly but distinctly on prozona by the first transverse sulcus, again at or slightly in front of middle, and more deeply by the principal sulcus (Fig. 106, e). The disk of prozona is often more or less strongly constricted while that 
of metazona is flat and usually much less rugose than among the members of Tribe I. Our species are all ammophilous or saxicolous in habitat, dwelling along the sandy beaches of sea or lake, in old fields or along roadsides in extensive sandy areas, or on rocky ledges in densely wooded districts. None of them inhabit the open pasture lands and meadows as do the Arphias, Spharagemons and other members of the tribe Hippisci. Four genera represent the tribe in the Lastern States.

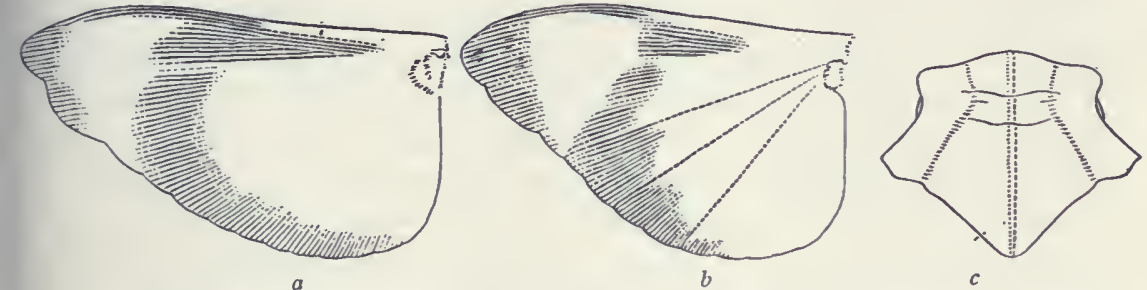

Fig. ro6. $a$, Wing of male of Hippiscus apiculatus; $b$, same of Circotettix verruculatus; $c$, pronotum of Trimerotropis maritima. (After Morse.)

KEY TO EASTERY GENERA OF TRIMEROTROPI.

a. Pronotum strongly constricted, its median carina subcristate, cut by the principal sulcus at or near the middle, the metazona but slightly longer than prozona; disk of vertex between the eyes as broad or broader than long; antennæ strongly flattened basally. those of male as long as or longer than hind femora; lower hind angle of lateral lobes not broadly rounded; smaller, females not over $25 \mathrm{~mm}$. in length.

b. Basal third of prozona not scutellate; occiput without tubercles; foveolæ small, shallow, subcircular; hind tibiæ dull greenishwhite with a dusky ring at basal third, the knee and apex fuscous.

I. Psixinia, p. 288

$b b$. Basal third of prozona between the notches scutellate, i. e., forming an ellipitical plate or disk with raised edges; occiput with a number of small tubercles; foveolæ (in our species) large. distizct, triangular; hind tibiæ pale blue with a whitish ring near base.

II. Mestobregma, p. 290

aa. Pronotum much less constricted at middle, its median carina low, cut by the principal sulcus in front of middle, the metazona distinctly longer than prozona; disk of vertex between the eyes longer than. broad; antennæ filiform, always shorter than hind femora; lower hind angle of lateral lobes broadly rounded; larger, the female 27 or more $\mathrm{mm}$. in length.

c. Hind tibiæ not fuscous near base and tip; general color light brown or buff, or pale gray; radiate veins of anal field of wings not enlarged.

III. TrImerotropis, p. 292

cc. Hind tibiæ fuscous toward base and at tip; general color dark gray or black; radiate veins of anal field of wings distinctly swollen.

IV. Circotettix, p. 299. 


\section{Psininia Stål, $1873,117$.}

Small, slender, compressed species, having the occiput much elevated; vertex with disk short, broad behind, strongly concave, its sides sharp, elevated, strongly converging and declivent; frontal costa sulcate throughout, the upper half very narrow, lower one feebly expanding; pronotum strongly constricted at middle, hind margin acute-angled; median carina sharp, straight and of equal height throughout, cut by two notches in front of middle; lateral carina rather distinct on metazona, ill defined on prozona; lateral lobes of pronotum deeper than long, front margin subvertical, hind one slightly concave, lower one curved, its front half ascending; tegmina narrow, exceeding the abdomen by about one-fourth their length, their basal half densely coriaceous, many of the cells in front half of middle third, two to four times as long as wide; hind femora reaching tip of abdomen, female, slightly exceeding it, male; valves of ovipositor slender, distinctly exserted, their tips acute, curved. One species of wide range oceurs in the Eastern States and Canada.

124. Psinidia fexestralis (Serville), 1838, 726. Long-horned Locust.

General color varying widely, according to environment, from pale clay-yellow to bright reddish-brown or even blackish. Face yellowishbrown, cheeks grayish, occiput and disk of pronotum darker; a narrow yellowish stripe extends back from eye onto disk of pronotum, the sides of

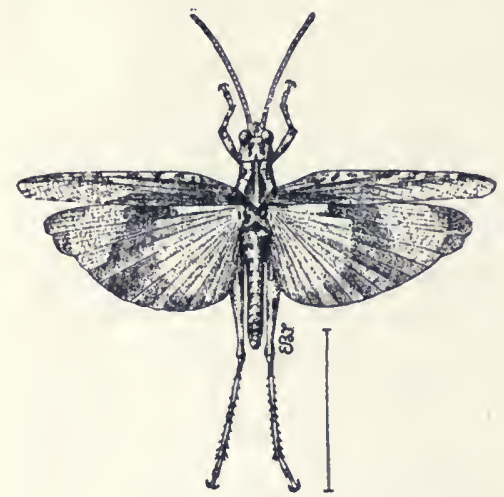

Fig. 107. Male. $\times$ 1.5. (After Lugger.) latter with a fuscous bar near middle. Tegmina dull clay-yellow or reddish-brown, the lower half of sides with numerous small alternating light and dark spots; upper half unspotted. Wings with basal third usually orange or vermilion red, often yellow; middle third with a broad curved black band which reaches nearly to anal angle, rront margin with a dusky bar reaching nearly to base; apical third pe]lucid. Hind femora reddish-brown. with three ill-defined dark, oblique bars on upper outer face; inner face with alternating bands of black and yellow. Hind tibiæ greenish-yellow with a dark ring at each end, and a broad fuscous one just above the middle, the apical halves of spines black. Length of body, $\hat{\sigma}, 15-18$, ㅇ, 19-25; of antennæ, $\hat{\sigma}$,

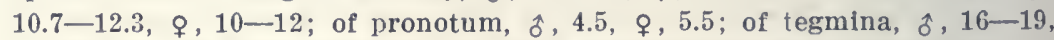
९, 18-25; of hind femora, ô, 9-11.5, ᄋ, 11-12.5 mm. (Fig. 107.)

In Indiana the long-horned locust has as yet heen noted only in Lake, Porter and Laporte counties, in the sandy area bordering 
Lake Michigan. It is most common along the beach within onehalf mile of the lake, in company with Trimerotropis maritima (Harris) and spharagemon wyomingianum (Thos.), though a few specimens were taken on sandy ridges five miles from the lake shore. It has a quick, short flight, and always chooses a bare, sandy spot on which to alight. Unless it is carefully marked down it is then very difficult to distinguish, since its colors harmonize so perfectly with its surroundings. By keeping an eye on it and stealthily approaching it can readily be taken by throwing the net quickly over it just as it is in the act of rising. The male makes a slight rattling sound as it flies, but the movement of the female is noiseless. The majority of the specimens taken had the inner wings a bright red at base, though variations in color, from light yellow to deep red, were noted. It probably occurs in sandy areas throughout the State.

In Florida $P$. fenestralis has been taken by me at Ormond, Sanford, Little River, Ft. Myers, Sarasota and Dunedin and is recorded from numerous localities by other collectors. About Dunedin it occurs in small numbers in both nymph and adult stages throughout the winter, frequenting sandy roadsides, old fields and orange orchards, often in company with S. m. picta, C. v. australior and other ammophilous species.

The known range of $P$. fenestralis extends from Maine to Minnesota and northwestern Nebraska, south and southwest to southern Florida, Mississippi and northern Texas. It is not known from the southern keys of Florida, but Rehn $(1909,204)$ records it from Guanabacoa and Havana, Cuba. Though Saussure $(1884,164)$ says it occurs "in Canada extensa," and Scudder (1900) gives its range as "U. S. and Canada east of Mississippi River," it is not recorded from that country in any of Walker's papers nor is it definitely recorded from Ohio or Michigan, though it should occur in both states.

Of its occurrence in New England Morse (1897, 112) says: "This is a common and widely distributed species, found nearly everywhere on sandy spots in southern New England, and probably throughout the entire district. On the seashore it is sometimes associated with T. maritima, (Harr.). It is usually plentiful where it occurs, though often very local in consequence of its habitat. When disturbed it flies but a short distance, often only a few feet, the male producing a rery slight, scarcely noticeable, crepitation." Vestal (1913) states that in "the bunch grass of the sand prairies of Illinois no species of the Oedipodinæ but Spharagemon outnumbers it," but in Minnesota Somes (1914) 
has taken it only along the Mississippi in the southeastern part. He adds: "The flight of fenestralis differs from that of Trimero. tropis in being low and direct, but is not as swift as in Mestobreg. $m a$. The male has a faint rerial stridulation. The coloration of this insect is such that when on its normal habitat of almost clear sand with scattered regetation and a background of broken lights and shadows, its detection is almost impossible. We have often been unable to see them, even when within a few inches, except by the movements or by the shadows they cast."

\section{Mestobregana Scudder, 1876a, 264. (Gr., "full" + "front.")}

Species in general facies resembling Psinidia, but having the occiput less elevated, more or less tuberculate, disk of vertex much as in Psinidia, but more shallow, broader in female, its sides more sinuous and strongly declivent to unite with those of frontal costa; foveolæ in our eastern species, large, prominent, triangular; frontal costa narrow, deeply sulcate throughout, slightly constricted above the ocellus; antennæ about as long as hind femora, the basal joints so depressed as to form one sharp edge; pronotum strongly constricted at middle, hind margin acute-angled, male, right-angled, female; median carina sharp, slightly higher on prozona, notched twice in front of middle, the interval between the notches scutellate, its carina arched; lateral carinæ rounded, visible only on metazona, represented on prozona by numerous tubereles; lateral lobes much as in Psinidia; tegmina narrow, the apical third membranous and semi-transparent; hind femora slender, reaching tip of abdomen, female, much surpassing it, male; valves of ovipositor as in Psinidia.

Kirby $(1910,247)$ accredits to Mestobregma (Trachyrachys ${ }^{44}$ ) 17 species, two from Mexico, the others from the western United States. Some of these are doubtless synonyms, and but one crosses the Mississippi into the western portion of our teritory. 125. Mestobregma thomasi Caudell, 1904f, 125. Ash-brown Locust.

Small, slender, compressed, the male moderately the smaller. General color ash-gray or yellowish-brown, spotted with fuscous. Face ash-gray, with minute dark spots; occiput and disk of pronotum darker, often with a yellowish $\mathrm{x}$-shaped mark extending back from eye along the sides of disk; lateral lobes of pronotum with traces of alternate lengthwise bars of pale and fuscous, the former the narrower. Tegmina yellowish-brown or grayish, often darker in male, the costal area with two squarish dark spots separated by an oblong whitish one, apical third transparent, often with a few small dark spots along the costal margin. Wings with basal third greenish- or lemon-yellow, a narrow curved faint fuscous band on middle

${ }^{44}$ Bruner (1905) wrongfully replaced Mestobregma by Trachyrachys Scudd. In this he was followed by Kirby, although R. \& H. (1906, 380) had shown that Bruner's replacement was incorrect. 
third; apical third smoky-transparent, with a few fuscous dots near tip. Outer face of hind femora ash-gray or dull yellow with three more or less distinct black spots on upper margin; inner face black with two narrow yellow cross-bars. Hind tibiæ pale blue, sometimes dusky, with a whitish ring near base, the spines black except at extreme base. Lower side of body dull yellow. Length of body, $\hat{o}, 17-19$, 우, 24-26; of antennæ, $\hat{\delta}, 11-12$, ㅇ, 12-13; of pronotum, $\hat{\delta}, 4.5$, ᄋ, 6 ; of tegmina, $\hat{\delta}, 18-20$, ㅇ, 23-25; of hind femora, ô, 11-12, ․, 13-15 mm. (Fig. 108.)

This locust, the Mestobregma cinctum (Thos.) of my former work $(1903,279)$ inhabits, as far as known, only the southern

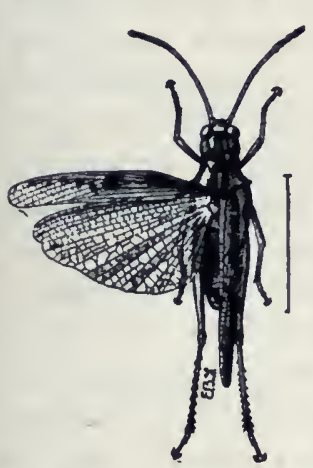
third of Indiana, where it frequents old abandoned fields. roadsides and bare rocky slopes, especially those on high wooded hills near streams. On the hills about Wyandotte Cave, and the Knobs back of New Albany, it is especially common. The earliest date on which it has been taken was July 7 , when it was found in numbers, and had doubtless been mature for some time. On September 24,1918 , it was found to be quite common on a slope leading up to a hemlock covered bluff Fig. 108. Male. $X$ r.3. in Owen County. This slope was nearly bare (After Lugger.)

and thickly covered with small weathered fragments of grayish-brown sandstone. Among these the locust was resting, and visible only when it moved. When first flushed they flew only a few feet, the males making a low whirring noise as they rose from the ground. When frightened by attempts at capture with the net they would often make a long flight into the branches of nearby trees. This was the most northern point at which it has been noted in Indiana.

The general range of $M$. thomasi is given by Scudder (1900) as "Upper Mississippi Valley and Colorado." Thomas and Hart have recorded it from Illinois, the latter noting it as common on the dunes near Havana and Moline, and occurring on dry barren ground throughout southern Illinois. Garman (1894) records it from Bowling Green and Glasgow Junction, Ky. East of the Mississippi it is known also from central and southern Ohio, Georgia, Tennessee, and Agricultural College, Miss., while west of that stream it ranges north and west to Minnesota and Colorado and southwest to Kansas, Arkansas, Oklahoma and northern Texas. Morse $(1904,36)$ states that its hues "vary, according to its environment, from nearly black to ashen or dust color. It flies freely, but weakly, on a warm day, and is easily captured."

M. thomasi is the Mestobregma cincta Thos. of most authors; 
Caudell (1904f) having shown that both T'rimerotropis cincta Thos. and $M$. cincta 'Thos. were based on the single description of Oedipoda cincta Thos. $(1870,80)$, the name cincta rightfully belonging to the former.

\section{Trimerotrop'Is Still, 1873, 118. (Gr., "three" + "part" + "keel.")}

Medium or rather large sized species, having the head slightly exceeding the prozona in width, but alwars narrower than metazona, which is considerably expanded; rertex with disk longer than broad, its sides distinct, often sinuous, gradually converging, and continuous with those of frontal costa; median carina, if present, faint; foveolæ small, distinct, triangular; frontal costa slightly narrower just below ocellus and at point of union with vertex, in our species with at least the lower two-thirds strongly sulcate; antenna filiform, longer than head and pronotum, male; pronotum with disk nearly flat, either smooth or with "minute tubereles on metazona; hind margin either acute- right- or obtuseangled; median carina low, especially on metazona, cut by two notches, the hindmost of which is much in advance of the middle (Fig. 106, c) ; lateral carinse rounded, indistinct; lateral lobes of Ironotum with front and hind margins nearly vertical, lower margin with its front half oblique, ascending, the posterior half arcuate, the angle well rounded; tegmina much exceeding the abdomen in both sexes; hind femora of average width, reaching or exceeding the tip of abdomen in both sexes; valves of oripositor slender, strongly exserted, their tips curred, pointed.

McNeill, in his monograph of this genus (1901), described and gave keys to 54 nominal species. Of these 49 were from the United States, 16 of which are confined to California, while but three occur east of the Mississippi River. One species and a rariety have been since described from our territory. Kirby (1910, 25.3, 255) divides the genus into two, Trimerotropis and Pseudrtrimerotropis. the latter a subgeneric name proposed by Rehn (1901, 334) to replace McNeill's subgenus Trimerotropis (1901, $399)$, which was wrongly used. To Trimcrotropis, with maritima as the type, Kirby accredits $\mathbf{1 7}$ species, and to Pseudotrincrotropis with cinctu Thos. as the type, 54 species. Caudell has shown $(1911,164)$ that Rehn's name is, as he proposed it, of subgeneric rank only.

KEY TO EASTERN SPECIES OF TRIMEROTROPIS.

a. Tegmina plain grayish-buff or brownish-yellow, not or faintly barred with fuscous; disk of prozona behind the first notch flat or nearly so; inner face of knees of hind femora pale. 
b. Hind tibiæ yellow or greenish-yellow, rarely with a pinkish tinge; frontal costa distinctly sulcate at point of union with vertex; head, lateral lobes of pronotum and hind femora rarely suffused with white.

126.' MARITIMA.

$b$. Hind tibiæ with apical two-thirds scarlet, the basal third mostly white; frontal costa but feebly sulcate at point of union with vertex; head, lateral lobes and outer face of hind femora usually strongly suffused with hoary white. 126a. ACTA.

aa. Tegmina with two or three well defined, almost solid fuscous crossbars, these sometimes faint on account of the slight contrast between them and the ground color; disk of prozona behind the first notch more or less convex and subtectiform; inner face of knees of hind femora fuscous.

c. Hind tibiæ in great part red; lower sulcus of hind femora yellow with two dark bands.

127. CITRIXA.

cc. Hind tibiæ greenish-yellow tinged with fuscous; lower sulcus of hind tibiæ black with one preapical pale band.

d. Metazona almost smooth; fuscous cross-bars of tegmina and hind femora very distinct; basal third and dorsal area of tegmina with numerous fuscous spots; saxicolous in habits.

128. SAXatilis.

dd. Metazona densely granulate-punctate; fuscous cross-bars usually poorly developed, often subobsolete; dorsal area of tegmina almost immaculate; ammophilous in habits.

129. IIURONIANA.

126. Trimerotropis maritima (Harris), 1841, 143. Seaside Locust.

Rather large, compressed, the male distinctly the smaller. General color light to dark gray, or pale reddish-brown, mottled with brown or fuscous; sides of head, lower parts of thorax, abdomen and front legs, often in part white. Tegmina as in key, the fuscous spots usually scattered along the sides, being most abundant on the basal third. Wings with disk pale yellow, the greatest width of curved black band one-fifth to onesixth the length of wing, the apical fourth or more transparent. Inner face of hind femora pale yellow with three black bands; lower sulcus pale with a black bar at apical third; outer face rarely with spots or bands of fuscous. Frontal costa sulcate throughout its length. Antennæ almost as long as hind femora, male, one-fourth shorter, female. Pronotum with median carina low throughout; metazona about twice as long as prozona, its disk flat, with a number of scattered minute rounded tubercles, hind

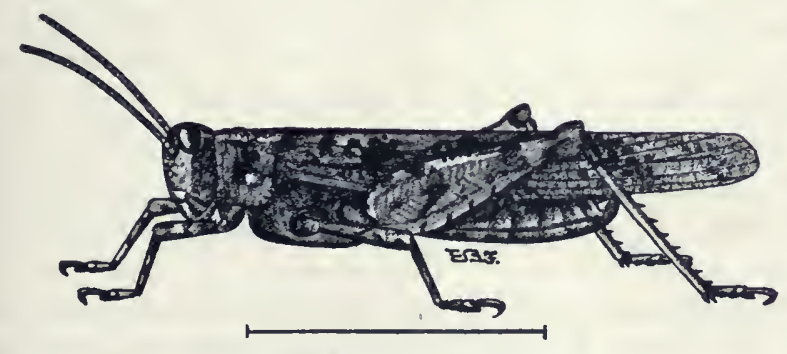

Fig. Iо9. Male. (After Lugger.) margin obtusely angulate. Wings twice as long as wide. Length of body, of, 1925 , 우, 26-35; of antennæ, $\hat{\sigma}$ $11-13$, ㅇ, 11 .5. -14 ; of pronotum, ô, 5 , 
, 6 ; of tegmina, $\widehat{\jmath}, 20-27, \uparrow, 27-35$; of hind femora, $\hat{\jmath}, 11.5-14, \&$, 14-17 mm. (Fig. 109.)

This species has been taken in Indiana only along the south shore of Lake Michigan, where it is common, and about lakes in Steuben Co., in the northeastern corner of the State. It flies rajidly and noiselessly for long distances and, unless carefully marked down, is very difficult to detect. The darker specimens are always found at some distance from the lake, where there is a scattering vegetation; the light colored ones on the pure sand of the immediate shore. It has been seen nowhere more than a half mile back from the water margin, and then only on the bare crests of the highest sand ridges and dunes. The earliest date on which mature specimens have been taken was July 25th, and the latest October 15th, though they are doubtless to be found both before and after those dates. It probably occurs about the margins of the larger lakes in the northern third of the State.

Walker $(1898,262)$ has separated the form found inland along the Great Lakes under the racial name interior. stating that they differ in the broader fuscous band of wings, more distinct fuscous markings and smaller size. All of these differences are comparative only, the series at hand from both sea and lake shores containing examples which could be easily and properly referred to either form. I, therefore, regard his name as wholly unnecessary.

The range of maritima is given by McNeill as "Atlantic States from Virginia northward and along the shores of the Great Lakes west to Illinois." In Michigan it is reported by Hubbell from Huron and Chippewa counties. In southern Ontario it is, says Walker (loc. cit.), found plentifully along the beaches of the Great Lakes and their islands, "where it flies about the coarse grasses which grow at a short distance from the water's edge." Westward it extends to Minnesota where, says Somes $(1914,60)$. it "occurs in some abundance on the sandy flats of the Mississippi and other streams in the southeastern prart of the State. There it delights in the open sunshine, often walking aimlessly about upon the sand for long periods without any attempt at feeding, and apparently merely enjoying the warmth. When approached too closely it crouches close to the sand prepared for flight, but seemingly aware of its protecting hues and not arising until some unusual or rapid movement alarms it. The flight is rery strong and it can, and does at times, cover unusual distances for an Oedipod."

Sontluward T. maritima is now known along the coast as far as Atlantic Beach, Fla. (R. \& $H ., 1916,190)$; some of the specimens 
from Virginia and North Carolina having the hind tibiæ suffused with reddish or pinkish, thereby approaching the southern Florida form. Davis $(1914,195)$ records a Fire Island, N. Y., specimen with pink tibiæ. Hart $(1907,261)$ has mentioned the finding of specimens at Waukegan, Ill., with well marked orange tibiæ.

126a. Trimerotropis maritima acta Hebard, 1915b, 402. Southern Seaside Locust.

More slender and somewhat smaller than typical maritima from which it differs mainly by the characters given in key. General color more buffy; anal fields of tegmina usually immaculate, rarely speckled with darker; discoidal and marginal fields usually much suffused or speckled with darker buff, these markings often concentrated to form two vague darker bands; other markings as in key. Disk of pronotum slightly more compressed and narrowed in front of the principal sulcus; hind margin less produced, the angle being normally rectangular. Measurements and variations in size all falling within the extremes as given for maritima.

Little River, Fla., March 17-19 (W. S. B.) ; Palm Beach, Fla., May 27-June 13. (Dury). There is no doubt but that acta is only a southern form of maritima, replacing the latter along the South Atlantic coast and bearing to it the same relation, be it color variety, race or what not, that $S$. picta does to $S$. marmoratu. Daris has numerous specimens taken at Riverhead, N. J., and near Ft. Monroe, Va., that are intermediate in coloration between maritima and acta. Of nine Ft. Monroe specimens, five have the hind tibire in great part pink, while in the others they are pale orange yellow. The secondary genital organs of male are the same in both forms.

T. m. acta is recorded by Hebard as being "widely distributed but few in numbers ererywhere along the middle and upper ocean beaches at Miani, Fla. Individuals were, without exception, encountered on loose sand, either along the landward border of the middle beach, or less often immediately back of this in areas of high seaside oats, Uniola paniculata $\mathrm{I}$. The flight much resembles that of maritima and is more direct than that of citrina." It is also known from Capron and Palm Beach, on the east coast, and from several islands in and about Charlotte Harbor on the west coast of Florida.

127. Trimerotropis citrixa Scudder, 1876a, 265. Citrus-winged Locust.

Form of T. maritima, the female somewhat larger. General color ashgray or yellowish-brown, sprinkled more or less with fuscous. Face usually light gray. Tegmina yellowish-brown, the dark spots aggregated into three dark cross-bars, often indistinct in female, usually plainly visible in male. Wings pale lemon-yellow at base, the fuscous band broad, its width from one-fourth to one-fifth the length of wing; submarginal ray short, extending less than half way to base. Inner face of hind femora yellow with 
three fuscous bands, outer face plain yellowish-brown or gray. Hind tibiæ pinkish-red, paler at base. Vertex slightly longer than broad, its median carina faint or wanting; foveolæ small, indistinct; frontal costa slightly narrowed and but feebly sulcate at point of union with vertex. Pronotum with median carina very low; disk flat, except on prozona, where the sides are moderately convex; metazona broad, its hind margin decidedly obtuseangled, the tip rounded; surface finely granulate-punctate, with a few minute scattered tubercles. Wings one and three-fourths times as long as broad. Length of body, $\hat{o}, 20-23$, 우, 28-32; of antennæ, ô, 11-12, 으, 10.5-12; of pronotum, $\hat{\sigma}, 5$, 우 6.5 ; of tegmina, $\hat{\delta}, 27-28$, 우, 31.5-35; of hind femora, of, 11-13, of, 15-16 $\mathrm{mm}$.

This species has been taken in Indiana only on a long sand and gravel bar along the north shore of the Olino River, a half mile below Vevay, Switzerland County, where it was common on September 23. Its flight along this gravelly bank was much less prolonged than that of maritima on the more extensive sand beach of Lake Michigan. When approached it would rise straight upward a few feet, and then move lazily and without noise eight to 15 feet, and alight again, always on the bare sand or gravel. The gravel bar was at the foot of a terrace 30 feet or more in height and a quarter of a mile wide, the surface of which was cultivated. No trace of citrina was found on this area, though other locusts were abundant. It is a somewhat larger and more bulky insect than Indiana examples of $T$. maritima, the male being nearly as large as the female of the latter. In general appearance the two closely resenuble one another and are apt to be confounded when they occur together.

In Florida citrina has been taken by me only at Ormond and Dunedin, where a few specimens were found in December and March along sandy roadsides and in old fields: It has, however, been recorded from numerous localities between Jacksonville, Pensacola and Key West by other collectors, and doubtless occurs throughout the State, though scarce in the southern portion. The general range of the species is southern, extending from eastern Pennsylvania and Maryland, west and north to Manitoba and Vernon, B. C., Minnesota and Colorado, and south and southwest to Arkansas, Oklahoma, Texas and New Mexico. Morse (1907, 39) calls it: "A very widely distributed species, of common occurrence throughout the Southern States from the seashore to a considerable elevation, frequenting, in company with Dissostcira carolina, roadsides and other spots bare of vegetation. Its coloring varies greatly according to the tint of the soil of its habitat, from dull white, through shades of yellowish- and reddish-brown to a dull gray." In Virginia Fox (1917) found it "on the sandy 
beaches of broad tidal estuaries, usually associated with Psinidia in areas characterized by the presence of the sand-bur, Cenchrus tribuloides $\mathrm{L}$. Inland it appeared to be of frequent though somewhat local occurrence, inhabiting open sandy fields and foot-paths and appearing to aroid locations where there was any considerable cover of vegetation."

128. Trimerotropis Saxatilis McNeill, 1901, 440. Rock-loving Locust.

Size medium, form relatively slender, strongly compressed, the males distinctly the smaller. Color extremely variable, usually gray, bluish-green or brown, strongly marked with fuscous. Occiput fuscous with gray markings; face gray, speckled with brown or fuscous dots; antennæ fuscous, the basal joint yellow. Pronotum with metazona and hind portion of lateral lobes usually dull yellow; prozona and front part of lobes largely fuscous with pale spots. Tegmina gray, usually with three very distinct fuscous cross-bars; apical third hyaline, mottled with fuscous dots. Wings with basal third pale yellow, the curved fuscous band rather broad, its greater width one-fourth to one-fifth the length of wing, apex hyaline with a few small dark spots. Front and middle femora annulate with dull yellow and fuscous. Outer face of hind femora trifasciate with fuscous; inner face largely black with two yellow cross-bars. Disk of vertex distinctly longer than broad, median carina evident but faint, sides low, moderately converging; foveolæ distinct, triangular, large for the genus. Frontal costa deeply sulcate nearly throughout, less so at junction with vertex. Prozona about two-fifths the length of metazona, median carina very low; hind margin of metazona rectangular or nearly so. Wings less than twice as long as broad. Length of body, $\hat{\sigma}, 18.5-22$, ㅇ, $23-28$; tegmina, $\hat{o}, 22-23$, ㅇ, 25-27; of hind femora, $\hat{\sigma}$ and $ᄋ, 11-13 \mathrm{~mm}$.

Union County, Ill., July 21. (McNeill). As its specific name indicates this is a-saxicolous or rock-frequenting species, ranging from southern Illinois west to Arkansas and Oklahoma, and southeast and south to the mountains of North Carolina and Georgia. Of its occurrence in Illinois Hart $(1906,79)$ says: "Restricted to the larger sandstone ledges of the Ozark hills in southern Illinois, the insects closely imitating the lichen-covered rock surfaces on which they rest."

Morse, who has traced its range more closely than anyone else, says $(190 \bar{\top}, 40)$ :

" $T$. saxatilis has been taken only on rock surfaces, sometimes lichen. crusted, sometimes bare and sun-scorched, either wholly unprotected from sun and storm or amid a considerable growth of forest which has sprung up since the station was colonized by the locust. In color and markings it so closely resembles the background of its habitat as to be indistinguishable therefrom when at rest. It is a sluggish, unsuspicious species, flying but a short distance when disturbed, often with a distinct but relatively faint crepitation, and is easily captured. On July 8 adults of both sexes were numerous, on Sand Mountain, Ga., the males actively searching for and at- 
tentive to the females, excitedly approaching them and fiddling with rapld vertical movements of the closed hind legs. Usually no sound was audible to me during this act of stridulation, but occasionally I could catch a distinct and rather pleasant seep' resembling a bird note at a distance rather than the note of an insest. The female made similar motions, but less often and less energetically. Active in direct sunshine, they became sluggish when clouds obscured the sun and then were very easy to approach, allowing the hand to come within two or three inches if it were advanced with caution."

129. Trimerotropis huroniana E. M. Walker, 1902, 6. Lake Huron Locust.

Size medium or rather small. General color ash-gray, varied with brown and white. Face pale ash-gray mottled with darker; occiput brownish-fuscous; a pale postocular stripe extending back on margins of pro- and metazona, sides of prozona with two whitish spots; antennæ grayish-brown, darker apically. Tegmina usually ash-gray or brownish with darker fus. cous cross-bars, one at basal third, a more solid one at middle; apical third transparent, usually with scattered fuscous spots; the bars and spots ofter! faint or wanting, the tegmina then with only an ill defined clouding of basal fourth. Wings with disk very pale yellow; width of fuscous median band one-sixth or slightly more the length of wing, the spur extending half way to base; apical portion hyaline, immaculate. Hind femora with outer face pale gray with a yellowish preapical band and faint basal and median oblique fuscous bars, these more distinct in male; inner face black with two pale bars. Hind tibiæ dull yellow the base sometimes paler. Vertex distinctly longer than broad, male, but feebly so, female, median carina low but distinct; sides moderately elevated, sinuous, converging gradually but not strongly to meet those of frontal costa; foveolæ small, triangular, well defined. Frontal costa rather wide, sulcate throughout, expanded at but feebly constricted just above and below the ocellus. Antennæ fourfifths, male, five-sevenths, female, the length of hind femora. Prozona about two-fifths the length of metazona, its median carina slightly the higher; metazona broad, its surface densely and finely rugose-punctate, the median carina very low; hind margin right-angled, male, obtuse-angled, female. Length of body, $\hat{\delta}, 19-21, \uparrow, 26-28$; of antennæ, $\hat{\delta}, 9.5-10.5$, ㅇ, 9.5; of tegmina, $\hat{\jmath}, 21-22$, 오, 26-27; of hind femora, $\hat{o}, 11$, 오, $13 \mathrm{~mm}$.

Southampton, Ontario, Ang. 21 ( $\mathrm{Wall} \cdot \mathrm{Cr}^{\circ}$ ). This species, says Walker (loc. cit.), seems to replace $T$. maritima on the northern part of the east coast of Lake Huron. In the vicinity of Soutlampton there is a limited extent of wide. sandy beach. north of which the sluore is continuously rocky. On this beach huromiana is to be found under very similar but more boreal conditions to those under which maritima is found further sonth. In flight it is extremely alert, and its stridulation is peculiar, being a rery rapid but not lond crepitation, interrupted abont tlurice in a second. so that at a little distance it seems to be composed of separate notes. Usually three, sometimes four of these, are produced at a time." 
As pointed out by Walker, T'. huroniana is closely related to both T. saxatilis MeNeill and vinculata Scudd. The principal differences between it and saxatilis are given in the ker. In vinculata the disk of prozona is strongly convex and tectiform, the front lobe of crest more elevated and much longer than the hind one, these characters easily separating it from both our eastern species.

IV. Circotettix Scudder, 1876a, 264. (Gr., "circle" + "locust.")

Rather large, compressed species, elosely related to Trimerotropis, the characters of vertex and frontal costa being nearly the same as there; antenna shorter, little longer than head and pronotum together; disk of prozona feebly tectiform, its length twothirds that of metazona, the latter wide, flat, with hind margin right-angled or nearly so; lateral carina faint and rounded on metazona, absent on prozona; tegmina rather broad, much surpassing the abdomen, with intercalary vein close to radial at tip, the axillary rein free. "Wings peculiar (Fig. 106, b), being falcate with more or less undulate margin; the falcation arising from the prolongation of the pre-anal area and the fullness of the middle of the anal area. The principal veins of the latter are supported on either side by spurious veins, running very close beside and parallel to them, to which the transverse veins are attached, while the spurious veins are themselves united to the principal nerrures by other cross veins, forming a more or less irregular network on either side of the principal reins." (Scudder.) Hind femora short, slender, about reaching end of abdomen, male, falling short of it $3-5 \mathrm{~mm}$., female; valves of ovipositor short, stout, feebly exserted. Other characters as given in key.

Kirby (1910) accredits 13 species to the genus, all trom the western United States, the range of our only eastern species being given as "British America."

130. Circotettix verruculatus (Wm. Kirby), 1837, 250. Cracker Locust.

General color dark gray, often almost black. Lower part of face usually gray with fuscous dots; occiput and pronotum fuscous or very dark brown with faint paler mottlings. Tegmina dark brown or black, sometimes immaculate, more often with a pale cross-bar just in front of middle and another behind it; apical third subhyaline with paler mottlings. Wings with basal third or more transparent with a yellowish tinge, curved fuscous bar faint, narrow, widened behind, apical fourth hyaline, the nervules and extreme tip fuscous. Front and middle femora annulated, hind ones with outer face dull yellow crossed by two oblique fuscous bars; inner face black with two yellow bars. Hind tibiæ dull yellow, the knees and apex fuscous, the middle sometimes tinged with that hue. Structural char- 
actèrs as above given. Length of body, $\hat{\sigma}, 21-24$,, $26-30$; of antennæ, ô , $9-11.5$, ㅇ, $10-11.5$; of tegmina, $\hat{o}, 21-26$, ㅇ, 24-30; of hind femora, ô, 11-12, 오, 13-14 mm. (Fig. 110.)

A species of northern distribution ranging from Newfoundland, Nova Scotia and New England, north and west to Hudson

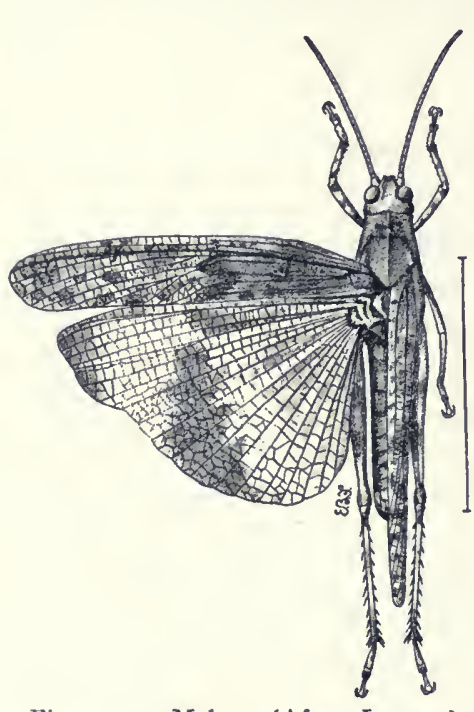

Fig. I 1 o. Male. (After Lugger.) Bay', Vanconver, B. C., Great Bear Lake and Aretic America, and south and southwest to the northern border's of New Jersey and Pennsylrania. It is not known from Indiana, but is frequent throughout northern Michigan, northern and eastern Minnesota arid northern and northwestern Nebraska, but is not recorded farther soutl than there west of the Mississippi. It has been recolded from Illinois by both 'Thomas and MeNeill, but the latter $(1901,440)$ refer's the record of Thomas to Trimerotropis saxatilis and it is probable that his own records were based on the same species.

In New England Morse $(1897,113)$ says that: "Its farorite haunts are bare ledges on elevated land and low mountains. On these it delights to bask in the sunshine, crawling abont orer the lichen-covered and weather-beaten rocks with whose tints its coloring harmonizes, or to hover in the air above them, sharply stridulating. Its 'song' in flight is the loudest produced by any of our locusts, and consists of a series of separate notes, clicks or snaps, not a rattle, and is readily distinguished by this peculiar snapping quality. It is one of the wariest of our locusts, being especially shy and difficult to approach during the warmer part of the day, when it often flies away to a distance of sereral rods and cireles about, returning to the place whence it started, or dances up and down in the air, snapping loudly. The female sometimes makes a soft flutter or shuffle of wings in flight, probably corresponding to the snapping of the male, and both sexes can fly silently at will. I have seen the male stridulate when at rest, also, by rubbing the hind thighs against the tegmina, producing a 'seritching' sound audible at a distance of three or four feet. The intercalary rein is toothed, in a low but continuous series, for its entire length in the male, and on the distal half or more in the female, in which the teeth are lower and barely perceptible." 
Piers (1918, 284) has written entertainingly of the habits of C. verruculatus as follows:

"When in flight it produces a loud, sharp snapping or cracking sound. klip. klip, klip, repeated usually about five or six times, which is familiar to every one on a hot summer day. From this sound it is usually called 'Cracker' or sometimes 'Snapper' by boys and others, it thus being the only species of locust which has been favored with a distinctive commonname in Nova Scotia. It also somtimes flies with a rustling or fluttering sound. When on the ground it is difficult to detect, as its color harmonizes well with that of its surroundings, but on the wing it at once proclaims itself by its note and the distribution of the yellow on its brightly colored wings. Its flight is often in a zig-zag course. It does not always wait to be flushed, but is in the habit of taking short flights over its location, cracking as it goes, in pure exuberance of spirits."

"I must say I have not much fondness for such a dusty, dirty-looking frequenter of hot, dry highways and other parched and stony places in the full glare of the sun. He delights in such dusty and arid spots, as well as the oily-smelling ballast of breezeless railway cuttings; and the hotter and more sweltering the day, the better he is pleased, the more active he becomes, and the quicker, louder, sharper and more gleefully he cracks his wings, like a man snapping his fingers derisively at the world which disagrees with him. Only when he rises from earth, do we catch a glimpse of the hidden gold in his sombre make-up."

\section{Somes $(1914,62)$ says of the species in Minnesota:}

"It is primarily an insect of dry or even dusty places and is somewhat saxicolous, loving rocky exposures. On the granite hills about Lake Vermillion it occurs in countless numbers and on a bright day the stridulation of the males in flight fills the air. The flight of this species is the strongest and longest of all our Oedipods, possibly excepting Trimerotropis, and is very indirect in its course, often completely circling about the observer and ending near the point from which it started. The ærial stridulation of the males is a sharp crackling, very like that of the Arphias but much louder and more continuous. We once noted an interesting performance by three males. Out in the center of a railway switch yard, these three were grouped closely together, and so intent were they that we were able to approach within a few feet without alarming them. First one would raise both hind femora bigh up and with a quick jerky movement rub them vigorously against the sides of the tegmina; after a time be would pause and stand at attention while one of his mates took up the performance. To our ear no 'music' was audible save a faint grating noise, far from melodious. This peformance was repeated time after time and we do not know how long it might have been continued had they not been interrupted by a heavily loaded ore train. As to the object of such demonstration, we have no explanation to offer since there were no females within a rod or more.

"In Tower and some of the other northern towns of Minnesota, this usually shy insect takes the place of Dissosteira in the streets and appears as thoroughly at home there as the 'Carolina loucst' in the soutbern cities. At Tower we have noted that while it is abundant on the streets during the warmer part of the day, it disappears by about five o'clock in the after- 
noon and upon search we found it on weeds, posts, and other somewhat elevated places, apparently having retired for the night. It remained thus until rather late in the morning, not becoming active until nearly nine o'clock. While thus at rest, the insect is very sluggish and does not start readily, making it easy to take such as may be desired. In the habit of poising motionless in the air, this insect also resembles Dissosteira and may be seen at times suspending itself in the air, much more like a butterfly in appearance than a locust."

\section{Subfamily III. LOCUSTIN 2 .}

\section{(ACRidina.)}

\section{The Spine-Breasted Locusts.}

"Onward they came, a dark continuous cloud

Of congregated myriads numberless,

The rushing of whose wings was as the sound

of a broad river headlong in its course

Plunged from a mountain summit, or the roar

of a wild ocean in the autumn storm,

Shattering its billows on a shore of rocks!"-Southey.

The species of this subfamily may be easily recognized by the presence of a distinct spine or tuberele on the prosternum between the front pair of legs. They vary much in size and general appearance, and among them are found our most injurious insects of the order Orthoptera. They have the head, in general, smaller and less swollen than in the two preceding subfamilies; face rarely (Leptysmi) very oblique, usually nearly perpendicular; disk of vertex seldom sunken or concave, its sides low, rounded, often obsolete; foreola usually wanting or indistinct; pronotum with disk always free from tubercles and prominent wrinkles, its hind margin usually broadly rounded, never acute-angled; median carina always low and usually of nearly equal height throughout; lateral carina, with few exceptions, rounded or obsolete; tegmina usually well dereloped, but in a number of species very short, and in a few wholly wanting; inner wings (except in Romalea) never brightly colored as in the Oedipodina, but usually transparent.

The prevailing color of most species of the subfamily is dull olivaceous brown, though a number of them are so striped or mottled with yellow, green or fuscous as to be decidedly handsome. Among the members of the principal genus (Melanoplus) there is considerable variation in color locally, according to the character of the station where found, and also seasonably, whether collected early or late in the fall. As a rule specimens collected after a number of hard frosts are duller, darker and more suffused than summer examples, the coloration of the individual being apparently considerably modified by such exposure. 
With few exceptions, all of our northern species pass the winter in the egg stage, and begin to reach maturity about June 1st, though most of them are not common until July. The Kentucky blue-grass and the different kinds of meadow grasses are then a darker green and, when rank, turn brown early in the autumn. The different species of Melanoplus and other locusts whose hues are olive green or brown, find in the falled clumps of these grasses places of hiding well suiting their color, as well as an abundance of food well suiting their taste. In Florida and other southern states more species pass the winter as adults, though even there the majority are represented during the winter months by the eggs alone.

The males of Locustina rarely stridulate, and then only when at rest, by rubbing the inner surface of the hind femora against the outer surface of the tegmina. Scudder $(1893,75)$ has mentioned the stridulation morements, withont record of sound, in Melanoplus femur-rubrum. Morse (Ms.) is inclined to doubt the production of sound by the majority of our species, though all have the "ear" or tympanal membrane present, stating that: "It seems to me not unlikely that they might make the movement (as a family characteristic) even if no sound was produced."

The literature, treating more or less especially of North American Locustine, is as follows: Scudder, $1875 \mathrm{~b}, 1878,1896 \mathrm{~d}, 1897$, 1897a, 1897b, 1899b, 1899c; Bruner, 1893; Morse, 189S; Rehn, 1902 ; Blatchler, 1903; Somes, 1914; R. \& H., 1916; Hebard, 1917b, 1918, 1919a.

For convenience of treatment, the Locustina of the Eastern States may be subdivided into four groups or tribes, separated as follows :

KEY TO TIIE EASTERY TRIBES OF TIIE SUBFAMILY LOCCSTIX E.

a. Inner wings carmine red with black border; hind tibiæ furnished abore with an apical spine on both sides; form very large and robust, length of body $50-60 \mathrm{~mm}$.; adult with tegmina shorter than abdomen.

Tribe I. Romali, p. 304.

aa. Inner wings transparent or nearly so; hind tibiæ with no apical spine on the outer side; form much more slender, rarely (Schistocerca) over $45 \mathrm{~mm}$. in length, usually much less; tegmina of adult usually equalling or exceeding the abdomen, when shorter, the body not over $30 \mathrm{~mm}$. in length.

b. Face very oblique; fastigium of vertex triangular, strongly produced in front of eyes; antennæ more or less ensiform, the joints of basal half flattened; front and middle legs very short.

Tribe II. LEPTYSMI, p. 307.

$b b$. Face nearly vertical; fastigium not triangularly produced; antennæ filiform; front and middle legs of moderate length. 
c. Lobes of mesosternum longer than broad, their inner margin straight; side margins of metazona rounded; size larger, the tegmina of female 30 or more $\mathrm{mm}$. in length; subgenital plate of male with a distinct U- or V-shaped notch at apex.

Tribe III. ScIIsTocercI, p. 310.

cc. Lobes of mesosternum transverse, their width at least equal to the length, their inner margins usually rounded; side margins of metazona angulate; size smaller, the tegmina rarely over $25 \mathrm{~mm}$. in length; apex of subgenital plate of male without notch.

Tribe IV. Melaxopli, p. 320.

\section{Tribe I. ROMALI.}

Very robust species, having the rertex flat, triangular, advanced in front of eyes a distance equal to two-thirds the interocular width, its median carina and foveole wanting, the margins raised, rather sharp, meeting in front at an obtuse angle; antennx acuminate, the joints very distinct, more or less flattened; pronotum with median carina distinct throughout, cut three times by the transverse sulci, prozona tectiform, metazona flat; tegmina and wings not over three-fourths the length of abdomen. One genus represents the tribe in the southern States.

\section{Romalea Serville, 1831, 280. (Gr., "strong of body.")}

In addition to the characters of the tribe, this genus has the face nearly vertical; frontal costa prominent, compressed, its sides converging above the antennæ, deeply sulcate from near its junction with rertex to below the ocellus; pronotum with front margin subtruncate, prozona one-third longer than metazona, the latter with hind margin prolonged, obtuse-angulate; lateral carinæ distinct but obtuse on metazona, obsolete on prozona; lateral lobes longer than deep, their front margin subvertical, hind one strongly oblique, lower one with posterior half straight, its hind angle obtuse, front half ascending; tegmina with humeral and anal veins very strong, the others weak; hind femora rather slender, exceeding the abdomen in both sexes; prosternal spine prominent, acute; abdomen carinate above; subgenital plate of male triangular, shorter than the preceding segment, its apex emarginate; valves of ovipositor large, strongly exserted. The genus is represented by one species, dimorphic in color, and therefore known under sereral names.

131. "Romalea microptera (Beauvois), 1805, 146. Southern Lubberly Locust.

General color of adults of typical form dull yellow; disk of pronotum clouded with fuscous; tegmina yellow with numerous scattered black dots, the apical two-thirds of discoidal area rosaceous; wings bright carmine red, the apical border black; apical half of antennæ, knees and sides of 
abdomen more or less fuscous; outer face of all the femora with numerous small black spots. The black markings vary greatly in number and size; in some specimens, var. marci Serv. $(1839,623)$, the black predominates, the side margins and median carina of pronotum and hind margin of abdominal segments alone being yellow, tegmina fuscous; inner wings as in the typical form. Structural characters as given above. Length of body, $\hat{\delta}, 50-54, \uparrow, 62-70$; of pronotum, ๙ิ, 15-17.5, \&, 20-22; of tegmina,

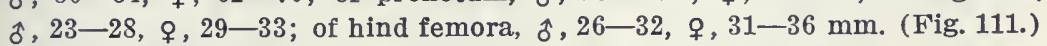

Ormond and Dunedin, Fla., June-August, adults; Ormond, Sanford, Sarasota, Lake Istokpoga, Citrus Center and Dunedin,

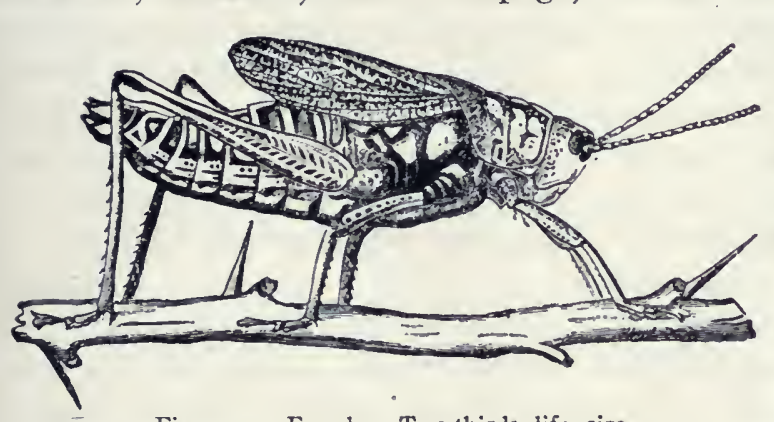

Fig. III. Female. Two-thirds life size. Feb. $20-$ April 10 , nymphs ( $W$. S. B.) ; Mobile a n d Tuscaloosa, Ala., July - August, var. marci (Loding). By other collectors R. microptera has been taken at nu. merous localities in Florida as far south as Homestead and Chokoloskee. It occurs especially along the margins of cultivated grounds, roadsides and railways, though often found on the undergrowth in open pine woods. The young begin to appear in southern Florida in February, the first ones becoming mature about June 10. Daris found the adults in numbers at Punta Gorda as late as Nov. 15, where "they were feeding on a papilionaceous plant along an old railroad embankment, and when disturbed would walk off in an amusingly stately, dignified manner. This lubber grasshopper can make a hissing sound, which is produced by the air being forced from the large stigmata near the base of the wings. This was more particularly noticed in recently matured individuals." IIorse $(1907,42)$ also notes this defensive action, stating that: "When disturbed, the tegmina are often elevated and the brilliant carmine wings rapidly vibrated, producing a buzzing noise. If taken in hand, a disagreeable dark-brown, frothy liquid is effused with a hissing sound from the mesothoracic spiracles, which probably is repugnatory in function."

The young of this lubberly locust differ much in hue from the adults being usually greenish-black in color with a narrow median dorsal stripe, hind edge of thorax, and often the fore femora and sides of head, blood-red. Sometimes they are a nearly uniform reddish-brown instead of black and red, and as they grow in size 
the red markings change to orange-yellow. During their early life they are more gregarious than the young of other species, 50 to 75 of them often occurring on a single weed or bunch of grass, whose leaves they wholly devour. They are very slow and elumsy in movement, crawling feebly over the ground when knocked off the plant to which they are elinging. Their natural enemies are few, they being apparently so nauseating that even chickens reject them as food. C. R. Dodge (1877) says that: "At times the insect is injurious on truck farms in the Gulf States, as it destrors all kinds of vegetables, melons, etc., even crawling up into peach and fig trees to devour the fruit. As they cannot fly and leap but short distances, they can be easily destroyed by sweeping into nets or by simply erushing them on the ground by the foot, first jarring them down from the plants on which they are feeding."

Of the stridulation of $R$. microptera Scudder $(1893,75 ; 1897$ d, 102) says: "I received two females of this species alive, and kept one of them for some time. She was excessively deliberate in her movements, cleaning her antennæ by treading upon one at a time and drawing it from under her feet. In the sunshine she stridulated by raising her tegmina directly upward against the halfopened wings, making a rough, scratching sound, which was repeated rather rapidly but variably from two to ten times." He adds that Dr. Shufeldt has recorded the males preceding mating as "keeping up a very audible buzzing racket with their fore wings which they elevated and lowered at a few seconds intervals, showing the lower earmine pair each time they did so, with telling effect."

The known range of $R$. microptera is principally confined to the Lower Austral zone, extending from Cabarrus Co., N. Car., west to Lookout Mountain, Tenn., and soutl and southwest throughout the mainland of Florida, Georgia and probably Alabama and Mississippi, to New Orleans, La. Adults of the black form marci are known only from the region north of Florida. As already noted, it has been mentioned or recorded under many synonymous names, chief among which are Dictyophorus reticulatus Thunb., D. guttatus Stoll and D. marci Serv., the latter being the melanistic form above described. The Rhomalea gloveri Kirby $(1910,370)$ and the $R$. centurio of Thos. $(1873,179)$ nee Drury, are also to be referred to $R$. microptcra. In fact, all records of very large, short-winged locusts from the southern United States east of the Mississippi are to be referred to $R$. microptera. the western lubberly locust, Brachystola magna (Gir.), not occurring east of that stream, while the Chromacris colorata Serv. (1839, 
674), described from South Carolina, is a Mexican species ${ }^{45}$; Serville's type, as pointed out by $R$. \& H. $(1916,194)$, having been probably based on a wrongly labelled specimen.

Tribe II. LEPTYSMI.

Very slender, subcylindrical species, possessing the characters given in the tribal key and having the vertex very narrow between the eyes; disk of pronotum'rounded, its median carina faint or wanting, hind margin broadly rounded; tegmina exceeding the abdomen, their tips acute; mesosternal lobes as wide as long, their inner margin rounded; hind tibia slightly widened toward apex, their outer margins acute. Two genera represent the tribe in North America.

KEY TO GEXERA OF YORTH AMERICAN LEPTYSMI.

a. Head as long as or longer than pronotum; fastigium of vertex as long as the eyes and with a deep median groove; face coarsely punctate.

I. Leptys MA.

aa. Head shorter than pronotum; fastigium shorter than eyes and without a median groove; face almost smooth.

II. Stexacris.

I. Leptysua Stål, 1873, 42. (Gr., "slender.")

Slender, subcylindrical species, having the fastigium prominent, horizontal, projected in front of eyes in the form of an equilateral triangle, the sides low, but distinct; frontal costa low, a little narrowed between the ocellus, shallowly sulcate throughout; eyes longer than wide, set very obliquely on the head; antennæ shorter than head and pronotum, strongly tapering; pronotum almost cylindrical, the metazona a little the wider, front margin truncate; median carina subobsolete, obrious only on the metazona, lateral carina wanting; lateral lobes longer than deep, their front margin oblique, hind one slightly concave, lower one subsinuate; prosternal spine short, its tip obtusely rounded; tegmina fully developed, the apical third gradually narrowed; hind femora very slender, slightly shorter than abdomen in both sexes; cerci of male slender, tapering, bent abruptly upward and forward near base; subgenital plate narrow, upturned, tapering to a point; upper valves of ovipositor much longer than lower ones, their dorsal margins with a row of prominent teeth. An Ameriean genus, nine species being recognized by Kirby $(1910,410)$, one from the United States, the others from Mexico and South America.

132. Leptysma Marginicollis (Serville), 1839, 591. Slender Locust.

Ground color of living specimens usually light yellowish-brown or fawn, unbroken except by a narrow, yellowish stripe extending from the

${ }^{45}$ Numerous specimens are in the writer's collection from Orizaba, Mexico. 
hind border of eye along the lower edge of pronotum to coxa of hind leg. In fresh specimens this is bordered above by one of darker brown, and sometimes the entire upper surface and antennæ are handsomely tinged with purplish or carmine red. In dried specimens the brown and the tips of tegmina become darker. Hind tibiæ tinged with bluish, their spines tipped with black. Face, vertex, occiput and pronotum, densely punctured. Tegmina exceeding the abdomen by 3 to $5 \mathrm{~mm}$. Wings transparent, equal to tegmina, male, slightly shorter, female. Other structural characters as

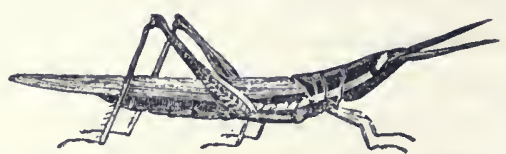

Fig. 112. Leptysma marginicollis (Serv.). given above. Length of body, $\hat{o}$, $28-31$, ९, 31-38; of antennæ, ô, 8 ,,, 6 ; of pronotum, $\hat{\jmath}, 4.5-5.2$, ㅇ, 5.5-6.5; of tegmina, $\hat{\delta}, 20-27$, , $25-34$; of hind femora, $\hat{\delta}, 12.5$. -14.5, ᄋ, 16-18 $\mathrm{mm}$. (Fig. 112.)

Vigo Co., Ind., May 21-Oct. 11; Gainesville, Little River, Moore Haven, Palm Beach Canal, Cape Sable and Dunedin, Fla., Nov. 4-April (W. S. B.). In Indiana this slender-bodied, graceful species has as yet been taken only in Vigo County, where it was first found in October, 1892. It was then quite common on the tall sedges and rushes which grew near the margin of a large pond in the Wabash River bottoms, nine miles below Terre Haute. Its range before that time had been supposed to be a strictly southern one, it having been recorded only from Florida and North Carolina. Its oceurrence in numbers as far north as central Indiana was, therefore, of especial interest, and can only be accounted for by the presence of the broad and sheltering valley of the Wabash, within the confines of which it finds a climate and a regetation congenial to its taste.

In 1893 and 1894 the insect was still present, though in rapidly decreasing numbers, as the pond was partially drained. I was much surprised to find, on May 21, 1893, a fully developed male with soft flabby wings, as though just moulted, though no others of any age were seen on that date. In October, 1917, I again visited the former site of the pond, but found only a rast cornfield, with no signs of this or the other rare Orthoptera, which formerly dwelt in numbers, in that locality. If still a member of the Indiana fauna, marginicollis will probably be found only about the margins of the larger ponds in the lower Wabash Valles.

At the Indiana locality mentioned, as well as in Florida, marginicollis has never been seen on the ground, and has never been noted to leap when disturbed, but always moves with a quick and noiseless flight for 20 or more feet to a stem of grass, sedge or rusli, on which it alights. The instant it grasps the stem it dodges quickly around to the side opposite the intruder. Then, holding 
the stem firmly with its short front and middle legs, it draws its slender hind femora close up against the body, and folding the tibix into position, hugs its support as closely as possible, and remains perfectly motionless. Its body is almost cylindrical, and being of the same general color of the plant on which it rests, it is almost impossible to detect it, unless one notes exactly where it alights. Eight times out of ten a person, by approaching quietls, can reach his hand about the plant stem and grasp the insect. Its habits thus excellently illustrate the so-called "protective mimicry" of form and coloring, as it always seems to choose a cylindrical object, and one similar to its own color before alighting.

Aside from the localities above mentioned, L. marginicollis has been recorded from numerous other stations in Florida and doubtless occurs in suitable environments throughout the mainland of that State. About Dunedin both adults and nymphs occur throughout the winter on and among the brown stems of tall sedges and grasses along the borders of ponds and marshes. A lialf dozen or more specimens of the pink individuals are taken each winter around the borders of a certain wet-weather pond. According to Dr. Hancock, these are the first pink Acridians which have been noted in the United States. The species ranges from Maryland and Virginia, west to southern Indiana and Nebraska, and south and southwest to Florida, Texas and Southern California. ${ }^{46}$

II. Stexacris F. Walker, 1870, 651. (Gr., "slender" + "locust.")

Very slender, subcrlindrical species, having the fastigium short, blunt, separated from the vertex by a transverse groove, its margin not raised, apex rounded; frontal costa shallowly sulcate, its margins parallel throughout; eves elliptical, oblique; antennæ feebly ensiform, slightly shorter than head and thorax together; pronotum subcylindricaI, its disk granulate-punctate, cut by three sulci, median and lateral carinæe wholly wanting, metazona twothirds the length of prozona; lateral lobes as in Leptysma; tegmina narrow, nearly as long as body, strongly surpassing the abdomen, their tips acute; hind femora slender, shorter than abdomen, male, reaching its tip, female; prosternal spine stout, cylindrical, obtuse; subgenital plate of male with median portion prolonged, subspatulate, each side produced into a distinct spine or cusp; valves of oripositor short, feebly exserted, the upper ones: strongly serrate above.

This generic name replaces Arnilia Stål (1873). Eleven spe-

${ }^{40}$ Scudder, Psyche, IX, 1900, I 6. 
cies are recognized by Kirby, one from the southern United States, the others from Mexico, Central and Sonth America.

133. Stenacris vitreipennis (Marschall), 1835, 214. Glassy-winged Locust.

Pale green, usually with a yellowish tinge, often with a pale lateral line on head extending back along the lower margin of lateral lobes; when dry often fading to dull yellow with tegmina and tibiæ only green, the pale stripe wholly disappearing; antennæ and tarsi of front.and middle legs dusky; wings transparent. Structural characters as given above. Length

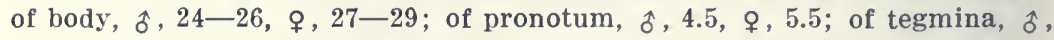
$24-25$, ㅇ, 27-29; of hind femora, ô, 12.5-13, ㅇ, 15-16 mm.

Enterprise, Sanford, Lake Istokpoga, Moore Haven, Sarasota and Dunedin, Fla.; Dec. 11-May 10 (W. S. B.) Recorded by other collectors from numerous localities between Appalachicola and Jacksonville in the north, and Miami and Ft. Myers in the south. At Dunedin, on March 22, 1913, it was found in abundance on the foliage of the pickerel weed, Pontedcria cordata L., then in full blossom along the margin of a pond. It has since been noted in small numbers each season, but only in the adult stage, along the pathways of low, open pine woods near the margins of wet hammocks. Much more wary than Leptysma, which it resembles closely in form and habits, it often flies long distances when flushed, and invariably alights on the leaves of eabbage palmetto or green grass or sedge where, slipping quickly behind a leaf or stem, it seeks to evade the pursuer. Sometimes, by approaching quietly, it can then be grasped by a quick motion of the hand, but is usually caught more readily with the net. Hebard has noted its partiality for cat-tails, and it probably occurs among green semi-aquatic regetation throughout the mainland of Florida.

The known range of S. vitreipennis is limited, extending only from Lake Ellis, N. Car., south and west through southern Georgia and Florida to Appalachicola in the latter State. The majority of the records of its occurrence have been made under the names Arnilia chlorizans and Stenacris chlorizans Walker, which are synonyms, while the Carolina record of Arnilia cylindrodes Stil $(1873,85)$ undoubtedly refers to a South American species.

Tribe III. SCHISTOCERCI.

To this tribe, as defined in the key, p. 304, belongs only the single genus:

I. Schistocenca Stål, 1873, 64. (Gr., "cleft" + "tail.")

Large, rather slender-hodied species, laving the fastigium of rertex sloping downward and passing insensibly into the frontal 
costa, its sides low, indistinct, median carina wanting, foveolae very small, often obsolete; face nearly vertical; eyes oblong-oval, prominent; antenmx of medium length, filiform; disk of pronotum with sides sloping on prozona, metazona usually flat or nearly so, front margin truncate, hind margin either broadly rounded or, in some males, obtuse-angled, median carina low but distinct, cut three times by the transverse sulci, lateral carina wanting; lobes of mesosternum longer than broad; tegmina always fully developed; wings of large expanse, transparent or nearly so; hind femora slender, usually equalling or exceeding tip of abdomen; hind tibia with numerous spines in regular rows on each side; second tarsal joint only half as long as first. Males with cerci wide, oblong, usually of nearly equal breadth throughout; subgenital plate strongly upcurved, its apex deeply notched. Valves of ovipositor strongly exserted.

This is a large, typically American genus, all of the species, according to Stal, its founder, being American or of American origin. Kirby (1910, 454) recognized 73 species, a number of which are known synonyms. Of these 12 were accredited to the United States, the others mostly to Mexico, Central and South America. We have in the Fastern States four species and two races or varieties.

KEY TO EASTERX SPECIES OF SCHISTOCERCA.

a. Median or discoidal area of tegmina with large, distinct isolated reddish-brown spots; disk of pronotum flat or nearly so, and with a broad pale median stripe; cerci of male feebly but distinctly tapering from base to apex.

134. AMERICANA.

ac. Median area of tegmina of males usually immaculate, of females sometimes with numerous small vague fuscous spots or dots; disk of pronotum more or less distinctly tectiform, its median pale stripe, when present, narrow; cerci of male of nearly equal breadth throughout.

b. Antennæ of male one-third or more longer than head and pronotum together; anal area of tegmina usually with a distinct pale stripe; larger, the female 45 or more $\mathrm{mm}$. in length.

c. Hind tibiæ reddish-yellow or pale brown in hue; notch of subgenital plate of male U-shaped, ahout as broad as deep; general hue of tegmina dark olive-green or rusty brown; length of body, female, usually less than $50 \mathrm{~mm}$.

d. Head, thorax and anal area of tegmina with a pale dorsal median stripe; tegmina immaculate; pronotum distinctly tectate; fastigium more elongate.

135. ALUTACEA.

$d d$. Dorsal surface without pale median stripe; tegmina usually with distinct fuscous spots; pronotum feebly tectiform; fastigium shorter.

135a. RUBIGINOSA.

cc. Hind tibiæ blackish purple; notch of subgenital plate of male 
deep, V-shaped; tegmina normally dark purplish-brown; female larger, 50-60 $\mathrm{mm}$. in length. 136. oBscura.

$b b$. Antennæ of male not more than one-fifth longer than head and pronotum together; anal or dorsal area of tegmina without distinct pale stripe; size smaller, the female rarely exceeding 42 $\mathrm{mm}$. in length; notch of male subgenital plate deep, narrowly V-shaped.

$e$. Form short, stocky; tegmina of female reaching only base of ovipositor and tips of hind femora, usually immaculate.

137. DAMNIFICA.

ee. Form more slender and more compressed; tegmina in both sexes distinctly surpassing abdomen and tips of hind femora, those of female usually sprinkled with numerous fuscous spots.

137a. CALIDIOR.

\section{Schistocerca americana ${ }^{47}$ (Drury), I, 1773, 128. American Locust.}

Size large, the female often two inches or more in length, the male distinctly smaller; form rather slender. Color reddish-brown, often with a slight vermilion tint; dorsal surface with a yellowish stripe extending from vertex along the middle of head, pronotum and anal area of tegmina as far as the tip of the abdomen; side of head with a dark brown line running from lower side of eye down the cheek; lateral lobes of prozona with a broad yellowish stripe on upper third, a short and narrow yellow dash near the center, the lower margin yellowish. Tegmina with numerous large dark brown spots, separated by light interspaces; the costal or lower margin whitish-yellow, mottled with darker. Wings transparent, the nerves of basal portion yellowish. Outer face of hind femora reddishbrown, with one or two dark streaks along the upper third. Hind tibix vermilion red, duller in dried specimens; the spines yellow, tipped with black. Vertex hexagonal, the disk a little depressed. Frontal costa broad, prominent, sulcate near middle below the ocellus; feebly narrowed below point of union with vertex. Antennæ but little, if any, longer than head and pronotum together. Disk of pronotum flat on metazona, the sides rounded and feebly sloping on prozona, the surface marked with minute shallow cells, or densely punctate, the hind margin obtusely rounded. Tegmina exceeding the abdomen one-fourth or more their length in both sexes. Hind femora slender, reaching or slightly exceeding tip of abdomen. Spine of prosternum large, curved somewhat backward. Notch of subgenital plate of male narrow, deep. Length of body, $\hat{\delta}, 39-42$, ㅇ, 48-55; of antennæ, ô, 12-13, , 13-15; of pronotum, $\hat{o}, 9$,,+ 11 ; of tegmina, $\hat{o}, 42-44$, 오, $50-57$; of hind femora, ô, $23-25$, ㅇ, 28-30 mm. (Fig. 113.)

This is the largest locust found in Indiana, and when freshly

${ }^{47}$ Hebard (r9r5b, 406) has replaced the long used specific name of this well known locust with that of serialis Thunb., basing his replacement on the ground that the Libellula americana of Drury, an Orthopteron, was preoccupied by Libellula americana L., a dragonfly. The placing of the locust under Libellula was an error by Drury and was later corrected by him. The error was not in the text but only occurred in using ditto marks on a plate on which the name Libellula had been used for a series of dragonflies. When americana, the specific name of the locust, was reached, a ditto mark instead of the name Gryllus was by mistake placed under the generic name Libellula. This was an obvious typographical error and was open to the correction made by Drury in a footnote on page XVIII, Volume III, of the same work. I, therefore, prefer to retain the name americana, believing that in time its use will be upheld by the International Commission of Zoölogical Nomenclature. 
moulted, one of the most handsome. It probably occurs in all the

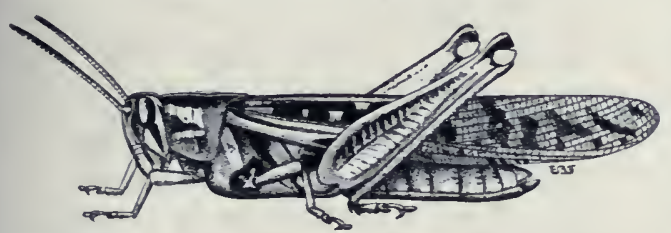

Fig. ri3. Male. Natural size. (After Lugger.) counties, but is much less common in the northern ones. Freshly moulted, mature specimens, from eggs hatched in spring, have been taken in Vigo County on June 18th, and on three different occasions numerous specimens have been seen as late as November 22d. On this date, in Marion County, when'the gorernment thermometer rgistered $17^{\circ}$ in the morning, several were flushed in the afternoon, though a cold, raw wind was blowing. In the central and southern parts of the State it is more abundant in mid-autumn than in summer. There occasionally may be two broods in one season, as I have found the nymphs common in Vigo Co. on October 15 and 21.

This species is noted for its extended migrations and when a second brood appears, they are doubtless from eggs laid by mature specimens which have entered the State in early spring. About 3 o'clock in the morning of April 11, 1893, the city of Terre Haute, Ind., was visited with a serere storm of rain and wind from the southwest. A number of buildings were unroofed and many shade and forest trees twisted and broken off. While on my way to the high sehool building several persons informed me that they had, that morning, seen specimens of "gigantic grasshoppers" on the street, but were unable to capture them. About 10 o'clock one of my former pupils brought me two living specimens of $S$. americana, which she had picked up from the sidewalk near her home. They had come sailing in on the wings of the wind from some distant point in the southwest, where they had passed the winter in the mature state or as an advanced form of the young. ${ }^{48}$ Mature individuals which had doubtless migrated hare also been taken in Lake County on Mar 13, and one is recorded by Fox (1916) as taken at Lafayette in late March.

In the southern portion of Indiana, americana is always found in dry, upland localities, such as the borders of roads, old meadows, weed and stubble fields, prairies, and especially in old abandoned fields which have grown up to oak and other shrubs. In the northern portion it occurs in damper localities, being found in the tall grasses and sedges along the borders of sloughs and marshes and in the meadows bordering lakes and tamarack

${ }^{40}$ See Psyche, VI, r893, 465. 
marshes. When flushed it rises quickly and with a fluttering noise, makes a long, wavering, jerky flight, and alights upon the bole or branch of tree or shrub, a fence, or some other object some distance above the earth; seldom, if ever, settling on the ground. If then approached, it dodges around the object upon which it rests, much as does a squirrel under the same circumstances.

In Florida s. americana has been taken by me at all points where collecting has been done. About Dunedin, it is frequent throughont the winter, especially so in old fields, and on Hog Island it occurs among the coarse grasses, within 50 feet of the strand. When flushed in the pine woods it often alights on the boles of the trees eight to 20 feet above the ground. It has been recorded many times from all parts of the State, including the southern keys. Adults are to be found any month in the year, but nymphs are scarce in winter. It is often called the "clickety bug" by the southern negroes, a name given it on account of the rustling noise made by the wings in flight, which, however, is not a true stridulation.

Of the distribution of the American locust Scudder (1899c, 474) has written: "Excepting S. peregrina, which has crossed the ocean and colonized another world, $S$. americana is the most widely distributed member of the genus, and merits its name, ranging as it does from North America east of the Great Plains and south of about latitude $40^{\circ}$; throngh the West Indies, Mexico and Central America to South America, where it occurs as far as Colombia in the west and Argentina in the east, though the records of its occurrence in South America are few. North of north latitude $40^{\circ}$ or thereabouts, sporadic cases of its appearance are recorded, notably in Massachusetts and southern Ontario; these are doubtless accidental visitants, flying from their proper home farther south." Since Scudder's writing, it has been recorded from Connecticut by Walden $(1911,108)$, and extreme northern Jowa by Somes $(1914,68)$, so that taking its northern Indiana, Michigan and other records into consideration, it is liable to be found anywhere in our territory sonth of north latitude $45^{\circ}$.

135. Scmistocerca alutacea (Harris), 1841, 139. Leather-colored Locust.

Size medium, the female much the larger, with more robust body. Color purplish-brown to olive-green, darker in old or dried specimens; dorsal surface with a narrow bright yellow median stripe running from front of vertex back over head, pronotum and anal area of tegmina; sides of tegmina rarely with a few minute fuscous spots. Wings transparent yellowish, the veins darker. Sides of abdomen with a row of black dots on the hind margin of each segment. Outer face of hind femora reddish- 
brown or yellowish, usually with a row of black dots along the upper and lower margins. Hind tibiæ brown, often with a reddish tinge, the spines yellowish, tipped with black. Vertex rather prominent, narrow; disk subrhomboidal, but little depressed, its sides low, distinct only on front half. Face vertical, frontal costa narrow, slightly sulcate below the ocellus, the joints slightly flattened. Disk of pronotum flat on metazona, the sides higher and sloping on prozona, hind margin broadly obtuse-angled, surface densely punctate, median carina low but distinct. Prosternal spine large, cylindrical, its apex rounded. Tegmina exceeding the abdomen about onefourth their length, male, one-sixth, female. Hind femora slender, reaching tip of abdomen, female, exceeding it 2 to $3 \mathrm{~mm}$., male. Cerci of male short, oblong, their upper edge concave or broadly notched. Length of body, $\hat{o}, 28-32$, $९, 42-50$; of antennæ, $\hat{o}$ and $\uparrow, 15-17 \mathrm{~mm}$; of prono-

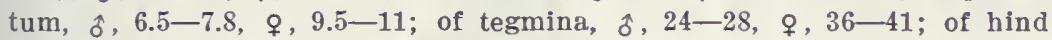
femora, $\hat{\delta}, 17.5-19.5$, $ᄋ, 22-27 \mathrm{~mm}$. (Fig. 114.)

This species has been taken only in the western half of Indiana, from Knox Co. northward, though it doubtless occurs in suit-

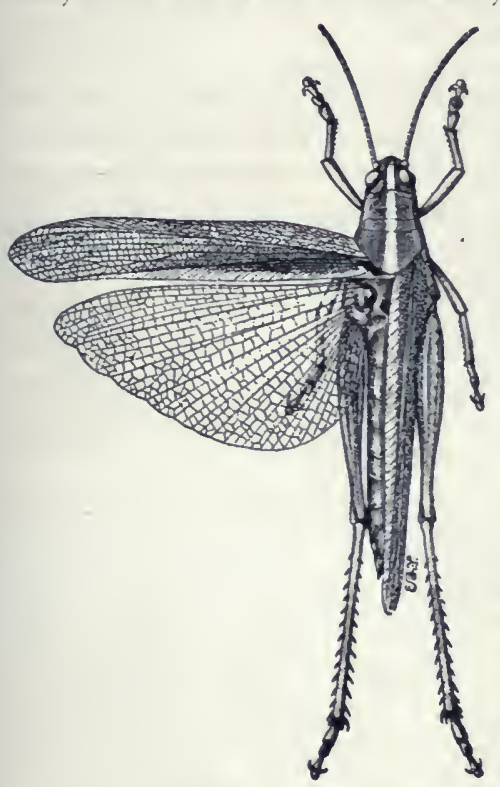

Fig. II 4. Female. (After Lugger.) able environments throughout the State. It is abundant about the marshy meadows and sloughs in Fulton, Lake and Starke counties, where it has been taken on August 15 th in numbers. There it makes its home in the rank grasses, weeds and rushes which grow in such places. The males are everywhere much more abundant and more active than the females, though they usually fly a shorter distance. In Vigo County it is frequent in jatches of raw, damp prairie and along the edges of thickets bordering them; also in many places along the railways, especially where they pass through prairie regions. Both sexes, when flushed, arise with a whirring noise which, howerer, is not a true stridulation. The males usually fly about 50 feet and settle down on the grass or on a low shrub.

I have not so far taken alutacea in Florida, but it occurs sparingly throughout the mainland of that State, as shown by the records of R. \& H., Morse and Davis. The form found on the southern keys is rubiginosa (Scudd.).

The known range of this typical form of alutacea is a rery wide one, extending from New England to California, and south 
to northern Mexico. Wherever found it occurs for the most part in moist places, preferring the rank mixed growth of grassy swamps and prairies to the drier fields and woodlands. The Acridium emarginatum Scudd. ${ }^{49}(1872,250)$ is a synonym.

135a. Schistocerca Alutacea rubioinosa (Scudder), 1862, 467. Rusty Locust.

Size medium, the body of female especially bulky. Color a nearly uniform rusty brown, without median yellow stripe above; tegmina usually with numerous rounded fuscous spots on sides. Wings transparent and glassy, slightly reddish toward tip. Head and pronotum wider than in alutacea, the fastigium broader and more declivent. Frontal costa wider and flatter than in alutacea, sulcate below the ocellus. Disk of pronotum broader, with the sides less sloping on both prozona and metazona, the median carina usually more prominent than in alutacea, otherwise the same Tegmina exceeding the abdomen in both sexes. Length of body, $\hat{o}, 30-36$, ㅇ, $43-54$; of antennæ, $\hat{o}, 13$, 오 15; of pronotum, $\hat{o}$, $7-8.5$, ㅇ, 9-11; of tegmina, ô, $25-32$, 우, 35-41; of hind femora, $\hat{o}$, 17-19, 오, 23-25 mm.

This seems to be a searce locust in Indiana, having been taken only in Marshall, Cass, Porter and Crawford counties; July 20 Oct. 12. It prefers dry upland pastures and woodland, especially those with a soil of sand, where scrub oak abounds. Its habits of flight are the same as those of alutacea. Numerous specimens are at hand from New England, in addition to those from Indiana, and in all the fuscous spots of tegmina are plainly visible in both sexes, whereas they are wholly absent in all males of alutacea, and present but very faint on but two or three of the numerous females of that species.

In Florida rubiginosa has been recorded from a number of places between Jacksonville and Key West, being the common form on the southern keys. $R . \& H .(1916,197)$ regard it as only a color phase of alutacea, stating that intermediate forms oceur in New Jersey, South Carolina and Georgia. Morse (1904, 39) says of the two: "There is considerable variation in this species in color and markings in the dirertion of alutacea. Possibly hybrids occur, but typically these two species differ in color, structure and haunts." Later $(1907,44)$ he says: "It is very probable that some so-called species of Schistocerca are but forms of one which varies greatly in color and structure. In New England the two forms known as alutacea and rubiginosa seem to be constantly different structurally. Southward and westward the structural gap between the two seems to be bridged and both vary much in size, color, form and proportion of parts." I prefer to retain

49 Kirby (1910, 458) accredits this name to Dodge (187r, 15 ). Dodge's paper was issued in 1872 and he gave the name only as Acridium emarginatum Uhler. 
rubiginosa as a variety, since it can be readily separated by the characters given in the key and habitually occurs in drier situations than does typical alutacea.

The distribution of rubiginosa is given by .Scudder (1899c, 462) as "The entire Atlantic Coast of the United States from Central Massachusetts to Key West, Fla., and in the interior, east of the Great Plains, from as far north as Iowa and Minnesota to the Gulf, extending into Mexico and even farther south."

136. Schistocerca onscura (Fabricius), 1798, 194. Larger Obscure

\section{Locust.}

Females very large, robust; males much smaller, more compressed. General color dark olive-green, usually with a narrow dorsal pale stripe as in alutacea; tegmina, in fresh specimens, a handsome purplish-brown, of ten fading to dull brown when dried, those of the unstriped female usually with vague indistinct fuscous spots. Antennæ yellowish, dusky toward tips. Hind femora often with short, oblique fuscous cross-bars on upper outer face; hind tibiæ blackish-purple, their spines yellow, tipped with black. Valves of ovipositor, sides of hind knees and a short stripe on mesopleura usually yellow. Structural characters much the same as in alutacea. Pronotum with median carina more sharply defined and slightly higher, especially on metazona, the hind margin more angulate. Cerci of male slightly narrower, their outer apical third concave and tips truncate. Notch of subgenital plate deep, V'shaped. Length of body, $\delta, 34-40$, , $50-61$; of antennæ, $\hat{\sigma}$ and $\$, 17-18.5$; of pronotum, $\hat{\delta}, 7.5-8.7, \quad$, 11-13; of tegmina, $\hat{\delta}, 31-36$, ㅇ, $44-48$; of hind femora, $\hat{o}, 20.5-22$, ㅇ, $28-31 \mathrm{~mm}$.

Ormond, Gainesville, Miakka and Dunedin, Fla., Oct. 11-Apr. 4 (IV. S. B.). This large and handsome species is not known from Indiana and is apparently scarce in Florida in winter and spring. having been noted only on three or four occasions. About Dunedin it was first seen on Hog Island, where three or four individwals were noted on the foliage of the Florida button-bush, Conocarpus erecta $\mathrm{I}_{\text {., }}$ just inside the fringe of black mangrore. On two other occasions a few individuals were flushed from high weeds and willows along the margins of a moist hammock. The flight of the male is prolonged and both sexes, when flushed, always alight on shrubs or trees some distance above the ground. A single female from Ormond is of the unstriped variety with the tegmina vaguely flecked with fuscous, thus resembling $S$. a. $r u$ biginosa but much larger. S. obscura has been recorded from numerous other Florida stations between Jacksonville and Ker Largo, but was nowhere found in large numbers.

The known range of the species extends from Baltimore, Md., south and southwest in the coastwise states to Texas and Mexico. According to scudder it is found throughout the latter country; 
also in New Mexico, eastern Colorado, Nebraska and Iowa. R. \& H. $(1916,200)$ state that in the southeastern states it is chiefly confined to the sands and gravels of the coastal plains and peninsular Florida. Fox (1917) says tliat in Virginia it "appears to occur most regularly in the reedy areas of tidal marshes, but it is also found in the dense herbage clothing the adjoining slopes of the dry land." Farther back from the coast, at Augusta and Albany, Ga., R. \& H. found it on high weeds in or near cotton fields and also in long-leaf pine woods. They state that from Delaware to Florida it was "common only occasionally, being generally but few in numbers and very frequently associated with alutacca."

137. Schistocerca DAMnifica (Saussure), 1861, 164. Mischievous Locust.

Female robust, medium in size; male smaller, subcompressed, much more slender. Color a nearly uniform dark rust red or russet-brown; occiput and carina of pronotum with a narrow reddish-brown or brownishyellow line. Tegmina of female rarely with small, dim dusky spots, the anal field usually pale brown. Outer face of hind femora sometimes whitish, with narrow dark oblique lines arranged herring-bone fashion. Head small, the disk of vertex hexagonal; frontal costa wide, feebly sulcate. coarsely punctate, the sides parallel below the ocellus, a little expanded and flat just above, then narrowed and convex at point of union with ver. tex. Disk of pronotum with the surface very rough with small pits and impressions, that of prozona strongly sloping, the median carina relatively high, nearly straight; hind margin right angled, male, very obtuse-angled

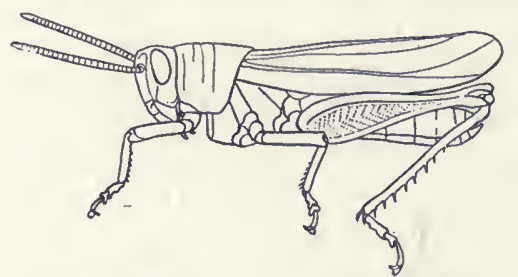

Fig. I 5. Male. $X$ 1.5. (After R. \& H.) or bluntly rounded, female. Tegmina of male slightly exceeding the abdomen; those of female reaching base of ovipositor and tip of hind femora, the latter shorter than abdomen. Length of body, $\hat{\delta}, 25$ -27 , ᄋ, $37-42$; of antennæ, $\hat{\delta}$, 10 , $९, 11$; of pronotum, $\delta, 6.5-7$, \&, 8.5-9.5; of tegmina, ô, $20-25$. ․, 26-29; of hind femora, $\delta, 14-16$,,, $19-21 \mathrm{~mm}$. (Fig. 115.)

This, our smallest eastern species of Schistoccrca, has been taken in Indiana only in Crawford and Harrison counties. A single female was secured May 10, 1899. This was probably a migrant, as that is a very early date for eggs hatched in spling to mature, and it is not known that the species winters so far north in either the adult or nymph stage. Other specimens were taken in June and July, 1902, and September, 191S. It frequents old fields and roadsides on the crests of the higher hills near Wrandotte, and is probably to be found in similar localities throughout the southern third of the State. When flushed the males fly long distances and usually alight on the limbs of trees or fence posts, 
around which they dodge, and from which they may often be taken with the hand. The females are more clumsy and usually try to escape by leaping or diving into a nearby clump of grass or shrubs.

The range of $S$. damnifica is southern, and is given by Scudder $(1899 c, 475)$ as "United States east of the Great Plains, from Pennsylrania, Indiana, Illinois and Arkansas to the Gulf." He included, however, the southern form calidior in the range as quoted. In Ohio it has been taken at Sugar Grove and Cincinnati. some of Scudder's specimens were from different localities in Texas. Saussure's type was from Tennessee, and Fox has recently taken it near Clarksvilie, that State. Allard (1916) states that "it is especially common in the cotton fields of northern Georgia, where it prefers to rest upon the bare earth rather than upon regetation, the almost uniformly reddish-brown color making it quite indistinguishable from the red-land soils of that region." According to Caudell ${ }^{50}$ the nymphs of damnifica found about Washington, D. C., are dimorphic, being either a bright green or brown. He has bred both forms to maturity and found the green color to persist to the last stage nymphs, but to disappear in the final moult.

The Cyrtaconthacris unilineata F. Walker $(1870,611)$ and the undescribed Acrydium appendiculatum Uhl. (Ms.) of Scudder $(1877 a, 86)$ are stated by Scudder to be synonyms of damnifica, but the latter name was based on specimens from Florida, and therefore is to be referred to the race calidior.

137. Schistocerca DAMNIFICA CALIDIor Rehn \& Hebard, 1912, 258.

More slender and compressed than typical damnifica. General color much as there, but the pronotum, discoidal area of tegmina and outer face of hind femora usually, female, rarely, male, thickly sprinkled with small rounded fuscous dots. Antennæ slightly longer and more filiform than in damnifica. Hind margin of metazona less obtusely angulate than in the typical form. Tegmina longer and more slender, distinctly surpassing the tips of hind femora in both sexes. Structural characters otherwise scarcely different. Length of body, $\hat{\delta}, 25-29$, $९, 39-46$; of antennæ, $\hat{\delta}$, 11, $ᄋ, 12.5$; of pronotum, $\hat{\delta}, 6.8-7.2, \uparrow, 9-10$; of tegmina, $\hat{\delta}, 24-26$. ․, 33-34; of hind femora, $\hat{\delta}, 17-21$,,, $21-23 \mathrm{~mm}$. (Fig. 116.)

This is one of the most common locusts in Florida during the winter months, the specimens at hand having been taken by me from November to April at all collecting stations except Ker West, and at Mobile, Ala., by Loding. It has been recorded from all parts of the mainland of the State by other collectors, but

${ }^{50}$ Proc. Ent. Soc. Wash., I916, 216. 


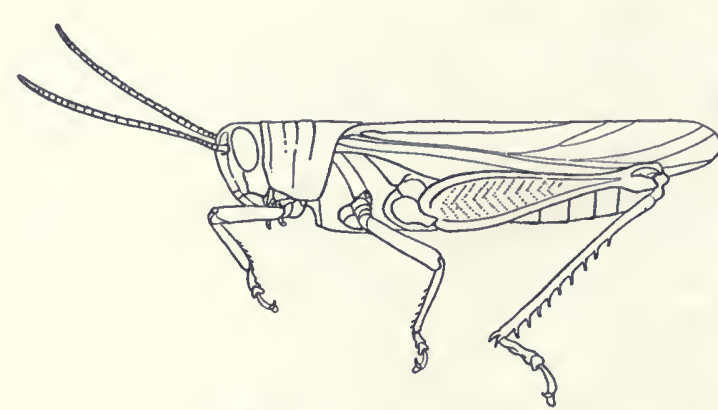

Fig. I 6. Male, $\times$ 1.5. (After R. \& H.) as yet only from Big Pine Key of the soutliern islands. About Dunedin and Ormond it occurs in old deserted fields and along pathways a $\mathrm{d}$ open spaces covered with wire grass in the pine and oak woods.

R. \& H. $(1916,206)$ give records of its distribution extending from Fayetteville, N. Car., south and west through southern Georgia and throughout Florida. They state that intergrading forms between it and damnifica occur about Florence, S. Car., and Wilmington and Fayetteville, $\mathrm{N}$. Car. The longer tegmina and more slender form easily distinguish the Florida specimens from those of typical domnifica at hand from Indiana and Arkansas, and while the two forms are very closely related, calidior is probably worthy of its racial name.

Tribe IV. MELANOPLI.

This tribe ('omprises the great majority of the true locusts or Acrididx of the Eastern United States and Canada. They are for the most part of small or medium size, and all agree in having the fastigium of vertex more or less declivent and gradually merging into the frontal costa; foveolæ wanting or very minute; face moderately oblique or subvertical; antennæ filiform, longer than the fore femora; eyes of moderate size, usually not very prominent, the interocular space generally narrow; frontal costa not prominent, generally sulcate below the ocellus; disk of pronotum nearly flat, nerer crested, prozona generally longer than metazona, smooth or feebly punctate; metazona usually densely punctate; lateral carina usually indistinct or wholly wanting; lateral lobes with hind margin straight or nearly so, their posterior lower angle obtuse; tegmina often very short, rarely wholly wanting, usually fully developed and tapering gradually throughout their length; wings transparent; prosternal spine rather prominent and conical, rarely truncate; hind femora generally surpassing the abdomen; liind tibire with nine to 14 spines on outer margin, the apical one lacking; second hind tarsal joint only half as long as the first; apex of male abdomen more or less enlarged and upenrved, the cerci and subgenital plate variable in the different genera. 
As pointed out by Scudder $(1897,4)$, the tribe is almost exclusively American, but one (Podisma) of the 30 genera recognized by him being represented in the old World. Of these 22 are represented in America north of Mexico, but only eleven of them in the territory corered by this work. These may be separated by the following key, which is abridged and modified from tliat of Scudder.

KEY TO EASTERY GENERA OF TRIBE MELAYOPLI.

a. Side margins of subgenital plate of male, viewed in profile, straight throughout or very feebly convex, never at all abruptly dilated or widened at base (Fig. $118 \alpha$ ); tegmina and wings wanting or much shorter than abdomen.

b. Form very slender, subcylindrical; prozona three times as long as metazona; tegmina and wings wanting; body almost glabrous.

I. Gyarsoscirtetes, p. 322 .

$b b$. Form stout; prozona not over one-half longer than metazona; tegmina as long as or longer than pronotum, generally half the length of abdomen; body rather thickly pubescent.

II. Campylacaxtha, p. 325 .

aa. Side margins of subgenital plate of male suddenly dilated or widened to a considerable degree at base (Fig. $118, c$ ) ; if not so widened then the entire margin strongly convex or sinuate; tegmina and wings variable in length, rarely (Podisma and Aptenopedes) wanting.

c. Subgenital plate of male with a distinct tubercle at apex, the margins of the plate meeting below the tubercle; cerci of male very slender and tapering. (Pl. III, a.)

d. Median carina of pronotum well developed throughout its length; lateral carinæ present on front half of prozona; tegmina not reaching middle of abdomen; prosternal spine sharply acuminate.

III. EоTETTIX, p. 327.

dd. Median carina feebly developed; lateral carinæ wholly wanting; tegmina usually nearly as long as or slightly longer than abdomen, rarely less than two-thirds its length; prosternal spine blunt at apex; general color green, the median pronotal carina reddish-purple. IV. HesperotetTIx, p. 329.

cc. Subgenital plate of male without a distinct tubercle at apex, or, if present, small and the cerci then very broad.

$e$. Interspace between the mesosternal lobes in both sexes much wider than long, as broad as or broader than the lobes them. selves; tegmina usually and typically abbreviate, sometimes wanting.

$f$. Head very large, face almost vertical; eyes small, prominent the interocular space nearly as broad as their greatest width; metazona rugulose-punctate; tegmina present, sometimes fully developed. V. Dexdrotetrix, p. 337.

$\mathrm{ff}$. Head of moderate size, the face slightly oblique; eyes large, less prominent, the interocular space distinctly less 
their greatest width; metazona almost smooth; tegmina represented by small pads or wholly absent.

VI. Podisma, p. 340.

$e e$. Interspace between the mesosternal lobes distinctly longer than broad in male, generally quadrate in female, in both sexes always much narrower than the lobes themselves; tegmina variable in length.

g. Face rather strongly oblique; eyes almost or quite twice as long as broad; tegmina linear and widely separated or wholly absent.

VII. Aptenopedes, p. 344.

$g g$. Face almost vertical or slightly oblique; eyes rounded, never more than one and one-half times longer than broad; tegmina always present, rarely linear.

$h$. Fastigium of vertex flat or convex; eyes widely separated, the interocular space twice as broad as the frontal costa; lateral carinæ distinct on both pro- and metazona; tegmina short, nearly as broad as long; cerci apically acuminate.

ViII. Paratylotropidia, p. 348.

$h h$. Fastigium more or less depressed, its side margins feebly elevated; eyes narrowly separated, the interocular space but little wider than frontal costa; lateral carinæ of pronotum rarely present; tegmina variable in length.

$i$. Dorsal surface of pronotum twice as long as the average breadth, the sides parallel; antennæ of male twice or more times as long as pronotum; subgenital plate of male broad, the apex truncate (PI. IV, t.)

IX. Paroxya, p. 349.

ii. Dorsal surface of pronotum never twice as long as the average breadth, generally only half as long again, the sides more or less constricted in the middle; antennæ of male less than twice the length of pronotum; subgenital plate of male with the apex usually rounded.

j. Head swollen, large in proportion to the pronotum, nearly half as long again as the long prozona; pronotum feebly flaring in front to receive the head; cerci of male styliform; subgenital plate very nar. row, the apical margin not elevated (Pl. IV, s.)

$\mathrm{X}$. Phoetaliotes, p. 356 .

$j j$. Head not large in proportion to pronotum, but little longer than the prozona; pronotum not enlarged in front to receive the head; cerci of male exceedingly variable, but very rarely styliform; subgenital plate never very narrow, often very broad, its apical margin usually elevated. XI. Melaxoplus, p. 358.

I. Gymnoscirtetes Scudder, 1897a, 195. (Gr., "naked" + "to leap.")

Long, slender, subcylindrical species, having the vertex feebly convex, triangular, the interocular area very narrow, sulcate in 
male; fastigium feebly declivent, much widened and concare in front of eyes; face distinctly, not strongly oblique; frontal costa wider than the interspace between the eyes, feebly constricted below the ocellus, deeply sulcate throughout; eyes large, prominent, especially so in male; antenna much longer than head and pronotum together; pronotum compressed, cylindrical, front and hind margins truncate, sides parallel, median carina low, distinct, feebly cut by front and hind sulci; metazona very short, lateral carinæ absent; lateral lobes short, their lower margin subangulate at basal third; hind femora very slender; hind tibia with S-10 short spines on outer margin; lobes of both meso- and metasterna attingent or nearly so. Two species are known, both from the Southern States:
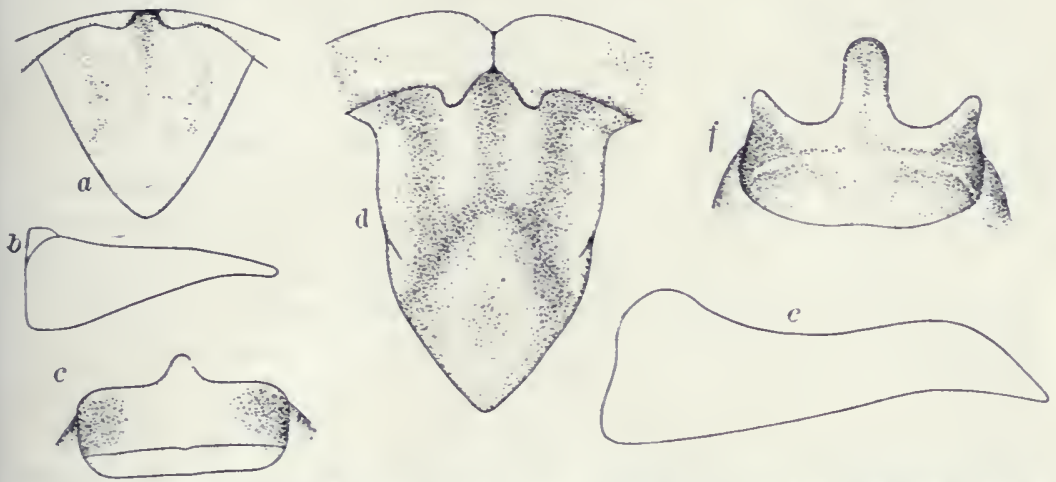

Fig. $117 . \quad a, b$ and $c$. Male supra-anal plate, outline of cercus and subgenital plate of Gymnoscirtetes pusillus; $d, e, f$, same of $G$. morsei; $b$ and $e \times 32$, the others by 21 . (After Hebard.)

\section{KEY TO SPECIES OF GYMNOSCIRTETES.}

a. Smaller, length of body, male, $13.5-15 \mathrm{~mm}$; apex of subgenital plate of male slightly elevated into a minute erect tubercle; cerci straight, suberect, tapering from base to apex, as long as the supra-anal plate (Fig. 117, $a, b, c$.)

138. PUSILLUS.

aa. Larger, length of body, male, $14.2-16.2 \mathrm{~mm}$; apex of subgenital plate strongly elevated in a large, medio-dorsal projection, which is fully twice as long as broad, with apex blunt and directed "dorsocephalad;" cerci much longer, subfalcate (Fig. 117, $d, e, f$. )

139. MORSEI.

138. Granoscirtetes Pusillus Scudder, 1897, 15. Little Wingless Locust.

General color dull greenish-yellow; face pale brown; sides with a broad shining blackish-brown stripe extending from eyes back along the upper halves of lateral lobes of pronotum to beyond middle of abdomen; dorsal surface of abdomen and pleura fuscous; hind tibiæ pale dull green, the spines black, paler at base. Occiput and disk of pronotum finely alutaceous. Prosternal spine erect, slender, tapering to a rather acute apex. Su. 
pra-anal plate of male large, triangular, with a narrow median and two broader lateral grooves on basal half; furcula represented by two feebly projecting rounded lobes. Valves of ovipositor slender, strongly exserted, the apical teeth acute in both pairs. Other structural characters as given above. Length of body, $\hat{\delta}, 12.5-15, \uparrow, 17-22$; of antennæ, $\hat{\sigma}, 5.7$,, 6.5 ; of hind femora, $\delta, 7-8$, ㅇ, $9.5-10 \mathrm{~mm}$.

Hastings, Fla., Aug. 27-Sept. 5. Scudder's types were from Jacksonville, and it has been recorded by $\mathrm{R}$. \& H. and Morse from Pablo Beach, Gainesville, Cedar Keys, Live Oak, DeFuniak Springs, Lakeland and Pine Island, so that it probably occurs throughout the State. The Pine Island specimens were nymphs taken by Hebard, May 18_20; the other records of adults, Aug.Norember.

G. pusillus is so far known only from Georgia and Florida, its northern stations being Jesup and Brunswick, Ga. Morse (1904, $39)$ recorded it as "locally abundant at Waycross, Ga., in the open, lower marshy portions of the pine barrens, inhabiting a matted growth made up of pipe-wort, sedge and juncus stems." R. \& H. (1916, 207) state that in southeastern Georgia and northeastern Florida it is "frequently exceedingly plentiful locally in the hearier under'gr'owth of the long-leaf pine forests, especially where the ground is low." Hebard says that "they are masters of the art of jumping. They can leap so quickly that the eye cannot follow them and can jump in any direction with such rapidity that it is impossible to see where they have gone. They jump from one tuft of wire grass to the top of another tuft, and there cling tightly to the highest straw, ready to make another leap." The species is one of the smallest and without doubt the most slender-bodied of all our eastern Acridians.

139. Grunoscintetes MoRsei Hebard, 1918, 142. Morse's Wingless Locust.

"Closely related to G. pusillus Scudder, agreeing in form, coloration and color pattern. The genitalia of both sexes, however, offer striking and constant characters for specific distinction. Male: Size larger than pusil. lus. Head with interocular space about as wide as first antennal joint. Prosternai spine rather elongate, beyond base rather slender, cylindrical, scarcely tapering to the bluntly rounded apex. Supra-anal plate elongate, shield-shaped, with surface longitudinally trisulcate, the lateral margins moderately reflexed and with two small, elongate, longitudinal convexities proximo-laterad of the small projecting apex. Cerci specialized, distinctive (Fig. 117, e.) Subgenital plate as described in key. Female.-Larger than male, larger than in pusillus. Interocular space broader than in male, prosternal spine heavier and shorter. Ovipositor valves elongate; the dorsal pair with disto-dorsal decilvity brief to the blunted apical tooth; the ventral pair with disto-lateral and apical tooth blunted, the portion beyond the disto-lateral tooth very brief. Length of body, ô, 14.2-16.2, ᄋ, 19.5-21.5; 
of antennæ, $\hat{\delta}, 5.3-6.2$, ㅇ, $6.5-7.2$; of pronotum, $\hat{o}, 2.3-2.6$, ㅇ, $3-3.1$; of hind femora, $\hat{o}, 6.8-7.9$, $\$, 9.4-9.7 \mathrm{~mm}$." (Hebard.)

Described from 17 males and 12 females taken at DeFuniak Springs, Fla., Aug. 30, 1915, in a "boggy area of wire-grass and bog plants which was not over 15 yards wide by 40 yards long." While the general facies of this species is almost exactly that of pusillus, it is very distinet by the characters given in key and description, and shown in Fig. 117. Although Hebard, as quoted above, states that morsci is larger than pusillus, R. \& H. have recorded $(1907,294 ; 1916,207)$ specimens of the latter from Pablo and Atlantic Beach, Fla., measuring, males, 15.3, and females, $22.6 \mathrm{~mm}$. in length of body.

II. Campriacantha Seudder, 1897a, 198. (Gr., "bent" + "spine.")

Short, robust, moderately compressed species, having the head rather prominent, especially so in male, the oeciput arched and elevated above the pronotum; fastigium strongly declivent, widened and feebly concave in front of eyes; face subrertical, frontal costa -shallowly sulcate, widest just abore the antennæ, its sides thence feebly converging to. clypeus; eyes of medium size, not prominent; interocular space subequal to, male, or one-half wider, female, than the greatest width of frontal costa; antenna rather stout, more than half the length of body, male, longer than head and pronotum together, female; disk of pronotum longer and with sides more parallel in male than in female, median carina very low, usually cut by only the principal sulcus; prozona onehalf longer than metazona, feebly tectiform, slightly rugulose, its front margin truneate; metazona nearly flat, distinetly rugose, its hind margin obtusely angulate; lateral earinæ absent; prosternal spine short, conical, obtuse, slightly inclined backward; front and middle femora swollen in male; hind tibia with $9-10$ spines on outer margin; abdomen of male feebly enlarged at apex, the subgenital plate terminating in a small tubercle. Five species are known, all from the western United States, one of which ranges eastward into our territory.

140. Campylacaxtha olivacea (Scudder), 1875b, 472. Olive-green Locust.

General color bright olive-green, varying occasionally to pale brown or even fuscous; occiput usually with a darker green median stripe broadening behind, and this often enclosing a median yellowish line, side of bead, and sometimes the face tinged with yellow; antennæ green at base, orange at middle, the tips dusky. Pronotum irregularly flecked with short yellow dashes. Legs greenish-yellow, the front and middle femora in part dull orange. Tegmina green, ovate-lanceolate, generally reaching middle of ab- 
domen, sometimes to apical fourth, their inner margins feebly overlapping. Supra-anal plate of male triangular, its apex acute-angled, the basal twothirds with a distinct median groove between two feebly converging elevated ridges. Cerci straight, suberect, shorter than supra-anal plate, feebly tapering and somewhat falcate, the apical half less than half as wide as base and slightly sulcate on outer face (Fig. 118, a.) Length of body, $\hat{\sigma}, 21-23, \uparrow, 28-31$; of antennæ, $\hat{\delta}$ and $\$, 10.5$; of tegmina, $\hat{\delta}$, $8.5-10$, ㅇ, $10-14$; of hind femora, ô, $13.5-16.3$, ㅇ, $17.5-20 \mathrm{~mm}$.

This olive-green locust is not known from either Indiana or Florida, but is recorded from Illinois and Georgia, and is in the Davis collection from Mississippi. Specimens at hand are from Lincoln, Neb., Fayetteville, Ark., Marcy, Okla., and Bosque Co., Texas; Sept. 5-Oct. 28. Ranges from Illinois and Georgia west to Nebraska and southeastern Colorado, and southwest through Kansas and Oklahoma to Fort Worth, Texas. In Illinois Hart found it moderately common in August on the grassy dunes near Havana and Meredosia and states (1907, 233) that it is "abundant on the lance-leaved ragweed, Ambrosia bidentata Michx., on the dry soils of the Illinoisan glaciation across southern Illinois." He also records $C$. acutipenis Scudd. from that State, but this record is based upon dark grayish examples of olivacca as $C$. acutipennis is only a color variety of that species.

R. \& H. $(1916,207)$ record the finding of one adult and numerous nymphs near Macon, Ga., on July 31. There they occurred in thick grasses and weeds along the edges of woods. They state that the young could be readily distinguished from other Locustid nymphs by their striking whitish antennæ annulate with dark brown, these colors greatly fading in the dried specimens.

Scudder says that in Texas Belfrage found $C$. olivacea frequently sitting on the fences in autumn. Bruner (1897) states that in Nebraska it occurs upon sunflowers, Helianthus, pigweed, Chenopodium, and beets. Of its occurrence in Arkansas, Okla-
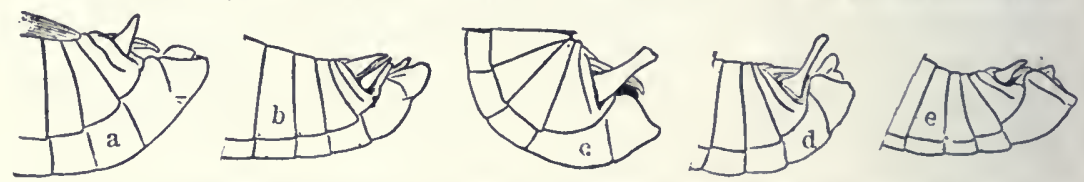

Fig. II8. Extremities of male abdomens of genera of Melanopli showing the form of cerci, etc. $\times$ 4. $a$, Campylacantha olivacea; $b$, Eotettix signatus; $c$, Podisma glacialis; d, Podisma variegata; $e$, Aptenopedes sphenarioides. (After Scudder.)

homa and Texas, Morse $(\mathbf{1 9 0 7 , 4 4 )}$ has written: "This species, with its color variety, acutipenmis, is a widely distributed and often locally very common locust, occurring among weeds in fields, along fence-rows and woodland edges. The green form rery greatly outnumbers the gray, though the latter is by no means 
uncommon. It matures late, young being common until Septem. ber, and the adults even seem relatively soft bodied, and usually discolor to a dull brown in drying. It is very sluggish, relying upon its protective coloration rather than actirity, to escape destruction."

\section{Eотеттіх Scudder, 1897a, 198. (Gr., "eastern" + "grass-}

$$
\text { hopper.") }
$$

Small or median sized species, having the body slender, elongate, feebly compressed; head short but rather large and prominent; vertex narrow between the eyes, the fastigium slightly declivent, broadening and more or less sulcate or concave in front of them; face slightly oblique; frontal costa about as wide as the interocular space, shallowly sulcate, with sides usually feebly conrerging below the antenne, slightly narrowed near rertex; an tennæ feebly flattened, slightly, female, or distinctly, male, longer than head and pronotum together; eyes large, prominent, longer than the cheek below them; pronotum with disk feebly tectiform, prozona smooth, metazona finely rugose, its hind margin broadly obtuse-angulate, median carina distinct, rather sharp; tegmina less than half the length of abdomen, broad, their inner margins usually meeting; hind femora reaching tip of abdomen, female, distinctly surpassing it, male; hind tibia with 11-12 spines on outer margin; abdomen of male compressed; furcula distinct; cerci styliform. Three species ${ }^{51}$ are known, all from the Southern Atlantic States.

\section{KEY TO SPECIES OF EOTETTIX.}

a. Hind tibiæ red; tegmina oval or ovate-lanceolate, their inner margins meeting or feebly overlapping.

b. Tegmina ovate-lanceolate, as long as or longer than pronotum, their tips acute or obtusely-angulate; apex of supra-anal plate of male bluntly rounded; larger, length of body, male 18 or more $\mathrm{mm}$.

141. SIGXATUS.

$b b$. Tegmina oval, shorter than pronotum, their tips rounded; apex of supra-anal plate acutely rounded; smaller, length of body, male, not over $16 \mathrm{~mm}$.

142. PALUSTRIS.

aa. Hind tibiæ greenish-yellow; tegmina subcircular or broadly ovate, shorter than pronotum, their inner edges not attingent; still smaller, length of body, male $10-12 \mathrm{~mm}$.

143. PusiluUs

141. Eotettix signatus Scudder, 1897, 54.

Size medium, robust for the genus, the females distinctly the larger. Pale bluish-green fading to greenish-yellow, shining; face and vertex marked with fuscous; side of head with a narrow, postocular shining black

${ }^{51}$ The Eotettix davisi and E. quercicola Hebard (1918, 153, 156) have been placed in the Scudderi Group of the genus Melanoplus. 
bar, this extending back along the upper third of pronotal lateral lobe, and bordered above and below with a bluish-white line; antennæ dull yellow, dusky toward tips; tegmina pale brown with a greenish tinge; hind femora 'grass-green, knees greenish-yellow; hind tibiæ pale red, the spines with tips black; dorsum of abdomen bluish-green, each segment in male with three or four black dots. Head wider than pronotum; fastigium with a rather deep, median groove, male, or concavity, female, feebly declivent; frontal costa widest just above the ocellus, where it is as wide as the interocular space, male, or two-thirds as wide, female. Disk of pronotum with sides parallel; median carina cut only by the principal sulcus; prozona nearly twice as long as metazona, male, one-third longer than metazona, female. Tegmina as described in key. Front and middle femora enlarged in male. Supra-anal plate of male triangular, the basal half with a pair of converging ridges enclosing a deep longitudinal groove; furcula consisting of a pair of oblong, divergent blunt projections; cerci tapering regularly to an acute point, as long as supra-anal plate (Fig. 118, b); subr genital plate longer than broad, terminating in a small rounded tubercle. Length of body, $\hat{o}, 18-21$, ㅇ, 25-28; of pronotum, ô, 4.7-5,, $6-7$; of tegmina, $\hat{\delta}, 6-6.5$, $ᄋ, 6.5-8$; of hind femora, $\hat{o}, 11.5-13$, 우, 14.5$-18 \mathrm{~mm}$.

Hastings and Dunedin, Fla., Aug. 23-Dec. 11 (W. S. B.). The Dunedin specimens were taken in tall grass on the bed of an old lake, Oct. 24-Dec. 11, mating on the latter date. Scudder's type was from eastern Florida, and it is known only from that State, having been recorded from various points between Jacksonville, Iakeland and Pine Island. It occurs mainly in moist grassy places in open pine woods and along the edges of hammocks, is nowhere common, and in life is one of the most handsome of the Melanopli. At Homestead and Detroit it was found by $R$. \& H. in .July in the prairie-like everglades and about pot-holes in the pine woods. They record females from Atlantic Beach measuring $30.6 \mathrm{~mm}$. in length of body, while at Homestead the smaller females were but $19.5 \mathrm{~mm}$.

\section{Eотетtix Palustris Morse, 1904a, 7. Swamp Eastern Locust.}

Intermediate in size between signatus and pusillus. Pale yellowishgreen, brown above and on tegmina, with fuscous postocular stripe as in signatus. Disk of pronotum more tectiform than there. Furcula more elongate and less divergent than in signatus. Subgenital plate narrower and more pointed. Other differences as given in key. Length of body, ô, 15-15.5, ㅇ, 21.5; of antennæ, ô, 8, 오, 9 ; of pronotum, ô, 4, 오, 5-6; of tegmina, $\hat{\delta}, 2-2.8$, ㅇ, $3.5-4 \mathrm{~mm}$.

Live Oak, Fla., Ang. 10 (Morse). Known only from Live Oak and Gainesville, Fla., the former being the type locality. There it was found by Morse $(190.1,40)$ in the scrubly undergrowth of palmettoes and bushes in the damper spots of the pine woods. At Gainesville ten specimens were taken August 16 by R. \& H. (1907) "in the rank vegetation around a flooded sink hole in pine woods." 
143. Eotettix pusillus Morse, 1904a, 7. Little Eastern Locust.

Short, rather robust. Fale yellowish-green, the dorsal surface and tegmina brownish; upper third of prozonal lateral lobes, upper sides of hind knees, tips of hind tibiæ, tibial spines, and tarsal claws, piceousblack; the entire body in life suffused with a metallic velvety lustre which mostly disappears in dried specimens. Head wider than pronotum; frontal costa above the antennæ four-fifths the width of interocular area, abruptly narrowed below the ocellus to two-thirds of its width above. Eyes very prominent. Pronotum relatively shorter than in the other species, its disk feebly tectiform; median carina sharp; prozona one-third longer than metazona, the latter finely rugose. Tegmina as described in key. Tip of male abdomen upcurved; supra-anal plate triangular, as broad at base as long, the median basal groove very short; furcula as in palustris; cerci slightly shorter than the supra-anal plate, awl-shaped, their tips acute. Length of body, $\hat{\sigma}, 10-12, \uparrow, 15.5-20$; of antennæ, $\hat{o}$ and $q$, $8-8.5$; of pronotum, $\hat{\sigma}, 3.5, \uparrow, 4.5-5$; of tegmina, $\hat{o}, 1.7-2, \uparrow, 3-3.3$; of hind femora, $\hat{o}, 7.5-8$, ㅇ, $9.5-11 \mathrm{~mm}$.

Denmark, S. Car., Aug. 15 (Morse). This, the prgmy of the genus, and one of the smallest of Acridians, has been taken in Florida only at Live Oak, Aug. 26, by R. \& H. It was described from Warcross, Ga., and Denmark, S. Car., and is known also from Fayetteville, N. Car., and several points in South Carolina and Georgia. It occurs principally on wire-grass in open pine and oak woods and seems to be scarce wherever found. The nymphs are said by $R$. \& $H$. to be "blackish, orerlaid with mars orange, the latter color forming a pale postocular stripe and strongly indicated over the face and the distal portion of the caudal femora."

\section{Hesperotettix Scudder, 1876ia, 262. (Gr., "western" + "grasshopper.")}

Small to median locusts, the sexes not differing greatly in size. They have the sides nearly parallel; head small; vertex opposite middle of eyes very narrow, often but little wider than second joint of antennæ; face but little oblique, frontal costa usually narrow, sulcate throughout, punctate; antennæe of female a little shorter than or equalling head and pronotum together, of male a fourth longer, the joints slightly flattened; eyes rather small, longer than the cheek below them; pronotum longer than in allied genera except Paroxya, the prozona usually half as long again as metazona, the sides of disk broadly sloping; median carina low, not cut by the first and second sulci; hind margin very obtusely angulate or broadly rounded; lateral lobes of pronotum with front and hind margins nearly straight, oblique, lower margin with its 
front half directed upward; tegmina variable in length, in our eastern species usually shorter than abdomen; fore and middle femora of male swollen; hind femora slender, surpassing abdomen in both sexes, strongly so in male; subgenital plate of male entire, but with a small subapical tubercle; furcula present as distinct projecting lobes; valves of ovipositor strongly exserted.

Scudder $(1897,56)$ recognized eight species of Hesperotettix from the United States and Mexico. Kirby $(1910,498)$ accredits 12 species to the genus. Two more have been recently described by Hebard. Of the 14 nominal species, five species and one variety are recognized from the Eastern States.

KEY TO EASTERN SPECIES OF HESPEROTETTIX.

a. Prozona of pronotum smooth or very sparsely punctate, nowhere rugulcse; metazona punctate; disk of pronotum feebly tectiform.

$b$. Tegmina fully twice or nearly twice as long as pronotum.

c. Dorsal face of hind femora without dark bars; larger, length of body, male, $15.5-18.5 \mathrm{~mm}$.

d. Hind margin of metazona broadly rounded; prosternal spine short, stout, conical; tegmina and wings abbreviated, covering about two-thirds of abdomen. 144. BREVIPENNIS.

dd. Hind margin of metazona obtuse-angulate; prosternal spine longer, more slender, subcylindrical, its tip rounded; teg. mina and wings usually surpassing the abdomen, male, only reaching its tip, female.

145. PRATENSIS.

cc. Dorsal face of hind femora (in living specimens) with two faint dark cross-bars; smaller, length of body, male, 14.5$15.5 \mathrm{~mm}$. ; hind margin of metazona and length of tegmina as in pratensis.

145a. GEMMICULA.

$b b$. Tegmina shorter than pronotum; hind femora without dark cross-bars.

146. OSCEOLA.

aa. Prozona and metazona both on disk and lateral lobes distinctly rugu.

lose; pronotum more obviously, not strongly, tectiform.

$e$. Tegmina elongate, three to five times as long as broad, their inner edges overlapping.

147. Speciosus.

$e e$. Tegmina ovate, at most one and a half times as long as broad, their inner edges scarcely meeting and dorsal and lateral areas not defined.

148. FLORIDENSIS.

144. Hesperotettix brevipenxis (Thomas), 1874, 67. Northern Purple-striped Locust.

Small, rather stout, not strongly compressed. General color peagreen; median carina of pronotum and a narrow stripe along only the outer margin of dorsal area of tegmina, purplish-red; femora and apical third of hind tibiæ more or less suffused with the same hue; antennæ pale red, the tips darker; a short stripe below the eye, a broad one on upper third of prozonal lateral lobe, a spot on vertex, sides of knees and sometimes in part the outer face of hind femora, fuscous. Fastigium very slightly concave in front of eyes and with a minute concavity between 
them. Frontal costa narrow, feebly constricted below the ocellus, deeply sulcate throughout, male, wider, more shallowly sulcate only below the antennx, female. Prozona with median carina more distinct than on metazona, its surface sparsely and coarsely punctate, metazona rather finely and densely punctate. Tegmina usually overlapping except near base, their tips rounded and discoidal and dorsal areas distinctly defined by the rather coarse ulnar veins. Supra-anal plate of male triangular, its lateral halves and apical third irregularly concave, the basal third with a median triangular groove lying between two low converging ridges. Furcula consisting of a pair of short sub-rounded lobes lying within the basal groove of supra-anal plate. Cerci shorter than supra-anal plate, conical, strongly tapering from the broad basal to apical third, their tips blunt. Length of body, $\hat{\delta}, 15.5-17$, ᄋ, 20-24; of antennæ, $\hat{\delta}, 7.3-8.5$, ㅇ, $6.3-$ 7.2 ; of pronotum, $\delta, 5$, ㅇ, $5.5-6$; of tegmina, ô, $7.6-10$, ․, $9.7-11.7$; of hind femora, ô, $9.5-10.5$, ㅇ, $11.8-12.7 \mathrm{~mm}$.

Wellesley, Mass., July 10-Aug. 8 (Morse). This handsome little locust is not known from either Indiana or Florida, but occurs in the coastwise states from Massachusetts southwest to Alabama. In New England it has so far been recorded only from Wellesley, Dover and Walpole, Mass. Of its occurrence there Morse $(1898,272)$ says: "This is one of our rarer locusts, and with its delicately contrasted tints of green and purple, is one of our daintiest and most attractively colored species. It is usually captured by sweeping vigorously the short tufted growth of beardgrass, Andropogon scoparins Michx., which, with other wild grasses and running blackberry vines, sparsely clothe the thin soil of the gravel plain formations on which it is found."

In New Jersey it was first recorded as inhabiting cranberry bogs, but Rehn (1909a) considers its occurrence in these bogs as accidental, stating that individuals taken near Stafford's Forge, Aug. 12-Sept. 5, were found "only in a small area of huckleberry and sweet fern barrens on the edge of pine forests." Fox (1914, $509)$ mentions a number of stations where it has been taken in New Jersey, stating that it is almost entirely restricted to the Pine Barrens where it frequents low scrub and undergrowth. In Virginia, Georgia and Alabama it occurs very sparingly in mountainous or hilly regions. R. \& H. (1916, 210) state that their specimens "were taken in bunch grass Cyperus, particularly where this was plentiful on open slopes, and in the luxuriant mountain undergrowth of grasses, vines and oak sprouts, under a low forest predominant in black-jack oak."

145. Hesperotettix pratensis Scudder, 1897, 64. Meadow Purple-striped Locust.

Slightly larger, the males more slender and more compressed, than in brevipennis. Color much as there, the face often purplish-brown or if 
green, with a row of purplish dots along each side of frontal costa. Median fuscous stripe of occiput and vertex more often complete and with a median thread of yellow. Tegmina with entire dorsal area purplish-red. Hind femora more strongly tinged with purplish. Differs structurally from brevipennis in having the fastigium in front of eyes with a rather deep median sulcus, male, or distinct concavity, female. Pronotum slightly longer and more narrow, the metazona less flaring and with hind margin distinctly but broadly obtuse-angulate. Tegmina and prosternal spine different as described in key, the inner edges of the former over. lapping their full length. Supra-anal plate of male with margins and median basal ridges much higher than in brevipennis, where the margins are scarcely at all raised and the ridges but feebly so. Cerci narrower at base, more regularly tapering from base to apex (Pl. III, a.) Length of body, $\hat{\sigma}, 17-18.5$, $९, 24-30$; of antennæ, ô, $8-8.3$, \&, $9-10.2$; of pronotum, $\hat{\delta}, 4.5-5$,,, $6-6.5$; of tegmina, $\hat{o}, 12-13$,., $17-20$; of hind femora, ô, 11-11.6, ᄋ, 13.5-16 mm. (Fig. 119.)

In Indiana this dainty and prettily colored species has been noted only in Lake County, where it has been taken in two locali-

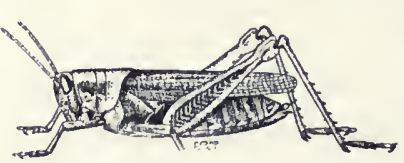
Fig. I I 9. Female, natural size.
(After Lugger.) ities. On September 19, 1898, a single pair were secured from the long grasses bordering the margin of a swale north of Millers. Though careful search' was made there and elsewhere in the northern counties, no others were secured until July 24, 1902, when they were fonnd to be rather common in a long, low, marshy tract, a mile southeast of Hammond. Here the males were especially active, leaping from one grass stem to another several times in succession, and dodging around the stem the instant they clasped it with their legs. The females were oftentimes easily picked up by the fingers. No attempt was made by either sex to use the wings in escaping.

In Florida $H$. pratensis has been recorded only from Carrabelle, Fort Barrancas, Warrington and Live Oak in the northern third of the State. Morse $(1904,16)$ says that in this region it is not uncommon in August along the Gulf shore among the xerophytic strand vegetation; while at Live Oak it was found by $R$. \& $\mathrm{H}$. among wire grass and other low plants in small clumps of dwarf oaks on the border of a sink.

After a careful comparison of numerous examples of $H$. pratensis from Indiana, Iowa and Nebraska with those of typical brevipennis from New England, I cannot agree with Morse and R. \& $\mathrm{H}$. that it is only a long-winged form of the latter species. Aside from the difference in wing length, which may be, and probably is a variable character, the other structural and color differences pointed ont in the key and description are constant in the 
series at hand, and are undoubtedly of sufficient importance to retain it as a valid species, especially if characters of less importance are held sufficient to separate other species of the genus.

The range of $H$. pratensis is a wide one, extending from Indiana and Florida, east of the Mississippi River, north and west to Minnesota, Washington and California, and southwest to Texas and Orizaba, Mexico. Hart records it from several localities in Illinois, principally from swales among the sand ridges of the northwestern portion. It is not recorded from Canada and appears to be scarce in Minnesota where, as in northwestern Indiana, it is found associated with Mlelanoplus angustipennis (Dodge.)

145a. Hesperotettix Pratensis gemmicula Hebard, 1918, 158. Little Gem Locust.

"Male-Size small for the genus, form slender. Medio-longitudinal torsal band of pronotum not solidly pink, the median portion distinctly paler than the margins. Dark bar of prozonal lateral lobes solid in col oration, the ventral border of this bar white and about equally broad. Tegmina and wings fully developed, extending nearly to apices of caudal femora, rarely only to apex of abdomen. Tegmina distinctively colored; dorsal and lateral fields green except for a broad longitudinal humeral band of pink. Genitalia of the same general type as in pratensis and brevipennis, cerci alone differing in being narrow and of subequal width in distal half, moderately incurved in this portion with apex sharply rounded. Prosternal spine shorter and stouter than in brevipennis, taper ing more rapidly in distal portion to the sharply rounded apex. Caudal femora green, the pregenicular pinkish annulus distinct; dorsal surface pale green with two weak but distinct broad transverse bands of darker green, and showing no trace of pink along the external margin as in brevipennis; external surface green, never washed with pink as in brevipennis. Length of body, $\hat{o}, 14.5-15.5$, ᄋ, 16.8-23.3; of pronotum, $\hat{\sigma}$, $3.6-4.1$, $ᄋ, 4.1-5.7$; of tegmina, $\hat{\delta}, 9.7-13$, + , 11.4-15.5; of hind femora, ô, 8.8-10.4, ९, 10.2-12.8 mm." (Hebard.)

Big Bayou, near Pensacola and Carrabelle, Fla., Aug. 28 Sept. 2 (Hebarl). The above are the salient points of the original description. The dried specimens at Philadelphia show only a faint trace of the dark bands on dorsal face of hind femora. The hind margin of metazona is obtusely angled as in pratensis, and the length of tegmina much as there. The size and color, are, howerer, more nearly those of brevipennis, the maximum length of gemmicula male, being the same as the minimum of male breviprnnis, while the length of the females of the two species are approximately equal.

I regard gemmicula, therefore, as only a small color variety of pratensis, differing slightly in form of cerci and prosternal spine. 
This opinion is the more enhanced by the fact that pratensis has been taken in the same region by Morse, who states $(1907,12)$ that "the Florida examples of $H$. pratensis present a distinctly different type of coloration--one seen in some California series of the species. They are also of small size like them but differ in having much longer tegmina and wings. H. pratensis as it stands to-day should be regarded as a variable and complex species represented in different parts of the country by several more or less distinct varieties." It is possible that a large series of all three forms will show that gemmicula is the real connecting link between brevipennis and pratensis, and that all three are only variable extremes of one widely distributed species which will bear the name brevipennis.

Hebard states that "the species is peculiar to very sandy areas; at Big Bayou it was found occasionally in a bushy low sand-loving plant, at Pensacola very scarce among the undergrowth of scant grasses and sand-loving plants in forest of long-leaf and small sand-pines. At Carrabelle very few were taken through the low bushes of the sand dune areas, which are covered heavily with arenicolous shrubs and bushes and some scrubby pine and oaks. Only with particular effort was it possible to secure the series. Heary beating was found to be the most productive method."

146. Hesperotetix osceola Hebard, 1918, 161.

Male-Larger and slightly more robust than in gemmicula. Dark bar of prozonal lateral lobe narrow, solid in coloration, its lower border white, as broad, or twice as broad as the bar itself. Hind femora green without dorsal dark bars or pink suffusion, the pinkish annulus near knee broad and distinct. Tegmina usually appreciably shorter than pronotum, rarely very slightly longer, feebly overlapping; their form broad ovate, the dorsal field distinctly defined from lateral one. Tegmina colored as in gemmicula. Genitalia as there, the cerci in the narrow distal portion with margins feeble convex. Furcula visible as small subquadrate projections. Basal half of supra-anal plate higher than the apical portion; pallium not conical and elevated as in gemmicula. Female-Size much larger, form more robust. Medio-dorsal stripe of pronotum decidediy broader, pale with very dark margins, continued on abdomen to near its apex. Length of body, $\hat{\delta}, 16.1-18.5$,, $21.4-24.5$; of pronotum, $\hat{\delta}$, $4.2-3.7$, $+5.1-5.7$; of tegmina, $\hat{\delta}, 3.8-4$,,$+ 4.7-5.8$; of hind femora, oิ, 11.7 , ᄋ, $13.2-15 \mathrm{~mm}$.

Ocala and DeLeon Springs, Fla., Sept. 8-20; two males, four females taken by $R$. \& $H$. "The species was exceedingly scarce, very long search on four days having been made to secure the six examples. Like gemmicula it was found peculiar to very sandy areas. At DeLeon Springs one individual was beaten from a 
dwarf oak in a wide sand scrub area, the other from dwarf oaks, bay cedar and other bushes more than a mile distant in the sand scrub. At Ocala the four specimens were secured in sandy flatwoods by beating the undergrowth, which was composed of a leguminous plant and bunch grass. The coloration and color pattern of this insect shows no important differences from that of gemmicula. It is possible that it may eventually prove to be a geographical race of that species, but we liave no evidence of this as yet." (Hebard.)

A study of the type series at Philadelphia leads me to believe this a disinct and valid species.

\section{Hesperotettix speciosus (Scudder), 1872, 250.}

Size large and form robust for the genus. Grass green, fading to yellowish-green in dried specimens, the tegmina and hind tibiæ alone retaining the original hue; median carina of pronotum and outer upper face and ring near knees of hind femora usually purplish- or pinkish-red; antennæ pale red, dusky toward tip; abdomen and inner surface of hind femora pale yellow; hind tibiæ green, the spines paler tipped with black. Vertex and occiput more or less rugulose; fastigium feebly concave in front of eyes, the concavity almost continuous with sulcus of frontal costa, male, separated by a rounded convexity of the costa, female. Frontal costa wider than in preceding species, deeply sulcate below the antennæ, female, throughout, male. Pronotum with median carina low; prozona one-fourth longer than metazona, female, one-half longer, male; hind margin broadly obtuse-angulate. Tegmina covering two-thirds to threefourths of abdomen. Supra-anal plate elongate, triangular, its sides low, feebly sinuate; its basal half with a rather deep median sulcus between two converging ridges which diverge, usually without merging, beyond the middle, thus forming another sulcus on apical third; furcula very short,

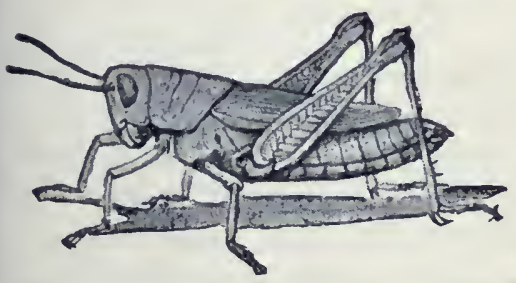

Fig. 120. Female, natural size. (After Bruner.)

triangular lobes. Cerci as long as supra-anal plate, their busal halves broad, strongly tapering, apical ones slender, incurved. Apical tubercle of subgenital plate broad, prominent, conical, its apex truncate or feebly bifid. Length of body, $\hat{o}, 22-24$, $\uparrow, 31-34$; of antennæ, $\hat{\sigma}, 10$, $q, 11.5$; of pronotum, $\hat{o}, 6-6.5$, ㅇ, 8-9; of tegmina, $\hat{o}$, $9-13$, ․ , 16-18.5; of hind femora, ô, $14-14.5$, ㅇ, 18-19 mm. (Fig.120.)

Sylvia, Kan.; Caddo and Foss, Okla. July 17-Aug. 8 (Davis). A species of western and southwestern lange, known east of the Mississippi only from the records of Hart $(1907,233)$ who reports it as occurring in August and September, with Campylacantha olivacea Scudd. on the grassy dunes near Havana and on the dry soils of southern Illinois. It ranges from southern Illinois west 
to Colorado and Montana and sonth and southwest to Texas and New Mexico. Somes $(1914,71)$ records a single pair from Mahtomedi, Minn., and states that in Muscatine Co., lowa, just across the river from Illinois, he had taken it in numbers on dry sandy soil. Bruner $(1897,135)$ says that speciosus is quite common over the entire State of Nebraska, but more common southward, where it has been known to occur in sufficient numbers to do some harm to growing crops; while Gillette $(1904,40)$ states that it occurs throughout eastern Colorado to the foothills, sometimes to a height of 6,000 feet. He gives its native food plants as sunflower (Helianthus) and a closely related Composita, Iva xanthifolia Nutt., and adds: "As this grasshopper feeds entirely upon native weeds it cannot be considered of economic importance."

148. Hesperotettix Floridensis Morse, 1901b, 130. Florida Purplestriped Locust.

Smaller and more slender than $H$. speciosus. Grass-green, yellowish beneath, drying to dull yellow; front faces of fore and middle femora and upper outer face of hind femora usually, and median carina of pronotum rarely, purplish-red; hind tibiæ bluish-green, the spines tipped with black. Pronotum more finely rugulose, its median carina lower, hind margin broadly rounded. Tegmina as described in key. Supra-anal plate of male, with median basal groove oblong, ending at middle; a cross carina near middle of plate dividing its upper surface into four concavities. Furcula very short, narrow, widely divergent lobes situated one on each base of the median ridges. Cerci more slender than in speciosus, twice as long as their basal width, their tips acute, not incurved. Valves of ovi. positor slender, the dorsal and ventral scoops elongate. Length of body, $\hat{\delta}, 17.5-21$, ㅇ, $24-30$; of antennæ, $\hat{\delta}$ and $ᄋ, 8-10$; of tegmina, $\hat{\delta}$, $4.5-6$, ㅇ, $5-7$; of hind femora, ô, 11.5-13, ㅇ, 15-16 $\mathrm{mm}$.

Hastings, Fla., Aug. 22. Known only from Florida and Georgia, Hastings being the type locality. Elsewhere in Florida it is recorded only from Pablo Beach and San Pablo, Aug. 13 (R. \& $H$., 1907 ), where it was found among grasses in marshy spots in the palmetto scrub and along a railway diteh, and from DeFuniak Springs, Oct. 17 (Davis. 1915). In Georgia it has been taken by R. \& H. $(1916,210)$ at Augusta, Warm Springs, Suwannee Creek and Homerville, July 29-Aug. 28. They state that "it acts in an unusual manner when pursued, hiding on the under side of leaves of low plants with only feet, antennie and eyes showing from above. It was taken among huckleberry, strawberry and other low plants in a sandy scrub oak area and on low open land cov. ered with wire-grass, low bushes and saw palmetto." 


\section{Dendrotetix Riley, ${ }^{52}$ 1893, 254. (Gr., "tree" + "grass- hopper.")}

Species of moderate size and robust form, having the head large, broad; eyes small, prominent, widely separated, no longer than the cheeks below them; fastigium much widened, strongly declivent and shallowly but distinctly concave in front of eyes, its sides continuous with those of frontal costa; face distinctly, not strongly oblique; frontal costa rather wide, low, shallowly sulcate, feebly constricted, its margins slightly converging below the ocellus; antennæ slender, about half the length of body in both sexes; pronotum short, its apical fourth flaring, rugose and upturned to receive the broad head; metazona much shorter and slightly wider than prozona, its surface rather strongly rugosepunctate, hind margin truncate or broadly rounded; lateral lobes with transverse sulci deep, the second and third feebly cutting the low interrupted median carina; tegmina variable in form and length; prosternal spine short, stout, subconical; hind femora slender, slightly shorter than abdomen, female, feebly surpassing its tip, male; hind tibia very hirsute, their marginal spines long; end of male abdomen not enlarged, subgenital plate scoop-shaped, its apex bluntly rounded; supra-anal plate long, triangular, with the usual median basal lengthwise ridges enclosing a shallow sulcus.

KEY TO SPECIES OF DENDROTETTIX.

a. Cerci of male oblong, twice as long as wide, their apical halves twisted, depressed, with tips blunt; Inner and lower faces of hind femora dark blood-red.

149. QUERCUS.

aa. Cerci styliform, tapering strongly and regularly from a broad base to a point; inner and lower faces of hind femora greenish-yellow, the former with two black bars.

150. SCUDDERI.

149. Dexdrotettix Quercus Packard, 1890, 214. Post Oak Locust.

General color yellow or greenish-yellow varied with piceous. Face yellow; occiput with variable black markings, usually with a black median stripe; antennæ yellow with dusky markings; side of head with a postocular black bar, widening on the prozona, where it covers the upper half of lateral lobe; metazona usually greenish-yellow; median carina and trans. verse sulci usually black. Tegmina dull brownish-yellow. Sides of ab-

${ }^{52}$ Caudell (19r5a) gives reasons why this genus should he accredited to Packard, that author ( 1890,214 ) having published a description copied verbatim from Bruner ( 1887,19 ) of the nymphs under the name of "Dendrotettix quercus Riley Ms." In this copied description Packard makes no mention whatever of generic characters, and the description of the nymphs is based almost wholly upon color, the only structural characters mentioned being: "The pupæ average almost an inch in length and are rather robust in form, with short broad head and powerful jaws," terms which could be properly applied to the last stage nymphs of a score or more of Acrididx. Following strictly the rules of priority Caudell may be correct, but from a common sense point of view, I believe that to Riley, who first gave a name to the genus (Proc. Ent. Soc. Wash. 1888, 86), and later (loc. cit. above) a full diagnosis of its characters, should belong the generic name, while to Packard, who described the nymphs, as above stated, should be accredited the species. 
domen, pleuræ, knees and subgenital plate of male black. Outer face of hind femora dull greenish-yellow rarely with a broad fuscous cross-bar on basal and apical thirds; hind tibiæ greenish-yellow with a brighter yellow ring near base Tegmina usually abbreviated and no longer than pronotum with tips well rounded; sometimes (D. longipennis Riley, 1893, 255) fully developed, then extending beyond abdomen in both sexes, their apical halves very broad; the inner edges in both forms not meeting on basal third but in the long-winged one often overlapping beyond middle. Furcula very small, triangular projections lying on the bases of the median ridges. Other structural characters as above given. Length of body, $\hat{\sigma}$, $24-25$,, $29-30$; of antennæ, $\hat{\delta}, 14$,, 13 ; of tegmina, (long-winged), o, 20-21, ㅇ, 22-23.5; of tegmina, (short-winged), $\hat{\delta}, 5$, ․, 6; of hind femora, ô, 12-13.5, ㅇ, $12-13 \mathrm{~mm}$.

Ridgeway and New Lisbon, N. J., July 17-Aug. 10 (Davis); Manor, Texas, July 15 (Caudell). East of the Mississippi this oak-inhabiting locust has been recorded only from Illinois, New Jersey and New York. The Illinois record by Bruner $(1893,15)$ is substantiated by specimens in the Urbana collection from Crete and Dubois. Davis (1912) has given an account of its occurrence about Ridgeway and Lakehurst, N. J., in 1910 and 1911, when they defoliated the oaks over large areas. He states that "the gayly colored grasshoppers were more common on the white oaks, though they ate the foliage of scarlet oaks and other members of the red oak group; as many as 40 of the insects were counted on the trunks of some trees, usually slowly making their way up to what remained of the foliage while the excrement of the grasshoppers already on the limbs fell with a rain-like patter onto the dry leares beneath. Some of the grasshoppers were fully winged and others were apterous. In addition to the oaks we noted where they had devoured parts of the leaves of a sumach, Rhus copallina L." In 1912 not a trace of the locusts could be found about Lakehurst, but in 1914 a single pair were taken, and the same year a new outbreak was recorded by Caudell (1915a) as occurring near New Lisbon, N. J., about 17 miles from Lakehurst. Here the locust infested an area of approximately two square miles, some of the tallest oaks being nearly defoliated. No later record of their presence in New Jersey can be found. In 1912 a single male was taken at Yaphank, Long Island, N. Y., this being the only record from that state (Davis, 1915b). The locust was first probably accidentally introduced near Ridgeway, N. J., and for a year or two only found conditions favorable for a rapid increase, then was kept in check by natural causes until 1914, when the second outbreak occurred at New Lisbon. The name D. longipennis Riley $(1893,255)$ is a synonym of $D$. quercus, having been given to the long-winged form. 
West of the Mississippi D. quercus ranges from Missouri, southern Iowa and southeastern Nebraska southwest to Wașington and Travis counties, Texas. It was from these Texas localities that Bruner $(1887,17$ ) secured his specimens, all nymphs, and therefore not given a scientific name by him, he designating them only as the "Post Oak Locust of Washington Co., Texas." As noted above, Packard copied Bruner's article verbatim under the name "Dendrotettix quercus Riley Ms.," that name having been given the nymphs by Riley but unaccompanied by a description. Of the habits of the locust in Texas Bruner wrote:

"The egg pods are deposited in the ground about the bases of trees or indifferently scattered about the surface among the decaying leaves, etc., like those of all other ground-laying species. The young commence hatching about the middle of March, and continue to appear until into April. After moulting the first time and becoming a little hardened, they immediately climb up the trunks of the trees and bushes of all kinds and commence feeding upon the new and tender foliage. The imago or mature stage is reached by the last of May or during the first part of June.

"The species is very active and shy in all its stages of growth after leaving the egg. The larva and pupa run up the trunks and along the limbs of trees with considerable speed, and in this respect differ considerably from all other species of locusts with which I am acquainted. I am informed that the mature insects are also equally wild and fly like birds. They feed both by day and night; and I am told by those who have passed through the woods after night, when all else was quiet, that the noise produced by the grinding of their jaws was not unlike the greedy feeding of swine."

150. Dexdrotettix scunderi (Morse), 1906, 120. Scudder's Tree Locust.

Male-Slender, subcylindrical. General color grayish-brown; a broad shining black stripe each side extending from eye along the upper half of lateral lobes almost to end of abdomen, this bordered below on prozona with an irregular ivory-white spot; face and dorsum of abdomen dull yellow; hind femora with two broad oblique black bars on both inner and outer faces; knees fuscous; hind tibiæ olive-green, the spines wholly black. Frontal costa slightly narrower and more deeply sulcate than in quercus. Pronotum narrower and slightly longer; metazona less rugose, with median carina higher. Tegmina elongate-oval or sublanceolate, much narrower than in quercus, reaching only to base of third abdominal segment; separated by more than their greatest width, their tips rounded. Prosternal spine stouter, more oblique. Furcula subcylindrical, twice as long as those of quercus, widely divergent, their tips blunt. Female-Larger, more robust. Color above mixed olive-green, fuscous and brown, the inner and outer faces of hind femora dull cherry-red; beneath dull yellow. Occiput less convex, disk of pronotum less constricted, its sides more parallel and metazona more feebly punctate with hind margin more squarely truncate than in females of quercus. Tegmina much narrower, more widely separated. Upper valves of ovipositor with concavity or scoop of 
dorsal surface much longer, their outer margins finely dentate, strongly sinuate. Length of body, $\hat{\delta}, 20$,, 25 ; of pronotum, $\hat{o}, 4.8, \uparrow, 5$; of tegmina, $\hat{o}, 3.5, \uparrow, 4$; of hind femora, $\hat{\sigma}, 11$,, $12 \mathrm{~mm}$.

The above, the first description of the male, is drawn from an unique taken by Davis, July 2, 1919, along the Catamount Trail, at an elevation of about 2,500 feet, near White Sulphur Springs, W. Va. The female described is in the U. S. National Museum collection and was taken by Fox, at a height of 4,000 feet on Sounding Knob, near Monterey, Va. It was found "on stony ground in the shrubby undergrowth of low open woods on the mountain side." Morse's unique type was a female taken on Cheawha Mountain, Ala., July 13, at a height of 2,300 feet, while sweeping grass and shrubbery in the vicinity of Pulpit Rock, near the extreme summit of the mountain. The three specimens mentioned and two males in the Philadelphia collections, taken by R. \& H. near Bald Knob, Bath Co., Va., are all the individuals known of this handsome tree locust. It appears to be a subalpine, forest-loving species, ranging from Virginia to Alabama. Morse first described it (loc. cit.) as Podisma scudderi, then (Psyche, 1907, 57) changed the name to $P$. australis, as the name scudderi had been previously used in Podisma. It has since been found to belong to the genus Dendrotettix, and the original specific name is therefore restored.

VI. Podisma Latreille, 1829, 188. (Gr., "measuring by feet.")

Medium or small, subcylindrical species, having the head little if any longer and but slightly wider than prozona; antennse rarely longer than hind femora; fastigium not strongly widened, but feebly declivent in front of eyes; face subvertical; frontal costa low, not broader, usually much narrower, than the interocular area; eyes rather large, rarely prominent; prozona longer than metazona, sometimes twice as long, smooth or nearly so; median carina low, sometimes obsolete on prozona ; lateral carina usualls wanting; lateral lobes vertical, as long as deep, their lower margin sinuous, its hind angle broadly rounded; tegmina nornally abbreviate, often wanting; prosternal spine short, stout, its tip bluntly rounded; interspace between the mesosterual lobes of male as wide as the lobes themselves, of female nearly twice as wide as long; abdomen compressed, carinate, female, subcylindrical with apex upcurved, male; subgenital plate of male with a distinct tubercle below the upper margin; cerci and furcula variable in the different species; valves of ovipositor narrow, strongly exserted.

Kirby $(1910,533)$ accredits to this genus 31 species, 12 from 
the United States, the others from the Old World. Of its distribution Scudder $(1897,97)$ says: "This genus is more widely extended than any other of the Melanopli, being the only one not confined to America. It is a distinctly boreal type and encircles the globe. The species are largely confined to high altitudes as well as high latitudes, a number being alpine or subalpine in their respective localities. In this country the species are known from two widely separated regions; in the west, the Rocky Mountain region from Alberta to northern New Mexico; and in the east from western Ontario and New York to Maine."

Our eastern species have the tegmina wholly wanting while those found in the western states, with the exception of one, have them present but abbreviated, thus resembling closely many forms of the genus Melanoplus. Two species and one race or variety have been described from our territory.

KEY TO EASTERT SPECIES OF PODISMA.

a. Upper and outer faces of hind femora nearly uniform green, or the upper face faintly banded above; antennæ of male not longer than hind femora; front dorsal margin of thorax slightly but obviously rounded and feebly emarginate at middle.

b. Antennæ distinctly shorter than hind femora, male, nearly threefourths as long, female; upper face of hind femora without darker bars; cerci stouter, not obviously narrower at middle than at apex (Fig. 118, c.)

151. GLACIALIS.

bb. Antennæ about as long, male, or five-sixths as long, female, as hind femora; upper face of hind femora faintly bifasciate with darker green; cerci longer, slightly narrower at middle than at apex or base.

151a. CANADENSIS.

aa. Upper and outer faces of hind femora distinctly bifasciate with fuscous; antennæ of male one-fourth or more longer than hind femora; front dorsal margin of thorax squarely truncate; cerci of male very slender, strongly narrowed at middle. (Fig. 118, d.)

152. VARIEGATA.

151. Podis ma glacialis (Scudder), 1863, 630. Wingless Mountain Locust.

Dark olivaceous green above, greenish-yellow beneath, sparsely clothed with erect hairs; often drying to dull reddish-brown. Head greenish-yellow, the face often with a darker streak, mouth parts paler. Pronotum dark green, the lower third of lateral lobes yellow bordered above by a shining black stripe extending back from eye but fainter on metazona and sides of abdomen, where it is broken to form quadrate blotches or short bars. Inner and lower faces of hind femora in great part coral-red. Hind tibiæ bluish-green, the spines black at tips. Vertex between the eyes as broad, male, or twice as broad, female, as the first antennal joint. Fastigium widened and sulcate, male, or very feebly concave, female, in front of eyes, its sides continuous with those of frontal costa. Face distinctly, not strongly, oblique; frontal costa as broad as interocular space, male, 
much narrower, female, sulcate only below the antennæ, its sides often evanescent below the ocellus. Pronotum short, subcylindrical, its median carina evident but very low, cut by three transverse sulci, male, by only the hind one, female, these sulci deep on the lateral lobes, the front one short; prozona with front margin feebly rounded, slightly emarginate; metazona faintly punctate, its hind margin truncate, very broadly and feebly emarginate. Front and middle femora short and swollen in male; hind ones slender, slightly surpassing abdomen, male, reaching base of ovipositor, female. Supra-anal plate of male long, triangular, acute at tip, its side somewhat sinuous, feebly elevated, its median sulcus deep, entire. Furcula consisting of a pair of slender, cylindrical subparallel projections,

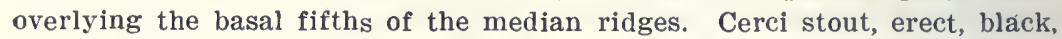
and but feebly tapering above the broad basal third, their tips oblique. Subgenital plate one-half longer than the preceding segment, its upper margin broadly rounded, truncate, but with a slight median notch, the tubercle broad, prominent and borne distinctly below the margin of the plate. Length of body, $\hat{\delta}, 15-17.5, \%, 19-28$; of antennæ, $\hat{\delta}, 8-9.2, \%, 7-9$; of head and pronotum, $\hat{\delta}, 5.5-5.8$, $~, 6.3-7$; of hind femora, $\hat{o}, 9-10.8$, ㅇ, $10-12 \mathrm{~mm}$.

This, the typical form of our eastern Podisma, is mainly a subalpine species, known only on the higher mountains of New England, the Adirondacks and Catskills of New York, and on one or two of the higher peaks of eastern Pennsylvania. It is also recorded by Walker (1915) from Price Edward's Island and St. Fabien, Quebec. Scudder (1898c, 12) says: "More than 35 years ago, as I used to climb the footpath to Mt. Washington from the Peabody Valley, one of the first creatures to meet my eye as I emerged above the forest at the Ledge would be this wingless grasshopper, then first found in the clumps of dwarf birch, Betula nana $\mathrm{L}$. Since then I have taken it many times at various points in the lower or subalpine portion of the barren summits of the Great Range, and it has also elsewhere been taken below the forest line." Morse (189S, 273) says that most of his specimens "were found on or among the various species of Vaccinium characteristic of the mountain tops and on Mt. Ascutney among dwarf cornel. It is a somewhat sluggish insect, relying chiefly for protection upon the similarity of its dark olive-green coloring to that of the surrounding vegetation, though on warm days the males become fairly active."

151a. Popisma glacialis canadexsis E. M. Walker, 1903, 300. Northern Wingless Locust.

Differs from glacialis mainly by the characters given in key. Color nearly the same, the inner and lower faces of hind femora often yellow instead of coral-red. Eyes of male slightly more prominent, the interocular space and fastigium in front of eyes slightly wider. Cercl of male about half as broad at middle as at base. Length of body, $\hat{\delta}, 15-18, q, 20-$ 
25.2 ; of antennæ, $\hat{\delta}, 8-10$, $\uparrow, 9-10.5$; of head and pronotum, $\hat{o}, 4.8-$ 5.8 , ㅇ, $6-7$; of hind femora, ô, 8.4-10.3, ㅇ, $10.2-12.6 \mathrm{~mm}$.

North Bay and Algonquin Park, Ont., Aug. 14-Sept. 12 (Walker). A northern race of glacialis, taken by Walker at the localities mentioned and at Ft. William and the Temagami District, Ont. Known also from the Porcupine Mts., Keweenaw Bay and Dickinson Co., Mich. Walker found them in both dry and moist situations in open woods on bushes, chiefly the beaked hazel, Corylus rostrata Ait. and the red raspberry, also on spruce. Hebard took them at Keweenaw Bay by beating similar bushes in August and early September, and states that the males are active jumpers, quickly on the alert, but trusting to their very protective coloration they would not move till almost touched by the net. "The females," he says, "were a clear dull grass-green, the exact shade of the cloth of a billiard table, the males deep emerald green, appearing almost translucent, the back purplishbrown with a median chain of cream-colored marks.".

Walker considers canadensis an intermediate form or race connecting $P$. glacialis with $P$. variegata, but the great length of antennæ in the males of variegata, taken in connection with the other structural and color differences as given in key and description, leads me to place that as a distinct species.

152. Ponisma variegata Scudder, 1897, 101. Variegated Wingless Locust.

Form and size of $P$. glacialis. General color chocolate-brown with an olivaceous or greenish tinge. Male (of dried specimens) with face, a broad pronotal median stripe narrowing and extending back along dorsal surface of abdomen, lower halves of pronotal lateral lobes, two cross-bars on dorsal face and a subapical annulus of hind femora, cream white or dull clay-yellow. Antennæ pale brown, dusky at tip. Lower face of hind femora pale red. Hind tibiæ olive-green, the spines black with a pale base. Abdomen clay-yellow. Female duller, lacking the pale dorsal stripe, the face in part brown, the lower face of hind femora clay-yellow. Eyes more prominent in male, with interocular space obviously wider than in glacialis. Antennæ of both sexes much longer and more slender than there. Pronotum slightly wider with metazona more evidently expanded, its hind margin squarely truncate. Hind femora longer and more slender than in glacialis, their tips distinctly surpassing the abdomen in male. Furcula slightly shorter and more tapering. Cerci of male longer, much more slender, dark brown, not black, the apex feebly widened and rounded, not oblique as in glacialis; those of female much more slender, with narrower base and more strongly tapering. Supra-anal plate of female shorter, with apex deflexed instead of horizontal as in glacialis. Subgeni. tal plate of male with upper margin more broadly and deeply notched above the tubercle than there. Length of body, of, 16.5-20, $\$, 21-26.5$; of antennæ, $\delta, 10-12$, $ᄋ, 9-11.5$; of head and pronotum, $\hat{o}, 5.3-6.3$, , $6.5-7.8$; of hind femora, $\hat{o}, 9.5-10.5$,,, $12-13.5 \mathrm{~mm}$. 
DeGrassi Point and Guilford, Ont., Sept. 9-Oct. 21 (Walker). Scudder's types were from Ithaca and Enfield Falls, N. Y., and the known range of the species extends from the Ontario stations mentioned south to the mountains of North Carolina, near Balsam and Pineola, where specimens were taken by Morse who says (1904, 41): "This locust seems to be rather widely distributed in the higher parts of the North Carolina mountains, inhabiting shrubby undergrowth and thickets of weeds and bushes throughout the mountains. It is a sluggish and secretive species, and but few examples were observed at any one point." At DeGrassi Point Walker found them in swampy ground, where the vegetation was of a boreal character. . In such places they were found on bushes and the branches and trunks of the Arbor-vita, sometimes eight or ten feet above the ground. Rehn $(1900,631)$ says that in Pennsylvania they usually occur on the branches of hemlock, and wherever taken have been in the vicinity of that tree. Vestal (1914, 107) has recorded it from near Douglas Lake, Mich., from specimens identified by Caudell.

Scudder in his key to the species of Podisma $(1897,97)$ used the form of the cerci and the color of hind femora as the principal characters in separating this species from glacialis. Walker $(1903,298)$ has endeavored to show that his race canadensis is a connecting link between glacialis and variegata, and has used the slight variation in form of cerei and color of hind femora in canadensis as his principal evidence. Admitting that in canadensis the cerci are more slender, the upper face of hind femora faintly barred and the antennæ slightly longer than in typical glacialis; the much greater length of antennæ, different general hue, strongly fasciate hind femora, squarely truncate front and hind margins of pronotum, longer hind femora of male and distinctly more slender cerci in both sexes of variegata present a combination of characters which, taken in connection with its range and habitat, lead me to regard it as more than an "incipient species" or race of glacialis, and I have therefore retained it as Scudder placed itas a distinct and valid species.

VII. Aptenopedes Scudder, 1877a, 83. (Gr., "unfledged" + "to leap.")

Slender-bodied, small or medium sized species, having the face strongly oblique, occiput and vertex horizontal; fastigium in front of eyes widened and subvertical; eyes large, elongate-oval, rather prominent with the interocular area as narrow as the apex of frontal costa, male, depressed, tapering above and with interocular 
space wider than the costa, female; antennæ slender, with joints somewhat flattened, about as long as, female, or slightly longer than, male, the head and pronotum together; frontal costa narrow, deeply sulcate, its margins usually parallel; disk of pronotum rugulose-punctate throughout, distinctly widening from apex to base and strongly tectiform, female, widening only on the metazona, male; median carina low, cut only by the principal sulcus; lateral carina wanting; prozona more than twice as long as metazona, its front margin usually feebly rounded; metazona with hind margin sub-truncate or broadly, feebly emarginate; lateral lobes subvertical, nearly twice as long as deep, narrowing downward, front margin strougly oblique, lower one sinuous, its hind angle broadly rounded; tegmina linear, about as long as pronotum or absent; prosternal spine slender, cylindrical, its apex blunt; inner margin of mesosternal lobes broadly convex, their interspace nearly linear, male, or less than half their width, female; hind femora slender, reaching base of ovipositor, female, slightly surpassing abdomen, male; abdomen compressed and strongly carinate, female, subcylindrical, usually nearly horizontal and with apex but little enlarged, male; supra-anal plate of male rather short, triangular or suboral, its margins reflexed and with a short basal median groove; subgenital plate rery short, its apical margin low, not tuberculate.

A genus confined to the South Atlantic States, where it is represented by two species and one geographic race.

KEY TO SPECIES OF APTENOPEDES.

a. Tegmina present as elongate linear pads; margins of frontal costa converging above the antennæ and uniting at the lower margin of the convex fastigium.

b. Cerci of male substyliform, nearly straight, tapering rapidly from base to middle (Fig. 118,e); shorter than supra-anal plate, the latter elongate-triangular, its sides subparallel and apex acute.

153. SPHENARIOIDES.

$b b$. Cerci of male with apical half falcate, bent inward, as long as or slightly longer than the supra-anal plate, the latter broadly oval, its sides curved and apex obtusely rounded. 153a. CLARA.

aa. Tegmina wholly wanting; margins of frontal costa feebly converging above the antennæ, not uniting but continued separately to the crest of the strongly flattened fastigium.

154. APTERA.

153. Aptexopedes sphexarioides, Scudder, 1877a, 84. Linear-winged Locust.

Male slender, subcylindrical; female much larger, strongly compressed. General color green, or (more often in female) sometimes a purplishbrown. Head and face usually flecked with fuscous dots; antennæ reddish-yellow, their tips dusky. Pronotum with a narrow pale yellow stripe each side along its dorsal margins, this extending forward along the ob- 
lique hind margin of eye and backward along the upper edge of the otherwise black tegmina. Outer face of hind femora green, male, or brown, more or less infuscate, female, inner and lower faces dull yellow; hind tibiæ dull bluish-green, the spines tipped with black. Abdomen of male usually with a dorsal median yellowish stripe, banded below each side witl a blackish-fuscous one; under surface, fore and middle femora and all the tarsi, dull yellow. Vertex of male with margins raised and meeting in a point, thus forming a triangular concavity between the eyes, in front of which it is extremely narrowed; of female with disk almost flat, the margin scarcely elevated, the apex more than twice as wide as in the male. Furcula short but distinct, widely separated, (not subattingent as stated by Scudder) cylindrical, lying on the sides of the basal median ridges. Cerci and other structural characters as described above and in key. Length of body, $\hat{o}, 16-21$, ㅇ, 22-28; of antennæ, $\hat{o}$ and $q, 7-8$; of teg. mina, $\hat{\delta}, 3$, ㅇ, , 4; of hind femora, ㅅ, 10, 우, 11-12 mm.

Ormond, Sanford, Hastings, Lakeland and Dunedin, Fla., August-March (W. S. B.). My first specimens of this peculiar and easily identified species were taken, at Ormond, March 7, 1899, and were noted $(1902,34)$ as follows: "On a patch of gieen weeds in an old orange orchard I found a pair of wingless, bright green locusts, the tegmina being represented only by narrow, oblong, whitish-yellow scales. They leap clumsily when disturbed. On a dead clump of grass in a neighboring field I took a brown female of the same species, so that it, like many other Acridians, secks a place of hiding with which it agrees in color. There, as long as motionless, it is quite secure from the eyes of those birds and reptiles which are ever on the search for a juicy locust." About Dunedin A. sphenarioides is frequent in both nymph and adult stages throughout the fall and winter months, occurring especially on wire-grass, dwarf huckleberry bushes and other low regetation along the pathways, roadways, ditches and streams of open pine woods. It occurs on Hog Island, where the males are intermediate between the typical form and the race clara. When flushed the males are much the more active, often leaping several feet and alighting on some supporting stem or shrub, a foot or more above the ground, where they can watch to better adrantage the approaching intruder, while the heavier bodied females usually attempt to burrow after a short leap or two. Scudder's types were from Ft. Reed and Jacksonville, and it has been recorded many times from all parts of the State east of DeFuniak Springs, the form taken sonth of Lakeland and Tampa being mostly of the race clara.

The known range of A. sphcnarioides is confined to Florida and the southern third of Georgia. The A. rufovittata of Scud. der $(1877 a, 85)$ has been shown by Davis $(1915,98)$ to have been 
based on males of aptera and immature females of sphenarioides, and hence falls as a synonym under those two species.

153a. Aptexopedes sphexarioides clara Rehn, 1902, 14.

Usually somewhat longer than typical sphenarioides, and agreeing with that form in color and structural characters except in the male genital organs, which differ as described in key. The furcula in typical clara, are short, broad, depressed lobes, sometimes so short as to be almost or wholly obsolete. Supra-anal plate shorter and wider with apex more bluntly rounded. "Cerci more elongate, basal half tapering, apical half decurved, falcate, bent inward, displaying a very marked internal shoul-

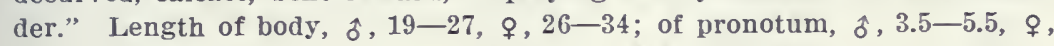
$5-7$; of tegmina, $\hat{o}, 3-5.5$, $\uparrow, 4.7-6.8$; of hind femora, $\hat{o}, 11-15$, $q$, $13-17 \mathrm{~mm}$.

Biscayne Bay, Miami, Ft. Myers, Sarasota, Tampa, Key West and Dunedin, Fla., August-April (W. S. B.). This so-called race occurs in the southern half of peninsular Florida, and is so close to the typical form that it is scarcely worthy of a varietal name. About Lakeland, Dunedin and Sarasota the two forms intergrade, the cerci being slightly shorter than in typical elara, with tips bent inward but without the "shoulder" above mentioned, the supra-anal plate intermediate in width and the furcula in form and length. The females are absolutely inseparable from those of typical sphenarioides, though usually a little larger. Its habits and haunts are essentially the same, though it more often occurs closer to the coast. It has been recorded from numerous localities in sonth Florida, including the southern Keys, Rehn's types being from Miami. R. \& H. (1914d, 109) state that the eridence, based on specimens from Lakeland, strongly indicates that clara is but a geographic race of sphenarioides, and Hebard $(1915 \mathrm{~b}, 40 \tau)$ has so placed it.

154. Aptexopedes APTERA Scudder, 1877a, 86. Wingless Florida Locust.

Female larger and more robust than in sphenarioides; males much smaller and more slender than females. Males in life green with a broad pinkish-red stripe along each side of pronotal disk, and a narrower paler reddish-yellow one along dorsal surface of abdomen; disk of pronotum and upper sides of abdomen chocolate-brown; antennæ dull green more or less dusky; hind tibiæ blue; hind tarsi pink, the claws black-tipped. Female either nearly uniform green or pale brown, the abdomen usually with a narrow median dorsal reddish-yellow stripe, the sides flecked with small scattered yellowish spots; hind tibiæ pale blue, tarsi as in male; all the colors fading much in drying. Head larger and broader than in sphenarioides; vertex in female narrower between the eyes; fastigium much more strongly flattened in front of them, the margins of frontal costa reaching its crest. Pronotum, especially that of female, much more strongly rugowe with sides of disk more tectiform, its front margin more produced for- 
ward being broadly obtuse-angulate in both sexes. First two or three abdominal segments strongly rugose-punctate. Supra-anal plate of male triangular, with sides subparallel on basal half, sinuous and converging toward the obtuse-angled apex; its surface with a median sulcus on basal half and another on apical third; furcula very short, narrow, strongly diverging flattened lobes. Cerci much as in typical sphenarioides, their apl. cal halves more acute. Length of body, of, 16-21, ㅇ, 25-33; of antennæ, $\hat{\delta}, 7.5-9.5$,, $6.5-8.5$; of pronotum, $\hat{\delta}, 3.8-4.5$, $९, 6-7.5$; of hind femora, $\delta$, 8.5-12, ᄋ, $11-15 \mathrm{~mm}$.

Ormond, Eustis, Lakeland and Dunedin, Fla., Dec. 11-April 6 (W.S. B.). The males of this wingless Acridian, with their pink margined pronotal disk, bright blue hind tibia and pink tarsi are in life among the most handsome of Florida locusts. They are much more scarce than the females and about Dunedin have mostly been taken by beating the foliage of a tall scurfy Ericad, Xolisma ferruginea Walt., which grows in clumps in very dry, sandy localities. The females occur on the same shrub, but more frequently on a much lower one, Xolisma fruticosa Michx, and on or among low huckleberries and other Ericads in open pine woods. Not more than three males and a dozen mature females have been taken in any one winter, though the nymphs are quite frequent from February to April. The species was described from Fort Reed, Fla., and has been recorded by other collectors from numerous localities throughout that State, and from some of the southern keys, but is usually everywhere much less common than sphenarioides. Davis $(1914,196)$ says: "This species is actire at night and it is no uncommon sight to see several of the grasshoppers devouring the leaves of the scrub palmetto, in which they make half-moon shaped cuts ; eating down to the midrib."

The known range of $A$. aptera is practically the same as that of sphenarioides, extending, according to R.\& H., "from Jesup and Homerville, Ga., southward over peninsular Florida and on Big Pine Key." As already noted, the males of A. rufovittata Scudder, are to be referred to this species.

VIIT. Paratylotropida Scudder, ${ }^{53}$ 1897, 117. (Gr., "beside" + "keel.")

Rather stout, somewhat compressed species, having the head large, protuberant, not broader than pronotum; face moderately oblique; vertex broadly arched, not elevated; fastigium very broad, swollen, feebly declivent, its apex rounded; eyes oval, one-half longer than broad; antenna slender, as long as, female, or longer,

\footnotetext{
${ }^{3}$ Brunner ( 1893,147 ) characterized and named this genus, basing it on the then undescribed species $P$. brunnea Scudd. which he did not name. Scudder was therefore the first to validate the genus by ascribing to it a fixed species.
} 
male, than head and pronotum together. Pronotum with both median and lateral carinæ, the latter straight in our eastern species, becoming obsolete near hind margin which is broadly obtuse-angulate; prosternal spine rather slender, pyramidal with rounded apex; interspace between the mesosternal lobes much longer than broad in both sexes; tegmina as described in generic key, narrowly separated or slightly orer-lapping; hind femora vers long; subgenital plate of male without apical tubercle; $a b-$ domen of female tapering, valves of ovipositor slender, strongly exserted, their lateral edges sinuous, without teeth.

Two species are known, one, $P$. brunneri Scudder $(1897,118)$, ranging from Dakota and Arkansas to Texas, the other known as ret only from North Carolina.

155. Paratylotropidia BeUtexyuelleri Morse, 1907a, 14. Beutenmüller's Locust.

"Reddish-brown above, the abdomen varied with yellow. Under surface, sides of head, pronotum and metepisterna dull yellow; hind tibia deep red, the spines tipped with black. Facial costa rather deeply sulcate, narrowed above at meeting with vertex; the latter subacute in profile, flat above, its front margins angulate over shallow foveolæ open below to the antennal fossæ. Pronotum evenly tectiform above, the sides plane, meeting dorsum at an angle less pronounced behind. Lateral lobes smooth above, longitudinally rugulose below on prozona, coarsely punctate on metazona, flavescent save for a narrow fuscous border below lateral carinæ. Metepisterna with distinct rugæ. Tegmina, short, nearly as broad as long, truncate, apex broadly rounded, dorsal field broad, scarcely angulate with the lateral one. Hind femora of moderate size. olivaceous, rufo-flavescent above. Cerci small, triangular, one and one-third times as long as broad, acutely pointed. Abdomen keeled above. Length of body, $\$, 27.5$; of hind femora, 13.6; of prozona, 4; metazona, 3 ; of tegmina, $5 \mathrm{~mm}$. Width of metazona, 5; of tegmina, $4 \mathrm{~mm}$." (Morse.)

The above is the original description, omitting the points covered under the generic diagnosis. It is so far known onls from three females taken by Beutenmüller near Black Mountain, $\mathbf{N}$. Car., Aug. 30, 1906, and July, 1912, one being in the Davis collection and another in that of the American Museum.

\section{Paroxya Scudder, 1877b, 28. (Gr., "near" + "sharp.")}

Medium sized, subcrlindrical species, having the head moderately large; face distinctly not strongly oblique; eres large, prominent, more than half as long again as the cheek beneath them; rertex strongly narrowed between the eres, the narrowest portion about three-fourths the width of frontal costa, male, as broad as costa between the antennæ, female; fastigium widened and with a broad lengthwise sulcus in front of eyes, male, or shallow angu- 
late concavity, female; foveolæ present as small rounded or oval pits ; frontal costa prominent but scarcely sulcate above the ocellus, less convex and more strongly sulcate below it; antennx of male usually half or more the length of body; disk of pronotum as in generic key, the surface flat or nearly so; median carina low, of equal height throughout, usually cut only by the last transverse sulcus; prozona one-third to one-half as long again as metazona, the latter with surface finely and densely punctate, its hind margin obtusely angulate or bluntly rounded; lateral lobes vertical, longer than deep, the lower margin with its front half strongly ascending; tegmina and wings variable in length, but in our species always much longer than the pronotum; hind femora of arerage stoutness, equalling or more usually surpassing the tip of abdomen; subgenital plate of male short, of subequal width throughout; valves of ovipositor strongly exserted, the edges of upper ones crenate, of lower ones smooth.

Kirby $(1910,505)$ recognizes seven species, some of which are synonyms. Two species and two varieties or races occur in our territory. The genus is very close to Melanoplus and seems to be connected with it by the variety $P$. a. paroxyoides Scudd. However, the species have a facies which is easily recognizable after a slight acquaintance, this being due largely to the slender, straight, parallel form.

KEY TO EASTERN FORMS OF PAROXYA.

a. Body shorter, of female rarely over $28 \mathrm{~mm}$; antennæ of male shorter than hind femora; tegmina at least as long as abdomen, male, often slightly shorter, female.

$b$. Inner upper face of hind femora nearly uniform in color, not or indistinctly barred with fuscous; form more slender, typical of the genus.

156. ATLANTICA.

$b b$. Inner upper face of hind femora with three fuscous bars and outer face often trifasciate with pale and dark bars (Fig. 122); form stouter, much resembling that of Melanoplus.

156a. PAROXYOIDES.

aa. Body longer, of female usually 30 or more mm.; antennæ of male longer than hind femora; tegmina variable in length.

c. Tegmina normally as long as abdomen, male, often slightly shorter, female; furcula relatively slender, subcylindrical, their inner margins not attingent; cerci of male with tips broadly rounded; sides of apical margins of subgenital plate not elevated.

157. CLAVULIGER.

cc. Tegmina covering at most two-thirds of abdomen; furcula stouter, more depressed, their basal halves attingent (Pl. IV. $t$ ); cerci with tips subtruncate, feebly emarginate; sides of apical margins of subgenital plate elevated and somewhat flaring.

157a. 1100sIERI. 
156. Paroxya Atlantica Scudder, 1877b, 29. Atlantic Locust.

Size small for the genus, the sexes more equal in size than in the other species. Metazona, tegmina and upper and outer faces of all the femora of male a uniform light wood-brown, occiput and prozona darker. A broad black stripe extends from the eye along the upper half of the latəral lobes of pronotum as far as the posterior transverse sulcus, where it merges gradually into the paler brown, this black stripe bordered below by one of ivory white, brightest on the head, and often flecked with fus. cous dots; metapleura also ivory white. Face grayish-olive, flecked or tinged with yellowish; basal two-thirds of antennæ the color of tegmina, apical third usually darker. Palpi and prosternal spine yellow. Sternites of thorax olive brown; those of abdomen yellow, as are also the lower faces of all the femora. Hind tibiæ dull pale green (basal third sometimes light brown), with a black spot at knee; the spines with their apical thirds black. Female darker, discoidal area of tegmina sometimes obscurely and sparingly flecked with fuscous, the yellow of under side dull or wanting. Prozona one-third longer than metazona, the latter with hind margins ob-

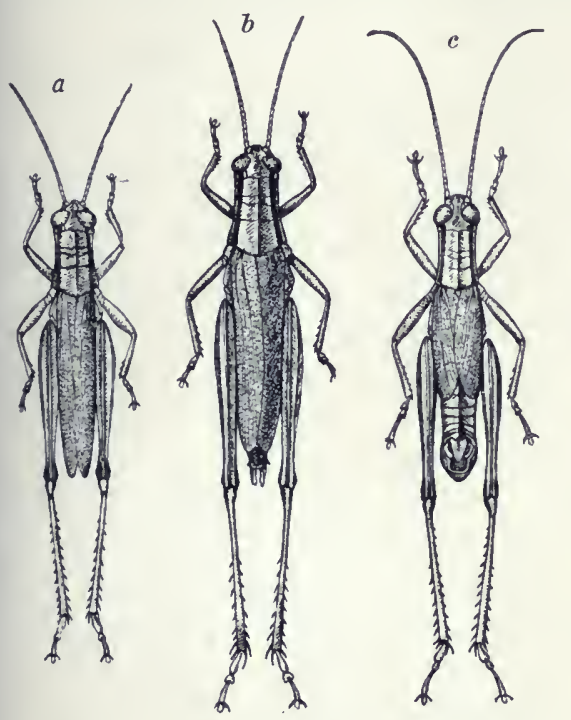

Fig. I21. a, Paroxya atlantica Scudd., male; $b$, female; $c$, P. clavuliger hoosieri (Blatch.), male. All X 1.3 (Original.) tuse-angulate. Supra-anal plate of male very short, triangular, with a short basal triangular sulcus, in which rest the furcula; these consisting, in northern individuals (scudderi Blatch.), of a pair of flattish, oblong plates with their inner edges parallel and tips rounded; in the southern ones (typical atlantica) they are subtriangular with the tips narrow and feebly diverging. Cerci long, slender, strongly incurved, narrowed at middle, the basal half stouter, apical third flattened, feebly concave and carinate on outer face, rounded at tip. Other structural characters as given 'above. Length of body, $\hat{\delta}, 16-24$, ㅇ, 22-28; of antennæ, $\hat{o}$ and $\uparrow, 8.5-12$; of pronotum, $\hat{\delta}, 4.2-5.8$, 오 $5.5-6$; of tegmina, $\hat{\delta}, 12-18$, १, 14.5-18; of hind femora, ô, 11-14, ㅇ, 13-16 mm. (Fig. 121, $a, b$. )

In Indiana this graceful-bodied species was first found in small numbers on July 27, about the grassy margins of a pond in the sand dune region north of Millers, Lake County, and within one-half a mile of the shore of Lake Michigan. On the following day a single pair were taken from a similar locality near Tolleston, in the same county, and about four miles from the lake, 
but still within the sand covered area. It was usually found clinging to the stems of the tall rushes and grasses common in such locations, and when disturbed the males used the wings in a noiseless flight, while the females depended upon their leaping powers to escape. When closely followed, they would attempt to hide by burrowing in the fallen grass. A single male was afterward taken from low ground along a railway southeast of Hammond, and on August 20th it was found in numbers in the tall grasses along a lobe of Bass Lake, Starke County.

Some of the first specimens taken were sent to Scudder who, basing his opinion largely on the form of the furcula, stated that they represented an undeseribed species allied to atlantica, but of smaller size and with longer cerci. Not having specimens of atlantica at hand for comparison, I described them $(1898,59)$ as Paroxya scudderi. R. \& H. $(1916,249)$ have shown that the Indiana specimens represent only a smaller incipient northern race of atlantica. With a large series of Florida atlantica for comparison, I agree with their opinion, though a number of characters other than the shape of furcula separate the northern and southern forms; the hind margin of metazona being less produced and more broadly angulate and the valves of ovipositor having longer, more slender points in the Indiana than in Florida specimens.

In Florida I have found $P$. atlantica to be a common locust between Nov.1 and April 15, it having been collected by me at all stations except Cape Sable and Key West. It occurs for the most part among grasses and sedges along the borders of inland lakes, ponds and streams and the bays and lagoons of the coast. On Hog Island, opposite Dunedin, several females have been taken having the face, disk and lower sides of pronotum and upper and lower faces of hind femora a bright purplish-red. Elsewhere in Florida it has been recorded from many places by other collectors, and doubtless occurs in numbers in both adult and nymph stages in all parts of the State throughout the year.

The known range of $P$. atlantica is mainly confined to the Atlantic coastwise states, extending from Jamesburg and Lakehurst, N. J., south and west at least as far as the sonthern extremity of Florida, Mobile, Ala., and Biloxi and Gulfport, Miss. Inland it is known only from Northern Indiana and Illinois. Morse $(1907,53)$ says it is "common in the piney woods of the Gulf Strip of the Coastal Plain, especially in grassy places among the inkberry shrubbery, Ilex glabra I., and also in swampy spots and sometimes in the salt marshes." In New Jersey Fox (1914) says it is "a characteristic species of the sphagnum bogs, fre- 
quenting especialls the areas of chain-fern, Woodwardia virginica L."

156a. Paroxya atlantica Paroxyoides (Scudder), 1897b, 28.

A rather robust form of medium size, separated from typical atlantica mainly by the characters given in the key. Form somewhat heavier. Tegmina shorter, those of female rarely reaching base of ovipositor, more often feebly maculate with small fuscous spots along the discoidal area. Hind femora slightly more robust. Hind tibiæ more distinctly glaucous or bluish-green, with a pale subapical annulus. Cerci of male longer, more slender, their apical thirds roundly spatulate. Otherwise as in typical atlantica. Length of body, ô, 18.1-20, ㅇ, 27-28; of antennæ, $\hat{o}$ and

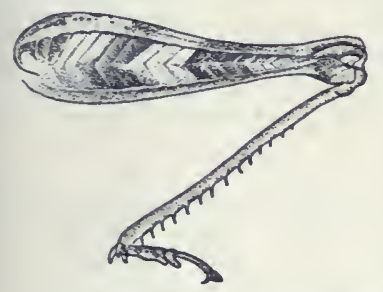

Fig. 122. Hind femur of male of $P$. a. paroxyoides, showing fuscous markin
3. (After R. \& H.) oplus paroxyoides, his types being from Key West and Tallahassee. R. \& H. (1912) first placed it as a race of atlantica, their specimens being from several of the southern keys and taken in the heary jungle-like tangled growth, as well as among the low regetation of the bare coquina rocks. In their opinion it is confined to the keys of South Florida, but a male at hand was taken at Ft. Mrers, March 12.

157. Paroxya clavuliger (Serville), 1839, 676. Olive-green Swamp

\section{Locust.}

Size large for the genus, the males usually much the more slender. Under surface, abdomen and femora olivaceous-green; occiput, disk of pronotum and tegmina uniform pale to dark brown. Face, lower sides of pronotum and pleura creamy-white, sometimes dull yellow in female. The usual shining black bar extends back from eyes to metazona, there merging into the brown. Antennæ fuscous-brown, the front margins of segments paler. Hind femora with outer face often infuscate, their knees and the claws and arolia of tarsi black. Hind tibiæ bluish-green with black spines. Vertex and frontal costa much as in atlantica. the foreolæ of the former more distinct. Pronotum with hind margin obtuse, often broadly rounded, and median carina sometimes feebly cut by all three sulci. Supra-anal plate of male long, triangular with a broad median rounded ridge extending two-thirds its length, on the summit of which, in the basal half of the plate, is a narrow, deep sulcus, this after interruption is again visible along the apical fourth; furcula as described in key. Cerci long. 
slender, incurved, narrowed at middle, the apical fourth flattened and con. cave without (Pl. IV. $t$.) Subgenital plate of male with apex subtruncate, the lateral margins low. Length of body, $\hat{\sigma}, 20-32$, $9,28-44$; of antennæ, $\hat{\delta}, 13-19$, ․, $9-15$; of pronotum, $\hat{o}, 4.5-6.7$, 우 $6-8.5$; of tegmina, $\hat{\delta}, 12-22$, $ᄋ, 16-28$; of hind femora, $\hat{\delta}, 12-16.5$, $९, 16-22 \mathrm{~mm}$.

Boston, Mass., Aug. 11 (Morse) ; Gainesville, Fla., Sept. 20Oct. 24 (Fattig) ; Sanford, Lake Okeechobee and Dunedin, Fla., Dec. 11-Apr. 4 (W. S. B.). In Florida I lave found this species in winter much less common than atlantica, not more than half a dozen being found at any one locality. There its habits and haunts are essentially the same as those of atlanticu. At other seasons it appear's to be more abundant, having been recorded from numerous stations as common, especially in the typical saw-grass of the everglades and among tall grasses growing near sink-holes and damp places in the pine woods.

The known range of typical clavuliger is much more extensive than that of the other speeies of Paroxya, but is mainly submaritime, extending from Arner, Ontario, and southern New England to southern Florida, Louisiana and Dallas, Texas. From most of its known stations it has been recorded under the name Paroxya floridana Thos., which R. \& H. $(1916,251)$ have shown to be a synonym. For a number of years it was confused with $P$. atlantica, and was often mentioned or recorded under that name. In New England Morse $(1898,296)$ says: "It oceurs locally in swamps and marshes, especially on cord-grass (Spartina) growing in the tide-water ditches of salt meadows and in the long sedge of bushy inland meadows and swamps. While active and alert it is readily captured, owing to its habit of trying to escape observation by getting out of sight behind the stouter stems of grass and weeds rather than by flight, to which it resorts only when alarmed. It leaps well and quickly but its flight is comparatively short." He has described (1893a) a melanistic form from near Cambridge, Mass., the males being "deep-greenish-black with a peculiar oily lustre."

In Virginia Fox (1917) records clumuligcr as "abundant in the tidal marshes of the Coastal Plain, frequenting the dense growths of Scirpus americamus Pers. and Spartina cynosuroides L., but not present in true salt marsh dominated by Spartina glabra Muhl. It also occurs inland in bogs and wet meadows overgrown with cat-tails, dense grasses, and other rank herbage. At Jarman Gap in the Blue Ridge the species was found in a small boggy spot near the head of a stream quite close to the summit." 
157a. Paroxya Clavuliger hoosieri (Blatchley), 1892a, 31. Hoosier Locust.

Size and form of $P$. clavuliger. The living males have the antennæ, pale reddish-brown, infuscated at tip, the apical sixth of each segment yellowish; face green, clypeus and mouth-parts yellow; rertex, disk of pronotum and tegmina, plain olive-brown, immaculate. Lower half of pronotal lateral lobes greenish-yellow, upper half with a broad, shining black stripe reaching from eye to hind margin. Under side of abdomen pale yellow; metapleura yellow, its hind margin black. Femora green, knees black; hind tibiæ greenish, yellowish-brown at base, with black spines. Females duller, the disk of pronotum and tegmina sometimes with minute fuscous spots, the black stripes of pronotum reaching only to metazona; abdomen with a black stripe each side, above which are numerous small black blotches. Foveolæ almost twice as long as wide, more distinct in female. Tegmina oblong, reaching to middle of abdomen and slightly overlapping on median dorsal line, the wings but little shorter. Supraanal plate of male as in clavuliger but somewhat shorter; furcula consisting of a pair of oblong, feebly convex adjacent plates, their inner edges so abruptly narrowed near middle as to form a blunt tooth, thence feebly tapering and diverging to the obtuse tips. Length of body, $\hat{\delta}, 20-22$, $q$, $29-34$; of antennæ, $\hat{\delta}, 12-15$, ㅇ, $11-13$; of pronotum, $\hat{\delta}, 5-6$, ㅇ, 6-7; of tegmina, $\delta, 9-10$,, , 11-13; of hind femora, $\delta, 12-14$, $ᄋ, 16-18 \mathrm{~mm}$. (Fig. 121, c.)

This handsome locust was first noted in Indiana about the margins of the "Goose Pond," Vigo Co., on October 11, 1891. It at once attracted attention on account of the length of the male antennæ, and the black stripes on the sides of the abdomen of the female. The pond was then almost dry, and the dense growth of sedges and rushes which had filled its shallow margins, were, in some places, burned away. Over the burned spots had sprung up a dense green regetation, and here this Paroxya flourished in company with Truxalis brevicornis and Dichromorpha viridis, while a few feet away Leptysma marginicollis found a suitable home aniong the rushes and sedges still standing. Both sexes of $P$. hoosieri were very active. leaping vigorously when approached, and difficult to capture except by throwing the net over them as they rested on the ground. On October 27th, the spot was again visited, and, although several heavy frosts had occurred, the species was still fairly common. At this time, however, they were all found in the small patches of grass which grew among the fallen leaves a few yards from the edges of the pond proper.

Since then the locust has been found to be rather common in the western and northern portions of the State, where it occurs about the borders of marshes, especially those bordering lakes and tamarack bogs. In Gibson Co. it was found mature on July 
10. Outside of Indiana $P$. hoosieri has been recorded only from near Oberlin, Ohio, where J)r. Lynds Jones found it "in abundance in the rank vegetation which sprang up in a dry swamp surrounded by woods," and from Milneburg, La., where Morse $(1907,54)$ captured a male at the edge of a swamp, which measured $26 \mathrm{~mm}$. in length of body, its antennx being 17 and tegmina $12 \mathrm{~mm}$. in length.

On one occasion I found a female of this species and also one of Chlocaltis conspersa Harr., a few inches apart on the stump of a downy poplar, Populus heterophylla $\mathrm{L}_{\text {., }}$ each with the abdomen buried to the full length in the soft wood, but no eggs could be discovered. Nothing has been recorded concerning the habits of oviposition of the members of the genus Paroxya, and it would be surprising if they, like the Chlocaltis mentioned, should seek wood rather than earth as the receptive matrix for the eggs.

$P$. hoosieri is closely related to $P$. clavuliger (Serv.), so close indeed, that after describing it I. recorded it $(1894,244)$ as a shortwinged form of $P$. atlantica, specimens of elavuliger having been sent me under the name of atlantica by Morse and Scudder. The differences in the abdominal appendages of male as set forth in key and description appear, howerer, to be constant, and it is therefore here retained as a northern or inland race of elavuliger.

X. Photchliotes Scudder, 1897a, 202. (Gr., "a roamer.")

Elongate, rather slender species, having the body feebly compressed; head large, prominent, nearly half as long again as prozona; vertex prominent, the narrowest portion one and one-lialf times as wide as frontal costa; fastigium declivent and with a broad median furrow or depression ; frontal costa with lower half much wider than upper, not sulcate but concave around the ocellus; antenna about three-fourths the length of hind femora; pronotum enlarged a little in front to receive the head; disk with sides feebly sloping, hind margin broadly obtuse-angled; median carina rather sharp, of equal height throughout; lateral lobes with lower margin obtuse-angled near middle; tegmina either abbreviate and a little longer than pronotum, broadly lanceolate. with inner margins sometimes attingent about the middle, but often well separated, or fully developed and surpassing the hind femora in both sexes; hind femora slender, surpassing the tip of abdomen, male, a little shorter, female.

This genus is closely related to Melanoplus, but is distinguished by its large head, feebly flaring prozona and substyliform cerci. One species, widely distributed west of the Mississippi and occasionally found east of that stream, is known. 
158. PHetaliotes xebrascexsis (Thomas), 1872, 455. Large-headed Locust.

General color olive-green, more or less marked with fuscous. Face olive-green, darker above. Antennæ reddish, dusky toward tips. A broad blackish band back of eye extends along side of pronotum to posterior transverse sulcus; disk of pronotum and tegmina wood brown. Abdomen of male with sides greenish, the posterior third of each segment fuscous; in female the fuscous predominates. Front and middle femora reddish. yellow; hind femora greenish tinged with reddish-brown, lower face reddish-yellow, knees black. Hind tibiæ dull green, the spines black. Under surface greenish-yellow. Male with abdomen compressed, carinate above, its apical fourth thickened and curved upward; cerci depressed, styliform; supra-anal plate short, broad, triangular, its apex obtuse, median basal ridges widely separated and at middle of plate sending off a spur at right angles towards the sides; furcula minute, subtriangular, widely separated (Fl. IV. s.) Other structural characters as given under generic heading. Length of body, $\hat{\delta}, 21-24, \mathcal{\imath}, 23-30$; of antennæ, $\hat{\delta}, 8-11$, ᄋ, $7-9$; of pronotum, $\delta, 4.5-5.5, ~ \&, 6-7$; of tegmina, (short-winged) $\hat{\delta}, 6-6.5$,, , $7-7.5$; of tegmina, long-winged, $\hat{\delta}, 18-19$, $\uparrow, 18-20$; of hind femora, $\hat{o}$, $11-13$, ᄋ, $12.5-15 \mathrm{~mm}$. (Fig. 123.)

Only the short-winged form of this dull colored locust has been taken in Indiana, and those only in Lake and Porter counties

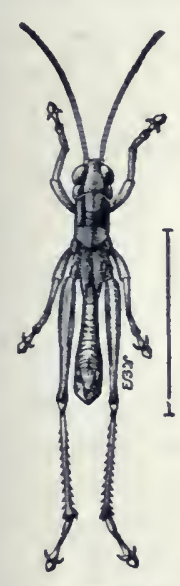
on October 11 and 12. Just east of Hammond, they were found in a long, low, marshy tract among the leares of blue flag. The next day they were more abundant about some marshes northwest of Dune Park. The males were strong and active leapers, oftentimes giring several great jumps to a tuft of bunch grass or weeds and gliding down it to the ground, where they squatted close until picked up with the fingers. The females were more sluggish and several were taken from between the stems of grass where they were standing on their heads, after endearoring to escape by diving downward.

With the exception of a single Massachusetts record, Porter Co., Ind., is the most eastern point from Fig. r23. Male. which the species has been recorded, its range extendger.) ing thence west and north to Ft. MrcLeod, B. C., Montana and Wyoming, and south and southwest through Texas and Arizona to Cordoba, Mexico.

In Illinois it was first recorded from Colona and Cordora by McNeill (1891, 76) under the name of Pesotettix autumnalis Dodge, a synonym. Hart (1907) mentions it also as occurring along swales between sand ridges near Waukegan; these and the Massachusetts record above noted being the only ones outside of 
Indiana east of the Mississippi. Morse (1907, 53) found it a "commoll campestrian species among the dense grass of the plains and prairies of Oklahoma and northern Texas. The young are often largely dull ivory white in color and present a very singular appearance with their absurdly large heads." Somes $(1914,96)$ records it from Iowa and Minnesota and says that:

"It appears at first glance very much like some of the brachypterous forms of Melanoplus, but the compressed body and large head seem to separate it, even in the field. We first took it in Iowa by sweeping tall grasses in an upland meadow; a more careful examination resulted in the discovery of numerous specimens crouching among the stems and dead leaves at the bases of the plants. In Minnesota we have taken it in low marshes, along lakes and at the tops of high gravelly hills sparsely covered with grasses and weeds."

From these notes it will be seen that $P$. nebrascensis may occur in almost any kind of a habitat within its range. The Caloptcnus volucris Dodge $(1877,112)$ is a name given the long-winged form, and the Melanoplus harrisi Morse (Psyche, XVI, 1909, 12) is a synonym. The latter was described from a single male taken at Needham, Mass., Aug. 23, "among the rank herbage of an abandoned upland field," and was probably adventive rather than a fixed resident of the region.

XI. Melanoplus Stål, 1873, 79. (Gr., "black" + "armor.")

Body moderately stout, generally feebly compressed; head not or very rarely prominent, but little if any longer than prozona; face usually almost vertical; eyes rounded-oval, never more than half as long again as broad; interocular space at most but little wider than the frontal costa; fastigium more or less declivent. merging gradually into the frontal costa, always more or less sulcate or concave, especially so in male; frontal costa of average width and prominence, usually sulcate below the ocellus; antennes slender, filiform, never longer than hind femora and never more than twice as long as pronotum; disk of pronotum variable in the different Series as described below, its lateral carinæ usually obsolete; lateral lobes of pronotum vertical or nearly so, their upper half usually with a blackish stripe; tegmina always present, in some species being mere oval or lanceolate scales, but little, if any, longer than pronotum, in others fully dereloped, and then attain-

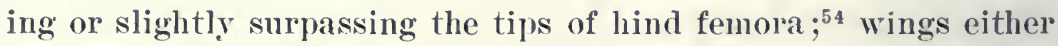
represented by minute scales or fully developed, transparent, al-

${ }^{34}$ Four of our eastern species, viz., dawsoni, fasciatus, borealis and ponderosus, are known to be dimorphic in wing length, but in the short-winged form of the last three the tegmina cover half or more of the abdomen. 
most colorless; hind femora moderately long and slender, usually reaching tip of abdomen, female, surpassing it, male; cerci of male exceedingly variable in form, often enlarged at apex, rarely styliform, and usually about the length of supra-anal plate; furcula usualls present and developed to a variable extent, also variable in form, so that they and the cerci furnish characters much used in separating the species one from another; oripositor usually strongly exserted.

This genus comprises more species than does any other of the North American Orthoptera, no less than $\mathbf{1 4 6}$ having been listed by Scudder (1900) from the United States and Canada, and treated by him in his "Revision of the Melanopli" and its supplement. Of the distribution of the species he says $(1897,123)$ : "The genus Melanoplus, so richly endowed with species, is naturally' very widely distributed, though so far as known it is completely confined to the continent of North America and does not occur, so far as reported, sonth of Mexico. Within this region it is as wide spread as all the other genera of Melanopli combined, extending from the Arctic Circle in Alaska and on the Mackenzie River, and from northern Labrador and perhaps southern Greenland on the north to the extremity of Florida and southern Mexico on the south, and from the Atlantic to the Pacific. It is, however, far richer in species in the west than in the east." Since 1900 numerous species have been described, and Kirby $(1910,509)$ listed 202 species of the genus from North America, including Mexico. From the territory covered by the present work 51 species and 10 varieties are recognized. Some of these, to the casual observer, may seem very similar in size, color and general appearance, but a close examination of the abdominal appendages of the male will at once prove their distinctness. The trro will probably have much difficulty in separating the females of the different species; in fact, he can only do so by taking the two sexes in the field. where ther are usually to be found associated together.

While dull colored and uninteresting to most people, the member's of this genus form the most characteristic group of our Acridida. To it belong our most common locusts and the ones which do the most injury. From mid-May until late Norember in the latitude of Indiana they leap from our pathwar in numbers, whether we stroll through open woodland, sunny meadow, or along the roadside; while in the back yards and on the lawns of our city homes they swarm in great profusion.

The Kansas or Rocky Mountain locust, Melanophes spretis (Thos.) belongs to this genus but does not occur east of the Mis- 


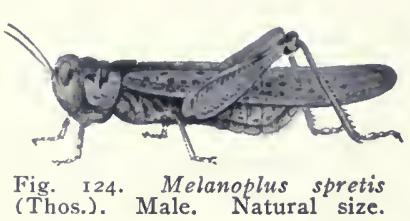

(Thos.). Male. Natural size.

sissippi (Fig. 124). Contrary to the general belief, it is not a large, robust species, being but little larger than our common eastern M. atlanis (Riley), and bearing to the latter a close general resemblance; so elose, in fact, that only specialists ean readily tell them apart. Millions of dollars of damage was done in the Western States by these small inseets in the summers of 1873 and 1875 . Migrating in vast elouds from one part of the country to another they would fall upon a cornfield and convert, in a few hours, the green and promising acres into a desolate streteh of bare, spindling stalks and stubs. In the words of the prophet Joel: "The land was as the garden of Eden before them, and behind them a desolate wilderness; yea, and nothing did escape them."

On account of the great number of eastern species they are, for convenience of treatment, first separated into two Divisions, and each of these is then farther divided into smaller groups or Series. The name given to each series in this work is that of the first described eastern species of the series, and in general, especially in Division I, the series bear but little if any relation to those of Seudder in his "Revision." The keys to series are based largely on the males, the females being so similar in color and structure that satisfactory characters for their inclusion could not be found.

KEX TO DIVISIOXS OF EASTERT SPECIES OF MELAXOPLUS.

a. Tegmina much shorter than abdomen, often shorter or no longer than the pronotum; furcula of male almost always feebly developed, often no longer than the last dorsal segment to which they are joined.

DIVISION I. p. 360 .

aa. Tegmina (except in the females of some boreatis) as long as or longer than the abdomen; furcula usually either well developed or obsolete.

DIVISION II. p. 408.

\section{Division I. Short-IVinged Species of Melanoplus.}

The short-winged forms of Melanoplus inhabit more commonly thickets, woodlands and sides of wooded ravines, gulches and mountain slopes rather than open fields and prairies. They seldom wander far from their original hatching place and are therefore more local in distribution and more secretive in habits than their long-winged congeners. The latter are 'considered the more primitive, the short-winged ones having gradually evolved from them by becoming adapted to a life where sustained flight is difficult or impossible. Hence along the wooded mountain slopes of 
New England and the southern States the short-winged forms are much the more numerous. Where a species is dimorphic in winglength, the long-winged individuals appear to be more numerous toward the northern part of its range and the brachypterous toward the southern. This is probably due, in part at least, to the length of the season and the consequent food supply, the short northern summers necessitating a mobility not possessed by the brachypterous forms.

As already noted, the form of supra-anal and subgenital plates and that of the cerci and furcula in Melanoplus are exceedingly rariable, even in the same species, and the number of described nominal species and races, based mainly upon the variations of these abdominal organs, is entirely too great. The eastern species of this Division are grouped into seven Series as follows:

KEY TO EASTERN SERIES OF SHORT-WLNGED MELANOPLUS.

$a$. Hind tibiæ green, glaucous, or greenish-yellow, never red; tegmina rarely as long as pronotum, usually distinctly shorter, their dorsal margins well separated, rarely (Series I,) attingent or feebly overlapping; median carina of pronotum low but usually distinct thróughout.

b. Prosternal spine conical or subcylindrical, its tips usually bluntly rounded, sometimes subacute; tips of tegmina broadly rounded.

c. Hind tibiæ pale to bright green; furcula minute, shorter than the last dorsal segment to which they are attached, the basal third not widened or thickened (Pl. III, $c, e$ ); prosternal spine short, stout, conical.

SERIES I, p. 362.

cc. Hind tibiæ glaucous or dull greenish-yellow; furcula as long as, usually much longer than the last dorsal segment, their basal thirds or more usually either widened or thickened.

d. General color greenish-yellow or pale brown; hind femora without fuscous bars on upper face; sides of pronotal disk subparallel, male, feebly divergent on metazona, female; prosternal spine rather slender, subcylindrical, its tip bluntly rounded. SERIES II, p. 367.

$d d$. General color dark reddish- or grayish-brown; upper face of hind femora usually obliquely bifasciate with fuscous; sides of pronotal disk strongly divergent behind in female; prosternal spine stouter, subconical, its tip rounded or subacute.

SERIES III, p. 372.

$b b$. Prosternal spine prominent, broad, flattened cylindric, the apex blunt, broadly rounded, usually transversely excised; tips of tegmina subtruncate, females, rarely broadly rounded, males; furcula shorter than the last dorsal segment or wholly wanting, rarely (strumosus) nearly half the length of supra-anal plate.

SERIES IV, p. 379.

aa. Hind tibiæ wholly or in great part red. ${ }^{55}$

${ }^{5}$ Rarely and abnormally dull greenish-yellow, the tegmina then distinctly longer than pronotum. 
e. Tegmina shorter than or but slightly longer than pronotum, at the most but slightly overlapping, their dorsal and median areas but feeb + if at all defined.

$f$. Median carini of pronotum distinct only on metazona and some. times the a)ical third of prozona; tegmina with dorsal margins well separated, rarely subattingent in male; prosternal spine, short; conical or pyramidal; furcula as long or longer than last dorsal segment.

SERIES $V$, p. 386.

ff. Median carina of pronotum low but distinct throughout; tegmina with dorsal margins attingent or slightly overlapping, their tips subacute or obliquely rounded; prosternal spine longer, subcylindrical with blunt rounded apex; furcula (except in dawsoni) distinctly shorter than last dorsal segment.

SERIES VI, p. 391.

ee. Tegmina distinctly longer than pronotum, their dorsal and median areas sharply defined, dorsal margins strongly overlapping, tips narrowly rounded or subacute; median carina of pro. notum distinct only on metazona; furcula no longer than the last dorsal segment, sometimes wanting. SERIES VII, p. 398.

Series I. The Gracilis Grovp.

Slender subcylindrical species of medium or small size and grayish-brown hue, having the postocular dark stripe extending back at least as far as metazona; hind tibiæ green; pronotum subcylindrical, its disk slightly convex with sides subparallel, male, feebly divergent, female, median earina pereurrent, sometimes less distinet on prozona than on metazona, the latter with hind margin subtruncate or broadly obtuse-angulate; prosternal spine short, conical, the tip bluntly rounded; tegmina shorter than or subequal to pronotum in length, either widely separated or slightly overlapping, their tips broadly rounded; extremity of male abdomen feebly swollen; furcula very short, cylindrical projections or minute rounded lobes; cerei slender flattened plates, usually obviously narrower at middle than at apex (PI. III, $c, e)$; subgenital plate small, distinetly narrower than long, with slightly elevated, sometimes tubereulate extremity.

KEY TO EASTERT SPECIES OF GRACILIS GROUP.

a. Tegmina narrowly oblong, their dorsal margins widely separated; hind femora green without dark cross-bars; hind margin of metazona subtruncate and with a feeble median notch. 159. GRAc1l.1s.

aa. Tegmina elliptical, slightly overlapping, male, feebly separated, female; hind femora dull yellow with two oblique brownish or fuscous cross-bars; hind margin of metazona obtusely angled or broadly rounded without trace of emargination. 160 . viniblpks.

159. Melaxoplus gracilis (Bruner), 1876, 124. Graceful Narrow-winged Locust.

Slender, subcylindrical, compressed, size small for the genus. Dull ash or wood brown above, greenish-yellow beneath. Head greenish-yel- 
Plate III.
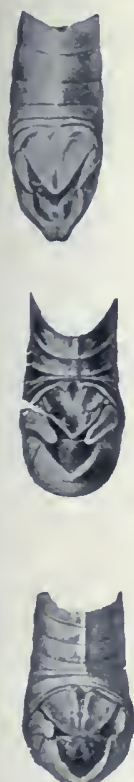

e
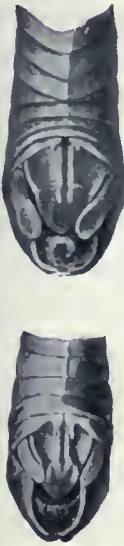

$a$

c

g
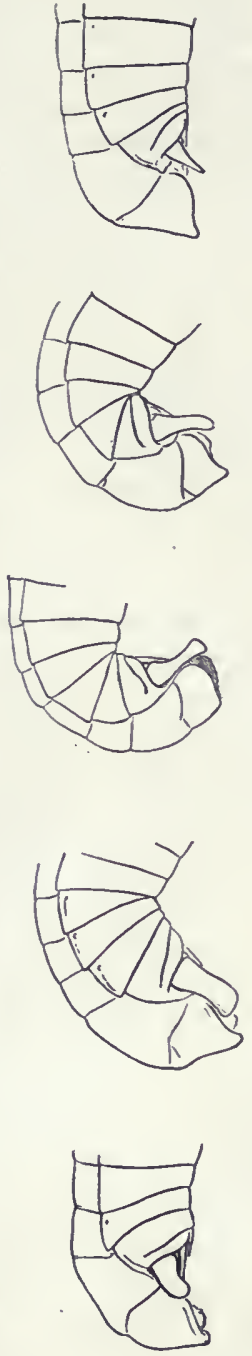
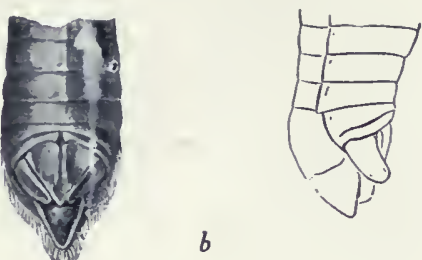

$b$

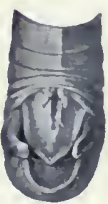

$d$
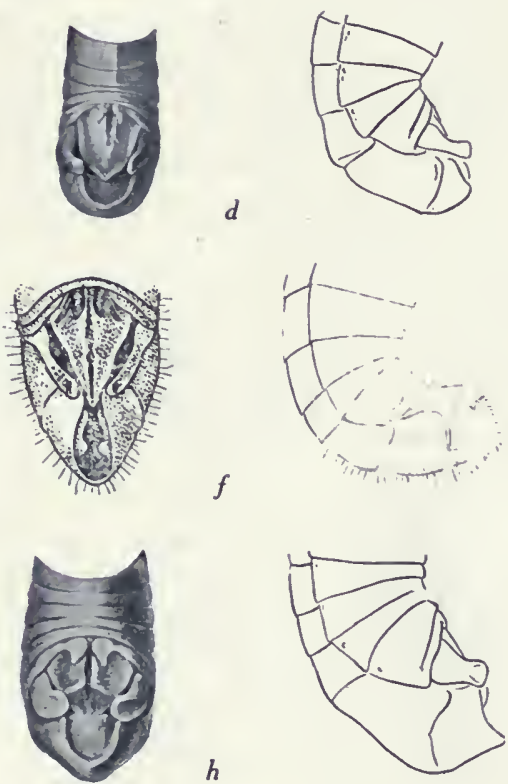

$h$
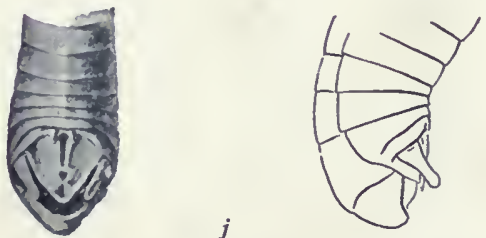

Plate III. Dorsal and side views of extremities of male abdomens of Hesperotettix and Melanoplus, showing the appendages, $\times 4 . a$, of $H$. pratensis; $b, M$. scudderi; $c, M$. viridipes; $d, M$. obovatipennis; $e, M$. gracilis; $f, M$. morsei; $g, M$. fasciatus; $h, M$. walshi; $i, M$. atlanis; $j, M$. impudicus. (After Scudder.)

low except on occiput, which is brownish or olivaceous, sometimes with a narrow median yellow line. Pronotum with a shining blackish bar extending backward from eye along the upper half of each lateral lobe to metazona; lower halves of lateral lobes greenish-yellow. Hind femora bright green, lower face yellowish, knees black; hind tibiæ green, the spines black; all the colors fading or becoming darker in drying. Vertex not swollen or elevated above the pronotum; interocular space very nar. 
row, about equalling the width of first antennal joint, male, nearly twice as broad, female; fastigium strongly declivent, narrowly but distinctly sulcate, male, broadly and shallowly concave, female. Frontal costa prominent, slightly wider than interspace between the eyes, feebly sulcate below the ocellus. Pronotum subcylindrical, faintly expanding on metazona; disk with sides feebly sloping; median carina low, distinct, equal throughout; prozona nearly twice the length of metazona. Tegmina about the length of prozona, narrowly oblong; tips subacuminate, male, narrowly rounded, female. Hind femora very slender, exceeding the abdomen in both sexes. Cerci as long as supra-anal plate, narrow, the middle third but half as broad as base, apical third slightly expanded, somewhat flattened and feebly curved backward or downward Supra-anal plate triangular, with obtuse apex and a rather deep, entire median groove; furcula usually consisting of a pair of minute oblong lobes, lying on the outer sides of the median ridges (Pl. III, e.) Length of body, $\hat{\delta}, 14-16$, 옹 18.5-20; of antennæ, ô, 8.5-9, ᄋ, 7.5-8; of pronotum, $\hat{\delta}, 4.5$, 오, 5-5.5; of tegmina, $\hat{\delta}, 2.5-3$, $q, 3.5-4$; of hind femora, $\hat{\jmath}, 9.5-10$, $ᄋ, 11-11.5$ mm. (Fig. 125.)

In Indiana this is one of the more common of the short-winged members of Melanoplus. It probably occurs throughout the State,

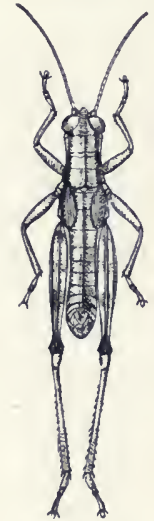
but has not been noted in the counties south of Monroe and Knox. It frequents rather low, wooded bluegrass pastures and is especially fond of resting and mating upon the foliage of the iron weeds (Vernonia) which grow abundantly in such places. Spots along the roads and pathways through such woods, where the ground iry carpets the earth and the great ragweed and jewel-weed grow luxuriantly, are also very attractive to this graceful bodied locust. It is also partial to the tall grasses growing in ravines and along the borders of sloughs and marshes. In central Indiana the males begin to reach maturity by June 15th, the females about a week later. By July 5th Fig. I25. Male. they are mating in numbers. They have also been

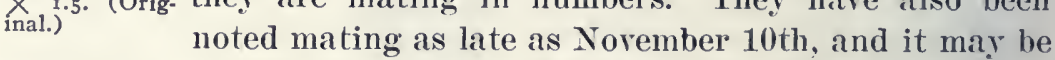
possible that in favorable seasons, a second brood matures. Like most other wingless species, they are active leapers, the males, especially, being noted for their somersaults while endearoring to escape capture.

The furcula of the males of gracilis vary much in size and form, ranging from minute rounded or triangular parallel lobes to much larger finger-like diverging projections, longer than the dorsal segment to which they are attached.

The known range of this easily distinguished little locust extends from central Ohio (Mead), Jackson Co., Mich. (Hubbell), 
and Monterey, Va. $(F \circ x)$, west and north to Minnesota, South Dakota and eastern Nebraska and southwest through Kentucky to Clarksville, Tenn., Mississippi and Arkansas. McNeill records it as rare in northwestern Illinois but more common in the central part of the State; Allen as "abundant in grassy groves in Iowa," and Somes $(1914,79)$ as uncommon in Minnesota, stating that there: "It prefers thickets of elder undergrown with blackberry. From one such spot I took twelve of these pretty little insects in less than half an hour." At Magazine Mountain, Ark., Morse $(1907,48)$ found it in "a cool damp thicket at a height of 2,400 feet where it was not uncommon but very alert and secretive, seldom showing itself and quick to leap away." The Pezotettix minutipennis Thos. $(1876,66)$ is a sruonym.

160. 'Melaxoplus riridipes Scudder, 1897b, 13. Green-legged Locust.

Rather slender, subcompressed; size medium. Males, brownish-fuscous above, dull yellow beneath, occiput darker. Side of head behind the lower half of eye with a broad shining black stripe, this extending backward the full length of upper half of lateral lobe of pronotum and bordered below by ivory white or yellowish. Disk of pronotum and tegmina wood brown. Fore and middle femora and all the tibix greenish; the hind tibiæ with a black basal ring followed by a pale one. Metapleuræ, hind knees, hind margins of three or four ventral segments and often both apical and hind margins of the last two, shining black or fuscous. Females duller, the black postocular stripe not extending downward on cheek as in male, and backward only to metazona, the dorsal surface and sides of abdomen more strongly fuscous, the dark bars of hind femora less distinct. Vertex moderately swollen, scarcely elevated above the pronotum, the portion between the eyes half as broad again, male, or twice as broad. female, as basal joint of antennæ. Fastigium rather strongly declivent, distinctly sulcate, male, more widely and shallowly so, female. Frontal costa feebly narrowed above the antennæ, shallowly sulcate in the region of the ocellus, male, almost flat, female. Pronotum with disk feebly expanding on metazona; prozona about half as long again as the densely punctate metazona, its median carina low, often in part subobsolete. Tegmina equalling, female, or slightly longer, male than pronotum, elliptical. their tips rounded. Supra-anal plate triangular, its apex acute-angled, median sulcus broad, shallow, interrupted at middle; furcula consisting of a pair of minute, widely separated, triangular lobes, lying outside the bases of the median ridges. Cerci extremely variable in shape, their typi. cal form being long (nearly three times as long as broad at base), tapering gradually from base to middle; the apical half or more slender, subequal, feebly decurved, the tip rounded on dorsal side only, its outer face concave and ventral angle slightly produced (Pl. III, c.) Apex of subgenital plate feebly prolonged upward into a small conical tubercle. Length of body, $\hat{\delta}, 16-18, \uparrow, 21.5-23$; of antennæ, $\hat{\delta}, 9.5, \uparrow, 8.5-9$; of pronotum, $\hat{\delta}, 5, \hat{\imath}, 6$; of tegmina, $\hat{o}$ and $\uparrow, 5-6$; of hind femora, $\hat{\delta}, 8.5-9.5$, ㅇ, 11.5-12 mm. (Fig. 126.) 
In Indiana this handsome short-winged form is the first locust to reach maturity from eggs hatched in spring, a mature male

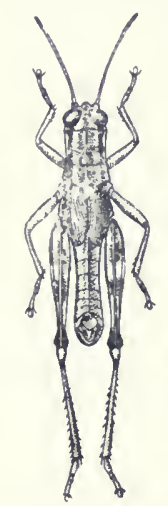

having been taken in Vigo County on May 11th, and a number of both sexes in Posey County on May 12 th. By June 1st it is common locally, and by August 1st has mostly disappeared. It frequents rather low, flat woods and clearings, being found about the margins of burned or bare places.

On June 3, 1900, I happened upon a large colony of viridipes in an upland woods in Marion Co. They were in an open, rather bare tract near the center of the woods, which was surrounded by beech and black maple trees. I took with the fingers, 40 of them in 20 minutes, and could have secured as many more. The Fig. r26. Male. males, when first disturbed, would leap two or three inal.) ${ }^{\mathrm{I} \cdot 3 .}$ (Orig- feet, almost perpendicularly, for several times in rapid succession, then give one or two sidewise leaps, and if still pursued, endeavor to hide the head beneath a dead leaf. The females were more clumsy and after giving one or two short leaps would squat close to the ground, when they were readily taken. One pair were mating and a number were yet in the nymph stage. On June 1, 1902, I found the species abundant in the same place, and again on June 5, 1904. In Lake Co. it was taken in a similar woods on the west side of Cedar Isake. It probably occurs in suitable localities over the greater portion of the state.

East of Indiana typical viridipes has been recorded definitely only from Vermont, Massachusetts and Ohio. In western New England it is very scarce, occurring among low shrubby dry upland thickets. In Ohio Mead reported it as fairly common in Franklin and Highland counties, and Hubbell (Ms.) reports it from Washtenaw Co., Mich. Farther west the species is known only from central and northwestern Illinois, where McNeill says that "it shows a decided preference for open grassy ravines," and from Nebraska, where Bruner reports it as "found only occasion. ally in woods along the Missouri River." It is probably a much more abundant species than the records show, its early appearance and sylvan habitat preventing it from being better known.

As noted in the description, the cerci of the male viridipes vary greatly in shape, not only in breadth but also in the degree of the concavity of the dorsal margin, and therefore in the appar. ent width of the apical expansion. Specimens are often taken in which they are much stouter than there described, being less than twice as long as wide at base, with both margins almost parallel 
from basal third to near apex, the apical third being more than half the width of base. Between this form and the typical one, there is one with the dorsal margin strongly concave at middle, the apical third therefore apparently broadened with apex obliquely excised. This was described by Morse (1904a, 9) as $M$. deceptus (Fig. 127, $f$ ). Another form with cerci very similar to the typical one but with dorsal margin more concave and tip transversely excised or subtruncate, he described (loc. cit.) as M. simiTis (Fig. 127, g). I regard both these nominal species as, at the most, only names for forms of male viridipes having the cerci extremely modified as described, the females being absolutels inseparable from those of viridipes. His deceptus was based upon specimens from Balsam, N. Car., Jasper Ga., and Vigo Co., Ind., the Vigo Co. male cotypes being collected by myself, with a colony of typical viridipes, one of them having been used by Scudder as a cotype of that species. Aside from the localities above given the form deceptus has been recorded by R. \& H. from Black Mountain, N. Car., Clayton, Ga., and Tennessee. Morse's southern specimens were taken at heights of 2,600 to 6,100 feet, and he mentions it as inhabiting "deciduous forests at high elevations."

II. similis was described by Morse from three male specimens taken July 25 at Murphy, Clierokee Co., N. Car., in dry upland forests of pine and oak. It las since been recorded br R. \& $H$. from near Bluemont, Va., and several points in Rabun Co., Ga., and by Kostir from Vinton, Ohio,

Including as synonyms deceptus and simitis, the known range of viridipes is thus extended from New England southwest to Rabun Co., Ga. A pair of the Georgia specimens labelled similis, kindly loaned me by Davis, were found to be typical viridipes, the cerci having the tips rounded on dorsal side, not transversely excised. In the opinion of R. \& H. $(1916,212)$ the $M$. juvencus Scudd. $(1897 \mathrm{~b}, 14)$ was based upon a specimen of viridipes placed by accident with his series of $M$. puer, the locality, Ft. Reed, Fla., being derived.from one of the latter.

Series II. The Decorus Group.

Slender bodied species of small or medium size, having the general color pale brown or greenisl-yellow with a dark shining postocular stripe extending back at least as far as metazona; hind tibiæ greenish-yellow; pronotum with median carina sharp, distinct throughout, hind margin subtruncate or broadly rounded, prozona one-half or more longer than metazona, sides of disk parallel, male, feebly divergent, female; tegmina oval, shorter 
than pronotum, their inner margins not overlapping, the dorsal and anal fields not defined, tips broadly rounded; hind femora slender, equalling or feebly surpassing tip of abdomen, male, reaching base of ovipositor, female, their color nearly uniform, without dark eross-bars; extremity of male abdomen but little enlarged, feebly upcurved; furcula and cerci variable according to

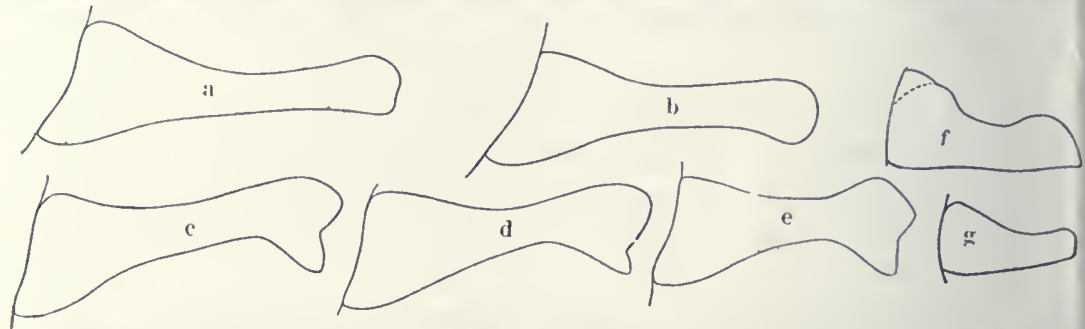

Fig. 127. Outlines of cerci of males of Melanoplus. $X 16, a$, decorus; $b$, australis; $c$, attenuatus; $d$, hebardi; $e$, nubilus; $f$, deceptus; $g$, similis. The last two synonyms of viridipes. (After R. \& H. and Morse.)

species; subgenital plate distinctly tapering from base to apex, the latter narrow, rarely tuberculate, but usually with a subapical tubercle. Five closely related forms comprise the group, all represented in the southern coastwise states and hygrophilous in habitat.

KEY TO EASTERX SPECIES OF DECORUS GROUP.

a. Postocular dark-stripe present but narrowed on metazona; middle of apical margin of subgenital plate of male projected upward as a distinct and slender tubercle; furcula one-third or more the length of supra-anal plate (Fig. 128, a.)

161. DECORUS.

aa. Postocular dark stripe ending abruptly at front margin of metazona; apical margin of subgenital plate without a tubercle, the plate usually with a blunt one below the margin.

b. Sides of abdomen without black markings; apical third of male cerci spatulate, the tips broadly rounded (Fig. 127, b.)

162. AUSTRALIS.

bb. Sides of abdomen with a black stripe or blotches; apical third of cerci but slightly widened, the tips subtruncate, feebly bifid (Fig. 127, c, d, e.)

c. Larger, length of body, male, 18.5-22; dorsal surface of abdomen pale.

d. Prozona one-half longer than metazona; basal third of lateral margins of supra-anal plate incised to form a prominent broadly rounded overlapping fold; furcula slender, evenly tapering, about one-fourth as long as supra-anal plate (Fig. 128, c.)

163. ATTENUATUS.

dd. Prozona nearly twice as long as metazona; basal marginal plications of supra-anal plate evident but feeble; furcula small knob-like plates with divergent angulate tips, scarcely one-fifth the length of supra-anal plate. (Fig. $128, d$.

163a. IIEBARDI. 
cc. Smaller, males not over $16.8 \mathrm{~mm}$. in length; dorsal surface of abdomen of male in great part fuscous; subapical tubercle of subgenital plate very distinct.

164. NUBILUS.
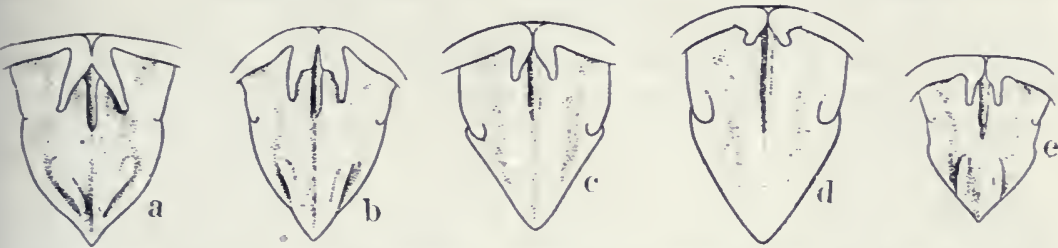

Fig. 128. Dorsal views of supra-anal plates and furcula of males of Melanoplus. $X$ Io. $a$, decorus; $b$, australis; $c$, attenuatus; $d$, hebardi; $e$, nubilus. (After R. \& H.)

161. Mela Noplus Decorus Scudder, $1897 \mathrm{~b}, 13$.

Size small, slender; females more robust, much the larger. Brown, more or less infuscated, greenish-yellow beneath. Occiput, disk of pronotum, metapleuræ and sides of abdomen in great part fuscous. Face greenish-yellow flecked with fuscous; antennæ reddish-yellow, darker toward tips; cheeks, lower half of pronotal lobes and front and middle legs yellow. Tegmina pale brown. Hind femora reddish-yellow, the outer face often infuscate, knees in great part black, inner and lower faces bright yellow. Hind tibiæ pale green, spines black. Female duller, sometimes melanistic, then a nearly uniform fuscous brown. Interocular space narrower than first antennal joint, male, as wide as frontal costa, female. Fastigium narrowly and shallowly concave, male, more broadly so, female. Frontal costa narrow, feebly or not at all sulcate. Prozona two-thirds longer than metazona, its disk feebly convex, male, strongly rounded into lateral lobes, female; metazona nearly flat, finely rugose-punctate, hind margin subtruncate or very broadly rounded. Tegmina oval, reaching front margin of third abdominal segment, slightly shorter than pronotum, male, one-third shorter, female, their inner margins slightly separated, male, by one-half their width, female. Supra-anal plate of male elongatetriangular, apex subacute, margins of apical half thickened, convex and paralleled within by a pair of short blunt ridges, these strongly converging but not meeting near apex; median sulcus narrow on basal half of plate, expanded on apical half (Fig. 128, a.) Furcula elongate, tapering, divergent, lying on sides of basal median ridges. Cerci longer than supraanal plate, basal third rather broad, strongly tapering, apical fourth feebly expanded, one-third as wide as base, strongly incurved, the tip broadly rounded (Fig. 127, a.) Length of body, $\hat{\sigma}, 17-20$,, $20.5-25.3$; of antennæ, $\hat{\sigma}, 12$,, 8.5 ; of pronotum, $\hat{\delta}, 4.1$, $\uparrow 5.5$; of tegmina, $\hat{\delta}, 4-4.8$. ․, 4; of hind femora, ô $9.5-11$, ᄋ, $13 \mathrm{~mm}$.

This locust is known only from North Carolina, where it has been taken near Wilmington, Winter Park, Lake Waccamaw, Dingo Bluff and Newbern, Sept. 7-Nov. 15. R. \& H. $(1916,215)$ state that their specimens from Winter Park were found "among low plants and scant grasses about a swampy depression in pine woods; those from Wilmington in the wet mucky border of a swampy tract which was corered thickly with grasses, pitcher plants and renus' fly-traps, and dotted with low bushes." 
162. Melaxoplus australis Morse, 1904à, 13. Southern Locust.

Somewhat larger and more slender than decorus. Pale yellowishgreen without fuscous markings on sides of abdomen. Postocular fuscous stripe of female frequently subobsolete or interrupted by narrow oblique yellowish-green fasciæ. Hind femora of female often with upper and outer faces in part infuscate; knees fuscous. Hind tibiæ grayish-green. the spines wholly black. Prozona one-half longer than metazona, the latter with surface distinctly reticulate-rugose, its hind margin broadly rounded. Tegmina obovate, their tips broadly rounded. Supra-anal plate much as in decorus, but wider, with apex more blunt, the subapical internal ridges not converging as there but subparallel (Fig. 128, b.) Furcula onethird the length of supra-anal plate, feebly divergent, broad at base, abruptly narrowed near middle, then tapering on inner side to finger-like tips. Cerci slender, three times as long as broad, the middle third onehalf or less the width of base, apical third subspatulate, thin, feebly incurved, convex and slightly carinate externally, concave internally (Fig. $127, b$.$) Upper margin of subgenital plate, viewed from above, broadly$ rounded or horse-shoe-shaped, the plate with a blunt subapical tubercle behind. Length of body, $\hat{\delta}, 16.4-22$, $\&, 23-27$; of antennæ, $\hat{\delta}, 12-13$, $\&$, $8-9$; of pronotum, $\delta, 5$,, 6.2 ; of tegmina, $\delta, 3.5-4.5$, 오 $5-5.7$; of hind femora, $\hat{o}, 11.5$, 우, $13-14 \mathrm{~mm}$.

Known only from South Carolina and Georgia. Morse's unique male type was taken August 14 near Savannah, Ga., from a "tangled growth of grass, sedge, weeds, etc., on swamps ground." R. \& H. found it in numbers at Yemassee, S. Car., and Sandfly, Ga., Sept. 3 and 4 . They state $(1916,216)$ that it is the most brilliantly colored species of the group, ranging from lemon chrome suffused with greenish or orange, to army-brown showing a yellowish suffusion. The brighter colored individuals were "taken on green plants, the duller ones among the yellowish and brown fronds of the brackens. The males were active but not alert, and were easy to capture, the females much less active and usually met with in the heavier undergrowth where much greater concealment was afforded." The species was found at Yemassee among low swamp-loving plants in wet ground through the shortleaf pine woods; while at Sandfly and Isle of Hope, Ga., it occurred in tall rank succulent undergrowth such as patches of rellow and brown bracken ferns in swampy gray-bark pine woods.

163. Melanoplus attexuatus Scudder, 1897b, 13. Slender-bodied Locust.

Size medium; form very slender. Color much as in decorus and australis; postocular black stripe confined to the prozona, strongly shining. Sides of four or five basal segments of abdomen with large quadrate black or fuscous blotches. Hind tibiæ pale dull green, basal third tinged with dull yellow, spines black, paler at base. Metazona densely punctate, less rugose than in austratis. Tegmina narrower, subelliptical, separated by about one-third their width, their tips broadly rounded. Supra-anal plate 
much as in decorus, the subapical inner ridges less distinct, converging as there; the basal third of lateral margins incised and overlapping (Fig. 128, c.) Cerci very slender, the middle less than half the width of base, the apical third feebly widened, incurved and slightly grooved on outer face, its lower portion expanded and flattened to form a blunt lobe, the tip subtruncate and feebly emarginate (Fig. 127, c.) Subgenital plate much as in australis. Length of body, ô, 18.5-20.6; of antennæ, 9.5-10.5; of pronotum, 4.5; of tegmina, 4-4.2; of hind femora, $11-11.5 \mathrm{~mm}$.

Magnolia, S. Car., Sept. 5 (Hebard). Scudder's types were taken in November at Smithville, $\mathbf{N}$. Car. Morse has recorded it from Denmark, S. Car., and R. \& H. (1916, 216) from Sullivan Island, Magnolia and Ashley Junction, S. Car., and Augusta, Ga. It occurs among low shrubs and grasses in swampy depressions in pine woods. The elongate, slender body, form of male cerci, shorter and broader subgenital plate and black sides of abdomen separate it from australis, to which it is otherwise very closely related. Only adult males have been recorded, though nymplis of both sexes were secured by R. \& H. in July and August.

163a. Melaxoplus attendatus mebardi (Rehn), 1906, 235. Hebard's Short-winged Locust.

Darker than attenuatus, dorsum and sides of abdomen often with a row of large pale spots. Prozona slightly longer; metazona more coarsely rugose. Tegmina shorter, more widely separated, their tips more rounded. Basal lateral margins of supra-anal plate more swollen and thickened, the median sulcus percurrent. "Tegmina about four-fifths the length of pronotum, subovate, the greatest width two-thirds the length, apical section rounded, subtruncate, separated above by a space equal to the width of frontal costa. Supra-anal plate elongate-triangular with sides in more than distal half straight, convergent, its surface very decidedly flattened with median sulcus less pronounced than in decorus and distal convergent ridges subobsolete (Fig. 128, d.) Furcula as described in key. Cerci tapering in the proximal half, slender mesad, distinctly expanded distad, rounded dorsad, and with a rectangulate lobule ventrad, the distal half distinctly bent mesad, and falling slightly short of the tip of supra-anal plate (Fig. 127, d.) Length of body, ô, 22; of pronotum, 5; of tegmina, 3.6 ; of hind femora, 12.5." (Rehn.)

A comparison of a male taken br Fox at Macon, Ga., with the types of both attenuatus and hebardi showed that the two are very similar, differing only in the minor characters given above and in the key. The Macon specimen shows intermediate characters, the furcula closely resembling those of attemuatus, the cerci those of hebardi. As the two forms occur in the same general region and but few specimens of either are as ret known, there is little doubt but that hebardi will prove to be only a variety or race of attenuatus, and I have so placed it. 
Fox (Ms.) states that about Macon "hebardi is, next to scudderi, the most frequent of the short-winged Melanopli, occurring in the undergrowth of woods, especially in low wet areas."

Rehn's unique male type, taken in Thomas Co., Ga., Jan. 6, is the only adult so far recorded. Several nymphs were found by R. \& H. at Albany, Ga., on August 1, in the "heavy undergrowth of the long-leaf pine forest along the Flint River."

\section{Melanoplus nubilus Rehn \& Hebard, 1916, 217.}

Size small for the group. Color of decorus, the males with dark postocular stripe ending at front margin of metazona, and dorsal surface as well as sides of abdomen fuscous. Females with postocular stripe on prozona subobsolete or interrupted and only the basal thirds of abdominal segments black. Prozona one-half longer than metazona, the latter with sides subparallel, surface rugose-reticulate and hind margin broadly rounded. Tegmina as in attenuatus. Supra-anal plate much as in decorus and australis, but somewhat shorter, the subapical internal ridges feebly converging and uniting to form the apex of the plate (Fig. 128,e.) Furcula very slender, subparallel, finger-like projections, about one-fourth the length of the supra-anal plate. Cerci very slender, the apical third feebly widened, its dorsal portion flattened and tips subtruncate and distinctly emarginate (Fig. 127, e.) Length of body, $\hat{o}, 15.8-16.8$,,, $21.2-25$; of pronotum, $\hat{o}, 3.7-4.1$, ᄋ, $4.9-5.3$; of tegmina, $\hat{o}, 2.6-3.8$, ㅇ, $3.8-4.5$; of hind femora, ô, $9.3-10$, o, 12.4-13.1 mm. (Fig. 129, a.)

This form is recorded only from the type locality, Fayetteville, N. Car., Sept. 9. It also appears to be very closely related to attenuatus, and a large series will probably prove that attenuatus, hebardi and nubilus are but forms of a single species varying slightly in color and in the structure of the male abdominal appendages. R. \& H. $(1916,219)$ state that nubilus "was taken in short-leaf pine woods around a mill pond at Fayetteville. The males were occasional on gall-berry and other bushes and were found usually two or three feet from the ground, sitting up warily or jumping away, while the females were decidedly less abundant and less active and by hiding often eluded pursuit."

\section{Series III. The Orovatipensis Group.}

This gloup comprises small or medium sized species, all of which agree in having the general color dull brown above, greenish-yellow beneath, with a shining postocular black stripe, usually extending back the full length of the pronotal lateral lobes and down the metapleuræ; hind tibire dull greenish-yellow with black spines; pronotum with sides of disk subparallel, male. strongly divergent on metazona, female, median carina low but distinct throughout; prozona one-half or more longel than meta- 
zona; tegmina oval or obovate, rarely over two-thirds the length of pronotum, their upper inner margins distinctly separated in both sexes, dorsal and anal fields not defined, tips broadly rounded; hind femora slender, slightly surpassing tip of abdomen, male, reaching tip or base of ovipositor, female ; furcula and cerci variable, according to species; subgenital plate rather broad, feebly narrowed above, rarely strongly tuberculate.

Six species and one variety comprise the group, all represented in our territory; five of them being known only from south of the Ohio River. They inhabit, for the most part, dry hillside thickets and wooded mountain slopes.

KEY TO SPECIES OF THE OBOVATIPENNIS GROUP.

a. Subgenital plate of male not strongly projected upward and backward into a prominent tubercle; vertex but moderately projecting in front of eyes.

b. Sides of abdomen without distinct fuscous stripes or blotches for two-thirds or more its length; tips of male cerci not obliquely excised with lower angle pointed and decurved.

c. Hind margin of metazona without a trace of median notch; furcula cylindrical, tapering.

d. Subgenital plate of male without a subapical tubercle; cerci of male truncate at tip (Pl. III, d.) 165. овогAtipennis.

dd. Subgenital plate of male with a distinct but feeble subapical tubercle; tips of male cerci broadly rounded. 166 . TEPIDUs.

cc. Hind margin of metazona with a minute but distinct median notch; cerci of male obliquely rounded at tip; furcula very broad at base, abruptly narrowed and more or less angled or bifid at middle. (Pl. III, $f$.)

167. MORSEI.

$b b$. Sides of abdomen with a distinct and sharply defined fuscous stripe or fuscous blotches, sometimes wanting in female; tips of male cerci usually obliquely excised with lower angle pointed and decurved.

$e$. Dark stripe of lateral lobes narrow and sharply defined from the pale ventral portion in both sexes; prosternal spine conical, acutely pointed; tips of male cerci with pronounced lower angle (Fig. 129, b.)

f. Furcula short, flattened, distant, parallel finger-like projections about as long as the last dorsal segment.

168. TRIBULUS.

ff. Furcula much wider and longer, feebly tapering, flattened from enlarged bases, their length one-third that of supraanal plate.

168a. TRIBULOIDES.

ee. Dark stripe of lateral lobes broader, and in the female feebly defined, with lower portion more or less infuscated; prosternal spine cylindro-conic, bluntly pointed; tips of cerci with lower angle blunt (Fig. 129, c.)

169. DEvIUS.

aa. Subgenital plate of male strongly projected upward and backward 
into a prominent apical tubercle (Fig. $129, d$.) ; vertex in both sexes strongly protuberant in front of eyes.

170. DECORATUS.
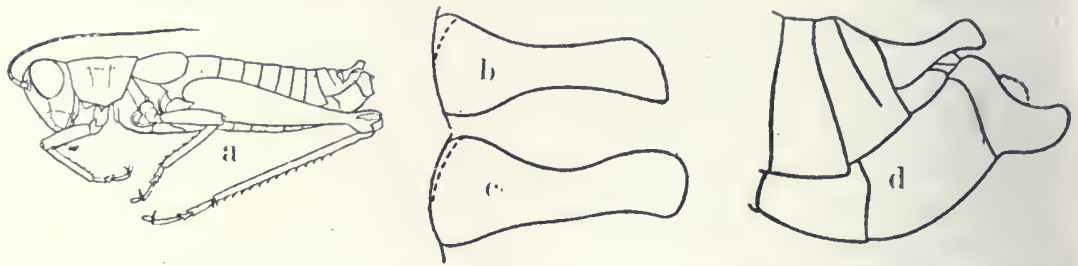

Fig. 129. $a$, Outline of $M$. nubilus $\times{ }_{2} ; b$, cercus of male of $M$. tribulus; $c$, same of M. devius $\times 16$; $d$, end of abdomen of male of $M$. decoratus $\times 6$. (After $R$. \& $H$. and Morse.)

165. Melayoplus obovatipenvis (Blatchley), 1894, 241. Obovate-winged Locust.

Male below the medium in size for the genus, female much larger and more robust. Above dull grayish-brown or tan, with the dark fuscous postocular stripe as described above, this bordered below by an ivory-white band extending back from cheek, covering the lower half of lateral lobe, then curving down between the front and middle coxæ; metapleura ivory white. Below dirty yellowish-brown with lower face of femora orangeyellow. Hind femora with two indistinct blackish bars on upper and outer faces; knees black. Hind tibiæ olive-green, annulate with whitish near base. Abdomen tinged with fuscous, rarely with dark blotches on sides of one or two basal segments. Antennæ with basal half reddishbrown, apical half fuscous. Interocular space nearly twice, male, or more than twice, female, the width of basal joint of antennæ; fastiglum strongly declivent, narrowly and shallowly sulcate, male, broadly depressed with distinct raised margins, female. Frontal costa about the width of interocular space, distinctly sulcate, male, slightly depressed about the ocellus, female. Pronotum rather long, faintly, male, distinctly, female, widening on metazona; hind margin truncate in female, a little rounded in male; prozona nearly twice as long as the densely punctate metazona. Tegmina about two-thirds the length of pronotum, obovate or broadly ovate in out line, a little longer than their greatest width, their inner edges widely separated, female, less widely but never attingent, male. Wings represented by a slender oblong scale. Supra-anal plate elongate-triangular, its apex rather blunt, margins and median basal ridges very low, the former but slightly recurved, the latter enclosing a narrow and shallow sulcus, which ends slightly beyond the middle of plate. Furcula consisting of a pair of tapering, cylindrical, diverging processes about one-third the length of supra-anal plate. Cerci rather slender, feebly incurved, middle third but little more than half the width of base, apical third again somewhat widened and slightly excavated on outer face, the apex subtruncate. Subgenital plate almost as broad as long, the apical margin not elevated. Length of body, ô, 15-16,, $24-29$; of antennæ, $\hat{\delta}, 10, \uparrow, 9.5-10.2$; of pronotum, $\hat{\delta}, 4.5$, $q 6$; of tegmina, $\hat{\delta}, 3-3.5$, $9,4-4.3$; of hind femora, ô, 10, ᄋ, 12.5-13.2 mm. (Fig. 130.)

This olive-brown, short-winged locust probably occurs throughout the southern two-thirds of Indiana, but has not been taken 
north of Tippecanoe Co. In central Indiana it reaches maturity about September 1, and frequents, for the most part, high, dry, open woods, especially those in which beech and oak trees predominate. On the tops of the hills, in the coal district of Vigo Co., and on the wooded slopes of the Knobs of southern Indiana, where the soil is a clay, and the herbaceous regetation somewhat limited, it is, in mid-autumn, the prevailing, and often only, representative of the family. While mostly xerophytic in habitat, in late October, if the season is dry, it is often found in company with Dichromorpha viridis and Truxalis brevicornis among the reeds and tall rank grasses near the border of marshes, and as late as November 22 , has been noted enjoying the afternoon sunshine from a perch on the bottom plank or rail of a fence. About Lafayette Fox $(1915,26)$ found it only in the herbaceous thickets surrounding marshes or damp spots. The females are always much more numerous
les, the ratio being about fire to one. Their larger,

Fig. 130. Female. $\times$ 1.5. than the males, the ratio being about fire to one. Their larger, robust form renders them more clumsy and hence more easily caught by the hand, the males being active leapers and requiring quick morement on the part of the collector to effect their capture. Like the other short-winged sylran species, obovatipennis often appears in colonies, a score or more being sometimes noted within an area of a few square rods and then no others seen for a long distance.

The known range of M. obovatipennis extends from sonthern Ohio (Kostir) and north-central Indiana west to Missouri and south and southwest to Tennessee, Arkansas, Oklahoma and Texas. Scudder $(1897,265)$ records it from High Bridge and Mammoth Care, Ky., St. Louis, Mo., and Dallas, Texas. Fox (Ms.) reports it as occurring near Clarksville, Tenn. McNeill (1899a, 369) states that it is a rather uncommon species in Washington and Sebastian counties, Ark., and that it is the species recorded by him (1891, 77) as Pczotettix mancus Smith from Running Lake. Ill. Hart $(1906,81)$ states that it occurs on "high wooded hillsides throughout Illinois." Morse $(1907,50)$ mentions it as "a very common species in xerophytic upland forests in Arkansas and probably much of the territory of the adjoining States," and records it from numerous stations in Arkansas and from Howe and Sonth McAlester, Okla. These are the only definite records which have been found of its occurrence. 
166. Melanoplus tepidus Morse, 1906, 121.

Size and form of obovatipennis. Color much as there, the dark postocular stripe more shining, broader, deflexed to cover all three pleuræ. Interocular space narrower, more deeply sulcate; eyes slightly larger. Pronotum a little more elongate, its sides more divergent on metazona; disk more tectiform, the prozona finely alutaceous; lateral lobes longer, less deep. Tegmina of male more elongate, less widely separated; of female somewhat broader, more approximate above. Furcula shorter, less tapering, their bases more swollen; apical halves subdepressed, the tips obtuse. Cerci with apical halves broadly and deeply sulcate without. Upper valves of ovipositor narrower at base in side view, the dorsum of scoop longer and more narrow.

Three pairs taken by Morse at Meridian, Miss., July 16, 1905. No additional records or notes regarding the habits can be found. He stated $(1907,23)$ that "the range of Melanoplus obovatipennis has been extended south to southern Mississippi in the nearly related form tepidus, which may intergrade." A comparison of his types with obovatipennis shows that the two differ as shown above, tepidus, in my opinion, being a very distinct form.

\section{Melanoplus Morsei Blatchley, 1903, 309. Morse's Locust.}

Male below the medium in size, female larger and more robust. Grayish or purplish-brown above, greenish-yellow below. Face greenish-yellow more or less sprinkled with fuscous; the usual postocular stripe shining black, bordered below with greenish-yellow. Tegmina wood-brown. Hind femora reddish-brown, sometimes with a fuscous tinge in female, upper and inner faces usually with two faint fuscous cross-bars; knees shining black; hind tibiæ pale green. Vertex but little swollen, not at all, male, or slightly female, elevated above the pronotum; interocular space about as wide, male, or less than one and one-half times as wide, female, as basal joint of antennæ; fastigium gently sloping, distinctly angulate at middle of each side, sulcate in male, flat in female. Frontal costa slightly wider than basal joint of antennæ, feebly sulcate below the ocellus in male. Eyes of male very prominent. Disk of pronotum faintly expanding on metazona, male, distinctly throughout, female; median carina low, subobsolete on posterior third of prozona, the latter nearly twice the length of the rather coarsely punctate metazona. Tegmina broadly ovate or subrounded, as broad as long, in female a little shorter than pronotum, their inner edges separated by a space equal to two-thirds their width. Supraanal plate as in obovatipennis, the shallow and narrow medium sulcus usually percurrent. Furcula as described in key, the outer fingers slender, feebly divergent, reaching nearly to middle of supra-anal plate, the inner ones forming a very short process or angulation (Pl. III, $f$.) Cerci rather broad, subfalcate, the middle third more than one-half the width of base, the apical third expanded and curved upward or forward, excavated on the outer face. Subgenital plate longer than broad, distinctly narrowing from below upward, its aplcal margin subelliptical. Length of body, ô, 17-18, 오, 23-25; of antennæ, ô, $10-11$, ㅇ, 8-9; of pronotum, 수, 4-5, 우, 5.5; 
of tegmina, $\hat{\delta}, 4, \hat{\imath}, 5$; of hind femora, $\hat{\delta}, 10-11, \hat{q}, 12-13 \mathrm{~mm}$. (Fig. 131.)

This small brown locust was originally described from numerous specimens taken in Crawford and Lawrence counties, Ind.,

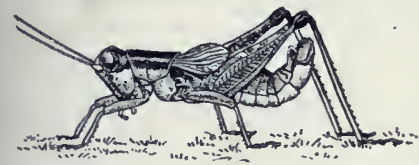

Fig. I3I. Male. $\underset{\text { (Original.) }}{ } \times 1.5$. between June 24 and July 15, and has not since been noted in the State. Near Wyandotte, Crawford Co., it occurred only along roadsides and in bare limestone glades on the crests and upper slopes of the high wooded hills.

In Lawrence County it was found to be rather common in midJuly among the underbrush of high wooded slopes on the State University farm, three miles southeast of Mitchell. Here the soil was very sparsely vegetated, sedges and wild asters being the prevailing herbs. The ground was covered with the dead leaves of the last season, with whose colors the hues of the locusts so blended that they were invisible while motionless. The males leap briskly when approached, but only for a short distance. The heavier bodied females are more clumsy, and are easily caught with the hand.

In color and general appearance this locust bears a close resemblance to $M$. obovatipennis, but on comparing the two, morsei is easily distinguished by its less prominent head, larger eyes, narrower interocular space, more feebly sulcate frontal costa, longer antennæ of male, more coarsely junctate metazona, broader tegmina of female and especially by the form of the male cerci and furcula. It reaches maturity some time in June, while adults of obovatipennis have not been noted till the last davs of August.

The general range of morsei is probably southern, the only records outside of Indiana being from Hocking Co., Ohio (Kostir), and Hattiesburg, Miss. At the latter place Morse mentions (1907, 50 ) the finding of a pair in woodland on sandy river-bottom land in company with M. viola. These he states were very large, the male measuring 22 , the female $28 \mathrm{~mm}$. in length of body. The locust should be found on dry woodland slopes in various localities in the sonthern thirds of Indiana and Ohio, and throughont Kentucky and Tennessee.

168. Melanoplus tribulus Morse, 1904a, 11.

Size medium, form of obovatipennis. Dark reddish-brown above, white and flavescent beneath. Postocular stripe continued into fuscous of sides of abdomen. Hind femora with indications of oblique fuscous bars, the knees fuscous. Hind tibiæ glaucous with black spines. Disk of pronotum somewhat convex above, once and a half, female, or twice, male, as 
long as wide, midcarina distinct, percurrent, hind margin slightly convex, emarginate. Tegmina broadly ovate, about three-fourths as long as pronotum. Male abdomen subclavate, considerably upturned. Subgenital plate with sides much expanded basally, the ventral face very short, convex, terminating in a very short blunt subapical fuscous tubercle. Supraanal plate shield-shaped, with convex sides abruptly narrowed to terminate in an acute point with straight sides. Furcula as described in key. Cerci slender, three times as long as basal width, tapering in basal third to about half the basal width, equal in middle fourth, expanded slightly distally into a laminate obliquely excised tip, the upper angle rounded, the lower acutely pointed, the whole organ gently incurved, the tip slightly decurved (Fig. 129, b.) Length of body, ô, 18.5-19, ㅇ, 26; of antennæ, $\hat{\delta}, 10.5$, $९, 8$; of tegmina, $\hat{\delta}, 3.5,-4.3$, ㅇ, 4.5 ; of hind femora, $\hat{\sigma}, 10.5$, , $12.5 \mathrm{~mm}$.

Great Falls and Round Hill, Va. (Davis). Morse's types were taken in highland forest on the summit of Sharptop Mountain, near Jasper, Ga., July 26. It ranges from Staten Island, N. Y., southern Pennsylvania and Stafford's Forge, N. J., southwest to Georgia, occurring among the undergrowth of deciduous forest and thickets on hillsides and mountain slopes.

\section{8a. Melaxoplus tribulus tribuloides Morse, 1906, 121.}

"Similar to $M$. tribulus but with the digits of the furcula much wider and longer, flattened from enlarged bases, in length equalling or exceeding the middle breadth of the cerci; the cerci narrower in the middle." (Morse.)

The above is the short original description based on two males, three females, taken at a height of of $2,000-2,400$ feet on Cheawha Mountain, Alabama, and one male, two females, at 1,000 feet near the base of the mountain. No other records can be found. A comparison of the types of the two forms tributus and tribuloides show that they differ only in the form and length of the furcula as shown in key. In tribulus they lie outside the median basal ridges, in tribuloides on the ridges. Since the furcula of $M$. gracilis and other short-winged ILclunophus are known to rary much in size and shape, tribuloides is considered as only a variety of tribulus.

\section{Melaxoplus devius Morse, 1904a, 12.}

Very similar to $M$. tribulus, the males almost inseparable, but having the prosternal spine stouter and more blunt; furcula longer, more tapering and less distant; cerci with apical half black or fuscous, "equal or a little expanded apically, laminate, transversely excised at apex, the upper angle more rounded than the lower, the dorsal margin sinuous, the ventral one concave." (Morse.) Females more robust than in tribulus with more widely infuscated lateral lobe of pronotum, the tegmina apically narrower and more acutely rounded (very broadly so in tribulus); hind margin of metazona scarcely emarginate at middle, valves of ovipositor shorter and 
broader. Length of body, $\hat{\delta}, 17-20,9,22-26.5$; of antennæ, $\delta, 9-10$, ९, 7.5-8.5; of tegmina, $\hat{\delta}, 2.5-3$,,$~ 2.8-3.5$; of hind femora, $\hat{o}, 10-11.5$, ค, $11.5-13 \mathrm{~mm}$.

specimens at hand from the U. S. National Museum and Morse collections are from Jefferson, N. Car., and Wytherille, Va., Aug. 15-Sept. 4. Morse's types were from the latter place and Topton, $\mathrm{N}$. Car. and were taken in dry mountain forests at elerations of 3,000 to 4,000 feet. Its known range extends from Wytherille and Bolar, Va., through the Carolinas to Mountain City, Ga. It occur's for the most part in rather scant undergrowth of heavy deciduous forests on the mountain slopes.

170. Melaxoplus decoratus Morse, 1904a, 12.

Size rather small and form slender for the group. Dark reddish-brown, greenish-yellow beneath, the postocular shining black stripe extending back nearly or quite to end of abdomen, male, sometimes rather faint, female. Upper and outer faces of hind femora usually with feeble fuscous cross-bars. Hind tibiæ dull greenish-yellow, with a blackish annulus near base and often more or less infuscate near tip. Median carina of pronotum faint on basal third of prozona. Hind margin of metazona truncate or nearly so. Tegmina asymmetrically obovate, the costal margin more convex, the tips rather broadly rounded. Supra-anal plate broadly triangular, the sides upcurved to form broad, rather deep concavities each side the narrow median sulcus, which extends from base to apical third, then widens between two short and converging higher ridges. Furcula rather broad at base, tapering, divergent, lying outside the bases of the median ridges. Cerci with apical third widened, concave without, the apex subrounded, with ventral apical angle somewhat produced. Subgenital plate with apical tubercle strongly enlarged, produced and curved upward so that the ventral length of the plate is almost or quite equal to its basal depth (Fig. 129, d.) Length of body, ô, 15-18, ᄋ, 21.5-25; of antennæ, $\hat{\delta}, 8.5-9.5$, $\uparrow, 8-9$; of tegmina, $\hat{\delta}$ and $\uparrow, 3.5-4$; of hind femora, $\hat{\delta}$, 9.5-11, , $10.7-12 \mathrm{~mm}$.

Clarksville, Tenn., June 27-July 7 (Fox). Morse's types were from Wytheville, Ta., Murphy and Topton, X. Car., and Blue Ridge, Ga., July 25-Sept. 4; taken among low shrubs in dry llountain forests at elevations of 1,700 to 4,000 feet. R. \& $H$. (1916, 220) record it also from Orange, Va., and Clayton and Macon, Ga. It is a rery distinct species, the males being readily recognized by the peculiar prolonged subgenital tubercle, which, as Morse says, "appears more like a malformation than otherwise."

\section{Series IV. The Puer Group.}

Species of small or very small size, with general hue reddishor gravish-brown, often more or less tinged or mottled with fuscous; postocular black or fuscous stripe present and extending 
back at least as far as metazona, male, often subobsolete, female; hind tibiæ glaucous or pale greenish-blue, often yellowish at base and tip, the spines black or pale at base; disk of pronotum with sides distinctly but feebly divergent, male, more strongly so, female, median carina low but distinet throughout, prozona onehalf or more longer than metazona; prosternal spine as described in key to Series; tegmina shorter than pronotum, oval or obovate, usually well separated but sometimes attingent or nearly so, their tips usually subtruncate, more often so in female; hind femora rather stout, distinctly surpassing abdomen, male, reaching or slightly surpassing its tip, female. Male abdominal appendages variable according to species.

Seven species of the group are known, all from the southern coastwise states. The males are readily separated by the characters given in the following key. The females are very similar in structure and general appearance, and no satisfactory key can be made for their determination.
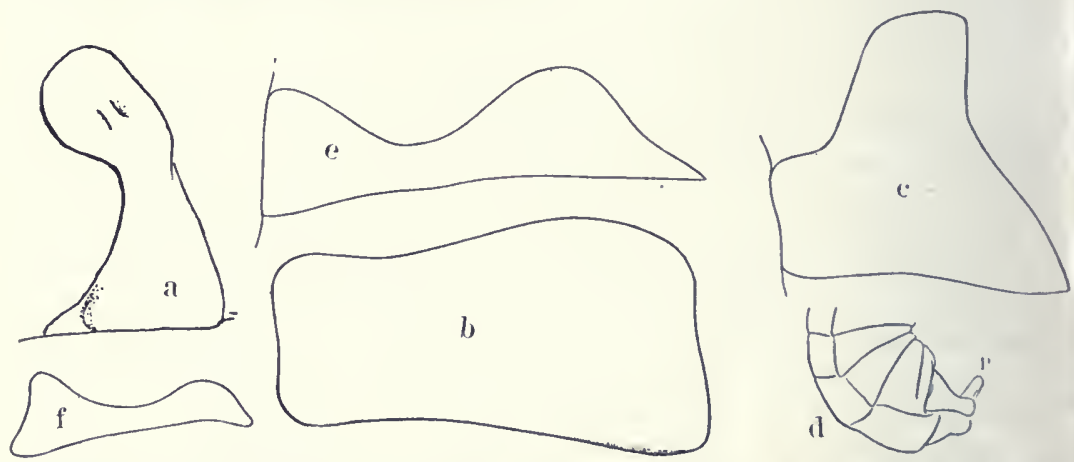

Fig. 132. Outlines of cerci of males of Melanoplus. $X$ 10. $a$, pygmaus; $b$, stegocer. cus; $c$, scapularis; $e$, mirus; $f$, strumosus; $d$, apex of male abdomen of $M$. rotundipennis, showing form of cercus and p, the strongly elevated pallium. $X$ 4. (After Davis, R. \& H. and Scudder.)

KEY TO SPECIES OF PUER GBOUP.

a. Furcula very short or absent; supra-anal plate of male without deep subapical lateral emarginations, which give its apex a trilobate appearance.

b. Furcula distinct but very short (Fig. 133, a) ; tegmina separated by one-half or more the width of one of them.

c. Hind margin of metazona with a distinct but small median notch; cerci of male substyliform, very slender, feebly tapering beyond the thickened base (Fig. 133, $a, b$ ); pallium not elevated above the tip of subgenital plate.

171. PUER.

cc. Hind margin of metazona rarely with a very minute median notch; cercl laminate, the apical third slightly wider than the middle; pallium conical, strongly elevated above the apex of subgenital plate (Fig. 132, d.)

172. ROTUNDIPENNIS. 
bb. Furcula wholly absent; tegmina usually less widely separated, often attingent.

d. Subgenital plate not greatly produced backward in the form of a conical scoop; cerci not as in $d d$. below.

e. Cerci subspatulate, the apex larger and more evenly rounded than in rotundipennis (Fig. 132, a); apex of subgenital plate produced into a short rounded knob; tegmina separated by $1.5 \mathrm{~mm}$.

173. PYGMAUS.

$e e$. Cerci not subspatulate; subgenital plate without an apical knob; tegmina subattingent or feebly overlapping.

f. Cerci broad at base, thence with sides almost straight, feebly widening into a broad subrectangular plate, its apex either subtruncate or broadly rounded (Fig. 132, b) ; tegmina of female obovate, the tips subtruncate.

174. STEGOCERCUS.

ff. Cerci broad at base, the apical half expanding into a lamellate plate resembling a scapula with apex broadly obtusely emarginate (Fig. 132, c); tegmina of female elongate-oval their tips broadly rounded. 175. SCAPULARIS.

dd. Subgenital plate greatly produced and compressed into a conical scoop with sharply rounded apex; cerci moderately broad at base, then narrowing sharply on dorsal margin to half the basal width at middle, again expanding to basal width and finally gradually narrowing to a sharp angle (Fig. 132,e.)

176. MIRUS.

aa. Furcula nearly half as long as supra-anal plate, the latter with deep subapical lateral emarginations which give its apex a trilobate aspect (Fig. 133, f.)

177. STRUMOSUS.
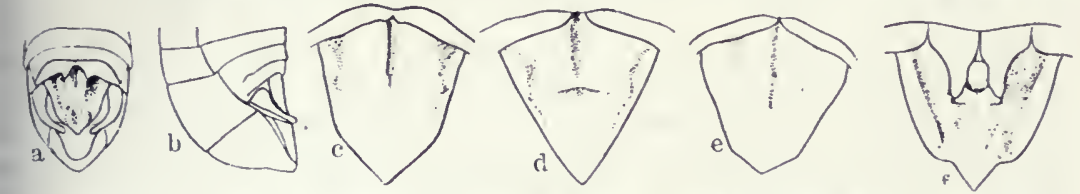

Fig 133. $a$ and $b$, Dorsal and side views of apex of male abdomen of M. puer. $\times$ 1.5. Supra-anal plates of males of Melanoplus. c, stegocercus; $d$, mirus; $e$, scapularis; $f$, strumosus. $X$ ro. (After R. \& H.)

171. Melanoplus PUer (Scudder), 1877a, 87. Least Short-winged Locust.

Very small for both genus and group, the females one-third the larger. Above dull reddish-brown; beneath dull yellow. Face yellow, usually dotted with small fuscous spots; occiput, disk of pronotum and dorsum of abdomen dark reddish-brown. Male with upper half of prozonal lateral lobe, meso- and metapleura and sides of two or three basal segments of abdomen shining black; female with these dark markings often vague. Hind femora dull yellow, their upper and inner faces usually bifasciate with fuscous; lower face reddish-yellow. Hind tibiæ purplish-green, the base and tip dull yellow mottled with brown; spines black, pale at base. Interocular space narrow, as broad as, male, or but slightly broader, female, than first antennal joint. Fastigium strongly declivent, widened and broadly sulcate in front of eyes. Frontal costa narrow, shallowly sulcate at and below the ocellus. Eyes subelliptical, those of male very prominent 
and longer than the cheek below them. Pronotum with disk flat and sides nearly parallel, male, rounded and distinctly divergent behind, female; prozona one-half longer than metazona, the latter densely and finely rugose-punctate. Tegmina elongate-oval or obovate, twice as long as broad, their tips subtruncate. Extremity of male abdomen feebly swollen, but little upcurved. Supra-anal plate short, broadly. triangular, apex subacute, side margins feebly elevated to form a large shallow concavity each side of the rather wide, tapering median basal sulcus which reaches only middle of plate. Furcula consisting of a pair of very short, divergent, oblong processes lying on the bases of the median ridges (Fig. 133, $a, b$.) Cerci as described in key, feebly incurved, shorter than supra-anal plate, their tips blunt. Subgenital plate small, subconical, the apex ending in a slight erect tubercle. Length of body, $\hat{\delta}, 10-16$, ㅇ, 16-21; of antennæ, $\hat{\delta}$, $5.5-6$, ㅇ, $6.5-7$; of pronotum, ㅅ․ $3-4$, 우 $4.2-5$; of tegmina, $\hat{\delta}, 2.2-3$, 오 , 2.5-3.5; of hind femora, ô, 7.5-8.5, , , 9-11.5 $\mathrm{mm}$.

Miami, Ft. Myers, Sarasota and Dunedin, Fla., Dec.-April (W. S. B.). This, the smallest known species of the genus. is known only from the mainland of the southern two-thirds of Florida. Scudder's types were from Ft. Reed and it has been recorded from numerous localities south of that place. The species varies nuch in size and color, some males at hand from Sarasota being but $10 \mathrm{~mm}$. in length, while $R$. \& $H$. record a series from Miami (1912) ranging from 13.5-17 and females $19-22.5 \mathrm{~mm}$. in length. About Dunedin puer is the only short-winged Melanoplus so far taken and occurs sparingly in both nymph and adult stages throughout the winter, mating from mid-January to April. It is found for the most part in small colonies in the wire-grass about moist places and along pathways in open pine woods, while in early spring it is often taken by sweeping huckleberry and other low shrubs. The males are rather slow to flush but very active after being once frightened. The living females are often a handsome purplish-gray in general hue and are much more sluggish in their movements. Several of the Dunedin males have the black postocular stripe very shining, extending back the full length of pronotum and half or more the length of abdomen.

172. Melanoplus Rotundipexis (Scudder), 1877a, 86. Round-winged Locust.

Size small for the genus, medium for the group. Color much as in puer, the black postocular stripe extending back nearly to middle of abdomen, male, only to metazona, female; meso- and metapleura black, the latter with crest yellow. Upper and inner faces of hind femora usually bifasciate with fuscous, the bars sometimes lacking in female; hind tibir dull glaucous, tinged with yellow near base and apex. Vertex and fastig. lum much as in puer, the latter more shallowly sulcate in female; frontal costa more deeply sulcate below the ocellus. Disk of pronotum feebly convex and rounded into lateral lobes in both sexes, otherwise as in puer. 
Tegmina elongate-ovate, one-third longer than broad, the tips subtruncate. Extremity of male abdomen strongly upcurved. Supra-anal plate broadly triangular, the apex obtuse; sides less elevated than in puer. the median basal sulcus much wider, more shallow and extending to apical third of the plate. Furcula very short, oblong, flattened, widely separated processes lying on the base of the median ridges; last dorsal segment almost separated at middle. Cerci rather stout, laminate, gradually narrowed to middle, the apical third slightly widened, feebly grooved without, the tips rounded and slightly incurved (Fig. 132, d.) Subgenital plate very small, feebly narrowed to apex, the apical margin but slightly elevated. Length of body, $\hat{\delta}, 13.6-17.5$, $\&, 17-23$; of antennæ, $\hat{\delta}, 7.5-8,8,8-8.5$; of pronotum, $\hat{o}, 3.5-4.5$, $\&, 4.2-4.8$; of tegmina, $\hat{o}, 3-3.8$, $\$, 3.3-4$; of hind femora, $\hat{o}, 9-11, \uparrow, 11-13 \mathrm{~mm}$.

LaGrange and Gainesville, Fla., Sept. 9-12 (Davis). Other specimens at hand from the U. S. National Museum and Morse collections are from Cedar Keys, Ocala and Live Oak, August 10-15. The known range of rotundipennis is limited, extending, according to R. \& H. (1916, 222), only from Prunswick to Thomasville in southern Georgia and sonthward throughout northern and central Florida to Lakeland. It is the prevailing short-winged Melanoplus in northern Florida, occurring among the saw palmettoes and underbrush of open pine woods and "varying much in general color according to environment, from mottled grayish on sand to dark red-brown among dead leaves and other plant debris." The Melanoplus inops of Scudder (1897, 329) and R. \& H. (1907, 295 ) is a synonym.

173. Melaxoplus pygareus Davis, 1915, 96. Pygmy Locust.

"Related to $M$. rotundipennis but differing in the distinctly broader and more truncate prosternal spine in both sexes, which is broader than long, and in the distinctive male genitalia. Size a little smaller and form more slender than in average rotundipennis. Color resembling the less heavily marked examples of that species; the hind femora with three fuscous blotches above, pale yellow beneath, male, weakly orange, female; hind tibiæ very pale blue with a slight purplish suffusion. Lateral lobes of pronotum almost immaculate in female. Dorsum of pronotum with lateral carinæ more divergent toward posterior margin than in rotundipennis. Eyes less protuberant; frontal costa distinctly sulcate throughout Tegmina much the same, separated by a width of $1.2 \mathrm{~mm}$. Supra-anal plate more elongate, distinctly longer than broad, the median ridge confined to basal third. Cerci as described in key (Fig. 132, a.) Length of

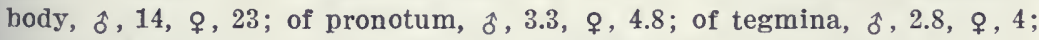
of hind femora, $\delta, 9.7, \wp, 12.7 \mathrm{~mm}$. Greatest width of tegmina, $\hat{\delta}, 1.8$, \&, 2.6 ; of hind femora; $\hat{\delta}, 2.3$,, $3.2 \mathrm{~mm} . "$ (Davis.)

The above, taken in connection with the key, presents the salient points of the original description of this species. It was described from a single pair taken by Mutchler and Watson at 
DeFuniak Springs, Fla., Oct. 17-19, the types being in the American Museum of Natural History. Other specimens collected by R. \& H. at the type locality, Aug. 30, are in the Davis collection.

\section{Melanoplus stegocercus Rehn \& Hebard, 1916, 223.}

Form of $M$. rotundipennis but slightly larger and more compact. Color much as there, the black postocular stripe extending the full length of pronotal lobes and along the sides to middle of abdomen in both sexes. Dorsal surface of abdomen and outer face of hind femora often largely fuscous; upper and inner faces of hind femora with three blackish cross-bars. Disk of pronotum rounded into the lateral lobes, the lateral carinæ very faint, feebly divergent backward, male, more strongly so, female; hind margin of metazona rounded, without trace of median notch. Tegmina almost as broad as long, tips subtruncate, more distinctly so in female. Supra-anal plate elongate-triangular, the median basal ridges very broad, the sulcus between them wide, shallow, ill defined, percurrent or nearly so (Fig. 133, c.) Cerci as described in key, the apical sixth impressed. Subgenital plate rather narrow, subcompressed, about $2 \mathrm{~mm}$. in length, its apex narrowly rounded. Length of body, $\hat{o}, 15-17.5$, ㅇ, 19-22; of pro. notum, $\hat{\delta}, 3.8-4$, ㅇ,, $4.8-5$; of tegmina, $\hat{\delta}, 3-3.2$, 우, $3.8-4.2$; of hind femora, ô, 10-11, 우 11.5-12.5 mm. (Fig. 134, a.)
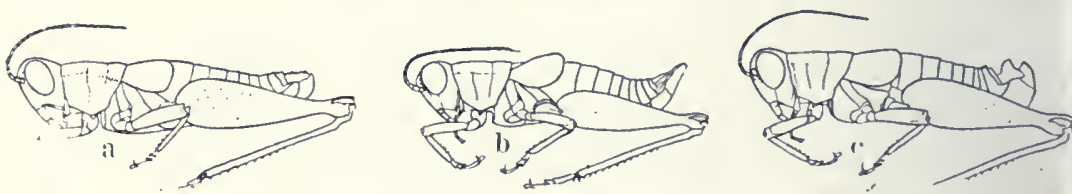

Fig. r34. Lateral outlines of males of Melanoplus. a, stegocercus; $b$, mirus; $c$, scapularis. $X$ 2. (After R. \& H.)

The above description was drawn from a series of specimens in the Philadelphia collections taken by R. \& H. near Groveland, Ga., Sept. 21. The unique male type collected by Bradley July 28 , was from the same locality. There is no record of its occurrence elsewhere, nor of its habits.

\section{Melanoplus scapularis Rehn \& Hebard, 1916, 226.}

Color and measurements as in stegocercus. The male differs in the form of cerci as described in key and shown in Fig. 132, the apical third being widely expanded, broadly emarginate, the upper outer lobe the longer with apex rounded. Subgenital plate a little shorter, less compressed with apex wider, subtruncate. The females differ only in having the tegmina a little more narrow with apex more evidently rounded (Fig. 134, c.)

Known only from Jesup, Sandfly and Isle of Hope, Ga., and Woodville, Fla., Sept. $1-3$. At Jesup it was found "in a restricted area of a sandr tract covered with low bushy plants, such as Myrica pumila Michx., Quereus minima Sarg., gall-berry bushes and saw palmettoes, and at the other localities "in scant 
undergrowth of the slightly more elevated portions of the flat, almost swampy gray-bark pine woods." (R.\& $H$.

Very close to stegocercus and may prove to be only a rariety of that species.

176. Melaxoples Mirus Rehn \& Hebard, 1916, 224.

"Size and form similar to moderately large South Florida males of $\boldsymbol{M}$. puer. Tegmina much as ir M. rotundipennis, their apices more or less noticeably truncate. Extremity of abdomen tumid, greatly produced and upcurved. Supra-anal plate simple as in scapularis, but with lateral margins very weakly convex and converging evenly caudad (Fig. 133, d.) Cerci as described in key, all of the narrowing and widening due to the curvature of the dorsal margin, the ventral margin almost straight, the apices of the two cerci subattingent just beyond the distal extremity of the supra-anal plate (Fig. 132, e.) Disto-ventral abdominal segment produced mesad in a very small sharp point. Subgenital plate as described in key. Females closely resembling the large ones of $M$. puer, the principal sulcus more decided on dorsum of pronotum; smaller and more compact with shorter and more robust limbs than those of $M$. rotundipennis. Color much as in rotundipennis, the males with ventral margins of caudal femora sharply pale and quite striking, this marking broader proximad (Fig. 134, b.) Length of body, $\hat{\sigma}, 15.5-16.2$,, , 18.8-20; of pronotum, $\hat{\sigma}$, $3.6-3.8, \%, 4.1-4.7$; of tegmina, $\hat{\delta}, 3-3.7$, $\uparrow, 3.7-4.3$; of hind femora, o, $9.4-9.8$, ᄋ, 10.6-11.2 mm." (R.\&H.)

The above comprises the salient features of the original description. The species was described from three pairs taken at Weldon, $\mathbf{x}$. Car., July 24, where it "was found very scarce in scattered woods of low pines and oaks, with a typical ammophrtic undergrowtlı of huckleberry and other low bushes and plants. The insects were wary, but were found to hide constantly, so that by careful approach they were picked up with ease." No other record is known.

177. Melayoplus strumosus Morse, 1904a, 11.

Deep reddish-brown above, whitish or flavescent beneath. Postocular fuscous stripe indistinct female, deep black and extending on to abdomen, male. Hind femora very faintly obliquely bifasciate with fuscous. Hind tibiæ glaucous, paler at base and tip, the spines black tipped. Disk of pronotum twice, male, or once and a half female, as long as wide, midcarina percurrent. Prosternal spine prominent, flattened, subcylindric, slightly curred backward, apex transversely excised, the angles rounded. Tegmina small, obovate, two-thirds as long as pronotum, attingent or slightly separated, their tips broadly rounded. Male abdomen subclavate, the subgenital plate and preceding segment tumescent, broader than deep, greatly elongated, the former elongate scoop-shaped, bluntly rounded at apex. Supra-anal plate as described in key, its disk with a prominent transverse median ridge crossing two-thirds its width; furcula broad at base, then suddenly narrowed to finger-like projections whose tips reach the ends of 
the transverse ridge, thus enclosing a shallow, subquadrate basal median sulcus (Fig. 133, f.) Cerci slender, two-thirds as long as supra-anal plate, tapering evenly in basal half to one-fourth the basal width, the apical half bent gently upward and inward, the tip slightly expanded, obliquely excised, with upper angle rounded, ventral one acute (Fig. 132, f.) Length of body, $\hat{\sigma}, 15-17, \uparrow, 17.5-26$; of antennæ, $\hat{o}, 6$,,+ 7 ; of tegmina, $\hat{o}$, 2.7 , ㅇ, $3.5-4$; of hind femora, ô, 10 , 우, 11.5-13 mm.

Morse's types, which I have examined, were taken at Denmark, S. Car., and JeFuniak Springs, Fla., Aug. 5-15, from anong shrubbery in open pine woods. The known range of the species extends from Faretteville, N. Car., to Lookout Mountain, Alabama. R. \& H. (1916, 228) record it from a number of localities in the Carolinas and Georgia, it having been found by them mainly among oak sprouts in pine woods and on mountain slopes. In the majority of their specimens the fuscous bars of hind femora were very faint or lacking, though in a few they were heary and very pronounced.

Series V. The Maxcus Group.

This group consists of short, rather small robust species of a dull brown and clay-yellow hue, having the antennæ shorter than lind femora; pronotum rather short, feebly widening behind, more distinctly so in female, its disk obviously tectiform; prozona not over one-third longer than metazona, the latter with liind margin broadly rounded or very obtuse-angulate, median carina distinct only on metazona; tegmina oval, shorter than yro-
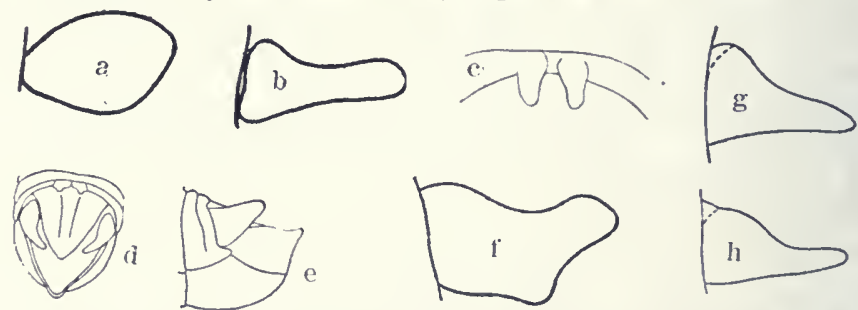

Fig. 135. $a, b, c$. Outlines of tegmen, cercus and furcula of $M$. mancus; $d, c$, dorsal and side views of apex of abdomen of $M$. islandicus; $f$, outlines of cercus of male of $M$. dirergens; $g$, same of $M$. cclatus; $h$, same of M. sylacstris. (After Morse and McDaniel.)

notun, their dorsal margins well seprarated, sometimes subattingent in male; prosternal spine short, blunt, conical or priamidal; hind tibiae red with black spines; abdomen compressed, calrinate above, its extremity in male but little enlarged, feebly upcurved; supra-anal plate triangular, the usual median groove narrow; furcula surall, triangular or subcylindrical projections lying on the bases of the median ridges; cerci usually short, nearly straight, sulıstyliform or laminate; subgenital plate small, con- 
ical, subpyramidal, erect, the apex not over one-fourth the width of base. Four species and one rariety are known from our territors.

KEY TO EASTERI SPECIES OF MAXCLS GROUP.

a. Cerci of male simple, not sub-bifurcate or boot-shaped.

b. Lateral carinæ of pronotum wanting; subgenital plate of male strongly narrowed to a prolonged conical apex; tegmina of female with tips broadly erenly rounded (Fig. 135, a.)

178. MAxcus.

$b b$. Lateral carinæ obvious, especially so on metazona of female; subgenital less narrowed and prolonged; tegmina of female with tips narrowly rounded or subangulate.

c. Cerci of male strongly tapering, the apex much less than onehalf the width of base (Fig. 135, $d, h$ ); prosternal spine stout, broad, the apex subtruncate or broadly rounded.

d. Median sulcus of supra-anal plate percurrent; cerci shorter, their length not more than one-half more than their basal width, the apical fourth concave on cuter side (Fig. 135,d.)

179. ISLAXDICUS.

dd. Median sulcus evanescent on apical half of supra-anal; cerci longer, much more attenuate, their length nearly twice their basal width, the apical fourth not concave without (Fig. $135, h$.)

179a. SYLVESTRIS.

cc. Cerci shorter, sublamellate, triangular, tapering much less rapidly to a flattened apex (Fig. $135 \mathrm{~g}$ ); prosternal spine more slender, cylindro-conic, its apex narrowly rounded.

180. CELATUS.

aa. Cerci of male sub-bifurcate or roughly boot-shaped, somewhat similar to those of $M$. confusus (Fig. $135, f$.)

181. DIVERGENS.

178. Melaxoplus Maxces (S. I. Smith), 1868, 149. Smith's Locust.

Short, rather robust, the female much the larger. Dark brown above, dull clay yellow beneath, abdomen and hind femora reddish-brown; face greenish-yellow flecked with fuscous; antennæ dull yellow, dusky toward tips; the usual pisceous postocular stripe, fainter on metazona, bordered below by dull yellow; mesopleura and front half of metapleura black; sides of basal half of abdomen of male with a dark stripe, of female much flecked with fuscous. Lower face of hind femora yellow; knees in part fuscous; hind tibiæ deep red, male, paler red, female. Vertex feebly convex; interocular space as wide as frontal costa between the antennæ; fastigium strongly declivent, rather deeply sulcate, male, shallowly concave, female. Frontal costa narrowed above the antennæ, male, nearly equal throughout, female, feebly concave at and below the ocellus. Prozona onefourth longer than metazona, its median carina obvious but low, transverse sulci deep; hind margin of metazona subtruncate or broadly rounded. Tegmina ovate, two-thirds the length of pronotum, separated by one-half their width, female, less than one-fourth, male. Prosternal spine rather short, conical, subdepressed, erect, blunt, male, shorter and more pointed, female. Supra-anal plate of male elongate-triangular, the side margins strongly elevated; median ridges low, terminating at middle; furcula sub- 
cylindrical, finger-like, parallel projections lying on the bases of the median ridges. Cerci longer than supra-anal plate, the apical two-thirds narrow, of nearly equal width, incurved and feebly concave on outer face near tip (Fig. 135, $a, b, c$.) Length of body, ô, 14-17.5, ㅇ, 18-25; of antennæ,

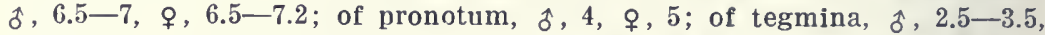
ㅇ, $3.5-4.5$; of hind femora, ô, 8.3-9, ․, 10-12 $\mathrm{mm}$.

Speckled Mountain, Maine (Morse); North Madison, Conn., Aug. 19-28 (W. S. B.). I first saw living specimens of this brown short-winged locust on the bare ledges of the Hammonasset River near North Madison, Conn., in August, 1896, where they were basking in the sunshine in company with spharagemon saxatile Morse. It is known definitely only from four or five New England localities, Lake Hopatcong, N. J., and Central, Pa., and is usually found on mountain slopes at a height of 2,500 to 3,300 feet, though often on hilltops at much lower levels. Morse (1898, $280)$ states that most of his specimens were taken on Speckled Mountain, Me., where: "It was plentiful, associated with Podisma glacialis among the various species of Vaccinium on the bare upper portions of the mountain. It is quite alert and agile, when approached springing suddenly and to a considerable distance, sometimes making several leaps in succession. It probably matures in late July or early Angust as it has been taken on the mountains from August 14 to September 6." The Running Lake, Illinois, record of McNeill (1891) was based on a specimen of M. obovatipennis (Bl.).

Two of the females at hand, one from Speckled Mountain, the other from North Madison, have the hind margin of pronotum with a distinct median notch, all the others being without trace of such emargination. All the males have the median ridges of supra-anal plate united just beyond the middle, the rery narrow median sulcus therefore confined to the basal half of the plate and not percurrent as stated by Scudder $(1897,219)$; the apical third of the plate beyond the ridges being concave, but not sulcate.

179. Meranoplus Islandicus Blatchley, 1898a, 196. Island Locust.

Males slender, size small for the genus; females larger, moderately robust. Dark wood-brown above, greenish-yellow below; antennæ uniform pale brownish-yellow. Face, lower halves of lateral lobes and metapleura dull yellow, ivory-white in life. Disk of pronotum dark brown, often with scattered vague dull yellow blotches; the usual dark bar on sides of prozona and abdomen distinct in male, vague in female. Hind femora with upper and inner faces faintly, obliquely bifasciate with fuscous. Hind tibiæ deep red with a vague black annulus near base. Frontal costa obviously but shallowly sulcate nearly throughout, male, only just below ocellus, female. Prozona but one-fifth longer than metazona, its median carina obsolete or but falntly indicated; lateral carinæ distinct on metazona, female, scarcely evident, male. Tegmina oval, about one-fourth 
shorter than pronotum, their inner margins well separated. Supra-anal plate of male elongate-triangular, its median sulcus very narrow, percurrent or nearly so; furcula short, flattish oblong projections lying somewhat obliquely on the bases of the sharp narrow median ridges (Fig. 135, d.e.) Cerci as described in key. Subgenital plate erect, conical, its sides compressed and apex subacute. Length of body, $\hat{o}, 14.5-17,9+19-24$; of antennæ, $\hat{\delta}, 6-7.5$, $९, 7-8.5$; of pronotum, $\hat{\delta}, 4$, $ᄋ, 5.5$; of tegmina, $\widehat{\jmath}, 3.5-4$, ․, 4-5; of hind femora, $\hat{\jmath}, 9-9.5$, ㅇ, $10.5-11.5 \mathrm{~mm}$.

LaSalle Island, Mich.; Steuben Co., Ind., August 11-19 (W. S. B.) ; DeGrassi Point, Ont. (Waller). The types of this species were taken by me on LaSalle Island, Aug. 17, 1897. They were found about the borders of a small clearing and along a narrow pathway through the dense spruce, birch and hemlock woods. When approached they would leap from the pathway into the mosses and liverworts bordering its sides, and there remain quiet while the intruder passed by. None were found at a distance of more than ten feet from this pathway, though especial search was made for them. On several subsequent visits to this and adjacent islands they were found fairly plentiful in similar habitats. Other locusts taken with them were Circotettix verruculatus (Kirby), Melanoplus dodgei huroni Bl., and Cammula pellucida Seudd. A single male of islandicus was taken from a path in a partly drained tamarack marsh near the border of Clear Lake, Steuben Co., Ind., Aug. 11, 1905.

Outside of these localities typical islandicus has been recorded only from DeGrassi Point, Ft. William, Aurora, Toronto and Georgian Bay, Ontario, and near Pequaming, Douglas Lake and Porcupine Mountains, Mich. At DeGrassi Point and Aurora Walker took his types of M. abortivus (Can. Ent. 189S, 92), a synonym of islandicus, "from openings in rich shady woods and on their borders, especially where the timber is of a coniferous growth. Seldom more than one or two were seen at once, though by diligent search specimens can be secured almost any day during the proper season, which lasts from the first week in July to the beginning of October." Near Pequaming Hebard (1909) found islandicus scarce and very local in distribution, only one colony of any size being found during three summers' collecting. This was in a growth of small hardwood trees. At Douglas Lake, Vestal (1914) took it in deep moist forests of beech, maple and hemlock, July 26-Aug. 12.

179a. Melayoplus islaxdicus syltestris Morse, 1904a, 10.

"A near relative of islandicus, differing chiefly in the form of the male cerci (Fig. 135, $h$ ) which, while of the same general structure, are narrower at base and have the distal half bent slightly upward and drawn out 
into a slender compressed, sub-styliform tip, the whole appendage being one and three-quarters or twice as long as the width of base." (Morse.) Females inseparable from those of islandicus. Furcula of males somewhat longer and stouter, finger-like projections lying parallel on or within the bases of the median ridges instead of somewhat obliquely across them as in islandicus.

1I. sylvestris was described from Blowing Rock, Linville and and Pineola, N. Car., the speciurens being taken July 13 and August 28 in cold deciduous forests, where they were found leaping actively about among the undergrowth of Vaccinium, Gaultherin. Galax, etc., at elevations of 3,500 to 4,000 feet.

Morse (loc. cit.) says: "The three species islandicus, celat"." and sylrestris are evidently nearly related descendants of the same parent form, modified by isolation. Intergrades may yet be discovered." R. \& H. (1916, 229) record sylicstris from several points in Rabun Co., Ga., and from Black Mountain, N.Car., and add: "This fol'm is clearly an offshoot of $J$. islandicus as stated by Morse, probably but a geographic race." since the form of the cerci, furcula, etc., are known to be extremely variable in other species of short-winged Melanoplus. I place sylvestris as a southern variety or race of islandicus.

180. Melaxoplus celatus Morse, 1904a, 10.

Closely related to $M$. islandicus, agreeing with it in size, coloration, markings and form. The males differ in the form of cerci, as described in key (Fig. 135, $g$ ) and in having the furcula longer, more robust, lying parallel on the bases of the median ridges; subgenital plate wider, much less tapering, its apex narrowly rounded, not conical as in islandicus. Females scarcely separable, somewhat stouter, pronotum wider, tegmina larger, more approximate above.

Monterey, Va., Aug. 20-Sept. 11 (Fox). Morse's types were from Wytheville, Va., where they were found in shrubby girowth among pines on dry stony soil at a height of 3,000 to 3,500 feet. In the mountain sections of Virginia Fox has taken celatus at Jarman Gap, Monterey and Hot Springs, .July :30-Sept. 7. He states (1917, 220) that it "appears to be very sporadic in distribution and usually rely scarce. All specimens were taken in or close to open deciduous woods on mountain slopes in grassy or slumbby undergrow th."

181. Melaxoptus nivergex's Morse, 1904a, 8.

Size and appearance of other members of the series, but easily distinguished by the sub-bifurcate cerci. General color as in the others, the fuscous markings on sides of hind femora more evident. Vertex blunt. Pronotum broad with flattened disk, subangulate at junction with lateral lobes, the midcarina distinct on metazona, absent on prozona. Prosternal spine short, usually conical with acutely pointed tip, sometimes much 
broadened laterally with wide, bluntly rounded apex. Tegmina shorter than pronotum, ovate or ovate-lanceolate, usually covering second abdo. minal segment, subattingent in male, widely separated in female, their tips sharply rounded. Subgenital plate with apex truncate or slightly emarginate, the sides, viewed from above, nearly straight. Supra-anal plate longer than wide, triangular, pointed at apex, the sides convex. Furcula stout, feebly tapering parallel projections about equalling the last segment in length and lying on the bases of the median ridges. Cerci roughly boot-shaped, the base very broad, a little longer than wide; apica; two-fifths bent abruptly upward at an angle of $35^{\circ}$ or $40^{\circ}$, narrowed to about one-half the width of base and tapering to a broad, evenly rounded blunt apex; the dorsal margin at the angle or bend, deeply concave, ventral margin strongly angulate and beyond the angle straight or slightly concare, thus forming a sub-bifurcate organ as long as the supra-anal plate; the whole appendage being thick, strongly convex externally, especially on tip which is curved gently inward (Fig. 135, f.) Length of body, $\hat{\delta}, 9-10, \uparrow, 11-20$; of antennæ, $\hat{\delta}, 6-6.5,9,6-7$; of tegmina, ๙ิ, 2-3, \&, 2-4; of hind femora, ô, 8.5-9.5, ㅇ, 9.5-11 mm.

"Balsam. Jackson Co., X. Car.. July 24-Aug. 19. Thirty-three specimens found in Vaccinium thickets and other low shrubbery in deciduous forests and clearings at an elevation of 5,000 to 6,000 feet." (.Morse.)

R. \& H. (1910a, 634) record six additional specimens taken Or.tober $\tau$ at the same place; the males exceding Mor:se's measurements by $4 \mathrm{~mm}$.

\section{Series VI. The Scctpert Groct.}

Species of medium or small size and rather robust form, having the general color grayish or russet-brown with the usual dark postocular stripe of the genus feebly developed. often absent in females; hind tibire red with black spines: disk of pronotum relatively slort with sides sulpmarallel. male, feebly divergent backward. female. surface slightly convex or feebly tectiform. median carina low, distinct throughout; prozona not over one-half longer than metazona, the latter finely rugose-punctate with hind margin obtuse-angulate or broadly rounded: tegmina usually about as long as or slightly longer than pronotum. oral or sub-lanceolate. their dor:sal margins attingent or overlapping. tips subacuminate or obliquely rounded. dorsal and lateral fields feebly if at all defined; prosternal spine stout, subeylindrical, with blunt rounded apex; hind femora rather slender, usually distinctly surpassing abdomen, male, reacling its tip or slightly beyond. female, their ('olor nearly uniform, rarels with faint fuscoms bars on upper face: extremity of male abdomen but slightly enlarged, nsually nearls horizontal. subgenital plate broad at base. rapidly tapering to a narrow apex, usually without apical or sub-apical tubercle. 
Four species and two varieties of the group occur in our territory, two of them with extended range, the others confined to the southern coastwise states.
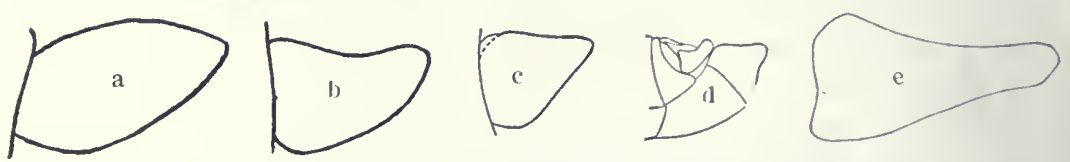

Fig. 136. $a$, Outline of tegmen of iemale of $M$. scudderi; $b$, outline of male cercus of same; $c$, same of $M$. carnegiei; $e$, same of $M$. quercicola; $d$, side view of apex of male abdomen of $M$. dazusoni. (After Morse and R. \& H.)

KEY TO EASTERN SPECIES OF SCUDDERI GROUP.

a. General color grayish- or dark reddish-brown; size smaller, the males not over $18.5 \mathrm{~mm}$.

b. Furcula nearly half the length of the supra-anal plate (Fig. 137); prozona as broad as or broader than long; tegmina ovate-lanceolate, subcuminate, slightly longer than pronotum (rarely fully developed.)

182. DAWSONr.

$b b$. Furcula very short or wanting, when present scarcely half the length of the last dorsal segment (Pl. III, b); prozona longer than broad.

c. Tegmina as long as or slightly longer than pronotum, their tips subacuminate; cerci subfalcate, their rounded tips about half as broad as base (Fig. 136, $a, b$.) 183. SCUDDERI.

cc. Tegmina shorter than pronotum, their tips narrowly rounded; cerci shorter, triangular, their tips less than one-fourth as broad as base (Fig. 136, c.)

d. Cerci rather broadly triangular, tapering evenly from base to apex; furcula short finger-like or triangular projections lying on the bases of the median ridges. 184. CARxegleI.

$d d$. Cerci elongate-triangular, tapering from base to middle, the apical half very narrow, of nearly equal width throughout; furcula represented only by swollen convexities of the margins of median notch of last dorsal segment.

184a. ACIDOCERCUS.

aa. General color pale reddish-yellow or ochraceous-tawny; larger, males 19 or more mm. in length.

$e$. Tegmina broadly oval with tips feebly truncate the females with dorsal and lateral fields slightly but obvously defined; cercus a triangular plate, slightly less than twice as long as its basal width, its apical fourth not incurved.

185. DAVISI. ${ }^{\text {so }}$

$e e$. Tegmina oval, their tips rounded and dorsal and lateral fields not defined; cercus more slender, slightly over twice as long as its basal width, its apical fourth much narrower and curved inward (Fig. 136,e.)

185a. QUERCICOLA. ${ }^{\text {G }}$

${ }^{30}$ These two forms were placed by Hebard in the genus Eotettir, he stating (1918, I53) that "in general appearance these insects suggest rather strongly a very large and exceedingly smooth development of the Scudderi group of the genus Melanoplus. The general structure, however, satisfies us that they must be assigned to Eotettix." "Now the principal structural characters of the genus Eotetix as given by Scudder, its founder (1897a, II), are the presence of a distinct subapical tubercle on subgenital plate of male, a sharply acuminate prosternal spine, distinctly developed furcula and styliform cerci, all of which characters fail in davisi and quercicola. I have, therefore, placed them in this series of Melanoplus. 
182. Meraxoplus Dawsoxi (Scudder), 1875f, 343. Dawson's Locust.

Size small or medium, the sexes subequal. Above grayish- or olivebrown, tinged with fuscous, beneath dull yellow; the piceous postocular stripe extending only to metazona, subobsolete in female; face and lower half of pronotal lobes olive-gray; metapleura in great part white. Hind femora reddish-yellow, their upper and inner faces usually with faint fuscous cross-bars. Interocular space about twice the breadth of first antennal joint. Frontal costa convex above the ocellus, female, nearly flat throughout, male distinctly punctate. Pronotum short, the disk convex;

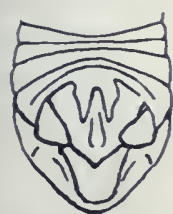

Fig. 137. Dorsal view of apex of male abdomen of M. dazesoni. (After Lugger.) prozona slightly longer than wide, male, subquadrate, female, less than one-third longer than metazona, the latter with hind margin obtuse-angled. Tegmina as described in key. Supra-anal plate elongate-triangular, its apex acute, lateral margins broader and more elevated on basal half; median sulcus rather shallow, percurrent. Furcula consisting of a pair of subparallel, slender, flattened tapering processes lying outside the median ridges (Fig. 137.) Cerci shorter than supra-anal plate, subfalcate, the apical third less than half the width of base, feebly concave without, the tips rounded. Subgenital plate small, longer than broad, subpyramidal, apically compressed, the apical margin but feebly elevated. Length of body, $\hat{\delta}, 14-17$, $\uparrow, 19-22$; of antennæ, $\hat{\delta}, 7.5$,

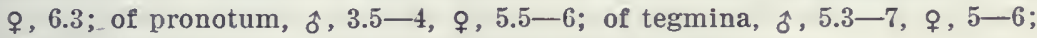
of hind femora, $\hat{\delta}, 8.7-9$, $10-10.5 \mathrm{~mm}$. (Fig. 138.)

Toronto, Ontario (Walker) ; Crawford Co., Iowa; Lincoln and Valentine, Neb. (Bruner). Scudder (1900a, 102) has recorded this species from Brunswick, Me.; Molse (1919) from Manchester, N. H., and Shull $(1911,226)$ from Saginaw Bay, Mich. It is also known from northern Pennsylvania. E. M. Walker $(1899,31)$ states that it is not uncommon near Toronto, "fre-

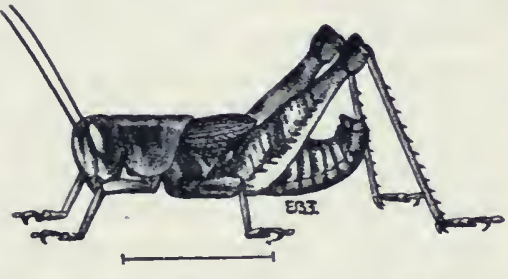

Fig. 138. Male. (After Lugger.) quenting dry sandy soil, generally somewhat bushy or scrubby, but also occurring in open sandy fields. At McDonald's Falls on the Severn River, Ont., it was found in a sandy and somewhat hilly district, thinly wooded with oak and white pine and with a scattered undergrowth of blueberry, Jersey Tea and Sweet Fern shrubs. The above are the only records from our teritory, the general range of the species extending orer central southern Canada, and from Iowa to Minnesota and Wroming, southwest to northern New Mexico. A long-winged form (rar. completus Scudder) with tegmina $15--17 \mathrm{~mm}$. in length, fully developed and greatly surpassing the hind femora, is known, but appears to be scarce. 
Brumer records dausoni as not rare in Nebraska on low grounds, while Somes $(1914,77)$ states that in Minnesota, between June 21 and Sept. 10, "it is a much more common and widely distributed species than $M$. scudderi and appears to adapt itself to more varied conditions of habitat than any other of our brachypterous forms, being most abundant amid such bruslyy growths as Symphoricarpos. Corylus and Taxus." It is said by Gillette to be common, up to 8,000 feet, on the foothills in Colorado, where mountainous plants and scrub oaks form practically the only regetation. Pezotettix tellustris Scudder $(1876,502)$ and P. abditum Dodge $(1877,113)$ are synonyms. M. dausoni is a somewhat aberrant form of the present groul, but is apparently more closely related to its members than to those of the next group with some of which it was classed by scudder.

183. Melayoplus scudderi (Uhler), 1864, 555. Scudder's Short-winged Locust.

Size small for the genus, medium for the group, the females distinctly the larger. Above dull reddish- or wood-brown, nearly uniform in the female; face greenish-yellow, much mottled with fuscous; the male, and sometimes the female, with an indistinct postocular fuscous stripe reaching thè metazona. Upper surface of abdomen often clouded with fuscous. Hind femora usually with two faint dark bars on upper and inner faces, knees blackish. Under surface dull clay- to bright yellow. Interocular. space about as broad as frontal costa, female, two-thirds as broad, male; fastigium strongly declivent, its median concavity shallow. Frontal costa feebly sulcate at and below the ocellus, female, nearly throughout, male. Pronotum with disk broadly convex, prozona from a fourth to a half longer than the densely punctate metazona; front margin truncate or nearly so, often faintly notched in middle, hind margin obtuse-angled. Tegmina, €longate-ovate, male, more broadly ovate, female, their inner edges slightly separated or attingent, male, usually slightly over-lapping, female. Supraanal plate triangular, its apex acute-angulate, the median ridges narrow, sharp, enclosing a narrow, deep, almost percurrent median sulcus which slightly widens apically (Pl. III, b.) Furcula minute triangular processes lying obliquely on the bases of the median ridges. Cerci as described in key, about twice as long as their basal breadth, slightly incurved. their apical halves broadly concave (Fig. 136, b.) Subgenital plate small. conical, the upper margin subacute. Length of body, $\delta, 16.2-18.5$, ,

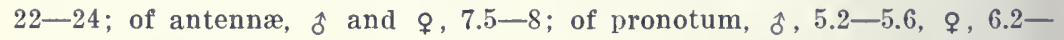
6.7 ; of tegmina, $\hat{\delta}, 5.2-5.5$, ㅇ, $7-8$; of hind femora, $\hat{o}, 10.5-12$, \&, $12.5-14 \mathrm{~mm}$.

In Indiana this dull colored locust is the most abundant of the short-winged species of Volanoplus, oceurring throughont the State, but more common in the sonthern portion. In the central counties it begins to reacl maturity about Angust 5tl, and los been taken as late as November 22d. It is one of the most com- 
mon of the late antumn locusts, frequenting the borders of open woods. fence rows and roadsides. especially in dry situations where blue-grass abounds. On warm sunnr afternoons in November. it may often be seen resting quietly on the sides of $\operatorname{logs}$. ol the lower part of rail or board fences, and apparentls enjoring the sunshine. In the center of the city of Indianapolis I have often noted it along the edges of walks, thongh it is less common on the lawns than its long-winged congeners. femur-rubrum and differentialis. It is able to withstand quite severe frosts and has been seen mating as late as November 15. From Florida M. scudderi is known only by a single male taken by Davis at Monticello. in the extreme northern part of the State.

The known range of scudderi is a wide one. extending from New England west to Minnesota and central Nebraska and sonth and sonthwest to northern Florida. Oklahoma and Ft. Worth. Texas. In New England Morse and Scudder have recorded it from Maine. Massachusetts and Connecticut, Morse stating (189S, 280) that it is a local but common species. preferring dry hillsides among bushes, roadsides and open woods. It is not recorded from Canada, and in Michigan is known only from Washtenaw Co.

Lngger (189S, 1S5) mentions it as uncommon in Minnesota, and Somes records it from only half a dozen localities. stating that there it reaches maturity about August 20. and is most common in open woodlands. Morse $(1907,52)$ records it from numerous localities in Arkansas, Oklahoma and northern Texas, and calls it a "locally common, even abundant, and very widely distributed species." Wherever $1 r$. scudderi occurs it appears to be, as in Indiana, one of the more common of the late antumn locusts. its gray and brown hues selving it well for protection among the fallen leaves, grass stems and other debris of that season.

184. Melayoplus Cariegiex Morse, 1904a, 10. Carnegie's Locust.

A medium sized species closely resembling scudderi in size and form. General color reddish- in stead of grayish-brown, the postocular black stripe of male more distinct. Frontal costa more deeply sulcate. Disk of pronotum scarcely as wide, its sides subparallel in both sexes, median carina more distinct. Tegmina shorter, usually slightly overlapping. Supra-anal plate shorter, its margins less elevated, median sulcus broader, terminating at middle of plate. Furcula minute, subcylindrical, parallel, lying straight on the bases of the median ridges. Cerci scarcely longer than their basal breadth, three-fifths as long as the supra-anal plate, thick at base, tapering evenly to the straight apex (Fig. 136, c.) Subgenital plate scoop-shaped, subconical, the apex narrow, rounded or subtruncate. Length of body, $\hat{o}, 14-17.5$,, $23-24$; of antennæ, $\hat{\jmath}, 7-8.5$. ㅇ, $8.5-10$; of pronotum, $\delta, 4.5$,, $6.3-6.7$; of tegmina, $\delta, 4-4.5$, $\odot, 5-6$; of hind femora, §., 10-12, ९, 13.5-14.5 mm. 
Specimens at hand are from Denmark and Yemassee, S. Car., August 10 -Sept. 4. Its known range is given by $\mathbf{R}$. \& H. (1916, 229 ) as extending "from Sulphur Springs, N. Car., Pinnacle Peak and Blue Ridge, Ga., snuth and east as far as Warm Springs and Macon, Ga., and Yema e, S. Car." It is sylvan in habitat, occurring on the ground am' the undergrowth of pine and oak woods.

184a. Mela yoplus carxe ieI acidocercus Hebard, 1919a, 290.

Very close to carneg $z i$. the males agreeing absolutely in color, size and measurements, differing only in the form of cerci and less developed furcula as described in key, and in having the median sulcus of supraanal plate percurrent and subgenital plate a little wider, less conical, its extreme apex feebly thickened to form a small tubercle. Females slightly paler with sides of pronotum a little less divergent; tegmina slightly longer, their edges feebly overlapping.

This locust was taken by R. \& H. in some numbers Sept. 5. 6, at Bainbridge, Ga. An examination of the type series at Philadelphia showed that the male cerci and furcula were both variable in form and development, the slender apical portion of cerci in some individuals being much shorter than in others, while the furcula occasionally had very short projections from the swollen bases, thus approaching those of earnegici. I therefore regard aeidocercus as only an offshoot or incipient species as yet worthy only of a trinomial name.

"The species was found common in oak shoots in areas of sandy soil overgrown with oaks, and occasional among the scant grasses and plants growing on sandy soil, in the bigher areas of the longleaf pine woods." (Hebard.)

185. Melanoplus Davisi (Hebard), 1918, 153. Davis's Oak Locust.

Size large for the group, the female especially so. General color pale brown to dull clay-yellow, the usual broad postocular black stripe, narrower in female, extending back to metazona; lower part of lateral lobes clayyellow; face russet to yellowish. Tegmina pale brown, male; dull clayyellow above, slightly darker on sides, female. Under surface dull yellow. Outer face of hind femora reddish-yellow with a paler ring near knee, upper face buffy with two broad brown cross-bars, these often absent in female; hind tibiæ coral-red, the spines black. Interocular space about as wide as basal joint of antennæ, male, four-fifths the width of frontal costa, female. Fastigium moderately produced and shallowly concave. Frontal costa broad, sulcate only in the region of the ocellus. Pronotum with median carina moderately high; hind margin broadly obtuse-angulate or subrounded. Tegmina broadly oval, usually slightly overlapping, as long as prozona and half the metazona. Prosternal spine short, subconical, its apex blunt, rounded. Furcula consisting of two nearly attingent slight convexities from each of which projects beyond the segment a minute rounded appendage. Supra-anal plate moderately broad, shield-shape, its 
basal third strongly sulcate with the margins of the sulcations carinate. Cerci as described in key, the margins feebly convergent to the narrowly rounded apex. Subgenital plate small, convex, tapering to the very narrow and produced rounded apex which is without a trace of the subapical tubercle found in the species of Eotettix. Valve: ' of ovipositor moderately elongate, not strongly curved distad to the dicute apices. Length of body, $\delta, 18.5-22, \rho, 25-27.2$; of pronotum, $\quad .8-5.2, q, 6.3-7$; of teg-

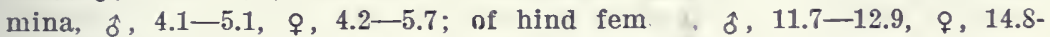
$-15.8 \mathrm{~mm}$.

This locust was taken by R. \& H. at DeFuniak Springs and Pensacola, Fla., Aug. 2s-30. At the former place "it was found in sandy long-leaf pine woods, with undergrowth of wire-grass and many oak shoots and dwarf oak. Whererer this type of country occurred the insect was found in large numbers, the oak undergrowth evidently being the food plant. The species is truly thamnophilus, not rapid in its morements, but jumping with great power. When approached, individuals often hid on the under side of the oak leares and when seized by a sudden grasp were found to cling tenaciously to their support." (Hebard.) At Pensacola it was very rare among gallberry bushes, Ilex glabra L., in low, sandy pine woods.

185̃a. Melanoplus Davisi QUercicola (Hebard), 1918, 156. Oak-loving Locust.

"Agrees in all respects with davisi except in the following features: Size somewhat smaller, form less attenuate. Tegmina slightly overlapping, oval, the curvature of the margin greatest distad, surface showing no definition between dorsal and lateral fields. Prosternal spine stouter, that of female somewhat flattened in front and behind. Supra-anal plate as in davisi except that a transverse carina runs for a short distance laterad from the extremities of the carinæ bounding the proximal median sulcus. Cercus slightly over twice as long as proximal width, dorsal margin very feebly concave to apex, ventral margin feebly convex and converging toward dorsal margin in proximal three-fourths; the remaining narrow dis. tal fourth of the cercus curved inward with margins parallel to the rounded apex, this portion about one-third as wide as the basal width (Fig. 136, e.) Subgenital plate with apex decidedly broader, feebly bilobate. Length of body, $\hat{o}, 16.3-21$,, $23.2-30.5$; of pronotum, $\hat{\jmath}, 4.1-5.2$,, $5.8-7.2$; of tegmina, $\hat{\jmath}, 3.9-4.8$, $q, 5.1-6.8$; of hind femora, $\hat{\jmath}, 10.5-12.3$, $q$, 13.5-16.5 mm." (Hebard.)

The above includes all the essential parts of the original description. The locust was taken bs R. \& H. at Woodrille, Carrabelle and Ocala; Fla., Sept. 1-19. Of its habits Hebard (1918, 158) says: "The species was found common in sandy long-leaf pine, Pinus palustris Mill, flatwoods among dwarf oak and oak shoots at Woodville; very few in scrub oak and oak shoots on flat 
saudy soil at Carrabelle, and few in oak clumps at from two to five feet from the ground at Ocala, in an environment very similar to that at Woodville. The species, like davisi, is thamnophilus, not rapid in movement, but extremely powerful in Jeaping and unusually able in hiding in the oak undergrowth to which it is peculiar."

An examination of the type series of both davisi and quercicola showed that the entire general facies of the two is the same; the color varying only in the slightly greater width of the dark pronotal stripe in the female of davisi. The definition between the dorsal and lateral fields of tegmina in that species is rerv slight and evident only in the females. The only difference of any note between the two is, therefore, that of the form of the male cerci as described in key, and this also is not greater than that shown among races of other species of short-winged Melanoplus. I therefore regard quercicola as only an incipient race or variety of davisi, it bearing the same relation to davisi that acidocercus does to carnegiei. In fact all four forms are so closely related that the tyro will have much difficulty in separating them. The cerci of davisi are of the same form as those of carnegiei, the figure 13 of Hebard (1918, Pl. VIII) showing the apex entirely too blunt.

\section{Series VII. The Fasciatus Group.}

Medium or large-sized species of robust form and dull hue, having the antenna about as long as, male, or two-thirds as long, female, as hind femora; prozona usually quadrate, flat or feebly tectiform, rarely more than one-fourth longer than metazona, its sides parallel, front margin trumcate; metazona flat, its sides parallel, male, usually, but never strongly, diverging, female, its hind margin obtuse-angulate; median carina low but distinct on metazona, absent or with a trace near front margin only on rrozona; lateral (arina wanting; tegunina sub-lanceolate, distinctly longel than pronotum, covering from one-lialf to thee-fourths the abdomen, their tips narowly rounded or subacute, inner margins overlapping, dorsal and median areas sharply defined; prosternal spine valiable; hind femora bifasciate with fuscous on upper and oliter faces; hind tibiae normally wholly or in gleat part red, often with basal third pale, the spines black; abdomen compressed, carinate, mol'e stlongly so in female, the extremity in male enlarged, upcurved; furcula, when present, very short, flattened, oblong or triangular projections lying on the sides of the median ridges of supra-anal plate; cerci and subgenital plate variable in the different species. 
In length and form of tegmina the members of this group are intermediate between the previous groups and the long-winged species' of Irclanoplus. Their feebly developed furcula, however, show that they are more closely related to the short-winged species previously treated than to the long-winged ones.
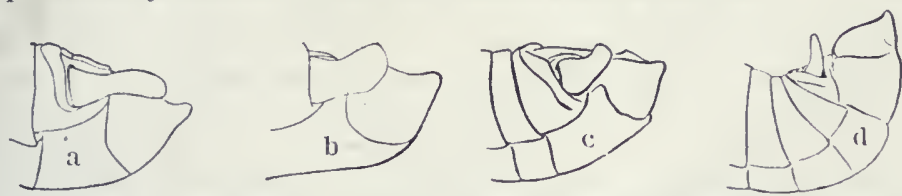

Fig. 139. Lateral views of apical portions of male abdomens of Melanoplus. $a$, fasciatus; $b$. querneus; $c$, nigrescens; $d$, huroni. $\times 4 . \quad$ (After Pettit, $R . \&$ H. and Scudder.)

KEY TO EASTERN SPECIES OF THE FASCIATUS GROUP.

a. Lower face of hind femora not deep red; interspace between mesosternal lobes of male distinctly longer than hroad; subgenital plate of male not or very feebly tuberculate at apex (Pl. III, g.)

b. Smaller, length of body, male, less than $20 \mathrm{~mm}$., of female, not more than $23 \mathrm{~mm}$; t tegmina covering two-thirds or more of abdomen; prozona of male but little if any longer than metazona.

186. Fasciatus.

$b b$. Larger, length of body, male, 21 or more, of female, 24 or more, $\mathrm{mm}$.; tegmina rarely (querneus) covering more than half the abdomen; prozona of male usually one-fourth or more longer than metazona.

c. Apical margin of subgenital plate of male rounded, not or but feebly elevated at middle; cerci of male, broad, flat, feebly narrowed at middle, the apical third as wide or slightly wider than base, the apex broadly rounded, not incurved (Fig. $139, b)$; tegmina slightly longer than head and pronotum together; furcula wanting or scarcely evident. 187. QUERxEUs.

cc. Apical margin of subgenital plate distinctly raised or prolonged at middle; cerci not as described in $c$. their apical third either incurved truncate, or obliquely transverse; tegmina not longer than head and pronotum together.

d. Furcula of male distinct but small; apical margin of subgenital plate feebly but obviously produced backward at middle.

e. Prozona not more than one-fourth longer than metazona; apex of male cerci subtruncate with angles rounded (Fig. 139, c); subgenital plate with a slight tubercle at apex.

188. NIGRESCEXS.

ee. Prozona one-third or more longer than metazona; apex of male cerci broadly rounded; subgenital plate without a tubercle at apex (Pl. III, h.)

189. WALSHII.

dd. Furcula wanting, the last dorsal segment narrowly parted at middle; apex of subgenital plate abruptly rounded and rather strongly elevated, but not prolonged backward; apical half of cerci expanded into an obliquely transverse oval lobe.

190. PONDEROSUS. 
aa. Lower face of hind femora deep red; interspace between mesosternal lobes distinctly broader than long in both sexes; apex of subgenital plate prolonged upward into a distinct tubercle (Fig. 139, d.)

191. HURONI.

186. Melanoplus Fasciatus (F. Walker), 1870, 680. Huckleberry Locust.

Size small for the group, medium for the genus, the sexes nearly equal; form robust. Dull grayish- or reddish-brown above, clay-yellow below, the male the darker. Antennæ reddish-brown, paler at base, dusky toward tips; occiput and disk of prozona fuscons; the usual black band behind the eye, extending back to metazona and bordered below by greenish-yellow. Tegmina dull reddish-brown, with often a few small fuscous spots on discoidal area. Hind femora dull brownish-yellow with two broad oblique blackish bars on upper, outer and inner faces; lower face pale or dull red; knees black; hind tibiæ red, rarely pale green, with a lighter ring near base, spines black. Occiput distinctly elevated above the pronotum; interocular space as broad, male, or nearly twice as broad, female, as basal joint of antennæ, fastigium strongly declivent, shallowly sulcate, its lateral margins distinct, male, very low, female. Frontal costa as broad as interocular space, feebly sulcate below the ocellus, male, slightly concave around it, female. Pronotum feebly expanding on metazona, disk rounded on prozona, flat on metazona; hind margin broadly rounded or obtuse-angled; median carina distinct only on metazona, faintly visible on portions of prozona. Tegmina usually covering two-thirds, female, or three-fourths or more, male, of abdomen, sublanceolate, their inner edges overlapping. Cerci of male straight, about four times as long as broad, middle third but slightly narrowed, apical third concave or sulcate, with tip rounded and incurved (Fig. 139, a.) Supra-anal plate broad, triangular, apex subacute, margins elevated, median ridges extending from base threefourths to apex, at apical third uniting with a cross carina which, with the ridges, form on the basal two-thirds of the plate a narrow median sulcus and two broad lateral concavities; furcula consisting of a pair of minute, widely separated subcylindrical projections lying outside the median ridges (Pl. III, g.) Subgenital plate longer than broad, the apical margin well rounded, feebly elevated at middle. Length of body, $\hat{\sigma}$, $17-19.5$, ․ , 20-23; of antennæ, ô, 7.5-9.5, 오, $6.5-8$; of pronotum, $\hat{o}$, $4.5-5$, ㅇ, $5-6$; of tegmina, $\hat{o}, 7.5-10$, 오 $8-11$; of hind femora, $\hat{o}$, $9.5-10.5$, , $11-12.5 \mathrm{~mm}$.

Winchendon and Sherborn, Mass. (Morse) ; Lake and Marshall Cos., Ind. (W. S. B.) ; Big Horn Mts., Wyo. This small locust has been taken in Indiana only in Marshall. Tippecanoe and Lake counties. In Marshall Co. it has been noted only in a low sandy oak woods, looldering Lost Lake, and just west of the station of Arlington at Lake Maxinkurkee. Here among low huckleberry and other bushes it is common from. July 15th on, the females, however, far outnumbering the males. Both sexes leap vigorously when disturbed, but often squat close to the ground after being flushed once or twice. In Lake County a few specimens lave been taken 
in the sand dune region near Millers, while a single male was taken June 28 by Fox near Lafayette.

The range of $M$. fasciatus is northern, extending from Labrador, Newfoundland, Nova Scotia and New England, north and west nearly or quite across the continent and south and west to New Jersey, northern Indiana, Missouri and Colorado, its southern linits being approximately that of latitude $40^{\circ}$, though a single male is recorded by Morse $(1907,47)$ from Cheahaw Mt., Ala. In New England Morse $(1898,281)$ sars: "It is a somewhat local but common and widely distributed species, found most frequently among huckleberry bushes growing in and along the edges of open pitch-pine woods, where it is frequently associated with Chlocaltis conspersa Harr. When startled it leaps well, but may usually be taken without a net. The species is rery variable in color, the upper parts, while usually of a dark reddish-brown, are sometimes dark olivaceous-gray and occasionally are strikingly raried with white. Adults appear in late June and may be found as late as October."

In Ontario Walker $(1899,32)$ found it "tolerably common in dry open woods, preferably on sandy or rocky soil, often in company with $C$. conspersa and sometimes with $M$. islandicus." In Nebraska Bruner reports it as "found only in the extreme northwestern part of the State, where it is rare." In Colorado Gillette (1904) sars it "appears to be confined to the mountains at altitudes varying from $\$, 000$ to 11,000 feet, where it occurs sparingly." It is not recorded from Ohio, but in Michigan appears to be common in suitable localities as shown by Hebard and Vestal. A long-winged form (M. $f$. volaticus Scudd.) with tegmina 19 to 20 mm. in length, occurs rarely in Michigan, and has also been recorded by Walker from DeGrassi Point, Ontario, and the Magdalen Islands.

I. fasciatus has been described and recorded under several different names, Melanoplus rectus Scudd., M. curtus, Scudd., and II. baconi McNeill being synonyms, while the Pezotettix borealis of Thomas $(1873,153)$, Fernald (188s) and numerous other authors, ncc borealis (Fieb.), are to be referred to 1 . fasciatus, a full synonyms being given by Scudder $(1897,267)$.

187. Melayoplus querxeus Rehn \& Hebard, 1916, 231.

Size abore the medium for the genus, large for the group; form moderately robust. Male-Grayish-brown above, greenish-yellow beneath. Face olive-gray flecked with fuscous; antennæ pale brown, darker toward tips. Sides of head and upper third of prozonal lateral lobes with a shining dark brown stripe; dorsal field of tegmina pale brown; meta-pleura 
dull yellow. Outer face of hind femora largely blackish-brown, shining, with two large spots on basal third and another behind middle, yellow. Apical half or more of hind tibiæ red (rarely dull yellow), basal portion fuscous with a paler annulus behind knee. Female duller, the stripe behind eye faint, dark bars on hind femora seal brown. Occiput convex, higher than pronotum; interocular space about two-thirds as wide, male, or three-fourths as wide, female, as frontal costa between the antennæ; fastigium as in fasciatus. Frontal costa low, rather wide, feebly sulcate below the ocellus, evanescent before reaching clypeus. Pronotum with median carina absent on prozona, transverse sulci very faint; prozona but about one-fifth longer than metazona. Tegmina covering two-thirds or more of abdomen. Hind femora slender, strongly surpassing tip of abdomen, male, reaching the tip, female. Supra-anal plate of male broadly triangular, basal median ridges low, more widely separated than usual, uniting with cross carina at middle of plate; furcula scarcely evident, being only slightly projecting convex points lying each side of the wide emargination of the last dorsal segment. Cerci and subgenital plate as described in key (Fig. 139,b.) Length of body, ô, 22.5-27, ㅇ, 32.2-32.8; of antennæ, $\hat{\delta}, 15.5$,, , 12.5; of pronotum, $\hat{\delta}, 6.2-6.5$,,, $6.7-7.9$; of tegmina, $\hat{\delta}, 10-11.7$,., $11.6-12.5$; of hind femora, $\hat{\delta}, 15.8-16.7$,, $17.3-$ $18.3 \mathrm{~mm}$.

This locust is recorded only from Thomasville, Ga., where Hebard took about 30 specimens, November 30-December 13. They were fir'st mentioned by R. \& H. $(1904,791)$ as $M$. nigrescens s.cudd., and were found in colonies in the vicinity of clumps of scrub oaks in pine woods. Hebard states that "the males seemed peculiarly unwary and occasionally one would be almost trodden upon before it would jump. The females were more wnwieldy than the males, but were very powerful. Both sexes. owing to the shortness of their wings, were wholly mable to fly." The female resembles closely those of $M$. walshii but is larger, with longer tegmina, the tips of which are narrowly rounded, not subacute as in that sex of valshii.

188. Melaxol'Lus Nigrescexs (Scudder), 1877b, 27. Black-sided Locust.

Size medium, form robust. Dull wood-brown, upper halves of lateral lobes and costal and discoidal areas of tegmina blackish. Antennæ reddish-brown, slightly infuscated at tip. Face flecked with fuscous. Metapleura yellowish, edged on either side with black. Hind femora brownish-yellow with a broad black band each side of middle, whose edges follow the impressed lines, the basal one sending a shoot to base; hind tibiæ vinous-red slightly infuscated at base. Frontal costa broad, shallowly sulcate throughout except just above the antennæ. Pronotum with median carina distinct only on metazona, disk separated from the lateral lobes by a distinct but bluntly rounded angle; front margin subtruncate, faintly emarginate in female, hind one very obtusely angulate. Prosternal spine rather long, cylindrlcal, apically tapering but blunt; interspace between mesosternal lobes half as long again as broad, male, quadrate, female. Tegmina longer than pronotum, covering only half the abdomen, tapering, apically 
subacute. Extremity of male abdomen clavate, slightly upturned; supraanal plate triangular with sides convex, apex acute and basal, not very deep, median sulcus; furcula consisting of a pair of slight approximate spines overlying the bases of the median ridges. Cerci compressed, tapering and straight on middle half, with an obscure inner superior basal tubercle, beyond the middle bent inward a little upward, equal, the tip squarely truncate with rounded angles (Fig. 139, c.) Subgenital plate small, longer than broad, slightly elevated and feebly prolonged at apex. Length of body, $\hat{\delta}, 23$,, 26.5 ; of antennæ, $\hat{\sigma}, 13, \uparrow, 11$; of tegmina, $\hat{o}$ and $\uparrow, 9.5$; of hind femora, $\hat{\delta}, 13.5$,,$+ 16.5 \mathrm{~mm}$.

Scudder's four specimens were from Georgia and Smithville, N. Car. R. \& H. (1916, 2:34) record the taking of 16 additional ones at Lake Waccamaw, X. Car., and St. Fimon's Island, Ga., so that it is known only from 20 specimens taken from the fom stations in those two states. R. \& H. state that "nigrescens is rosely related to ualshii, the male differing (hiefly in details of dorsum of pronotum, in the peculiar offset or twist of the distal section of cercus, and in the more pronounced ajex of the subgenital plate. The females are almost indistinguishable, the more delirate median carina, straighter ovipositor jaws and less distinctly tapering prosternal spine of nigrescens, being the only tangible distinguishing characters." Their specimens were secured in heary undergrowth of bushes in short-leaf pine woods, and among dead leaves nnder live oaks. All known specimens have been taken between August 30 and November 22.

189. Meidayoplus Walshil Scudder, 1897b, 11. Walsh's Locust.

Size medium for the genus, rather large for the group; form robust. Dark grayish-brown above, yellowish below. Face dull brown, occiput darker; the usual black postocular stripe rather narrow, often indistinct or wanting, especially in female; disk and lower half of lateral lobes of pronotum and tegmina grayish-brown, often more or less flecked with fuscous; dorsal field of tegmina pale brown. Hind femora reddish- or yellowish-brown, with two cross-bars of black on upper and outer faces, these sometimes indistinct in female; lower face pale or vermilion red, knees black. Hind tibiæ red, with a pale ring on basal third, the spines black. Interocular area nearly, male, or fully, female, twice as broad as first joint of antennæ, fastigium moderately sloping, broadly sulcate, male, feebly concave, female. Frontal costa short, not reaching clypeus, sulcate at and slightly below the ocellus. Pronotum feebly expanding on metazona, disk flat or nearly so, hind margin broadly obtuse angled. Tegmina about one-fourth longer than pronotum, sublanceolate, their inner edges slightly overlapping and tips subacute. Fore and middle femora much swollen in male, hind femora slightly surpassing abdomen, male, reaching base or middle of ovipositor, female. Extremity of male abdomen strongly recurved. Cerci coarse, heavy, the middle third two-thirds as broad as base, apical third slightly enlarged, curved abruptly inward (Pl. III, $h$ ), com- 


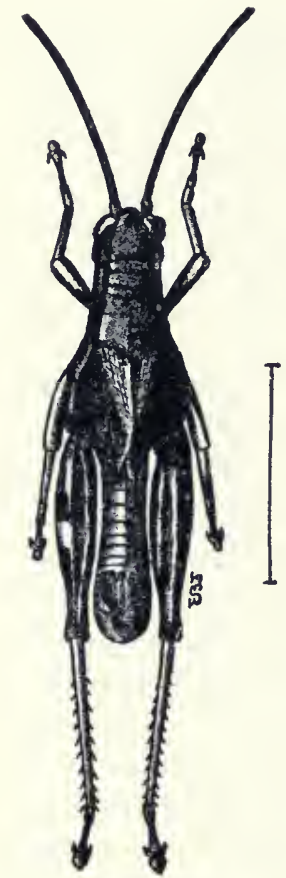

Fig. I40. Male. $X$ 2. (After Lugger.)

pressed and concave, the tip broadly rounded. Furcula consisting of a pair of short, rather broad and flat triangular teeth lying on the sides of the basal median ridges. Subgenital plate broader than long, the apex at middle feebly elevated. Length of body, $\hat{o}, 19-25$, ㅇ, 23-29; of antennæ, \&̇, 11-14, $\&$, $9.5-10.5$; of pronotum, $\hat{\delta}, 5-5.7$, ㅇ, $6-6.5$; of teg. mina, $\hat{\delta}, 6.2-9$, $९, 8-9$; of hind femora, $\delta, 11.5-$ 14, \&, 14-16 mm. (Fig. 140.)

Hudson, Mich.; Cloverdale, Ohio; various points in Indiana, June--November (W. S. B.). This clumsy bodied insect, the $M$. blatchleyi of my former work, is among the least common of our Indiana Melanopli, having been taken only in Crawford, Kuox, Monroe, Vigo, Putnam and Marion counties. Seldom more than a dozen or two are seen each season. It frequents, for the most part, upland woods and thickets, though it is sometimes found along the borders of marshes and swamps, but never close to the water. It is more arboreal than many of our locusts, having been taken in autumn on prickly ash and buttonbush shrubs, several feet above the ground, also from the boles of hackberry and oak trees, where it was probably sunning. In central Indiana it begins to reach maturity by June 14th, and ragged, forlorn looking specimens have been seen as late as November 3rd.

M. walshii has had a varied and somewhat strange career in Orthopterological nomenclature. It was first described by $\mathbf{B r}^{\circ}$ ner $(1876,124)$ under the name of Pezotettix occidentalis. This specific name, having been preoccupied by Thomas (1872, 453). was changed by Scudder $(1897,322)$ to blatchleyi. He, however, had described the insect as $M$. walshii on page 235 , and as $M$. amplectens on page 260 of the same work. M. walshii, therefore, stands, occidentalis Bruner, nec Thos., and amplectens and blatchleyi Scudder being synonyms.

The known range of walshii, based largely on the records of the above synonyms, is a wide one, extending from Ohio and Mich. igan, southeast to Virginia, North Carolina and Georgia, and west and north to Nebraska and Minnesota. Morse (1904, 50) notes it as an inhabitant of the "Transition zone of the Central and Appalachian regions, being a characteristic and dominant species among the mountains of western North Carolina. There 
it inhabits thickets of shrubbery, and herbage in and near deciduous woodlands at high elevations ( 3,000 to 6,000 feet) and sometimes extends its habitat into adjoining fields. Adults begin to appear about the middle of July, but the great majority do not reach maturity until August, and roung are still plentiful in September at high elevations."

Lugger (1898, 188) states that in Minnesota "it is rery common, preferring the edges of forests or places overgrown with bushes and vines. The graperine, especially, is preferred by these locusts, and they soon destroy its foliage by eating big holes in the leaves."

Somes $(1914,78)$ records the finding of a female drilling in a piece of dead wood in very much the same way as does Chlocaltis conspersa. Two fresh holes, one $8 \mathrm{~mm}$., the other $15 \mathrm{~mm}$. deep, were found in the stick within a space of 3 inches. R. \& H. (1916, 235) state that the size and color of the locust, and numerous structural features of the cerci, furcula, etc., are variable in the large series in their possession, and conclude that: "It is quite possible that the acquisition of more material from the Mississippi and Missouri valleys will show the desirability of recognizing two races of this species, one a western one to which the name blatchleyi should be limited, and the other (from the southeastern states) to which typical walshii with amplectens as a synonym would be applied."

190. Melaxoplus POXderosus ${ }^{57}$ (Scudder), 1875b, 473.

Size above the average for the genus, large for the group; form very robust. Dull olive to ash-brown; under surface greenish-yellow. Face, lower halves of lateral lobes, metapleura and pale portion of hind femora, clay-yellow. The usual dark postocular stripe faint, reaching to metazona, male, often obsolete, female. Disk of metazona, and dorsal area of tegmina pale brown, the discoidal area often flecked with fuscous. Hind femora with two broad black or brown bands on outer face, three on upper inner face; knees fuscous; tibial groove of under side often pinkish-red. Hind tibiæ usually red, often yellow tinged with red, the basal third fuscous with a black basal annulus, followed by a pale one, spines wholly black. Interocular space broad but narrower than frontal costa. Fastigium strongly declivent, shallowly and broadly sulcate, male, almost flat, female. Frontal costa low, very wide, shallowly sulcate at and below the ocellus. Frozona one-fourth, male, or less, female, longer than metaziona; median carina very faint on prozona; hind margin broadly obtuse-angulate, more so in male. Tegmina in short-winged form about equal to head and pronotum together, covering from one-third to slightly more than half the $a b$ -

\footnotetext{
${ }^{57}$ Scudder (loc. cit.) described ponderosus and robustus from the same place and on the same page, the former first. He later (1897, 354) placed ponderosus as a synonym of robustus, but precedence on the page of original description requires that ponderosus be retained and robustus made the synonym.
} 
domen, their tips narrowly rounded; in typical form reaching, female, or slightly surpassing, male, the tips of hind femora, the latter surpassing the abdomen $5 \mathrm{~mm}$., male, reaching its tip or slightly beyond, female. Supraanal plate broadly triangular, nearly flat, its tip obtuse; median sulcus percurrent or nearly so, expanded at apical fifth. Cerci short, very broad, the apical half bent upward and widened ventrally to form an obliquely: transverse oval lobe, much wider than the base; its apex broadly and obliquely rounded, the dorsal angle more produced and more narrowly rounded than the ventral one. Subgenital plate as described in key. Length of body, $\hat{\delta}, 25-29$, $\&, 27-34$; of antennæ, $\hat{\delta}, 13.5-15,, 12-14$; of pronotum, $\hat{\delta}, 6.5-7$,, $7-8.2$; of tegmina, $\hat{\delta}, 11.5-13$, $\$, 9-12$; of hind femora, $\hat{\delta}, 16-18$,, $17-21 \mathrm{~mm}$. Length of tegmina, long-winged form, ô, 21, ᄋ, $24 \mathrm{~mm}$.

This large bulky species varies greatly in wing-length, but only the short-winged form, the Pezotettix viola of Thomas $(1876,68)$ is known from east of the Mississippi, having been recorded from Illinois, Kentucky and Hattiesburg, Miss. The types of Thomas were from central and southern Illinois, while those of the longwinged form, typical ponderosus. were from l)allas, Texas. Scudder, in his key (1897, 138) separates the two forms only by the comprative lengtl of tegmina and color of hind tibix. Cotypes (labelled "types") of ponderosus ("robustus") from I)allas, received from him are at hand, as well as undoubted specimens of viola from Fayetteville and Cane Hill, Ark., and are almost exar.tly alike except in length of tegmina and color of hind tibiae, the aprical two-thirds of the latter in ponderosus being "yellow tinged with red," instead of distinctly red as in the Arkansas shortwinged form. The male cerci and other abdominal organs ne the same, with the exception of the median sulcus of supra-anal plate which in robustirs is interrupted or closed for a short distance at apical third. Morse (1907, 51) records robustus from mumerous points in Arkansas, Oklalıoma and Texas, stating that it "is a characteristic inhabitant of woodlands, usually xeropliytic". where it hops about among the nuderbrush with vigorous leaps." He states that "it is very variable in wing-length but not dimorphic, the tegmina of the male ranging from 12 to 24 and female from 13 to $24 \mathrm{~mm}$; and also in the color of the hind tibix, the distal two-fifths of which range from pale yellow to bright coral red." He donbtless had both forms before him but did not recognize the shorter winged ones as the violu of Thomas, thongh he had previously (1907, 50) taken M. riola at Hattiesburg, Miss.

Garman (18:4) has recorded the short-winged form from several points in central and western Kentucky, stating tluat it is "moderately common on low land along streams and increases in 
abundance toward the Mississippi River:" West of that stream it has been recorded only from Arkansas, Missouri and Nebraska. Ic.Neill has recorded viola from Running Lake, Ill., and states $(1899 \mathrm{a}, 345)$ that it is abundant in northern Arkansas and probably throughout the State, occurring on wooded hillsides between June 30 and October 26 , and that it is sometimes known to lay its eggs in small holes in rocks in stone fences. Bruner mentions it as "occasionally met with in the southeastern part of Nebraska," and Riley $(1878,220)$ as reaching maturity about St. Louis, Mo., on Angust 18. These are the only definite records of the form viola which can be found, and Scudder $(1897,357)$ not recognizing that it was only a form of his robustus, says: "It appears to have a rather narow range in the central Mississippi Valley between latitude $37^{\circ}-40^{\circ}$, and longitude $86^{\circ}-96^{\circ} . "$ This form bears a close general resemblance to $\mathrm{M}$. ualshii. but is larger, much more robust, with widely different male cerci, wider frontal costa and relatively shorter prozona.

The typical form robustus has been definitely recorded ontside of Texas only by Morse as abore mentioned. In Texas it seems to be widely distributed. Bruner $(1893,17)$ mentions, it as oceasionally doing much damage in central Texas, and states that it "is also quite closely related to Pezotettix riola Thomas, which occurs in Illinois, Indiana and Missonri." Hart (1906a, 159) records robustus as common at Houston and College station, Texas, "in margins of heary forests and on low flat bottom land asso(-iated with 1 . plebcjus stall."

191. Melayoples DoDgei IIURoxi Blatchley, 189Sa, 195. Huron Shortwinged Locust.

Size medium for the genus, large for the group; form robust. Dark brown marked with fuscous above, clay-yellow beneath. Face reddishrellow flecked with fuscous dots, male, dark gray, female. Sides of head with the usual shining dark stripe extending back to metazona, black in male, brown and less distinct in female, bordered below by clay-yellow. Tegmina dark brown mottled with small, quadrate fuscous spots, (larger and more prominent in female); these forming a row along the middle of discoidal area. Hind femora dull yellow, with two oblique black bars on outer, upper and inner faces; knees fuscous, preceded by a pale ring; lower face and hind tibiæ deep pinkish-red. Interocular area one-fourth wider than frontal costa between the antennæ, male, nearly two-thirds wider, female. Frontal costa prominent, rather narrow, strongly punctate, feebly sulcate only just below the ocellus, with median carina sharp and distinct on metazona, evident but very low on apical third of prozona, otherwise obsolete; prozona but slightly longer than the coarsely and densely punctate metazona; lateral carinæ evident but rounded; hind margin broadly obtusely angulate. Tegmina one-third to one-half longer than 
pronotum, covering slightly less than half the abdomen, their tips narrowly rounded. Hind femora short, reaching or slightly surpassing tip of abdomen, male, distinctly shorter than abdomen, female. Supra-anal plate short, triangular, the basal median ridges uniting slightly beyond the middle and continued as a single ridge to the rounded apex, the median sulcus, therefore, confined to the basal half; furcula consisting of a pair of short, blunt, widely separated, finger-like projections lying just outside the median sulcus. Cerci with basal third swollen, strongly tapering, apical twothirds equal, very slender, feebly curved forward and inward, the apex blunt (Fig. 139, d.) Length of body, ô, 19-21, \&, 28-32; of antennæ, $\hat{\delta}$, 8 , , 9 ; of pronotum, ô, 5 , ㅇ, $6.5-7$; of tegmina, ô, $9-10$, 우, 11-14; of hind femora, ô, 11.5-12.5, ㅇ, 13-15 mm.

This dull colored robust locust was originally described from a score or more of specimens taken by me at LaSalle Island, Mich., Aug. 17, 1897. They were found for the most part in a small clearing an acre or more in extent, where a cabin had formerly stood. Along its margins and over part of its area grew clumps of the wild red raspberry, Rubus strigosus Michx., and among the numerous remains of stumps were small bunches of wire-grass and the trailing vines of the dewberry. Here $M$. huroni had its home, and the females, leaping lubberly from one bunch of grass to another, were readily secured, but the more sprightly males would often have to be chased quite a distance before their capture was effected. Specimens were sent Scudder for examination, and he reported them as unknown to him. The species was then described as Melanoplus huroni and under that name was recorded by Rehn (1904d) and Hebard (1909) from Pequaming, Mich., and by Morse (1909) from Isle Royale. Caudell (1903, 798) placed it as a synonym of $M$. altitudinum Scudd., a species ranging from South Dakota and Wyoming to New Mexico. It was recorded under that name by E. M. Walker $(1909,207)$ as occurring at Ft. William and Nipigon, Ontario, both brachypterous and macropterous specimens having been found in open scrubby woods on the top of Mt. McKay. Hebard (who has been making an exhaustive study of the Melanopli) informs me that both huroni and altitudinum are distinct and valid geographic races of Melanoplus (Podisma) dodgci (Thos.), a common and widely distributed alpine species of the Rocky Mountain region and as such, on Hebard's anthority, it is listed above. The records noted above are all that can be found of its occurrence in the territory covered by this work.

Division II. Long-Winged Speches of Melanoplus.

The long-winged forms of Mclanoplus inhabit cultivated fields, meadows, prairies, roadsides, railway embankments and open 
waste places generally, and are seldom found in any numbers in the favorite wooded and sheltered latunts of the short-winged species. Being possessed of ample powers of flight they travel long distances from their birth-place. At times some of them, as spretis and atlanis, and rarely fomur-rubrum and differentialis, become possessed of the migratory instinct and congregating in vast numbers, as do blackbirds in autumn, fly for scores or eren hundreds of miles, stopping wherever food appears plentiful, and then moring again onward, learing behind them a waste more desolate than did the Huns in northern France.

The number of species of long-winged forms of the genus known from the eastern States is 18 as against 33 of the shortwinged ones, but what the former lack in number of species is more than made up in individuals, for they comprise the most common and therefore the most injurious of our locusts. Many nominal species have in the past been described, based upon the color of the hind tibia, slight variations in the form of the male cerci and furcula, length of tegmina and other minor and variable characters. Fire of these have been placed as rarieties and a number as synonyms in the pages which follow and time will doubtless show that several of those retained as ralid species should be so reduced. For convenience of treatment the eastern species of Division II are grouped into ten Series numbered consecutively with those of Division I.

KEY TO EASTERT SERIES OF LOXG-WIXGED MELANOPLUS.

a. Apical hind margin of subgenital plate of male more or less elevated and usually distinctly and narrowly notched at tip, rarely with only a deep posterior subapical impression (Fig. 141, $a, c)$; cerci short, flat, nearly equally broad throughout, their length not much more than twice as great as the middle breadth (Pl. III, $i$ ); mesosternum of male with a blunt rounded tubercle in front of lobes.

Series VIII, p. 412.

aa. Apical hind margin of subgenital plate never distinctly narrowly notched, rarely with a broad and feeble emargination; cerci three or more times as long as the middle breadth; mesosternum of male without a tubercle.

b. Cerci of male beyond the middle either subequal or tapering, the apical half never distinctly spatulate or forked and but rarely slightly wider than the middle.

c. Furcula two-thirds as long as supra-anal plate, with basal halves broad, flat, their inner edges attingent, the apical halves strongly obliquely narrowed and divergent; hind tibiæ blue; tegmina immaculate or nearly so.

SERIES IX, p. 416.

cc. Furcula variable in length, but with basal halves never broader than the apical ones and at the same time flattened and attingent. 
d. Furcula either minute triangular processes or flat, tapering and distinctly less than half the length of supra-anal plate; cerci narrowing but little in apical half; subgenital plate of male nearly as broad at apex as at base, the apex more or less elevated above the lateral margins.

$e$. Furcula shorter than last dorsal segment to which they are attached (Pl. III, $j$.)

f. Supra-anal plate without a transverse carina, its sides straight, and median sulcus confined to basal half; apex of subgenital plate slightly elevated and terminating in a small subapical tubercle.

SERIEs X, p. 417.

ff. Supra-anal plate with a transverse carina at apical third, its sides sinuous, and median sulcus percurrent; apex of subgenital plate not elevated into a tubercle.

FAsciatus. ${ }^{59}$

ee. Furcula nearly half the length of supra-anal plate.

DAWSOXI. ${ }^{58}$

dd. Furcula slender, tapering, subcylindrical, half or more as long as supra-anal plate; cerci subfalcate, the apical half usually distinctly narrowing, the upper angle of tip prolonged ( $\mathrm{Pl}$. IV, $k, l$ ); subgenital plate of male distinctly narrower at apex than at base, the apical margin not ele. vated nor notched or tuberculate. Series XI, p. 418.

$b b$. Cerci of male with apical half more or less expanded so as to be distinctly broader at some point beyond the middle than at the middle (Pl. IV, $m . r$.)

$g$. Cerci of male spatulate or subspatulate, the apex rounded and entire, the outer face of apical third concave; furcula always distinct.

$h$. Supra-anal plate at apical third suddenly and strongly narrowed or constricted; furcula not strongly diverging, onethird or more the length of supra-anal plate; subgenital plate with apical hind margin subtruncate, vaguely and widely emarginate (Pl. IV. $m$.) SErIEs XII, p. 425.

$h h$. Supra-anal plate with apical third gradually narrowed and depressed; furcula very strongly divergent, not over onefourth the length of supra-anal plate (Fig. 145, b); subgenital plate not apically subtruncate nor vaguely emarginate.

Series XIII, p. 428.

$g g$. Cerci of male distinctly forked or their ventral margin with a submedian process or angle, or else expanded so as to be very much broader at tip than at base (Pl. IV, o, q); furcula usually wanting or minute.

$i$. Tegmina without distinct rounded fuscous spots scattered irregularly over the surface; interval between mesosternal lobes of male distinctly longer than broad.

j. Size medium or small, the males rarely over $25 \mathrm{~mm}$. in length; cerci either always forked or their ventral mar-

sxThese two species are nornally short-winged and have been treated under Division I, pp. 400 and 393. Their insertion here is only to cover the very rare long-winged individuals. 
Plate IV.
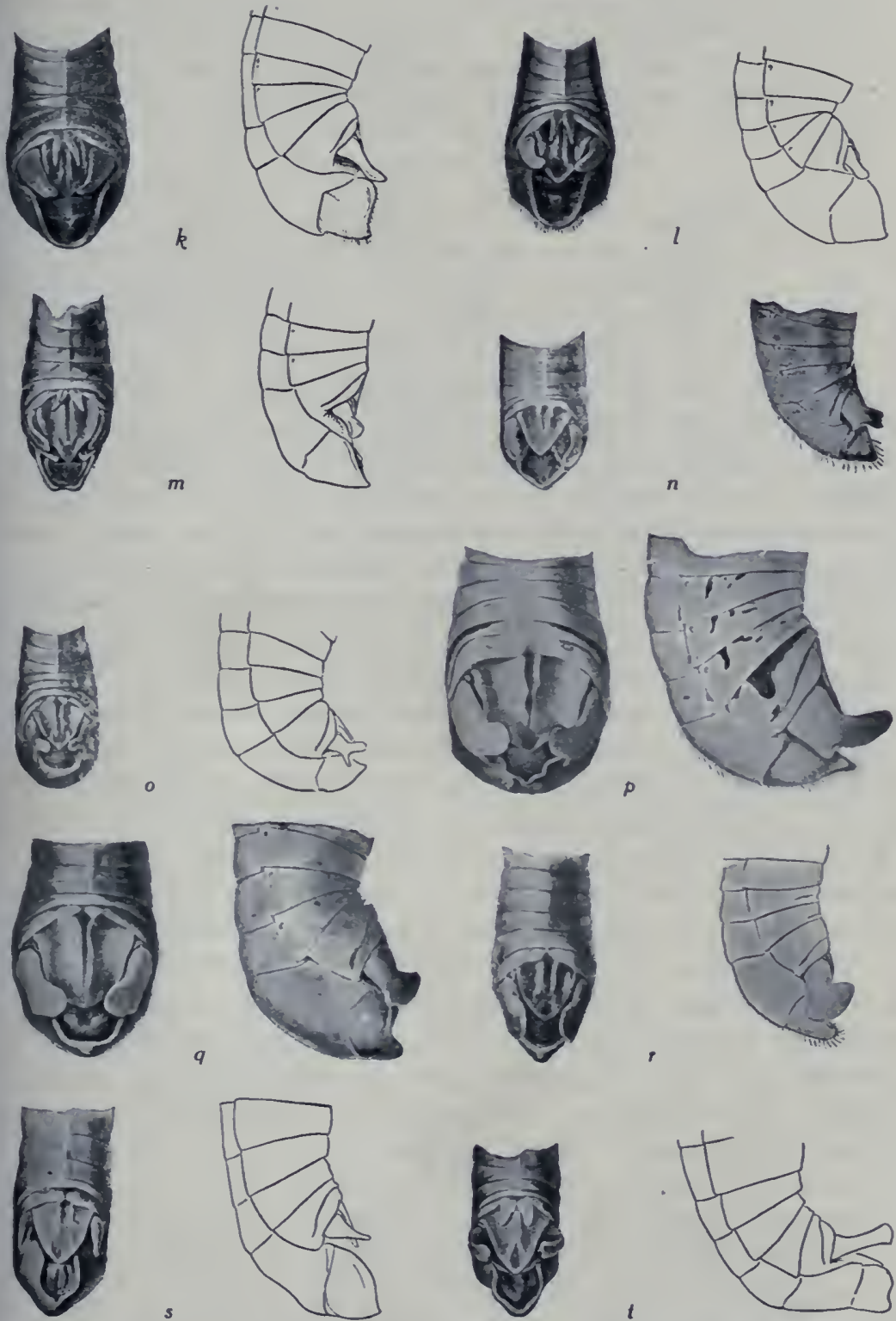

Plate IV. Dorsal and side views of extremities of male abdomens of Melanoplus, Photaliotes and Paroxya, showing the appendages. $X 4 . \mathrm{k}, M$. femur-rubrum; $1, M$. borealis; $\mathrm{m}, M$. angustipennis; $\mathrm{n}, \boldsymbol{M}$. confusus; $\mathrm{o}, M$. keeleri luridus; $\mathrm{p}, M$. differentialis; q. M. bicittatus; r, M. punctulatus; s, Phataliotes nebrascensis; t, Parorya clavuliger hoo. sieri. (After Scudder.) 
gin with a submedian angulation (Pl. IV, $n, 0$ ); furcula distinct but very short.

Series XIV, p. 433.

jj. Size much larger, the males 27 or more mm. in length; cerci with apical half much enlarged, rarely (furcatus) forked.

$k$. Disk of pronotum without light colored lateral stripes; furcula wholly wanting (Pl. IV, p.) Serres XV, p. 439.

$k k$. Disk of pronotum with pale marginal lateral stripes; furcula present but very short $(\mathrm{Pl} . \mathrm{IV}, q$.

Series XVI, p. 445.

ii. Tegmina with distinct rounded fuscous spots; interval between mesosternal lobes of male subquadrate; lower face of hind femora coral red; front margin of pronotum slightly flaring to receive the head.

SERIES XVII, p. 450.

Series VIII. Tile Atranis Group.

Species of medium size and grayish- or reddish-brown hue, having the postocular dark stripe feebly developed, often subobsolete; antenna rather short, subequal in the sexes; occiput convex, slightly raised above the level of pronotum, the latter with disk of prozona transverse or quadrate, its sides parallel and rounded into the lateral lobes, those of metazona somewhat divergent, with lateral carina evident but vague; tegmina distinctly surpassing abdomen and tips of hind femora; interspace between the mesosternal lobes of male longer than broad, the mesosternum in front of the lobes elevated to form a low, blunt conical tubercle; hind tibire (in our eastern species) normally red, sometimes dull yellow or glaucous; supra-anal plate and furcula variable as to species; cerci broad, nearly straight, almost flat plates, one and a half, female, to twice, male, as long as broad, the apical half but slightly narrower than the basal one, generally through the oblique excision of its ventral margin, the apex obliquely and broadly rounded.

The Utahensis and Spretus Series of Scudder have been shown by E. M. Walker $(1909,206)$ to merge, the species bruncri, by reason of its variable subgenital plate, forming the connecting link. But two of the ten species of the two series recognized by Scudder (1897) occur in our territory, the others inhabiting the Rocky Mountain region or the Pacific slope.

KEY TO EASTERT SPECIES OF ATLAXIS GROUP.

a. Median carina of pronotum percurrent, less distinct on prozona; apex of subgenital plate strongly elevated above the lateral margins, its tip either with a median notch or a subapical impression; prosternal spine appressed-conical, the tip bluntly rounded; lower face of hind femora dull yellow.

192. BRUNERI.

aa. Median carina of pronotum subobsolete on prozona; apex of subgenital plate feebly elevated, slightly thickened and with a shallow but distinct median notch (Fig. 141, c); prosternal spine conical, usually distinctly tapering, the tip subacute; lower face of hind femora pinkish-red or rosaceous.

193. ATLANIS. 
192. Mela yoplus BRuxeri Scudder, $1897 \mathrm{~b}, 18$. Bruner's Locust.

Size medium for the genus, the sexes subequal. Reddish-brown above, greenish-yellow beneath, occiput and disk of prozona dusky; upper third of prozonal lateral lobes with a fuscous or piceous patch. Tegmina pale reddish-brown, the median area with a row of vague fuscous spots, more distinct in female. Hind femora dull yellow, the upper and inner faces with three faint oblique darker bars. Hind tibiæ pale red fading to dull yel-
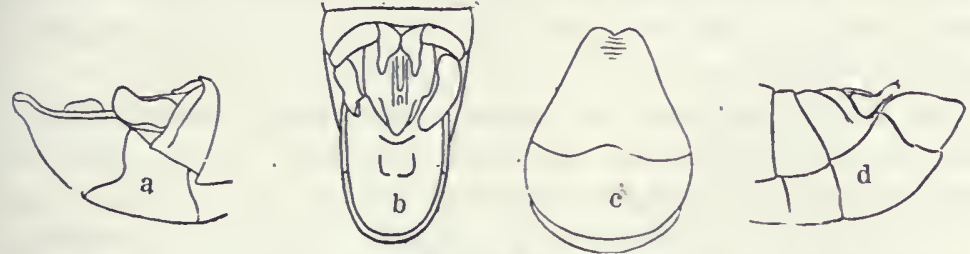

Fig. I4I. Extremities of male abdomen of Melanoplus. $\times$ 4. a, b, bruneri; $\approx$, atlanis; d, flavidus. (After McDaniel, Morse and Scudder.)

low, the spines black. Interocular space as wide as first antennal joint, male, as frontal costa above the antennæ, female. Fastigium feebly declivent, widely not deeply sulcate, male, more shallowly so, female. Frontal costa wide, strongly convex above the antennæ, deeply concave just below the ocellus. Pronotum short, the disk nearly flat above; prozona but slightly longer than metazona, the latter finely and densely punctate, its hind margin broadly obtuse-angulate. Extremity of male abdomen strongly upturned. Supra-anal plate narrowly oval, the apex obtuse, margins strongly upcurved, median sulcus deep, percurrent, widening on apical third. Furcula elongate, rather slender, subparallel processes reaching beyond middle of supra-anal plate, their sides sinuous, basal thirds attingent, apical ones well separated. Cerci as described under the series heading. Subgenital plate with apex wide, much prolonged and elevated. the tip broadly rounded or subtruncate, with a distinct subapical depression which sometimes extends upward to form an apical notch. (M. alaskanus Scudd.) Length of body, $\hat{\delta}, 20-25, \stackrel{\rho}{2} 22-23.5$; of antennæ, $\hat{\delta}$, 7.5 , ९, 7 ; of pronotum, $\hat{\delta}, 5.5$, ᄋ, 5.5-6; of tegmina, $\hat{\delta}, 16-20$, ᄋ, 1524 ; of hind femora, ô, $11.5-14$,, $13-14 \mathrm{~mm}$.

Isle Royale, Mich. (Hubbell) ; Montana and Fort McLeod, Alberta (Bruner). Known from east of the Mississippi only from Nipigon and Dwight, Ontario, and Pequaming Bay and Isle Rosale, Mich. At Nipigon E. M. Walker $(1909,205)$ says it "occurs in great abundance, far outnumbering all the other Melanopli together, being particularly abundant in a rough bushy clearing on a sandy loam where it was associated with large numbers of Camnula pellucida. The Nipigon specimens exhibit great range of variation in size, color, wing-length and in the development of the depression or $^{\circ}$ notch below the apical margin of the subgenital plate in the male. All gradations of this notch exist between individuals in which the apical margin is entire (typical bruneri) and those in which the margin itself is as deeply or more deeply 
notched than in II. atlanis, the latter agreeing perfectly with Scudder's description $(1897,169)$, and figure of $M$. alaskanus." At Pequaming, Mich., Hebard $(1909,158)$ found bruneri in meadow land in rather scarce numbers. Mor'se $(1909,301)$ states that $M$. alaskanus Scudd., described from Alaska, is "apparently the dominant form of the genus occurring on Isle Royale, judging from its abundance in the material examined and the localities where derived. It is recorded from clearings, along trails, rock ridges, the beach heath zone, etc."

The known range of $I$. bruneri, as given by Scudder (1897, 166), extends from the points above mentioned northwest through Saskatchewan and Alberta to Spilmatcheen, B. C., and Alaska, west to Moutana. Idaho and Washington and sonth to Nebraska, Colorado and New Mexico. It is not recorded from Minnesota by Somes nor from Colorado by Gillette; and R. \& H. $(1906,406)$ mention the taking of only a single specimen in Yellowstone Park, Montana.

193. Melaxoplus atlaxis (Riley), 1875, 169. Lesser Migratory Locust.

Size medium for the genus, the females but slightly the larger; form rather slender. Color either dark grayish- or reddish-brown above, greenish-yellow beneath. Head olive-brown mottled with darker; the usual postocular dark. stripe confined to the prozona and in the reddish-brown specimens and females often indistinct or broken into smaller spots. Tegmina grayish-brown, flecked distinctly with fuscous along the median area. Hind femora reddish-yellow with two oblique dark bars across the upper and outer faces, the lower face usually pinkish or pale orange red; knees blackish. Hind tibiæ usually pale red, sometimes pale glaucous. Sides of abdomen dull yellow, often flecked with fuscous. Interocular space nearly, male, or fully, female, twice as broad as basal joint of antennæ; fastigium strongly declivent, distinctly sulcate, male, shallowly concave, female. Frontal costa short, not reaching clypeus, feebly or not at all sulcate below the ocellus, the upper third a little narrowed. Pronotum rather short, distinctly expanding on metazona, the disk flat or nearly so, hind margin obtuse-angled; metazona densely punctate, almost equalling the prozona in length. Extremity of male abdomen but little upcurved. Supra-anal plate broadly triangular, apex subacute, basal halves of side margins broadened and distinctly elevated; median sulcus narrow, rather deep, percurrent or nearly so. Furcula consisting of a pair of moderately diverging, slender subcylindrical tapering spines, almost one-third the length of supra-anal plate. Cerci as described above and shown in Pl. III, $i$. Subgenital plate narrowing regularly from below upward, the apex somewhat thickened and elevated, and with a distinct median notch. Fallium hood-shaped, raised above the lateral margins of the subgenital plate. Length of body, $\hat{o}$, $17-21.5$, ᄋ, 18-27; of antennæ, $\delta, 7-9, \uparrow, 6.5-8$; of pronotum, of, 5 , ․ 5.5 ; of tegmina, $\hat{\delta}, 16-21$,,, $15-22$; of hind femora, $\hat{o}, 11-13$, , 11-14 mm. (Fig. 142.)

This is a very common locust throughout Indiana, laving been 
taken in every county in which collections have been made. It

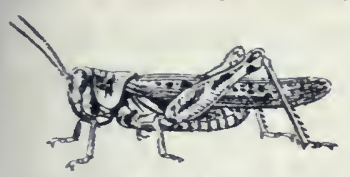
begins to reach maturity the latter part of May, and from then until late November may be noted almost anywhere in open bluegraiss pastures and woods, borders of roadFig. r42. Male. Natural size. sides and cultivated fields, meadows and lawns. Numerous examples have been found pairing as late as November $22 d$, and it may be that there are two broods each season. In late spring and early summer ther are often seen resting on iron-weeds and thistles in companr with .1I. gracilis. M. luridus and other species. The cast of skin of their final moult is often noted on such weeds, showing that the nymph climbs thereon to change its garment of youth for one of maturity.

Atlanis is very often found associated with the more common 1I. femur-rubrum and is considered that species by most persons who deign to notice such a thing as a locust. The male. howerer, may be readily distinguished from that of femur-rubrum by the notched apex of subgenital plate. the shorter and less tapering cerci, and by the greater relative length of the tegmina, which extend one-fourth or more their length beyond the tip of abdomen. The dark spots on tegmina are also larger and more distinct in atlanis. The female of atlanis may be known by the rellow color of the under side of abdomen which in femur-rubrum is reddishbrown; and also by the more distinctly banded hind femora and more tapering and sharper pointed prosternal spine. The earlier specimens of atlanis are in general lighter colored and have relatively longer tegmina than those of late antumn, which are very dark gray in hue. The hind tibiae are normally pale red, but in about $S$ per cent. of the specimens ther are either red at tip and otherwise colored, or dull rellow, or glancous, the males having them more variable in hue than the females.

The range of atlanis is a rery wide one. extending from New England and Nora Scotia north to latitude $50^{\circ}$ and the Yukon River, west to the Pacific and south to northern Florida, Texas and middle California. In Florida it has been recorded onls from Marianna, where Morse took specimens on August 6. He states $(1904,42)$ that it "is probably the most widely and generally distributed of all the loeusts inhabiting the Southeastern States, breeding from sea-level to the summit of Roan Mountain." R. \& H. $(1916,237)$ state that atlanis is "relatively infrequent in the Coastal Plain south of North Carolina and the lower Gulf drainage of Sonthern Georgia," the only known South Georgia locality being Thomasville. 
Scudder $(1897,182)$ says of atlanis: "Next to Mr. spretus this is our most destructive locust, and east of the Mississippi probably the only one ever doing much damage. Its injuries, however, are not for a moment to be compared with those inflicted by M. spretus, for, though possessing good powers of flight and on rare occasions known to migrate in swarms, its injuries can only be classed as local, and they are never so serious as those inflicted by M. spretus; nevertheless they are by no means slight, and immense destruction of grain is to be laid at its door. While it occurs over an extended territory, it appears to be partial to hilly or mountainous regions; it seems also to prefer a wooded or mixed country to the open prairies or plains."

In Old Mexico atlanis is replaced by $M$. mexicanus Sauss. $(1861,160)$, of which Hebard $(1917 \mathrm{~b}, 271)$ considers atlanis a northern race. He states that individuals from there show both red and glaucous tibia, the glaucous type being much more frequently encountered in Mexico than in the United States.

Series IX. The Flavidus Group.

Since this group is represented by but a single species, its principal diagnostic characters are given in the key and in the specific description and their repetition is unnecessary.

194. Melaxoplus Flavidus Scudder, 1879, 74. Blue-legged Locust.

Size slightly above the medium for the genus, the females one-third the larger; form slender. Pale olive-brown above, greenish-yellow beneath. Face sometimes mottled with fuscous; the black postocular stripe, when present, usually narrow and reaching only to metazona, often subobsolete, sometimes widened and extending along the sides of disk as well as those of pronotal lobes. Antennæ uniform dull yellow. Tegmina with a vague narrow median pale stripe, this often with a few small fuscous spots. Hind femora dull yellow, the upper half of outer face dusky, the upper and inner faces usually with two oblique dusky bars. Hind tibiæ blue, the spines white, tipped with black. Interocular space slightly wider than first antennal joint, male, as wide as frontal costa, female. Fastigium feebly declivent, strongly sulcate, male, feebly concave, female. Frontal costa prominent, broadly and rather deeply sulcate at and below the ocellus. Disk of prozona slightly convex, the sides parallel and rounded into lateral lobes; of metazona nearly flat, the sides feebly divergent, hind margin obtuse-angulate; median carina low, distinct on metazona, often vague on prozona. Tegmina narrow, slightly surpassing tip of abdomen, male, reaching tip or base of ovipositor, female. Supra-anal plate of male broadly triangular, the apical third elevated and abruptly subacute. Furcula as described in series key, their tips ending in slightly widened knobs. Cerci with base broad, triangular, the apical two-thirds slender, less than half as wide as base, incurved, the sides nearly parallel, tip bluntly rounded (Fig. 141, d.) Subgenital plate scoop-shaped, well rounded above, the tip slightly produced. Length of body, ô, $21-26, q, 25-32$; of anten- 
næ, ô, 12-14, ㅇ, 10-11; of pronotum, ô, 5-5.5, 오, 6-6.5; of tegmina,

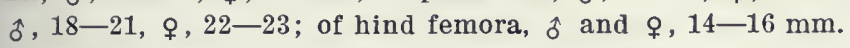

Lake County, Ind.; Moline, Ill.; Sidney, Neb.; Timnath, Colo.; August-September. Known from Indiana only from near Pine, Lake Co., where specimens were taken by J. D. Hood, Sept. 3. Ranges from northwestern Indiana to Montana and Colorado, south and southwest to Kansas, southern Texas, Las Cruces, New Mex., and Tucson, Ariz.

This trim graceful-bodied locust is a xerophytic species occurring mainly in dry sandy places. Scudder's types were from Colorado. McNeill $(1891,75)$ first recorded and described it from Illinois under the name $M$. cenchri, a synonym, stating that it oceurred only on "high sandy ground where the sand-bur, Cenchrus tribuloides $\mathrm{L}$. was the only regetation. They were colored so nearly like the yellow sand that they were difficult to see when only two or three feet away." Hart $(1907,233)$ states that it is "common everywhere in blowouts and on very sandy ground" in northwestern Illinois, and also records it from Lone Rock, Wis. Vestal $(1913,23)$ states that from July 19 to October 10 it is the "most characteristic locust of the bare sand, blow sand and bare basins of blowouts" in northern Illinois. It is not recorded from Iowa or Minnesota, though it probably occurs in both states. Bruner reports it as rare in southwestern Nebraska. Gillette $(1904,50)$ states that in Colorado it is "a plains species, occurring sparingly in the southern portion of the State. It is abundant in grass pastures along the foothills, near Fort Collins, and has been taken feeding upon alfalfa, cabbages, leaves of plum and cherry trees and upon Artemisia trifolia, so that wherever a food supply of native plants becomes scarce this species is likely to become seriously injurious to cultivated crops."

Series X. The Impudicus Group.

This group being represented by but a single species its principal characters are given in the series key and in the description.

195. Melayoplus Impudicus Scudder, 1897b, 22. Immodest Locust.

Size medium for the genus, the females but little the larger. Color much as in atlanis, the dark spot on upper part of pronotal lobe smaller in the male, often obsolete, female; median area of tegmina with fewer and smaller fuscous spots; dark bars of hind femora narrower and less distinct; lower face orange-red. Hind tibiæ bright red, the spines black, paler at extreme base. Occiput slightly swollen, distinctly elevated above the pronotum; interocular space as broad, male, or one and a half times as broad, female, as first joint of antennæ. Fastigium strongly sloping, feebly sulcate in both sexes. Frontal costa short, not reaching clypeus, rather 
narrow, feebly or not at all sulcate. Pronotum with median carina visible throughout, more distinct on metazona; hind margin broadly obtuse-angled; prozona longer than broad and one-fifth longer than the finely punctate metazona, male, subquadrate and subequal in length to metazona, female. Tegmina ${ }^{50}$ reaching tip of hind femora in both sexes, moderately broad and tapering. Supra-anal plate broadly triangular, almost flat, the apex acute-angulate, margins scarcely elevated; median sulcus confined to basal half, its bounding ridges rather high. Furcula consisting of a pair of very short triangular processes lying upon the bases of the median ridges of supra-anal plate (Pl. III, $j$.) Cerci narrow, slightly shorter than supra-anal plate, compressed, straight, the middle third about one-half as broad as the extreme base, the apical third but little expanded, the tip rounded. Subgenital plate scarcely longer than broad, subconical. Length of body, $\hat{\sigma}, 18-19$, $\$, 22-23$; of antennæ, $\hat{\delta}$ and $q, 8$; of pronotum, $\hat{\jmath}, 5$, ㅇ, 5.5; of tegmina, $\hat{\delta}, 15-16$, 오, 15-18; of hind femora, $\hat{\delta}$, $11-12$, ㅇ, $12.5-13 \mathrm{~mm}$.

So far as known this species has been taken in Indiana but once. 'This was on July 10, 1902, when I found it plentiful on a sandy wooded slope in Gibson County, about ten miles southeast of Mt. Carmel, Ill., and at a point where the terrace on the Indiana side of the Wabash River meets the sandy uplands. Here, among the scant grass and weeds the insect had found a suitable abiding place. The males take to wing readily when disturbed, but the females seem to depend only on their short hind legs to take them out of sight of their pursuer.

The known range of impudicus is mainly southern, its most northern recorded station being Havana, Ill., where Hart found it in small numbers in August in sandy areas covered with blackjark oak. He states $(1907,234)$ that it is "common on high rocky slopes of the Ozark ridge in southern Illinois." Its main distribution east of the Mississippi is from New Jersey southwest to Meridian and Monticello, Miss. West of that stream it is recorded only from northwestern Arkansas and Oklahoma. Morse (1907, $49)$ calls it "a widely distributed but somewhat local species frequenting the grasses of dry open woodlands and sometimes also fields of sandy or stony soil." In New Jersey Fox (1914, 514) says it is restricted to the Pine Barrens where it appears to be locally frequent, occurring only in pine or mixed pine and oak woods.

\section{Series XI. The Femur-rumbum Grour.}

Medium or small sized species of a dull reddish- or gravishbrown hue, having the postocular dark stripe usually distinct on prozona in both sexes; median carina of pronotum percurrent,

${ }^{5}$ Scudder, in his original description, gives them as "surpassing a little, male, or considerably, female, the hind femora," but this is not true of Indiana specimens. 
sometimes faint on prozona; tegmina reaching or surpassing tip of abdomen and usually the hind femora, withont or usually with rery faint spots along the median area; hind tibia normally red with black spines; prosternal spine erect, cylindrical, usually somewhat appressed, the apex bluntly rounded; supra-anal plate of male elongate-triangular, usually constricted at middle; furcula and cerci variable as to species; subgenital plate broad at base, narrowed to about half the basal width at apex, the apical margin rarely elevated, not notched or tuberculate.

KEY TO EASTERY SPECIES OF FEMUR-RUBRUM GROUP.

a. Tegmina always distinctly surpassing the tips of hind femora, male, usually so, female; cerci of male strongly narrowing on basal half, at apical third less than half the width of base; furcula distinctly tapering and widely separated beyond the basal third (Pl. IV, $k$.)

b. Furcula not or scarcely reaching the middle of supra-anal plate; general color darker, the fuscous spots of median area of tegmina very small and confined to its basal half.

196. FEMUR-RUBRUM.

bb. Furcula longer, reaching considerably beyond the middle of supraanal plate; general color paler, the fuscous spots of median area of tegmina larger and extending throughout its length.

196a. PropixquUs

aa. Tegmina not or rarely surpassing the hind femora in either sex, often much shorter; cerci not or very feebly narrowing on basal half, at apical third more than half the width of base; furcula feebly tapering, parallel and but slightly separated beyond the basal third. (Pl. IV, l.)

197. BOREALIS.

196. Melayoplus femur-rubrum (DeGeer), 1773, 498. Red-legged Locust.

Size medium for the genus, the males slightly the smaller. Reddishbrown or brownish-fuscous above, dull greenish-yellow beneath. Head olive to brownish-yellow, occiput darker with usually a pair of widening fuscous stripes on its sides. Disk of prozona generally darker than the lower half of its lateral lobes; the upper half of these lobes with a broad black bar, often subobsolete in female. Meso- and metapleura in great part, and usually the sides of two basal segments of abdomen, black. Hind femora reddish-brown, the upper half of outer face usually more or less clouded with fuscous, which often forms two oblique cross-bars on upper face; lower and inner faces dull yellow or orange. Hind tibiæ deep red, rarely pale yellowish-green, the spines black. Interocular space a fourth wider than, male, or fully twice as wide, female, as first antennal joint; fastigium strongly declivent, distinctly and broadly sulcate, male, feebly so, female. Frontal costa as broad as the interocular area, deeply sulcate at and below the ocellus, male, less so, female. Pronotum feebly expanding on posterior half, the disk flat or nearly so, and rounded into the lateral lobes; hind margin obtuse-angled, more broadly so in female; median carina visible throughout, more distinct on metazona; prozona slightly longer than metazona, male, subequal to it, female. Tegmina narrow, obviously though very gradually tapering. Extremity of male abda- 
men distinctly enlarged, moderately upcurved; supra-anal plate elongatetriangular, its apex subacute, lateral margins thlckened and strongly elevated to form a deep, elongate concavity each side the median sulcus, the latter rather wide, percurrent, its apical fourth distinctly expanding; pallium not or scarcely elevated. Furcula consisting of a pair of tapering subcylindrical spines, about half as long as supra-anal plate, their basal third flattened and attingent, apical two-thirds well separated and lying just outside the median ridges (Pl. IV, $k$.) Cerci as in key and figure cited. Subgenital plate with apex less than half the breadth of base, its margins not elevated, truncate and strongly rounded. Length of body, $\hat{o}$, 17-23, ㅇ, 18-27; of antennæ, $\hat{\delta}, 8-10$, ㅇ, 8-8.5; of pronotum, $\hat{\delta}$, $4.5-5$, ㅇ, $5-6$; of tegmina, $\hat{o}, 15-20$, 오 , 17-23; of hind femora, $\hat{o}, 11-$ 13, ㅇ, 12-14.5 mm. (Fig. 143.)

This is the most common and one of the most injurious of our Indiana locusts. It oceurs everywhere in blue-grass pastures and

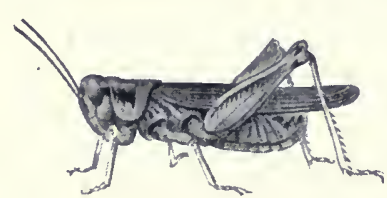

Fig. 143. Male. Natural size. meadows, along roadsides and borders of cultivated fields, on eity lawns and in open woodlands. In central Indiana it begins to reach maturity about June 5th, aud has been seen in numbers and mating as late as November 25th. Those which oceur in low, damp places are usually darker thatn those in dry upland localities. The second crop of clover is, in a dry season. often almost wholly destroyed by this species and $M$. differentialis. When disturbed they either hop vigorously to one side, or fly swiftly and noiselessly straight ahead for 30 or more feet and then suddenly drop to the ground.

The range of $M$. femur-rubrum is practically that of America north of central Mexico. In the southeastern states and Florida the typical form is replaced by that of the doubtful race propinqums scudd. It is not known from Alaska, and some of its most northern records perhaps properly belong to 1 . borealis (Fieb.). Wherever found it is very common and the aggregate amount of damage it annually does thronghout North Ameriea is an enormous one. The northern for $m$, in spite of its wide distribution, varies but little in color and structure; the hind tibia being very rarely dull vellow, green or greenish. The tegmina vary somewhat in lengtl, reaching from the tips of hind femora to $5 \mathrm{~mm}$. beyond in both sexes, being rarely $1 \mathrm{~mm}$. shorter than the tips in female.

of the habits of the red-legged locust much has been written. Scudder, in his Revision $(1897,278)$ and in his Index to North American Orthoptera (1901c) has given full references to all its literature. I quote, therefore, only the concluding paragraphs of his notes on this species in the former work, as follows: 
"The immediate distribution of this insect appears to be controlled altogether by climatic conditions, the chief of which is the presence of a certain amount of humidity. It is a frequenter of low grounds, cultivated fields, shady margins of woods, etc., where regetation is rank and tender. It is rarely found upon dry hillsides when meadows close at hand may swarm with them, while the opposite is true of other species, M. luridus for instance; yet such specimens as do so occur will be found to differ from those inhabiting more favored localities, in being lighter colored and more uniformly grayish in tone, with slighter contrasts; those from dryer stations appear also to have on the average rather shorter wings. There is but a single annual brood which begins to appear full fledged in New England late in July. According to Riley, the eggs are not laid in a single mass, but at intervals in several; he has twice obtained four successive pods from a single female, covering a period of nearly two months and containing eggs amounting in all to from ninety-six to one-hundred and ten.

"At Andover, Massachusetts, on October 5 many years ago, I observed a pair of this species, male and female, near together alternately signaling to each other with a slight quick movement, of the hind legs upon the tegmina, as if stridulating. I made no note of whether any sound was actually produced and do not now recall any."

The Caloptenus devorator. Scudder (1875l), 474) and the Mclan. oplus interior Scudder $(1879,71)$ are stated by their author (1897, 283 ) to be synonyms of $M$. femur-rubrum, as is also Caloptenus sanguinolentus Prov.

196a. Mela yoplus femur-rubrum PropinquUs Scudder, 1897b, 24. Southern Red-legged Locust.

Differs from typical femur-rubrum mainly in the characters given in key, the color of fresh specimens being usually a pale or olive-brown, tinged with rosaceous, sometimes with greenish. Fuscous spots of tegmina, especially in female, larger and more abundant. Hind femora dull greenishyellow, the fuscous bars of upper face faint or wanting. Supra-anal plate with apex more blunt and margins less thickened. Furcula longer, more evenly tapering, their apical halves less widely separated. Average size somewhat larger, a male at hand from Gainesville, Fla., being 26, and a female $27 \mathrm{~mm}$. in length.

This, the southern form of femur-rubrum, lias been taken by me at Ormond, Gainesville, Sanford, Sarasota, Ft. Mrers and Dunedin, Fla. It is almost as common in northern Florida as femur-rubrum is in Indiana but becomes scarce in the southern part of the State and is not known from the southern kers. My first specimens were taken at Ormond on March 27, 1899, and recorded $(1902,115)$ as found in "an old abandoned orange grove. The males were abundant, the females just emerging from the final moult. It is a slender-bodied, long-winged species, dull in color but graceful in movement. They are active leapers, and when flushed usually fly noiselessly for several rods, then settle down upon a bunch of grass, the color of which is grayish-brown, 
like that of their backs." About Dunedin both nymphs and adults occur throughout the winter along roadsides, in yards and gardens and old fallow or abandoned fields. Sonth of Lakeland it has been hitherto recorded only from Marco.

It is very doubtful whether the racial name propinquus is worthy of retention. The females, except for the slight difference in color, are absolutely inseparable from those of the typical form, and the males readily so only by the longer and less divergent furcula. R. \& H. (1916, 239) record the taking of intermediate forms between it and femur-rubrum in North Carolina, and give the range of propinquus, outside of Florida, as extending over the Southern Coastal Plain from extreme soutler'n North Carolina through South Carolina and Georgia as far west as Flonaton, Alabama. It has, however, been recorded by Morse $(190 \bar{\tau}, 51)$ from Gulfport, Miss.

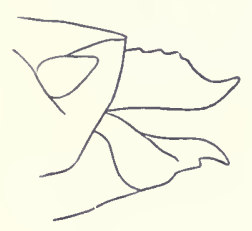

a

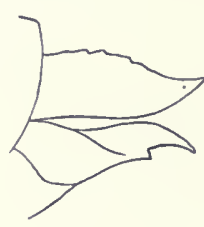

b

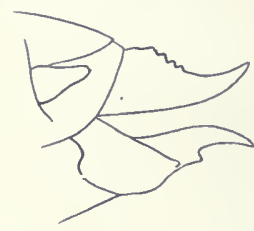

c

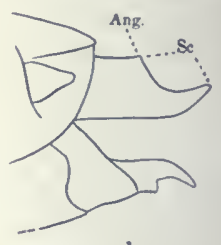

d

Fig. 144. Extremities of female abdomens of Melanoplus, showing the valves of ovisositor. a, of atlanis; b, borealis; c, luridus; d, confusus. Sc. $=$ scoop of upper valves; Ang.= angulation at base of scoop. (After Morse.)

\section{Melanoplus borealis (Fieber), 1853, 120. Northern Locust.}

Size small, the sexes subequal. Above dark reddish-brown or greenish-yellow tinged with fuscous, beneath dull clay-yellow. The usual dark stripe on upper third of prozona distinct in both sexes, somewhat broken in female. Tegmina almost or wholly devoid of fuscous markings. Hind femora in northern individuals (borealis) broadly bifasciate with fuscous on upper and inner faces, lower face, except near base, deep red; knees black; hind tibiæ deep red, the spines wholly black; in southern specimens (extremus) the femora are dull yellow, tinged with reddish-brown. usually without traces of dark cross-bars, the lower face generally pale orange; knees feebly infuscated; hind tibiæ pale red or dull yellow. Interocular space one-half wider than basal joint of antennæ, male, as wide as frontal costa, female; fastigium rather strongly declivent, distinctly sul. cate, male, broadly and shallowly so, female. Frontal costa very shallowly sulcate around and below the ocellus. Pronotum short, feebly widening backward in both sexes; prozona quadrate, slightly longer than metazona. male, transverse and equal to it in length, female; hind margin broadly obtuse-angulate, the angle more rounded in female; median carina clistinct on metazona, often subobsolete on basal portion of prozona. Extremity of male abdomen but slightly swollen, feebly upcurved. Supra-anal plate elongate-triangular, its apex acute-angulate, sides not thickened, distinctly upcurved; median sulcus percurrent, expanding at apical third, its bound- 
ing ridges thence elevated and convergent to apex, the sulcus therefore spear-shaped in outline. Furcula cylindrical, strictly parallel, equal, finger-like projections lying on the crests of the basal halves of the median ridges. Cerci broad, slightly falcate, shorter than supra-anal plate, their dorsal margin broadly concave, ventral one curved gradually into the blunt rounded or slightly produced apex (Pl. IV, l.) Subgenital plate scoopshaped, longer than broad, its apical margin broadly rounded, not elevated. Pallium elevated above the floor of the subgenital carity as an oblong hood-shaped tubercle. Length of body, $\hat{o}, 15-19,+$, $17-24$; of antennæ, ô, $8-9$, 오 $6-8$; of pronotum, $\hat{o}, 4-5$, 오 $5-5.3$; of tegmina, ô, $10-16$, ९, 9.5-18; of hind femora, ô, 9.5-12, ㅇ, 11-12.5 $\mathrm{mm}$.

After carefully studying typical specimens of M. borealis from Ft. Rae, Mackienzie, Can. (Pribble), in $m r$ collection and from Rama, Nain and Hopedale, Labrador, in the E. M. Walker and Scudder collections, and comparing them with what has hitherto been called $I$. cxtremus (F. Walker) from New England and Northern Indiana, I have no hesitancy in combining the two forms under Fieber's name. The southern individuals (cxtremus) average a little smaller in size, are mostly of a paler general hue, have the tegmina usually shorter, the median carina of pronotum often subobsolete on a portion of the prozona and the prosternal spine somewhat shorter and stouter, but in the genital characters of the male and otherwise thes agree with borealis in all particulars.

This, the $M$. extremus of $m y$ former work $(1903,319)$ first

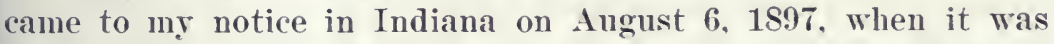
found near DeLong, Fulton County, in an open peat bog which was surrounded on all sides by a heary growth of tamarack, Larix americana Michx. But about a dozen specimens were secured, all of which were of the short-winged form. When disturbed ther gave several short, quick leaps, and then burrowed as far as the could into the dense mass of sphagnum moss which ever?where covered the bog. It has since been taken several times in the same place; also in a marsh near the south end of Lake Maxinkuckee; and probably occurs about the most of the peat bogs and marshes of the northern third of the State:

As its specific name indicates, the known range of trpical $M$. boreatis is northern, extending from Labrador, Nova Scotia, Hudson Bay and Greenland, north and west to Alaska and south and west to northern Massachusetts, northern Indiana and Illinois, Nebraska and Wyoming. Fieber's types of borealis were from Greenland, while those of Walker's extremus were from "Aretic America." Scudder's Labrador specimens were taken in August from the banks of a mountain brook. Ther were most abundant where the low shrubbr vegetation was most luxuriant between 200 
and 1,500 feet above tide. Caudell $(1900,511)$ records the taking of five adults by Prof. Kincaid at Kukak Bay, Alaska, on July 3. "They were taken within a few feet of a small pool in a sphagnum swamp. This pool, only about ten feet in diameter, was surrounded by regetation in which the locusts lived. They were captured by causing them to leap into the water where they were easily secured."

In northern New England borealis is said by Morse to be common in suitable habitats, making its appearance early and reaching maturity in late June or early July, and in the White Mountain region is not uncommon in early September. There, as elsewhere, it is partial to damp surroundings, frequenting the dense grass of moist meadows, bogs, sedgy swamps and mountain tops.

Seudder $(1897,289)$ gave the varietal name scandens to the long-winged form of extremus and states that "it appears to affect high latitudes and altitudes, being found in all the localities in the far north, on the Big Horn Mountains in Wyoming, and on the summits of the mountains in New England, where it is the prevailing or exclusive form." E. M. Walkel found it common about Ft. William and Nipigon, Ontario, the brachypterous form greatly outnumbering the macropterous. As extremus he also records it $(1910,334)$ from a number of stations in western Canada between Winnipeg, Man., and Field, B. C. Hebard $(1909,157)$ mentions extremus as searce about Pequaning, Mich., always in damp meadows, where the grass was luxuriant and deep. Somes $(1914,86)$ states that in western Minnesota its numbers are possibly equal to those of $M$. femur-rubrum, and that it is "found in habitats varying from flat open prairie to divg gravelly hills, and at times even in the tamarack growths of the north. It is one of our earliest species and closely follows $M$. minor, specimens having been taken June 14, and mating in the field on June 24."

The Pezotettix septentrionalis Sauss. $(1861,159)$, the Caloptenus arcticus F. Walker $(1870,681)$ and the C. parvus Provancher $(1876,110)$ are synonyms, while numerous records of $P e$ zotettix borealis and Melanoplus borealis from Minnesota and other points in the northern United States and southern Canada are to be referred to $M$. fasciatus.

The Pezotettix junius Dodge $(1876,9)$ deseribed from Nebraska and usually recorded as a short-winged form of $M$. $e x$ tremus, differs from typical borealis in having the apex of subgenital plate somewhat broader and less produced, the basal portion of the furcula more flattened and the pallium not elevated. It is probably to be considered as a western race of borcalis. 
Series XII. The Angustipexis Group.

Medium sized species of slender form and grayish- or fuscousbrown hue, having the piceous bar of prozonal lateral lobes narrow, often vague in female; disk of pronotum with sides subparallel, male, feebly expanding on metazona, female; median carina distinct but low on metazona, subobsolete or wanting on prozona; tegmina fully developed; prosternal spine rather slender, subcylindrical, the apex obtusely pointed, male; usually stouter, subconical, with apex very blunt, female; hind femora with outer face usually tinged with fuscous, upper and inner faces with faint fuscous cross-bars; hind tibire either glaucous or red in the same species; supra-anal plate as in Series ker; furcula and cerci variable as to species; subgenital plate large, as broad as long, apex feebly narrowed, but slightly if at all elevated, the median portion truncate and impressed behind; valves of ovipositor short, the lower ones with tips decurved and bastl tooth very blunt.

Scudder ascribed to his Angustipennis Series four species, which he separated in his key $(1897,136)$ only by the color of hind tibire, length of male furcula and degree of maculation of tegmina, all extremely variable characters. Two of his species, which he separated from the others only by the color of the hind tibia, are known to be dimorphic in this respect, and it is very probable that three of his so-called species, riz., comptus, coccineipes and angustipennis, will in time be found to be only forms of one widely distributed and variable species. Three of his nominal species are known from the territory corered by this work. One of them is, without doubt, a synonym of angustipennis. The two which are sufficiently different to be included as valid may be separated as follows:

KEX TO EASTERN SPECIES OF THE ANGUSTIPEXNIS GROUP.

a. Furcula more strongly divergent, subcylindrical, less than one-third as long as supra-anal plate (Pl. IV, $m$ ); tegmina often immaculate, male, usually with obscure and feeble maculation along the median area, female; smaller and more slender, length of body, male, rarely over 22 , or female, over $24 \mathrm{~mm}$. 198 . AxGUSTIPExNis. aa. Furcula but slightly divergent, one-half as long as supra-anal plate; tegmina with very distinct and rather prominent fuscous spots along the median area; larger and stouter, length of body, male, usually 24 or more, female, 25 or more $\mathrm{mm}$.

199. IMPIGER.

198. Melaxoplus Axgustipexis (Dodge), 1877, 111. Narrow-winged Locust.

Size medium, rather slender, the females but little the larger. Dark grayish-or fuscous-brown, often with a reddish-brown tinge. Occiput and disk of prozona fuscous; metazona and lower halves of lateral lobes paler. 
Tegmina as described in key. Hind femora dull yellowish-brown, lower face dull yellow; knees blackish. Hind tibiæ either pale greenish-blue or dull red, the spines black. Interocular space one and a half times, male, or twice, female, as broad as basal joint of antennæ; fastigium strongly declivent, distinctly and broadly sulcate throughout, male, almost flat, female. Frontal costa rather wide, nearly equal throughout, faintly sulcate at and below the ocellus. Pronotum as described above, its hind margin broadly obtuse-angled; prozona distinctly, male, or scarcely, female, longer than the closely punctate metazona. Tegmina reaching or slightly surpassing tips of hind femora, slender, tapering. Supra-anal plate strongly and abruptly narrowed at apical third, the narrowed portion in a lower plane, its apex rather blunt; sides of basal portion thickened, curved and upturned; median sulcus wide, rather shallow, confined to the broad basal portion of the plate. Furcula as described in key, lying outside the bases of the median ridges (Pl. IV, $m$.) Cerci rather short, spatulate, incurved, the middle third narrowest, apical third nearly as broad as base, concave without, its tip broadly rounded. Subgenital plate as long as broad, the apex a third narrower than base, its median portion a little elevated, sub. truncate, broadly and feebly impressed behind, thus causing it to appear slightly emarginate. Length of body, $\hat{\delta}, 19-22$, $\uparrow, 21-22$; of antennæ,

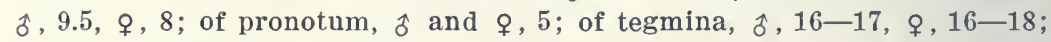
of hind femora, $\hat{o}, 11-12$, $\&, 12-13 \mathrm{~mm}$.

This locust is known in Indiana only from the northwestern counties, where it is one of the most common species abont the south shore of Lake Michigan, occurring in company with $\boldsymbol{M}$. atlanis (Riley), Spharagemon wyomingiamum (Thos.) and other's over a large part of the sandy area within five miles of the lake. It seems to prefer such barren localities to those more promising in plant food, since Bruner mentions its partiality for "old breakings and well-fed pastures of many years' use." It probably begins to reach maturity some time in June, as numerous pairs have been found mating in late July. Specimens were also taken from along railway embankments near Kewanna, Fulton Co.. July 14.

The hind tibia of at least a third of the specimens of angustipennis taken in Indiana are red instead of blue. Since Scudder based his sepraration of his nominal species coccincipes on the color of the tibia and degree of maculation of the tegmina. I (1903, $322)$ definitely placed roccincipes as a synonym of Dodge's species. A year later Gillette $(1904,46)$ recorded coccincipes as occurring in moderate numbers over the entire plains region of Colorado and extending for some distance into the foothills, and added: "It seems quite probable that this species is nothing more than a form of angnstipennis having red hind tibis." R. \& H. $(1906,412)$ record two Colorado specimens of coccincipcs as having glancons tibiae, and state that "they are much inclined toward the opinion recently expressed by Gillette to the effect that $. M . c o c$ - 
cincipes is but a red-legged form of 1 . angustipennis." Walker (1910, 338) mentions angustipennis from Aweme, Man., with both blue and red hind tibire, and says: "The red-legged individuals, commonly knowu as M. eoccineipes, are certainly not distinct from the typical blne-legged form." The two forms are therefore again placed as a single species.

The general range of angustipcnnis (including its synonym, coccineipes) is mainly to the west and northwest of its Indiana station, extending from Sudbury, Ont:, and Douglas Lake, Mich., to Aweme, Man., and Yellowstone, Montana, south to southern Colorado, Kansas and Texas. At Douglas Lake Vestal $(1914,108)$ found it rather common, July 1-August 14, in open aspen thickets among plants of bracken and blueberry near the borders of the lake. Hart $(1907,234)$ recorded it as very abundant everywhere on waste sandy land in northwestern Illinois; also at Waukegan on sandy ridges near Lake Michigan. Testal (1913) also says that "it is the most abundant and most characteristic locust in the bunch-grass, being the chief plant-eater in the Illinois sandprairie from July until frost." From the records it appears to be scarce in both Iowa and Minnesota, but in Nebraska Bruner $(1897,136)$ mentions it as "quite common on low grounds in the eastern half of the State, preferring Artcmisiu ludoviciana as a food plant." He also states that it is increasing rapidly in numbers, and is likely in places to become a serious pest. The regetation of the area which it is known to inhabit in Indiana is not sufficient in quantity and value to enable it to do much damage. Several successive favorable seasons might, however, enable it to so increase in numbers as to cause it to migrate into the richer agricultural regions to the south and east.

\section{Melanoplus IMPiger Scudder, 1897b, 26.}

Distinctly larger and more robust than angustipennis, the sexes subequal in size. General color darker, the prozonal dark bar wider, usually more vague in female. Tegmina as described in key. Hind femora with upper outer face more or less suffused with fuscous, lower face often feebly roseate. Hind tibiæ normally glaucous, sometimes red, paler at base and tips, the spines with only the apical halves black. Interocular space wider and fastigium more broadly and shallowly sulcate than in angustipennis. Prozona one-fourth longer than metazona, male, the two subequal in length, female. Tegmina but slightly surpassing the hind femora in either sex. Supra-anal plate much as in angustipennis, with basal two-thirds relatively longer and less broad, its sides less curved but thickened and upturned as there. Cerci stouter, with dorsal margin more distinctly concave, the outer face of apical half broadly sulcate (Fig. 145, a.) Subgenital plate.slightly longer, its posterior apical portion more distinctly truncate, 


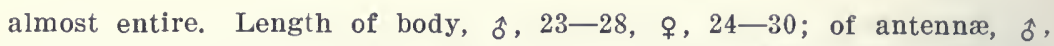
$10-11$, ㅇ, 10 ; of pronotum, $\hat{o}, 5.5-6.5$, ᄋ, 5.7-6.8; of tegmina, $\hat{o}, 20-22$, ㅇ, $21-23$; of hind femora, ô, 14-15.5, ㅇ, 15-16.5 $\mathrm{mm}$.

This species is included here on the single record of $\mathrm{R}$. \& $\mathrm{H}$. $(1916,240)$ who found it at Augusta, Ga., July 29, "in moderate numbers in a sandy area scatteringly covered with scrub oak." It was described from various points in Texas and Barber Co., Kansas, and west of the Mississippi has since been reeorded from Oklahoma, Arkansas and Minnesota. MeNeill (1899a, 366) says that in Arkansas it is "a not uncommon species among vegetation in the sandy bottoms and along the banks of streams." Somes (1914, 88) states that in Minnesota it occurs only on sandy areas along the Mississippi River in the southeastern part of the State.

The specimens at hand are from Oklahoma and Bonita, Texas, and have the hind tibire glaneous as described by Seudder, but Morse $(190 \bar{\tau}, 48)$ says their color varies from deep blue to cherryred and R. \& H. state that in their Georgia specimens "the color of the caudal tibixe ranges from dark orient blue to nopal red." Structurally the species is very close to angustipennis, but differs especially in its larger, stouter form and the longer, more parallel furcula which, as there, lie wholly outside the ridges of the median sulcus.
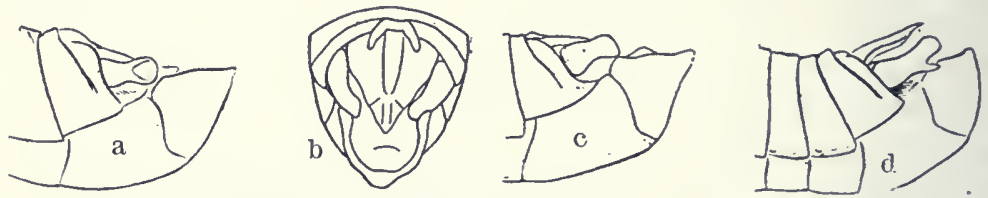

Fig. 145. Extremities of male abdomens of Melanoplus. $\times 4$. a, impiger; b, $c$, packardii; d, keeleri. (After Pettit \& Scudder.)

Series XIII. The Packardi Group.

The members of this group are somewhat larger and stonter than those of the preceding Series. They differ mainly in the much shorter widely dirergent fureula and in the form of the apical margin of the subgenital plate which is not subtruncate and vaguely concave as there, but at extreme tip well rounded and feebly thickened to form a small, backward projecting tubercle. They all agree in having the pronotal disk with sides subparallel in male, feebly divergent behind, female, hind margin broadly obtuse-angulate or sub-rounded, median carina distinct on metazona, wholly wanting on prozona; tegmina equalling or but slightly surpassing hind femora; supra-anal plate with apical third depressed, gradually narrowed and usually separated from the basal portion by an evident but narrow transrerse ridge; cerci 
much as in angustipennis, being shorter than supra-anal plate, subspatulate, incurved, the apical third concave on outer side.

Scudder, in his "Revision," ascribed five species to his Packardii Series. Of these but one has been recorded from our eastern territory, while two others, then unknown to him, are here included.

\section{KEY TO EASTERN SPECIES OF PACKARDII GROUP.}

a. Interval between mesosternal lobes of male fully twice as long as broad; general color brownish-yellow or pale grayish-brown.

b. Lower face of hind femora yellow; larger and much more robust, length of body, male, rarely less than $24 \mathrm{~mm}$., of female, 26 or more $\mathrm{mm}$.

200. PACKARDII.

$b b$. Lower face of hind femora bright coral-red; smaller and much more slender, length of body, male, less than 24 , of female less than $26 \mathrm{~mm}$.

201. FLUViatilis.

aa. Interval between mesosternal lobes of male subquadrate, about as broad as long; general color dark fuscous-brown. 202. stoxer.

200. Melaxoplus Packardi Scudder, 1878a, 287. Packard's Locust.

Size usually above the medium for the genus, the sexes subequal. Brownish-yellow or pale reddish-brown above; dull clay-yellow beneath. Face usually uniform dull yellow, sometimes sprinkled with fuscous dots. Occiput with a broad median dark reddish-brown or fuscous stripe, this usually widened and extending back along the full length of the middle of pronotum, but often absent from the latter; upper third of prozonal lateral lobes with the usual dark postocular stripe of the genus, this often broken and obscure in female. Tegmina pale grayish- or reddish-brown, often immaculate, male, usually with a row of small fuscous spots along the median area, female. Hind femora dull yellow, the upper half of outer face usually with a narrow ill-defined fuscous stripe; upper face with two narrow fuscous cross-bars; inner and lower faces, bright to dull yellow. Hind tibiæ either glaucous or bright red, the apical halves of spines black. Occiput swollen, distinctly elevated above the pronotum; interocular space half as wide again, male, or twice as wide, female, as basal joint of antennæ; fastigium strongly declivent, widely and rather deeply concave in both sexes. Frontal costa as broad as interocular space, distinctly sulcate below the ocellus. Pronotum as described above, the prozona about onefourth longer than metazona. Tegmina but slightly surpassing the tips of hind femora, distinctly the narrower in the male. Supra-anal plate as above described, its apex acute; median sulcus broad, rather shallow, percurrent, its apical third less distinct. Furcula consisting of a pair of short, flattened, well separated, unequally tapering, widely divergent processes. Cerci and subgenital plate as described above, the former with apex usually broadly rounded, sometimes subtruncate (Fig. $145, b, c$.) Length of

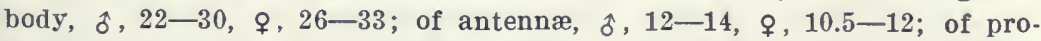
notum, $\hat{\delta}, 6.5-7$,, $7-8$; of tegmina, $\hat{\jmath}, 21-24.5, \stackrel{\imath}{2} 22-24$; of hind femora, ô, 14-16, ㅇ, 15-16.5 mm. (Fig. 146.)

A species of western and northwestern range, included here 
by reason of the record of Shull $(1911,227)$, who took it at Sagi-

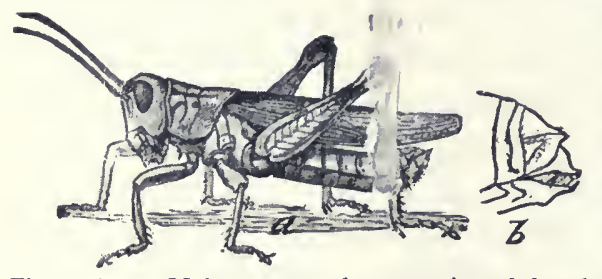

Fig. 146. $a$, Male. $\times 1.3 ; b$, extremity of female abdomen. (After Bruner.) naw Bay, Huron Co., Mich., June 22-August 3. Specimens (identified for him by Morse as M. focdus Scudd.) were taken "on bare or somewhat grassy beaches or in sandy woods, always in dry places and found on sand or soil, not on regetation." Three of the males from the University of Michigan collection. are at hand and agree exactly in everything but size with red-legged individuals of $M$. packardii from Colorado. They measure from $22-24 \mathrm{~mm}$. in length of body, the western males from 24 to $30 \mathrm{~mm}$. The range of $M$. packardii, including its synonym, $M$. forlus Scudder $(1879,69)$ extends from the Michigan station mentioned, north and west to Nicola Valley, B. C., and the Pacific Coast of the U. S. and south and west to Iowa, Texas and New Mexico. Specimens at hand collected by Bruner, Gillette and others, are from Valentine, Nebraska, and Greeley, Ft. Collins and Golden Gate, Colorado, some being labelled $M$. packardii, others $M$. fœdus. The latter, neither in color nor structure, have any fixed characters separating them from packardii. Scudder, in his original description of fœdus says: "This insect is closely related to $M$. packardii, but by its dingy coloring presents a very different appearance." In his notes on the same form $(1897,312)$ he says that the original types from Pueblo, Colo., are all that he has seen and that it "differs but slightly from $M$. packardii and may prove to be merely a varietal form of it, dependent upon station, which in this species (fodus) is in the dank vegetation of river bottoms where $1 \%$ parkardii occurs but rarely."

Morse $(1907,50)$ records packardii from varions stations in Oklahoma and Texas and states that he found it "common among weeds and tall grass, varying greatly in amount of fuscous markings on pronotum and hind femora, as well as in color of hind tibia, apparently running into foclus." R. \& H. $(1906,413)$ mention the great variation in color of Utah, Colorado and Montana specimens, and state that "most of them were taken from luxuriant weeds growing along ditches and drains, or abont damp depressions in the prairies. The insects were active, but often clung tenaciously to the weeds in which they hid, and it was consequently easy to capture as many as desired." In Colorado, says 
Gillette (1904, 94), packardii is a con mon species everywhere, June 24-Oct. $\&$, in grassy glades and $m$ intain parks up to $\$, 000$ feet or more. Of the 127 specimens in he college collection at Ft. Collins, the hind tibia of 54 were lue and of 73 red. Of M. foedus, Bruner (1S93, 22) wrote: "is is locust is in reality a mountain form that occurs mainly at at elevation of about 5,000 feet, and that frequents the edges of valleys and sumny slopes within the semi-arid portion of the United States. In its general appearance and structure $M$. forlus is rery much like the insect which is known bs the name of $U$. puckardii Scudder. In fact there is but little difference save in color between the two species." It will be seen that Scudder, Bruner and Morse, three of the best Orthopterologists this country has produced, have found no fixed characters separating fordus from packardii, but for some reason lave hesitated in combining the two names. I have no such hesitation and herewith place fœdus as an absolute synonym of packardii.

201. Melaxoplus fluviatilis Bruner, 1897, 136. Sand-bar Locust.

Size medium; form slender, male, more robust, female. Above grayish- or pale olive-brown, beneath pale to dull greenish-yellow. Face and lower portion of lateral lobes pale olive-green, usually immaculate. Occiput and disk of pronotum greenish-gray contrasting strongly with the distinct dark prozonal stripe below them. Tegmina pale grayish-brown, either immaculate or with a few faint scattered fuscous dots. Hind femora dull yellow, the upper face with two more or less distinct fuscous bars, lower face coral red; knees fuscous. Hind tibiæ pale glaucous, the spines black, pale at base. Occiput and frontal costa much as in angustipennis. Fastigium less declivent, feebly and broadly sulcate, male, shallowly concave, female. Disk of pronotum almost flat, the prozona one-fourth longer than metazona, male, scarcely longer, female. Tegmina of male very narrow, feebly tapering from base to the rounded tips; of female broader, of nearly equal width throughout. Prosternal spine slender, subcylindrical, its tip somewhat pointed, male, stouter with blunt apex, female. Supraanal plate as described under the series heading, its margins not thickened and but feebly upcurved; median sulcus vague, very shallow, its bounding ridges very broad and low. Furcula consisting of very short widely divergent processes, lying outside the median ridges, their basal halves broad and suddenly constricted into the very slender apical portion. Cerci scarce$1 \mathrm{y}$ differing from those of angustipennis, slightly longer and more incurved. Subgenital plate scoop-shaped, as broad as long. its apical margin not ele-

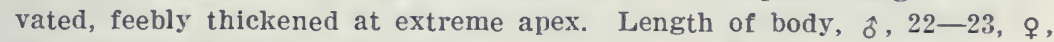
$25-26$; of antennæ, $\hat{\delta}, 10$, ㅇ, 9 ; of pronotum, $\hat{\delta}, 5$, ㅇ, 6 ; of tegmina, $\hat{o}$, $17-20, \&, 20-21$; of hind femora, ô, 12-12.5, \&, 13.5-14 mm. (Fig. 147.)

Ashland, Neb. (Bruner); Iowa City, Ia. (Caudell). This prettily colored, slender-bodied species is known east of the Mis- 


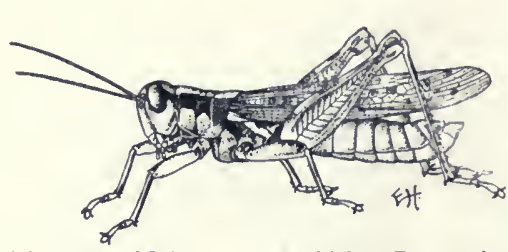

Fig. 147. Male. $X$ 1.5. (After Bruner.)

sissippi only from near Moline, III., where Hart (1907) recorded it as occurring with $M$. angustipennis and flavidus at the edge of a large blowout on a sand hill. As it was not treated in Scudder's "Revision" he described it as new under the name of $M$. macneilli, which falls as a synonym to fluviatilis. Bruner's description (loc. cit.) is very brief, and he states that it is "rather common along river valleys in eastern Nebraska, where it is to be found among vegetation growing on sand bars." No other mention of its occurrence can be found in the literature at hand.

\section{Melanoplus stonei Rehn, 1904b, 85. Stone's Locust.}

Size medium, the females slightly the larger and more robust. Dark fuscous-brown above, dull reddish-brown or dirty clay-yellow beneath. Face greenish-yellow, strongly mottled with fuscous; occiput with a broad, often ill-defined, reddish-brown median stripe extending back along the middle of pronotum, this bordered each side by a narrow dull yellow stripe, below which is the usual black postocular stripe of the genus on upper halves of pronotal lobes; lower halves of these lobes pale brown; metapleura dull yellow. Tegmina fuscous-brown, the median area with a row of subquadrate dull yellow spots. Hind femora dull yellow, the outer face with two broad oblique blackish bars, these often fused to form a continuous stripe; upper and inner faces with three fuscous cross-bars; lower face yellow; knees black, their lower outer lobes pale. Hind tibiæ red or vinous brown, darker or sometimes greenish toward base with a black ring behind the knees. Occiput and frontal costa much as in packardii; fastigium more narrowly and shallowly concave. Pronotum as described under the series heading; prozona in both sexes slightly longer than metazona, median carina faintly visible on prozona of female. Tegmina feebly surpassing tips of hind femora in both sexes. Supra-anal plate as described above, its apex obtuse; median sulcus wide and distinct on hasal portion, narrower and ill-defined on the depressed apical third. Furcula widely separated, strongly divergent, their basal portion flat, apical one much narrowed, scarcely tapering. Cerci as described above, less narrowed at middle than in fluviatilis, their ventral margin nearly straight, dorsal one broadly concave, outer surface thickly punctate. Subgenital plate as in fluviatilis, the apical tubercle more distinct. Length of body,

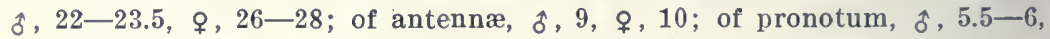
९, 7.5-8; of tegmina, $\hat{\delta}, 17-18, \uparrow, 20-21$; of hind femora, $\hat{\delta}, 12-12.5$, ㅇ, $14-14.5 \mathrm{~mm}$.

Chatsworth and Harris, N. Jer., Aug. 13-20 (Davis). Described from New Jersey and so far recorded only from that State, though it has been taken hy Walker (Ms.) at Godbout, Quebec, and Ft. William, Ont. At the former place "they were the only 
long-winged Melanoplus present, and occurred on the coarse grasses of a sea-beach and sparingly in open jack-pine barrens."

Fox $(1914,514)$ says that stonei is restricted to the northern part of the New Jersey Pine Barrens, having been taken only between Harris and White Horse (type locality) and near Atsion and Stafford's Forge. Smith $(1910,184)$ states that it occurs "in the low scrub under mixed pine and oak and on bare sand near pine woods."

In general color M. stonei is the darkest of our eastern species of the genus, M. keeleri and M. punctulatus ranking next in darkness of hue. Rehn prefaced his original description as follows: "A member of the packardii group and related to $M$. packardii and fœdus but distinguished by the smaller size, more compressed and excavated rertex and fastigium, narrower frontal costa, smaller furcula, greater interval between the mesosternal lobes in both sexes and in the rich and striking coloration." The fastigium in the specimens at hand is more shallowly sulcate than those of packardii, while the interval between the mesosternal lobes of the female is but slightly wider than in that sex of packardii.

Series XIV. The Keeleri Group.

Medium sized species of rather robust form and reddish-or fuscous-brown hue, haring the usual dark postocular stripe of the genus vague or wanting; male with prozona subquadrate and interspace between mesosternal lobes half or more as long again as broad; tegmina fully developed, reaching to or berond tips of hind femora, their median area usually distinctly maculate with fuscous spots; hind femora with outer, upper and inner faces bifasciate with fuscons; hind tibia usually red, sometimes pale blue or dull greenish-rellow; extremity of male abdomen not greatly enlarged, but feebly upcurved; supra-anal plate broadly triangular, its margins but slightly recurved; cerci either distinctly forked or with a strongly angulate submedian process on rentral margin; subgenital plate variable in form.

Two species and one rariety of the group occur within the limits of the territory covered by this work. They were included by Scudder in his Collinus Group, but since M. collinus Scudd. is now recognized as a synonym of M. Turidus (Dodge), the name of the group is likewise changed.

KEY TO EASTERN SPECIES OF KEELERI GROUP.

a. Lower fork of male cerci very short, represented by an angle or median process ( $\mathrm{Pl} . \mathrm{IV}, n)$; furcula rather slender spines, longer than the last dorsal segment to which they are attached; median area of 
tegmina immaculate, male, very faintly flecked with fuscous, female; scoop of upper valves of ovipositor very short, the base of their outer edges entire (Fig. 144, d.)

203. coxfusus.

$a a$. Forks of cerci usually distinct, the lower one the narrower; furcula minute triangular lobes, shorter than last dorsal segment. (Pl. IV, o:); median area of tegmina slightly maculate with fuscous; scoop of ovipositor longer, the outer basal margin crenulate (Fig. 144, c.)

b. Subgenital plate of male longer than broad; upper fork of cerci strongly oblique, scarcely bent upward (Fig. 145, $d$ ); lower valves of ovipositor relatively long, almost straight; females rarely under $26 \mathrm{~mm}$. in length.

204. KEELERI.

$b b$. Subgenital plate as broad as long; upper fork of cerci bent distinctly upward (Pl. IV, o) ; lower valves of ovipositor relatively short, distinctly decurved (Fig. 144, c); females rarely over $25 \mathrm{~mm}$. in length.

204a. LURIDUs.

203. Melanoplus confusus Scudder, 1897b, 29. Little Yasture Locust.

Size medium for the genus, small for the group, the sexes subequal. Above, dark brownish or fuscous, often with a reddish-brown tinge; below dull yellowish. Occiput and disk of prozona darker than metazona; the usual shining black bar on upper third of lateral lobes of prozona, small in male, often broken or subobsolete in female, bordered below with brownish-yellow. Hind femora brownish-yellow, lower face reddish-orange; knees black above. Hind tibiæ usually pale blue, pinkish at tip, sometimes red or dull yellow; spines black. Interocular space nearly twice, male, or three times, female, as wide as first joint of antennæ; fastigium but feebly declivent, distinctly and widely sulcate in male, depressed but scarcely sulcate in female, the lateral margins sharp. Frontal costa faintly narrowed between the antennæ, feebly sulcate at and below the ocellus. Pronotum short, but slightly widening on metazona; hind margin broadly obtuse-angled; median carina low, visible throughout, a- little less distinct on prozona; disk of prozona broadly convex, a fourth longer than the finely punctate metazona. Tegmina reaching tips of hind femora, female. slightly surpassing them, male, of nearly equal width throughout. Supraanal plate short, broad, triangular, the apex acute; median sulcus rather wide, confined to basal half. Furcula consisting of a pair of well separated parallel cylindrical spines about a fourth the length of supra-anal plate and overlying the ridges of its median sulcus (Pl. IV, n.) Cercl with basal portion stout, rectangular; apical portion nearly as long but narrower, bent slightly upward and inward, its dorsal margin rounded and outer face concave, an inferior angle or process at point of bend; the apex broadly rounded. Subgenital plate very short, apex rounded, the lateral margins incurved near base; apical margin thickened and slightly prolonged. Length of body, $\hat{\delta}, 16-18, \uparrow, 19-24$; of antennæ, $\hat{\delta}, 7-8, \uparrow, 8-9$; of pronotum, $\hat{\delta}, 4.5, \uparrow, 5$; of tegmina, $\hat{\sigma}, 11-15$,,, $14-17$; of hind femora, ô, $10-11.5$, ㅇ, $12-13.5 \mathrm{~mm}$.

In Indiana this appears to be one of the least common of the Melanopli, having been noted only in Monroe, Vigo, Putnam and Marion counties. It has been found in numbers but once, on June 
30 , on the blue-grass corered slope of an open woods pasture in Putnam Co. At the otler localities only one or two specimens were secured, the earliest date being that of a single male in Marion Co., on June 1. It frequents blue-grass pastures, roadsides and borders of cultivated fields in upland or sandr regions, and when disturbed flies noiselessly for a short distance. In the field the red-legged form closely resembles. . femur-rubrum and atlainis in general appearance and is rery likely to be confounded with them. It is probably, therefore, more numerous than my observations would denote and perhaps occurs throughout the State.

This small, trim-bodied locust is the $M$. minor (Scudd.) of my former work $(1903,322)$ and of most authors. The name minor, as first pointed out by Caudell (1915), was preoccupied by $\mathbf{F}$. Walker $(1870,699)$ and the oldest synonym, M. confusus Scudder, therefore takes its place. The known range of $M$. confusus is a wide one, extending from Maine north and west to Toronto, Ont., Winnipeg, Man., Wyoming and Washington, and south and southwest to Havelock, N. Car., Missouri, New Mexico and Arizona. Morse (1898, 293) says that in New England it is the first member of the genus to reach maturity, adults having been taken on June 7. There it is found "most numerous among sweet rernal and blue-grasses in pastures and mowing-lands on gravelly or sandy upland soils. The hind tibire are very variable, ranging from cherry-red to greenish or blue. The red tibixe are more common among the females (25-33 per cent., males $17-20$ per cent.); among the males, howerer, they are frequently glaucous at base and pinkish at tip." In Ohio it has been recorded only from Newark, and in Michigan only from Douglas Yake and Saginaw Bay.

Somes $(1914,90)$ states that in Minnesota the males are nearly all of the red-legged type and that the young appear in August and pass the winter in an adranced stage of derelopment, both these conditions being different from those reported by observers in other States. In Colorado Gillette $(1904,52)$ reports it as occurring only in moderate numbers on the plains and lower foothills up to 7,000 feet in the northeastern part of the State, where it matures as early as June 6. Bruner records it as found orer the entire State of Nebraska, and common early in July. About Charlottesville, Va., Fox (1917) found it "the dominant grasshopper during late May and early June, although rather strictly limited to the higher, drier areas and not occurring in any considerable numbers on farm lands. Its choice appeared to be for old upland fields and pastures over-run with coarse grasses (Andropogon, Danthonia), etc." 
204. Mela oplus Keeleri (Thos.), 1874, 69. Keeler's Locust.

Larger and comparatively more slender than its variety, $M$. $k$. luridus. General color usually darker, above fuscous-brown, often with a tinge of purplish-red; beneath dull olive or dark greenish-yellow. Tegmina of female with larger fuscous spots along the median area. Oblique fuscous bars of hind femora and black ring at base of hind tibiæ usually wider and more prominent. In structure very similar to $M$. $k$. luridus, the principal differences being those given in the key. Cerci extremely variable in form, the lower fork in two of the males at hand being only a sharp tooth-like projection less than one-fifth the length of the upper one, while in another the lower fork is represented only by an angular protuberance, less distinct than in $M$. confusus. Length of body, $\hat{\delta}, 19.5-27$,,$+ 26-35$; of antennæ, $\delta, 10-10.5$,, $9-10$; of pronotum, $\delta, 5-5.5$,, $6.3-6.7$; of tegmina $\hat{\delta}, 17-22$, ㅇ, 19.5-26; of hind femora, $\hat{\jmath}, 13-15$, ㅇ, $15.5-18 \mathrm{~mm}$.

Gainesville and Dunedin, Fla. (W. S. B.) ; Mobile, Ala. (Loding) ; Thomasville, Ga. This is a species of southern range, which has been recorded from numerous stations in northern Florida by Davis and R. \& H., and probably occurs throughout the mainland of the State, though apparently scarce in winter and in the southern portion so far known only from Miami. Thomas described it from a single Florida female. Only one pair has been taken at Dunedin. They were swept from wire-grass in open pine woods on December 4. The Thomasville, Ga., specimens were collected by Hebard among the undergrowth in similar woods, Dec. $3-10$. The difference in size between the sexes is much greater than in the northern race luridus, the females being much the larger.

The known range of keeleri extends from Petersburg, Ta., along the Atlantic coast to Dallas and San Antonio, Texas, Scudder's types of $M$. deletor, now recognized as a synonym of liecleri. being from Dallas. Fox (1917) records liecleri from a number of stations in Virginia, stating that there it "occurs trpically in the grasses and low shrubbery of dry open woodlands." MeNeill (1899a, 366) recorded it from Alkansas, but his sjecimens were probably in great part those of the northern form as he was the first to give an opinion that kecleri, deletor and luridus are forms of a single species. Morse $(1907,49)$ states that he too was unable to separate satisfactorily Arkansas specimens of the three forms and records them all under the name liceleri from numerous localities in Arkansas, Oklahoma and Texas. stating that it is a very common species in and near woodlands, apparently not occurring on the treeless plains. The $M$. tencbrosus Scudder (1S79, 63 ) is a synonym of kecleri. 
204a. Melaxoplus Keeleri Luridus (Dodge), 1876, 11. Broad-necked Locust.

Size medium for both genus and group, the females but little the larger. Above dark grayish-brown varied with fuscous; greenish-yellow beneath. Face dull bluish-gray with mottlings of brownish-purple; occiput and disk of prozona usually fuscous, the metazona paler. Upper half of lateral lobe of prozona with the usual black bar, this often subobsolete in female. Tegmina brownish-fuscous, often grayish in female, with a row of fuscous spots along the discoidal area; rarely immaculate. Hind tibiæ bright coralred, the basal third often paler and with a more or less distinct fuscous ring near the knee; spines black. Interocular area'slightly wider than, male, or fully half as wide again, female, as first antennal joint. Fastigium moderately sloping, shallowly and broadly sulcate in male, plane in female. Frontal costa of nearly equal width throughout, faintly sulcate at and below the ocellus. Fronotum feebly and regularly widening on posterior half, more strongly so in female; median carina distinct on metazona, obvious but faint on prozona; hind margin broadly obtuse-angulate, the angle rounded; prozona one-third, male, or but slightly, female, longer than the distinctly punctate metazona. Tegmina reaching tips of hind femora in male, often a little shorter in female. Supra-anal plate with apical third somewhat abruptly and strongly narrowed, the apex rather obtuse; median sulcus broad, usually confined to basal half (sometimes percurrent and slightly widening on apical third) its bounding ridges sharp, high and uniting each side near their tips with a short, low transverse ridge. Furcula as described in key and lying obliquely across the bases of the median ridges. Cerci forked as shown in plate IV, o. Subgenital plate as broad as long, its apex usually broadly rounded, sometimes feebly thickened, slightly elevated and subtruncate at middle. Length of body, $\hat{o}$, 17-20,, , 19-25; of antennæ, $\hat{o}, 8.5-9, \&, 8-9.5$; of pronotum, $\hat{o}, 5$, , 6 ; of tegmina, $\hat{\sigma}, 13-16, \uparrow, 14-17$; of hind femora, $\hat{o}, 10-12$, , $12-15 \mathrm{~mm}$.

This compact, dull colored locust occurs in all parts of Indiana, frequenting open blue-grass pastures, the borders of gravelly and sandy terlaces, prairies, and hillside slopes. Like $\boldsymbol{M}$. gracilis and $M$. bivittatus it delights, in early autumn, to carry on its courtship among the leares and branches of the iron weeds. The species begins to reach maturity about July 20, and may be taken until late November. While of about the same length, the females of luridus are wuch more robust than those of either 1 . femurrubrum or $M$. atlanis, and the tegmina just reach the tip of or are a little shorter than the abdomen, instead of exceeding it as in those species.

In my former work (1903, 325) the $M$. collinus Scudder, whose distribution as given by its anthor $(1897,348)$ was limited to the region east of the Mississippi, was first placed as a synonym of II. Iuridus Dodge, recorded up to that time only from points west of that stream. This placement of collinus has been adopted by 
most recent writers, and there is no doubt but that the two forms represent a single species, though Kirby (1910, 528) lists them as distinct, and in the most recent local list of American Orthoptera, that of McAtee \& Caudell (1918), the name collinus is retained. R. \& H. (1916, 242) give their opinion regarding the eastern and western forms as follows:

"It would be difficult to imagine individuals, without even racial significance, differing more greatly in general appearance than do the longwinged slender examples of luridus from the northwestern portion of its range, from the heavy, short-winged type which is often found in Connecticut and New Jersey southward through the Appalachians. This is particularly true of the female sex; northwestern material bearing a strong superficial resemblance to $M$. atlanis, while the southeastern is vastly heavier with a different general appearance. Intergradation between these types is, however, almost everywhere to be found and no valid reason exists for separating the eastern and western material as geographic races."

The known range of $M . k$. luridus is a very wide one, extending from Maine north and northwest to North Bay, Ont., Aweme, Man., Minnesota and Montana, soutl to the crests of the higher mountains of North Carolina and Georgia and west to Kansas, Nebraska and Colorado. According to Walker $(1899,33)$ it is quite plentiful in Ontario in late summer, frequenting sandy or gravelly uplands and the more or less open or rocky unsettled country such as characterizes the Laurentian area in that region. Along the Severn River he found it in August to be the most abundant locust, far outnumbering any other Melanoplus. McNeill (1891, 74) states that in northern Illinois it is "closely restricted to the tops of hills and sides of ravines too barren for pasturage." Fox (1917) calls it "a typical sylvan species, frequenting the grassy and shrubby undergrowth of dry woodlands, and abundant in the Apjalachian region of Virginia along the margins of the woods and in clearings on the mountain slopes." Ii. \& H. (1910a, 63\%) record luvidus "as being the most plentiful species of Melanoplus on all the mountains of North Carolina, at altitudes above 4,000 feet." Morse $(1904,44)$ mentions it from numerous stations in Virginia, North Carolina, Georgia and Tennessee and calls it "an expert leaper, using its legs, as a means of escaping its enemies, quite as freely as its wings, though flying freely on occasion." West of the Mississippi $M L$. $\%$. luridus is stated by liruner to be quite common, especially on the prairies over the most of Nehraska, while Gillette says it is an abundant species in northern Colorado, east of the mountains, the native food plant being the wormwood or sage brush, Artemisia dracunculoides Pursh." 
Series XV. The Differestialis Group.

Species of large size and robust form, having the general hue brownish-rellow or reddish-brown, the postocular dark stripe faint or wanting; disk of pronotum with sides subparallel, male, feebly expanding, female, median carina vers low, usually percurrent, hind margin broadly obtuse-angulate; tegmina rariable as to species, fully dereloped or slightly abbreviated; prosternal spine long, rather slender, subcylindrical; interval between mesosternal lobes of male twice or more as long as broad; extremity of male abdomen strongly swollen, usually distinctly upcurved; supra-anal plate broad, shield-shaped or subtriangular; furcula wanting; cerci variable as to species; subgenital plate longer than broad, comparatirels narrow, the apex but slightly elerated and entire.

Six closely related forms of this group are known from east of the Mississippi, two of them of rather wide distribution, the other four recorded in small numbers only from Georgia and Florida.
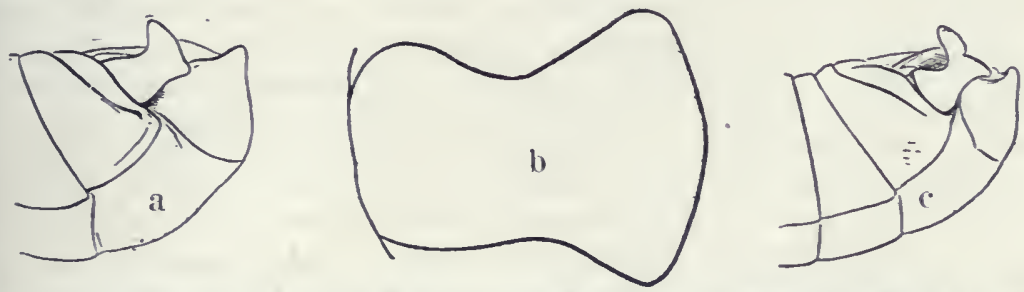

Fig. 148. a, Extremity of male abdomen of Melanoplus clypeatus; c, same of $M$. furcatus; $\mathrm{b}$, outline of male cercus of $M$. sj'mmetricus. (After Scudder and Morse.)

KEY TO EASTERY SPECIES OF DIFFEREXTIALIS GROUP.

a. Cerci of male roughly boot-shaped, the apical foot as long as the basal leg (Pl. IV, $p$ ); hind tibiz yellow, rarely red in Pacific Coast specimens.

205. DIFFEREXTIALIS.

aa. Cerci of male not boot-shaped; hind tibiæ usually red.

b. Apical margin of male cerci regularly obliquely convex or broadly rounded.

PONDEROSUS,

bb. Apical margin of cerci not regularly convex or broadly rounded. c. Cerci of male not forked.

d. Tegmina covering three-fourths of abdomen, subequal in length to hind femora, their costal field dark testaceous, discoidal field blackish, anal field light testaceous or wood. brown; apical margin of cerci broadly angulate, prolonged above to form a triangular lobe (Fig. 148, a.)

206. CLYPEATCS.

$d d$. Tegmina reaching tip of abdomen, distinctly longer than hind femora, their color brownish-yellow, but faintly marked

This species is dimorphic in wing-length and bas been treated under Division I, p. 405 , the short-winged form only being so far known from our territory. 
with fuscous; apical margin of cercl subtruncate, above less prolonged, with angle more rounded (Fig. 148, b.)

206a. SYMMETRICUS.

cc. Cerci distinctly forked or deeply emarginate.

e. Upper fork of cerci slightly longer than the lower one (Fig. $148, c)$; anal field of tegmina grayish-yellow; discoidal field darker with numerous small fuscous spots or blotches.

207. FURCATUS.

$e$. Lower fork of cerci longer, with apex more narrowly rounded, than the upper one; discoidal field of tegmina a uniform fuscous-brown.

207a. PEgASUS.

205. Melanoplus differentialis (Thomas), 1865, 450. Differential Locust.

Very large and robust, the females distinctly the larger. Color usually a nearly uniform dark brownish-green or olive-brown above, bright to dull yellow beneath. Face olive-green, often with oblique fuscous streaks. Pronotum with transverse sulci and pleural incislons black. Tegmina olive-brown, immaculate. Metapleura yellow; sides of basal.segments of abdomen in part black. Hind femora either dull or bright yellow, the outer face with narrow black marks arranged herring-bone fashion; upper inner face with three oblique black bars; lower face yellow; knees black, their lower outer lobes bright yellow. Hind tibiæ yellow, with a narrow black basal ring, the spines black. Interocular space twice or more as broad as first antennal joint; fastigium gently sloping, broadly but not deeply concave. Frontal costa broad, but narrower than interocular space, broadly and shallowly sulcate at and below the ocellus, male, less distinctly so, female. Disk of pronotum flat or nearly so; median carina distinct and sharp on metazona, less distinct but visible on front half of prozona, the prozona subquadrate, slightly longer than the finely rugulose metazona. Tegmina exceeding tips of hind femora in both sexes, the narrowest apical portion about half as wide as the broadest basal portion. Supra-anal plate very broad, the sides of apical third rounded and thence strongly oblique to the obtuse apex; margins upcurved to form broad, shallow con. cavities each side of the deep, percurrent median sulcus. Cerci as in key and Plate IV, $p$. Subgenital plate short, broad, the middle of apical margin thickened, slightly prolonged upward, usually entire, rarely feebly notched. Upper valves of ovipositor short, stout, tips strongly upcurved, outer margins distinctly crenulate. Length of body, $\delta, 28-34$, $\$, 34-44$; of anten-

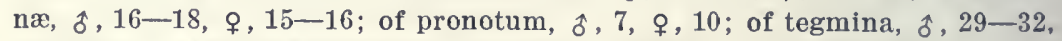
오, 32-35; of hind femora, $\hat{\delta}, 18.5-20$,, $21-23 \mathrm{~mm}$. (Fig. 149.)

This is the largest and at the same time one of the most common and destructive of our Melanopli. It occurs throughout Indiana, reaching maturity in the central portion about July 25th, and may be found in farorable seasons until December 1st. In late autumn the females are always worn and bedraggled, while many of the males are bright colored and evidently freshly moulted. The species becomes darker with age and those which mature in autumn are darker than those of mid-summer, often in great 
part melanistic. In autumn it is common on the lawns, vacant lots and sidewalks of Indianapolis, and in 1918, together with II. femur-rubrum and bivittatus, did a vast amount of damage throughout the State to clover and other forage crops.

In Indiana, this lubberly locust delights in low, damp waste places, such as the margins of lakes and ponds, the borders of streams, fence rows and the margins of low-land cultivated fields. It is especially fond of the greater rag weed, Ambrosia trifida L., of the river bottoms, and is often seen by scores feeding upon its

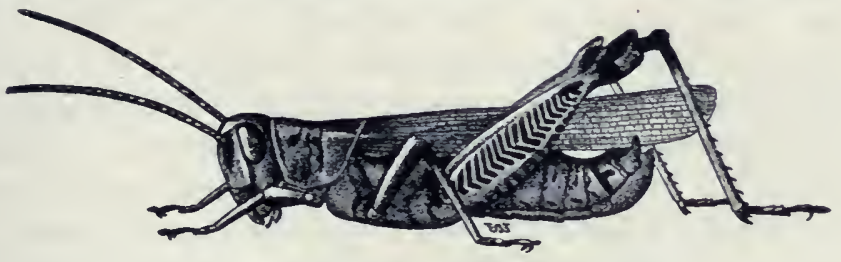

Fig. 149. Male. $\times$ 1.5. (After Lugger.)

leaves, or mating among its foliage. The various species of smartweed, Polygonum, which grow in shallow water, are also much frequented by it in early autumn. Occasionally vast numbers are seen along the edge of a field of low-land corn, the leares of the marginal rows of which they have almost wholly destroyed. When a stalk is approached they do not desert it but dodge quickly around to the opposite side, much as does a squirrel around the trunk of a tree when pursued. If, howerer, one takes alarm and jumps, all the others in the immediate vicinity do likewise.

In late autumn, as night approaches, this locust, as well as M. femur-rubrum and other species, often climb or fly to the tops of liigh weeds where, sheltered by the leaves, they eling to the stems or branches until the sun warms them up the next day. If the night is cool or frosty one can pick them off these weeds by scores in early morning. I have often gathered them thus for bait, getting all I needed in a few minutes for an entire day's fishing.

On one occasion a specimen of differentialis was found feeding upon a dead example of Dichromorpha viridis, half or more of the abdomen of the latter having been devoured. The Loggerhead shrike, Lanius ludoriciamus L., catches many of these and other locusts and often impales them on the barbs of wire fences. On one October day I gathered fully a pint of such impaled insects from a fence row half a mile long, and found that they represented sixteen species; eight of grasshoppers, two of katydids, and 
six of beetles, all injurious, so that this bird, although savage and blood-thirsty, is of great benefit to the farmer and fruit grower.

East of the Mississippi the known range of $M$. differentialis extends from New Jersey and Pennsylvania north and west to Cheboygan Co., Michigan and Illinois, south and west through Tennessee to Agricultural College, Miss. It appears to be scarce and recently introduced east of the Appalachian Mountains, having been recorded only from near Camden and several other points in New Jersey and the vicinity of Philadelphia, Pa. Rehn (1900a) says that it was first seen about Philadelphia in 1896. - In 1898 they "appeared about August 1 on the weeds on lots and even in the iron manufacturing sections of the eity, where there is absolutely no vegetation." Fox $(1914,514)$ states that it was then abundant in the low maishy lands adjoining the lower Delaware River and its tributaries. It is not mentioned by Fox (1917) nor by MeAtee and Caudell (1918) and therefore apparently does not occur in the east as far south as Virginia and Washington, D. C. In Tennessee it is known from Clarksville, Danville and Chattanooga. The Mississippi specimens at hand were taken by $\mathrm{H}$. E. Weed in September, 1892. It is not recorded from Canada, and but once from Michigan, Vestal $(1914,108)$ stating that at Douglas Lake it was "not abundant, being near the northern limit of its range."

West of the Mississippi differentialis ranges from $45^{\circ}$ north latitude over practically the entire country as far west as the Pacific and south to Southern Mexico. Scudder says that he does not think it occurs above 6,000 feet, and Gillette states that in Colorado, where it is abundant and destructive in the lower altitudes, it has not been taken above 5,500 feet. In Minnesota Somes $(1914,92)$ states that it has been taken as yet only in the southern part of the State, it and $M$. bivittatus being "the only locusts found far in from the margins of thoroughly worked lands such as corn fields. 'The eggs are deposited in loose soil or even sand, often in cultivated fields. In September we have noted great numbers, literally thousands, of the females drilling and ovipositing in an abandoned melon patch where the soil was a soft and very sandy loam. They were not under the vines, for the most part, but every spot of bare soil was occupied by one or more of the females."

Brumer, on the other hand $(1893,16)$, says that:

"The eggs are laid in cultivated grounds that are more or less com. pact, preferably old roads, deserted fields, the edges of weed patches and well grazed pastures adjoining weedy ravines. Egg laying begins about 
the middle of August and continues into October, varying, of course, according to latitude and climatic conditions. Usually, but not always, only a single cluster of eggs is deposited by each female. Frequently there are two, and in extreme cases perhaps even three of these clusters deposited by a single female. One hundred and seventy-five eggs have been counted in a single mass."

Riley $(18 \pi 8,223)$ states that around Dallas, Texas, Boll "found the eggs of differentialis very numerously placed under the bark of elm and hackberry logs that had been felled in low land."

Finally, quoting in part from Scudder and Bruner, this giant Melanoplus is certainly occasionally one of the most destructive pests of the Upper Mississippi Valley States, having been noted as injuring grass, alfalfa, Indian corn, beets, orchard trees, mulberry, poplar and catalpa trees, and even grape vines. Dahlias, hollyhocks and other garden flowers have also been specified as its food, not to mention the greater rag-weed, Ambrosia trifida. It is one of the few species of locusts that has thus far shown a tendency toward civilization. This it has done readily, since its habits are in unison with the cultivation of the soil. It is only since the settlement of the country where it originally occurred that it has multiplied so as to become sufficiently numerous as to become a serious pest.

The variation in color and structure of differentialis is very slight for a locust of such wide range. Scudder says that in California occasional specimens are found having the hind tibiæ bright coral-red, and Gillette states that in Colorado individuals that are black, except for yellow bands upon the legs and light posterior lateral margins of pronotum, are sometimes taken. This lack of variation and large size leads to its easy identification, and it is one of the few older described Melanopli which lias no synonyms.

206. Melayoplus Clypeatus (Scudder), 1877, 40. Shield-tailed Locust.

Size large for the genus, medium for the group; form robust, the sexes subequal. General color dull brownish-yellow, the usual postocular dark stripe represented by a very narrow streak, or obsolete. Color of tegmina as described in key. Hind femora stout, outer face dull yellow, often suffused with fuscous, inner face yellow with black bars, lower face coral-red. Hind tibiæ dull red, paler at base, the spines wholly black. Interocular space narrow for the group, not as wide as frontal costa in either sex, slightly depressed centrally in both sexes. Fastigium gently sloping, broadly and shallowly concave. Frontal costa rather wide, deeply and briefly concave below the ocellus, its margins feebly convergent below in female. Pronotum as described under the series heading and tegmina as in key. Supra-anal plate with median sulcus percurrent, rather shallow, narrowing apically. Cerci stout, the basal three-fifths slightly longer 
than wide, with subequal parallel sides; apical portion as in key and Fig. $148, a$. Length of body, $\hat{\delta}, 28, \uparrow, 36$; of antennæ, $\hat{\delta}, 15$,, , 14.5; of tegmina, $\hat{\delta}, 17-18$, ㅇ, 18.5; of hind femora, ô, 16-18, ㅇ, $21 \mathrm{~mm}$.

This species is known only from a few stations in Georgia. Scudder's types were from that State without definite locality. He at one time $(1880,75)$ expressed the opinion that clypeatus was the long-winged form of his $M$. nigrescens, but evidently changed his views as he redescribed both under different series in his "Revision." R. \& H. $(1916,245)$ have recorded clypeatus from Thomasville and Sandfly, Ga. At the latter place it was "found to be very scarce in the heaviest undergrowth in graybark pine woods, in more or less swampy situations."

206a. Melaxoplus clypeatus symmetricus Morse, 1904, 8. Symmetrical Locust.

Very close to $M$. clypeatus. Color much the same, the discoidal field without spots and only slightly darker than the costal one. Inner face of hind femora coral red on basal two-thirds and with three oblique fuscous bars. Lateral lobes of pronotum shorter and deeper in the female than in that sex of clypeatus. Apex of subgenital plate less elevated than in clypeatus, its tip without a tubercle. Other differences as given in key. Length of body, ô, $28-30$, 우, 31-34.5; of tegmina, ô, 19-22, ㅇ, 21-23; of hind femora, $\hat{o}, 16-18$, ㅇ, $18-20 \mathrm{~mm}$.

Known only from Florida. Morse's types, which I have examined, were taken at Carrabelle, August 9. He states that they were secured in a grassy swamp not far from the beach and were associated with Paroxya atlantica and clavuliger and Schistocerca alutacea. It is a campestral species resembling femoratus in size, appearance and haunts, save for some minor differences in coloring. Some of the specimens in the Philadelphia collections taken at Pensacola, Aug. 28, have the upper lobe of cerci more prolonged than in the ones from Carrabelle, approaching those of clypeatus, of which I regard it as only a variety.

\section{Melanoplus furcatus Scudder, 1917b, 30. Fork-tailed Locust.}

Size very large, form robust. Brownish-ferruginous, the top of head and prozona faintly dotted with fuscous. Tegmina colored as described in key. Hind femora with inner face twice barred with black, which sometimes shows feebly above and on outer face where it is diffused; lower face dull red. Hind tibiæ as in clypeatus. Interocular space broad, but distinctly narrower than frontal costa; fastigium very feebly depressed, running without break into the frontal costa which is broad, equal, shallowly sulcate at and below the ocellus. Pronotum as described under the series heading, its median carina very low, distinct only on metazona; prozona about a fourth longer than the finely and closely punctate metazona. Supra-anal plate with a deep basal median sulcus reaching beyond 
middle, narrowing apically. Cerci stout, heavy, incurved, narrowing toward middle, then rapidly expanding and furcate, the upper lobe longer and more equal than lower, well rounded apically; the lower one subtriangular, bluntly pointed, turned but little downward (Fig. 148, c.) Length of

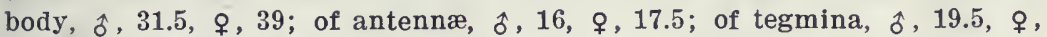
23 ; of hind femora, $\hat{\delta}, 18.5$, $ᄋ, 22.5 \mathrm{~mm}$.

Known only from Florida. Scudder's types were taken at Jacksonville. Other specimens in the Philadelphia collections were taken at Pomona, Fla., Sept. 7.

207a. Melanoplus furcatus Pegasus Hebard, 1919a, 293. Swift Locust.

"Closely related to $M$. furcatus. Differs in the more solid coloration, in this respect closely resembling $M$. clypeatus, and in the form of the male cerci, the branches of the forked distal portion being more elongate and slender, and the ventral branch exceeding the dorsal branch in length. General color varying from prout's brown dorsad and tawny olive laterad to a maximum intensive condition in which the head and pronotum are blackish chestnut brown with a comparatively broad blackish postocular bar, while the lateral fields of the tegmina are darker than the pronotum. Pale ventro-external bar of caudal femora much more sharply defined than in furcctus." (Hebard.)

This is a form of furcatus, bearing the same relation to it that symmctricus does to clypcatus or that luridus bears to kceleri. the principal differences being those given in the key. It is the II. furcatus of R. \& H. $(1916,244)$, nec. Scudder, the type series being from Billy's Island, Okefenokee Swamp, Ga. There it was found July 15-19, in "thick, rich bushy undergrowth surrounding wet depressions filled with swamp loving trees, these areas scattered through the long-leaf pine woods. The males frequently flew short distances in a direct plunging manner; the females were less likely to fly and were more difficult to locate."

The four forms, clypeatus, symmetricus. furcatus and pegasus, are very closely related. All are so far known only from small series taken at isolated stations in an area less than 200 miles square in the States of Georgia and Florida. While the extremes of these series appear at present sufficiently different to cause them to have been described as distinct species, they will in time, through more extensive collecting, probably be found to represent varieties of the one species, clypeatus; these varieties differing somewhat in details of coloration, wing-length and form of male cerci, all very plastic characters among the Melanopli.

Series XVI. The Bivitatas Group.

Only one of the five species ascribed to this group by Scudder is here recognized as occurring in our territory, the characters of 
that speeies being sufficiently set forth in the key to Series and in the following description:

208. Melanoplus bivittatus (Say), 1825, 308. Yellow-striped-Locust.

Females very large for the genus, the males much the smaller. Dull olive-brown to brownish-fuscous above, pale yellow to dull greenish-yellow beneath. Face either yellow or olive-green, often flecked with fuscous; occiput and disk of pronotum dark olive-brown. A narrow yellowish stripe extends back from the upper inner angle of each eye along the sides of disk of pronotum nearly to tips of tegmina; this usually bordered below with blackish on head and lateral lobes of pronotum. Tegmina usually immaculate, often with a few fuscous dots along the median area. Hind femora dull yellow, usually with a fuscous stripe along the upper half of outer face; inner half of upper face with three more or less distinct fuscous bars; lower face yellow; knees in great part fuscous. Hind tibiæ usually bright coral red, with black spines, often purplish-brown or greenish-yellow. Interocular space wide, equalling the frontal costa and about three times the width of first antennal joint; fastigium feebly declivent, broadly and shallowly concave. Frontal costa broad, subequal, convex above the antennæ, slightly sulcate at and below the ocellus. Pronotum widening feebly on posterior half, more distinctly so in female, disk nearly flat, hind margin broadly obtuse-angulate or subrounded; median carina distinct on metazona, very low, sometimes in part subobsolete on prozona, the latter fully one-half, male, or about one-third, female, longer than the closely and very finely punctate metazona. Tegmina reaching or slightly surpassing the hind femora, sometimes a little shorter in

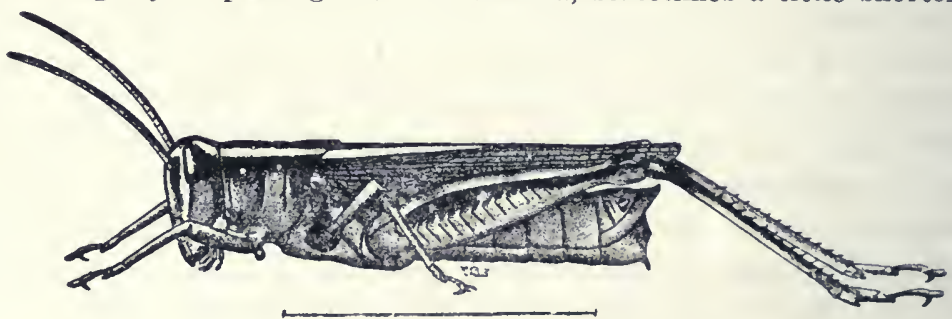

Fig. 150. Female, $X$ 1.3. (After Lugger.)

female, tapering regularly and gradually from base to the rounded tips. Hind femora distinctly surpassing abdomen, male, reaching its tip or slightly beyond, female. Supra-anal plate broadly triangular, abruptly narrowed and sharply incised each side near the blunt apex; its margins upcurved to form a broad lengthwise concavity each side of the deep, rather narrow median sulcus. Furcula consisting of a pair of very short, much swollen, triangular widely separated lobes. Cerci as shown in Plate IV, $q$. Subgenital plate short, rather narrow, the apex slightly elevated and ending in an obtuse tubercle. Length of body, $\hat{\sigma}, 23-29$, 운, $31-40$; of antennæ, $\delta, 14-16$, $ᄋ, 11-14$; of pronotum, $\hat{\jmath}, 6-7, \uparrow, 8-9$; of tegmina, $\hat{\delta}, 17-22$, $ᄋ, 20-25$; of hind femora, $\hat{o}, 13-16$, $ᄋ, 17-22$ mm. (Fig. 150.)

In Indiana this is one of the most common of our early summer locusts, oceurring everywhere throughout the State. It begins 
to reach maturity about June 15th, perhaps earlier in the southern counties, and has mostly disappeared by mid-September. It frequents clover fields, open blue-grass pastures, prairies and roadsides, and is to be found in both moist and dry localities. When flushed, it usually leaps vigorously, seldom flying, and then noiselessly and for a short distance. It delights to rest on the branches and foliage of the iron-weeds and other Compositre, and is often found after death, clinging to them and to tall grasses, where it has fallen a prey to the locust fungus. More than any other of our Melanopli it seems to be subject to the attacks of the red locust mite, Trombidium locustarum Riley. In August I once noted a large male with a dozen or more of the mites in different stages, attached to the membrane of the inner wings. A female near br, with both tegmina and wings absent, had more than 20 of the mites clinging to the thin membrane beneath the metathorax. Old and worn examples of this locust usually have the wings badly damaged.

After more than 15 years additional observation I see no reason to change my former $(1903,331)$ placement of Burmeister's redlegged femoratus as an absolute synonym of Say's bivittatus. Most of the recent writers have either retained femoratus as distinct or made it a variety of bivittatus, but none of them have as ret pointed out a single fixed structural character of specific or even varietal value on which to base their retention of the name femoratus. Scudder in his key $(1897,138)$ separated them solely by the difference in color of the tibix, and in his subsequent description of bivittatus (p. 367) adds: "Besides the differences in the hind tibix, there are other slight ones which I have attempted to state, in the abdominal appendages and in the tegmina, besides some distinction in the color," but he nowhere points out definitely these minor distinctions except in the cerci as mentioned farther on. In Indiana one can find in almost erery colony not only red-legged and greenish-legged individuals, but often those in which the tibire are brown at base, greenish or glaucous in the middle and red on the apical third.

As far back as 1859 that astute observer, Philip R. Uhler (1859, II, 238), said of bivittatus: "Belongs to Caloptenus and is identical with $C$.femoratus Burm. It is very common on the salt marshes near Baltimore and I hare once or twice seen it in company with $C$. femur-rubrum (DeGeer) in considerable swarms in the air." Scudder himself $(1862,466)$ followed Uhler without comment, but (1S7S, 285) reversed his opinion without giving reasons other than distributional as follows: "M. femoratus is 
the species generally called Caloptenus bivittatus. The latter, however, is an interior species while femoratus extends across the continent."

Rehn (1904d, 267) mentions Pequaming, Michigan, specimens as "having the posterior tibiæ uniformly blood-red, varying slightly in intensity, thus placing them in femoratus. The form of the cerci is also that figured by scudder as typical femoratus." $\mathrm{He}$ adds: "Personally, I believe femoratus and bivittatus to be geographic forms of the same species very closely related but still typical of each other over large areas." Now Scudder's figures (1897, pl. XXIV, figs. 4 and 5) show very little difference in the form of the cerci, and in the description of the cerci of bivittatus $(1897,365)$ he says that they are "shaped almost precisely as in $M$. femoratus, but more elongate and with the upper lobe of the expanded extremity bent at a lesser angle with the basal portion." It has already been shown that the form of the cerci in $M$. viridipes, M. keeleri and other species of Melanoplus varies exceedingly and $\mathrm{R} . \& \mathrm{H} .(1905,40 ; 1907,297)$ reduced $M$. deletor to a synonym under keeleri on account of the variability in the form of that organ. One may pick at random 20 males of bivittatus from any colony throughout its range, and no two of them will have the cerci exactly alike and the extremes in form will be as great or greater than described by Scudder.

As to the two being geographic forms, that is controverted by the known distribution, both forms being found together from Ohio or farther east, to Oregon and Washington, and from Central Canada to at least as far sonth as latitude $40^{\circ}$. Scudder says that typical bivittatus does not occur along the Atlantic seaboard nor along the Pacific coast south of Washington. It is very probable that in these regions moisture and other conditions of habitat are such that all the tibia are red, just as in certain localities the inner wings of Arphia xanthoptera are yellow and in others orange-red. Numerous species of Melanopli and other locusts, as M. atlanis, eonfusus, angustipennis, packardii. etc.. are known with tibiæ both red and otherwise colored, yet we do not give varietal names to each of these.

The entomologists of the East who, for the most part, have seen only the red-legged form in the field, and have perhaps judged bivittatus as distinct from a few specimens received in exchange, should observe the two forms as they appenr together by thousands on a mid-summer day in the meadows and pastures of the central West. They will then probably arrive at the same conclusion as has Somes, who says $(1914,93)$ : 
"M. femoratus Burm, is identical with $M$. bivittatus in size, general appearance and form of cerci and furcula, but differs mainly in the fact that the posterior tibiæ are red. It can but be considered as a mere color form of this species by one observing the two in the field. It has no more basis for specific distinction than have two other color forms which $I$ have occasionally taken-one in which the hind tibiæ are clear yellow throughout, and the other having the hind tibiæ entirely and almost uniformly dark rose purple. All of these color forms, including the one termed $f e$ moratus, occur together through the northern part of Minnesota, with typical bivittatus, and I have on many occasions observed specimens in coitu in which the sexes had differently colored hind tibiæ."

As noted above, the known range of $M$. bivittatus is a wide one, extending from Newfoundland, Nova Scotia, Hudson Bay and Vernon, B. C., south to North Carolina, the mountains of northern Georgia, Texas and Old Mexico, and from the Atlantic to the Pacific. While it is seldom if ever migratory like spretis and attanis. it often occurs locally in sufficient numbers to be highly injurious to clover, blne-grass and other forage plants.

Bruner $(1893,19)$ has well summed up its habits as follows:

"Next to Dissosteira carolina (L.) the two-striped locust is perhaps the most familiar to the greatest number of people in the United States. It occurs in nearly every locality over the entire country from the Saskatchewan River in the north to the Gulf of Mexico at the south, and from ocean to ocean. It is found in the low valleys near the seashore and upon the mountain slopes of the Rocky range and the interior.plateaus to an elevation of nearly 10,000 feet above tide water. In fact, this particular species appears to be able to withstand more climatic variations than any other of the North American species, without showing marked variations in color and form. No wonder, then, that it occasionally becomes sufficiently numerous over limited areas to do considerable injury to crops. Like M. femur-rubrum and differentialis, bivittatus is a lover of rank and succulent vegetation such as is found upon bottom lands, along the edges of cultivated fields, at the margins of woodlands, and on the shaded mountain slopes. When nature has specially favored the species, as it sometimes does, in the way of favorable climatic conditions, the absence of enemies, etc., and it develops in large numbers, then these haunts are forsaken to a greater or less extent and it spreads over cultirated fields, eating the choicest of everything.

"The egg-laying habits of bivittatus differ considerably from those of the smaller migratory species, insomuch as but one or two clusters or pods are deposited by a single female. Nevertheless, just as many eggs are laid by each female insect. These eggs are deposited in prairie sod or any compact soil in the vicinity of the regular haunts or feeding places. Old roads and closely cropped pastures when located handily are favorite resorts for the heavily-laden females when attending to this mission of theirs. Conditions which favor the rapid multiplication of other locusts. such as the migratory kinds, also favor the increase of this and other of our native species. Hence when we hear of the increase and spread of the former, we may also look for the latter to become more numerous. 
By keeping down weed patches and by plowing waste places about fence corners, along ravines, the edges of groves and old roads, this insect can usually be kept moderately scarce and harmless."

Piers $(1918,306)$ states that in Nova Scotia $M$. bivittatus ranks next to $M$. femur-rubrum, $M$. atlanis and the crickets among destructive Orthoptera. He also writes of its habits as follows:

"Near the mouth opening of insects are salivary glands which in the Acrididæ usually secrete a brown-colored fluid, which is also probably defensive in character as many species when captured very readily exude it from the mouth. This is particularly noticeable in M. bivittatus, and country children have everywhere given the dark-coloured secretion the name of 'grasshopper molasses,' and to the insect itself they occasionally apply the name 'molasses bug.' This species is often captured by Nova Scotian children for the sole purpose of seeing it exude the fluid, their invariable saying on such an occasion being, 'grasshopper, grasshopper, give me some molasses and I'll let you go.' It is also known to many children as a doughty fighter, boys often amusing themselves by bringing two large specimens together so that they wrestle vigorously with their front legs and endeavor to bite each other. These gay coloured locusts bring back childish memories of half forgotten summer days when we dallied waist-deep in the lush timothy, the air filled with what might be termed the 'green' scent of trampled grass; or of afternoons in early autumn when we loafed about the rank vegetation of fence-rows with its odour of dank decay."

\section{Series XVII. The Punctulatus Group.}

As this group is also represented by only a single species and its variety, the characters are as given in the Series key and in the following description:

209. Melaxoplus punctulatus (Scudder), 1862, 465. Grizzly Locust.

Size medium for the genus, the males but little the smaller. Above dark gray, much mottled with blackish; beneath dull reddish-brown to clay-yellow. Head and face greenish-gray mottled with fuscous; occiput and disk of prozona darker, the usual black bar behind eye on upper half of lateral lobes often broken and somewhat indistinct. Disk and sides of metazona and entire surface of tegmina sprinkled with numerous rounded or quadrate fuscous spots, which give to the insect a grizzly appearance, quite distinct from that of any other of our Melanopli. Hind femora alternately and plainly barred with blackish and dull yellow on the upper and outer faces, the lower face and basal third of inner face coral red. Hind tiblæ either dull red or gray, or a mixture of both, the spines black. Head prominent; occiput swollen and distinctly elevated above the pronotum; fastigium rapidly sloping, sulcate throughout, the margins much raised between the eyes, which are separated by a space scarcely as wide as basal joint of antennæ, male, one-half wider, female. Frontal costa convex and prominent above the antennæ, of equal width throughout, feebly sulcate below the ocellus. Eyes large, very prominent in male. Pronotum with front border slightly flaring to receive the head; disk but little if any widening 
behind; median carina usually visible throughout, low and often indistinct on prozona; hind margin broadly obtuse-angled; prozona about a third, male, or scarcely, female, longer than the finely rugulose metazona. Tegmina slightly surpassing the hind femora in both sexes, very gradually tapering to a well-rounded apex. Supra-anal plate of male very broadly triangular, almost flat, the apex acute; median sulcus wide, shallow, confined to the basal half. Furcula wanting. Cerci large, broad, roughly boot-shaped; basal half oblong, apical half expanded to nearly double the width of the basal, the upward expansion twice or more as large as the downward; the latter thin, and extended back as a wing-like border along the basal half (Pl. IV, $r$.) Subgenital plate of moderate width, its apex abruptly elevated into a conical tubercle. Lower valves of ovipositor almost straight, the lateral tooth nearly or quite obsolete. Length of body, $\hat{\delta}, 19-24$, ․, 27-29; of antennæ, $\hat{\delta}, 13-14,, 11-12$; of pronotum, $\hat{\delta}$, $4.6-5.5$,,$+ 5.7-6.3$; of tegmina, $\hat{\delta}, 17-20$,,$+ 18.5-22$; of hind femora, $\hat{\delta}, 11.5-13$, 우, $12-14.5 \mathrm{~mm}$.

In Indiana this prettily mottled locust has been taken in nuneerous localities throughout the State, but is nowhere common, seldom more than half a dozen being seen each season. It is preeminently an autumn insect, the first mature specimen having been taken on August 20th, while most of those seen were in October and November after heary frosts, several pairs having been found mating on September 24. In central Indiana it frequents for the most part low wooded tracts along streams, where it may often be noted resting on the trunks of trees, two or three feet above the ground. In the northern part of the State it has been found only in the depths of the tamarack swamps of Fulton and Marshall counties. While other Acrididre are common up to the rery border of the tamarack growth, this and two species of grouse locusts were the only ones found within this border. It is more arboreal in habits than any of our other northern Melanopli, in most places frequenting the vicinity of pine or coniferous trees, but in Indiana these are rare, and it has been taken mostly on those of oak, beech and maple. In action it is rather sluggish, after one or two short leaps usually squatting close to the earth, and seemingly depending upon the close similarity of its hues to the grarish lichens or debris about it to aroid detection.

The general range of typical punctulatus is northern, extending from Maine and Ontario west to Minnesota and Nebraska, south to Virginia and Georgia and southwest to Dallas, Texas. It is noted as scarce wherever found except near Thompson's Mills in northern Georgia, where Allard $(1916,278)$ states it "was a. very common species in all upland fields in company with $M$. femur-rubrum." From Ohio it has been recorded only from Cedar Point, while it is not mentioned in any of the Michigan lists. 
Somes says it is very rare in Minnesota, but that he las taken it in northern Iowa in low thickets of willow. Bruner states that in Nebraska it is "found in rather small numbers in oak groves in the extreme eastern part of the State."

In Ontario the grizzly locust has been recorded only from Toronto and DeGrassi Point. Of its habits at the latter place E. M. Walker $(1901,22)$ has given an interesting account as follows:

"I found them most numerous on dead stumps and logs, in a wood of second growth white pine. They were sometimes seen on the trunks and branches of living trees, but most often on the stumps and fallen trunks of the old forest, and on the pine rails of a snake fence enclosing the wood. They were found only on the borders and more open parts of the woods, where they were to be seen upon almost every stump. I have seen ten females on a single stump. It is in these dead stumps and logs that the females deposit their eggs, in which operation I have observed them repeatedly. The female chooses a crack in the wood or an old beetle boring of suitable size and lowers her abdomen down this, sometimes nearly as much as an inch. Sometimes when the hole is of a large size, only the head and legs of the insect can be seen above it. Unlike Chloaltis conspersa, the female of $M$. punctulatus apparently never bores herself, unless merely to make her way through any loose rubbish that might be obstructing the hole. She generally chooses sound or only partly decayed wood.

"I managed to obtain several fragments and one complete packet of eggs. The latter was fixed by the cement substance at its lower end to the wall of the beetle-boring three-eighths of an inch in diameter. It was attached at a distance of about three-quarters of an inch down the hole, and except at the lower end, which was imbedded in a depression in the wall, the packet was quite free. It was covered with a rather thick coating of a porous or vesicular cement substance, which also filled all the spaces between the closely packed eggs. The latter were twenty-three in number, and their arrangement was in general in a longitudinal direction, the anterior ends pointing toward the free end of the packet, but was otherwise irregular. The eggs are 4 to $4.8 \mathrm{~mm}$. long, elongate-elliptical in form, finely and densely punctate and reddish-brown in hue."

The Caloptenus griseus Thomas $(1872,454)$ and the C. helluo Scudder $(1875 \mathrm{~b}, 476)$ are both synonyms of $M$. punctulatus.

209a. Melaxoplus punctulatus arboreus Scudder, 1897b, 31. Southern Grizzly Locust.

Larger than typical punctulatus. Color much as there. Metazona shorter and broader, its hind margin more broadly obtuse-angulate. Furcula evident, consisting of a "pair of slight triangular projections at the inner angles of the divided last dorsal segment and overlying the ridges of the supra-anal plate." Subgenital plate with apical tubercle larger, more inflated and more prolonged upward. Length of body, $\delta, 27.5-30$,, $36-44$; of antennæ, $\hat{\delta}, 18$,, 16.5 ; of pronotum, $\hat{\delta}, 6.2, \uparrow, 8.2-8.9$; of

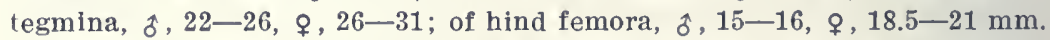

This, the sonthern race of $M$. punctulatus, was originally de- 
scribed from specimens taken at Dallas, and the Gulf Coast of Texas and in Arizona. It has since been taken east of the Mississippi at Lake Drummond, Dismal Swamp, Va., Southern Pines, X. Car., Stone Mountain, Ga., and in Walton Co., Fla. These records are given by R. \& H. $(1916,247)$ who state that the Florida specimen was "taken from the stomach of a turkey killed in a pine forest," while the single Georgia specimen was "found in a dusty road bordered on each side by heary pine roods."

\section{Family VII. TETTIGONIID.玉. ${ }^{61}$}

\section{Katydids ayd Their Kix.}

"I sit among the leaves here, when erening's zephyrs sigh, And those that listen to my voice I love to mystify;

I never tell them all I know, altho' I'm often bid,

I laugh at curiosity, and chirrup, 'Katy did.' "

The family Tettigoniida comprises those insects commonly called katydids, green or long-horned grasshoppers, cone-headed grasshoppers and stone or camel crickets, the name "grasshopper" rightfully belonging to its winged members and not to the shorthorned locusts or Acridida. The principal distingnishing characters of the members of the family Tettigoniidse, as given in the key, p. 149, are the long, slender, tapering. many-jointed antenna which, when turned back, usually extend far beyond the tip of abdomen; almost universal absence of ocelli or simple eyes; the four-jointed ${ }^{62}$ tarsi or feet; and the sword-shaped or falcate ovipositor of the females, which is made of four flattened plates with the edges near its tip often horny and serrate. The head in many of the species is wedge-shaped and the mouth-parts are well developed, the maxillars palpi being vers long and the wandibles especially long and sharp-pointed. This enables the insect to dig into plant tissue or to eat the seeds of grasses, as many of them do. The tegmina, when present, are usually leaf-like and of a delicate structure, having no stiff chitinous anterior veins. When closed the left one usualls orerlaps the right, and, in the larger forms, they slope obliquely downwards instead of being bent abruptly, as in the Grrllida or true crickets, while in most cases, the wings are slightly-longer than the tegmina. The mesoand metathorax are less closely united than in the Acrididx,

-1This family of the suborder Saltaloria was for many years known as Locustidx. but the genus Locusta of Linneus was founded for a true locust and not for a katydid, hence recent American writers have used the name Tettigoniidæ, which is based upon the Linnaan genus Tettigonia, given to a European katydid and meaning "grasshopper" and "angle," on account of the shape of the tegmina. In Enrope Kirby and some of the other writers use the family name Phasgonuridx for the same insects, while Karney and others still retain "Locustidæ."

62The members of the genus Daihinia, no one of which occurs in our territory, have the fore and hind tarsi three-jointed. 
Plate v.

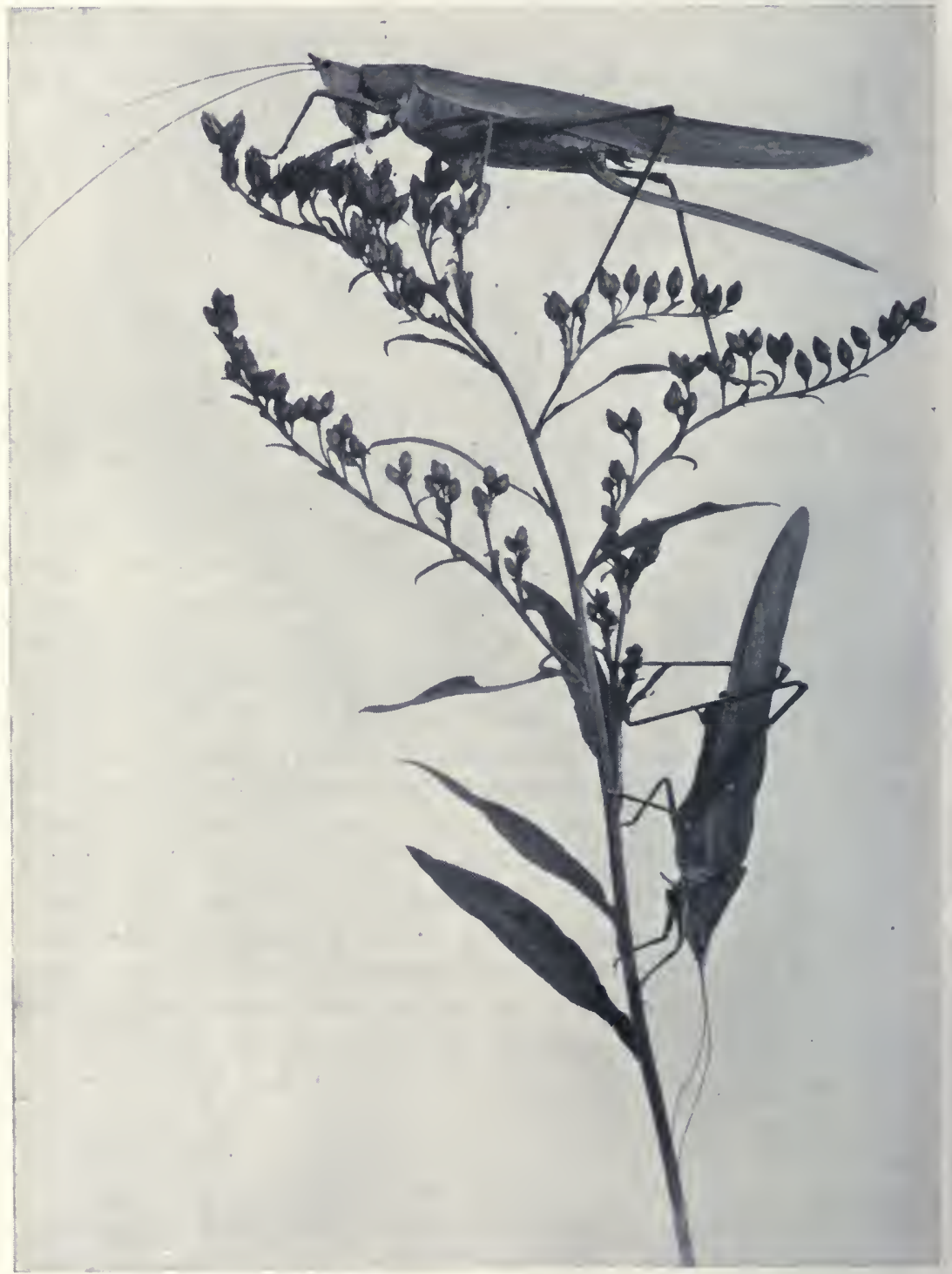

A Pair of Cone-head Grasshoppers, Neocoxocephalus exsiger Harris, ox GOLDEX-18OD,

Female above: male below. (From a photograph of living specimens by Dr. J. L. Hancock, Lakeside, Mich.) 
and in the winged forms the hind legs are usually longer and much more slender. The males have, in mans instances, abdominal appendages corresponding to the parts of the oripositor which are used as clasping organs.

The stridulating or musical organ of the males is quite similar in structure to that of the male cricket, being found at the base of the overlapping dorsal area of the upper tegmen and usually consisting of a transparent membrane, of a more or less rounded form, which is crossed by a prominent curved rein, which, on the under side, bears a single row of minute file-like teeth. In stridulating, the tegmina are mored apart and then shuffled together again. when these teeth are rubbed orer a rein on the upper surface of the other wing cover, producing the familiar, so-called "katydid" sound. Each of the different species makes a distinct call or note of its own, and many of them have two calls, one which they use by night and the other by day. Any one who will par close attention to these different calls can soon learn to distinguish each species by its note as readily as the ornithologist can recognize different species of birds in the same manner.

In the northern States the notes of the katydids and green grasshoppers are not heard till in July, as they do not attain their wings until then. C. V. Riley who, like our own belored Indiana Riles, had within his soul a true love for the poetry of nature, has well set forth $(1874,153)$ his ideas of the why and wherefore of the songs of this family thus: "During spring, while our birds are making love, and the males rival each other in their attempts to please the females with happy, jubilant song. Dame Nature is rearing a troupe of insect mnsicians, which, in their turn, will string their lyres and play their courtship-tunes in the later seasons. when the song of the feathered performers is mostly hushed.

"Leyden's lines-

'Oft have I listening mused the sultry day

And wondered what thy chirping song might say'-

but express an inquiry often made as to the purpose and object of the grasshopper song. He who believes all things made for man and his enjoyment, and that nothing can have a purpose that does not include him in its scope, will not find an answer to the query; and should remember that ere man grew out of savagery the earth rang again with song and sound.

"But to the mind of the naturalist, trained in deciphering Nature's hieroglyphs, the chattering song is very plainly inspired by love. The male Katydid doubtless feels something of the same satisfaction in playing to his companions, and especially to Katr, 
as a prima donna does in singing to an audience. There is a pleasure in the act which is the outcome of its being; and the fact that the males are principally the players, shows that the gift is not only a sonrce of pleasure, but one of much importance to the species; for the rivalry among the males is as great as among higher animals, and a good instrument becomes, in this light, most important to the individual and to the species. The best player wins his coveted love, while the feeble and the cripples stand no chance to impair the vigor of the race."

While only the males are musicians, both sexes of the winged forms are provided with supposed auditory organs or ears. These, when present, are similar in structure and position to those of the cricket, being oblong or oval cavities covered with a transparent or whitish membrane, known as the drum or tympanum, and situated one on each front leg, near the basal end of the tibir. The drum is a thin, tense membrane corering a network of nerves, ganglion cells and auditory rods. In all the wingless Tettigoniida the stridulating organs are necessarily absent and as the insect can make no sound, it has no use for ears and these are also absent. This is taken as strong evidence that the eavity on the fore leg is in reality an anditory organ, which is denied by Forel (1857) and some other writers, who believe that all insects are deaf with no special organs of hearing, but that sounds are heard or appreciated by their tactile organs.

The color of each species of Tettigoniidæ is, as in most Orthoptera, admirably adapted to its usual surroundings. The winged forms, as the katydids and cone-headed grasslıoppers, live amidst the foliage of trees or clumps of grass, and are therefore a nearly uniform bright green, while the wingless forms, which dwell in caves or hollow trees and beneath rocks and logs are, for the most part, gray or brown in hue. Our larger species, with wings fully developed, use them as their principal means of travel, their slender hind legs being used only to give themselves an upward impetus at the beginning of flight.

In both the northern and southern states the members of this family winter chiefly in the egg stage, the eggs being laid in grasses, reeds, galls on willow, stems of plants, bark of trees and shrubs and even between the upper and lower lavers of leaves, the ovipositor being especially adapted for this method of egg deposition. In southern Florida some of the species pass the winter, in part at least, as nymphs, or even as adults, but the number of both species and individuals then there found is far less numerous than of the Acrididx. The young of the Tettigoniidx, like 
those of the other families of Orthoptera, when hatched from the egg resemble the adults in form but are wholly wingless. As they increase in size they moult or shed the skin five times, the wings each time becoming more apparent, until after the fifth moult, when they appear fully dereloped, and the insect is mature or full grown, never increasing in size thereafter. Throughout their entire lives they are active feeders, mostly herbivorous in habit, and when present in numbers necessarily do much harm to growing regetation. Most of the species can be easily reared from the young nymphs, their successive monlts being of much interest. They may be fed on lettuce and it is said that some of the larger species will eat flies and other soft-bodied insects. The males are very pugnacious, and often try to devour one another, so that they should be kept apart.

The species of Tettigoniida occurring in the United States are distributed among eight subfamilies, seren of which are represented in the eastern states.

\section{KEY TO EASTERY SUBFAMILIES OF TETTICONIIDE.}

a. Tegmina and wings present; ${ }^{63}$ general color green, rarely pale brown; fore tibiæ always with an auditory organ near the base.

b. Prosternal spines absent; vertex ending in a blunt spine or rounded and deflexed, rarely or never with a projecting tubercle or cone; tegmina shorter than wings, rarely (Phrixa) subequal to them; hind tibiæ with an apical spine on each side.

Subfamily I. Phaxeropterixe, p. 458.

$b b$. Prosternal spines present; vertex either terminating in a sharp flat spine or produced upward and forward into a rounded tubercle or prominent cone; hind tibiæ with an apical spine on outer side only or on neither.

c. Tegmina leaf-like, very broad, concave within, longer than the wings; vertex terminating in a sharp, flat spine; disk of pronotum crossed by two distinct transverse sulci.

Subfamily II. PseUdorirllixa, p. 494.

cc. Tegmina narrow, expanded but little, if any, at middle, usually shorter than the wings; vertex terminating in a rounder tubercle or prominent cone; disk of pronotum without, or with only one, transverse sulcus.

d. Front and middle femora spined beneath; ${ }^{64}$ vertex produced forward into a long, usually sharp cone; larger and more robust species, the length of body 24 or more $\mathrm{mm}$.

Subfamily III. COPIPIIORIx E, p. 502.

Wings absent, tegmina very small and general color brown in the aberrant genus Belocephalus; both tegmina and wings absent in the female of Odontoriphidium.

\footnotetext{
${ }^{4}$ Except in some of the species of Neoconocephalus. Although both Redtenbacher (r89r, r3) and Scudder (1897c, 54) separate their tribes Conocephalini and Xiphidini by the sole character of the presence or absence of spines on the fore and middle femora, there are several species of Neoconocephalus, the principal genus in the former tribe, which have these femora wholly unarmed beneath.
} 
dd. Front and middle femora unarmed beneath; vertex terminating in a rounded tubercle with concave sides; smailer, more slender species, length of body less than $24 \mathrm{~mm}$.

Subfamily IV. CoxocephaLIx E, p. 533.

aa. Tegmina and wings absent, or the former rudimentary; general color gray or brown.

$e$. Pronotum extending back to the abdomen; prosternal spines usually present; tegmina present, usually rudimentary; fore tibiæ with a hearing organ near the base.

Subfamily V. Decticixж, p. 586.

ee. Pronotum short, not covering the whole top of thorax; prosternal spines absent; tegmina and wings absent; fore tibiæ without a hearing organ near the base.

$f$. Eyes elongate-ovate, vertical, situated at the side of the basal joint of antennæ; ovipositor ensiform, curved strongly upward; tarsi depressed, their joints lobed beneath.

Subfamily VI. Gryllacrive, p. 602.

ff. Eyes subrotund, situated partly above the basal joint of antennæ; ovipositor nearly straight; tarsi compressed, the joints not lobed. Subfamily VII. Rhaphidophorixæ, p. 606.

\section{Subfamily I. PHANEROPTERINZE.}

\section{The Bush and Round-Headed Katydids.}

The species of this subfamily are among the largest of our winged Tettigoniidr, and, with those of the Pseudophyllina, are commonly known as "Katydids." The name Phaneropterina is based upon the typical old world genus, Phaneroptera Serv., meaning, "visible wing," and refers to the exposed tips of the inner" wings which extend beyond the tegmina in repose. They all agree in having the head short, face vertical, or nearly so; vertex varying greatly in width, the fastigium either ending in a blunt deflexed spine or broadly rounded, never projected in frout of eyes as a cone or sharp spine; eyes small, variable in form, situated close to and at the side of basal joint of antenna; pronotum slort, its disk flat or concave, more or less narrowed in front, usually meeting at right angles the perpendicular lateral lobes, its posterior lobe prolonged distinctly belind them with usually a wide, deep humeral simus or emargination at the junction; median carina wanting or very faint, lateral ones more or less distinct, hind margin broadly rounded, rarely (Arethaca) obtuse-angled; lateral lobes flat, their hind margin and lower posterior angle broadly rounded; lower margin rounded or sinuous, front margin variable; tegmina as described in key, nsually a bright uniform green in color; wings long and strong, folded like a fan; meso- and metasterna broadly lobed along their median line; legs variable 
in length as to genus, the front and middle ones always much shorter than the hind pair; ovipositor and male genitalia variable as to genus.

These "round-headed" and "bush katydids" are mostly arboreal in habitat, the great majority of them passing their entire lives on shrubs and trees, where they feed upon the leaves and tender twigs, and, when present in numbers, often do much injury. The color and form of their wings serve admirably to protect them against their worst foes, the birds; and as they live a solitary life, i. e., do not flock together in numbers as do the green or meadowgrasshoppers, they are but seldom noticed by man. Their love calls, or songs, howerer, make the welkin ring at night from midJuly until after heary frost, and though but one or two of the species make a note in any way resembling the syllables "katy did, she did," yet all are accredited with this sound by the casual observer, and hence the common name usually given to the members of this subfamily. Their call is seldom made by day for the obrious reason that it might attract the attention of the birds and so lead to the destruction of the songster. As twilight approaches, however, the male of each species begins his peculiar note, which is often kept up with little or no intermission until the approach of day warns him that his feathered enemies will soon be on the alert, and that silence will be, for a time, the best policy to pursue.

From the other Locustide, these katydids differ widely in their habits of oviposition. The eggs are rarely deposited in the earth or in twigs, but are either glued fast in donble rows to the outer surface of slender twigs, or are inserted in the edges of leaves. On account of this method of oviposition, the ovipositors of the katydids are broader, more curved, and more obtuse at the end than in the other subfamilies, whose members oriposit in the earth, in rotten wood or in stems of grass.

The subfamily is represented in the eastern states by eight genera, the principal literature treating especially of their species being as follows: Riley, 1874; Brunner, 1878; Scudder, 1893, 1898; Blatchley, 1893, 1903; Saussure \& Pictet, 1897-1899; Rehn \& Hebard, 1914, 1914a, 1914b, 1916; Rehn, 1917.

KEY TO EASTERN GENERA OF PHANEROPTERIX E.

a Hind legs nearly or fully four times as long as body (Fig. 151); pronotum saddle-shaped, its hind margin obtuse-angled; eyes oblongoval, nearly twice as long as wide.

I. Arethis, p. 460.

aa. Hind legs at most less than three times as long as body; pronotum not saddle-shaped, its hind margin broadly rounded; eyes usually glo. bose, at most but one-half longer than wide. 
b. Tegmina distinctly shorter than wings, their apex not broadly obliquely truncate (Fig. 157,a); apex of ovipositor not acuminate.

c. Tegmina long, narrow, but little or slightly broader at middle than at apex; fastigium of vertex horizontal or but feebly deflexed, but little if any wider than basal joint of antennæ.

d. Middle femora unarmed beneath; eyes subglobose; subgenital plate of male long, slender, upcurved, its apical notch usually V-shaped.

II. SCudderia, p. 462.

dd. All the femora spinulose beneath; eyes oblong-oval, one-half longer than wide; subgenital plate of male short, broad, nearly straight, its apical notch broad and rounded.

III. SyMMLTROPLEURA, p. 475.

cc. Tegmina broad, distinctly wider at middle than at extreme apex.

$e$. Fastigium of vertex deflexed to nearly the same plane as the frontal fastigium, obtuse, usually twice or more than twice as as wide as first antennal joint.

t. Hind femora long, reaching to or beyond apical fourth of tegmina; fore and middle tibiæ flat or sulcate above, their margins raised, acute; tegmina oblong-elliptical or ovate; ovipositor long, curved gradually upward, usually strongly serrate on both edges. IV. Amislycorypha, p. 476.

$f f$. Hind femora shorter, stouter, not reaching beyond apical third of tegmina; fore and middle tibiæ smooth and rounded above without angular margins; teglıina ovatelanceolate, sometimes very broadly so; ovipositor short, bent abruptly upward, finely or not at all serrate.

g. Disk of pronotum flat, its margins rounded or subacute, entire; smaller, length of body not over 33, of tegmina, not over $50 \mathrm{~mm}$. V. Microcextrui, p. 484 .

gg. Disk of pronotum concave, its margins elevated and crenulate; larger, length of body 37 or more, of tegmina 60 or more mm. (Fig. 163, a.)

VI. StilpxochlokA, p. 489.

ee. Fastigium of vertex not as wide as basal joint of antennæ, but slightly deflexed and meeting the narrower frontal fastigium at almost a right angle; disk of pronotum coarsely and thickly punctate; length of tegmina not over $33 \mathrm{~mm}$.

VII. TURpilia, p. 492.

$b b$. Tegmina as long as or slightly longer than wings, very broad, the apex obliquely truncate; apex of ovipositor acuminate; fore and middle tibiæ flat or sulcate above, their margins raised, acute.

VIII. PHirixa, p. 493.

\section{AReThжа Stăl, 1876, 55 .}

Elongate, very slender species, having the face flat, perpendicular, fastigium triangular, depressed, declivent, sulcate, continuous with the front; antenna very long, slender, the basal joint twice as long as broad, set in shallow. widely margined sockets; pronotum saddle-slaped with faint median carina; prozona with 
sides rounded into the lateral lobes, metazona triangular, prolonged backward and upward; humeral sinus feeble; lateral lobes sloping, longer than wide, their hind margins very oblique, so broadly rounded into the sinuous lower margin that the angle is scarcely evident; tegmina rery long, narrow, basal fifth of costal border widened, tips rounded; wings $\&-9 \mathrm{~mm}$. longer than tegmina; legs very long, extremely slender, hind tibia longer than the femora, lower lobe of knees ending in a pointed spine.

The genus is confined to the United States and Mexico, one of the 11 known nominal species occurring in Georgia and Florida, the other's from Texas and Nebraska to California.

210. Arethied phaldigium (Scudder), 1877, 40.

Size large for the genus; form elongate, compressed. General color green. Head with a narrow pinkish-purple stripe behind each eye these extending back, narrowing and converging on prozona; hind margins of metazona and lateral lobes white bordered within by pinkish. Hind femora tinged with pinkish-purple. Tegmina one-third to one-half longer than body, broader at apical fourth than at basal third, the stridulating field of male shorter than the disk of pronotum. Male with supra-anal plate very short, its apex broadly rounded; cerci short, stout, apically incurved, their tips acute; subgenital plate long, rigid, truncate at tip; styles very short, placed on the outer angles of the plate. Female with ovipositor rery short, broad, upturned, strongly compressed, bluntly pointed, its sides rugose and margins finely crenate. Other structural characters as above given. Length of body, ô, 16-22, \&, 19-24; of antennæ, §ิ, $65-68$, 우, 61 ; of pronotum, ô, 4.8-5.3, 우, 5-5.8; of tegmina, $\hat{\jmath}, 28-32$, \&, $31-36$; of wings, $\hat{o}, 36.5-43$, ㅇ, $36.5-40$; of hind femora $\hat{\jmath}, 33-37$, \&, $36-40$; of hind tibiæ, ô, 41 , ㅇ, 42 ; of ovipositor, $5-5.8$ mm. (Fig. 151.)

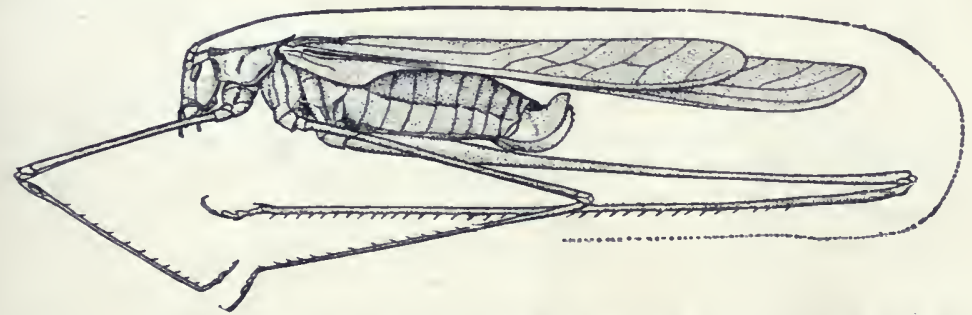

Fig. I5r. Lateral view of female of Arethaa phalangium. $\times$ 2. (After R. \& H.)

This peculiar long-legged, slender-bodied species was described from Georgia, is known only from that State and Florida, and seems to be very scarce wherever found. In Florida it has been recorded only from Hastings, Gainesville, Sanford, Miami, Homestead, Pine Island and Ft. Myers. Nymphs were taken at Miami and Ft. Myers in Marcl and April, and adults at the other stations between Mar 18 and Aug. 16. Hebard (1916) says that it is 


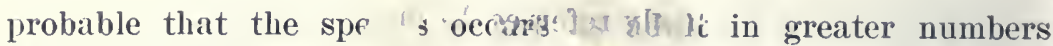
earlier than do most o Tettigon and that by August only occasional survirors at to be fovind: Tt occurs for the most part on the undergrowth of open pine wools. In Georgia it is known only from Thomasville, Hebardville and Augusta.

Scudder $(1877,38)$ founded for this species and one other the genus Aegipan which has since been placed as a synonym of Arethac. The Arethoca multiramosa Brunner $(1878,235)$ is a synonym of $A$. phalangium.

\section{Scudderia Stål, 1873a, 41. (In lionor of S. H. Seudder.)}

Bush Katydids. Narrow-Winged Katydids.

This genus includes katydids of medium size, having the vertex compressed, hollowed out on either side for the better accommodation of the eyes; disk of pronotum flat; tegmina as described in key, their tips rounded; fore coxæ armed with a spine; fore tibire sulcate above with margins acute; hind femora long, slender, almost equalling the length of tegmina in some species; all the knees with lobes armed with two feeble spines. Males with subgenital plate as described in key; last dorsal segment, in all but one of our eastern species, greatly prolonged, decurved, forked or

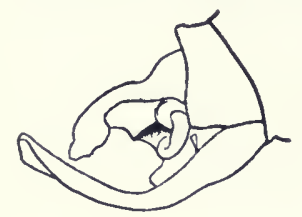

a

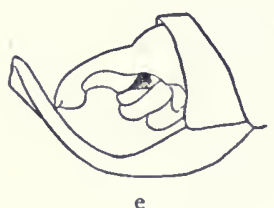

Fig. I52. Lateral view of extremities of male abdomen and dorsal view of male abdominal process of Scudderia. a, b, of texensis; c, d, pistillata; e, f, curvicauda; $\mathrm{g}$, h, furcata. (After Scudder.)

notched at tip to receive or partially embrace the apical portion of the upcurved subgenital plate (Fig. 152). Females with ovipositor short, broad, usually curved sharply upward, the apical third finely erenate on both margins (Fig. 153).

The genus Scudderia is mainly confined to Ameriea north of Panama and up to 1898 , when it was monographed by Seudder, the synonyuy was so badly mixed that it is difficult to say just 
what species was previc to . $r$ io ny writer. Mr. Scudder in his IIonograph (1., mully bre bt order out of chaos and fixed the present stancirg of most of he species. The genus was later again monographed by R. \& H. i914a), and of the 11 species and three varieties recognized by them, six species and two varieties are herein treated as occurring in the eastern states and Canada. The females are very similar and difficult to separate unless taken with the males in the field. The following key is therefore based mainly upon the latter sex.

KEY TO EASTERN SPECIES OF SCUDDERIA.

a. Last dorsal abdominal segment of male subtriangular, without an elongate, decurved median process; subgenital plate not compressed toward apex; cerci long, slender, tapering (Fig. 153, $h$ ); tegmina rather broad, dull, with swollen veinlets; ovipositor with both margins curved, not bent, more than half as long agaiu as pronotum (Fig. 153, a.)

211. SEPTENTRIONALIS.

aa. Last dorsal segment of male with an elongate, median, decurved process either notched or forked at tip (Fig. 152, $a, g$ ); subgenital plate narrowed and compressed towards apex; cerci shorter, very strongly incurved (Fig. 153, $i$,) their apical third thickened; ovipositor bent as well as curved, distinctly less than half as long again as pronotum.

b. Apex of decurved process of male not distinctly and deeply forked as shown in Fig. 152, $h$, but either with a very wide and shallow or a narrow median notch.

c. Notch of dorsal abdominal process of male subquadrate, with a minute median tooth, the notch as wide as the middle of the upturned subanal plate and embracing the sides of the latter when in natural position, its lateral processes slender and compressed (Fig. 152, $a, b$ ); ovipositor suddenly and strongly bent upward, its base distinctly broader than the middle (Fig. 153, b.)

212. TEXENSIS.

cc. Notch of dorsal abdominal process without a median tooth, much narrower than the subgenital plate and touching only, not embracing, the upcurved subanal plate (Fig. 152, c, $f$.)

d. Tegmina usually distinctly wider than length of pronotum, not striped with dark brown; ovipositor less suddenly bent upward and (except in strigata) not wider at base than at middle.

e. Lobes or lateral processes (each side of notch) when viewed from above, narrow and distinctly tapering apically; teg. mina wide, not over four times longer than the middle breadth; ovipositor sharply bent upward, its base and middle subequal in width (Fig. 153, c.) 213. PIstillata.

$e e$. Lobes or lateral processes of notch well rounded, subequal in width, their margins thinner; tegmina usually no broader than depth of body, nearly or more than five times longer than the middle breadth. 
$f$. Tegmina at middle distinctly broader than length of pronotum; disk of pronotum with side margins diverging backward, subacute, not broadly rounded into the perpendicular lateral lobes.

214. CURVICAUDA.

$f i$. Tegmina narrower, at middle no wider than length of pronotum; side margins of pronotum more parallel, broadly rounded into the more sloping lateral lobes; ovipositor distinctly broader, less suddenly bent upward. (Fig. 153, c.)

214a. LATICAUDA.

dd. Tegmina much narrower than the length of pronotum, strongly reticulate, each with a blackish-brown stripe along its dorsal field; notch of abdominal process very shallow, the lobes each side short, broad, strongly flattened; lateral angles of pronotum broadly rounded; ovipositor wider at base than at middle (Fig. 153, $f$.)

215. STRIGATA.

$b b$. Apex of decurved abdominal process of male distinctly and deeply

forked (Fig. 152, $g, h$ ), usually embracing the sides of the upcurved subgenital plate; size smaller and form more slender than our other common species.

$g$. Lobes of forks of abdominal process shorter, subcylindrical, rounded above, widely separated at tips. 216. FURCATA.

$g g$. Lobes of forks of abdominal process obliquely compressed, their upper edges subacute, more narrowly separated, especially at tip.

216a. CUNEATA.

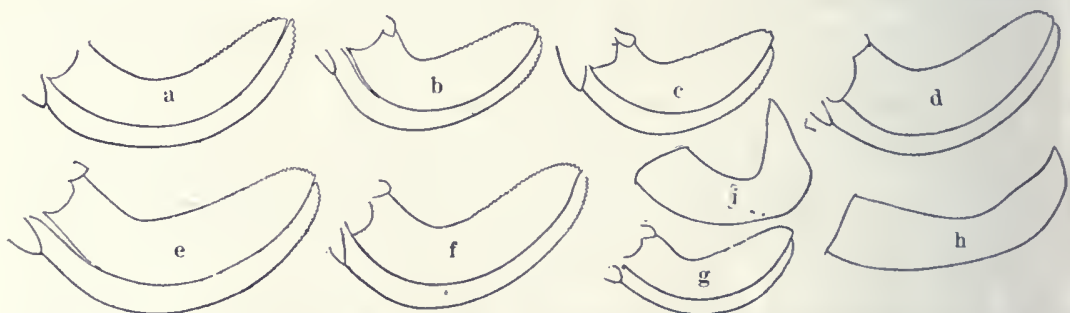

Fig. I53. a-g, Outlines of ovipositor of Scudderia; a, of septentrionalis; b, texensis; c, pistillata; d, curvicauda; e, laticauda; f, strigata; g, furcata; h, Outline of male cercus of S. septentrionalis; $i$, same of $S$. pistillata. All much enlarged. (After R. \& H.)

211. Scudderia septextrionalis (Serville), 1839, 416. Northern Bushkatydid.

Size very small for the genus; form slender. General color pale green more or less tinged with yellow; tegmina, basal half of pronotum, hind femora and all the tibiæ a uniform rather dark green; apical half of antennæ brownish. Disk of pronotum with sides feebly divergent behind, lateral carinæ evident only behind middle, basal lobe broader than in $S$. furcata. Tegmina shorter and broader than in furcata, more strongly reticulate and of a coarser texture. Male abdominal appendages as described in key, the subgenital plate narrowing gradually, strongly upcurved, its apex deeply and broadly notched. Ovipositor one-third as broad as long, gently curved, finely crenate above (Fig. 153,a.) Length of body, ô, 1618.5 , ․ 20 ; of pronotum, of 4.7 , ᄋ, 5 ; of tegmina, of, 25-28, ㅇ, 26-27; of hind femora, $\delta$ and $ᄋ, 18-19.5$; of ovipositor, $8.7 \mathrm{~mm}$. Greatest width of tegmina, ô, $7-7.3$, $ᄋ, 7.5 \mathrm{~mm}$. (Fig. 154.) 
Greenport, Long Island, N. Y., Aug. 3; taken at light (Davis). A very scarce species wherever found, its known range extending

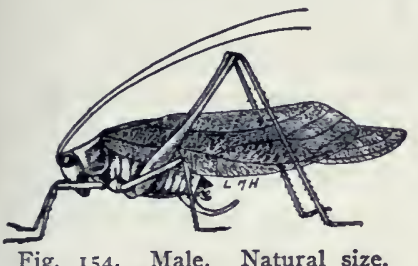

Fig. 154. Male. Natural size. (After Lugger.) from Norway, Maine, to West Point, Nebraska, and south to Vineland, N. Jer. The male was figured by Lugger $(1898,221)$ as that of Scudderia pistillata Brunner, and therefore doubtless occurs in Minnesota, though not definitely recorded by him. The figure from Lugger's work was also carelessly used by me $(1903,347)$ as that of the male of pistillata. The species is not known from Indiana, though it probably occurs about peat bogs in the Transition Zone of the northern third of the state. It is not recorded from Canada or Michigan, though a specimen from Lone Rock, Wis., is in the U. S. Nat. Museum. The few specimens in collections throughout the eastern states have mostly been taken from undergrowth in woods. The S. truncata Beutenmüller $(1894 \mathrm{a}, 252)$ is a synonym.

212. Scudderia texensis Saussure-Pictet, 1897, 328. Texan Bush-Katydid.

Size large for the genus. Tegmina, wings and legs bright grass green, body and face tinged with yellow, pale clay-yellow in dried specimens. Pronotum much longer than broad, narrower in front than behind, usually with a yellowish line along the lateral carinæ. Hind femora very slender, armed beneath on inner carina with three or four minute spines. Male genitalia as described in key. Length of body, $\hat{\delta}, 21-25, \quad$,, $24-28$; of

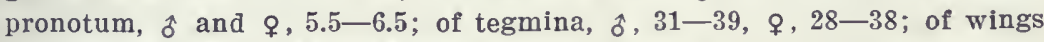
beyond tegmina, 6 ; of hind femora, $\hat{\delta}, 26-30, \rho, 27-32$; of ovipositor, 7$8 \mathrm{~mm}$. Width of tegmina, $6.3-8.5 \mathrm{~mm}$. (Plate I.)

This large, narrow-winged species is, in Indiana, one of the most abundant of the bush-katydids, occurring everywhere throughout the State, but is much less common in the sonthern counties, where it probably reaches maturity about July 15. The earliest date on which adults have been taken was July 22, in Putnam County. This insect is probably less arboreal than any other species of katydid, as it is often found clinging to the tall. coarse grasses and sedges which grow near the borders of lakes and ponds and in damp ravines, and to the coarse weeds along the margins of prairies and meadows. When approached it flies rapidly in a zigzag, noiseless manner for a long distance to another clump of grass or weeds, or to the lower branches of an oak, a tree in which it delights to dwell.

Aside from Indiana specimens others are at hand from North Madison, Conn., and Lake City, Gainesville, Dunedin and Ft. Myers, Fla. The two males from Lake City are very much smaller 
with distinctly narrower tegmina than those from the north, the length of body being but 18 and of tegmina but $28 \mathrm{~mm}$., while the greatest width of tegmina is less than $1 \mathrm{~mm}$. more than the length of pronotum. About Dunedin the nymphs are frequent from Jan. 15 to April 10, but the only adults seen were taken on October 31 and December 18. There it occurs on grasses and sedges about the borders of low places in pine woods, along railway embankments and in old abandoned fields. It has been recorded from numerous localities throughout Florida, adults having been taken at Miami in January and at LaBelle and Marco in April.

Until 1898 S. texensis was confused by most American collectors with S. curvicauda, and many of the older records of the latter species refer to the former. The specific name given the species by Saussure and Pietet was an ill-fitting one, as it ranges from New England and Ontario west to Montana and Wyoming and south to southern Florida and western Texas, being everywhere found in suitable habitats within the bounds of the area mentioned. Walker $(1904 a, 325)$ states that it is "quite common in southwestern Ontario, but seems to be confined to that part of the province." R. \& H. (1914a, 295) mention it as "one of the very few destructive Phaneropterids found in the United States, doing particular damage to eranberry crops. In New Jersey it has been frequently observed along the salt marshes where, after dark, it would be found locally abundant in areas of Scirpus, resting head down and motionless near the tips of these rushes and frequently beaded with dew. On bright warm afternoons it was observed in the taller vegetation near the border of the salt marshes, where the males were moving actively about emitting their rather prolonged and harsh stridulation."

\section{Of the notes of S. texensis Allard $(1911,30)$ says:}

"I have heard two distinct methods of stridulation produced at will by this Scudderia. The usual note heard from Massachusetts to Georgla is a soft $s h-s h-s h-s h-s h$-sh, occasionally repeated. This noto is produced by a rapid shuffling of the wings very briefly. At other times and much more rarely the call consists of a succession of sharp, keen, distinct rasping notes slowly delivered, zeet-zeet-zeet-zeet. These notes, which are so unlike the usual call, are usually at once answered in a similar manner by another individual elsewhere. One is at first tempted to assign them to some other insect. By creeping carefully toward the musician, the writer has watched this mode of stridulation close at hand. The tegmina are very slowly and deliberately opened and rasped upon each other slowly several times. These notes are really more in keeping with the incisive notes of other Scudderias and it is evident that they are not accidental. They probably convey some definite meaning to other individuals within earshot. S. texensis 
becomes noisy as soon as the afternoon sun gets low, and continues to stridulate into the evening. These katydids sometimes congregate in small colonies of half a dozen or more in favorite spots. It is a persistent singer, though its notes are delivered at rather rare, irregular and infrequent intervals, a characteristic of most species of Scudderia."

The eggs of texensis are laid in the edges of leaves between the upper and lower epidermis, and at first are so thin that they are not noticeable except when the leaf is held between one's self and the light. They are loosely inserted in these pockets made by the ovipositor of the mother, and as ther swell in coming in contact with the ruptured tissues of the plant, they are held tight$1 y$ in place. In the northern states the winter of this, as well as of the other species of the genus, is passed in the egg stage, the young appearing about the last of April.

213. Scudderia Pistillata Brunner, 1878, 240. Broad-winged Bush-katydid.

Size medium for the genus. Color as in curvicauda to which it is closely allied. It is, however, shorter-bodied, broader-winged and shorterlegged. Tegmina broader than in any other species, with heavy veinlets which give them a very leaf-like appearance. Notch of dorsal abdominal process of male very similar to that of male curvicauda, but its lateral processes subtriangular, distinctly tapering instead of well rounded and of subequal breadth as in the latter species. Subgenital plate shorter than in curvicauda. The short, broad tegmina and short hind femora of pistillata are the characters which most readily distinguish the two. Length of body, $\hat{\delta}$ and $\rho, 19-20$; of pronotum, $\hat{\delta}$ and $\rho, 4.7-5.7$; of tegmina, $\hat{\sigma}$, $29-33$,,$+ 25.5-28$; of hind femora, ô, $21-29$,,$+ 19.5-21$; of ovipositor, $6.5 \mathrm{~mm}$. Greatest width of tegmina, ô, 9-11, ㅇ, $8-9 \mathrm{~mm}$.

This is apparently a scarce insect in Indiana, having been taken in small numbers only about the peat bogs and borders of lakes in Steuben, Fulton and Koscinsko counties; Aug. 13-Oct. 7. Specimens are at hand from the White Mountains, N. H., Sherborn, Mass., DeGrassi Point, Ont., and Tecumseh, Mich., July 25Sept. 3. It is a species of northern range, its known distribution extending from Nova Scotia and New England north and west to Fort Williams, Ont., Regina, Sask., and Bozeman, Mont., and south and west to Monterey and Bolar, Va., southern Illinois and northeastern Nebraska.

Piers (1896) has given an interesting account of pistillata as it occurs in Nova Scotia as follows:

"This handsome katydid is very common about Halifax. It is found upon the foliage of bushes, chiefly alders, in or near swampy places. Although plentiful, its protective similitude to a leaf, both in color and form, and its usual slow movements, make it very difficult to detect. Usually it can be readily captured with the fingers while it clings to a leaf. Oc- 
casionally, on a near approach to the bush upon which it rests, it will drop suddenly a foot or two to a branch beneath.

"Attention is chiefly directed to it by the loud stridulation of the males at nightfall. During the day they are usually silent, or at rare intervals produce a short sharp zip. After dark, however, they make the swamp resound with thelr loud calls, and we then become aware of their abundance. On close examination at such a time the males-usually only one on each bush-may be seen walking very slowly over the leaves and twigs. Occasionally they suddenly slightly lift and part the wing covers and close them again, thereby producing a sharp zip or crick, this being their usual day note. After making this sound at irregular intervals for some time, the tegmina are opened to a greater extent, and are then again closed, producing a long-drawn, exceedingly loud $c r-r-r-r-r-i c k$, which is repeated in couplets several times in succession. This challenging cry is immediately answered by one after another of its neighboring fellows, until numbers are rasping out their ear-piercing notes, as notable a rura] chorus as that of the tree toads."

Walker $(1904 a, 327)$ states that pistillata is much more abundant in northern than in southern Ontario, being "common on bushes, tall herbs and grass on the border's of low woods and along fence rows." Hebard says that at Pequaming, Mich.: "I heard the first katydid about Angust 12, and as pistillata is the only large Locustid found in this region, I knew what species was producing the sound. Before this date there was no insect which made a loud noise at night. Now in the evenings ' $\approx i k k$-zikl- ilikziki'_ ‘ikk-zikk, zikk, sikk' could often be heard. A week later they were plentiful and in the meadows and pastures their daytime note of ' $\sim$ ikl' was to be heard on all sides. Having found that they preferred the tops of bushes where they could sun themselves, eat and stridulate, I found them easy to capture, for, approaching cautiously, one could usually get within a few feet of the musician before it took alarm and ceased its music."

Fox (1917) states that "at Monterey, Va., pistillata was found in briers and low shrubbery on dry stony mountain slopes close to the woods covering the summit where it was associated with s. furcata. At Bolar it occurred in the tall herbage of an old meadow in the intermontane valley. This is, I believe, the most southern anthentic record of this species." Saussure \& Pictet $(1897,332)$ record pistillata from Georgia. Scudder says this record is "surprising," and R. \& H. (1914a, 280) say "this locality is certainly an error, as the insect is not known to occur in the Appalachians south of northern Pennsylvania." Since they wrote Fox has found it in Virginia and S. \& P. were probably correct in their record. 
214. Scudderia curvicauda (DeGeer), 1773, 446. Curve-tailed Bush Katydid.

Size large for the genus. Closely resembling texensis in size and appearance. General color pale green; head, pronotum, fore and middle femora and under surface tinged with yellow, usually fading to dull clayyellow in drying. Lateral margins of pronotum with yellow lines faint or wanting. Pronotum broader in front and less distinctly divergent behind than in texensis; humeral sinus less rounded, lateral lobes distinctly longer, their hind margin less oblique. Tegmina shorter and somewhat broader. Hind femora proportionally shorter. Notch of abdominal process very different, as described in key. Female more robust with ovipositor broader, much less suddenly and strongly bent upward and with serrations less prominent than in texensis. Length of body, $\hat{\delta}, 18-23$,

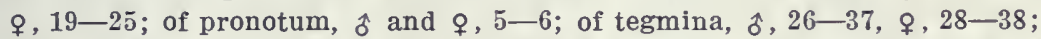
of hind femora, $\hat{\delta}, 21-30, q, 21-32$; of ovipositor, $7-8 \mathrm{~mm}$. Width of tegmina, $\hat{\delta}$ and $q, 6-8 \mathrm{~mm}$.

This, the most robust of our northern species of Scudderia, probably occurs in all portions of Indiana, but is apparently less common than texensis, especially in the southern counties. It is abundant about the marshy meadows bordering some of the lakes and tamarack swamps of northern Indiana. The earliest date on which a mature specimen was taken was July 10 in Knox Co. In autumn 1 have, for several years, found both it and texensis present in numbers in company with Mecostethus lineatus and Chorthippus curtipennis in a muck meadow forming part of a long narrow swamp five miles northeast of Indianapolis. The two katydids are so similar in appearance and habits of flight that they cannot be told apart in the field, but when closely examined are easily separated by the characters given in the key. As already noted, the earlier records of this species were largely based on specimens of texensis, both Bruner and Scudder for many rear's confusing the two. The $S$. curvicauda of my first work on the family $(1893,99)$ should be referred to texensis and the $S$. furculata (p. 100) to curvicuula. The Phancroptera angustipennis Harris $(1841,129)$ is also a synonym of curvicauda.

The known range of s. curvicauda, as here recognized, extends from Maine and Nova Scotia north and northwest to the Serern River, Ont., and Aweme, Man., and south and west to New Jersey, Virginia, Tennessee and Nebraska. The species varies much in size and appearance, R. \& H. (1914a, 281) separating the smaller northern individuals under the name $S$. $c$. borealis. The characters which they give in their key are comparative only, being "size small, form compact; tegmina rather broad and short," and in their original description they give not a single fixed char- 
acter of differential value. No one can satisfactorily separate a species, or even a race based on such a diagnosis, and as specimens at hand taken by Gooderham in Nova Scotia and Quebec show that the structural characters of the genital organs are precisely the same, I regard their name no more necessary than would be one for the small narrow-winged individuals of texensis recorded above from Florida. In the southern and southwestern states S. curvicauda merges with a form, the S. laticauda Brunner, which has some definite structural characters which are evident and which probably represent a valid race.

The more recent records of curvicauda, which can be relied upon as belonging to that species, show that in the east and north it is more arboreal than in Indiana. Walker $(1904 a, 326)$ states that his Toronto specimens all came from trees and bushes in more or less open, partly wooded country. In Pennsylvania Fox $(1914,518)$ found S. curvicauda to be "essentially a sylvan species frequenting the trees and underbrush of both dry and moist woodlands, less frequent in the border thickets of open meadowlands," while about Tappahannock, Va., the few examples taken were found in bushes and briery thickets in the vicinity of woodland. R. \& H. $(1914$ a, 284) state that the speeies is "common and widely distributed through the undergrowth of the woods in

a
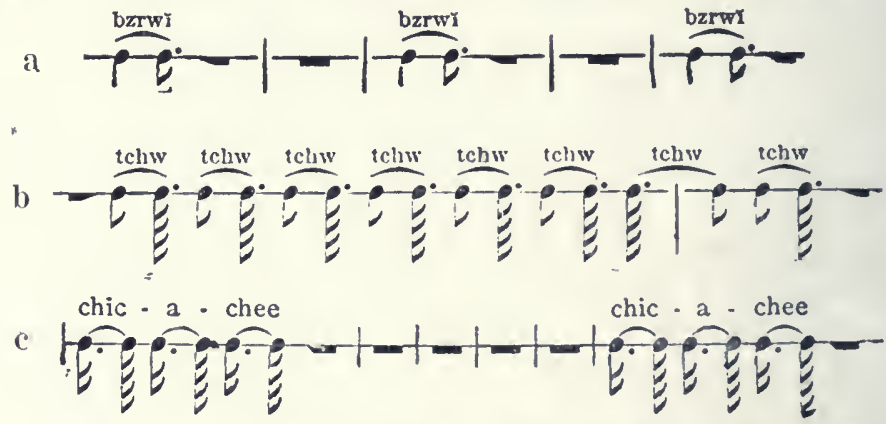

Fig. 155. a, Note of Scudderia curvicalla by day; b, note of same species by night; $c$, note of Amblycory'pha rotundifolia. (After Scudder.)

the Pine Barrens of New Jersey; in this region S. texensis is also common, but is found only in marshes, swamps or bogs."

Scudder (1893) has set the day and night songs of S. curvicanda to scale, and las given a pleasing account of their notes as follows:

"It is more noisy by night than by day; and the songs differ considerably at these two times. The day song is given only during sunshine, the other by night and in cloudy weather. I first noticed this while watching one of the little creatures close beside me; as a cloud passed over the sun he suddenly changed his note to one with which I was already famil- 
iar, but without knowing to what insect it belonged. At the same time all the individuals around me, whose similar day song I had heard, began to respond with the night cry; the cloud passed away, and the original note was resumed on all sides. Judging that they preferred the night song to that of the day, from their increased stridulation during the former period, I imitated the night song during the sunshine, and obtained an immediate response in the same language. The experiment proved that the insects could hear as well as sing. * * * The note by day is bzrwi and lasts for one-third of a second. The night song consists of a repetition, ordinarily eight times, of a note which sounds like tchw. It is repeated at the rate of five times in three-quarters of a second, making each note half the length of the day note."

214a. Scudderia curvicauda LATICAUdA Brunner, 1878, 238. Broad-tailed Bush-katydid.

Larger and more robust than typical curvicauda. Color as there. Pronotum larger, being both wider and nearly one-fifth longer, its side margins more parallel and more broadly rounded into the lateral lobes. Tegmina more narrow, nearly five times as long as greatest width. Dorsal abdominal process of male broader, the notch as in curvicauda. Ovipositor distinctly broader and less strongly bent upward, its median and basal width equal or nearly so. Length of body, $\hat{\delta}, 21-23$, 오, 23-27; of pronotum, $\hat{\delta}, 6-7$, ㅇ, $6-8$; of tegmina, $\hat{\delta}, 33-39$,,, $36-40$; of hind femora, $\hat{\delta}, 29-32.5$, ㅇ, $30-35$; of ovipositor, $9.5-11 \mathrm{~mm}$. Greatest width of tegmina, $7-8 \mathrm{~mm}$.

Mobile, Alabama, July 3 (Lorling) ; Billy's Island, Ga., June; LaGrange, Fla., Sept. 13 (Davis). Brunner's types were from Georgia. From Florida it has been definitely recorded only from Jacksonville, Atlantic Beach, Gainesville and Iive Oak, though R. \& H. (1914a, 288) give its range as extending from "Wilmington, N. Car., to Sanford, Fla., and westward as far as Monticello, Miss." It occurs mainly in the undergrowth of open pine woods. They state also that intermediate forms connecting laticauda with curvicauda have been found in numerous localities from Virginia to Oklahoma, Arkansas and Texas, the area of intergradation between the two forms being very wide.

215. Scudperia strigata Scudder, 1898, 280. Striped Bush-katydid.

Size medium; form very slender. Dull pale green the tegmina with a blackish-brown stripe extending along the side of dorsal area from base nearly to apex of each tegmen; anal area pale brown with a large blackish sub-basal spot. Margins of pronotal disk yellow; upper portion of lateral lobes with an obscure brown stripe. Sides of abdomen with a broad interrupted brown stripe, this bordered above and below with a yellowish one. All the femora usually flecked with dark brown. Disk of pronotum more narrow than in curvicauda, its side margins broadly rounded into the lateral lobes. Tegmina and male abdominal process as described in key. Ovipositor as long as in curvicauda, bent sharply upward near basal third, the ventral margin evenly and strongly curved. Length of body, $\hat{\sigma}$ and 


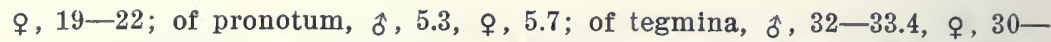
33 ; of wings, $\hat{\sigma}$ and $ᄋ, 37-39.5$; of hind femora, $\hat{\delta}$ and,+ 27.5 ; of ovipositor, $8.2 \mathrm{~mm}$.

A very handsome and striking Floridian species. Taken in August and September in some numbers by R. \& H. between DeFuniak Springs and River Junction; also at Grand Ridge and near Kissimmee. It occurs only in low swales between the sand ridges. Scudder's types were taken near Jacksonville, and he considered it as only a color variety of laticauda, it having been raised to specific rank by R. \& H. (1914a, 289).

216. Scudderia Furcata Brunner, 1878, 239. Fork-tailed Bush-katydid.

Size small for the genus; form slender, the sexes subequal. General color a dark leaf-green, rarely suffused with brown, the head, pronotum and under surface greenish-yellow, fading to dull clay-yellow, lateral carinæ of pronotum rarely yellowish; antennæ green at base, the apical threefourths dusky. Hind tibiæ greenish or purplish-brown, fading to dull yellow or often to dull brown. Disk of pronotum short with sides parallel, the margins or lateral carinæ rather sharp; humeral sinus relatively narnow, deep; all the margins of the lateral lobes broadly rounded. Tegmina subequal in width throughout, coarsely reticulate. Notch of male abdominal process as described in key, forming a curious, fork-like appendage (Fig. 152, $h$,) the lateral processes of which are subcylindrical, much swollen, and normally embrace the sides of the upcurved subgenital plate near the end of the latter. Ovipositor rather short, the dorsal margin suddenly bent upward, the basal and median width subequal. Length of body, $\hat{\delta}, 15-20$, ㅇ, 19-21; of pronotum, $\hat{o}$ and $q, 4.6-5$; of tegmina, $\hat{o}$ and $q$, $26-32$; of hind femora, $\hat{o}$ and $\rho, 19-20$; of ovipositor, $6-7 \mathrm{~mm}$. Width of tegmina, 6-6.2; of ovipositor, $1.8-2.2 \mathrm{~mm}$.

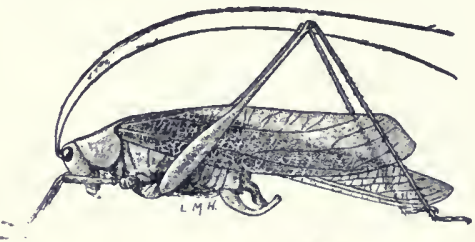

a

Fig. I56. a, Male; b, female. Natural size, (After Lugger.)

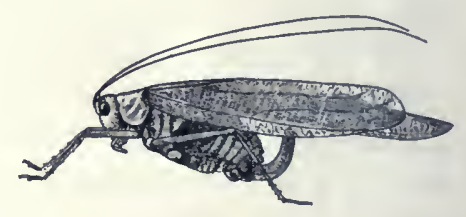

b

This fork-tailed katydid occurs in all portions of Indiana, having been taken in every county where collections have been made. In the hilly regions of the southern counties it is very common and practically the only species of Scudderia noted, texensis and curvicauda occurring about the marshes of the more level country. In central and southeln Indiana the first mature specimens of furcata appear about July 15 , but they do not become plentiful before the first of August, and I have seen the nymphs in Vigo Co. as late as September 18. It is most frequently seen on the low 
bushes and trees about the margins of thickets and along fence rows, but in the prairie country north it frequents coarse grasses and weeds in company with the other species. Its flight is noiseless, seemingly without definite direction, and is not so prolonged as that of S. texensis.

This is the most widely distributed and abundant species of the genus, ranging from Maine, Nora Scotia and Quebec north and west to North Bay, Ont., British Columbia and the Pacific coast, and south and west to central Florida, the Gulf coast of Texas, and cential California. In a part of its southwestern range it intergrades with the race or variety $S$. $f$. furcifera Scudder, full details of the distribution of both forms being given by $R$. \& $H$. (1914a). In Florida it has been recorded definitely only from Jacksonville, Monticello, Pensacola, Gainesville, LaGrange and Lakeland, the last being its most southerly known station in the State.

Walker (1904a, 328) says: "It seems to be quite generally distributed throughout Ontario as far north as Lake Nipissing, but is commoner in the southern part. It frequents trees and bushes about the edges of woods and thickets on both dry and marshy ground, but most often on the latter. I' have also taken it at Agassiz, B. C., where it was common on September 9." In Michigan it appears to be scarce, having been definitely recorded only from Huron Co. by Shull. Bruner (1893a) mentions it as found in the middle and southern districts of Nebraska, but less common than curvicauda. The S. fasciata Beut. (1894a, 251) is a synonym.

C. V. Riley $(1874,169)$, under the name of S. curvicauda, gives the following account of the egg-laying habits and call note of furcata; his figure 51 showing beyond doubt that the latter species was the one to which he referred:

"The female stations herself firmly by the middle and hind legs on twigs or leaves contiguous to the one selected to receive the eggs. This leaf is then grasped by the front feet and held in a vertical position, while the edge is slightly gnawed or pared off by the jaws to facilitate the en. trance of the point of the ovipositor. When this is done the abdomen is curved under and brought foward, and the ovipositor is seized on its convex edge by the mandibles and maxillæ, which, with the aid of the palpi, guide the point to that portion of the leaf prepared to receive it. After gentle, but repeated efforts, the point of the instrument is finally inserted between the tissues of the leaf, and gradually pushed in to more than half its length. As soon as the cavity is formed, the egg is extruded, and passed slowly between the semi-transparent blades of the ovipositor. As the egg leaves the ovipositor the latter is gradually withdrawn, while the egg re- 
mains in the leaf, retained in place, probably, by a viscid fluid that is exuded with it. As many as five of the eggs are sometimes deposited in one row in the same leaf, but more often they are single.

"The shrill of the male is by no means so loud as that of the oblongwinged katydid, Amblycorypha oblongifolia (DeGeer), in which its sound is always drowned in the woods. It consists of a softer zeep, zeep, sometimes uttered singly, but generally thrice in succession. The call is occasionally responded to by a faint chirp from the females, produced by stretching out their wings as if for flight, and is as often heard in the day as at night."

216a. Scudderia furcata cuneata Morse, 1901b, 130.

Averaging slightly larger than typical furcata, but otherwise differing only in the form of the fork of the decurved abdominal process of male, the base of which is narrower and more compressed, the cavity of the fork narrower, slightly deeper, with the processes each side compressed so that their upper edge is very narrow and subacute, not swollen and subcylindrical as in furcata. Females of the two forms absolutely inseparable. Length of body, $\hat{\sigma}$ and $\$, 18-22$; of pronotum, $\hat{o}, 5-6.7$, $\&, 4.8-6.4$; of tegmina, $\hat{\delta}$ and $\uparrow, 27-34$; of hind femora, $\hat{o}, 25-29, \stackrel{\imath}{2}, 23-30$; of ovi. positor, $6.3-7.4 \mathrm{~mm}$.

Jacksonville and Miami, Fla., Sept. 7-24(Davis); Tappahannock, Va., Sept. $9(F \circ x)$. The Florida specimens at hand are typical cuneata as described by Morse, while the Virginia male is intermediate between cuneata and furcata, the processes of abdominal fork being more narrow and less swollen than in the latter, but much less compressed than in typical cuneata. In my opinion cuneata is but a variety of furcata connecting the latter with S. mexicana (Sauss.), a smaller and more strongly compressed species with the lobes of the fork more deeply emarginate beneath, which occurs in Texas, Arizona and along the Pacific coast; the three being probably only well marked forms of one widely distributed and variable species which will bear DeGeer's name.

In Florida S. f. cuneata has been recorded from Jacksonville, Gainesville, Monticello, Pensacola and Miami, Aug. 11-Oct. 14. Davis $(1914,197)$ says: "The apical expanded portion of the anal segment shows considerable variation in specimens from Florida, all referred to this species."

R. \& H. (1914a, 312) give the known range of cuneata as extending from Raleigh, N. Car., south to Miami, Fla., and west to Alabama, Morse's type having been from the latter State. "It has been found to be a scarce but rather generally distributed species, in the low country below the fall line in the region defined." The records show that it is found principally among the undergrowth of pine and other woods. Fox (1917) records it from near Nor- 
folk and Tappahannock, Va., the single male from the latter place having been taken in company "with numerous examples of furcata in an Andropogon thicket close to the margins of woods." He has also taken both it and furcata at Macon, Ga., and states that some of the specimens "were intermediates, possibly hybrids."

\section{Srmmetropleura Brunner, 18i8, 245. (Gr., "equal" + "side.")}

Slender-bodied species of medium size resembling Scudderia but having the fastigium between the eyes, sulcate and very narrow; eves oblong-oval; disk of pronotum flat, two-thirds longer than wide, its sides just visibly divergent toward base, lateral carinze obtuse, front margin truncate, hind one broadly rounded; lateral Iobes perpendicular, longer than deep, their hind margin obliquely broadly rounded into the lower one; tegmina proportionally shorter than in scuddcria, their texture coarser, the reticulation much finer and more close, without the prominent cross reins of Scudderia, the costal field visibly narrowing from middle to apex. Male with last dorsal segment not prolonged into a decurred spine; supra-anal plate triangular, deflexed between the cerci, the latter slender, tapering, surpassing the short, broad subgenital plate, their tips incurred. To this genus Kirby $(1906,446)$ accredits five species, two from Africa, two from South America, the other from Carolina.

217. Symatropleuba modesta Brunner, 1878, 246. Modest Bush Cricket.

Pale green, fading in great part to pale clay-yellow; pronotum often tinged with reddish-brown, especially along the lateral carinæ, spines of tibiæ and femora white. Tegmina four times longer than their greatest width, the anal or sutural margin behind the flattened dorsal field straight. Ovipositor one-third longer than pronotum, abruptly upcurved near base, the upturned portion feebly tapering, apex rounded, the margins of apical half crenulate-dentate. Other structural characters as given abore. Length of body, $\hat{o}, 15-16, \uparrow, 18-20$; of pronotum, $\hat{\delta}, 4-4.5$,, , $3.8-4.5$; of tegmina, $\hat{\delta}, 25-26$,, 25 ; of hind femora, $\hat{o}, 17-18.5$, , $16.5-17.5$; of ovipositor, $5 \mathrm{~mm}$. Width of tegmina, $\hat{o}$ and $q, 6$; of ovipositor, $2 \mathrm{~mm}$.

Dunedin, Fla., June 10; one male taken at porch light (W. S. B.). Bosky Dell, Ill.; one female (Field Museum). This seems to be a very scarce species whose range is confined to the Austral Life Zone. Brunner's type, a single male, was from "Carolina." Scudder $(1898,287)$ records a female from North Carolina. Davis has received it from Mississippi and R. \& H. (1907) mention the capture of a male from floating water hyacinth near Palatka, Fla., Aug. 18. It is also recorded by them $(1916,255)$ as having been 
taken in Florida at Fernandina, Atlantic Beach, Crescent City and Enterprise, May 25-August 25; and at Raleigh, N. Car., and Billy's Island and Spring Creek, Ga., June 7-Aug. 8. Sherman and Brimley (1911) list it from Raleigh and Southern Pines, N. Car., and Brimley (1908) states that at Raleigh it has been taken only from mid-July to early August, both at light and on sugar, but not in ordinary collecting. No one of the records given mention more than two specimens from any one locality and most of them only one. The female in the Field Museum was taken by W. J. Gerhard at Bosky Dell, near Carbondale, southern Illinois, on Sept. 27, 1909. This extends greatly its known range to the north and west, all other records having been from North Carolina to central Florida.

IV. Amblycorypha Stål, 1873a, 40. (Gr., "blunt" + "head.")

\section{'The Round-Headed Katydids.}

Species of medium or small size, having the fastigium rounded, strongly deflexed, more than twice as broad as first antennal joint; eyes elliptical or oblong-oval; antennæ setaceous, reaching to middle of tegmina or beyond; pronotum with disk flat, narrowed in front, hind margin broadly rounded, front one subtruncate, lateral lobes usually shorter than deep, their hind margin obliquely broadly rounded into the lower one; tegmina but slight-
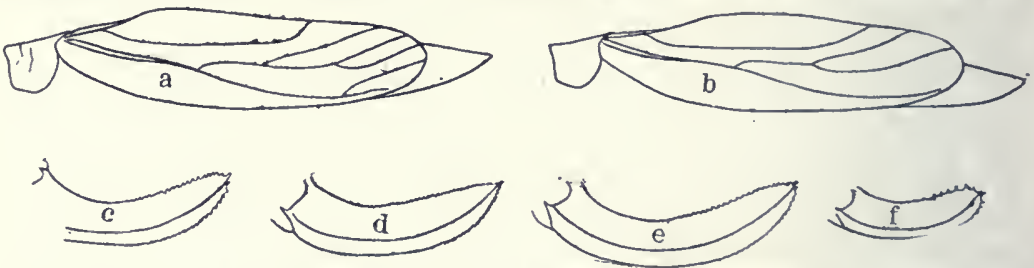

Fig. 157. Lateral outlines of pronotum, tegmen and exposed wing of Amblycorypha. $\times 2$. a, of floridana; b, of carinata. Outlines of ovipositors of Amblycorypha. $\times 4$. c, of oblongifolia; d, floridana; e, carinata; $\mathrm{f}$, whleri. (After R. \& H.)

ly wider at middle than apex, the latter broadly rounded; femora slender, all armed beneath with sereral short spines. Male with stridulating organ brownish, opaque, traversed by a strong green cross-vein; supra-anal plate short, broad, truncate; cerci long, tapering, inbent and crossed, their tips acute; subgenital plate broad at base, feebly tapering, carinate beneath, apex usually deeply notched, the blunt process each side bearing a short, cylindrical style. Ovipositor broad, of medium length, curved gradually upward from near middle, apical half sharply and usually strongly serrate on both edges, the apex rounded.

R. \& H., in the latest treatise on the genus (1914b) recognize 
seven species and three races or varieties from North America. Three species and two varieties fall within the scope of this work. KEY TO EASTERY SPECIES OF AMBLYCORYPHA.

a. Tegmina oblong-elliptical, of subequal width throughout, the wings distinctly protruding beyond their tips (Fig. 157, a); metasternal lobe each side longer than broad, its hind margin narrowly rounded or acute; humeral sinus deep, distinct.

b. Larger, tegmina always more than $30 \mathrm{~mm}$. in length; hind femora not surpassing tips of tegmina, distinctly shorter in male; apex of subgenital plate of male with a deep V-shaped notch.

c. Stridulating area of male tegmina larger, much exceeding that of pronotal disk; ovipositor more evenly and regularly curved, more strongly serrate (Fig. 157, c); lateral carinæ evident but rounded, often obsolete on apical fourth or more of pronotum.

218. OBLONGIFOLIA.

cc. Stridulating field of male tegmina smaller, but little greater than that of pronotal disk; ovipositor less evenly and regularly curved, more finely serrate.

d. Lateral carinæ in front of middle of pronotum rounded into the lateral lobes; stridulating vein of male proportionally narrower; ovipositor shorter, when compared with caudal femora weaker (Fig. 157, d.) 218a. FLoRIDANA.

dd. Lateral carinæ of pronotum distinct and continuous throughout; stridulating vein of male broader; ovipositor longer, heavier (Fig. 157, e.)

218b. CARLNATA.

bb. Smaller, tegmina not over $28 \mathrm{~mm}$. in length; hind femora surpassing tips of tegmina in both sexes; apex of subgenital plate of male subtruncate, not or feebly notched.

219. UHLERT.

aa. Tegmina ovate, distinctly broader at middle, the wings but slightly surpassing their tips (Fig. 160); metasternal lobe each side broader than long, its hind margin subtruncate; humeral sinus shallow or subobsolete.

220. ROTUXDIFOLIA.

218. A.MbYCoRYPHA obloxgIFoliA (DeGeer), 1773, 445. Oblong-winged Katydid.

Size large for the genus; form robust. General color a bright peagreen, the shrilling organ of male brownish, with a heavy green cross-vein; abdomen and usually the fore and middle femora, yellowish or brownishgreen; hind femora often brownish-yellow. Disk of pronotum with sides distinctly dirergent on basal two-thirds, subparallel with lateral carinæ less distinct on apical third; humeral sinus well impressed; hind margin of lateral lobes broadly rounded. Tegmina elongate-elliptical, about 3.3 times as long as wide. Wings in repose surpassing tegmina 6 or more mm. Hind femora very slender, usually scarcely reaching tip of tegmina, female, distinctly shorter, male, their inner lower carina armed with six to 12 rather strong teeth. Length of body, $\hat{o}, 21-23$, of $\$, 22-25$; of pronotum, $\hat{\alpha}, 6-6.5, q, 7$; of tegmina, $\hat{\jmath}, 36-38, \uparrow, 35-37$; of posterior femora, $\hat{\sigma}$ and $\$, 30-31$; of ovipositor, $11.5-13 \mathrm{~mm}$. Width of tegmina, 11-12 mm. (Fig. 158.) 
The oblong-winged katydid is a frequent insect throughout Indiana, becoming mature in the southern part about July 20,

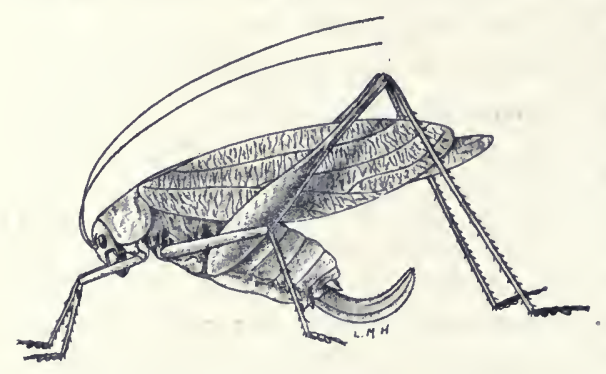

Fig. 158. Female. Natural size. (After Lugger.) and in the northern counties probably a fortnight later. It oceurs for the most part on shrubbery and flowers of golden-rod and other Composita along fence rows and edges of thickets and woods, especially in damp localities; and when flushed flies with a kind of whirring noise, alighting on fence or the lower branch of tree. I have often located the male by its note, which to me is a creaking squawklike the noise made by drawing a fine-toothed comb over a taut string. It is usually but once repeated, though sometimes three times. On several occasions it has been made after the insect was in my fingers.

A number of pink specimens lave been taken from low meadows near Bass Lake, Starke County. The causes which produce this curious "sport," by which a grass-green is changed to a delicate pink, are, as yet, unknown. Scudder has said that "one thinks at once of autumn leaves and their change from green to red and notices that these pink katydids all occur in the autumn." In Indiana the pink specimens have been taken in early August, long before frost and before any noticeable change in the surrounding vegetation.

Several of the species of Amblycorypha are known to occur occasionally in the pink form, which appear much more frequent in this genus than in any other of the Tettigoniidx. Wheeler (1907), Knab (1907), Hancock (1916) and other authors have published interesting papers on the subject of pink katydids. Hancock succeeded in rearing a family of a cross between a pink female and a green male of oblongifolia. He found that the eggs of this species are laid in the ground and require two to three years to hatch. Of the 13 young, nine were pink and four green, the color remaining practically the same throughout their lires. He concludes, as did Wheeler, that the pink color, as well as the green, is hereditary, the pinkness therefore being congenital or germinal in character and not the result of conditions of environment.

The known range of typical oblongifolia is from New England and Montreal west to southwestern Ontario, Michigan, Minnesota 
and Colorado, and south and southwest to Maryland, North Carolina, Alabama, Louisiana and Texas. In the southern coastwise states it is replaced by the nominal race or variety, $A$. o. floridana R. \& H. In Ontario Walker $(1904 a, 329)$ states that it is rare about Toronto, but common from Hamilton westward to the St. Clair River, occurring for the most part on shrubs and tall weeds. The note of the male, he says, "is very harsh and scraping in character and is usually of about three-fifths of a second's duration. At a little distance it sounds something like 'kizizik.' I have heard it at night and in the afternoon while the sun was still shining."

Lugger $(1898,223)$ states that both $A$. oblongifolia and rotundifolia occur abundantly in Minnesota, frequenting bushes and tall weeds in low places. Both appear to be scarce in Michigan, Hubbell (Ms.) listing oblongifolia only from Wayne, Ingham and Jackson counties, and rotundifolia from Washtenaw Co. Abont Moline, Ill., McNeill (1891) found oblongifolia more common in the vicinity of houses than the species of Scudderia, and states that its note is "a quick shuffling sound which resembles 'katy' or 'katydid,' very slightly. It sometimes flies in the evening, but much more rarely than does S. curvicauda."

Hancock (1916) has given an account of the egg-laying habits of oblongifolia as follows:

"When ready to oviposit the female comes down to the ground from the vegetation which she frequents. She then searches about on the ground, often among the dead leaves, to find a suitable place to deposit her eggs. She does this very deliberately and slowly, feeling her way with her palpi, often nibbling the surface as if testing a suitable place. At times she appears to be quite exacting in her choice of location, one of these requisites being a certain amount of dampness of soil, as well as certain surface conditions. When she finds a suitable spot, she curves her abdomen, which is now distended with eggs, forward underneath her body and at the same time seizes the end of the large ovipositor in her mandibles. In this way she directs its point to the desired place in the ground. Then she forces or drills a hole in the earth for the reception of each egg or cluster of eggs. Sometimes they are laid at such a shallow depth in the ground that the rains splash away the dirt covering, fully exposing them to the air."

Bruner (1891, 73) described Amblycorypha scudderce from Nebraska, stating that it differs from oblongifolia by its smaller size, more evenly rounded or arcuate edges of tegmina, comparatively shorter hind legs and more strongly serrated point of ovipositor. R. \& H. (1914b, 320) have made scudderce a synonym of oblongifolia, stating that "the characters mentioned by Bruner are worthless," though they use two of them, viz., the arcuate edge 
of tegmina and degree of serration of ovipositor, in their key in separating oblongifolia from their floridana and carinata.

218a. Amblycorypha oblonglfolia Floridana Rehn \& Hebard, 1905, 42.

A form or race of oblongifolia differing only by the characters given in the key, which are taken from the key of R. \& H. (1914b, 319), and by having the disk of pronotum slightly longer, its sides less divergent backward in the female. Length of body, $\hat{o}, 25-25.8$, ㅇ, 21-28.3; of pronotum, ô, 6.6 , ㅇ, $7-7.4$; of tegmina, ô, $34.6-35.8$, $९, 32-36.8$; of hind femora, $\hat{\delta}, 28.7-30.4$, $\&, 28.5-32.6$; of ovipositor, $11-12.2 \mathrm{~mm}$. (Fig. 159.)

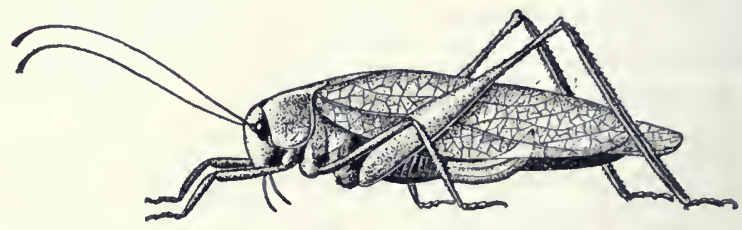

Fig. 159. Female type. Natural size. (After R. \& H.)

The original description of this form was prefaced thus: "Allied to $A$. oblongifolia but differing in the straighter oripositor and less angulate angles of disk of pronotum." Later $(1907,301)$ R. \& H. say: "The less eurved form and rather smaller size of the ovipositor will serve to separate the female of floridana from that of oblongifolia, while in the male the tympanum is distinctly narrower, both actually and proportionally, than in oblongifolia. The lateral angles of the disk of the pronotum are as a lule by no means as sharply rectangulate as in oblongifolia and the disk is broader caudad in the latter species. From the evidence in hand it appears that floridana represents the southern extreme of $o b$ longifolia, specimens from Thomasville, Ga., being as near floridana as oblongifolia." Still later $(1914 b, 322)$ they state that the Thomasville specimens connect "true floridana with a northern sub-species (S.f. carinata) of the same stock, which in its turn is perfectly distinct from oblongifolia."

All of the differences which they give, both in descriptions and keys, separating the three forms, are comparative only, aud readily come within the limits of variation of a single species over a wide extent of territory. The lateral carina of northerm and eastel'n oblongifolia are always rounded on the prozona, and vary greatly in continuity, in the majority of Indiana specimens being wanting on the apical third or fourth of pronotum, where the disk is rounded directly into the sides. The disk of pronotum is also variable in length and divergence and the ovipositor in length and degree of curvature. While extremes of the three forms are obviously different, I regard both floridana and carinata as varieties 
of oblongifolia, as no permanent fixed characters separating them have as yet been pointed out.

About Dunedin, Fla., nymphs of S. o. floridana are frequent from February 1 to April 15, but the adults have been taken only in October. It occurs in the tall grasses about the margins of brackish marshes and on weeds in low wet places in pine woods. During the summer and autumn months this appears to be a common katydid throughout Florida, having been recorded from numerous localities by other collectors. At Homestead it was found by R. \& H. (1914c, 399) "on the prairie-like everglades, where they were scarce in the day time, but plentiful at night, perched on the grasses, stridulating fearlessly. Their note is an indescribable buzz and click."

The range of this southern form is given by $R$. \& $H$. (1914b, 322 ) as "extending from Big Pine Key and Detroit, south Florida, as far north typically as Jacksonville, Fernandina and Atlantic Beach, westward as far as eastern Texas, intergrading in the Atlantic Coast region, at least, into the northern subspecies (carinata) over an extensive area covering from southern Georgia to eastern South Carolina."

218b. AMBLycoryPHA obloxgIFolia CARINATA ${ }^{85}$ Rehn \& Hebard, 1914b, 323.

"Differing from floridana floridana in the lateral-margins of the pronotal disk being more angulate and carinate almost or quite continuously; in the stridulating field of the male tegmina being proportionally broader, in the sutural margin of the tegmina distad of the anal field being more arcuate and in having a longer and heavier ovipositor. Length of body, $\hat{\delta}, 20.8-24$, ㅇ, 21-27.2; of pronotum, ิิ, $6.3-7$, 우, $6.9-7.4$; of tegmina, $\hat{\jmath}, 33-35.5$, 오, $30-35.5$; of hind femora, $\hat{\delta}, 29-32$, 우, 26.6-32.6; of ovipositor, $12.3-14.5 \mathrm{~mm} . " \quad(R . \& H$.

Charlottesville, Va., July 17 (Fox) ; Sherborn, Mass. (Morse). It will be noted that the width of the stridulating field of tegmina is said by $\mathrm{R}$. \& $\mathrm{H}$. to be broader than in floridana, whereas the leading character given in their key to separate floridana from typical oblongifolia is the narrower stridulating field of the former. The measurements are also in great part intermediate between typical oblongifolia and floridana. They record numerous intergrading forms between floridana and carinata. but I regard the latter as only an intermediate form, connecting oblongifolia and its southern race, floridana and therefore scarcely worthy of a special name. As noted above the extremes are sufficiently dis-

\footnotetext{
65This form should probably bear the varietal name saussurei Bruner, as he first mentioned it (1886, 196) as follows: "A sixth species (of Amblycorypha) occurs along the Atlantic coast from Maryland southward. It is nearly of the same size as oblongifolia but differs from it in having the dorsum of pronotum very smooth and also in several other important features. It might therefore be called $A$. salssurei after M. Henri de Saussure." As R. \& H. claim that this description, as such, is unrecognizable, I have retained their name.
} 
tinct, but the means merge, so as to be practically indistinguishable unless one wishes to juggle with words and names.

The range of typical carinata is given by $R . \& H$. as extending from southern Massachusetts west to New Jersey and Pennsylvania, and south over southeastern Virginia to eastern North Carolina and north-central Georgia, while Davis has it from Agricultural College and Lucedale, Miss. Fox (1917) states that in Virginia carinata inhabits similar situations as does oblongifolia, but is more frequent in tidewater areas.

\section{Amblycorypha villeri Stål, 1876, 57. Uhler's Katydid.}

Size small for the genus. Above gress-green fading to pale greenishyellow, shrilling organ of male brown or blackish, the cross-vein green; beneath greenish-yellow fading to dull clay-yellow. Antennæ pale reddish-brown, surpassing the tips of tegmina. Pronotum strongly narrowed in front, lateral carinæ distinct on basal two-thirds, rounded into lateral lobes in front of middle; hind margin broadly rounded, lateral lobes deeper than long, their hind margin broadly rounded. Tegmina oblongelliptical, not reaching tips of hind femora. Wings protruding beyond tegmina 3-5 mm. Metasternal lobe each side longer than broad, its hind margin rounded. Male with cerci strongly tapering, thickly clothed with bristling hairs; tegmina longer and narrower than in female. Ovipositor broad, of equal width throughout, slightly longer than pronotum, not strongly curved, the apical half rather strongly serrate on both margins (Fig. 157, $f$ ) Length of body, $\delta, 14-15$, $\&, 16-17.5$; of pronotum, ๙ิ, 4.8-6, $\uparrow, 5.5-7$; of tegmina, $\hat{\delta}, 23-27$, $९, 20-28$; of hind femora, $\hat{\delta}, 21-27$,, $22.5-28$; of ovipositor, 7.5-10. Width of tegmina, $\hat{\delta}$, $7-9$, ㅇ, $6-8.5 \mathrm{~mm}$.

This, our smallest species of the genus, is much less common in Indiana than either oblongifolia or rotundifolia, not having been taken north of Vigo Co., where it frequents the tall sedges and willows bordering the large ponds in the Wabash River bottoms. In southern Indiana it was. once fonnd plentiful, September 3-4, near Wyandotte Cave, Crawford Co., where a number were secured on grass and lierbs. In Posey, Warrick and Harrison counties, single specimens have been taken by sweeping willows in late September. The young sometimes feed npon the leaves of the black and scarlet oaks, Quercus velutina Lam., and Q. coccinea Wang, and the perfect insect is often found on or beneath these trees.

In Florida A. uhlcri is also scarce, occurring for the most part on bushes and other undergrowth in open pine woods. A single male, taken at light at Dunedin, Oct: 14, is at hand, and is larger, with longer tegmina than any of those from Indiana. It probably occurs throughout the State, having been recorded in small num- 
bers from Jacksonville to Ft. Barrancas south to Homestead; adults, July 7-August 23, nymphs March 6.

The known range of $A$. uhleri is mainly southern, extending from New Jersey west and north to central Indiana and Minnesota, and south and west to southern Florida, eastern Oklahoma and central Texas. It is not recorded from Canada or Michigan, and only from a single specimen without definite locality, from Minnesota. In habitat it appears to be largely hygrophilous, most of the records mentioning it as occurring on weeds or bushes in or near low, damp woods from tidewater to 2,600 feet abore. In Virginia Fox (1917) says it is "apparently the most abundant representative of the genus in the Piedmont and tidewater sections, occurring chiefly in open country on the trees, bushes, weeds and tall grasses of fields, pastures and roadsides."

Of the call note of uhleri Allard (1912) says: "It consists of a rapid silken shuffling sound, sh-sh-sh-sh, occasionally repeated. At other times the notes become brief, staccato lisps, $i$-tsip-i-tsip$i$-tsip-i-tsip, followed by the usual sh-sh-sh-sh. Abrupt modifications of this sort nearly always get a similar lesponse from the other individuals."

220. Amblycorypila rotuxpmolia (Scudder), 1862, 445. Round-winged Katydid.

Size medium for the genus. Color essentially the same as that of oblongifolia. Disk of pronotum with sides subparallel, female, feebly diverging behind, male; lateral carinæ evident but rounded on basal twothirds; humeral sinus very shallow; hind margin of lateral lobes more oblique and less broadly rounded than in oblongifolia. Tegmina ovate, proportionally much broader, the wings but slightly protruding from beneath their tips. Hind femora reaching tips of tegmina in male, slightly longer, female, armed on the lower, inner carina with four or five minute teeth. Ovipositor more distinctly curved and more strongly serrate than in either-oblongifolia or uhleri. Length of body, $\delta$ and $\$, 19-20$; of

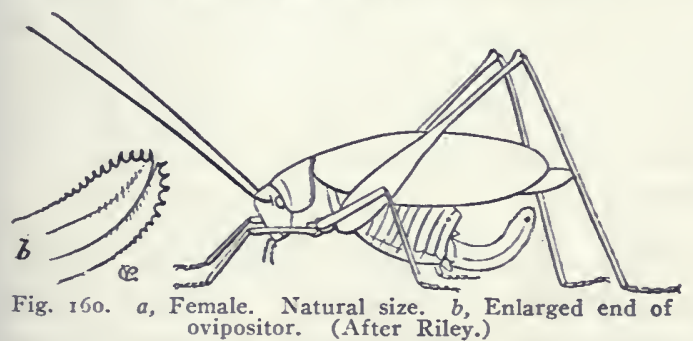
pronotum, $\hat{\delta}, 5-6$, ㅇ, $5.8-6.4$; of teg. mina, $\delta$ and $\circ, 24-$ 27 ; of hind femora, o, $22-25$, ᄋ, 2427 ; of ovipositor, 9 -11 mm. Width of tegmina, $\quad 8.5-9.5$ mm. (Fig. 160.)

The round-winged katydid occurs frequently throughout Indiana, though more abundant in the southern half of the State. It is more of a terrestrial species than oblongifolia, being often 
seen on the ground, or on the clumps of tall grass and weeds, which grow in damp ravines, while its flight is comparatively noiseless and less prolonged. In southern Indiana the males become mature about the fifth of July, the females a week later.

Pink individuals of rotundifolia have been recorded from Pennsylvania and New Jersey, but they appear to be much more scarce than those of oblongifolia.

The known range of typical $A$. rotundifolia extends from the White Mountain region of New England west to Michigan and Minnesota, and south and west to South Carolina, northern Georgia and western Arkansas. In western North Carolina, southern Georgia and Alabama it is said by R. \& H. (1914b, 336) to have shorter wings, less evident humeral sinus and a broader disk of pronotum, thus showing an intermediate form between typical rotundifolia and the western race $A . r$. parvipennis Scudder. R. \& H. have also reduced $A$. isclyi Caud., described from Kansas and known from Iowa and Missouri, to a race or variety of rotundifolia. It is not recorded from Canada, though it should occur along the southern border. Ingger mentions it as common in Minnesota, and Bruner (1893a, 29) as a "not uncommon species" in the eastern part of Nebraska. In Virginia Fox says it is "taken in shrubbery and undergrowth in or close to open deciduous woods and apparently confined to the mountain sections of the State."

Of the note of rotundifolia, Scudder $(1893,68)$ says: "This insect stridulates both by day and by night, and without rariation (Fig. 155, c). The song consists of from two to four notessounding like chic-a-chee-repeated rapidly so as to be almost confounded, and when three requiring just one-third of a second; the song is repeated at will, generally once in about five seconds, for an indefinite length of time."

Allard (1911) says that near Oxford, Mass., in September, A. rotundifolia "occurs everywhere in the grass, weeds and shrubbery of fields and pastures. Its notes may be heard at all times during the day as well as during warm nights. They are soft, lisping, continuing indefinitely, and may be expressed thus: 'T'sip-i-tsip-i-tsip-i-tsip-i-tsip.'"

V. Microcentruu Scudder, 1862, 446. (Gr., "small" + "point.")

Species of medium or large size, having the occiput convex, fastigium obtuse, deflexed, more or less sulcate; eyes subglobose, prominent; disk of jronotum flat, sides subparallel, lateral carina distinct, hind margin broadly rounded; humeral sinus deeply impressed; lateral lobes perpendicular, much deeper than long, the 
hind margin broadly rounded into the lower one; tegmina coriacrous, ovate lanceolate, broadest at middle, both costal and sutural margins tapering to the much narrower but rounded apex, the overlapping dorsal field forming a right angle with the median area; wings distinctly projecting beyond the tegmina their tips acuminate; all the femora armed beneath with sereral small spines; hind ones short and rery slender; meso- and metasternal lobes elongate, their tips acute or narrowly rounded. Males with supra-anal plate oblong-triangular, deflexed between the cerci, the latter long, slender, subcylindrical, their tips usually incurved and mucronate; subgenital plate composed of two separate lobes, uniting beyond the middle, then tricarinate beneath, the terminal processes bearing rather long, cylindrical styles. Female with ovipositor very short, bent strongly upward, usually finely crenulate, with apex obtuse; subgenital plate triangular, compressed, obtuse.

This is an American genus whose species are mostly tropical, Kirby $(1906,480)$ including 26 under the name Orophus Serv. which he wrongly used for Microcentrum. Of these but two are known from the United States, both occurring east of the Mississippi.

KEY TO EASTERT SPECIES OF MICROCEXTRUM.

a. Front margin of pronotum sinuate, and with a more or less distinct median tooth; cerci of male with the tips incurved and mucronate; ovipositor with apex subtruncate or very broadly rounded; general color dark grass-green. 221. RHOMBIFOLIUM.

aa. Front margin of pronotum squarely truncate; cerci of male with apical third thickened, the tip blunt, feebly or not at all incurved; ovipositor with apex attenuate, narrowly rounded; general color pale green, the head and under surface tinged with yellow.

222. RETINERVE.

221. Micbocextrum rhoмbifolium (Saussure), 1859, 204. Larger Angular-winged Katydid.

Size large both for the family and the genus, the sexes subequal. Dark grass-green, the face, under surface, fore and middle legs and often the front half of pronotum greenish-yellow often fading to dull clayyellow. Fastigium faintly sulcate or, in the male, with a shallow median pit. Disk of pronotum short, subquadrate, the median tooth of front margin variable in size and form, always small, often vague; hind margin broadly rounded. Tegmina ovate-lanceolate, surpassing the tips of hind femora by two-fifths their length. Male with stridulating area elongatetriangular, opaque, coarsely punctate; subgenital plate with outer carinæ subparallel, apex with a deep rounded notch. Other structural characters as given in key and under generic heading. Length of body, $\hat{\delta}, 25-28$,

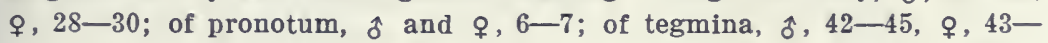


47 ; of hind femora, ô, $22.5-24$; $\uparrow, 23-25$; of ovipositor, $4.5-5 \mathrm{~mm}$. Greatest width of tegmina, 13-14 mm. (Fig. 161.)

This is the $M$. laurifolium of my previous work $(1903,354)$ and of most American authors up to 1906, Kirby having then shown that the name laurifolium rightfully belongs to a tropical species of Stilpnochlora. M. rhombifolium is the largest of our northern katydids and is frequent throughout the southern half of Indiana, but has not been noted north of Lafayette, where Fox (1915) says it "appears to be common since its notes were heard continuously throughout late .July and August." In the

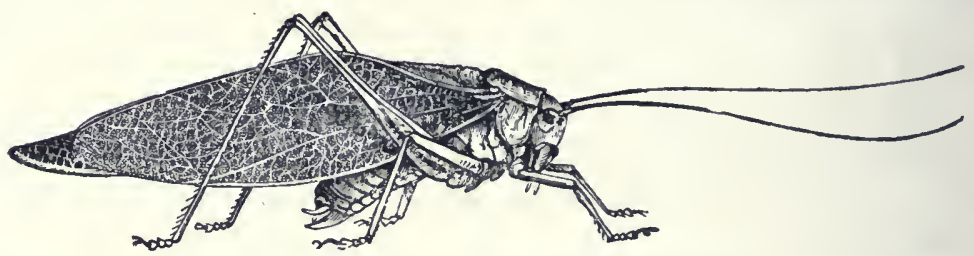

Fig. 16\%. Male. Natural size. (After Riley.)

country it is most commonly called "the katydid," and the note of the broad-winged katydid, Pterophylla camellifolia (Fab.) is usually attributed to it, but its true note may be represented "by the syllable 'tic,' repeated from eight to 20 times at the rate of about four to the second." However, M. rhombifolium is probably less common in Indiana than the broad-winged katydid, with which it is confused. As it frequents low bushes and other shrubbery it is more often seen, the true katydid being commonly found in the taller trees. It is often attracted to light and in Indianapolis numerous examples have been found on porches and in the gutters beneath electric lights. In movement $M$. rhombifolium is very sluggish, seldom taking to flight when approached and readily picked up by the fingers. It probably occurs in small numbers in all parts of the State.

About Dunedin, Fla., adults of rhombifolium have been taken from November to April, but are very scarce. The nympls in all stages are, however, frequent during the winter and often taken by sweeping. It occurs throughout Florida and on the southern keys, adults being recorded from numerous localities and in nearly every month of the year. At Miami it was noted by Hebard (1915b) to be "not uncommon in early March about the town on trees and shrubbery, as could be determined on warm erenings by the frequently heard stridulations. On nights when the temperature fell at dusk below $65^{\circ}$ all Orthopteron stridulations ceased."

The known range of rhombifolium extends from Staten and Long Islands, X. Y., north and west to Michigan, Minnesota and 
eastern Nebraska, and south and west to southern Florida, Oklahoma, southwestern Texas, Arizona and Claremont, California. From the west and northwest the published records are few for so widely a distributed species and are mostly under the name $\boldsymbol{M}$. laurifolium (Linn.). Scudder $(1862,447)$ gave Massachusetts as one of the localities of his $M$. affiliatum, a synonym of rhombifolium, and S. I. Smith $(1873,357)$ mentions it from Connecticut, but no definite localities were given and no other New England records can be found. It is not mentioned in either of the Iowa lists, nor is a definite locality recorded from Michigan. Garman says it is "common ererywhere in Kentucky on black locust and other trees." Lugger records it only from Winona, Minn., and Bruner, as occurring only in eastern Nebraska south of the Platte River. From New Jersey south and southwest the records are more numerous, especially those from Georgia and Florida. J. Smith $(1910,187)$ states that it occurs throughout New Jersey, and R. \& H. $(1916,256)$ give numerous records between there and central Georgia, as do they and other authors from Georgia, southwest to California. At Claremont in the latter State Baker (1905, iS) found it common among the orange trees, and one of his specimens is at hand.

The eggs of M. laurifolium are usualls glued in double rows on the sides of slender twigs, which have been previously roughened

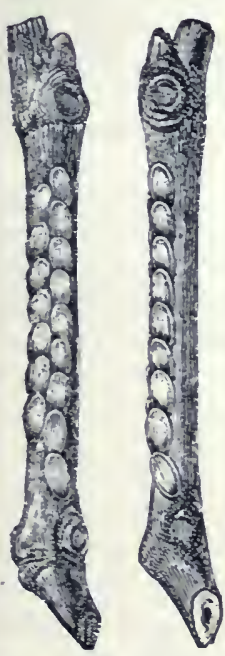
with the jaws and otherwise prepared for a place of deposit. The two rows are contiguous and the eggs of one alternate with those of the other. Those of the same row overlap about one-fourth their lengtll. They are of a grayish brown color, long oral in shape, very flat, and measure 5.5x3 mm. They are usually deposited in September, hatch the following May, and the young, in central Indiana, reach maturity during the first half of August. These eggs have, on a number of occasions, been brought to me by persons who found them on their fruit trees, and thought thes were the San Jose scale or some other injurious scale insect.

Of the habits of this species Daris $(1857,56)$, undel" the name $M$. retinerve, says: "It often lays Fig. 162. Eggs of the its eggs on the hones suckle and I once obserred
Angular-winged Katydid. (After Riley.) a female on the 16th of Sentember, oripositing on a low tree by the roadside, gradually biting the bark into a ridge along which the eggs were laid tile fashion. The male produces 
two somewhat different songs, or varies the same song in time or extent of utterance, so that unless the same individual is listened to for some time, the notes might be attributed to different species."

Riley $(1874,155)$, as his figures show, confused $M$. rhombi. folium also with $M$. retinerve (Burm.) and under the latter name gave a full account of the habits of rhombifolium from which I quote as follows:

"The females commence to oviposit early in September, and continue to lay at intervals until the first severe frost. The eggs are occasionally deposited during the day, but the operation usually takes place at night. The number of eggs laid at one time varies from two to 30 , the first batches containing more than those deposited later in the season. Each female produces from 150 to 200 , or perhaps more, and I have known them to lay on the edge of a leaf, or of a piano-cover, or along a piece of cord.

“These eggs are rather flat when laid, but become more swollen, so that they have a narrower look as they approach the hatching period in spring. During the early part of May, the embryo larva-which lies straight in its egg, completely filling it, with the legs bent up as in a pupa, and the long antennæ curling around them-attains its full development, and after hours of tedious contracting and expanding movements, manages to burst the egg open at its top or exposed end, along the narrow edge, and generally about half way down. Through this opening young Katy slowly emerges, undergoing a moult during the process, and leaving its first skin, in a crumpled white mass, attached to the empty bivalvular egg shell. Including hind legs and antennæ it measures at this time, rather more than an inch in length, the body alone being one-eighth of an inch long; and in contemplating it, one can not but wonder how the long, stiff legs and great length of antennæ, together with the plump body, could so recently have been compressed into the comparatively small shell to which we see it clinging.

"In from ten to twenty minutes after hatching, these little belngs essay their first leaps, and soon begin to eat with avidity. They feed with almost equal relish upon a great variety of foliage, but I have found that when reared upon very succulent leaves, such as lettuce, cabbage, purslain and the like, they are less hardy, and do not attain so great an age as when nourished upon more ligneous food, as the leaves of oak, apple or cherry.

"The first notes of this katydid are heard about the middle of July, and the species is in full song by the first of August. The wing covers are partially opened by a sudden jerk, and the notes produced by the grad. ual closing of the same. The song consists of a series of from 25 to 30 raspings, as of a stiff quill drawn across a coarse file. There are about five of these raspings or trills per second, all alike, and with equal intervals, except the last two or three, which, with the closing of the wing covers, run into each other. The whole strongly recalis the slow turning of a child's wooden rattle, ending with a sudden jerk of the same; and this prolonged rattling, which is peculiar to the male, is invariably and instantly answered by a single sharp 'chirp' or 'tschick' from one or more 
females, who produce the sound by a sudden upward jerk of the wings.

"Both sexes are for the most part silent during the day, but during the period of their greatest activity their stridulations are never for an houl remitted, from the time the great setting sun hides behind the purple curtains of the west till he begins to shed his scarlet rays in the eastthe species being so numerous that the sound as it comes from the woods is one continuous rattling, not unlike the croaking of frogs, but set to a higher key."

222. Microcextruar retiverve (Burmeister), 1838, 692. Smaller Angular-winged Katydid.

Size medium for the genus, the sexes subequal. Smaller than rhombifolium which it very closely resembles. Fastigium as there but slightly narrower, more distinctly sulcate. Pronotum with front margin truncate, not toothed; humeral sinus more narow. Tegmina proportionally shorter, less strongly tapering, their tips more broadly rounded, surpassing hind femora one-third their length. Front and middle femora with only one or two very minute spines beneath. Male with stridulating field narrow, the cross-vein usually pale brown; cerci longer than in rhombifolium, less incurved, their apical third distinctly swollen; subgenital plate with outer carinæ converging, both apex and apical notch distinctly narrower than in rhombifolium. Other differences as given in key. Length of body, $\hat{o}$, $20-22, q, 24-26$; of pronotum, $\hat{o}, 5-5.5$, ㅇ, $5.5-6.5$; of tegmina, $\hat{o}$, $36-38$, $9,38-41$; of hind femora, $\hat{o}$ and $\$, 18-20$; of ovipositor, $5.5-$ $6.5 \mathrm{~mm}$. Width of tegmina, $12-13 \mathrm{~mm}$.

Martin Co., Ind., Aug. 20, one male; Vigo Co., Ind., Sept. 26, one female; Plummer's Island, Md., Sept. 10 (W. S. B.). Probably occurs throughout the Austral life zone of the southern third of Indiana. Recorded from Florida only by Scudder (1877a, \$3), who states that "a male, a female and two pupæ were taken at Ft. Reed between April 24 and May 2."

The known range of retinerve is more southern than that of rhombifolium, extending from New Jersey west through southern Indiana, Kentucky and Clarksville, Tenn., to Kansas and Nebraska, and south and southwest to central Georgia, Oklahoma, Texas, New Mexico, Arizona and, if Brunner's record (1878, 340) can be relied upon, to Orizaba, Mexico, and Guatemala. It appears to be a common form on Plummer's Island, Md., as I took three males there in a few hours' collecting on Sept. 10. They were found on the ground or the branches of low shrubs. Bruner has recorded it as not common but more widely distributed in eastern Nebraska than rhombifolium. From the records the males seem to far outnumber the opposite sex.

VI. Stilpachlora Stål, 1S73a, 40. (Gr., "glisten" + "green.")

Species of rery large size, having the fastigium horizontal, sulcate, slightly wider than first antennal joint, its apex obtuse; eyes 
small, subglobose; antennæ very slender, reaching beyond middle of tegmina; disk of pronotum slightly concave, narrowed in front; lateral carinæe distinct, obtuse in front, higher, sharper and crenate on basal third; front margin feebly sinuate, hind one very broadly rounded or subtruncate; humeral sinus narrow, deep; lateral lobes much deeper than long, their lower margin broadly rounded into both the hind and front ones; tegmina subcorneous, broadly lanceolate, their anal fields flat, forming a right angle with the median one, dorsal margin behind the anal field slightly sinuous and at apical fourth abruptly decurved to the narrowly rounded apex; lower margin broadly curved from base to middle, thence nearly straight to apex (Fig. 163, a) ; wings with folded tips acuminate, distinctly longer than tegmina; front and middle femora terete, unarmed, hind ones armed beneath with a number of small distant spines; lobes of knees bispinose; hind tibia foursided, the upper, inner and outer sides rather wide, flat, feebly concave, the lower one narrow, the four margins raised and armed with numerous teeth; meso- and metasterna with large triangnlar lobes. Male with supra-anal plate triangular, sulcate; cerci excavated above, abruptly incurved; subgenital plate as in Microcentrum. Ovipositor very small, narrow, gradually curred upward, its apex obtusely pointed.

This American genus of giant katydids has been recently (1917) reviewed by Rehn, who recognized eight species as belonging to the faunas of South and central America and the West Indies, one of which is known to extend into Florida as far north as Gainesville.

223. Stilpnochlora couloniana (Saussure), 1861, 128. Giant Katydid.

Size very large. Above green; pronotum with rounded front portion of lateral carinæ yellow, the sharp crenulate portion and hind margin narrowly edged with black; face, fore and middle femora and under surface greenish-yellow, the face often with a short, median reddish-brown stripe. Basal half of sharp margins of flat anal field of tegmina crenulate and often edged with black. Structural characters as given under the genus heading. Length of body, $\hat{\delta}, 30-32$, $ᄋ, 35-40$; of pronotum, $\hat{\delta}, 8-9$,,, $11-12$; of tegmina, $\hat{\delta}, 55-60,9,63-68$; of hind femora, $\hat{o}$, $29-34$, ᄋ, $34-39$; of ovipositor, $6-7 \mathrm{~mm}$. Greatest width of pronotum, 9-11, of tegmina, $20-25 \mathrm{~mm}$.

Eustis, Fla., April 6, one female; Cape Sable, Fla., Feb. 26, one female (W. S. B.). The Eustis specimen was taken with the fingers as it was resting on a leaf along the border of a cultivated field, while the Cape Sable one was beaten from the foliage of a saffron-plum, Bumclia angustifolia Nutt., growing along the edge of a salt marslı lammock. The other Florida localities recorded 
are Tortugas Islands, Key West, Chokoloskee, Miami, Lake Worth, Ft. Myers, Sanford and Gainesville. At Key West Hebard took a female containing 124 fully dereloped and 14 partially developed eggs from a bush of dahoon holly, Ilex cassine L., on March 16. Davis captured a male at electric light in Ft. Myers on March 31, and saw several others. At Miami Hebard found a young female on March 5, and Daris a male and two nymphs on Sept. 22, all in Brickell's Hammock. At Gainesville a male and female were taken Sept. 26-Oct. 2, and at Sanford a female on Nor. 28. These are the only published Florida records, and for so large an insect they are very few. They indicate that the species must as yet be very scarce in the State, and passes the winter in the adult stage. Rehn $(1917,111)$ states that $S$. couloniana is known only from Cuba, the Isle of Pines and Florida. Saussure's type was from Cuba, and it is said to occur over the whole Island.
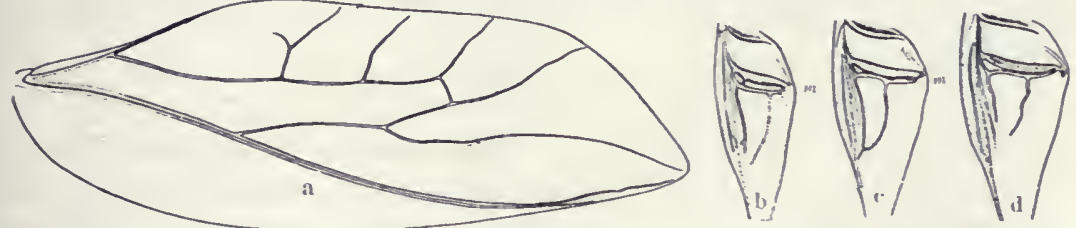

Fig. 163. a, Lateral outline of tegmen of Stilpnochlora conloniana, natural size. Siridulating field of left tegmen of male; $b$, of $S$. marginella; c, of $S$. conloniana; d, of $S$. quadrata. (After Rehn.)

This, the largest Tettigoniid known from the easter'n Cnited States, was first recorded and described from this country by Scudder $(1862,447)$ under the name of Microcentrum thoracicum, his specimen being a female from the Tortugas Islands. Scudder's name was placed by Brunner $(1878,359)$ as a synonym of Stilpnochlora marginella (Serr.), and the species has been recorded as such a number of times from Florida and is listed under that name by Scudder and Kirby in their catalogues. Rehn $(1917,111)$ has separated our insect from $S$. marginella and placed it under Saussure's S. couloniana, a name considered by Brunner, Scudder and Kirby as a synonrm of S. marginella. Rehn gires his reasons for his action thus: "The chief feature which distinguishes the species is the form of the stridulating field of the male tegmina. This is least extensive, with its free margin almost regularly arcuate and hardly angulate, and haring a short stridulating rein in marginella; in couloniana the field is broader, with a rounded obtuse angulation at the extremity of the rein, which is somewhat hearier and longer."

Two females in my collection from Mexico, one from Jalapa, the other from Orizaba, differ from the Florida specimens onls 
in their slightly larger size and more divergent lateral carina of pronotum. These are probably what Rehn considers S. quadrata Scudder (1869c, 331), as that is the only species he mentions as inhabiting Mexico. This species he also separates from marginella and couloniana only "by the greater breadth of the male tegminal field, with margin more obtuse-angled and the more elongate stridulating vein," and states that Florida females of couloniana "are almost indistinguishable from Mexican individuals," i. e., females of what he considers quadrata.

An examination of a series of males of the three forms, marginella, conloniana and quadrata, in the Philadelphia collections, shows that the free margin of the left tegmen ( $m$. Fig. 163, b, c) is slightly more obtusely rounded in quadrata than in couloniana, and slightly less so in marginella than in couloniana. A large series would probably show that quadrata is a synonym of couloniana and that the latter is at the most only a race or form of marginella.

\section{Tunpilia Stål, 1S74, 16.}

This genus is closely allied to Microcentrum, its species differing mainly by their smaller size and the characters given in the generic key. They have the fastigium much narrower, but slightly decurved; disk of pronotum proportionally longer and narrower, much more strongly punctate; tegmina relatively more lanceolate and more densely reticulate; lobes of meso- and metasterna longer, triangular, their tips acute.

224. Turpilia rostratum (Rehn \& Hebard), 1905, 43. Narrow-beaked Katydid.

Size medium, the sexes subequal. Bright green, more or les.s suffused with yellow; in dried specimens the apical half or more of tegmina and protruding tips of wings usually alone green, the remainder dull brownish-yellow. Fastigium as described in key, distinctly sulcate, its apex rounded. Disk of pronotum with lateral carinæ evident but rounded, more distinct on basal balf, front margin broadly and shallowly concave, hind one strongly rounded; humeral sinus rather broad and shallow. Tegmina ovate-lanceolate, apex narrowly rounded, surpassing tips of hind femora about one-third their length. Wings protruding $4-5 \mathrm{~mm}$. beyond the tegmina. All the femora feebly spinulose beneath. Male cerci very long, tapering, nearly straight, surpassing the subgenital plate, their tips armed with a pair of minute apical teeth, and a third ventral subapical one; subgenital plate broad, tapering, its lateral carinæ faint, apex subtruncate, with a minute median rounded notch; styles short, feebly tapering. Ovipositor with both ventral and dorsal margins of apical half finely crenulate, the apex broad, bluntly rounded. Length of body, $\delta, 20-21$, ᄋ, 25-26; of pronotum, $\hat{o}, 5.3$,, $5-5.7$; of tegmina, $\hat{o}, 29-32$, 우, 
$31-33$; of hind femora, $\hat{\delta}$ and $\uparrow, 15.5-16.5$; of ovipositor, $5.5 \mathrm{~mm}$. Greatest width of tegmina, $7.5-8 \mathrm{~mm}$. (Fig. 164:)

Punta Gorda, Fla., Nor. 15-17 (Davis). Known only from the southern third of Florida and the adjacent kers, March-No-

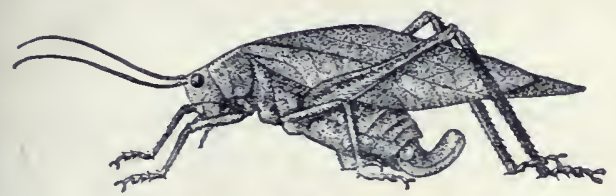

Fig. I64. Female type. Natural size. (After R. \& H.) vember. R. \& $\mathrm{H}$. (1914c, 400) state that at Key West in July it was taken only at night on buttonwood, Conocarpus erecta stalked with flash lamp, by the aid of their song which was low and rasping, much like zrrp-srp-zrp. At Punta Gorda Davis found it not uncommon in November in a clump of mangroves.

\section{Phrixa Stål, 1874, 16. (Gr., "bristling.")}

Species of large size and broad form, having the occiput convex; fastigium of rertex horizontal, subterete, often sulcate, not continuous with frontal fastigium; eyes small, globose; antennæe longer than body, setaceous; disk of pronotum compressed, conrex, rounded into the lateral lobes, the latter perpendicular, deeper than long, their front and hind margins nearly straight and rounded into the subangulate lower margin; tegmina rery broad, coriaceous, opaque, longer than wings, their apical third obliquely truncate, the overlapping anal field triangular, vers short in male, densely punctate-reticulate, with stridulating vein subobsolete above on the left tegmen; all the femora sulcate and armed with several small spines beneatl, lobes of mesosternum rounded, of metasternum, transverse, truncate behind. Males with supra-anal plate elongate-triangular; cerci and subgenital plate variable as to species. Females with ovipositor rather long, moderately curved ; narrower at base than middle, the apex oblique, subacuminate, remotely serrate on both edges; subgential plate triangular, obtuse.

This genus forms a sort of connecting link between the subfamilies Phaneropterinæ and Pseudophyllinæ, and was, until 1914, supposed to be confined to Mexico, six species having been described from that country, one of which is now known to occur in Florida.

225. Phrixa maya Saussure \& Pictet, 1897, 334. Yucatan Katydid.

Size large, form robust. Uniform leaf-green, the abdomen fading to greenish-yellow. Occiput sparsely subgranulate; fastigium of vertex distinctly impressed, but slightly surpassing the scrobes of antennæ; lower margin of lateral lobes oblique, subsinuate. Tegmina as described above, 
the tympanum of male more or less infuscate, the stridulating vein not visible above. Cerci of male terete, very long, strongly semicircularly curved, their apical portion attenuate, upcurved, the tips black, acute. Subgenital plate deeply grooved below, the lobes narrow, oblique, triangular, the apical notch shallow. Other characters as given above. Length of body, $\delta, 21$; of pronotum, 7; of tegmina, 33; of hind femora, $23 \mathrm{~mm}$.

This Mexican species, described from Yucatan, has been taken at Miani, Fla., by both Davis and Hebard. The former (1914, 197) records the taking of a single male after night, Sept. 22, while "shining the road" that leads through Brickell's Hammock with a lantern. Hebard (1915b, 457) mentions the taking, on March 5, of a nymph by beating heavy shrubbery in a dense jungle at the same place; these two records being the only ones of both genus and species from the United States.

Like the small mantis, Mantoida maya S. \& Z., also originally described from Yucatan, $P$. maya is a tropical introduced form which will probably be found only sparingly in the southern third of Florida.

\section{Subfamily II. PSEUDOPHYLLIN $\mathbb{E}$.}

\section{The True Katydids.}

Our eastern species of this subfamily are insects of large size, having the head very broad, fastigium of vertex short, triangular, acute, grooved above, crowded by the prominent, widely margined antennal scrobes; eyes small, subglobose, very widely separated; antenna reaching far beyond the closed tegmina; pronotum saddleshaped, its disk with faint lateral carina, rounded into the perpendicular lateral lobes, front margin truncate, hind one broadly rounded; prosternum armed witl two slender tapering spines; tegmina very broad, ovate, leaf-like, usually strongly concave within, wholly enclosing the abdomen, their anal field short, triangular, overlapping, the sutural margin beyond straight or feebly curved into the broadly rounded tips, the costal field crossed by numerous straight parallel veinlets; wings shorter than tegmina; membranous, very thin, rarely used in flight; meso- and metasterna not lobed; all the femora sulcate and armed beneath; fore tibia without apical spines, hind ones 4 -sided with all the margins spined; first two joints of hind tarsi with sides sulcate. Males with stridulating organ very highly developed, the transparent speculum of each tegmen depressed or sunken and set in a strong half-oval frame, the left or upper one with a strong stridulating cross-rein near the base; cerci broad at base, widely forked, the 
tips of the forks usually incurred and mucronate; subgenital plate long, narrow, more or less spear-shaped. Females with oripositor more than twice as long as pronotum, sickle-shaped, apex acute, apical third of lower margin very finely serrate; supra-anal plate narrow, twice or more as long as wide, apex rounded or subtruncate.

This subfamily is richly represented in the tropical countries of the world, but very poorly so in the United States, where only three genera and half a dozen or so species occur. They are for the most part strictly arboreal, dwelling amidst the foliage of the tallest of trees, but where these are absent thes live in the orchards and shrubbery about small towns and country houses. Caudell $(1906,32)$ well describes their habits when he sars: "The nights may resound with the song of the males and yet the listener never sees one of the songsters. This is accounted for by the habitat of the insect which is in the tallest trees arailable. The young feed on the leaves and rery probably rarely or never leave the shelter of the tree upon which they were born. * * * Considerable doubt exists as to whether or not these tree katydids ever fly. I have repeatedly endeavored to persuade specimens to fly and have succeeded in getting them to spread their wings and sail to the ground, alighting with a thud, but no attempt was made by the insects toward actual flight. They probably soar from one tree to another after the manner of the flying squirrel."

The principal literature treating of our species of Pseudophyllinæ is by Riley, 1874; Brunner, 1895; Blatchley, 1903; Caudell, 1906, and R. \& H., 1916.

\section{KEY TO EASTERY GENERA OF PSECDOPHYLLIX..}

a. Disk of pronotum scarcely longer than wide, the lateral lobes subquadrate or deeper than long; tegmina broadly ovate; subgenital plate of male with apex entire.

I. Pterophyll.

aa. Disk of pronotum distinctly longer than wide, the lateral lobes longer than deep; tegmina somewhat narrower, elliptical; subgenital plate of male with apex deeply forked.

II. LEA.

I. Pterophyla Kirby, 1828, 218. (Gr., "wing" + "leaf.")

Very large green katydids, possessing the characters as above set forth and haring the lateral caring of pronotum evident only near the base; front tibia unarmed abore, middle coxæ with a basal tubercle; hind femora with not more than seren spines on the lower outer carina; supra-anal plate in both sexes entire or sulcate above only on basal fourth; male with supra-anal plate about as broad as long, forks of cerci strongly divergent, their 
tips separated by a distance greater than the length of lower fork; subgenital plate produced into a long spear-shaped appendage, grooved above.

As pointed out by Kirby $(1906,343)$ this generic name replaces Cyrtophyllus Burm. $(1838,697)$ for our common eastern true katydids. Caudell $(1906,37)$ recognized four species as belonging to Cyrtophyllus, three of which he described as new. One of these (elongatus) is now known to be a synonym of $P$. camellifolia (C. perspicillatus) while another is placed by $\mathrm{R}$. \& $\mathrm{H}$. (1916) as a southern race of that species. Our two eastern forms were separated by Caudell as follows:

KEY TO EASTERN FORMS OF PTEROPHYLLA.

a. Lower branch of male cerci with incurving apical portion scarcely as long as the less tapering basal portion, the apex of the broad base of the cercus between the two branches less enlarged; tegmina of female broadly rounded apically, the posterior (sutural) margin usually as convex as the costal margin.

226. CAMELLIFOLIA.

aa. Lower branch of male cerci with incurving apical portion as long as the thick, uniformly tapering basal portion, the cercus between the two branches much enlarged, forming a triangular projection; tegmina of female narrowly rounded apically, the posterior margin almost straight.

226a. INTERMEDIUS.

226. Pterophylla Camellifolia (Fabricius), 1775, 283. Northern True Katydid.

Size large, form robust, the sexes subequal. Tegmina dark green; body, head, pronotum and legs paler green tinged with yellow, often becoming dull greenish-yellow in drying; tympanum of male brown. Disk of pronotum saddle-shaped, coarsely and densely punctate; metazona broader than prozona, usually distinctly sloping from the broadly rounded or subangulate hind margin to the principal transverse sulcus, the latter descending on lateral lobes much farther than the anterior sulcus; prozona about as long as metazona, crossed at middle by the deep anterior sulcus, its front margin truncate; lateral lobes subquadrate, all their margins nearly straight, the lower angles rounded. Tegmina as described under subfamily heading, those of female about two and one-half times as long as broad. Male with lower branches of cerci about one-fourth shorter than upper ones, their tips strongly incurved and partly clasping the sides of the elongate subgenital plate, the upper forks crossing each other, each ending in a minute sharp black spine. Ovipositor as described under subfamily heading. Length of body, $\hat{\delta}, 25-30, \$, 26-34$; of pronotum, $\hat{\delta}$ and $\&, 5.5-6$; of tegmina, $\delta, 32-38$, $९, 34-37$; of hind femora, $\hat{\delta}, 18-21$, $\uparrow, 19-23$; of subgenital spine, $\hat{\delta}, 12-14.5$; of oviposi-

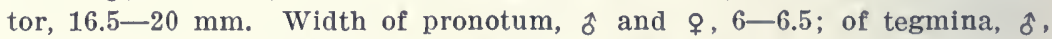
17-20, ᄋ, 14-16; of ovipositor, $3.2 \mathrm{~mm}$. (Fig. 165.)

This broad-winged katydid occurs in considerable numbers throughout Indiana, but is much more commonly heard than seen, 


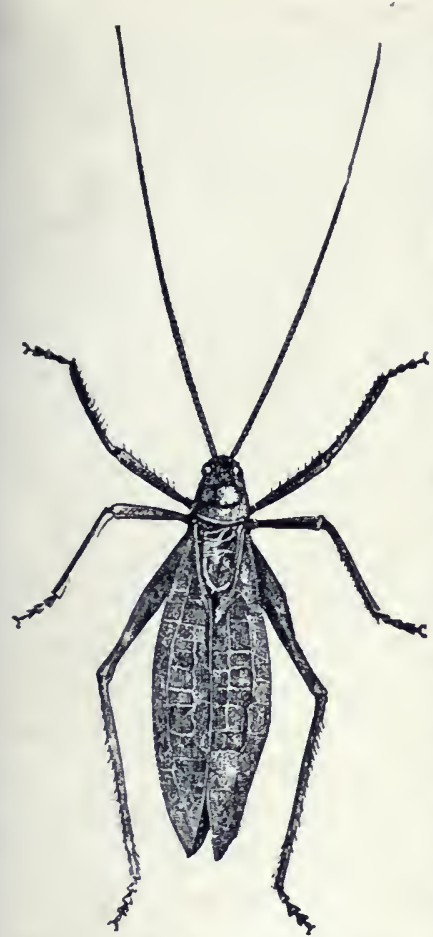

Fig. 165. Male. Natural size.

as it dwells in small colonies in the densest foliage which it can find, such as the tops of shade and forest trees, the entwining vines of the grape arbor, the shrubbery of yards and orchards and the trees along fence rows. Its note is the loudest made by any member of the family, the male having the musical organ larger and better developed than in any other. The call is almost always begun soon after dusk with a single note uttered at intervals of about five seconds for a half dozen or more times. This preliminary note gives the listener the impression that the musician is tuning his instrument, preparatory to the well-known double call which is soon begun and kept up almost continuously from dark till dawn. Occasionally, in warm cloudy weather, this call is made by day, and if the musician is located he will sometimes be found resting on the topmost leaf of a shrub, swinging to and fro as the breezes blow, and sounding his cymbals in seeming unison with the movement. This katydid reaches maturity in southern Indiana by mid-July. The song has been heard in Crawford County as early as July 10 , and as late as Oct. 27 , and a single female was captured in LaPorte County, near Lake Michigan, on October 15 .

In a Putnam County farmyard I listened for hours, one August night, to the serenade of a band of katydids. They seemingly tried to outdo themselves for my benefit. But to them I was a nonentity-an unknown being. No thought of me or of my attentive ear lurked in or passed through their brains, as they clashed their cymbals in every shrub and tree around the old farm house. One idea alone possessed the minds of the male musicians. That idea was love-passion- "that greatest thing in the universe." Long and loud the cymbals sounded, each shuffle, each note, doubtless accompanied by the wish that the next would call from the skies, from the branches above or about them-from anywhere, it mattered not-one of their form and kind. One to whom they could "whisper sweet nothings"- one whom they could caress tenderly 
with long antennæ- one whom, in time, they could clasp lovingly with their slender limbs and forget cymbals, calls, skies, food, esirth, everything in that long embrace which is to them the acme, the one, the highest object of their mature existence.

The serenade continued thus, almost unbroken, from dusk till dawn. A serenade it was in truth-a song of love-of passion, poured out to the listening ears of the other sex. At times a single player dropped out of the chorus. His work, his love-calls had not been in vain. From some leafy retreat, where she had been hidden by day, a lady katydid slowly emerged, and, entranced by the song-by, to her ears, the tender wooing notes-drew nearer and nearer unto the charmed circle whence the cymbals clanged and shuffled. Their notes became less vigorous. More softly they fell upon her ear, until finally, as she coyly advanced they ceased and the caress of the antennæ took their place. The other musicians noted the absence of one of their chorus, and sounded their drums the louder, but for most of them their labor was in vain. Many of them doubtless go through life unblessed by the presence of the gentler sex, clanging their nightly calls from mid-July to the coming of the hoar-frost, and to its biting nips finally succumbing, possessed by the thought-if a katydid can think-that this earth is a desolate and cruel abiding place for such as they. So have the most of bachelors-human and otherwise-doubtless thought, as in the past they yielded up the ghost.

The known range of this true katydid extends from New England and London, Ont., west to Michigan and northern Illinois, and south and west to North Carolina, northern Georgia and central Kansas. In New England it has been definitely recorded only from Massachusetts and Connecticut, Scudder (1900a, 103) stating that it is found in isolated colonies in the former State and more generally but still locally in Connecticut. Davis (1889) mentions it as occurring on Staten Island, N. Y., in late July and August. Walker (1904a, 330) states that it is common at Niagara, and that he had often heard it at Yonkers, N. Y. Caulfield (1888) records the only Ontario specimen as taken at electric light in London. It is not mentioned in any of the local Michigan lists at hand, though stated by Pettit and McDaniel to have been recorded from the State. Lingger, though giving a description and an account of its habits $(1898,226)$, does not record it from Minnesota but says: "If found in this State it will very likely occur in small colonies." Ball (1897) mentions it as rare at Ames, Towa, while Bruner (1893a, 29) records it as not rare in the eastern or wooded part of Nebraska. The records south and 
southwest of New England are more numerous, a number of them, as far as northern Georgia, being given by R. \& H. $(1916,257)$. Candell $(1906,38)$ states that it is found in Kansas.

Most of the above records have been made under the names Platyphyllum concavum Harr. (1S41, 12S), Cyrtophyllus concavus Scudder $(1862,444)$ and Cyrtophyllus perspicillatus Burm. (18:38, 697 ), all of which are synonsms of Pterophyl'a camcllifolia (Fab.). The female was described by Fabricius as, Locusta camellifolia. and in the next line he described the male as $L$. perspicillata, the former name therefore having priority. The Cyrtophyllus clongatus Caudell $(1906,40)$ is also a synonym of $P$. camellifolia.

Of the call of this species Scudder (1S75e) has written:

"The note, which sounds like $x r$, has a shocking lack of melody; the poets who have sung its praise must have heard it at the distance that lends enchantment. In close proximity the sound is excessively rasping and grating, louder and hoarser than I have heard from any other of the Locustarians in America or in Europe, and the Locustarians are the noisest of all Orthoptera. Since these creatures are abundant wherever they occur, the noise produced by them, on an evening specially favorable to their song, is most discordant. Usually the notes are two in number. rapidly repeated at short intervals. Perhaps nine out of ten will ordinarily give this number, but occasionally a stubborn insect persists in sounding the triple note-('Katy-she-did'); and as katydids appear desirous of defiantly answering their neighbors in the same measure, the proximity of a treble-voiced songster demoralizes a whole neighborhood, and a curious medley results; notes from some individuals may then be heard all the while, scarcely a moment's time intervening between their stridulations, some nearer, others at a greater distance; so that the air is filled by these noisy troubadours with an indescribably confused and grating clatter."

Caudell $(1906,32)$ sars: "The female of this katydid is unique among Orthopterous insects, so far as known. in that they stridulate in a manner similar to that of the males. The tegmina are partially opened and closed just as are those of the males during stridulation. The roughened surface of the triangular anal areas rub orer each other, like the tympani of the males, the right tegmen sliding beneath the left one. The resulting sound is a sharp, scraping note, heard easily for several yards. This sound is made by the female when disturbed by handling. but whether or not it is erer made roluntarily in nature is not known, but it presumably is when the insect is disturbed by anr cause."

According to Riley $(18 T 4,167)$ the eggs of the true katydid are thrust, by means of the sharp ovipositor, into crevices and soft substances, and probably, in a state of nature, into the crevices of loose bark, or into the soft stems of woods plants. They are of a 
dark slate color, about $6.5 \times 2 \mathrm{~mm}$. in size, very flat, pointed at each end, and with the edges beveled off or emarginate. Caudell $(1906,33)$ mentions a female that was found on Plummer's Island, Md., with the ovipositor inserted into the bark of a small elm tree a few feet above the ground. I Later $(1918,112)$ he records one as ovipositing in the bark of the black walnut.

226a. Pteropitylla camellifolia intermedia (Caudell), 1906, 41. Southern True Katydid.

Smaller than the average camellifolia. Color the same. Pronotum with anterior transverse sulcus less deeply impressed. Tegmina of female narrower, the hind margin, when spread, nearly straight, the tip narrowly rounded. Cerci of male as described in key. Length of pronotum, $\hat{\delta}, 5$,

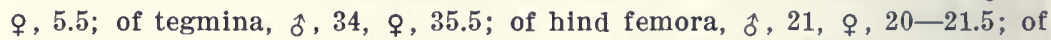
subgenital plate $\hat{\delta}, 13$; of ovipositor, $18 \mathrm{~mm}$. Width of tegmina, $\hat{o}, 18$, \&, $14 \mathrm{~mm}$.

Hollister, Mo., July 22 (Davis). Caudell's types were from Biloxi, Miss., and Wellsboro, Texas. R. \& H. (1916, 257) have recorded a male from North Carolina and placed intermedia as the southern race of camellifolia, stating that their male is intermediate between Caudell's types and typical camellifolia. The Missomri specimen at liand is a female luaving the tegmina as described by Caudell. A large series from the territory soutl of the known range of camellifolia will be necessary to fix the true status of intermedia.

\section{Lw Caudell, 1906, 42. (WVithout meaning.)}

Larger, more elongate species than those of Pterophylla, having the head narrower, vertex much the same; disk of pronotmm abont one-half longer than the middle width, rugose, the prozona one-fourth longer than metazona; lateral lobes perpendicular, onethird longer than high, hind margin straight, oblique, rounded into the straight lower one; tegmina elongate-elliptical, two and a half times as long as the middle breadth, both margins feebly curved into the broadly rounded tips, the venation of the costal field as in Pterophylla. All the femora armed below and the middle and hind tibiae above. Male with shrilling organ as in Pter. ophylla; supra-anal plate triangular, nearly twice as long as wide; cerci widely forked, the base between the forks concave, branches slender, tapering, the mper ones incurved and crossed, the lower ones upcurved and subparallel; subgenital plate long, slender, upcurved, grooved ahove and beneath, deeply and narrowly forked at apex, the tips acute. Female with ovipositor nuch as in Pterophylla, slightly narrower and more upenred; supra-anal plate 
twice as long as wide, its apex narrowly rounded; cerci subcylindrical, tapering, the tips slightly forked. A rery distinct genus, as shown by the characters giren in kes and above. Only one species is so far known.

227. LEA FLoRIDExsis (Beutenmüller), 1903, 637. Florida Katydid.

Green or greenish-yellow fading to dull yellow, the tympanum of male brown. Antennæ twice as long as body. Pronotum with two transverse sulci feebly impressed, front margin broadly convex, hind one subtruncate or very broadly rounded, lateral carinæ rounded and vague on prozona, more distinct on metazona; lower front angle of lateral lobes narrowly rounded. Other structural characters as given above. Length of body, $\delta, 32-43$, ․, 35-39; of pronotum, $\hat{o}, 6.5-8, \mathcal{q}, 7.2-8.5$; of tegmina, $\hat{o}, 32-37$, , $34-35$; of hind femora, $\hat{\delta}, 23-28, \stackrel{q}{ }, 26-27$; of subgenital plate, $\hat{o}$, 12 ; of ovipositor, $14 \mathrm{~mm}$. Width of tegmina, $\delta, 13-15,+, 15-18 \mathrm{~mm}$.

LaGrange, Fla., June; Pablo Beach, Fla., Aug. 13 (Davis). Known only from Florida, and so far found only in a narrow strip along the east coast from Pablo Beach to Miami. The type of Beutenmüller was from near Grant, and he says that it lives in the tops of live-oak trees, the note of the male, being a continuons "kerr-kerr-kerr-kerr," with about one second interval of rest. R. \& H. $(1907,302)$ record the taking in August of numerous specimens at Pablo Beach, where it was apparently abundant "in bushes about eight to ten feet high growing on the land face of the dunes. The note is much lower than in P. camellifolia, decidedly weaker, and consisting of single notes separated by regular intervals."

Davis $(1914,198)$ records $L$. floridcnsis from LaGrange, Sept. 10-12. and says: "We sometimes heard among the oaks and cabbage palms, but not in the pine woods, a low chluck, chluck, evidently the call of some large insect, though its carrying power was poor and one had to be quite near in order to hear it. There were several of the insects about, and one evening when the moon was shining brightly and with the aid of a lantern, one was discovered among the leaves of a cabbage palm. Enough was seen to identify it with Cyitophyllus floridensis and the next day I knocked a female of the same species from a cabbage palm into my umbrella. A nymph was found at night hanging from moss on a low palmetto, drying itself, having just shed its skin. This nymph was brownish in color, but the adult niale and female were all green. Near Miami, 180 miles to the south of LaGrange, one of these insects was heard stridulating every evening in the latter part of September. It lived among the Spanish moss in a large oak in a clearing, and as it always took alarm at the light of my lantern it could not be obserred, much less collected." 


\section{Subfamily III. COPIPHORINÆ.}

The Cone-Heaved Grasshoppers.

"Happy insect! what can be In happiness compared to thee?

Fed with nourishment divine,

The dewy morning's gentle wine,

Nature waits upon thee still,

And thy verdant cup does fill;

'Tis filled wherever thou dost tread,

Nature's self thy Ganymede."-Cowley.

Species of medium or large size, having the vertex projected forward in the form of a cone, sometimes blunt, more often prolonged and pointed, this usually bearing on its lower surface a small basal tooth; face long, very oblique; eyes small; pronotum with not more than one transverse sulcus; prosternum with two slender spines; tegmina seldom expanded at middle, both they and the wings fully developed (except in Belocephatus); shrilling organ of male well developed, its cross-vein prominent; hearing organs present near base of front tibix; front coxæe with a spine on outer side; fore tibiæ withont apical spines; hind femora slender, much thickened at base; hind tibiæ armed beneath with two rows of short spines and above with three pairs of apical spurs; tarsi depressed, their first two joints sulcate lengthwise on the outer side.

Karney (1912) recognized 43 genera as belonging to this subfamily, only four of which occur with us. The principal literature dealing especially with the American species is as follows: Redtenbacher, 1891; Blatchley, 1893, 1903; Saussure \& Pictet, 18971899 ; Karney, 1907, 1912; Davis, 1912a, 1914, 1915; Rehn \& Hebard, 1915, 1916.

KEY TO EASTERY GENERA OF COPIPHORINA.

a. Tegmina lobiform, covering less than half the abdomen; wings wanting or very rudimentary.

I. BELOCErHaLUs.

aa. Tegmina and wings well developed.

b. Fastigium triquetrous or three-sided, flat, very rugose above and ending in a short, strongly decurved. spine. II. Pyrgocomyrila.

$b b$. Fastigium not triquetrous, usually conlcal, convex and nearly smooth above, the tip not ending in a decurved spine.

c. Fastigium with a tooth beneath, its lower face on a slightly higher plane and well separated from the median facial ridge; tegmina much surpassing hind femora, their tips broadly rounded.

III. Neocoxocepilalus.

$c c$. Fastigium without a tooth beneath, its lower face on the same plane and scarcely separated from the median facial ridge; tegmina usually surpassed by hind femora, their tips then acute or narrowly rounded.

IV. HOMOROCORYPHUS. 
I. Belocephalus Scudder, 1875, 458. (Gr., "sharp" + "head.")

\section{The Wingless Cone-Headed Grasshorpers.}

Medium sized Tettigoniids of rather robust form, having the rertex usually strongly produced in the form of a stout, sharply pointed cone bearing on its lower face a small basal tooth; eyes small, not prominent; pronotum subcrlindrical, front and hind margins subtruncate or rounded, transverse sulcus at apical third very faint, lateral lobes longer than deep, their lower margin nearly straight, its angles obtusely rounded; tegmina of males shorter than pronotum, with shrilling organ well dereloped, partly transparent, those of females very small, widely separated lateral pads reaching only to second dorsal abdominal segment; front and middle femora subequal in length, armed beneath on outer margin with two to five minute teeth; hind femora slender, their lower outer margins with eight to ten, and inner with three to fire rather stout teeth, lower lobe of knees ending in a small, acute spine. Male with supra-anal plate very broad, triangular, deeply emarginate at apex; cerci very stout, strongly incurved and deeply forked at apex, the upper prong of fork the more slender (Fig. $166, \mathrm{c}, \mathrm{x})$; subgenital plate broad, feebly emarginate and bearing
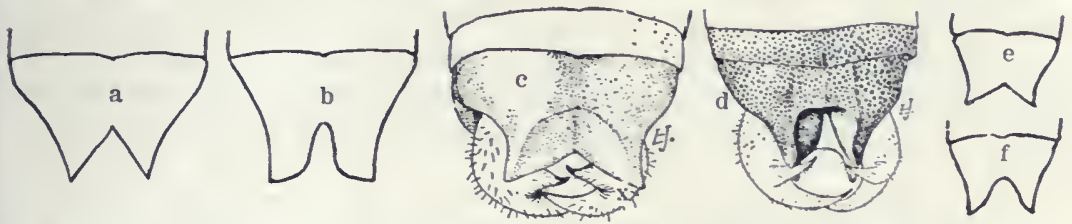

Fig. 166. Supra-anal plates of males of Belocephalus, showing the form of the notch $\mathrm{a}$, of sabalis; b, sleighti; c, subapterus; d, excavatus; e, rehni; $\mathrm{f}$, micanopy; $\mathrm{x}$, male cerci of subapterus. (After Davis.)

each side of the notch a very small, one-jointed style set in a shallow socket. Ovipositor rather stout, nearly straight, half or more the length of body.

The species are usually dimorphic in color, either a nearly uniform pale green or pale brown, the males being more often of the former hue. Since they cannot fly and are not active walkers, each colony is confined closely to its original enrironment, thus causing minor modifications of structure in isolated areas.

The genus was founded on a single Florida species and up to 1912 was considered monotypic. Since that date seren additional nominal species hare been described br Daris and R. \& H., all from the southern States. As only one of the eight has been taken by me, Mr. Daris kindly prepared the following key to the species. This is based largely upon the males, the females being rery diffi- 
cult of separation. As will be noted farther on, I consider some of the forms treated in the key as only varieties of the older named species.

KEY TO SPECIES OF NORTII AMERICAN BELOCEPIIALUS.

.a. Vertex of head produced as a stout" subcylindrical thorn, tapering apically.

b. Outer extremities of subgenital plate not bent upward and inward, nor produced into points.

c. Antennæ unicolorous; body of male about $40 \mathrm{~mm}$. in length.

d. Supra-anal plate with inner sides of $\mathrm{V}$-shaped notch nearly straight (Fig. 166,a); hind femora about $20 \mathrm{~mm}$. in length.

228. SABALIS.

dd. Supra-anal plate with inner sides of $\mathrm{V}$-shaped notch curved (Fig. 166, $b$ ); hind femora about $18 \mathrm{~mm}$. in length.

228a. SLEIGHTI.

cc. Antennæ spotted or annulated; body of male usually less than $40 \mathrm{~mm}$. in length.

e. Length of body more than $30 \mathrm{~mm}$.

t. Supra-anal plate with V-shaped notch broadly open, and with sides straight (Fig. 166, c); length of body about $34 \mathrm{~mm}$;; a more slender species than davisi.

229. SUBAPTERUS.

ff. Supra-anal plate with V-shaped notch not broadly open; sides of notch curved; length of body about $35 \mathrm{~mm}$.

229a. DAvisi.

ee. Length of body about $24 \mathrm{~mm}$.; supra-anal plate with Vshaped notch narrow, its inner sides a little curved, the excavated part surrounding the notch with sides declivitous (Fig. 166, d.)

230. EXCAVATUS.

$b b$. Outer extremities of subgenital plate bent upward and inward and produced into sharp points; antennæ spotted; length of body about $34 \mathrm{~mm}$.

229b. IIEBARDI.

aa. Vertex of head rounded, not produced as a sharp pointed thorn.

g. Outer extremities of subgenital plate not bent upward and inward into points; supra-anal plate with V-shaped notch rery broad, its inner sides straight (Fig. 166, e); length of body of male about $25 \mathrm{~mm}$.

231. REIINI.

gg. Outer extremitiés of subgenital plate bent upward and inward and produced into points; supra-anal plate with $\mathrm{V}$-shaped notch not very broadly open, its inner sides curved (Fig. 166, f); length of body of male about $30 \mathrm{~mm}$.

232. MICAXOPY.

228. Beloceifialus sabalis Davis, 1912a, 123. Palmetto Cone-head.

Male.-Size large for the genus, form robust. Color usually uniform green, mandibles and often the clypeal suture black. Fastigium nearly as long as head behind the eyes, sharply pointed, its tip and that of the lower basal tooth black. Antennæ about as long as body, uniform pale yellow. Disk of pronotum feebly rugose, lateral lobes more strongly so. Tegmina less than two-thirds the length of pronotum, their tips broadly obliquely rounded. V-shaped notch of supra-anal plate about as wide as deep, 
reaching one-third to middle of plate. Female.-Usually pale brown with two very narrow fuscous stripes extending from near tip of fastigium back to middle third of abdomen or beyond (these also present in the brown males), the space between them darker on head and pronotum. Tegmina very small, oblong pads, their inner edges not reaching the darker stripes on abdomen. Ovipositor strongly tapering to an acute apex, its apical half feebly upcurved. Length of body, $\hat{o}, 40-41$, $\$, 45$; of fastigium beyond base of antennæ, $\hat{\delta}, 3.5,9,4.5$; of pronotum, $\hat{o}, 8.6-10.4, q, 9-$

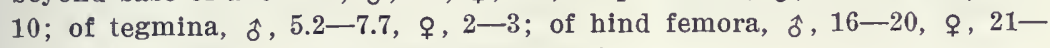
21.8; of ovipositor, 16-18 mm. (Fig. 167.)

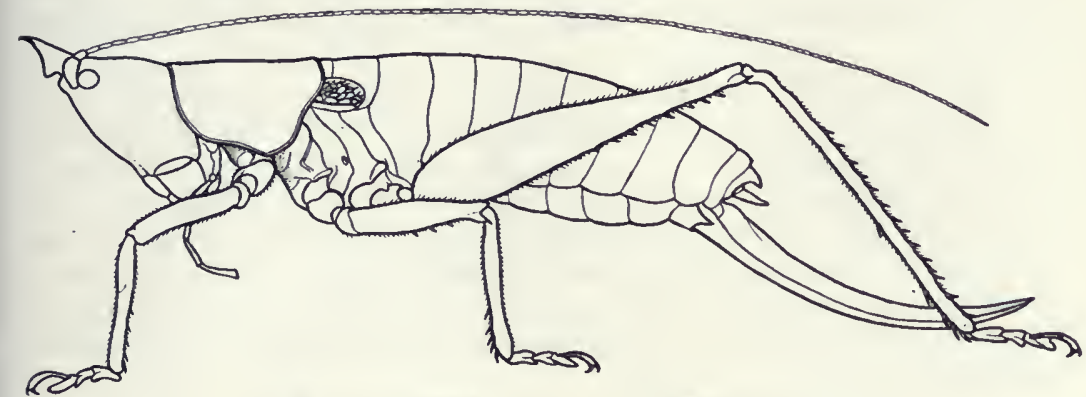

Fig. 167. Female. $X$ 1.7. (Original, by Fox.)

Miami and Parish, Fla., Sept. 22-Oct. 17 (Davis). Ft. Myers, Fla., Sept. 17, one green female, Gainesville collection. Described from Punta Gorda and recorded also by $R$. \& H. and Davis from Homestead, Marathon, Cocoanut Grove and Pineland, Fla., July -November. A subtropical species kuown only from the southern third of Florida. The females appear to be far less numerous than the males.

Of its habits Davis (1912a, 122) says: "At Punta Gorda in November, the males would perch on the topmost leaf of a scrub palmetto and stridulate a song hardy to be distinguished from the rapid $i k-i k-i k$ of the Conocephalus ensiger of the northeastern United States. They fed on the palmetto, their powerful jaws enabling them to gnaw the tough leaves." At Homestead R. \& H. (1914c, 401) found "the species very common on scrub palmetto, Screnoa serrulata (Michx.) in the pine woods, and only at night, when their stridulations permitted stalking with a flash-lamp. The song was faint, and ceased on an approach of even as much as twenty feet. However, they were easy to capture when located, as they almost invariably made no attempt to escape, but instead merely slipped down the palmetto leaf a few inches or around to the other side and there flattened themselves out with caudal limbs extended backward and cephalic limbs forward. When picked up they would violently attempt to bite their captor, and if successful could inflict a painful bite on a tender portion of 
the hand. Their note is very low and consists of a succession of sounds like zip-zip-zip-zip-zip-zip-zip-zip." of a specimen kept in captivity Hebard $(1915 b, 458)$ says: "Its actions show how absolutely nocturnal the species is; this specimen resting rigid in some concealed position during the day, with cephalic limbs and antennæ directed straight forward and median and caudal limbs straight backward, but at night moving actively about and extremely alert and rapid in its movements."

228a. Belocephalus sabalis sleighti Davis, 1914, 199. Pine Key Cone. head.

Size, form and color of $B$. sabatis. Differs only in having the fastigium and hind femora a little shorter and in the form of the V-shaped notch of supra-anal plate. In sabalis the sides of this notch are straight with the apical angle (point of the V) acute. The prongs formed by the $\mathrm{V}$ have their extreme tips acute and located at the middle of each prong, (Fig. 166, a.) In sleighti the notch is slightly deeper, the apical angle narrowly rounded and the inner sides of the $\mathrm{V}$ concave, so that the tips of the resulting prongs are more obtuse and located on their outer margins (Fig. 166, b.)

Big Pine Key, Fla., July 19, Sept. 19 (Davis). In the measurements of a series of sabalis given by R. \& H. (1914c, 401) the length of the hind femora is shown to vary from 15.9 to $19.7 \mathrm{~mm}$. and the "length of fastigium from the eyes" from 3.1 to $4.5 \mathrm{~mm}$. The measurements of these parts given by Davis in his description of sleighti and in the key fall well within the individual variations of sabalis shown by R. \& H. The slight difference in the form of supra-anal notch of male I consider also as well within the limits of specific variation of such organs, as it has been previously shown that the secondary genital organs of the males of Orthoptera are more subject to variation than any other part of the body. I therefore regard sleighti as only an incipient species or variety of sabalis, the slight differences in structure being due to some feature of environment or inherited tendeney, as yet unexplained. B. sleighti was described from Big Pine Key and has not been recorded elsewhere. It was also found on saw palmetto and, says Davis, had a "song much like that of $B$. sabalis," its habits and note thus being additional evidence of its specific identity with that species.

229. Belocepitalus subapterus Scudder, 1875, 459. Half-winged Conehead.

Male.-Size medium for the genus; form moderately robust. Color usually pale green tinged with yellow, with two narrow dark stripes ex. tending from middle of fastigium to hind margin of pronotum; tip of fastigium, basal tooth of same, clypeal suture and mandibles shining 
black; basal halves of antennæ spotted or ringed with dark brown; fore femora often with a row of small brown dots on outer face. Fastigium as long as the occiput, strongly tapering to a sharp decurved point. Disk of pronotum twice as long as wide, slightly rugose, the lateral lobes much more so. Tegmina as long as pronotum, their tips narrowly obliquely rounded. Notch of supra-anal plate distinctly wider than deep (Fig. 166, c.) Female.-Usually brown, with the interval between the narrow fuscous stripes on head and pronotum darker. Tegmina as in sabalis. Ovipositor slightly longer than hind femora, less tapering and with tip more obtuse than in sabalis. Length of body, $\hat{\sigma}, 28-34$, 우, 30-38; of fastigium beyond the eye, $\hat{\delta}, 2.6-3.2$, ㅇ, $3.5-4$; of pronotum, $\hat{o}, 6.2-8$, ㅇ, $8-8.5$; of tegmina, $\hat{\delta}, 8-8.5$, ․ $3-3.5$; of hind femora, $\hat{o}, 14-17$, 오 17-19; of ovipositor, $19-21 \mathrm{~mm}$. (Fig. 168.)

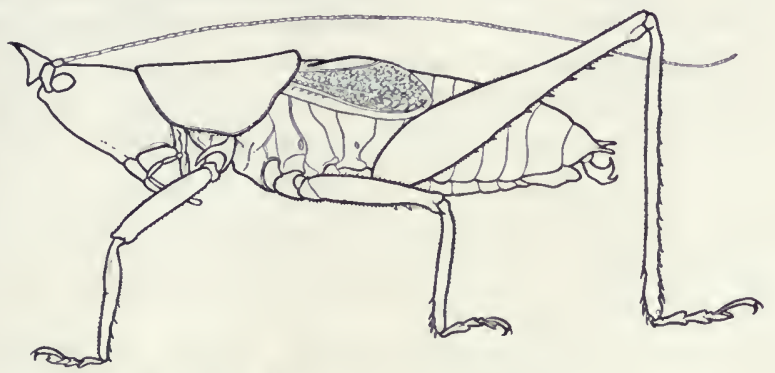

Fig. 168. Male $\times$ 2. (Original by Fox.)

Gainesville, Sanford and Dunedin, Fla., Oct. 14-Jan. 13 (IV. S. B.). Three specimens were taken at Sanford Jan. 11 and 12, from between boards of a lumber pile and two at Dunedin, Jan. 13, from beneath a board near the border of a pond, thus showing that the adults in central Florida sometimes hibernate. Scudder's types were females from N. E. Florida, and the species has been recorded from many points in the northern half of that State. It has also been taken by R. \& H. (1916, 258) at Florence, Ashley Junction and Yemassee, S. Car., and at numerous stations in Georgia. They state that it is most abundant in Georgia in early December, and is then found mostly amongst the shrubbery and other undergrowth of open pine woods and palmetto hammocks.

229a. Belocephalus subapterus davisi Rebn \& Hebard, 1916, 259. Davis's Cone-head.

Somewhat larger and more robust than subapterus. Color and black markings on head, antennæ and pronotum as there. Differs in the form of the emargination of the supra-anal plate of male, the notch being more rounded than in typical subapterus. "It is not quite as deep as in sleighti, and has the sides convex and angle very broadly rounded. The lateral productions formed by this emargination have evenly converging sides with blunt and sharply rounded apex situated mesad." ( $R$. \& $H$. Length of body, $\hat{\delta}, 33-40$, $\$, 36$; of vertex, 3.7-4.5; of pronotum, $\hat{\sigma}$, 
$7.9-8.9, \uparrow, 8.1$; of tegmina, $\hat{\delta}, 5.6-8.1, q, 2.3$; of hind femora, $\delta, 16.4-$ -18.8 , ․, 18.4; of ovipositor, $19.2 \mathrm{~mm}$.

An examination of the type, and also of a pair of this form in the U. S. National Museum from Chuluota, Fla., shows it to be intermediate in size between sabalis and subapterus, with the supra-anal notch also intermediate in form. It has not only the black markings of subapterus but the relative length and form of the male tegmina are exactly as in that species and not as in sabalis and sleighti as stated by R. \& H. In subapterus, davisi, hebardi and rehni the tegmina are one-fourth longer than broad, as long as or slightly longer than pronotum and with tips narrowly obliquely rounded, while in sabalis and sleighti they are as broad ol slightly broader than long, less than two-thirds the length of pronotum, the tips broadly obliquely rounded. As R. \& H. admit $(1916,261)$ that there is a "considerable amount of size rariation" and a "decided amount of variation in the shape of the supraanal notch" in their type series, I can only regard davisi as a variety of subapterus, it being apparently an intermediate form between that species and sabalis.

The types of davisi were from Billy's Island, Okefenoke Swamp, Ga., where subapterus also occurs. The males were taken at night when they were found in numbers stridulating in the undergrowth of the pine woods.

229b. Belocephalus subapterus hebardi Davis, 1912a, 123. Hebard's Cone-head.

Differs from subapterus only in having the extremities of the subgenital plate, near the insertion of the styles, bent upward and inward and slightly produced into sharp points. The form, size, color, dark markings of antennæ, head and thorax, length and form of tegmina and supra-anal notch of male are precisely as in subapterus. The females of the two forms are very similar, the ovipositor of hebardi being slightly longer, straighter and more slender than in typical subapterus.

Parish, Fla., July 26, Sept. 21 (Davis). I)escribed from Punta Gorda, Fla., where it occurred in November on the same clumps of palmetto as $B$. sabalis. In the Philadelphia collections also from Ft. Myers. Davis states that it was "more retiring in habits than subalis and sang a slow zeel-zcek-zeck." I regard it as only a variety of subapterus.

230. Belocephalus excavatus Davis, 1915, 98.

Smaller than subapterus, color and black markings on antennæ, head and pronotum as in that species. Fastigium sharp-pointed, slightly bent downward and tipped with black. Antennæ longer than body. Abdomen with a well defined interrupted carina. Femora and tibiæ of all legs 
blotched with brown and tips of spines black. Notch of supra-anal plate narrow with inner sides but little curved, the excavated part surrounding the notch with sides more declivitous than in any other known species of the genus (Fig. 166, d.) Length of body, $\hat{\delta}, 24$; of fastigium beyond base of antennæ, 2.5; of pronotum, 7; of tegmina, 7; of hind femora, $13.5 \mathrm{~mm}$.

Not seen by me. The above are the salient points of the original description. Known definitely only by the unique brown male type taken at Gainesville, Fla., Oct. 2, and now in the American Museum of Natural History.

231. Belocephalus remni Davis, 1912a, 124. Rehn's Cone-head.

Agrees with subapterus in color and general markings. Differs in its smaller size and in having the fastigium shorter and blunt pointed. Femora and tibiæ of all the legs blotched with brown; abdomen finely flecked with the same color. Styles about four times as long as broad. Length of body, $\hat{\delta}, 24$, $\uparrow, 29$; of fastigium beyond base of antennæ, $\hat{\delta}$, $1.5, \uparrow, 2$; of pronotum, $\hat{\delta}$ and $\uparrow, 6.5$; of tegmina, $\hat{\delta}, 7-7.5, q, 2$; of hind femora, ô, 13, $\&, 17$; of ovipositor, $21 \mathrm{~mm}$.

Described from five specimens taken from beneatl loose bark of pine and between boards at Newberry, Fla., in Norember. Knnown also from Ocala, Orlando and Dunellon, Fla. The small size and blunt fastigium are probably sufficient to separate it specifically from subapterus which it otherwise very closely resembles.

232. Belocephalus micaxopy Davis, 1914, 200.

Size and form of a small subapterus. Mandibles, lower edge of front, base of antennæ beneath, tip and lower tooth of fastigium, black; upper surface of head and pronotum with a faint yellowish line on either side, bordered within by blackish, these extending backward to base of thorax, male, onto abdomen, female; in the latter sex the entire area between the lines dark brown. Antennæ longer than body, male, slightly shorter, female, the joints of basal third or more in both sexes spotted or annulate with black. Femora and tibiæ of all legs blotched with brown at knees. with tips of spines black. Fastigium short, blunt pointed, somewhat intermediate in form between subapterus and hebardi. Male with notch of supra-anal plate and outer extremities of subgenital plate as described in key. Styles about three times as long as broad. Length of body, $\hat{\delta}$ and $\rho, 30$; of fastigium beyond base of antennæ, 2 ; of pronotum, $\hat{\delta}$ and $q, 9$; of tegmina,

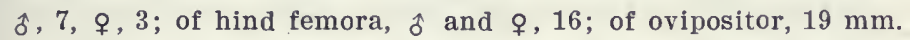

Big Pine Key, Fla., Sept. 19 (Davis). Recorded only from that island, where it was taken in September and October from "among the leaves of the silver palm, Coccothrinax argentea Lodd. The song is slow and readily distinguished from that of $B$. sleighti." (Davis.)

From the key and descriptions it will be noted that we have three groups or types of Belocephatus in Florida, viz.: (a). The 
sabalis group-large bulky forms with antennæ unicolorous, fastigium very long and sharply pointed, and male with short broad tegmina and supra-anal notch deep. $(b)$. The subapterus group - species of medium size with antennæ spotted, fastigium of moderate size and sharply pointed and male with longer, narrower tegmina and supra-anal notch broadly and shallowly concave. (c). The rehni group-species of small or medium size, with antennæ spotted and tegmina as in $(b)$, fastigium short and blunt, and supra-anal notch of moderate width and depth. A careful study of a large series of specimens from all parts of the State would perhaps show that only three forms, sabalis, subapterus and rehni are sufficiently differentiated to be regarded as valid species; the other nominal forms being only offshoots, intermediate subspecies or varieties, based upon slight modifications of the very plastic secondary genital organs of the males.

\section{Pyrgoconypha Stål, 1873a, 50. (Gr., "tower" + "head.")}

Rather robust species of medium size, having the fastigium prolonged, triquetrous, acute, flat above and with a prominent hasal tooth on the lower side; eyes small, prominent; antennae very slender, about as long as body; pronotum with disk flat, front and hind margins subtruncate; lateral carinæ obtuse; lateral lobes perpendicular, longer than deep, their front margin broadly obliquely rounded into the lower one, this short, oblique, its posterior angle obtuse, hind margin broadly rounded; humeral sinus broad and deep; tegmina elongate, their tips rounded; front and middle femora armed beneath with three to five spines on outer margin; hind femora slender with numerous spines on both lower margins; all the tibia armed beneath with numerous slender spines; meso- and metasternal lobes triangular, acute. Cerci of male stout, subcylindrical, curved, each ending in two claw-like appendages, these flattened, strongly incurved and ending in a sharp spine. Ovipositor slender, straight, acute, of nearly equal width throughout, not reaching tips of tegmina.

Kirby (1906, 239) recognized nine species, distributed throughout the world, only one of which inlabits the United States.

233. Pxrgocorypha uncinata (Harris), 1841, 132. Hook-faced Cone-head.

Green or pale reddish-brown; mandibles black; tegmina with numer ous widely scattered, minute black dots. Fastigium elongate-triangular, about as long as occiput, flat and very rugose above, its tip ending in a minute, sharp decurved spine. Disk and lateral lobes of pronotum strongly rugose-punctate. Hind femora short, reaching slightly beyond 
middle of tegmina. Other characters as given under the generic heading. Length of body, $\hat{o}, 32-34$, $\stackrel{\imath}{3} 35-42$; of fastigium beyond eye, $\hat{o}, 3.5-$

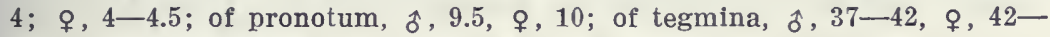
46 ; of hind femora, $\hat{\delta}, 18$,,+ 20 ; of ovipositor, $19-21.5 \mathrm{~mm}$.

Gainesville, Miami, and Cape Sable, Fla., Sept. 24-Feb. 23. The Miami specimens from the Daris collection are labelled: "This and eight or ten others eating grass at night." It does not appear to be widely distributed in Florida, having been recorded only from Miami, Marco, Chokoloskee, Everglade and Charlotte Harbor, all in the southern third of the State. Daris states that their song resembles $a z i k$, azik, azik, azik, and that they are very sly when singing and difficult to capture. At Charlotte Harbor Hebard says $(1916,20)$ "They were heard on May 19 and 20 everywhere after dark on Useppa Island, singing in the tops of the cabbage palmettoes, where they were usually located in the berry clusters. A few were also heard in the undergrowth of the heavier tangles and in mangroves on the edge of the swamp. While singing the males were very wary when approached, usually ceasing their song at a distance of 15 or more feet. The insect is slow in movements, elinging tenaciously to its support and easily seized if approached cautiously." The Cape Sable specimen, taken on Feb. 23, was a nymph of the third instar.

The wariness of $P$. uncinata mentioned by Daris and Hebard was not noted by Allard who captured a single male in stridulation at Thompson's Mills, Ga., in October. He says (1911b) "The insect was traced by its note to the low grass and weeds on a bank almost in the midst of the settlement. By the strong light of a bull's eye lantern the writer approached within a foot or two of the insect which continned to stridulate vigorously for some time, eren though in the full glare of a strong light. After its notes had ceased, the insect at intervals jerked its body and wings sjasmodically without producing any sound. This peculiar behavior is characteristic of a number of species of Conocephalus when disturbed during stridulation. On the grass and weeds rery near where this male was taken, the writer a night or two before heard sereral locusts in stridulation, presumably individuals of $r$ uncinata. As the notes of these insects were heard but one or two nights, it is possible that their stridulation period is rery

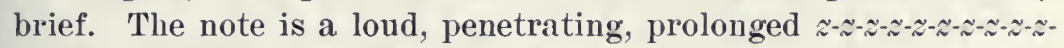
$\approx-\approx-z-\approx$ quite like that of a Conoccphalus."

The type of Harris was from Alabama and the species is known to range from Clarksville, Tenn., and Raleigh, N. Car., west 
and sonth to Arkansas, Texas, Cuba, Mexico and Central America, thongh very few records of its occurrence in the United States have been made.

III. Neoconocephalus Karney, 1907, 22. (Gr., "near" + Conocephalus.)

This generic name takes the place of Conoccphalus of my Orthoptera of Indiana $(1903,363)$. The members of the genus are readily known by having the fastigium of vertex prolonged forward and more or less upward into a cone which much exceeds in length the first segment of the antennæ, and bears a pointed basal tooth beneath. This cone is never hooked downward at tip as in Pyrgocorypha and is much less rugose above than there. In addition they have the eyes small, subrotund, rather prominent; spines of prosternum long and slender; pronotum with disk usually nearly twice as long as wide, its sides feebly diverging from apex to base; front margin subtruncate, hind one broadly rounded, lateral carinæ distinct but obtuse, humeral sinus usually broad, shallow, rounded; lateral lobes as deep or slightly deeper than long, their front margin broadly obliquely rounded into the lower one which is short and also rounded into the hind one, the posterior angle usually obsolete; tegmina long, narrow, rounded at end, much surpassing the abdomen and slightly exceeding the wings; stridulating organ on left tegmen of male opaque and of a coarse texture, on right or lower one, transparent at the center; front and middle femora rather short, usually armed beneath with a few very short spines; hind femora long. slender, usually with both lower margins armed beneath with numerous fine spines. Male with supra-anal plate broadly emarginate at apex, the lobes each side of notch ending in a spine; rerci much as in Pyrgocorypha, the appendages at end not flattened, but incurved and spinose as there; subgenital plate emarginate, the styles very short and set in sockets on the extreme tips of the projections each side of notch. Ovipositor rather narrow, nearly straight, oftentimes of excessive length; the eggs of those species in which the oviposition has been noted, being deposited between the stems and root leaves of grasses, reeds and sedges.

Althongh these larger cone-heads are said to be rather common by those writers who have prepard lists of Orthoptera from other states, they appear to be, in Indiana, the least abundant of all the winged 'Tettigoniidae, 20 years collecting having vielded fewer than 30 specimens. They appear to be more common in 
the northern than in the southern half of the State. As in Belocephatus the color is dimorphic, green and brown forms of most of the species being known, the former largely predominating.

Of the habits of the species as found in Illinois, McNeill (1891) has written: "All the species of Conocephalus seem to possess more intelligence than is usual among the Orthoptera, and they are about the most difficult of the order to approach. In escaping they usually slip or fall into the grass instead of jumping or flying; but they seem to fully understand that they are very well protected by their color and form. If approached very cautiously they often remain quite still upon the stem of grass upon which you have surprised them with the usually well founded expectation that you will not be able to distinguish them from the green herbage around. If they think it worth while to make some active movement to escape they will frequently slip around on the other side of the stem and walk down the stem to the ground or off upon another plant. Unlike most Orthoptera they do not use their front legs in holding to the mouth the thing upon which they feed. Instead of biting they seem to wrench or tear away pieces from the stems or leaves."

Allard (1910c) says: "The stridulations of the species of Neoconocephalus, like the notes of all the Locustidae, entirely lack any musical tone or trill so characteristic of the crickets. Their notes are always loud, buzzing and penetrating, and differ not so much in sound-quality as in the manner of delivery. The notes of all species may be definitely classed as intermittent or prolonged. These insects are almost strictly terrestrial, are persistent singers, and most species stridulate most actively at night."

Redtenbacher, in his monograph (1891), recognized 101 species of Conocephalus from all parts of the world. Scudder $(1900,72)$ listed $16 \mathrm{from}$ the United States. Under the generic name Conocephaloides Kirby $(1906,241)$ recognized 143 sprecies of the insects. Karney $(1907,22)$ proposed a number of subgenera for this aggregation and in 1912 elevated his name Neoconocephalus to generic rank, the older names Conocephalus and Conocephaloides having been shown to belong rightfully to other groups of 'Tettigoniidae. Rehn \& Hebard, in their Synopsis (1915) recognized only 11 species and one variety from America north of Mexico, all of which occur in the territory covered by this work.

KEY TO AMERICAN SPECIES OF NEOCONOCEPHALUS.

a. Fastigium or cone of vertex distinctly longer than wide, its apex not broadly and evenly rounded.

b. Fastigium narrowing rapidly from near base or middle to apex. 
much longer than its basal width, its tip (except in melanorhinus) narrowly rounded (Fig. 169, $a-e_{\text {. }}$ )

c. Lower surface of fastigium in part or wholly black.

d. Both lower margins of hind femora armed with spines; under surface of fastigium almost wholly shining black (Fig. 169, $a-d$.)

e. Larger and more robust, length of body, female, 38 or more $\mathrm{mm}$.; of fastigium of female in front of eyes, 5.3 or more $\mathrm{mm}$.

234. EXILISCANORUS.

ee. Smaller and more slender; iength of body, female, less than $36 \mathrm{~mm}$; of fastigium rarely more than $4.5 \mathrm{~mm}$.
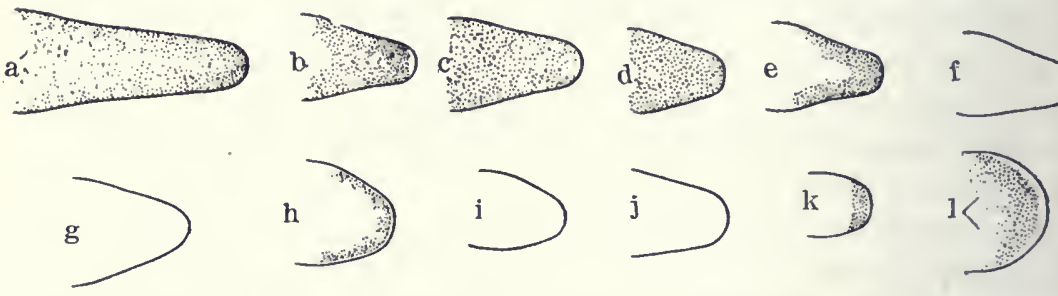

Fig. 169. Ventral views of fastigium of males of Neoconocephalus. $X$ 6. a, exiliscanorus; $\mathrm{b}$, nebrascensis; c, lyristes; $\mathrm{d}$, melanorhinus; e, ensiger; $\mathrm{f}$, robustus; $\mathrm{g}$, crepitans; $\mathrm{h}$, caudellianus; $\mathrm{i}$, palustris; $\mathrm{j}$, velox; $\mathrm{k}$, retusus; 1 , triops. (After R. \& H.)

$t$. Ovipositor distinctly longer than hind femora; tip of fastigium narrowly rounded (Fig. 169, b, c.)

g. Ovipositor surpassing tips of tegmina $5-7 \mathrm{~mm}$; form of male siightiy more robust; fastigium usually slightly depressed above. 235. NEBRASCENSIS.

gg. Ovipositor not surpassing tips of tegmina; form of male more slender; fastigium subcylindrical, usually slightiy longer, more attenuate. 235a. LYRIsTEs.

ff. Ovipositor shorter than hind femora; fastigium about twice as long as its basal width, its tip subtruncate (Fig. 169, d.)

236. MELANoRHINUS.

$d d$. Under surface of fastigium with only the sides and tip black

(Fig. 169, e); usualiy the inner lower carina of hind femora alone armed with spines; ovipositor longer than hind femora.

237. ENSIGER.

cc. Lower surface of fastigium without black markings; form robust; both lower margins of hind femora usually spinose; ovipositor about as long as hind femora. 238. RoBUstus.

$b b$. Fastigium narrowing but little if at all from near base to apex, its tip rounded or subtruncate (Fig. 169, $g-l$.)

$h$. Ovipositor but little if any shorter than hind femora; form robust.

$i$. Lower surface of fastigium immaculate. 238a. CREPITAxs.

ii. Lower surface of fastiglum with black margins (Fig. 169, h.) 239. CAUdELliaNus.

$h h$. Ovipositor distinctly shorter than hind femora; form more slender; under surface of fastigium immaculate (Fig. $169, i, j$.) 
j. Length of hind femora, male, 15.2-19.4 mm.; male smaller, less slender; tip of vertex less broadly rounded; lower carinæ of hind femora darker near bases of spines.

240. PALUSTRIS.

jj. Length of hind femora $22.5-25.7 \mathrm{~mm}$.; male larger, form very slender; tip of vertex more broadly rounded; lower carinæ of hind femora immaculate.

241. VELOX.

aa. Fastigium of vertex not or but very slightly longer than wide, its apex broadly, evenly rounded, and lower surface with a black mark near tip (Fig. 169, $k$, l.)

$k$. Ovipositor much longer than hind femora; form slender; vertex slightly longer than wide, convex above (Fig. 169, $k$ ); tegmina surpassing hind femora less than $11 \mathrm{~mm}$. 242. RETUsus.

$k k$. Ovipositor but slightly if any longer than hind femora; form more robust; vertex usually wider than long, almost flat above (Fig. 169, l); tegmina surpassing hind femora 15 or more $\mathrm{mm}$.

243. TRIOYS.
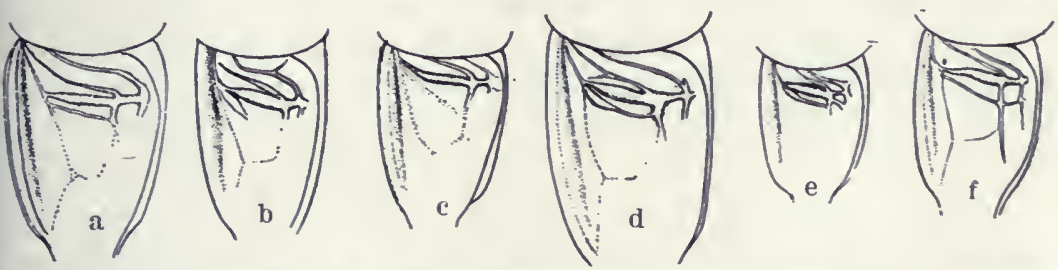

Fig. 170. Stridulating fields of male tegmen of Neoconocephalus. $X 3$. canorus; b, lyristes; c, ensiger; d, caudellianus; e, palustris; f, retusus. (After R. \& H.)

234. Neocoxocephalus exiliscaxorus (Davis), 1887, 57. Slightly Musical Cone-head.

Size large for the genus, form moderately robust. Pea-green tinged with yellowish on head, pronotum and fore femora, or brown with tegmina irregularly dotted with fuscous spots; the green individuals with a narrow yellowish line along the lateral carinæ of pronotum, this absent on occiput but present on lateral margins of fastigium; also often with a short and very narrow oblique yellowish line behind each eye; mandibles yellow; tarsi and apical joints of palpi more or less infuscated. Fastigium very prominent, extending $5-7.5 \mathrm{~mm}$. in front of eyes, subdepressed and with a slight median furrow on basal half, gradually tapering from base forward, its apical half curved slightly upward, the apex narrowly rounded; lower basal tooth small, blunt. Pronotum subequal in length to fore femora, of more than average breadth; lateral carinæ evident but dull, hind margin broadly rounded; lateral lobes flaring noticeably outward rather than perpendicular as in most of the other species, their surface slightly rugose. Tegmina reaching slightly beyond middle of ovipositor, their basal third rather broad, apical two-thirds tapering very gradually to the rounded apex. Stridulating organ of male large, very broad, the main vein long, moderately swollen (Fig. 170, a.) Wings equalling the tegmina in length. Fore and middle femora short, stout, usually armed beneath on front carina with a few very short spines. Hind femora rather short, slender, armed beneath on each carina with 5 to 9 small but sharp spines. Hind tibiæ slightly shorter than the femora. Ovipositor 
slender, of more than average length and nearly equal width throughout. Length of body, $\delta, 33-37$, ㅇ, 38-44; of fastigium, $\delta, 4.2-6.1$, ․, 5.37.5 ; of pronotum, $\delta, 7.6-9$; $\$, 7.9-9$; of tegmina, $\delta, 33.5-46.4$, ㅇ, $40-$ 53 ; of hind femora, $\delta, 19.3-24.8$, $९, 24-32$; of ovipositor, $35-47 \mathrm{~mm}$. (Fig. 171.)

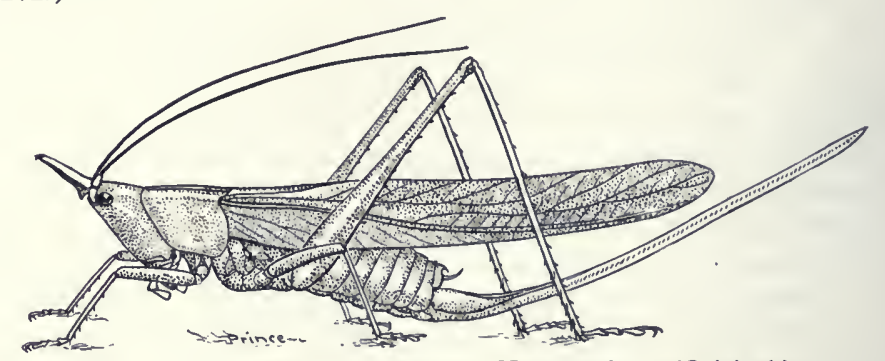

Fig. 171. Female. Natural size. (Origina1.)

New Harmony, Ind., September. Staten and Long Islands, N. Y., August, (Davis.) The only known Indiana specimen of this large, long-headed Tettigoniid is the female type of my Conocephalus bruneri (1903, 367) taken at New Harmony, Posey Co., by the late Arthur Dransfield. Not being able to identify it by the literature available, it was sent to P'rof. Lawrence Bruner, who wrote me that it was evidently an undescribed form. Karney $(1907,30)$ first placed it as a synonym of cxiliscanorus and comparison with State Island females of that species shows that lie is probably correct, though the Indiana specimen is distinctly larger and with longer fastigium than any of those received from I)avis.

The types of Daris were found amongst the cat-tails that grew on the salt marshes of Staten Island, and it ranges along the Atlantic coast from New Haven, Conn., to Raleigl, $N$. Car., and Mississippi, and inland to Clarksville, Tenn., Thompson's Mills, Ga., and Dallas, Texas. Of its habits Davis (1S87) says: "This insect keeps very close to the ground, hiding well in the vegetation, and is not easily discovered. The sound produced when stridulating is very faint, not louder than that made by Gryllus abbreviatus and I was much surprised to hear such a faint song flom so large an insect. I lhave in consequence named it the 'slightly musical Conocephalus.'" Later (1SS9) he adds that "exiliscanorus devours the heads of the meadow grass (Spartina) and is such a slow singer that one can easily estimate the number of times one wing is drawn over the other, which is about 115 times a minute." Again (1911) he says that the song varies considerably in loudness according to the age of the singer, while its volume is also to some extent dependent upon the temperature. 
About Tappahannock, Va., Fox found it "frequent between August 9 and September 10 in tidal marshes occurring most commonly in tall reeds, Spartina cynosuroides (L.) but spreading in small numbers through the briery thickets and corn fields of the adjoining dry land."

R. \& H. $(1915,374)$ state that the song of $N$. exiliscanorus

"Is a ziit-ziit-ziit-ziit-a vibrant rattling note, rising and falling in intensity, often ceasing as if from exhaustion. The song is rapid, the sounds being emitted on warm evenings about three to the second. When near a colony of this species on favorable evenings after dark the air is vibrant with the sound; as several singers cease others take up the constantly rising and falling song, but at no very great distance the sound is inaudible. The insects were found not to begin to sing until nearly sunset and before dark often ceased their song upon any attempt to approach the spot After dark the singing was much more vigorous and the singers could then even be approached with a light, cautiously seized while singing and moving about in the bushy weeds and heavy grasses into which they climbed while stridulating. Toward midnight, after the air is chilled, the singers become audibly fewer and their stridulations less intense. The species is found very local but often in large numbers in the heavier tangles of weeds, low bushy plants or heavy reeds in both fresh and salt water marshes. The females were found often in grasses near the singers; one was taken ovipositing in a grass blade at dusk."

235. Neoconocepiralus Nebrascexsis (Bruner), 1891, 72. Nebraska Cone-head.

Size median, form slender. General color either bright grass green or a yellowish brown or tan with usually narrow yellowish lines along lateral carinæ of pronotum; antennæ in the brown individuals often tinged with pinkish; hind tibiæ together with all the tarsi more or less infuscated. Fastigium slender, as long as occiput, male, distinctly longer, female, projected upward, moderately tapering, its tip narrowly rounded, under surface shining black. Fronotum with disk narrow, lateral carinæ almost parallel, hind margin rounded, surface rugose-punctate, humeral sinus rather deep and narrow. Stridulating field of male tegmen large, broad, very similar to that of $N$. r. crepitans. Femora armed beneath as in exiliscanorus. Anal cerci of male stout, with strong internal books. Ovipositor long, slender, lanceolate, a little curved upward and extending 5 $-7 \mathrm{~mm}$. beyond the closed tegmina. Length of body, $\delta, 27-30, \%, 32-$ 33 ; of fastigium, $\hat{o}, 3.2-3.5$,,$+ 3.7-4$; of pronotum, $\hat{o}, 7.6-8,8,7.2-$ 8 ; of tegmina, $\hat{\delta}, 36-38$, ㅇ, $40-42$; of hind femora, $\hat{o}, 20-23, \stackrel{+}{,}, 23-$ 24.7; of ovipositor, $29-32.5 \mathrm{~mm}$.

Putnam, Vigo, Fulton and Lake Counties, Ind. (W.S.B.); Moline, Homer, Savanna and Normal, Ill. (Urbana coll.) In central and northern Indiana this is the most common of the three species of Neoconocephalus there occurring. It frequents the same haunts as $C$. ensiger and when approached often attempts to escape by burrowing beneath the fallen grass. In Nebraska 
Bruner (1891) says it is found throughout the eastern part of the state, occurring more frequently in the natural groves growing along the principal streams.

The known range of typical nebrascensis extends from Sarnia, Ont., and Ohio west to Minnesota, eastern Nebraska and northeastern Kansas and south and west to Clarksville, Tenn., and St. Lonis, Mo.

Walker (1904a, 338) states that at Sarnia, Ont., by tracing their song to its source, he found four males on August 12 in a large stretch of open grassy marshland bordering the St. Clair River. "The song was a loud penetrating continuous whirr, quite suggestive of the dog-day cicada, but less clear and very unlike that of $N$. ensiger. It was heard only in the morning during bright sunlight."

235a. NeoconocepHalus Nebrascensis LYRIStes (Rehn \& Hebard), 1905, 45.

Differs from typical nebrascensis by the characters given in key, the males separable only by their slightly less robust form, and in having the stridulating field more narrow and elongate, the secondary veins heavy only at junction with the primary one (Fig. 170, b.) Fastigium variable both in length and breadth, in extremes in females extending $5 \mathrm{~mm}$. beyond the eyes. Ovipositor ranging in length from 23 to $30 \mathrm{~mm}$. but not surpassing the tegmina in any of the specimens seen; in New Jersey females somewhat stouter with apical fourth usually more tapering than in typical nebrascensis from Indiana. Length of body, $\hat{o}$ and $\$, 28-35$; of fastigium, $3.7-5$; of pronotum, $7.2-8.8$; of tegmina, $\hat{\delta}, 35.7-42.4$, $ᄋ$, $44-52$; of hind femora, ô, 20-24, ㅇ, 23-26; of ovipositor, $23.3-30.7 \mathrm{~mm}$.

After studying at Philadelphia the types of both forms and comparing with them Indiana specimens of what Bruner named for me as nebrascensis and New Jersey, Virginia and Florida specimens of what is known as lyristes, I have placed the latter as the eastern and southern representative or race of nebrascensis. No fixed character of specific importance has been given separating the two. Rehn (1906b) says the males differ in that nebrascensis "is of a more robust build, with broader tegmina, wider and more arcuate tympanum, more expanded caudal section of pronotum and deeper lateral lobes of the same;" all of which characters are comparative only and fall within the limits of individual variation as shown by the specimens examined. $R$. \& $H$. in their key $(1915,369)$ separate the two only by the terms "form robust, vertex slender," nebrascensis and "form slender, rertex heavy," lyristes. In their later treatment they do not compare lyristes with nebrascensis, but only with melanorhinus, a species with much shorter fastigium and ovipositor. Daris (IIs.) states that 
he was unable to separate the males from Indiana and New Jersey except by the labels they bore, and Fox (Ms.) says that the only differences he could find in both sexes was the slight one afforded by the fastigium.

The type of lyristes was a male labelled "Chokoloskee, Fla.," a locality which R. \& H. (1915, 384) seriously question, but which is borne out by a Palm Beach female at hand, which agrees in all particulars with the type and New Jersey specimens except in color, it being a nearly uniform purplish-brown instead of green and in its having a slightly longer and more slender fastigium.

The known range of the race lyristes extends from Long Island, $\mathbf{X}$. Y., and various points in New Jersey, soutliwest to Tappahannock, Va. It is also known from the type locality and Palm Beach, Fla., but not from intervening points from Virginia southward. R. \& H. $(1915,381)$ state that lyristes is "locally common in New Jersey in bogs, fresh water marshes and in the coastal salt water-marshes in areas of Scirpus and high marsh plants near the mainland, but never out on the tidal flats where melanorhinus occurs. It has nowhere been found more than a few miles from the seacoast. * * The song is a high-pitched continuous buzzing, very much like that of $N$. retusus, but distinctly longer." 236. Neocoxocephalus meraxorhixus (Rehn \& Hebard), 1907, 304. Black-nosed Cone-head.

Size small for the genus; form rather robust. Green or smoky brown with sides of fastigium and lateral carinæ of pronotum yellowish, sides of tarsi brown; dark form often with a narrow shining purplish-brown stripe on upper fourth of lateral lobes, this extending back along the principal veins of tegmina. Fastigium as described in key, narrowed

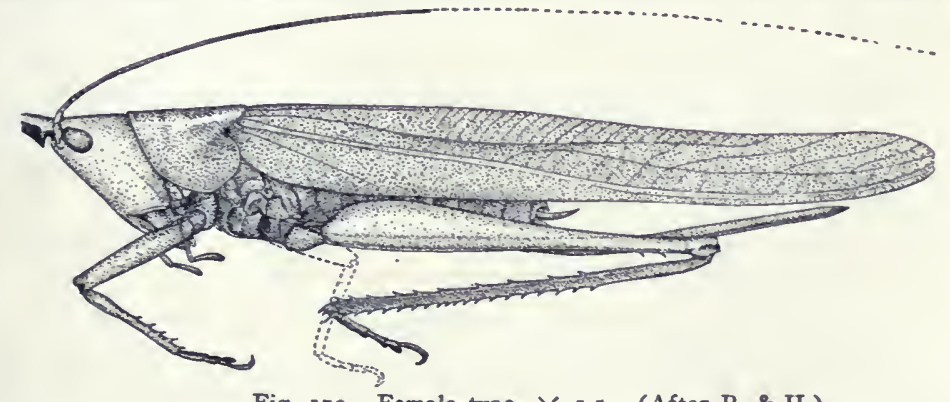

Fig. 172. Female type. $X$ I.5. (After R. \& H.)

from the middle forward, its upper surface sparsely punctate and with a fine median groove. Antennæ but little longer than the hind femora. Pronotum with lateral carinæ distinctly but feebly divergent backward, surface coarsely and closely punctate; lateral lobes slightly longer than deep, their lower margin oblique, its angle obtuse. Tegmina surpassing the hind femora about one-third their length, cross-veinlets prominent, 
tips narrowly rounded. Front and middle femora unarmed beneath. Hind femora rather short, inner lower carina armed beneath with three to eight slender spines, outer one usually unarmed. Median notch of subgenital plate of male, broad, the styles hirsute, longer and stouter than in allied species. Ovipositor rather wide, almost straight. Length of body, $\hat{\delta}, 28$, ㅇ, 32-35; of fastigium, $\hat{\delta}, 2.6-2.8$, ㅇ, 2.9-3.1; of pronotum, $\hat{o}$, $6.9-8.5$, ㅇ, $6.7-8$; of tegmina, of $29.3-37.5$, $9,35-47.5$; of hind femora, ô, 17.5-21.5, ㅇ, 19.3-27; of ovipositor, 16.3-22.8 mm. (Fig. 172.)

Tuckerton and Cape May, N. Jer., Aug. 21-Sept. 1 (Davis); Ocean View, N. Jer. (Fox). A submaritime species described from a single female taken at Cedar Keys, Fla., but not elsewhere recorded from that State. Ranges from New Jersey along the Atlantic coast to Virginia and probably to Florida. Davis $(1913,177)$ took the first known male Sept. 1, 1907, at Tuckerton, N. Jer. R. \& H. $(1915,378)$ give an account of the habits of melanorhinus as follows:

"This species was found in large numbers on the salt marsh tidal flats of New Jersey in areas of the salt meadow-grass, spartina patens (Ait.), growing near one foot in height, but it was also found there rather abundant in areas of the low marsh spike-grass, Distichlis spicata (L.). When first met with in the summer of 1914, the males of a large colony were stridulating vigorously early on a somewhat cloudy afternoon; the song was a weak, high-pitched continuous buzzing, giving much the same vibrating resonance as a bit of rubber stretched in the wind. The note was very much weaker, richer in quality and less harsh than that of $N$. robustus. During daylight the singers invariably seemed further away than was the case, and time and again specimens were passed over until this fact was realized. At night the song was somewhat louder and very similar to that of $N$. lyristes, almost inappreciably higher pitched and more strident. When an individual was alarmed while singing the note ceased abruptly, the singer dropping or leaping to the ground and there remaining motionless, perfectly concealed. $* * *$ The abundant green color-phase of this insect blends perfectly with the broader green leaves of Spartina patens, while the brown individuals of pale to very dark shades blend as perfectly with the brown and yellowish bases of the same plant and the bare dark muck beneath. The insects were seen to fly but short distances while singing individuals were observed to be resting motionless on the grass or climbing nervously about."

237. Neoconocephalus ensiger (Harris), 1841, 131. The Sword-bearer.

A species of small size and slender form. Green, rarely brown, often fading to dull yellow in drying; margins and tip of lower face of fastigium black, the tooth green; lateral carinæ of pronotum often yellow; tarsi, hind tibiæ and tip of ovipositor sometimes darker. Fastigium slender, slightly constricted in front of eyes, narrowed from the middle forward (Fig. 169, e.) Pronotum with lateral carinæ feebly divergent, disk finely punctate; humeral sinus shallow, very broadly rounded. Tegmina long and narrow. Stridulating veln of male long, feebly swollen (Fig. 170, c.) Front and middle femora usually unarmed. Length of body, ô, 24-26, 
९, 28-30; of fastigium, $\hat{\delta}, 3$, , $3.2-3.5$; of pronotum, $\hat{\delta}$ and $ᄋ, 7-7.5$; of tegmina, $\hat{\delta}, 37-42$, ․, 44-48; of hind femora, $\hat{o}, 20-21, ㅇ, 22-23$; of ovipositor, 27.5-33 mm. (Figs. 173, 174 and Pl. V.)

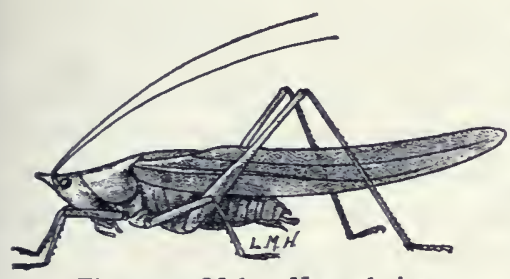

Fig. I73. Male. Natural size. (After Lugger.)

This is a rather common cone-head in northern Indiana, where it frequents the tall grasses along ditches and the borders of damp prairies. In the central and southern counties it is more scarce. Its known range extends from Norway, Me., west and north across southern Ontario to Bismark, N. Dak., and Julesburg, Col., and south and sonthwest to $\mathrm{N}$. Carolina, Tennessee, Kansas and New Mexico. It is therefore the most widely distributed species of the genus in the United States. The female of ensiger has been recorded as depositing her eggs between the stem and the root leares of Andropogon, a genus of tall coarse grasses which grow in dry, sandy localities. The young. hatched in May, reach maturity in central Indiana about July 10, though an adult male was taken in Vigo Co. on June 8 .

Scudder, who has set the note to music, says of the song $(1874,368)$ : "This insect has but a single song and stridulates only by night, or during cloudy weather. It begins its song as soon as the sky is obscured or the sun is near the horizon. It commences with a note like $b r w$, then pauses an instant and immedi-

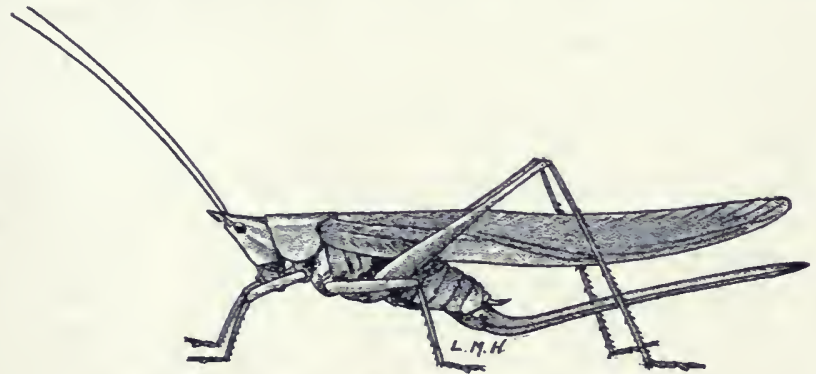

Fig. 174. Female. Natural size. (After Lugger.)

ately emits a rapid succession of sounds like chui at the rate of about five per second, and continues them for an unlimited time. Davis (1887) likens its note to the srllable ' $i k-i k-i k$;' as if sharpening a saw, enlirening the low bushes, and particularly the cornpatch, as it seems to especially delight in perching near the top of a cornstalk and there giving forth its rather impulsive song."

Walker (1904a, 337) mentions ensiger as "a very common in- 
sect in Ontario, ranging northward about as far as Muskoka and the Bruce Peninsula. It frequents fields, vacant lots and roadsides, which resound at night with the incessant monotonous song. During the summer and autumn * * * I have occasionally heard it stridulating in bright sunshine in the afternoon. It is the most easily approached of all our locustarians while thus engaged and is in fact difficult to find in any other way, hence the females are but seldom seen. Although it usually perches upon tall weeds, I have occasionally traced its song to a tree or vine, the insect being sometimes stationed at a considerable height."

Allard (1911) says that in September near Oxford, Mass., ensiger is a very common species in all upland localities where it "prefers the fresh herbage of cultivated fields and is especially to be looked for in fields of corn. One oftentimes finds a noisy singer perched six or seven feet from the ground on a corn stalk $\mathrm{or}^{2}$ tassel. One also sometimes meets with it in large colonies among the luxuriant weeds and grasses of the lowlands. Its call notes are intermittent and follow each other rather brisklytsip-tsip-tsip-tsip. They are rather soft and lisping, recalling to mind the staccato lisps of an Orchelimum."

R. \& H. (1915, 355) have placed the Conocephalus attenuatus Scudder $(1872,249)$ as a synonym of $N$. ensiger.

238. Neoconocephalus robustus (Scudder), 1862, 449. Robust Conehead.

Size large, form robust. Pale green, rarely brown; fore and middle legs, hind tibiæ and tarsi and under surface greenish-yellow; sides of fastigium and lateral carinæ of pronotum yellowish; antennæ pale reddishyellow. Fastigium with under surface immaculate, ${ }^{86}$ about as long as occiput, distinctly narrowed from middle to apex, its upper surface convex, tip narrowly rounded (Fig. 169, f.) Pronotum with lateral carinæ distinctly divergent, more strongly so in male, hind margins broadly rounded, surface finely punctate; lateral lobes almost as deep as long their lower margin oblique, obtusely angulate; humeral sinus shallow, broadly rounded. Tegmina broader than in allied species, surpassing hind femora about $13 \mathrm{~mm}$. Stridulating field of male large, its main vein heavy. Fore and middle femora either unarmed beneath or with a few small spines. Hind femora long, slender, armed beneath with three to 12 rather short spines on each carina. Length of body, $\hat{\sigma}, 30$, $q, 31-37$; of fastigium, $\delta, 2.7-3.6$,,$+ 3.1-3.7$; of pronotum, $\hat{\delta}, 8-9.9,9,7.3-8.3$; of tegmina, $\hat{o}, 40-48$, ㅇ, $43-54$; of hind femora, ô, $23-28$, 우, 24-28; of ovipositor, $25-31 \mathrm{~mm}$. (Fig. 175.)

\footnotetext{
${ }^{67}$ This is true of all the specimens at hand and R. \& H. (1915, 387) say that the vertex is always immaculate, but Scudder, in his original description, loc. cit., says of the type: "tubercle of the vertex tipped with black, not extending or but very faintly anil narrowly, down the sides."
} 


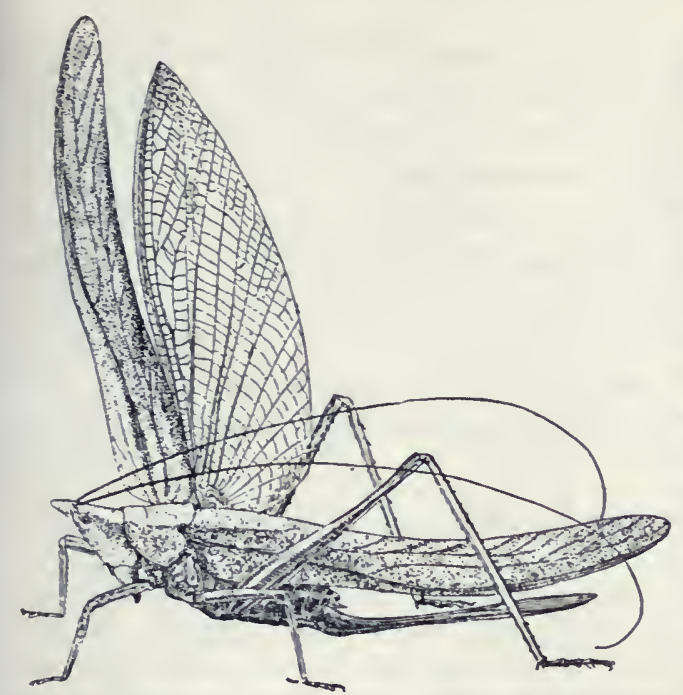

Laporte Co., Ind., Oct. 15. Woodhaven, Long Island, N. Y., August (Davis). This is a xerophytic species, inhabiting sandy districts and is known only from along the Atlantic sea coast from Cape Cod. Mass., to Charlottesville, Va., and along the shores of the larger inland lakes. In Indiana it is known definitely only from Laporte county where it occurs Fig. 175. Female. Natural size. (After Beutenmüller.) quite frequently along the shores of Lake Michigan. R. \& H. $(1915,390)$ state that typical robustus has not been taken over 60 miles from the coast, and without seeing the Laporte Co. specimens have assigned them to N. robustus crepitans; but they are identical in form of fastigium. size and all other characters with Scudder's type at Cambridge and with specimens from Long Island sent me by Davis as typical vobustus. They also fully agree with the key and description of $\mathrm{R}, \mathrm{E}$. of that form.

Scudder $(1874,376)$ describes the note of robustus as heard in New England thus: "This insect is exceedingly noisy and sings equally, and I believe similarly, by day and night. The song resembles that of the harrest fly, Cicada canicularis. It often lasts for many minutes, and seems, at a distance, to be quite uniform. On a nearer approach one can hear it swelling and decreasing in rolume * * * and it is accompanied by a buzzing sound, quite audible near at hand, which resembles the humming of a bee $0^{\circ}$ the droning of a bag-pipe."

Daris $(\mathbf{1 8 5 7}, \mathbf{5 T})$ says that on Staten Island $\mathrm{N}$. robustus "resides for the most part mid the grass on sandy ground near the sea shore, though an occasional individual finds its way inland. Along the sea beach they stridulate in early afternoon, especially if slightly cloudy, and when approached they have a curious fashion of dropping to the ground. I have often found them on such occasions actually standing on their heads in the soft sand. leaning against the grass stems which grow so close together 
without in any way holding on to them. Whether this position is intentional or not, I cannot say, but certain it is that when looked for from above they offer the smallest extent of their bodies to view and may thus escape many enemies."

Hart (1907) records robustus as occurring on waste sandy land iis central and southern Illinois, and has observed them resting, head downward, on a green stem, thus elosely resembling a grass leaf. At Tappahannock and Charlottesville, Va., Fox (1917) found robustus frequent on dry land or at the borders of tidal marshes, occurring on tall grasses and herbage in fields, pastures and roadsides.

238a. Neocoxocephalus robustus crepitans (Scudder), $1862,450$. Crepitating Cone-head.

Size very large for the genus; form very robust. Color of robustus, the brown form more often found than there. Differs mainly in the shape of the fastigium which is distinctly broader, but feebly narrowed on apical third, and with tip bluntly rounded (Fig. 169, g.) Disk of pronotum broader, that of female with lateral carinæ parallel or nearly sonot feebly divergent as in robustus. Hind femora proportionally longer, with spines of lower carinæ longer and more slender. Length of body, $\hat{\delta}, 38$, ㅇ, 40; of fastigium, ô, 2.7-3.6, ㅇ, 3-3.8; of pronotum, ㅅ․ $8.2-$ 10.8 , 오 8.3-9.3; of tegmina, ô, 39-53, 우, 49.4-58.4; of hind femora, ô, 22.8-31, 우, 28.8-35.1; of ovipositor, $27-36.9 \mathrm{~mm}$.

Vigo Co., Ind., Aug. 8, one male; St. Louis, Mo.; Sedgewick Co., Kansas, Angust, taken at electric light by E. S. Tucker. In addition to the single Vigo Co. male this form is known from Indiana only from Lake Maxinkuckee (R. \& H., 1915, 394) and from Tippecanoe County, where Fox (1915) took two specimens in the corn plats of Purdue University farm on August 26.

In Florida it has been recorded from Warehard, Lery Co., Atlantic Beach, Hastings and Fort Barrancas. Scudder's types of crepitans were from Texas and Nebraska and its range is given by R. \& H. (1915, 392) as extending from "extreme southern New Jersey over the entire coastal plain of the southeastern United States as far south as Hastings, Fla. Westward it is widely distributed over the entire Mississippi Valley region as far as White Bear Lake, Minn.; Garden City, Kan.; Clarendon and Cisco, Texas, and Nugent, Miss." They state $(1915,389)$ that in the vicinity of Ocean View, $\mathbf{N}$. Jer., and on the Delaware River near Philadelphia intergrading specimens between $N$. rolustus and $N$. crepitans oceur and on the basis of this intergradation they place crepitans as a race of robustus.

Davis $(1913,178)$ states that at Erma, N. Jer. the song of crepitans (so-called by R. \& H.) "while it consisted of the same 
continuous whirr as in robustus, was not nearly so ear-splitting." Commenting on this R. \& H. $(1915,390)$ attribute the difference to possible climatic conditions and state that "in the west, in the center of its typical distribution, we have heard it singing with the full burring, buzzing whirr which is characteristic of and fully as loud as, the song of typical robustus."

239. Neocoxocephalus Caudelliaxus (Davis), 1905, 289. Caudell's Cone-head.

"A robust species, either green or brown, the tegmina often flecked with black. Fastigium obtuse, its sides with a faint yellow line, beneath which there is a black line extending from the base to the base of the antenna, or nearly so; lower basal tooth blunt but distinct. Anterior and middle femora unarmed beneath; posterior femora armed beneath on both carinæ with numerous spines." (Davis.) "Closely resembles $N$. robustus but the vertex very decidedly shorter with the sides usually very weakly convergent distad and apex rotundato-truncate, more so than in typical robustus crepitans. Stridulating field of male slightly more elongate with veins heavier than in robustus (Fig. 170, d.) Green color distinctly richer than in that species." $(R . \& H .1915,395$.$) Length of body, \hat{\delta}, 33$; of fastigium, $\hat{\delta}, 2.4-3.3$, $\uparrow, 3.1-3.2$; of pronotum, $\hat{\delta}$ and $\uparrow, 8-8.9$; of

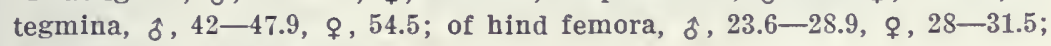
of ovipositor, $33-35.4 \mathrm{~mm}$.

Jamesburg, Cold Spring and Erma, N. Jer., Aug. 16-Sept. 18 (Daris.) The known range of this species extends from New Jersey to Atmore, Ala., but it appears to be nowhere very common. The three male types were found in a cranberry bog at Lakehurst, N Jer., and of them Daris says: "The song is a slow zip-zip-zip. repeated many times and much resembling that of Conocephalus exiliscanorus of the salt meadows." No females were found until 1910, when two were taken by Davis (1911) at Cold Spring, N. Jer. Of males taken near Tuckerton he wrote: "Ther were in a diy field and some of them, when disturbed, flew several hundred feet and lit in cedar trees. This was an unusual proceeding for they generally seek safety by dropping to the ground and hiding among the thick regetation."

R. \& H. $(1915,396)$ say: "The present insect is very widely distributed not only along the coastal strip in truck gardens, waste fields, and marshy fresh water areas, but also in boggy portions of the adjacent pine barrens and in fields there located. Usually no more than three or four widels scattered individuals are to be heard at one time. The song is loud, resonant and constant-dzeeeet-dzeeeet-dzeeeet, always the same, not rising and falling, the notes given deliberately, counted as areraging twelve to ten seconds. The males would continue their loud song fear- 
lessly until approached to within about eight feet, then ceasing abruptly they would fly into the darkness with a swift powerful zigzagging flight. In alert swiftness this species and $N$. velox are distinctive."

Aside from the black margined under surface of the fastigium this insect is an exact replica of a small $N$. robustus crepitans, the form of the cones being identical. That species is said to sometimes have the fastigium "very briefly and narrowly darkened ventrad." I would consider caudellianus to be only a form of crepitans were it not for the difference in song as noted by Davis and R. \& H.

240. Neoconocephalus Palustris (Blatchley), 1893c, 89. Marsh Conehead.

Males small for the genus, form rather slender; females larger, more robust and with abdomen distinctly enlarged. General color of females usually a bright grass green; of males more often brown varying in shade; fastigium of green form tipped with dull yellow, which extends half way down the sides; labrum and apical segments of all the palpi rose red tinged with violet; antennæ and apical third of ovipositor reddish-brown; tarsi somewhat infuscated. Fastigium short, stout, apical third feebly narrowed, tip bluntly rounded (Fig. 169, $i$ ); under surface with a low obtuse carina, the usual basal tooth represented by a small blunt tubercle. Pronotum with lateral carinæ feebly divergent, hind margin very broadly rounded; lateral lobes longer than deep, their lower margin oblique, its

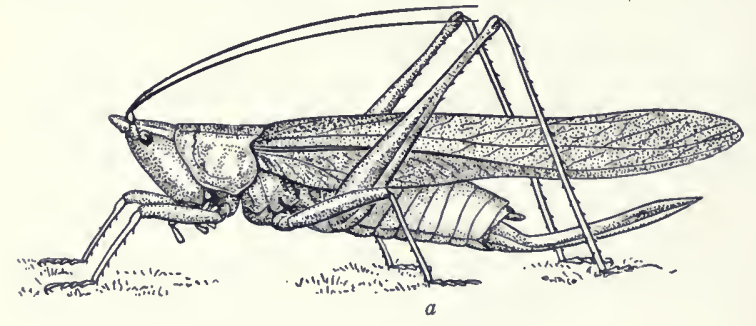

Fig. 176. $a$, Female. $X 1.3 ; b$, head of same from above. (Original.)

hind angle obtuse; humeral sinus very shallow. Tegmina very slender, tapering but little to the narrowly rounded tips. Stridulating field of male small, broad, basal three-fourths of stridulating vein coarse, apical fourth very weak (Fig. 170, $\dot{e}$.) Fore and middle femora usually with $1-3$ short, stout spines on apical third of lower outer carina. Hind legs short, tibiæ but little more than half as long as closed tegmina; femora with $3-9$ spines on each of the lower carinæ. Ovipositor slightly shorter than hind tibiæ, broadest at a point about two-thirds the distance from base, thence tapering regularly to a sharp apex. Length of body, of, 24-26, ㅇ, 2735 ; of fastigium, $\delta, 2.3-3$, $\&, 2.6-4$; of pronotum, $\delta, 6.3-8, \mathcal{8}, 5.6-$ 8.7 ; of tegmina, $\delta, 28-34$, ㅇ, $29-45$; of hind femora, $\delta, 16-19,+$,, $16-$ 25 ; of ovipositor, $16-21 \mathrm{~mm}$. (Fig. 176.)

Vigo Co., Ind., Oct. 24, type female (W.S.B.) ; Alexandria, 
Va., Sept. 2 and Raleigh, N. Car., Aug. 4 (Davis). This trimhodied cone-head was described from a single female taken oct. 2,1891 , from the fallen grasses on the margins of a large lowland pond in Vigo County. This pond, now extinct, was surrounded on all sides by heavy timber, and its margins yielded a number of interesting Orthoptera found nowhere else in the county. Among them were Leptysma marginicollis (Serv.), Paroxya hoosieri (B1.), Anaxipha exigua (Say), Phylloscirtus pulchellus (Uhler) and Conocephahus nigropleurus (Bruner). The first four mentioned are insects of a southern range, and N. palustris, as predicted at the time, has been found to be more common southward. Elsewhere in Indiana N. palustris is known only from Tippecanoe County, where Fox $(1915,30)$ found it in August and September of regular occurrence but not especially frequent in the open bogs of the rice cut-grass, Homalocenchmis oryzoides (L.).

Outside of Indiana $N$. palustris has been taken at various stations in Pennsylvania and New Jersey, near Columbus and Castalia, Ohio, Washington, D. C., Tappahannock, Va., Raleigh, N. Car., Clarksville, Tenn., and New Orleans, La. Of its habits in New Jersey and Pennsylvania R. \& H. $(1915,400)$ have written: "The males were found to be at night very alert and shy, much the most difficult of the species to take excepting $\mathbf{Y}$. caudellianus. The method of escape is, however, to hide with agility in the tangles of regetation in which the species is usually found, rather than to seek safety in flight. The song is a continuous dzеeеееесеесе, very high pitched and rery weak."

"The series taken at Cornwells, Pa., was captured during the day by beating the tangled regetation, and particularly a small area of Panieularia septentrionalis in a marshy spot. In the latter plant the females were exceedingly numerous, nearly all being taken there. In the daytime individuals are sluggish, moving but slowly about, but the clinging powers were found to be remarkable and the use of the spines on the limbs for this purpose was quickly apparent."

About Tappahannock, Va., Fox (1917) found N. palustris common in tidal marsh on the tall marsh-grass, Spartina cynosuroides (L.), less frequent on the three-square rush, Scirpus americanus (Pers.) ; also on cat-tails and in moist depressions filled with succulent grasses at the heads of gullers."

241. Neocoxocephalus velox Rehn \& Hebard, 1914c, 402. Swift Conehead.

Size medium for the genus; form compressed, slender, elongate. Pale brown or tawny olive; head with a median stripe of darker brown, this 
dividing and extending back along the lateral carinæ; tegmina with numerous very small, scattered brown spots; spines of the femora and tibiæ tipped with brown. Fastigium constricted at base, widest at middle, then feebly narrowed to the rounded apex. Pronotum with lateral carinæ very obtuse, feebly divergent, both its disk and the occiput finely rugose-punctate; lateral lobes much longer than deep, their lower margin broadly rounded into the front and hind ones; humeral sinus broad, very shallow, male, much deeper, female. Tegmina elongate, surpassing the hind femora about $16 \mathrm{~mm}$, tip of ovipositor, $5 \mathrm{~mm}$.; stridulating field of male rather small and broad, its main vein heavy, the others very weak. Front and middle femora armed beneath on the outer carina with two or three small spines. Hind femora very slender, armed beneath with six to eight slender spines on each carina. Subgenital plate of male with median notch narrow, the styles stouter and broader than in any other species, their tips bluntly rounded. Length of body, $\hat{\delta}, 33-40$; of fastigium $2.6-3$; of pronotum, $8.7-9$; of tegmina, $40-42$; of hind femora, $23-25$ mm. (Fig. 177.)

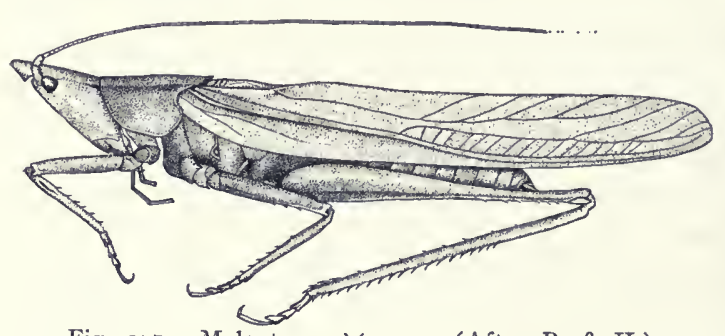

Fig. I77. Male type. $X$ I.3. (After R. \& H.)
LaGrange and Parish, Fla., June -July 31 ; Logtown and Ratliff, Miss. (Davis.) Recorded only from Homestead, Fla., a n d Billy's Island, Ga., June-July, the for-

mer being the type locality. R. \& H. $(1915,399)$ state that: "The scng of this very shy and vigorous species is a loud and continuous buzzing. It is apparently a native of the undergrowth of the pine forests of the extreme southeastern United States."

\section{NeocoNocephalus Retusus (Scudder), 1879a, 93. Round-tipped Cone-head.}

Size small for the genus; form slender. Color usually green, often pale brown with tegmina faintly maculate; fastigium with margins yellowish, its apex only with a curved black line on under surface; lateral carinæ of pronotum often yellowish; tibiæ, tarsi and apical half of ovipositor usually more or less fuscous. Fastigium shorter than the interocular width, convex above, its sides subparallel, (Fig. 169, $k$, ) basal tooth obtuse. Pronotum coarsely and thickly punctate, transverse sulcus distinct, metazona three times as long as prozona, hind margin very broadly rounded, lateral carinæ feebly divergent, female, rather strongly so, male; lateral lobes with lower margin oblique, its hind angle obsolete, hind margin broadly rounded; humeral sinus broad, shallow. Tegmina relatively short, surpassing the hind femora only $8-10 \mathrm{~mm}$., thelr tips rather broadly rounded. Front and middle femora usually unarmed beneath, rarely with a single small spine. Hind femora with 2-6 small spines on each of the lower carinæ. Notch of subgenital plate of male broad, the styles slender, 
acute. Ovipositor much surpassing the tegmina. Length of body, $\hat{\sigma}$,

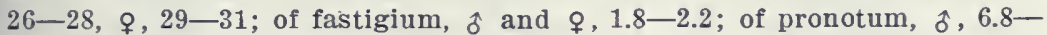
7.5 , ᄋ, 5.3-7.8; of tegmina, $\hat{\delta}, 29-34$, ㅇ, $30-42$; of hind femora, $\hat{o}$, 18.5-21, ᄋ, 21-27; of ovipositor, $27-39 \mathrm{~mm}$.

Putnam Co., Ind., Aug. 27-Sept. 18; Washington, D. C., Aug. 23 ; Norfolk and Tappahannock, Va., Ang. 23-Oct. 8: Staten Island, N. Y., Sept. 3 . The Indiana specimens were taken from a marshy spot in a blue-grass pasture, the first one in 1914, and only females are so far known from that State. In Florida it is recorded only from Jacksonville, St. Augustine, Daytona and Gainesville and probably inhabits only the nortlern third of the State. Scudder's type was a female from Georgia and the known range of the species extends from Connecticut west to central Indiana and St. Louis, Mo., and southwest to northern Florida and Nugent. Miss.

R. \& H. (1915, 403) describe the song and habits of retusus as follows: "The present insect is an inhabitant of the grasses in waste fields, along the borders of marshes and in the drier portions of the marshes proper, and is usually to be found in large numbers. The song is of the exact pitch of that of $\mathbf{X}$. lyristes but weaker, a continuous zecceceece. In New Jersey the species is the last of the genus to appear, reaching the adult condition toward the end of August." R. \& H. (1915, 401) have placed the Conocephalus atlanticus Bruner (1899, 3S) as a synonym. They state that the Conocephahes triops and $C$. dissimilis of many American author's also refer rightfully to retusus, triops being a larger, more robust form with shorter ovipositor and shorter, flatter, broader fastigium.

243. Neocoxocephalus triops (Linnæus), 1758, 430. Broad-tipped Conehead.

Size rather large; form robust. Green or brown; tip of fastigium beneath and often the tips of mandibles black; lateral carinæ of pronotum and margins of fastigium rarely yellowish; brown form often with a purplish stripe along the upper third of lateral lobes and humeral vein of tegmina; under surface of hind femora and tibiæ very dark in some individuals. Fastigium as described in key. Pronotum broader and smoother than in retusus; humeral sinus broader; lateral lobes deeper in proportion to their length. Front and middle femora unarmed or with a few small spines. Hind femora with six to ten rery small spines on each lower carina. Ovipositor but slightly surpassing the tips of tegmina, its apical third feebly decurved. Length of body, $\hat{o}, 27.5-32,9,32-36$; of fastigium, $\hat{\delta}$ and $\uparrow, 2.1-2.6$; of pronotum, $\hat{\delta}$ and $\uparrow, 8.7-9.7$; of tegmina, $\hat{\delta}, 40-44, \uparrow, 43-53$; of hind femora, $\hat{\sigma}, 22-24, \uparrow, 23-26$; of ovipositor, $21-25 \mathrm{~mm}$. 
Ormond, Gainesville, West Palm Beach, Lake Istokpoga, Cape Sable and Dunedin, Fla. (W.S. B.) ; Mobile, Ala. (Loding) ; Agricultural College, Miss. (Weed); October-March. Recorded from numerous places in Florida, and oceurs everywhere throughout the State and on the southern keys. These records have been made under different names, viz., Conocephalus triops (Linn.), C. fusco-striatus Redt., C. mexicanus Sauss. and C. nietoi Sauss., the second and third being synonyms of triops and the fourth belonging rightfully to an extralimital species of Homorocoryphus.

My first field acquaintance with $C$. triops was made at Ormond on March 16, 1899. These I determined as C. nietoi Sauss. by comparison with Mississippi specimens which I had received under that name from $\mathrm{H}$. C. Weed and they were so recorded by me $(1902,70)$. About Dunedin $N$. triops oceurs in small numbers throughout the winter, frequenting for the most part the dense masses of fallen grasses about the borders of marshes and ponds. but sometimes noted amidst the wire-grass of open pine woods. There as elsewhere the males are mostly brown and the females green, there being but one brown female and one green male among the 24 specimens at hand. I have never seen it fly when disturbed, but it is an adept at burrowing and also at remaining perfectly motionless by the side of or on some object with whose hue its own color blends. On the other hand, Hebard states (R. \& $H ., 1904$ ) that at Thomasville, Ga., the brown fusco-striatus phase of this species "appeared early in March and was soon plentiful in the woods, especially in the broom sedge in damp locations. The specimens, when pursued, always took to wing and made off with a strong but zigzag flight, never alighting until quite a distance had been traversed."

$N$. triops is found, say R. \& $H .(1915,408)$ "almost everywhere in the southern United States, inhabiting the forest undergrowth, fields and semi-marsh situations. Over most of its range it is one of the earliest Tettigoniids to appear, the adults being found in south Georgia in late March." Its known range extends from the vicinity of Washington, D. C., south and west to Stillwater, Oklahoma, Central Texas, Arizona and Los Angeles, Cal. Redtenbacher (1891, 399) gives also for his fusco-striatus, Missouri, Cuba, Port Au Prince and Quita.

Allard (1910a) has given an excellent account of the habits and song of the brown color phase of $N$. triops which is, in part, as follows:

"The careful observer of insect stridulations who visits the upper 
Piedmont region of Georgia in March or April, will hear, during warm evenings, a loud, continuous, noisy buzz, sometimes in the tallest pines and oaks, or again in the weeds and low herbage of fields. This is the stridulation of a cone-headed grasshopper known as Conocephalus fusco-striatus Redt. In this region the notes of this interesting locust together with the familiar trillings of the ubiquitous field cricket, Gryllus pennsylvanicus Burm., are among the earliest insect stridulations to be heard in spring. Here it is the only Conocephalus to be heard in early spring, and, judging from the individuals in song during warm evenings, it is a fairly common species.

"This cone-head is strictly a nocturnal insect and stridulates most freely during warm, moonlight evenings. The note is a loud, harsh, snappy $z-z-z-z-z-z$ continued for many minutes at a time. Within a few feet of the stridulating insect a strong, penetrating buzzing hum is noticeable, attended by almost continuous harsh, snappy, unmusical creptitations which are audible for long distances, and constitute the notes usually heard by the distant observer. It is somewhat difficult, especially for those who have not studied insect-stridulations, to locate one of these insects in a big field. Its powerful, penetrating notes seem to permeate the herbage on every hand, frequently causing no little bewilderment in the mind of one who attempts to locate the musician too carelessly. It is a very shy insect and cannot readily be captured unless approached with considerable care. It takes to wing readily, and flies long distances in the fields or from tree to tree."

Of the two synonyms of $N$. triops above noted, the name mexicanus Sauss. (1859, 208) has usually been given by American authors to the green form, and fuseo-striatus Redt. (1891, 399) to the brown one. R. \& H. (1914c, 402) first placed the latter as a synonym of mexicanus and in 1915 referred both names to triops. Other synonyms of triops as stated by them are Conocephalus obtusus Burm. (1838, 705), C. dissimilis Serv., (1839, 518), C. dissimilis Harris $(1862,164), C$. hebes Scudd. (1879a, 92), and Neoconocephalus mexicanus var. tibialis Karney $(1907,33)$.

\section{Homorocoryphus Karney, 1912, 36. (Gr., "contiguous" + "vertex")}

Species of large size and robust form, rery similar in structure and general facies to those of Neoconocephalus, with which they were formerly grouped. Fastigium slightly shorter than width of interocular space, its apical half convex, swollen, bluntly rounded; antennæ longer than body, very slender; pronotum with posterior lobe very short, lateral carina subobsolete, hind margin truncate, lateral lobes longer than deep, humeral sinus distinct but shallow; tegmina variable in length; wings shorter than or equal to tegmina; fore and middle femora short, subequal, armed with only one or two short spines on lower, outer carina; hind 
femora short, but slightly surpassing the abdomen, female, their lower carina armed with three to seven short, stout spines. Male with apex of supra-anal plate very broadly concare or emarginate, the projection each side acute; cerci much as in Neoconocephalus; subgenital plate with a narrow median noteh; styles short, broad, concave above, their tips bluntly rounded. Ovipositor more than one-half longer than hind femora, slightly widened and feebly decurved beyond the midlle, its apex very acute. Other characters as in Neoconocephalus.

But one species of the genus occurs in the United States.

244. Honorocoryphus Malivolaxs (Scudder), 1879a, 90.

Pale brown, the female darker; disk of pronotum with a narrow dark brown stripe each side, sometimes almost wholly blackish-brown; tarsi and hind tibiæ often in great part infuscated. Occiput and sides of head rather coarsely and very irregularly punctate. Disk and sides of pronotum rugosely punctate, more strongly so in female. Tegmina dimorphic in length, in the more common brachypterous form not reaching tips of hind femora, slightly longer than abdomen, male, shorter than abdomen, female. their tips acute or narrowly rounded; in macropterous form surpassing hind femora $12-15 \mathrm{~mm}$. and extending far beyond tip of abdomen in both sexes, their apices rounded; wings usually shorter than tegmina, equal to latter in macropterous individuals. Other characters as given under the generic heading. Length of body, $\hat{\delta}, 27-29$, ㅇ, 39-43; of fastigium, $\hat{\delta}$, 2 ;, 2.7 ; of pronotum, $\delta, 7$,, $9-10$; of tegmina, short-winged, $\delta, 19-$ 20 ,,$+ 23-24$; long-winged, $\hat{o}, 40$,, $47-50$; of hind femora, $\hat{\jmath}, 17$,, , 22.5-24; of ovipositor, $37-38.5 \mathrm{~mm}$. (Fig. 178.)

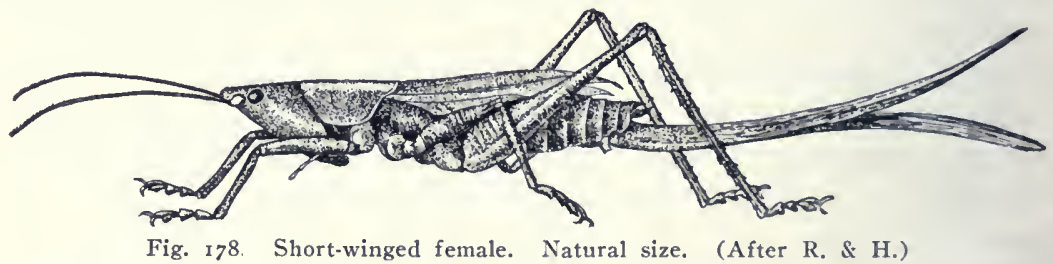

Tappahannock, Va., July 14 (Fox); Citrus Center, Fla. (Davis). Seudder's type was a unique male taken at Cedar líeys. Fla., June 4 by E. A. Schwarz. This was the only specimen known until 1905, when R. \& H. described a single female from Cholioloskee, Fla., under the name of Conoccphalus hoplomachus. I second male was taken by them July 12, 1912 "from saw-grass growing in knee-high water on the edge of the everglades" at Detroit. Fla., and was properly placed $(1914 c, 405)$ under scudder's name. The only other Florida locality recorded is Citrus Center, where Davis secured two males on May 2, but he has a male taken at Parish, August 25, in which the tegmina are $40 \mathrm{~mm}$. in length.

Outside of Florida the species is recorded only from Wilming- 
ton, x. Car., Tappahannock, Va. and Victoria, Texas. At Tappahannock Fox (1917) took 29 males and 12 females, July 13Aug. 18, which he found mostly "in dense stands of the tall marshgrass, spartina cynosuroides (L.), in tidal marshes, a few occurring in briery thickets on nearby knolls. Observed oripositing in the Spartina." It probably occurs sparingly orer the areas of the marshes covered by this and allied grasses and reeds all along the Atlantic coast from Virginia to ext eme southeln Florida and also along the gulf coast of Florida on which the type was taken. As Scudder has noted, the male, vn account of its short tegmina and blunt rounded fastigium, resembles somewhat a large Orchelimum.

Caudell (191Sa) records a macropterous female of $H$. malivolans from Victoria, Texas, in which both tegmina and wings are $50 \mathrm{~mm}$. in length, thus giving the "insect an appearance of being larger and more bulky than its brachypterous relatives."

\section{Subfamily IV. CONOCEPHALINE.}

\section{The Meadow Grasshoppers.}

"The poetry of earth is never dead:

When all the birds are faint with the hot sun, And hide in cooling trees, a volce will run From hedge to hedge about the new mown mead: That is the grasshopper's-he takes the lead In summer luxury-he has never done With his delights; for when tired out with fun

He rests at ease beneath some pleasant weed."-Keats.

Species of small or medium size, having the vertex projected upward and forward in the form of a blunt rounded tubercle, concave on each side to accommodate the basal joint of antenna; eyes rather large. subglobose; antenna very slender; tapering, often of excessive length; pronotum with not more than one transverse sulcus; prosternum toothed or with two slender spines, rarels unarmed; tegmina usually well dereloped but often dimorphic in the same species, sometimes reduced to mere pads, or even wanting, their color usually green, rarely pale brown; wings usually present and fully developed, absent or very minute in Odontoxiphidium and much aborted in some species of Conocephalus. Other characters much as in the Copiphorinze.

To this sub-family belong those slender-bodied green grass- 
hoppers, with long, tapering antennæ which are so common in summer and early autumn in damp meadows and prairies and aiong the margins of streams, ditches and ponds. They are mostly terrestrial in their habits, and the color of their bodies corresponds closely with that of the stems and leares of the sedges and grasses among which they dwell, thus protecting them from the sight of the few birds which frequent a like locality. Their songs, produced in the same manner as those of their larger cousins, the katydids, are as frequent by day as by night, but are usually soft and low in comparison with those of the former. Their day song differs from that of the night, and, says Scudder $(1868,116)$ : "It is curious to observe these little ereatures suddenly changing from the day to the night song at the mere passing of a cloud and returning to the old note when the sky is clear. By imitating the two songs in the daytime the grasshoppers can be made to represent either at will ; at night they have but one note."

The eggs of the Conocephalina are deposited between the stems and root leaves of grass, in the pith of twigs, or sometimes in the turnip-shaped galls so common on certain species of willows. The ovipositor, being thus used as a piercer, has in time developed into a slender and sharp pointed instrument which is but little curved and is frequently of excessive length, in some species being over twice as long as the remainder of the body.

The subfamily is represented in the eastern United States by three genera, the literature of especial interest regarding them being as follows: Redtenbacher, 1891; Blatchley, 1893, 1903; Scudder, 1898b; MeNeill, 1900a ; Hancoek, 1904, 1911; Karney, 1913; Rehn \& Hebard, 1915a, 1915b, 1916.

KEY TO EASTERN GENERA OF CONCEPHALINA.

a. Cerci of males more or less curved, swollen at middle or base and bearing a single tooth; tegmina present in both sexes.

b. Prosternal spines rather long cylindrical, slender; ovipositor stouter, usually distinctly falcate or upcurved; tegmina fully developed, surpassing abdomen in all our species; body more robust, usually more than $18 \mathrm{~mm}$. in length.

I. ORCHELFuUM, p. 535 .

$b b$. Prosternal spines very short or wholly wanting; ovipositor slender, straight or nearly so; tegmina usually abbreviated, shorter than abdomen in most species; body more slender, usually less than $17 \mathrm{~mm}$. in length.

II. Coxocepialus, p. 562.

$a a$. Cerci of males long, slender, subcylindrical or subdepressed and with both a post-median lateral and a basal dorsal tooth; tegmina and wings absent or the former concealed, in female, tegmina present but very short in male.

III. Onoxtoxipindus, p. 584. 


\section{Orchelimum Serville, 1839, 522. (Gr., "to dance" + "meadow.")}

\section{The Larger Meadow-Grasshoppers.}

Tettigoniids below the medium in size and possessing the characters of the subfamils above noted. They also have the face short, moderately oblique, its dorsal portion prolonged upward at middle to meet the rentral spine of fastigium; pronotum short, usually smooth, more or less saddle-shaped, the metazona prolonged backward to form a posterior lobe, its hind margin usually broadly rounded; lateral lobes deeper than long, their front margin oblique, lower one usually straight and rounded into the hind one, the latter usually with the adjoining lower portion bulging to form what is called the "convex callosity;" humeral sinus usually present but varying much in width and depth; tegmina narrow, usually strongly tapering, the apical width much less than the basal, almost always slightly shorter than wings; stridulating organ of male well developed, its reins prominent, the speculum transparent on botll tegmina; front and middle femora subequal in length, unarmed beneath; hind femora slender but stouter than in Conocephalus, their under surface either armed with a few short spines or wholly unarmed. Male with apex of supra-anal plate emarginate and usually deflexed; cerci stout, rarying much in form, armed near middle with a single stout tooth; subgenital plate with apex U-or V-shaped, its styles short one-jointed, set in sockets at the upper outer margins of the concavity. Ovipositor stout, rather broad, its apical half usually distinctly upenrved; when straight or nearly so above, the apical third, except in militare, tapering or curved on under side to a fine point.

This genus is very close to Conocephalus (Tiphidium) and is. bJ some writers, united with it. Redtenbacher (1891. 494) placed it as a subgenus of Xiphidium, separating its members from those of Xiphidium proper by the same characters as did Serville. The species have a general facies or appearance which enables one after a little experience to separate them at a glance from those of Conocephalus, but as R. \& H. $(1915 b, 156)$ have well said, "when the characters of the two are compared, the rariation in each leares us unable to state a single absolute difference." As noted in the key to genera, the larger, heavier bods, longer prosternal spines, and shorter and broader falcate ovipositor are the chief distinguishing characters of Orchelimum. The tegmina are 
nore uniform in length, and the color, while of slightly different shades of brown or green in the same species, according to season and habitat, does not run to the extremes of variation as in Conocephalus.

The generic name, Orchelimum, the literal meaning of which i.s "I dance in the meadows," is a most appropriate one, for low, moist meadows everywhere swarm with these insects from July to November; and thongh waltzes and quadrilles are probably not indulged in, yet the music and song, the wooing and lore-making which are the natural accompaniments of those amusements, are ever present, and make the short season of mature life of the partieipants a seemingly happy one.

Allard (1910b) says: "In attempting to capture the Orchelimums it is amusing to observe their attempts to hide by moving around the stalk of grass they are resting on. As the hand moves toward the stalk to grasp one, the wary creature always moves to the opposite side so as to keep the stalk directly between it and the observer, just as a gray squirrel moves around a tree trunk to escape the hunter. In this protective movement it hugs the grass stem as close as possible, stretching out its long, slender hind legs behind it, until they are parallel with and almost flat against the grass stem."

Redtenbacher recognized but eleven species of his subgenus Orchelimum, ten of these from the United States. Scudder $(1900,73)$ admitted 18 to his catalogue. Kirby $(1906,371)$ increased the number to 24 . R. \& H. in their synopsis (1915a,) founded a new genus for one of these, restricted the genus Orchelimum to North America and Mexico, deseribed five new species and relegated so many of those recognized by Redtenbacher, Seudder and Kirby to synonymy that, in the end, they had only 17 North American species treated as valid in their work.

In my opinion the synonymy of the genus is even yet in a very unsettled state. R. \& H. made a laudable attempt to straighten it out but their conclusions regarding the older names of the European writers were based on the very brief descriptions of those writers and not on an examination and eomparison with the types. For that reason I cannot agree with all their conchusions and synonymy.

The speeies of Orchclimum are so numerous and so alike in general appearance that it is very difficult to prepare a key which is satisfactory and at the same time easily followed. R. \& H. have shown that one of the major eharacters used by both MeNeill 
(1900a) and myself $(1903,382)$ in our former treatment of the genus, viz., the presence or absence of spines on the under side of the hind femora, is unreliable as it is variable in the same species. They have used instead the form of the male cerci as their principal differential character and have supplemented this with other characters pertaining to the form of lateral lobes of pronotum, form and size of oripositor of female, etc. Their keys are open to the objection, that they contain a number of merely comparative terms such as "form more robust" and "oripositor with general form less arcuate," as against "form nore slender" and "ovipositor with general form more arcuate." Such terms, as I loug ago discovered by personal experience, are confusing and misleading to a student who has only a few specimens at hand. Aside from this, the keys in their synopsis are so much better than any previously known that I have used them as the basis for the one given below, modifying them here and there in sequence and by the addition of any fixed character which, in my opinion, would make them more simple and more easily understood by the begimner. On account of the great confusion in the synonymy of a number of the species, it is impossible in giving the distribution and notes on habits to always refer each record made by past collectors to the species to which it rightfully belongs. I have, however, where following the synonymy as given by R. \& H., assigned the notes and records of synonyms to the species under which they are placed by those authors.

Fifteen species and two varieties of Orchelimum are herein recognized as occurring in the territory covered by this work. For convenience of treatment these are first separated into two groups as follows:

KEY TO GROUPS OF EASTERY SPECIES OF ORCHELIMUM.

a. Cerci of male of moderate length, the apical portion behind the median tooth not much if any longer than the basal portion in front of it (Fig. 179); ovipositor in the majority of the species not disdistinctly more than half as long as hind femora and (except in gladiator) with upper margin always evidently and regularly curved.

Group I. p. 537.

aa. Cerci more elongate, the apical portion behind the tooth distinctly longer than the portion in front of it (Fig. 183); ovipositor (except rarely in concinnum) distinctly more than half as long as hind femora, its upper margin either straight or curved. Group II. p. 551.

Group I. The Agile Group of Orchelinum.

This group as defined above contains eight species. In general its nembers are larger and more robust than those of Group II. 

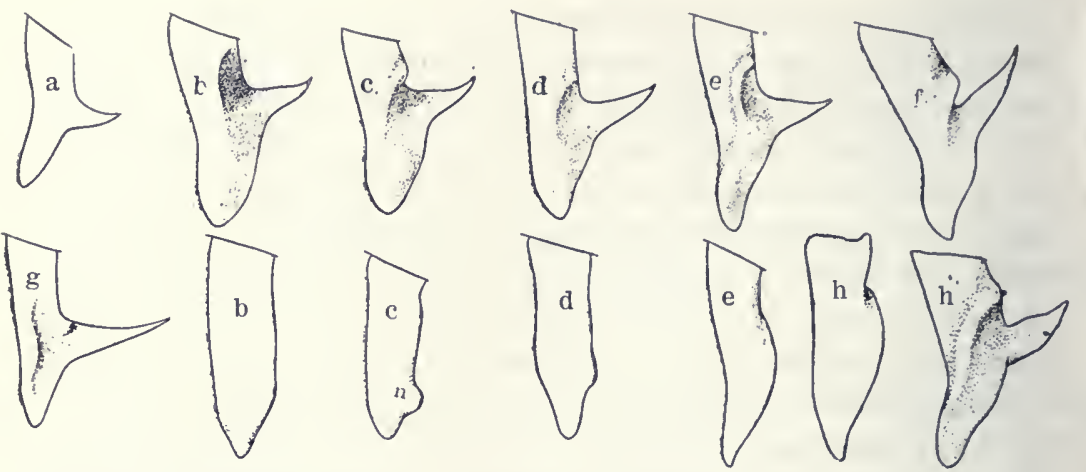

Fig. 179. Dorsal and lateral outlines of left cercus of male Orchelimum, $\times$ ro. a, agile; b, erythrocephalum; c, vulgare; d, gladiator; e, pulchellum; f, nigripes; $\mathrm{g}$, calcaratum; $\mathrm{h}$, bullatum; $\mathrm{n}=$ node on cercus of vulgare. ( $\mathrm{a}-\mathrm{g}$, After $\mathrm{R} . \mathrm{B} \mathrm{H} . ; \mathrm{h}$, original.)

KEY TO EASTERN SPECIES OF GROUP I OF ORCHELIMUM.

a. Tooth of male cercus not longer than apical portion of the shaft and not strongly aciculate (Fig. 179, $a-f$.)

b. Upper surface of male cercus without a distinct sinuate carina; ovipositor. (except in gladiator) not or very little more than half as long as hind femora (Fig. 180.)

c. Cercus distinctly depressed, its tooth flattened at base and set at right angles to the shaft; ovipositor deeper at base than at any other point; humeral sinus distinct but shallow (Fig. $180, a$.

245. AGILE.

cc. Cercus not distinctly depressed, its tooth more or less thickened at base; ovipositor deepest at some point beyond the base.

d. Cercus without a rounded tubercle or node above and between the tooth and apex; head more or less reddish; speculum of stridulating field of male longer than broad (Fig. 182, b.)

246. ERYTHROCEPIIALUM.

dd. Cercus with a rounded tubercle or node above on apical half (Fig. $179, c, n$ ); head rarely reddish; speculum subquadrate (Fig. 182, a.)

e. Humeral sinus of lateral lobes distinct (Fig. 180,c); tooth of cercus shorter than apical half of shaft, tip of shaft bluntly rounded (Fig. 179,c); ovipositor less than half the length of hind femora, its upper margin distinctly curved.

247. VULGARE.

ee. Humeral sinus scarcely evident; tooth of cercus as long as apical half of shaft, the tip of shaft subacute; ovipositor almost two-thirds as long as hind femora, its upper margin nearly straight (Figs. 179, 180, d.) 248. GLADIATOR.

$b b$. Upper surface of cercus with a distinct obtuse sinuate carina; ovipositor more than half the length of hind femora.

f. Humeral sinus distinct; tibiæ not blackish; notch of male supra-anal plate U-shaped, as broad or broader than deep; tooth 
of cercus distinctly shorter than that portion of shaft behind it, its apical half straight or nearly so (Figs. 179, 180,e.)

g. Outer carina of hind femur in both sexes armed on apical third with two to eight stout spines; form slender; tegmina in female scarcely reaching the tip of ovipositor.

249. PULCHelluar.

gg. Outer carina of hind femur unarmed in male, with one or two minute spines on apical third, female; form much stouter; tegmina of female distinctly surpassing the tip of ovipositor.

250 BULLATUM.

ff. Humeral sinus almost obsolete; tibiæ all blackish; notch of supra-anal plate V-shaped, deeper than broad; tooth of cercus almost as long as the portion behind it, distinctly inclined toward base of cercus, its apical half curved (Figs. 179, 180, $f)$; tegmina but feebly if at all surpassing hind femora.

251. NIGRIPES.

aa. Tooth of male cercus distinctly longer than apical portion of shaft and strongly aciculate (Fig. 179, $g$ ); humeral sinus scarcely evident (Fig. 182, c); outer lower carina of hind femora always spined.

252. CALCARATUM.
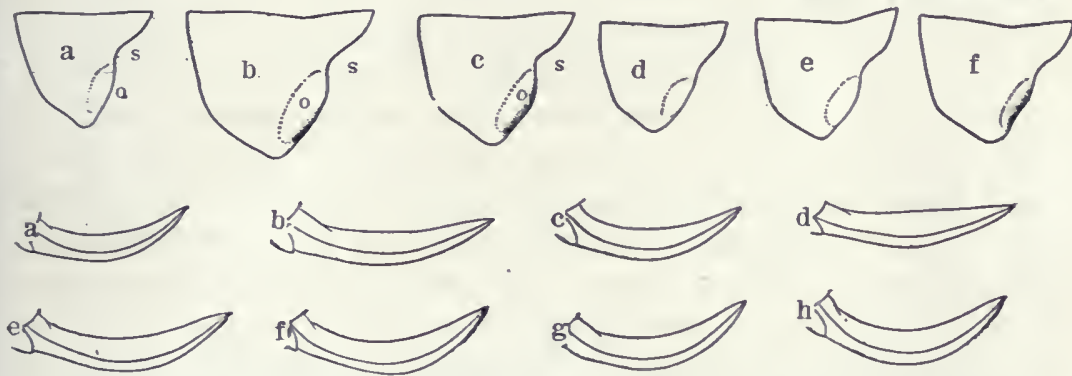

Fig. 180. Outlines of lateral lobes of male pronotum, $X 3$, and of ovipositors, $\times 2$, of Orchelimum. a, agile; b, crythrocephalum; c, inlgare; d, gladiator; e, pulchellum; f, nigripes; $\mathrm{g}$, calcaratum; b, bullatum; s, humeral sinus, $\mathrm{c}=$ convex callosity. (After R. \& H.)

245. Orchelimum AGILE (DeGeer), 1773, 457. Agile Meadow Grass-hopper

Size medium for the genus; form moderately robust. Color variable; usually dull reddish-brown, with lateral lobes of pronotum, costal or lower edge of tegmina, tibiæ and apical half of hind femora green or with a greenish tinge, sometimes nearly uniform pale green with dorsal surface tinged with clay yellow; pronotum often with a pair of dark brown diverging stripes. Fastigium broader at apex than at base, the former rounded and with a fine median line above. Antennæ twice or more as long as body. Disk of pronotum short; lateral lobes with lower margin oblique, its hind angle obtuse; humeral sinus broad, shallow. Tegmina surpassing hind femora about $3 \mathrm{~mm}$., exceeded by wings about $2 \mathrm{~mm}$. Outer lower carina of hind femora with one to five spines. Cerci of male and ovipositor as in key and Figs. 179, 180. Apex of subgenital plate of male subtruncate or rery feebly and broadly emarginate. Length of body, $\hat{\sigma}$ and $\$, 21.5-$ 22.5; of pronotum, $\hat{\jmath}, 5$, ㅇ, 5-5.6; of tegmina, $\widehat{o}, 23.5-24.5$, ㅇ, 25-25.7; of hind femora, $\hat{o}, 17.6-18.6$, ․ $18.5-20.8$; of ovipositor, $7-8 \mathrm{~mm}$. 
Marshall and Vigo Counties, Ind., Aug. 7-Oct. 1; Washington, D. C., Aug. 30; Thomasville, Ga., Aug.-Sept. 8; Dunedin and Gainesville, Fla., Oct. 24 (W. S. B.). This species, as determined by R. \& H., I have found to be scarce in Indiana, less than half a dozen specimens having been taken; while Fox found but one near Lafayette. It was not included in my Orthoptera of Indiana as I had not then separated it from vulgare. My Indiana specimens agree very well with the description of McNeill's sylvaticum which $\mathbf{R}$. \& $\mathrm{H}$. have made a synonym of agile, except that McNeill specifically states that in the male of his species the wings do not exceed the tegmina, which is not true of the Indiana males nor of those from Thomasville, Ga., received from Hebard under the name of $O$. nitidum Redt. The synonyms of $O$. agile as determined by R. \& H. (1915a, 29) are 0 . glaucum Serv. $(1839,524)$, O. silvaticum McNeill $(1891,26), X$. (O.) nitidum and spinulosum Redt. (1891, 503) and O. molossum R. \& H. $(1907,307)$, but until some one makes a careful examination of DeGeer's type, if it be still in existence, the fixation of any American form as that species may still be considered an open question.

In Florida $O$. agile has been taken by collectors at a dozen stations, but appears to be rather scarce and to be mostly confined to the northern portion, though recorded as far south as Detroit and Everglade. There it occurs in the undergrowth of pine woods and among weeds in waste places; also in the sawgrass along the edge of the everglades.

The range of $O$. agile, including its synonyms, is given by R. \& H. as extending from S. E. Pennsylvania and southern New Jersey south and southwest to southern Florida and Louisiana and north and west to northern Illinois and Wichita, Kansas. Of silvaticum as occurring at Moline, Ill., McNeill $(1891,26)$ says: "I have found this Orchelimum first on corn, afterwards more commonly in open places in woods. Its stridulation is quite distinct from that of vulgare. It consists of the same two elements but the $\approx i p$ is repeated many times very rapidly so as to make almost a continuous sound and the zec-e-e-e is comparatively short and very constant, lasting about eight seconds. The first part of the song lasts from three to five seconds." Of the habits of agile, as found in Virginia, Fox (1917) wrote: "Usually abundant, in wet or moist areas, especially in the scirpus americanus Pers. formation of tidal marshes and the marginal fringe of succulent grasses; but never occurring in true salt marsh-grass, spartina stricta (Ait.); also common in cat-tail, sedgy and 
grassy bogs inland at the head of sluggish streams. Occasionally it spreads to the adjoining dry land, specimens laving been taken in goose-grass, Eleusine indica L., crab-grass, foxtail-grass and Audropogon."

246. Orchelimum erythrocephalum Davis, 1905, 288. Red-headed Meadow Grasshopper.

Size medium to large for the genus, form robust. Green or greenishyellow, hind knees and tarsi fuscous; occiput and prozona with a broad median dark brown dorsal stripe, in the larger specimens this often faint or wanting; entire head and face usually blood-red in life, fading to reddish-brown in drying; pronotum short, smooth, its posterior lobe short, with hind margin broadly rounded; lower margin of lateral lobes with hind angle närowly rounded, hind margin with convey callosity broad; humeral sinus broad, very shallow. Tegmina surpassing tips of hind femora 2-4 $\mathrm{mm}$., exceeded by wings the same distance. Hind femora usually armed beneath on each carina with one to six spines. Cerci as described in key and shown in Fig. 179, the tooth suddenly constricted into a slender, sharp bent spine. Ovipositor as shown in Fig. 180, b, slightly less than half the length of hind femora. Length of body, $\hat{i}$ and $q, 20-$

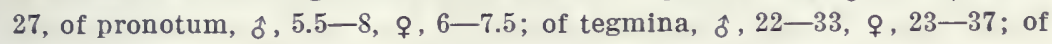
hind femora, $\hat{\delta}, 17-23$, $q$ 18-22; of ovipositor, $9-10$.

This meadow grasshopper, as described above, is the species which R. \& H. (1915a, 34) call O. glaberrimum (Burm.). The original description $(1838,70 \tau)$ of that species is rery brief and rot distinctive. It is as follows: "Verticis et pronoti medio fulvo, nigro-marginato; elytris ab alis dimidia linea superatis. Long. corp., 11"'," Burmeister knew but two species from the United States, and this short description was sufficient for him to distinguish these, but of the 18 or more species now known it is impossible to say just which one he had at hand. R. \& H. by "tracing the movements of Zimmerman, who collected the material on which Burmeister founded his glaberrimum." have concluded that his type came from Georgtown, s. Car., and have picked out the species found in that general region which, in their opinion, fits most closely the above brief description and have called it glaberrimum. In doing this they made the erythrocephalum of Daris a srnonym. They have also placed as a synonym of their glaberrimum Burm. the O. cuticulare Serv. (1839, 523), a species of which Serville said: "J'ignore sa patrie."

As stated in the introduction to this work, p. $\bar{\tau}$, in cases of this kind, where the insect cannot be definitely fixed as the one so briefly described by a foreign author, it is better to disregard his name and to adopt a later one of undoubted status. ${ }^{67}$

\footnotetext{
" See quotation from R. \& H. under O. concinnum, page 555 .
} 
I have, therefore, restored the name erythrocephalum given to this grasshopper by Davis.

The known range of 0 . erythrocephalum extends from central New Jersey southwest along the coast to southern Florida, Mobile, Ala., and southern Mississippi, and inland to Raleigh, N. Car., Macon, Ga., and Agricultural College, Miss. As will be noted by the measurements it varies much in size, the northern specimens being the smaller. It has been taken at various points in the Pine Barrens of New Jersey and about Norfolk and Cape Henry, Va. Davis (1905) says that in life "its most noticeable feature is a very red face, often the whole head being of a blood red color. It appears as if the insect had eaten of ripe cranberries and gotten its head stained with the fruit, for the color is the same. About Lakehurst it is far more common than O. vulgare."

Fox $(1914,527)$ states that it is apparently restricted to sphagnum bogs, where it frequents the dense growth of chain fern, tall sedges, rushes and associated plants. Of its occurrence about Cape Henry, Va., he says (1917): "In addition to being common in the rank regetation of dune hollows and ditches, it was not infrequent in the tall bunch grasses on the surrounding dry sand dunes. Farther inland it appeared to prefer areas of stiff, but not always moist soil, occurring in the rank plant growth of ditches, woodland borders and scrub. It evidently has a strong predilection for sylvan surroundings."

I have not taken erythrocephalum in Florida but it has been recorded from a number of localities as far south as Everglade, being apparently more common in the northern third of the State. There it occurs for the most part in wet grassy spots along the edges of hammoeks and in palmetto barrens.

247. Orchelinum vulgare Harris, 1841, 130. Common Meadow Grasshopper.

Size medium, form robust. General color green or pale reddish-brown; face pale green or light brown without fuscous marks; occiput and disk of pronotum with a reddish-brown band, widening on the latter, where it is often, especially in male, bordered each side with a darker line; male with two short black dashes on each tegmen, the four forming the angles of an assumed square, enclosing the tympanum; legs usually pale brown, tars 1 dusky. Pronotum long, its posterior lobe but slightly, if at all, upturned above the plane of prozona; lateral lobes nearly as long as deep, the lower hind angle obtusely rounded; convex callosity wide, prominent; humeral sinus broad but well defined (Fig. 180, c.) Tegmina reaching to or slightly beyond tips of hind femora, and usually equalling, male, or very llttle shorter, female, than wings. Hind femora rarely armed with one or two spines beneath. Cerci of male as described in key, a little depressed; sub-basal 

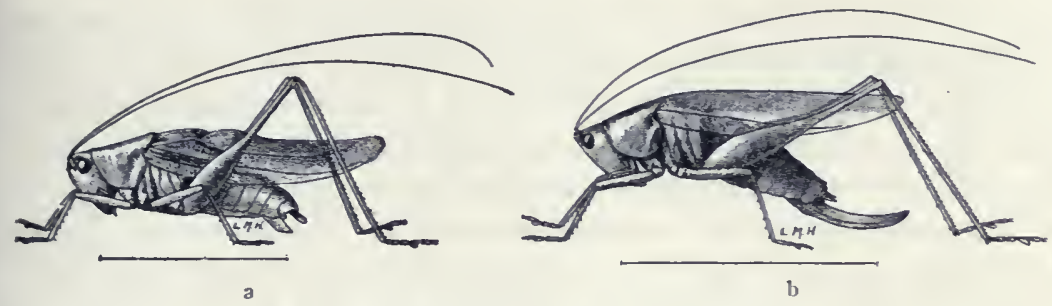

Fig. I8I. $a$, Male; $b$, female. (After Lugger.)

tooth somewhat flattened with tip sharp, decurved (Fig. 179, c.) Length of body, $\hat{\delta}, 18-22$, $q, 18.5-23$; of pronotum, $\hat{o}, 5-6$, ㅇ, 5.4-6.5; of tegmina, $\hat{\delta}, 18-26$, ㅇ, 19-27; of hind femora, $\hat{o}, 14-19$, ㅇ, 14.5-20; of ovipositor, 7.5-8.5 mm. (Fig. 181.)

This meadow grasshopper is probably the most abundant member of the family Tettigoniidæ found in Indiana. It begins to reach maturity in the central part of the State about July 10th, and more frequently than any other of our species of Orchelimum is found in upland localities, along fence rows, and in clover and timothy meadows. In early autumn it seems to be very fond of resting on the leaves and stems of the ironweed, Vcrnonia fasciculata Michx., so common in many blue-grass pastures.

At times $O$. vulgare appears to be somewhat carnirorous in habit, as, on two occasions, I have discovered it feeding upon the bodies of small moths which in some way it had managed to capture; while on another date I surprised a female on the flowers of a golden-rod, feasting upon a soldier beetle, Chauliognathus pennsylvanicus DeG. According to Hancock (1904) it is not only carnirorous but also a cannibal, as a female kept in captivity captured her mate and "holding his body between her fore legs ate the larger portion of the soft parts, after first eating a hole in the back." He suggests that the "long spines of the fore and middle tibia are occasionally used and connected in this species with its carnivorous habits."

O. vulgare is not only the most common member of the genus locally but is more widely distributed than any other, its known range extending from southern Maine and southern Quebec, north and west through Ontario to northern Minnesota, Colorado and eastern Wyoming, and south and southwest to North Carolina, Macon, Ga. $(F \circ x)$, northwestern Arkansas and northeastern Texas. The larger, longer winged individuals have by many writers, including myself $(1903,385)$ been wrongfully recorded as o. glaberrimum (Burm.), a species which R. \& H. aver replaces vulgare in the southern states and which I have included abore as o. erythrocephalum Davis. 
In Ontario Walker $(\mathbf{1 9 0 5}, \mathbf{3 4})$ found vulgare "the only species of Orchelimum distributed generally over a large part of the province. It becomes gradually scarcer to the north of Lake Simcoe, and, I believe, does not range much farther north than Muskoka. Where found it is usually common in upland fields as well as low meadows and is fond of perching in clumps of tall grass. It reaches maturity in this latitude towards the end of July and lasts until about the beginning of October."

Scudder set the call note of the male of $O$. vulgare to scale and (1893, 73) wrote of it as follows:

"When about to sing on a hot, sunny day, the male mounts a stalk of grass to about a foot from the ground where it clings with its four front legs, allowing its hind legs to dangle on either side of the stalk that they may not interfere with the movements of the tegmina. Beginning with $t s$ it changes almost instantly to a trill of $z r$; at first there is a crescendo movement which reaches its volume in half a second; the trill is then sustained for a period varying from one to twenty seconds (generally from six to eight seconds), and closes abruptly with $p$. This strain is followed by a series of very short staccato notes sounding like jip, jip, jip, repeated at half second intervals; the staccato notes and the trill alternate ad libitum. The staccato notes may be continued almost indefinitely, but are very rarely, heard more than ten times in direct succession; they ordinarily occur three or four times before the repetition of the phrase, but not more than two or three times when the phrase is not repeated. The night song differs from that of the day in the rarer occurrence of the intermediate notes and the less rapid trill of the phrase; the pitch of both is at B flat."

Hancock (1904) has given an excellent description of the egglaying habits of $O$. vulgare (glaberrimum) in captivity, from which I quote as follows:

"On the 6 th of September a female was noticed exhibiting rather restless actions among the loosely spread stems of one of the boquets of flowers, and soon after I found her ovipositing in a stem of the bur marigold. Before selecting the marigold as the proper plant for her immediate needs, she tested a number of different kinds of plants by biting the stems. When at last the coveted stem was found, she started very vigorcusly biting, moving her head from side to side in an endeavor to get a stronger hold with her jaws. A gash into the outer layer of the stem was soon made, about an eighth of an inch in length, the insect finally going back over the course of the incision with the evident purpose of more deeply penetrating to the pith. During this first stage in the process the female stood with her head directed downwards, but as soon as the spot was prepared with the mouth she reversed her body preparatory to the act of oviposition. Firmly grasping the plant stem with her feet she curved the abdomen underneath, at the same time bringing the pointed extremity of the ovipositor into the breach made in the stem. Now she stood with her ovipositor under the abdomen with the blades slightly imbedded, but grad- 
ually as it was worked within the stem she almost imperceptibly moved forward a little at a time Finally when the ovipositor was buried to its utmost length it was directed backwards. It was now appreciated how well adapted the beautiful curre and structure of the organ are for this purpose. A moment later the blades were spread apart, allowing the elongate egg to be lodged within the center of the pith, the latter having been pressed to either side for the accommodation of the egg. As soon as the first egg was deposited, she withdrew the ovipositor and immediately turning around she again bit the same spot, spending several minutes chewing the fibers and pinching the sides together with her powerful jaws. This was done in order to use the same opening to deposit the second egg. She next moved a little way down the stem, but this time her head was di. rected downwards so that she might insert the ovipositor in the same hole, but deposit the second egg in a reversed position to that of the first. When the third and fourth eggs were about to be deposited she moved down the stem to a new site about half an inch away, varying the distance, and the process with its several stages was repeated The interior of the stem was finally filled for a considerable distance with eggs, about ten minutes being consumed in the deposition of each one, nine incisions being made in the one stem and 18 eggs deposited. It may be of interest to note that Riley $(1884,187)$ mentions that this species oviposits in the stems of various pithy plants, and especially in the tassel stem of Indian corn."

Yotwithstanding its wide distribution and common oceurrence O. vulgare has not a single synonym. Redtenbacher $(1891,500)$ placed vulgare as a synonym of DeGeer's Tiphidium agile, stating as his reason for so doing that Harris and Scudder had separated the two "on account of small differences in the color and size of the wing covers, as well as in the length of the ovipositor." I pointed out $(1903,384)$ that his relative measurements of $T$. agile as given, did not agree with specimens of undonbted vulgare in my possession, and retained the latter species as distinct. In this I have been upheld by recent writers.

248. Orciedrmud GLAdiator Bruner, 1891, 71. Gladiator Meadow Grasshopper.

Size medium, form robust. Pale transparent grass-green throughout; the usual dark brown markings on the occiput and disk of pronotum; on the latter composed of two well defined, narrow, slightly diverging lines; antennæ rufous, tarsi and extreme tip of ovipositor tinged with rufous. Fastigium short, obtuse, the extreme tip shallowly sulcate. Pronotum much as in vulgare, the metazona a little more upturned; lateral lobes deep, their lower hind angle subrectangular. Tegmina somewhat variable in length, usually but slightly passing tips of hind femora, female, more distinctly so, male; inner wings of same length as tegmina, male, a little longer, female. Hind femora usually unarmed beneath, rarely with one or two short spines on outer margin. Cerci of male as in key and Fig. 179 ; subgenital plate as in vulgare, the styles longer. Ovipositor as described in key. Length of body, $\hat{o}, 17, \uparrow, 18-20$; of antennæ, $\hat{\delta}, 43$, $\uparrow$, 
35 ; of pronotum, $\hat{\delta}, 4.3-5$, ᄋ, 4.7; of tegmina, $\hat{\jmath}, 19-23$, ९, 19-21; of hind femora, ô, 12-14,, , 15.5-17; of ovipositor $10 \mathrm{~mm}$.

In Indiana this species has been found only in the northern counties, where it is quite common in damp prairies, meadows and marshes, and begins to reach maturity about July 10. A pair were found mating in Marshall County on July 29.

The range of gladiator is almost as great as that of vulgare, but it is nowhere as common as that species. It is known from Montreal and New England west to Washington and northern California, and south and southwest to New Jersey, 'Tennessee and northeastern Kansas. Walker (1910, 352) redescribed the male from Ashdown, Manitoba as $O$. manitobense. It is not recorded definitely from Michigan and in Ohio only from Cedar Point. Specimens are at hand from Algonquin, Ill. (Nuson.) Walden does not include it in his Orthoptera of Connecticut, though it had been taken in that State by Morse in 1894. It lias been erroneously recorded a number of times as $O$. vulgare. but the females are easily separated by the form of the ovipositor and the males by the long tooth of cercus and the very feeble humeral sinus.

249. Orchelimum Pulchellum Davis, 1909, 33. Handsome Meadow Grasshopper.

Size medium; form moderately robust. Pale green; head often in great part reddish, face yellow; pronotum with the usual dorsal dark stripe; sides bottle green; under surface yellow, that of abdomen notably so; femora lemon-yellow below and within, the apical third of hind pair reddish; tibiæ of all the legs reddish, tarsi fuscous. Fastigium narrow, its apical half scarcely wider; eyes very prominent. Pronotum short, subsellate, metazona less than one-half the length of prozona; lateral lobes deeper than long, lower margin short, its hind angle narrowly rounded; humeral sinus evident but shallow. Tegmina with apical half strongly tapering, surpassing hind femora $3 \mathrm{~mm}$. exceeded by wings the same distance. Cerci as in key and Fig. 179, e, its upper outer edge raised in an obtuse carina and apical half oblique, concave within, the tip obtuse. Notch of subgenital plate broadly V-shaped, the styles very short, obtuse. Ovipositor rather wide, moderately curved, distinctly more than half the length of hind femora, its apex slightly surpassing the tips of tegmina (Fig. 180, c.) Length of body, $\hat{\sigma}, 18-19$,, , 18.3-22.8; of pronotum, $\hat{\delta}$ 5 , 우 $4.2-5.7$; of tegmina, $\hat{\delta}, 20-23$, ㅇ, 18.7-28.3; of hind femora, $\hat{\delta}$, 16-18, 오, 15.3-19.2; of ovipositor, $9-11 \mathrm{~mm}$.

Helmetta, Dennisville and Jamesburg, X. Jer., Sept. J-21 (Daris) ; Tappahannock, Ta., Sept. 19 (Fox) ; Rosslyn. Va.. Sept. 12 (C'audell). Described from the first two localities above mentioned, where Davis found them on the tall grass in a rely wet swamp. 
R. \& H. (1915a, 53) have made this a srnonym of 'O. laticanda Redt. (1891, 504) deseribed from a single female taken at New Orleans, La. This was done without examination of the type of liticanda and only by comparison with Redtenbacher's brief description. In this there are sereral notable discrepancies, when compared with undoubted specimens of $O$. pulchellum, viz.: "lobi lateralis pronoti margine postico sinuato." This is not true of pulchellum and R. \& H., in their ker to females of Orchclimum separate laticauda from nigripes by the former having the "caudal margin of lateral lobes gently arcuate ventrad of humeral sinus," whereas in nigripes it is said to be "sinuate or subsinuate rentrad." Again, Redtenbacher says: "Elytra femora postica valde superantia, alis multo breviora," whereas in pulchcllum the tegmina at most surpass the hind femora $3-4 \mathrm{~mm}$., and are only $3-4$ mm. shorter than the wings. Finally Redtenbacher in his key separates laticauda from four other species by its having the "femora postica utrinque spinulosa," while in pulchcllum, as K. \& $H$. admit, "the vast majority have the internal margin unarmed." What laticuuda was or is I know not nor do I believe any one else can tell without an examination of the type. I have therefore restored the name given by Davis to this grasshopper.

Of the types of this species Davis wrote: "When seen in life the insect is particularly beautiful and is conspicuous for its bottle-green colored tegmina, with a bluish tinge, its lemon-yellow markings and its reddish legs. Its song was a zip, zip, zip-z, z, $\approx$. $--z i p, z i p, z i p-\approx, z, z,-q u i t e$ a distinguishable song from that of o. vulgare."

The range of laticauda so-called by R. \& H., including pulchetlum Davis, is given by them $(1915 \mathrm{a}, 54)$ as "Covering the Atlantic Coastal Plain region from north central New Jersey south to southern Florida, westward to New Orleans, La.; in the eastern states occurring at suitable valley localities in the Piedmont region above the fall line." In Florida it has been recorded from Atlantic Beach, Jacksonville, Ortega, Sanford, Palatka, Detroit, Lakeland and Chokoloskee, most of the records being made under the names nitidum and pulchellum.

McAtee and Caudell record (1917) pulchellum (under the name laticauda) from numerous localities about Washington, D. C., and Fox (1917) states that about Tappahannock, Va.. it is "occasional in a variety of situations, occurring regularly in tidal and fresh water marshes and pond borders, but the males, at least, spreading in small numbers to upland districts where the 
species was taken in a field of dense millet and in a thick growth of ragweed bordering tlie fence of a town lot. In the tidal marshes it was found in the tall marsh-grass, spartina cynosuroides (L.) and in a marginal fringe of switch-grasses. In fresh water bogs it was taken on various grasses, cat-tails, sedges and bushes. Unlike most nembers of the genus it appears to have a strong preference for woodland habitats."

250. Orchelinum bullatum Rehn \& Hebard, 1915a, 50.

Size above the medium for the genus; form robust. Pale green fading to dull yellow, the tegmina alone remaining in great part green; the usual dark bars on occiput and pronotum vague, often broken into small oblong fuscous spots; antennæ and tibiæ uniform dull reddish-yellow. Fastigium prominent, its sides divergent from base and rounded beyond the middle, the apex therefore distinctly wider than base. Pronotum short, broad, feebly sellate; metazona two-thirds the length of prozona, the transverse sulcus in male deeply and broadly impressed, lateral lobes slightly deeper than long, lower margin much less oblique, with hind angle much less narrowly rounded than in nigripes; humeral sinus distinct, in male deeper than in pulchellum. Tegmina surpassing hind femora $3-5 \mathrm{~mm}$, exceeded by wings $3-4 \mathrm{~mm}$; their cross-veins very prominent, especially so in female. Cercus of male stouter than in nigripes, its apical portion more evenly tapering; tooth shorter, stouter, more erect. Ovipositor distinctly wider throughout its length than in either nigripes or pulchellum, less curved than in the former, longer than in the latter (Figs. 179, 180, $h$.) Other differences as given in key. Length of body, $\delta, 18-19$, $ᄋ, 19-21$; of pronotum, ㅅ․ $5-5.3$, ㅇ, 5.2-6; of tegmina, $\delta, 23-25$, ㅇ, 25-27; of hind femora, $\hat{\delta}, 17-18$, $\circ, 19-20$; of ovipositor $10-11.5 \mathrm{~mm}$.

Tippecanoe Co., Ind., three males, five females $(F \circ x)$. This is the Orchelimum recorded by Fox $(1915,318)$ as "O. nigripes Seudd. (variety.") He states: "On October 13 and 14 I found a form of this genus in a cat-tail marsh on the upland northwest of Lafayette which I was unable to determine, but which Mrr. Rehn, to whom I submitted specimens, informs me is a race of $O$. nigripes from the typical form of which it differs in the absence of black from the tibiae and, so far as my Lafayette material is concerned, in its somewhat greater size. On the dates mentioned it literally swarmed in the mixed cat-tail and rice cut-grass areas of the marsh, but was entirely lacking in the marginal thickets."

That this is a rery distinct species from both nigripes and pulchellmm is shown by the differences I have pointed out in key and description. I was at first inclined to consider it an undescribed form, but Dr. Fox, who made for me a drawing of the male cercus, called my attention to its close similarity to that of bullatum as figured by R. \& H. A comparison with their descrip- 
tion shows that while the Indiana males are somewhat smaller than the measurements given, they agree otherwise so closely that there is little doubt but that they represent the northern form of that species, hitherto known only from Louisiana and eastern Texas. R. \& H. state that in Texas it was "found frequenting high grasses along streams or in depressions. The note was a long buzzing zсесесес somewhat resembling that of some cicadas, with but few interspersed clicking sounds."

251. Orchelimum Nigripes Scudder, 1875, 459. Black-legged Meadow Grasshopper.

Size medium for the genus; form robust. General color green or reddish-brown, the former prevailing in male, the latter in female; occiput and disk of pronotum with the usual brown markings; front and sides of head, and fore and middle femora, reddish-yellow; antennæ and all the tibiæ and tarsi, together with apical third of hind femora, black or dark brown at least above; in one specimen at hand the whole body, except tegmina and femora, black. Fastigium narrow, its sides subparallel, and apex very feebly if at all widened. Pronotum short, distinctly saddle-shaped in male where the metazona is rather strongly upturned; lateral lobes distinctly deeper than long, their lower margin very oblique, its hind angle narrowly rounded; convex callosity narrow but distinct. Tegmina equalling the wings, male, a little shorter, female. Shrilling organ of male unusually large and prominent with strong crossveins; behind it the tegmina taper rapidly on both margins, their shape and the size of the tympanum causing the male to appear somewhat peculiar and more robust than it really is. Hind femora armed on apical half of lower outer carina with one to four small spines. Cerci of male slender, tapering, concave within. its apex obtuse. Ovipositor strongly curved, broadest at middle, tapering

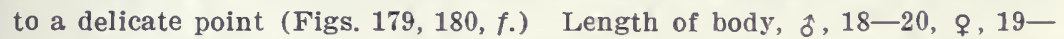
21 ; of antennæ, $66-80$; of pronotum, $\hat{\delta}$ and $\uparrow, 4.3-5$; of tegmina, $\hat{\delta}$, $20-22$, ᄋ, 22-25; of hind femora, of, 16-17, ㅇ, 17-19; of ovipositor, $9-$ $10.5 \mathrm{~mm}$.

Next to $O$. vulgare this handsome black-legged grasshopper is the most common Conocephalid in Indiana, occurring by hundreds about the margins of every lake, pond and marsh in the State. It is essentially a lowland or hygrophilous species and is seldom found about the drier uplands where vulgare has its favorite haunts. It reaches maturity about July 20 , and frequents the tall grasses and especially the stems and leaves of the different species of smartweed, Polygonum, growing in the shallow water of the larger ponds and lakes. Near Lafayette Fox (1915) found it "an abundant and characteristic species of open grassy bogs and damp situations generally, being especially common in the rice cutgrass, Homalocenchrus oryzoides (L.)." Examples of the parasitic hairworm, Gordius sp.?, have been taken from the abdomens of a number of specimens. 
The type of Scudder was from Dallas, Texas, and the species luas its main distribution west of the Mississippi, ranging from Ohio and southern Ontario south to Tennessee and Louisiana, and west to Colorado and central Texas. Of its habits in Ontario Walker (1905, 36) has written: "On August 7, 1901, while collecting at Point Pelee in a low woods bordering a strean, I heard a sound very like the stridulation of $O$. vnlgare, but more subdued, the "zips" coming at much shorter intervals, and more of them produced at a time. I succeded in tracing the song to its source and found an Orchelimum quite new to me which proved to be $O$. nigripes. Another male was taken in the same way. and I heard others but was unable to find them. In several cases the sound proceeded from trees at a height of some ten or fifteen feet. but as a rule it came from tall weeds and vines which grow in great luxuriance upon the rich black soil."

At Moline, Ill., McNeill (1891, 25) found it "about as common as vulgare. It is not at all shy but even shows a preference, I have thought, for human society. I have known a male to keep a place over the wooden finish of a doorway for more than a week. If lie ate during that time he must have been obliged to leave his post to satisfy his hunger and he probably returned many times to the place. The song is difficult to distinguish with certainty from that of vulgare but usually the aip-zip is repeated only once or twice very rapidly and the $z-e-e-e-e$ does not continue so long."

The $\Gamma$. (O.) robustum Redt. $(1891,499)$ described from New Orleans, La., is placed by R. \& H. as a synonym of $O$. nigripes.
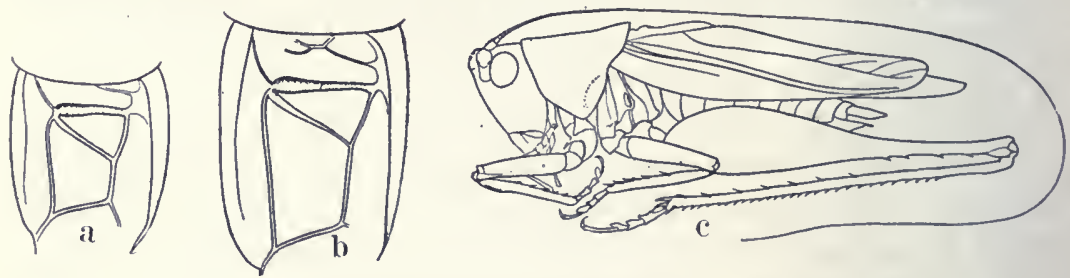

Fig. 182, a, Outline of stridulating field of male of $O$, $\tau^{\prime} u l g a r c ; b$, same of $O$. erythrocephalum, $\times 3$; c, outline of male type of $O$. calcaratum, $\times 2$. (After $R$. \& H.)

252. Orchelimum calcaratum Rehn \& Hebard, 1915a, 46. Long-spurred Meadow Grasshopper.

Size medium for the genus; form moderately robust. Pale green, oc ciput and disk of prozona with usually a median pale brown stripe, this darker on the sides; stridulating field of male with three spots of blackish brown as in vulgare, two at base and one on left near apex; abdomen of male often with a dark blotch above; ovipositor pale brown. Fastigium feebly ascending, but slightly wider than basal jolnt of antennæ. Antennæ nearly four times as long as body. Pronotum slightly saddle-shaped, met- 
azona feebly ascending, two-thirds the length of prozona; lateral lobes slightly longer than deep, lower margin straight, oblique, its hind angle obtuse; humeral sinus scarcely evident. Tegmina not or very rarely reaching tips of hind femora, surpassed by wings about $2 \mathrm{~mm}$. Hind femora robust, armed on lower outer carina with three or four spines. Cerci as in key and Fig. 179, $g$, their tips subdepressed and tapering to a dull point; notch of subgenital plate shallowly U-shaped; styles short, their tips obtuse. Ovipositor about half as long as hind femora, rather broad, regularly curved. Length of body, $\hat{o}, 19.5-23, \uparrow, 17-20$; of pronotum, $\hat{\delta}, 5.2-$ $6.2, \uparrow, 5.6-6$; of tegmina, $\hat{\delta}, 16-19$, o , 16.5-18; of hind femora, $\hat{o}, 17-$ 21, \&, 19-20; of ovipositor, 9-9.6 mm. (Fig. 182, c.)

Clarksville, Tenn., Aug. 13, 31 (Fox). The known range of this species is mostly sonthwestern extending from southeastern Illinois and north-central Tennessee west to Colorado and southwest to central Texas. East of the Mississippi it luas lefore been recorded only from Olney, Ill., a female taken there by Ridgeway being in the U. S. National Museum collection.

It is a rather sliort bulky species, resembling a small rulgure. the male being easily known by the long. slender. sharp-pointed tooth of cerci, the female more difficult to separate but known by the less robust fastigium, very faint lumeral sinus, and armed hind femora. R. \& H. (1915a, 4S) state that "This species is clumsy in its actions, and once located, easy to capture. In Texas it was found in a great variety of situations, ranging from high grass to 12 feet above the ground in post oak. It was taken in grass among cotton, in green weeds. low bushes and in tall nettles as well as in bushes in pine woods. The stridulation is not lond."

The X. (O.) cuticulare Redt. (1S91, 503) nec. Serville is placed by R. \& H. as a synonym of calcaratum.

\section{Group II. The Coxcixsum Group of Orchelisum.}

Here belong seven nominal species and two varieties having the apical portion of male cercus distinctly longer than the basal portion. In size and form (except in superbum) they are generally smaller and more slender than the members of Group I, and the ovipositor, except rarely in concinnum, is always more than half the length of hind femora.

KEY TO EASTERY SPECIES OF GROUP II OF ORCIELIMUM.

a. Apical portion of male cercus not strongly tapering to an acute apex: tooth of cercus (except in superbum) arising as usual from the inner side of shaft and not strongly recurved toward base (Fig. 183 . $a-c)$; upper margin of ovipositor (except in delicatum) regularly and evenly curved.

b. Humeral sinus of lateral lobes distinct (Fig. 184, a); tooth of male cercus normal in point of origin; smaller and more slender, length of body in both sexes less than $21 \mathrm{~mm}$. 
c. Lower outer carina of hind femora with 3 to 5 spines beneath; lateral lobes of pronotum slightly longer than deep; ovipositor more than two-thirds the length of hind femora (Fig. 184, e.)

253. MIYOR.

cc. Lower outer carina of hind femora very rarely armed beneath; lateral lobes of pronotum deeper than long (Fig. 184, a.)

d. Ovipositor very slender, distinctly falcate, but little more, or even less, than half as long as hind femora (Fig. 184, a); males larger, (length of body 17 or more mm.) and more robust.

e. Face with a dark reddish-brown stripe down its center; hind femora more robust and relatively shorter, 14-17 $\mathrm{mm}$.

254. coxcixinum.

ee. Face green without a median brown stripe; hind femora relatively longer and more slender, $16-18 \mathrm{~mm}$.

254a. CAMPESTRE.

dd. Ovipositor distinctly broader and much straighter, nearly three-fourths the length of hind femora (Fig. 184, $f$ ); males smaller (not over $16 \mathrm{~mm}$.) and more slender.

254b. DELICATUM.
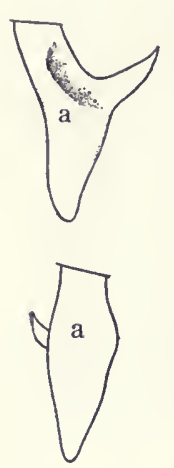
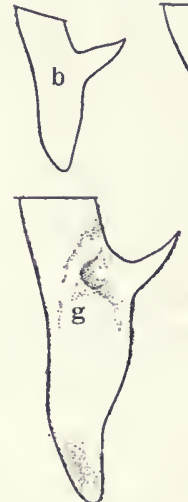
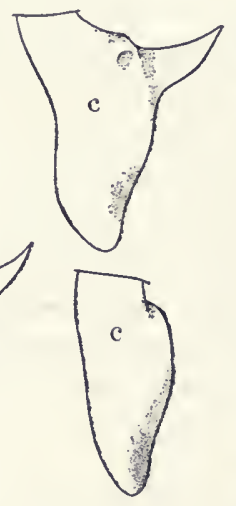

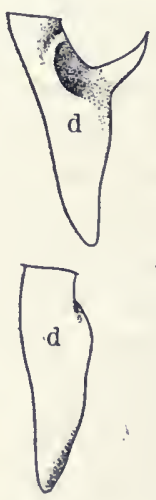

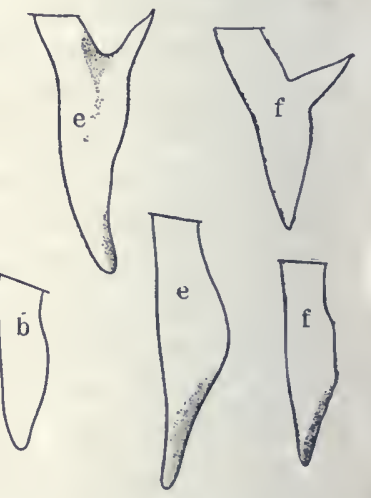

Fig. I83. Dorsal and lateral outlines of left cercus of male Orcheimum (X 9). a, minor; $\mathrm{b}$, concinnum; $\mathrm{c}$, superbum; $\mathrm{d}$, fidicinium; $\mathrm{e}$, militare; $\mathrm{f}$, volantum; $\mathrm{g}$, bradleyi. (After R. \& H.)

$b b$. Humeral sinus very faint or obsolete (Fig. 186, $b$ ); tooth of male cercus arising from the lower face of shaft and strongly recurved toward base of latter (Fig. 183, c); larger and more robust, length of body, 22-25 mm.; ovipositor broad, but slightly more than half the length of hind femora.

255. SUPERBUM.

$a a$. Apical portion of cercus distinctly and strongly tapering to a subacute apex (Fig. 183, $d-g$ ) ; tooth of cercus, except in volantum, either arising from the inner lower face of shaft or directed strongly backward; upper margin of ovipositor, except in fidicinium. straight or nearly so.

f. Ovipositor two-thirds or more the length of hind femora; speculum of stridulating field of male but slightly longer than wide (Fig. 187, $a$ ) ; form more slender. 
g. Lateral lobes of pronotum as long as deep, their humeral sinus evident but shallow; cercus more robust, less tapering; ovipositor less than $12 \mathrm{~mm}$. in length, its upper margin with a slight but evident regular curve (Fig. 184, b.)

256. FIDICIXIUM.

gg. Lateral lobes deeper than long, the humeral sinus very distinct; cercus much longer, more slender, strongly tapering; ovipositor 15 or more $\mathrm{mm}$. in length, its upper margin straight or nearly so (Fig. $184, c$ )

257. MILITARE.

$f f$. Ovipositor less than two-thirds the length of hind femora (Fig.

$184, d$ ) ; speculum of male distinctly longer than wide (Fig. 187,

b) ; lower outer carina of hind femora always armed beneath.

$h$. Tooth of cercus diverging on a plane with dorsum of cercal shaft, but slightly recurved toward base of latter (Fig. 183, $f)$; apical portion of cercal shaft regularly tapering, quite acute.

258. volaNTUM.

$h h$. Tooth of cercus diverging from the lower inner face, more strongly recurved; apical portion of shaft subarcuate, less acute, more strongly depressed when viewed from the side (Fig. 183, g.)

259. BRADLEYI.
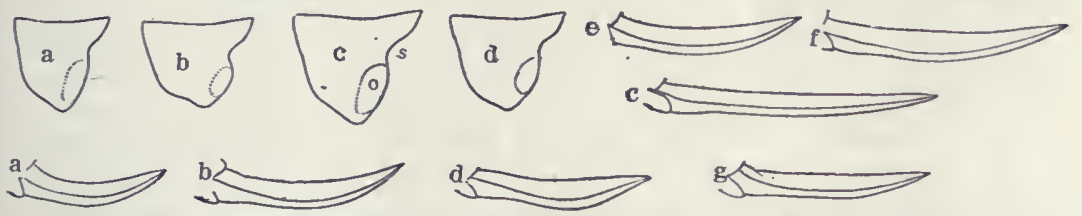

Fig. I 84. Outlines of lateral lobes of male pronotum, $X .3$, and of ovipositor, $X .3$, of Orchelimum. $\mathrm{a}$; concinnum; b, fidicinium; c, militare; d, iolantum; $\mathrm{e}$, minor; $\mathrm{f}$, delicatum; g, bradleyi; s=humeral sinus; o=convex callosity. (After R. \& H.)

\section{ORChelimum Mixor Bruner, 1891, 72. Pine Tree Grasshopper.}

Size small; form slender. Usually pale reddish-brown with face, lateral lobes of pronotum and all the femora green; the usual dark brown stripe of pronotum bordered outside with a narrow yellowish one. Fastigium slender, strongly ascending, its apex but little wider than base with sides feebly rounded. Pronotum of male subsellate, of female with metazona not upturned; lateral lobes with lower margin feebly sinuate, its hind angle narrowly rounded; humeral sinus distinct but shallow. Tegmina short, scarcely reaching tips of bind femora, very slightly shorter than wings, male, surpassing the femora $1.5 \mathrm{~mm}$. and exceeded by wings the same distance, female. Cerci as in key and Fig. 183, $a$, their apical portion feebly concave within, the tip obtuse. Ovipositor broad, three-fourths as long as hind femora, but slightly falcate, Fig. 184, e. Length of body, ๙ิ, 15-16.5, ᄋ, 15.4-19; of pronotum, ô, 4.2-4.5, ㅇ, 4.2-5; of tegmina, $\hat{o}, 15-16.5$, $9,14.8-17.5$; of hind femora, $\hat{o}, 13.2-14$, ㅇ, 14-15; of ovipositor, $11 \mathrm{~mm}$. (Fig. 186,a.)

Lakehurst, N. Jer., Sept. 4-6 (Davis) ; Tappahannock. Va., Sept. 14, $22(F o x)$. A small species of eastern distribution, ranging from central New Jersey to Georgia and west as far as the mountain valless of North Carolina, at an elevation of 2,500 
feet, and the vicinity of Washington, I. C. Bruner's type was from the District of Columbia and was rery briefly described. It appears to be a pine-loving arboreal species and Davis (1904) has given an interesting account of its habits from which I quote as follows:

"Those who visit the pine-barrens of New Jersey know what a pleas. ure it is to ramble along the narrow wooded-paths among the pine trees; old paths that after once being made continue for many years, and may seldom entertain a pedestrian. Along these paths and by the side of the sandy roads, any time during late summer and until frost, one may hear a faint, lisping little song from a grasshopper coming from the pines, often from their topmost branches. It is an easy matter to climb the pitchpine, which is usually arranged admirably for the purpose, and the grass. hopper is also friendly to investigation, and commonly continues to stridu. late.

"Two stout insect-nets clapped together suddenly about the center of the music will often disclose the grasshopper in one of them, but not always. He is a tree-loving insect, and being subject to the tossings of the wind, holds on tighter than most grasshoppers that I have had dealings with. It is, in fact, the only arboreal orchelimum that I have found in New Jersey.

"Sometimes Orchelimum minor can be observed on the low branches of a pine especially if the tree stands in the open, and the insect may occasionally be beaten into an umbrella. When the trunks of the pines are 'sugared' for moths the little minor also attends, and, like many other members of the genus, it is active and musical both by day and night."

Of its habits in Georgia Allard $(1910 b, 35)$ wrote: "Its notes are a succession of brief, feeble, silken lisps followed by a pause about as long, then repeated $s-s-s-s-s-s-s-s-s-s-s-s-s-s-s-s-s-s$. I hear it during the warm, sunny hours of the day, even in the highcrowned pines around my house. So faint and fugacious are its notes that it is probably nerer identified by ordinary ears. If a good breeze is blowing, the feeble lisps are lost amidst the sighing and rustle of the pines upon which they dwell. In no manner do the notes to me recall those of any other Orchelimum. The short staccato lisps so characteristic of the songs of most Orcheli. mums are entirely wanting and the tone quality more nearly resembles the leg and wing stridulations of some of the Stenobothri than the Orchelimums."

254. Orcilelimum coxcixyum Scudder, 1862, 452. Dusky-faced Meadow Grasshopper.

Size medium for the genus; form slender. Color variable, fresh specimens usually with tegmina and wings translucent pale brown, tinged with green on costal margin; sides of pronotum and abdomen, and all the femora, pale green; tibiæ and tarsi of a brownish hue; face yellowish-white. 
with a dark reddish-brown stripe the width of labrum, starting with mouth aud passing upward to vertex, where it narrows to the width of that organ; then, broadening on occiput, passes back to front border of pronotum, where it divides into two narrow streaks which enclose a whitish area and extend slightly onto metazona; subgenital plate of male yellow; basal third of ovipositor dark brown, the remainder pale reddish-brown. Fastigium short, feebly ascending, its apical portion slightly wider than base with sides and apex rounded. Fronotum short, metazona but slightly ascending. male, not at all, female; lateral lobes with lower margin feebly sinuate its hind angle rounded. Tegmina narrow, tapering; slightly shorter than wings and of a delicate texture. Hind femora slender, shorter than the clcsed tegmina, unarmed beneath or very rarely with one or two spines on the outer carina. Cercus of male longer than subgenital plate, tapering to a

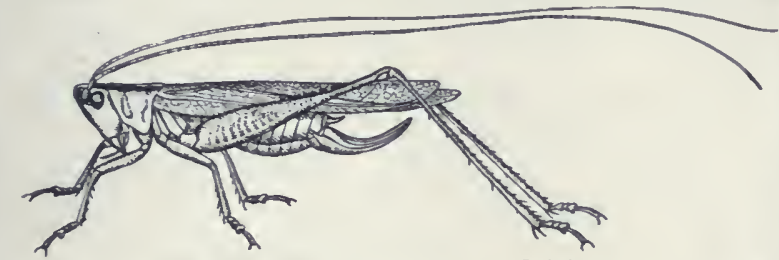

Fig. 185. Female. $X$ 1.5. (Original.) dull point; its tooth short, erect, with a broad base and very sharp, slightly bent point (Fig. 183, b.) Ovipositor of less than average width, about half the length of hind femora, its apical half with a gentle upward curve. Length of body, $\hat{\sigma}$ and $\rho, 16.5-18$; of pronotum, $\hat{\delta}, 4-$ 5.5 , ㅇ, 4-5; of tegmina, ô, 19-23, ㅇ, 17-24; of hind femora, of, 14-16. ९, 13.5-17; of ovipositor, 7.5-8.2 mm. (Fig. 185.)

In northern Indiana this graceful and prettily marked species is quite common among the rank grasses and sedges growing about the margins of tamarack swamps and lakes. where it reaches maturity about July 20th. It occurs also in small numbers about a lirge marsh in Marion County but has not been taken in the southern part of the State.

R. \& H. (1915a, 60) have restored the $O$. concinmum of Scudder as a valid species and have made my indianense $(1893 c, 90)$ and six other forms synonyms of it. They are probably correct as regards indianense, although Scudder gave an opinion that it was a new form before it was originally described. In his later writings Scudder regarded his concinnum as a synonym of herbaceum Serv. (1839, 524), a name which R. \& H. have placed with a questıon mark under their $O$. fidicinium, adding: "We have no definite proof that herbuceum is the same as fidicinium and, until we have some positive information of this sort we do not care to replace a well understood name by another of doubtful status." It would have been better if the same course had been followed with 0 . agile, glaberimum. nitidum and laticauda.

S.'udder's trpes of concinmum were from Cape Cod, Mass., and the species, as determined by R. \& H., ranges from sonthern New 
England and Ontario west to northern Michigan, southeastern Minnesota and central Montana and south and southwest to Florida, Mississippi, central Texas and New Mexico.

In Florida it has been taken by me at Dunedin in December and January from tall grasses about the margins of shallow ponds where it occurs in company with Leptysma marginicollis and Conocephalus gracillimus. It has also been recorded from scattered localities throughout the State, but the adults were usually scarce, though Hebard (1915b) says that "In July the marshes of the region about Miami swarm with the young."

Under the name of $O$. indianense Walker $(1905,37)$ recorded it as common in August near Sarnia, Ont., in a large tract of open grassy land, and also as found in marshes at Arner and on Walpole Island. R. \& H. (1915a, 65) state that: "From the eastern States we know of no correct record of the occurrence of the species at a locality away from the general vicinity of the coast." Ir Virginia Fox found it abundant among the grasses and sedges of the tidal marshes.

254a. Orchelimum Concinnum CAMPestre Blatchley, 1893c, 91.

Differs from typical concinnum in its slightly larger, more robust form, generally paler color, the ground hue being more often green than pale brown, uniform green face, longer, more narrow and less tapering: tegmina and relatively longer and more slender hind femora. Length of body, ô, 17.5, ᄋ, 19 ; of antennæ, 46 ; of pronotum, ô, 4.2-4.5, ᄋ, 4.5-5; of tegmina, $\hat{\delta}, 21-24$, $\&, 20-25$; of hind femora, $\hat{o}, 16-17, \stackrel{\imath}{,} 16-17.5$; of ovipositor, $7-7.5 \mathrm{~mm}$.

While this form agrees with concinnum in the size and shape or the male cerci, it differs sufficiently in the characters given to justify at least a varietal name. In Indiana it is frequent as far south as Knox County, inhabiting for the most part upland bluegrass pastures and the tall grasses of the dryer prairies and being seldom, if ever found about the lakes and marshes in company with typical concinnum. I have taken it at Buffalo, X. Y.. on Sept. 4, and it has been definitely recorded from Ontario, Ohio, New Jersey, Illinois and Minnesota. It is also known (Fox Ms.) to occur near Clarksville, Tenn.

254b. Orchelimum concinnum delicatum Bruner, 1892a, 264. Delicate Meadow Grasshopper.

Smaller and more slender than 0 . concinnum. Color much the same, the face without a dark stripe. Pronotum shorter and narrower. the hind margin of metazona more rounded; lateral lobes less deep, the humeral sinus more evident. Strldulating field narrower, the cross-veln shorter, more slender. Subgenital plate of male narrower, more strongly keeled be- 
neath. Ovipositor very feebly curved above, distinctly longer and broader than in concinnum, its lower margin more strongly tapering to the acute point (Fig. 184, f.) Length of body, $\hat{\sigma}, 16, q, 17.5$; of antennæ, $\hat{\delta}$ and $q$, about 50 ; of pronotum, $\hat{\delta}, 3.8, \mathcal{q}, 4$; of tegmina, $\hat{\delta}, 19, \mathcal{\imath}, 20$; of hind femora, ô, 14, $\uparrow, 15$; of ovipositor, 10.5-13 $\mathrm{mm}$.

Lincoln and West Point, Neb., September (Bruner); Starke and Marshall counties, Ind., July 30-Aug. 20 (WV. S. B.). I cannot follow R. \& H. (1915a, 60) in making this a synonym of concimmum. If the size and form of the ovipositor is of any value whaterel in separating the females of this genus (and they lave used its rariations as the principal differential character in their key to the females) its greater length and distinctly straighter form in delicatum at once separate it from concinnum or its rariety campestre. In order to accommodate their synonymy R. \& H., in this key to females, have had to lead up to concinnum in two different places, as when delicatum was included with it it would not go under "Ovipositor" less than half the length of caudal femur." The differences as given in key and above gre sufficient to retain it as a distinct variety.

This Orchelimum was described from West Point and Lincoln, Nebr., where Bruner found it common about the margins of ponds and along the edges of streams, also at electric lights. In Indiana it has been noted only in Marshall and Starke counties, wliere a half dozen specimens were secured in lowland meadows near large lakes on July 30 and August 20, 1902. It probably occurs throughout the lake region of the northern third of the State and is not elsewhere recorded east of Nebraska.

The 0 . gracile Brumer $(1891,70)$, a preoceupied name, is a sỹnonỹm.

255. Orchelimey superbum Rehn \& Hebard, 1915a, 76. Superb Meadow Grasshopper.

Size large for the genus; form robust, subcompressed. Pale green: tegmina, basal third of hind femora, and sometimes the fore and middle femora, pale brown; dorsal stripes on prozona chocolate-brown, bordered without by paler; abdomen brown above, dull yellow beneath; tibial spines black, pale at base. Fastigium stout, scarcely ascending, but slightly narrowed at base, rounded at apex. Antennæ twice or more as long as body, the basal joint with a rounded tubercle within. Pronotum distinctly subsellate, male, faintly so, female, lateral lobes as long as deep, their lower margin very oblique, its hind angle narrowly rounded; convex callosity elongate, narrow. Tegmina surpassing hind femora about $9 \mathrm{~mm}$, exceeded by wings $4 \mathrm{~mm}$., their tips narrowly rounded. Stridulating area of male shorter and no wider than disk of pronotum, its main vein nearly transverse. Cercus as in key and Fig. 183, c, its middle third robust and inflated, apical third subdepressed and apparently twisted, the tooth stout, 
its tip very sharp and bent. Apex of subgenital plate subtruncate; styles slender, cylindrical, obtuse. Ovipositor stout, distinctly though not strongly falcate, the lower margin of apical half strongly tapering to the acute apex. Length of body, $\hat{\sigma}, 19.6-24.6, q, 24$; of pronotum, $\hat{\delta}, 5-6$, , 7.5 ; of tegmina, $\hat{\delta}, 22-25.4$, ㅇ, 28 ; of hind femora, $\hat{o}, 16-18$, 우 19 ; of ovipositor, $10 \mathrm{~mm}$. (Fi६ 186, b.)

Tappahannock, Va.; July 6; Morristown, N. Jer., July 9 (For). The types were taken by Fox in a bog among clumps of fern, Wooduardia virginica (I.) near Winslow Junction, N. Jer. The species is known only from a few localities in New Jersey and at Tappahannock, Va., where it was found on the three-square rush, Scirpus americanus Pers. in tidal marshes. Two of the Vir. ginia specimens had the outer lobes of the hind knees bispinose instead of unispinose as in the types, thus showing that this character has little if any differential value.
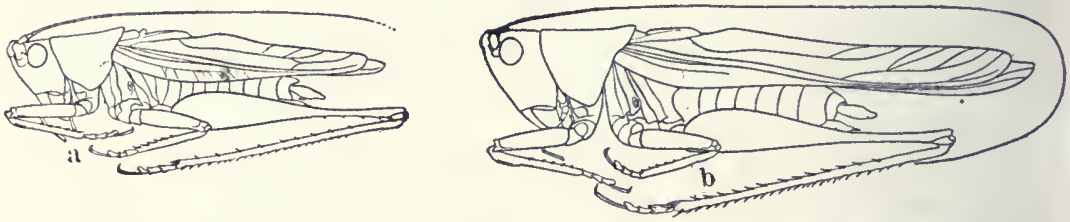

Fig. $186 . \quad$, Outline of male of $O$. minor; b, same of 0 . superbum. $\times 1.8$. (After R. \& H.)

\section{Orchelimum Fidicinium Rehn \& Hebard, 1907, 309.}

Size small to medium for the genus; form slender. Pale green, fading to brownish or clay-yellow; occiput with a median dark brown stripe, this usually extending back, but broken and paler, to metazona; fore and middle femora often mottled with numerous small purplish dots; hind tibiæ and all the tarsi reddish-brown. Fastigium rather stout, feebly elevated above the occiput, its sides subparallel and apex rounded. Antennæ about three times the length of body. Pronotum with metazona on same plane as prozona, its hind margin very broadly rounded; lateral lobes with lower margin oblique, its hind angle obtusely rounded. Tegmina surpassing tips of femora $1.5 \mathrm{~mm}$., exceeded by wings $2 \mathrm{~mm}$., their tips narrowly rounded. Hind femora usually armed on outer lower carina with one to four spines. Cerci as in key and Fig. 183, $d$, the tooth strongly recurved, acute; notch of subgenital plate, broad, shallow; styles short, stout, obtuse. Ovipositor more than half the length of tegmina and extending beyond their tips, very feebly curved, tapering beyond the middle to an acute apex (Fig. 184. b.) Length of body, $\hat{\delta}, 16-18.5$,, $16-19$; of pronotum, $\hat{\delta}, 3.8-4$, , $4-4.5$; of tegmina, $\hat{\delta}, 17-21$,, $21-22$; of hind femora, $\hat{o}, 14-16$, , 16.8-17.5; of ovipositor, $10-11.5 \mathrm{~mm}$.

Tuckerton, N. Jer., Sept. 1 (Davis) ; Ocean View, N. Jer., and Whitestone, Va., Aug. 30, Sept. 26 (Fox), Described from Cerlar Keys, Fla., where 20 or more specimens were taken by $R$. \& $H$. Angust 15, from among tall grasses in the flooded salt marshes. 
Not known elsewhere from that State. The hind femora in the original description were said to be unarmed, and Davis $(1908,223)$ therefore redescribed this species as 0 . crusculum from specimens taken at Tuckerton, N. Jer., and on Staten Island, N. I., most of which had the femora armed. Since that date it has been found at numerous places along the coast from Long Island to south Georgia. It occurs for the most pait among the tall marsh grasses, spartina, and rushes, Scirpus, growing on the tidal flats and in the adjoining brackish marshes.

257. Orchelimum militare Rehn \& Hebard, 1907, 311. Military Meadow Grasshopper.

Size medium for the genus; form moderately slender. Green fading to clay-yellow; head dull yellow, sometimes brick red or with a reddish stripe down middle of face; occiput and prozona with two more or less distinct reddish-brown divergent lines. Fastigium feebly ascending, longer than broad, narrower at base than apex, the latter rounded. Antennx three and one-half times the length of body. Metazona feebly ascending, male, not at all, female, finely punctate; lateral lobes with lower margin short, very oblique, its hind angle obtusely and narrowly rounded; convex callosity prominent, elliptical. Tegmina very narrow, surpassing hind femora $3 \mathrm{~mm}$., exceeded by wings $2 \mathrm{~mm}$., their tips narrowly rounded. Cerci as in key and Fig. 183, e, their tips divergent and tooth directed strongly toward base of shaft; subgenital notch widely V-shaped. Hind femora unarmed, rarely with one or two spines beneath. Ovipositor straight and subequal in width to apical fourth, thence tapering and slightly upcurved to the very acute apex (Fig. 184, c.) Length of body, $\delta$ and $q, 18-22$; of pronotum, $\delta$ and $\$, 4.5-5$; of tegmina, $\hat{\delta}, 2 \hat{\jmath}-25.5, q, 24-25.4$; of hind femora, $\hat{\delta}, 17-17.8$,, $17.5-18$; of ovipositor, $15.2 \mathrm{~mm}$.

LaGrange, Fla., Sept. 13 (Davis). Described from three specimens taken Aug. 17 at Gainesville, Fla., from a marshy sinkhole in pine woods. Other recorded localities in that State are Jacksonville, Atlantic Beach, Crestriew and Detroit. The known range of this trim-bodied species extends from Speedwell, N. Jer., south to southern Florida, Nugent, Miss., and southeastern Louisiana. It is an inland species, found for the most part among grasses in open pine woods and along the borders of marshes and lakes.

258. Orcheimum volaxtum McNeill, 1891, 26. Nimble Meadow Grasshoppér.

Size medium or above; form moderately robust. Pale translucent brownish-green; lower half of lateral lobes and meso- and metapleura brighter green; occiput and prozona usually with two dark stripes which are feebly divergent; hind tibiæ and ovipositor pale reddish-brown. Fastigium narrow at base, moderately ascending, its apical portion wider with sides rounded. Pronotum short, subsellate in male; lateral lobes as long 
as deep, both their hind and lower margins oblique and meeting in a rounded angle; humeral sinus distinct but broad and rather shallow (Fig. 184, d.) Tegmina surpassing hind femora about $2 \mathrm{~mm}$., exceeded by wings $3 \mathrm{~mm}$., those of female strongly reticulate. Hind femora rather short and stout, armed beneath with one to four very short spines. Cerci as in key and Fig. 183, $f$, the tooth with base broad and flat. Apex of subgenital plate subtruncate, styles short and very slender. Ovipositor very similar to that of $O$. gladiator, being very long and stout, nearly straight above, the under side regularly curved, its apical third sloping rapidly to an acute apex. Length of body, ô, 17-20, ㅇ, 20-25; of pronotum, ô, 3.7-4.5, 우, $4-5$; of tegmina, $\hat{\delta}, 19-24$,, $24-30$; of hind femora, $\hat{\delta}, 15-16.5$, 17-19; of ovipositor, $9-10.5 \mathrm{~mm}$.

In Indiana voluntum has been taken in Vigo, Fulton, Marshall and Starke counties. It is found most abundantly during August and September on the leaves and stems of a tall, broad-leared knotweed, Polygonum amphibium L., which grows luxuriantly in the shallow waters about the margins of the larger ponds and lakes. Several other "green grasshoppers," notable among which are Conocephalus attenuatus (Scudd.) and Orehelimum nigripes Scudd., frequent this plant in large numbers. Keeping company with them an occasional specimen of $O$. volantum is seen, but,
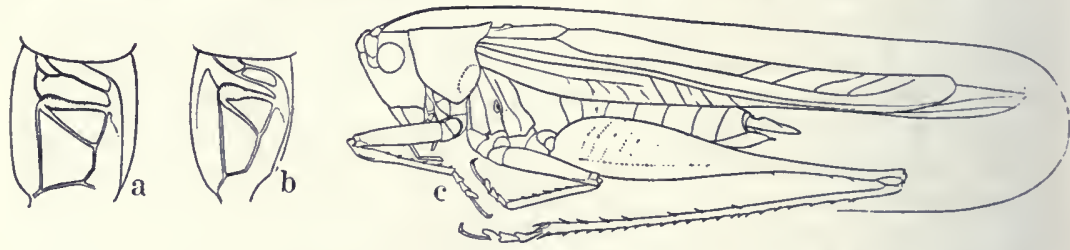

Fig. 187 . a, Outline of stridulating field of male of $O$. militare; b, same of $O$. volantum, $\times 3$; c, outline of male type of $O$. bradleyi, $\times$ 1.8. (After R. \& H.)

heing an active leaper, it often escapes amidst the dense foliage of the knot-weed before its rapture can be effected. Its less robust body, longer armed yosterior femora and long tegnima readily distinguish the female of this species from $O$. gladiator, the only other Indiana form which has an ovipositor shaped like that of voluntum. The 0 . mumeri Blatchley $(1893 \mathrm{c}, 92)$ is a synonym.

The known range of typical $O$. volantum is rather limited, extending from sarnia, Ont., and northern Ohio west to eastern Nebraska and south to central Indiana and 1)ouglas (Co., Kiansas. M( Neill (1891,) took his types "from a clump of ratnk growing s'agittaria variabilis linglun., on the banks of Rock River, Henry ('o., 111., being attracted to them by their peculiar stridulation." Their song, he satys, "had a new note in it and may be represented as follows: $z i p-z i p, k \cdot r-z c-c-c$, lir-zc-c-c, the last part of the song not lasting more than a half to three-quarters of- a second and always preceded by the somd which I represent imperfectly by lir." 
Walker $(1905,38)$ found volantum vers abundant in southern Ontario where it occurs among the rushes and Sagittaria. growing ir open marshes bordering the streams. He sars: "McNeill has well represented its song, but I have never noticed the preliminary zip-zip."

259. Orchelimu m bradtey Rehn \& Hebard, 1915a, 73. Bradley's Meadow

Grasshopper.

Very similar to 0 . volantum. Differs in its larger size, with fore and middle femora more distinctly tapering and basal two-thirds of hind femora more swollen. Male with cercus differing as described in key, the dorsal surface of the shaft inflated near middle and with a curved carinate ridge on basal half. Ovipositor more than half the length of hind femora. its apical half gradually narrowing to apex; upper margin nearly straight, the lower one straight from base to middle (Figs. 183, 184, g.) Length of

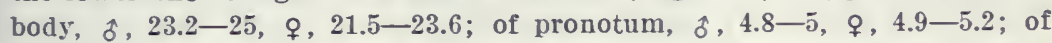

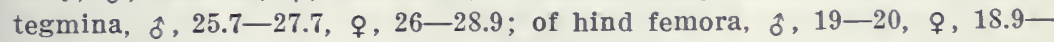
21.2; of ovipositor, $10.4-11.5 \mathrm{~mm}$. (Fig. 187, c.)

Dunedin, Fla., June 10 (W. s. B.) ; Wilmington, N. Car., Aug. 1 (Davis.) Ranges from southeastern North Carolina south to central western Florida and inland as far as the Okeefenokee Swamp of southern Georgia. In Florida it is known only from Jacksonville, Tallahassee and Dunedin. Dr. J. C. Bradley, who collected the types, furnished the following notes to R. \& H. regarding their habits:

"In the eastern half of the Okeefenokee Swamp are extensive so-called prairies. These are really inundated plains grown up with sawgrass and maiden-cane, or in places open shallow lakes covered with a multitude of water plants. The natives of the Okeefenokee told us of diving grasshoppers which lived on these prairies, and in making the trip to the Chase Prairies in September, 1913, I found these grasshoppers in great abundance in the grass-like plants growing out of the water or along the banks of the old canal. As the boat approached them they jumped from the grass into the water, completely disappearing, and so quick were they to do this when alarmed that it was only after some difficulty that I succeeded in catching a series of specimens."

This aquatic habit is also recorded by Engelhardt ${ }^{68}$ who says: "Of interest is the aquatic habit of Orchelimum volantum which was abundant about the grassy borders of Greenfield Pond near Wilmington, $\mathbf{x}$. Car. When pursued and hard pressed it would dive into the water and cling to the submerged grass stems or the under side of a water-lily leaf, where it remained for several minutes, sustained by a supply of air which showed in glistening

Nourn. N. Y. Ent. Soc., XVIII, 19ro, 130. The first records of O. bradleri, R. \& H. (I9II) and Sherman and Brimley (IgII) were made under the name of rolantum McNeill, to which it is very closely allied and of which it may prove to be only a southern race. 
bubbles adhering to its body." R. \& H. $(1915 a, 71)$ have recorded O. militare as having a similar habit, and it may be quite common among the subaquatic species of the genus.

VI. Conocephalus Thunberg, 1815, 271. (Gr., "conical" + "head")

\section{The Smaller Meadow Grasshoppers.}

This genus, the Xiphidion or Xiphidium of most recent writers and of my former work $(1903,371)$, comprises the smallest of our winged Tettigoniidæ. The genus is very close to Orchelimum, the characters given in the generic key, p. 534 being the principal ones used for their separation. In addition, as stated by R. \& H. (1915b, 156), in Conocephalus "the stridulating field of thie male tegmen is normally smaller, narrower and less extensive than in Orchelimum, the vicinity of the areuate vein not strongly produced or overhanging and, when looking from the dorsum, the humeral trunk is never hidden. The male cerci, though variable, do not in any of our species, exhibit the type found in the majority of the species of Orchelimum in which the tooth is placed in a more or less decided socket-like depression. All of the American sprecies have the cerci unispinose and the subgenital plate is truncate distad in the great majority of them." The ovipositor is for the most part straight and often of great length, though distinctly curved in $C$. nemoralis and evidently though faintly so in a few other forms. As already noted under Orchelimum, all these minor differences are comparative only, there being not a single fixed differential character to distinguish the two genera. Their separation in literature is therefore really more a matter of convenience for treatment of an otherwise very bulky aggregation of forms than a natural grouping of allied insects.

The tegmina and wings of most of the species of Conoccphalus are dimorphic in length. $\tilde{\mathbf{A}}$ smaller number are dimorplic in color, while a few possess ovipositors differing greatly in length. The variations in wing length and color in the same species seem to be abrupt, with no intervening forms. There are long-winged and short-winged forms of the same species, but none with the wings of medium length; and when a brown form is tinged with green, or vice versa, the amount of the different color varies but little. Ten of the 13 eastern species are thus dimorphic as regards the length of the wings, the short-winged individuals, as far as my observation goes, far outnumbering those with the wings fully developed. All the macropterous forms have the wings sur- 
passing the tegmina 2 to $4 \mathrm{~mm}$, while in the brachypterous forms the tegmina are as long as or longer than the wings. Of the rariations in the length of the tegmina Bruner (1891, 59) has well said: "In the genera Xiphidium and Orchelimum wing length is a character not to be relied upon as a specific or even varietal difforence"; yet Redtenbacher, in his "Monographie der Conocephaliden," separated a number of his species by this character alone, and $I$ can find no mention in his work of the fact that such a variation exists.

The majority of the inland species of Conocephalus are more xerophytic in habitat than those of Orchelimum, occurring for the most part in dry upland localities rather than in marshes or about the margins of lakes and streams. The borders of cultivated fields, orchards and gardens, edges of thickets and clumps of vines or briers in open woodland are their favorite abiding jlaces. The call notes of the males are in general lower, softer and more lisping than those of the same sex of Orchelimum. Allisd, (1914) writes of these notes as follows:

"Very noticeable differences in the manner of stridulation characterize many of the species of Xiphidion. According to the character of the notes these insects may be grouped into three classes. Those of the first class always produce a few, brief staccato lisps followed by a more or less prolonged, lisping, monotone, or in the case of $X$. nemorale the staccato lisps precede from two to thirty-two brief phrases rapidly repeated. A number of Xiphidions in this class stridulate in quite the same manner as the more common species of Orchelimum. Although barely audible, the stridulations of $\boldsymbol{X}$. fasciatum in delivery and duration are an almost perfect reproduction of the staccato lisps and succeeding monotone characteristic of Orchelimum vulgare or O. molossum.

"The notes of Xiphidions in the second class consist of weak, lisping phrases alone, as staccato lisps are quite wanting. The stridulations of $X$. allardi are of this character. Among the orchelimums this is also the habit of stridulation of 0 . minor. In the stridulations of Xiphidions of the third class, staccato lisps are also wanting, but the note is a long-continued, lisping monotone, similar to that of some of the cone-headed grasshoppers, although not nearly as loud and penetrating. $X$. strictum stridulates in this manner."

The reasons for the replacement of the well known generic name Xiphidium by Conocephalus, a name formerly used for the large cone-heads now placed under Neoconoccphalus, are set forth by Caudell (1910a) and by R. \& H. (1915b, 156), as follows: "In 1815 Thunberg erected the genus Conocephalus including in it 24 species; under one of these C. hemipterus (p. 272) he placed as a synonym Locusta conocephalus of Fabricius, which citation 
forms, under the International nomenclature rules, type designation by tautonomy and in consequence the species becomes the type of the genus Conocephalus." ${ }^{99}$

Kirby $(1906,274)$ did not adopt this ruling but included the species formerly known as Xiphidion Serv. (1831) and Xiphidium. Burmeister (1838) under the name Anisoptera Latreille (1829) which has priority over both. While I personally believe that the International ruling in this case is technical, arbitrary and nonsensical, I have followed it for two reasons. (a) It has been adopted by $R . \& H$. in their synopsis of the genus and by other recent American writers, and not to adopt it would cause more confusion than even now exists. (b) If not adopted the name Anisoptera would have priority over Xiphidion and Tiphidium and a change of name would anyhow be necessary.

The genus Conocephalus as here recognized comprises a large number of species and is represented in all parts of the world. Kirby included 91 species under Anisoptera, 14 of· which were from the United States, but of these several are known synonyms. Since his catalogue appeared seren additional species have been described by Caudell, R. \& H. and Fox. In their synopsis of the North American forms R. \& H. recognized 16 species and one variety. Of these 13 occur in the territory covered by this work. The portions of the following key pertaining to the male cerci and other characters of that sex are based largely on the key of R. \& H. in their synopsis which was for the males only.
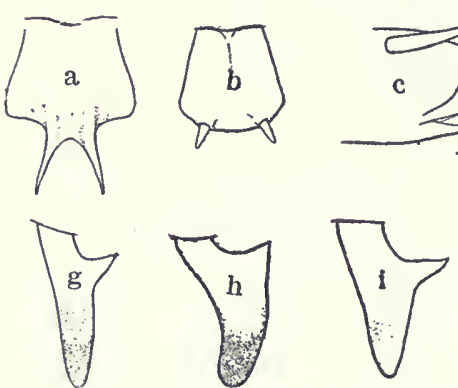

Fig. 188. ciatus, $X$ 5.5. Extremities of hind tibiae of Conoccphalus, $X$ 20. c, fasciatus; $d$, sal tans. $\mathrm{e}-\mathrm{m}$, Outlines of male cerci of Conocephalus, $\times$ io. e, allardi; $\mathrm{f}$, fasciatus; $\mathrm{g}$, gracillimus; h, brevipeunis; i, nemoralis; $\mathrm{j}$, strictus; $\mathrm{k}$, stictomerus; 1 , aigialus; m, nigropleurus. (After R. \& H.)

\section{KEY TO EASTERN SPECIES OF CONOCEPHALUS.}

a. Hind tibiæ armed at apical extremity with three pairs of spurs (Fig.

${ }^{6}$ Caudell (Ms.) also states that the properly designated type of Xiphidion has been proven to be congeneric with the Grylius (Tettigonia) conocephaius of Linnaus, of which Conocephalws hemipterus Thunberg, the type of the genus Conoceplaius is a synonym. As we cannot change the type of Xiplidion and its type is in the older genus Conocephalus, it falls in synonymy under that genus. 
$188, c)$; prosternum bispinose; tegmina (except in female of strictus) always distinctly longer than the pronotum.

b. Apex of subgenital plate of male emarginate and armed with two strong, straight, feebly divergent spines (Fig. 188, $a$ ) ; styles absent; ovipositor longer than hind femora. 260. ALLARDi.

bb. Apex of subgenital plate of male not emarginate, usually truncate, unarmed; styles present, small and filiform (Fig. 188, b); ovipositor variable in length.

c. Cerci of male armed on inner margin near middle with a stout tooth, the base of which is plainly visible from above (Fig. $188, e-j$ ); hind femora very rarely armed beneath.

d. Apical portion of cerci more or less depressed, its apex broad and rounded (Fig. 188, $e-h$ ); smaller and more slender, length of body, female, rarely over $14 \mathrm{~mm}$.

$e$. Tegmina always fully developed and longer than abdomen, exceeded by wings 2 to $3 \mathrm{~mm}$.; form very slender; cerci of male slender, not strongly flattened on the inner side.

$f$. Fastigium broader at apex than base, but slightly produced in front of eyes; abdomen feebly trifasciate, the median dark stripe broad; tympanum. of male not unusually elongate; general color green. 261. Fasciatus.

ff. Fastigium with sides parallel or nearly so, produced in front of eyes a distance equal to width of eye; abdomen distinctly trifasciate, all the stripes narrow; tympanum of male unusually elongate; general color pale brown with a pinkish tinge.

262. GRACILlimus.

ee. Tegmina and wings abbreviated, shorter than abdomen, very rarely fully developed; form more robust; cercl shorter, stouter, strongly flattened on the inner side.

263. BREVIPENIIS.

dd. Apical portion of cerci not at all or very weakly flattened, the apex narrow, usually acuminate (Fig. 188, i. j); larger, length of body, female, 15 or more $\mathrm{mm}$.

g. Ovipositor about three-fourths the length of hind femora, its apical half with a gentle but evident upward curve (Fig. 189, $j$ ) ; cerci with apical portion short, conical, the tip rather blunt (Fig. 188, $i$ ); general color smoky or greenish brown.

264. NEMORALIS.

gg. Oripositor always much longer than hind femora, straight or nearly so (Fig. $189, k$ ); cerci with apical portion very elongate, slender, the tip subacuminate (Fig. 188, j); general color green.

265. STRICTUS.

cc. Cerci swollen at middle and armed on under side with a more slender tooth the base of which is scarcely visible from above (Fig. 188, $k-m$ ) ; apical portion of cerci strongly flattened; hind femora very rarely unarmed beneath.

h. Cerci with swollen middle portion abruptly strongly narrowed, not attenuate-elongate (Fig. $188, k . l$ ); abdomen of male including cerci, with apical portion bright yellow in life. (Submaritime species.) 
i. Ovipositor almost straight, slightly longer than hind femora, the latter in life with prominent spots and dots of coral red (Figs. $189, l ; 191, b$ ); face orange with a vertical median reddish-brown stripe; fastigium narrow, about half the width of basal antennal joint.

266. STICTOMERUS.

ii. Ovipositor broader, slightly shorter than hind femora, (Fig. $189, m)$, the latter without prominent reddish spots; face without median stripe; fastigium wider, about twothirds the width of basal antennal joint. 267. AIGLALUS.

$h h$. Cerci with swollen middle portion not abruptly narrowed, but gradually attenuate-elongate (Figs. $188, m ; 189, a-c$.)

j. Sides of abdomen shining black, its upper surface dark brown; ovipositor straight, rather broad, slightly longer than hind hind femora.

268. NIGROPLEURUS.

jj. Sides of abdomen not shining black.

$k$. Ovipositor much longer than body; cerci stout, feebly tapering, their apical half curved outward and flattened portion horizontal (Fig. 189, a.) (Inland species.)

269. ATtexuAtús.

$k k$. Ovipositor at most but slightly longer than body; cercl more slender, the apical half distinctly tapering and in. curved, the flattened portion, therefore, oblique (Fig. 189, $b, c$.$) (Submaritime species).$
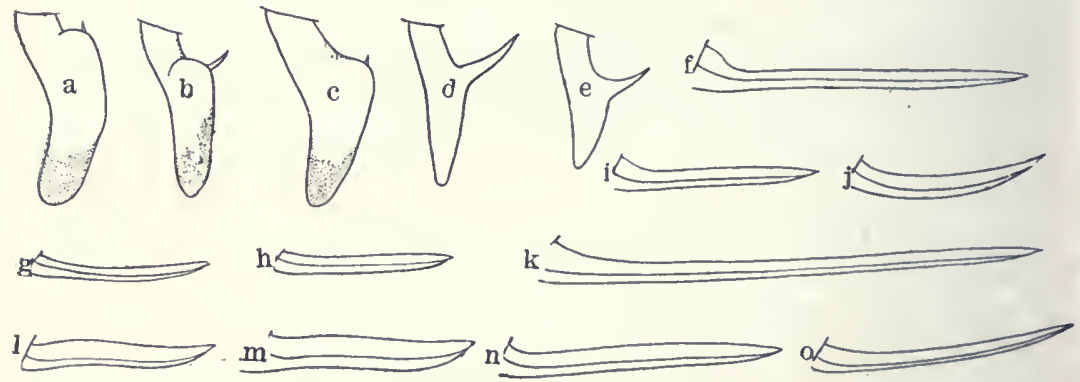

Fig. 189. a-e, Outlines of male cerci of Conocephaius, $X$ 10. a, attenuatus; $h$, nigropleuroides; c, spartine; d, saltans; e, viridifrons. $\mathrm{f}-\mathrm{k}$, Outlines of ovipositors of Conocephalus, $X$ 2. $\mathrm{f}$, allardi; $\mathrm{g}$, fasciatus; $\mathrm{h}$, gracillimus; $\mathrm{i}$, brevipennis; $\mathrm{j}$, nemoralis; $\mathrm{k}$, strictus; 1 , stictomerus; $\mathrm{m}$, aigialus; $\mathrm{n}$, spartinc; o, viridifrons. (After R. \& $\mathrm{H}_{.}$)

l. Fastigium distinctly ascending, about one-half the width of basal antennal joint, its sides parallel; lateral lobes in great part dark brown; abdomen of male (in life) with basal half dark brown above, apical half bright orange.

270. NigropLEUROIDES.

Il. Fastigium slightly ascending, two-thirds as wide as basal antennal joint, its sides feebly diverging from base forward; lateral lobes green or pale brown; abdomen of male pale brown above, its apical half pale orange.

271. SPARTINA.

aa. Hind tibiæ armed at apex with but one pair of spurs (Fig. 188, d) ; prosternum without spines; tegmina pad-like, scarcely longer than pronotum; hind femora unarmed beneath. 
$m$. Face with a median reddish-brown stripe or blotch; apical portion of male cercus (beyond the tooth) longer than basal portion, distinctly incurved or twisted, its inner face near tip flattened, the tooth bent inward and downward (Fig. 189, d.)

272. SALTANS.

$m m$. Face a pale uniform green; apical portion of cercus short, conical, not twisted or flattened within, the tooth stouter, horizontal or nearly so (Fig. 189, e.)

273. VIRIDIFRONS. 260. Coxocephalus allakdi (Caudell), 1910, 58. Allard's Meadow Grasshopper.

Size medium for the genus; form robust. General color green; head and pronotum with a dark stripe extending from vertex to hind margin of metazona, less distinct posteriorly; tegmina pale brownish-green, male, uniform green, female; hind femora spotted with reddish-brown, the knees fuscous; dorsum of abdomen including cerci dark brown. Fastigium feebly ascending, its greatest width about two-thirds that of basal joint of antennæ. Lateral lobes of pronotum very broad, their front margin straight, oblique and broadly rounded into the lower one which is nearly horizontal, its hind angle narrowly rounded; humeral sinus obsolete; convex callosity very broad. Tegmina covering three-fourths of abdomen, male, one-half, female, their tips broadly rounded. Hind femora unarmed beneath. Cercl of male stout, the tooth triangular, flat and broad at base, the apical portion of cercus behind it about twice as long as the basal width, the apex depressed, concave (Fig. 188, e.) Ovipositor straight, its apical fourth abruptly tapering (Fig. 189, f.) Length of body, $\hat{\delta}, 12$, ㅇ, 15; of pronotum, $\hat{\delta}$ and $\uparrow, 3-3.4$; of tegmina, $\hat{\delta}, 6.5, q, 5$; of hind femora, $\hat{\delta}, 11.5-12.5$, ․, 13 ; of ovipositor, $15-17 \mathrm{~mm}$.

Caudell's types were taken by Allard on Tray Mountain. North Georgia, at an altitude of 4,309 feet. Known elsewhere only from Wytheville, Va., and Rabun Co., Georgia. Of the type specimens Allard furnished Caudell the following notes:

"I first heard and captured specimens of this Tiphidion late in September, in a sunny, grass spot in the woods at Indian Grave Gap, Towns County, North Georgia. A few days later I found it in similar sunny, open situations on Tray and Blue Mountains, in the immediate ricinity of Indian Grave Gap. It prefers the low weeds and short grass, and was very musical during the sunny hours of the day. Its song is strikingly unlike the notes of Tiphidion fasciatum or Tiphidion memorale, as no staccato notes whatever precede the more or less prolonged lisping phrases. These phrases are soft, faint and often greatly prolonged. In sound quality they recall to mind the notes of Orcheliri um minor."

261. Coxocephalus Fasciatus (DeGeer), 1773, 458. Slender Meadow Grasshopper.

Size small for the genus, form very slender. Face, sides of pronotum 
and abdomen, and basal portion of ovipositor, green; tegmina and apical third of ovipositor pale reddish-brown; upper side of abdomen, and stripe on occiput and disk of pronotum darker brown; legs green, tarsi tinged with fuscous. Fastigium not ascending, its sides feebly diverging from base forward. Lateral lobes deeper than long, lower margin strongly oblique, its hind angle narrowly rounded; humeral sinus obsolete; convex callosity low, narrow. Tegmina surpassing hind femora 1 to $2 \mathrm{~mm}$., exceeded by wings 2 to $3 \mathrm{~mm}$. Cerci as in key and Fig. 188, $f$. Subgenital plate of male truncate. Ovipositor straight, about two-thirds as long as hind femora. Length of body, $\hat{o}, 12-13.5$, ㅇ, 12-14.5; of pronotum, $\hat{\sigma}$, $3-3.5$, ㅇ, 2.8-3.2; of tegmina, $\hat{o}, 14-18$, ㅇ, 15-19; of hind femora, ô, $11-12$, ㅇ, 11.5-13; of ovipositor, $7.3-9.4 \mathrm{~mm}$.

This handsome little meadow grasshopper is abundant throughout Indiana in timothy and clover meadows and especially so about small streams in low-ground, blue-grass pastures. It is one of the first of the Tettigoniidae to reach maturity, specimens having been taken in Vigo County as early as July 5, and it may be found until mid-October. In Florida it is also a common species having been taken by me at Gainesville, Lakeland and Dunedın, Oct. 24-Jan. 26, and recorded by other collectors from numerous stations, as far south as Miami and Detroit, but not from the southern keys. About Dunedin it oceurs in old fields, along railway embankments and among the undergrowth in open pine woods. If no frosts occur adults are found until midwinter, and nymphs are very frequent in March and April.

The known range of $C$. fasciatus is probably the widest of any American Tettigonid, extending from New England and Nora Scotia north and west to Aweme, Manitoba, Wyoming and New Mexico, and south at least to Bermuda, southern Florida and northern Mexico. Piers $(1918,324)$ records it as very common throughout Nova Scotia, where it is the only true meadow grasshopper known. He says: "It frequents damp situations such as wet meadows and marshes and is found among moist thick patches of succulent and rank-growing grasses. Adults are met with from the middle of July until after hoar-frosts. The stridulation of the male is rather weak and to me sounds like the syllables, plece-e-e-e-e, $t \approx i t, t \approx i t, t \approx i t, t z i t$, the first part of the call being a rapid, vibrating note." Walker $(1904,338)$ says it is much the most abundaut locustid found in Ontario, being as abundant at North Bay as along the southern boundary, adults appearing about mid-July and remaining until October.

Allard (1911) notes its habits in New England as follows: "The tiny Xiphidium fasciatum DeGeer prefers the tangles of weeds and grasses bordering the grass fields, and may oftentimes 
be found in large colonies. Its notes are extremely faint and in manner of delivery are the exact counterpart of an Orchelimum's notes. The staccato lisps nearly always precede the phrase tsесесеесесесесе. The entire song may be written thus: Tip-tiptip-tsесесеесесесее. The entire stridulation is so faint as to almost escape the hearing. The staccato lisps tip-tip-tip were so feeble the writer could hear them only by the closest attention, although the wings could be seen in motion at the time."

MeNeill (1891, 24), writing of it about Moline, Ill., says: "It is abundant everywhere, in blue-grass meadows especially. Its song is a faint echo of that of Orchelimum vulgare, with the "ripzip' omitted. It is, I believe, the first of the green grasshoppers to reach maturity and its faint little quarer is the first note of the great chorus that sounds in all the meadows from mid-July until the first of October."

The Orchelimum gracile Harris $(1841,131)$ is placed by R. \& H. as a synonym of $C$. fasciatus, although not so considered by Bruner (1892a, 265) and not so figured by Harris, loc. cit.

262. Conocephalus gracillimus (Morse), 1901, 236. Graceful Meadow Grasshopper.

Size and form of fasciatus. Pale brown; face and sides of abdomen usually greenish; occiput and disk of pronotum with a conspicuous dark brown median stripe; lateral lobes often also with a median dark stripe; abdomen usually with three narrow dark stripes, one above and one each side, the intervening spaces yellowish. Fastigium very narrow, feebly as. cending, its sides very faintly divergent. Disk of pronotum subsellate, male, not at all, female; lateral lobes slightly longer than deep, subtriangular in outline, their front and lower margins continuous with a scarcely visible angle, lower hind angle narrowly rounded; humeral sinus distinct, shallow; convex callosity broad. Tegmina fully developed, very narrow, surpassing hind femora about $1.5 \mathrm{~mm}$., exceeded by wings $2-3 \mathrm{~mm}$., their tips narrowly rounded. Hind femora very slender, unarmed. Cerci as in Fig. 188, $g$, more elongate than in fasciatus, their apical third strongly depressed. Ovipositor straight, about two-thirds the length of hind femora the apical half tapering evenly to an acute point (Fig. 189, h.) Length of body, $\hat{\delta}, 12-14$, $\uparrow, 13-15$; of antennæ, 40-58; of pronotum, $\hat{o}, 3$,, , 3.2 ; of tegmina, ô, 14.5-17, \&, 17-18.5; of hind femora, $\hat{o}, 10.5-12$, + , 12-13; of ovipositor, $8 \mathrm{~mm}$.

Biscayne Bay, Miami, Cape Sable, Key West, Ft. Myers, Passe Grille and Dunedin, Fla.; Dec. 12-March 14 (W. S. B.). The types of Morse were from Capron and Biscayne Bay, and the spiecies is recorded from numerous localities in the southern half and on the southern keys of Florida to which region it is apparently confined. About Dunedin it is found in small numbers throughout the winter, on both Hog Island and the mainland, 
occurring mostly in the tall grasses about the margins of shallow ponds and low places in open pine woods. At Miami and Homestead R. \& H. found the nymphs in great abundance during March in the high grass of the everglades, while in July it was found to be common among the grasses on several of the keys. Dunedin i.s the most northern point at which it has been taken on the west coast.

This is one of the smallest of our meadow grasshoppers and closely resembles $C$. fasciatus in general facies. It is readily distinguished, however, by its more slender form, more reddishbrown hue, with stripe of head and pronotum darker, and stripes of abdomen more distinct and especially by the different shape of lateral lobes and the longer, more tapering and more flattened male cerci.

263. Conocephalus BRevipennis (Scudder), 1862, 451. Short-winged Meadow Grasshopper.

Size medium for the genus; form rather robust. Pale reddish-brown; the face and sides of pronotum usually green; stripe on occiput and disk of pronotum a very dark brown, margined each side with a narrow yellow line; tegmina and wings pale reddish-brown; ovipositor reddish-brown, darker toward apex. In the larger specimens (ensifer Scudd.) the general color is more green than brown; the sides of abdomen and fore and middle femora being usually green. Fastigium scarcely ascending, its sides feebly divergent, apex not as wide as basal joint of antennæ. Lateral lobes of pronotum about as long as deep, lower margin oblique, its front angle obtuse, hind one broadly rounded; humeral sinus scarcely evident. Tegmina usually reaching bases of cerci, male, covering only two-thirds of abdomen, female, rarely fully developed. Wings slightly shorter than tegmina in the common form, exceeding them $2-3 \mathrm{~mm}$. in the long-winged form. Hind femora rather short, stout, usually unarmed beneath, rarely with 1-4 short spines. Cerci of male as in key and Fig. $188, h$, the apical third strongly compressed and obtuse, armed behind the middle with a rather flat, sharp-pointed tooth. Ovipositor straight, varying much in length, rarely with a faint upward curve, the lower margin with apical fifth tapering to the acute apex (Fig. 189, i.) Length of body, $\hat{o}, 11-12.5$, ᄋ, 11-14; of pronotum, $\hat{\sigma}, 3-3.5$, ㅇ, $3-4$; of tegmina, short-winged, $\hat{o}$, $7-10$,,$+ 7-8.5$; of tegmina, long-winged, $ᄋ, 14$; of hind femora, $\hat{o}$, 10-13, ㅇ, 11-13.5; of ovipositor, 9-14 mm. (Fig. 190.)

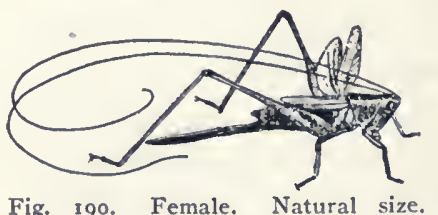

Fig. 190. Female. Natural size. (After Beutenmuller.)

An abundant species throughout Indiana, frequenting the same localities as fasciatus and reaching maturity about a fortnight later. The X. ensifer Scudder $(1862,451)$, described from Illinois has, as suggested by me $(1903,375)$, been shown to be only a large form of 
C. brevipennis and has been placed by $R$. \& H. as a synonym of that species.

This larger form differs from other meadow grasshoppers in the manner of oviposition, as, instead of always depositing its eggs in the stems of grasses, it sometimes seeks the turnip-shaped gall so common on certain species of Salix (willow), and oviposits between their scales. The gall is not formed by the grasshopper, but by a dipterous insect belonging to the family Cecidomyidae. Although I have never seen the eggs deposited I have on a number of occasions found them within the galls, but did not know to what insect they belonged until Wheeler (1890) published his excellent account of the oviposition of this species as noted in Wisconsin. From that I quote as follows:

"On September 8th I observed a female in the act of oviposition. She was perched with her head turned toward the apex of the gall. Slowly and sedately she thrust her sword-like ovipositor down between the leaves, and, after depositing an egg, as slowly withdrew the organ in order to recommence the same operation, after taking a few steps to one side of where she had been at work. She soon observed me and slipped away without completing her task. The number of eggs found in a gall varies considerably. Sometimes but two or three will be found, more frequently from 50 to 100 . In one small gall I counted 170. The egg is cream-colored, very thin, elongate oval in outline, and measures $4 \times 1 \mathrm{~mm}$."

In Indiana the young of $C$. brevipennis emerge about the middle of May and reach maturity about August 10. One which was still in the nymph stage on October 21st, was found to have a white hairworm, Gordius sp? eight and a half inches long in its abdomen. The development of the nymph had probably been retarded by the presence of the parasite. Long-winged forms of this species are occasionally met with, but I have taken only one, and $R$. \& H. state that only 3.2 per cent of the 555 specimens examined by them were macropterous. Two macropterous females sent in by Hubbell from Jackson Co., Mich., vary but slightly in size, yet the ovipositors measure respectively 9.3 and $12 \mathrm{~mm}$. in length.

The known range of $C$. brevipennis is a wide one, extending from Maine and Montreal north and west to Algonquin Park, Ontario, northern Minnesota and Nebraska, and south and southwest to northern Florida and Dallas, Texas. In Florida it appears to be very scarce, being known definitely only from Atlantic Beach, South Jacksonville and Gainesville.

\footnotetext{
${ }^{70}$ B. D. Walsh (Proc. Ent. Soc. Phil., III, 1864, 232), recorded the finding on numer ous occasions, of the eggs of an Orchelimum in the turnip-shaped galls of Salix cordata. Their shape and proportional dimensions, as given by him, differ much from those of $C$. brevipennis, as they were cylindrical, .16 to .17 of an inch long, and seven times as long as wide (W.S. B.).
} 
Walker $(1904 \mathrm{a}, 339)$ says that $C$. brevipennis is "nearly as common as fasciatus in southern Ontario, but becomes scarcer to the north of Muskoka. It reaches maturity about the first of August and remains well into October. It was not very common in Algonquin Park where it seems to prefer the vicinity of rank herbs and bushes in more or less shady spots. The note of the male is very like that of fasciatus. The zips are emitted at intervals of about one second, one or two being produced at a time."

Of the song of $C$. brevipennis Allard (1911) has written:

"I could not determine its stridulations in the field, so a number of males and females were placed in a pasteboard box together with some grass. In a few minutes a number were in continuous song throughout the afternoon and night. The stridulations of this Xiphidium are the least audible of any locust the writer has ever observed. Although a persistent singer, the notes become inaudible only a few feet away. In the fields they are quite lost amidst the sounds of rustling foliage, the chirpings of crickets, etc. The notes of brevipenne are very brief and much more hurried in their delivery than those of $X$. fasciatum. In this respect they approach more nearly the dainty stridulations of $X$. nemorale scudd. In the song of brevipenne usually only one or two almost inaudible staccato lisps precede one, two or even three of the brief, faint phrases, tseeeeeee. tseeeeee. These are of much longer duration in the song of fasciatum, and are rarely heard without the preceding staccato lisps which are of in. definite number."

In addition to $X$. ensifer Scudder, R. \& H. have made $X$. gossypii Scudd., (1875, 461), described from Texas and Mississippi, a synonym of $C$. brevipennis.

264. Conocephalus Nemoralis (Scudder), 1875, 462. Woodland Grasshopper.

Size medium; form robust. General color dark greenish-brown; tegmina yellowish-brown with front or costal area fuscous; dorsal stripe of occiput and pronotum a paler grayish-brown margined each side with a narrow yellowish line; all the femora punctate with reddish dots; tarsi and knees of hind femora dusky. Fastigium but faintly ascending, its sides strongly diverging from base forward, the apical portion bluntly rounded, as wide as or slightly wider than basal joint of antennæ. Pronotum distinctly subsellate, male, very feebly so, female; lateral lobes with front margin broadly curved into the lower one, the usual intervening angle obsolete, lower hind angle broadly rounded, humeral sinus wanting. Tegmina covering two-thirds of abdomen, male, about one-half, female; very rarely fully developed, their tips broadly rounded; veins and cross-veins unusually prominent, giving them a coarse and scabrous look; tympanum of male broad and elevated. Hind femora unarmed beneath. Cerci and ovipositor as in key and Figs. 188, 189. Length of body, $\hat{o}, 13-14$, $q, 14-15$; of pronotum, $\hat{o}$ and $\$, 3.7-4.2$; of tegmina, $\hat{o}, 6-8, \uparrow, 5.5-6.2$; of hind femora, $\hat{\delta}, 11-12$, ㅇ, 13; of ovipositor, $8-9.2 \mathrm{~mm}$.

This handsome brown species is a common insect in central 
and southern Indiana, but has not ret been taken north of Lafayette. It reaches maturity about August 1st, and from then until after heary frosts may be found in numbers along the borders of dry, upland woods, fence rows, and roadsides, where it delights to rest on the low shrubs, blackberry bushes, or coarse weeds usually growing in such localities. On sunny afternoons of mid-autumn it is especially abundant on the lower parts of the rail and board fences, the male uttering his faint and monotonous love call-a sort of ch-e-e-e-e-ch-e-e-e-c,continuously repeated-the female but a short distance away, a motionless, patient, and apparently attentive listener. When in coitu the male does not mount the back of the female, but, with his body rerersed, is dragged about by her, this being the common practice of all the species of Conoccphalus and Orchclimum. The fenales at times evidently oviposit in decaying wood, as on several occasions I have found them on old fence posts and rails with their oripositors inserted the full length in the wood.

The types of Scudder were from Dallas Co., Iowa, and the known range of nemoralis extends from eastern New York and I'ennsrlvania north and west to Minnesota and Lincoln, Nebr., and south and southwest to Asheville, N. Car., Clarksville, Tenu., and Wichita, Kansas. It is not known from Michigan but Bruner silys it is common in the wooded portions of Nebraska, and McAtee and Caudell mention it as the most common species of the genus about Washington, D. C. At Moline, Ill., McNeill (1891) found it "most commonly on sparsely wooded and rather barren hillsides. The song is louder than that of fasciatum. It consists of two parts, the first a short, abrupt zip, and the second the familiar $z-e-e$, which lasts about half a second, and is made from one to five times. The zip is not repeated."

C. nemoralis appears to be a sort of connecting link between Orchclimum and Conocephalus. In its rather bulky body, large trmpanmm of male and curved ovipositor it resembles an Orcheli$m m m$ but the short tegmina and the truncate subgenital plate of male agree better with the characters of Conocephalus. Macropterous individuals are very rare, fewer than half a dozen having been recorded. The Tiphidium curtipcnne Redt. (1891, 522) is a synonym.

265. Coxocepialus strictus (Scudder), 1875, 460. Straight-lanced Grasshopper.

Size large for the genus; form rather slender. Sides of head and body and all the femora green; occiput and pronotum with the usual reddish- 
brown stripe narrowly edged with whitish, especially on the fastigium; tegmina reddish-brown; dorsum of abdomen with a dark brown band, darker where it meets the green on sides; cerci and ovipositor dark brown. Fastigium not at all ascending, its sides diverging, broadly rounded, its greatest width more than one-third the interocular space. Pronotum not at all sellate; lateral lobes deeper than long, their front and lower margins straight, their angle broadly obtusely rounded, the lower hind angle broadly rounded; humeral sinus evident but very shallow. Tegmina about half the length of abdomen, male, one-third its length, very short and padlike, female, their tips broadly rounded; in the very rare long-winged form almost reaching the hind knees and exceeded by wings $4 \mathrm{~mm}$. Hind femora unarmed beneath. Cerci as in key and Fig. 188, $j$. Ovipositor straight, very slender, longer than the body (Fig. 189, $k$.) Length of body, $\hat{o}, 14-15, q, 17-18$; of pronotum, $\hat{o}, 3.5-4,9,4-4.5$; of tegmina, shortwinged, $\hat{\jmath}, 5-6$, ㅇ, $3.5-4.5$; long-winged, $ᄋ, 16$; of hind femora, $\hat{o}, 13-$ 14, ㅇ, 15-16.5; of ovipositor, 18-32 mm. (Fig. 190a.)

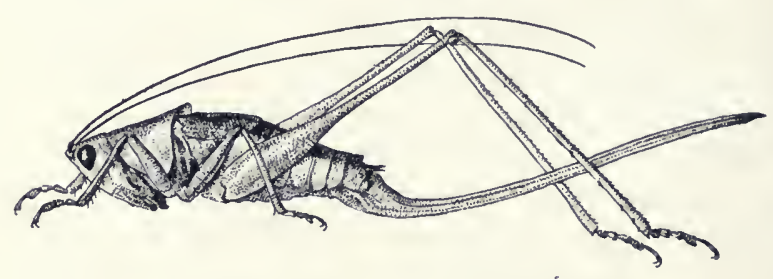

Fig. 190a. Female. $X$ 2. (After Forbes.)

This is a common species in the western a n d northern parts of Indiana, where it frequents, for the most part, dry upland meadows, open pastures and prairies, and reaches maturity about August 1st. The mature females are usually much more abundant than the males and vary much in size. It is an active leaper and tumbler and like several of its allies, often strives to escape detection by burrowing beneath fallen weeds and grasses. About Lafayette Fox (1915) found it "abundant il. dry open grass land and a common associate of Syrbula admirabilis (Uhler). Adults were taken July 31, were common until Sept. 5, but by October 3 had become very scarce." The longwinged form is everywhere very scarce, only one female from Vigo County having been noted in Indiana, while $R . \& H$. report only eleven in more than 500 adults examined. The species is the largest of the genus occurring in the United States and the range in the length of the ovipositor is greater than in any other, being over $14 \mathrm{~mm}$.

The types of Scudder were from Dallas, Texas, but it is known from Staten Island, N. Y., north and west to western South Dakota and Nebraska and south and southwest to North Carolina, Oklahoma, Texas and Arizona. Mead (1904) reported it as common in central and northern Ohio, but in Michigan it is known only from Washtenaw County. In Virginia Fox (1917) found it 
"moderately frequent in open undisturbed dry grasslands, especially partial to Andropogon, but taken also on Danthonia." In the dune region of northwestern Illinois Hart found it "common in damp grassy bottoms of old blow-outs," and in Nebraska Bruner (1893a) says it "is found over the entire State but is more common southward than elsewhere." Regarding the song of the male, Allard (1914) says:

"The notes of this species are much louder than those of any Xiphidion known to me. No staccato lisps precede the long lisping monotone $s-s-s-s$ $s-s-s-s-s-s$, which may continue several minutes without pause. Its note is thus similar to that of certain species of Neoconocephalus which have acquired the habit of prolonged stridulation. Although the Xiphidions usually keep well within the grass and low herbage of fields and meadows, the writer has observed $X$. strictum resting on shrubs sereral feet from the ground during stridulation."
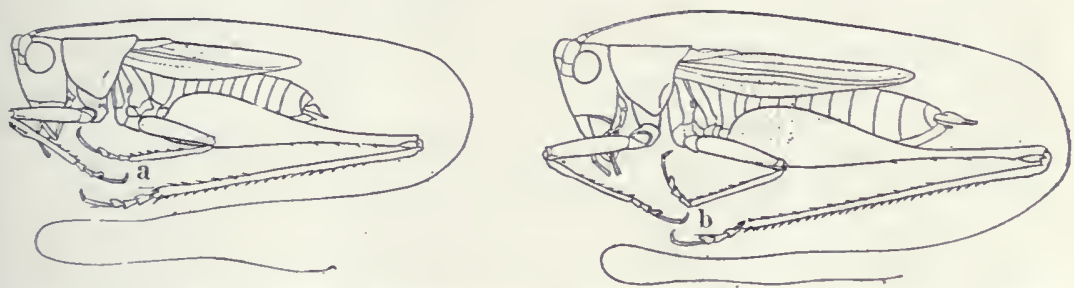

Fig. I9ı. a, Lateral outline of male type of Conocephalus aigialus; b, same of C. stictomerus, $X$ 2.5. (After R. \& H.)

266. CoNocephalus stictomerus Rehn \& Hebard, 1915b, 199. Spottedlegged Meadow Grasshopper.

Size rather large; form slender. General color pale green; occiput and disk of pronotum with a broad median stripe of the same hue; tegmina and wings translucent pale yellowish-brown; all the femora with numerous small spots and dots of reddish-brown. Fastigium distinctly ascending, its sides feebly divergent Lateral lobes deeper than long, front margin nearly straight, broadly obtusely rounded into the weakly concave lower one, the hind angle of latter broadly rounded; humeral sinus scarcely evident. Tegmina usually corering three-fourths of abdomen, male, half its length, female, their tips sharply rounded. Hind femora armed be. neath on outer carina with one to six short stout spines. Cerci as in key and Fig. 188, $k$. Length of body, $\delta, 12.4-15$, , , 11.1-16; of pronotum, $\hat{o}, 3-3.5$, 우 $2.9-3.7$; of tegmina, short-winged, ㅅ․ 8-11.6, ㅇ, 6.9-9.8; long-winged, $\hat{\sigma}, 18.3$,, , 18.5; of hind femora, $\hat{o}, 12.3-15$,, $12.6-15.6$; of ovipositor, 13.7-19.8 mm. (Fig. 191, b.)

Tappahannock, Va., Sept. $10(F \circ x)$. The types of R. \& H. were from Cedar Springs, N. Jer., and were taken from "a heavy growth of panic grass, Panicum virgatum L., interspersed with various marsh plants in a limited marshy area on the border of a brackish stream." 
The known range of the species extends from the type locality to Raleigh, N. Car., along the middle Atlantic coastal plain where it inhabits the luxuriant grasses growing about the borders of marshes near botlı fresh and brackish water. In Virginia Fox (1917) found it "Occasional in tidal marshes, especially in the tall reeds, spartina cynosuroides (L.) upon the spikelets of which it was observed feeding. It was apparently active only at night."

267. Coxocephalus aigialus Rehn \& Hebard, 1915b, 202. Sea Shore Meadow Grasshopper.

Size medium; form robust, compact. Pale green; occiput and disk of pronotum with a broad pale brown stripe. Tegmina pale translucent brownish-yellow; apical half of male abdomen (in life) bright yellow, fading to dull clay-yellow; hind knees and all the tibiæ tinged with fuscous. Fastigium slightly ascending, its sides almost parallel. Eyes very large and prominent. Lateral lobes with front and lower margins merged, without evident angle; lower hind angle narrowly rounded; humeral sinus very shallow. Tegmina of delicate structure, usually abbreviate and covering three-fourths of abdomen, male, two-thirds, female, their tips obliquely sharply rounded; in macropterous form, surpassing hind femora $3 \mathrm{~mm}$, exceeded by wings $4 \mathrm{~mm}$. Hind femora armed beneath on outer margin with one to seven spines. Cerci as in key and Fig. 188, l. Length of body, ô, 12-15, ㅇ, 11.6-17.2; of pronotum, ô, 3.1-3.8, 우, 3.2-4.1; of tegmina,

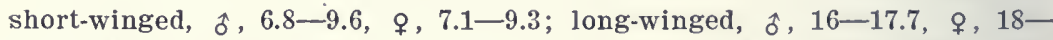
19.7 ; of hind femora, ô, $10.7-13$, 우 $12.1-15.3$; of ovipositor, $10.6-13.7$ mm. (Fig. 191, a.)

South Jacksonville, Fla., Sept. 7 (Davis). The types were from Wrightsville, $\mathrm{N}$. Car., and the known range of the species extends from Cape Henry, Va., to Pablo Beach, Fla. According to $R$. \& $H$. $(1915 \mathrm{~b}, 203)$ it "inhabits salt marsh regetation on the beaches and along the tidal rivers of the Atlantic coast where its habits are very similar to those of $C$. spartince (Fox); in the present case, however, the insect is found not out on the marshes, but in the halophytic regetation along their borders and in similar regetation on the beaches."

268. Coxocejihalus Nigropleurus (Bruner), 1891, 58. Black-sided Meadow Grasshopper.

Size medium; form robust. Dimorphic in color; either with tegmina. legs, margins of lateral lobes and metazona bright grass-green or with these parts brownish-yellow, the green wholly absent; both forms with stripe on occiput and sides of abdomen shining black, the former narrowing in front to the width of fastigium and bordered each side with yellowish. white; the usual brown stripe on disk of pronotum but faintly defined in green form, in the brown one very evident; face and median areas of lateral lobes dark brown. Fastigium feebly ascending, its sides slightly di- 
vergent, greatest width one-half that of basal antennal joint. Lateral lobes with front margin broadly rounded into the lower one, the angle between them very obtuse, scarcely evident; lower hind angle narrowly rounded, humeral sinus obsolete. Tegmina usually abbreviated, covering four-fifths of abdomen, male, two-thirds, female, their tips narrowly rounded; rarely macropterous, then exceeding hind femora $1.5 \mathrm{~mm}$., surpassed by wings $3.5 \mathrm{~mm}$. Hind femora armed beneath on outer margin with one to five spines. Cerci as in key and Fig. 188, $m$. Length of body, $\hat{o}, 14-17$,, , $15-16$; of pronotum, $\hat{\delta}, 3-3.5, \uparrow, 3.2-3.6$; of tegmina, $\delta, 8-9,9,8-$ 8.5, ९, long-winged, 17-19; of hind femora, $\hat{o}, 13-14$,, $13.5-15$; of ovipositor, $16-17.5$. $\mathrm{mm}$.

This, one of the most handsome of North American Orthoptera, occurs in suitable localities throughout Indiana, but is nowhere very common. It is a hygrophilous species, inhabiting only the margins of streams, ditches, large ponds and lakes, where it abides in the tall, rank grasses and sedges growing in the shade. It reaches the perfect stage about July 1st in sonthern Indiana. and in Fulton County has been taken as late as October 24th. The males leap actively when approached. The females are more clumsy and usually dive headlong into a bunch of fallen grass. They can then be most readily captured by clasping the hand about a bunch of grass stems or branches of shrubs, on the under side of which the insects have taken refuge. The long-winged form is very rare but a single fenrale from Wells County being in the collection at hand. About Lafayette, Fox (1915, 33) found nigroplemrus frequent in herbaceous thickets, especially those forming the margins of bogs dominated br the rice cut-grass, Homalocenchrus oryzoides (L.), in both open and woodland situations and usually associated with Orchelimm nigripes scudd."

The known range of nigropleurus is somewhat limited, extending from Ithaca, X. Y., and southwestern Ontario west to Wisconsin and Nebraska, and south, so far ás recorded, only to the Ghio River in Indiana. Bruner's types were from eastern Nebraska, and of its habits in that state he wrote: "This beantiful insect, which is our most active species of the genus, is quite plentiful among the rank regetation on low moist ground, and is especially common in wet places where the 'cut grass' (Leersia oryzoides Swartz) grows. The supposition is that this grass offers a better place than usual for the deposition of its eggs, which are deposited between the leaves and stems of grass. Graperines and other creeping plants which form matted clusters that afford shelter from the noonday sun and the bright light of day are favorite haunts of this and other species of our nocturnal grasshoppers and a few of the arboreal crickets. It occurs throughout 
the eastern half of Nebraska along all the streams the banks of which are lined with shrubs and trees."

269. Conocephalus attexuatus (Scudder), 1869, 305. Lance-tailed Meadow Grasshopper.

Size rather large; form very slender. General color dull brownish yellow, in some specimens tinged with greenish; occiput and pronotum with the usual median stripe reddish-brown; abdomen pale brown, male, reddish-brown, female; femora greenish-brown, rarely bright green, mottled with numerous small reddish dots; tibiæ and tarsi darker. Fastigium distinctly ascending, three-fourths as wide as basal joint of antennæ, its sides subparallel Antennæ very long, $73 \mathrm{~mm}$. in one specimen at hand. Lateral lobes with front and lower margins merged without visible angle, lower hind angle sharply rounded, the margins forming it strongly upcurved; humeral sinus obsolete. Tegmina, when abbreviated covering about three-fourths of abdomen, female, reaching or slightly surpassing its tip, male; when fully developed, twice the length of abdomen and exceeded by wings $4 \mathrm{~mm}$. Hind femora long, slender, armed beneath on outer carina with one to five spines. Cerci of male long, broad, with apical third

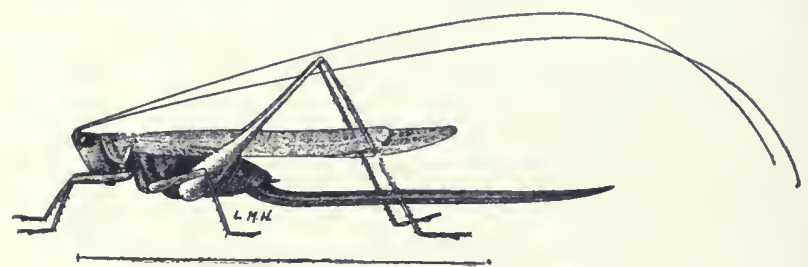

Fig. 192. Female. (After Lugger.) curved ou tward, the basal tooth minute, slender (Fig. 189 , a.) Ovlpositor excessively long and s 1 e $n$ d e r, stralght or gently curved upward, the margins very finely serrulate and apex acuminate. Length of body, ô, 12-15, 오, 13-16; of pronotum, $\hat{o}, 2.6-3$, 오 , 2.93.2 ; of tegmina, short-winged, $\hat{o}, 8.5-9.5$, ㅇ, 8.5-10; long-winged, $\hat{o}$, $16.5-19$,, 19 ; of hind femora, $\hat{o}, 11-14$, $ᄋ, 12-14$; of ovipositor, $20-$ $28 \mathrm{~mm}$. (Fig. 192.)

The short-winged form of this species is much more abundant locally in Indiana than the long-winged one. In Vigo County it was, at one time very plentiful about the borders of two large ponds in the Wabash River bottoms. In Knox County a few specimens were secured from the margin of a similar pond bordering a large cypress swamp, while in Koscinsko County it was found to be quite common in some narslies near Tippecanoe and Turkey lakes. In all these places the insects dwelt among the tall rank grasses and rushes growing in shallow water. The males are. as far as my experience goes, the most active leapers among the winged 'Tettigoniida, jumping a half dozen or more times without pause when flushed, and in the net leaping so rapidly from side to side as to prevent capture with the fingers. The females are evidently handicapjed in their leaping powers by the excessive 
length of the oripositor, and so more often endearor to escape by burrowing beneath the dense masses of fallen grass and reed stems which are alwars found in their accustomed haunts.

The long winged form was first taken in some extensive low ground meadows in Kosciusko County. Here the long and short winged forms were about equally abundant. The former flew readily when approached, but to no great distance. A few of the long winged ones were also taken near Bass Lake, Starke Countr. The specimens from these northern counties are more slender bodied than those from the south, where only the short winged form has been found.

Scudder's types were from Illinois and the known range of the species extends from eastern Pennsylvania and southwestern Ontario west to Minnesota, eastern Nebraska and Kansas, while Knox County, Ind., is the most southern station recorded east of the Mississippi. Walker states $(1904,341)$ that'in southern Ontario it is plentiful but limited in distribution. "It frequents open marshy borders of creeks and ponds, where it leaps about with wonderful agility among the tall grasses and sedges."

R. \& H. (1915b, 209) state that at Cornwells, Pa., they found attenuatus "very scarce in high grasses and plants along the shore of the Delaware River, and in moderate numbers in a small marshy area adjoining. The males were usually found in the grass or perched on nearby plant leaves, whence they sprang awar with alacrity. The females were never as conspicuous and sprang away with great swift leaps, then, hiding on the opposite sides of grass stems and leaves in the deepest tangles of regetation, they proved very difficult to locate. Orer its wide distribution it is doubtless restricted to damp spots and marsh areas."

My Xiphidium scudderi (1892b. 26) was based on the shortwinged form of $C$. attematus while the $X$. lanceolatum mentioned by Bruner $(1891,59)$ also refers to attenuatus. I find that the length of the oriprositor among the different species of Conocephalus is not at all dependent upon the age of the insect. In attemuatus it is almost as long after the third, and fully as long after the fourth moult as it is in the adult; while a female of strictus has been taken, with no vestige of tegmina, in which the ovipositor measured $18 \mathrm{~mm}$. The eggs of attenuatus, as the length of the ovipositol indicates, are laid between the stems and leaves of the tall rank grasses among which the insect lives.

270. Coxocephalus yigropleuroides (Fox), 1912, 116.

Size small, form slender. Dark brown, often with a grayish-olive tinge; occiput and prozona with the usual median stripe broaa and very 
dark brown on the former, paler and often ill-defined on the latter, bordered each side with grayish-white; tegmina, legs and male cerci usually bluish- or sea-green, the base of tegmina often pale brown; abdomen as described in key, the sides grayish-brown. Tegmina almost reaching base of cerci, male, covering two-thirds or slightly more of abdomen, female, their tips narrowly rounded. Hind femora usually unarmed beneath, sometimes with one or two spines on lower outer margin. Cerci very sim1lar to but more attenuate than those of spartince (Fig. 189, b.) Ovipositor slightly longer than hind femora, usually straight, sometimes with a distinct upward curve. Length of body, $\hat{\delta}, 11-13.2$, 우, 11.2-13.5; of pronotum, $\hat{\delta}, 2.3-2.6$, ㅇ, $2.6-3$; of tegmina, $\hat{\delta}, 7$, $९, 5.5-6.8$; of hind femora, o. , 10, 오, 11-12; of ovipositor, 11-16 $\mathrm{mm}$.

Ocean View, N. Jer., August 30 (Fox). The types of Fox were from Cape May County, N. Jer., and the species ranges from that State along the Atlantic coast to southern Georgia, while on the Gulf coast it is known only from Cedar Keys, Fla. It occurs only on the salt marsh tidal flats, where, says Fox, "it is associated with $\dot{C}$. spartince but is much scarcer than the latter and is almost entirely restricted to the tall Spartina grasses which fringe the banks of the numerous channels and ditches traversing the marshes."

271. Conocepinalus spartine (Fox), 1912, 111. Salt Marsh Meadow Grasshopper.

Size small; form slender. Usually grass-green in life, sometimes pale brown; tegmina translucent pale brown tinged with green, especially near apex; dorsal stripe of occiput and pronotum dark brown, sharply defined, bordered each side with yellowish; lateral lobes often with median area brown; abdomen of female with tip only orange; all the femora greeu with numerous reddish-brown dots; hind tibiæ tinged with dusky; tarsi brown. Fastigium as in key. Lateral lobes with front margin broadly rounded into lower one, their intervening angle absent; lower hind angle broadly rounded, humeral sinus wanting. Tegmina usually reaching last abdominal segment, male, covering about three-fourths of abdomen, female, their tips narrowly rounded; sometimes fully developed and then exceeding tips of hind femora by $3 \mathrm{~mm}$. Hind femora usually armed beneath with one to four spines. Cerci as in key and Fig. 189, c. Ovipositor almost or fully as long as hind femora, rather broad and with a rery slight upward curve (Fig. 189, n.) Length of body, $\hat{\delta}, 10.8-13.5$, 우, $11-15$; of pronotum, $\hat{\delta}, 2.3-3$, ㅇ, $2.5-3$; of tegmina, $\hat{\delta}, 6-10.8$, ㅇ, $5-5.8$; of hind femora, 소, 8.2-10.5, ㅇ, 9.2-11.2 mm., of ovipositor, $7.1-9.9 \mathrm{~mm}$.

Whitestone, Va., Sept. 26 (Fox) ; Cape Sable, Fla.. Fel. 23 (W.S. B.) This is also a coastwise species ranging from Maine and Massachusetts to Caple Sable, Fla., and on the Gulf coast from Trerglade, Fla., to sontheastern Texas. As its specific name indicates, it occurs mostly among the salt marsh grasses of the genus spartina. Only two males, one a nymph, were taken at 
Cape Sable and they br sweeping these grasses on the tidal flats. Elsewhere in Florida it has been recorded definitels only from Miami and Everglade.

R. \& H. (1915b, 215) state that on the coast of New Jersey spartine is frequently to be found in great numbers on the salt marshes both in Spartina patens (Ait.) and Panicularia fluitans (L.) and can there be taken with ease. At Virginia Point. Texas. the series taken was chiefly macropterous and found in high and heary grasses. "It was there difficult to capture as individuals were very restless and immediately sought shelter by jumping down low in the bunches of grass where they were very hard to follow."

Morse, (1919) states that it is locally abuudant on salt marshes along the New England coast from Old Orchard, Me., to Stamford, Conn., thus agreeing closels in extent of distribution with the seaside locust, Trimerotropis maritima (Harr.)

The true status of the submaritime species, $C$. spartina, stictomerns, aigiahus and nigropleuroides, is, in my opinion, as ret an unsolved problem. The first two named are very close to brevipennis and the last one to both attenuatus and nigropleurus. They differ mainly from these older named species in the form of the male cerci, length and form of ovipositor and details of coloration, all exceedingly plastic and rariable characters. They are also closely related among themselves. For example, Fox states that the males of spartince and nigropleuroides are so close "that it was only after a long and arduous analysis and comparison that I was enabled to determine some apparently constant structural differences." Again, R. \& H. (1915b, 210) state that nigropleuroides, though decidedly smaller and more slender than spartince ir. New Jersey, increases southward in size and robustness so that in Florida it is distinctly the larger and more robust of the two. They also say: "The rariation in shape of the ovipositor is far greater in nigropleuroides than in any other American species of the genus," ranging from rather broad and approximately straight in New Jersey specimens to a distinctly though not strongly upward curve in part of the series from Cedar Kess, Fla. Before the descriptions of any of the four species as new forms were made, R. \& H., one or both of them, had recorded spartince as $X$. nemorale and brevipenne; stictomerus as $C$. ensiferus; aigialus as $X$. nigropleurum? and C. brevipennis, and nigropleuroides as $X$. nigropleurum. This fact is mentioned to show which of the older species each of the new forms superficially most closely resembles. 
From these statements and from the study of the individuals at hand I believe that it will eventually be found that some of the four forms mentioned are only southern races or offshoots of one $\mathrm{Or}^{\circ}$ more of the better known northern species, and that the modifications of color and secondary sexual organs have been brought about by the environment of the salt marsh areas which they inhabit. The series of specimens of each at present available is not sufficient for me to express a more exact opinion of their relationship, and I have therefore left them as placed by their anthor's.

272. Conocephalus Saltaxs (Scudder), 1872, 249. Wingless Prairie Grasshopper.

Size very small; form very slender. General color dull reddish-brown; occiput and pronotum with the dark brown stripe bordered as usual each side with one of pale yellow, the latter prominent in fresh specimens; sides of abdomen also with a narrow yellow stripe. Fastigium strongly ascending, its sides rounded or distinctly divergent forward, the apex one-third wider than basal joint of antennæ. Lateral lobes with lower front angle obsolete, hind one obtusely rounded; humeral sinus evident, very shallow; convex callosity prominent. Tegmina usually strongly abbreviate, covering only about one-fourth of abdomen, their tips rounded; rarely macropterous, with the tegmina slightly exceeding the tips of hind femora, and exceeded by wings $5 \mathrm{~mm}$. Cerci as in key and Fig. 189, d. Ovipositor as long as or longer than body, very feebly curved. Length of body, $\hat{o}, 11-$ 14, ㅇ, 12.8-15.5; of pronotum, $\hat{\delta}$ and $\odot, 3-3.5$; of tegmina, short-winged $\hat{\delta}, 3-3.5$, ㅇ, 2.5-2.7; long-winged $ᄋ$, 22 ; of hind femora, $\hat{\delta}$ and $ᄋ$, 11-12; of ovipositor, 13.5-15 mm. (Fig. 193.)

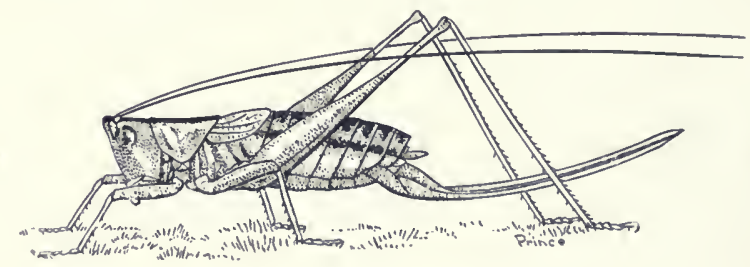

a

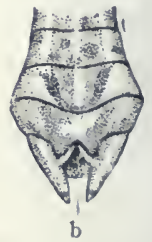

Fig. 193. (a) Female. Two and one-half times natural size. (b) Tip of male abdomen, showing form of cerci. (Original.)

'This, one of the smallest of the Conocephalinx, luas as yet been noted only at four localities in Indiana, namely, the border of a raw prairie near Heckland, Vigo Co., where it was found in small numbers Sept. 29-Oct. 21; near Lafayette, where Fox took a single male in company with $C$. attenuatus in a cat-tail cut-glass Iuarsl, ; at Dune Park, Porter Co., Oct. 12, where a few individuals were taken from the clumps of grass on the base of a sand ridge. and near l'ine, Iake Co.. Whele a female was taken fejut. :3 by j. 1). Hood. It apprears to be less active than any other Como- 
cephalus, leaping a shorter distance when disturbed, and frequenting the surface. of the ground rather than the stems of the tall prairie grasses among which it makes its home. It will probably be found, by close search, to inhabit most of the few remaining patches of raw prairie in the western part of the state.

The known range of saltans cannot be definitels stated as it Las heretofore been confused with the next species. Scudder's trpes were from the Platte River, Yebr., and its natural home and center of distribution is probably on the prairies of the middle west, extending from western Indiana north and west to Mandan and Hillsboro, N. Dak., Livingston, Mont.. and Manitou, Col.. and south and rest to Thomasville, Ga.. Dallas. Texas. and Springer. $\mathbf{X}$. Mex. Long-winged examples from Dallas are in the Cambridge collection. It appears to be xerophilous in haloits, as it occurs mainly on dry upland prairies and sandy harrens. The $X$. modestum Bruner $(1891,5 \tau)$ from Nebraska, and the I. tcriatum Redt. (1S91, 520) are synonyms.

273. Coxocephialts riridifroxs sp. nov. Green-faced Grasshopper.

Shorter and more compact than saltans. Pale bluish-green, fading to dull greenish-yellow, the face immaculate; median stripe of vertex and pronotum paler brown than in saltans, the yellow stripe below less prominent; that on abdomen vague or wanting. Fastigium but slightly ascending, its sides subparallel, but slightly rounded, apex scarcely as wide as basal joint of antennæ. Pronotum as in saltans. Tegmina of male reaching nearly to middle of abdomen; one-fourth longer, better developed, with tips more narrowly rounded in both sexes than in saltans. Cerci as described in key and Fig. 189, e, their apical portion conical, not at all twisted, incurved or flattened within near tip as in saltans. Ovipositor shorter a little stouter and with a less evident upward curve than there. Length of body, $\delta, 11-13$,,$~ 12.5-14$; of pronotum, $\hat{\delta}$ and $\$, 2.8-3.2$; of tegmina, $\hat{\jmath}, 4.5-5, \mathcal{}, 3$; of hind femora, $\hat{\delta}$ and $\$, 10-12$; of ovipositor, $9.5-12.5 \mathrm{~mm}$.

Toronto, Ont., Aug. 10 (Waller) ; Central Park, Long Island. X. Y. Sept. $S$ (Daris). This species is rery distinct from saltans by the characters given in kes and description. Comparisons have been made with the types of both saltans and its synonym, mortestum at Cambridge and Philadelphia. The male in the Scudder' collection from Red River Settlement, Man. mentioned by him (1862a. 288) as T. brevipenne but placed by R. \& H. (1915b, 216) nnder $C$. saltans is a specimen of viridifrons.

Walker $(1904 a, 340)$ took the Toronto specimens above mentioned Aug. 9-Sept. S, at High Park in company with J/elanoplns dursoni (scudd.). They were found in open grassy uplands on sandy soil, where they were plentiful among Jerser-tea, sweet 
fern and lupine. He stated: "My specimens are all peculiar in thieir coloration, being of a pale, almost bluish-green, instead of dull reddish-brown the usual color of saltans, according to the description."

On account of the previous confusion of viridifrons with saltans the definite range of the former cannot be given. It is known, as stated, from the Red River of the North east to Toronto and south and southwest to Long Island, N. Y., New Jersey and Virginia.

Morse $(1919,17)$ reports it, under the name of saltans, as "locally common on the sandy moors of Nantucket, Mass., among bunch grass, wild indigo and huckleberry bushes. The presence of this flightless grasshopper on Nantucket is of especial significance in its bearing on the geological conditions which resulted in the dispersal and present distribution of the characteristic plants and animals of the sandy coast-plain of New Jersey northeastward." In Virginia Fox found it at numerous localities during September and October, usually in coarse dry grasses, Andropogon, in the vicinity of wooded areas.

VII. Onontoxiphidium Morse, 1901b, 129. (Gr., "toothed" + "sword.")

Closely allied to Conocephalus. Differs by the characters given in the generic key, and in having the "pronotum subsellate, prolonged backward, covering the base of abdomen both above and on the sides, in correlation with the absence of flight organs." (Morse).

274. Odontoxiphidjum Apterum Morse, 1901b, 129. Wingless Meadow Grasshopper.

Size small for the subfamily; form moderately robust. Reddishbrown; face, hind femora and sides of body green or greenish; occiput and prozona with the usual median stripe reddish-brown bordered each side by a narrow yellowish one; sides of abdomen, male, entire abdomen, female, fuscous-brown; all the femora thickly mottled with small reddish-brown dots. Antennæ very slender, four times as long as body. Fastigium feebly ascending, its sides slightly diverging forward, apex two-thirds as wide, male, fully as wide, female, as basal joint of antennæ. Disk of pronotum exceedingly smooth, the usual transverse sulcus obsolete; lateral lobes longer than deep, their front margin broadly rounded into the feebly sin. uate lower one, the, latter with hind angle obtusely rounded; hind margin straight, oblique; humeral sinus absent. Tegmina of male conjointly oval, shorter than pronotum, the speculum of left tegmen strongly convex, its basal cross vein slender, covered by metazona, oblique vein abbreviated, the others subobsolete. Hind femora elongate, unarmed beneath, the basal third very stout. Cerci of male straight, very slender, cylindrical, bear- 
ing on inner side of apical third a stout, straight, obtusely pointed tooth and at basal third a small black-pointed subdorsal denticle. Subgenital plate prolonged, almost reaching tips of cerci, broadly scoop-shaped, its tip subtruncate; styles very short, blunt. Ovipositor slender., straight, usually about five-sixths the length of hind femora but sometimes nearly one and a half times that of body. Length of body, $\hat{o}, 11-14$,, $11-18$; of pronotum, $\hat{o}, 3.5-4, \hat{\imath}, 4.5-5.3$; of tegmina, $\hat{o}, 2-3$; of hind femora, $\hat{o}$, $10-12$,, , 13-15; of ovipositor, $10.5-15 \mathrm{~mm}$.

Hastings, Orlando and Dunedin, Fla., July 5-Jan. 1 (W.S.B.). About Dunedin this small Tettigoniid is frequent in late autumn and early winter but apparently succumbs to the first frost. It occurs mainly amidst the wire-grass and low huckleberry bushes of open pine woods, but also among the taller grasses growing in old fallow fields and on the sites of wetweather ponds. It was described from Hastings, Fla., and is recorded by other collectors from numerous localities throughout the entire mainland and on the southern keys. As will be noted by the measurements, the females vary much in size and in the length of ovipositor. They have been heretofore described as being totally apterous, but they have rudinientary tegmina concealed by the pronotum. In a specimen from Orlando these are large enough to protrude slightly besond the pronotum. The males usually carry the cerci in a reflexed, almost perpendicular position within the cavity of the long projecting scoop-shaped subgenital plate.

The known range of 0 . apterum extends from Faretterille, N. Car., to Key West, Fla., its main distribution being in Georgia and Florida. R. \& H. (1916, 267) say that "Throughout the low country of the Carolinas, Georgia and Florida this is one of the most ubiquitous species in the undergrowth of the pine woods and on the palmetto flats. At a number of localities it was particularly numerous about oak shoots in such situations. The stridulation is a rery faint and intelmittent zip-zip-zce-zee-zcezip-zee-zee, etc. The males when stridulating often climb high up in the undergrowth, sometimes three or four feet from the ground."

274a. ODOXTOXIPHIDIUM APTERUM AFFINE var. nov.

Size and form of 0 . apterum. Differs as follows: Color paler; median dark stripe of occiput and prozona vague, the yellowish ones below it faint or wanting; abdomen without dark markings in either sex. Fastig. ium of vertex more strongly ascending, its apical half with sides rounded, distinctly wider than middle. Pronotum less sellate; humeral sinus evident but faint. Cerci of male distinctly stouter, subdepressed, their apical portion subtriangular, the tooth at apical third stouter and slightly curved 
inward and downward. Ovipositor more slender, and with an evident but faint downward curve beyond the middle. Other characters as in apterum. the measurements approximately the same.

Ft. Myers and LaBelle, Fla., March 2-5; three males, two females (W. S. B.). Swept from low huckleberry bushes and other foliage along the margins of swales. The differential characters as ahove given are deemed sufficient to place this as a form of apiterum worthy of a rarietal name. It will probably be found only in the southern third of Florida.

\section{Subfamily T. DECTICINÆ. \\ The Shield-Bearers.}

Tettigoniids of large size and peculiar appearance in that they are nearly wingless and have the pronotum more or less prolonged backward orer one or more of the basal segments of ahdomen, thus forming a buckler or shield, whence the common name. Our eastern forms agree in having the face broad, perpendicular or nearly so; eyes small, subglobose, separated by at least three times their own diameters; antennæe very slender, arising from between the inner lower margins of eyes, bnt little longer than the body; rertex short, one-third or more the width of interocular space, strongly declivent between the antennæ; pronotum with front margin truncate, lind one rounded or subtruncate; lateral lobes longer than deep; prosternum usually armed beneath with two erect spines; tegmina very short, rarely as long as pronotum, developed only as shrilling organs in male, often scarcely visible, female; wings absent or rudimentary; tarsi more or less depressed, their first two segments sulcate lengthwise on the sides: front tibia with a slit-like foramen (hearing organ) each side near base and an apical spine on their upper outer side; front coxre spined; hind tibiae armed below with four apical spines; hind tarsi with a free lobe (plantula) at base of first joint; cerei of male variable as to genera and species; ovipositor stout, nearly straight.

According to Caudell only abont 225 species of Decticina distributed among $4 \tau$ genera, were known in 1908 . They are confined mostly to the temperate zones, 20 or more of the genera occurring in the United States. The main distribuation of these is west of the Mississippi, where some of the species are very abundant and do much damage to regetation. East of that stream but two genera are represented, one of them by a single species. But little is known of the life history of our eastern forms. They ap- 
pear to be omnivorous in their choice of food. and, when kept in captirity, even cannibalistic. They are found for the most part in dry, upland open wooded districts or mountainous regions. where they are active during the dar. On account of their comraratively wingless condition they probably do not wander far from their hatching place. In color they are usually a dull grayish- or rellowish-brown, their hues thus corresponding closely with the dead leares and other herbage of their abiding places. As the males stridulate only at night, and the adults of both sexes more slowly and only when closely approached, they are seldom seen and are probably more plentiful than ther apiear to be. The principal literature pertaining to the subfamily which will be of interest to the American student is as follows: Hernian, 18т4; Scudder, 1S94a; Caudell, 1907, 1908; Rehn \& Hebard, 1916a.

KEY TO EASTERY GEXERA OF DECTICIX.E. ${ }^{i 1}$

a. Oripositor straight or nearly so (Fig. 195); tegmina of male shorter than pronotum; prosternum usually armed with a pair of spines; lateral lobes longer than deep.

I. Atraxticus.

aa. Ovipositor distinctly curved upward (Fig. 199); tegmina of male longer than pronotum, sometimes fully developed; prosternum unarmed; lateral lobes as deep as long.

II. IDIохотU:.

I. Atuanticus Scudder, 1894a, 179. (Gr., "a mythical island.")

The nembers of this genus possess the characters of the subfamily above given. In addition ther have the head of medium size, not prominent, disk of pronotum much produced belind orer the base of abdomen, front margin truncate; latelal carince always evident, sometimes gently rounded. again sharp and prominent; lateral lobes longer than deep, their front margins nearly straight and vertical, lower one short, oblique, the angle between the two obtuse, lower hind angle broadly rounded. hind margin loug. oblique and sinuate; tegmina of male vaulted. overlapping. their stridulating field large but mostly concealed beneath the jronotum; tegmina of female wholly concealed; fore femora unarmed or with one to five spines on outer lower margin; hind f(rnora variable in length and stoutness. their lower margins unarmed, or the inner one with sereral spines; last dorsal segment deeply emarginate at middle, the notch enclosing the small triangular or rounded deflexed supra-anal plate. Cerci of male subcylindrical, variable in length and thickness, armed within.

\footnotetext{
"1 A single specimen of Pediodectes (Stipator) nigromarginata Caudel!, is recorded by that author $(1907,346)$ as being in the Scudder collection from Georgia, but it cannot be found and the record is probably erroneous, the species being otherwise known only from Kansas, Oklaboma and Texas.
} 
at or behind the middle with a single tooth; subgenital plate of male either notched or subtruncate, its styles variable in length and thickness; of female always notched, usually deeply so. Ovipositor variable in length, usually straight, sometimes feebly curved downward, its tip acute.

The synonymy of the species of the genus Atlanticus is rery much confused. Until 1894 only three species, now included under that name, were known from the United States, two described from South Carolina by Burmeister (1838) under the names Decticus pachymerus and dorsalis, and one from Tennessee by Saussure (1859) as Orchesticus americanus. Burmeister's names were placed by Scudder (1862) under the Old World genus Thyreonotus (Serv.) and by him applied to two well known northern forms (one of them the americanus of Saussure) which R. \& H. (1916a) aver are not the same as those described by Burmeister, though they have not seen the latter's types and base their conclusions mainly on the fact that the species to which Scudder applied the names do not, as far as known, occur in South Carolina. Scudder (1894a) founded Atlanticus and refer'ed to it the northern forms which he had previonsly placed under Thyreonotus, and a third species, gibbosus, from Florida. Later (1900) he described a fourth species, testaceus, from Missouri?, R. \& H. (1912) described A. glaber from Florida and Davis (1915a) $A$. monticola from North Carolina. Finally R. \& H. in their Revision (1916a) applied Burmeister's names to two souther'l forms, placed Saussure's americanus (dorsalis of most authors) under Atlanticus, referred the northern form previously known as "pachymerus Burm." to testaceus Scudd., and described two forms as new, thus recognizing nine species of Atlanticus, all occurring east of the Mississippi, and all but two confined to that area. ${ }^{72}$ Since no one knows, or probably ever will know, to what forms Burmeister's names should in reality be rightfully applied, I judge that the conclusions of $R$. $\&$ H. are as good as any that can be made, and to avoid stirring the hodge-podge still farther I have, in the main, adopted them.

But two species of Atlanticus occur in Indiana and in their various stages are quite frequent from April 1st to September 15th in dry upland woods and on sloping hillsides with a sonthern exposure, but are seldom, if ever, found in damp localities. On the first warm days of early spring the young begin to emerge and in suitable places for a month or more are among the most common

${ }^{72}$ Scudder (1894a) and R. \& H. (1916a) stated that Atlanticus was confined to the Atlantic slope of North America, but Rehn has recently described a species from China. 
Orthopterans seen. They are much more active during early life than in the mature state when they crawl rather than leap. In captivity they feed as readily upon animal as upon regetable food, and in the natural state probably feed upon the dead bodies of such small animals as they can find. The earliest hatched reach maturity in central Indiana about the first of June, and may then often be found resting on the leares and stems of low shrubs and weeds, but seldom climb over two or three feet from the ground. The adults are far less numerous than the roung, the vast majority of the latter probably falling a prey to the nany ground-frequenting sparrows and other birds, as they do not hide by day as do the members of the genus Ceuthophilus.

The following key is based largely on that of $\mathrm{R}$. $\& \mathrm{H}$. in their Revision, the order being changed to agree with the sequence of the species treated, the language simplified and some additional characters given.
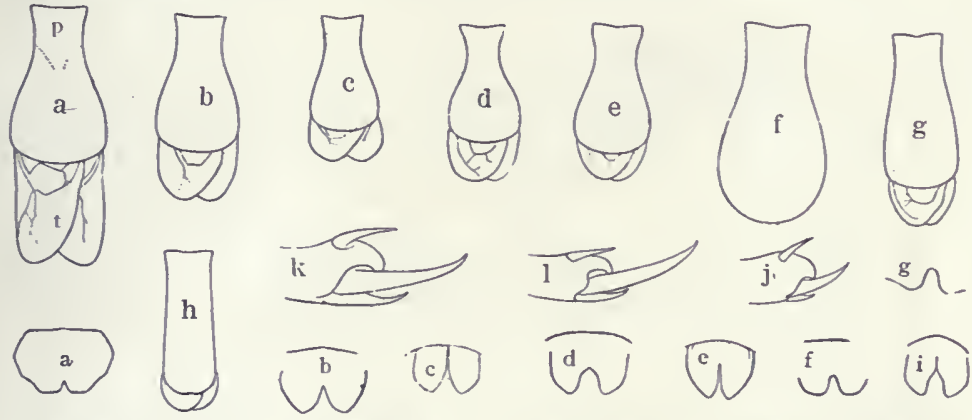

Fig. 194. Structures of Atlanticus. a-i, Dorsal outlines of disk of male pronotum $(p)$ and tegmina $(t)$ when projecting, $\times 1.5$; also outlines of subgenital plate of female showing shape of notch, $\times 2$. a, of testaceus; b, pachymerus; $\mathrm{c}$, davisi; $\mathrm{d}$, monticola; $\mathrm{e}$, americanus; f, gibbosus; $\mathrm{g}$, dorsalis; $\mathrm{h}$, calcaratus; $\mathrm{i}$, glaber. $\mathrm{j}-\mathrm{l}$, Outlines of tips of hind tibia showing the inner apical spurs, $X 5, \mathrm{j}$, testacens; $\mathrm{k}$, glaber; 1 , calcaratus. (After R. \& H.)

REY TO AMERICAY SPECIES OF ATLANTICUS.

a. Disk of pronotum distinctly narrower near apical third or fourth, its margins or lateral carinæ thence distinctly diverging backward, its length never twice the greatest width (Fig. 194, $a-g$.)

b. Lateral carinæ of disk of pronotum sharp, the angles very distinct; tegmina of male never completely covered by the pronotum.

c. Subgenital plate of male angularly emarginate but never deeply and narrowly cleft; notch of subgenital plate of female V-or U-shaped, the projections each side never long and sublanceolate (Fig. 194, $a-d$ ) ; cercus of male in front of tooth stout.

d. Length of exposed portion of male tegmina more than half that of pronotum; hind femora less than twice as long as pronotum; notch of subgenital plate of female narrowly Vshaped, its side projections short, broadly rounded (Fig. 
$194, a)$; ovipositor with apex tapering only on upper side, its tip therefore ventral (Fig. 195, a.) 275. TESTACEUs.

dd. Length of projecting male tegmina not more than one-third that of pronotum; hind femora at least twice as long as disk of pronotum; lateral projection each side of notch of subgenital plate of female not broadly rounded.

$e$. Ovipositor with apex tapering only on upper side, its tip therefore ventral (Fig. 195, b) ; hind femora of male 19 or more mm. in length; tegmina of male with tips slightly produced.

276. PACHYMERUS.

$e e$. Ovipositor with apex tapering both above and below, the tip therefore median (Fig. 195, $c, d$ ); hind femora of male less than $19 \mathrm{~mm}$.; tegmina of male with tips broadly rounded.

f. Ovipositor straight; notch of subgenital plate of female very narrowly V-shaped (Figs. 194, 195, c.)

277. DAVISI.

ff. Ovipositor feebly but distinctly curved; notch of subgenital plate of female U-sbaped (Figs. 194, 195, d.)

278. MOXTICOLA.

cc. Subgenital plate of male narrowly and deeply cleft; notch of subgenital plate of female very deep, the projections each side elongate and narrowly rounded; cercus of male rather long, slender, subcylindrical (Fig. 195, $j$ ); ovipositor with apex tapering only on upper side, the tip ventral (Figs. 194, 195. e.) 279. AMERICANUS.

$b b$. Lateral carinæ of disk of pronotum obtusely rounded, distinct only on the posterior lobe; tegmina of male almost or wholly covered by the pronotum (Fig. 194, f.)
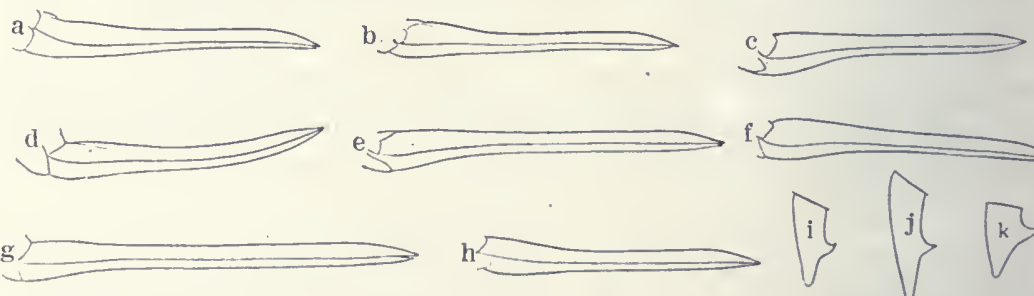

g

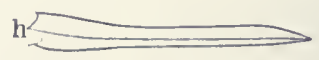

Fig. 195. a-h, Outlines of ovipositor of Atlanticus, $X$ I.5: a, of tcstaceus; b, pachymerus; c, davisi; d, monticola; $\mathrm{e}$, americauns; $\mathrm{f}$, dorsalis; $\mathrm{g}$, gibbosus; $\mathrm{h}$, giaber. i-k, Outlines of left cercus of male, $\times 4 ; i$, dazisi; $\mathbf{j}$, americanus; $k$, dorsalis. (Ifter R. \& H.)

g. Size large, length of body, male, $26-33 \mathrm{~mm}$; cercus of male elongate, tapering and with a long slender curved sub-basal tooth (Fig. 197, b); basal half of hind femora strongly swollen; disk of pronotum more narrow at apical fourth than at front margin (Fig. 194, f.) 280. Girbosus.

gg. Smaller, length of body, male, less than $26 \mathrm{~mm}$.; cercus of male short, robust, its tooth short (Fig. 195, $k$ ) ; basal half of hind femora much more slender; disk of pronotum not more narrow at apical fourth than at front margin. 281. Do1ssalis. aa. Disk of pronotum not or very feebly narrowed at any point, its lat- 
eral carinæ subparallel or nearly so, its length always more than twice its greatest width (Fig. 194, h.)

$h$. Middle apical spur on inner margin of hind tibiæ but little if any more than twice as long as the lower inner one (Fig. 194,k); prosternal spines present, elongate, slender. 282. GLABER.

$h h$. Middle inner apical spur of hind tibix two and a half times or more as long as lower inner.one (Fig. 194, l); prosternal spines absent or very short.

283. Calcaratus

275. Atlaxticus testaceus (Scudder), 1900, 97. Short-legged Shieldbearer.

Size medium for the genus, form robust. Male.-Grayish or fuscousbrown; sides of pronotum and tegmina blackish, the former often shining. especially in the young; lateral lobes with a narrow curved yellowish line along the hind margin; exposed dorsal field of tegmina light brown; femora with numerous minute pale spots. Female.-Usually grayish or reddish-brown throughout, except the yellow line on side of pronotum, which is bordered above with a dash of black. Head large, set into pronotum almost to eyes. Antennæ slender, less than twice as long as body, the basal segment strongly flattened, about as wide as fastigium. Pronotum with disk large, its greatest width about two-thirds its length; lateral carinx sharp, distinctly converging from base to apical fifth, then feebly diverging to apex; hind margin broadly rounded or subtruncate; lateral lobes with hind margin long, sinuous, very oblique. Tegmina of male exposed a distance at least equal to greatest width of pronotum, often more, their tips broadly rounded. Cerci of male subcylindrical, stout, tapering, feebly curved, rather bluntly pointed, the tooth at inner apical third short, blunt; apex of subgenital plate broadly shallowly emarginate; styles short, obtuse. Ovipositor straight, about as long as hind femora, its apical sixth tapering above to the acute tip. Length of body, $\hat{\delta}, 18-24$, 오, 19-25; of pronotum, $\hat{\delta}, 9-10.8$,,$~ 8.8-10.4$; of tegmina, $\hat{o}, 7-9$; of hind femora, $\hat{o}$, 14.5-17, $९, 16.5-21$; of ovipositor, $18.5-23 \mathrm{~mm}$. Greatest width of pro-

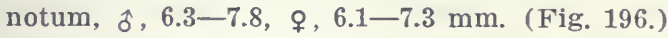

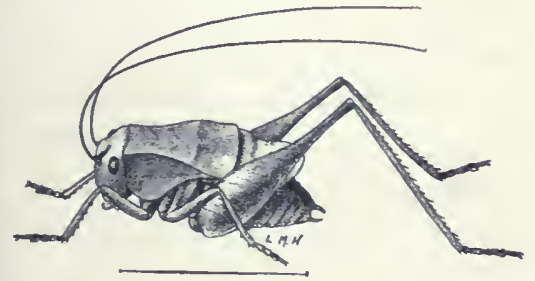

Fig. 196. Male. (After Lugger.)

This bulky brown Orthopteron occurs throughout Indiana but is more common in the northern counties. It frequents for the most part dry open woodlands, thinls wooded rocky slopes and border's of thickets, where it crawls slowly over the fallen leaves being very clumsy in its morements. The earliest date on which a mature specimen has been noted was June 6th, in Vigo County, numerous specimens being taken between that date and June 20 , while they may be found until after heary frosts.

The general range of $A$. testaceus is northern, it being the most common Atlanticus north of the Ohio and east of the Mis- 
sissippi, its known dirtribution extending from Vermont, Massachusetts and southern Ontario, west to Minnesota and central Illinois and south to irginia and central Kentucky. It is the species heretofore re ded by most writers, myself included (1903, 393), as A. pac /merus (Burm.) and there is no direct evidence to prove that it is not that species.

Davis (1893) has given a pleasing account of the song and habits of testaceus as noted on Staten Island, in part as follows:

"On June 26 I heard in a moist pasture a stridulation that was unknown to me. It much resembled that of Orchelimum vulgare, with the preliminary $z i p$, zip omitted. It was a continuous $z-e-e-e$, with an occasional short $i k$, caused by the insect getting its wing covers ready for action after a period of silence. In due time I discovered, in a tussock of rank swampgrass, the brown songster, Thyreonotus pachymerus, perched on a dead leaf. He was transferred from the tussock to a tin can and at home I made a home for him in a larger can in which was a branch of post oak whose leaves soon dried, furnished innumerable nooks and crannies in which to hide. Usually, however, the insect did not hide at all but perched himself on one of the topmost leaves and there waved his antennæ after the manner of all long-horned Orthoptera. Starting with raspberries, he had the rest of the fruits in their season, including watermelon, of which he showed a marked appreciation. If I offered him a raspberry and then gradually drew it away, he would follow in the direction of the departing fruit, and would finally eat it from my hand. At night he stridulated with unabated zeal to the first of August when he began to be less sprightly. Finally his song, instead of filling the room, was but a faint sound and the end came on the tenth or eleventh of September."

Allard $(1911 b, 118)$ says of the song of A. testaceus on Plummer's Island, Md.: "One was singing after dark very close to the ground on a dry rocky thinly-wooded hillside. Its notes have the same lisping character as an Orchelimum. The phrases are brief, but rapidly repeated, with irregular intervals of silence interven-

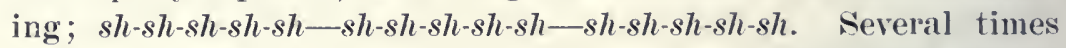
while watching the insect stridulate by candle-light the writer lisped an approach to its notes and got an immediate response."

At Moline, Ill., McNeill (1891) found the first adults on Aug. 9 and states that those kept in captivity showed a decided taste for animal food so that in the wild state it may be at least partly carnivolous.

Osborn records a specimen from Camp Douglas, Wis., and Lugger figures and describes the species from Minnesota, stating that only a few were found but giving no definite locality. In Michigan it is known only from the Poreupine Mts. and Gun Lake. Walker $(1905,113)$ states that the ouly Ontario specimens he 
had seen were taken at Arner, Aug. 9. "Tues were found in the more open parts of a dry upland wood consisting chiefly of oak. Most of them were found on the short gre ; which was growing on the slopes of a ravine in the wood." ,

276. Atlaxticus pachymerus (Burmeister), 18; 712.

The important features of difference between ithis species, as identified by R. \& H., and A. testaceus are given by those authors $(1916 \mathrm{a}, 54)$ as follows: "Caudal femora in both sexes of pachymerus at least twice, male, or more than twice, female, as long as pronotal disk; cephalic and median limbs relatively longer; greatest caudal width of pronotal disk equal to 54 to 66 per cent of greatest length of same; prosternal spines more aciculate and elongate and mesosternal lobes more acute. Male with pronotum less expanded caudad, the divergence of lateral carinæ less pronounced; tegmina well produced, the portion distad of the stridulating field distinctly shorter than in testaceus (Fig. 194, b); cerci more slender and more acuminate, the apex more produced, the tooth more nearly median than in testaceus; subgenital plate with distal margin rectangulate-emarginate to acutely subfissate; styles slender and relatively elongate. Female with lateral carinæ of abdomen distinctly and median carina slightly more pronounced; ovipositor of approximately the same length as in testaceus but relatively much shorter, being considerably less than length of caudal femora. Subgenital plate more deeply divided, the lateral portions rotundato-rectangulate" (Fig. 194, b.) Length of body, ô, 23.2-26.7, , 2028.2 ; of pronotum, $\hat{o}, 9.5-11.4,9,9.1-10.6$; of tegmina, $\hat{\delta}, 5.4-7.6$; of hind femora, $\hat{o}, 19.8-24.2$, $९, 21-24.2$; of ovipositor, $18-24 \mathrm{~mm}$. Greatest width of pronotum, of $5.8-7$,, $5.7-6.5 \mathrm{~mm}$.

Southern Pines, N. Car., July 2 (Daris). Burmeister's types of pachymerus were from Germar's collection and labelled "Sonth Carolina," without name of collector or region of the State. His brief description was as follows:

"Fusco-griseus, pronoti lateribus infuscatis, macula ad sinum marginis postica flara; vertice abdomineque toto unicoloribus. Male, elytris liberis fornicatis. Female, elytris nullis; vagina recta, abdomine longior. Long. corp. 9" (18.7 mm) ; femor. post. 8" (16.6 mm)."

Of this description and their placement of the species R. \& H. (loc. cit.) say: "We are able to place Burmeister's name on this species by a process of elimination, * * * the three words describing the male, 'elytris liberis fornicatis,' clearly referring to this species, testaceus or davisi; of these only the present form occurs near the coastal region of South Carolina from which the original material of pachymerus probably came. The characters given for the female are only sufficient to separate that sex from monticola. The length of the body and of caudal femora as given by Burmeister, while less than any found in the material before us, do not at all invalidate the claim of this species to his name. 
The body length given could easily be accounted for by the abdomen being shrunken, while geographic or individual size variation could easily cause the discrepancy seen in the femoral length." Later on they admit that they have no exact record of the occurrence of pachymerus in South Carolina and give its lnown distribution as extending from Greensboro and Raleigh, $\mathrm{N}$. Car., to the Ozark Mountain region of Arkansas. At Goldsboro, N. Car., the species was found "among fallen leaves of deciduous trees in a rather open forest composed chiefly of shortleaf pine."

As already noted none of the evidence thus submitted by h. $\&$ H. is, in my opinion, conclusive that the species thus fixed by them is the one described by Burmeister, and the latter must continue to remain a matter of question unless his types ean be found and compared with our different forms.

277. Atlanticus davisi Rehn \& Hebard, 1916a, 58. Davis's Shield-bearer.

Slightly smaller and more slender than testaceus. Male usually dark sooty brown flecked everywhere with grayish; apical third of hind femora paler, yellow line on lower border of pronotum indistinct or wanting. Female dull reddish- or yellowish-brown; posterior lobe of pronotum, dorsum of abdomen and ovipositor dark brown; face often with a blackish spot below each eye; sides of pronotum with obsolete fuscous markings. Fastigium slightly narrower than eye, feebly declivent. Disk of pronotum shorter than in testaceus, its lateral carinæ not as sharp as there, converging from base to apical third, then feebly diverging to apex, its greatest width two-thirds its length, hind margin subtruncate, its angles broadly rounded (Fig. 194, c); lateral lobes two-thirds longer than deep, lower margin straight, obtusely rounded into front one, hind margin oblique, fee-

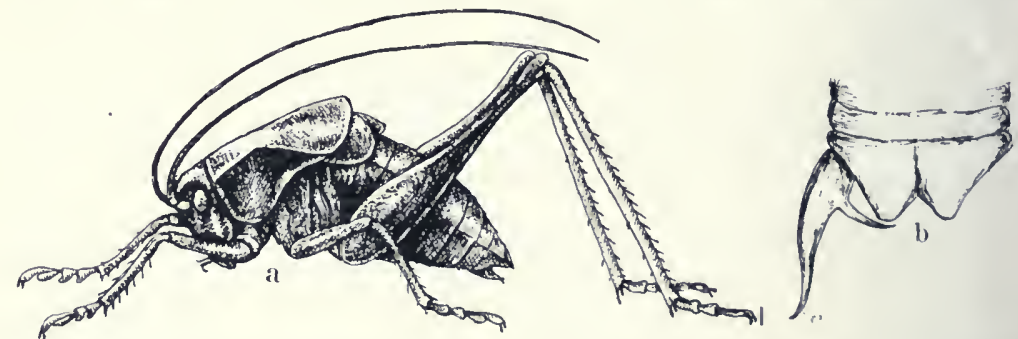

Fig. 197. $a$, Male of Atlanticus davisi, $\times$ r.7; $b$, tip of male abdomen of A. gibbosus, showing form of cercal tooth. (After Caudell.)

bly sinuate. Tegmina of male exposed a distance equal to about one-half that of width of hind margin of pronotum, their tips well rounded. Hind femora with lower inner margin often armed with one to four very short spines. Male with cerci rather short, feebly curved, the basal portion stout, apical third much less so; the tooth at apical two-fifths short, slightly inbent (Fig. 195, $i$ ); subgenital plate with a triangular notch; styles short, stout. Female with notch of subgenital plate very narrowly V-shaped; ovi- 
positor slightly longer than hind femora, straight or nearly so, the apical fifth tapering on both margins to the median acute tip (Fig. 195, c.) Length of body, $\hat{o}, 16.8-23$, ᄋ, 17-26.5; of pronotum, $\hat{o}, 7.7-9.5$, 오, $8-10.6$; of tegmina, $\hat{\delta}, 3.5-5.5$; of hind femora, $\hat{\delta}, 15-18$, 오, 17.5-22; of ovipositor, $18.4-23 \mathrm{~mm}$. Greatest width of pronotum, $\hat{\delta}, 5.2-6.2$,, $5-5-$ $6.6 \mathrm{~mm}$. (Fig. 197, a.)

Southern half of Indiana, frequent, June 4-Sept. 28 (IV.S.B.) ; East Jewett, N. Y., and Great Falls, Va. (Duris). This is the species treated in my formel work $(1903,394)$ as Atlanticus dorsalis (Burm.), a name which R. \& H. have ajplied to a form occurring in Georgia and Florida. In Indiana A. davisi has been taken from Marion and Putnam counties southward, and occurs most frequently on the high rocky, thinly wooded slopes of the southern counties where it is more abundant than testaceus. From the latter species it may be readily known by the shorter, less rounded hind lobe of pronotum, less exposed male tfguina, longer and more slender apical portion of male cerci, and by the tip of ovipositor being formed by the tapering of both mairgins, not the upper one alone as in testaceus.

The known range of davisi extends from Iake George, N. Y., west to southern Iowa and south to southern Virginia. In the eastern States it occurs in company with A. amcricanus among the dead leaves and scattered undergrowth of deciduous woods.

278. Atlanticus Moxticola Davis, 1915a, 104. Mountain Shield-bearer.

Size and form of $A$. davisi. Female "brown, the sides of pronotum streaked with black, particularly at the posterior portion, also an interrupted band of black on the outer sides of femora. Pronotum narrowel in front than behind, somewhat pinched before the middle, the lateral carinæ well defined. Ovipositor stout, swollen at base with a gradual upward curve from about the middle and symmetrically narrowed to a point from both above and below (Figs. 194, 195, d.) Notch of subgenital plate U-shaped." (Davis). Tegmina of male covering about one-fourth of abdomen, their marginal field broader at base and narrowing toward apex instead of quite narrow and subequal throughout as in davisi. Length of body, $\delta, 17.6-19.8$, $\&, 20-23.2$; of pronotum, $\hat{o}, 8-9$, 우 $8.3-9.9$; of teg. mina, $\hat{\delta}, 4.4-6$; of hind femora, $\hat{\delta}, 14.8-18.8$, + , 18.5-20.2; of ovipositor, $17.6-19.4 \mathrm{~mm}$. Greatest width of pronotum, $\hat{o}$ and $\$, 5.7-6.4 \mathrm{~mm}$.

Lake Toxaway, N. Car., and Clayton, Ga. (Davis). The single paratype female at hand resembles that sex of davisi closely, but differs in the narrower disk of pronotum, with lateral carina less convergent, its posterior lobe more rugose above with angles much less rounded; the distinctly shorter lower half of lateral lobes with hind margins therefore much more oblique, the lower hind angle more narrowly rounded and humeral sinus more 
distinct, the very evidently upeurved ovipositor and the broader, more U-shaped notch of subgenital plate.

The known range of this mountain-loving species extends from near Durbin, W. Va., to Clayton, Ga., at elevations of 2,000 to , 000 feet. At Jones' Knob, N. Car., it was taken by R. \& H. on July 19 and Oct. 7 in the undergrowth of the deciduous forest immediately below the spruce belt.

279. Atranticus americanus (Saussure), 1859, 201. American Shieldbearer.

Size medium or above for the genus; form robust. Brownish-yellow to dark reddish-brown, lateral lobes of pronotum often in part darker; hind femora and sides of abdomen occasionally with small fuscous blotches. Fastigium and pronotum much as in testaceus, the latter with disk often subcarinate behind the middle, narrowest at apical third. Tegmina of male projecting beyond pronotum a distance about half that of width of front margin of pronotum. Hind femora as long as or slightly longer than body. Male cercus with apical portion feebly tapering; tooth small, sharp, situated at apical two-fifths (Fig. 195, $j$.) Ovipositor as in key and Fig. 195, $e$, as long as or slightly longer than hind femora. Length of body, $\hat{o}$, $20-30$, ㅇ, 22-28; of pronotum, $\hat{\sigma}, 9.4-11$, ㅇ, 10-11.3; of tegmina, ô, $4.8-6.2$; of hind femora, $\hat{o}, 22-28$, 우, $24.5-29.4$; of ovipositor, $24-28.3$ $\mathrm{mm}$. Greatest width of pronotum, ô, 5.4-6.9, 우, $6.2-6.7 \mathrm{~mm}$.

North Madison, Conn., Aug. 25, one pair from the crests of high rocky ledges along the Hammonasset River (IV. S. B.). Yaphank, Long Island and Lakehurst, X. Jer., Aug. 27, Sept. 6 (Davis). A common form of the northeastern states and, according to R. \& H., the one to which Scudder (1S62) and most subsequent authors applied the name dorsalis Burm. Its known range extends from central New England west to the Appalachian Mountains and southwest to northern Florida, central Alabama and Natchez, Miss. Saussure's types were from Tennessee. The Connecticut record above given is the first definite one for that State. The only known Florida station is River Junction where on August 31 R. \& $H$. took five males and four females from "among tree shoots in heary forest of beech, hickory, oak and magnolia on limestone hills." They state (1916a, 79) that americamus is a "frequenter of the areas of dead leaves and low undergrowth in pine and deciduous forests, occasionally being more numerous along the edges of the timber than in the depths of the woods. Its presence will often be signalized by the patter on the leaves as it jumps away from the disturbing footsteps. The insects are so thoroughly protected by their coloration that it is often difficult to see them, even when moving, much less when 
stationary. 'Their activities are chiefly nocturnal and work with a flash lamp will sometimes reveal them in many situations."

Daris (1911a) mentions the finding of eight specimens of this large Orthopteron in a single burrow of the wasp, Chlorion ichneumonea L., the "cricket" being so chumsy in motion that it easily falls a prey to the wasp. He also states (1915a) that this and other species of Atlanticus "are often attracted to the trees sugared for moths and they may be likewise collected in traps consisting of jars or old tin cans sunk in the ground and baited with molasses. More females than males seem to be attracted by the above methods."

\section{Atlanticus gibbosus Scudder, 1894a, 180. Robust Shield-bearer.}

Large for the genus; form robust. Pale brownish-yellow to cinnamon-brown, more or less sprinkled with fine fuscous markings; upper half of lateral lobes usually blackish-fuscous. Fastigium wider than basal joint of antennæ, its tip broad, rounded. Pronotum with disk large, strongly produced backward, its hind margin broadly and evenly rounded; lateral lobes twice as long as deep, lower margin short, oblique, its front angle obtuse, hind angle very broadly rounded, hind margin very long, humeral sinus scarcely evident. Tegmina usually concealed in both sexes, rarely feebly protruding in male. Hind femora very stout, about two and a half times the length of pronotum, their inner lower margin armed with two to nine short spines. Male with notch of subgenital plate deep, narrow; styles short, obtuse; cerci as in key and Fig. 197, b. Female with subgenital notch narrowly U-shaped, the lobes each side broadly rounded (Fig. 194, f.) Ovipositor straight, twice or slightly less than twice as long as pronotum, its apical fifth tapering above, and tip therefore ventral (Fig. 195, g.) Length of body, ô, 26-33, , 27-34.5; of pronotum, $\hat{o}$, $11.6-14$, ㅇ, $12.5-14.7$; of hind femora, ô, $28.5-34.8,+$, $31.7-37$; of ovipositor, 25-29 mm. Greatest width of pronotum, $\delta, 6.7-7.9$, ㅇ, $7.1-8.2$ $\mathrm{mm}$.

Dunedin, Fla., July 1ð̌-Oct. 29 (W.S. B.) ; Lake Ciț̃, Fla., May 28 (Gainesville Coll.). Recorded also from numerous places in the northern part of Florida, Ft. Reed being the most sonthern station on the east coast and Dunedin on the west one, at which it has been taken. About Dunedin the young are quite common in dry open pine and scrub-oak woods during March and April and probably reach maturity in June. At Pablo Beach $\mathrm{R}$. \& $\mathrm{H}$. found it in palmetto scrub and salt marsh. They state (1907) that the adults "possess greater strength in the jaws than any other North American orthopterous insect known to us. A single bite can easily pierce the cuticle and cause the blood to flow. In consequence the field collector quickly acquires a wholesome respect for their defensive abilities. Individuals showed surprising 
artivity in escaping when alarmed by seeking hiding places under the scrub palmettoes, to which they hurried with seeming ungainliness but nevertheless considerable speed."

Part of Scudder's types were from North Carolina and the known range of gibbosus extends from that State to I)unedin, Fla., and inland to Warm Springs, Ga. It oceurs from sea level to about 2,000 feet in elevation and is chiefly found among the wire-grass and dead leaves of oak and pine woods.

This is the largest of our species of Attanticus and the males may be readily known by the large size taken in connection with their concealed tegmina and long tooth of cerci, while the females are distinguished mainly by the size, obtuse lateral carince and long, strongly rounded posterior lobe of pronotum.

281. Atlanticus porsalis (Burmeister), 1838, 713.

"Coriicolor, lateribus omnino fuscis, pronoto macula in sinu flava; vertice pedibusque griseo-fuscis, tibiis extus dilutioribus. Male elytris sub pronoto absconditis. Long. corp. 11"! (22.9 mm.); femor post 1". (25.4 mm.)" (Burmeister.) "Male with tegmina projecting very slightly caudad of the caudal margin of pronotal disk; cerci short, robust, the distal portion moderately acute (Fig. 195, $k$ ) ; subgenital plate slightly acute-angulate emarginate. Female with subgenital plate deeply and broadly emarginate, tips of lateral sections well rounded (Fig. 194, g); ovipositor straight, but little more than two-thirds the length of caudal femur. Length of body, $\hat{\delta}, 25.4$, $ᄋ, 25.7$; of pronotum, $\hat{\delta}, 10.7$, $\&, 12.2$; of hind: femora, ô, 24.3, ㅇ, 29.8; of ovipositor, $20.6 \mathrm{~mm}$." (R.\& H.)

The original description of Burmeister was of a single male from South Carolina in the Germar collection. R. \& H. (1916a, 87) assigned the name to one adult pair and some nymphs taken at Billy's Island and Thomasville, Ga., stating that they have arrived at their conclusion "by a process of elimination," since they feel certain that it must occur in eastern South Carolina and that it is the only species found anywhere near that agrees with the particular character given by Burmeister of having the tegmina of male hidden under the pronotum, etc.

Known definitely only by an adult male from Billy's Island and a female from Thomasville, Ga., and some nymphs from the latter place and Jacksonville, Fla. At Thomasville they were found among the wire-grass in damp areas in the pine woods.

The present status of the dorsalis of Burmeister is, in my opinion, the same as that of his pachymervs, i. e., an open question. From a truly scientific basis the evidence cited by $R$. \& H. in both cases has little value, as they have seen specimens of neither from South Carolina. However, for the time being, the 
names of Burmeister may as well be assigned to the species to which they are attached by $\mathrm{R}$. \& $\mathrm{H}$. as to any other and I have so retained them.

282. Atlaxticus glaber Rehn \& Hebard, 1912, 269. Smooth Shield-bearer.

Size medium, form rather slender. Pale brown; lateral lobes of pronotum black, their lower margin ivory-white and apical half suffused with olive-gray; sides of abdomen with vague blackish triangular blotches. Fastigium slightly wider than basal joint of antennæ. Disk of pronotum elongate, narrow, convex, subequal in width throughout, its hind margin broadly rounded (Figs. 194, $h, 198$.) Tegmina of male scarcely, or not at all, exceeding the hind margin of pronotum. Hind femora slender, nearly

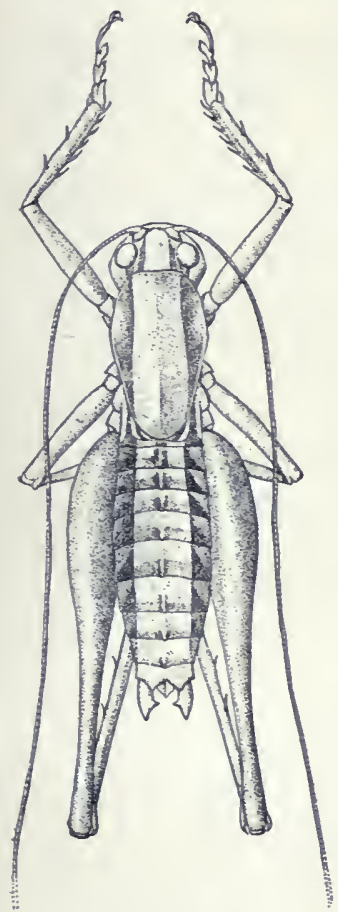

Fig. 198. Male type. $\times$ I.5. (After R. \& H.) as long as body, armed with four to nine spines on inner lower margin. Male with apex of subgenital plate acutely emarginate; cerci short. stout, depressed toward apex, the latter rather blunt; the tooth at apical two-fifths short, sharp, slightly recurved. Female with notch of subgenital plate rather broadly U-shaped, the lateral angles subacute (Fig. 194, $i$ ); ovipositor straight, nearly one-third shorter than hind femora, the apex ventral (Fig. 195, $h$ ). Length of body, $\hat{0}, 24-31$, 우 $24.5-32$; of pronotum, of $10.6-12,+$, $11.2-11.8$; of hind femora, $\hat{o}$, $25.8-27, \&, 28-30.2$; of ovipositor, $17.5-20.4$ $\mathrm{mm}$. Greatest width of pronotum, $\hat{\delta}, 4.1-4.7$, ㅇ, $4.1-4.9 \mathrm{~mm}$. (Fig. 198.)

Dunedin and Sarasota, Fla., Nor. 2March 1, (W.S.B.). The tyjes of R. \& H. were from Miami and the species seems to replace A. gibbosus in central and southern Florida. It has so far been recorded only from Ft. Reed, Tampa, Pineland, Marco. Miami and Homestead, Fla., the adults having been taken from March 6 to May 20, mostly among the undergrowth of pine woods, sometimes among the grasses of adjoining marshes. At Marco Davis took them "by treading closely and more or less shoving the feet through the tangled grasses of a small moist meadow on the interior of Key Marco." North of Florida it is known only from IBilly's Island, Ga., where Hebard found it in July, 1917.

283. Atlaxticus calcaratus Rehn \& Hebard, 1916a, 93. Long-spurred Shield-bearer.

Closely related to $A$. glaber. Differs according to $R$. \& H. by "the shorter pronotum, truncate caudal margin of disk of same, deeper and 
shorter lateral lobes which have an appreciable indentation at the sinus, more acute angles of the disto-dorsal abdominal segment; less exserted and shorter cerci and subfissate subgenital plate of male, the more robust limbs and the greatly elongate medio-internal distal spur of the caudal tibiæ." In addition $A$. calcaratus has the black stripe on sides of pronotum wider, more shining and extending back along sides of abdomen, the yellow one below it wider, more prominent; outer face of hind femora darker. Tegmina extending $2-3 \mathrm{~mm}$. beyond pronotum, their dorsal field black. Prosternal spines often represented by small conical teeth. Ovipositor feebly upcurved beyond the middle, its apex median. Length of body, $\hat{\delta}$, $22.5-24.4, \&, 28$; of pronotum, $\hat{\delta}$ and $\$, 10-11$; of tegmina, $\hat{\delta}, 3.6-$ 5.2 ; of hind femora, $\hat{o}, 23.9-24.8$, ㅇ, 26.5; of ovipositor, $17 \mathrm{~mm}$. Greatest width of pronotum, $3.8-4 \mathrm{~mm}$.

Known only from a series in the Philadelphia collections taken at Billy's Island, Ga., and a single male in the Morse collection from Hastings, Fla.

\section{Idionotus Scudder, 1894a, 179. (Gr., "peculiar" + "back.")}

Medium sized species having the vertex more than one-half as broad as interocular space; pronotum not greatly produced backward, its disk flat and with a submedian U-shaped transverse sulcus; lateral carine sharp, strongly converging near apical third of pronotum to narrow its disk to nearly one-half the caudal width; median carina present behind the transverse sulcus; front tibia armed above on onter margin with three spines; hind femora more than twice the length of pronotum, unarmed beneath; tegmina overlapping, as long as or longer than pronotum, male, one-half its length, female, their tips broadly rounded. Other characters as given in key.

284. Idionotus SpHagnorui (F. Walker), 1869, 258.

Pale reddish-brown; lateral lobes of pronotum blackish-fuscous, the front and lower margins and basal third pale yellow; sides of abdomen with a row of black spots; outer face of hind femora with fuscous stria; hind tarsi and sides of vertex black in female. Pronotum narrow, its hind margin broadly rounded, male, subtruncate, female. Tegmina dimorphic in male, in the macropterous form surpassing tips of hind femora. Male with cercl cone-shaped, armed within near base with a sharp black curved spine, this invisible from without; supra-anal plate broad, deeply and narrowly notched, the lobes each side squarely truncate; subgenital plate scoop-shaped, with a deep, broad, triangular apical notch; styles subcylindrical, movable, twice as long as broad. Ovipositor as long as hind femora, strongly upcurved. Other characters as given above. Length of body, $\hat{o}$, 17-20, $९, 24.5$; of pronotum, $\hat{\sigma}$ and $\uparrow, 5.2-5.5$; of tegmina, $\hat{o}, 6, \quad$,, 2.5 ; of hind femora, $\hat{\delta}, 12$, $\&, 14.5$; of ovipositor, $11-14 \mathrm{~mm}$. Width of pronotum, of front margin, 2.7; hind margin, $3.7 \mathrm{~mm}$. (Fig. 199.) 
This interesting Decticid has been taken on several occasions by E. M. Walker at Ft. William, Ont., where it was first found in rather long grass. He records it also (1909, 210) from Aweme, Man., and Millarville and Calgary, Alta. Caudell informs me that his Idionotus brevipes $(1907,396)$ from "Arctic America" is

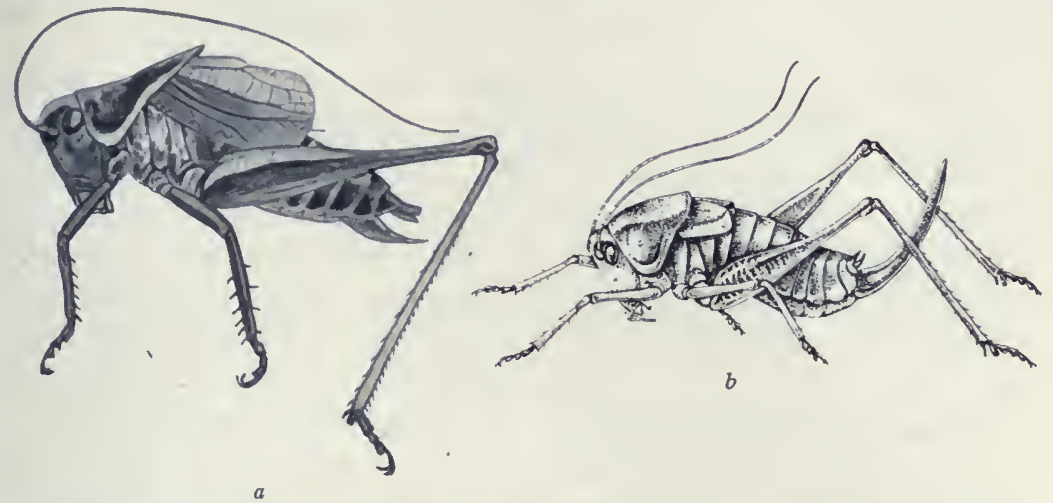

Fig. 199. Idionotus sphagnorum (F. Walker.) a, Male, $X$ 2. (After E. M. Walker.) b, Female, $X$ r.3. (After Caudell.)

the male, and his Platycleis fletcheri (1907, 403) the female, of I sphagnorum. The known lange of the species extends from northwestern Ontario to western Alberta and northward to Arctic America, F. Walker's tỵes being from St. Martin's/Falls, Hudson's Bay.

Of the habits of $I$. sphagnorum, as noted at Ft. William, E. M. Walker (1911) says:

"In addition to open grassy places it occurs also in paths and old lumber roads in the depths of spruce swamps. The tree growth in these swamps consists mainly of black spruce, interspersed with tamarack, white cedar and balsam fir. With the exception of a single female, which I found squatting close to the ground on a path in the swamp, all the specimens taken were males, and were all traced by their stridulation. When discovered, they were sometimes found perching in a conspicuous position upon the upper side of a leaf or twig of some shrub, a few feet from the ground, but several times the sound was traced to the trunk of a tree, and the musician was in some cases too high up to be detected.

"The stridulation of this grasshopper is a soft trill of little volume, audible at a distance of but a few yards. It is sometimes continuous for some seconds, but is generally interrupted rythmically, the divisions being produced at a rate varying according to the amount of sunshine. In bright sunshine I counted forty in fifteen seconds, the rate being thus two and two-thirds divisions per second, but on an afternoon when the sun was almost wholly overcast the rate was reduced to forty-one or forty-two in thirty seconds, or about half the rate in sunshine. When close to the strid- 
ulating insect I could detect that there were no absolute pauses between the trills, a very low trilling sound filling in all the intervals. The rhythm is not always quite regular. Sometimes after a succession of trills of apparently equal length one may be shortened or lengthened, and then the regular trilling resumed."

\section{Subfamily VI. GRYLLACRINE.}

Small or medium sized wingless Tettigoniids, in our species having the head short, globose, face vertical; vertex broad, twothirds as wide as interocular space, bluntly rounded, strongly declivent; pronotum covering only prosternum, its lateral carina absent; lateral lobes as deep as long, their front and hind margins broadly rounded into the lower one; meso- and metanotum similar to dorsal abdominal segments, their hind margins truncate; fore and middle femora feebly curved, unarmed beneath; fore and middle tibia armed with four long distant spines on each of their lower carinæ; hind tibiæ armed with four or five spines on each carina. Male with supra-anal plate thickened, decurved, emarginate; cerci long, slender, awl-shaped; subgenital plate with a wide deep transverse notch, the lateral projections each bearing at tip a short obtuse style. Ovipositor but slightly longer than hind femora, strongly curved upward, its valves compressed, acute.

According to Kirby the subfamily is represented throughout the world by 15 genera and about 240 nominal species, 172 of which belong to the single genus Gryllacris. But one genus occurs in the United States.

\section{I. Самртолотus Uhler, 1864, 548. (Gr., "curved" + "back.")}

Form similar to Ceuthophilus Scudd. Head large, oval, much broader than pronotum, not deeply sunken into it; eyes elongateovate, vertical, situated a little behind the basal joint of antennx, and exceeding it slightly in length; maxillary palpi long, the last joint as long as preceding one, feebly inflated at tip; antenna at least five times the length of body; dorsal abdominal segments subequal in length, the last two slightly shorter; legs very short, moderately stout; hind femora armed beneath with two to six very short spines on each carina; tarsi stout, four-jointed, with split cushions beneath, the first joint equal in length to the two following ones conjoined. Other characters as given nnder subfamily heading. A single species is known from the eastern United States. 
285. Caмptoxotus carolinexsis (Gerstæcker), 1860, 276. Carolina Leaf-roller.

Size medium; form rather slender, subcylindrical. Reddish-brown above, yellowish-white beneath; face and all the tibiæ and tarsi yellowish;

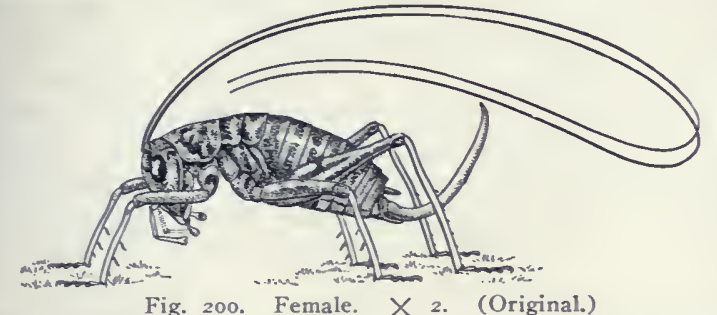

Fig. 200. Female. $X$ 2. (Original.) femora, especially the middle and hind pair, mottled with dark brown; a transverse bar of the same color on the three posterior dorsal seg. ments of abdomen. Structural characters as given above.

Length of body, $\hat{\delta}, 13-14$,, , 12-15; of pronotum, $\hat{\sigma}, 3, q, 4$; of hind femora, $\hat{\delta}$ and $\circ, 7.5-\delta$; of ovipositor, $8-9 \mathrm{~mm}$. (Fig. 200.)

Marion, Parke, Vigo, Lawrence and Crawford counties, Ind.; adults Sept. 9-Oct. 11; nymphs, July 15-22. Probably occurs sparingly on oak shrubs and trees throughout southern Indiana. Only four adults and the same number of nymphs have been seen by me. The nymphs were beaten from oak shrubs. While eating lunch beneath a syeamore tree in Vigo County, Sept. 25, 1917, a male fell from the tree onto my neek; the others were found on the ground beneath oak trees.

Uhler in 1864 redescribed the species as Camptomotus scudderi. his types being from near Baltimore, where, he says, it appears in the larval state as early as the first of August and reaches maturity the latter part of September. It is there found upon oak trees, where it is said to spend the daytime curled up in the leaves.

Caudell (1904e) and IfeAtee (190s) have each given a most interesting account of the leaf rolling habits of this Camptonotus. The former first found the nymphs in rolled papaw leares near Washington in July. Later he placed one in a glass tube with some willow leaves corered with plant lice. On the next day he found that it had constructed for itself a pocket in one of the leaves. This was made:

"By cutting the leaf through on each side to the midrib and at right angles to it and again one-third of an inch farther along the midrib, this time the incision being formed at an angle with it. The flaps thus formed on either side were then folded together and their edges fastened together with silk-like strands, and I have subsequently seen cases with one end completely closed by a solid mat of this silk. The manner of constructing the pockets or rolls is not uniform. In some cases the incisions are made near the apex of the leaf and then only the two basal cuts are made, the tip of the 
leaf being folded back, thus making the terminal cuts unnecessary. Sometimes the pocket is formed altogether on one side of the midrib.

"When supplied with fresh leaves the insect at once commenced making a new house, cutting with its mandibles incisions from the edge of the leaf; then grasping the thus movable edges each with the three legs on each side and forcing them together, it spun what was apparently silk thread from the mouth, fastening the edges together. The. whole performance did not take five minutes after it was begun. The insect accurately measured the proper places for the cuts by placing itself on the leaf and realizing how much was needed. This being determined, the work went on rapidly. Within these pockets the nymphs live, coming out mostly at night to feed on plant lice, which seem to form their entire food supply during their early life."

McAtee found $C$. carolinensis in numbers in Angust on PlumIner's Island, Md., inhabiting the fruit pods of the bladder-nut, Staphylea trifoliata L. Of its habits he says:

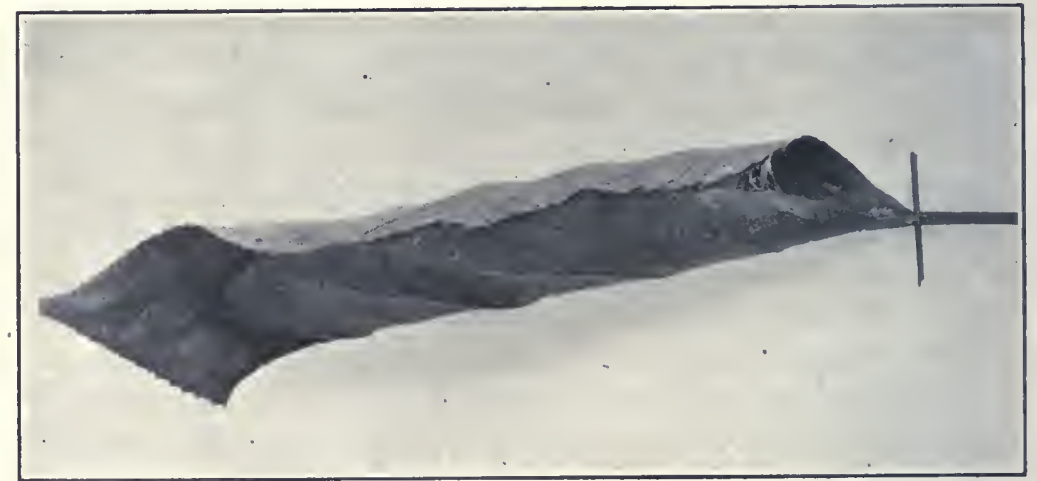

Fig. 201. Leaflet of bladder-nut, Staphylea trifolia L., rollod by Camptonotus carolinensis. (After McAtee.)

"Carefully examining the first pod in which a Camptonotus was found, it was seen that as usual, a large irregular opening had been made in one of the cells, but it had been closed by a loosely constructed door, composed of bits of the pod and a network of fine spun silk-like threads. The locustid was snugly curled within, the long antennæ, to my surprise, being completely withdrawn. It scuttled about when the pod was handled, but did not attempt to bolt out. Several other pods were found to be similarly inhabited.

"Some of the insects and twigs of Staphylea were brought home and in a large jar two females and one male were confined with a twig bearing several entirely uninjured pods and many leaves. They were watched for some time by a light but did nothing with the plant. They sometimes moved nervously about, sometimes sat motionless, but they also spent much time cleaning all accessible parts of the body (even including the ovipositor in the case of the females), with the mouth. During this process 
they showed wonderful control of the long antennæ, which after being pulled down one at a time by the fore legs, by great muscular power at the base were slowly drawn between the mandibles for their whole length. The dexterity with which they manipulate these seemingly unwieldy appendages (which are about five times the length of the body), leaves the observer in no doubt as to how they stow them away in the cramped confines of their improvised retreats. Leaving the locustids in darkness for a while, no change was noticed upon returning except that the male had ensconced himself in his old cell in a pod that had been left lying on the floor of the receptacle. From it he was reluctantly dislodged. They were then left for the night. In the morning it was found that both females had made cells for themselves, not however in the pods, but in leaves. Although the three specimens were afterwards confined for two days with uninjured pods and no leaves, not a pod was disturbed. Hence it is not proven that the locustids enter them through openings of their own making. Nevertheless, it is very probable that they do so; certainly they have mandibles equal to the task."

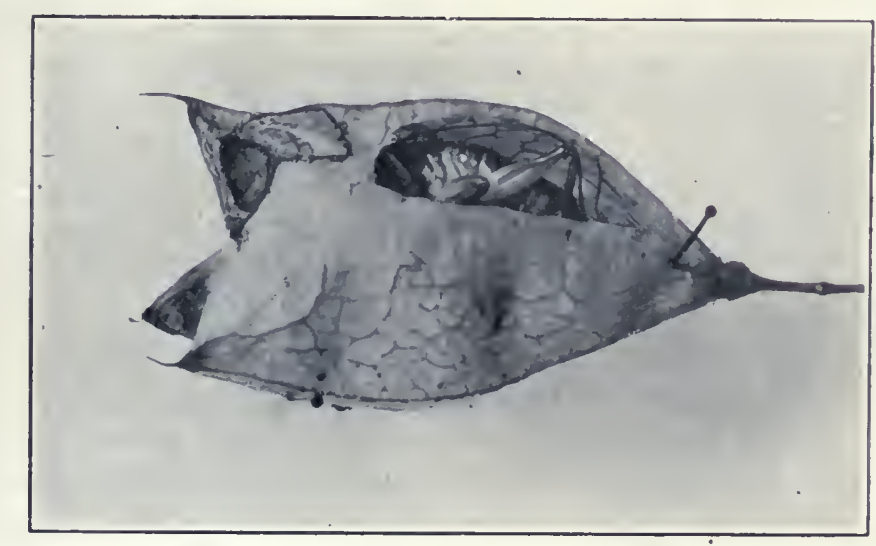

Fig. 202. Pod of bladder-nut with walls of cell cut away, showing a Camptonotus within. At upper left hand part there is a woven sheet closing the entrance to cell. (After McAtee.)

The known range of $C$. carolinensis is southern, extending from New Jersey west to southern Indiana and soutliwest to Clarksville, Tenn., Thompson's Mills, Ga., Agricultural College, Miss. and St. Augustine, Fla., a single male from the last named place being the only record for Florida. For so wide a known range the records are very few and usually based upon single specimens, though about Washington, D. C., it appears to be common. Brunner (1S88, 381) records it also from Mexico, but probably confused it with the species since described as $C$. affinis Rehn. 


\section{Subfamily VII. RHAPHIDOPHORINA.}

The Cave and Camel Crickets.

Wingless 'Tettigoniids of medium or large size having the body robust, subcylindrical, more or less curved; antennx apjroximate at base, filiform, of excessive length; head small, subrotund, received within and partly covered by the ajical portion of jolonotum; vertex short, narow, usually deflexed, sometimes tuberculate; pronotum short, without lateral carina, of the same general form as the meso-and metanotum; lateral lobes much longer than deep, their front and hind margins broadly rounded into the lower one; fore and middle femora slender, usually unamed beneath; hind femora very robust, armed or not, the angle of their insertion on the inner and not on the outer side beneath; hind tibiar often very long, armed above on each carina with numerous short

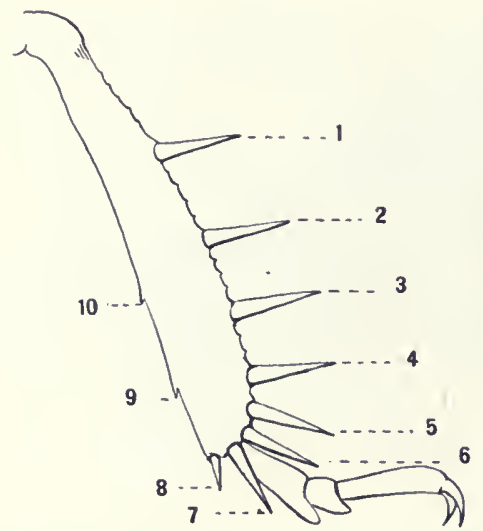

Fig. 203. IIind tibia and tarsus of Rhaphidophorinx, showing the dorsal spines, $1-5$. apical spurs, $6-8$ and ventral spines, 9-Io, of tibia; also the compressed joints of tarsus. (After Caudeli.) species are more numerous in the more long novable dorsal spines. theil tips also with three pairs of apical spurs (Fig. 203) ; tarsi long, slender, the joints compressed without pulvilli beneatl. Supranal plate of male usually in great part concealed beneath the last dorsal segment. Cerci long, slender, tapering, unarmed. Oripositor stout at base, strongly tapering towald apex, which is usually rather blunt, the inner valves armed beneath.

The subfanily is represented in all parts of the earth, but its teeth, and usually with four or United States than in any other country. Its member's are mainly nccturnal or crepuscular in habits, living in caves, quarries, walls of old wells, cellars, crevices of stone walls, beneatl or in deraying logs and stumps, hollow trees and burlows of mammals or reptiles. Without wings, stridulating organs or ears, ther comprise a group of queer forms among our Orthoptera. living in total or semi-darkness during the day, they move silently and stealthily about at night, guided principally by their long antenne. Their food habits and life histories are as yet practically mknown and offer an interesting and virgin field of research to aspiring stud- 
ents, especially those living in the vicinity of caves where one or more species of the group can usually be found in numbers. The principal information concerning the North American forms of the subfamily will be found in the following works: Scudder, 1861, 1862, 1894 ; Brunner, 1Ss8; Packard, 18i3, 18s8; Blatchley, 1893, 1S97, 1903; Caudell, 1916; R. \& H., 1916.

Of the 12 genera recognized by Candell (1916) as inhabiting North America but four are known to be represented in the Lastern States, though a single species of another may occur.

KEY TO EASTERX GENERA OF RHAPHIDOPHORIX E.

a. Fore femora more than twice as long as pronotum; last joint of palpi scarcely longer than third and cleft beneath only apically; lateral lobes of pro-, meso- and metanotum very shallow, not covering the corresponding epimera (Fig. 204.)

I. Hadexecus.

aa. Fore femora less than twice as long as pronotum; last joint of palpi (except in Phrixocnemis) distinctly longer than third and usually cleft beneath for almost its entire length; lateral lobes of pro-, meso- and metanotum deeper, covering in great part the epimera (Fig. 206.)

b. Hind tibiæ armed above on both margins with very numerous short, close-set teeth of subequal length and one longer pair near apical fourth; vertex with a pair of conical tubercles between the antennæ; basal joint of hind tarsi prolonged above second joint into a short, sharp spine; surface pubescent (Fig. 205.)

II. Diestram Mexa.

$b b$. Hind tibiæ armed above with short teeth and several pairs of long movable spines; vertex not or feebly tuberculate; basal joint of hind tarsi not prolonged above; surface glabrous.

c. Second hind tarsal segment no longer than deep, subequal in length to third; hind tibiæ shorter or at most but little longer than hind femora.

d. Fore tibiæ armed above about the middle of the inner margin with a distinct spine; third joint of palpi shorter than fifth.

III. UdEOPSYLLA.

dd. Fore tibiæ not armed above; third palpal joint as long as fifth; hind tibiæ with five or fewer short teeth between the longer dorsal spurs.

Phrixocnenis. ${ }^{73}$

cc. Second hind tarsal segment distinctly longer than deep, third not more than half as long as second; front tibiæ not armed except toward apex; hind tibiæ usually distinctly longer than hind femora and with numerous serrations between the longer dorsal spurs.

IV. Ceuthophilus.

73The genus Phrixocnemis Scudder $(1894,102)$ is here included since it may be represented by a single species east of the Mississippi, as the female type of $P$. inhabilis Rehn (I904e) ( $=P$. truculentus Scudder?) was taken at St. Louis, Mo. 
I. Hanexoncus Scudder, 1862, 439. (Gr., "the nether world" + "to dwell in.")

The True Cave Crickets.

Slender bodied cave crickets having the antennæe very long and slender $(80-100 \mathrm{~mm})$; face small, perpendicular; eyes small, narrowly triangular; maxillary palpi very long and slender, second joint twice as long as first, third twice as long as second, and one-fourth longer than fourth; fifth slightly longer than third, its apical portion thickened, slightly curved and feebly cleft beneath at tip; vertex armed above with a small bilobed tubercle; pronotum short, front margin rounded, hind one truncate; lateral labes of pronotum longer than deep, extending but slightly below those of meso- and metanotum; fore and middle legs very long and slender, their femora and tibia subequal, the former unarmed, tibiae with 5-7 slender spines on each lower carina; hind femora unarmed, longer than body, their basal half much swollen; hind tibiæ one-third longer than femora, armed above on each carina with numerous very fine, close-set inclined teeth, and with $S$ or 9 pair's of much longer alternating distant morable spines, also armed beneath toward apex with several spines; basal segment of hind tarsi longer than the others combined, second segment three times as long as third. Subgenital plate of male emarginate; styles wanting. Ovipositor swollen at base, nearly straight, its apical portion feebly upcurved.

Two species of these long-legged cave insects are known, both described by Scudder and separated by him $(1894,22)$ as follows:

KEY TO SPECIES OF HADENCECUS.

a. Body pale testaceous; ovipositor nearly or quite as long as body; subgenital plate of male broadly emarginate at apex.

286. SUBTERRANEUS.

aa. Body dark brown; ovipositor only half as long as body; subgenital plate of male narrowly emarginate at apex.

287. Puteaxus.

286. Hadencecus subterbaneus (Scudder), 1861, 8. Common Cave Cricket.

Form subcylindrical, arched, rather robust, but less so than most species of Ceuthophilus. Pale yellowish-brown; eyes black; dorsal segments of abdomen often with more or less transverse fuscous blotches. Male cerci as long as last four dorsal segments of abdomen, strongly tapering to an acute point; apex of subgenital plate with a deep median U-shaped notch, the projections each side narrow, cylindrical, obtuse. Apical fifth of ovlpositor feebly upcurved, its lower margin tapering to a very sharp apex. the inner valves serrulate beneath. Other structural characters as given above. Length of body, $\hat{\sigma}$ and $\$, 16-20$; of pronotum, 4-4.5; of fore 
femora, 14-16; of hind femora, 19-24; of hind tibiæ, 26-32; of ovipositor, 12-15 mm. (Fig. 204.)

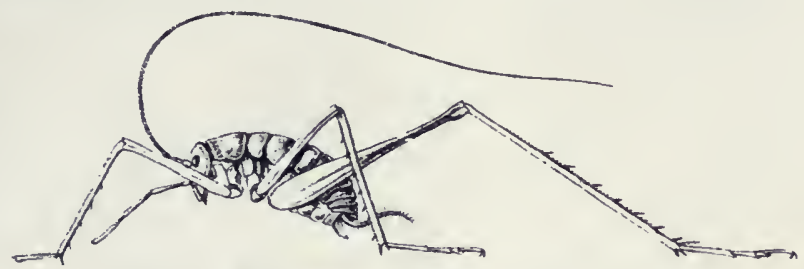

Fig. 204. Male. Natural size. (After Brunner.)

Mammoth Cave, Ky., (Call). This is a true cave inhabiting species, occurring in numbers in many of the cares, both large and small in Kentucky and adjoining southern states but not as yet taken in any of those of southern Indiana. Scudder's types were from Mammoth Cave, where it appears to be the only cave cricket found, and of them he wrote $(1861,9)$ : "They were found throughout the cave to the remotest parts (seren miles or thereabouts), though not near the entrance, especially in damp, moist situations, where they abound. They were usually jumping about with the greatest alacrity upon the walls, where only they are found, and even when disturbed, clinging to the ceiling, upon which they walked easily; they would leap away from approaching footsteps, but stop at a cessation of the noise, turning about and swaying their long antenna in a most ludicrous manner, in tlie direction whence the disturbance had proceeded. The least noise would increase their tremulousness while they were unconcerned at distant motions unaccompanied by sound, even though producing a sensible current of air; neither did the light of the lamp appear to disturb them. Their eyes are perfectly formed throughout, and they could apparently see with ease, for they jump away from the slowly approaching hand, so as to necessitate rapidity of motion in seizing them. Late in October, females were obtained enormously distended with eggs."

Garman $(1894,5)$ says that $H$. subterraneus is the species of cave Orthoptera "most completely adapted to life in the cares. It is a large brown creature so fragile that it is almost impossible to get perfect specimens. Those taken alive from the caves in summer invariably soon died, probably because of the sudden change of temperature. It is usually most abundant a short distance within the entrance but is encountered in the remotest depths of the largest caverns."

Packard $(1888,69)$ recorded $H$. subterraneus from 24 small cares in the vicinity of Mammoth and also from Nickajack Cave, 
Tenn. Many of these were found close to the entrances and he remarks that "This species does not vary perceptibly either in its eyes or appendages, whether occurring in large or small cares or living in total darkness or in partial daylight."

Of specimens taken in White's Cave, Ky., he $(1889,199)$ wrote:

"The 'taste cups' are highly developed in this 'cave cricket,' being rounded papillæ with the nucleus at the top or end. There are more than 100 in all where in Ceuthophilus there are only nine or ten. These gustatory cups, being so much longer, better developed and much more numerous in the cave Hadenccus than in Ceuthophilus, which lives under stones, etc. out of doors, it would seem as if the sense of taste were much more acute in the cave dweller than in the out-of-doors form, though it does live for the most part in twilight."

Garman (1891) mentions a pair of peculiar gland-like white fleshy appendages protruding from slits between the ninth and tenth dorsal abdominal segments in the male of $H$. subterraneus and suggests that they may be scent glands, "the sense of smell being best calculated to bring the sexes together in the darkness of the caves."

According to Caudell $(1916,659)$ the Rhaphidophora cavernarum Saussure, of which $H$. subterraneus was long supposed to be a synonym, was not published until 1862 , so that Scudder's name has priority and $R$. cavernarum is a synonym.

287. Hadenecus Puteanus Scudder, 1877, 37.

"Dark fuliginous brown, slightly tinged with castaneous. Head and under surface of body dull luteous; antennæ luteo-fuscous, darkest on basal half; palpi slightly infuscated beyond the base. Upper surface of thorax and abdomen sparsely covered with excessively short hairs, giving it a punctulate appearance. All the femora and tibiæ brownish-fuscous, the base of femora and extreme tips of tibiæ a little paler; tarsi, as well as the longer tibial spines, pale luteous. Cerci brownish-luteous; ovipositor testaceo-luteous, slender, not very long, in the apical half gently tapering, the tip upcurved, finely pointed. Length of body, $\hat{\delta}, 11, \rho, 17$; of antennæ, $\hat{\delta}, 60,+$,, 80 ; of maxillary palpi, $\hat{\delta}, 7$, ㅇ, 9.5 ; of hind tibiæ, $\hat{o}, 18,+$, 20.5; of cerci, ô, 4.6, ㅇ, 5; of ovipositor, $7.7 \mathrm{~mm}$." (Scudder.)

The types were from North Carolina where they were found under boards covering an old well. It is known also from Corning, Rockville and Allentown, Pa., Thompson's Mills, Billy's Island and Rabun Co. Ga., and Monticello; Miss. The supra-anal plate of male is broadly triangular, and has on each side above an oblique lozenge-shaped raised disk.

II. Dinstrammexa Brunner, 1858, 298. (Gr., "distorted.") The Greenhouse Camer, Crichets.

Head oblong, as broad as front of pronotum; vertex with a pair of conical tubercles between the antenna, these about twice 
as long as the basal width; antennæ about three times longer than body, second segment one-half the size of first; palpi long, slender, fifth segment nearly twice as long as either third or fourth, which are subequal; lateral lobes of pronotum longer than deep, their lower margin broadly rounded, meso- and metanotum together barely as long as but fully as deep as pronotum; fore femora armed on outer side of apex with a long movable spine; fore and middle tibia with one or two morable spines beneath; hind femora armed on lower inner margin with five or six short stout spines; hind tibia and tarsi as in key. Male with subgenital plate short, broad, apically truncate; styles absent; cerci long, slender, cylindrical, tapering to a point. Female with apex of subgenital plate triangularly notched; ovipositor about twice as long as pronotum, its apical half gently upcurved with inner valves finely crenate beneath and tips acuminate. Two introduced Asiatic species have been taken in the greenhouses of this country, but one of which has become established.

288. Diestrammexa Japaxica nom. nov. Japanese Camel Cricket.

Pale brownish-yellow mottled with chestnut-brown; surface pubescent with very fine appressed yellowish hairs; legs long and slender, the femora all blotched with fuscous. Front femora nearly twice as long as pronotum. Hind tibiæ longer than the femora. Ovipositor scarcely onehalf the length of hind femora. Length of body, male and female, 14-16; of pronotum, 7 ; of front femora, 13-14; of hind femora, 23; of hind tibiæ, $\hat{o}, 28$, ᄋ, 26; of ovipositor, $11.5 \mathrm{~mm}$. (Fig. 205.)

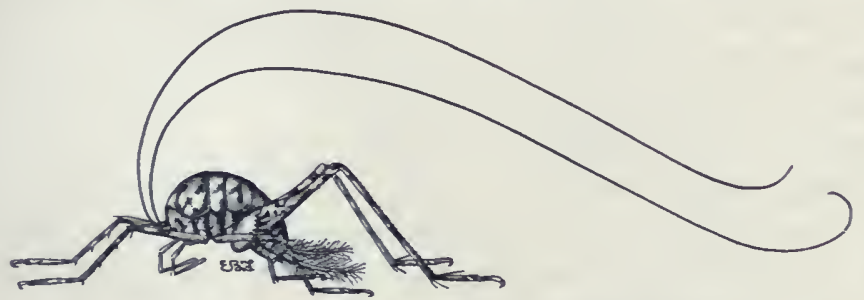

Fig. 205. Male. Natural size. (After Lugger.)

This is the species hitherto known in literature as Diestrammena marmorata DeHaän $(1843,21 \tau)$. It was described by him as Locusta marmorata and is therefore a primary homonrm of Locusta (Scirtetica) marmorata Harris (1S41, 145). A new specific name is therefore necessary for DeHaän's insect.

While this species is not known to have been taken in Indiana, it doubtless occurs in some of the greenhouses of the State, as Hart (Ms.) stated that it was common in those of Illinois and a specimen is at hand from Ann Arbor, Mich. It is a Japanese 
species and is known to occur from New England west to Minnesota and Colorado. Morse $(1919 a, 28)$ says that it has been introduced "into greenhouses and cellars in several parts of New Ingland. It multiplies rapidly and quickly becomes abundant, the adults and young occurring throughout the year." His specimens were from Kennebunk, Me., and Danvers and Springfield, Mass. It has been taken in New Jersey (Weiss) and at Clintonville and Springfield, Ohio (Kostir). Lugger (1898, 254) said that at that time it had succeeded in finding a new home in the Conservatory of the State University at Minneapolis, and, according to Oestlund, that they "had been there three years and multiply freely. They were at first noticed in connection with a shipment of Japanese umbrella plants from Florida." While not as yet recorded from Florida, the above would indicate that they occur in greenhouses in that State.

A single specimen of Diestrammena unicolor Brunner (1S85, 299), the Chinese greenhouse camel cricket, was received by Morse from a greenhouse at Chicago and recorded by him (Psyche, XI, 1904, 80). It differs from $D$. japanica in its nearly uniform piceous hue and in having the front femora less than onehalf longer than pronotum. It is liable to be found in any greenhouse that imports plants from China, its native country.

III. Coeopsylua Scudder, 1862a, 284. (Gr., "ground" + "flea.")

Robust wingless Orthoptera, having the head larger and body stouter than in Ceuthophilus; vertex deflexed, flattened vertically; antenna slender, not much longer than body, the third joint twice as long as second; eyes small, triangular, the apex below; third joint of palpi longer than first and second united, but shorter than fifth, fourth half the length of third; pronotum one-half longer than either meso- or metanotum; hind femora flattened, broad throughout the length, rather thin, outer lower margin with $\&$ to 20 small teeth, inner with eight or more longer stouter ones; hind tibiac armed above on each margin with four long alternating, movable spines, between each pair of which are three or four short teeth; apex with three pairs of stout spurs, the inner median one the longer; hind tarsi with first and fourth joints subequal in length, each more than twice as long as second and third united.

289. Udeopsylia robusta (Haldeman), 1850, 346. Robust Camel Cricket.

Color extremely variable, in typical robusta dark brown to reddishbrown, often blotched with fuscous; in var. nigra Scudd., black with dorsum of pronotum and legs often paler; in var. devius Scudd., uniform pale 
reddish-brown. Dorsal segments of abdomen with numerous small scattered prickles or nodules. Subgenital plate of male deeply impressed but not cleft; the lobes much swollen at middle, apex feebly notched. Ovi-

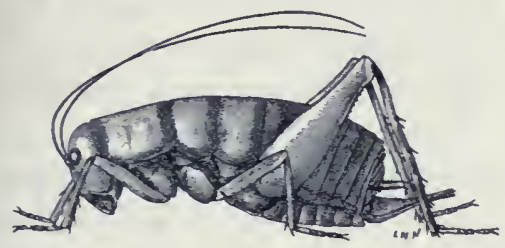

Fig. 206. Female. $\times$ ז.3. (After Lugger.) positor short, very stout at base, strongly tapering to middle, subequal beyond, the apex of outer valves obliquely excised, ending above in a sharp spine; lower valves armed beneath with four slender, unequally spaced teeth, and a slender decurved terminal hook. Length of body, $\hat{\sigma}$ and ᄋ , 18-26; of pronotum, 6-9; of hind femora, 14-23; of hind tibiæ, 1620 ; of ovipositor, $6.5-8 \mathrm{~mm}$. (Fig. 206.)

This, our most robust camel cricket, varies greatly in color and size and has therefore been described under nine different names. It ranges from eastern Illinois nortl and west to Saskatchewan, Idaho and Utah and south and west to Kansas, Texas, New Mexico and Pasadena, Cal. The more eastern individuals are mostly of the black variety, U. nigra Scudd. (1S62a, 2S4). Specimens of this form are in the Urbana collection from numerous points in Illinois (Hart \& Malloch Ms.) while the brown form, typical robusta, was also taken at Havana, Ill., by Hart from beneath logs. Bruner (1S86) sars of its habits: "This 'cricket' is generally to be seen running rather sluggishly over plowed fields and along old roads on cloudy days or during early morning or in the evening just before sunset. It is nocturnal in habit and lives singly in burrows which it digs in the loose soil.

Caudell (1916) first placed the different forms of Udeopsylla under one species and in addition to $U$. nigra placed the following as synonsms of U. robusta; Marsa arcuata F. Walker (1S69, 254), Udeopsylla compacta Bruner (1S91, 3S), Ceuthophilus niger Scudd. (1S62, 437), $C$. devius Scudd. (1894, 99), $C$. politus and $C$. ater Scudd. and Cock. (1902, 56,5T) and Daihinia gigantea Bruner $(1855,127)$. The forms $U$. nigra and $U$. devius represent color varieties and may be thus labelled if the student so desire. IV. Ceuthophilus Scudder, 1862, 433. (Gr., "to hide" +
"to love.")

The Cayel or Stone Crickets.

Wingless Tettigoniidie of medium or large size with a thick body and arched back; head large, oral, bent downward and backward between the front legs; antenna long, slender, cylindrical, tapering to a fine point; eyes subpyriform, the narrow end down- 
ward, placed a little above and close to the basal joint of antenne; maxillary palpi long, slender, the apical joint longest, somewhat curved, split on the under side three-fourths of its length, which is nearly equal to that of the two preceding taken together; lateral lobes of pronotum covering the corresponding epimera; meso- ancl metanotum of the same form but shorter than pronotum; prosternum unarmed; fore and middle femora slender, relatively short, the former armed beneath on lower inner carina with one to four short spines, the latter on both lower earina with two to four similar spines; hind femora thick, heavy, turned inward at base, channeled beneath, with the margins of channel either serrate or spined in males, very feebly armed in females. Male with subgenital plate broad, usually emarginate or deeply cleft, rarely entire; sometimes with a pair of infracercal or podigal plates, incurved between the bases of the cerci. Ovipositor nearly straight, usually stout at base, and strongly tapering to middle, beyond which it is subequal, the outer valves obliquely exeised and slightly upturned at tip; inner valves with three to seven teeth on under side of apical fourth, the tips of the valves ending in a curved tooth or "terminal hook." Cerci of both sexes long, slender, usually very hairy.

These insects are seldom seen except by the professional collector. They are nocturnal in their labits, and during the day hide beneath stones along the margins of small woodland streams, or beneath logs and chunks in damp woods, in which places seldem less than two, nor more than three or four, are found associated together. Being wingless they make no noise, and, like most other silent creatures are supposed to be deaf, as no trace of an ear-drum is visible.

That they are well-nigh omnivorous in their choice of food, I have determined by keeping them in confinement, when they fed upon meat as well as upon pieces of fruit and regetables, seemingly preferring the latter. The majority of the species evidently reach maturity and deposit their eggs in late summer or early autumn, as the full grown insects are more common then, but have been taken as late as December 1st. The eggs, which are supposed to be laid in the earth, usually hatch in April, but some are hatched in autumn and the young live over winter, an anomaly among the Tettigoniidx, as I have taken them on a number of occasions throughout the winter. Several of the species inhabit caves and are usually of larger size, with longer antennse and smaller compound eves than those found above ground. 
The genus Ceuthophilus is one of the largest among the Tettigoniidx, and is confined to North America, and mostly to the United States. Scudder (1894) revised it, reducing to synonrms a number of those previously described, but describing so many new forms that, in the end, he had 57 species, 24 of which were ascribed to the eastern states. His key and descriptions were based mainly on slight differences in the relative length of the fore and middle femora and hind tibix; the spination of the hind femora and other variable characters, so that the ker is practically worthless. A number of his nominal species were based upon nymphs, in some of which the structural characters differ much from those of the adult.

On account of the great number of forms, the absence of tegmina and wings, the similarity of hue and general facies, the study of this genus has been by far the most difficult part of this work, and the results in the end are not on the whole satisfactory. Scudder in his key did not take into consideration the characters pertaining to the secondary genital organs, which I have mainly used and which I have found far more stable than in most other groups of Orthoptera. My studies have shown that the adult males are quite readily separated by the variation in the form of the subgenital and supra-anal plates and the last dorsal segment of abdomen, while the females can usually be distinguished by the form and arrangement of the teeth on the inner valves of the ovipositor. As the two sexes are colored alike and are usually found in close proximity, the student who collects his own specimens will find little difficulty in placing the females by the liey given below, which pertains mainly to the male sex. The color characters rary so greatly according to age and environment that except in latens, brevipes, uhleri and one or two others, ther cannot be used in a key, while the armature of the lower carina of lind femora is constant only in nigricans, brevipes and terrestris. Many of the records in the local lists hitherto published are based on wrong identifications and the known range of the rarious species is, therefore, difficult to state. ${ }^{74}$

\section{KET TO EASTERY SPECIES OF CEUTHOPHILUS.}

a. Each inner valve of ovipositor with six or seven very short and apically rounded teeth; ovipositor shorter than fore femora; male unknown.

290. EXSIFER.

aa. Each inner valve of ovipositor with four (rarely three or five) teeth and a terminal hook, the tips of teeth acute (Pl. VII, $i-s)$ except in tenebrarum.

it All the drawings for the original illustrations showing the structure of abdominal appendages of Ceuthophilus were made by Dr. H. Fox. 
Plate vi.
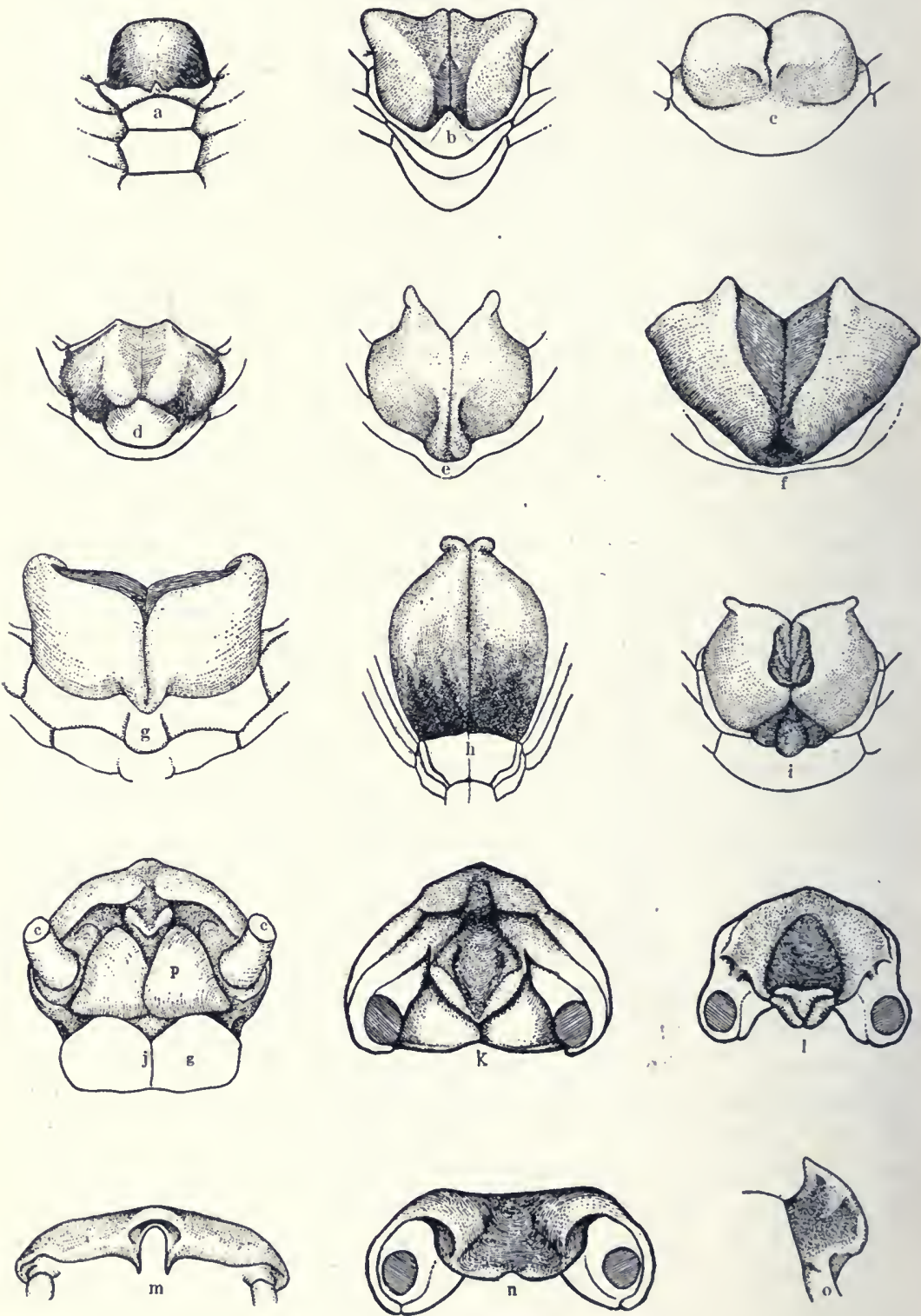

Plate VI. a-i, Showing form of male subgenital plates of Ceuthophilus; a, of $C$. nigricans; b, maculatus; $c$, tenebrarum; d, rehcbi; e, uhleri; $f$ gracilipes; $g$, latens; $h$, terrestris; $i$, cacus. $\mathrm{j}$, Posterior dorsal view of extremity of male abdomen of $C$. tenebrarum showing- $p$, podigal plates lying between the bases of the cerci, $c$, and in front of the bilobed subgenital plate, $g . k-n$, Showing form of male supra-anal plates; $k$, of C. nigricans; 1 , latens; $\mathrm{m}$, seclusus; $\mathrm{n}$, rehebi. o, Side view of last dorsal segment of $C$. seclusis showing its upward turn. (Original drawings by Fox.) 
Plate vit.
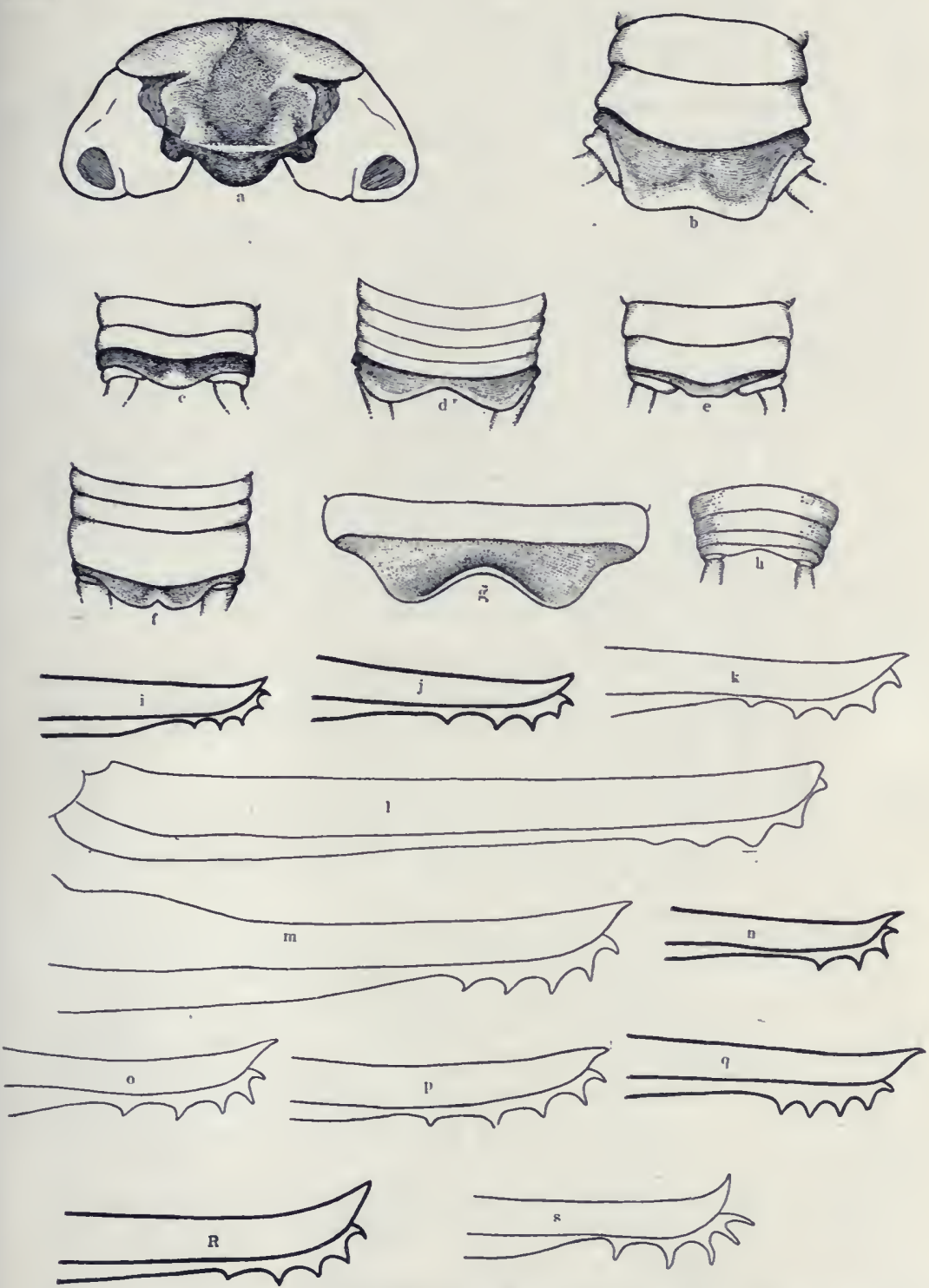

Plate VII. Structures of Ceuthophilus. a, Male supra-anal plate of gracilipes. b-h, Dorsal views of last dorsal plate of males; b, of graciipes; c, nigricans; $\mathrm{d}$, maculatus; $\mathrm{e}$ rehebi; $\mathrm{f}$, latens; $\mathrm{g}$, scclusus; $\mathrm{h}$, cacus; in $\mathrm{c}$ the last dorsal visible is the eighth, in the others the ninth. $i-s$, Outlines of apical portion of ovipositors showing number, form and arrangement of teeth of each inner valve; $\mathrm{i}$, nigricans; $\mathrm{j}$, maculatus; $\mathrm{k}$, brevipes; 1 . tenebrarum; m, darisi; $\mathrm{n}$, rehebi; o, uhleri; $\mathrm{p}$, seclusus; $\mathrm{q}$, latens; $\mathrm{r}$, gracilipes; $\mathrm{s}$, cacus; 1 and $m$ are of the full ovipositor. All greatly enlarged. (Original drawings by Fox.) 
b. Subgenital plate of male entire, scoop-shaped (PI. VI, $a$ ); hind femora of male armed on each lower carina with 25 or more small, nearly equal teeth; ovipositor with four, rarely five, slender, nearly equally spaced teeth on each valve, the terminal hook sometimes bifid (Pl. VII, i.)

291. NIGRICANS.

bb. Subgenital plate of male either narrowly and deeply cleft or with a wide, V-shaped emargination between its lobes (Pl. VI, $b, f$ ) ; hind femora of male, except in terrestris, not armed as in nigricans.

c. Hind margin of ninth dorsal of male broadly and deeply emarginate (Pl. VII, $d$ ) ; hind tibiæ of adult male distinctly bowed or curved on basal third; teeth of ovipositor triangular, of equal size, widely and unevenly spaced (PI. VII, $j$.)

292. - maculatus.

$c c$. Hind margin of ninth segment usually entire, rarely with a small median notch or shallow concavity; hind tibiæ not distinctly bowed except occasionally in adult males of gracilipes.

d. Male with a pair of prominent scoop-shaped or broadly spatulate, infracercal or podigal plates between the bases of the cerci (Pl. VI, $j$ ); subgenital plate thin, membranous, deeply cleft, the inner edges of its lobes feebly overlapping, their tips broadly and obliquely rounded and incurved (Pl. VI, c.)

e. Hind femora stout, distinctly shorter than body, their lower outer carina with about 15 very short unequal teeth; general color pale brown mottled with paler yellow but not with fuscous.

293. BREVIPES.

ee. Hind femora more slender, almost as long or longer than body, their outer carina armed with 7 to 10 stouter unequal, very unevenly spaced teeth; general color reddish. brown mottled with fuscous.

$t$. Ovipositor slender throughout but feebly tapering, the tips of outer valves bluntly obliquely rounded; teeth of inner ones slender, unevenly spaced, unequal in size, often apparently very obtuse (PI. VII, l.)

294. TENEBRARUM.

$f f$. Ovipositor much swollen at base, strongly tapering, tips of outer valves acute, upcurved; teeth of inner ones triangular, acute, subequal in size and evenly spaced (PI. VII, m.)

295. DAVISI.

dd. Male with infracercal or podigal plates very short or invisible; lobes of subgenital plate with tips not thin, nor broadly rounded and incurved.

g. Each inner valve of ovipositor armed with but three teeth and a terminal hook (Pl. VII, $n$ ); supra-anal plate of male tongue-shaped, its apex subtruncate and with $a$ slight median notch (PI. VI, $n$ ); terminal claws of hind tarsi less than half the length of their supporting segment.

296. REHEBI.

gg. Each inner valve of ovipositor armed with four teeth and a terminal hook. 
$h$. Hind femora of male distinctly longer than body, very stout, strongly projecting behind the body, the upper inner and outer faces of their apical halves distinctiy scabrous or roughened with numerous small raised points; general color above reddish-brown, never with a strongly contrasting median paler stripe.

i. Surface of male dull, not polished or shining; teeth of ovipositor narrow, the basal one remote from the second (Pl. VII, o.)

297. UHLERI.

ii. Surface of male strongly shining; female unknown; terminal claws of hind tarsi three-fourths the length of their supporting segment.

298. spinosus.

$h h$. Hind femora of male not distinctly longer than body and at the same time very stout and strongly scabrous; upper surface of body with distinct blackish or fuscous markings, these often so arranged as to leave a paler median line on thoracic segments.

j. Supra-anal plate of male short, wide, deeply notched at middle, the lobes each side of notch produced into a sharp acute spine (Pl. VI, $m$ ); middle of ninth dorsal of male prolonged, curved and upturned (Pl. VII, $g$ ) ; teeth of ovipositor short, widely separated, the basal one.the smaller and remote from the second (Pl. VII, p.)

299. SECLUSUS.

jj. Supra-anal of male not notched and armed as in $j$; ninth dorsal, if prolonged, not curved.

$k$. Subgenital of male so cleft as to leave a wide, deep, V-shaped notch, this in great part filled with a membrane (Pl. VI, $f$ ); middle of ninth dorsal of male distinctly projecting beyond the eighth ( $\mathrm{Pl}$. VII, b.)

l. Teeth of ovipositor closely and evenly spaced, broadly triangular, tapering regularly to an acute tip (Pl. VII, $q$ ) ; hind margin of projection of ninth segment of male rounded and with a minute median notch ( $\mathrm{Pl}$. VII, $f$ ); thoracic seg. ments very dark and with a wide pale median stripe.

300. LATENS.

il. Teeth of ovipositor unevenly spaced, the basal one distinctly more remote from the second than the others from one another (Pl. VII, $r$ ); middle of ninth dorsal truncate or nearly so (Pl. VII, $b$ ); median pale stripe narrow or absent.

$m$. Fore femora of male not over one-half longer than pronotum; teeth of ovipositor triangular, not suddenly constricted at middle; antennæ distinctly less than four times the length of body; basal third of hind tibiæ of adult males usually bowed; thoracic segments often with $a$ 
narrow pale median stripe; species not cave inhabiting.

n. Hind femora stouter and shorter, not over four times longer than broad; supra-anal plate short oval or subcircular, concave only at center, its hind margin not broader than the middle (Pl. VII, $a$.) 301. GRACILIPES.

$n n$. Hind femora very slender, more than five times as long as broad; supra-anal plate fanshaped, concave across its full width, the hind margin much broader than the middle.

301a. IHEROS

$m m$. Fore femora three-fourths or more longer than pronotum; teeth of ovipositor suddenly constricted at middle, their apical halves very slender; antennæ of males four or more times the length of body; hind tibiæ straight; thoracic segments never with a pale median stripe; cave inhabiting species. 302. STYGIUS.

$k k$. Subgenital plate deeply and narrowly cleft without $a$ wide V-shaped notch (Pl. VI, $h, i$ ); middle of ninth dorsal but feebly projecting beyond the eighth.

o. Hind femora of male armed with 25 to 30 small subequal, unevenly spaced teeth on each lower carina; subgenital plate narrow, deeply cleft, each lobe ending in a short, cylindrical projection, these subparallel and subcontiguous their tips curved outward (Pl. VI, $h$ ); teeth of ovlpositor short, triangular, the basal one one-half more distant from the second than the others from one another.

303. TERRESTRIS.

oo. Hind femora with eight to $\mathbf{1 5}$ unequal teeth on each lower carina; subgenital plate broad, its lobes feebly diverging to form a shallow apical notch, which is not filled with a membrane as in $k$ ( $\mathrm{Pl}$. VI, i.)

p. Ovipositor with rather stout, triangular, nearly equally spaced teeth, terminal hook short. stout, feebly decurved; lobes of male subgeni. tal with outer angles prolonged but not divergent; inner median spurs of hind tiblæ nearly one-half longer than basal joint of hind tarsus.

304. LATIBULI.

$p p$. Ovipositor with long, feebly curved, very slender needle-like teeth, terminal hook very slender, strongly decurved (Pl. VII, $s$ ); lobes of subgenital plate with outer angles ending in short, strongly divergent cylindrical projections ( $\mathrm{Pl}$. VI, i); inner medlan spurs of hind tiblæ shorter than basal joint of tarsus.

305. CACUS. 
290. Ceuthophilus exsifer Packard, 1881, 882.

Female.-Size rather small; form slender. Dull brownish-yellow, maculate with fuscous, especially on sides and hind margins of abdominal segments; pronotum with a large blackish T-shaped median spot; hind femora with oblique bars and subapical ring of fuscous. Fore femora about twice as long as pronotum, the lower inner carina with three or four spines; middle femur with three spines on outer and four on inner carina. Hind femora slender, shorter than tibiæ, slightly less than twice as long as fore femora, outer face with a few scattered small nodules, both lower carinæ armed with a few small distant slender teeth. Ovipositor short, less than two-thirds the length of hind femora, its apical third slender, upcurved, apex acute; inner valves armed with six or seven very short and broad apically rounded teeth, the basal one one-half more distant from the second than the intervals between the others; terminal hook very small, feebly decurved. Length of body, + , 19.5-22; of pronotum, 5.2 ; of fore femora, 10; of hind femora, 18.7-20; of hind tibiæ, 20; of ovipositor. $7-8 \mathrm{~mm}$.

Known definitely only from the Nickajack Cave, Tenn., one of the two female types being an alcoholic specimen in the Cambridge Nuseum. Vers distinct from all other species in the armature of the ovipositor, which is crenulate, not serrate in character. Aside from the type locality this species has been recorded only from Sugar Grove and Columbus, Ohio (Kostir), but this record is due to an error in identification, an examination of the specimens showing them to be $C$. tenebrarum Scudd.

291. Cevtiophules migricars Scudder, 1894, 61. Yellow-bellied Camel Cricket.

Size medium, form robust. Upper surface fuscous-brown, more or less mottled, especially on abdomen, with paler spots; pronotum with a median stripe, often obscure, of dull yellow, this sometimes extended back onto the abdomen, but there usually much interrupted; face, lower halves of lateral lobes of pro- meso- and metanotum, sides of abdomen and under surface uniform dull yellow; hind femora with vague oblique fuscous stripes, the basal third paler. Head short, vertex flattened, its terminal cone blunt, not compressed. Fore femora but slightly longer than pronotum. Hind femora of male stout, about as long as body, equally curved above and beneath, armed as described in key; of female more slender, with a number of very fine teeth on apical third of both lower margins. Hind tibiæ slender, straight, about as long as femora. Male with supra-anal plate triangular, tongue-shaped (Pl. VI, $k$ ); subgenital plate scoop-shaped, its apex rounded, entire, sometimes impressed behind. Oripositor half or more as long as hind tibiæ, straight, rather strongly tapering, tip of upper valves acute, slightly upcurved; inner valves armed as in key and Pl. VI, $i$. Length of body, $\hat{o}$ and $९, 12.5-14$; of pronotum, $\hat{\delta}, 4.4-6$,, $4.6-6$; of fore femora, $\hat{\delta}, 5-6.5$, $\uparrow, 5-5.6$; of hind femora, $\hat{\delta}, 12-16, \uparrow, 10.5-$

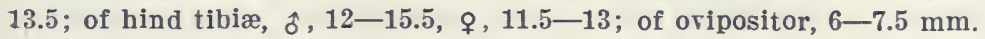


Putnam Co., Ind.; North Madison, Conn. (W.S. B.) ; Cabin John Run, Md. and Alexandria Co., Va., Sept, trapped in molasses jar (Davis). This is the species usually known as ('euthophilus neglectus Scudder $(1894,67)$, an examination of the types of both showing them to be the same, the name nigricans having a six-page priority in Scudder's 1894 paper. The unique male type of nigricans from Tyrone, Ky., in the Agricultural Experiment Station collection at Lexington, Ky., is a small, rather dark, complact-bodied individual, but in the distinctive form of subgenital and supra-anal plates and in the armature of hind femora, it agrees in every respect with the Ithaca, New York type of $C$. neglectus in the Scudder collection.

The known range of $C$. nigricans extends from New England and Ontario west to central Indiana and Kentucky, and south to Orange, Va. R. \& H. $(1916,277)$ state that $C$. neglectus, the synonym, is one of the more abundant if not the most abundant species of the genus in the region above mentioned. Morse (1919a) says that it probably occurs throughout New England in woodlands, and (1919) that the male "can usually be recognized at once by the yellowish color of the underparts, and by having the ninth tergum completely hidden by the crescentically thickened farabolic margin of the eighth tergum; and in the subgenital plate being short, scoop-shaped, with thickened semicircular, nearly horizontal margin."

Walker $(1905,117)$ records a single pair of half-grown young of $C$. neglectus from Niagara Glen, Ont. About Washington, D. C. it is the dominant species of the genus, mating September 24 and eggs laid September 29. West of New York nigricans, as neglectus, has heretofore been recorded only from Jefferson, Ohio (Kostir). It is the $C$. terrestris of my former work $(1903,406)$, specimens having been so identified for me by Scudder, who confused his torrestris and neglectus. The young are darker and more maculate with yellow than the adults.

292. Ceutropmlus maculatus (Harris), 1841, 126. Spotted Camel Cricket.

Size medium, form robust. Dark sooty-brown, with often a median stripe of paler brown on thoracic segments; below dull brownish-yellow; dorsal surface of abdomen with a number of small yellow spots, these often confluent and sometimes in regular transverse rows; antennæ and legs pale reddish-brown; hind femora with numerous narrow oblique dark brown bars. Vertex ending in a subdepressed triangle. Fore femora one-fourth to one-third longer than pronotum. Hind femora about the length of body, outer carina in male with 8 to $\mathbf{1 5}$ unequal, rather coarse teeth, inner carina 
with about the same number of much smaller subequal teeth; female with a number of small, inconspicuous spinules on each carina. Hind tibiæ slightly longer than femora, the basal third in adult males distinctly arcuate or bowed. Male supra-anal plate with basal portion corneous, widely forked, the interval between the forks membranous, the apex truncate; subgenital plate wide, deeply cleft, the interval membranous, the outer angle of each lobe thickened, broadly rounded, projected obliquely outward (Pl. VI, b.) Ovipositor two-thirds as long as hind femora, gently tapering, the tips of outer valves slightly upturned; inner valves armed as in key and Pl. VII, $j$, the terminal hook decurved. Length of body, $\hat{\delta}, 14-15.5$,

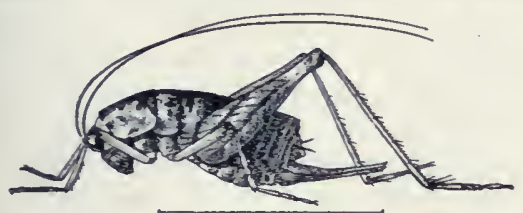

Fig. 207. Female. (After Lugger.) १, 16-19; of pronotum, î, 4.65 , , 4.8-6; of fore femora, $\hat{o}$ and $9,6-7$; of hind femora, $\hat{\delta}$ and $9,15-16$; of hind tibiæ, $16-17$; of ovipositor, $9.3-10$ mm. (Fig. 207.)

Frequent throughout southern Indiana, June 28-Sept. 7; not as ret taken, though doubtless occurs in the northern counties. It is found beneath logs and stones in both dry and moist situations. The known range of this stone cricket is northern, extending from Nova Scotia and New England west to Minnesota and Colorado and south to Kentucky, Missouri and Kansas. Some of the southern and western records are, however, doubtful.

Piers (1918, 326) calls it "an ungainly insect with a cringing attitude," and records specimens taken by Gooderham at Truro and Granville Ferry, X. S. in August. Walker found it in Quebec associated with terrestris under flat stones at the bottom of a wooded hill and also at Niagara Glen, Ont. Morse (1919a) calls it "Our commonest camel-cricket, probably found throughout New England; gregarious under stones, logs and in cellars." Lugger says it is the most abundant species in Minnesota and Bruner reports it as occurring rather commonly in eastern and middle Nebraska. The most definite southeastern record which can be found is that of Smith $(1910,180)$ from Morris Plains and Ft. Lee, N. Jer.

The $C$. latebricola and $C$. bicolor Scudder $(1894,37,72)$ are in my opinion srnonrms of maculatus. The former is represented in the Cambridge collection by only two females. At Lexington, Ky., there are however a nymph and two adult males and two females labelled by Scudder as latebricola. The males have the concave ninth dorsal and bowed hind tibia of maculatus. The subgenital differs slightly in the form of the apical notch, it being more U-shaped and with a shorter intervening membrane than in typical maculatus. Tro or three of the spines of the outer carina 
of hind femora are much swollen at base, a worthless character, used by Scudder in his key. One of the females is a typical maculatus; the other more robust and with inner valves of ovipositor with but three teeth and terminal hook is a specimen of $C$. rehcbi described below. C. bicolor was based upon a single immature male of $C$. maculatus taken at Bee Spring, Ky. and now in the Cambridge collection.

293. Ceuthophilus brevipes Scudder, 1862, 434. Short-legged Camel Cricket.

Small for the genus; compact, robust. Pale dull brown, thickly marked with rather large yellowish spots, these arranged in a cross-row on each abdominal segment and scattered irregularly over the hind femora, aggregated near the knee to nearly form a pale ring; thoracic segments less mottled than abdomen, the pronotum sometimes with a narrow median pale stripe; face, palpi and under surface uniform dull yellow. Fore and middle legs subequal. Hind femora very short and stout, both lower carinæ armed with 10 to 15 very minute unequal teeth, male, almost unarmed, female. Hind tibiæ slightly longer than femora, their inner middle apical spur almost as long as basal joint of tarsi. Supra-anal plate of male, membranous, triangular, prolonged between the cerci, its sides and apical margin subangulate; infracercal or podigal plates, strongly developed, oblong-spatulate, curved inward, their tips attingent; subgenital plate deeply cleft, its lobes thin, membranous, contiguous or feebly overlapping, their tips separated to form a small apical notch, each tip broadly and obliquely rounded. Ovipositor with apical half very slender; inner valves with four very short, slender, subcylindrical teeth, the basal one the smaller, obtuse, remote from the second; hook strongly curved, acute (Pl. VII, $k$. ) Length of body, $\hat{\delta}, 14, \hat{\imath}, 15.5$; of pronotum, $\hat{\delta}$ and $\$, 4-4.5$; of fore femora, 5.5- 6 ; of hind femora, $\hat{\delta}, 11$, $\&, 13$; of hind tibiæ, $\delta, 12$, ㅇ, 13.5; of ovipositor, $8-8.5 \mathrm{~mm}$.

Described from Grand Manan Isle, Maine. Known elsewhere definitely only from St. Johns, New Brunswick. The Vigo Co., Ind. specimens, identified and recorded by Scudder, are $C$. scclusus and $C$. tencbrarum; while the ones recorded by Walden, on $\mathrm{my}$ anthority, from North Madison, Conn., are C. maculatus and $C$. nigricans.

294. Ceuthophilus texebrarum Scudder, 1894, 70.

Size medium, form slender. Above reddish-yellow, thickly maculate with large blackish blotches; these arranged each side on the hind margins of thoracic segments, leaving a broad, pale, median stripe; this usually bordered below on front half of pronotum by a black line; abdomen mottled with black and round yellow dots the latter usually in transverse rows; face, antennæ and fore and middle legs dusky or brownish-yellow; outer face of hind femora often with a broad fuscous stripe in addition to the usual oblique bars; hind tibiæ tinged with fuscous. Vertex ending in a blunt, convex triangle. Fore and middle tibiæ slender, subequal, one- 
third longer than pronotum. Hind femora slender, the lower sulcus deep, narrow, armed in both sexes on outer margin with 5 to 9 short, subequal, unevenly spaced teeth, on inner margin with 7 to 12 still smaller ones. those of female very minute. Hind tibix scarcely longer than femora, their marginal spines short, stout; inner median spur shorter than metatarsus; terminal spurs of hind tarsus less than half the length of fourth segment. Male with ninth dorsal entire, feebly prolonged and upturned, its margin rounded; supra-anal with broad corneous deeply emarginate base, the membranous portion within the notch forming a concave disk, with lower apical portion compressed and projected back between the rery large, incurved, spatulate infracercal or podigal plates. Subgenital plate as in $d$ of key and Pl. VI, c. Ovipositor as in key and Pl. VII, $l$. Length of body, $\hat{\delta}, 14-17$, $ᄋ, 13-16$; of pronotum, $\hat{\delta}, 6-7,9,5-6$; of fore femora, $\hat{\delta}$ and $\$, 8-9$; of hind femora, $\hat{o}, 14-1 \delta$, $q, 13-19$; of hind t1biæ, $\hat{o}, 15-19$, ㅇ, 14-20; of ovipositor, $9-11 \mathrm{~mm}$.

Vigo Co., Ind. (W.S.B.) ; Rabun Co., Ga.,. July (Daris); Sugar Grove and Columbus, Ohio (Kostir) ; U. S. Nat. Mus., Ohio. This species is very distinct from all others in the form of the supra-anal plate of male, and especially in the slender, bluntpointed oripositor, the inner valves of which are often corered with a membrane, their armature then appearing as four rery luw, wide lumps or convexities, the basal one scarcely evident (Pl. VII, l.) The Bee Spring, Ky., male type in the Scudder collection, so fixed by R. \& H. (1912b, 70), as well as the specinens in the Lexington collection are immature and not distinctive of the species as above described. The type, in fact, appears more like a male of $C$. brevipes, than one of tenebramm. The known range of this species extends from Port Byron, Ill. (female allotype) east to Kentucky and central Ohio and south to Beaufort and Rabun Co., Ga.

\section{Ceuthophilus davisi sp. nov. Davis's Camel Cricket.}

Size small for the genus; form slender. Dark reddish or dusky brown; thoracic segments usually in great part fuscous, their lateral lobes with a few small yellow spots, and dorsum of pronotum with an indistinct narrow pale stripe; hind femora dusky brown or fuscous above, dull yellow beneath, all the tibiæ dull yellow; hind margin of each abdominal segment dusky; sides of abdomen with a few faint yellowish spots. Vertex ending in a blunt compressed cone. Fore and middle femora subequal in size and length, about one-fifth longer than pronotum. Hind femora about fivesixths the length of body, those of male armed beneath on outer lower carina with eight to ten very short, blunt, unevenly spaced teeth; on inner one with six to eight more slender, sharper ones; wholly unarmed in female. Last dorsal of male entire, not prolonged; supra-anal tongue-shaped, deeply grooved along the middle; subgenital and infracercal plates as described in key. Ovipositor as in key and Pl. VII, $m$. the terminal hook slender, strongly decurved. Length of body, ô, 14-16, 오, 13-15; of pronotum, 4.5-5; of hind femora, 12.5-13.5; of ovipositor, $7 \mathrm{~mm}$. 
Staten Island, N. Y., July-August. Davis states (Ms.) that he has taken specimens "on numerous occasions in the forested parts of Staten Island by baiting tin cans with molasses and fusel oil."

Named in honor of W. T. Davis, of New Brighton, Staten Island, N. Y., whose enthusiasm as a naturalist and generosity as a scientist are highly appreciated by all his co-workers.

\section{Ceuthophilus remebi sp. nov. Rehn \& Hebard's Camel Cricket.}

Size medium; form compact, robust. Ground color above pale to dark reddish-brown blotched with fuscous, the blotches varying in intensity, usually most distinct on abdomen, where they are broken by numerous small rounded dull yellow spots; face, fore and middle legs and under surface a nearly uniform dull yellow; hind femora with the usual narrow oblique dusky stripes; tips of spines and teeth of hind tibiæ brown. Vertex ending in a blunt convex cone. Fore femora scarcely one-sixth longer than pronotum, the inner lower carina with two subapical spines; middle femora slightly longer, more slender, both carinæ with three slender spines. Hind femora longer than body, of moderate width, gradually tapering, the upper and outer apical half feebly roughened with very minute appressed spines; lower sulcus deep, narrow, its outer carina in male with 9-14 unequal, irregularly spaced teeth, the three middle ones usually the longer; inner carina with fewer, shorter teeth; outer carina in female with three or four, inner, with eight or more very short, sharp teeth. Hind tibiæ distinctly longer than femora, their marginal spines and teeth relatively short and stout; inner median spur one-third longer than outer median one, slightly shorter than metatarsus; terminal spurs of hind tarsus less than half the length of those of $C$. spinosus. Ninth dorsal of male very short, feebly projecting, its apex rounded (Pl. VII, e); supra-anal plate tongue-shaped, produced backward between the bases of the cerci, its apex subtruncate and with a slight median notch (Pl. VI, $n$.) Subgenital cordiform, deeply cleft, its lobes each swollen at middle, feebly overlapping within, their tips subangulate but not produced (Pl. VI, d.) Ovipositor strongly tapering, the apex of outer valves obliquely truncate, ending in a sharp spine; inner valves with but three slender, irregularly spaced teeth; terminal hook very slender, rather strongly decurved (Pl. VII, n.) Length of body, $\hat{\delta}$ and $q$, 14.5-16.5; of fore femora, 7 ; of hind femora, $\hat{o}, 16-17, \rho, 14-15$; of hind tibiæ, $\delta$, 17-18, o, 15-16; of ovipositor, $11-12 \mathrm{~mm}$.

Yaphank and Staten Island, N. Y. (Davis.) This is the species treated by R. \& H. $(1916,274)$ as $C$. spinosus Scudd. Its known range extends from New York, southwest to Atlanta, Ga. and west to Lexington, Ky. Davis has trapped numerous specimens in molasses jars at various points. I have named it in honor of K. \& H., that pair of enthusiastic entomologists who, by their extended field work and numerous writings, have done so much to put the science of Orthopterology on a par with that of other orders of insects. 
297. Ceuthophilts uhleki Scudder, 1862, 435. Uhler's Camel Cricket.

Size medium or above; form robust; surface dull, smooth. Pale reddish-brown or clay yellow, irregularly flecked with fuscous, especially on pronotum and abdomen, the female and young somewhat darker; legs pale brown, apical portions of femora more or less infuscated. Vertex strongly deflexed, ending in a compressed triangular cone. Fore femora more than a third longer than pronotum, male, one-fourth longer, female. Hind femora of male longer than body, the apical half of outer face scabrous with numerous small projections; of female, shorter, almost smooth; lower sulcus in mature males usually exceptionally broad and shallow, its outer carina with seven to nine very unequal irregularly spaced spines, the middle two slightly the larger; inner carina armed with 16 to 20 small teeth; lower sulcus in female much less broad, the inner carina with numerous, the outer with only a few small teeth. Hind tibiæ slightly longer than the corresponding femora in both sexes. Male with supra-anal plate strongly deflexed, triangular, grooved at middle, its apex broadly rounded; subgenital plate emarginate at apex, deeply cleft, the tip of each lobe thickened, suberect or obliquely rounded (Pl. VI, e.) Outer valves of ovipositor with tips considerably upturned, their lower margins strongly tapering to the acute apex; inner valves armed as in key and Pl. VII, o, the terminal hook short, sharp, strongly uncinate or decurved. Length of body, $\hat{o}$, $13 . \overline{-15.5}$, ㅇ, 13-16; of pronotum, $\hat{\delta}, 4.8-6$, ㅇ, $4.6-5.3$; of fore femora, $\hat{\delta}, 6.5-8$, ㅇ, $6-7.3$; of hind femora, $\hat{\delta}, 15-18$, ㅇ, 13-14.5; of hind tibiæ, ô, 15.3-19, ㅇ, 15-16; of ovipositor, $8-9.5 \mathrm{~mm}$. (Fig. 208.)

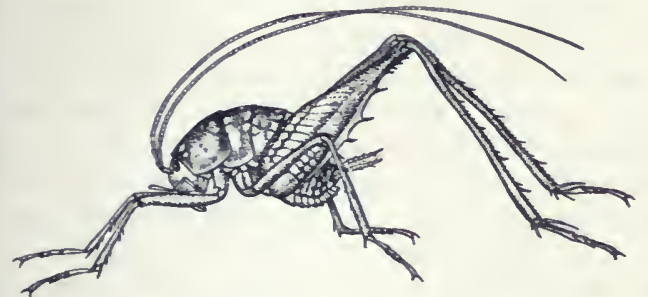

Fig. 208. Male. $\times$ I.3. (Original.)

Vigo, Putnam and Marion connties, Ind., Aug. 25-Nov. 17; (II. S. B.) ; Alexandria Co., Va., Sept. 24 (Davis). In central Indiana uhleri is one of the more common species of Ceuthophilus. It is usually found from July to November in small colonies of three to six or more, beneath rails and logs in rather dry situations, being especially fond of low, open second bottom woods, with a loamy or sandy soil. The young have been taken in similar places in December and February, but evidently the larger number of eggs do not hatch until spring. It has not, as set, been taken in either the northern or southern third of the State, but probably occurs throughout.

After a careful study of Scudder's types of both forms, as well as of a number of paratypes of each named for me by him, I have placed his $C$. blatchleyi $(1894,57)$ as a synonym of uhleri. it having been based on immature males, in which the hind femora 
are more slender, with lower sulcus narrower than in the adults. 'The number, spacing and size of the spines on the lower margins is variable and unreliable as a specific character. The form of the male subgenital plate as well as that of the armature of the ir ner valves of oviposition jimilar in the two forms.

The known range? lleri is southern, extending from New York and New Jersey ito central Indiana and south to Tennessee and northeaste ${ }^{-1}$ Georgia. Wherever found it usually oceur's in some numbers. ${ }^{\top}$ At Cabin John Run, Md. Davis trapped 14 males and 34 females in molasses jars. It is recorded from Ohio without comment by Mead; from Tennessee by Brunner and from numerous stations about Washington, D. C., by McAtee and Candell. Lugger describes $C$. blatchleyi fully but gives no record for Minnesota and Bruner records a species as doubtfully uhleri from Nebraska.

298. Ceuthophilus spinosus Scudder, 1894, 58.

Size rather large, form robust; surface of male shining. Reddish brown; under surface, legs and lower third of thoracic segments nearly uniform dull yellow; meso- and metanotum each with an irregular transverse row of small yellow spots; hind femora with the usual narrow oblique dusky bars. Vertex ending in a blunt cone. Hind femora longer than body, its basal three-fourths very stout, upper and outer faces strongly scabrous with numerous short nodules or spines; outer lower carina of basal two-thirds with six to nine teeth, these gradually increasing in size, the three distal ones spinose, much the larger; these followed by four or five smaller subapical teeth; inner carina with numerous small subequal teeth. Hind tibiæ distinctly longer than femora, their upper marginal spines very long and slender, inner median spur longer than metatarsus; terminal spurs of hind tarsi very long, strongly tapering, three-fourths the length of the fourth segment. Ninth dorsal slightly projecting, feebly concave at middle. Supra-anal tongue-shaped, concave, its apex bluntly rounded; subgenital deeply cleft, its lobes thin, their inner margins contiguous throughout or slightly overlapping at middle, the tip of each either subtruncate or ending in a very short subspatulate knob. Length of body, A, 13-16; of pronotum, 5-6.8; of fore femora, 7-9; of hind femora, $15-20$; of hind tibiæ, $16-21 \mathrm{~mm}$.

Dunedin, Fla., Dec. 9, one male (W.S.B.) Scudder's unique male type was from Georgia and the Dunedin specimen differs from it only in its larger size, longer and more swollen hind fenora and in loving the tips of lobes of subgenital plate subtruncate. not ending in very short projections, as there. The two males are the only specimens known, the $C$. spinosus Scudd. of R. \& H. (1916, 274) being a very different species. The Dunedin specimen was taken from beneath a clunk on sandy soil in ojen pine woods, only 200 yards from the beach of the bay. 
The Phalangopsis scabripes of Haldeman $(18.53,364)$ is eridently closely related to both $C$. uhleri and $C$. spinosus and may be the same as one of them. The type appears to be lost. His brief description is as follows:

"Flavous mottled with black, especially unn the posterior margins of all the segments; knee joints of all the d base of the antennæ, brown. Upper extremity of the femora st. curred inwards toward the base; externally and above regularly $\mathrm{r}_{\mathrm{l}}$ ate with blackish and scabrous with raised points which are mostly . sfined to the dark portions; under margin with a row of small spiıes enlarging posteriorly. Length, ô, 11 lines, antennæ, 48, posterior femora, 11, tibiæ 121/2, tarsi 41/2. One specimen Selma, Alabama. Resembles Ph. lapidicola Burm. and gracilipes Hald. in size but differs from the former by the smaller femoral spines and from the latter by the scabrous femora."

The "scabrous hind femora" furnishes the only character giving any clue to the proper placement of this species. That and the great length of body, hind femora and tibix show its close relationship to $C$. spinosus, but the color, as described, is widely different. I can, therefore, only publish the description and leare to others so inclined the privilege of attaching the name to some definite form.

\section{Ceuthophilus seclusus Scudder, 1894, 45.}

Size medium, form robust. Above blackish-fuscous, shining, thickly mottled with rounded, often more or less confluent, dull yellow spots; pronotal and basal segments often with a narrow median reddish-yellow dorsal stripe; face, front and middle legs and under surface dull yellow; hind femora with narrow oblique fuscous bars; knees fuscous. Fore and middle femora subequal. Hind femora slender, gradually tapering, nearly as long as body, both lower carinæ in both sexes armed with 20 or more very small, unequally spaced teeth. Hind tibiæ with inner median spur as long as basal joint of tarsus. Ninth dorsal of male with median portion produced, strongly upcurved, its hind margin broadly rounded (Pl. VII, $g$ ); supra-anal plate as in key and Pl. VI, $m$; subgenital plate broad, the membranous median portion shallowly cleft, not emarginate, the corneous forks or lobes forming the sides of plate swollen at middle. Ovipositor as in key and Pl. VII, $p$; terminal hook short, nearly straight. Length of body, $\hat{\sigma}$, $12-17, \uparrow, 16-18$; of pronotum, $\hat{o}, 3.5-6, \uparrow, 5.2-6$; of fore femora, $\hat{\jmath}$,

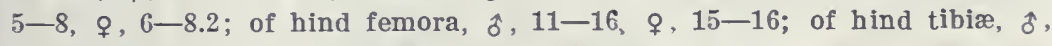
$11-18$, ᄋ, 16-17; of ovipositor, $9.5-10.5 \mathrm{~mm}$.

Vigo Co., Ind., Sept. 21 (W.S.B.). Described from Dallas and Crawford Cos., Iowa and West Point, Neb. My Vigo Co. male (brevipes in part 1903,407 ) agrees in all respects except in its larger size with the types at Cambridge. The upturned ninth dorsal appears broadly and shallowly concave, due to its curved form. The peculiar form of the spined supra-anal at once distinguishes the male from all others. 
300. Ceuthophilus latexs Scudder 1862, 437. Black-sided Camel Cricket.

Size medium; form robust. Dull brownish-yellow or reddish-brown, with two broad bands of shining fuscous or blackish along the pro- mesoand metanotum, these extending half way down the sides and separated from one another by a rather wide median stripe of pale reddisb-brown; sides below the black stripes, face, under surface and legs dull clayyellow; dorsal surface of abdomen and outer face of apical half of hind femora dotted with brownish-yellow, the dots sometimes confluent, some. times in apparently regular rows; hind femora with numerous faint oblique rery narrow dark lines; knees fuscous; spines of hind tibiæ black at base. Vertex strongly flattened vertically ending in a blunt cone. Fore femora nearly one-third longer than pronotum, male, but slightly longer, female. Hind femora about as long as body, the swollen portion very gradually tapering; both outer and inner carinæ in both sexes armed with only a few minute spines. Hind tibiæ straight, no longer than the femora, the inner median apical spur as long as basal joint of tarsus. Male with last dorsal as in key and Pl. VII, $f$; supra-anal plate short, broad, feebly notched at middle of hind margin (Pl. VI, l); subgenital plate broad, deeply and widely cleft, lobes not thickened, each with apex broadly obliquely rounded (Pl. VI, g.) Ovipositor about two-thirds as long as hind femora, straight, tapering; inner valves armed as in key and Fl. VIII, $q_{*}$ the terminal hook shorter than the teeth, slightly decurved. Length of body, $\hat{\sigma}, 14-15$, , $15-17$; of pronotum, of , 4.6-5.5, 오, $5-5.9$; of fore femora, $\hat{o}, 5.8-6.8$, 우, $5.4-6$; of hind femora, $\hat{\delta}, 13-14.7$,, $12-15$; of hind tibiæ, $\hat{o}, 13.4-$ 15.5, 오 , 13-15; of ovipositor, $8.1-9.2 \mathrm{~mm}$.

Putnam and Vigo counties, Ind., July 20 -Oct. 20 (W. S. B.). Alexandria Co., Va., Sept. (Davis). This handsome species has been taken in Indiana only in the counties mentioned, where it is most commonly found beneath flat stones near the margins of small streams in upland hilly localities. It reaches maturity in July, probably from specimens hatched in spring, though I have taken the young on two different occasions in February. It is sometimes affected by the parasitic hairworm, Gordius sp.

The known range of $C$. latens extends from Connecticut and Ithaca, N. Y., west to Illinois and southwest to Virginia. Seudder has also recolded it from Texas and Bruner from eastern Nebraska. In Virginia Davis trapped 36 males and 26 females in molasses jars. Hubbell reports it as taken in Cheboygan Co., Mich. and Caudell as mating at Plummer's Island, Md., on Sept. 24.

301. Ceutiopinlus gracilipes (Haldeman), 1850, 346. Slender-legged Camel Cricket.

Very large for the genus; form robust. Brownish-yellow or reddishbrown, shining; above heavily marked with fuscous-brown, the latter usually forming a bar across the hind margin of most of the dorsal segments and covering the greater part of pro- and mesonotum, often separated on 
these by a median row of large elongate spots of the paler hue; sides of the segments, especially those of abdomen in female, sprinkled with small yellow spots; legs dull yellow, hind femora with the usual narrow oblique dusky lines; tips of all the spines brown. Vertex ending in an obtuse triangular cone. Antennæ three times or more the length of body, evenly tapering. Legs very long and slender. Fore and middle femora subequal, nearly one-half longer than pronotum. Hind femora about as long as body, the upper surface nearly smooth; male with outer lower carina elevated and armed with 7 to 13 unequally spaced spines, which vary much in size; the inner with numerous much smaller teeth; in female both carinæ of equal width and armed with a few very small denticles. Hind tibiæ straight or in old males feebly curved near base, about one-sixth longer than femora, the inner median subapical spine scarcely longer than the outer, distinctly shorter than basal joint of tarsi. Male with middle of ninth dorsal strongly produced backward and slightly upward, subtruncate (PI. VII, $b$ ); middle of supra-anal plate membranous, transversely oval, deeply concave, its apex either subtriangular and subacute or rounded (Pl. VII, $a$ ); subgenital plate cleft almost to base, its lobes separated by a wide and deep V-shaped notch filled with a membrane; each lobe triangular, thickened at middle, its tip obtuse, rarely slightly prolonged (PI. VI, f.) Ovipositor slender, feebly tapering, about three-fourths the length of hind femora; outer valves with apex obliquely truncate, the tips subacute; inner valves armed with four rather short, broadly triangular teeth, the basal one one-half more distant from the second than the average distance between the others, the terminal hook, short, stout, blunt, decurved (PI. VII,

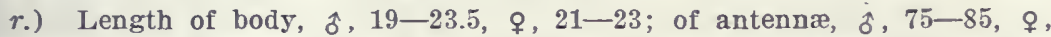
90 ; of pronotum, $\hat{\delta}, 5.1-6.2$, ㅇ, $6.7-7.2$; of fore femora, $\hat{\delta}, 9-11.5$, $\%$, 10.6-12; of hind femora, $\hat{\delta}, 18-24$, ㅇ, 19-25; of hind tibiæ, $\hat{o}, 21-26$, ․, 22-26; of ovipositor, $11-14.5 \mathrm{~mm}$. (Fig. 209.)

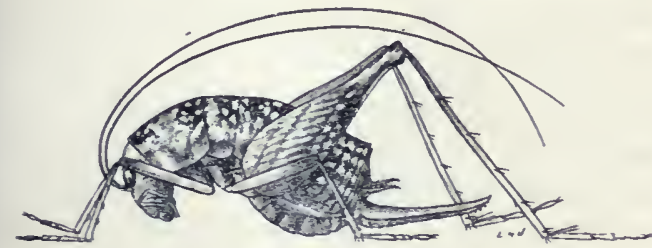

Fig. 209. Female. $\times$ I.3. (After Lugger.)

This camel cricket occurs in small numbers throughout Indiana. In color and in the armature of hind femora of the males, it varies $e x$ ceedingly, the younger and more northern specimens being often much darker than adults from the South, some of the larger northern adults having a pattern very similar tr. that of $C$. latens. In Indiana it occurs for the most part in rather moist woods, but often beneath $\operatorname{logs}$ and other debris near the borders of ponds and lakes.

An examination of the types at Cambridge shows that Caudell $(1916,666)$ and $\mathrm{R} . \&$ H. $(1916,270)$ were right in placing $C$. grandis Scudder $(1894,38)$ as a synonym of gracilipes; also that the 
form which Scudder described in his last work on Ceuthophilus (1894, 50) as C. lapidicola Burm. (1838, 723) cannot be distinguished by any good structural character from what I recognize above as $C$. gracilipes. He separates them in his key only by the hind tibire of male being "at least a tenth longer than hind femora"

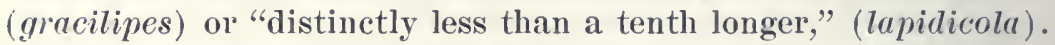
The specimens which he set aside in the Cambridge collection as lapidicola differ from those of gracilipes only in their general darker hue, the secondary genital characters of both sexes being very nearly the same as those of gracilipes, the only appreciable difference being that in lapidicola the lobes of the subgenital plate of male are a little more rounded at apex. The original description of both lapidicola and gracilipes are very brief, being as follows :

"Ph. lapidicola Germ.: Testacea nitida, dorso vitta utrique longitudinali fusco-nebulosa s. marmorata. Long. corp. 10"', ped. post 11/3". Aus Virginien und Sud- Carolina, 2 weibliche examplare in Germar's Sammlung."

"Ph. gracilipes, Hald. Shining yellowish-brown, mottled; colors arranged transversely; limbs longer than in any other American species, the posteriar femora of male being 12 and the tibiæ 13 lines, in a specimen ten lines long. This species is from central Pennsylvania and is nearest allied to Ph. lapidicola Burm., which extends from eastern Pennsylvania to Georgia. Ph. maculata Harris is allied to the latter, but it has the poster ior tibiæ in the male waved at base."

Haldeman's description is scarcely more distinctive than Burmeister's, but it has the advantage of having a certain form applied to it from the time it was made until the present, while no one can tell to what species the two females in the Germar collection, described by Burmeister, belong. Scudder and other writers for many years applied Burmeister's name to the form herein recognized as $C$. terrestris Scudd. It is better, therefore, to drop the name lapidicola from our lists until the species to which it was originally applied can be correctly identified by an examination of the types, if they still exist.

The C. pallidipes Walker $(1905,115)$ is, as R. \& H. $(1916,272)$ have shown, only a small dark form of what they recognize (following Scudder) as C. lapidicola Burm. Specimens of this form are at hand from various points in Michigan, some of them received from Hubbell as $C$. meridionalis Scudd. (1894. 66), described from Chihuahua, Mex. An examination of the type of that form at Cambridge shows that it is at the most only a southwestern race of gracilipes. 
The known range of $C$. gracilipes, as above recognized, therefore extends from central Ontario and southern New England west to Manitoba, Minnesota, Nebraska and Colorado, and south and southwest to Georgia, Mississippi and Chihuahua, Mex. While the size, color and armature of the hind femora vary greatly over this large range, the prolonged truncate last dorsal and form of subgenital of male, and the form and arrangement of teeth of oripositor remain almost coustant and furnish characters of easy recognition.

Walker states that in central Ontario his C. pallidipes is the most common species of the genus, usually occuring under chunks and small $\operatorname{logs}$ in woods, or in rotten sodden $\operatorname{logs}$, from two to seren being usually found together. A few pass the winter in the nymph stage though most of them reach maturity in July from eggs hatched in spring.

In Connecticut gracilipes has been taken by Walden in cellars and under bark of trees. Smith $(1910,190)$ records it from two points in New Jersey where it was taken in dark cellars and barns, under stones and in hollow trees. In Maryland and Yirginia Davis has trapped numerous specimens in molasses jars.

301a. Ceuthophilus gracilipes Hekos Scudder, 1894, 54.

Size, form and color much as in gracilipes. Hind femora proportionally much more slender, being $25 \times 4 \mathrm{~mm}$. in greatest dimensions as against $23.5 \times 5.5$ in gracilipes of the same size; the spines of their lower outer margin more equal in size and more evenly spaced. Supra-anal plate very different in form, being fan-shaped, twice as broad as long with the concarity extending across its full width; its hind margin much broader than in gracilipes, subtruncate or broadly rounded. Ovipositor proportionally longer and more slender, the teeth of inner valves more aculeate, less broad at base and nearly equidistant one from another; terminal hook more slender, subcylindrical, obtuse at tip, feebly decurved. Length of body, $\delta$, 23.5 , ㅇ, 21; of antennæ, $\hat{\delta}, 85$, ㅇ, 92 ; of pronotum, $\hat{\delta}, 6.3, \hat{q}, 7.2$; of fore femora, $\hat{\delta}, 11.5, \hat{q}, 12$; of hind femora, $\hat{\delta}$ and $ᄋ, 25$; of hind tibiæ, 25.526 ; of ovipositor, $15 \mathrm{~mm}$.

After examining the types of heros at Cambridge and the paratype at Philadelphia, I cannot agree with R. \& H. in making it an absolute synonym of gracilipes. The differences between the two are very evident and are set forth in the ker and above description. Scudder's types of heros were taken in North Carolina by Morrison, orer 200 haring been found in one old hollow tree. It has been recorded elsewhere only from Ohio, but the specimens so recorded are gracilipes. 


\section{Ceuthophilus stygius (Scudder), 1861, 9. Cave Camel-cricket.}

Form and size of gracilipes. General color the same, though averaging somewhat paler. Antennæ longer, in the males often four times or more the length of body. Fore femora from three-fourths to nearly double the length of pronotum. Spines on outer carina of hind femora smaller and more even in size than in typical gracilipes, ranging from 15 to 20 in number. Hind tibiæ straight, never with the slight basal sinuation usually seen in the larger males of gracilipes. Teeth of inner valves of ovipositor much more slender with sharper tips; terminal hook longer, more decurved. Ninth dorsal of male much less prolonged backward and upward than in gracilipes; subgenital with apex of lobes broadly rounded. The measurements of the larger adult specimens taken in Indiana average about as follows: Length of body, $\delta, 30, \uparrow, 26$; of antennæ, $\hat{\delta}, 103$, $q$, 96 ; of pronotum, $\hat{\delta}, 7.5$, ㅇ, 6.5 ; of front femora, $\hat{\delta}, 15, q, 12.5$; of hind

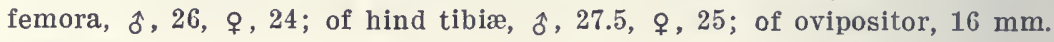
(Fig. 210.)

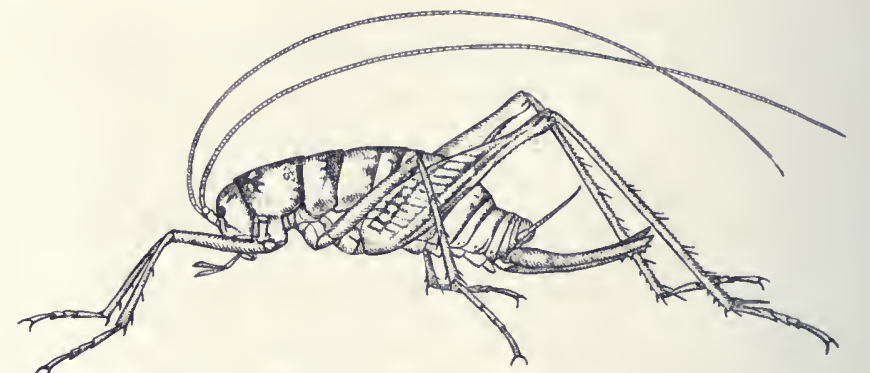

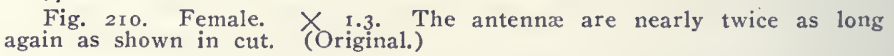

In Indiana this "cave cricket" occurs abundantly in crevices in the walls and roof near the months of Wyandotte, Little Wrandotte, Sibert's WVell Cave and Saltpetre Cave, Crawford County, and a few immature specimens have been taken in Porter's Cave, Owen County and Truett's and Strong's caves, Monroe County, s) miles farther north. In the Crawford County caves no specimens were found further back than 250 feet from the mouth, except in Wyandotte, where a few were taken on "Monument Mountain," one-half mile from the mouth. In the other caves they were found back beyond the reach of any rays of light.

The adults of this species are the largest stone or camel crickets occurring in the State and seem to be more or less gregarious. In one instance, in Sibert's Well Cave, more than 20 were found in a small cranny in the wall. They were grouped in a circle, in a space about six inches square, with their antemne pointing toward the center of the circle, and appeared to be holding a conference or cricket convention.

In regard to the life history of this insect, but little is known. 
I found a number of specimens of half grown young in Sibert's Care on May 16. The adults were common in July, and in November the young, about one-third the size of mature specimens, were frequent in Saltpetre Care, but could not be found elsewhere. The species may be represented in winter by the eggs as well as by the young, as is the case among some other members of the genus.

In Saltpetre Care, where in July stygius was very plentiful, all were found within 100 feet of the entrance. They were never seen on the floor, unless they leaped there when disturbed, but were found resting on the sides of small projections and in small carities of the walls or roof, with their antenne spread out before them. If a lighted candle was held close to them they paid no attention to it, but were very sensitive to its heat and to touch. When disturbed they leap with agility, sometimes to a distance of six feet, but with a little care can usually be readily picked up with the fingers before they become frightened.

The immature specimens from cares in Monroe and Owen counties were darker than typical stygius, and were found on the floors of the cares-in one or two instances beneath loose rocks. From their habits I was at first inclined to doubt their being stygius, since it is quite difficult to name correctly the young of any species of Ceuthophilus. Howerer, Packard (1S8S, 70) states that in Kentucky those living in the smaller cares are darker and less bleached than those in the larger ones.

Outside of Indiana $C$. stygius is recorded by Packard and Scudder from a half dozen or more caves in Kentucky. Brunner $(1888,309)$ records it from a care at Dallas, Texas, and Morse (1919a) from Bererly, Mass. It doubtless occurs in most of the smaller cares of the northern states between New England and the Mississippi.

Caudell $(1916,666)$ placed stygius as a varieț of gracilipes, stating that the "only separating characters seem to be the proportional length of the legs and the armature of the hind femora, characters useless in this instance through rariation." Howerer the teeth of ovipositor are so different in shape that, taking them in connection with the other differences given in key and description, I retain it as distinct. It is found only in the immediate vicinity of or within cares while gracilipes has a wide distribution in regions where no cares exist. The C. sloanii Packard $(1585,63)$ is stated by Scudder to be based upon immature specimens of stygius. 
303. Ceuthophilus Terrestris Scudder, 1894, 46. Woodland Stone Cricket.

Size small for the genus. Dark reddish-brown, mottled with small pale spots, especially on the abdomen, where the spots have a tendency to arrange themselves in longitudinal rows; dorsum of pronotum rarely with a median pale stripe bordered by darker fuscous blotches; legs paler; outer face of hind femora with the usual dark narrow oblique bars, the apex fuscous. Head short; vertex flattened vertically, ending in a blunt cone; antennæ twice as long as body. Fore femora one-third longer than pronotum, armed within with a single subapical spine. Hind femora of male shorter than hind tibiæ, rather slender, their lower carinæ each armed with 20 to 30 small, unequal, unevenly spaced teeth, male, with fewer, much smaller ones, female Supra-anal plate of male short, concave, its margin very broadly rounded; subgenital plate as in key and PI. VI, $h$. Inner valves of ovipositor with four short, equal,. triangular teeth, the basal one a little more distantly spaced than the others; terminal hook short, curved. Length of body, $\hat{o}, 12-15$, $ᄋ, 14-15.5$; of pronotum, $\hat{o}$ and $ᄋ, 4-4.5$; of fore femora, $\hat{o}, 6-6.3$, $ᄋ, 5.7-6.5$; of hind femora, $\hat{o}, 13-14,9,12.7-15$; of hind tibiæ, ô, 14.5-15.5, ㅇ, 14-15; of ovipositor, 7-8 mm.

Not known from Indiana, though it may occur in the northel'n counties. Scudder, in his original description, confused $C$. terrestris and neglectus (nigricans), a part of the series used as his types of terrestris being of the latter species as first pointed out by Walker $(1905,118)$. The locality records as given by him are therefore in part unreliable, but the general range is northern, extending from Newfoundland, New England and Nova Scotia, north and west to Nipigon, Ont., Michigan and Minnesota, and south at least to the Catskill Mts. and Ithaca, N. Y.

Morse (1919a) says it is "a common species in cool moist woodlands and forests in Vermont and New Hampshire." Gooderham has taken it at Truro, N. S. in July and August. Hebard (1915a) has recorded it from Humber Mouth and other points in Newfoundland. WValker $(1905,118)$ mentions it from several places in Ontario but says it is nowhere common in that Province, though he found it in considerable numbers on the Isle d'Orleans, Quebec, beneath flat stones at the foot of a wooded hill. Rehn (1904d, 269) records the taking by Hebard of 19 from beneath flat stones in an old Indian graveyard at Kieweenaw Bay, Mich. "They were good jumpers, but the majority relied on their protective coloration and remained motionless when the stone underneath which they were was turned over."

304. Ceuthopinilus latibuli Scudder, Insect Life, VI, 1894, 313.

Size large, form robust. Dark brownish-fuscous, thickly blotched with reddish-yellow ovate spots on abdomen and sides of thoracic segments. Hind femora dark with oblique pale markings. Fore femora one-half longer than pronotum, the inner lower carina of apical half with two to 
four spines. Hind femora about as long as body, its upper and inner faces rery finely and evenly scabrous; outer margin of lower sulcus wider than inner, armed with eight or nine unequally spaced short spines, male, unarmed, female; inner carina with 13 or more small teeth, male, 6 or 8 , female. Hind tibiæ distinctly longer than femora, its marginal spines very long and sharp; inner and outer median apical spurs subequal, slightly longer than first tarsal joint. Ninth dorsal of male entire, slightly projecting at middle; supra-anal projected between the cerci, as a broad, feebly concave lobe, with sides constricted near base and apex broadly rounded; subgenital deeply cleft, its lobes with inner angles prolonged and projected forwards, separated by a wide but shallow median notch. Ovipositor with four rather stout, triangular, nearly equally spaced teeth, the hook short, stout, feebly decurved. Length of body, $\delta$ and $\$, 17-18$; of pronotum, $5-6$; of antennæ, $55-60$; of fore femora, $8-8.5$; of hind femora, 18; of hind tibiæ, 19.5; of ovipositor, $10 \mathrm{~mm}$.

Mobile, Ala., Sept. 14 (Loding.) Scudder's types were taken by H. G. Hubbard from within the burrows of the gopher-turtle, Terobates polyphemus (Daudin), at Crescent Cits. Fla. Hubbard (1894) states that in January he found the walls and particularls the roof of the burrow alive with specimens of the Ceuthophilus, it being found in all stages of growth and in great numbers in every burrow.

R. \& H. have recorded the species from Enterprise. Clearwater and Jupiter, Fla. and Bainbridge and Thomasville. Ga.. their $C$. virgatipes (1904, 798$)$ from the latter place being a syillonym.

305. Ceuthophilus cecus Scudder, 1894, 60.

Size small to medium, body short, compact, robust. Above chestnutor dark mahogany-brown, the thoracic segments and abdomen with numerous reddish-yellow spots, the former usually with a narrow pale median line; lower sides of thoracic segments, antennæ, fore and middle legs and under surface uniform reddish-yellow; hind femora with the usual oblique fuscous bars. Fastigium ending in a prominent subcompressed triangular spine. Hind femora as long as body, stout, tapering, the apical fourth subequal; outer lower carina with 8-10 distant, unequal spines, the middle ones the longer, male, with a few small teeth only on apical half. female; inner carina in both sexes with a few small, equidistant spines. Hind tibiæ slightly longer than femora, their inner median apical spur subequal in length to basal joint of tarsus. Male with ninth dorsal very short, its middle very broadly and shallowly concave, but slightly projected beyond the eighth (Pl. VII, $h$ ); supra-anal membranous, short, broad, concave, its hind margin subtruncate or broadly rounded; subgenital in great part membranous, deeply cleft, the upper outer angle of each lobe ending in in very short, cylindrical, outward-directed projection (PI. VI, i.) Ovipositor very short, the teeth of inner valves cylindrical, needle-like, more slender and curved than in any other species; terminal hook long, very slender, strongly curved (Fl. VII, s.) Length of body, ô, 11.5-16, ㅇ, 10- 
14.5; of pronotum, $\hat{\delta}$ and $\$, 4-5.7$; of fore femora, $\hat{\delta}, 5-6, \uparrow, 4.5-7$; bf hind femora, $\hat{\sigma}, 12.5-17.5$, 오, 11.3-14.8; of hind tibiæ, $\hat{o}, 13.5-18$, ․, 11.7-15; of ovipositor, $4.5-6 \mathrm{~mm}$.

A careful study of the type of $C$. sallci Scudder (1894 63) at Cambridge and direct comparison with that of $C$. caecus from Lexington, $\mathrm{K} y$., shows no material difference except in size. The form of the subgenital and supra-anal plate in each is the same and the very distinctive teeth of the ovipositor exactly similar. 1 have, therefore, combined the two. Scudder separated them in his key only by the size, slightly different color and the relatively longer hind tibia of the smaller northern form cacus which has page priority of name. The $C$. cacus as such is definitely known only from the one male and two females taken by Garman at Lexington, Ky., June 28, and which served as Seudder's types and a second male in the Lexington collection taken by Garman at Hickman, Ky. C. sallei was described from New Orleans and recorded by R. \& H. (1916, 274) from De Funiak Springs, Fla. The type of $C$. occultus Scudder $(1894,77)$, a female from Georgia in the Cambridge collection, is a nymph of his $C$. sallci. The two other specimens by its side and probably considered occultus by Scudder, are a pair of immature $C$. tenebrarum.

306. Ceuthophilus pexinsularis R. \& H., 1914c, 408.

This is based upon a male nymph so immature that its proper relationship cannot be fixed. It is colored much like latens with the median pale stripe of dorsum more narrow. The subgenital plate of male is deeply cleft, the lobes incurved at tip; supra-anal tongue-shaped and with a deep median lengthwise groove; infracercal plates present and black in hue.

The unique type was taken near Homestead, Fla., from beneath a coquina boulder near the edge of pine woods. Two still smaller nymphs, named $C$. peninsularis for me by Hebard, are in my collection from Dunedin, Fla.

\section{Family VIII.'GRYLLIDA.}

\section{The Crickets.}

"And crickets sing at the oven's mouth,

As the blither for the drouth."-Shakespeare.

"The crickets are heard in the grass, chirping from everlasting to everlasting."-Thoreau.

The fourth family of Orthoptera belonging to the suborder Saltatoria comprises the Gryllida or crickets. From the other leaping Orthoptera they are distinguished mainly by the characters given in the key, page 149. They have the form usually subcylindrical, robust; head broad, usually perpendicular or nearly 
so, the vertex closely merged with front of face; eyes rather small, usually oral or elliptical, widely separated; ocelli variable in size, form and position, sometimes wanting; antennæ usually long and filiform; pronotum short, broad, usually depressed above; tegmina flat abore, bent abruptly downward at sides, usually fully developed, though (Gryllotalpinæ, Myrmecophilinæ and Nemobius) often abbreviated or even wanting; wings folded like a fan, usually shorter than tegmina, often very-rudimentary or wholly absent; fore tibia variable in structure and usually with a hearing organ on both sides; hind femora usually much enlarged, though in the tree crickets (Oecanthina) rery slender; hind tibixe armed abore either with numerous spines or fine teeth or both on each margin, except in the Gryllotalpinge and Tridactylina, where only the inner margin is so armed; also armed near apex with two or more pairs of subapical spurs; tarsi usually three-jointed (in Tridactylinæ one- or two-jointed or wanting) the first joint often very long; pulvilli wanting; cerci very long. lairy, tapering; oripositor as described below.

The name Gryllidx is derived from that of the principal genus Gryllus, a Latin name for cricket. By Kirby and some of the European authors the family name Achetida is used for these insects. The family is widely distributed over the earth, but in this country the species are less numerous than those of either the Acrididie or Tettigoniidæ.

The tympanum or calling organ of the males of Gryllida, when present, is, as in the Tettigoniida, located near the base of the dorsal surface of the tegmina, but is wider and broader, extending across both anal and median areas of the tegmina. In the males of Gryllus, as Lutz (1906) has shown, the right tegmen almost always overlaps the left and the "file" or stridulating ridge on the under side of the left is therefore rarely used, set it apfears as fully developed as the other. Lutz changed the position of the tegmina in a freshly moulted male, placing the left one above, and after they had hardened the cricket "could chirp just as well as one whose tegmina had not been tampered with, although he was using the sound-producing organ which would naturally not have been used at all." More than one-third of the 742 females of Gryllus examined by Lutz carried the left tegmen uppermost, and in that sex the position of the tegmina were during life frequently changed by the insects themselves, but were never so changed in the males.

The chirps or lore calls of the different species of crickets make 
up the greater part of that ceaseless thrill which, in the northern states, fills the air, usually at night, from mid-July until after frost. These sounds are made only by the males, and are not vocal, as most persons suppose; but are produced by the tympanum, the insect rubbing the veins in the middle of one wing cover over those of the other. It is often difficult to locate one of these chirpers by its song. The distance and even the direction are usually most deceiving; the crickets being exceedingly shy, much more so than katydids and grasshoppers. Those which live in the

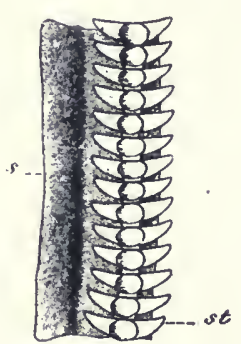

Fig. 211. Stridulating ridges in a h o u s e-cricket; $s$,
stridulating ridge; st, stridulating teeth.

(After Landois.) ground generally chirp near the entrance to their burrows, and retreat thereto at every approaching footstep. Those which live upon trees or shrubs resemble closely the hues of bark or foliage, and are therefore difficult to find even when close at hand; while the majority, dwelling as they do, among grasses and beneath logs and chips, find also a safe protection in their color, which is usually closely like that of the objects beneath which they rest while sounding their cymbals.

The inner wings of the crickets are, for the most part, short, weak, and comparatively useless as flying organs, though sometimes they are nearly twice as long as the outer pair. Like their nearest relatives, the grasshoppers and katydids, these insects, therefore, travel mostly by leaps and, in the course of time, their hind femora have thus be, come greatly enlarged.

The ovipositor of the females of most Gryllida, when exposed, is usually a long, cylindrical spear-shaped organ, consisting apparently of two pieces. Each of these halves, however, when closely examined, is seen to be made up of two pieces so united as to form a groove on the inner side, so that when the two halves are fitted together, a tube is produced, down which the eggs pass to the repository in the earth or twig, fitted to receive them.

The eggs of most crickets are laid singly in the ground. A few of the burrowing species deposit them in irregular masses in underground cavities. Some tree crickets place them uniformly in a single row in the pith of twigs. In Indiana and other northern states most species are represented in winter by the eggs alone. $\triangle$ few, however, pass the cold season as nymphs, or as adults. The mole crickets are said to live for several years. 
Among the families of Orthoptera the Grrllida and Tettigoniidre take a rank superior to all others. As Scudder (1S69b, 233) bas pointed out, the high specialization of the ovipositor of the female and the perfection of structure of the stridulating organ of the male place these two families above all others in the scale of Orthopteron life. That the two are very closely related can we readily seen by any one who will carefully compare them, organ with organ. The Gryllida are placed first, howerer, by most entomologists, as the great variety of form of almost any given organ among them, when compared with its relative uniformity of structure among the Tettigoniida, seems to indicate the higher rank of the former. Scudder adds: "I do not think it is without meaning that the crickets often live in company, that ther sing both in concert and during day and night and are the closer attendants upon man. Their stridulating organ too is more complicated and more extensive and the pitch of their song is higher."

The North American species of Gryllidie are herein divided among eight subfamilies, all of which are represented in the territory corered by this work. The following key is largely based upon that of Saussure $(1577,185)$ which was used by Scudder (1597c, 62). The Tridactylii have been separated from the Gryllotalpina, of which they heretofore formed a group or tribe, and made a separate subfamily. The form of the antenna and the one- or two-jointed tarsi are sufficient of themselves to justify this proceeding, without taking into account the other important differences. The Mogoplistii have also been raised to subfamily rank as they are very different both in structure and habits from the Mrrmecophiling with which ther have previously been placed as a tribe.

KEY TO SUBFAMILIES OF NORTH AMERICAN GRYLLID E.

a. Tarsi compressed, the second joint minute, compressed.

b. Fore tibiæ enlarged, fitted for digging; tympanum of male, when present, without a speculum; female without an exposed ovipositor. (Burrowing crickets.)

c. Antennæ setaceous, their joints very numerous; two large ocelli present; size large, 18 or more mm.; body thickly clothed with short hairs; all the tarsi three-jointed. (Mole crickets.)

I. Gryllotalpixж, p. 642 .

cc. Antennæ filiform, 11-jointed; three small ocelli present; size small, less than $10 \mathrm{~mm}$; body smooth, shining; fore and middle tarsi two-jointed, hind tarsi one-jointed or wanting. (Sand crickets.)

II. TRIDACTYLIx $\approx$, p. 654.

$b b$. Fore tibiæ not enlarged; tympanum of male, when present, furnished with a speculum; female with well developed external ovipositor. 
d. Body subspherical, wingless; pronotum covering the occiput and eyes, the latter very small; hind femora ovate, very strongly swollen; hind tibiæ armed above with only a few movable spines. (Ant-loving crickets).

III. MyrmegopiliLiNe, p. 659.

dd. Body more elongate, usually winged; occiput and eyes not covered by pronotum, the eyes well developed; hind femora more elongate, not exceptionally swollen.

$e$. Hind tibiæ armed above on both margins with minute teeth, but no spines; body covered with translucent scales; pronotum of males usually prolonged backward; species wingless or males usually wih very short membranous tegmina. (Wingless bush crickets.) IV. Mogorlistixe, p. 662.

ee. Hind tibiæ armed above with two rows of spines; body not covered with scales; pronotum not prolonged backward in either sex; tegmina always present, sometimes much ab. breviated.

f. Head short, vertical or nearly so; hind tibiæ rather stout, armed with stout spines without teeth between them; ocelli present; color black or brown. (Ground and field crickets.)

V. Grylline, p. 670 .

ff. Head elongate, horizontal; hind tibiæ slender, armed with delicate spines (except in the genus Neoxabea) with minute teeth between them; ocelli absent; color white or pale green. (White tree crickets.) V1. Oесахтипхж, p. 709.

aa. Second tarsal joint distinct, depressed, heart-shaped.

g. Hind tibiæ armed above with two rows of spines without teeth between them and with only two apical spurs on inner side; ovipositor in our species compressed and distinctly upcurved. (Small brown or black bush crickets.) V11. Trigonidis e, p. 728.

gg. Hind tibiæ armed above with two rows of spines with small teeth between them, the apical spurs three on both outer and inner sides; ovipositor in our species subcylindrical, but little upcurved. (Larger brown bush crickets.)

VIII. ENEOPTERIX A, p. 737.

\section{Subfamily I. GRYLLOTALPIN E.}

The Mole Crickets.

Crickets of large size, laving, in addition to characters given in key, the antenna much shorter than body; eyes rery small; monotum subcylindrical, arched, prolonged more or less backward, its hind margin rounded; lateral lobes with lower margin straight or concave, oblique; tegmina somewhat triangular, usually abbreviated; wings often fully developed; fore femora dilated and compressed; fore tibia with a tympanum on outer face, strongly dilated, coarsely toothed; middle and hind legs slender, compressed; hind femora slender, scarcely saltatorial, divergent from the body; abdomen cylindrical, its apex obtuse, 9-jointed, 
male, 7- or 8 -jointed, female; subgenital plate of male large, transrerse; oripositor not visible. Both the two known North Ameri(an genera are represented in our territors. The principal literatrie treating of them is as follows: Saussure, 1S74, 187T; Scudder, 1869a ; Blatchley, 1892, 1903; R. \& H., 1916.

KEX TO EASTERI GEXERA OF GRYLLOTALPIX

a. Front tibiæ with four dactyls; hind femora shorter than pronotum.

I. Grillotalpa. aa. Front tibiæ with two dactyls; hind femora usually longer than pronotum.

II. SCAPTERIScUS.

I. Gryllotalpa Latreille, 1802, 275. (L., "cricket" + "mole.")

The principal characters of this genus have been given above under the subfamily heading and generic key. Among all our Gryllida these mole crickets rank first in size and singularity of siructure. When full grown they measure from an inch and a fourth to an inch and a half in length, are pale brown in color and have the body covered with very short hairs, giving it a soft, velrety appearance. The females have no visible oripositor, and, externally, may be separated from the males only by the difference in the reining of the uppermost of the tegmina. By their labit of burrowing beneath the soil in search of such food as the tender roots of plants, earthworms and the larra of various insects, the anterior tibia of these crickets have, in the course of ages, become so modified in structure as to closely resemble the front feet of the common mole, whence the generic name. The dactyls or claws of these tibia are four in number, the upper two, the larger, being movable; the others immorable. The compound eres have, on account of the underground life, become much aborted, being not more than one-fourth the size of those of the common field crickets of the genus Gryllus. As the mole crickets crawl rather than leap, the hind femora are but little enlarged, and are always shorter than the pronotum. The hind tarsi are short, seldom exceeding half the width of the pronotum. The genus is widely distributed over the earth, three species occurring in the eastern United States.

\section{KEX TO EASTERT SPECIES OF GRYLLOTALPA.}

a. Hind tibiæ not spined above except at apex.

b. Apex of hind tibiæ armed with eight spines, four long ones on in. ner face and four shorter ones on outer; front trochanters short, nearly semicircular, armed with spinous hairs.

307. HEXADACTYLA. ${ }^{\text {TS }}$

${ }^{75}$ Kirby considers the characters given under $(b)$ of generic importance and has founded $(1906,2)$ for hexadactyla and allied forms the genus Ncocurtilla. I prefer to retain all of our species under the old name Gryliotalpa. 
$b b$. Apex of hind tibiæ armed with seven spines, four on inner and three on outer side; processes of front trochanters knife-shaped, curved, acute.

308. MAJOR.

aa. Apical half of hind tibiæ armed above on inner margin with three or four long spines; processes of front trochanters curved, acute.

309. GRYLLOTALPA.

307. Gryllotalpa hexadactyla Perty, 1832, 119. Common Mole Cricket.

Size medium for the genus; form robust. Cinnamon-brown or darker, covered with short fine hairs of the same hue; claws and veins of tegmina darker; occiput and abdomen more or less blotched with fuscous. Ocelli small, ovate, located between the upper inner margins of the eyes. Dactyls (fingers) of the fore tibiæ stout, curving outward, the outer movable ones the longer. Tegmina covering one-half to three-fourths of abdomen; wings slightly exceeding tegmina in short-winged form, extending beyond tip of abdomen in long-winged form (columbia Scudder). Anal cerci nearly one-half longer than pronotum. Length of body, $\hat{o}$ and $\$, 21-30$;

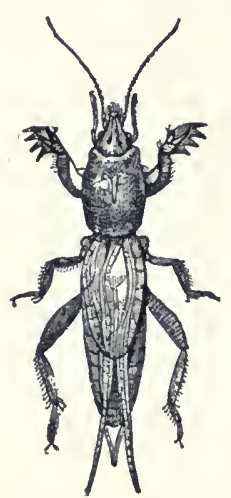

Fig. 212 . Longwinged male. of pronotum, 7.5-10.5; of tegmina, $6.5-12$; of hind femora, $6-8.2$; of cerci, $9.5-13 \mathrm{~mm}$. (Fig. 212.)

This, the $G$. borcalis of my former work (1903, 411) and of most American authors, is a common insect in suitable localities througlout Indiana, thongl nnknown to most of the inhabitants of the State. About one-third of those taken have the wings elongate, extending beyond the abdomen as shown in Fig. 212. On one occasion a $\log$ deeply buried in the sand on the southern shore of Lake Maxinkuckee was overturned and nine specimens were secured. Of these six were long-winged and three short-winged.

In the moist mud and sand along the margins of the smaller streams and ponds the runs or burrows of this cricket, exactly like those of a mole though much smaller, can in late summer and early autumn be seen by those interested enough to search for them. The burrows are, in the main, very superficial, lying just beneath the surface and running in very irregulat directions. They frequently fork, and often end beneath a stone or small stick. The insects themselves are seldom seen, as they are nocturnal, forming their burrows by night, and scarcely ever emerging from beneath the gromnd. Moreover, like a mole, they move backward as readily as forward, and so easily escape their enemies. Apparenty one insect, or a single pair oceupy these burrows; the males, though several are often heard at the same time, being usually at quite a distance apart.

The burrows occasionally enlarge into side cavities large enough for the insect to turn around, and in such lateral chambers 
the eggs are sometimes found in masses of 60 to 100 , adhering to the rootlets of rarious plants. These eggs are spherical, white or aimost colorless, and have a diameter of $0.7 \mathrm{~mm}$. The roung are active leapers, and are said to be about three rears in reaching maturity. On July 19, 1894, a hundred or more of the halfgrown young were captured in a small meshed seine while collecting fishes in a small stream in Montgomery County. They were evidently burrowing in the soft mud close to shore or perhaps in the mud beneath the shallow water. Just a year later a number of young were also taken in a seine from the waters of the outlet of Lake Wawasee, Koseiusko County. Since ther feed, during their lives, mainly upon the tender roots of various plants, ther are necessarily very injurious and it is fortunate that with us they are not more eommon than they are.

The known range of this mole cricket is a rery wide one extending from British America to the southern part of South America, Perty's types having been from Minas Gerses, Brazil. R. \& H. $(1916,277)$ first placed the G. borealis of Burmeister as a srnonym of hexadactyla and as Scudder and Saussure in their kers separated the two only by the length of the inner wings and the form of the projection at the base of the second lateral dactrl of the fore tibix, the two names are doubtless synonymous. The long-winged form, colmmbia Scudder (1869a, 26) was first placed as a synonym of borealis by me in 1903. Other synonyms of hexadaetyla are brevipennis Serr. $(1839,368)$ and longipennis seudder $(1862,426)$.

In Florida $G$. hexadactyla has been taken by me only at St. Augustine (at light), Ormond, Lake Okeeehobee and Dunedin, though its runways have been noted at almost all collecting stations. Elsewhere in the State it has been reeorded only from Leon County, where Hebard found one in a cherre tree, Enterprise and Lake City. About Dunedin its runways oceur in numbers around the numerous small lakes and ponds, and on Mareh 11, 1918, I took nine males and three females by digging in the muek on. the margin of one of these. The speeimens thus taken were all brachypterous and were much more sluggish in their actions than when uneovered in a runwar. They were smaller and darker than those from Indiana and the terminal joints of the palpi were also distinctly paler. When first uncorered the smooth silken-like luster of their surface was notable. To it not a particle of mud, muck or water adhered. There is little doubt but that this mole cricket oecurs in numbers in all parts of the mainland of Florida 
but has to be especially sought for in its mucky abiding places and the records for the State are therefore few.

Morse (1919a, 31) says that hexadactyla "probably oceurs throughout New England but is very local and difficult to capture." I can find but one record from Ontario, that of Fletcher (1892) who had received it from Leamington and wrote an excellent account of its habits. There is no definite locality recorded from Michigan, though Hubbell has it from Washtenaw County. Bruner mentions it as not rare in the eastern half of Nebraska and McNeill as found about Moline, Ill. in August. The latter states $(1891,4)$ that it "can be made to eject from its rerci a grayish viscid substance which can be thrown several inches. The ejected mass does not have any noticeably bad odor, and if used to repel the attacks of enemies it is probably efficient by entangling the feet and covering the eyes of attacking insects." of this habit Baumgartner (1910 316) says: "If one seizes a mole cricket of either sex it squirts from its anus a brown liquid of nauseating fetidity. This liquid is formed in part by excrement from the rectum and is in part the secretion of a special gland. It is protective in function, operating both as a repellent by its fetidity and as a restardant by its great viscidity or stickiness."

The note of the male mole ericket is a sharp di-syllabic chirp. continuously repeated and loud enough to be heard sereral rods away. It is usually attributed, by those who have given little attention to insect sounds, to the field cricket or to some of the smaller frogs. The cricket is very difficult to locate by this note, and I have on several occasions approached cautiously, on hands and knees, a certain spot, and remained silent for several minutes while the chirping went on apparently beneath my very eyes; yet. when the supposed exact position of the chirper was determined and a quick movement was made to unearth him, he could not be found. Indeed, it is only by clance, as by the sudden turning over of a $\log$ in a soft mucky place, that a jerson can happen upon one of them unawares. Even then quick motion is usually necessary to capture him before he scrambles into the open mouth of one of the burrows which he has ever in readiness. I have heard their note in the forenoon of cloudy days, but it is much more common in the afternoon. Scudder who has set the note to scale says of it $(189363)$ :

"Our common mole cricket usually begins its daily chirp at about four o'clock in the afternoon, but stridulates most actively at about dusk. On a cloudy day, however, it may be heard as early as two or three o'clock; 
this recognition of the weather is rather remarkable in a burrowing insect, and the more so as it does not appear to come to the surface to stridulate, but remains in its burrow, usually an inch below the surface of the ground. Its chirp is a gutteral sort of sound, like grii or greeu, repeated in a trill Indefinitely, but seldom for more than two or three minutes, and often for less time. It is pitched at two octaves above middle $\mathrm{C}$, and the notes are usually repeated at the rate of about 130 or 135 per minute; sometimes, when many are singing, as rapidly as 150 per minute. Often, when it first begins to chirp, it gives a single prolonged trill of more slowly repeated notes, when the composite character of the chirp is much more readily detected, and afterward is quiet for a long time. When most actively chirping, however, the beginning of a strain is less vigorous than its full swell, and the notes are then repeated at the rate of about 120 per minute; it steadily gains its normal velocity. It sounds not unlike a feeble distant croaking of toads at spawning season."

McNeill (loc. cit.) says he has "been struck with the resemblance of the note to that of the tree cricket, Occanthus niveus. To my ear the only discernible difference is that of pitch. The song is a simple chirp, very low in pitch for an Orthopteron, repeated at intervals of about a second."

Baumgartner (loc. cit.) sars that the female mole cricket has a partly dereloped chirping organ on its tegmina. With this it produces a single note used as a means of recognition in the darl: tunnels which it inhabits; both this organ of somd and the protective secretion above mentioned being adaptations to an underground life.

308. Gryllotalpa major Saussure, 18 $\mathbf{7 4}$, 343. Giant Mole Cricket.

Size very large, form robust. Brownish-yellow; pronotum velvety brown, with a faint narrow median groove or oval space smooth, shining and prolonged backward in sereral lines. Tegmina abbreviated, reaching only the fourth abdominal segnient; wings fully developed, surpassing the abdomen. Front legs stout, the trochanter large and of the same shape as in G. gryllotalpa. Hind femora more slender than in that species; hind tibiæ feebly enlarged at middle, armed as described in key. Claws of hind tarsi equal. Length of body, ô, 41; of pronotum 13 , of tegmina, $19 \mathrm{~mm}$. Width of pronotum, $10 \mathrm{~mm}$.

The above are the salient points of the original description, the trpe of which was from Illinois. The only published record of its occurrence elsewhere, which can be found, is that of Bruner (1855, 126) who mentions and briefly describes a speciunen from Labette County, Kansas under the name of Gryllotalpa ponderosa n. sp.? Caudell (Ms.) reports that he has receired specimens from Carthage, Mo., Lonisville, Miss. and Oklahoma. and specimens in the Philadelphia collections are from Riley County and Manhattan, Kansas, and Stillwater, Okla. All stud- 
ents of Orthoptera in the states mentioned should look for this giant mole cricket about the boggy places of ponds, lakes and sireams.

309. Gryllotalpa Gryllotalpa (Linnæus), 1758, 428. European Mole Cricket.

Size large, form robust. Reddish- or brownish-yellow, tinged with fuscous above, pale brownish-yellow beneath. Ocelli very small, subrotund. Antennæ scarcely longer than pronotum. Tegmina short, pointed, covering about half the abdomen; wings fully developed, caudate very rarely abbreviated. Front trochanters produced to a point. Hind tibiæ armed as in key. Anal cerci longer than pronotum. Length of body, 35-40; of pronotum, 13; of tegmina, 13-19; of hind femora, $9-11$; of anal cerci, 14.5-16 mm. (Fig. 213.)

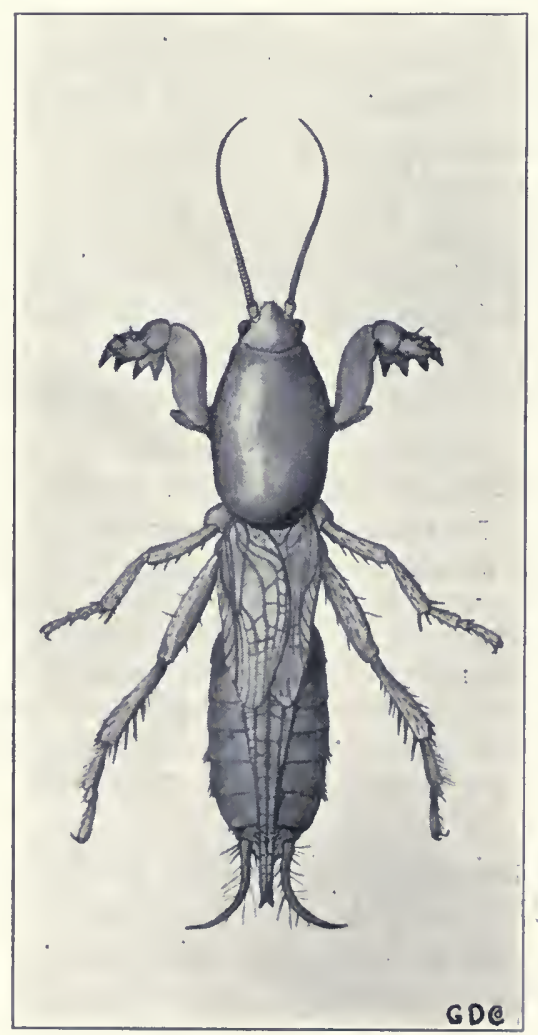

Fig. 213. European Mole Cricket. Male

This large mole aricket has been introduced and become established at a few points in the eastern states. Single adventive specimens have been mentioned by several authors, scudder (1869, 19) recording one as received in a collection from Vermont, but doubted its having been obtained there. Weiss (1915) first recorded its establishment in this country in a nursery at Rutherford, N. Jer., stating that the firm on whose premises they were found claimed to have destroyed at least 20,000 , including eggs. Later he and Dickerson (1918) gave an extended account of its occurrence at Rutherford, stating that: "This infestation, which is undoubtedly of several years' duration, extends over several acres planted to herbaceous and ornamental stock, a large number of plants being yearly imported from Europe. The soil is rather light and porous and contains a variety of shrubs, shadetrees, etc., such as one would naturally find in a nursery. No 
preference is shown by the cricket for any particular plant, its zig-zag burrows being found in different parts of the area irrespective of the kinds of plants growing there. The insects have been numerous enough for the nursers to detail sereral men at certain periods to hunt them out and destroy as many as possible every few days."

Morse $(1919,18)$ records three specimens as found in a local collection at Nantucket, Mass., where it was doubtless introduced br importations of European plants. Burr $(1897,67$ ) states that in England: "It lives in holes in damp places. potato fields, and also in sandy places. The burrow is a long winding passage at the end of which is a chamber in which the female lars about one hundred dirty rellow eggs. It feeds on roots, etc., and animal food if it can get it. The stridulation of this mole cricket has been likened (by Gilbert White) to the churr of the nightjar, but 'more inward' as the insect churrs in its burrow. It is to be heard about dusk on warm spring erenings. In France they are rery numerous, and do damage by eating the roots of grass, etc., but may be killed by pouring boiling water mixed with a little oil into their holes; they then come up to die. They may be kept in cages and fed on potatoes, turnips, meat, etc., but individuals should be kept separately or they will fight and mutilate each other. It takes about two years for this mole cricket to pass through its transformations; the larve, and perhaps the adult insects, hibernate."

Gilbert White says of this mole cricket: "When it flies it mores curso undoso, rising and falling in wares or curres like woodpeckers. In different parts of England people call them fern-crickets, churr-worms and eve-churrs, all very apposite names. Anatomists who have examined the intestines of these insects, astonish me with their accounts for they say, that from the structure, position and number of their stomachs or maws, there seems to be good reason to suppose that ther ruminate or chew the cud like many quadrupeds."

The majority of the European records of this insect have been made under the name of Gryllotalpa vulgaris Latr., a synonym; Burr $(189 \pi, 67$ ) first restoring the older name of Linnæus.

II. Scapteriscus Scudder, 1868c, 385. (Gr., "a little digger.")

Medium sized burrowing crickets resembling closely the species of Gyllotalpa in general appearance but easily distinguished by having only two dactyls on each of the expanded fore tibia. 
They differ also in having the fore trochanters much longer, the free portion equalling the tibial dactyls in length; hind tibia always armed above on inner margin as well as at apex; basal joint of hind tarsi ending on each side with a sharp spine, the inner one the longer; apical third only of the hind tarsal claws naked; anal cerci shorter than pronotum.

The habits of these smaller mole crickets are much the same as those of the larger ones, but in tropical countries, where they are much more numerous, they often do extensive damage to crops. Barrett (1902) prepared a special bulletin on the damage done by S. didactylus (vicinus Scudd.) in Porto Rico, estimating the annual damage on that island at more than $\$ 100,000$. All the species feed on the roots, stems and leaves of living plants, especially those of cane, tobacco, rice and vegetables, growing in moist places. The species are all tropical or subtropical in range, three being recognized as occurring in our southern states.
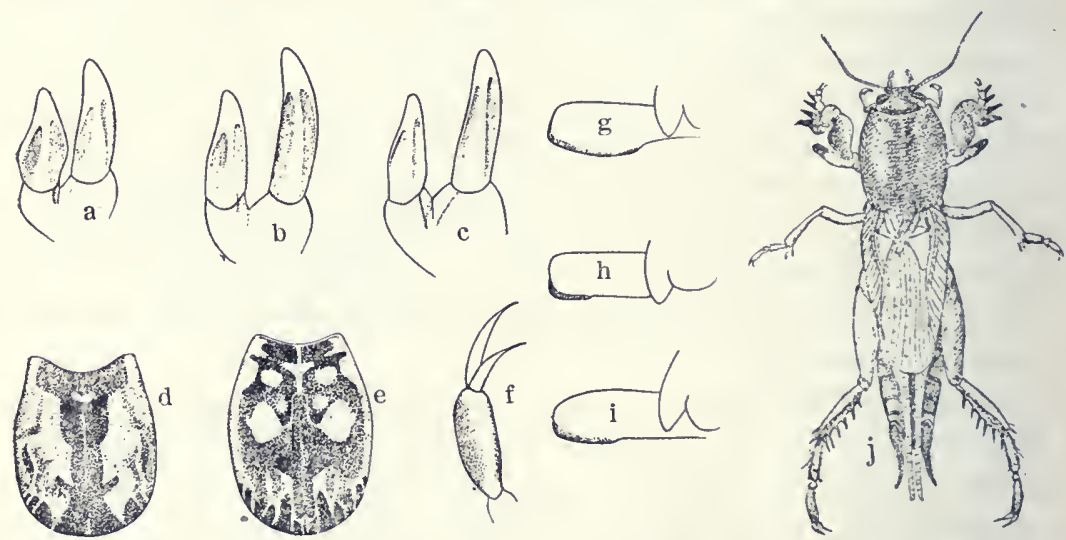

Fig. 214. Structures of Scafteriscus, a, Lateral outlines of dactyls of front tibie of female, $\times 4 ; d$, dorsal view of pronotum, $X 2 ; g$, lateral outline of fore trochanter or spatula, $X 4$, all of $S$. vicinus; $b, e, h$, same of $S$. abbreziatus; $c$, $i$, dactyls and forc trochanter of' $S$. acletus; $f$, lateral outline of terminal joint of hind tarsus and claws of abbreviatus, $\times 3.5 ; j$, dorsal view of $S$. vicinus. (After R. \& II. and Barrett.)

KEY TO EASTERY SPECIES OF SCAPTERISCUS.

a. Dactyls of front tibiæ almost or quite touching at base; pronotum without definite spots or figure of a distinct pattern (Fig. 214, $a$, d) ; ocelli obovate.

310. Vicixus.

$a a$. Dactyls of front tibiæ separated by a distance at least equal to onehalf their basal width; pronotum either with distinct spots or fig. ure of a definite pattern (Fig. 214, $b, e$ ) ; ocelli rounded or elongateoval.

b. Tegmina covering only one-third of abdomen; pronotum and abdomen mottled with numerous large rounded pale spots; ocelli very small, subrotund.

311. ABrReviatus.

$b b$. Tegmina covering three-fourths of abdomen; pronotum and abdo- 
men not strongly mottled; ocelli larger, twice as long as broad.

312. ACLETUS.

310. Scapteriscus vicivus Scudder, 1869a, 12. "Changa."

Size medium for the genus; form robust. Above pale brownish-yellow or fawn, an irregular blotch on disk of pronotum and veins of tegmina fuscous; beneath pale brown. Pronotum oval, one-third longer than wide, front margin concave, hind one broadly rounded. Tegmina usually covering three-fourths of abdomen, slightly surpassing the hind femora; wings fully developed, usually surpassing the anal cerci. Fore trochanter oblong or subspatulate, concave beneath, its tip rounded. Dactyls of fore tibiæ broad at base, subparallel, narrowly separated, their apical halves tapering, feebly decurved, the lower one the shorter and stouter (Fig. 214, a.) Dactyls of fore tarsi elongate-triangular, subacute, the inner one much the larger. Hind femora about one-fourth longer than pronotum. Hind tibiæ armed above on inner margin with four long sharp spines and at apex with two long and one short one on inner side and three short ones on outer side. Third hind tarsal joint strongly compressed, its inner terminal claw nearly as long as the segment, the outer one one-fourth shorter. Anal cerci two-thirds the length of pronotum. Length of body, $\hat{\delta}$ and $q$, $26-29$; of pronotum, $8-10.5$; of tegmina, $15-20$; of hind femora, $9.5-$ 11.5; of cerci, $6.5-8 \mathrm{~mm}$. Width of pronotum, $6.5-8.5 \mathrm{~mm}$. (Fig. 214, j.)

St. Simon's Island, Ga. (Hcbarl) ; Brunswick, Ga., Feb. 5Apr. 7 (Goodyear) ; Culebra and Guayama, Porto Rico (Pearson). This species is said br R. \& H. $(1916,27 S)$ to occur abundantly in the southeastern United States, the West Indies and portions of South America. It has been usually recorded as $S$. didactylus Latr. but they state that our species is somewhat heavier with width of pronotum distinctly greater in proportion to its length and with the basal width between the tibial dactyls averaging less than in didactylus, which was described from Surinam and does not occur north of Costa Rica.

No definite record of the occurrence of $S$. vicimus in Florida can be found. Scudder $(1869 a, 11)$ mentions nymphs doubtfully belonging to $S$. didactylus, as having been received from Fort Jefferson, Fla. Hebard (Ent. News, XY, 179) first recorded ricinus from the United States, his specimens coming from Darien, Ga., where they were reported to have destroyed a great portion of the grass on the golf grounds. It has since been found at a number of places in southern Georgia, and is said by R. \& H. to be a serious pest in portions of that State. In Porto Rico. on account of its face having a fancied resemblance to that of a pet monkey which there goes by the name of "Chango." it is the species known as the "Changa." It is said by Barrett (1902) to be "by far the most serious insect pest" of that island. He states that: 
"The young changa very seldom leaves the ground unless driven out by water, but the adults are frequently to be seen hurrying over the surface even in the daytime. The adult males frequently fly at night and are attracted to light. Though their flight is laborious, like that of a large beetle, and not long sustained, they sometimes rise to a light 20 feet or more above the ground. They seem to prefer dark, cloudy nights in which to make their ærial excursions. Whenever the soil is moist and not too hot, be it night or day, its work of destruction is carried on, though, of course much the greater amount of damage is done at night. Its habit of burrowing just beneath the surface in a great measure saves it from the attacks of lizards, but not entirely from fowls and blackbirds, that are quick to notice the slightest movement of the earth on top of the burrow and to recognize the cause thereof. These burrows, ramifying through the soil in the vicinity of food plants, are kept open and utilized for a considerable length of time by all the mole crickets frequenting that soil area. Thus it will be seen a changa can readily pass from the roots of one food plant to those several feet, or perhaps even yards, distant without emerging from the ground or making any new gallery.

"When removed from the ground, or sometimes when surprised on the surface, the adult changa has the habit of feigning death. This 'possum' act may be prolonged several minutes. After a few minutes of intense activity directly after coming to a light, the changa usually strikes an attitude of meditation, as it were, and remains absolutely motionless for a considerable length of time.

“The changa's food consists almost wholly of living plants; the stomach, however, is always found to contain more or less mud and sand, which is probably unavoidably eaten along with the roots. Portions of decaying plants and leaves and stems of living plants are sometimes eaten. In captivity, even with plenty of its normal food, the changa will eat the dead and dying individuals of its own kind; and we suspect that it varies its normal diet with an occasional earthworm, as we have kept specimens in cages on an unmixed diet of earthworms for a week or more."

311. Scapteriscus Abbreviatus Scudder, 1869a, 14. Lesser short-winged Mole Cricket.

Size medium; form robust. Brownish-fuscous blotched with pale yellow on thorax and abdomen; head blackish, maculate with yellow; veins of the tegmina fuscous. Ocelli minute, rounded, nearly flat. Pronotum elongate- oval, one-third longer than wide. Tegmina scarcely reaching middle of hind femora, wings rudimentary. Fore trochanters long, straight, slightly twisted at base, the sides parallel, tip broadly rounded; lower margin, except near apex, armed with numerous slender spines (Fig. $214, h$. ) Dactyls of fore tibiæ well separated at base, narrower than in vicinus, feebly curved, the lower one the shorter. Upper dactyl of fore tarsi distinctly longer, stouter and more curved than the lower. Hind femora shorter than pronotum, strongly compressed. Hind tiblæ with four spines on upper inner margin, these gradually increasing in length, the basal one the shorter; lower inner apical spine distlnctly longer than any of the others. Inner hind tarsal claw as long as its supporting segment. Length of body, $\hat{\delta}$ and $\rho, 21-24$; of pronotum, 10-11; of tegmina, $\hat{\delta}$, $4.5-5.2$,, 6 ; of hind femora, $\delta, 8, \&, 10 \mathrm{~mm}$. Width of pronotum, $7 \mathrm{~mm}$. 
Port Tampa Fla., Feb. 7. Ybor City, Fla., Nor. 7. This is the only species of these lesser mole crickets definitely recorded from Florida. In addition to the above localities it has been taken at Lemon City, Miami, Key West and Ft. Myers by R. \& H. or Davis. At Kiey West it was found on the sea beach in burrows in the damp sand and at Miami Hebard (1915b) "dug it out of sands soil in a grape fruit grove. Individuals were found to burrow but a few inches beneath the surface, coming to feed beneath decaying grape fruit. Ererrwhere about Miami in sands soil this insect, which is locally called 'ericket mole,' is said to do decided damage, particularly to farm truck. It is reported to have been introduced in this region in manure from Key West. The soft fat abdomen is in life whitish and distinctly paler than the hard portions of the insect." Specimens in the Gainesville collection are dark fuscous in general hue, the legs and scattered spots alone paler. This short-winged species was described from Pernambuco, Brazil, and is recorded only from that country, the V'est Indies, Southern Florida and White Oak, Ga.

312. SCAPTERiscl's ACLETUs Rehn \& Hebard, 1916, 279. Unwelcome Mole Cricket.

"Size medium, form rather slender. Pinkish-buff; head with occiput blackish-brown; dorsum of pronotum with an oval of blackish-brown, this interrupted cephalad and mesad by rounded incursions from each side of pinkish-buff; tegmina and wings buffy with veins darker; caudal femora except the proximal fourth of dorso-external portion suffused with darker; abdomen dark above, pale below. Lateral ocelli over twice as long as broad. Tegmina similar to vicinus, the reins not as heavy and cross veinlets fewer; wings slightly surpassing apex of abdomen. Dactyls of cephalic tibiæ separated by a space equal to basal width of one of the dactyls. Spatula with distal half of ventral margin chitinous, straight, the distoventral angle nearly rectangulate, sharply rounded (Fig. 214, c, i.) Median tibiæ armed interno-distad with four heavy spurs. Caudal tibiæ with ventro-internal margins each bearing four long spines, the last situated slightly proximad of the three long distal spurs; disto-external margin with three short spurs, the dorsal one widely separated from the other two. Distal joint of caudal tarsus slender, no wider than metatarsus (Fig. 215.) Length of body, $\hat{o}, 26.4-34.4$, $ᄋ, 26.5-35.5$; of pronotum, $\hat{\delta}, 8.8-11.3$, ㅇ, 8.5-10.3; of tegmina, $\hat{o}, 14.6-17.8$, ᄋ, 15-19.2; of caudal femora, $\hat{o}$, $10-11.7$, ㅇ, $10.2-12 \mathrm{~mm}$. Width of pronotum, 6.4-8.9 mm." (R. \& H.)

This species is known only from Jesup, Hebardville and White Oak. Ga. At Hebardville, "the type locality, it was found in great numbers in sandy soil. Tunnels recently made were ever where apparent. Digging into these and the flooding of such areas revealed few examples, but a row of lettnce in a dring condition was investigated, and beneath the wilted leaves, resting on 
the ground at the base of these plants, many specimens were found. The roots of the lettuce, tomatoes and beets were found

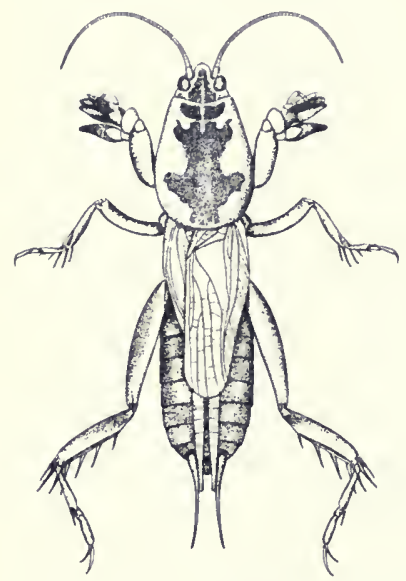

Fig. 215. Dorsal view of male type, $X$ I.5. (After R. \& H.)

to be extensively damaged by this insect, in many cases all but the main root having been completely devoured. When disturbed individuals always sought to escape under the ground, disappearing in the sandy soil with astonishing rapidity; on the surface they could run rery nimbly, occasionally giving a short hop, but not attempting to fly. There is no doubt, however, but that both this species and vicimus can fly vigorously and during migrations, which undoubtedly occur, probably resort almost wholly to this method of locomotion. At night the rich gutteral "grrr" of the cricket could be heard on all sides, but no individuals were found on the exposed surface of the ground." (R.\& H.)

\section{Subfamily II. TRIDACTYLINA.}

The Sand or Pygny Mole Crickets.

Burrowing erickets of very small size, having the body smooth, shining; ocelli three, very small; antenne 11-jointed, ${ }^{76}$ widely separated at base, differing from those of all our other Gryllidie in being submoniliform, the segments distinct and similar to those of many Coleoptera; pronotum short, covering but little of the head, not prolonged backward; tegmina of male without a tympanum; front tibixe without a hearing organ; hind femora much swollen, strongly saltatorial; tarsi of front and middle legs in our genera two-jointed, of hind ones one-jointed or wanting; abdomen ending in four slender, tapering, bristly appendages, the lower pair styliform.

The above characterization shows clearly the important differences between these pygmy mole crickets and their larger cousins the Gryllotalpina. In any other group of insects such a combination of different characters would be deemed sufficient for family ranking and I have no hesitancy, therefore, in raising them to subfamily standing. 'Two of the three known genera occur in our eastern states. The principal literature pertaining to

\footnotetext{
${ }^{76}$ Saussure $(1877,210)$ says there are only ten joints but in both our American genera there are eleven.
} 
them is as follows: Saussure, $1874,34 i-361,18 \pi 7,210-225$, 1897; Scudder, 1902; Blatchley, 1892, 1903; Morse, 1901a ; I \& H., 1916.

KEX TO EASTERX GEXERA OF TRIDACTYLIXE.

a. Species more than $5.5 \mathrm{~mm}$. in length; pronotum with a weak transverse sulcus; hind tibiæ with four pairs of long slender plates used in swimming; hind tarsi one-jointed.

I. Tridactilus.

aa. Species less than $5.5 \mathrm{~mm}$. in length; pronotum with no transverse sulcus; hind tibiæ with a single pair of short plates used in swimming; hind tarsi wholly wanting.

II. Elutpes.

I. Tridactylus Olivier, 1789, 26. (Gr., "three" + "finger.")

These little sand crickets are among the smallest of the Gryllidre. The principal characters of the genus are given above under the subfamily heading. In addition they have the head subconical; ocelli rounded, arranged in a transrerse row, the latelal ones very close to the lower inner margin of the eyes; labial ralpi short, robust, the terminal joint club-shaped; pronotum short, somewhat shield-shaped, convex above, sides sloping, front margin truncate, hind one broadly rounded and meeting in a sharp angle the oblique lateral or lower one; tegmina corneous, usually abbreviate, reaching middle of hind femora; wings translucent, fulls dereloped, slightly surpassing the abdomen; legs strongly compressed, front pair very short, their tibiæ usually broad, thin, four-fingered, concave within to receive the rery slender two-jointed tarsi ; middle legs very slender, their tarsi twojointed and, like the fore ones, ending in a pair of long curred claws; hind tibia with apical half bearing four pairs of long, slender "natatory lamellæ." preceded by slight serrations, also armed at tip on each side with two very unequal spurs. Abdomen slender, last dorsal segment large, deeply cleft; cerci slender, tajering, bristly, two-jointed; beneath them a pair of slightly shortex, equally slender bristly one-jointed appendages.

Ten species of Tridactylus have been described from North America. Scudder (1902) reduced these to three and founded for one of them the genus Ellipes. R. \& H. $(1916,283)$ combined the two left by Scudder so that we have remaining only the one species described by Sar. Those reductions and combinations were largely due to the paper of Morse (1901a) who showed that the fore tibia of the males varp exceedingly in form, being usually more "or less irregularly orate in outline and terminating apically in four prominent equidistant teeth, with the convex outer face thickly set with hairs, * * * the tarsus being inserted be- 
tween the first and second teeth and lying on the anterior face." From this normal form it varies in progressive degree to a remarkably bifurcate organ in which the inner limb is elongated and devoid of hairs, the innermost tooth nearly disappears, the second is greatly prolonged into a claw-like organ, while the femur acquires tooth-like projections on its upper, inner ventral angle and becomes greatly enlarged.

"These sand crickets," says Seudder, "are in general appearance, miniature Gryllotalpas, though, not being heavy bodied, they can leap vigorously, bounding high in the air. Nothing is more curious than these lively and pygmy mole-crickets; they live in similar places, and make burrows like the mole-crickets, but their forelegs, though constructed for burrowing, are very different in detail. They are not, however, found in quite such wet spots as the mole-cricket haunts, preferring the sandy margins of ponds rather than mudy ones. Their burrows are at first vertical, but immediately turn, running not more than an inch below the surface of the ground, and are very narrow, as would be expected of such little creatures; one measured was hardly a twentieth of an inch in diameter. The males are not provided with any tambourine upon the wings, and therefore can not sing."

313. Tridactylus Apicalis ${ }^{77}$ Say, 1825, 310. Larger Sand Cricket.

Color variable, usually black or dark brown; occiput and thorax with pale markings; tegmina with dorsal area and a spot behind middle yellowish; fore legs dull yellow; hind femora dull yellow with upper half of outer face brownish or with three dark cross-bars. Disk of pronotum with apical fourth constricted and a faint median groove. Tegmina with tips broadly rounded. Other characters as given above. Length of body, 6-9.5; of pronotum, $2-3$; of tegmina, $3-3.3$; of wings, $7.5-8.5$; of hind femora, $3.5-5 \mathrm{~mm}$. (Fig. 216.)

This sand cricket appears to be common locally in southern Indiana, but has been noted only in Lake County in the north. It occurs mainly along the sand bars of the larger streams. In (owen County it has been seen by hundreds in Angust and Sep)tember on the damp bars along White River, often in company with Ellipes minuta, while in Putnam and Vigo counties adults have been taken in early Jume. It occupies small pits or burrows in the sand, and may sometimes be seen resting with the head, and half the body, ontside the opening of the pit, into which it backs as one draws near. When out at a distance from any convenient pit, it leaps vigorously when approached, often to

\footnotetext{
r'Say's first spelling of this name was apicialis, a word without meaning and an evident error, which was corrected by Burmeister (1838, 741.)
} 
a height of five feet and a distance twice as great. Br close search if will probably be found to occur along the damp sand bars of the lakes and streams of northern Indiana.

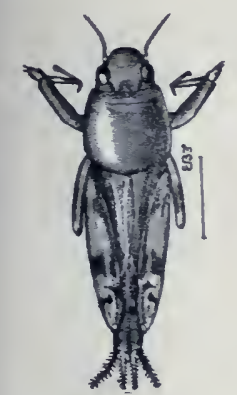
Fig. 216. TriSay.

(After Lugger.)

The known range of $T$. apicalis is a verr wide one, extending from sonthern New England, Ithaca, $\mathrm{X}$. Y. and near Toronto, Ontario west to Minnesota and south and southwest, according to Scudder (1902), to Georgia, Lonisiana, Texas, Southern California, Mexico, Ecuador and South America. The only Florida record which can be found is that of the type locality of Say (loc. cit.). who states that it is "numerous on St. John's River in East Florida, and on the Missouri as far as Council Bluff."

Saussure $(1874,352)$ was the first to suggest that the T. terminalis Scudder (1S62.425) "is probably onl a a northern variety of $T$. apicalis in which the organs of flight have not arrived at their full development." Later he evidently considered terminalis as only a synonrm as he does not mention it in his revision (1897a).

In Ontario Walker $(1904,144)$ first found two specimens of apicalis near the Humber River and later in numbers along a small stream near York Mills. This is its most northern record. Lugger (1S9S, 259) mentions a single specimen as having been taken near Ft. Snelling, Minn.

Thomas $(1865,442)$ says that in Illinois his $T$. illinoiensis, a synonym of apicalis, is abundant throughout the State. "living in the soft sandy banks of branches close to the water. Here their little holes may often be seen in great numbers, from which individuals of all ages will emerge if the earth is forcibly pressed. While walking along the banks of the river I have seen them by hundreds leap on to the water along which they float for an instant and then spring back on the bank. Ther have a singular eriemy in the bug, Galgulus oculatus Fab., which, being of a mud color and lying flat close to the ground, mores slowly along and, when close to its victim, with a sudden upward and forward leap it grasps the unsuspecting cricket with its fore legs and plunges its beak into it."

On Staten Island, N. Y. Daris (1S91) found apicalis "not uncommon at Watchouge in damp places. Their small size and marvelous agility made them most entertaining insects to capture. The power of leaping is so great that ther seem to disappear quite 
mysteriously, and one wonders which way they have gone, it being seldom that their departure can be accurately followed by the eye."

In addition to T. terminalis, the following species of Tridactylus described from the United States are now considered synonyms of T. apicalis: T. tibialis Guer. (1844, 336), mixtus Hald. (1853, 364), illinoiensis Thomas $(1863,104)$, fissipes Sauss. (1874, 352) and incertus Sauss. (1897, 418.)

\section{Ellipes Seudder, 1902, 309. (Gr., "omitted" + "foot.")}

The principal distinguishing characters of this genus are given in the key. They have the pronotum short, not constricted near apex; fore tibia of males simple like those of females, never eleft; hind tibiæ with margine of upper basal half smooth, armed at tip on each side with two very unequal ealearia, the longest half the length of the tibia. But one species is known.

\section{Ellipes minuta (Scudder), 1862, 425. Smaller Sand Cricket.}

Blackish or fuscous-brown; head and pronotum mottled with paler, the lower margins of latter broadly pale; all the femora and middle tibiæ with pale cross-bars; hind tibiæ dusky. Tegmina short, covering less than half the abdomen; wings variable, sometimes twice as long, usually slightly surpassing the abdomen. Length of body, 4-5; of pronotum, 1.5-2; of hind femora, $3-3.5 \mathrm{~mm}$.

This small sand cricket occurs throughout Indiana, frequenting damp sandy places which are sparsely covered with grass or other vegetation, where it is often found in company with the grouse loeusts or with the larger sand cricket, Tridactylus apicalis Say. While more active in its movements it does not leap as high nor as far as that species. The best way to capture them, after discovering a colony, is to use a sweep net rapidly just above the ground. The pair of minute subapical swimming plates of hind tibix are sometimes wanting, and rarely there are two on the outer margin. The long apical so-called "calearia" are finely fringed above. They are not, therefore, spurs in the true sense and are doubtless used as swimming organs.

In Florida this is also a common insect and has been taken by me at all collecting stations except Cape Sable and Key West. There, as elsewhere, it is more abundant about ponds and lakes than along the flowing streams, and has been recorded by other collectors from numerous localities on the mainland, but not as yet from the southern keys.

The known range of $E$. minuta is a wide one, extending from Ocean City, N. J. and Stafford County, Va., west to Minnesota 
and south and west to Mississippi, Texas, Southern California, Cuba and Mexico. It is not known from New England nor from Canada. For an insect of so wide a range definite records of $E$. minuta are very few. Kostir mentions it as occurring at Columbus, Cedar Point and Sugar Grove, Ohio. No localits has been recorded for Michigan, though it doubtless occurs in the State. Lugger does not record it from Minnesota though Scudder says he does. Bruner states that it or $T$. mixtus Hald. occurs in the south half of Nebraska. McNeill records it from Champaign, I11. without other mention. R. \& H. (1916, 2S4) give a number of records from Virginia south to Georgia, and state that it is found on wet sand near water, often in great numbers orer the entire region of the southeastern United States.

The T. histrio and T. histrionicus, described by Saussure from Central America, Texas and Cuba, are placed by Scudder (1902) as synonyms of $E$. minuta.

\section{Subfamily III. MYRMECOPHILIN E.}

The Ant-Loving Crickets.

As here restricted this subfamily complises very small, subspherical wingless crickets having the ocelli absent; face much narrowed by the very large antennal pits; pronotum in both sexes of much the same form but longer than meso- and metanotum, its lateral lobes very short; fore tibiae without a heariug organ; hind femora ovate, compressed, very greatly enlarged; hind tibia armeri above on inner margin with three or four long movable spines; basal joint of hind tarsi distinctly longer and stouter than the other two.

The subfamily is represented by the single genus:

I. Mrruecophila Latreille, 1829, 183. (Gr., "ant" + "to love.")

Form ovate, very convex; head almost hidden beneath the pronotum; rertex rounded, strongly declivent; eyes small, situated above the very large antennal fossie and usually in great part concealed by the pronotum; antenna stout, about as long as body. setaceous, their basal joint very large, compressed, the others rery short, exceedingly numerous; pronotum slightly wider behind than in front, its fore and hind margins subtruncate; meso- and metanotum similar in form to segments of abdomen, sometimes slightly wider; fore and middle legs slender; hind tibia shorter than the femora, compressed, lower margin curved, upper one ciliate, its inner carina with three long movable spines, outer carina with one, apex with two pairs of slender spurs, the upper 
pair the longer ; anal cerci long, cylindrical, tapering, very bristly. Male with subgenital plate boat-shaped, its apex rounded, feebly upcurved, deeply cleft. Ovipositor short, rather stout, straight.

The species of Myrmecophila are among the smallest of Orthoptera, and occur in all parts of the earth. They are always found either in company with ants or on the ground beneath corer where ants are very likely to occur. The principal literature treating of our American forms is as follows: Bruner, 1854; Scudder, 1899d; Wheeler, 1900; Blatchley, 1903; Schimmer, 1909.

Wheeler (1900) has given an interesting account of the habits of one of these little crickets from which I quote at length as follows :

"In the present paper I wish to call attention to the peculiar habits of
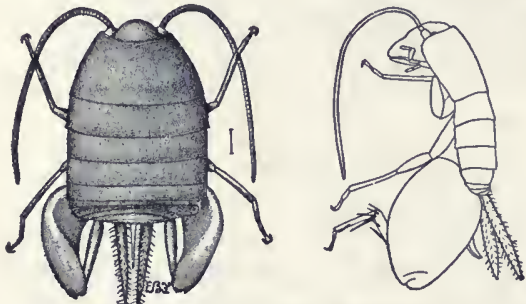
Fig. 217. Myrmecophila nebrascensis Brun.
(After Lugger.)
Myrmecophila nebrascensis Bruner which is very common in the vicinity of Austin, Texas, where it may be found in the nests of no less than five very different species of ants. My observations on the habits of this Myrmecophila began early in March. The little crickets were taken from the Formica or red ants' nests

and placed in artificial nests of the agricultural ant, an insect of much larger size, slower movements and in many other respects more satisfactory for purposes of observation than the Formica.

"On April 3d I placed in the artificial nest twenty Myrmecophilas, eight or ten of which had been squeezed or had lost one or both saltatory legs during capture. All the disabled individuals were at once seized and dispatched in so vindictive a manner, that I could not doubt that the ants were irritated by the pungent red ant nest-odor still clinging to the crickets. In an instant all the ants in the compartment of the nest had gathered in little groups, each devouring a Myrmecophila. The uninjured crickets made not the slightest attempt to escape, but felt themselves perfectly at home as soon as they set foot on the floor of the nest. Their adaptation to a new nest and to an ant of a larger size and belonging to an entirely different sub-family from their former host, was immediate and complete. With constantly vibrating antennæ they began dodging in and out among the little groups of assembled ants. From time to time one of them would be seen cautiously approaching an ant, that was busy with its dinner of Myrmecophila, and fall to nibbling at its legs or the tip of its abdomen. There could be no doubt that the cricket derived some benefit from the oily secretion covering the surface of the ant's body. At first the ant disregarded this nibbling, which probably resembles the attentions of the toilet habitually received from sister ants, but the cricket's scraping mandibles and maxillæ soon grew annoying and the ant would either more away or turn its head, open its mandibles and make a lunge at the Myrmecophila like a large dog annoyed by a puppy But before the huge mandi- 
bles had closed, the cricket was far away, already nibbling at the abdomen of some other ant. The cricket can get at only the legs and abdomen of its host, since the spreading legs prevent it from reaching the thorax. It often stands on its hind legs, and places its forelegs on the ant's leg, in order to reach the femur or tibia. For very obvious reasons, it avoids nibbling at or even approaching the ant's head. It is always alert, as if perpetually aware of danger and ready to dodge at the slightest morement made by the ant.

"Occasionally in the narrow confines of an artificial nest the ants do succeed in capturing and devouring one of their vigilant little guests, but the fact that of the eleven sound crickets left after the above observation was made, eight were still alive June $22 \mathrm{~d}$, when I had to discontinue my ob. servations for the summer, shows that the crickets are extremely expert in keeping out of danger. The attitude of the ants during all this time underwent no change as far as I could observe, for they would still occasionally make lunges at the crickets.

"The crickets do not derive all their substance from cleansing their hosts. In earthen nests they are often seen haunting even the galleries that have been abandoned by the ants, scrutinizing the walls and nibbling at them from time to time. There can be no doubt that they find here the same substance which covers the ants, for the walls of the galleries of a populous nest soon become greasy from the attrition of the constantly passing ants. Sometimes the crickets may be seen nibbling at dead ants that have been temporarily abandoned in the galleries or placed on the kitchenmidden of the nest. The intestine of a Myrmecophila which I dissected was found to contain oil-globules and a granular whitish substance."

Kirby $(1906,53)$ recognized 15 species of these little crickets. Of these but one occurs in all Europe, where it is very widely distributed, while fire nominal species have been described from the United States. But one of these is known east of the Mississippi.

315. MYrMecopHILA PERGaxdei Bruner, 1884, 42.

Broad oval, depressed, nearly twice as long as broad; very thinly clothed with exceedingly short, subprostrate yellowish bristles. Dark reddish-brown; front and hind margins of pronotum, hind margins of the other dorsal segments and apex of ovipositor piceous-brown; legs, cerci and base of antennæ and ovipositor paler brown, extreme front margin of pronotum yellowish. Pronotum about twice as long as either the meso- or metanotum, the front margin about one-fourth narrower than hind one; meso- and metanotum subequal, longer than the succeeding dorsal segments, which are equal in length. Hind femora pyriform, more curved below than above, less than twice as long as broad. Outer hind tibal spurs more than half as long as tarsi. Cerci about as long as hind femora. Length of body, $\hat{\delta}, 3-4.3$, $९, 4-5$; of hind femora, $\hat{\delta}, 2.5, \uparrow, 3$; of ovipositor, $2.5 \mathrm{~mm}$.

Southern half of Indiana, April 26-Sept. 6; Dunedin, Fla., Dec. 3-March 24 (W.S. B.).

This small ant-loving cricket was first taken in Indiana near New Harmony, Posey County, on April 26, 1901. It was after- 
ward found to be rather common in the region thereabouts as well as in Knox, Perry, Dubois, Crawford, Orange and Lawrence counthes; the northernmost point at which it has been observed being near Mitchell, Lawrence County. Since its known general range is: southern it probably does not occur in the northern half of the State. With us it is found in company with a half dozen species of ants, the most common of which is a rather large yellowisli-red form, Camponotus melleus Say. The ericket seems to be always on the move, and when disturbed leaps with great agility. Those taken in Crawford County in September were almost double the size of those noted in the spring and probably more accurately represent the mature insect.

At Dunedin four specimens have been taken, each singly beneath half buried logs, two of them without an ant beneath the lugs where they were found. One of them liad only one hind leg, yet leaped a foot in height and a distance of 18 inches several times when first uncovered. Dunedin is the most southern station known for M. pergandei and it is elsewhere known in Florida only from Crescent City, a single nymph from there being in the Philadelphia collection.

This was the first of these little crickets deseribed from North America, Bruner's types being from the "Atlantic States from Maryland southward." Its known range now extends from Washington, D. C. west to southern Indiana and south and west to Clayton, Ga. and Dunedin, Fla. In Ohio it has been taken by Dury near Cincinnati. The other four species of United States Myrmecophila are seprarated by Scudder (1899d, 425) only by minor characters of size and color, and it is very probable that two or three of them will prove to be but synonyms or varieties. Bruner in his original description of pergandei stated that the characteristic feature of that species is "the two light colored elliptical markings upon the disk of the pronotum," but these are not found in any of the Indiana or Florida specimens at hand.

\section{Subfamily IV. MOGOPLISTIN Æ.}

\section{The Wingless Bush Crickets.}

Small slender-bodied depressed wingless or subapterous Gryllids, thinly clothed with transhucent, easily abraded scales and having the head short, depressed; vertex truncate in front; upper portion of face strongly swollen, protuberant between the antennæ, separated from vertex by a transverse sulcus; ocelli very small or absent; eyes well developed not covered by pronotum; palpi variable in length and form of segments; pronotum of males 
usually produced backward into a rounded lobe, its lateral lobes elongate, very narrow; tegmina absent in females, usually abbreviated, membranous and furnished with tympanum in males; hind femora moderately swollen; hind tibia serrulate above on both margins, without true spines and with three pairs of subapical spurs; basal joint of hind tarsi with two curved subapical spurs; oripositor straight, sublanceolate.

This subfamily has been previously placed as a group or tribe of the Myrmecophilina, but the differences in structural character's are so great and the habits so different that I here raise it to subfamily rank. The species are mostly tropical or sub-tropical in distribution and occur for the most part on bushes or beneath debris in sandy localities near water. The principal literature treating of the American species of the subfamily is that of Scudder, 1S68b, 1897f; Saussure, 18т4, 422-427, 18тT, 461-47т; I:runer, 1891; Redtenbacher, 1S92; R. \& H., 1905, 1912a.

R. \& H. in their revision (1912a) recognized 11 genera of their group Mogoplistii, five of which they state to be represented in the United States or Mexico and three in the territory covered by this work. Anyone who compares their characterizations given on Fages 193 and $20 S$ of the two genera Cryptoptilum and Cycloptilum, will find them word for word exactly the same with the exception that in the proposed new genus Cryptoptilum the tegmina are said to be "concealed by pronotum in male," whereas in Cycloptilum they are mentioned as "projecting beyond pronotum in male." This and "size small" and "very small" are also the sole characters used in the separation of the two genera in their key, p. 1SS. As the representatives of the two nominal genera at hand show no other structural differences of generic value whaterer, and as wing length in Orthoptera is no longer regarded as of eren specific value, ${ }^{78} \mathrm{I}$ have placed all the species under the older name Cycloptilum Scudd. If the projecting tegmina is a character of generic importance in this group, it should also be used in Atlanticus, and A. gibbosus and dorsalis be separated from the other species under a new generic name. Banks (1906) has well said: "If the characters which distinguish genera are of less value or are less constant than the characters that separate the species, such genera are worthless. They mean nothing. They are of no value to science. Why then accept them?"

${ }^{79}$ As proof of this I need only quote R. \& H. (I9r5C, 294) as follows: "The work of Lutz has already demonstrated the error of using length of tegmina, wings and ovipositor as characters of specific importance in the genus Gryllus. The mass of evidence upon these features in Lutz's paper is absolutely convincing; from studies of other genera we have found such characters to be of minor importance generally throughout the Orthoptera." 
KEY TO EASTERT GENERA OF MOGOPLISTINA.

a. Facial protuberance between the antennæ very convex and with a distinct but shallow median vertical groove; pronotum of male distinctly widening from apex backward and prolonged behind in the form of a rounded lobe; tegmina present in male but often wholly concealed; fore tıbiæ with a tympanum on outer face.

I. Cycloptilum.

aa. Interantennal protuberance subdepressed, without a vertical groove; pronotum of male not or very feebly widened backward, its hind margin truncate; tegmina and wings absent in both sexes; fore tibiæ without a tympanum on outer face. II. Oljgacanthopus.

I. Crcloptilum Scudder, 1868b, 142. (Gr., "circle" + "wing.")

In addition to the characters above given the nembers of this genus have the head very small; antenna very long and slender, widely separated at base, first joint large, the others much smaller, subequal; pronotum about half the length of body, male, shorter and subquadrate, female; tegmina of male either projecting beyond pronotum or wholly hidden, the tips of the dorsal field strongly curved and lateral field well developed; abdomen depressed nearly equally broad throughout, slightly tapering at apex; hind femora much dilated, more than twice as long as broad; hind tibia with three pairs of apical spurs, the upper inner ones shorter than the lower ones; basal joint of hind tarsi sulcate above, serrate on both margins,${ }^{79}$ ending in an apical spur each side; anal cerci tapering, more than half as long as abdomen. Ovipositor straight, variable in length, its apex not serrulate beneath.

\section{KEY TO EASTERT SPECIES OF CYCLOPTILUM.}

a. Pronotum of male short and broad, its length about one-fourth more than its greatest breadth, its hind margin almost semicircular; ovipositor short, not over $3.5 \mathrm{~mm}$. in length. 316. SQUAMOSUM. aa. Pronotum of male longer, Iess broad proportionally, its length nearly

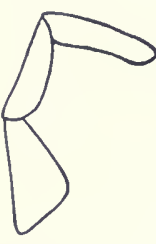

a

Fig. 218. Maxillary palpi of Cycloptilum, a, of $C$. antillarum; b, of trigonipalpum, greatly enlarged. (After R. \& H.) one-half more than its greatest breadth, its hind margin less broadly, rounded and basal third less flattened; ovipositor Ionger, 4.5 or more $\mathrm{mm}$.

b. Terminal joint of maxillary palpi moderately elongate, widening feebly from base to apex, but slightly obliquely truncate.

317. ANTiLLARUM.

$b b$. Terminal joint of maxillary palpi shorter, strongly widening from base to apex, very obliquely truncate (Fig. 218, b.)

318. TRIGONIPALPUM.

${ }^{79}$ Scudder in his key $(1897 \mathrm{c}, 64)$ says: "First joint of hind tarsi neither sulcate nor serrate," but an examination of the generic type, $C$. squainosum, by Davis showed he was mistaken. 
316. Crcloptilum squamosum Scudder, 1868b, 142. Scaly Bush Cricket.

Size small for the genus. Body elongate-oval, thinly clothed with silvery or yellowish scales; head and pronotum reddish-yellow, often with a postocular stripe of darker scales, extending as a narrow line along the upper edge of lateral lobes; legs, antennæ and mouth parts paler yellow; dorsal surface of abdomen, except at base, fuscous-black, under surface dusky. Terminal joint of maxillary palpi one-third longer than the one preceding, its tip obliquely truncate. Male with disk of pronotum distinctly broadening from apex to base, its apical half rounded into the sides; posterior lobe strongly flattened, longer than the narrow lateral lobes. Tegmina with exposed portion as wide as abdomen, varying in length from .5 to $1.3 \mathrm{~mm}$., its sides embracing those of abdomen. Subgenital plate short, scoop-shaped, its apex entire. Female with pronotum subquadrate, slightly narrower in front; tegmina absent; ovipositor about one-third shorter than hind femora, slightly curved upward at base. Other structural characters as above given. Length of body, ô, 5.4-7.5, 우, 67.2 ; of pronotum, $\hat{\delta}, 3-3.4$, $९, 2-2.2$; of hind femora, $\hat{\delta}, 3.5-4.1$, , $3.7-4.4$; of ovipositor, $3-3.6 \mathrm{~mm}$. Greatest width of pronotum, ô, 2.62.9, , , 1.9-2.1 mm. (Fig. 219.)

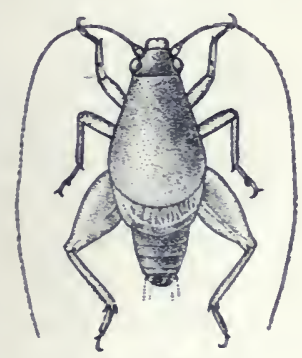

Fig. 219. Male. Dorsal view of type, $\times 4$. (After R. \& H.)

Dunedin, Fla. (W. S. B.) ; Carrizo Springs, Texas (Hebard). Only one adult male and sereral female nymphs have been taken about Dunedin. The former was found December 17 while sifting rubbish for beetles. Elsewhere in the State it has been taken by others at Atlantic Beach, San Pablo, Live Oak, Gainesville and Lakeland, mostly under boards or on grass or weeds.

The unique male type of Scudder was from Texas and the known range of $C$. squamosum extends from Long Island, $\mathrm{X}$. Y. southward along the coast to Dunedin, Fla.; westward across Texas and Arizona to the Mojave Desert, Cal., and in the middle west north to northern Colorado, central Nebraska and southern Illinois, three specimens being in the Urbana, Ill. collection taken by Hart and Shiga at Metropolis on the Ohio River in that State. It occurs in both moist and dry situations and ranges from sea lerel to 3,600 feet in elevation. At Cottonwood, Cal. R. \& H. (1912a, 212) found it "common under creosote bushes (Covillea), where among the collected refuse the males were heard shrilly stridulating at dusk and later. The sound produced was an incessant and highpitched zeeee-zeeee-zeeee." Along the Atlantic coast they "have found it under boards and other debris on the ground, usually along the edge of or in forest growth, and almost always in very small numbers. Howerer, at St. Simon's Island, Ga., mrriads 
were found jumping about among the dead leaves and low plants and grasses growing on the sandy soil under" live oaks."

At Lakehurst, N. J. Davis (1909a) found $C$. squamosum in October in the pine woods, and likens its song to a low sounding chink, chink, chink. He later (1914a) took well grown nymphs at East Marion, Long Island on Aug. 2.

The Cycloptilus borealis Bruner $(1891,37)$ is a synonym of $C$. squamosum and the latter has also been recorded from Florida by R. \& H. (1907, 316) as Liphoplus krugii Sauss.

316a. Cycloptilum squamosum zeBRa (Rehn \& Hebard), 1905, 49.

Distinguished from C. squamosum "by its smaller size, relatively more regularly convex dorsal surface of male pronotum, which is less expanded caudad and much shorter. In the female the pronotum is very small and narrows somewhat more cephalad. Proportionally the limbs are shorter and the caudal femora more flea-like. Scaly covering silvery, usually with limbs barred and body spotted and mottled with dark brown scales (Fig. 220.) Length of body, ô and o , 4.9-5.5; of pronotum, ô, 2.4-2.9; ㅇ. 1.5-1.7; of hind femora, $\hat{\delta}$ and $ᄋ, 3.1-3.7$; of ovipositor, $2.7-2.9 \mathrm{~mm}$." (R. \& H. 1912a, 215.)

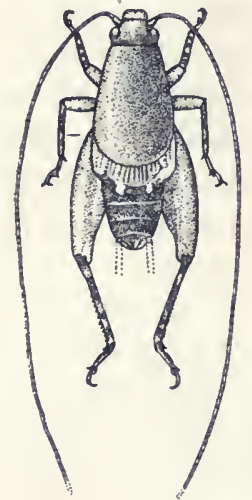

Fig. 220. Male. Dorsal view of type, X ${ }_{\text {Affer R. \& H.) }}$

Miami, Fla. (Davis); Long Key, Fla., Mch. 13 (Hebard.) The differences between this form and typical squamosum are so slight that they cannot be set forth in a key. I regard it as only a depauperate southern race of Scudder's species. Its known distribution is confined to southern Florida, where it has been taken from Lake Worth southward to Key West. R. \& H. (loc. eit.) state that "the entire territory over which this species is known has much of its surface composed of rough coquina rock which is very white. The species is wholly terrestrial and its coloration (as given above) so imitates the surface of the coquina that the little insects are practically invisible when at rest. * * * Nearly all the specimens taken have been found hiding under the coquina boulders on or near the strand. When first exposed they usually remain motionless and closely pressed to the surface of the rock; when disturbed, however, they spring about wildly and are hard to follow with the eye." They state (1914c) that "the song is a faint krik-krik-krik-krik, suggesting that of a species of Nemobius but much fainter." Davis (1914) mentions the taking of 13 specimens on Sept. 23 from under and in the folds of an old pair of trousers lying on the up-beach at Ocean Beach, Miami. 
317. Cycloptilum axtillakum (Redtenbacher), 1892, 218. Antillean Bush Cricket.

Size large for the genus; form rather slender. Reddish-brown, thinly clothed with silvery scales; lateral lobes of pronotum, legs and under surface except abdomen paler; outer and upper faces of hind femora often dusky; abdomen in great part dull black. Interantennal space prominent, rounded and with a narrow and shallow but distinct median sulcus. Eyes ovoid-triangular, set obliquely behind the antennæ. Male with pronotum as described in key; tegmina wholly concealed; anal cerci as long as abdomen; apex of subgenital plate broadly rounded, entire. Female with disk of pronotum distinctly longer than broad, its sides nearly parallel; tegmina invisible, apex of subgenital plate narrowly, acutely emarginate; ovipositor but little shorter than hind femora, straight, its apex sublanceolate. Length of body, $\hat{o}, 6.7-9, \hat{+}, 6.5-9.3$; of pronotum, $\hat{o}, 3.8-$ 4.2 ; ㅇ, $2-2.7$; of hind femora, ô, $4.1-5.5$, ㅇ, $5-6.2$; of ovipositor, $4-5.6$ mm. (Fig. 221.)

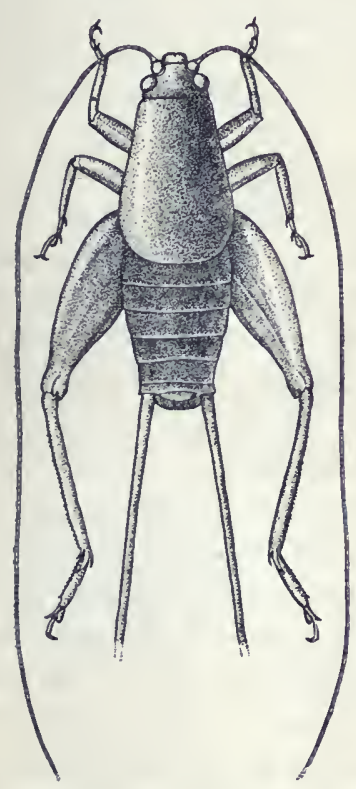

Fig. 221. Dorsal view of male, $X$ 4. (After R. \& H.)

Lake Okeechobee, La Belle, Cape Sable, Key West and Dunedin, Fla., Jan. 29-Mch. 7 (W.S.B.) About Dunedin this bush cricket is in winter much less common than the next, my only adult male having been taken Jan. 29 by beating mangrove on $H o g$ Island. At Cape Sable and Key West it was taken in number's by beating mangrove and other shrubs. It is, in the main, a submaritime species and has been recorded from numerous stations in Florida between Jacksonville and Key West. On the souther'n keys it is especially common on the dahoon holly, Ilex cassine $\mathrm{L}$.

This species was originally described from St. Vincent's Island and is known from the Bermudas, Bahamas and Cuba. In the United States it inhabits the southern portion of the Lower Austral zone from Beaufort, N. Car. as far west as Brazos County, Texas. Over this range it is said by $\mathbf{R}$. \& $\mathbf{H}$. (1912a, 200) to be rather plentiful in bayberry and other heavy bushes, and is sometimes found in numbers on the ground among leaves and low plants under live oaks.

The Liphoplus krugii Sauss. (1897, 232) from Cuba, the Mogosiplistus slossoni Scudder (1897f) from Biscayne Bay, Fla., and the $M$. barbouri Morse $(1905,21)$ from Nassau are placed by 
I. \& H. as synonyms of $C$. antillarum. The majority of the records from Florida have been made under the names of the first two synonyms mentioned. The first specimens from that State were taken by Mrs. A. T. Slosson under bark of fallen trees, and she speaks of them (1901) as "silvery iridescent pearly little creatures, very agile and slippery."

318. Cycloptilum trigonipalpum (Rehn \& Hebard), 1912a, 204.

"Differs from $C$. antillarum in the average smaller size, more graceful build, more pronounced interantennal sulcus and very different terminal joint of maxillary palpi, the edges of which, when viewed from the side, form an isosceles triangle since this joint expands widely distad and is very obliquely truncate. Pronotum proportionally narrower and smaller in both sexes; caudal femora less strongly inflated. Subgenital plate of male very slightly less produced obtuse-angulate; of female semi-ovate, broadly obtuse-angulate at apex. Color very similar to that of antillarum. Maxillary palpi never dárkly suffused; dorsal surface of abdomen wholly black (Fig. 222.) Length of body, ô, 6.8-7.1, $ᄋ, 7.8-8.5$; of pronotum,

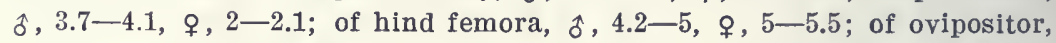
4-6.2 mm." (R. \& H.)

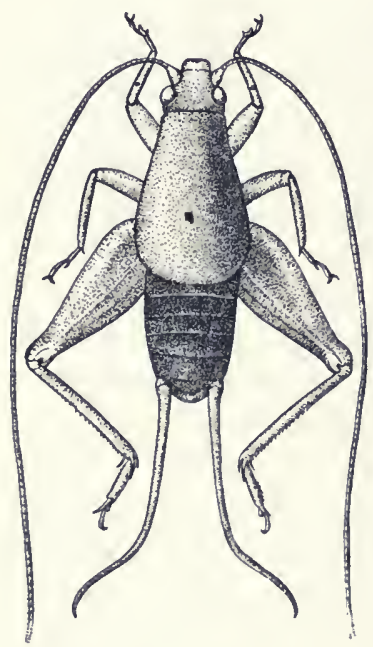

Fig. 222. Dorsal view of male type, $\times 4$. (After R. \& H.)

Dunedin and Cape Sable, Fla., March 2-25 (W.S. B.). About Dunedin the nymphs of this form are frequently taken by sweeping low shrubs during the winter months, and adults by beating oak and bayberry about the middle of March. In two of the males the tegmina are slightly prolonged beyond the pronotum. It is very close to antillarum, the only fixed differential character being that of the form of the terminal joint of palpi. The insects are thickly clothed with nearly transparent seales and in the field they frequently appear to have the black abdomen ringed above with whitish scales at the intersection of the segments.

The known range of $C$. trigonipalpum extends from Petersburg, Va. to Key West, Fla., Agrieultural College, Miss. and the Bahama Islands. It has been taken by Ii. \& H. and Davis at numerous stations in both Georgia and Florida, having been found mainly on the shrubby undergrowth of open pine woods, sometimes beneath the loose bark of trees in hammocks. 
II. Oligacaxthopus Rehn \& Hebard, 1912a, 218. (Gr., "small" + "thorn" + "feet.")

Very small scaly wingless crickets having the head small, horizontal, wider than long, the interantennal protuberance subdepressed, broadls rounded, without a dividing sulcus; antenna rery slender, tapering, twice or more as long as bods; exes triangular-oroid, rather prominent; disk of pronotum depressed, subquadrate, female, slightly longer than wide, male, its sides nearly yarallel, front and hind margins truncate; legs all short; femora unarmed, hind ones feebly dilated; hind tibire heary, short, the upper margins minutely serrulate, and apical fourth with three pairs of vers short spurs; first hind tarsal joint more than half the length of tibire, minutely serrulate above. Males with subgenital plate transverse, its apex broadly curved; anal cerci slender, tapering, rery bristly, as long as hind femora. Oripositor about two-thirds the length of hind femora, rather stout. its apical third sublanceolate with lower margins very finely serrulate. But one species is known.

319. Oligacaxthopus Prograptus Rehn \& Hebard, 1912a, 219.

Size small; form depressed. General color pale brown but hidden everywhere except on front of face with a thick coating of silvery and fuscous scales; face between the antennæ with four vertical dark brown stripes; antennæ and palpi yellowish, their basal portions annulated with fuscous; legs all barred or ringed with fuscous scales; abdomen thickly clothed with similar scales interrupted with many silvery ones. Structural characters as given above. Length of body, of and $\$, 6-6.7$; of pronotum.

L.5-1.7; of hind femora, $3.7-4.2$; of ovipositor, $2.5-3$
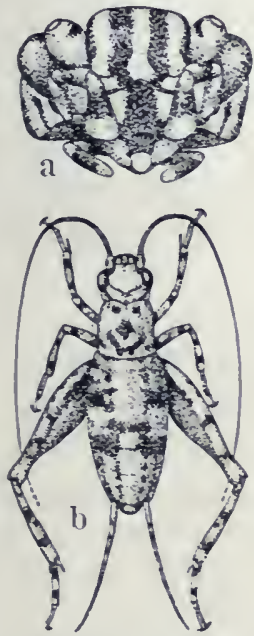

Fig. 223. $a$, Front view of head; $b$. adult male. $\times 4$. $\mathrm{mm}$. Width of pronotum, $1.4-1.6 \mathrm{~mm}$. (Fig. 223.)

Miami, Fla., March (Hebard). Known onlr from Brickell's Hammock, Miami, on the Atlantic Coast and by a single nympl taken by Hebard on Captiva Island, Charlotte Harbor on the Gulf Coast of Florida. Of its habits at Miami Hebard (1915b, 461) says: "A series of 57 specimens was taken March $4-15$ by peeling off loose bark on two typical trees of the hammock jungle, the inkwood, Exothea panieulata Juss. and the pigeon plum, Coccolobis laurifolia Jacq. and on live oaks, Quercus virginiana Mill. Often sereral trees would be thoroughly examined without success, but usually two or three specimens would be found and rarely six or seven, on the same tree. When revealed, the tiny insects either fell with the bark or re- 
mained usually motionless when they could easily be made to jump into the beating net, which was held below the spot under inrestigation to catch the bark and any specimens which might fall with it. Without such use of a net the species would prove very difficult to capture. The insect is apparently wholly nocturnal and individuals probably seldom leave the tree trunks. This latter is indicated by the peculiar silvery general coloration of the insects, mottled and speckled with dark brown, which blends perfectly with the bark of the trees upon which they are found, but which would cause them to be conspicuous under many other environmental conditions."

\section{Subfamily V. GRYLLINÆ. \\ The Ground and Field Crickets.}

This subfamily comprises our most numerous and best known crickets. They are of small or medium size, usually robust and stubby in form and have the head large, vertical or nearly so, vertex broad, rounded into the face; antennx long, setaceous; ocelli three, usually arranged in a very obtuse triangle; pronotum short, subquadrate, its front and hind margins truncate or nearly so; tegmina and wings variable in length; stridulating organ of male furnished with a speculum; fore tibiæ with a tympanum on one or both faces; femora unarmed, hind ones very stout; hind tibire armed above with two rows of spines, without serrations between them, and with six subapical spurs; joints of all the tarsi compressed; anal cerci long, tapering, bristly. Ovipositor variable in length, straight, slender, cylindrical, feebly lanceolate at apex.

About 20 genera of the subfamily are known, six of which are represented in the eastern United States. The principal literature treating of these is as follows: Saussure, 1874, 379, 1877, 226; Eilatchley, 1892, 1900, 1903; Scudder, 1896a, 1896b, 1896c, 1901b, 1902a; Walker, E. M. 1904; Morse, 1905; Lutz, 1908; Hebard, 1913, 1913a, 1915, 1915c; R. \& H., 1915c, 1916.

KEY TO EASTERY GENERA OF GRYLLIN 2.

a. Spines of hind tibiæ long, movable, pilose; last joint of maxillary palpi at least twice the length of the one preceding; basal joint of hind tarsi (in our species) unarmed above; smaller, length of body less than $12 \mathrm{~mm}$.

b. Lower front angle of lateral lobes of pronotum rounded; tegmina of male with a tympanum; hind tibiæ armed above with four spines on each margin and with three subapical spurs on each side.

I. Nemobius, p. 671.

$b b$. Lower front angle of lateral lobes rectangular or acute; tegmina of male without a tympanum; hind tibiæ armed above with 
three spines on each margin and with only two subapical spurs on inner side (Fig. 235, c.)

II. HYgroxemobius, p. 688. $a a$. Spines of hind tibiæ stout, immorable; last joint of maxillary palpi not more than one-third longer than the one preceding; basal joint of hind tarsi serrate above on both margins; larger, length of body rarely under $14 \mathrm{~mm}$.

c. Ocelli arranged in a nearly transverse row; upper inner subapical spur of hind tibiæ as long as the middle inner one; ovipositor very short, scarcely visible.

III. Axurogrylles, p. 690.

cc. Ocelli arranged in an obtuse triangle; upper inner spur of hind tibiæ shorter than the middle one; ovipositor at least half as long as hind femora.

d. Vertex between the antennæ scarcely wider than basal joint of antennæ; lower margin of lateral lobes very short, rounded into both front and hind margins. IV. GrrLlodes, p. 692.

$d d$. Vertex between the antennæ twice or more as wide as basal joint of antennæ; lower margin of lateral lobes elongate, nearly straight.

e. Hind tibiæ not more than two-thirds the length of hind femora, armed above with four or five spines on each mar. gin; fore tibiæ in short-winged forms with a tympanum on outer side only.

V. Miogrylles, p. 693 .

ee. Hind tibiæ three-fourths or more the length of hind femora, armed above with five to eight spines on each margin; fore tibiæ with a tympanum on both outer and inner sides.

VI. Grylles, p. 696.

I. Nemobius Serville 1839, 345. (Gr., "a grove-dweller.")

The Ground Crickets.

Size small, form compact; body and legs sparsely clothed with long bristle-like hairs; vertex rounded into the face; ocelli small, round, arranged in a triangle; ejes oral, prominent; disk of pronotum subquadrate, but slightly wider than head; lower margin of lateral lobes horizontal, its front and hind angles rounded; teg. mina of male usually shorter than abdomen, their tips rounded $\mathrm{or}^{\circ}$ subtruncate, the tympanum with but a single oblique ulnar vein; tegmina of female with a few prominent longitudinal reins and numerous connecting cross-reinlets; wings variable in length, often absent; inner or hind face of fore tibix only with a tympanum; hind femora strongly swollen; basal joint of hind tarsi not sulcate above, armed only at apex with two small teeth and with a long spine on each side, the inner one the longer; cerci of both sexes very slender, tapering, half the length of hind femora clothed with short hairs and long bristles. Oripositor variable as to species.

Of all the Gryllide which occur with us, these little brown ground crickets of the genus Nemobius are the most numerous and the most social. Unlike their larger cousins, the field crickets, 
they do not wait for darkness before seeking their food, but whereever the grass has been cropped short, whether on shaded hillside or in the full glare of the noonday sun along the beaten roadway. nature specimens may be seen by hundreds during the days of exrly autumn. Even the tangled masses of sphagnum mosses and othel semi-aquatic growth of fen and marsh furnish shelter and frod to certain species which, in the ages of the past, have becom! adapted to a life of such surroundings.

They appear to be omnivorous, feeding upon carrion, cow dung and grasses with equal avidity. Though small in size, their enormous numbers, as well as the fact that they are constant, greedy feeders from the time the eggs hatch in spring until laid low by the hoar frost of autumn, renders them particularly injurious. The aggregate damage which they cause to grass and kindred plants in the course of a single season must be great, and there is little doubt but that all species of the genus should be classed among those insects highly destructive to forage plants.

The small size, nearly uniform color and variability in length of tegmina, wings and ovipositor have led to many synonyms among the species of Nemobins. Up to 1900 but four species were known from the Eastern States. In that year I described three additional ones from Indiana, and a fourth in 1903 . Hart, Walker, Caudell and Hebard have
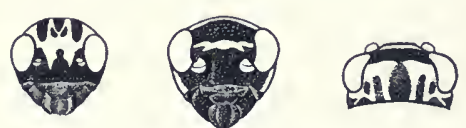

Fig. $\begin{aligned} & a \\ & 224\end{aligned} \quad$ Color pattern of face and head of Nemobius. a, grisens, b, c, ambitiosus, $\times$ 4. (After Hebard.) since described other forms. Hebard in his Rerision (1913) placed several of the previously known forms as synonyms or varieties, and recognized 12 species and seven races or varie-

ties from America north of Mexico. In the present work most of his conclusions have been adopted and the following key is based largely upon the one prepared by him.

KEY TO EASTERN SPECIES OF NEMOBIUS.

a. Lower pair of apical spurs of hind tibiæ unequal in length, the inner one much the longer; apex of ovipositor with only the upper margin serrulate.

b. Ovipositor straight or nearly so, at least as long as, or barely shorter than hind femora (except in the race funeralis.)

c. Ovipositor distinctly longer than hind femora (except in races socius and funeralis); black markings of body not scattered in blotches and dashes to give a mottled appearance; wings often fully developed.

d. Face below the antennæ not a uniform shining piceous; general color without a grayish suffusion. 
e. Ovipositor longer than hind femora; species of northern range.

f. Occiput with four dark stripes; general color rusty black to sooty brown; larger, length of body, males $7.5-10$, females, 8-11 $\mathrm{mm}$.

320. FASCLATUS.

ff. Occiput without evident black stripes; general color very dark; smaller, males, 6.7-8, females, 7.3-9 $\mathrm{mm}$.

320a. ABORTIVUS.

$e e$. Ovipositor no longer than hind femora; species of southern range; color and size of fasciatus. $320 \mathrm{~b}$. socrus.

dd. Face below the antennæ a uniform shining piceous (Fig.

$224, a)$; general color with a grayish suffusion; lateral margins of dorsal field of male tegmina narrowly yellow.

g. Oripositor much longer than hind femora; distribution northern.

321. GRISEUS.

gg. Ovipositor nearly one-third shorter than hind femora; distribution southern and southwestern. 321a. FUNERALIs.

$c c$. Ovipositor no longer than hind femora; black markings, especially in females, scattered to give a mottled appearance; brachypterous, wings absent.

$h$. Head without an ivory-white bar between the eyes; hind femora without two lengthwise fuscous stripes; general range northern.

322. Maculatus.

$h h$. Head with a narrow white cross-bar between the eyes, this bordered above with a wider shining black one (Fig. 224, $b)$; hind femora usually with two fuscous stripes; general range southern.

323. A arbitiosus.

$b b$. Ovipositor evidently but not strongly curved, about two-thirds as long as hind femora (Figs. 229, 231.)

i. Larger, length of body, male, rarely under $6 \mathrm{~mm}$.; color not a uniform pitchy brown; habitat not confined to sphagnum bogs.

j. Pronotum and femora clay-yellow mottled with fuscous; wings absent; apex of ovipositor armed above with rather stout, very sharp teeth; general range northern.

324. VARIEGATUS.

jj. Pronotum and femora not distinctly mottled with fuscous; wings usually present and longer than abdomen; ovipositor armed with very fine, close-set teeth; general range southern.

$k$. Occiput without a narrow dark cross-line; tegmina of females as long as abdomen, their tips narrowly rounded; general color dark brown, not distinctly mottled.

325. cUBENSIS.

$k k$. Occiput with a narrow dark cross-bar behind the eyes; tegmina of female about three-fifths the length of abdomen, their tips subtruncate; general color paler brown mottled with fuscous.

325a. MorMoNIUs.

ii. Smaller, length of body, male, rarely more than $5.8 \mathrm{~mm}$.; general color uniform piceous (rarely, southern specimens, dull 
yellow with only the tegmina piceous); habitat confined to sphagnum bogs.

326. PALUSTRIS.

aa. Lower pair of apical spurs of hind tibiæ equal in length; apex of ovipositor with both upper and lower margin serrulate, the teeth of the latter very fine and widely spaced (Figs. 233, 234.)

l. Last two joints of maxillary palpl not wholly white; general color pale brown; dorsal surface of abdomen of female dark brown with three rows of paler spots.

327. CAROLINUS.

ll. Last two joints of maxillary palpi pure bone-white; general color very dark brown; dorsal surface of female abdomen without pale spots.

328. confusus.

320. Nemonius fasciatus (DeGeer), 1773, 522. Striped Ground Cricket.

Size large for the genus. General color dark reddish-brown to dusky black; head and pronotum usually darker than the other parts; occiput with four more or less distinct blackish stripes; tegmina in great part, lower part of lateral lobes and cheeks pale brownish-yellow; nymphs usually with a median dorsal dark stripe on abdomen and a broad dark band on lateral lobes. Pronotum about one-third wider than long, its bristly hairs very numerous. Tegmina dimorphic in length, nearly as long as hind femora and reaching nearly to tip of abdomen in both sexes (fascia$t u s$ ), often one-half shorter and reaching only the middle of abdomen in female (vittatus). Wings also dimorphic, surpassing tip of ovipositor in macropterous female, represented by mere scales in brachypterous one. Ovipositor, rigid, straight, apical fourth very feebly sublanceolate at tip, with upper valves serrulate above. Length of body, of, 7.2-10.6, ㅇ, 811.5 ; of pronotum, $\hat{\delta}, 1.8-2.1, \uparrow, 1.7-2.4$; of tegmina, $\hat{\delta}$ and $\$$, long form, 7-7.5, short form, $\hat{\delta}, 4.1-5.5$, ㅇ, 3.7-6.1; of hind femora, $\hat{\delta}, 5.7-$ 7.6, , 6-8; of ovipositor, 6.8-9.4 mm. (Fig. 225.)

The long-winged or typical form of this ground cricket is much less common in Indiana than the short-winged one. I have

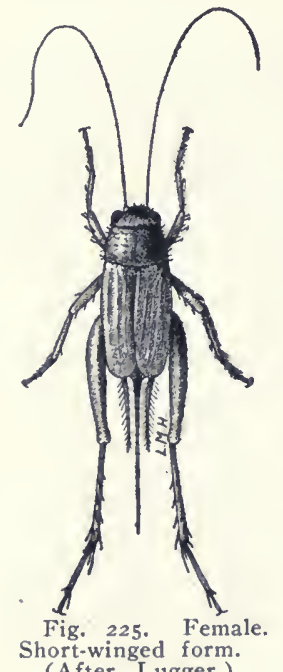

(After Lugger.) taken it in the field on but two or three oceasions, and then in small numbers on the stems of tall grasses about the margins of marshes. However, many have been taken from the walks and streets of Indianapolis, Fort Wayne and other cities and towns in the northern part of the State, but none, as yet, in the sonthern half, not even in Terre Haute, where I resided for seven years. Where the long-winged form breeds, and feeds by day is to me unknown. It appears to reach maturity about July 15th as, at times, in the first week in Angust, swarms composed of myriads have appeared about the lights of some of the cities. The newspapers the next day had a column or more deroted to the insects but nothing, except wild guesses, as to whence they came. 
The short winged form (vittatus) begins to reach maturity in central Indiana about July 15th. Living specimens have been seen as late as December 1st. Although present in rast numbers, but little is known of its life habits. When disturbed ther are very difficult to capture, making enormous leaps with their stout hind legs, no sooner striking the ground than they are up again, even if not pursued, until they find a leaf or other shelter beneath which to take refuge.

The known range of $\lambda$. fasciatus is a very wide one, extending from Nora Scotia and New England, west to Manitoba, Wyoming and Utah, and south and southwest to Tennessee, central Georgia, Arkansas and New Mexico. Trest of Manitoba typical fasciatus is replaced by its northern race abortixus Caudell, and south of North Carolina and central Georgia by the southern race socius Scudder. It is recorded as common wherever found and in number of individuals is perhaps the most abundant of all our eastern Crthoptera.

Piers $(1918,331)$ sars it is one of the most numerous species of Orthoptera in Nova Scotia, all the specimens noted, however, being the short-winged form.

"Around Halifax they begin to reach maturity about July 20, but the males do not commence stridulating till a fortnight later. At first a few are heard and only at night and so very faintly as to be all but inaudible except to a trained ear. In a few days they may be heard in daytime as well as at night and the notes become more noticeable. They are last heard at Halifax about Nov. 10, ** some of them surviving as many as four ice-forming frosts, frozen ground and even evanescent snow falls.

"The stridulation or shrilling note of the male is produced by the insect lifting the wing-covers about $45^{\circ}$ above the body, and then shuffling them very rapidly together so as to ribrate the resonant organ at their base; thus producing a trilling sound or tremolo, of a prolonged character, resembling the syllable ple-e-e-e, ple-e-e-e. ple-e-e-e, repeated at rather short intervals or sometimes continued for several seconds or even much longer. The sound has a peculiar silvery timbre, and when myriads are shrilling all over the fields at night, or on fine days in late autumn, when other sounds are hushed and the air filled with the mystic charm of the hour or season, it produces a peculiarly drowsy, ceaseless tremor, pulsation or 'shimmer' of sound which is very familiar and loved by all dwellers in the country. It is, however, ineffably associated with a sad feeling that summer is on the wane or past, for it is our most characteristic autumnal sound in grassy places, and is linked with the sight of golden-rods and purple asters and the odour of falling leaves."

Scudder (1S68a) has set the note of the male to scale and sars: "The chirping of the striped cricket is very similar to that of the 
black field cricket; and may be expressed by $r-r-r-u$, pronounced as though it were a French word. The note is trilled forcibly, and lasts a variable length of time. One of these insects was once observed while singing to its mate. At first the song was mild and frequently broken; afterwards it grew impetuous, forcible and more prolonged; then it decreased in volume and extent until it became quite soft and feeble. At this point the male began to approach the female, uttering a series of twittering chirps; the female ran away, and the male, after a short chase, returned to bis old haunt, singing with the same vigor but with more frequent pauses. At length, finding all persuasions unavailing, he brought his serenade to a close."

Allard (1910) states that throughout October and early November " $N$. $f$. vittatus fairly swarms in the grass fields and pastures of much of New England," but he had never taken there the long-winged one. Around Washington, D. C. he found the two forms intermingling in some localities, and in others the longwinged one wholly absent. He adds:

"About Oxford, Mass., two singing forms of $N$. $f$. vittatus are very common. The stridulation of one of these is a very high pitched, prolonged trill, $t i$-ti-ti-ti-ti-ti-ti-ti-ti; that of the other form is a very brief, shrill, intermittent tiiii-tiiii-tiiii. A considerably lower pitch quite sharply distinguishes the brief intermittent notes, tiiii-tiiii, from the prolonged trill. These two trilling forms of vittatus are quite definitely confined in separate colonies, and in different localities. The prolonged trilling form occupies almost exclusively the dry, grassy upland fields and pastures. In the damp and marshy low grounds in fields and pastures this form is replaced almost entirely by pure colonies of the intermittent trilling form. Only where the wet and dry conditions overlap is there a noticeable intermingling of the two forms. At Oxford this is the most abundant insect of late autumn, and continues to trill in the fields until overcome by the keen, freezing nights of November."

The known syuonyms of $N$. fasciatus are Acheta hospes Fab. (1775, 281) ; Acheta vittata Harris (1835, 576), the short-winged form above mentioned; Nemobius exiguus Scudder $(1862,429)$ and $N^{\top}$. utahensis Scudd. 1S96a, 103). The $N$. canus Scudder of my former work $(1903,423)$ is also placed by Hebard as only a pale form of $N$. fasciatus, the true $N$. canus being a synonym of $N . f$. socius scudd.

320a. Nemonius fasciatus abontivus Caudell, 1904b, 248.

Smaller than typical fasciatus. Color darker, in some specimens almost black; tegmina transparent sooty brown, the main veins darker, the lateral or costal field blackish, not pale as in fasciatus; femora usually black; dorsum of abdomen dark brown. Tegmina shorter than hind femora. Ovipositor with apex enlarged for a shorter distance and serrate 
as in fasciatus. Length of body, $\hat{\delta}, 6.7-8, \uparrow, 7.3-9$; of tegmina, $\hat{\delta}$, $4.3-5.8$,,$~ 3.1-4.6$; of hind femora, $\delta, 4.9-5.5, \&, 5.4-6.2$; of ovipositor, $6.2-7.4 \mathrm{~mm}$.

Moose Jaw, Assiniboia, Aug. 24 (Caudcll). This small dark form of $\mathbf{X}$. fasciatus is included in this work on the Ft. William, Ont., record of E. M. Walker $(1911,304)$ who states that: "The specimens were confined to a small sandy area thinly clothed with grass and weeds. They were rer's small and the stridulation was a low continuous trill differing from that of typical fasciatus. It is thus possible that this form is specifically distinct." He also states (1910, 354) that a series of abortivus from Aweme, "show great variation in color and length of tegmina and ovipositor. Some individuals approach $\mathrm{N}^{\top}$. maculatus Bl. from Indiana in all of these character's and are scarcely distinguishable except by the longer and more numerous hairs of the jronotum, but as a rule the ovipositor is distinctly longer than in $\mathrm{N}$. maculatus."

Caudell's types were from Moose Jaw where he found them "hopping actively about in the grass in and along the border's of a draw or small hollow in the prairie." Hebard (1913, 429) gives the distribution as "the prairie region of Manitoba, Saskatchewan and Alberta and the adjacent portions of the United States. Only brachypterous individuals are known."

320b. Nemobius fasciatus socius Scudder, 1877, 37.

Size and form of typical fasciatus. Color same as there, ranging from pale reddish (canus Scudder) to fuscous-brown, the dark stripes on occiput often wanting in very pale or very dark specimens. Differs from fasciatus only in having the ovipositor as short as or shorter than the hind femora. "Nearly allied to our common N. vittatus with which it agrees in size, although a little slenderer; tegmina, however, much longer and ovipositor proportionally a little shorter." (Scudder.)

Lake Okeechobee, Ft. Mrers, Lakeland, Sarasota and Dunedin, Fla. (W. S. B.) ; Thomasville, Ga. (Hebard) ; Dallas, Tex. (Boll.) About Dunedin both adults and nymphs occur throughout the winter among the low grasses and beneath boards and logs along the borders of ponds and low marshy places in open pine woods. Recorded from numerous localities on the mainland of Florida but not as yet from the southern keys.

The range of this form, which is so close to $N$. fasciatus that it is hardly worthy a distinctive name, extends from North Carolina and Tennessee south throughout Florida, west to Brownsville, Texas and north to Arkansas and Oklahoma, where it merges into typical fasciatus. It appears to be nowliere so abundant as is fasciatus vittatus in the north and macropterous individuals are 
said to be more numerous than short-winged ones, though this is not true in the series at hand from Florida.

Hebard has placed both the $N$. canus and the male of $N$. aterimus of Scudder $(1896 a, 103,105)$ and also the $N$. hastatus Sauss. $(1897,221)$ as synonyms of $N . f$. socius. Of canus, described from Texas, Scudder states: "This is possibly only a geographic race of fasciatus remarkable for its cinerous aspect and the striped appearance of the female tegmina." A female cotype from Dallas, sent me by Scudder, has the ovipositor fully as long as in fasciatus and there is little doubt but that fasciatus, vittatus, socius, canns and abortivus should all be merged under DeGeer's name. The trinomial names are retained here only that the student may thus label his specimens if he so desire.

\section{Nemobius griseus E. M. Walker, 1904, 182. Gray Ground Cricket.}

Size rather small; form moderately slender. Dull reddish-brown covered with fine, short closely appressed gray or brown hairs; occiput dull yellow with three dark fuscous stripes; face piceous; maxillary palpi reddish-brown, the terminal segment fuscous; lateral lobes of pronotum dark brown their lower margin yellowish. Tegmina translucent, the dorsal field pale brownish-yellow, often with a few fuscous blotches near base, in male narrowly margined with pale yellow; lateral field in great part fuscous. Femora fuscous-brown with numerous small pale spots. Abdomen above with a median row of large fuscous spots. Disk of pronotum about one-fourth wider than long, sparsely clothed with long black bristles, its front half or more with a distinct impressed median line. Tegmina of male covering three-fourths or more of abdomen, in repose forming an oblong quadrangle with sides very feebly converging from base, their tips broadly rounded; of female more than half as long as hind femora with tips broadly obliquely rounded. Wings absent. Ovipositor stout, straight; apical sixth feebly swollen, finely serrulate above. Length of body, $\hat{\delta}$, $6.8-8, \hat{q}, 7.6-8.2$; of pronotum, $\hat{o}, 1.4-1.8$, 우 $1.6-2.1$; of tegmina, $\hat{o}$, $4-4.9$, ㅇ, ,2.8-3; of hind femora, $\delta, 4.9-6$, ㅇ, $5.7-6.9$; of ovipositor, 7.2-8.9 mm. (Fig. 226.)

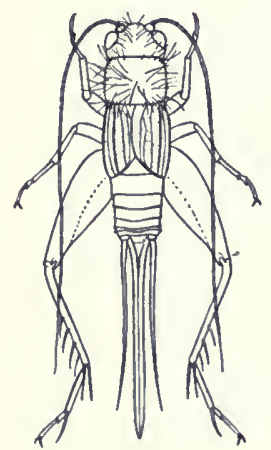

Fig. 226. Female, $\times$ (After IIebard.)

Toronto, Ontario, Aug. 9-16 (Walker). Vigo and Crawford Counties, Ind., Sept. $4-$ Oct. 9, three males $(W . S \cdot B$.$) . The Indiana$ specimens are in part treated by me (1900, 54; $1903,425)$, upon the authority of Scudder, as N. cubcnsis Sauss. Hebard $(1913,434)$ has placed them as griscus. They differ from typical male Ontario griscus in being less gray and lacking the fuscous blotches on base of tegmina. in the distinct yellow discoidal veins of ter. mina, and in the single Craw ford County one being much larger, it furnishing all the maximum measmements for that sex above given. 
As I have no Indiana female. I have adopted Hebard's conclusions. Those from Vigo County were taken from the sandr bed of the old canal five miles north of Terre Haute.

Of his types Walker (loc. cit.) wrote: "This is a well marked species, easily distinguished from $N$. fasciatus by its much smaller size, grayish coloration, more distinct dark markings and longer ovipositor. It occurs only on sandy soil where the regetation is somewhat scanty. The pale colors render it very inconspicuous against the sand. The chirp of the male is a feeble continuous trill, more high pitched and much shorter than that of fasciatus."

N. griscus has been recorded only from central eastern Ontario, Maine, Massachusetts and the Indiana localities abore giren. A single long-winged female was taken by Walker. It is closely allied to fasciatus, its xerophytic habitats having produced slight color and structural changes which are probably sufficient to retain its specific standing.

321a. Nemobius griseus funeralis Hart, 1906a, 159.

"Differs from $N$. griseus only in its darker coloration, more obscure color pattern and much shorter ovipositor, the latter being but little over three-fourths the length of caudal femur." (Hebard.) Length of body, $\hat{\delta}, 8.9$, ,, $7.9-9.2$; of pronotum, $\hat{\delta}, 2, q, 1.7-1.9$; of tegmina, $\hat{\delta}, 5.8$, , $2.7-3.8$; of hind femora, $\hat{\delta}, 6.6$, ㅇ, $5.6-6$; of ovipositor, $4-4.4 \mathrm{~mm}$.

Hart's unique female trpe was taken Dec. 26, at College Station, Tex. It is placed as a southern race of griscus by Hebard $(1913,437)$. R. \& H. $(1916,288)$ have recorded a single female from Macon, Ga., and a male from Winslow, Ark.

\section{Nemobius maculatus Blatchley, 1900, 52. Larger Spotted Ground Cricket.}

Size medium for the genus; form robust. Dark brown with a yellowish suffusion, more or less dotted with piceous, especially on occiput, cheeks, disk of pronotum and hind femora; occiput with a narrow median yellowish line and another about the eyes; maxillary palpi reddish-brown, apical half of terminal segment fuscous; tegmina of male with dorsal field translucent brown, the discoidal vein narrowly ivory-white; lateral field and upper two-thirds of lateral lobes in both sexes dark brown. Head rather large, as wide as pronotum. Disk of pronotum about two-fifths wider than long, feebly narrowing from base to apex, its front margin and lateral lobes sparingly beset with stiff black bristles. Tegmina of female less than half as long as hind femora, covering one-third of abdomen, their tips both of dorsal and costal fields obliquely subtruncate and meeting at an angle, the longitudinal veins prominent, cross veinlets feeble; those of male covering two-thirds of abdomen, their tips broadly obliquely rounded. Ovipositor straight, the apical sixth tapering evenly to the acute tip, finely and sharply serrulate above (Fig. 227.) Length of body, $\hat{\sigma}$, 
$6.5-8.4$, ㅇ, 7.5-9; of pronotum, ô, 1.8-2, ㅇ, 1.9-2.2; of tegmina, ô,

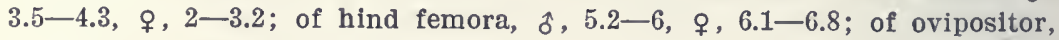
$5-6.8 \mathrm{~mm}$. (Fig. 228.)

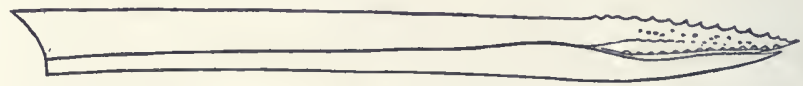

Fig. 227. Ovipositor of N. maculatus, $X$ 12. (After Hebard.)

This handsome mottled species occurs sparingly throughout Iudiana, frequenting for the most part low, dry open woods and borders of thickets. In Marion County I once found it quite frequent on October 6 amongst dead leaves and beneath logs where the ground ivy, Nepeta glechoma L., covered most of the earth. A week later, a heavy hoar-frost meanwhile intervening, not a specimen could be found.

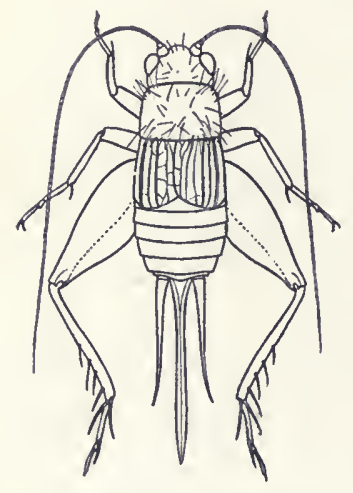

Fig. 228. Female, $\mathrm{X} \quad 3$.

From the short-winged form of $N$. fasciatus this species is readily distinguished by its average smaller size, shorter tegmina of female, shorter and straighter ovipositor, fewer hairs on head and pronotum and finer cross-veinlets of female tegmina. The serrulations of the ovipositor are sharper than in fasciatus. The two also differ in color, the ground of maculatus being paler and the piceous more generally sprinkled where in fasciatus it is in lengthwise bars.

The known range of $N$. maculatus extends from New Canaan, Conn. and Long Island, N. Y. west to northern Indiana and south and southwest to Maryland, Virginia, Raleigh, N. Car. and Rabun Co., Ga. It is not definitely recorded from any locality in Illinois or Michigan, though it doubtless occurs in the former and probably in the latter State. Walker's record $(1904,185)$ from Tobermory, Ont. is said by Hebard to be based upon a small fasciatus. It has been taken at several stations in Ohio and at Clarksville, Tenn. About Washington, D. C. it is said to be common, but Fox records only a single female from Tappalıannock in his Virginia paper. No raacropterous specimens are known.

323. Nemobius ambitiosus Scudder, 1877a, 81.

Size small; form compact, robust. Dark reddish-brown; males often with a yellowish and females with a grayish tinge. Head vertically compressed, the occiput very convex, reddish-brown, with a broad shining 
black bar between the eyes; face also shining piceous, sharply separated from the black above by a narrow ivory-white bar (Fig. 224, $b, c$ ); last joint of maxillary palpi fuscous, the preceding one dull yellow. Tegmina of male piceous with the narrow margins (discoidal veins) and extreme tips pale yellow. Legs reddish-brown flecked with fuscous; outer face of hind femora with two fuscous stripes, the lower one the more distinct: basal third or more of dorsum of abdomen piceous, the remainder dark brown. Disk of pronotum subquadrate, very slightly wider than long. Tegmina of female often in great part buffy, flecked with darker brown, less than half as long as hind femora, the tips of dorsal field obliquely rounded; those of male covering three-fourths or more of abdomen, and forming an even oblong quadrangle with sides parallel and tips broadly rounded, wings absent. Ovipositor straight, its apex not thickened, finely serrulate above. Length of body, $\hat{\delta}, 5.9-7.8, \uparrow, 6-8.2$; of pronotum, $\hat{\delta}$, $1.2-1.9$; $q, 1.6-2.1$; of tegmina, $\hat{\delta}, 3.2-4.5$,,$+ 2.2-3.3$; of hind femora, ô, 4.8-6, ㅇ, 4.9-6.3; of ovipositor, $4-6 \mathrm{~mm}$.

Ormond, Ft. Reed, Lake Istokpoga, Ft. Myers, Sarasota, Lakeland and Dunedin, Fla. (W.S.B.) ; Macon, Ga. (Fox). I first saw this handsome and well marked little cricket at Ormond in March 1899 where it was frequent among dead leares and short glasses along the roadways, hedge-rows and borders of the pine woods: About Dunedin it is by far the most common of the three ground erickets there taken, both nymplis and adults occurring in numbers throughout the winter, especially among and beneath the dead leaves and other debris in dry sandy open oak and pine woods. The numerous records by other collectors show that it occurs in like situations throughout the mainland of the state, adults being found during every month of the year.

The known range of ambitiosus is limited, extending from eastern South Carolina and northern Georgia south to Homestead. Fla. Only the brachypterous form is known. Allard (1911a, 156) describes its habits and song in northern Georgia as follows: "This pretty Nemobius is the first species to appear at Thompson's Mills and dwells among leares in deciduous woods. It is especially common on a warm, heavily wooded slope bordering a small brook just east of the settlement. The trill is very brief, high-pitched and shrill, tiiiiiii-tiiiii-tiiiiiii-tiiiiiii. . It is one of the commonest species of Nemobius in this vicinity and begins to stridulate as soon as spring opens in March and April. In April, 1910, very cold periods of weather with considerable sleet and snow completely silenced these hardy crickets. Notwithstanding this inclement weather these crickets were always in active stridulation as soon as the days became warmer." 
324. Nemobius variegatus (Bruner), 1893a, 32. Smaller Spotted Ground Cricket.

Size medium; form robust. Dull clay yellow, mottled with blackishbrown; face below the antennæ shining dark brown; occiput, disk of pronotum and femora mottled with fuscous; apical half of terminal segment of maxillary palpi brown; tegmina translucent brownish-yellow, the upper third of lateral field with a blackish bar; dorsal field in female often with black fleckings; the mottled appearance sometimes due, however, to the black of dorsal surface of abdomen shining through them. Head large, rounded, as wide as pronotum, both it and the latter with scattered long bristly black hairs. Pronotum nearly one-third wider than long, its apical two-thirds with a feebly impressed median line. Tegmina of male as long as hind femora, reaching tip of abdomen; those of female covering half the abdomen, their tips broadly obtusely rounded. Wings absent. Ovipositor dark brown, a little upcurved, moderately stout, the apical serrulated portion longer than usual, nearly one-fourth the entire length, the teeth rather stout with sharp tips (Fig. 229.) Length of body, $\hat{o}, 6.4-7.5$, ㅇ, $6.6-9.4$; of pronotum, $\hat{o}, 1.4-1.7$, ㅇ, $1.9-2$; of tegmina, $\hat{o}, 3.9-4.4$, 우, 2.8-3.7; of hind femora, $\hat{o}, 4.7-5.6$, ㅇ, $6-6.7$; of ovipositor, $3.4-4.1 \mathrm{~mm}$.

Marion, Vigo, Put-

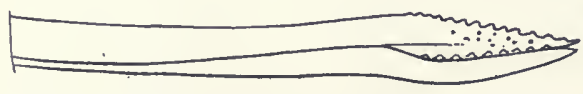

Fig. 229. Ovipositor of $N$. variegatus, $X 14$. (After Hebard.) nam and Knox counties. Ind., Oct. 1-27. In Indiana this prettily marked little species

has been found to be rather common on the grass-covered banks of streams and along the fence rows of open woods in the counties mentioned and it probably occurs in like situations throughout the sonthern two-thirds of the State. In general appearance it is a diminutive form of $N$. maculatus above described, but its small size and short arcuate ovipositor at once distinguish it.

This is the $N$. carolinus Scudd. of my former works $(1900,1903)$, it having been so named for me by Scudder from specimens sent him for examination. As shown by me $(1903,427)$ it was also regarded as the species called Cyrtoxyphus? varicgatus Bruner. Hebard has shown that the true $N$. carolimus is a different insect and has redescribed $(1913,452)$ the present species as $\lambda$. bruneri, claiming (p. 455) that Bruner's name "was unidentifiable from the literature." - In a previous letter (Jan. 16, 1913) he wrote: "This species must be called Ncmobius varicgatws (Brun$\mathrm{er}^{\circ}$ ) as this is the earliest description and the type specimen is in my collection. Bruner called it a Cyrtoxyphus which caused it to be overlooked." While Bruner's mention of the species is admittedly very brief he said: "I have given it the name variegatus on account of its being variegated," and as it was the only variegated form of Nemobius at that time known I lave restored his name. 
The known range of $\lambda$. variegatus extends from Maryland and Virginia west to northeastern Nebraska and south and southwest to Charlotte, N. Car. and Wichita, Kansas. It appears to be rery late in reaching maturity, all of the Indiana specimens having bcen taken in October, and none of the adults recorded elsewhere from our territory earlier than Sept. 6. No macropterous individuals are known.

\section{Nevobics cubexsis Saussure, 1874, 384. Cuban Ground Cricket.}

Size small and form slender for the genus. Dull brownish-yellow; occiput, pronotum and tegmina fuscous brown, often with small paler markings; dorsal surface of abdomen black; cerci brown. Head as wide as base of pronotum, compressed vertically. Disk of pronotum evidently but feebly narrowed from base to apex, about one-third wider than long, sparsely clothed with long black bristles. Tegmina in both sexes nearly or fully as long as abdomen, those of male forming in repose an oblong quadrangle with sides feebly converging from base, their tips rounded; of female slightly narrowed toward apex, their tips narrowly rounded. Wings usually fully-developed, twice as long as tegmina and surpassing tip of ovipositor $2-3 \mathrm{~mm}$.; sometimes absent. Ovipositor feebly curved, its apex sublanceolate with tips very finely serrulate abore (Fig. 230.) Length of body, $\hat{\delta}, 5.7-7.2$, ᄋ, 5.6-7.4; of pronotum, $\hat{\sigma}, 1.2-1.7$, ᄋ, 1.3-1.7; of tegmina, $\hat{o}, 3.9-4.8$, $\uparrow, 3-4.9$; of hind femora, $\hat{o}, 4.2-5.6, \uparrow, 4.7-5.6$; of ovipositor, $2.7-4 \mathrm{~mm}$.

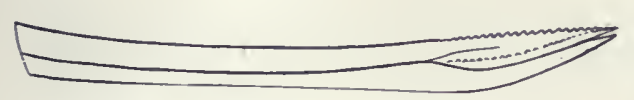

Fig. 230. Ovipositor of $N$. cubensis, $X 17$. (After Hebard.)

O r m o n d, LaBelle and Lake Okeechobee, Fla., Ifch. 6-Apr. 13 (TV. S. B.) ; Washington, D. C., Aug. $2 \mathrm{~S}$ (Caudell). In Florida it has been recorded from numerous points throughout the mainland but not from the southern kers. The general distribuation in our territory is southern and submaritime, extending from Staten Island, N. Y. to Homestead, Fla. It was originally described from Cuba, Mexico and Brazil.

The long-winged or typical form of eubensis is more generally known than the short-winged one as most of the specimens in collections were taken at light. R. \& H. (1912) found the brachypterous form in numbers March 17 in the high grass of the everglades at Homestead, Fla., and Hebard (1915b) records the shortwinged form from bare muck in a red mangrove swamp at Cape Florida and Key Biscarne. Fox found a single female at Tappahannock, Va., on a road through a tidal marsh, so that the natural home of the species is probably in or among the tall grasses of marshes and tidal flats. 
The $N$. volaticus Scudd. $(1877,36)$ and the female of $N$. aterrimus Scudd. (1896b, 432) are synonyms of $N$. cubensis.

325a. Nemobius cubensis mormonuus Scudder, 1896a, 106. Mormon Ground Cricket.

General color as in key but exceedingly variable; pronotum dull yellow usually distinctly blotched with fuscous; tegmina of female with the veins, a humeral stripe and costal margins pale. Last joint of maxillary palpus one-half longer than fourth. Ovipositor longer than head and pronotum together. Length of body, $\delta$ and $\$, 6.5-8$; of tegmina, $3-4$; of hind femora, 5-5.8; of ovipositor, $3.5-4 \mathrm{~mm}$.

This western form is here included on the record given by $\mathrm{He}$ bard of a single female taken by F. M. James at Biloxi, Miss. Its known range extends from that point to the Pacific coast, north to St. George, Utah (type locality) and south to the state of Tabasco, Mex. A macropterous female at hand from Yuma, Cal., is notably paler than cubensis but otherwise appears very similar. The great majority of known specimens are brachypterous.

Hebard $(1913,466)$ says that "in the desert regions of the southwestern United States this insect is but very occasionally met with in the short grasses growing near streams and other restricted damp areas but in the semi-arid mesquite region of Texas it is widely distributed in the short grasses. Still farther eastward it is found in the typical undergrowth of the long-leaf pine forests. The macropterous form is scarcely ever encountered except at light."

\section{Nemobius Palustris Blatchley, 1900, 53. Marsh Ground Cricket.}

Size very small; the body of male especially short and broad; female more slender. Head, tegmina and body of most specimens a uniform dark piceous; disk of pronotum piceous or fuscous sprinkled with piceous; antennæ, legs and ovipositor fuscous; maxillary palpi yellowish except the apical joint which is wholly piceous. Disk of pronotum one-third broader than long, the sides subparallel, rather thickly beset with stiff black bristles, as are also the occiput and dorsal surface of fore and middle femora. Tegmina of female covering slightly more than half the abdomen, their tips broadly rounded; of male forming an elongate quadrangle with sides

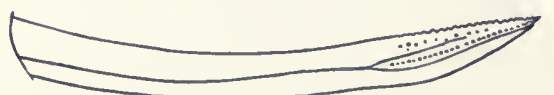

Fig. 23I. Ovipositor of $N$. palustris, $X \quad$ I 5 . (After IIebard.) distinctly but feebly converging from base, the tips more narrowly rounded. Ovipositor distinctly though feebly arcuate, the apical fifth but little enlarged, above very finely and closely serrulate with dull, rasp-like teeth (Fig. 231.) Length of body, $\hat{\delta}, 5.2-6.2$, $\&, 6-6.8$; of pronotum, $\hat{o}, 1-1.5$, $\&$,

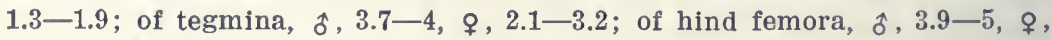
$4-5.4$; of ovipositor, $3.1-3.8 \mathrm{~mm}$. (Fig. 232.) 


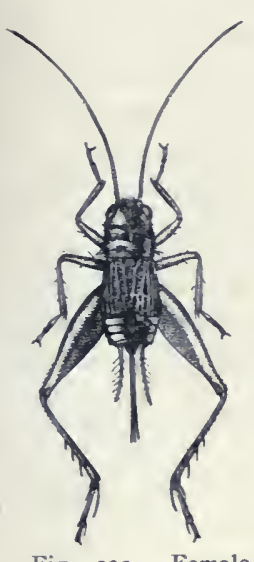

Fig. 232. Female. $\times 3 . \quad$ (Original.)

In Indiana this handsome little pitch brown cricket has been found onls among the tamarack swamps and cranberry bogs of the northern counties, where it finds a congenial home in the midst of the dense, damp sphagnum mosses. Sometimes they are so plentiful that a half dozen or more are seen in an area a foot square. Like the other members of the genus they are very active, when disturbed leaping vigorously, a few inches at a time, and finally seeking safety by burrowing in the masses of mosses. It has been taken in Marshall, Fulton and Starke counties and probably occurs wherever peat bogs and sphagnum mosses are present.

The known range of this little marsh cricket extends from northern New England and Algonquin Park, Ontario, west to northern Indiana and south and southwest to Washington, D. C., Wilmington, N. Car. and Thomasville, Ga. Morse (1919a) says it is "locally common in sphagnum bogs at Orono, Me., in eastern Massachusetts and Connecticut." Walker $(1904,185)$ records the finding of a colony in a floating sphagnum bog at Algonquin Park, Ont. "They were present in numbers but were difficult to capture. By pressing the masses of sphagnum down under water it was often possible to bring the crickets to the surface. My attention was first called to them by the chirp of the male which is a continuous and rather feeble trill."

- R. \& H. (1911, 597) have described a form of $\mathrm{N}$. palustris taken in a sphagnum bog at Thomasville, Ga. as a geographic race under the name of $N . p$. aurantius. Specimens at hand from the Davis and Hebard collections show it to differ only in having the ground color reddish-brown, the tegmina and upper surface of abdomen alone piceous-brown. In my opinion it is, as doubtfully suggested by Hebard $(1913,472)$, only a "mere color variety" of palustris.

327. Nemobius Carolixus Scudder, 1877, 36. Carolina Ground Cricket.

Size medium; body slender. Antennæ, head, pronotum and femora brownish-yellow; maxillary palpi pale yellow throughout or with apical third of terminal joint fuscous. Tegmina brownish-yellow with a narrow piceous bar on upper third of lateral field and basal third of dorsal field often more or less piceous, male; dorsal field usually heavily shaded with blackish, female; upper surface of abdomen blackish, the exposed portion in female dark brown with four rows of small pale spots; lower surface brownish-yellow. Head prominent, as wide as base of pronotum, eyes 
small, broadly ovate. Pronotum about one-third wider than long, its apex very slightly narrower than base, its sides and front margin with a few long bristly hairs. Tegmina of male translucent, delicate, covering threefourths or more of abdomen, often reaching its tip; lateral field widened to embrace the sides of the broad abdomen; of female covering about twothirds of abdomen, their tips obliquely subtruncate. Wings usually absent, rarely fully developed and much surpassing the abdomen. Ovipositor distinctly though feebly curved, the valves with apical fifth slightly sublanceolate and both upper and lower margins curved, the teeth of former

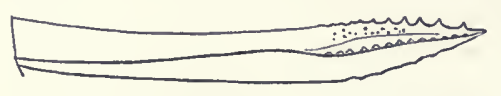

Fig. 233. Ovipositor of $N$. carolinus, $\times 13$. (After Hebard.) stout, rather widely and irregularly spaced, those of lower minute, wide. ly separated (Fig. 233.) Length of body, ๙ิ, $7.4-8.5$, ㅇ, $6.5-8.4$; of pronotum, $\hat{\sigma}$ and $ᄋ, 1.7-2$; of tegmina, $\hat{\delta}, 5.5-6$, ㅇ, 3-3.8; of hind femora, $\hat{\sigma}, 5.5-6.4$, ㅇ, $5-6.4$; of ovi. positor, $3-3.9 \mathrm{~mm}$.

This species, the $N$. exiguus of my former work $(1903,426)$, occurs thronghout Indiana where it is fully one-half as common as the short-winged form of $N$. fasciatus. It occurs most frequently among moist fallen leaves and beneath stones along fence rows and borders of thickets and streams. The long-winged form is very rare, two females, taken in Wells County by E. B. Williamson, being the only ones seen from the State.

Ontside of Indiana specimens of $N$. carolinus are at hand from De Grassi Point, and Owen's Sound, Ont. (Walker) ; South Natick, Mass. (Morse); North Carolina (Scudder); North Madison, Conn. and Sanford, Lakeland, La Belle, Sarasota and Dunedin, Fla. (W. S. B.). About Dunedin it is very scarce in early spring but several long-winged females have been sent me which were taken at light in June. It is recorded from numerous localities from the southern mainland of Florida by R. \& H., but the records from the northern part of the State are few. Near Miami, Hebard found it locally common "on sodden leaves under a labyrinth of roots in a dense red mangrove swamp."

The known range of $N$. carolinus is a wide one, extending from Truro, Nova Scotia and New England north and west to the Temagami District, Ont., Minnesota and Nebraska and south and southwest to southern Florida and central Texas. From Truro, $\mathrm{N}$. S. but a single male is recorded, but in Ontario Walker (1904, 187, as $N$. angusticollis) found it, as it is in Indiana, next to fasciatus the most common Nemobius in the Province. There, he says:

"It frequents low grounds of almost any kind, but delights especially in low grassy borders of swampy woods or clearings in swamps. I have found it in abundance in sphagum moss when growing in such localities, but have not met with it in the open peat-bogs where N. palustris occurs. 
It is also found beneath stones along the margins of lakes and streams. I first discovered this insect through its stridulation, which was a highpitched continuous trill of considerable volume."

Allard (1916a) says that abont Clarendon, Va, the tiny Nemobius carolinus is rery common beneath the leaves and grass of the roadsides throughout the summer. Its stridulation is a weak, continuous trill indefinitely prolonged. They are persistent singers and may be heard throughout the night. In the coolness of the early morning they appear to be especially musical. They keep well concealed beneath the dead and matted herbage, and are exceedingl difficult to capture."

Owing to numerous wrong identifications by Scudder and the confusion by him of the species above described as $N$. variegatus with his $N$. carolinus, the synonyms of the latter are numerous. In addition to my Nemobius exiguus above cited, as placed by Hebard $(1913,473)$, are $N$. septentrionalis Prov. $(1877,24), N$. volaticus Scudd., female $(1877,36), N$. affinis Beut. (1894a, 249), N. angusticollis Walker $(1904,186)$ and $N$. janus Kirby $(1906,19)$. It has been recorded many times under these synonyms, especially that of $N$. exiguus Blatch., a name used by Say for a species of Anaxipha and wrongly applied by Scudder $(1862,429)$ to Nemobius fasciatus Sar. Hebard in his Rerision (1913) has given a detailed account of the synonymy of this and other species of Nemobius. Two races of $N$. carolinus are recognized by him, viz: N. c. brevicaudus Bruner $(1904,57)$ from Colorado and N. c. ncomexicamus Scudd. (1596a, 100) from Texas, Arizona and New Mexico.

328. Neмoвius coxfusus Blatchley, 1903, 428.

Size rather small; form moderately robust. Head, pronotum and tegmina piceous, shining, last two segments of maxillary palpi ivory-white, the basal ones piceous; dorsal surface of abdomen dark brown; legs and under surface dull yellow. Pronotum about one-third wider than long, with a median impressed line on front half, its disk, as well as that of occiput and fore and middle femora, with scattered black bristly hairs. Tegmina of male translucent, covering end of abdomen, in repose forming an elongate quadrangle with margins subparallel; of female half as long as hind femora, their tips broadly slightly obliquely rounded. Ovipositor but little more than half as long as hind femora, dark brown in color, its apical third wider and a little upturned; armed both above and below, the upper teeth rather stout, sharp, and more than usually distant one from

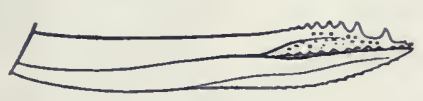

Fig. 234. Ovipositor of $N$. confusus, $X$ 14. (After Hebard.)

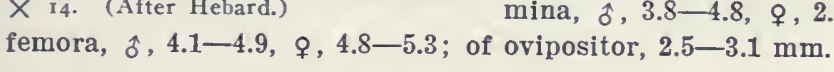

another, the lower ones very fine and also widely spaced (Fig. 234.) Length of body, $\hat{\delta}, 5.7-7$, $9,6.8-7.3$; of pronotum, $\hat{\delta}, 1.4-1.7$, $ᄋ, 1.4-1.9$; of tegmina, $\hat{\delta}, 3.8-4.8$, $q, 2.8-3.1$; of hind 
Kosciusko, Knox and Posey counties, Ind., Aug. 17-Oct. 25 (W. S.B.) ; Cabin John Run, Md. (Davis). This sombre-lued little cricket was first found in Kosciusko Co. Aug. 26, 1902, in some low, damp woods bordering Tippecanoe Lake. Here it had its home among the fallen leaves and beneath small chunks and chips. From Posey County a single specimen was procured also from a tract of low woods and on Oct. 5, 1917, about twenty were taken from beneath dead leaves on the side of a thickly wooded little slope leading down to the margin of a cypress swamp in Knox County. It appears that I had no males in the type series of confusus taken at Tippecanoe Lake and unfortunately got hold of a male of $N$. maculatus in drawing up the original description, so that the characters therein pertaining to that sex are mis. leading.

Outside of Indiana $N$. confusus has been recorded from a number of stations in Maryland and Virginia, from Raleigh, N. Car. and from Rabun County and Buckhead, Ga. At Raleigh Brimley (1908, 21) found it "in damp places not far from water from mid-August to late November," while at Buckhead a nymph was taken by $R$. \& $H$. from the undergrowth of mixed oak and pine forest. No macropterous specimens are known.

It seems that each of the different species of this genus taken in Indiana has its special abiding place, fasciatus and carolinus being the only ones which may be looked for anywhere in open fields and along roadways; maculatus occurs in open woods usually in dry situations; griscus in sandy districts; variegatus along the banks of streams and on gravelly hillsides; palustris nowhere except among the sphagnum mosses of dense swamps and bogs, while confusus likes best the shadows of dense woods which are low and moist. Each form has, therefore, its special habitat where the food on which it thrives is most abundant, and where, during the ages past, it has become so, modified in organ and lue as to receive from man a distinctive specific name.

\section{Hygronemobius Hebard, 1913a, 451. (Gr., "moist" + "grove-dweller.")}

Small compact crickets closely allied to Nemobius ${ }^{80}$ and having the body pubescent, sparsely clothed with hairs, head and pronotum similar to Nemobius, the lower front angles of lateral lobes rectangular and much shavper than the lower hind ones;

${ }^{80}$ Also very close to Pseudonemobius Sauss. (1877, 23t, 234; $1878 ; 510$ ), the differen. tial characters given by Saussure in his key being almost exactly the same as those given by Hebard for the present genus. 
tegmina of males short, lacking a tympanum; wings usually absent; inner or hind face of front tibix with a very small, scarcely erident tympanum; hind femora greatly dilated; hind tibiæ with upper margins each armed with three pairs of long, distant, movable spines and with five subapical spurs, two on inner and three on outer side, the usual lower inner one absent, the upper one as long as basal joint of tarsus.

Hebard (1915) recognizes fire species of the genus, all tropical or subtropical in distribution. One of these occurs in Florida.

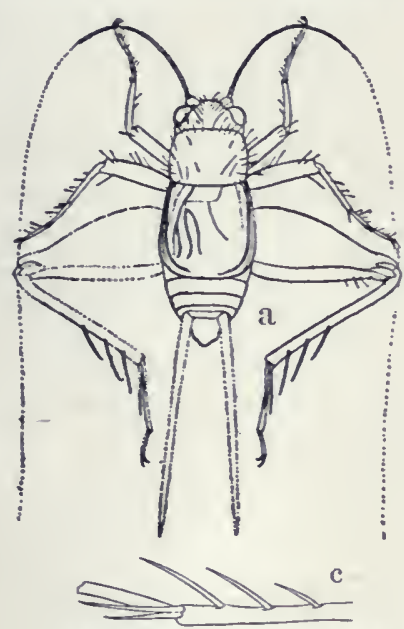

Fig. 235. Hygronemobius hind tibia; $d$, of ovipositor.

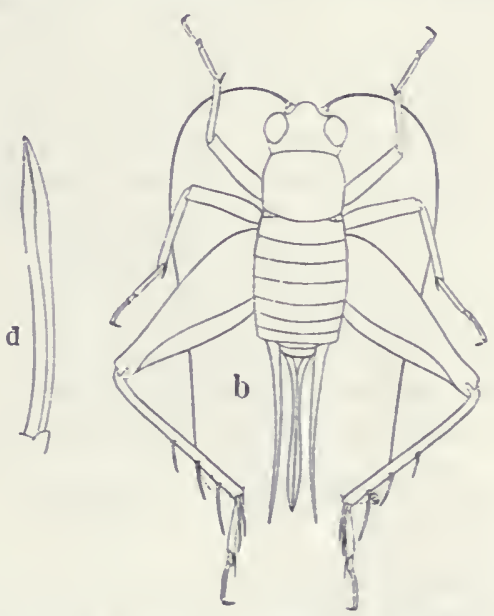

, male; $b$, female; $c$, outline of (Afler ${ }^{4}$. ${ }^{a}$,

329. Hygroxemobius Aluexi (Morse), 1905, 21. Allen's Ground Cricket.

Body short, stout, somewhat depressed. Beneath brown; above fuscous finely maculate with brown; maxillary palpi dark; hind femora with three transverse fuscous bars on apical three-fifths, the base brown with numerous narrow oblique fuscous stripes. Antennæ about three times as long as body, very slender. Tegmina of male covering two-thirds of abdomen, their tips subtruncate; of female minute, lateral pads almost concealed by pronotum. Wings absent. Ovipositor compressed, feebly curved, the tip slightly lanceolate and very finely crenulate above. Other characters as above given. Length of body, $\hat{\delta}, 5-6, \uparrow, 6$; of hind femora, $\hat{\delta}$, 4.5, ㅇ, 5; of ovipositor, $4 \mathrm{~mm}$. (Fig. 235.)

Miami, Fla. (Hebard). This little cricket is a submaritime species known from the United States only from a series taken at Miami, Fla. by Hebard who says $(1915,195)$ : "They were found March 15 on the black soil and among drift in a mangrove swamp which at high tide was under more than a foot of water. The series was taken when the tide was out. At the time the weather was cool and the individuals were not rapid in their movements 
but were difficult to capture owing to the environment, their sombre coloration and their habit of hiding under the drift or the sodden mangrove leaves."

Morse's types were taken July 13 at Moraine Cay, Bahama Islands by Dr. G. M. Allen who furnished Morse the following notes regarding its habits:

"This interesting little cricket was found abundantly along the edge of a mangrove swamp that extended for some distance out from the shore. On approaching this swamp from the landward side my attention was attracted by a faint but continuous cricket-like note which seemed to come from all about me. After a careful search among the black roots of the mangroves and the water-soaked leaves at their bases, I found numbers of the little insects. They were extremely quick and agile, and although it was easy enough to see them as they leaped aside at my approach, they immediately became invisible on alighting, so closely did they harmonize in color with the dark sticks and leaves. In this thick undergrowth the use of a net was practically out of the question, even if I could have been quick enough to sweep up the active little creatures. I found, however, that I could easily drive two or three at a time onto a sheet of newspaper that I spread on the sodden surface of the swamp, and with a slow but steady motion a wide-mouthed bottle could be brought above a resting in. sect and clapped over him before he could escape."

\section{Anurogryllus Saussure, 1877, 283. (Gr., "withont" + "tail" + "cricket.")}

Robust crickets of medium or large size, in our species having the body sparsely and finely pubescent; head subglobose, vertical, the occiput very convex; eyes rather small, situated each side of antennal pits; ocelli small, the median one narrowly elliptical; disk of pronotum slightly narrower than head, subquadrate. rounded into the lateral lobes, the latter with lower margin oblique, its front angle obtuse, hind one rounded; tegmina about as long as abdomen and furnished with a tympanum, male; wings variable in length; front tibiæ with an oblong-oval tympanum on outer face; hind femora strongly dilated, longer than the combined tibiæ and tarsi ; hind tibix armed with two rows of stout. immovable spines and three pairs of subapical spurs; anal cerei long, very slender, feebly tapering. Other characters as given in generic key. One widely distributed tropical species occurs in the southern states.

330. ANurogryllus iruticus (DeGeer), 1773, 520. Short-tailed Cricket.

Size medium, form robust. Nearly uniform pale brownish-yellow; occiput often tinged with fuscous; tegmina in part dusky; lower front angle of pronotum often very pale. Disk of pronotum subquadrate, wider than long, with an impressed median line, feebly narrowed in front, male, 
sides subparallel, female. Tegmina of female covering one-half to twothirds of abdomen. Wings usually absent, male, often exceeding the abdomen, female. Ovipositor not visible. Other characters as above given. Length of body, $\hat{\delta}, 12-16, \uparrow, 17$; of pronotum, $\hat{\delta}$ and $\$, 3.5$; of tegmina, $\hat{\jmath}, 12-17$, $ᄋ, 11.5$; of hind femora, $\hat{o}$ and $q, 10.8-11.2 \mathrm{~mm}$.

Tappahannock, Va.. June 9 (Fox). A tropical or subtropical form occurring in the United States mainly along the Atlantic coast from New Jersey south and southwest to southern Florida, Louisiana and Victoria, Texas, and also in the West Indies, Mexico, Columbia and Guiana. In Florida it has been recorded from Jacksonville, Lawtey, Gulf Hammock, DeLand and Miami. At the latter place Hebard trapped a single male in a molasses jar.

Caudell $(1904 \mathrm{~g})$ records that as early as 1857 they were reported as doing much damage about Jena, La., to cotton, sweet and Irish potatoes, peas, strawberries and tobacco, his correspondent writing that "their holes in the ground are scattered promiscously from a few inches to several feet apart, the burrows being seldom over a foot deep in the uplands but much deeper in the swamps where the subsoil was softer. The insects are seldom visible in das and do their cutting at night, taking all they want down in the ground, where they eat as they please or feed their young ones. They appear to go in colonies and we find that rapid cultivation, large flocks of poultry and numerous birds are necessary to keep them in check." In 1903 specimens were sent in to Washington from Beech Island, S. Car. which had been taken in cotton fields where they burrow to a depth of 18 inches, lining the holes with shreds of cotton leaves and in so doing destroying the young cotton for several feet in the row. The young were found in these burrows in June.

Manee $(1908,461)$ states that at Soutlern Pines, N. Car. the "mounds" of this cricket are rery common and are "built near some small weed, whose leares furnish the wide but shallow horizontal chamber," the latter connecting with one or more perpendicular or oblique tunnels which serve as 'retreat shafts' when the insect is disturbed." This is probably the species mentioned by Scudder (1S94c) under the name Gryllodes sp. as taken by Maynard near Jacksonville, Fla. in similar burrows.

At Clarendon, Va. Allard (1916a) found A. muticus in numbers in early June in a pine grove where they occurred upon the trunks of the pines from one to eight feet above the ground. The males stridulated only on warm evenings, beginning about sundown and continuing in the early part of the night. "The trill is loud, continuous, high-pitched, much resembling that of an 
Oecanthus." Fox (1917) reports that about Tappahannock, Va. they are "frequent in fields and pastures and along fence rows, nocturnal in habits, singing at or close to the mouth of the burrow."

The following names are now regarded as synonyms of $A$ muticus: Acheta guadeloupensis Fab. $(1793,32)$; Gryllus angustulus F. Walker $(1869,27)$ and Gryllodes clarazianus and G. caribeus Sauss. (1874, 412, 413).

\section{Gryllodes Saussure, 1874, 409. (Gr., "a leaper.")}

Medium sized crickets of slender form having the head short. occiput not strongly convex; antennæ very slender, twice as long as body, the basal joint large, compressed, as wide or wider than the inter-antennal protuberance; pronotum short, transverse, about one-half wider than long, hind margin of lateral lobes very oblique; tegmina variable in length, in our species much shorter than abdomen, the mediastinal vein undivided, female, one-branched, male; front tibiæ without a tympanum on inner face; hind tibiæ with five or six spines on each margin, the inner middle and lower subapical spurs subequal; ovipositor straight, very slender. longer than hind femora.

Kirby $(1906,40)$ recognized 56 species as belonging to the genus, most of them tropical in distribution. Only one has become established in the eastern United States.

331. Gryllodes sigillatus (F. Walker), 1869, 46. Decorated Cricket.

Form depressed, slender, pubescent. General color pale brownishyellow mottled and banded with dark brown; head with a cross-bar between the eyes, another, less distinct, at hind border of occiput, and a vertical stripe between the antennæ, dark brown; pronotum with a basal and median brown cross-bar, the former curving forward onto lateral lobes, the latter interrupted; tegmina pale brown; legs mottled with dark brown; abdomen in great part brown mottled with yellow. Head obliquely depressed. Tegmina of male covering half the abdomen, the stridulating organ large, tips broadly rounded; of female very short lateral pads, with tips of both dorsal and costal field obliquely truncate. Wings absent. Legs slender. Length of body, $\hat{\delta}, 14-16$, $\&, 15-21$; of pronotum, $\hat{o}$ and ㅇ, $3-3.5$; of tegmina, $\hat{\delta}, 5-6, \uparrow, 1.7-2.3$; of hind femora, $\hat{\delta}, 9.5-10$, ㅇ, 11-13; of ovipositor, $12-16 \mathrm{~mm}$.

Miama and Big Pine Key, Fla., Sept. 25-Oct. 4 (Davis) ; Dunedin, Fla., Jan. 27, nymph (W.S.B.) Recorded also from numerous stations in sonthern Florida and on the keys, Lakeland being the most northern. The first record for the United States was that of R. \& H. (1905) from Miami, where Hebard found them in numbers in February beneath bricks and between stones. "The 
males emit a shrill sound easily distinguished from that of Gryllus luctuosus by its higher pitch and the longer duration of the stridulation. When exposed it waves its long slender antennæ about continually." Later (1914c) they state that "at Key West in July it was everywhere common about the town and that, with the aid of a flash-light, individuals were easily taken when carefully approached and suddenly seized; this was apparently due to the insects being blinded by the light for they are certainly the most active gryllid found within the United States."

Daris (1914) records them as occurring in a house on Big Pine Key where "they were reported as doing some damage by eating clothing, etc. At night when the lights were out they would come out of their hiding and the males would sing their cheerful and very energetic song."

The species is tropical and practically cosmopolitan, Walker's type coming from Australia. It is said to be rery common in Cuba and the Bahamas. Caudell (Psyche, 1908, 96) has recorded it as appearing in countless numbers in the hot-houses of the U. S. Department of Agriculture at Washington, D. C., where they did considerable damage to rarious seedlings which they cut off near the ground. The Gryllus pustulipes F. Walker $(1869,51)$, the Gryllodes poeyi Sauss. $(1874,420)$ and the Miogryllus transversalis Scudd. (1901b, 257) are synonyms of G. sigillatus.

V. Miogryluus Saussure, 1877, 194. (Gr., "less" + "cricket.")

Crickets of small or medium size, the species differing from those of Gryllus in the usual absence or extremely inconspicuous nature of the tympanum on inner side of fore tibiæ; simple or one-branched mediastinal nerve of the tegmina; strictly longitudinal course of the veins on the dorsal field of the female tegmina; shortness of the hind tibire which are only two-thirds as long as the hind femora and armed above on each side with only four or five spines, and in the usual striped or banded summit of the head.

The tegmina and wings vary much in length in the same species but the short-winged forms are by far the more common. Ir. macropterous individuals the wings are two and one-half or more times the length of tegmina, while in brachypterous ones they are represented by mere pads. One of the fire species recognized by Hebard (1915c) occurs in the Eastern States.

332. Miogrimlus verticalis (Serville), 1839, 343.

Size large for the genus but smaller than most forms of Gryllus; form robust. Color exceedingly variable, ranging from dark brown to almost wholly black; head usually shining black with a narrow yellow stripe 
above each eye and two shorter ones on middle of occiput; palpi yellowish, the apical joint dusky; antennæ dark brown, paler at base; pronotum blackish, mottled with paler; lateral lobes piceous above, the lower third or more dull yellow; tegmina reddish-brown to fuscous, the lateral field darker; abdomen dark brown, often with a narrow paler median line. Head large, strongly convex, wider than front margin of pronotum. Last joint of maxillary palpi obliquely truncate. Pronotum two-thirds or more wider than long, its sides subparallel, front margin feebly concave, hind one truncate. Tegmina of female usually but little longer than pronotum, scarcely attingent, covering about one-third of abdomen, the inner apical margin of dorsal field obliquely rounded. Tegmina of male covering threefourths or more of abdomen, broadly overlapping, their tips rounded. Hind femora very stout. Tympanum on outer face of fore tibiæ elongateoval, nearly one-fourth the length of tibiæ; in the rare long-winged form present and nearly as large on both faces. Ovipositor straight, as long as hind femora, its tip feebly enlarged. Length of body, $\hat{\sigma}, 10-16$,, , 1117; of pronotum, $\hat{o}, 1.9-3.1$, ․, $2.1-3.2$; of tegmina, $\hat{o}, 3.6-7.6, \uparrow, 2.2-$ 4 ; of hind femora, $\hat{o}, 6.8-10.4$, $\$, 7.4-11$; of ovipositor, $7.2-12 \mathrm{~mm}$. (Fig. 236.)

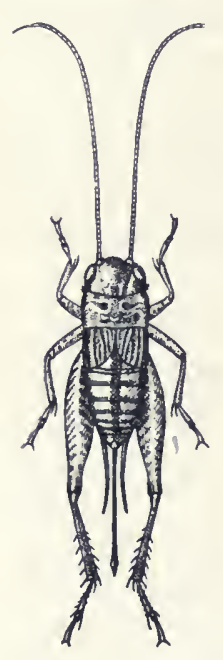

Fig. 236. Fe male. $\times$ 1.3. (Original.)

Southern third of Indiana, April 1S-July 10; Dunedin and Lake Okeechobee, Fla. Dec. 3 -Mch. 2 (W.S.B.) ; Mobile, Ala., Sept. 14 (Loding). In southern Indiana this species, resembling in general appearance a large Nemobius, has been taken in Franklin, Clark, Posey, Knox, Gibson and Crawford counties, where it occurs on dry wooded hillsides beneath flat stones and logs. It seems to like best places devoid of grass and other regetation. In that region it probably reaches maturity about the middle of June, as it seems to be most abundant by the last of that month, when quite a number of specimens were taken in the vicinity of Wyandotte Cave.

The Florida specimens above mentioned were nymphs and were taken beneath boards along the margins of ponds and lakes. Elsewhere in that State it has been recorded from a number of stations between Jacksonville and Homestead and also from Key West.

This species is the Miogryllus saussurei Scudd. $(1877,35)$ of most American authors, myself included (1903, 442). Hebard (1915c) has placed saussurei as a synonym of Gryllus verticalis. which was based on a long-winged female from Carenne, French Guiana. This was done without seeing Serville's type and the placement is therefore open to question, though, judging from 
Serville's description, probably correct. Other synouyms of verticalis as given by Hebard are Gryllus laplatee Sauss. (1874, 408) from Buenos Aires, Gryllodes guyennensis Sauss. (187T, 384) from Surinam and Miogryllus ollahome Caudell (1902, 90) from Perkins, Okla., the last named synonym being based upon an almost uniform black color variety.

If these synonyms of $M$. verticalis are correct the range of the species embraces most of the American continent. In the United States its known range extends from Staten Island, N. Y. west to Nebraska, Kansas and Oklahoma and south and sơnthwest to Key West, Fla. and southern Texas. But one macropterous individual, a female taken by Brimley at Raleigh, $\mathrm{X}$. Car., is recorded from this country and but three others besides the type have been noted elsewhere.

Daris (1909b) notes the habits of $M \cdot$ rerticalis as follows: "At Lakehurst, $\boldsymbol{N}$. Jer. it is found under dead leares and other objects lying on the ground. My attention was first called to the insect by hearing the males stridulating at night. Their song is a slow, zee, repeated at intervals of sereral seconds. Later the females were also found. At Lakehurst and on Staten Island, several individuals were taken on sandy ground. It reaches maturity in June. Individuals of this species of cricket differ markedly in the derelopment of the hearing organ on the inner side of the fere tibix. In two of the examples collected this organ is totally absent, in four it is slightly dereloped, and in one it is slightly dereloped on the inner surface of the right tibia, but absent on the same surface of the left leg."

Allard (1911a) describes its habits at Thompson's Mills. Ga., in part as follows: "It is a ground-dwelling species and keeps itself well concealed beneath the matted leares and grass of gardens and orchards. Its notes are rery brief, high-pitched musical trills, tzcee-tzece-tzeee. with brief intermissions. One individual delivered from 38 to 39 trills in a minute. This cricket mar be heard in stridulation vers early in the morning and more or less throughout the day and at night. It is rather difficult to locate and capture one by its notes, for these are quickly silenced by one's approach. This cricket is rery lively, and if uncorered leaps about rigorously. Its light brown coloration makes it rery inconspicuons among the similarly colored leares and soil."

Isely (1905, 248) says that the black form, M. oklahomo Caud. is the first cricket to reach maturity at Wichita, Kansas, adults being taken on Mar 22. "In a few dars they became very 
numerous and the males' stridulation could be heard on all sides in the afternoon and evening. They were especially abundant in thick short dead grass on a hillside." He found some in small perpendicular burrows from one to two inches deep, and others beneath stones. No specimens were taken after June 23, though specimens of the pale form $M$. saussurei were found on August 8.

VI. Gryllus Linnæus, 1758, 425. (L., "cricket.")

\section{The Field and House Crickets.}

"The voice of the crickets, heard at noon from deep in the grass, allies day to night. It is a midnight sound heard at noon, a midday sound heard at midnight."-Thoreau.

This, the typical genus of the family Gryllidæ, comprises crickets of medium or large size and robust form, having the head large, subglobose, usually slightly broader than pronotum; eves rounded, prominent; antennæe very slender, setaceous, longer than the body; pronotum broader than long, its disk rounded into the lateral lobes, which are longer than deep, with lower margin oblique or feebly curved, the front and hind angles rounded; tegmina and wings variable in length, the former with large shrilling organ in male; hind femora very much enlarged, shorter than tibiæ and tarsi united; hind tibiæ armed above on each side with five to eight large stout movable spines and at apex with three pairs of unequal spurs; basal segment of hind tarsi stout, armerl above with a row of short spines on each margin, its apex terminating in two stout spurs, the inner one the longer; second joint very small, compressed; apical segment slender, about half as long as the basal one; anal cerci nearly as long as hind femora, slender, bristly, tapering; ovipositor as long as or longer than the hind femora, variable in length in the different forms, its extreme apex feebly enlarged, not serrulate.

To this genus belong those dark colored thick-bodied insects known as house and field crickets. The latter are the best known examples of the family Gryllidx and in Indiana are abundant from June 1st till after heary frosts, beneath logs, boards, stones, and especially beneath rails in the corners of the old-fashioned and rapidly disappearing Virginia rail fences.

Regarding the general habits of the field crickets Bruner $(1886,194)$ has written: "Usually most of our North American Girylli live singly or in pairs in burrows which they dig for themselves. These are used as retreats during the day time and serve as shelter from ordinary inclemencies of weather. These 
burrows are generally forsaken about mid-summer for some sort of abore-ground shelter. From this time on, until fall, they appear to be more social and live in colonies under various sorts of rubbish. Grain shocks are a farorite haunt for them and since twine has been used for binding, the crickets have been quite troublesome by cutting the bands. During late summer and fall the females commence preparations for the continuance of their kind, by thrusting their long, slender ovipositors into the loose soil and dropping their eggs. These sometimes hatch the same year, but, as a rule, lie over until the following spring. The young generally live above ground, where they hide among fallen leaves, grasses and other debris, though sometimes they also creep into chinks and crevices in the earth."

The remarks of Bruner apply in Indiana mostly to the form luctuosus, one of our largest and only social field cricket. Here the young of $G$. pennsylvanicus and vernalis are, for the most part, hatched in autumn and survive the winter in the nymph stages, while $G$. domesticus, the house cricket, passes the winter either as adult or nymph.

The synonymy of the American forms of this genus is greatly confused, due largely to the fact that foreign writers have attempted to monograph the genus with but a limited number of specimens at hand; and again to the fact that the different forms, especially the males, are rery difficult to separate.

Lutz (1908) after studying carefully the variations in length of tegmina, wings and ovipositor of a large number of forms of Gryllus from all parts of the world concluded that "species in an any way natural sense do not exist in the genus." R. \& H. (1915c) came to about the same conclusion regarding the native American forms, placing them all under the one name, Gryllus assimilis Fab. $(1775,280)$ described from Jamaica, qualifying this placement, howerer, by stating (p. 299): "We have found that in general certain types do predominate over certain regions. These constitute the bases of many of the supposed species but in our opinion should be characterized by symbols rather than varietal names, owing to their complexity and the erident fact that none of these are distinct, either specifically or as geographic races, and really show only the various phases resultant from varied environmental conditions."

There is no doubt but that the different forms of natire Gryllus intergrade and merge, just as do those of Nomotcttix cristatus, Nemobius fasciatus and numerous other forms of Orthoptera for 
which varietal or racial names have been retained by recent American authors. Since the characters of all such races, varieties, or even species, for that matter, are resultant in great part from "variable environment," and since the grouping or placing of any series of closely related forms is largely a matter of personal opinion or viewpoint of the worker, and as names are more readily grasped and remembered than symbols, I have retained the older names of the more distinct forms of Gryllus as trinomials. The student may either use them as such and call them variants, varieties or forms of assimilis, or discard them altogether and lump his native field crickets under the one name Gryllus assimilis as R. \& H. and Morse have done, a procedure which Piers (1918, 338) terms a "simple solution of the Gordian knot."

KEY TO EASTERN SPECIES AND VARIETIES OF GRYLLUS.

a. Black species, the tegmina and parts of the body sometimes dull yellowish or reddish-brown; head never with distinct blackish crossbars; first joint of antennæ not projecting beyond front of head.

(ASSIMILIS ${ }^{81}$ ).

b. Hind femora wholly or in great part pale reddish-brown; tegmina, cerci and legs usually wholly or in great part dull reddish-brown.

c. Larger, length of body, male and female, 20 or more mm.; hind tibiæ with seven or eight spines on each upper margin.

333a. FIRMUS.

cc. Smaller, less than $16 \mathrm{~mm}$; hind tibiæ with only five or six spines on each margin.

$333 \mathrm{~b}$. SCUDDERIANUS.

$b b$. Hind femora black or fuscous with only the basal third reddishbrown beneath; tegmina and legs rarely reddish-brown.

d. Ovipositor nearly or fully half as long again as hind femora, 16 or more $\mathrm{mm}$. in length; head of male swollen, distinctly wider than front of pronotum. 333c. LUCTUosus.

$d d$. Ovipositor less than half as long again as hind femora, rarely over $14 \mathrm{~mm}$. in length; head of male but little if any wider than front of pronotum.

e. Color in fresh specimens not shining black, but with a very fine grayish pubescence or "bloom:" tegmina of female with their inner edges either overlapping or attingent their full length; length of ovipositor $13-14 \mathrm{~mm}$.

333d. pennsyluanicus.

$e e$. Color shining black, tegmina rarely piceous or dull brownish. yellow; tegmina of female with the basal halves overlapping or attingent, the apical halves (always in vernalis.

81The typical form of Grvllus assimilis is suhtronical and occurs in the United States only along the coast of Southern California. The form integer Scudder (1901a, 268) bas been recorded by Caudell from near Washington, D. C., and by Kostir (on Caudell's determination) from Cedar Point, Ohio. As Scudder described it from the Pacific States and R. \& H. (rg/Fc) restrict its range to the mountains of the arid portions of the southwestern United. States and California, it is not included in the key. It is distinguished from pennsylianicus by Scudder by having the pronotum nearly twice as broad as long. 
rarely in neglectus) separated by a wide V-shaped notch, (Fig. 238.)

f. Ovipositor scarcely if any longer than hind femora; tegmina of female strongly reticulate. 333e. vervalis.

ff. Ovipositor nearly one-third longer than hind femora; tegmina of female less strongly reticulate. 333f. NEGLECTUS.

aa. Straw-colored species; head with distinct dark brown or blackish cross-bars; first joint of antennæ projecting slightly beyond front of head.

334. DOMESTICUS.

333a. Gryllus Assimilis FIrmus Scudder, 1902a, 295.

Size very large for the genus; form robust. Color largely piceous, head and pronotum black or piceous; mouth parts and lower half of lateral lobes reddish-brown; tegmina a nearly uniform dull reddish-brown, often with a narrow pale humeral stripe; femora dark reddish-brown, usually more or less tinged with fuscous. Head large, tumid, vertex prominent. Disk of pronotum one-half wider than long, hind margin slightly convex, median impressed line faint, lower margin of lateral lobes almost straight, its front angle evident, obtuse. Tegmina covering three-fourths or more of abdomen, female, as long as abdomen, male, their tips narrowly rounded. Wings usually shorter than tegmina, sometimes exceeding the abdomen. Inner apical spur of basal segment of hind tarsi very short, two-thirds as long as last segment. Ovipositor one-third or more longer than hind femora. Length of body, $\hat{\sigma}$ and $\$, 20-29$; of pronotum, o , 4-5.2, ㅇ, 4.5-5.5; of tegmina, $\delta, 14-17$, ㅇ, 12-13; of hind femora, $\hat{\delta}, 14-16$, $\&, 14-17$; of ovipositor, $19-23 \mathrm{~mm}$.

Gainesville, Dunedin and Ft. Mrers, Fla. Oct. 11-Feb. 24 (W.S.B.) ; Agricultural College, Miss., Dec. (Weed). About Dunedin this large field cricket occurs sparingly throughout the winter beneath cover in old orange groves, gardens and dry sandy fields. Cnder the names firmus and scudderianus it has been recorded by other collectors from numerous stations throughout the mainland and southern kers of Florida. At Key West "they were found in and near their holes situated in the short heary grasses growing on the scant soil near depressions." $R$. \& H. $(1914 \mathrm{c}, 411)$ speak of the song of $G$. firmus as a "loud, sharp, vigorous chirping," and of that of G. luctuosus (rubens) as a "slower stridulation noticeably different from the hearty chirp of $G$. firmus."

One of Scudder's types of G. a firmus was from Brookville. Ind. and the form ranges from that place and from southwestern Ohio (Kostiv) southeastward and south to North Carolina, Key West and Texas. It merges gradually into the smaller scudderianus Sauss., from which it is mainly distinguished by the charactors given in key. Scudder states that about one-third of his individuals of firmus were macropterous, but only short-winged specimens have been seen by me. 
333b. Gryllus assimilis scudperianus Saussure, 1874, 402. Scudder's Field Cricket.

Size small to medium; form rather slender. Color much as in firmus, tegmina usually paler reddish-brown; hind femora sometimes with apical half of inner and outer faces blackish; abdomen shining black. Head but little if any wider than pronotum, the latter with hind margin truncate, lower margin of lateral lobes shorter and more curved than in firmus. Tegmina covering about two-thirds of abdomen, female, or more, maie. Wings very narrow, shorter than tegmina. Hind femora proportionally slender. Hind tibiæ with dorsal and median inner apical spurs subequal in length. Inner terminal spur of basal segment of hind tarsi slender, only half the length of last segment. Ovipositor longer than body, one-half longer than hind femora. Length of body, of and $\$, 14-15$; of pronotum, $3.5-4$; of tegmina, $\hat{\delta}, 8-9$, 우 $7-8$; of hind femora, ô, 9-10, 오 $10.5-$ 11.5 ; of ovipositor, $14.5-16.5 \mathrm{~mm}$.

Lake, Marshall, Fulton and Vigo counties, Ind. (TV. S. B.). This is the $G$. arenaceus of my former work $(1903,443)$. It is lather plentiful in the sand dune region of northern Indiana, where it occurs in September and October beneath cover in dry bare sandy places. The reddish-brown hue of tegmina, legs and cerci usually contrasts strongly with the deep black of pronotum and abdomen. R. \& H. (1915c) have made firmus a synonym of scudderianus, but as Saussure gives the measurements of the latter as length of body 14, hind femora 9 and ovipositor $14.5 \mathrm{~mm}$., I believe that his name does not rightfully belong to as large a varient as firmus, though the two forms probably merge, through G. rubens Scudd. (1902a, 295) which R. \& H. also place under scudderianus.

The range of the form scudderianus is open to question. Saus. sure's types were from "l' Amerique Septentrionale" without more definite locality. Scudder considered it a form of abbreviatus, i e., luctuosus. If rubens be taken as a connecting link orerlapping scudderianus in the north and firmus in the south. the distribution of scudderianus, sensu strictu, may be said to be limited to the sandy districts of the norther'n and eastern states. As arenaceus it has been recorded by Kostir from Cedar Point, Ohio, and reported by Hubbell (Ms.) from Cheboygan Co., Mich.

333c. Gryllus assimilis luctuosus Serville, 1839, 335. Common Field Cricket.

Size medium to large for the genus; form very robust. Black, often tinged with rusty brown; head and pronotum shining black; tegmina usually a dark reddish- or fuscous-brown, sometimes pale brownish-yellow; hind femora black or dark reddish-brown, the basal third of under 
and inner sides almost always brick-red, more prominently so in male. Pronotum one-half or more wider than long. Tegmina usually covering three-fourths or more of abdomen; female, all of abdomen, male; sometimes shorter in latter sex. Wings either reduced to mere pads (abbreviatus) or fully developed and reaching middle of ovipositor. Hind femora very stout. Hind tibiæ usually armed with six spines on outer margin, their upper and middle inner spurs slender and subequal. Length of body, $\hat{\delta}$, 18-20,,$+ 18-22$; of pronotum, $\hat{\delta}$ and $\circ, 4.5-5$; of tegmina, $\hat{o}, 12-14$, ㅇ, 11-13; of hind femora, $\hat{o}, 11-13$, o , 10.5-13.5; of ovipositor, 17$21 \mathrm{~mm}$.

In late summer and early autumn this is the most common field cricket in Indiana. Here it is represented during winter by the eggs alone. In southern. Indiana these hatch in late Mar or early June and the mature males appear about July 1st, but in the central and northern parts of the State the first males appear about a month later. This large field ericket is, in habits, nocturnal, omnivorous, and a cannibal. Aroiding the light of dar. it ventures forth, as soon as darkness has fallen, in search of food, and all appears to be fish which comes to its net. Of fruit, regetables, grass and carrion, it seems equally fond and does not hesitate to pres upon a weaker brother when opportunity offers. I have often surprised them feasting on the bodies of their companions, and of about 40 imprisoned together in a box; at the end of a week but six were living. The heads, wings and legs of their dead companions were all that remained to show that the weaker had succumbed to the stronger-that the fittest, and in this case the fattest, had survived in the deadly struggle for existence.

This is the G. abbreviatus Serr. of most authors, including myself $(1903,435)$. Serville described two forms, luctuosus on page 335 and abbreviatus on page 336 . The latter is now considered only the short-winged form of luctuosus, though McNeill $(1891,5)$ says it is his opinion that abbreviatus is distinct and that luctuosus is probably the long-winged form of pennsylvanicus Burm. The short-winged form (of luctuosus) is by far the more common in Indiana, only a few long-winged individuals having been noted.

The range of G. a. luctuosus, including the short-winged $a b$ lreviatus, is a wide one, extending from New England and Ontario west to Manitoba and Colorado, and south to southern Florida, Louisiana and Texas. In Florida it has been taken by me at Sanford, Key West, LaBelle, Ft. Mrers and Dunedin, and recorded by others, mostly under the name G. rubens Scudd., from numerous other points, both on the mainland and kers. About 
Dunedin it is the most common field cricket noted, both adults and nymphs occurring throughout the winter, the long-winged forms, there frequent, being often attracted to light. Hebard eaptured them in numbers on Feb. 9 berzath boards and stones along the main street of Miami, where "after dark they were strid. ulating at a great rate."

In Ontario Walker $(1904,250)$ says that adults begin to appear about the second week in August and in September and October become very numerous and congregate in large numbers under every chunk, log or board, under the loose bark of old logs or in burrows in the sand. Late in the season they may be seen by hundreds sunning themselves on fences close to the ground.

About Moline, Ill., according to McNeill (1891), "the eggs of abbreviatus hatch in July and the first adults appear as early as the second week in August. During every stage of life they are social, feeding together, seeking shelter in company and when egg laying time comes, in October, the females collect by hundreds in some suitable locality, an abandoned or little used roadway suits them well, and each lays several hundred eggs in an irregular mass. After this duty is performed their business on this planet seems to be finished and they succumb to the cold, none surviring the winter. The eggs do not hatch until the following July, or if in rare cases they do they probably perish with cold."

Allard (1911a, 157) says that about Washington abbreviatus "not infrequently takes up its quarters in the house, announcing its presence by its stridulations which are intermittent chirps, possibly louder than the chirp of G. pennsylvanicus."

333d. Gryllus assimilis pexssylvanicus Burmeister, 1838, 734. Pennsylvania Field Cricket.

Size medium; form broad. Head of male not so swollen as in abbreviatus, slightly wider than pronotum. Pronotum proportionally a little wider and shorter, the length contained in breadth nearly 1.6 times; hind margin slightly sinuate, median impressed line plainly visible on anterior half. Tegmina varying in color from deep black to smoky or grayishbrown, rarely a dull reddish-brown, often with a yellowish-brown line along the humeral angles, their inner edges straight, overlapping or attingent their full length; those of female reaching nearly to tip of abdomen in short-winged form, slightly exceeding the tip in long-winged form; those of male reaching tip of abdomen in both forms. Wings either narrow and shorter than tegmina or extending considerably beyond tegmina in the form of tall-like projections. Pronotum, legs and under side of body in freshly matured specimens with a minute grayish pubescence or "bloom" which becomes abraded with age, leaving these parts shining black. Hind femora short, stout, its average length contained in that of ovipositor 1.1 


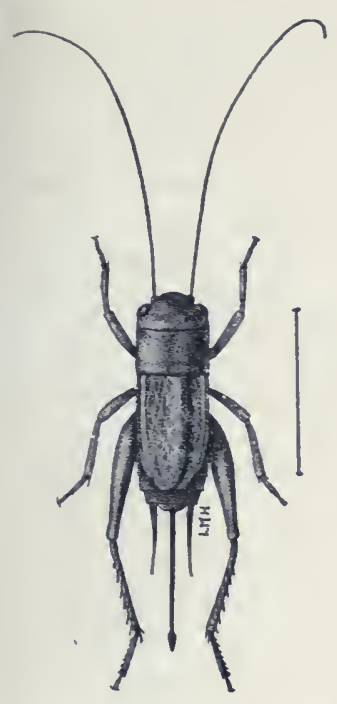

Fig. 237. Short-winged female. (After Lugger.) times. Length of body, $\hat{\delta}$ and ㅇ, 17-17.5; of pronotum, $\hat{o}, 3-3.5$, ᄋ, $3.5-4.2$; of tegmina, $\hat{o}, 11.5$, $q$, short-winged form, 10 , long-winged form, 12.4; of hind femora, $\hat{\delta}, 10-12.2$, 오 , 10.5-12.4; of ovipositor, $13-14 \mathrm{~mm}$. Width of pronotum, $\hat{\delta}$ and $\$, 6.3 \mathrm{~mm}$. (Fig. 237.)

From luctuosus this form may be distinguished by the shorter body, less swollen head of male and especially by the short ovipositor, which in Indiana specimens ranges betrieen 13 and $14 \mathrm{~mm}$. in length. The main distinguishing characters between pennsylianicus and vernalis are set out under the latter form. Another, very noticeable in the field in spring, is the dull grayish tinge of fresh specimens of permsylianicus, especially on the legs and pronotum, the whole body of rernalis being shining black.

In Indiana pennsylvanicus is also everswhere a common cricket and for the most part survives the winter in the nymph stage, the young, on the approach of cold weather, making for themselves cone-slaped cavities an inch or two across the top and about as deep, in the mold beneath decaying logs and rubbish. Sometimes the margins of these burrows are surrounded by fragments of grass stems and pieces of decaying leares. In warm, sheltered localities, some individuals evidently reach maturity in late autumn or early winter; a full grown, freshly moulted female having been taken in a greenhouse in Marion County, on December 14th. The males begin to pass their final moult in central Indiana about May 15th, and from then on through June and July the open woods pastures and the angles of old rail fences echo with the music of their seng. The young hatch in July and August, and after the second or third moult form their winter abiding places, while the adults perish with the coming of the hoar frost. The long winged form is much less common than the short winged and is seldom met. with in the field; but may often be found about electric and other lights during the summer nights. However, on two occasions in June, I have taken a long winged male in company with two short winged females beneath logs.

The range of the form or variant $G$. a. pennsylvanicus is even wider than that of luctuosus extending from Prince Edward Is- 
land, Nova Scotia and New England west to British Columbia and California and south and southwest to southern Florida, eastern Texas and New Mexico. R. \& H. (1915c, 302) say that "it is the dominant variant of the species in the well watered regions of temperate North America."

In Florida I have taken pennsylvanicus at Ormond, Sanford. LaBelle, Sarasota and Dunedin. Elsewhere in the State it is recorded definitely only from Orange City Junction by Caudell (1905) and Miami by Hebard (1915b). About Ormond it was the only field cricket noted in March and April, while around Dunedin both adults and nymphs are fairly plentiful from December to April.

Of pennsylvanicus in Ontario Walker says (1904, 251): "The chirp of the adult is first heard about the third week in May, the last toward the end of July. They are numerous about midsummer, when the fields and pastures resound with their song. They are very difficult to obtain, for they are not gregarious like $a b$ breviatus, but usually occur in pairs hidden in the rubbish under some thick tuft of grass or weeds or under the edge of a stone. It requires the utmost care and patience to trace the song to its source, but if this is done successfully one is often rewarded by finding the female as well as the male." Of its habits in the south Allard (1911c, 147) says:

"Careful studies of a number of musical insects have shown the writer that very marked differences of stridulation may characterize certain species in different parts of their range. This bas been found especially true of Gryllus pennsylvanicus. The sprightly intermittent chirps of the New England individuals no more resemble the weak, continuous Oecanthus- like trill of the northern Georgia individuals than the notes of Oecanthus niveus resemble the very dissimilar trill of Oecanthus latipennis. Not only is the stridulation very dissimilar, but the general habits are unlike. In New England Gryllus pennsylvanicus fairly swarms in grass fields and pastures during autumn, chirping everywhere in plain sight. In northern Georgia this cricket becomes exceedingly abundant in March, April and May. In this region it is very shy and secluded in its habits, stridulating beneath matted leaves, clods of earth, and grass in fields, and oftentimes in deep burrows in pastures. It is rarely seen unless deliberately uncovered and unearthed. By midsummer its stridulations are rarely heard." 333e. Gryllus assimlis verxalis nomen. nov. ${ }^{82}$ Spring Field Cricket.

Size small for the genus. Female short-bodied, robust, male more slender. Nearly uniform black, shining; tegmina of female sometimes with a reddish-brown tinge at base and along humeral angle; hind femora with lower and inner sides of basal third feebly or not at all tinged with

${ }^{82}$ To replace the name Gryllus americanus of my former work $(1903,433)$ which was preoccupied by the $G$. americanus Drury $(1773,121$. 
reddish-brown, never with the large reddish-brown spot so common in $G$. luctuosus and pennsylvanicus; cerci and hind tibiæ dark chestnut brown. Head no broader than pronotum; vertex prominent, straight, declivent. Disk of pronotum about one-third wider than long, median impressed line very distinct on apical three-fourths, front margin truncate, hind one slightly sinuate. Tegmina of female covering two-thirds of abdomen, overlapping or attingent only on their basal halves, the apical halves with inner margin obliquely rounded and therefore, in repose, widely separated, Fig. 238. Tegmina of male usually covering three-fourths of abdomen, rarely reaching its tip. Wings represented by narrow thin scales. Hind femora short, stout. Hind tibiæ armed above on each margin with five or six spines. Inner subapical spines of basal joint of hind tarsus slender, but little more than one-third the length of apical segment. Length of body, $\hat{\sigma}, 13-14, \uparrow, 15-16.5$; of pronotum, $\hat{\delta}, 3.5, \uparrow, 4.2$; of tegmina, $\hat{o}$, $7-8$, ᄋ, 7.5-8; of hind femora, $\hat{o}, 10$,, 11 ; of ovipositor, $10.5-11.5 \mathrm{~mm}$. Width of pronotum, $\hat{\delta}, 5, \uparrow, 5.6 \mathrm{~mm}$. (Fig. 238.)

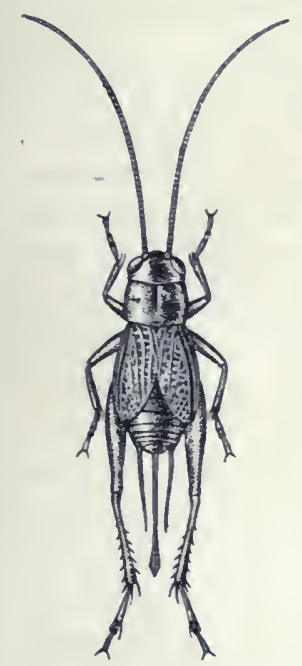

Fig. 238. Gryllus vernalis nom. nov. Female $\times$ 1.2. (Original.)

This shining black field cricket has been taken in Crawford, Posey, Vigo, Putnam, Marion, Marshall, Wells and Lake Counties, Indiana, and probably occurs throughout the State. It is here the first species of Gryllus to become mature in the spring, the note of the male-the first Orthopteran song of the season-lhaving been heard on a number of oceasions in the central counties as early as May 5th. The young of this species, as well as of $G$. pennsylvanicus, survive the winter as nymphs. In September and October, after passing the second or third moult, they seek the shelter of loose bark on log or stump, or crawl beneath chunk or rail where they form for themselves small, inverted cone-shaped burrows in the earth, in which they abide until spring. Those which attempt to pass the winter with only a shelter of bark above them almost always succumb to the changing temperatures of that season, but those which choose more wisely a burowing place beneath some half buried $\log$ or chunk for the most part survire. The temperature of their hibernaculnm is much more equable, and the insects becoming sluggish in late autumn remain so until called into new activity by the sunshine of spring, unless, meanwhile, they fall a pres to some shrew, mouse or other active winter insectivorous mammal. They emerge from their hiding places about April 1st, and after changing their garb two or three times, 
reach the mating stage in early May, when the males begin to greet the passer-by with their merry chirp.

Neither this species nor pennsylvanicus are social erickets. Sometimes two or three of the young have adjacent burrows beneath the same chunk, but more often both they and the adults are solitary. The eggs are laid in June and July, and the newly hatched young are to be found in numbers during July and August.

Caudell $(1907 \mathrm{~d}, 292)$ has stated that this form is the same as G. nigra Harris $(1841,123)$, but that form was regarded both by Uhler $(1862,152)$ and Scudder as a synonym of pennsylvanicus which Harris did not mention. Moreover, the type of Harris is destroyed and his original description is so short and incomplete that no one can tell what species he had in hand. ${ }^{83}$ I therefore have retained this as a middle-western variant or form of $G$. assimilis.

From pennsylvanicus, with which form vernalis was confused until 1903, the latter may be readily separated by its smaller size, narrower pronotum, more uniform shining black color, shorter cvipositor, and the shape, and position, when at rest, of the female tegmina. The reticulation of the dorsal field of these tegmina is more noticeable in vernalis than in pennsylvanicus, the main diagonal nerves being eloser together and the cross nervules more elevated and prominent. Moreover, vernalis reaches maturity in the spring about a fortnight the sooner.

Outside of Indiana, vernalis (as G. americanus) has been recorded from Illinois and Texas by Hart $(1906,91 ; 1906 \mathrm{a}, 160)$ and from Franklin County, Ohio by Mead $(1904,110)$. Hart mentions it as "undersized, tegmina wholly black, usually divergent in female, peculiarly crinkled," and (1906a) says: "From what I have seen of this in Illinois I should think it was clearly distinct."

333f. Gryllus Assimilis Neglectus Scudder, 1862, 428. Neglected Field Cricket.

Size small to medium for the genus. Nearly a uniform piceous-black; tegmina sometimes black, frequently a light ochraceous brown. Pronotum about one-half wider than long. Tegmina of females covering two-thirds or more of abdomen, those of male reaching to its extremity. Ovipositor about one-third longer than hind femora. Other characters as given in key. Length of body, ô, 15.5-21,,$+ 18-23$; of pronotum, $\hat{\delta}, 3.2-3.4$, ㅇ, 3.3-4; of tegmina, ㅅ, $9-11$, ㅇ, $7.5-10.5$; of hind femora, $\hat{o}, 9.4-10.8$, 오, 9.4-11.5; of ovipositor, $12.5-15 \mathrm{~mm}$.

\footnotetext{
${ }^{83}$ It was as follows: "We have another species with very short or abortive wings; it is entirely of a black color and measures six-tenths of an inch in length from the head to the end of the body. It may be called Acheta nigra, the black cricket."
} 
This form or rariant is, according to Scudder, (loc. cit.) the most common one in New England. R. \& H. (1915c, 302) state that it is "found in the northeastern part of the distribution of G. assimilis, ranging southward in the high Appalachians to northern Georgia and is known from the Piedmont plateau only in Pennsylvania." To this form Piers $(1918,343)$ refers the only form of Gryllus found in Nova Scotia and says (p. 352) :

"In the vicinity of Halifax it is usually found on dry, sloping banks, with scant regetation and therefore somewhat earthy and having some flattish stones scattered about, on country roadsides, the borders of fields, and similar places. It does not seem to congregate in numbers but is usually met with in pairs, a male and a female, under small stones, and when the stone is lifted it runs rapidly about, this way and that, in a bewildered manner, looking for a hiding place or its little burrow. Itš leaping power is plainly not so great as that of Nemobius, and it makes but short jumps, and prefers if possible to find a place of concealment by running away. Its timidity and secretive nature cause it to be seldom seen about Halifax; but its notes draw attention to its hiding-place beneath a stone or piece of rubbish, where it can easily be captured.

"The eggs are deposited in loose soil in the latter part of the autumn and hatch the following year, possibly early in June or thereabouts. Its notes or shrilling are apparently first heard near Halifax about August 2 and are frequently heard during both day and night in suitable places; but by October the number is much lessened in daytime and few or none shrill at night. The note is considerably louder, and is a shorter, slowertimed, and more distinct and noticeable trill than that of Nemobius fasciatus. It sounds like the trilled syllable plee-e-e. After eack such trill it is silent for a moment and then calls again, thus: plee-e-e; plee-e-e; and so on. These notes sound out distinctly louder and more staccato from the omnipresent undertone and lower-toned tremolo resultant from the intermingled shrilling of countless numbers of Nemobius on all sides. When both species call more faintly at the beginning of the season, it is much more difficult to differentiate between the two."

This form occurs at high altitudes and has a more northern range than $G$. a vernalis. It averages larger in size, has the ovipositor longer in comparison with the hind femora, the reins of female tegmina less reticulate and matures at a much later date. 334. Gryllus domesticús Linnæus, 1758, 428. House Cricket.

Size medium; form slender. Pale yellowish-brown or straw color; head with a dark reddish-brown bar on occiput just in front of pronotum; another between the upper portions of eyes; a third between the bases of antennæ and a fourth across the labrum, the lower two sometimes united. - Pronotum with four or five irregular shaped spots of reddish-brown on dorsal surface, and a narrow bar of the same color each side; its hind margin slightly convex. Tegmina reaching nearly or quite to end of abdomen; sometimes with a reddish-brown spot on basal third. Inner wings either short and covered by, or extending considerably beyond, the tegmina. Hind femora short, rather slender. Ovipositor one-fifth longer than hind 
femora, pale brown except the tip, which is darker. Length of body, $\hat{\delta}$, 16.5 , $\$, 15$; of pronotum, $\delta$ and $q, 3.5$; of tegmina, 11; of hind femora, 10 ; of ovipositor, $12 \mathrm{~mm}$. (Fig. 239.)

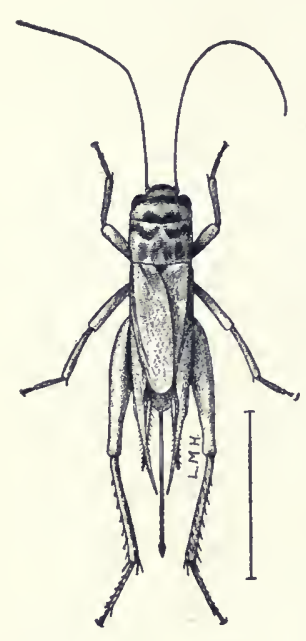

Fig. 239. Female. (After Lugger.)

The "house ericket" or "cricket of the hearth" appears to be scarce in Indiana. Until January 1, 1903, I had in my collection but three specimens, two long-winged males and a short-winged female, taken from beneath rubbish in a gravel pit near West Terre Hante, Vigo County, in October, 1894. On the later date mentioned I secured a dozen or more adults and nymphs in a greenhouse just north of the city of Indianapolis. The proprietor informed me that the males utter their eall note throughout the winter and that the insect is seemingly most abundant at that season. It has also been noted near Bainbridge, Putnam County by J. S. Michaels.

This is an Old World cricket and probably occurs sparingly in most of the states east of the Rocky Nountains, though recorded from the south only from "Carolina," Georgia, Alabama and Texas. Scudder states that he has seen no short-winged speeimens from the United States, though they are common in Europe. It is probable that in many instances the so-called "house-eriekets" of the present country homes are field crickets, especially G. huctuosus, which have striven to prolong their existence by seeking shelter within the domiciles of man. Marlatt $(1896,52)$ has given the following pleasing account of the habits of this house cricket:

"In Europe, and in some parts of the United States, no insect inhabitants of dwellings are better known than these domestic or house crickets. not so much from observation of the insects themselves as from familiarity with their vibrant, shrilling song notes. These notes, wbile thoroughly inharmonious in themselves, are, partly from the difficulty in locating the songster, often given a superstitious significance and taken, according to the mood of the listener, to be either a harbinger of good and indicative of cheerfulness and plenty, or to give rise to melancholy and to betoken misfortune. The former idea prevails, however, and Cowper expresses the common belief that the-

'Sounds inharmonious in themselves and harsh,

Yet heard in scenes where peace forever reigns,

And only there, please highly for their sake.'

"The house cricket usually occurs on the ground floor of dwellings and evinces its liking for warmth by often occurring in the vicinity of fire- 
places, concealing itself between the bricks of chimneys or behind baseboards, frequently burrowing into the mortar of walls. It is particularly apt to abound in bakehouses. It is rarely very abundant but at times multiplies excessively and becomes a very serious nuisance. During cold weather or in cold rooms in winter, it remains torpid, but under the influence of warmth it becomes active and musical. It is easily kept in captivity as a pet, and will reward the possessor by furnishing an abundance of its peculiar melody, and in Spain it is often kept, it is reported, in cages, as we do singing birds. It is in the main nocturnal in its habits, coming out in the dusk of the evening and roaming about the house for whaterer food materials it may discover. It feeds readily on bread crumbs or almost any food product to which it can get access, and is particularly attracted to liquids, in its eagerness to get at which it often meets death by drowning. It is a very pugnacious insect and will bite vigorously if captured, and is often predaceous or carnivorous, like most of its outdoor allies It is supposed to feed on various other house insects, such as the cockroach and is also probably canibalistic. A pair of native species kept in a cage by the writer, for a short period manifested the greatest friendliness, but the male shortly afterwards made a very substantial meal of his companion.

"These Crickets, in common with most other Orthoptera, will occasionally in pure wantonness seemingly, cut and injure fabrics, and are particularly apt to cut into wet clothing, evidently from their liking for moisture. Any of the common field grasshoppers or crickets, entering houses, are apt to try their sharp jaws on curtains, garments, etc., and Dr. J. A. Lintner records the case of a suit of clothing just from the tailor which was completely ruined in a night by common black field crickets (Gryllus luctuosus), which had entered an open window in some numbers. There is a popular superstition also to the effect that if a cricket be killed its relatives will promptly cut the garments of the offender.

"The house cricket may be readily destroyed by taking advantage of its liking for liquids, and any vessel containing beer or other liquid placed about will usually result in crickets being collected and drowned in numbers. It may also be destroyed by the distribution of uncooked regetables, such as ground up carrots or potatoes, strongly poisoned with arsenic. In the use of poisoned baits in dwellings great care, however, should always be exercised."

Walker $(1904,252)$ records the taking of all stages of $\mathrm{G}$. domesticus in late autumn in the basement of the General Hospital at Toronto, Ontario. They were "lurking in the chinks between the bricks of the wall and positively swarmed under loose bricks close to the furnace. Morse does not mention it from New England (1919a) thougl R. \& H. (1915c) state that it has been recorded from Connecticut.

\section{Subfamily TI. OECANTHINÆ.}

The White Tree Crickets.

Slender bodied crickets of a pale color having the head elongate, horizontal or nearly so; reltex declivent, passing gradually 
into the face; eyes large, ovate, lying obliquely behind the basal joint of antennæ; ocelli absent; antennæ more than twice as long as body, filiform, the two basal joints usually ornamented with black markings; pronotum longer than broad, somewliat narrowed in front; lower margins of lateral lobes with front and hind angles rounded; tegmina of males rather firm, rigid, semi-transparent, flat, much wider than the abdomen, their tips broadly rounded; of females narrow, membranous, wrapped closely about the body; wings usually longer than tegmina; legs very slender: fore and middle tibiæe unarmed, the former dilated near base and furnished each side with a large elongate-oval tympanum; all the femora unarmed beneath, the hind ones rery slender; hind tibia usually armed above on each margin with a row of rery numerous minute teeth and three to six longer spines, also with three pairs of subapical spurs; tarsi three-jointed, the basal joint longer than the others united. Subgenital plate of male scoopshaped, its apex rounded. Ovipositor straight, shorter than hind femora, the tips of inner valves wedge-shaped, of outer ones armed with four short, rather blunt curved teeth.

All our species of Oecanthus are mainly arboreal, living on trees, vines, shrubbery and the taller herbaceous plants. They especially frequent the various species of golden-rod and wild sunflowers, and often three or four ean be found on a single one of these plants. For the most part they remain quiescent during the day, but are quite active at night.

The first mention in this country of the peculiar mating habits of Oecanthus was made in my former work $(1903,452)$ as follows :

On September 18,1898 , I was in late afternoon in a wet prairie near Hammond, Indiana, where $O$. fasciatus was more than usually abundant on clumps of wild sunflower. A half dozen or more pairs were seen in copulation. In this act it seems that the female mounts the body of the male, the latter first raising the tegmina until they stand at an angle of about 45 degrees, so as to give the female access to a pair of glands which lie immediately beneath the base of wings. The female worked at these glands with her mandibles, the male meantime moring the inner wings gently sideways, in and out. After working over the glands for ten or fifteen minutes, the female would usually leave the body of the male and crawl onto an adjacent head of the sunflower. The male meantime kept the tegmina raised, seemingly in waiting for her return, which was always at the end of five or six min- 
utes. During the process, no intromittent organ of the male was noticeable, nor was any union of the parts at the end of the abdomen seen. Is it possible that in the mating of these Oecanthids the female removes the semen from the glands whose openings are beneath the tegmina of the male and then fertilizes her ova?

Since then the mating habits of the different species of Oecanthus have been carefully studied and described by Hancock (1905, 1911) and Houghton (1909) and they are concisely stated by Fulton $(1915,3)$ as follows :

"The interest in these insects centers chiefly about their remarkable reproductive structures and instincts and their peculiar oviposition habits. The song of the male, which serves to attract the female, is produced by a minute rasp on the under side of the forewing which is scraped by a structure on the inner edge of the opposite wing. In producing the sound the wings are raised at right angles to the body and vibrated rapidly. When the wings are so raised, there is exposed on the metanotum a glandular hollow, the secretion of which is very attractive to the female. The latter climbs over the abdomen and feeds on the secretion. The male takes advantage of the position and inserts the barbed capillary tube of a spermatophore into the genital opening of the female and the sperms pass into the seminal receptacle. The spermatophore is formed in a peculiar pouch at the tip of the abdomen of the male by the hardening of a viscous liquid about a mass of sperms."

"The female prepares for oviposition by chewing a small pit in the bark of the plant. The drilling is accomplished by quick downward thrusts of the ovipositor and a slower twisting motion. After the egg is deposited a quantity of mucilaginous substance is discharged into the hole, and with most species the female plugs up the opening with chewed bark or excrement."

"The songs of tree crickets form a considerable part of the insect sounds to be heard in late summer and autumn. The males generally place themselres in some hidden retreat among the leaves, with only their long antennæ projecting to warn them of approaching danger. They stop singing at the slightest jar of the ground or movement of the plants in which they are located, but at night a strong light can be thrown on them withcut appreciably disturbing them.

"In preparing to sing the male raises the fore wings or tegmina perpendicular to the body. This movement automatically unfolds them so that the inner portion, which normally lies over the back, and the inflexed outer portion, come to lie in the same plane when the wings are raised. The sound is produced by the fore wings vibrating rapidly in a transverse direction, so that the orerlapping inner portions rub against each other.

"The mechanism which produces the sound is found near the base of the wing, the broad expanded distal part serving as a resonator to increase the volume of sound. A short but prominent transverse vein, about onefourth way from the base, is modified beneath to form a minute filiform rasp. It is from one to one and a half millimeters long according to species, and bears from 20 to 50 short teeth which are inclined slightly toward 
the opposite wing. In all of many specimens examined the right wing laps over the left. The latter has a fine thickened ridge along the inner edge just opposite the file. This scrapes against the teeth of the file on the right wing and thus produces the sound vibrations. The underside of the left wing has a file practically identical to the other but this is apparently seldom, if ever, used."

The eggs of the white tree crickets are deposited either singly and irregularly in the bark of trees or shrubs, or singly but usually in more or less regular rows in the pith of twigs, berry canes, grape vines and weed stems. By these habits of oviposition they often cause much damage to the growing plants, which is in part offset by their habits of feeding upon aphids and perhaps the young of other injurious insects.

In addition to the works above cited treating especially of the mating habits the principal literature treating of our North American species of the subfamily is as follows: Fitch, 1856; Saussure, 1874, 456-464, 1878, 591-597; Riley, 1881; Blatchley, 1903 ; Forbes, 1905; Fulton, 1915; R. \& H., 1916. Kirby $(1906,62)$ recognized 34 genera of Oecanthinæ. Of these but two are represented in the eastern United States.

$$
\text { KEY TO EASTERN GENERA OF GCANTHIN Æ. }
$$

a. Hind tibiæ armed above with both spines and small teeth; base of thorax not suddenly dilated; wings but little if any longer than tegmina.

I. Oecaithus.

aa. Hind tibiæ not armed above and with only two very small spurs each side at apex; base of thorax suddenly strongly dilated to form a distinct border; wings nearly twice as long as tegmina.

II. Neoxabea.

I. Oecanthus Serville, 1831, 134. (Gr., "to inhabit" + "flower.")

The principal characters of the genus are given under the subfamily heading and in the above key. In addition they have the fourth segment of maxillary palpi nearly as long as third; tegmina of female regularly reticulated with the oblique longitudinal vein plainly visible; tegmina of male with humeral angle distinct and mediastinal vein weakly bowed; hind tarsi imperfectly 4 jointed, the suture between the third and fourth segments visible, but the fourth one immovable; the first or basal segment much longer than the others united, and armed each side with a single apical spur; anal cerci straight, slender, tapering, bristly, nearly as long as abdomen.

The name Oecanthus, signifying "I dwell in the flowers," does not truly represent the liabits of the insects as they are more often found upon the twigs and foliage than in the flowers them- 
selves. Kirby $(1906,72)$ recognized 27 species of the genus, 16 of them from America. Of these six species and one color variety occur in our territory. Hart (1892) first showed that the form and arrangement of the black markings on the basal joints of antennæ of Oecanthus furnish reliable character's for determining the species, and these markings have since been used as the principal differential character in all kess.
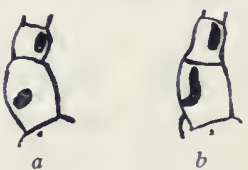

$b$
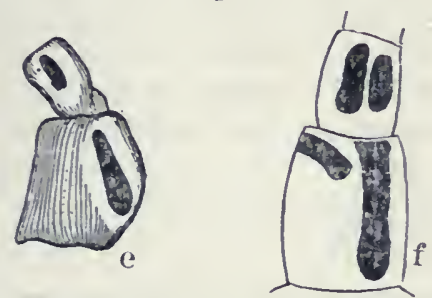
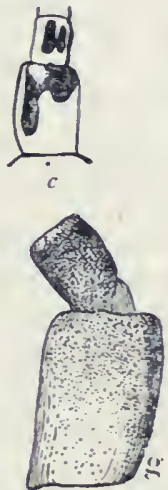
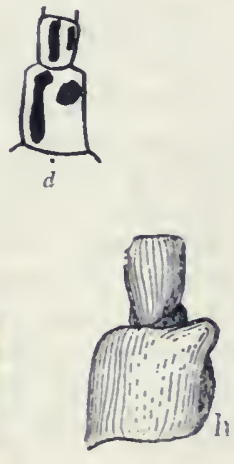

Fig. 240. Basal joints of antennze of Oecanthus and Neorabea showing the black markings. $a, O$. nir'eus;, b, angustipennis; $c$, nigricornis; $d$, quadripunctatus; $e$, exclamationis; $f$, pini; $g$, latipennis; $h, N$. bipunctatus. (After Lugger \& Fulton.)

KEY TO EASTERT SPECIES OF ECANTHUS. ${ }^{84}$

a. Antennæ with one or more black spots on under side of the first two basal segments; tegmina of male less than half as broad as long, their greatest width not over $6 \mathrm{~mm}$; front of head and base of antennæ never pinkish.

b. First and second basal segments of antennæ each with a single black mark.

c. Black marks on both segments in the form of small round spots (Fig. 240, a.)

335. NIVEUS.

cc. Basal segment with an elongate black mark.

d. Mark on basal segment j-shaped, hooked at base (Fig. 240, b.)

336. AYGUSTIPENTIS.

dd. Mark on basal segment club-shaped, not hooked (Fig. 240, e.)

337. EXCLAMATIOXIS.

bb. First and second segments each with two black marks or wholly black.

e. Head and thorax pale yellowish-green or black or marked with both colors.

f. Marks on basal segment broad, often confluent (Fig. 240,c); antennæ usually in great part black; head and thorax either black or trifasciate with black; lower surface of abdomen in part black.

338. NIGRICORNIS.

${ }^{84} \mathrm{I}$ have not included $O$. forbesi Titus (Can. Ent. XXXIV, 260) as it was probably described from a specimen with malformed palpi. Hart (Ms.) states that the unique male type without the palpi is in the collection at Urbana, Ill., and looks to him "like an ordinary 4-punctatus." As far as I can ascertain only the one specimen is known. 
ff. Marks on basal joint usually narrow, parallel, distinct (Fig. $240, d$ ) ; head, thorax and abdomen wholly pale greenishyellow.

338a. QUADRIPUNCTATUS.

$e e$. Head, thorax and antennæ reddish-brown; wings in life with conspicuous green veins; black marks on basal antennal segment broad, rarely confluent (Fig. 240, f.) 339. PINI.

aa. Antennæ without black marks on basal segment (Fig. 240, g) ; tegmina of male more than half as broad as long, their greatest width more than $6.5 \mathrm{~mm}$; head and basal joints of antennæ usually suffused with pinkish.

340. LATIPENNIS.

335. Oecanthus niveus (DeGeer), 1773, 522. Snowy Tree Cricket.

Form moderately slender. Ivory white, more or less tinged, especially in female, with a very pale green; top of head and basal segments of antennæ usually suffused with pale orange-yellow; black spots on both basal segments round. Pronotum almost as broad as long. Tegmina of male broader than in any species except latipennis. Wings but slightly exceeding tegmina, male, surpassing them about $4 \mathrm{~mm}$., female. Ovipositor short, straight, tipped with black. Length of body, $\hat{o}$ and $ᄋ, 12-14.5$; of tegmina, $\hat{\delta}, 13-14$, $ᄋ, 12-13$; of hind femora, $\hat{o}, 8.5-9$, $ᄋ, 9-10$; of ovipositor, $5.5 \mathrm{~mm}$. Greatest width of tegmina, $\hat{o}, 5.5-6 \mathrm{~mm}$. (Fig. 241.)
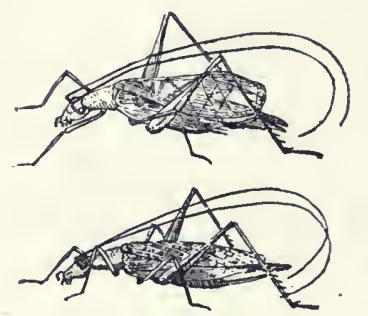

Fig. 24I. Male and female.

(After Beutenmuller.)

While the snowy tree cricket occurs in all parts of Indiana, it appears to be less common in the State than either O. angustipennis or quadripunctatus, and much of the published literature relating to it has doubtless been of these and other species. Like the other members of its genus niveus reaches maturity in southern Indiana about July 1st, and in the central part a fortnight later, and exists in that stage until after heavy frosts. The females appear to be more plentiful than the males, the latter being more often heard than seen. During the day they keep themselves hidden among the foliage and flowers of various plants, but as night approaches they come forth and the male begins his incessant, shrill, chirping note, which he continues with little or no intermission till the approach of morning warns him to desist.

The range of nivens is said by Fulton (1915) to be wider than that of any other Occanthus, extending from New England and Ontario to Minnesota and Utah, south and southwest to Georgia, Texas, Cuba and Mexico. It is not recorded from Florida and K. \& H. $(1916,296)$ state that Thompson's Mills, Ga. and Cranberry, N. Car. are the only reliable definite records from the southeastern United States. 
Fulton (loc. eit.) says that $O$. niceus "is a tree- and bushinhabiting form. It is found most abundantly in apple orchards and is more or less common in plantings of other fruit trees and in raspberry plantations, shrubberies, vines and bushy fence rows. Among forest trees it is less common, although a few can often be heard singing in such places, especially along the edge of a wood. In general this species prefers a cultivated region to a wilderness. Howerer, in orchards that are regularly sprayed with arsenicals, the crickets do not become very abundant."

Morse (1919a) states that nivens is common throughout southern New England in shrubbery near houses, orchards and gardens from late August till October. Walker (1904, 253) sars that nivens is rerr common in the cultivated parts of Ontario and that of native trees he had found it most partial to butternut, where the females are found on the trunk and lower branches, but the males higher up and more difficult to obtain. He adds: "O. niveus is generally held responsible for a great deal of mischief done to raspberry and blackberry canes by the females in laying their eggs. It is my belief that most of this damage, at least in this locality, is done by 0 . fasciatus and quadripunctatus which abound on raspberry bushes, while nivens is seldom if ever found on them." This belief, as will be noted below, has beell since proven to be correct.

The first definite account of the song and habits of niveus is that of Fitch $(1856,406)$ in part as follows:

"In the southern part of New York the song of the snowy tree cricket begins to be heard as early as the first of August. Perched among the thick foliage of a grapevine or other shrubbery, some feet up from the ground, and remaining in the same spot day after day, its song begins soon after sunset and before the duskiness of twilight arrives. It is distinctly heard at a distance of several rods, and the songster is always farther off than is supposed. Though dozens of other crickets and katydids are shrilling on every side at the same time, the peculiar note of this cricket is at once distinguished from all the rest, consisting of repetitions of a single syllable, slowly uttered, in a monotonous, melancholy tone, with a slight pause between. The children regard the cricket as no votary of the temperance cause; they understand its song to consist of the words treat-treat-treat-treat. which words, slowly uttered, do so closely resemble its notes that they will at once recall them to the recollection of almost erery reader. And the song is thus continued without the slightest variation and without any cessation, I think, the whole night through. I, however, have sometimes heard it at the first commencement of its evening serenade uttering three syllables resembling the words treat, treat, two; treat. treat, two-as though the songster was supplicating a libation for his voiceless mate as well as himself, a longer pause following each 
third note. This prelude is probably performed in limbering or otherwise adjusting his organs, preparatory to performing the regular carol, which is struck into in a few moments."

Houghton (1904, 1909a) and Parrott and Fulton (1914) have shown that $O$. nigricornis and not $O$. niveus is the tree cricket that does so much damage by ovipositing in rows in rasplerry canes and that niveus deposits the eggs singly in apple, plum, elm and other trees, though sometimes singly in the raspberry cenes. The method of ovipositing by niveus is thus described by Parrott \& Fulton:

“The female selects a suitable spot on a tree or bush and prepares to oviposit by first chewing a small hole in the bark, choosing the upper side of a branch in preference to the lower side, and working with the head uppermost when on a sloping or vertical surface. Upon the completion of the cavity she then walks forward a little, arches her back so as to bring the ovipositor about perpendicular to the branch and begins moving it up and down until she strikes the hole. She then starts to drill by giving the ovipositor quick thrusts and at the same time slowly turning it around by twisting the abdomen 30 or 40 degrees to each side. As the ovipositor is forced in it takes a more or less oblique course, according to the thickness of the bark, so that the egg usually comes to lie nearly parallel to the surface. It generally takes from six to seven minutes to force the ovipositor to its base the first time, but in some cases it takes much longer, depending on the resistance of the bark. After the operation this organ is pulled nearly out and drilled in again several times, each effort taking about one and a half or two minutes. When the hole is sufficiently reamed out and the ovipositor drilled in for the last time the female forces out a drop of excrement and, by stretching out the tip of the abdomen, fastens it to the bark just below the hole. The egg is then forced down and the ovipositor is slowly withdrawn. The female pauses with only the tip remaining in the hole and deposits some mucilaginous substance. She then removes the ovipositor, moves a slight distance backward, seizes the drop of excrement in her mouth and places it over the opening; then spends several minutes packing it in and smoothing it out so that the wound is neatly cappea. The whole process of depositing an egg, from starting to drill until the hole for the reception of the egg is sealed, may consume from twenty min. utes to three-quarters of an hour.

"In trees having a rather soft, fleshy bark, such as apple and plum, niveus prefers to oviposit in fairly large branches from one to three inches in diameter. The eggs may be placed in almost any area in the bark, but a favorite location is in a lenticel where the initial drilling is more easily accomplished. In bushes and trees in which the large branches have a tough bark the eggs are commonly laid in the smaller branches in thick places in the bark on each side of the base of a small twig or bud. In raspberry canes, where the eggs are sometimes fairly common, oviposition usually occurs in the fleshy area at the side of the bud in the axils of the

${ }^{85}$ Other interesting accounts of the song of $O$. nireus are given by McNeill (t89r), Scudder (1893), Shull (1907) and Allard (1911.) 
leaves, and we have nerer found more than one egg on each side of a bud. However, the egg never extends through the woody layer into the pith, as is the case with nigricornis."

Whatever injury $O$. nivcus mas do in oripositing is, in part at least, offset by its carnivorous propensities, as the young which hatch in May or early June, feed, until they reach maturity, largely upon the various species of aphids or plant lice which infest the shrubbery they frequent. Walsh $(\mathbf{1 S 6 7}, 54)$ was the first entomologist to call attention to this carnirorous habit, but it scems little attention was given to the matter until Murtfeldt (1889) gave an interesting account of some experiments and observations concerning this habit from which the following extract is taken:

"Some leaves of plum infested with a delicate species of yellow aphis were put into a jar with the young of oecanthus niveus, but attracted no immediate attention. As twilight deepened, however, the crickets awakened to greater activity. By holding the jar against the light of the window, or bringing it suddenly into the lamplight, the little nocturnal hunters might be seen hurrying with a furtive, darting movement, over the leaves and stems, the head bent down, the antennæ stretched forward, and every sense apparently on the alert. Then the aphids provided for their food would be caught up one after another with eagerness and devoured with violent action of the mouth parts, the antennæ meanwhile playing up and down in evident expression of satisfaction. Unless I had provided very liberally not an aphis would be found in the jar the next morning and the sluggish crickets would have erery appearance of plethora."

336. Oecaxthus Axgustipexis Fitch, 1856, 413. Narrow-winged Tree Cricket.

Form very slender. Pale greenish-white; vertex and base of antennæ often yellowish; each of the first two basal joints of antennæ with a black mark, that on the first one elongate and hooked inward at base; the one on second joint oblong, slightly curved; tegmina of male translucent with a greenish tinge. Head smaller and pronotum slightly longer and narrower in front than in niveus. Tegmina of male narrower than in any other species except quadripunctatus. Wings slightly surpassing tegmina in length. Length of body, $\hat{o}, 12-14,9,11.5-13$; of pronotum, 2.8 ; of tegmina, ô, $10-12$, $\uparrow, 12$; of wings, 13.5 ; of hind femora, 8.5 ; of ovipositor, $5.5 \mathrm{~mm}$.

The narrow-winged tree cricket does not appear to be a common insect in Indiana, haring so far been taken only in Vigo, Putnam, Lawrence, Flosd and Crawford counties. It frequents the borders of groves and especially ironweeds in open pastures and reaches maturity about July 15.

About Dunedin, Fla. I have taken adults of angustipennis by beating and sweeping in October, December, January and March, and it has been sent in as taken at porch light in Mar and June. 
It appears to be much less common in that State than quadripunctatus, having been recorded only from Gainesville, Monticello, LaGrange and Lakeland. At LaGrange it was collected by Davis (1914) "among the golden rods and other low plants by the side of the road; also on small oaks and other trees. The song is loud, about three or four seconds long, with an equal interval of rest."

The known range of $O$. angustipennis extends from New England west to Minnesota and Nebraska and south and southwest to Georgia, Dunedin, Fla., Mississippi and, according to Allard, Texas. In New England it is definitely known, says Morse, only from near Boston and at various points in Connecticut, where it "frequents orchards, fruit trees and even low thickets of sweet fern." Beutenmüller $(1894,270)$ says that about New York City it is "not as common as niveus and inhabits the higher parts of different kinds of forest and fruit trees. The note is fainter than that of niveus and may be represented by reeeeeee, lasting about five seconds, and terminating abruptly, with an equal interval of rest. It usually sings at night only, but sometimes also late in the afternoon in shady places, and on cloudy days." Fox (Ms.) reports it from Clarksville, Tenn. and Hubbell from Washtenaw Co., Mich. In Nebraska Bruner found it "pretty well distributed over the easter'n part of the State."

Fulton (1915, 27, 29) says of angustipenuis:

"It is often found in company with niveus and is generally abundant in apple orchards. It is more strictly arboreal than the latter species, and seems to be confined to woody plants, either trees or large bushes. About Geneva, N. Y., it has never been taken on raspberry, grape or weeds of any kind. Among forest trees it is more common than niveus. Many specimens have been collected from scrub and post oaks on Long Island, and from alder in a swamp near Geneva. The song of this species is not so loud as that made by niveus and is of a more mournful quality. It is, like that, intermittent, but can be readily distinguished by its longer notes and rests and its nonrythmical character. Each trill continues from one to five seconds. The periods of rest vary more and may be from one to eight seconds or longer. On trees where angustipennis occurs in equal abundance with niveus, its song is nearly drowned out by the synchronous beat of the latter species and only by listening intently can it be detected. So far as observed it sings throughout the night and remains silent during the day."

Allard (1910b) wrote of the song of angustipennis in north Georgia as follows:

"It sings on cloudy afternoons, though its song is best heard after sunset. As the shadows become deeper in the oak trees and the breezes have ceased, a faint, brief high-pitchd $p r-e-e-e$ is heard. This is soon repeated by others in different keys at brief intervals. The notes of this cricket, to me, inspire a weird pathos, unlike any 
other insect music. The phrase $p r-e-c-e$ does not sustain the same uniform pitch, but dies away in a slightly lower ker, a change which is hardly noticeable to the untrained ear. Each note is a nyysterious, momentary wail amidst the shadowy foliage of the caks, and seems like the roice of a complaining spirit interrupting the serenity of the night."

337. Oecaxthus exclanatioxis Davis, 1907, 173. Davis's Tree Cricket.

Somewhat larger and stouter than angustipennis. Pale greenishwhite; occiput and vertex pale to orange yellow; first antennal segment swollen in front, the protuberance with a black club-shaped mark, second segment with a short dash directly above, the two marks together appearing like an inverted exclamation point. Pronotum slightly shorter and wider than in angustipennis, the lower portion of lateral lobes more flattened. Tegmina of male slightly longer and broader. Wings more strongly protruding, exceeding tips of cerci. Length of body, $\hat{\delta}$ and $\rho 12-15$; of tegmina, $\hat{\delta}$ and $\$, 13-14$; of oripositor, $5 \mathrm{~mm}$. Width of tegmina, $\hat{o}$, $5-5.5 \mathrm{~mm}$.

Central Park and Staten Island, N. Y., August (Davis). Not yet identified from Indiana, though it doubtless occurs in the State, as the known range extends from Connecticut west to Cedar Point, Ohio and Hollister, Mo. and southwest to Clarksville and Johnson City, Tenn. About New York City Daris finds it mainly on the post-oak, Quercus minor (Marsh) and other species of oak, often in company with $O$. angustipennis to which it is very closely related.

Fulton $(1915,31)$ states that "The song of exclamationis is intermittent and non-rhythmical and most resembles the song of angustipennis. The beginning of each note is comparatively weak, but the sound increases in volume and slightly in pitch and continues uniformly until it abruptly ends. In quality it most resembles the distant singing of the common toad." Females kept in captirity deposited many eggs in the bark of oak branches between half an inch and an inch in diameter. The habits of oriposition are very similar to those of $O$. niveus as the female "would fasten a drop of excrement to the bark before depositing the egg and after pulling out the ovipositor would pick the pellet up and force it into the hole. She would then chew off small pieces of bark and add them to the plug, and spend five or ten minutes putting on the finishing touches."

338. Oecaxthus Nigricoris F. Walker, 1869, 93. Black-horned Tree Cricket.

Size medium and form robust for the genus. Greenish-yellow; head and pronotum either wholly black or with three more or less distinct lengthwise black stripes; legs yellowish with a blackish tinge or wholly black; 
tibiæ and tarsi black; abdomen black beneath, yellowish-green above.

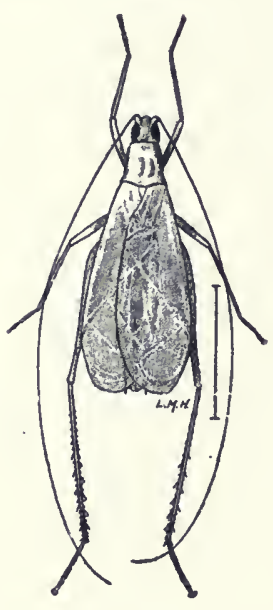

Fig. 242 . Antennæ longer than in any other species, often two and a half times the length of body, either wholly black or with two black marks on each of the two basal segments; the inner mark on the first one twice the length of the other, the two often merged above. Tegmina slightly narrower than those of niveus. Wings equalling or slightIy surpassing the tegmina. Apical spurs of hind tibiæ stronger and more acute than

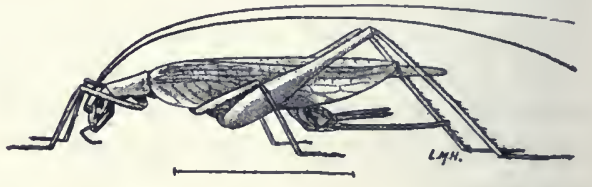

$a, \stackrel{b}{\text { male; } b \text {, female. }}$

in allied species. Ovipositor with apical third slightly but distinctly upcurved. Length of body, $\delta$ and $9,12-14$; of pronotum, 3 ; of tegmina, $10-12$; of inner wings, $12.5-13.2$; of hind femora, $9.2-10$; of ovipositor, $5.7 \mathrm{~mm}$. Width of tegmina, ô, 4.5-5 mm. (Fig. 242.)

This is the 0 . fasciatus Fitch of most American authors, myself $(1903,450)$ included, Fitch having wrongly identified DeGeer's Nemobius fasciatus as the present insect. The next older name has therefore been given it in recent years. Scudder $(1862,431)$ was very caustic in his remarks about Fitch's misidentification, but himself on the next page wrongly made Fitch's fasciatus a symonym of $O$. niveus and later in both his catalogues used $O$. fasciatus as the name of the cricket.

This striped tree cricket is the most common Oecanthus in Indiana. In August and September, nearly every stalk of goldenrod and wild sunflower along roadsides, in open fields or in fence corners, will have from one to a half dozen of these insects upon its flowers or branches. It is also especially abundant upon the tall weeds and bushes along the borders of lakes and ponds, and ii sloughs and damp ravines.

The note of fasciatus is a shrill continuous $w h i-r-r-r-r$ which is lept up for several minutes with the intervals of irregular length. It is continued for most of the night and on cloudy days. When the sun is shining brightly it usually begins about mid-afternoon and continues with but little pause until the dawn of the next day, muless the caller is, in the meantime, successful in wooing with his music one of the opposite sex within reaching distance. 
The known range of typical $O$. nigricornis is a wide one extending from New England and Ontario west across the continent and southwest to North Carolina, Texas and Arizona. It is not as ret recorded from Georgia or Florida and numerous records under the name of fasciatus are not to be relied upon. It occurs in numbers throughout New England and Walker (1904, 254) records it as "by far the commonest tree cricket in Ontario, and during August and September it abounds on shrubs and tall herbs. especially golden-rod, and is partieularly plentiful on low grounds. Partially cleared bush lands supporting a rank growth of raspberry bushes, golden rod, boneset and other tall herbaceous plants are favorite haunts. It is so common on raspberry bushes that there is little doubt that the female is responsible for much damage to the canes, though I have no proof of this assumption. I have found it in cultirated raspberry bushes in gardens, but it is more partial to wild districts."

It is now known that $O$. nigricornis and its variety quadripunc-

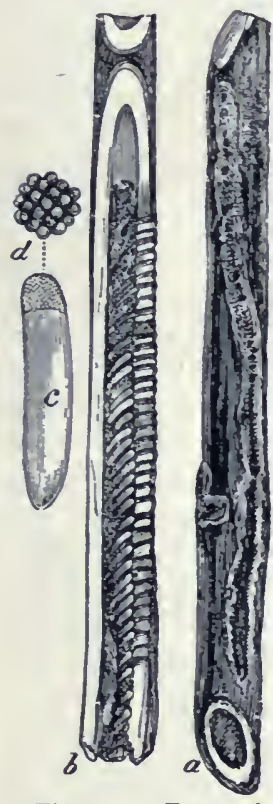

Fig. 243. Eggs of Tree Cricket in raspberry cane. (a) Cane, showing puncture. (b) Cane split to show eggs. (c) Egg enlarged. (d)
egg enlarged. (Aficr Riley.) tatus are the tree crickets which do much harm by ovipositing in the tender canes or shoots of various eultivated fruits, as the raspberry, blackberry, grape, plum, peach, etc.; no less than 321 eggs, by actual count, having been found in a raspberry cane 22 inches in length. So partial is it to the stems of raspberry and blackberry as receptacles for its eggs that in some localities scarcely a cane escapes without being more or less damaged. The eggs are laid in antumn, and at first the injury is shown only by a slight roughness of the bark, but afterwards the cane or branch frequently dies above the puncture, or is so much injured as to be broken off by the first high wind. If the injured and broken canes containing the eggs be collected and burned in early spring the number of insects for that season will be materially lessened.

Bruner $(1895,112)$ has written of the hab its of oriposition of niveus with which he confused those of nigricornis in other plants as follows :

"In addition to cultivated fruits the snowy tree cricket also deposits its eggs in the stems of a large variety of other plants and trees-the main 
requirements being a soft fibre and pithy interior to the twigs selected. Among the trees the white willow suffers most. I have seen hedges of this tree so completely utilized that scarcely a twig escaped being deposited into. Other species of willow, cottonwood, elm, maple, box elder, cherry, dog-wood, black locust, sycamore, ash, honey-locust, and in fact almost all kinds of trees, are sometimes attacked. Elder is a great favorite, too. After these come weeds, as the artichoke, sunflower, golden-rod, ambrosia, and many others. All of these latter being annuals, or dying to the ground each year, whether attacked by the cricket or not, the conclusion is plain. All the cricket requires is a receptacle for her eggs. It matters but little whether a dead or a living plant furnishes that oondition.

"While woody plants are known to be very commonly used as receptacles for the eggs of this cricket, it is by far the most numerous upon such weeds as those mentioned above during its entire career; but more particularly so during its latter days when looking after the perpetuation of its kind."

The mating habits, oviposition and song of $O$. nigricornis have been fully described by Hancock, Houghton and Jensen in the works previously cited. Allard (1911) says that in New England "It dwells among weeds, grass and golden-rods nearly everywhere in fields and pastures. Its song is a steady, quarering, sustained trill. The trill of some individuals is strong, deep and rich-toned, recalling the mellow trill of $O$. latipennis. The pitch and volume of sound vary noticeably with different individuals."

338a. Oecanthus Nigricornis QUadripunctatus Beutenmuller, 1894a, 250.

Four-spotted Tree Cricket.

Size and form of nigricornis. Pale yellowish-green; antennæ pale brown, the two basal segments pale green with two black marks on each; those on second segment oblong, parallel, the inner about double the length of outer; the inner mark on lower or basal segment two-thirds the length of segment, its upper end curved outward but not united with the outer mark, which is short and almost round (Fig. 240, d.) Tegmina of male translucent with greenish-yellow veins, the wings protruding slightly beyond their tips. Legs dull greenish-yellow, the tarsi often in part fuscous. Ovipositor brownish with black tip. Length of body, 'ô and $q, 11.5$. -14 ; of pronotum, $2.4-2.6$; of tegmina, $10-12$; of wings, $12.5-13.5$; of hind femora, 8-8.5; of ovipositor, $5.5 \mathrm{~mm}$. Width of tegmina, $\hat{o}$, $4.5-4.7 \mathrm{~mm}$.

In central and southern Indiana this tree cricket is almost as common as nigricornis but in the northern part of the State it appears to occur in fewer numbers. It frequents shrubbery and weeds in gardens, along roadsides and borders of cultivated fields, and is often found in company with nigricornis. An adult female was taken in Crawford County on June 28, an early date for a tree cricket in Indiana.

In Florida I have found quadripunctatus the most common of 
the tree crickets in late fall and winter, specimens having been taken at Sanford, Cape Sable, Sarasota and Dunedin. About Dunedin it occurs on the tall grasses and weeds growing about low places in the pine woods and is also often swept from huckleberry bushes and other low shrubs; adults having been taken during every month from October to April. It has before been recorded from numerous localities in the State as far south as Ft. Myers.

By some authors, notably Fulton and R. \& H., quadripunctatus is regarded as a distinct species, but numerous specimens at hand show that intermediates occur. It is often found in numbers on the same clumps of weeds or bushes in company with nigricornis. Walker $(1904,255)$ says: "I beliere this form to be merely a pale variety of $O$. fasciatus as $I$ have a series of intergrades and am unable to draw a definite line to separate the two." Caudell i: quoted by Houghton (1909a, 114) as stating that specimens bred from the same egg clusters sent in by Houghton represented both nigricornis and quadripunctatus and that he considered the litter only a rariety of the former. Houghton quotes other evidence to show that Caudell's opinion is correct.

On the other hand $R$. \& $H$. (1916) regard them as distinct. stating that in addition to color differences nigricornis has a heavier and wider pronotum and a depression between the eves not "at all or rarely weakly indicated in quadripunctatus." Fulton (1915) separates them in his ker only by color characters, but states that they have "constant differences in liabits," quadripunctatus occurring in larger numbers in upland fields abounding in medium sized weeds such as aster, sweet clover, daisy, golden-rod, ragweed, and especially the wild carrot or Queen Ann's lace. Quite often in a field of this character where quadripunctatus is prevalent, the brushy fence rows surrounding the area will be inhabited by nigricomis. In general nigricornis prefers larger plants and more dense growth than quadripunctatus. and its habitat is more varied, it being usually found in tall, rank growths of weeds, such as in swamps and river bottoms, in brush or second growth, in fence rows grown up with bushes, briers and vines, in raspberry plantings, rinerards, nurseries and even occasionally in orchards."

As noted abore specimens are at hand showing not only all intergradations in color from almost black nigricornis to the palest of quadripunctatus, but also in the form of the thorax and depression on head mentioned by R. \& H. Moreover, Fulton states 
that the "song of nigricornis so closely resembles that of quadripunctatus that it is very dififeult to distinguish the two," and Allard (1911) says that he "has been unable to find any constant differences which serve to distinguish the trills of these two species." I therefore regard quadripunctatus as only a color var'iety of nigricornis, gradually replacing the latter south ward and wholly so in Florida. In Indiana, as perhaps elsewhere as far as can be judged from the records, the typical form nigricornis is more abundant in the cooler and moister regions and the variety in warmer and drier localities.

The range of $O . n$. quadripunctatus as given by Fulton is almost exactly that of nigricornis, Florida, Colorado and Utah being added to the list of states mentioned and California not given. R. \& H. (1916) record it from many localities from Virginia southwestward to Ft. Myers, Fla., and state that it is "the most abundant species of Occanthus in the eastern United States." Morse says that it is widely distributed and locally abundant in southern New England and extends as far north as Brunswick, Maine. Lugger recognized two forms of nigricomis as occurring in Minnesota but evidently was not aware of Beutenmüller's name for the pale one. I once found it abundant on the north shore of the Niagara River opposite Buffalo, N. Y., where it was the only Occanthus seen in early September. Specimens are also at land from Sherborn, Mass., North Madison, Conn., Mobile, Ala. and Agricultural College, Miss.

339. Oecantuus pini Beutenmuller, 1894b, 56. Pine T'ree Cricket.

Size medium, form rather robust. Head and pronotum nearly uniform dull reddish-brown, the latter with a paler stripe each side; antennæ dull brown, the two basal segments paler, the first with an elongate black spot along inner edge and a small oblique one near apex; second with two ob. long, parallel black spots; tegmina of male transparent greenish-yellow with green veins; those of female greenish-yellow, pale yellow along the fold, tinged with brown near base; legs dull brown, hind femora green; tarsi piceous; body beneath brown with sides yellowish-green. Ovipositor dull brown, the tip black. Disk of thorax subquadrate. Wings scarcely surpassing tegmina, male, a little longer, female. Length of body, $\hat{o}$ and o, 12-15; of tegmina, 11-13; of ovipositor, $6 \mathrm{~mm}$. Width of tegmina, ô, $4.5-5 \mathrm{~mm}$.

Delaware County, Penn., Sept. 29 (Hebard). Deseribed from Windham County, Conn. and ranges from Gloucester. Mass. west to Bloomsburg, Pa. and southwest to Raleigh, N. Car. Hart (1907, 235) has recorded it from northwestern Illinois but (Ms.) reports that his specimens were not from pine and their identification uncertain. 
Beutenmüller (loc. cit.) sars of it: "Resembles 0 . fasciatus but readily distinguished by the grass green renation. The insect lives only on pine trees and usually on the higher branches. Its song is a continuous soft and metallic reeeee with numerous undulations. When many individuals are heard together their stridulation sounds not unlike the distant jingling of sleigh-bells." Fulton and Daris found it in numbers on the pitch pine, Pinus rigida Mill. near Central Park, Long Island, and Davis on the Jersey or scrub pine, $P$. virginiana Mill. at Bloomsburg, Pa. Fulton $(1915,41)$ states that the female deposits the eggs about $3 \mathrm{~mm}$. apart in regular rows in pine bark.

340. Oecanthus Latipexxis Riley, 1881, 61. Broad-winged Tree Cricket.

Size large for the genus. Greenish-white, male, pale yellowish-green, female; occiput and eight or ten basal joints of antennæ pinkish, the former sometimes with four faint dusky streaks; pronotum often with a median dusky stripe, darkest in front; tegmina and wings of female often dusky at tips; legs white, knees yellowish; hind femora with a small dark spot near tip. Tegmina of male wider than in any other species. Wings much shorter than tegmina, male, surpassing their tips, female. Length of body, $\hat{o}$ and $q, 13-17$; of pronotum, 3-3.3; of tegmina, $\hat{o}, 13-16, q, 13-14.5$; of wings, $\hat{\delta}, 12, \stackrel{\imath}{, 15-17}$; of hind femora, $\hat{o}$ and $q, 10$; of ovipositor, $6.5 \mathrm{~mm}$. Width of tegmina, $\hat{\delta}, 6.5-8 \mathrm{~mm}$.

This, our largest species of Oecanthus, occurs throughout southern Indiana but has not as yet been taken in the northern half of the State. It is found mostly on shrubs and vines along fence rows, roadsides, and especially in thickets along the borders of streams and with us appears to be most abundant in October, though adults have been taken the last of August.

The known range of 0 . lutipennis is southern extending from Iong Island and New Jerser west to Missouri and Nebraska and south and southwest to Georgia and Alabama. Fulton mentions it from Michigan and Lugger, without definite locality, in his Minnesota work. Riley records a male from Columbia, Texas, but afterward states that it had black marks on antenur, which would preclude its being latipennis.

The eggs of the broad-winged tree cricket are usually laid in the pith of the smaller twigs of shrubs and vines, preferably in the slender twigs of the wild and cultivated grapes. Riley (loc. cit.) has described the method of oriposition as follows:

"The jaws are first used to slightly tear the outer bark. With the antennæ stretched straight forward and the abdomen bent up so as to bring the ovipositor at right angles with the cane, the female then commences drilling, working the abdomen convulsively up and down about twice each second. The eggs are laid lengthwise in the pith, but always in 
two sets, one on each side of the hole. The number varies according to the size of the cane, and the distance between the holes is also variable. The hole is usually filled up with a white mucous secretion, though there is very little of it about the eggs. This secretion also doubtless serves to facilitate the drilling. The same female will lay over $200 \mathrm{eggs}$, and will sometimes puncture the same cane at intervals of one-third of an inch for one and a half feet or more."

The day note of the male of latipennis is louder than that of any other species. I have heard it when 60 feet distant; have traced it up, and found the musician beneath a leaf or on a post in the angle of a rail fence, industriously sounding his cynbals. The note is kept up for 20 to 30 seconds, and is then succeeded by a pause of about five seconds, when it is begun once more. Riley has written of it, probably of the night song: "The shrill of latipennis is continuous and recalls the trilling of a high-pitched log-whistle in the distance. The key varies, however, and is sometimes much less high and more musical than at others. The commingled shrill of this species recalls also the distant croaking of frogs in spring. The broad wings are thoroughly elevated during the act, or even bent forward, and the vibration is so rapid that there appears to be no motion."

Fulton (1915) states that the song of latipennis is a loud clear whistle with a musical ringing quality. The eggs are usually laid in grapevines, though sometimes in large stalks of golden-rod growing near the vines. A single hole in the outer woody layel of the stem serves for the deposition of from four to twelve eggs which are placed side by side in the pith in two groups, one above and one below the opening. "The size of the pith determines the number of eggs. The grapevine has a small pith and will hold only two or three eggs on a side, while in the golden-rod as many as six can be found in a single cluster."

\section{Neохавеа Kirby, 1906, 76. (Gr., "near" + Xabea.)}

The principal characters separating this genus from Oecanthus are given in the generic key. In addition they have the maxillary palpi with third and fifth segments subequal, each twice as long: as fourth; tegmina of female irregularly reticulated, the oblique longitudinal veins not conspicuous; male tegmina with medias. tinal rein strongly curved, the humelal angle wanting; first joint of hind tarsi unarmed, the tarsi clearly but three-jointed, the second joint very short; anal cerci stout, strongly sinuate, only half as long as abdomen. But one species is known. 
341. Neoxabea bipcxctata (DeGeer), 1773, 523. Two-spotted Tree Cricket.

Pale pinkish-brown; tegmina of female with two pairs of rather large blackish spots, one near base, the other at middle. Antennæ pale yellow, the basal segments without black marks, the first segment slightly prolonged at its upper inner angle, forming an acute blackish tooth (Fig. $240, h)$; legs pale with a pinkish tinge. Head strongly depressed between the eyes. Fronotum nearly one-half longer than wide; subcylindrical with sides subparallel to near basal fifth, then suddenly expanded to form a much wider strongly pitted basal margin, this separated from the disk proper by a distinct cross-suture. Wings very long, protruding like tails beyond the abdomen. Length of body, $\hat{\sigma}$ and $9,13-16$; of pronotum, 3.3 ; of tegmina, $11-13$; of wings, 20 ; of hind femora, $9-10$; of ovipositor. $6 \mathrm{~mm}$. Width of tegmina, $\hat{o}, 4.5 \mathrm{~mm}$.

This long-winged tree cricket appears to be very scarce, not only in Indiana, but usually wherever found. Here it has been taken only in Vigo and Marion counties, Aug. 3-2 7 . Its known range is southern and a very wide one, extending in the United States from Connecticut west to Illinois and Kansas and south and southwest to North Carolina, Georgia and Mississippi. It is also recorded by Saussure and others from Mexico and Central America. DeGeer's type was from Pennsylvania. Morse (1919a) records it from New Canaan, Portland and New Haven, Conn., Aug. 14-Sept. 11; Smith (1910) from rarious points in New Jersey and Fulton (1915) from Ohio and Kansas. Near Cedar Point, Ohio, it was found by King on oak, willow and wild grape vines along the forest border or standing isolated at the edge of open sandy areas. R. \& H. $(1916,300)$ mention it as "extremely retiring, living only in the densest tangles of heary forest undergrowth, where solitary examples can be found only after long continued and rigorous beating."

Allard (1910b) describing its habits in north Georgia sars:

"This cricket prefers the dense leaf-canopy of grape-vines, and usually begins to sing at nightfall. It is an intermittent triller, and its low, deep, mellow trills, $t r-r-r-r$, continued only a few seconds, are separated by short intervals. Its notes are deeper, stronger, and richer than those of oecanthus angustipennis. In tone quality they more nearly approach the song of Oecanthus latipennis. .This cricket is not uncommon at Thompson's Mills, but usually congregates in small communities whererer conditions are favorable, generally in wild grape-vines by the roadside or in low trees near dwellings."

The genus Tabea Riley (nec. Walker) of my former work $(1903,453)$ and of most American writers, was replaced by Neoxabea by Kirbs, who gave as synonyms of $\mathrm{Y}$. bipunctata (DeG.) the Occanthus punctulatus Fitch $(1856,415)$ and 0 . formosus Walker (1869, 94). 


\section{Subfamily VII. TRIGONIDIIN}

\section{The Winged Bush Crickets.}

Very small crickets of a pale brown, rarely blackish hue, having the body short, stout; head large, subquadrate, as wide or wider than pronotum; antennæ very slender, three or more times as long as body; eyes rather large, subglobose or oblong-oval, separated by twice or more their own width; pronotum subquadrate, flat or feebly convex above, without carinx, its front and hind margins subtruncate; tegmina of male as long as or longer than abdomen, usually furnished with a prominent rhomboidal tympanum which is not divided and has only one long curved oblique vein; tegmina of female more narrow, usually 'slightly shorter than abdomen, the longitudinal veins straight, prominent, usually comnected by numerous alternating cross veinlets; wings when present often much longer than tegmina; fore and middle legs slender, subequal; hind femora stout, unarmed beneath; hind tibix no longer than femora armed above with three pairs of long movable spines and also near apex with two long inner spurs and three very short outer ones; tarsi slender, the basal joint longer than the other two united; second short, cordiform, depressed, third very slender; subgenital plate of male conical or scoop-shaped; cerci short, very slender; ovipositor sabre-like, much shorter than hind femora, compressed, strongly curved, acutely pointed.

But little has been written of the habits of these little crickets. The species are all hygrophilous' in habitat, liring for the most part on the foliage and stems of tall grasses and weeds and low shrubs along the margins of ponds, lakes ditches and streams. None of them are ever numerous enough to do much damage, the plants on which they dwell being of little, if any economic value.

Four genera represent the subfamily in our territory. The literature pertaining to them is scant in quantity and widely scattered, the following being the most important: Uhler, 1864; Saussure, 1874, 361, 1878, 598; Blątchley, 1903; Rehn, 1903f; R. \& H., 1912c, 1916, 300 ; Hebard, $1915 b$.

\section{KEY TO EASTERN GENERA OF TRIGONIDIINA.}

a. Last joint of maxillary palpi club-shaped; basal joint of antennæ wider than long; pronotum subquadrate, as wide as or wider than long; color never red and dark brown.

$b$. Interocular area convex, vertex strongly declivent; eyes subrotund, deeper than long; color in life dull yellow or pale to dusky brown. 
c. Front tibiæ with an auditory opening on one or both faces; males with a large stridulating area; larger, length of body, male, 4.5 or more $\mathrm{mm}$.

I. Axixipha.

cc. Front tibiæ without an auditory opening; males with a minute stridulating area; smaller, length of body, male, $4 \mathrm{~mm}$.

II. Falcicula.

$b b$. Interocular area strongly flattened, vertex but little declivent; eyes compressed, longer than deep; color in life pale greenishyellow.

III. Crrtoxipha.

aa. Last joint of maxillary palpi lobate, deeply concave; basal joint of antennæ longer than wide; pronotum subcylindrical, longer than wide; head and thorax red, tegmina dark brown. IV. PHYlloscrites.

I. Axaxipha Saussure, 1S74, 370. (Gr., "upraised" + "sword.")

Very small brown or dusky erickets having the head rertieal; front oblique, declivent and forming a protuberance between the antennæ; ocelli very small, arranged in a triangle; antennæ excessively long, setaceous; last joint of maxillary palpi longer than the one preceding, its apex dilated and truncate; pronotum short, broad, bearing numerous erect stiff hairs; tegmina of male with dorsal field very wide, their tips rounded; the speeulum on apical half prominent, undivided by a cross nerve; tegmina of female more narrow and closely embracing the sides of abdomen; wings either absent or present and nearly twice as long as tegmina; legs long, pubescent; front tibia with hearing organ present on both faces in winged forms, on outer face onls in wingless forms; spines of hind tibire usually much longer than the spaces between their bases. Other characters those of the subfamily. The genus is mostly tropical in distribution, five nominal species being recorded from the eastern and southern states.

KEY TO EASTERY SPECIES OF AXAXIPHA.

a. Ovipositor one-half as long as hind femora; hind femora of male longer than tegmina, in fresh specimens with a dark stripe along the lower half of outer face in both sexes.

342. EXIGUA.

aa. Ovipositor distinctly less than one-half the length of femora; hind femora of male shorter than tegmina, without a dark stripe.

b. Color a uniform pale brown, usually without distinct dark markings on head or tegmina; form compact. 343. PULICARIA

$b b$. Color blackish or dusky brown or head with dark stripes; form more elongate, less compact.

c. Sides of body without a prominent dark brown stripe; spurs of hind tibiæ longer than the spaces between their bases; form very slender.

d. General color pale brownish-yellow; occiput usually with two dark stripes which extend downward onto face.

343a. VITTATA.

dd. General color dusky or smoky brown.

344. SCIA. 
cc. Sides of body with a wide dark brown stripe, extending from eye back along sides of thorax and including the lateral field of tegmina and exposed portion of wings when at rest; spines of hind tibiæ shorter than the spaces between their bases.

345. IMITATOR.

342. Anaxipha exigua (Say), 1825, 309. Say's Bush Cricket.

Dull yellowish-brown or clay yellow; head and pronotum in fresh specimens dark reddish-brown; face usually with three stripes and dots and dashes of reddish-brown; tegmina and legs pale brown; spines of hind tibiæ with bases and tips dusky; abdomen of male blackish; of female, dark brown, paler on sides; ovipositor dark brown, paler at tip. Pronotum about one-fourth wider than long. Tegmina of male but slightly surpassing tip of abdomen. Other characters as in key. Length of body, $\hat{o}$, $5-6$, 우, 6-7; of antennæ, $\hat{o}, 32$; of tegmina, $\hat{\delta}, 4-4.5$,,, $3-3.5$; of hind femora, $\hat{\sigma}$ and $९, 6$; of ovipositor, 3.5-4 mm. (Fig. 244.)

This handsome little cricket occurs in numbers in suitable localities throughout Indiana. In the northern counties it is found among the sphagnum mosses growing in dense tamarack swamps, and also on the shrubs about the margins of lakes and marshes. Farther south it is often very abundant on the leaves and stems of the arrow alum, cat-tail flags, button-bush and other semiaquatic plants. It is very active and difficult to capture, and, on account of its small size, is doubtless overlooked in many localities where it occurs in numbers. In central Indiana it reaches maturity about August 1st, and exists until after heavy frosts. Unlike the Nemobids, which it most closely resembles, it is never found on the ground, but clings to the stems of bushes and grasses. a few feet above the surface. No long-winged individuals have been taken in Indiana but R. \& H. (1916) have recorded sereral from other states and note that they have open "auditory foramina" on both faces of fore tibia, while the brachypterous specimens have them only on the outer face of the tibire.

This is our largest and most widely distributed Anaxipha, its known range extending from southern New England west to Minnesota and Nebraska and south and southwest to Jacksonville, Fla. and Brownsville, Texas. Say's types were from Missouri and the species has been many times recorded as $A$. pulicaria Burm.

In New England cxigua is recorded only from Westbrook. Conn., where it occul's in tangled vegetation on or near salt marshes. Davis (1889) says that on Staten Island "it is not uncommon along the ditches in the salt meadows where the high tide bushes, Iva frutescons $\mathrm{I}$., grow. It clings from six inches to a foot up the stems and its song has a particular silvery tone." In 
Virginia Fox found it on Scirpus americana Pers.

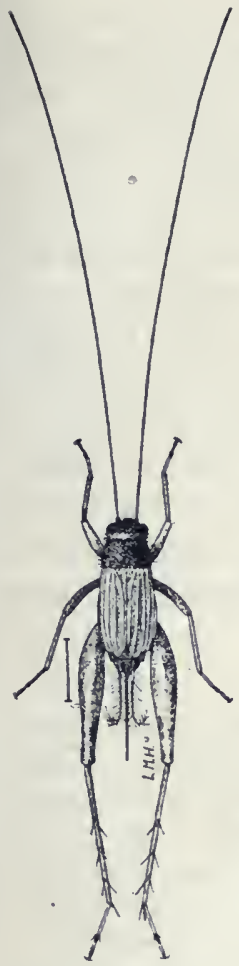

Fig. 244. Female, much enlarged.

(After Lugger.) in a tidal marsh. Allard (1910b) describes the habits and nots of exigua in north Georgia as follows: "This pretty cricket is very active, and not readily captured in its natural hiding places in the deuse regetation of wet situations. Its notes are a faint, shrill, prolonged tinkling ti-ti-ti-ti-ti-ti-ti-ti. Dwelling in almost impenetrable tangles, it is exceedingly difficult to separate the notes of the single singer from among the ting tinkling medley which seems to pervade the atmosphere of the locality. This cricket is musical by day and at night."

343. Axaxipila pulicaria (Burmeister), 1838, 732.

Pale brownish-yellow, often with a slight infuscation on head, pronotum and hind femora; basal dorsal segments of abdomen brown. Pronotum more than onehalf wider than long, distinctly widening from apex to base. Tegmina much longer and narrower than in exigua, reaching 2 to $4 \mathrm{~mm}$. beyond tip of abdomen, male, to its tip, female. Tympanum of male one-half or more longer than its width. Other characters as in key. Length of body, $\hat{\delta}, 4.5-5$; of tegmina, $\hat{\delta}, 5$, 우, 3 ; of hind femora, $\hat{\delta}$ and $\$, 4-5$; of ovipositor $2.2 \mathrm{~mm}$.

This small compact Gryllid has been taken by me at Dunedin, Fla., where it was found in small numbers in March on the low herbage of a recently cleared garden tract in the midst of a dense hammock. There it occurred in company with Acrydium arenosum blatchleyi and other ground frequenting Orthoptera. A single male was taken Feb. 7 on Hog Island while sweeping low shrubs, and another at Lakeland Feb. 16, from between the stems and leaf sheaths of a saw-grass. It was described from Jamaica, is known also from Mexico and in this country from Raleigh, N. Car. southwest to Brownsville, Tex. In Florida it has been taken by others at Gainesville, Miami, Sand Point and Ft. Reed, Scudder's types of Cyrtoxipha delicatula (1877a, 82) from Ft. Reed having been based on the long-winged form of A. pulicaria as shown by R. \& H. (1912c.) It appears to be much less thamnophilous in habits than exigua being more often found in tangles of low grasses. weeds and vines in moist woods and on the edges of the salt marshes. 


\section{3a. Axaxipila pulicaria vittata (Bolivar), 1888, 159.}

Differs from pulicaria by its smaller, more slender form, usually distinctly striped occiput and face and by having the spines of hind tibiæ more closely spaced. The under side of abdomen is often wholly black. Wings in macropterous examples exceeding the tegmina by $4 \mathrm{~mm}$. Length of body, $\hat{o}, 4-4.5$; of tegmina, 4 ; of wings, 8 ; of hind femora, $4 \mathrm{~mm}$.

A West Indian form known in this country from Albany, Ga. and Atlantic Beach, Punta Gorda and Key West, Fla. From the specimens examined at Philadelphia it appears to be only a slender variety of $A$. pulicaria, the dark stripes of occiput and face being often absent, while in pulicaria they are sometimes evident on the occiput. It occurs in similar habitats as pulicaria and, like that species, in both the macropterous and brachypterus forms. R. \& H. (1916, 305) state that the individuals devoid of black marks "can only with difficulty be separated from small individuals of pulicaria, which species is, however, appreciably more l'obust."

344. Axaxipita scia Hebard, 1915b, 465.

Dull clay-yellow, clouded with smoky brown; occiput dusky brown, the lower face of vertex with a very narrow pale median stripe; tegmina nearly uniform smoky brown; femora dull yellow with dark blotches; apical fourth of hind femora and entire tibiæ pale dull yellow. Basal joint of hind tarsi equal in length to the longest tibial spine; legs longer and more slender than in vittata. Cross veinlets of female tegmina more distinct than in pulicaria. Length of body, $\hat{\delta}$ and $\$, 5.2$; of tegmina, $\hat{\sigma}$, 4.5, ㅇ, 3.3; of hind femora, 4.7; of ovipositor, $2.7 \mathrm{~mm}$. (Fig. 245, a.)

Described and known from three specimens taken "from among the roots above black muck, sodden leaves and tidal litter in a red mangrove swamp on the edge of Brickell's Hammock, Miami, Fla.,
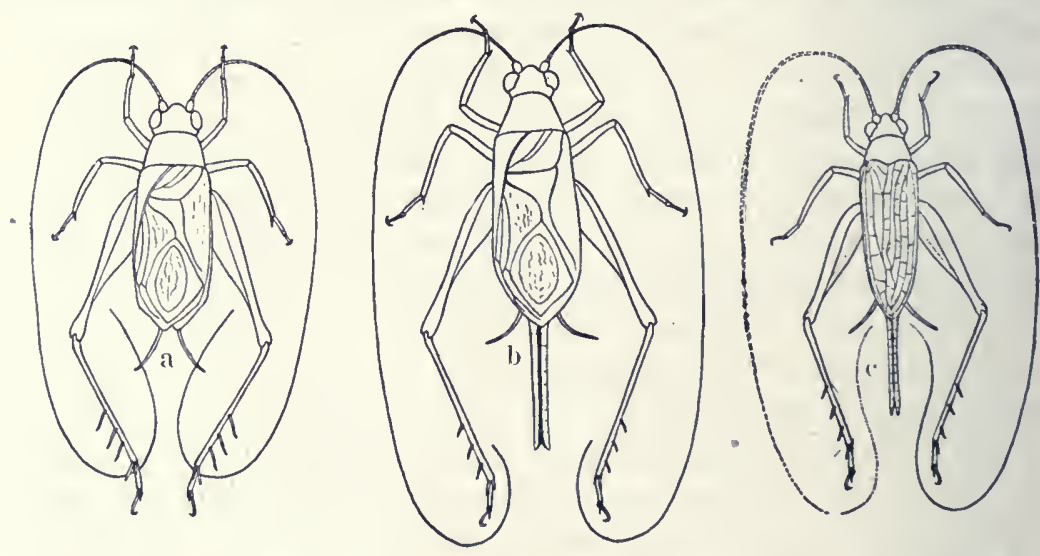

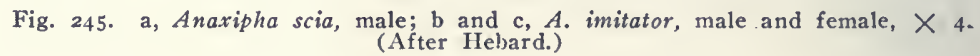


March 15-16." (Hebard.) A large series may perhaps show that this is but a color form of pulicaria due to its peculiar habitat.

345. Axaxipha mitator (Saussure), 1878, 487.

Elongate-oblong. Dull smoky brown; sides of body with a solid dark brown stripe as described in key; lower face with a wide, V-shaped chocolate-brown mark, often also a narrow reddish-brown oblong one between the antennæ; occiput and pronotum with dusky blotches. Pronotum distinctly widening from apex to base, the latter in male nearly twice the width of former; tegmina surpassing abdomen $2-3 \mathrm{~mm}$., exceeded by wings $4-5 \mathrm{~mm}$. in both sexes. Hind femora and tegmina reaching tip of ovipositor in female. Basal joint of hind tarsi more than twice the length of the other two united. Ovipositor stout, feebly curved, very acute. Length of body, $\hat{\delta}, 5.3-6.2$, ᄋ, 4.7-5.4; of tegmina, $\hat{\delta}, 5-5.4, \stackrel{+}{,}, 4.4-$ 4.7; of wings, $\hat{\delta}, 7.7-8.6, \hat{q}, 7.4-7.8$; of hind femora, $\hat{\delta}$ and $\&, 4.3-5$; of ovipositor, $2-2.5 \mathrm{~mm}$. (Fig. $245, b, c_{\text {. }}$ )

Miami, Fla., March 15-16 (Hebard.) A Cuban species taken in numbers by Hebard (1915b), "on the narrow border of sloping ground between the jungle of Brickell's Hammock and the red mangrove swamp. There, on the ground among a litter of the dried leares of the species of wild coffee, Psychotria undata Jacq., individuals were found jumping and flying nimbly about. They never flew more than a foot or two from the ground, in flight suggesting numerous species of small tropical roaches. At 11 1. M. on a cloudy day with temperature $70^{\circ}$, the few specimens heard stridulating emitted a trilling note, not loud but penetrating, the trills lasting one to two seconds, with the normal interval between a little less than one second. This song was not nearly as tinkling as that of Cyrtoxipha gundlachi, but still pleasant to the ear."

\section{Falcicula Rehn, 1903f, 25S. (Gr., "sickle" + "little.")}

Very small bush crickets closely allied to Anaxipha, but having the terminal joint of palpi triangular witl apex squarely truncate; stridulating organ of male much smaller, confined to the basal fourth of the tegmen, the stridulating vein sliort, trans. rerse; cross veinlets of female tegmen wanting; hind femora rery short and stout; subgenital plate of male conical, scoop-slaped; cerci elongate, tapering, reaching the tips of hind femora. One species is known.

34C. Falcicula ineBardi Rehn, 1903f, 258. Hebard's Bush Cricket.

Oblong, compact, robust. Uniform pale yellowish-brown; pronotum often with a very narrow pale median line. Antennæ about twice the length of body; pronctum nearly one-half wider than long, both it and head with numerous stout-erect bristles; tegmina slightly surpassing abdomen, male, 
reaching base of ovipositor, female, their tips subtruncate. Wings wanting. Ovipositor stout, strongly curved, very minutely serrate. Length of body, ô, 4,,$+ 4.5-5$; of tegmina, 2.5 ; of hind femora, 3.2 ; of ovipositor, $1.5 \mathrm{~mm}$.

This, one of the smallest of our eastern Orthoptera, was described from Thomasville, Ga. and ranges from Atlantic Co., $\mathbf{N}$. Jersey south and southwest to Beaumont and Dickinson, Texas. In Florida it has so far been recorded only from two stations. At Gainesville it was found in numbers by R. \& H. (1907) in the wire grass in long-leaf pine woods, while at Pine Island, Hebard found a single pair in similar habitat. It probably occurs in suitable environment throughout the northern portion of the State. Wherever found it has been taken mainly among the wire grass and fallen pine needles of dry open pine woods, where its colors harmonize perfectly with its surroundings. The Cuban record of Rehn (1909) was an error, based on a specimen of Anaxipha vittata.

III. Cyrtoxipha Saussure, 1874, 373. (Gr., "curved" + "swold.")

Very small slender-bodied bush crickets possessing the characters given in the generic key, and having the head longitudinal, bloadly flattened between the eyes; last joint of maxillary palpi shorter than fomth, expanding very strongly from base to apex, the latter squarely truncate; pronotum much narrowed in front; wings always present and prolonged in the form of a tail or queue; front tibia slightly enlarged at base, with auditory for: men present on both faces; hind femora very slender; spines of hind tibiae very delicate and but slightly longer than the spares between their bases.

KEY TO EASTERN CYRTOXIPHA.

a. Ovipositor shorter, more slender, not surpassing tips of hind femora, its teeth acute; size somewhat smaller, form. more slender.

347. GUNDLACHI.

aa. Ovipositor longer and stouter, distinctly surpassing tips of hind femora, its teeth bluntly rounded; size larger, form stouter.

347a. COLUMiBias.

347. Cyrtoxipha guxdlacin Saussure, 1874, 373. Gundlach's Bush Cricket.

Uniform pale green fading to brownish-yellow; tips of tibial spines and apical half of ovipositor blackish. Pronotum one-third broader at base than apex, its greatest width one-half more than its length. Tegmina in both sexes surpassing abdomen $2-3 \mathrm{~mm}$., exceeded by wings the same distance, those of males hyaline with tympanum and subapical spectrum much as in Anaxipha exigua; those of female with cross veinlets distinct, not prominent, the tips narrowly rounded. Hind femora slightly surpassing 
tips of tegmina. Length of body, $\hat{\delta}, 5.5-6, \hat{q}, 6-6.5$; of tegmina, $\hat{o}$, $4.5-5.5$, ㅇ, 5.5--6.3; of hind femora, $\hat{o}, 3.8-4$, ㅇ, $4.2-4.7$; of ovipositor, $2.6-3 \mathrm{~mm}$.

Ormond, Lakeland, Lake Okeechobee, Ft. Mrers, Cape Sable, Key West and Dunedin, Fla., Oct. 26-Apr. 13 (W.S.B.) Recerded from many localities in the southern two-thirds of Florida by other collectors. About Dunedin both nymphs and adults occur throughout the winter being often beaten from the low branches of oak and bayberry into an umbrella, where their movements are so agile that they are captured with difficulty. They occur for the most part on shrubs in the vicinity of ponds and lakes and about the borders of wet hammocks, though a number have been taken from mangrove and other shrubs on Hog Island.

In the United States, typical gundlachi is known only from Florida, Ormond and Silver Springs being its most northern stations. It is said by R. \& H. (1916) to be widely distributed in the West Indies and known from Central and northern South America. Hebard (1915b) states that in March "the very pleasant tinkling song of gundlachi is to be heard everywhere on warm evenings about Miami."

347a. Cуктохірна guxdlachi coldmbiaxi Caudell, 1907b, 237.

Differs from typical gundlachi only by the characters given in key. The average size is perhaps a little larger, but not greater than the larg. est individuals of gundlachi. Length of body to apex of tegmina, $\hat{\delta}$ and ㅇ, 8.5 ; of pronotum, 1.5 ; of tegmina, $5.6-6.8$; of wings, $7.3-9.4$; of hind femora, 5-5.8; of oripositor, $3.2-3.6 \mathrm{~mm}$.

Orlando, Fla., August 2 (Cotton) ; Ft. Monroe, Va. (Davis.) I regard this as a northern race of $C$. gundlachi, the only difference of any note being in the size and armature of the ovipositor. The cross-reinlets of the female tegmina, one of the characters used in its separation, are as numerous and almost as prominent in some females of gundlachi as in the northern form. Caudell's types of columbiana were from Washington, D. C. and Falls Church, Va. and its known range extends from those points south and southwest to Dallas and Doucette, Texas. From Florida it has been previously recorded only from Atlantic Beach. Of its habits R. \& H. (1916) say: "The species is thamnophilous and dendrophilous and has nerer been found in the least abundant. Its small size and retiring habits make it a very difficult insect tu collect." It occurs on shrubs and small trees, usually near water.

Allard (1910b) says of its song as noted at Thompson's Mills, Ga.: "I have never heard it singing less than six or seren feet 
from the ground. I found it abundant on the foliage of peach trees and the tallest oaks, also in the low trees and grape vines and very active so that it is not easily taken. Its notes are very brief, exceedingly high pitched trills which are uttered rapidly and persistently by day and by night. It is, however, more strictly a night singer and its great chorus begins late in the afternoon and continues far into the night. Once begun it is impossible to single out a note; the evening atmosphere everywhere being seemingly filled with an indistinguishable silvery trilling."

\section{Phylloscrntus Guerin, 1844, 333. (Gr., "leaf" + "curved.")}

Head wider than pronotum, strongly flattened and declivent between the eyes; vertex broad, rounded into the face; eyes prominent, wider than deep; ocelli wanting; maxillary palpi stout, terminal joint very large, spoon-shaped, deeply and widely concave above, fourth joint small, triangular; pronotum as in key, its lateral lobes longer than deep, their lower margin nearly straight, recurved; tegmina leathery in texture, slightly exceeding the abdomen in both sexes; stridulating organ of male much as in Anaxipha; alternate longitudinal veins of female tegmina more prominent, cross veinlets absent; wings slightly shorter than tegmina; fore tibiæ with a tympanum on both faces; hind tibix shorter than the femora, their spines shorter than the interspaces; subgenital plate of male short, conical; ovipositor as in Anaxipha. An American genus, 14 species being listed by Kirby, only one of which occurs with us, the others inhabiting Mexico and South America.

348. Phylloscyrtus pulchellus Uhler, 1864, 544. Handsome Bush Cricket.

Head and pronotum bright crimson red; recurved lower margin of lateral lobes yellow; antennæ twice the length of body, blackish at base and tip, the middle portion yellowish; palpi bluish-black; dorsal field of tegmina reddish- or chocolate-brown, the sides black with paler nervules; cerci and legs pale yellow; abdomen shining black. Ovipositor brown, paler at base. Head and pronotum finely and closely punctate. Structural characters under the genus heading. Length of body, $\hat{o}$ aud $\rho, 6-7$; of tegmina, 5.5; of hind femora, 5.2-6; of ovipositor, $3.2-3.5 \mathrm{~mm}$.

This handsome vari-colored little ericket occurs in small numbers in the southern half of Indiana, but has not been taken north of Marion County. It reaches maturity about mid-August and occurs on low shrubs and vines about the margins of ponds and marshes, being especially partial to the foliage of the buttonbush, Cephalanthus occidentalis L. When approached cautionsly 
it may often be seen vibrating its large maxillary palpi in a rapid and curious manner. Uhler's types were from Maryland where he said it "was found quite abundantly amongst the grass and low bushes near ditches and jumps about with great rapidity."

The known range of $P$. pulchellus extends from Staten Island, $\mathrm{N}$. Y., west to central Indiana, Kentucky and Illinois and south and southwest to central Florida and northern Georgia. In Florida it appears to be very scarce, having been taken, as far as known, only at Jacksonville, Monticello, Gainesrille and Sanford. Of its habits on Staten Island Davis (1896) says: "It commonly occurs on bushes and young trees and is often discorered on the sweet gum. If there is a dead curled leaf on the branch a male cricket will crawl within the chamber thus formed and sing. This is particularly the case on chilly days in the fall."

Allard (1910b) writing of pulchellus, as noted at Thompson's Mills, Ga., says:

"This pretty cricket dwells on shrubbery usually within two or three feet of the ground, and is musical both by day and at night. It is most abundant in low grounds bordering streams, although I have occasionally found it in thickets in upland situations, and even in the foliage of asters and cotton plants. Its song is a weak, high-pitched trill recalling that of Oecanthus quadripunctatus. although not as smooth and as uniform in tone. Heard close at hand, the trill is wavering, irregular, with an attendant unmusical shuffling or scraping of the wings, as if these were rather slowly and loosely vibrated upon each other. During the act of singing the tegmina are elevated almost perpendicular to the back, as is the habit in Oecanthus, a rather unusual procedure for almost all our other species of crickets."

\section{Subfamily VIII. ENEOPTERINAE.}

\section{The Larger Brown Bush Crickets.}

Crickets of medium size and usually slender form, having the budy and legs finely pubescent; head as wide or wider than pronotum; occiput convex; vertex forming a blunt oblong protuberance between the basal joints of antenna; this bearing near its middle the anterior ocellus and near its base each side one of the other two; eyes widely separated, rather small, not prominent; antennæ setaceous, not more than three times the length of body; pronotum subquadrate; tegmina not usually reaching the tip of abdomen; wings present, usually concealed by the tegmina; fore and middle legs slender, their tibix and femora unarmed, the basal joint of their tarsi but little if any longer than the third; hind femora only moderately enlarged; hind tibia armed above on each margin with six to eight rather slender spines with small 
teeth between them, also with three long inner and three short outer subapical spurs; basal joint of hind tarsi stout, usually longer than the second and third united; second joint small, flattened, dilated and bilobed; subgenital plate of male triangular, conical and scoop-shaped; cerci long, slender, tapering, very bristly; ovipositor as in key, its apex slightly enlarged. Kirby (1906) recognized 49 genera as belonging to this subfamily. These are mostly found in the Old World, only three being represented in the eastern States.

KEY TO EASTERN GENERA OF ENEOPTERIN A.

a. Tegmina of male with a stridulating organ; fore tibiæ with a hearing organ; length of body less than $20 \mathrm{~mm}$.

b. Fore tibiæ with an auditory organ on inner face only; tegmina rarely surpassing tip of abdomen; wings rudimentary or shorter than tegmina; terminal joint of maxillary palpi at least onethird longer than the one preceding.

I. Hapitilus.

$b b$. Fore tibiæ with auditory organ on both faces; tegmina in both sexes surpassing the abdomen; wings slightly surpassing the tegmina; terminal joint of maxillary palpi but little longer than the fourth.

II. OROcharis.

aa. Tegmina of male without a stridulating organ; fore tibiæ without a hearing organ; length of body 23 or more mm. III. TAFalisca.

I. Hapithus Uhler, $1864,546$.

In addition to characters given in key the species of Hapithus have the head almost globular, narrower than base of pronotum; antennæ about three times the length of body, their basal joints much thickened and cylindrical; maxillary palpi with last segment enlarged at tip, obliquely truncate; pronotum short, narrower in front than behind, the lateral angles rounded, front and hind margins truncate; tegmina of male with humeral vein prominent, forming a carina along the humeral angle; those of female with anastomosing oblique veins and veinlets; wings rudimentary; hind femora quite broad, though but little thickened. Three species of the genus are known from our territory, one being an adventive only.

INEY TO EASTERN SPECIES OF HAPITHUS.

a. Form short, robust; tegmina covering three-fourths or more of abdomen.

b. Antennæ not or very faintly annulate with fuscous; pronotum and tegmina a nearly uniform pale brown. (Native species.)

349. AGITATOR.

$b b$. Basal half of antennæ distinctly annulate with fuscous; head, thorax and tegmina thickly and irregularly sprinkled with fuscous markings; much larger and more robust. (Adventive.)

VAGUS. 
aa. Form elongate, rather slender; tegmina covering less than two-thirds of abdomen.

350. BREYIPEXXIS.

349. Hapithu's agitator Uhler, 1864, 546. Restless Bush Cricket.

Short, compact, robust. Pale brownish-yellow or dull reddish-brown, a narrow line along the humeral vein of tegmina, especially in male, often yellow; face, tegmina and femora of female sometimes flecked with small fuscous dots; hind femora often tinged with fuscous; occiput, pronotum and all the femora rather thickly clothed with prostrate brownish-yellow hairs. Pronotum feebly widening from apex to base. Tegmina corering three-fourths or more of abdomen, female, usually reaching its tip, male. Ovipositor nearly as long as hind femora, very slender, feebly curved, its tip black, but slightly enlarged, crenulate beneath. Length of body, $\hat{o}$, $9-10$, ㅇ, $10-14$; of pronotum, ô, $1.5-2$, ㅇ, 2-2.5; of tegmina, $\hat{o}, 5.5-$ 6.5 , ㅇ, 6-9; of hind femora, ô, 7.5-9, 오.7.5-11; of ovipositor, 7-10 mm.

In Indiana this modest brown bush cricket has been taken only in the southwestern counties from Terre Hante to the Ohio River, the adults occurring from August to November. In Vigo Co. the first ones discovered were on the slender twigs of some prickly-ash shrubs which grew in a damp upland woods. The place was visited a number of times and the crickets were always $\mathrm{f}$ (.und, perfectly motionless, and immediately above or below one of the thorns or prickles jutting forth from the twigs. The tips of the hind femora were raised so as to project above the body, thus causing them to resemble the thorns; and the color of the insect, corresponding closely to that of the bark, made them very difficult to discorer even when in especial search of them. On every clump of prickly-ash in the woods mentioned a number of specimens were secured, but they could be found nowhere else thereabouts. A second locality was about the roots of a scarlet oak, Quercus coccinea Wang, which grew on a sandy hillside. Here ther were plentiful, and resting motionless in the depressions of the bark or beneath the leaves in the carities formed by the roots of the tree. A pair were also noted in another place on the flowers of golden-rod.

Of all the males taken in Indiana but one or two had the tegmina entire, and usually both tegmina as well as the rudimentary wings were wholly absent, while erery female had both pairs unharmed. I at first ascribed this wing mutilation to the males fighting among themselves, but finally discovered a female in the act of derouring the wings of a male. Why this curious habit on the part of one sex? Possibly the females require a wing diet to requite them for their bestowed affections, or, perchance, they are a jealous set, and, having once gained the affections of a male, 
derour his tegmina to keep him from calling other females about him. It is more than probable, however, that the mating of the sexes takes place in a similar manner to that of the white tree crickets (Oecanthis), the females gnawing away the tegmina of the males in order to more readily reach the alluring glands which lie beneath. 'The openings of these glands, located on the dorsum or the metathorax, are visible in dried specimens at hand.

In Florida I have found $H$. agitator more common than in Indiana, a few specimens having been secured at most of the collecting stations. About Dunedin it is taken in winter more commonly in dense hammocks where it hibernates in bunches of dead leaves which have lodged in the thick tangles of vines and shrubs. The males at that season probably represent a late fall brood which have not yet mated as the tegmina are mostly intact, while those taken in spring have them partially eaten away. It lias been recorded by other collectors from numerous localities throughout the State, mostly under the name $H$. quadratus Scudder (1868b. 140), a form relegated to synonymy by both Scudder and Saussure, but restored as a valid species by $R$. \& H. (1905, 52), and again reduced by them to a southern race $(1916,309$.$) No dif-$ ferential character's which can be used in a key can be found in comparing southern Indiana and Florida specimens, some of the former being fully as large with tegmina and hind femora as long as those from Dunedin. As R. \& H. (loc. eit.) admit that the two so-called races merge in North Carolina and at the most "show little definite differentiation," I do not consider the name quadratus worthy of retention. The known range of agitator, as here recognized, extends from Long and Staten Islands, $\mathbf{N}$. I., west to southern Indiana and eastern Nebraska and south and sonthwest to southern Florida, Cuba and Brownsville, Texas. Uhler (1864) says that about Baltimore it inhabits grape vines and dense shrubbery and is found fully developed about the middle of September. The Ororharis uhleri McNeill $(1891,9)$ is a synonym of $H$. agitator.

(—). Hapithus Vagus Morse, 1916, 178.

Very large and robust. Dull yellowish-brown, thickly and irregularly mottled with darker brown and fuscous; dorsal fleld of tegmina of female often with three or four dusky lines along the veins. Tegmina nearly or quite covering the abdomen; wings as long as tegmina. Hind femora relatively short and stout. Ovipositor shorter than hind femora, its apex armed beneath with one large and several small blunt teeth. Length of body, $c$ and $\circ, 13-15$; of tegmina, $9.5-10$; of hind femora, 10-12; of ovipositor, $8.5-9 \mathrm{~mm}$. 
An adventive species found between 1900 and 1905 in the greenhouses of the Botanic Garden at Cambridge, Mass., where they did some damage by eating the tender green leares of many kinds of plants, especially ferus. They were thought to have come originally from Jamaica. From the descriptions I judge this to be rery elose to, if not identical with, the Apithis annuliemrnis Sauss. (1874, 491) described from Surinam.

350. Hapituus BRevipexis Saussure, 1597, 2C8. Short-winged Bush Cricket.

Elongate-oblong, rather slender. Pale reddish-brown; males with margin of dorsal field of tegmina yellow, bordered below with a fuscous line. Apical half of terminal joint of palpi much enlarged its apex obliquely truncate. Tegmina reaching middle of abdomen, their tips broadly rounded; those of female much less reticulate than in agitator. Hind femora relatively slender, three-fourths the length of body. Ovipositor straight, very slender, its tip not upturned. Length of body, $\hat{\delta}, 11-16$, ㅇ, 15-19; of tegmina, $\hat{o}$ and $\$, 6-9$; of hind femora, $\hat{o}, 11-13.5$, + , 12.5-15; of ovipositor, $9-11 \mathrm{~mm}$.

This handsome bush cricket is known only from Georgia, Florida and Louisiana, and appears to be scarce wherever found. In Florida it has been definitely recorded from Atlantic Beach, Gainesville, Live Oak, LaGrange and Cocoanut Grove. It occurs for the most part among the tangled undergrowth of rather dry open oak and pine woods, the adults being found from July to October.

\section{Orocharis Uhler, $1864, \tilde{j} 44$.}

Elongate, rather slender crickets luaving the body subdepressed; head short, narrower than base of pronotum; rertex flattened, strongly declivent, prolonged to form a slort heak between the antenna; maxillary palpi slender, third joint longest, cylindrieal, fifth slightly longer than fourth, enlarged gradually from base, its apex obliquely truncate; antennse setaceous. three times the length of body, the basal joint very stout; pronotum subquadrate, wider than long, front margin truncate, ciliate, hind one usually feebly bisinuate; tegmina surpassing abdomen 4-6 n!m., exceeded by wings $2-4 \mathrm{~mm}$, gradually tapering berond the middle, the marginal area closely enveloping the abdomen; subapical spectrum large, enclosing in front a curved rein which parallels the boundary rein of the area; fore and middle legs stout, basal joint of their tarsi short, dilated, apical joint very slender, nearly as long as the other two united; hind femora slender, not reaching tips of tegmina; oripositor straight, rery slender, the tip crenate beneath. 
KEY TO EASTERY SPECIES OF OROCHARIS.

a. Beak of vertex not compressed, wider than basal joint of antennæ, its apex rounded; ocelli very small, widely separated; pronotum thickly pubescent, one-half wider than long. 351. SALtator.

aa. Beak of vertex compressed, narrower than basal joint of antennæ, its apex subacute; ocelli large, transverse, subcontiguous; pronotum scarcely wider than long, almost smooth.

352. GRYLLODES.

351. Orocharis Saltator Uhler, 1864, 545. Jumping Bush Cricket.

Color more or less dimorphic, usually a nearly uniform pale reddishbrown, the face flecked with darker brown, sometimes with a faint brown ish or fuscous stripe along the side of head and pronotum; often grayish more or less maculate with fuscous, when of the latter hue the tegmina of female each usually with a small black basal spot and with cross-veinlets darker than those running lengthwise, thus giving the dorsal field a checkered appearance; humeral vein of tegmina in male often yellow; spines of hind tibiæ tipped with fuscous. Pronotum about one-half wider than long, its base but slightly wider than apex. Ovipositor dark brown, about a third longer than hind femora, nearly straight. Other structural characters under the genus heading. Length of body, $\hat{o}$ and $q, 14-16$; of pronotum, $\hat{\sigma}, 2.3-2.7$, ㅇ, 2.4-2.9; of tegmina, $\hat{\delta}, 11-14$, ․,13-14.5; of hind femora, $\hat{o}, 7-8$, $\&, 8-10$; of ovipositor, $11-13 \mathrm{~mm}$. (Fig. 246.)

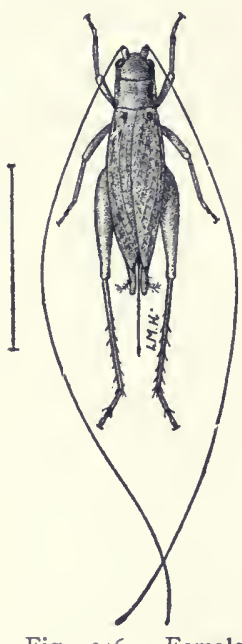

Fig. 246. Female. (After Lugger.)

This slender bodied bush ericket oceurs in small numbers throughout the southern half of Indiana, frequenting the undergrowth of dense woods, the thickets along the borders of streams and the shrubbery of orehards and yards. A half dozen specimens were once found on Aug. 22 concealed in the folds of an old coat hang. ing in a grape arbor near the center of the eity of Indianapolis. When disturbed it often seeks safety in flight and when it alights flattens out its body close against its resting place.

In Florida it is much more common than in Indiana, scores of specimens in both nymph and adult stages lraving been taken about Dumedin during the winter and spring months. There it is often beaten from the lower limbs of oak and other trees and also from bunches of leaves, and especially the large epiphyte, Tillandsia utriculata I., in which it is hibernating. Elsewhere in the State I have taken it at Ormond, Sanford, Utopia, Lakeland, Cape Sable and Ft. Myers. By other collectors it is mentioned only from Jacksonville, Silver Springs, Pablo Beach and Miami.

The known range of $O$. saltator extends from New Jersey west 
to Nebraska and south and southwest to southern Florida, Mississippi and Texas. About Baltimore, the type locality, Uhler found it very common on Cratagus during September and October. Bruner mentions it (1893a) as occurring only occasionally in southeastern Nebraska. Southern specimens have been often erroneously recorded as 0 . gryllodes. Of the egg-laying and song habits of this cricket Riley $(1881,62)$ wrote as follows:

"In December, 1877, I watched a female of 0 . saltator ovipositing in the end of a dead and rather soft twig of the soft maple at Kirkwood. Missouri. The twig had been pruned and the bark was somewhat gnawed by the cricket and the eggs thrust in irregularly from the end and from the sides. Both wood and pith were crammed with eggs, but all longitudinally inserted. The favorite nidus of the species is, however, the soft and somewhat corky, rough bark of the trunk and older branches of the American elm, the eggs being thrust in singly or in small batches, either longitudinally with, or very slightly obliquely from, the axis of trunk or branch. The female is rery intent in the act, working her abdomen deliberately from side to side during the perforation.

"The stridulation of this cricket is a rather soft and musical piping of not quite half a second's duration, with from four to six trills, but so rapid that they are lost in the distance. The key is very high, but varies in different individuals and according to moisture and temperature. It most resembles the vibrating touch of the finger on the rim of an ordinary tumbler when three-fourths filled with water-repeated at intervals of from two to four per second, and it may be very well likened to the piping of a young chick and of some tree frogs. As the species is very common in the southwest its chirp is everywhere heard and is so distinctive that when once studied it is never lost amid the louder racket of the katydids and other night choristers. It is frequently heard during the day time in cloudy or damp weather, and I have heard it at St. Louis the first days of November after a slight frost.

"The courting of the sexes is amusing. They face each other and play with their antennæ for the best part of an hour or more than an hour. The female is, otherwise, pretty quiet, but the male continually mouths the twig or the bark upon which the courting is being done, and plays his palpi at a great rate, very stealthily approaching nearer to his mate meanwhile. At last the antennal fencing ceases and those of the female bend back and then the male approaches until their heads touch. He then deliberately turns round, elerates the elytra and slips his abdomen under the female, who virtually mounts and assists him, his elytra overshadowing her head."

352. Orocharis Gryllodes (Pallas), 1772, 16.

Elongate, slender. Pale reddish-brown; lateral lobes of pronotum with a shining black stripe occupying their upper third and often passing back as a narrow line along the humeral vein of tegmina; abdomen black above. Pronotum as long as wide, feebly but obviously widening from apex to base, its disk concave along the median line. Tegmina surpassing abdomen $4-6 \mathrm{~mm}$., exceeded by wings $3-4 \mathrm{~mm}$. Hind femora rery slender, two-thirds the length of body. Ovipositor longer than hind femora, very 
slender, tips of the valves strongly tapering, acute, armed with one large and several small rounded crenations. Length of body, $\delta$ and $q, 17-19$; of pronotum, 3-3.2; of tegmina, 15-18; of hind femora, 12-13; of ovipositor, $13-15 \mathrm{~mm}$.

Dunedin and Cape Sable, Fla., Dec. 21-Feb. 2:3 (W.S. B.) Everglade and Useppa Island, Fla. April (Davis.) My single Dunedin female was beaten from mangrove overhanging the water on the eastern or bay side of Hog Island, and was at once recognized as different from saltator by the less pubescent surface and the broad shining black stripe of lateral lobes. It is a West Indian species taken in this country only in southern Florida, having been recorded, principally under the name of $O$. saulcyi (Guerin), a synonym, from several places south of Punta Gorda and Miami, but not heretofore north of the former place. On Key Largo it was found by R. \& H. (1912) "in the twilight of the heary jungle growth by vigorously beating the foliage of the lower limbs of the trees and the tangled grape and other vines." About Miami in March Hebard (1915b) found small colonies in shrubbery and trees about hotels and also several beneath bark in Brickell's Hammock. Of its note he says :

"The song of this insect was, next to that of Cyrtoxipha gundlachi, the most frequent sound heard on warm evenings. The note is resonant, baaaaa, repeated incessantly at irregular intervals of a few seconds. When singing, the males were found perched upon the leaves of heary bushes with tegmina raised high above their backs; considerable difficulty was experienced in locating individual singers."

\section{ThFalisca F. Walker, 1869, 52.}

Large robust, subcylindrical crickets having the head vertical as broad as thorax; occiput strongly convex; vertex prolonged to form a broad beak between the antenna; ocelli very small; ejes of medium size, longer than wide; maxillary palpi with joints $3-5$ subequal in length, the fifth club-shaped, concave within; antenna setaceous, more than twice the length of body; tegmina variable in length, usually shorter than abdomen, alike in, the sexes, their tips narrowly acutely rounded, slightly surpassed by the wings; legs short, stout; femora grooved but nnarmed beneath; spines of hind tibia very stout, unequal, those on inner margin the longel; basal joint of hind tarsi as wide as the tibire, armed above with three stout spines and at apex with a pair of spurs longer than the joint itself; third joint rel'y slender, as long as the other two united. 
353. TAfalisca LuRidA F. Walker, 1869, 53.

Dull brownish-yellow, often tinged with fuscous; finely pubescent; antennæ and hind tibiæ dark reddish-brown; abdomen fuscous; oripositor dark brown. Hind femora rather slender, feebly surpassing abdomen. Ovipositor slender, the tips of its valves black, flattened, their outer margins very finely crenate and apical fourth nodulose above. Other struc. tural characters as given abore. Length of body, $\hat{o}, 23-25$, ㅇ, 25-30; of

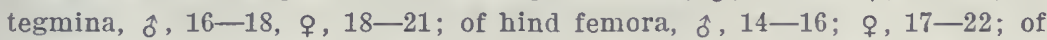
ovipositor, $15-16 \mathrm{~mm}$.

Dunedin, Lake Okeechobee, Cape Sable and Kéer West, Fla., Feb. 23-March 26, nymphs only (W.S. B.) ; LaGrange and Big Fine Key, Fla., September, adults (Davis.) At Dunedin I took a single nymph, March 26, by beating the Florida buttonwood, Conocarpus erecta L. on Hog Island. This is also a Mest Indian species but is recorded from a number of stations in the southern third of Florida, where it occurs in the nymph stages during the winter and spring months and evidently rearches maturity about June 1st. Dunedin is its most northern known locality.

\section{Area axd Life Zones Cotereil.}

As has been noted on page three this work deals primarily only with those species of Orthoptera known to occur in the United States east of the Mississippi River and in Canada east of the 90tl Meridian. However, many of the species of which it treats range over a much mider area to the north and west and a number of them have their principal distribution west of the Mississippi, the prairies and sand areas of Illinois and Indiana comprising the eastern limits of their range.

All of the recognized Life Zones of the United States and their characteristic faunas are represented in the area covered. The student must bear in mind that the famna of no one of these life zones has a definite sharp and fixed boundary line. but that each orerlaps and merges with the one above and the one below. Moreover, aside from those of the Hudsonian and Tropical zones, but few of the species of Orthoptera are limited to any one zone and some of them, as Conocephalus fasciatus (DeGeer). occur in all the zones. Mentioned in order from the most northern, these life zones and faunas are as follows:

Hudsoniax Life Zone.-Of the area treated this zone includes all of Labrador, Newfoundland, New Brunswick and Quebec, eastern Nora Scotia, the northern portions of Ontario and New England, the northern Peninsula of Michigan and isolated areas on the summits of the higher mountains of New York, Pennsyl- 
vania, Virginia and western North Carolina. The fauna of this zone is known as the Boreal, three of its typical Orthoptera being Circotettix verruculatus (Kirby), Podisma glaeialis (Scudd.) and Melanoplus borealis (Fieb.)

'Transition Life Zone.-The area of this zone treated includes southern Ontario, Michigan and New England, the greater portıons of New York, Pennsylvania and Wisconsin, the northerm fourth of Ohio, Indiana and Illinois, and the region of the Alleghany Mountains in West Virginia and North Carolina. Its fauna is known as the Alleghanian. Among its characteristic Orthoptera are Chorthippus curtipennis (Harr.), Cammula pellucida (Scudd.) and Melanoplus fasciatus (Walker.)

Upper Austral Life Zone.-This zone as covered, includes the greater portion of Ohio, Indiana, Illinois, Kentucky, Tennessee, New Jersey and Maryland, western North Carolina and the northern portions of South Carolina, Georgia and Alabama. Small areas near the Great Lakes in Wisconsin, southern Michigan and New York are also included. Its fauna is known as the Carolinian and comprises the great majority of our common northern and best known Orthoptera. Among them may be mentioned Chloaltis conspersa Harr., Melanoplus femur-rubrum (DeGeer) and Pterophylla camellifolia (Fab.)

Lower Austral Life Zone.-This comprises in our territory eastern Virginia and North Carolina, the most of the southern two-thirds or more of South Carolina, Georgia and Alabama, almost all of Mississippi, the western thirds of Kentucky and Tennessee and a portion of the southern thirds of Illinois and Indiana. This zone embraces, for the most part, the Coastal Plain region of the South Atlantic States, its soft incoherent deposits and extensive marsh areas being separated from the harder rocks and rugged topography of the Piedmont Plateau on the north and west by what is known as the "fall line." This line extends in a curve from near Washington, D. C. to Columbus, Ga. The fauna of the Lower Austral Zone is known as the Austroriparian, and among its characteristic Orthoptera may be mentioned Stagmomantis carolina (Joh.), Schistocerce dammifica (Sauss.) and Amblycorypha uhleri Brunn.

Sabalian Life Zone.-Whis zone comprises the northern threefourths of peninsular Florida and a narrow strip known as the Lower Coastal Plain along the Atlantic and Gulf coasts from Pamlico Sound, North Car., to New Orleans, La. Its famma is known as the Subtropical and comprises such species as Aglaopteryx gem- 
ma Hebard, Belocephalus subapterus Scudd. and Atlanticus calcaratus $\mathrm{R}$. \& $\mathrm{H}$.

Tropical Life Zove.-This zone, which on this continent embraces the West Indies, Central America and a part of Mexico and northern South America, covers in our territory only the southern fourth of peninsular Florida and its southern keys. Its fauna is also known as the Tropical and the Orthoptera are largely introduced species from the West Indies and other countries. Among them may be named Blaberus craniifer Burm., Mantoida maya S. \& Z. and Tafalisca lurida Walker.

Of the 353 indigenous or established species and 58 varieties of Orthoptera recognized from the region corered, 139 species and 17 rarieties occur in Indiana and 181 species and 32 varieties in Florida. Of these 60 species and seven varieties are common to both states, thus leaving 93 species and 16 varieties which occur in the region corered outside of these two states. The distributıon by families is as follows:

\begin{tabular}{|c|c|c|c|c|c|c|c|c|c|c|}
\hline$=$ & \multicolumn{2}{|c|}{ Indiana. } & \multicolumn{2}{|c|}{ Florida. } & \multicolumn{2}{|c|}{$\begin{array}{l}\text { Common to } \\
\text { Both States. }\end{array}$} & \multicolumn{2}{|c|}{$\begin{array}{l}\text { Outside } \\
\text { Territory. }\end{array}$} & \multicolumn{2}{|c|}{$\begin{array}{l}\text { Total No. } \\
\text { Recognized. }\end{array}$} \\
\hline Forficulidæ & $\begin{array}{c}\text { Sp. } \\
3\end{array}$ & Var. & $\begin{array}{c}\text { Sp. } \\
9\end{array}$ & Var. & $\begin{array}{c}\text { Sp. } \\
1\end{array}$ & Var. & $\begin{array}{c}\text { Sp. } \\
1\end{array}$ & var. & $\begin{array}{l}\text { Sp. } \\
12\end{array}$ & Var. \\
\hline Blattidæ & 11 & & 24 & 1 & 7 & & 2 & 1 & 30 & 2 \\
\hline Mantidæ & 2 & & 7 & & 2 & & 2 & & 9 & \\
\hline Phasmidæ & 3 & & 5 & & 1 & & 5 & & 12 & \\
\hline Tetrigidæ & 8 & 5 & 9 & 3 & 6 & 1 & 5 & 1 & 16 & 8 \\
\hline Acrididæ & 50 & 3 & 52 & 11 & 22 & 1 & 50 & 7 & 130 & 20 \\
\hline Tettigoniidæ & 40 & 3 & 46 & 9 & 10 & 1 & 21 & 3 & 97 & 14 \\
\hline Gryllidæ & 22 & 6 & 29 & 8 & 11 & 4 & 7 & 4 & 47 & 14 \\
\hline Total & 139 & 17 & 181 & 32 & 60 & 7 & 93 & 16 & 353 & 58 \\
\hline
\end{tabular}

\section{BIBLIOGRAPHY.}

This is a list only of the works cited in this volume, arranged alphabetically by authors and years of publication. See p. 8 of the Introduction. A more complete Bibliography of Orthopterological literature up to the year 1900 , especially that of foreign authors, will be found in Scudder's "Index to North American Orthoptera."

Altard, H. A.-1910-Some New England Orthoptera Observed in Late October.<Ent. News, XXI, 352-357.

1910 - Concephalus fusco-striatus in North Georgia.<Ent. News, XXI, $291-292$.

1910b-Musical Crickets and Locusts in North Georgia.<Prce. Ent. Washington, XII, $32-43$, pl. IV.

1910c-The Stridulations of Some Cone-headed Grasshoppers (Conocephalus).<Proc. Ent. Soc. Wash., XII, 121-124, pI. VI.

1911-The Musical Habits of Some New England Orthoptera in September.<Ent. News, XXII, 28-39.

1911a-The Stridulation of some Eastern and Southern Crickets.<Ent. News, XXII, 154-157.

$1911 \mathrm{~b}-$ The Stridulations of Two Interesting Locustidæ.<Psyche, XVIII, $118-119$. 
1911c-Studying the Stridulations of Orthoptera.<Proc. Ent. Soc. Wash., XIII, 141-148.

1912-Variations in the Stridulations of Orthoptera.<Ent. News, XXIII, $460-462$.

1914-Locust Stridulation.<Ent. News, XXV, 463-466.

1916-Some North Georgia Acrididæ.<Can. Ent., XLVIII, 274-279.

1916a-Some Musical Orthoptera at Clarendon, Virginia.<Can. Ent., XLVIII, $356-358$.

BAKer, C. F.-1905-Second Report on Pacific Slope Orthoptera. <Invertebrata Pacifica, I, 71-84.

BALI, E. B. - 1897-Notes on the Orthopterous Fauna of Iowa. <Proc. Iowa Acad. Sci., IV, 234-241.

Banks, Nathan-1906-A Plea for the Genus.<Proc. Ent. Soc. Wash., VIII, $37-43$.

1909-Directions for Collecting and Preserving Insects.<Bull. 67, U. S. Nat. Mus., 1-135.

Barrett, O. W.-1902-The Changa or Mole Cricket (Scapteriscus didactylus Latr.) in Porto Rico.<Bull. No. 2, Porto Rico Agr. Exp. Sta., $1-19$.

Baumgartier, W. J.-1910-Observations on the Gryllidæ; III. Notes on the Classification and on some Habits of Certain Crickets.<Kansas Univ. Sci. Bull., V, 309-319.

1910a-Same, IV. Copulation. <Ibid. 323-345.

Beaurois, A. M. F. J. PALISOT DE-1805-Insectes recueillis en Afrique. et en Amerique dans les royaumes d'Oware a Saint-Domingue et dans les Etats-unis pendant les annees $1786-1797$. Fp. $16+276$, pls. $1-90$. Paris.

BeutenMuller, WM.--1894-Descriptive Catalogue of the Orthoptera Found Within Fifty Miles of New York City.<Bull. Amer. Mus. Nat. Hist., VI, 253-316, pls. V-X.

1894a-Notes on some Species of North American Orthoptera, with Descriptions of New Species.<Bull. Amer. Mus. Nat. Hist., VI, $249-252$.

1894b-Description of a New Tree Cricket.<Journ. N. Y. Ent. Soc., II, 56.

1903-A New Katydid from Florida.<Bull. Amer. Mus. Nat. Hist., XIX, $637-638$.

Blaxcharo, E. C.-1836-Mante. Mantis Linne.<Guerin-Meneville, Mag. de Zool.-Insectes, V, Classe IX, pl. 135.

Blatchley, W. S.-1891-Some Indiana Acrididæ-I.<Can. Ent., XXIII, $74-81,98-100$.

1892-The Gryllidæ of Indiana.<Proc. Ind. Acad. Sci., 1891, 126-144. Indianapolis.

1892a-Some Indiana Acrididæ-II.<Can. Ent., XXIV, 28-34.

$1892 \mathrm{~b}-$ Two New Orthoptera from Indiana.<Can. Ent., XXIV, 26-27.

1893-The Locustidæ of Indiana. <Froc. Ind. Acad. Sci., 1892, 92-153.

1893a-The Blattidæ of Indiana.<Proc. Ind. Acad. Sci., 1892, 153-165.

$1893 \mathrm{~b}$-An Unusual Appearance of Schistocerca Americana. $<$ Psyche, VI, $465-466$.

1893c-Some New Locustidæ from Indiana.<Can. Ent., XXV, 89-93.

1894--Some Indiana Acrididæ-III.<Can. Ent., XXVI, 217-223, 241245.

1895-Notes on the Winter Insect Fauna of Vigo County, Indiana.< Psyche, VII, 248-250.

1896-Miscellaneous Notes. $<$ Can. Ent., XXVIII, 265-266.

1897-Indiana Caves and Their Fauna.<21st Ann. Rept. Ind. Dept. Geology and Nat. Resources, 1896, 121-212, pls. IV-XII. Indianapolis.

1898--Some Indiana Acrididæ-IV.<Can. Ent., XXX, 54-64.

1898a-Two New Melanopli from Les Cheneaux Islands, Michigan. $<$ Fsyche, VIII, 195-197.

1899-Katydids and Their Kin: or the Orthoptera of Indlana.<Gleanings from Nature, $197-244$, figs. $41-70$. Indianapolis. 
1900 - On the Species of Nemobius Known to Occur in Indiana.<Psyche, IX, 51- 4 .

1902-A Nature Wooing at Ormond by the Sea. Pp. 1-245, pls. I-XIr, figs. $1-63$. Incoianapolis.

1903-The Orthoptera of Indiana. An Illustrated Descriptive Catalogue of the Species Known to Occur in the State, with Bibliography, Synonymy and Descriptions of New Species.<27th Ann. Rep. Ind. Dep. of Geol. and Nat. Resources, pp. $123-471$, pls. I-II, figs. 1-122. Indianapclis.

Bolivar, Igxacio-1887-Essai sur les Acridiens de la tribu Tettigidæ.< Ann. Scc. Ent. Belg., XXXI, 175-313, pls. 1-2. Bruxelles.

1888-Enumeration des Orthoptéres de l'Ile de Cuba.<Mem. Soc. Zool. Fr. I, 116-164.

Brimley. C. S.-1908-Notes on the Orthoptera of Raleigh, North Carolina, $<$ Ent. News, XIX, 16-21.

Brittox. W. E.-1904-New England Records for Eritettix carinatus Scudder and Conocephalus triops Linn.<Psyche, XI, 23.

Bruner. LAwaxce-1876-New Species of Nebraska Acrididæ.<Can. Ent., VIII, $123-125$.

1884-Two New Myrmecophilæ from the United States.<Can. Ent., XVI, $41-43$.

1885-First Contribution to a Knowledge of the Orthoptera of Kansas. <Bull. Washburn College Lab. Nat. Hist., I, 125-139. Topeka.

$1885 \mathrm{a}$ - Contributions to the North Trans-Continental Survey.-Orthoptera.<Can. Ent., XVII, 9-19.

1856-Second contribution to a Knowledge of the Orthoptera of Kansas.<Bull. Washburn Coll. Lab. Nat. Hist., I, 193-200.

1887-Report on Locusts in Texas during the Spring of 1886. < Bull. 13 (O. S.). U. S. Div. Ent., 9-19.

1890-New North American Acrididæ found North of the Mexican Boundary.<Proc. U. S. Nat. Mus., XII, 47-82., pl 1.

1891-Ten New Species of Orthoptera from Nebraska, with Notes on the Habits, Wing Variation, etc. $<$ Can. Ent., XXIII, 36-40, $56-59,70-73$.

1892-Report on Destructire Locusts.<Bull. 27 (O. S.), U. S. Div, Ent. 9-33.

1892a-A Change in the Name of a Recently Described Species of Orchelimum. < Ent. News, III, 264-265.

1893-The Mcre Destructive Locusts of America North of Mexico.< Bull. 28 (O. S.), U. S. Div. Ent., $1-40$.

1893a-A List of Nebraska Orthoptera.<Publications Neb. Acad. Sci.. III, 19-33. Lincoln.

1893b-The Insect Enemies of Small Grains.<Rep. Neb. St. Bd. Agr., 359-468. Lincoln.

$1893 \mathrm{c}$ - Notes on the Wing Color of North American Locusts belonging to the Subfamily Oedipodinæ and its Seeming Relation to Climatic Conditions.<Science, XXI (O. S.), 133.

1895-Insect Enemies of the Grape Vine.<Neb. St. Hort. Rep.. 68-162.

1895a-Directions for Collecting, Preparing and Preserving Specimens of Orthoptera for the Cabinet.<Special Bull. Dep. Ent. Univ. Neb., II, $1-8$.

1897-The Grasshoppers that Occur in Nebraska.<Ann. Rep. Ent. Neb. State Bd. Agr., 1896, 105-138.

1899-A New Conocephalus.<Ent. News. X, 38-39.

1904-Some New Colorado Orthoptera.<Bull. No. 94, Agr. Exp. Sta. Col., $57-67$.

1905-Concerning the Locust Genus Mestobregma Scudder.<Ent. News, XVI, 259-260.

Brtxiser. YOx WATtExwY. CARL-1865-Nouveau Systeme des Blattaires.

Pp. $1-426$, pls. $1-13$. Vienna.

1878-Monographie der Phaneropteriden.<K. K. Zool. Botan. Gesells. in Wien. Pp. 1-401,.pls. I-VIII. Vienna.

1888-Monographie der Stenovelmatiden und Grillacriden.<Verhand. Zool. Botan. Gesells., XXXVIII, 247-394, pls. V-VIII. Wien. 
1893-Revision du Systeme des Orthopteres et Descriptiones des Especies Rapportees.<Ann. Mus. Civ. Stor. Nat., 1-230, pls. I-VI. Geneva.

1895-Monographie der Pseudophylliden.<Der K. K. Zool. Botan. Gesell. in Wien. Pp. iv +282 , pls. $\mathrm{I}-\mathrm{X}$.

1907-Phasmidæ Anareolatæ (Clitumnini, Lonchodini, Bacunculini). < Die Insekten-familie der Phasmiden, 4to., Pt. II, $181-338$, pIs. VII-XV. Leipzig.

Bunmeister, Herman-1838-Handbuch der Entomologie, II-Orthoptera. Pp. 459-756. Berlin.

Burr, Malcolm-1897-British Orthoptera. Pp. 1-69, pls. I-V. London.

1902-Monograph of the Genus Acrida Stål (Truxalis Fabr.) With Notes of some Allied Genera and Descriptions of New Species.< Trans. Entom. Soc. London, Pt. II, 149-187.

1904-Synopsis of the Orthoptera of Western Europe-Division II: Acridiodea.<Entom. Rec. \& Journ. Var., XVI, 317-323.

1907-A Preliminary Revision of the Forficulidæ and of the Chelisochidæ, families of the Dermaptoptera.<Trans. Ent. Soc. Lond., 91134, pl. IV.

1910-The Dermaptera (Earwigs) of the U. S. National Museum.< Proc. U. S. Nat. Mus., Vol. 38, 443-467.

1911-Dermaptera.<122d Fas. Gen. Insect. 4to. Pp. 1-112, pls. I-IX.

1911 - - Vorlaufige Revision der Labiiden.<Deutsch, Ent. Nat. Biblioth., II, $58-61$.

1915-On the Male Genital Armature of the Dermaptera. Part II, Psalidæ.<Journ. Roy, Micros. Soc., 521-546, pls. X-XII.

Caudell, A. N.-1900-Orthoptera of the Harriman Alaska Expedition.<

Proc. Wash. Acad. Sci., II, 511-512.

1902- Notes on Orthoptera from Oklahoma and Indian Territory with Descriptions of Three New Species.<Trans. Amer. Ent. Soc., XXVIII, $83-91$.

1903- Notes on Orthoptera from Colorado, New Mexico, Arizona and Texas, with Descriptions of New Species.<Proc. U. S. Nat. Mus., Vol. 27, 775-809, pl. LV.

1903a-The Phasmidæ or Walking-sticks of the United States. $<$ Proc. U. S. Nat. Mus., Vol. 26, 863-885, pls. LVIII-LIX. Washington.

$1903 \mathrm{~b}$ - Notes on Nomenclature of Blattidæ.<Proc. Ent. Soc. Wash., V, $232-234$.

1904-Two Orthoptera Hitherto Unrecorded from the United States.< Proc. U. S. Nat. Mus., Vol. 27, 949-952.

1904a-A New Species of the Locustrian Genus Amblycorypha from Kansas.<Journ. N. Y. Ent. Soc., XIII, 50.

1904b-Some Orthoptera taken at Moose Jaw, Assiniboia.<Can. Ent., XXXVI, 248.

$1904 \mathrm{c}$-Orthoptera from Southwestern Texas.<Science Bull. Vol. I, No. 4, Mus. Brook. Inst. Arts \& Sci., 105-116, pls. VI-VIII.

1904 d-Notes on Some Orthoptera from British Columbia.<Ent. News, $\mathrm{XV}, 62-63$.

$1904 \mathrm{e}$-An Orthopterous Leafroller.<Proc. Ent. Soc. Wash., VI, No. 1. $46-49$.

1904f-Synonymy of Oedipoda cincta Thomas.<Proc. Ent. Soc. Wash., VI, No. 2, 125.

1904 g-Injury by a Cricket in the South.<Bull. 44, U. S. Div. Ent., $88-89$.

1905-Notes on Some Florida Orthoptera.<Ent. News, XVI, 216-219.

$1905 \mathrm{a}-$ On a Collection of Orthoptera from Southern Arizona with Descriptions of New Species.<Proc. U. S. Nat. Mus., Vol. 28, 461477.

1905b-Aplopus mayeri, New Species.<Journ. N. Y. Ent. Soc., XIII, $83-85$.

1905 c-A New Bacunculus from Indiana.<Journ. N. Y. Ent. Soc., XIII, 212.

1905d-Kirby's Catalogue of Orthoptera, Vol. I.<Proc. Ent. Soc. Wash., VII, $84-88$. 
1906-The Cyrtophylli of the United States.<Journ. N. Y. Ent. Soc., XIV, $32-45$, pl. I.

1907-The Decticinæ (A Group of Orthoptera) of North America.< Proc. U. S. Nat. Mus., Vol. 32, 285-410.

$1907 a-O n$ some Forficulidæ of the United States and West Indies. $<$ Journ. N. Y. Ent. Soc., XV. 166-170.

$1907 \mathrm{~b}-\mathrm{A}$ New Cyrtoxipha from the United States.<Journ. N. Y. Ent. Soc., XV, 237.

$1907 \mathrm{c}$ - Notes on United States Orthoptera with a Description of One New Species.<Proc. Ent. Soc. Wash., VIII, Nos. 3-4, 133-135.

1907d-Kirby's Catalogue of Orthoptera, Vol. II.<Can. Ent., XXXIX, $287-292$.

1908-Orthoptera-Family Locustidæ-Subfamily Decticinæ.<72d Fasc.. Gen. Insect. 4to. Pp., 1-43, pls. 1-2.

1908a-Notes on Some Western Orthoptera with a Description of One New Species.<Proc. U. S. Nat. Mus., Vol. $34,71-81$.

1910-A New Xiphidion from Northern Georgia.<Ent. News, XXI, 5859.

$1910 a-O n$ the Genus Conocephalus. <Proc. Ent. Soc. Wash., XII, 95-96.

1911-Some Remarks on Kirby's Synonymic Catalogue of Orthoptera, Vol. III, with Additional Notes on Vols. I and II.<Ent. News, XXII, $158-167$.

1912-Notes on the Mantid Genus Gonatista Sauss.<Psyche, XIX, $160-162$.

1913-Notes on Nearctic Orthopterous Insects: I-Nonsaltatorial Forms.<Froc. U. S. Nat. Mus., Vol. 44, 595--614.

1915-Notes on Some United States Grasshoppers of the Family Acrididæ.<Proc. U. S. Nat. Mus., Vol. 49, 25-31.

1915a-Dendrotetix quercus Packard.<Psyche, XXII, 52-54.

1916-The Genera of the Tettigoniid Insects of the Subfamily Rhaphidophorinæ Found in America North of Mexico.<Proc. U. S. Nat. Mus., Vol. 49, 655-690.

1916a-Nomenclatorial Consistency.<Science, N. S., XLIII, 852-853.

$1916 \mathrm{~b}$-An Economic Consideration of Orthoptera Directly Affecting Man.<Proc. Ent. Soc. Wash., XVIII, 84-92.

1918-Regarding Diapheromera veliei Walsh and Manomera blatchleyi Caudell.<Ent. News, XXIX, 258-260.

1918a-Homorocoryphus malivolans Scudd. in Texas; <Bull. Brook. Ent. Soc., XIII, 21.

1918b-Two New Species of the Blattid Genus Arenivaga.<Proc. Ent. Soc. Wash., XX, 154-157.

Caudelt, A. N. \& Hebard, Morgax-1912-Fixation of the Single Type (Lectotypic) Specimens of Species of American Orthoptera (Described by Caudell).<Proc. Acad. Nat. Sci. Phil., 157-168.

Caclfield, F. B. - 1888- Sketch of Canadian Orthoptera. $<18$ th Ann. Rep. Ent. Soc. Ont., 59-72. Toronto.

Coмsтock. J. H.-1888-Orthoptera.<An Introduction to Entomology, I, $87-122$. Ithaca.

Comstock, J. H. \& A. B.-1895-A Manual for the Study of Insects. Pp. $12+701$, pls. I-VI. Ithaca.

Daris, W. T.-1887-Notes on the Locustidæ with Description of a New Species.<Can. Ent., XIX, 56, 57 .

1889 -List of the Orthoptera found on Staten Island.<Entom. Amer., $\mathrm{V}, 78-81$.

1891-Additions to the List of Staten Island Orthoptera.<Proc. Nat. Sci. Assoc. Stat. Isl., Feb., 14, 1891.

1893-The Song of Thyreonotus.<Can. Ent., XXV, 108-109.

1895-Insects at Watchogue and Beulah Land, Staten Island, N. Y.< Journ. N. Y. Entom. Soc., III, 140-143.

1896-Notes on Crickets and Other Staten Island Orthoptera.<Proc. Nat. Sci. Assoc., of Stat. Isl., V, 96-07.

1904-An Arboreal Orchelimum.<Can. Ent., XXXVI, 132.

1905-The Red-headed Orchelimum and Some Other New Jersey Orthoptera.<Can. Ent., XXXVII, 288-289. 
1907-A New Tree Cricket from Staten Island and New Jersey.<Can. Ent., XXXIX, $173-174$.

1908-A New Orchelimum from Staten Island and New Jersey.<Journ. N. ^. Ent. Soc., XVI, 222-223.

1909-A New Orchellmum from New Jersey.<Can. Ent., XLI, 33-34.

1909 a-A uricket New to New Jersey.<Journ. N. Y. Ent. Soc., XVII, $187-188$.

$1909 \mathrm{~b}$ - Notes on New e ersey Orthoptera.<Ent. News, XX, 138.

1911-Notes on Two Conocephalids. $<$ Can. Ent., XLIII, 413.

1911a-Miscellaneous Notes on Collecting in Georgia.<Journ. N. Y. Ent. Soc., XIX, 216-219.

1912-An Injurious Grasshopper at Ridgeway, New Jersey.<Ent. News, XXIII, $2-3$.

1912a-Three New Species of Belocephalus from Florida.<Journ. N. Y. Ent. Soc., XX, $122-125$.

1913-Two Additions to the List of New Jersey Cone-headed Grasshoppers.<Journ. N. Y. Ent. Soc., XXI, 177-178.

1914- Notes on Orthoptera from the East Coast of Florida with descriptions of Two New Species of Belocephalus.<Journ. N. Y. Ent. Soc., XXII, 191-205.

$1914 a-A$ Cricket New to Long Island, N. Y.<Journ. N. Y. Ent. Soc., XXII, 171.

1915-List of the Orthoptera Collected in Northern Florida in 1914 for the American Museum of Natural History with Descriptions of New Species.<Journ. N. Y. Ent. Soc., XXIII, 91-101.

1915a-A New Species of Atlanticus from the Mountains of Georgia and North Carolina.<Bull. Brook, Ent. Soc., IX, 1914, 104-106.

1915b-Dendrotettix quercus Riley, at Yaphank, Long Island, N. Y. $<$ Bull. Brook. Ent. Soc., X, 33-34.

1918-Introduction of Palæarctic Preying Mantids into the North Atlantic States.<Bull. Brook Ent. Soc., XIII, 73-76.

1919-A New Stagmomantis from Florida.<Bull. Brook. Ent. Soc., XIV, $4-7$, pl. 1.

1919a-The Males of the Roach, Pycnoscelis surinamensis.<Journ. N. Y. sint. Soc., XXVII, 108-109.

Dodge, CHAS. R. - 1872-Notes of a Cowcatcher Ride Through Nebraska.< Can. Ent., IV, $14-16$.

1877-The "Lubber" Grasshopper.<Field and Forest, II, 160-161.

DodGE, G. M.-1876-New Species of Acridini from Nebraska.<Can. Ent., VIII, $9-12$.

1877-New Species of Orthoptera.<Can. Ent., IX, 111-113.

DruRY, D. - 1770-1782-Illustrations of Natural History, 3 Vols. I, pp. $28+130$, pls. $1-50$; II, $7+92$, pls. $1-50$; III, $26+76$, pls. $1-50$. 4 to.

London.

Fabricius, Johaxx C.-1775-Systema entomologiz sistens insectorum, synonymis, locis, descriptionibus, observationibus. Pp. $32+832$.

Flensburgi et Lipsiæ.

1781-Species insectorum exhibentes eorum differentias specificas, etc. I. Pp. $8+552$; II, $2+494$. Hamburgi et Kilonii.

1793-Entomologia Systematica emendata et aucta secundum classes, etc. -II, Pp. 1-62. Hafniæ.

1798-Supplementum Entomologiæ Systematicæ, 4+572 pp. Hafniæ.

Fernald, C. H. - 1888-The Orthoptera of New England.<Ann. Rep. Mass.

Agr. Coll., XXV, 89-145. Auth. Sep., pp. 1-61.

Fieber. F. X.-1852-I Kelch Grundlage zur Kenntniss der Orthoptera Oberschlessens. $<\mathrm{Zu}$ der Off. Prufung., 1-20, Apr. 5 and 6 .

1853-Synopsis der Europaischen Orthopteren mit besonderer rucksicht auf die in Bohmen vorkommender arten.<Lotos, III, 90-104, $115-129,138-154,168-176,184-188,201-207,232-238,252-$ 258. rrag.

Fisciner. L. H.-1853-Orthoptera Europæa. Pp. $20+454$, pls. 1-18. Lipsiæ.

Fıтст. AsA-1856-Third Report on the Noxious and Other Insects of the State of New York.<Trans. N. Y. State Agric. Soc., XVI, 321-507. Albany. 
Fletcher, JAMes-1892-The Northern Mole Cricket.<Can. Ent., XXIV, $23-25$.

Forbes, S. A.-1905-The More Important Insects Injurious to Indian Corn. <23rd Rep. St. Entom., Ill. pp. 1-273, pls. I-VIII.

Forex, A.-1887-Experiences et remarques critiques sur les sensations des Insects.<Recueil Zool. Suisse., IV, 145-240.

Fox, Hexry - 1912-Two Apparently Hithero Undescribed Species of Xiphidium from the Salt Marshes of the Atlantic Coast of the United States.<Ent. News, XXIII, 111-119, pls. VIII-IX.

1914-Data on the Orthopteran Faunistics of Eastern Pennsylvania and Southern New Jersey.<Proc. Acad. Nat. Sci. Phil., 441-534.

1915-Notes on Orthoptera and Orthopteran Habitats in the Vicinity of Lafayette, Ind. <Proc. Ind. Acad. Sci., 1914, 287-321, Auth. Sep. pp. $1-35$.

1917-Field Notes on Virginia Orthoptera.<Proc. U. S. Nat. Mus., Vol. $52,199-234$.

1918-On a Long-winged or Caudate Phase of Neotettix proarus Rehn and Hebard.<Ent. News, XXIX, 347-349.

Fultox, Bextley B.-1915-The Tree Crickets of New York; Life History and Bionomics.<Tech. Bull. No. 42, N. Y. Agr. Exp. Sta.. Geneva, N. Y., pp. $1-47$, pls. I-VI.

Garmax, H.-1891-On a Singular Gland Possessed by the Male of Hadenœecus subterraneus.<Psyche, VI, 105.

1894-The Orthoptera of Kentucky. <Sixth Ann. Rep. Ky. Agr. Exp. Sta., 23-24. Auth. Sep., pp. 1-10.

GEer, DE KAREL-1773-Memoires pour servir a l'histoire des insectes. Orthoptera, III, 399-554, pls. 21-25. Stockholm.

GÉxe, Guistrpe-1832-Saggio di Una Monografia Delle Forfícule Indigene.<Ann. Sci. Nat. Regn. Lomb.-Venet., II, 4to., 215-22S. Auth. Sep., pp. 1-16.

GEoffroY, M.-1764-Histoire abregee des Insecten-Orthoptera, I, 379407. Paris.

Germar, Erxest F.-1838-In Burmeister's Handbuch der Entomologie, II. Berlin.

Grrstecker, Carl Enward-1860-Ueber die Locustinen gattung Gryilacris. <Wiegm., Arch. naturg., XXVI, 245-278. Berlin.

1863-Arthropoden (Orthoptera). < Hartwig \& Carus Handbuch der Zoologie, $37-67$.

Giglio-Tos. E-1894-Viaggio del dott. Alfredo Borelli nella Republica Argentina e nel Paraguay; VII. Ortotteri.<Boll. Mus. Torino, IX, No. 184 , Vol. IX, $1-46$, pl. 1 .

Gillette, C. P.-1904-Annotated List of Colorado Orthoptera from Material in the Collections of the Colorado Agr. College and Agr. Experiment Station.<Bull. 94, Colo. Agr. Exp. Sta., 17-56.

Glover, Towxexp-1871-Report of the Entomologist.<Ann. Rep. U. S. Dept. Agr., 1870, 65-91. Washington.

1872-Report of the Entomologist.<Ann. Rep. U. S. Dept. Agr., 1871, $69-88$.

1872a-Illustrations of North American Entomology-Orthoptera. Pp. $5+11$, pls. $1-18$. Washington.

1875-Report of the Entomologist. <Ann. Rep. U. S. Dept. Agr., 1874, $122-146$.

Gooderhay, C. B. - 1917-The Acrididæ of Nova Scotia.<Proc. Ent. Soc. N. Scot., 1916, 21-30, pl. V.

GraY. GEorge R.-1835-Synopsis of the Species of Insects Belonging to the the Family of Phasmidæ. Pp. $4+48$. London.

Grentx-Mexeville. F. E.-1829-1844-Iconographie du Regne Animal de G. Cuvier, etc. Pp. 576, 104 pls. Paris.

HAAx. DE Willex-1842-Bijdragen tot de Kennis der Orthoptera.<Verhand. de Natur. Gesch. der Nederl. Overzeesch. Bezitt. etc. Orthop.. pp., $45-248$, pl. $10-23$. Leiden.

Haldemax, S. S. - 1850-History of Phalangopsis, a Genus of Orthoptera with three new Species.<Proc. Amer. Assoc. Adv. Sci., II, 346. 
1853-Description of some New Species of Insects, with Observations on Described Species.<Proc. Acad. Nat. Sci. Phil., VI, 361-365.

Haxcock, Dr. J. L.-1894-Unusual Flights of the Grouse Locust. (Tettigidea lateralis Say) in Northeastern Illinois.<Amer. Nat., XXVIII, 483-487, pl. 13.

1896-On Illinois Grouse Locusts.<Trans. Amer. Ent. Soc., XXIII, 235244 , pls. VI-IX.

1897-The Grouse Locusts of Minnesota.<Bull. 55, Minn. St. Exp. Stat., $105-111$.

1898- The Species of the New Genus Neotettix with a Key to the Genera of North American Tettigidæ.<Ent. News. IX, 137-141, pl. VIII.

$1898 \mathrm{a}$ - The Food Habits of the Tettigidæ.<Entom. Rec. \& Journ. of Var., $\mathrm{X}, 6-7$.

1899-Some Tettigian Studies.<Ent. News, X, 275-282.

1900-Synopsis of Subfamilies and Genera of North American Tettigidæ. $<$ Psyche, IX, $1-7$.

1902-The Tettigidæ of North America. Pp. vii+188, pls. I-XI. Chicago.

1904-Oviposition and Carnivorous Habits of the Green Meadow Grass. hopper (Orchelimum glaberrimum Burmeister). $<$ Psycie, $\mathrm{XI}_{4}$ $69-71, \mathrm{pl}$. V.

1905-The Habits of the Striped Meadow Cricket, Oecanthus fasciatus Fiteh.<Amer. Nat., XXXIX, 1-11.

1906-Orthoptera-Family Acrididæ-Subfamily Tetriginæ.<48th Fasc. Gen. Insect. Pp. 1-77, pls. 1-4.

$1906 \mathrm{a}-$ On the Orthopteran Genus Ageneottix with a Description of a New Species from Illinois.<Ent. News, XVII, 253-256.

1909 -Further Studies of the Tetriginæ in the Oxford University Museum.<Trans. Ent. Soc. of London, 1908, pt. III, 387-426, pl. XXII.

1911-Nature Sketches in Temperate America. Pp. 1-451. Illustrated. Chicago.

1916-Pink Katydids and the Inheritance of Pink Coloration.<Ent. News, XXVII, $70-82$.

1918-A New Genus and Two New Species of Tettigids with a Note on Nomotettix borealis Walker.<Ent. News, XXIX, 343-347, pl. $\mathrm{XX}$.

Harris, Thaddeus W.-1835-A Catalogue of the Animals and Plants in

Masssachusetts.-Insects.<Hitch, Edw., Rep. Geol. Mass., 2nd. ed.,

pt. IV, 553-602.

1841-A Report on the Insects of New England Injurious to Vegetation. 1st ed. Pp. viii +459 . Cambridge.

1862-A Treatise on Some of the Insects of New England which are Injurious to Vegetation. 3rd ed. Pp. $12+640$, pls. I-VIII.

Hart, Chas. A.-1892-On the Species of Oecanthus Serv.<Ent. News, III, $33-34$.

1906-Descriptive Synposis of Insect Collections for Distribution to Illinois High Schools, II, Orthoptera. Pp. 67-92.

1906 a-Notes of a Winter Trip in Texas, with an Annotated List of the Orthoptera.<Ent. News, XVII, 154-160.

1907-Zoological Studies in the Sand Regions of the Illinois and Mississippi River Valleys.<Bull. Ill. State Lab. Nat. Hist., VII, pt. III, 195-272, pls. VIII-XXIII.

Hebard, Morgan-1909-Additional Notes on the Orthoptera of the Keweenaw Bay Region of Baraga County, Michigan.<Ent. News. XIX, $155-158$.

1913-A Revision of the Species of the Genus Nemobius found in North America North of the Isthmus of Panama.<Proc. Acad. Nat. Sci. Phil., 394-492.

1913a-A New North American Genus belonging to the Group Nemobiites.<Ent. News, XXIV, 451-452.

1915-The Genus Hygronemobius with a Description of One New Species.<Ent. News, XXVI, 193-199, pl. VI.

1915a-Records of Orthoptera from Newfoundland.<Ent. News, XXVI, 306. 
$1915 \mathrm{~b}$-Dermaptera and Orthoptera found in the Vicinity of Miami, Florida, in March, 1915.<Ent. News, XXVI, 397-408, 457-469, pls. XVIII, XX.

1915c-The American Species of the Genus Miogryllus.<Journ. N. Y. Ent. Soc., XXII, 101-121.

1916-Spring Orthoptera found on the Islands in the Vicinity of Charlotte Harbor, Florida.<Ent. News, XXVII, 14-21.

1916a-The Genus Ceratinoptera.<Trans. Am. Ent. Soc., XLII, 125-134.

$1916 \mathrm{~b}-\mathrm{A}$ New Genus, Cariblatta, of the Group Blattellites.<Trans. Amur. Ent. Soc., XLII, 147-186, pls. XI-XIII.

$1916 \mathrm{c}$ - Studies in the Group Ischnopterites.<Trans. Am. Ent. Soc., XLII, 337-383, pls. XVI-XIX.

1916d-Nomenclatorial Facts.<Science, N. S., XLIV, 172-173.

1917-Notes on the Earwigs (Dermaptera) of North America North of the Mexican Boundary.<Ent. News. XXVIII, 311-323.

1917 a - The Blattidæ of North America North of the Mexican Boundary. <Memoirs Amer. Entom. Soc., No. 2, 4to, 1-284, pls. I-X.

$1917 \mathrm{~b}$ - Notes on Mexican Melanopli.<Proc. Acad. Nat. Sci. Phil., 251275.

1918-New Genera and Species of Melanopli found within the United States.<Trans. Amer. Ent. Soc., XLIV, 141-169, pl. VIII.

1919-Remarks on the Species Assigned to Cavotettix Hancock, a Synonym of Neotettix Hancock. <Ent. News XXX, 78-82.

$1919 \mathrm{a}$ - New Genera and Species of Melanopli Found within the United States.<Trans. Amer. Ent. Soc., XIV, 257-298, pls. XXIXXXXI.

Hermax, C. O.-1874-Die Decticiden der Brunner von Wattenwyl'schen Sammlung. $<$ Verh. Zool. - bot. Gesellsch., XXIV, 193-210, pls. 3-6.

Hockhtox, C. O.-1904-An Unusual Injury by the Snowy Tree-cricket and

Notes on its Feeding Habits.<Ent. News, XV, 57-61.

1909-Observations on the Mating Habits of Oecanthus.<Ent. News, $\mathrm{XX}, 274-279$.

1909a-Notes on Oecanthus.<Can. Ent., XLI, 113-115.

HowARD. L. O.-1892-A Genus of Mantis Egg Parasites.<Insect Life, IV, $242-245$.

1895-Damage by the American Locust.<Insect Life, VII, 220-229.

1902-The Insect Book. Pp. xxvii+429, pls. I-XLVIII. New York.

HubBarD, H. G.-1894-The Insect Guests of the Florida Land Tortoise.< Insect Life, VI, $302-315$.

IsELY. F. B.-1905-Notes on Kansas Orthoptera.<Trans. Kan. Acad. Sci., XIX, 238-249.

Jexsex, J. P.-1909-Courting and Mating of Oecanthus fasciatus. $<$ Can. Ent., XLI, 25-27.

1909a-Observations on the Oviposition of Oecanthus quadripunctatus. $<$ Ent. News, XX. 25-28, pl. II.

Johasssox. Bos.-1763-Centurio insectorum rariorum.<Amœn. Acad., etc., VI, 384-415. Holmiæ.

Jores, D. W.-1917-The European Earwig and its Control.<Bull. No. 566, U. S. Bur. Ent., Pp. 1-12.

Karxey, H.-1907-Revisio Conocephalidanum.<Abh. K. K. Zool.-Bot. Ges. Wien. IV, Heft. 3, pp. 1-114.

1912-Orthoptera. Fam. Locustidæ-Subfam. Copihorinæ.<139th Fasc. Gen. Insect. Pp. 1-50, pls. 1-7.

1913-Orthoptera-Fam. Locustidæ. Subfam. Conocephalinæ. $<135$ th Fasc. Gen. Insect. Pp. 1-16, pls. 1-2.

KIRBY. WMr.-1837-Fauna Boreali- Americana. The Insects. Pt. IV, 4 to. Pp. $39+325$, pls. I-VIII. London.

KrrbY. Wy. \& SPExce, WM.-1828-An Introduction to Entomology, 5th ed. Pp. 1-607. London.

1859-An Introduction to Entomology or Elements of the Natural History of Insects, etc. Seventh ed. Pp. 1-607. London.

KrRBY, W. F.-1904-A Synonymic Catalogue of Orthoptera-Vol. I-Euplexoptera, Cursoria et Gressoria. Pp. xx+501. London. 
1906-Same, Vol. II. Ortnoptera Saltatoria, Pt. I. (Achetidæ et Phasgonuridæ). Pp. viil +562.

1910-Same, Vol. III. Orthoptera Saltatoria, Pt. II. (Locustidæ vel Acrididæ). Pp. vii +674 .

KNAB, FreDErICK-1907-Color Varieties of Locustidæ.<Science, XXVI, $595-597$.

Kostik, W. J.-1914-Additions to the Known Orthopterous Fauna of Ohio.<Ohio Naturalist, XV, $370-374$.

Latreille, P. A.-1802-1805-Histoire Naturelle des Crustaces et des In. sectes.-Orthoptera, Vol. III, 267-284 (1802); Vol. XII, 81-164 (1804), pls. $94-95$.

1817-Insecta.<Cuvier G.,-Le Regne Animal, etc.-Orthoptera, Vol. III, $365-384$.

1829-Same, second edition.

1831-Same. American edition translated from the French with notes and additions by H. M'Murtrie. 4 vols. Orthoptera in Vol. IV, pp. 1-18.

LEACH, W. E.-1815-Article Entomology.<Edinburgh Encyclopedia, IX, $57-172$.

LINNeUS, CARI roN-1758-Systema naturæ. Edito deciria reformata. Orthoptera, I. $423-434$. Holmiæ.

1763-Centuria insectorum rariorum.<Amœn. Acad., VI, 384-415. Auth. Sep., Pp. $6+32$. Upsaliæ.

1767-Systema naturæ. Editio duodecima reformata. OrthopteraVol. II, $686-703$.

Lucas, H.-1847-A New Forficesile.<Bull. Soc. Ent. France, (2) V. p. LXXXIV.

Lugger, OTTo-189'i-The Orthoptera of Minnesota.<Bull. No. 55, Minn. State Exp. Stat., 1-296. St. Paul.

1898-Same.<Third Ann. Rep. Entomologist State Exper. Stat. Univ. Minn., 1897, pp. 1-296.

Lutz, F. E.-1906-The Tegminal Position in Gryllus.<Can. Ent., XXXVIII., 207-209.

1908-The Variation and Correlation of Certain Taxonomic Characters of Gryllus. <Publ. No. 101, Carnegie Institution, 1-63. Washington.

Maxee, A. H.-1908-Some Observations at Southern Pines, North Carolina. $<$ Ent. News, XIX, 459-462, pls. XX-XXI.

Marlatt, C. L.-1896-The Principal Household Insects of the United States.<Bull. 4, (N. S.), U. S. Div. Ent., Pp. 1-130. Washington. 1902-Cockroaches. Circ. 51, (2nd Ser.) U. S. Div. Ent., 1-15.

Marschald, A. F.-1836-Decas Orthopterorum novorum.<Ann. Wien. Mus., I, 207-218, pl. XVIII.

McAtee, W. L.-1908-Notes on an Orthopteron Leaf-roller. <Ent. News, XIX, 488-491, pl. XXV.

McAtee, W. L. \& CAUdel, A. N.-1918-First List of the Dermaptera and Orthoptera of Plummer's Island, Md. and Ticinity.<Proc. Ent. Soc. Wash., XIX, 1917, 100-122.

MCNEILL, JEROME-1887-Dissosteira carolina.<Can. Ent., XIX, 58-59. 1889-Notes upon Gryllus and Oecanthus.<Entom. Americana, V. $101-104$.

1891-A List of the Orthoptera of Illinois. $<$ Psyche, VI, 3-9, 21-27, $62-66,73-78$.

1897-Revision of the Truxalinæ of North America.<Proc. Daven. Acad. Nat. Sci., VI, $179-274$, pls. I-VI. Davenport, Iowa.

1897 a-Some Corrections in Generic Names in Orthoptera.<Psyche, VIII, 71.

1899-Notes on Arkansas Truxalinæ.<Can. Ent., XXXI, 53-55.

1899a-Arkansas Melanopli.<Psyche, VIII, 332-334, 343-346, 366371.

1900-The Orthopteron Genus Trimerotropis.<Psyche, IX, 27-36.

1900a-Orchelimum Serville.<Can. Ent., XXXII, 77-83.

1901-Review of the Orthopteron Genus Trimerotropis.<Proc. U. S. Nat. Mus., Vol. 23, 393-449, pl. XXI. 
Mead, Chas. S.-1904-A List of the Orthoptera of Ohio.<Ohio Naturalist, IV, 109-112.

Morse, A. P.-1893-A New Species of Stenobothrus from Connecticut with Remarks on Other New England Species.<Psyche, VI, 477-479.

$1893 \mathrm{a}$-A Melanistic Locust.<Fsyche, VI, 401.

1894-A Preliminary List of the Acrididæ of New England.<Psyche, VII, 102-108.

1894a-Notes on the Acrididæ of New England.-I. Tettiginæ.<Psyche, VII, $147-154,163-167$, pl. 6.

$1894 \mathrm{~b}-$ Spharagemon; a Study of the New England Species.<Proc. Bost. Soc. Nat. Hist., XXVI, 220-240.

1895- New North American Tettiginæ,-I.<Journ. N. Y. Ent. Soc., Vol. III, 14-16;-II, 107-110; Vol. IV, pl. II.

1895 - A Revision of the Species of the Genus Spharagemon. $<$ Psyche, VII, 287-299.

1896-Notes on the Acrididæ of New England,-II. Tryxalinæ.< Psyche, VII, 323-327, 342-344, 382-384, 402-403, 407-411, $413-422,443-445, \mathrm{pl} .7$.

1896 - Some Notes on Locust Stridulation. <Journ. N. Y. Ent. Soc., IV, $16-20$.

1897-Notes on New England Acrididæ,-III. Oedipodinæ.<Psyche, VIII, $6-8,35-37,50-51,64-66,80-82,87-89,91-114$, pl. 2.

1898-Notes on New England Acrididæ,-IV, Acridiinæ.<Psyche, VIII, $247-248,255-260,269-273,279-282,292-296$, pl. 7 .

1899-New North American Tettiginæ,-III.<Journ. N. Y. Ent. Soc., VII, $198-201$.

1899a-The Distribution of the New England Locusts.<Psyche, VIII, $315-323$.

1900-Tettiginæ.<Biol. Cent. Amer.,-Orth., II, 3-19.

1901-A New Xiphidium from Florida.<Can. Ent., XXXIII, 236.

1901a-Variation in Tridactylus. <Psyche, IX, 197-199.

1901b-New North American Orthoptera.<Can. Ent., XXXIII, 129-131.

1904-Researches on North America Acrididæ.<Publ. No. 18, Carnegie Inst. of Washington, Fp. 1-55, pls. 1-8.

1904a-New Acrididæ from the Southeastern States. < Psyche, XI, 7-13. 1905-Some Bahama Orthoptera. <Psyche, XII, 19-24.

1906-New Acrididæ from the Southern States.<Psyche, XIII, 119-122.

$1906 \mathrm{a}$ - The Ecological Relations of the Orthoptera in the Porcupine Mountains, Michigan.<Rep. State Bd. Geol. Surv. of Mich., 1905, $68-72$.

1907-Further Researches on North American Acrididæ.<Publ. No. 68, Carnegie Inst. of Washington. Pp. 1-54, pls. 1-9.

1907 a-Paratylotropidia beutenmülleri sp. nov.<Psyche, XIV, p. 14.

1908 - Tettigidean Notes, and a New Species.<Psyche, XV, 25.

1909 -Report on the Isle Royale Orthoptera of the 1905 Expedition. < An Ecol. Survey of Isle Royale, Lake Superior,-Orthoptera, 299-303. Lansing.

1916-A New England Orthopteran Adventive.<Psyche, XXIII, 178180.

1919-New Records of Orthoptera in New England.<Psyche, XXVI, $16-18$.

1919a-A List of the Orthoptera of New England. <Psyche, XXVI, 21 -39 .

Morse. A. P. \& Hebard, Morgax-1915-Fixation of Single Type (Lectotypic) Specimens of Species of American Orthoptera (Described by Morse).<Proc. Acad. Nat. Sci. Phil., 96-106.

MotschulskY, V.-1863-Essai D'un Catalogue des Insectes de l'ile Ceylon. <Bull. Soc. Nat. Mosc., XXXVI, 1-153.

Murtfeld, Mary E.-1889-The Carnivorous Habits of Tree Crickets.< Insect Life, II, $130-132$.

Newmax, EDw.-1838-Entomological Notes.<Ent. Mag., V, 168-181.

OLIvier, G. A.-1789-1792-Encyclopedie methodique dictionaire des insectes (Orthoptera treated in Vol. IV, 1789; VI, 1791; VII, 1792.)

Paris. 
Packard, Alpheus S.-1869-Orthoptera.<Guide to the Study of Insects and a Treatise on Those Injurious and Beneficial to Crops. Pp. $556-577$.

1873-On the Cave Fauna of Indiana.<Ann. Rep. Peabody Acad. Sci., V, $93-97$.

1881-The Fauna of the Nickajack Cave.<Amer. Nat., XV, 877-882, pl. VII.

1888- The Cave Fauna of North America with Remarks on the Anatomy of the Brain and Origin of the Blind Species.<Memoirs Nat. Acad. Sci., IV. Pp. 1-156, pls. I-XXVI. Washington.

1889-Notes on Epipharynx and Epipharyngeal Organs of Taste in Mandibulate Insects. < Psyche, V, 1889, 193-199.

1890 - On Insects Injurious to Forest and Shade Trees. $<$ Rep. U. S. Ent. Comm., V. Pp. $8+958$, pl. I. Washington.

Pallas, Peter S.-1772-Spicelegia zoologica quibus novæ imprimis, etc.Orthoptera, Vol. I, fasc. IX, 87 pp., 5 pls.

PARrotT, F. J. \& Fulton, B. B.-1914-Tree Crickets Injurions to Orchard and Garden Fruits.<Bull. No. 388, N. Y. Agr. Exp. Sta., 417-461, pis I-X. Geneva, N. Y.

Perty, M.-1832-Insecta Brasiliensia.-Orthoptera.<Delectus Animalium Articulatorum Brasil, 116-124, pls. XXIII-XXIV.

Pettit, R. H. \& McDaniel, Evgenia-1918-Key to Orthoptera of Michigan, With Annotations.<Spec. Bull. No. 83, Mich. Agr. Coll. Exp. Stat., $1-48$.

Piers, HarkY - 1896-Preliminary Notes on the Orthoptera of Nova Scotia. $<$ Trans. Nov. Scot. Inst. Sci., IX, 208-218. Halifax.

1918-The Orthoptera of Nova Scotia with Descriptions of the Species and Notes on their Occurrence and Habits.<Trans. Nov. Scot. Inst. Sci., XIV, Pt. 3, 201-356, pls. 1-4.

Provancirer, L.-1876-Petite faune Entomologique du Canada.-Les Orthopteres.<Nat. Can., VIII, $13-26,52-62,72-81,106-116,134-143$.

1877-Faune Entomologique du Canada et particulierement de la Province de Quebec.-Les Orthopteres et les Neuropteres. Pp. $6+157$. Quebec.

1883-Same, Vol. II. Fascicle 1. Les Orthopteres. Pp. 1-53.

REDTENBACHER, JoseF-1891-Mongraphie der Conocephaliden.<Verhand. der K. K. Zool.-Bot. Gesellschaft in Wien, 315-562, pls. 3-4. Auth. Sep., 1-248. Wien.

1892 - On the Orthoptera of the Island of St. Vincent, West Indies.< Proc. Zool. Soc. Lond., XVII, 196-221, pls. XV-XVII.

REHx, J. A. G.-1900-Notes on the Distribution of Fodisma variegata Scudder.<Ent. News, XI, $630-631$.

1900a-Melanoplus differentialis in New Jersey \& Pennsylvania.<Can. Ent., XXXII, 28.

1901-Random Notes on North American Orthoptera.<Trans-Amer. Ent. Soc., XXVII, 331-337.

1901a-The Linnæan Genus Gryllus. $<$ Can. Ent., XXXIII, 118-121.

1902-A New Aptenopedes from Florida.<Ent. News, XIII, 14.

1902a-Schistocerca alutacea and rubiginosa.<Ent. News, XIII, 89.

$1902 \mathrm{~b}$-Nomenclatural Notes on Two Genera of Orthoptera.<Ent. News, XIII, 101-102.

1902c-Records of New Jersey and Pennsylvania Orthoptera.<Ent. News, XIII, $309-316$.

1902d-A Contribution to the Knowledge of the Orthoptera of Mexico and Central America.<Trans. Amer. Ent. Soc., XXIX, 1-34.

1903 - Notes on some Interesting Species of Forficulidæ and Blattidæ from the Eastern United States.<Ent. News, XIV, 125-126.

$1903 a-S t u d i e s$ in American Blattidæ.<Trans. Amer. Ent. Soc., XXIX, $259-290$.

1903b-Notes and Remarks on North American Blattidæ, Mantidæ ana Phasmidæ.<Ent. News, XIV, 325-329.

1903c.-A Revision of the Orthopterous Genus Homœogamia.<Proc. Acad. Nat. Sci. Phil., 177-192. 
1903d-A New Roach of the Genus Ischnoptera from Florida.<Ent. News, XIV, 234.

$1903 \mathrm{e}-$ Notes on the Orthoptera of New Mexico and Western Texas.< Proc. Acad. Nat. Sci. Phil., 1902, 717-727.

$1903 \mathrm{f}$-Description of a new Genus of Gryllidæ, with a note on the Genus Aphonogryllus.<Ent. News, XIV, 258-259.

1903g-Studies in Old World Mantidæ.<Proc. Acad. Nat. Sci. Phil., $701-718$.

1904-Notes on Orthoptera from Northern and Central Mexico.<Proc. Acad. Nat. Sci. Phil., 513-549.

1904 - Notes on Orthoptera from Arizona, New Mexico and Colorado.< Proc. Acad. Nat. Sci. Phil., 562-575.

1904b-A New Melanoplus from New Jersey.<Ent. News, XV, 85-87.

$1904 \mathrm{c}$ - A New Roach of the Genus Chorisoneura from South Carolina. <Ent. News, XV, 164.

$1904 d-N o t e s$ on the Orthoptera of the Keweenaw Bay Region of Baraga County, Michigan.<Ent. News, XV, 229-236, 263-270.

$1904 \mathrm{e}-\mathrm{Tw} 0 \mathrm{New}$ Species of North American Stenopelmatinæ.<Ent. News, XV, 280-282.

1904f-Notes and Records of New Jersey Orthoptera.<Ent. News, XV, $325-332$.

1904g-A New Species of Roach of the Genus Kakerlac from Southern Texas. < Psyche, XI, 72-73.

1905 - Notes and Descriptions of Orthoptera from the Western United States in the Entomological Collection of the University of Kansas.<Trans. Kan. Acad. Sci., XIX, 221-231.

1906-A New Species of Eotettix from Georgia.<Ent. News, XVII, 234237.

1906a--Some Utah Orthoptera.<Ent. News, XVII, 284-288.

$1906 \mathrm{~b}$-Conocephalus lyristes.<Ent. News, XVII, 366-367.

$1906 \mathrm{c}$ - Orthoptera of the Bahamas. <BuIl. Amer. Mus. Nat. Hist., XXII, $107-118$.

1907-Records of Orthoptera from the Vicinity of Brownstille, Texas. $<$ Ent. News, XVIII, 209-212.

1907a-Notes on Orthoptera from Southern Arizona with Descriptions of New Species.<Proc. Acad. Nat. Sci. Phil., 24-81.

1909-A Catalogue of the Orthoptera of Cuba and the Isle of Pines.< Sec. Rep. Cent. Exper. Stat., Republic of Cuba, 175-226.

1909a-New Jersey Records of Hesperotettix brevipennis (Thomas). < Ent. News, XX, 104-105.

1917-Some Critical Notes on the Giant Katydids Forming the Groun Steirodontia (Phaneropterinæ).<Ent. News, XXVIII, 107-122. pl. X.

1911-Orthoptera-Family Mantidæ, Subfamily Vatinæ.<119th Fasc. Gen. Insect. Pp. 1-28, pl. I.

1919-A Study of the Orthopterous Genus Mermiria Stål.<Proc. Acad. Nat. Sci. Phil., 55-120, pls. V-VII.

Reirx, J. A. G. \& Hebard. Mongax-1904-The Orthoptera of Thomas County, Georgia and Leon County, Florida.<Proc. Acad. Nat. Sci. Phil., 774-802.

$1905-A$ Contribution to the Knowledge of the Orthoptera of Southern and Central Florida.<Proc. Acad. Nat. Sci. Phil., 29-55, pl. I.

1906-A Contribution to the Knowledge of the Orthoptera of Montana, Yellowstone Park, Utah and Colorado.<Proc. Acad. Nat. Sci. Phil., 358-418.

1907-Orthoptera from Northern Florida.<Proc. Acad. Nat. Sci. Phil., $279-319$.

1908-An Orthopterological Reconnaisance of the Southwestern United States, Pt. I.-Arizona.<Proc. Acad. Nat. Sci. Phil., 365-402.

1909-Same. Pt. II.-New Mexico and Western Texas.<Proc. Acad. Nat. Sci. Phil., 111-175.

1910-A Revision of the North American Species of the Genus Ischnoptera.<Proc. Acad. Nat. Sci. Phil., 407-453.

1910a-Preliminary Studies of North Carolina Orthoptera.<Proc. Acad. Nat. Sci. Phil., 615-650. 
1911-Records of Georgia and Florida Orthoptera with descriptions of one New Species and one New Subspecies.<Proc. Acad. Nat. Sci. Phil., 585-598.

1912-On the Orthoptera found on the Florida Keys and in Extreme Southern Florida.-I.<Proc. Acad. Nat. Sci. Phil., 235-276.

1912a-A Revision of the Genera and Species of the Group Mogoplistii found in North America North of the Isthmus of Panama.<Proc. Acad. Nat. Sci. Phil., 184-234.

$1912 \mathrm{~b}$-Fixation of Single Type (Lectotypic) specimens of Species of American Orthoptera (Described by Bruner, Scudder in part and Rehn \& Hebard).<Proc. Acad. Nat. Sci. Phil., 60-128.

$1912 \mathrm{c}-$ On the Genus Anaxipha.<Ent. News, XXIII, 411-412.

1914-A Revision of the Orthopterous Group Insaræ.<Trans. Amer. Ent. Soc., XL, 37-184.

1914 a-A Synopsis of the Species of the Genus Scudderia. $<$ Trans. Amer. Ent. Soc., XL, 271-314, pls. IX-XI.

$1914 \mathrm{~b}-\mathrm{A}$ Synopsis of the Species of the Genus Amblycorypha found in America North of Mexico.<Trans. Amer. Ent. Soc., XL, 315-344, pls. XI-XII.

1914c-On the Orthoptera found on the Florida Keys and in Extreme Southern Florida,-II, <Proc. Acad. Nat. Sci. Phil., 373-412.

1914d-Records of Dermaptera and Orthoptera from West-central and Southwestern Florida, Collected by W. T. Davis.<Journ. N. Y. Ent. Soc., XXII, 96-116.

$1914 \mathrm{e}$-United States and Mexico Records of Species of the Genus Doru. $<$ Journ. N. Y. Ent. Soc., XXII, 89-96.

$1914 \mathrm{f}-$ On the Genus Phœtalia of Authors. $<$ Ent. News, XXV, 216-217. $1914 \mathrm{~g}-$ On the Blatta ægyptiaca of Drury.<Ent. News, XXV, 121-123.

1915-A Synopsis of the Species of the Genus Neoconocephalus found in North America North of Mexico.<Trans. Amer. Ent. Soc., XL, 365-413, pls. XV-XVI.

$1915 \mathrm{a}-\mathrm{A}$ Synopsis of the Species of the Genus Orchelimum.<Trans. Amer. Ent. Soc., XLI, 11-83, pls. I-IV.

$1915 \mathrm{~b}-\mathrm{A}$ Synopsis of the Species of the Genus Conocephalus found in North America North of Mexico.<Trans. Amer. Ent. Soc., XLI, $155-224$, pls. XV-XX.

$1915 \mathrm{c}$ - The Genus Gryllus as found in America.<Proc. Acad. Nat. Sci. Phil., 293-322, pl. IV.

1916-Studies in the Dermaptera and Orthoptera of the Coastal Plain and Piedmont Region of the Southeastern United States.<Proc. Acad. Nat. Sci. Phil., 87-314, pls. XII-XIV.

$1916 \mathrm{a}-\mathrm{A}$ Revision of the Species of the Genus Atlanticus.<Trans Amer. Ent. Soc., XLII, 33-100, pls. VI-VIII.

1917-Studies in West Indian Earwigs (Dermaptera).<Bull. Amer. Mus. Nat. Hist., XXXVII, 635-651, pls. LXII-LXIII.

Riley, Chas. V.-1869-First Annual Report on the Noxious, Beneficial and other Insects of the State of Missouri. Pp. 1-181. Jefferson City, Mo.

1873-Fifth Annual Report on the Insects of Missouri. Pp. 1-160.

1874-Katydids. < Sixth Ann. Rep. on the Insects of Missouri, 150-169.

1875-Seventh Annual Report on the Insects of Missouri. Pp. viii+196.

1876-Eighth Annual Report on the Insects of Missouri. Pp. 1-185.

1877-Ninth Annual Report on the Insects of Missouri. Pp. vi+129.

1878-Habits and Natural History of Locusts.<First Rep. U. S. Entom. Comm., 212-257.

1879-The Thick-thighed Walking-stick.<Rep. U. S. Dept. Agr., 1878, $241-245$, pl. III.

1881-General Index and Supplement to the Nine Reports on the Insects of Missouri.<Bull. U. S. Entom. Comm., VI, 1-178. Washington.

1884-Orthoptera.<The Standard Natural History, II., 167-203. Boston.

1886-Report of the Entomologist.<Ann. Rep. U. S. Dept. Agr., 1885, $10+137$, pls. I-IX. Washington. 
1887-Our Shade' Trees and their Insect Defoliators.<Bull. U. S. Div. Ent. (O. S.), X, 1+69. Washington.

1888-Injury done by Roaches to the Files in the Treasury at Washington. $<$ Insect Life, I, 67-70, 190-191.

1890-Some Insect Pests of the Household-IV.-Cockroaches. < Insect Life, II, 266-269.

1891-Destructive Locusts.<Bull. 25, U. S. Div. Ent. (O. S.), 1-62, pls. $1-12$, map.

1891a-A Viviparous Cockroach.<Insect Life, III, 443-444.

1893-The Genus Dendrotettix. < Insect Life, V, 254-256.

Riley, C. V., Thomas, C. \& PACKand, A. S.-1878-First Annual Report of

the United States Entomological Commission for the year 1877, re-

lating to the Rocky Mountain Locust. Pp. $16+477+295,3$ maps, 5

plates. Washington.

1880 - Second Report of the United States Entomological Commission for the years 1878 and 1879 , relating to the Rocky Mountain Locust and the Western Cricket. Pp. $18+322+80,17$ plates.

1883-Third Report of the United States Entomological Commission relating to the Rocky Mountain Locust, the Western Cricket, the Army Worm, Canker Worms and the Hessian Fly. Pp. 14+347$+12,4$ maps, 64 plates.

SAussure, Hexri DE-1859-Orthoptera Nova Americana (Diagnoses Præ-

liminares) - I. <Rev, et. Mag. Zool. (2) XI, 59-63, 201-212, 315-317,

390-394. Auth. Sep., pp. 1-16.

1861-Same-II.<Rev, et. Mag. de Zool. (2) XIII, 126-130, 156-164, 313-324, 397-402. Auth. Sep., pp. 1-33.

1862-Etudes sur Quelques Orthopteres du Musee de Geneve.<Ann. de la Soc. Entom. de France, (4), I, 469-494, pls. 11-12.

1862a-Orthoptera Nova Americana-(Diagnoses Præliminares.)-III. <Rev. et Mag. de Zool., (2), XIV, 163-171, 227-234. Auth. Sep., $1-17$.

1863-Melanges Orthopterologiques-Fascicule I.-Blattides.<Mem. de la Soc. de Phys. et d'Hist. Nat. de Geneve, XVII, 129-170. Auth. Sep. $1-44$, pl. I.

1864-Orthopteres de l'Amerique Moyenne.<Mem. d'Hist. Nat. Mex., IV, $1-279$, pls. $1-2$. Geneva and Paris.

1869-Essai d'un Systeme des Mantides.<Mittheil. der Schwiez Entom. Gesells., III, 49-73.

1869a-Melanges Orthopterologiques-Fascicule II.-Blattides et Phasmides.<Mem. Soc. Phys. et. Hist. Nat. de Geneve, XX, 4to., 227326. Auth. Sep., 45-148, pls. 2-3.

1870-Etudes sur les Insectes Orthopteres-Famille des Blattides.< Miss. Scient. au Mexique et dans l'Amerique Centrale, Pt. VI, 4to., 1-123. pls. 1-2. Paris.

1870a-Melanges Orthopterologiques-Fascicule III.-Mantides.<Mem. Soc. Phys. et Hist. Nat. de Geneve, XXI, 1-214. Auth. Sep., $149-362$, pls. $4-6$.

1870b-Additions au Systeme des Mantides.<Mitth. Schwiez Ent. Ges. III, $221-244$.

1871-Synopsis des Mantides Americains.<Mem. l'Hist. Nat. du Mexique des Antilles et des Etats Unis, 4th Memoir, 1-181, pls. 1-2. Geneve.

1871a-Melanges Orthopterologiques-Supplement au Fascicule III.Mantides.<Mem. Soc. Phys. et Hist. Nat. de Genere, XXI, 4to. 239 -336. Auth. Sep., 363-460, pl. 7 .

1872-Melanges Orthopterologiques-Fascicule IV.-Mantides et Blattides.<Ibid., XXIII, 1-164. Auth. Sep., 1-164, pls. 8-10.

1874-Etudes sur les Insectes Orthopteres-Famille des Gryllides.< Miss. Scient. au Mexique et dans l'Amerique Centrale, Pt. VI, 296-516, pls. 7-8. Paris.

1877-Melanges Orthopterologiques, Fasicule V.-Gryllides.<Mem. Soc Phys. et Hist. Nat. de Geneve, XXV, Pt. I, 1-352. Auth. Sep., $169-504$, pls. $11-15$. Geneve. 
1878-Melanges Orthopterologiques-Fascicule VI.-Gryllides, Pt. II.< Ibid, XXV, Pt. 2, 369-702. Auth. Sep., 505-836, pls. 16-19.

1884-Prodromus Oedipodiorum Insectorum ex ordine Orthopterorum.< Mem. Soc. Phys. et Nat. de Geneve, XXVIII, 1-254, pl. I. Geneve.

1888-Additamenta ad Prodromus Oedipodiorum.<Ibid., XXX, 1-180, pl. 2.

1897-Orthoptera Genuina.-Gryllidæ.<Biol. Cent. Amer., Zool.-Orthoptera. I, $198-294$, pls. XI-XIII.

1897a-Revision du Genre Tridactylus. $<$ Revue Suisse de Zool., IV, 407420.

Saussure, Henri \& Zehntwer, Leo-1893-1894-Orthoptera genuina.Blattidæ, Mantidæ.<Biol. Cent. Amer., Orthoptera, I., 13-197, pls. I-X, 4to. London.

1894a-Notice Morphologique sur les Gryllotalpiens.<Revue Suisse de Zool., II, 403-430, pls. XVI-XVII.

Saussure, H. \&. Pictet, Alphonse-1897-1899-Orthoptera genuina.-Lo-

custidæ.<Biol. Cent. Amer.,-Orthoptera, 285-458, pls. 14-22. London.

SaY, Thomas-1824-American Entomology, or descriptions of the Insects of North America-I. Pp. $8+112$, pls. 1-18.

1824a-Appendix to the Narrative of an Expedition to the Source of St. Peter's River under the Command of Stephen H. Long. <Western Quarterly Reporter, Vol. 2, 268-378.

1825-Description of New Hemipterous Insects collected in the Expedition to the Rocky Mountains, under Command of Major Long. $<$ Journ. Acad. Nat. Sci. Phil., IV, 307-345.

1828-American Entomology.-III. Pp. 1-138, pls. 37-54.

1859-The Complete Writings of Thomas Say on the Entomology of North America. Edited by John L. Leconte. I, Pp. 24+412, pls. 1-54; II, Pp. 4+814. New York.

Schimmer, Fritz vox-1909-Beitrag zur einer Monographie der Grylloden gattung Myrmecophila Latr.<Zeitschr. Wissensch. Zool., XCIII, 409534 , pls. XXII-XXIV.

Scudder, Samuer H.-1861-On the Genus Raphidophora Serville with descriptions of Four Species from the Caves of Kentucky, and from the Pacific Coast. < Proc. Bost. Soc. Nat. Hist., VIII, 6-14.

1862-Materials for a Monograph of the North American Orthoptera, Including a Catalogue of the Known New England Species.< Journ. Bost. Soc. Nat. Hist., VII, 409-480.

1862a-List of Orthoptera Collected on a Trip from Assiniboia to Cumberland.<Can. Nat.-Geol., VII, 283-288. Montreal.

1863-Remarks on some Characteristics of the Insect Fauna of the White Mountains, New Hampshire.<Bost. Journ. Nat. Hist., VII, $612-631$, pls. $14-15$.

1868-The Songs of the Grasshoppers. <Amer. Nat., II, 113-120.

$1868 \mathrm{a}$ - Notes on the Stridulation of some New England Orthoptera.< Proc. Bost. Soc. Nat. Hist., XI, 306-313.

$1868 \mathrm{~b}-\mathrm{A}$ Century of Orthoptera. Decade I,-Gryllides.<Proc. Bost. Soc. Nat. Hist., XII, 139-143.

$1868 \mathrm{c}-$ Considerations drawn from the Study of Mole Crickets. <Proc. Bost. Soc. Nat. Hist., XI, 384-387.

1869-Descriptions of new species of Orthoptera in the Collection of the American Entomological Society.<Trans. Amer. Ent. Soc., II, $305-307$.

1869a-Revision of the Large, Stylated Fossorial Crickets.<Memolrs Peabody Acad. Sci., I. Pp. 1-28, pl. I. Salem, Mass.

$1869 \mathrm{~b}$ - The Arrangement of the Families of Orthoptera.<Proc. Bost. Soc. Nat. Hist., XII, 226-235.

1869 c-Notes on Orthoptera Collected by Prof. Jas. Orton on efther side of the Andes of Equatorial South America.<Proc. Bost. Soc. Nat. Hist., XII, $330-345$.

1872- Notes on the Orthoptera Collected by Dr. F. V. Hayden in Nebraska.<Final Report U. S. Geol. Survey. Nebraska and Adjacent Terr. 247-261. Washington. 
1874-The Distribution of Insects in New Hampshire.<Hitchcock's Rep. on Geol. of New Hamp., I, 331-380, pls. A-C. Concord.

1875-A Century of Orthoptera. Decade II.-Locustariæ.<Proc. Bost. Soc. Nat. Hist., XVII, 454-462.

$1875 a-S p h a r a g e m o n .-A$ Genus of Oedipodinæ, with a Revision of the Species. <Proc. Bost. Soc. Nat. Hist., XVII, 467-471.

1875 b-A Century of Orthoptera. Decade III.-Acrydii (Pezotettix, Cal. optenus).<Proc. Bost. Soc. Nat. Hist., XVII, 472-478.

$1875 \mathrm{c}-$ Revision of Two American Genera of Oedipodidæ. $<$ Proc. Bost Soc. Nat. Hist., XVII, 478-485.

1875d-Entomological Notes, IV. Pp. 1-91. Boston.

$1875 \mathrm{e}-$ The Note of the Katydid.<Fsyche, I, 93-94.

$1875 \mathrm{f}$ - Notice of the Butterflies and Orthoptera Collected by Mr. Geo. F. Dawson, as Naturalist of the B. N. A. Boundary Commission. <Rep. Geol. Resources, 49th Par.; App. D., 341-345. Montreal.

$1875 \mathrm{~g}$ - A Century of Orthoptera, Decade IV.-Acrydii.<Proc. Bost. Soc. Nat. Hist., XVII, $510-517$.

1876-Report on the Orthoptera Collected by the U. S. Geographical Survey West of the 100 th Meridian, under the Direction of Lieut. Geo. M. Wheeler during the Season of 1875.<Ann. Rep. Chief of Engineers for 1876. Appendix JJ, 498-515. Washington.

$1876 \mathrm{a}$-List of the Orthoptera Collected by Dr. A. S. Packard in Colorado and the Neighboring Territories During the Summer of 1875. <Bull. U. S. Geol. \& Geog. Surv. Terr., II, No. 3, 261-267.

1876b-Brief Synopsis of North American Earwigs, with an Appendix on the Fossil Species.<Bull. U. S. Geol. \& Geog. Surv. Terr., II, No. $3,249-260$.

1876c-Synoptical Table for Determining North American Insects. Orthoptera.-U. S. Forficulariæ.<Psyche, I, 177-178.

$1876 \mathrm{~d}-$ Critical and Historical Notes on Forficulariæ Including Descriptions of new Generic Forms and an Alphabetical Synomic List of the Described Species.<Proc. Bost. Soc. Nat. Hist., XVIII, $287-332$.

$1876 \mathrm{e}$ - The Chirp of the Mole Cricket.<Amer. Nat., X, 97-98.

1876f-A Century of Orthoptera. Decade VI.-Forficulariæ (N. American). < Proc. Bost. Soc. Nat. Hist., XVIII, 257-264.

$1876 \mathrm{~g}$-Odoriferous Glands in Phasmidæ.'<Psyche, I, 105-106.

1877 - New Forms of Saltatorial Orthoptera from the Southern United States.<Proc. Bost. Soc. Nat. Hist., XIX, 35-41.

$1877 \mathrm{a}-$ The Florida Orthoptera Collected by J. H. Comstock.<Proc. Bost. Soc. Nat. Hist., XIX, 80-94.

$1877 \mathrm{~b}-\mathrm{A}$ Century of Orthoptera. Decade VII.-Acrydii. $<$ Proc. Bost. Soc. Nat. Hist., XIX, 27-35.

1878-Remarks on Calliptenus and Melanoplus with a Notice of the Species found in New England.<Proc. Bost. Soc., Nat. Hist., XIX, $281-286$.

$1878 \mathrm{a}-$ Brief Notice of the American Species of Melanoplus found West of the 117th Meridian.<Froc. Bost. Soc. Nat. Hist., XIX, 286-290.

1879-A Century of Orthoptera. Decade VIII.-Acridii (Melanoplus). $<$ Proc. Bost. Soc. Nat. Hist., XX, 63-75.

1879a-A Century of Orthoptera. Decade X.-Locustariæ (Conocephalus). < Proc. Bost. Soc. Nat. Hist., 87-95.

1880-A Few Notes on North American Acridii. $<$ Can. Ent., XII, 75-76.

$1880 \mathrm{a}-\mathrm{A}$ List of Orthoptera Collected by Dr. A. S. Packard in the Western United States in the Summer of 1877.<Rep. U. S. Ent. Comm., II, Appendix 2, 23-28, pl. 17. Washington.

1890 - Some Genera of Oedipodidæ rescued from the Tryxalidæ. $<$ Psyche, $\mathrm{V}, 431-442$.

1892-The Orthopteron Genus Hippiscus.<Psyche, VI, 265-274, 285$288,301-304,317-320,333-336,347-350,359-363$.

1893-The Songs of our Grasshoppers and Crickets. $<$ Twenty-third Ann. Rep. Ent. Soc. of Ontario, 1892, 62-78. Toronto.

1894-The North American Ceuthophili.<Proc. Amer. Acad. Arts \& Sci., $\mathrm{XXX}, 17-113$. 
1894a-A Preliminary Review of the North American Decticidæ.<Can. Ent., XXVI, 177-184.

$1894 \mathrm{~b}-$ Walking Sticks.<Harper's Mag., LXXXVIII, 454-461.

$1894 \mathrm{c}$-Biological Notes on American Gryllidæ. $<$ Psyche, VII, $3-5$.

1895-Summary of the United States Phasmidæ.<Can. Ent., XXVII, $29-30$.

1896-Index to the Mantidæ of North America North of Mexico.<Can. Ent., XXVIII, 207-215.

$1896 \mathrm{a}-$ North American Species of Nemobius.<Journ. New York Ent. Soc., IV, 99-107.

$1896 \mathrm{~b}$ - The Species of Nemobius found in North America.<Psyche, VII, 431-434.

1896c-Some American Crickets.<Harper's Mag., XCIII, 691-696.

1896d-The New England Melanopli.<Psyche, VII, 367-370.

1897-Revision of the Orthopteran Group Melanopli (Acrididæ) with Special reference to North American Forms.<Proc. U. S. Nat. Mus., Vol. 20, 1-421, pls. I-XXVI.

$1897 a-T h e$ Genera of North American Melanopli.<Proc. Amer. Acad. Arts \& Sci., XXXII, 193-206.

1897b-The Species of the Genus Melanoplus.<Proc. Amer. Phil. Soc., XXXVI, $5-35$.

1897c-Guide to the Genera and Classification of the North American Orthoptera found North of Mexico. Pp. 1-87. Cambridge, Mass.

1897d-Biological and Other Notes on American Acrididæ.<Psyche. VIII, 99-102.

1897e-Diapheromera femorata.<Psyche, VIII, 30-31.

$1897 \mathrm{f}-\mathrm{A}$ Genus of Gryllidæ hitherto unrecorded from the United States. $<$ Psyche, VIII, 55.

1898-The Orthopteran Group Scudderia.<Proc. Amer. Acad. Arts \& Sci., XXXIII, 271-290.

1898a-A Preliminary Classification of the Tryxalinæ of the United States and Canada.<Psyche, VIII, 231-239.

$1898 \mathrm{~b}$ - The Described Species of Xiphidium in the United States and Canada.<Can. Ent., XXX, 183-184.

1898c-The Alpine Orthoptera of North America.<Appalachia, VIII, $299-319$, pls. XLI-XLIV. Auth. Sep., 1-21.

1899-The North American Species of Orphulella.<Can. Ent., XXXI, $177-188$.

1899a-Short Studies in North American Tryxalinæ.<Proc. Amer. Acad. Arts \& Sci., XXXV, $39-57$.

$1899 \mathrm{~b}$-Supplement to the Revision of the Melanopli.<Proc Davenp. Acad. Nat. Sci., VII. 157-205, pls. VII-IX. Davenport, Iowa.

1899 c-The Orthopteran Genus Schistocerca.<Proc. Amer. Acad. Arts \& Sci.; XXXIV, $441-476$.

1899 d-The Species of Myrmecophila in the United States.<Psyche. VIII, 423-428.

$1899 \mathrm{e}$-Pseudopomala and its Allies.<Psyche. VIII, 436-438.

1900 - Catalogue of the Described Orthoptera of the United States and Canada.<Proc. Davenp. Acad. Nat. Sci., VIII, 1-101, pls. I-III.

1900a-A List of the Orthoptera of New England.<Psyche, IX, 99-106.

$1900 \mathrm{~b}$ - The Distribution of Leptysma marginicollis Serv.<Psyche, IX, 116.

1900c-The Species of Circotettix, a North American Genus of Oedipodinæ.<Psyche, IX, 135-141.

1901-The Species of Diapheromera (Phasmidæ) found in the United States and Canada.<Psyche, IX, 187-189.

1901a-The Species of Gryllus on the Pacific Coast.<Psyche, IX, 267270.

1901b-Miogryllus and its Species in the United States.<Psyche, IX, $256-258$.

1901c-Alphabetical Index to North American Orthoptera described in the Eighteenth and Nineteenth Centuries.<Occasional Papers, Bost. Soc. Nat. Hist., VI. Pp. $1-436$.

1901d-Four New Species of Hippiscus.<Can. Ent., XXXII, 88-92. 
1902-On the United States Orthoptera which have been referred to the Genus Tridactylus.<Psyche, IX, 308-310.

$1902 \mathrm{a}$-The Species of Gryllus found in the United States East of the Sierra Nevadas.<Psyche, IX, 291-296.

Scudder, S. H. \& Cockerell, T. D. A.-1902-A First List of the Orthoptera of New Mexico.<Proc. Davenp. Acad. Nat. Sci., IX, 1-62, pls. I-V. Serville, J. G.-1831-Revue Methodique des Orthopteres.<Ann. des Sciences naturelles, XXII, 28-65, 134-167, 262-292. Paris.

1839-Histoire Naturelle des Insectes.-Orthopteres. Pp. xviii+777. pls. 1-14. Paris.

Severix, H. P. \& H. C. -1911 -The Life History of the Walkingstick, Diapheromera femorata Say.<Journ. Econ. Ent., IV, 307-320.

$1911 \mathrm{a}$ - The Mechanism in the Hatching of the Walking-stick, Diapheromera femorata Say.<Ann. Ent. Soc., Amer., IV, 187-190, pl. XIV.

1913-The Effect of Temperature on the Molting of the Walking-stick, Diapheromera femorata Say.<Ent. News, XXIV, 14-19.

Sirelford. R.-1906-Studies of the Blattidæ.<Trans. Ent. Soc. London. Pt. II, 231-278, pls. XIV-XVI.

1307 -Studies of the Blattidæ, (Continued).<Ibid., Pt. IV, 487-519, pl. XXX.

1907a-Orthoptera; Fam. Blattidæ; Subfamily Ectobinæ.<55th Fasc. Gen. Insect. Pp. 1-15, pl. I.

1908-Orthoptera; Fam. Blattidæ; Subfamily Fhyllodromina.<73d. Fasc. Gen. Insect. Pp. 1-29, pls. 1-2.

1908a-Orthoptera; Fam. Blattidæ; Subfam. Nyctcborinæ.<74th Fasc. Gen. Insect. Pp. 1-5, pl. I.

1910 -Orthoptera; Fam. Blattidæ; Subfam. Epilamprinæ.<101st Fasc. Gen. Insect. Pp. 1-21, pls. 1-2.

1910a-Orthoptera; Fam. Blattidæ; Subfam. Blattinæ (Periplanetinæ). $<109$ th Fasc. Gen. Insect. Pp. 1-27, pls. 1-2.

1911-Preliminary Diagnoses of some new Genera of Blattidæ.<Ent. Month. Mag., (2), XXII, 154-156.

Silermax. F. \& Briarley. C. S.-1911-Orthoptera of North Carolina.<Ent. News, XXII, 387-392.

Sirlt, A. F.-1907-The Stridulation of the Snowy Tree Cricket (Oecanthus niveus ). <Can. Ent., XXXIX, 213-225.

1911-The Thysanoptera and Orthoptera of the Sand Dune Region on the South Shore of Saginaw Bay, Mich.<Publ. 4. Biol. Ser. II, Mich. Geol. \& Biol. Surv., 177-231.

Srmpsox. C. B. - 1903-The Yellow-winged Locust (Camnula pellucida Scudder).<Circ. No. 53, U. S. Div. Ent., 1-4.

Siossox. Mrs. A. T.-1901-On a Florida Beach.<Ent. News, XII. 10-12. SмIтH. JoII B.-1910-The Insects of New Jerser-Orthoptera.<Ann. Rept. N. Jer. St. Museum, 1909, 173-193.

Sirth. SidNey I.-1868-On the Orthoptera of the State of Maine.<Proc. Portland Soc. Nat. Hist., I, 143-151.

1873 -Report of the Entomologist.<Ann. Rep. Connecticut Board of Agr., 1872-1873, 345-383. Hartford.

Snyes. M. P.-1914-The Acrididæ of Minnesota.<Bull. Dir. Ent. Minn. Agr. Exp. Sta., No. 141, 1-98, pls. I-IV. St. Paul.

1916-The Phasmidæ of Minnesota, Iowa and Missouri.<Ent. News, XXVII, 269-271.

Stal. CarL-1873-Recensio Orthopterorum. Revue Critique des Orthop. teres decrits par Linne, De Geer et Thunburg.-I. Fp. $4+154$.

$1873 a$-Orthoptera nova.<Ofv. Vet. Ak. Forh. XXX. No. 4, 39-53. Stockholm.

1874-Recensio Orthopterorum. Revue Critique des Orthopteres decrits par Linne, DeGeer et Thunburg.-II. Pp. $4+121$.

1875-Same, III. Pp. 4+105.

1876-Observations Orthopterologiques.<Bihang. Srenslia Akad., IV. No. 5. 1-58. Stockholm.

1S77-Systema Mantodeorum.<Bihang. Srenslia Akad.. IV, No. 10. 1-9s, pl. I. Stockholm. 
Stoll, Caspar-1787-1813-Representation exactement coloreé d'apres nature des spectres ou phasmes, etc. Rassemblees et decrites.-I. Spectres et Mantes. Pp. $6+79$, pls. 1-25. Amsterdam.

Thomas, Cyrus-1863-Written Communications.<Proc. Ent. Soc. Phil., I, 104.

1865-Insects Injurious to Vegetation in Illinois.<Trans. Ill. State Agr. Soc., V. 401-468. Springfield, Ill.

1870 -Descriptions of Grasshoppers from Colorado.<Proc. Acad. Nat. Sci. Phil., 74-84.

1871-A List and Descriptions of New Species of Orthoptera. < Prelim. Rept. U. S. Geol. Surv. of Wyoming \& Adjacent Terr., II, 1870, $265-284$.

1872-Notes on the Saltatorial Orthoptera of the Rocky Mountain Regions.<Prelim. Rep. U. S. Geol. Surv, of Montana and Portions of Adjacent Terr., 1871. 423-466, pls. I-II.

1873 - Synopsis of the Acrididæ of North America.<Hayden's Rep. U. S. Geol. Surv. Terr., V, $1-258$, pl. I.

$1873 \mathrm{a}-$ Notes on Orthoptera.<Sixth Ann. Rep. U. S. Geol. Surv. of Montana, Idaho, Wyoming and Utah, 719-725.

1874-Descriptions of some New Orthoptera, and Notes on some Species but Little Known.<Bull. U. S. Geol. \& Geogr. Surv. Terr., I, No. $2,63-71$.

1875-Report upon the Collections of Orthoptera made in Portions of Nevada, Utah, California, Colorado, New Mexico and Arizona during the Years 1871-1874.<Wheeler's Rept. on Geol. \& Geogr. Explor. and Surveys West of the 100th Merid., V, 843-908, pls. XLIII-XLV.

1876-A List of the Orthoptera of Illinois.<Bull. Ill. Mus, Nat. Hist., I, $59-69$.

1880-The Acrididæ of Illinois.<Rep. State Entom. of Illinois, IX, $73-140$.

TIIUNBerg, C. P.-1815-Hemipterorum maxillosorum genera illustrata.< Mem. Acad. Imp. Soc. St. Petersburg, V, 4to., 211-301, pl. 3.

Townsend, C. H. T. -1891 - Notes on Acrididæ in Michigan.<Proc. Ent. Soc. Wash., II, $43-44$.

Uhler, P. R.-1859-(Notes on Orthoptera).<The Complete Writings of Thomas Say on the Entomology of N. America.

1862-(Notes on Orthoptera).<Harris, Insects Injurious to Vegetation, 3rd ed. Footnotes, pp. 141-191.

1864-Orthopterological Contributions.<Proc. Ent. Soc. Phil., II, $543-555$.

1884-Natural History of the Arthropods-Hemiptera.<Stand. Nat. Hist., II, 204-288.

Vestal, A. G.-1913-An Associational Study of Illinois Sand Prairies. $<$

Bull. Ill. State Lab. Nat. Hist., X, $1-96$, pls. I-V.

1914 - Notes on the Habits of Grasshoppers at Douglas Lake, Michigan. $<$ Ent. News, XXV, 105-109.

Vosseler, J.-1902-Beitrage zur Faunistik und Biologie des Orthopteren Algeriens und Tunasiens.<Zool. Jahrb. f. Syst. Bd. 17, 1-98.

Walden, B. H. - 1911-The Euplexoptera and Orthoptera of Connecticut. $<$

Bull. No. 16, State Geol. \& Nat. Hist. Surv. Conn., 39-169, pls. VI-XI.

Walker, E. M.-1898-Notes on some Ontario Acrididæ.-I.<Can. Ent.,

XXX, 122-126: II, 258-263.

1899-Same,-III.<Can. Ent., XXXI, 29-36.

1901-Same.-IV.<Can. Ent., XXXIII, 20-23.

1902-The Canadian Species of Trimerotropis.<Can. Ent., XXXIV, 111.

1902a-A Preliminary List of the Acrididæ of Ontario.<Can. Ent., XXXIV, 251-258.

1903-The Genus Podisma in Eastern North America.<Can. Ent. XXXV, 295-302, pl. 6 .

1904-The Crickets of Ontario.<Can. Ent., XXXVI, 142-144, 181-188, $249-255$, pl. 4 . 
1904a-Notes on the Locustidæ of Ontario.<Can. Ent., XXXVI, 325$330,337-341$.

1905-Same.<Can. Ent., XXXVII, 34-38, 113-119.

1906-Records in Orthoptera from the Canadian Northwest.<Can. Ent., XXXVIII, 55-59.

1909-On the Orthoptera of Northern Ontario.<Can. Ent., XLI, 137$144,173-178,205-212$, pl. 7 .

1910 - The Orthoptera of Western Canada.<Can. Ent., XLII, 269-276, $293-300,333-340,351-356$.

1911-On the Habits and Stridulation of Idionotus brevipes Caudell, and otber Notes on Orthoptera.<Can. Ent., XLIII, 303-304.

1914-A New Species of Orthoptera, Forming a New Genus and Family. $<$ Can. Ent., XLVI, 93-99, pl. VI.

1915- Notes on a Collection of Orthoptera from Prince Edward Island and the Magdalen Islands, Quebec.<Can. Ent., XLVII, 339-344.

WaLker, Fraxcis-1868-A Catalogue of the Specimens of Blattariæ in the

Collection of the British Museum. Pp. $4+239$. London.

1869-Catalogue of the Specimens of Dermaptera Saltatoria in the Collection of the British Museum. Pt. I. Pp. 1-224; Pt. II, 225423.

1870-Same, Pt. III, pp. 424-604; Pt. IV, pp. 605-809.

1871-Same, Pt. V, pp. 810-850.

WalsH. B. D.-1864-On Phytophagic Varieties and Phytophagic Species.

<Proc. Ent. Soc. Phil., III, 403-430.

1867-Habits of the Tree Cricket (Oecanthus nireus). $<$ Practical Entomologist, II, 54, 94 .

Webster, F. M.-1907-The Grasshopper Problem and Alfalfa Culture.< Circ. No. 84, U. S. Bur. Entom., Pp. 1-10.

WEIss. H. B.-1914-Some Facts about the Egg Nest of Paratenodera sinensis.<Ent. News, XXV, 279-282.

1915-Gryllotalpa gryllotalpa, the European Mole Cricket in New Jersey.<Journ. Econ. Entom., VIII, 500.

Weiss, H. B. \& Dickersox, E. L. -1918-The European Mole Cricket, Gryllotalpa gryllotalpa L., an Introduced Insect Pest.<Journ. N. Y. Ent. Soc., XXVI, 18-23, pl. II.

WEstwood, J. O.-1889-Revisio Insectorum Familiæ Mantidarum speciebus novis aut minus cognitis descriptis et delineatis. Pp. $2+54+3,14$ pls. London.

WheELeR, W. M.-1890-Notes on the Oviposition and Embryologic Development of Xiphidium ensiferum Scudder. <Insect Life, II, 222-225.

1900 - The Habits of Myrmecophila nebrascensis Bruner.<Psyche, IX, $111-115$

1907-Pink Insect Mutants.<Amer. Nat., XLI, 778-780.

YERSIX. M. A.-1860-Note sur Quelques Orthopteres Nouveaux on Peu connus d'Europe.<Ann. Soc. Ent. France, (3) VIII, 509-537, pl. 10.

\section{GLOSSARY OF TERMS USED IN TEXT.}

The names of the more common parts or organs of an Orthopteron are fully explained on pages $13-23$ and are not included in the glossary.

Abbreviated.-Shortened; not of usual length.

Aborted.-Imperfectly developed.

Abrupt.-Suddenly or without gradation.

Accessory.-Added, or in addition to.

Acuminate.-Tapering to a point.

Acutely.-Sharp; sharply pointed.

Adult.-The imago or winged stage of an insect.

Ammophilous.-Living in sandy places.

Anal.-Situated at or near the anus.

Annulus. annulate.-Ringed; furnished with ring-like bands.

Anterior, anteriorly.-Situated near the front of any part.

A pex.-The terminal portion of any organ or part of the body.

Apical, apically. - That part of any organ farthest from the body or base.

Appressed.-Pressed closely against; fitting closely to. 
Approximate.-Near to; near together.

Apterous.-Wingless.

Arboreal.-Living on or among trees.

Arcuate.-Arched; bowed.

Arolia.-A pad between the tarsal claws.

Articulated.-Divided into distinct segments.

Attenuated.-Drawn out; slender; tapering.

Auditory organ.-Ear; hearing organ.

Attingent.-Touching; with edges meeting.

Band.-A tranverse marking broader than a line.

Base.-That part of an appendage which is nearest the body; on the thorax that portion nearest the abdomen; on the abdomen that portion nearest the thorax.

Basal.-Next to the body.

Bifid.-Cleft; cloven in two.

Calcaria.-The spines or spurs at the apex of the tibia.

Carina, carina.-A keel or ridge.

Carinate.-A surface having carinæ.

Cerci.-Appendages issuing from the sides of last abdominal segment.

Chitin.-The horn-like substance of the skin of an insect.

Cinerous.-Ash-colored; gray tinged with blackish.

Clavate.-Having a thickened, club-like extremity.

Concave.-Hollowed out.

Conical.-Cylindrical, with a flat base, tapering to a point.

Contiguous. - So near together as to touch.

Convex.-A surface with the center the highest.

Cordiform, cordate.-Heart-shaped.

Coriaceous.-Leather-like; tough and somewhat rigid.

Corneous.-Of a horny texture.

Cosmopolitan.-Liable to be found anywhere on earth.

Costa. - A ridge or wide carina with crest rounded.

Costal.- The front margin of tegmen or wing.

Crenate.-Scalloped with rounded teeth.

Crest.-A sharp ridge.

Cristate.-With a prominent longitudinal carina on its upper surface.

Dactyls.-Fingers or tibial projections of the mole crickets.

Declivent.-Sloping downward.

Decurved.-Bent downward.

Deflexed.-Abruptly bent downward.

Dendrophilous.-Living in trees.

Depressed.-Pressed downward; more or less flattened vertically.

Dentate.-Furnished with a tooth or teeth.

Denticulations.-With fine tooth-like notches.

Dilated.-Broadened; expanded.

Dimorphic.-Existing in two forms.

Disk.-The middle of a surface; the surface within the margins.

Distal.-Farthest distance from the base or body.

Distant.-Remote from; standing considerably apart.

Diurnal.-Active during the day.

Dorsum.-The upper surface or back of thorax, abdomen, etc.

Dusky.-Somewhat darkened; pale fuscous.

Elliptical.-Oblong-oval, the ends equally rounded.

Elytra.-The wing covers; the tegmina.

Emarginate.-Edged; notched; terminating in a notch at tip.

Ensiform.-Sword-shaped; sharp on both edges and tapering to a point.

Evanescent.-Disappearing; becoming gradually less.

Evident.-Easily seen or recognized.

Exserted.-Protruding. so as to be visible.

Facies.-General appearance.

Falcate.-Sickle-shaped; curved like a sickle.

Fascia.-A transverse band or broad line.

Fastigium.-The extreme point of front or vertex of head.

Fauna.-The animals of a locality.

Ferruginous.-Rusty brown. 
Filiform.-Slender, thread-like.

Fossorial.-Fit or used for digging or burrowing.

Foveola.-A cavity or small depression.

Front, frons.-Upper forward part of the head.

Frontal.-Relating to the front or face.

Fuliginous.-Sooty; dark brown.

Fulvous.-Tawny or light yellowish brown.

Furcula.-Frocesses of the last dorsal abdominal segment of male.

Fuscous.-Dark brown, approaching black.

Fusiform.-Spindle-shaped.

Geophilous.--Living on the ground.

Gibbous.-Protuberant; swollen.

Glabrous.-Smooth or polished, not hairy.

Glaucous.-Whitish-blue, inclining to gray.

Granulated.-Furnished with minute prominences like grains of sand.

Gregarious.-Living in societies or communities, but not social.

Griseous.-Light gray (white and black).

Habitat.-The place or region which an insect inhabits.

Halophilous.-Salt-loving.

Hexagonal.-Six sided.

Hibernate.-To pass the winter in a dormant state.

Host.-The individual furnishing food to a parasite.

Humeral.- Situated on or near a humerus or front angle of the tegmen.

Hyaline.-Transparent, with a greenish tinge.

Hygrophilous.-Living in wet places.

Imago.-An adult or winged insect.

Immaculate.-Not marked; unspotted.

Incised.-Notched or deeply cut into.

Infuscated.-Smoky gray-brown, with a blackish tinge.

Integument.-Outer covering, slin.

Intercalary vein.-See p. 19.

Interocular.-Between the eyes.

Interrupted.-Suddenly stopped or broken.

Lanceolate.-Lance-shaped.

Linear.-Very slender.

Longitudinal.-Lengthwise.

Luteous.-Pale clay yellow.

Maculate.-Spotted, marked with spots.

Mandibles.- Hard and horny jaws.

Marginal.-Situated on or near the margin.

Median.-Occupying the middle.

Membrane, membranous.-A thin tissue; consisting of a thin tissue.

Mesonotum.-Upper or dorsal surface of the mesothorax.

Mesosternum.- Under surface of the mesothorax.

Mesothorax.-Middle part of thorax, to which the tegmina and middle pair of legs are attached.

Metamorphosis.-Changes an insect undergoes before reaching maturity.

Metanotum.-The upper or dorsal surface of the metathorax.

Metathorax.-The hind part of the thorax to which the wings and hind pair of legs are attached.

Metazona.-The hind dorsal part of the pronotum.

Millimeter (mm.).-The thousandth part of a meter, equal to 0.03937 of an inch.

Nebulous.-Clouded; with uneren, cloudy markings.

Nerves. - The large ribs or veins of tegmina and wings, extending from the base toward the apex.

Nervules.-The smaller connecting veins of the tegmina and wings.

Nocturnal.-Active at night.

Nymph.-An immature insect, active and feeding in the larral and pupal stages.

obconic.-Conical, with the vertex pointing downward.

Oblique.-Slanting; any direction between perpendicular and horizontal.

oblong.-Longer than broad.

Obovate.-Inversely egg-shaped; the narrow end downward. 
Obsolete.-Wanting or nearly so; indistinct.

Obtuse.-Blunt.

Ocellus, ocelli.-The simple eyes.

Occiput.-The back part of the head.

Omnivorous.-Eating everything eatable.

Oötheca.-A case enclosing eggs.

Opaque.-Without lustre; impenetrable by light rays.

Ovipositor.-The organ for depositing eggs.

Oviposition.-The act of laying eggs.

Pallium.-See page 23.

Palpus, palpi.-Articulated and movable organs attached to the maxillæ and labium.

Parasite.-An animal or plant which grows and lives upon another.

Pellucid.-Transparent; translucent, but not necessarily colorless.

Pentagonal.-Five-sided.

Percurrent.-Running through the entire length.

Piceous.-Pitchy black; the color of pitch.

Pilose.-Having long, sparse hairs.

Plane.-Level, flat; applied to a surface.

Plasticity.-Capable of easy modification by environment, etc.

Plumbeous.-Pale, blue-gray, like lead.

Pre-apical.-Before the apex.

Produced.-Drawn out; prolonged; extended from.

Prosternum.-The fore-breast; the sclerite between the fore legs.

Prosternal spine.-A spine projecting from the prosternum.

Prothorax.-The first thoracic ring or segment bearing the front legs but no wings.

Proximal.- Nearest the body; opposite of distal.

Prozona.-Front dorsal part of the pronotum.

Pubescent.-Downy; clothed with soft, short, fine hairs.

Punctate, punctured.-Containing numerous small, point-like depressions or punctures.

Pulvillus, pulvilli.-Little pads on under side of tarsal joints.

Pyriform.-Pear-shaped.

Quadrate.-Four-sided; square or nearly so.

Restricted.-Confined to a limited area.

Reticulate.-With net-like veins or markings.

Rudimentary. - Not sufficiently developed to be of use.

Rugose.-Rough, wrinkled; furnished with numerous small elevations.

Rufous.-Dark reddish-brown.

Saltatorial.-Fitted for leaping.

Saxicolous.-Living on rocky ledges or bare rocks.

Scabrous.-Covered with small, slight elevations; rough like a file.

Segment.-Ring-like division or joint, as of the antennæ.

Sequence.-The order in which things follow.

Serrate.-Saw-toothed.

Serrations.-Teeth like a saw.

Serrulate.-Finely serrate; having minute cerrations.

Setaceous.-Bristle-shaped.

Sinuate.-Winding in and out; twice or more curved.

Sinus.-An excavation as if scooped out.

Smooth.-Without elevations or wrinkles.

Spatulate.-Paddle or spoon-shaped; flattened and broad at the apex.

speculum.-A special enclosed area on the apical half of tegmen of some Gryllidæ.

Spinose.-Armed with spines.

Spinulose.-Furnished with spinules or diminutive spines.

Spurs.-The strong spines at the apex of the tibiæ.

sternite.-The ventral part of each abdominal segment.

Sternum.-The ventral part of a body segment.

Stridulate.-To make a shrill sound; to grate, scrape or creak with the stridulating organs.

Styliform.- Shaped like a style.

$s u b .-$ A prefix meaning nearly; almost, somewhat; under, etc. 
Sub-costal vein.-See page 19.

Sub-clavate.-Somewhat thickened toward tip; but not quite club-shaped. Subequal.-Similar but not quite equal in size, form or other characters.

Sub-median vein.- See page 19.

Subulate.-Awl-shaped; linear at base, attenuate at tip.

Sulcate.-Grooved, furrowed.

Sulcus, sulci.-A linear groove or channel.

Suture.-A seam or impressed line.

Sylvan.-Living in woods or forests.

Synonym.-A name applied to a species or genus that has been previously described and named.

Tarsus, tarsi (tarsal).-The jointed foot.

Tectiform.-Ridged in the middle and sloping down on each side.

Tegmina.-The fore wings, upper wings or wing covers.

Terete.-Subcylindrical; straight without enlargements.

Tergite (tergum).- The dorsal part of a body segment.

Terrestrial.-Living on the ground.

Testaceous.-Dull yellowish-brown; tile or brick colored.

Thamnophilous.-Living on shrubs.

Tip.-The extremity; the part furthest removed from the base.

Transition zone.-The transcontinental belt in which the austral and boreal elements overlap.

Translucent.-Transmitting very little light.

Transverse.-Broader than long, with the longest diameter across the body.

Tribe.-A term of classification less than a subfamily; usually ending in ini.

Truncate.-Cut off squarely at tip.

Tubercle.-A little solid pimple or small chitinous button.

Tuberculate.-Formed like a tubercle; a surface covered with tubercles.

Type.-A unique or single specimen selected from a series and labelled by the describer to represent his name and description.

Typical.-The normal or usual form of a species; agreeing with the type form.

Unarmed.-Without spurs, spines or armature of any kind.

Unequal.-Unlike in size, form, development or other characters.

Unique.-One only; unlike any other.

Variety.-Any departure from the normal type of a species which, whlle retaining the specific characters, is yet recognizably different because of the climatic, seasonal or other influences; may occur with the type form or as a geographical race.

Vertex.-The top of the head between the eyes, front and occiput.

Vestiture.-The surface clothing, whether of a hairy or scaly character.

Vittate.-Striped.

Xerophilous.-Living in dry places. 


\section{Index to Srnonyms and New Generic Assignments as}

Recognized in This Work.

Acheta guadeloupensis Fabricius $=$ Anurogryllus muticus (DeG.)...6690. Acheta hospes Fabricius=Nemobius fasciatus (DeG.)...........6.674. Acheta nigra Harris $=$ Gryllus assimitis pennsylvanicus Burm........ 702. Acheta vittata Harris =Nemobius fasciatus (DeG.)..............6 674. Aegipan phalangium Scudder $=$ Arethoxa phalangium (Scudd.)....... 461. Acridium alutaceum Harris= Schistocerea alutacea (Harr.).......... 314. Acridium americana Drury $=$ Schistocerca americana (Drury)...... 312. Acridium appendiculatum Uhler Ms.=Schistocerca damnifica calidior

R. \& H. ............................. 319 Acridium clavuliger Serville=Paroxya clavuliger (Serv.).......... 353. Acridium damnificum Saussure=Schistocerca damnifica (Sauss.)... 318. Acridium differentiale Thomas=Melanoplus differentialis (Thos.)... 440. Acridium emarginatum Scudder=Schistocerca alutacea (Harr.)..... 314 Acridium femur-rubrum DeGeer=Melanoplus femur-rubrum (DeG.). 419. Acridium frontalis Thomas=Hesperotettix speciosus (Scudd.)....... 335. Acridium micropterum Beauvois=Romalea microptera (Beauv.)..... 304. Acridium obscura (Fabricius) $=$ Schistocerca obscura $($ Fab.)........... 317. Acridium rubignosum Scudder $=$ Schistocerca alutacea rubiginosa ........

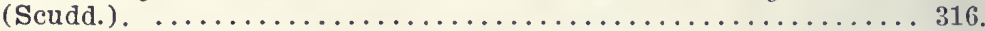
Acrydium laterale $\mathbf{S a y}=$ Tettigidea lateratis (Say).................... 182. Acrydium tuberculatum Beauvois=Hippiscus apiculatus (Harr.)..... 264. Acrydium viridifasciatum DeGeer=Chortophaga viridifasciata (DeG.). 256. Ageneotettix arenosus Hancock=Ageneotettix deorum (Scudd.)..... 237. Ageneotettix occidentalis Bruner=Ageneotettix deorum (Scudd.)..... 237. Amblycorypha carinata R. \& H.=Amblycorypha oblongifolia carinata

R. \& H. ................................ 481 Amblycorypha floridana R. \& H.=Amblycorypha oblongifolia floridana R. \& H. Amblytropidia subhyalina Scudder=Amblytropidia occidentalis

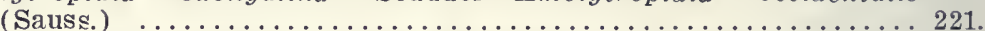
Anisolabis azteca Dohrn=Anisolabis annulipes (Lucas)........... 47. Apotettix minutus R. \& H.=Neotettix bolteri Hancock............ 173. Aptenopedes clara Rehn=Aptenopedes sphenarioides clara Rehn.... 347. Aptenopedes rufovittata Scudder =Aptenopedes aptera scudd......... 347. Arcyptera gracilis Scudder $=$ Mecostethus gracilis (Scudd.)......... 241. Arcyptera lineata Scudder =Mecostethus lineatus (Scudd.)............... 239. Arcyptera platyptera. Scudder=Mecostethus platypterus (Scudd.)..... 242. Arethea multiramosa Brunner $=$ Aretha phalangium (Scudd.)....... 461. Arnilia chlorizans (Walker) =Stenacris vitreipennis (Marsch)....... 310. Arphia sanguinaria Stål=Arphia pseudonietana ('Thos.)........... 251. Arphia tenebrosa (Scudder) =Arphia pseudonietana (Thos.)........ 251. Atlanticus dorsalis (Blatchley nec. Burm.)=Atlanticus davisi R. \& H. 594. Atlanticus dorsalis (Amer. auth. nec. Burm.)=Atlanticus americanus

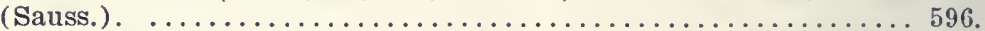
Atlanticus pachymerus (Amer, auth. nec. Burm.) =Atlanticus testa-

ceus (Scudd.). ............................... 591 Aulocara scudderi Bruner =Ageneotettix deorum (Scudd.)............ 237. Bactromantis virga Scudder=Stagmomantis carolina (Johann.)..... 118. Bacunculus tenuescens Scudder=Manomera tenuescens (Scudd.)..... 139. Bacunculus blatchleyi Caudell=Manomera blatchleyi (Caudell)...... 140. Batrachidea carinata Scudder=Nomotettix cristatus (Scudd.)....... 157. Batrachidea cristata Scudder $=$ Nomotettix cristatus (Scudd.)........ 157. Blatta americana Linnæus=Periplanata americana (Linn.)......... 99. Blatta australasie Fabricius=Periplanata australasia (Fabr.)....... 101. Blatta cubensis Saussure $=$ Supella supellectilium (Serv.).......... 70. Blatta germanica Linnæus $=$ Blattella germanica (Linn.)............. 73. Blatta nitidula Fabricius = Holocompsa nitidula (Fabr.)................ 107. Blatta pennsylvanica DeGeer=Parcoblatta pennsylvanica (DeG.).... 86. Blatta supellectilium Serville=Supella supellectilium (Serv.)...... 70. Blatta surinamensis Linnæus=Pycnoscelus surinamensis (Linn.)..... 104. 
Page.

Blattella adspersicollis (Amer. auth. nec. Stål.)=Latiblattella rehni

Hebard. ................................... 69. Caloptenus angustipennis Dodge=Melanoplus anoustipennis (Dodge). 425. Caloptenus atlanis Riley=Melanoplus atlanis (Riley)............. 414. Caloptenus bivittatus (Say) = Melanoplus bivittatus (Say).......... 446. Caloptenus borcalis Fieber =Melanoplus borealis (Fieb.)........... 422. Caloptenus clypeatus Scudder=Melanoplus clypeatus (Scudd.)...... 443. Caloptenus deletor Scudder=Melanoplus keeleri (Thos.)........... 436. Caloptenus devorator Scudder =Melanoplus femur-rubrım (DeG.)..... 419. Caloptenus extremus Walker=Melanoplus borealis-(Fieb.).......... 422. Caloptenus fasciatus F. Walker=Melanoplus fasciatus (F. Walker)... 400. Caloptenus femoratus Burmeister=Melanoplus bivitattus (Say).... 446. Caloptenus floridanus Thomas $=$ Paroxya clavuliger (Serv.)........ 353. Caloptenus griseus Thomas=Melanoplus punctulatus (Scudd.)....... 450. Caloptenus helluo Scudder=Melanoplus punctulatus (Scudd.)....... 450. Caloptenus keeleri Thomas=Velanoplus keeleri (Thos.)...........436. Caloptenus luridus Dodge $=$ Melanoplus keeleri luridus (Dodge)....... 437. Caloptenus minor Scudder=Melanoplus confusus Scudd........... 434. Caloptenus nigrescens Scudder =Melanoplus nigrescens (Scudd.)..... 402. Caloptenus extremus F. Walker=Melanoplus borcalis (Fieb.)........ 422. Caloptenus punctulatus Scudder=Melanoplus punctulatus (Scudd.).. 450. Caloptenus robustus Scudder=Melanoplus ponderosus (Scudd.).... 405. Caloptenus sanguinolentus Provancher=Melanoplus femur-rubrum

(DeG.). . . . . . . . . . . . . . . . . . . . . . . . . 419 Caloptenus volucris Dodge=Photaliotes nebrascensis (Thos.)...... 357. Camptonotus scudderi Uhler =Camptonotus carolinensis (Gerst.)..... 603. Campylacantha acutipennis (Scudder)=Campylacantha olivacea

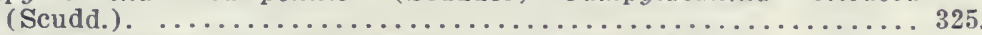
Cavotettix apterus Hancock $=$ Neotettix proavus R. \& H.......... 174. Ceratinoptera diaphana (Amer. auth. nec. Fabr. =Aglaoptery $x$ gemma Hebard. Ceratinoptera iutea Saussure \& Zehntner=Cariblatta lutea (S. \& $\ddot{Z}$. $)$ Ceuthophilus ater Scudder=Udeopsylla robusta (Hald.) ...........612. Ceuthophilus bicolor Scudder=Ceuthophilus maculatus (Harr.)..... 622. Ceuthophilus blatchleyi Scudder=Ceuthophilus uhleri Scudd........ 627. Ceuthophilus devius Scudder $=$ Udeopsylla robusta (Hald.)........... 612. Ceuthophilus grandis Scudder=Ceuthophilus gracilipes (Hald.) ...... 630. Ceuthophilus heros Scudder=Ceuthophilus gracilipes heros Scudd..... 633. Ceuthophilus latebricola Scudder=Ceuthophilus maculatus (Hald.).. 622. Ceuthophilus latisulcus Blatchley=Ceuthophilus uhleri Scudd....... 627. Ceuthophilus neglectus Scudder=Ceuthophilus nigricans Scudd........ 621. Ceuthophilus niger Scudder =Udeopsylla robusta (Hald.)........... 612. Ceuthophilus pallipes E. M. Walker=Ceuthophilus gracilipes (Hald.) 630. Ceuthophilus politus Scudder=Udeopsylla robusta (Hald.).......... 612. Ceuthophilus sallei Scudder=Ceuthophilus caecus Scudd............. 637. Ceuthophilus spinosus R. \& H. nec Scudd.=Ceuthophilus rehebi sp. nov.

Ceuthophilus virgatipes $\mathrm{R} \& \mathrm{H}$. Chlocaltis brunnea Scudder=Dichromorpha viridis (Scudd.) ........... 230. Chloaltis canadensis Provancher=Amblytropidia occidentalis

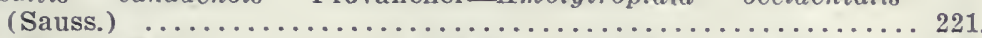
Chloaltis curtipennis Harris=Chorthippus curtipennis (Harr.)........ 234. Chlocaltis punctulata Scudder=Dichromorpha viridis (Scudd.)........ 230. Chloaltis viridis Scudder=Dichromorpha viridis (Scudd.).......... 230. Chorisoneura plocea Rehn $=$ Chorisoneura texensis (S. \& Z.)........ 111. Chortophaga australior R. \& H.=Chortophaga viridifasciata australior R. \& H.

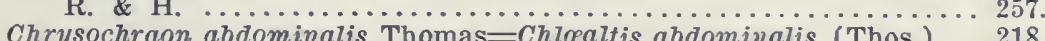
(Thos.) ... 218 Chrysochraon deorum Scudder=Ageneotettix deorum (Scudd)....... 237. Chrysochraon obscurus Scudder=Pedeticum obscurum (Scudd.)...... 213. Clinocephalus pulcher R. \&. H.=Clinocephalus elegans Morse....... 232. Conocephalus atlanticus Bruner $=$ Neoconocephalus retusus (Scudd.).. 528. Conocephalus attenuatus Scudder=Neoconocephalus ensiger (Harr.) .. 520. 
Conocephalus bruneri Blatchley $=$ Neoconocephalus exiliscanorus (Da-

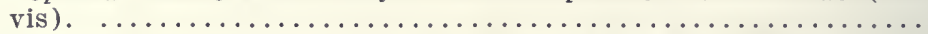
Conocephalus caudellianus Davls $=$ Neoconocephalus caudellianus (Davis )

Conocephalus crepitans Scudder $=$ Neoconocephalus robustus crepitans (Scudd.).

Conocephalus dissimilis (Amer. auth. nec. Serv.) $=$ Neoconocephalus retusus (Scudd.). ............................. 528.

Conocephalus dissimilis Serville $=$ Neoconocephalus triops (Linn.).... 529. Conocephalus ensiger Harris $=$ Neoconocephalus ensiger (Harris)..... 520. Conocephalus fusco-striatus Redtenbacher $=$ Neoconocephalus triops....

(Linn.). . ............................... 529.

Conocephalus hebes Scudder $=$ Neoconocephalus triops (Linn.)...... 529.

Conocephalus . hoplomachus R. \& H.=Homorocoryphus malivolans

(Scudd.). ............................. 532

Concephalus lyristes R. \& H.=Neoconocephalus nebrascensis lyristes

(R. \& H.). .............................. 518

Conocephalus malivolans Scudder=Homorocoryphus malivolans

(Scudd.) ............................... 532

Conocephalus melanorhinus R. \& H.=Neoconocephalus melanorhinus

(R. \& H.). ............................... 519

Conocephalus mexicanus Saussure=Neoconocephalus triops (Linn.)... 531.

Conocephalus nebrascensis Bruner $=$ Neoconocephalus nebrascensis

(Brun.) .................................. 517

Conocephalus nietoi (Amer. auth. nec. Sauss.) =Neoconocephalus triops (Linn.). ............................. 531

Conocephalus obtusus Burmeister $=$ Neoconocephalus triops (Linn.)... 531.

Conocephalus palustris Blatchley $=$ Neoconocephalus palustris

(Blatch.). ................................ 526

Conocephalus retusus Scudder $=$ Neoconocephalus retusus (Scudd.)... 528. Conocephalus robustus Scudder=Neoconocephalus robustus (Scudd.) 522.

Cryptoptilum antillarum (Redtenbacher) $=$ Cycloptilum antillarum

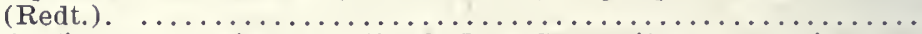

Cryptoptilum trigonipalpum R. \& H.=Cycloptilum trigonipalpum

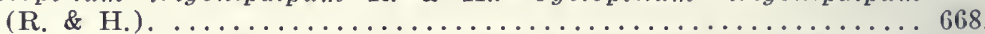

Cycloptilus borealis Bruner $=$ Cycloptilum squamosum Scudder....... 665.

Cyrtacanthacris unilineata F. Walker=Schistocerca damnifica (Sauss.). . ............................... 318.

Cyrtophyllus concavus Scudder =Pterophylla camellifolia (Fab.).... 406.

Cyrtophyllus elongatus Caudell=Pterophylla camellifolia (Fab.).... 406.

Cyrtophyllus floridanus Beutenmüller=Lea floridensis (Beut.)...... 501.

Cyrtophyllus intermedius Caudell=Pterophylla camellifolia intermedia (Caud.).

Cyrtophyllus perspicillatus Burmeister $=$ Pterophylla camellifolia (Fab.). ............................... 406

Cyrtoxipha delicatula Scudder=Anaxipha pulicaria (Burm.)....... 731.

Cyrtoxipha columbiana Caudell=Cyrtoxipha gundlachi columbiana

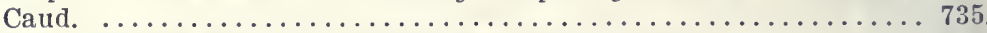

Daihinia gigantea Bruner $=$ Udeopsylla robusta (Hald.) . . . . . . . . . 612

Decticus derogatus F. Walker=Atlanticus americanus (Sauss.)....... 596.

Decticus dorsalis Burmeister $=$ Atlanticus dorsalis (Burm.)......... 599

Decticus pachymerus Burmeister=Atlanticus pachymerus (Burm.)... 593.

Dendrotettix longipennis Riley =Dendrotettix quercus Pack........ 337.

Diapheromera dentricus Stål=Megaphasma dentricus (Stål)........ 142.

Diapheromera sayi Gray =Diapheromera femorata (Say)........... 133.

Dictyophorus reticulatis Thunberg=Romalea microptera (Beauv.) . .. . 304.

Dissosteira bolli crepitans Saussure=Spharagemon crepitans (Sauss.) 278.

Diestrammena marmorata (DeHaïn)=Diestrammena japanica nom nov. .................................... 611

Ectobia flavocincta Scudder =Parcoblatta pennsylvanica (DeG.) ..... 86.

Ectobia lithophila Scudder =Parcoblatta uhleriana (Sauss.)......... 81.

Engoniaspis testacea Scudder =Atlanticus testaceus (Scudd.) ........ 591. 
Page.

Eotettix davisi Hebard=Melanoplus davisi (Hebard)........... 396. Eotettix hebardi Rehn- = Melanoplus attenuatus hebardi (Rehn)..... 371. Eotettix quercicola Hebard=Melanoplus davisi quercicola (Hebard).. 397. Eritettix carinatus (Scudder) =Eritettix simplex (Scudd.)......... 211. Eritettix sylvestrus Blatchley =Pedeticum obscurum (Scudd.)........ 213. Euborellia annulipes (Lucas) $=$ Anisolabis annulipes (Lucas)...... 47. Eurycotis ingens (Scudder) $=$ Eurycotis floridana (F. Walker)...... 97. Forficula aculeata Scudder=Doru aculeatum (Scudd.)........... 55. Forficula annulipes Lucas =Anisolabis annulipes (Lucas)......... 47. Forficula bidens Olivier=Labidura bidens (Oliv.).............. 48. Forficula maritima Gené=Anisolabis maritima (Gené)............. 47. Forficula minor (Linnæus) $=$ Labia minor (Linn.)............... 51. Forfiscelia curvicauda Motsch.=Labia curvicauda (Motsch.) . ........ 52. Gomphocerus carinatus Scudder=Eritettix simplex (Scudd.)........ 211. Gomphocerus pelidna Burmeister=Orphulella pelidna (Burm.)....... 225. Gryllacris carolinensis Gerstæcker =Camptonotus carolinensis (Gerst.) 603. Gryllodes caraibeus Saussure=Anurogryllus muiticus (DeG.)........ 690. Gryllodes clarazianus Saussure=Anurogryllus muticus (DeG.)...... 690. Gryllodes guyennensis Saussure=Miogryllus verticalis (Serv.)....... 693. Gryllodes poeyi Saussure=Gryllodes sigillatus (F. Walker)........ 692. Gryllotalpa borealis Burmeister =Gryllotalpa hexadactyla Perty...... 644. Gryllotalpa ponderosa Bruner=Gryllotalpa major Sauss............ 647. Gryllotalpa vulgaris Latreille=Gryllotalpa gryllotalpa Linn........ 64S. Gryllus abbreviatus Serville=Gryllus assimilis luctuosus Serv...... 700. Gryllus americanus Blatchley=Gryllus assimilis vernalis Blatch..... 704. Gryllus angustulus F. Walker=Anurogryllus muticus (DeG.)......... 690. Gryllus angustus Scudder=Gryllus assimilis pennsylvanicus Burm... 702. Gryllus arenaceus Blatchley=Gryllus assimilis scudderianus Sauss... 700. Gryllus bipunctatus DeGeer =Neoxabea bipunctata (DeG.)......... 727. Gryllus bivittatus Say=Melanoplus bivittatus (Say).............. 446. Gryllus brevicornis. Linn $=$ Tryxalis brevicornis (Linn.)........... 198. Gryllus carolinus Johannson=Stagmomantis carolina (Johann.) .... 118. Gryllus firmus Scudder $=$ Gryllus assimilis firmus Scudd........... 699. Gryllus laplate Saussure $=$ Miogryllus verticalis (Serv.)............693. Gryllus luctuosus Serville=Gryllus assimilis luctuosus Serv........ 700. Gryllus muticus DeGeer=Anurogryllus muticus (DeG.)...........690. Gryllus neglectus Scudder=Gryilus assimilis neglectus Scudd.......706. Gryllus nigerrimus F. Walker=Gryllus assimilis pennsylvanicus Burm.

Gryllus nigra (Harris) = Gryllus assimilis pennsylvanicus Burm..... Gryllus niveus DeGeer=Oecanthus niveus (DeG.)..............7714. Gryllus obscurus Fabricius=Schistocerca obscura (Fabr.) ........ 317. Gryllus pennsylvanicus Burmeister $=$ Gryllus assimilis pennsylvanicus

Burm.

Gryllus pustulipes $\ddot{F}$. Walker $=$ Gryllodes sigillatus (F. Walker)..... 692. Gryllus mbens Scudder $=$ Gryllus assimilis scudierianus Sauss...... 700. Gryllus scudderianus Saussure=Gryllus assimilis scudderianus Sauss. 700. Gryllus serialis Thunberg=Schistocerca americana (Drury)........ 312. Gryllus sigillatus F. Walker=Gryllodes sigillatus (F. Walker)....... 692. Gryllus sulphureus Fabricius=Arphia sulphurea (Fabr.)......... 253. Gryllus verticalis Serville=Miogryllus verticalis (Serv.).......... 693. Gryllus virginianus Fabricius=Chortophaga viridifasciata (DeG.)... 256. Gryllus vitreipennis Marschall=Stenacris vitreipennis (Marsch.) ... 310. Hapithus quadratus Scudder=Hapithus agitator Uhler.......... 739. Haplopus evadne Caudell nec. Westwood=Aplopus mayeri Caudell... 144. Hesperotettix gemmicula Hebard=Hesperotettix pratensis gemmicula

Hebard.

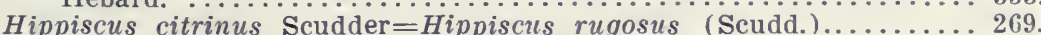
Hippiscus compactus Scudder=Hippiscus rugosus (Scudd.)......... 269. Hippiscus immaculatus Morse=Hippiscus rugosus (Scudd.)........ 269 Hippiscus nanus Saussure=Hippiscus haldemanii (Scudd.)........ 268. Hippiscus suturalis Scudder=Hippiscus rugosus (Scudd.)......... 269. 
Hippiscus texanus Scudder =Hippiscus phonicopterus (Burm.)...... 266. Hippiscus tuberculatus Beauvois (Amer. auth.) =Hippiscus apiculatus

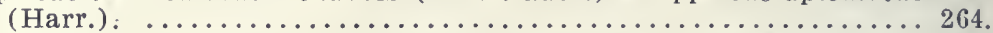
Hippiscus variegatus Scudder=Hippiscus rugosus (Scudd.)........ 269. Idionotus brevipes Caudell=Idionotus sphagnorum (F. Walker.)..... 601. Ischnoptera bivittata Thomas $=$ Blattella germanica (Linn.) . . . . . . . 73 . Ischnoptera bolliana Sauss. \& Zehnt.=Parcoblatta bolliana (S. \& Z.)... 80. Ischnoptera borealis Brunner=Parcoblatta virginica (Brunner)..... 82. Ischnoptera couloniana Saussure=Parcoblatta pennsylvanica (DeG.).. 86. Ischnoptera divisa Sauss. \& Zehnt.=Parcoblatta pennsylvanica divisa (S. \& Z.).

Ischnoptera fulvescens Sauss \& Zehnt.=Parcoblatta fulvescens (S. \& Z.).

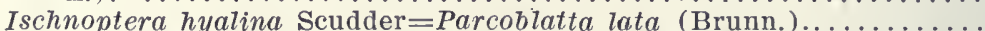
Ischnoptera inaqualis (Sauss. \& Zehnt.)=Parcoblatta pennsylvanica

(DeG.).

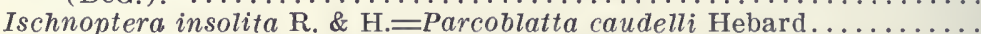
Ischnoptera intricata Blatchley=Parcoblatta uhleriana (Sauss.)..... Ischnoptera johnsoni Rehn=Ischnoptera deropeltiformis (Brunn.)... Ischnoptera lata Brunner=Parcoblatta lata (Brunn.)............ Ischnoptera major (Sauss \& Zehnt.)=Parcoblatta lata (Brunn.)..... Ischnoptera nigricollis F. Walker=Ischnoptera deropeltiformis

(Brunn.).

Ischnoptera nortoniana Saussure=Parcoblatta pennsylvanica (DeG.). Ischnoptera translucida Saussure=Parcoblatta pennsylvanica (DeG.). Ischnoptera uhleriana Saussure=Parcoblatta uhleriana (Sauss.).... Kakerlac fuliginosa Serville=Periplanata fuliginosa.(Serv.)...... Kakerlac schofferi Rehn=Parcoblatta bolliana (S. \& Z.) .......... Labia brunnea Scudder=Prolabia arachidis (Yersin)............ Labia burgessi Scudder $=$ Prolabia pulchella (Serv.).............. Labia guttata Scudder=Prolabia pulchella (Serv.)................ Labia melancholica Scudder=Prolabia pulchella (Serv.)............ Labia minuta Scudder $=$ Labia minor (Linn.). . . . . . . . . . . . . . Labia unidentata Burr nec Beauv.=Prolabia pulchella (Serv.)...... Labidura riparia (Amer. Auth. nec. Pallas)=Labidura bidens (Oliv.). Latindia cucullatus Sauss. \& Zehnt.=Compsodes cucullatus (S. \& Z.).. 108. Libellula americana Drury =Schistocerca americana (Drury)......... 312. Liphoplus krugii (Amer. auth. nec. Sauss.) =Cycloptilum squamosum Scudd.

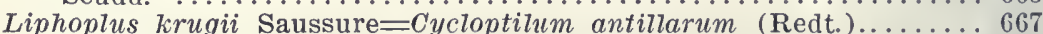
Liphoplus zebra R. \& H.=Cycloptilum squamosum zebra (R. \& H.) ... 666. Locusta abortiva Harris=Chloaltis conspersa (Harr.)............ 215. Locusta apiculata Harris=Hippiscus apiculatus (Harr.)........... 264. Locusta camellifolia Fabricius=Pterophylla camellifolia (Fabr.)..... 406. Locusta carolinus Linnaeus =Dissosteira carolina (Linn.)......... 272. Locusta corallina Harris=Hippiscus apiculatus (Harr.).......... 264. Locusta curvicauda DeGeer =Scudderia curvicauda (DeG.).......... 469. Locusta eucerata Harris=Psinidia fenestralis (Serv.)............ 288. Locusta fasciata DeGeer=Conocephalus fasciatus (DeG.)............ 567. Locusta (Dictyophorus) guttatus Stoll=Romalea microptera (Beauv.). 304. Locusta infuscata Harris=Chortophaga viridifasciata (DeG.)....... 255. Locusta marmorata DeHaän=Diestrammena japanica nom. nov....... 611. Locusta marmorata Harris=Scirtetica marmorata (Harr.) . . . . . . . . . 284 Locusta maritima Harris=Trimerotropis maritima (Harr.)........ 293. Locusta nebulosa Harris=Encoptolophus sordidus (Burm.)......... 259. Locusta oblongifolia DeGeer =Amblycorypha oblongifolia (DeG.)..... 477. Locusta radiata Harris=Chortophaga viridifasciata (DcG.)......... 256. Locusta verruculata Kirby =Circotettix verruculatus (Kirby)....... 299. Macneillia obscura (Scudder) =Pedeticum obscurum .(Scudd.)...... 213. Manomera orthostylus Caudell=Manomera tenuescens (Scudd.)....... 139. Mantis carolina Burmeister=Stagmomantis carolina (Johann.)..... 118. Mantis chloropho'a Blanchard=Phyllovates chlorophera (Blanch.)... 129. 
Mantis dimidiata Saussure =Stagmomantis carolina (Johann.)...... 118. Mantis grisea Fabricius = Gonatista grisea (Fabr.)................ 125. Mantis phryganoides Serville=Gonatista grisea (Fabr.)........... 125. Mantis stolli Saussure =Stagmomantis carolina (Johann.).......... 118. Mantis wheeleri Thomas=Stagmomantis carolina (Johann.)........ 118. Marsa arcuata $\mathrm{F}$. Walker $=$ Udeopsylla robusta (Hald.).............612. Melanoplus abortivus Walker=Melanoplus islandicus Blatch......... 388. Melanoplus acidocercus Hebard=Melanoplus carnegiei acidocercus

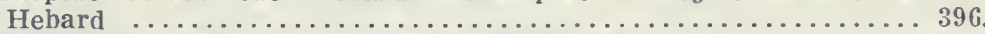
Melanoplus alaskanus Scudder=Melanoplus bruneri Scudd........ 413. Melanoplus amplectens Scudder=Melanoplus walshii Scudd......... 403. Melanoplus arboreus Scudder=Melanoplus punctulatis arboreus Scudd.

Melanoplus baconi McNeill=Velanoplus fasciatus (F. Walker)...... 400. Melanoplus blatchleyi Scudder=Melanoplus walshii Scudd......... 403. Melanoplus cenchri McNeill=Melanoplus flavidus Scudd...........4 416. Melanoplus coccineipes Scudder=Melanoplus angustipennis (Dodge). 425. Melanoplus collinus Scudder=Melanoplus keeleri luridus (Dodge)... 437. Melanoplus curtus Scudder=Melanoplus fasciatus (F. Walker)..... 400. Melanoplus deceptus Morse=Melanoplus viridipes Scudd........... 365. Melanoplus deletor Scudder =Melanoplus keeleri (Thomas)........ 436. Melanoplus femoratus (Burmeister)=Melanoplus bivittatus (Say).... 446. Melanoplus fodus Scudder=Melanoplus packardii Scudd........... 429. Melanoplus griseus (Thomas) =Melanoplus punctulatus (Scudd.)..... 450. Melanoplus harrisi Morse $=$ Photaliotes nebrascensis ( Thomas)....... 357. Melanoplus huroni Blatchley=Melanoplus dodgei huroni Blatch...... 407. Melanoplus interior Scudder=Melanoplus femur-rubrum (DeG.)..... 419. Melanoplus inops Scudder=Melanoplus rotundipennis (Scudd.)..... $3 \$ 2$. Melanoplus juvencus Scudder=Uclanoplus viridipes Scudd.......... 365. Melanoplus luridus (Dodge)=Melanoplus keeleri luridus (Dodge)... 437. Melanoplus macneilli Hart=-Melanoplus fluviatilis Bruner......... 432. Melanoplus minor (Scudder) =Melanoplus confusus Scudd.......... 434. Melanoplus paroxyoides Scudder=Paroxya atlantica paroxyoides (Scudd.). ................................. 353.

Melanoplus pegasus Hebard=Melnnoplus furcatus pegasus Hebard... . 445. Melanoplus rectus Scudder=Melanoplus fasciatus (F. Walker)....... 400. Melanoplus similis Morse=Melanoplus viridipes Scudd............. 365. Melanoplus sylvestris Morse=Melanoplus islandicus sylvestris

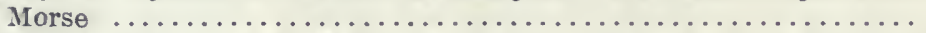

Melanoplus symmetricus Morse=Melanoplus clypeatus symmetricus Morse .................................. 444 Melanoplus tribuloides Morse=Melanoplus tribulus tribuloides Morse. 378. Mermiria belfragii Stål=Mermiria neomexicana (Thos.)............ 204. Mermiria vigilans Scudder=Mermiria alacris Scudd.............. 203. Mestobregma cineta Thomas=Mestobregma thomasi Caudell.......... 290. Microcentrum affiliatum Scudder=Microcentrum rhombifolium (Sauss.). ............................... 485

Microcentrum laurifolium (Amer. auth. nec. Linn.)=Microcentrum rhombifolium (Sauss.). ......................... 485. Microcentrum rostratum R. \& H.=Turpilia rostratrum (R. \& H.) ... 492. Microcentrum thoracicum Scudder=stilpnochlora couloniana (Sauss.). ................................... 490

Miogryllus oklahoma Caudell=Miogryllus verticalis (Serv.) ........ 693. Miogryllus saussurei Scudder=Miogryllus verticalis (Serr.).......... 693. Miogryllus transversalis Scudder=Gryllodes sigillatus (F. Walker). 692. Mogisoplistus barbouri Morse =Cyclopilum antillarum (Redt.)...... 667. Mogosiplistus slossoni Scudder=Cycloptilum antillarum (Redt.)..... 667. Nemobius abortivus Caudell $=$ Nemobius fasciatus abortivus Caudell.. 676. Nemobius affinis Beutenmüller $=$ Nemobius carolinus Scudd.......... 685. Nemobius angusticollis E. M. Walker=Nemobius carolinus Scudd..... 685 . Nemobius aterrimus Scudder $(q)=$ Nemobius cubensis Sauss......... 683. Nemobius aterrimus Scudder $(\hat{o})=$ Nemobius fasciatus socius Scudd. 677. 
Page.

Nemobius aurantius R. \& H.=Nemobius palustris Blatch...........684.

Nemobius bruneri Hebard $=$ Nemobius variegatus (Bruner).......... 682.

Nemobius canus Scudder $=$ Nemobius fasciatus socius Scudd......... 677.

Nemobius carolinus (Blatchley nec. Scudd.) $=$ Nemobius variegatus

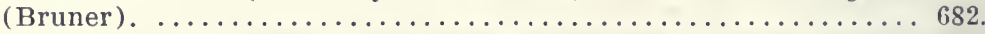

Nemobius cubensis (Blatchley nec. Sauss.) =Nemobius griseus Walker 678.

Nemobius exiguus Scudder $=$ Nemobius fasciatus (DeG.)...........674.

Nemobius exiguus Blatchley $=$ Nemobius carolinus Scudd........... 685.

Nemobius funeralis Hart $=$ Nemobius griseus funeralis Hart. . . . . . . . 679.

Nemobius hastatus Saussure $=$ Nemobius fasciatus socius Scudd...... 677.

Nemobius janus Kirby $=$ Nemobius carolinus Scudd.............. 685.

Nemobius septentrionalis Provancher $=$ Nemobius carolinus Scudd..... 685.

Nemobius socius Scudder $=$ Nemobius fasciatus socius Scudd........ 677.

Nemobius utahensis Scudder $=$ Nemobius fasciatus (DeG.) ......... 674.

Neoblattella adspersicollis R. \& H. nec. Stål=Latiblattella rehni

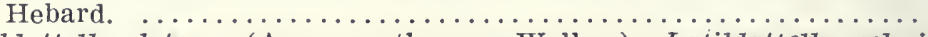

Neoblattella detersa (Amer, auth. nec. Walker)=Latiblattella rehni

Hebard. ................................. 69.

Neortus carolinus Brunner =Camptonotus carolinensis (Gerst.)...... 603.

Neotettix bolivari Hancock $=$ Neotettix femoratus (Scudd.) . ........ 172.

Neotettix coarctatus Hancock $=$ Neotettix bolteri Hancock.......... 173.

Neotettix hancocki Blatchley $=$ Neotettix bolteri Hancock.......... 173.

Neotettix variabilis Hancock $=$ Neotettix femoratus (Scudd.)........ 172.

Neotettix rotundifrons Hancock $=$ Neotettix femoratus (Scudd.)...... 172.

Neotettix variabilis Hancock $=$ Neotettix femoratus (Scudd.)........ 172.

Nomotettix arcticus Hancock $=$ Nomotettix validus Hancock......... 161.

Nomotettix arcuatus Hancock $=$ Nomotettix cristatus (Scudd.) ....... 157.

Nomotettix borealis E. M. Walker $=$ Nomotettix cristatus sinuifrons

Hancock.

160.

Nomotettix compressus Morse $=$ Nomotettix cristatus compressus Morse 157.

Nomotettix floridanus Hancock $=$ Nomotettix cristatus floridanus

Hancock.

Nyctobora lavigata (Amer. auth. nec. Beauv.)=Leurolestes pallidus

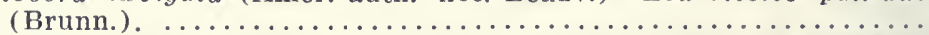

Nyctobora sericea (Amer. auth. nec. Burm.) $=$ Nyctobora levigata

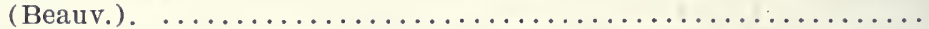

oecanthus bipunctatus (DeGeer) $=$ Neoxabea bipunetata (DeG.) . . . . 727.

Oecanthus fasciatus Fitch=Oecanthus nigricornis F. Walker........ 719

oecanthus forbesi Titus=oecanthus nigricornis quadripunctatus

(Beut..). ................................ 722 .

Oecanthus formosus F. Walker $=$ Neoxabea bipunetata (DeG.). ..... 727.

Oecanthus punctulatus Fitch $=$ Neoxabea bipunetata (DeG.).......... 727.

oecanthus quadripunctatus Beutenmiiller=Oecanthus nigricornis

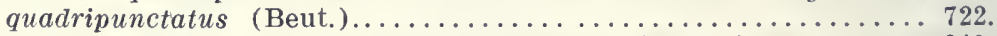

Oedipoda carinata Scudder=Arphia xanthoptera (Burm.) ........... 249.

Oedipoda discoidea Serville=Hippiscus phnnicopterus (Burm.)...... 266.

Oedipoda fenestralis Serville $\doteq P$ sinidia fenestralis (Serv.).......... 288.

Oedipoda haldemanii Scudder=Hippiscus haldemanii (Scudd.) ...... 268.

Oedipoda obliterata Germar=Hippiscus apiculatus (Harl.).......... 264.

oedipoda pellucida Provancher=Encoptolophus sordidus (Burm.) .... 259.

Oedipoda pellucida Scudder=Camnula pellucida (Scudder)......... 261.

oedipoda phonicoptera Burmeister=Hippiscus phonicopterus

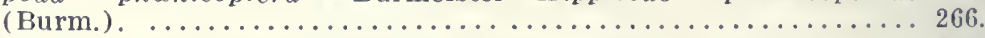

Oedipoda rugosa Scudder=Hippiscus rugosus (Scudd.) ............ 269.

oedipoda sordida Burmeister=Encoptolophus sordidus (Burm.) . . . . . 259.

Oedipoda sulphurea Fabricius=Arphia sulphurea (Fabr.)......... 252.

Oedipoda tenebrosa Scudder=Arphia pseudonietana (Thos.)......... 251.

oedipoda wyomingiana Thomas $=S p h a r a g e m o n$ vyomingianum

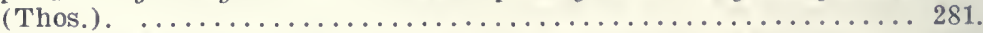

Oedipoda xanthoptera Burmeister=Arphia xanthoptera (Burm.).... 249.

Oligonyx uhleri Stål=oligonyx scudderi Sauss....................... 
Page.

Ommatolampis brevipennis Thomas=Hesperotettix brevipennis

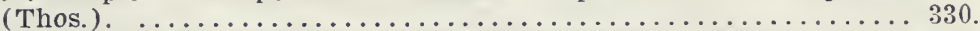
opomala aptera Scudder =Pseudopomala brachyptera (Scudd.)...... 200. opomala bivittata Serville=Mermiria bivittata (Serv.)............. 205. Opomala brachyptera Scudder=Pseudopomala brachyptera (Scudd.). 200. Opomala marginicollis Serville=Leptysma marginicollis (Serv.)..... 307. Orchelimum bruneri Blatchley=Orchelimum volantum McNeill...... 560. Orchelimum campestre Blatchley=Orchelimum concinnum campestre Blatch. 556. Orchelimum crusculum Davis=Orchelimum fidicinium R. \& H..... 558. Orchelimum glaucum Serville=Orchelimum agile (DeG.)........... 539. Orchelimum gracile Harris=Concocephalus fasciatus (DeG.)......... 567. Orchelimum gracile Bruner=Orchelimum concinnum delicatum Bruner

orchelimum gracilimum Griffini=orchelimum concinnum delicatum Bruner. ................................. 556.

Orchelimum indianense Blatchley=Orchelimum concinnum Scudd.... 554. Orchelimum longipennis Scudder=Orchelimum concinnum Scudd..... 554. orchelimum manitobense E. M. Walker=orchelimum gladiator

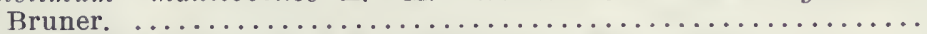
Orchelimum molossum R. \& H.=Orchelimum agile (DeG.) ........... 539. Orchelimum nitidum Redtenbacher=Orchelimum agile (DeG.)...... 539. Orchelimum silvaticum McNeill=Orchelimum agile (DeG.) .......... 539. Orchelimum spinulosum Redtenbacher=Orchelimum agile (DeG.)..... 539. Orchesticus americanus Saussure=Atlanticus americanus (Sauss.)... 596. Orocharis uhleri McNeill=Hapithus agitator Uhler........... 739. Orphulella pratorum Scudder=Orphulella peliana (Burm.)........... 225. Panchlora poeyi Saussure $=$ Panchlora cubensis (Sauss.)........... 105. Panchlora viridis (Amer. auth. nec. Sauss.)=Panchlora cubensis (Sauss.).

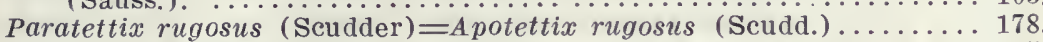
Paratettix texanus Hancock=Paratettix cucullatus (Burm.)........ 175. Paroxya floridana (Thomas) $=$ Paroxya clavuliger (Serv.) .......... 353. Paroxya hoosieri (Blatchley)=Paroxya clavuliger hoosieri (Blatch.) . 355. Paroxya scudderi Blatchley=Paroxya atlantica Scudd............. 351. Periplaneta floridana $\mathrm{F}$. Walker $=$ Eurycotis floridana ( $\mathrm{F}$. Walker) ... 97. Periplaneta orientalis Burmeister=Blatta orientalis Linn.......... 94. Periplaneta semipicta F. Walkel=Eurycotis floridana (F. Walker) .. 97. Periplaneta truncata Krauss =Periplaneta brunnea Brunn.......... 101. Pezotettix abditum Dodge $=$ Melanoplus dausoni (Scudd.).......... 393. Pezotettix acutipennis Scudder =Campylacantha olivacea (Scudd.)... 325. Pezotettix autumnalis Dodge=Photaliotes nebrascensis (Thos.).... 357. Pezotettix dawsoni Scudder=Melanoplus dawsoni (Scudd.).......... 393. Pezotettix glaciatis Scudder =Podisma glacialis (Scudd.)............ 341. Pezotettix gracilis Bruner=Melanoplus gracilis (Bruner).......... 362. Pezotettix hoosieri Blatchley=Paroxya clavuliger hoosieri (Blatch.) .. 355. Pezotettix minutipennis Thomas =Melanoplus gracilis (Bruner)..... 362. Pezotettix nebrascensis Thomas=Photaliotes nebrascensis (Thos.). 357. Pezotettix obovatipennis Blatchley=Melanoplus obovatipennis

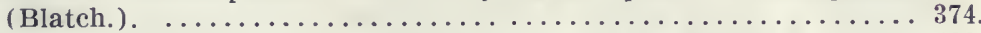

Pezotettix occidentalis Bruner=Melanoplus walshii Scudd......... 403. Pezotettix olivacea Scudder=Campylacantha olivacea (Scudd.)..... 325. Pezotettix puer Scudder=Melanoplus puer (Scudd.).............. 381. Pezotettix rotundipennis Scudder=Melanoplus rotundipennis

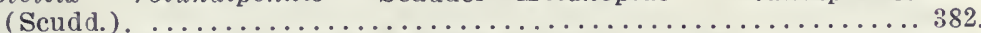

Pezotettix scudieri Uhler=Melanoplus scudderi (Uhler) ........... 394. Pezotettix septentrionalis Saussure=Melanoplus borealis (Fieb.) .... 422. Pezotettix speciosa Scudder =Hesperotettix speciosus (Scudd.)....... 335. Pezotettix tellustris Scudder =Melanoplus dawsoni (Scudd.)......... 393. Pezotettix unicolor Thomas =Melanoplus scudderi (Uhler) . ......... 394. Pezotettix viola Thomas=Melanoplus ponderosus (Scudd.)........ 405. Pezotettix viridipes Walsh Ms.=Melanoplus viridipes Scudd....... 365. 
Phaneroptera septentrionalis Serville=Scudderia septentrionalis

(Serv.). ................................... 464.

Phasma buprestoides Stoll=Anisomorpha buprestoiles (Stoll).... .. 145. Phasma ferruginea Beauvois=Anisomorpha ferruginea (Beauv.)..... 146. Phyllodromia borealis Saussure=Parcoblatta pennsylvanica (DeG.)... 86. Phylloptera retinerve Burmeister=Microcentrum retinerve (Burm.). 489. Phylloptera rhombifolium Saussure=Microcentrum rhombifolium

(Sauss.). ................................. 485 .

Phylloptera rotundifolia Scudder $=A m b l y c o r y p h a$ rotundifolia

(Scudd.). ................................. 483.

Platamodes unicolor Scudder=Parcoblatta uhleriana (Sauss.)...... 81. Platycleis fletcheri Caudell=Idionotus sphagnorum (F. Walker)..... 601. Platyphyllum concavum Harris=Pterophylla camellifolia (Fabr.)... 496. Platyzosteria ingens Scudder=Eurycotis floridana ( F. Walker)..... 97. Platyzosteria sabalianus Scudder=Eurycotis floridana (F. Walker)... 97. Plectoptera poeyi (R. \&. H. nec. Sauss.)=Plectoptera floridana

Hebard. .............................. 112

Podisma australis Morse $=$ Dendrotettix scudderi (Morse).......... 339. Podisma scudderi Morse=Dendrotettix scudderi (Morse)........... 339. Pycnoscelus obscurus Scudder =Pycnoscelus surinamensis (Linn.) ... 104. Radinotatum peninsulare R. \& H.=Radinotatum brevipenne (Thos.) .. 195. Rhaphidophora maculata Harris=Ceuthophilus maculatus (Harr.)... 622. Rhaphidophora stygia Scudder=Ceuthophilus stygius (Scudd.)...... 634. Rhaphidophora cavernarum Saussure=Hadenrcus subterraneus (Scudd.). .................................. 608 . Rhaphidophora subterranea Scudder=Hadenocus subterraneus (Scudd.). ................................... 608. Rhomalea centurio Thomas=Romalea microptera (Beauv.)......... 304. Rhomalea gloveri Kirby=Romalea microptera (Beauv. )......... 304. Romalea marci Serville=Romalea microptera (Beauv.)............ 304. Scapteriscus didactylus (Amer. auth. nec. Latreille) $=$ Scapteriscus vicinus Scudd. .............................. 651 . Schistocerca calidior R. \& H.=Schistocerca damnifica catidior R. \& H. 319. Schistocerca rubiginosa (Scudder)=Schistocerca alutacea rubiginosa

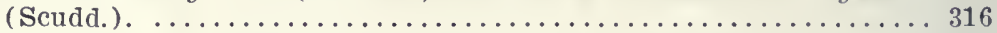
Schistocerca serialis (Thunb.) =Schistocerca americana (Drury)..... 312. Scirtetica picta (Scudder) =Scirtetica marmorata picta (Scudd.)..... 285. Scudderia cuneata Morse $=$ Scudderia furcata cuneata Morse....... 474. Scudderia curvicauda borealis R. \& H.=Scudderia curvicauda (DeG.). 469. Scudderia fasciata Beutenmüller =Scudderia furcata Brunn........ 472. Scudderia truncata Beutenmüller=Scudderia septentrionalis (Serv.). 464. Spectrum bivittatum Say=Anisomorpha buprestoides (Stoll)....... 145. Spectrum femoratum Say =Diapheromera femorata (Say).......... 133. Spharagemon aquale scudderi Morse $=$ Spharagemon wyomingianum

(Thos.). ................................... 281. Spharagemon balteatum Scudder=Spharagemon bolli Scudd......... 276. Spharagemon collare scudderi Morse=Spharagemon wyomingianum

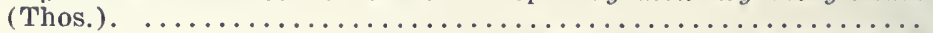
Spharagemon oculatum Morse=Spharagemon wyomingianum

(Thos.). .................................... 281. Spongophora brunneipennis (Serville)=Vostox brunneipennis (Serv.) 50. Stagmomantis ferox Saussure=Stagmomantis carolina (Johann.)... 118. Stenacris chlorizans F. Walker =Stenacris vitreipennis (Marsch.)..... 310. Stenobothrus admirabilis Uhler $=$ Syrbula admirabilis (Uhler)...... 209. Stenobothrus aqualis Scudder=Orphulella speciosa (Scudd.)......... 229. Stenobothrus bicolor Thomas =Amphitornus bicolor (Thos.)........ 220. Stenobothrus bilineatus Scudder =Orphulella speciosa (Scudd.)...... 229. Stenobothrus coloradensis McNeill=Chorthippus curtipennis (Harr.). 234. Stenobothrus coloradus Thomas =Amphitornus bicolor (Thos.)....... 220. Stenobothrus gracilis Scudder=Orphulella speciosa (Scudd.)......... 229. Stenobothrus longipennis Scudder=Chorthippus curtipennis (Harr.). 234. 
Page.

Stenobothrus maculipennis Scudder=Orphulella pelidna (Burm.).... 225. Stenobothrus occidentalis Saussure=Amblytropidia occidentalis

(Sauss.). . . . . . . . . . . . . . . . . . . . . . . . . . 221. Stenobothrus propinquans Scudder=Orphulella pelidna (Burm.)..... 225. Stenobothrus speciosa Scudder=Orphulella speciosa (Scudd.)........ 229. Stenobothrus subconspersus $\mathrm{F}$. Walker=Amblytropidia occidentalis

(Sauss.). . . . . . . . . . . . . . . . . . . . . . . . . 221. Stenobothrus unicolor Thomas $=$ Amphitornus bicolor (Thos.) ....... 220. Stilpnochlora marginella (Amer. auth. nec. Serv.)=Stilpnochlora

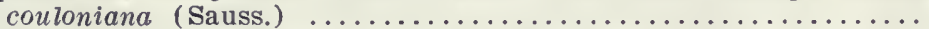

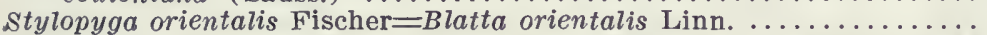
Temnopteryx deropeltiformis Brunner=Ischnoptera deropeltiformis

(Brunn.).

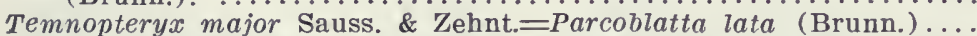
Temnopteryx marginata Scudder=Parcoblatta pennsylvanica (DeG.). Temnopteryx virginica Brunner=Parcoblatta virginica (Brunn.)..... Tenodera aridifolia sinensis Saussure=Paratenodera sinensis (Sauss.). sinensis Saussure=Paratenolera sinensis

Tetrix arenosus Burmeister $=$ Acrydium arenosum (Burm.)........ 169. Tetrix parvipennis Harris=Tettigidea lateralis parvipennis (Harr.). 183. Tetrix polymorpha Burmeister =Tettigidea lateralis (Say) ......... 182. Tettigidea acadica Scudder=Acrydium acadicum (Scudd.)........... 167. Tettigidea acuta Morse $=$ Tettigidea lateralis (Say)............... 182. Tettigidea davisi Morse $=$ Tettigidea armata Morse............... 185. Tettigidea medialis Hancock=Tettigidea lateralis (Say).......... 182. Tettigidea obesa Scudder =Paxilla obesa (Scudd.)............... 179 Tettigidea pennata Morse=Tettigidea lateralis parvipennis (Harr.)... 183. Tettigidea spicata Morse=Tettigidea armata spicata Morse.......... 186. Tettix angustus Hancock =Acrydium arenosum obscurum (Hanc.)... 169 Tettix blatchleyi Hancock=Acrydium arenosum blatchleyi (Hanc.). 170. Tettix brunneri Bolivar =Acrydium brunneri (Bolivar)............ 165. Tettix crassus Morse $=$ Acrydium ornatum Say. ............... 165. Tettix cucullatus Burmeister =Paratettix cucullatus (Burm.)......... 175. Tettix decoratus Hancock =Acrydium arenosum obscurum (Hanc.)... 169. Tettix femoratus Scudder $=$ Neotettix femoratus (Scudd.) ........... 172. Tettix fluctuosus Hancock =Acrydium arenosum obscurum (Hanc.)... 169. Tcttix gibbosa Hancock=Acrydium arenosum obscurum (Hanc.)..... 169. Tettix hancocki Morse $=$ Acrydium ornatum hancocki (Morse) ........ 167. Tettix inflatus Hancock =Acrydium arenosum obscurum (Hanc.)..... 169. Tettix luggeri Hancock $=$ Acrydium granulatum Kirby............ 164. Tettix morsei Hancock =Acydium granulatum Kirby............. 164. Tettix rugosa Scudder $=$ Apotettix rugosus (Scudd.) ............... 178. Tettix tentatus Morse $=$ Acrydium brunneri (Bolivar) ............ 165. Tettix triangularis Scudder $=$ Acrydium ornatum Say............. 165. Thyreonotus pachymerus (Amer, auth. nec. Burm.) =Atlanticus tes.

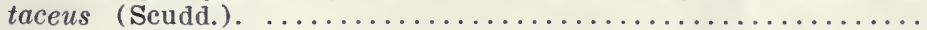

Tomonotus nietanus Thomas $=$ Arphia pseudonietana (Thos.)........ 251 Tomonotus pseudonietanus Thomas=Arphia pseudonietana (Thos.)... 251. Tomonotus zimmermanni Saussure=Chortophaga viridifasciata

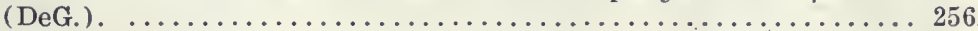

Tragocephala viridifasciata Harris=Chortophaga viridifasciata (DeG.). . . . . . . . . . . . . . . . . . . . . . . . . . 256.

Tridactylus fissipes Saussure $=$ Tridactylus apicalis Say. .........656. Tridactylus histrio Saussure $=$ Ellipes minuta (Scudd.)............ 658 . Tridactylus histrionicus Saussure $=$ Ellipes minuta (Scudd.).........658. Tridactylus illinoiensis Thomas=Tridactylus apicalis Say.......... 656 . Tridactylus incertus Saussure $=$ Tridactylus apicalis Say. . . . . . . . . 656. Tridactylus minutus Scudder =Ellipes minuta (Scudd.)............. 658. Tridactylus mixtus Haldeman=Tridactylus apicalis Say...........656. Tridactylus terminalis Scudder Tridactylus apicalis Say.......... 656 . Tridactylus tibialis Guerin=Tridactylus apicalis Say...........656. 
Trimerotropis acta Hebard=Trimerotropis maritima acta Hebard.. 295. Trimerotropis maritima interior Walker=Trimerotropis maritima

(Harr.). ................................ 293 . Trimerotropis picta Scudder =Scirtetica marmorata picta (Scudd.)... 285. Truxalis angusticornis Stål=Dichromorpha viridis (Scudd.)......... 230. Tryxalis brevipennis Thomas $=$ Radinotatum brevipenne (Thos.)..... 195. Udeopsylla compacta Bruner=Udeopsylla robusta (Hald.)..........612. Udeopsylla nigra Scudder =Udeopsylla robusta (Hald.).............612. Xabea bipunctatus (DeGeer) $=$ Neoxabea bipunctata (DeG.)........ 727. Xiphidium allardi Caudell=Conocephalus allardi (Caudell)........ 567. Xiphidium attenuatum Scudder=Concephalus attenuatus (Scudd.)... 578. Xiphidium brevipennis Scudder $=$ Conocephalus brevipennis (Scudd.). 570. Xiphidium curtipenne Redtenbacher=Conocephalus nemoralis (Scudd.). ................................ 572. Xiphidium ensifer Scudder=Conocephalus brevipennis (Scudd.).... 570. Xiphidium fasciatum (DeGeer) =Conocephalus fasciatus (DeG.)..... 567. Xiphidium gossypii Scudder=Conocephalus brevipennis (Scudd.)..... 570. Xiphidium gracillimun Morse=Conocephalus gracillimus (Morse)... 569. Xiphidium lanceolatum Bruner=Conocephalus attenuatus (Scudd.). 578. Xiphidium modestum Bruner=Conocephalus saltans (Scudd.)...... 582. Xiphidium nemorale Scudder=Conocephalus nemoralis (Scudd.)..... 572. Xiphidium nigropleuroides Fox=Conocephalus nigropleuroides (Fox). 579. Xiphidium nigropleurum Bruner=Conocephalus nigropleurus

(Bruner). ................................. 576. Xiphidium (O.) robustum Redtenbacher=Orchelimum nigripes Scudd. 549. Xiphidium saltans Scudder=Conocephalus saltans Scudd.......... 582. Xiphidium scudderi Blatchley=Conocephalus attenuatus (Scudd.).... 578. Xiphidium spartino Fox=Conocephalus spartina (Fox)........... 580. Xiphidium strictum Scudder=Conocephalus strictus (Scudd.)....... 573. Xiphidium taniatum Redtenbacher=Conocephalus saltans (Scudd.).. 582.

\section{General Index}

Families end in idæ; subfamilies in inæ. Species and varieties are indexed only where a genus is represented by five or more, when they are indexed under the gencric name.

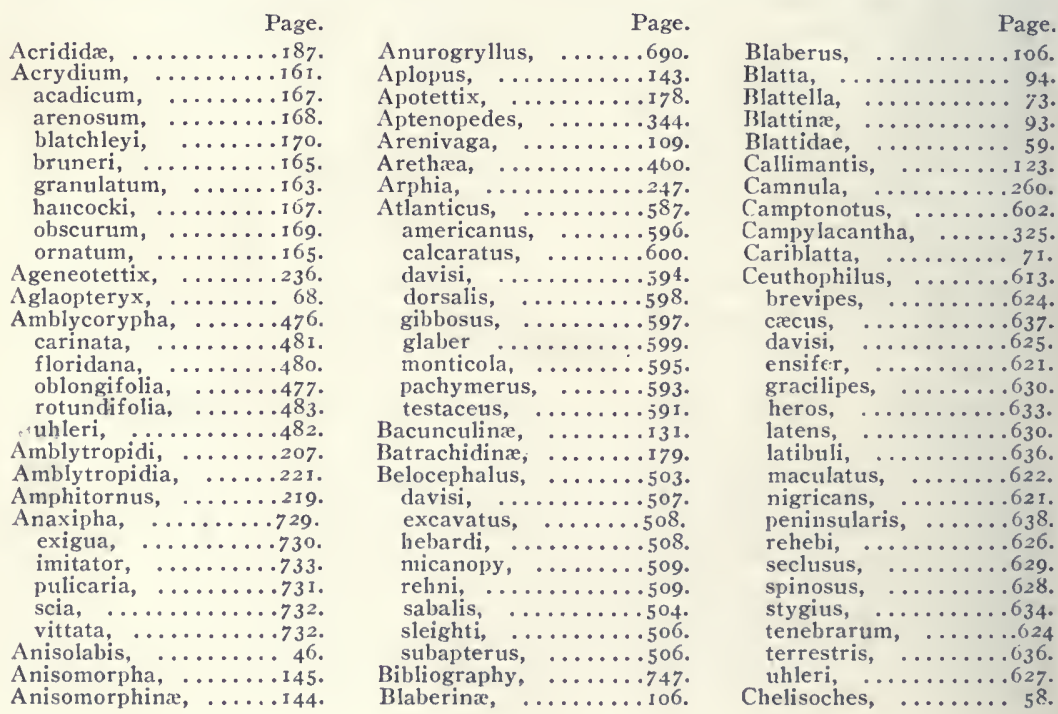


Page.

Chlcealtis, .........2I4. Chorisoneura, ........III.

Chorthippi, ........233.

Chorthippus, ........234

Chortophaga, ......254.

Circotettix, .........299.

Clinocephalus, ......232.

Compsodes, ...........

Conocephalinæe, .....533.

Conocephalus, .......562 aigialus, .........5756. allardi, .........567. attenuatus, $\ldots \ldots \ldots 578$ brevipennis, ......570. fasciatus, .......5567. gracillimus, .......569. nemoralis, ........572. nigropleurus, $\quad \ldots \ldots .576$. nigropleuroides, ...579. saltans, .........582. spartinæ, .........580. stictomerus, ......575. strictus, $\ldots \ldots \ldots .573$ viridifrons, .......583.

Copiphorina, .....5.502. Corydiinz, ..........107. Cryptocercus, ..........II3. Cursoria, .......... 59. Cycloptilum, .......664. Cyrtoxipha, .......734. Decticina, .........586. Dendrotettix, ......337. Dermaptoria, ....... $4^{2}$. Diapheromera, .....132. Dichromorpha, .....230. Diastremmena, .....610.

Dissosteira, ........271.

Doru, ............ 55 . Ellipes, ..........6.6.6.

Encoptolophus, ....25

Eneopterinx, .......737.

Eotettix, ...........327.

Epilamprinæ, ...... 93 Eremiaphilinæ, .......128. Eritettix, ........210.

Eury cotis, .........99. Falcicula, .........733. Forficula, ........ 57 .

Forficulidae, $\ldots \ldots \ldots .42$. Forficulinx, ........ 54 . Glossary, .........757.

Gonatista, .........124. Gressoria, ..........114. Grvllacrina, ......6.60z. Gryllidx, .........6.6.6. Gryllinae, .........670. Gryllotalpa, .......6.643. Gryllotalpine, $\ldots \ldots \ldots 642$. Gryllodes, ........6.692. Gryllus, ..........696. assimilis, .......6.698. domesticus, .......zoz. firmus, ........699. Juctuosus, $\quad \ldots \ldots \ldots 700$. neglectus, ........706. pennsylvanicus, $\quad \ldots .702$. scudderianus, .....70o. vernalis, ........704.

Gymnoscirtetes, .....322.

Hadencecus, .......6.68.

Hapithus, ............738.

Hesperotettix, ......329.

brevipennis, ......330.

floridensis, .......336.

gemmicula, .........333.

osceola, ..........334.

pratensis, ........33 I.

speciosus, ........335.
Page.

Heteronemia, ........141.

Hippisci, ...........246.

Hippiscus, .........262

Holocompsa, …...107.

Homorocoryphus, ...531.

Hygronemobius, ....688.

Idionotus, ..........600.

Ischnoptera, ....... 75 .

Labia, ............ 51

Labidurinz, ........ 46.

Labidura, ..........4 48

Labiinx, ......... 49 .

Latiblattella, ......6.69.

Lea, ............ 500.

Leptysma, ..........307

Life Zones, .......745

Locustina, . . . . . 302.

Manomera, .........138.

Mantidx, .........115

Mantinx, ..........117.

Mantis, ..........121.

Mantoida, ......... 28 .

Mecostethi, ........238

Mecostethus, .......238

Megaphasma, ........142

Melanopli ..........320.

Melanoplus, ........358. acidocercus, ......396. angustipennis, $\ldots .425$. arboreus, .......4.452. atlanis, ........... attenuatus, $\ldots \ldots \ldots 370$ australis, $\ldots \ldots \ldots .370$ bivittatus, ........446 borealis, ........4.422. bruneri, ........4.43. carnegiei, ........395. celatus, ........390. clypeatus, .......443. confusus, $\quad \ldots \ldots \ldots .434$. davisi, ...........396. dawsoni, ..........393. decoratus, .......379. decorus, $\quad . . \ldots \ldots .350$. devius, $\ldots \ldots \ldots \ldots .378$. differentialis, ....440. divergens, ........390. fasciatus, .........400. femur-rubrum, ....419. flavidus, $\ldots \ldots \ldots \ldots+16$ fluviatilis, $\ldots \ldots \ldots 43 \mathrm{r}$. furcatus, .........444. gracilis, .........362. hebardi, ..........37 huroni, .........407. impiger, ..........427. impudicus, .......417 islandicus, ..........388. keeleri, .........4.436. luridus, $\ldots \ldots \ldots \ldots .437$ mancus, ..........387. mirus, ...........385. morsei, ..........376. nigrescens, $\quad \ldots \ldots .402$ nubilus, ..........372. obvatipennis, $\ldots \ldots 374$. packardii, .......4.429. pegasus, ........445. ponderosus, ......405. propinquus, …..421. puer, ............381. punctulatus, .....450. pygmzus, ..........383. querneus, .......401. quercicola, .......397. rotundipennis, $\quad \ldots .382$. scapularis, .......38. scudderi, ........394.
Page.

stegocercus, $\ldots . . .384$ stonei, ..........432. strumosus, $\ldots \ldots \ldots 385$. sylvestris, $\ldots \ldots \ldots .389$ symmetricus, . .....444. tepidus, .........376. tribuloides, ........378 tribulus, $\ldots \ldots \ldots \ldots 377$ viridipes, ........365 walshii, ..........403. Mermiria, .........202.

Mestobregma, ......290.

Microcentrum, ......484

Miogryllus, ........6.69.

Mogoplistinx, .....66z.

Myrmecophila, ......659.

Myrmecophilinx, ....659.

Nemobius, ........67 abortivus, ......6.676. ambitiosus, ......680. carolinus, .......685. confusus, $\quad . \ldots \ldots \ldots 687$ cubensis, ........6.683. fasciatus, .......674 funeralis, .......679 griseus, ........678 maculatus, $\ldots \ldots .6679$. mormonius, ......684. palustris, .......684. socius, ..........677 variegatus, $\ldots . . .6 .682$

Neoconocephalus, ....512 caudellianus, $\ldots . .525$ crepitans, .......5524 ensiger, .........520 exiliscanorus, $\ldots \ldots .515$. lyristes, ..........518 melanorhinus, ......519. nebrascensis, .....5 ז 7 . palustris, .......526. retusus, $\ldots \ldots \ldots \ldots .528$. robustus, $\ldots \ldots \ldots \ldots 522$ triops, $\ldots \ldots \ldots \ldots .529$ velox, ........5.527.

Neotettix, .........171.

Neoxabea, ..........726. Nomotettix, ........156

Nyctobora, ........... 91

Nyctoborina, ....... 9r.

Oecanthinx, .......709.

Oecanthus, ...........712. angustipennis, $\quad \ldots$.717. exclamationis, .....719. latipennis, .......725. nigricornis, ......7 7 I9. niveus, $\ldots \ldots \ldots \ldots$. 714 pini, ............724 quadripunctatus, $\ldots 77^{22}$

Oedipodine, ......243.

Odontoxiphidium, ...584

Oligacanthopus, .....669.

Oligonyx, ..........126.

Orchelimum, …..535. agile, $\quad \ldots \ldots \ldots \ldots .539$. bradleyi, .........561. bullatum, .......5.548. calcaratum, . . . . 550 . campestre, ......556. concinnum, ......554 delicatum, ......5556. erythrocephalum, ..541. fidicinium, .......558. gladiator, ........ 545 . minor, ...........553. militare, ........559. nigripes, $\quad . . . \ldots \ldots 549$. pulchellum, ......556. superbum, .......557. 


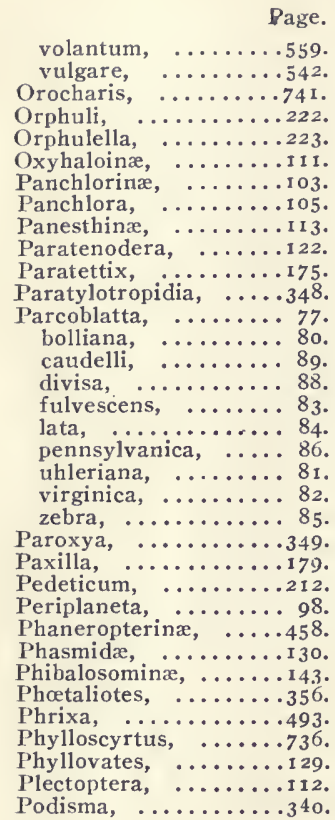

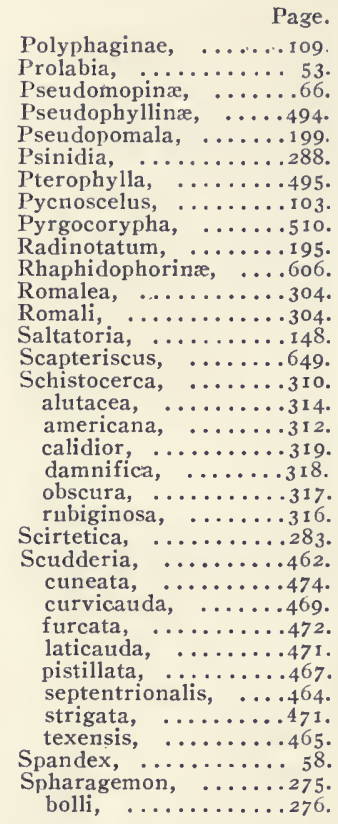

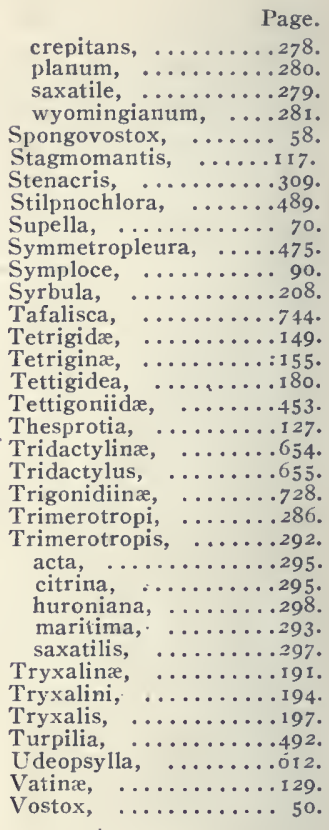

\begin{abstract}
"Truth wears no mask; bows at no human shrine; seeks neither place nor applause; she only asks a hearing."
\end{abstract}

(Date of publication of this volume, May 3, 1920.) 


\title{
Peoverir on Pguni
}

NOTES ON THE ORTHOPTERA OF THE EASTERN UNITED STATES

\author{
By W. S. Blatchley, \\ INDIANAPOLIS, INDIANA.
}

Since my "Orthoptera of Northeastern America" appeared in May, 1920, a number of notes on the distribution, habits, etc., of certain species have accumulated. In order that our knowledge of this interesting order of insects may be kept somewhat up to date, I have brought these together in the present paper. I have also made brief mention of such new species and varieties as have been described by other authors from the territory covered by that work since its appearance. The serial number before the name of each species is that of the same species in the "Orthoptera."

(2). Anisolabis annulipes (Lucas). Since 1920 this earwig has been taken in numbers at Dunedin, Fla., from beneath and in decaying grape fruit and in piles of rotting unhulled rice.

(..). Anisolabis (Euborellia) ambigua Borelli. Heb$\operatorname{ard}^{1}$ has recently recorded the taking of a number of specimens of this West Indian form from beneath tidal litter along the edge of a mangrove swamp near Miami, Florida.

(10). Doru aculeatum (Scudder). While hunting near Indianapolis for Donacia on skunk cabbage, Spathyema fæctida (L.), I took on May 1, 1921, 42 specimens of this earwig from between the bases of the leaves of the plants. They were below the surface of the ground, one to five in each clump of the plant, though usually in pairs, resting head downward in the groove which extends along the petiole of the leaf. Associated with them I found ten specimens of the chrysomelid beetle, Donacia rufa Say, and examples of several other species of beetles. I believe that the natural habitat of a number of our inland species of earwigs will be found to be between the base leaves and stems of grasses, sedges and other plants in damp localities. ${ }^{2}$ From this retreat they emerge only at night in search of food.

${ }^{1}$ Trans. Amer. Ent. Soc., XLVII, 1922, 321.

${ }^{2}$ See Orthoptera of N. E. America, p. 57. 
(39). Arenivaga floridensis Caudell. Two additional males of this Floridian roach have been found near Dunedin. They were taken in April while flying tow along sandy roadways in the pine woods.

(57). Manomera blatchleyi (Caudell). W. T. Davis ${ }^{3}$ has recently described an eastern race of this species under the name Manomera blatchleyi atlantica. His specimens (females only) were from Staten Island, Long Island, New York, New Jersey, Connecticut and Virginia. From typical blatchleyi it differs mainly in its broader and more tapering head, longer legs and shorter cerci.

(60). Megaphasma dentricus (Stal). The first known Indiana specimens of this giant walking-stick were taken at Wyandotte, Crawford County, on August 2, 1921. A male, 105 $\mathrm{mm}$. in length, was found crawling slowly along a woodland pathway and two others on the ceiling of the hotel porch.

(64b). Nomotettix cristatus floridanus Hancock. The second known example of the long or caudate form of this grouselocust was taken March 30,1920, while sweeping herbage in a cypress swamp on the margin of Lake Istokpoga, Florida.

(76). Paxilla obesa (Scudder). A single male of this bulky species was swept from the same swamp at Lake Istokpoga. It was the first specimen I had taken personally during all my collecting.

(79.) Tettigidea armata Morse. A female of this form was taken at Moore Haven, Florida, on March 24.

(102). Ageneotettix deorum (Scudder). The known range of this species has been extended eastward by Hubbell, ${ }^{4}$ who records the taking of a specimen at Three Oaks, Michigan.

(105). Mecostethus platypterus (Scudder). A number of specimens taken at Cambridge, Nebraska, July 19, 1921, have been sent me by A. P. Morse. Not before recorded west of Iowa and Minnesota.

\footnotetext{
${ }^{3}$ Journ. N. Y. Ent. Soc., XXXI, 1923, 52.

'Occasional Papers of the Museum of Zoology, Univ. of Mich., No. 116,39 .
} 
(145). Hesperotettix pratensis Scudder. I was surprised to find. on August 4, 1921, several specimens of this handsome little locust by the side of a roadway running along a high wooded ridge near Wyandotte, Crawford Co., Ind. This county is in the extreme southern end of the State, adjoining the Ohio River. The only other Indiana localities previously known were in Lake County, adjoining Lake Michigan, where it occurs only in swales or low marshy tracts between the sand dunes. The tegmina of these southern upland examples were shorter than in those from the marshlands of the North, but the form of prosternal spine, of hind margin of metazona and of supra-anal plate of male are very distinctive in the species and differ conspicuously from those of $H$. brcuipennis (Thos.).

(160). Melanoplus viridipes Scudder. Morgan Heb. ard, ${ }^{5}$ of Philadelphia, has, both in Mss. and in print. taken occasion to caustically criticise my treatment of this and allied species, and has described (loc. cit.) a new eastern race. M.v. curyccrcus. using in part as cotypes, material I furnished him from Indiana. As stated by me in my notes on this species (p. 367 of the "Orthoptera"), some of the cotypes of Scudder's viridipes came from a colony discovered by me in Vigo County, Indiana. One of Morse's cotypes of $M$. deceptus came from this same colony. The species occurs mainly in isolated colonies of 30 to 70 or more in open blue-grass wooded pastures. It is very probable that these colonies emerge from one or two egg masses deposited by the same female. From such a colony occupying not over 100 square feet in a pasture of Marion County, Indiana, I have taken numerous examples which showed all the variations of the male cerci on which were based the three forms, viridipes Scudder, deceptus Morse, and eurycercus Hebard. The females of these forms are absolutely inseparable, as is admitted by Hebard (loc. cit., p. 394). If the egg pods of a single female, or of two or three females which originally came from the same colony, give rise to males whose variation in cerci is such as to lead to the founding of three species or races, where is the hair-splitting of nomenclature to end?

${ }^{3}$ Trans. Anter. Ent. Soc., XLVI, 1920, 357, 393. 
Hebard (loc. cit., p. 393) states that "from over the wide range of viridipes eastward from Lake Co., Indiana, not a single male before us shows a cercal development intermediate in character between the typical condition of viridipes and eurycercus"; yet on the very next page he says "the males before us from Ann Arbor, Michigan, are intermediates, referable to $v$. eurycercus but showing distinct variation toward v. viridipes." Ann Arbor is 165 miles east of Lake Co., Indiana.

Hubbell (loc. cit., p. 50) states that all but two of the 31 males of viridipes taken by him in Berrien Co., Michigan, are of a type intermediate between typical viridipes and eurycercus. Although I may not be able, as Hebard claims, "to recognize the true value of species or races wherever finesse or elaborate analysis is necessary," I do not believe in trammeling nomenclature by giving a new name to every individual that has an extra spot on its side or an extra curve in its tail.

(..). Melanoplus calloplus Hebard. Under this name Hebard (loc. cit., p. 398) describes and refers to the Gracilis Group a form from Collison Ridge, Bath Co., Virginia, which he calls "an annectant type between $M$. similis Morse and $M$. viridipes Scudd."

(..). Melanoplus alabamæ Hebard. This name is given by Hebard (loc. cit., p. 374) to a form taken at Evergreen, Conecuh Co., Alabama. He states that it is very closely related to $M$. querneus R. \& H., "differing apparently in the slightly smaller size and slightly more slender form, but strikingly in the shape of the male cerci."

(..). Melanoplus tunicæ Hebard. From Strickton, Rankin Co., Mississippi, Hebard (loc. cit., p. 370) describes a form under this name. He states that it differs from Melanoplus ponderosus viola Thos. in its "slightly more slender form, average longer tegmina, usually somewhat more solid coloration and distinctive male cerci."

(194). Melanoplus flavidus Scudder. Hubbell (loc. cit., p. 53) records this species from Berrien Co., Michigan, this being its most eastern known station and the first record for that State. 
(258). Orchelimum volantum McNeill. The known range of this species has been extended eastward to New Jersey by Dr. H. Fox ${ }^{6}$, who took specimens near Rancocas and Delanco, that state, in August and September, 1920. Its most eastern station hitherto recorded was Cedar Point on the shore of Lake Erie, Ohio.

(264). Conocephalus nemoralis (Scudder). This species has been taken in Berrien Co., Michigan, by Hubbell (loc. cit., p. 65), this being the first and only record for that State.

(269). Conocephalus attenuatus (Scudder). Dr. Fox reports (loc. cit., p. 268) the taking of this meadow grasshopper at several localities in New Jersey. Its former most eastern station was Cornwells, Pennsylvania.

(273). Conocephalus viridifrons Blatch. According to Hubbell, ${ }^{7}$ this little meadow grasshopper occurs in numbers in the eastern part of North Dakota, where it was found in dry fields and pastures in company with, but even more numerous than, $C$. fas ciatus (DeGeer).

(337). Oecanthus exclamationis Davis. In fulfillment of my prediction (p. 719 of the "Orthoptera") that this species "doubtless occurs in Indiana," specimens were taken in Knox County September 13, 1920, and July 5, 1921; also in Marion County in July and August of the latter year. All were swept from low shrubs in dense woodlands.

(..). Oecanthus nigricornis argentinus? Saussure. Among specimens of $O$. n. quadripunctatus taken in Knox Co.. Indiana, on Sept. 18, 1922, I found several having a shorter, broader body than that variety and with the outer black mark on basal joint of antennæ larger and set almost at right angles to the inner one; while the two on the second joint were shorter, thicker, subequal in length and with their lower ends converging to form a rough $\mathrm{V}$. As I could not determine them satisfactorily from the literature at hand, I sent them to A. N. Caudell of Washington, who wrote that "they are what I call $O$. nigricornis var. argentinus

'Ent. News, XXXII, 1921, 265.

${ }^{7}$ Occasional Papers of the Museum of Zoology, Univ. of Mich., No. 113 , p. 49. 
Sauss.", and he stated that he had specimens from a number of the Western States and from Delaware; also that breeding, as shown by Houghton ${ }^{8}$ had proven them to be intermediate between typical nigricornis Walker and quadripunctatus Beut. That this is their status, there is probably no doubt, but that they are the form described by Saussure from La Plata, Argentina, is strongly problematical. His description ${ }^{9}$ calls for a species very similar to $O$. niveus but having joints 1 and 2 of antennæ with a single black line beneath. He afterward treated a species under that name more fully in the "Biologia" (1897, p. 263, not to me now available), where, according to Caudell, ${ }^{10}$ there was "considerable variation from his original description in the length of the wings and the marking of the antennæ." As Caudell originally determined the United States form from Texas specimens and from the Saussure literature without comparison with the types, he may have been mistaken in its naming, as he infers when he says "specimens of what I take to be this species," etc. As individuals with the peculiar markings of the antennæ, as described above, will probably be found at various points in the Eastern States, I have mentioned these facts in order that they may be properly placed.

(341). Neoxabea bipunctata (DeGeer). Within the past three years this species has been taken in some numbers in Knox, Putnam and Marion Counties, Indiana, while sweeping vegetation in low alluvial woodlands along streams. At the time of writing the "Orthoptera" I had taken but two specimens in over thirty years' collecting in that state.

(349). Hapithus agitator Uhler. A female of this species with a pupal case of a parasite, almost as large as the body of the host. attached to the abdomen, was taken in Knox Co., Indiana, Sept. 18, 1922. Through Mr. Caudell the parasite was determined by Mr. Rohwer as probably the hymenopteron, Rhopalosoma poeyi Cresson. Specimens of that parasite from the same species of cricket have been reared by J. D. Hood of Washington, D. C.

\footnotetext{
${ }^{8}$ Ent. News, XX, 1909, 274 ; Can. Ent., XLI, 1909, 113.

${ }^{2} \mathrm{Mission}$ Scientifique at Mexique, 1874, 460.

${ }^{20}$ Proc. Ent. Soc. Wash., V, 1903, 166.
} 
QL

507

.1

B6
Blatchley, Willis Stanley Orthoptera of northeastern America

\section{PLEASE DO NOT REMOVE}

CARDS OR SLIPS FROM THIS POCKET

\section{ERINDALE COLLEGE LIBRARY}

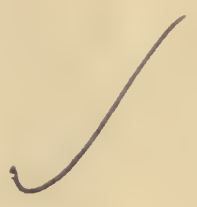


